\title{
INTEGRATED MID-CONTINENT CARBON CAPTURE, SEQUESTRATION \& ENHANCED OIL RECOVERY PROJECT
}

Final Scientific / Technical Report

Reporting Period:

November 16, 2009 - August 31, 2010

Principal Authors:

Black \& Veatch

Blue Source, LLC

CAP CO2, LLC

Headwaters Clean Carbon Services

Schlumberger Carbon Services

University of Utah

Date Issued:

September 2010

DOE Award Number:

DE-FE-0001942

Submitting Organization:

Brian McPherson

University of Utah

423 Wakara Way, Suite 300

Salt Lake City, Utah 84108

Black \& Veatch

11401 Lamar

Overland Park, Kansas 66211 
Blue Source, LLC

3165 East Millrock Drive, Suite 340

Salt Lake City, Utah 84121

CAP CO2, LLC

125 N. Market Street, Suite 1735

Wichita, Kansas 67202

Headwaters Clean Carbon Services

10653 S. River Front Parkway, Suite 300

South Jordan, Utah 84095

Schlumberger Data and Consulting Services

6501 S. Fiddler's Green Circle

Greenwood Village, Colorado 80111

\section{DISCLAIMER}

This report was prepared as an account of work sponsored by an agency of the United States Government. Neither the United States Government nor any agency thereof, nor any of their employees, makes any warranty, express or implied, or assumes any legal liability or responsibility for the accuracy, completeness, or usefulness of any information, apparatus, product, or process disclosed, or represents that its use would not infringe privately owned rights. Reference herein to any specific commercial product, process, or service by trade name, trademark, manufacturer, or otherwise does not necessarily constitute or imply its endorsement, recommendation, or favoring by the United States Government or any agency thereof. The views and opinions of authors expressed herein do not necessarily state or reflect those of the United States Government or any agency thereof. 


\begin{abstract}
A consortium of research partners led by the Southwest Regional Partnership on Carbon Sequestration and industry partners, including CAP CO2 LLC, Blue Source LLC, Coffeyville Resources, Nitrogen Fertilizers LLC, Ash Grove Cement Company, Kansas Ethanol LLC, Headwaters Clean Carbon Services, Black \& Veatch, and Schlumberger Carbon Services, conducted a feasibility study of a large-scale CCS commercialization project that included large-scale $\mathrm{CO}_{2}$ sources. The overall objective of this project, entitled the "Integrated Mid-Continent Carbon Capture, Sequestration and Enhanced Oil Recovery Project" was to design an integrated system of US mid-continent industrial $\mathrm{CO}_{2}$ sources with $\mathrm{CO}_{2}$ capture, and geologic sequestration in deep saline formations and in oil field reservoirs with concomitant EOR. Findings of this project suggest that deep saline sequestration in the mid-continent region is not feasible without major financial incentives, such as tax credits or otherwise, that do not exist at this time. However, results of the analysis suggest that enhanced oil recovery with carbon sequestration is indeed feasible and practical for specific types of geologic settings in the Midwestern U.S.
\end{abstract}




\section{TABLE OF CONTENTS}

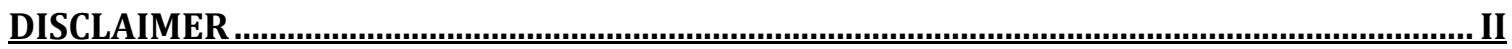

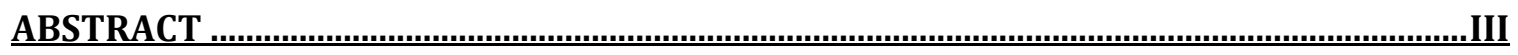

TABLE OF CONTENTS

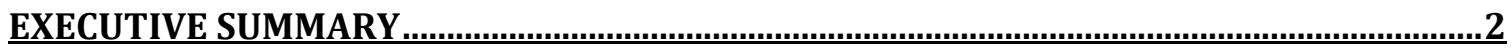

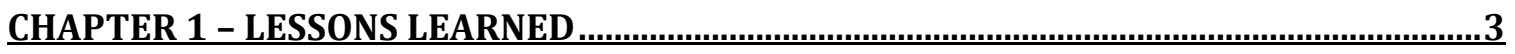

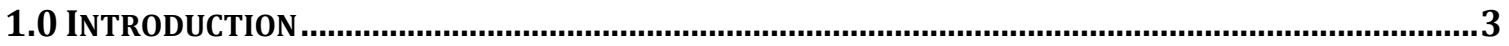

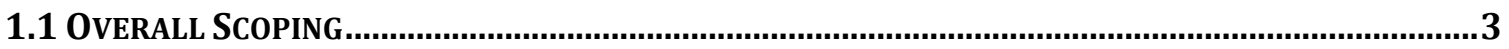

$\mathrm{CO}_{2}$ CAPTURE

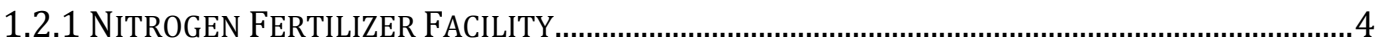

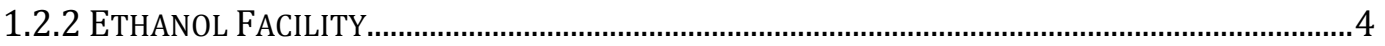

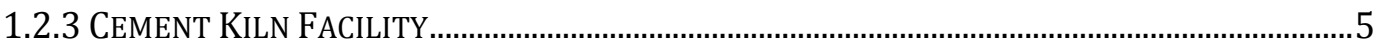

$1.3 \mathrm{CO}_{2}$ TRANSPORT

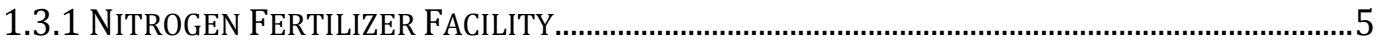

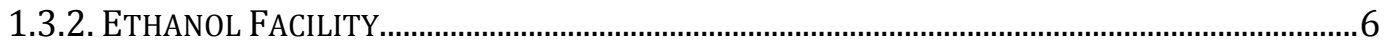

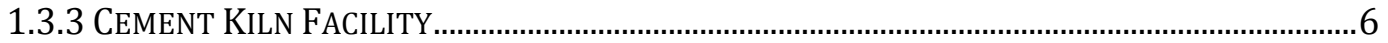

$1.4 \mathrm{CO}_{2}$ ENHANCED OIL RECOVERY

1.4.1 PRAIRIE HILLS (DEEP BARTLESVILLE EOR) ………..............................................................

1.4.2 KEGE ENERGY (GENESEO EDWARDS GRAVITY STABLE FLOOD) …….................................. 7

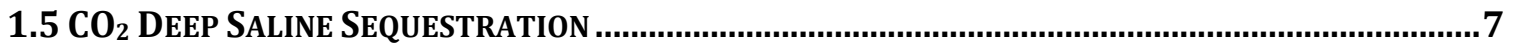

1.5.1 ARBUCKLE (BELOW DEEP BARTLESVILLE EOR) .....................................................................

1.5.2 ARBUCKLE (BELOW GENESEO EDWARDS GRAVITY STABLE FLOOD) ….................................

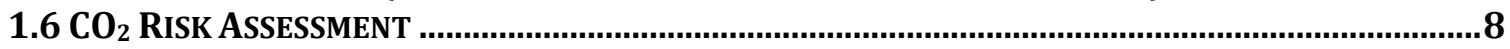

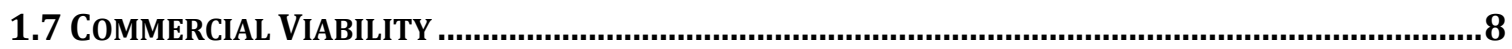

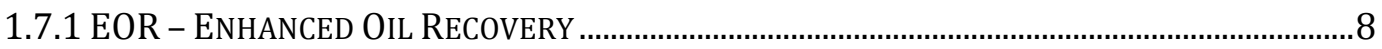

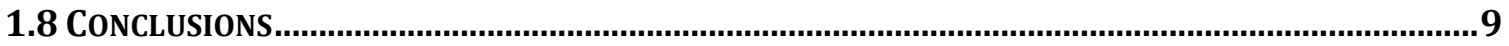

CHAPTER 2 - $\mathrm{CO}_{2}$ CAPTURE

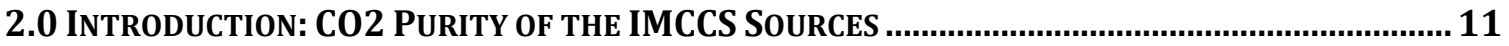

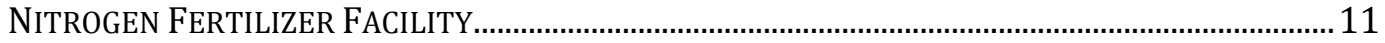

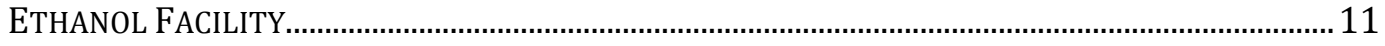

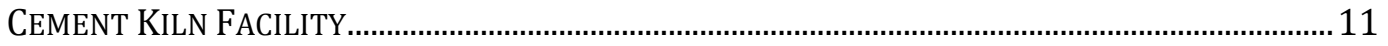

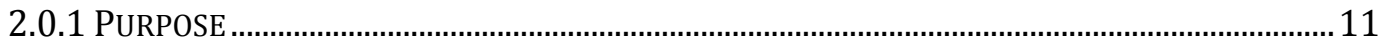

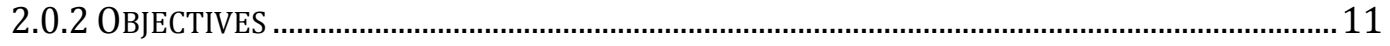

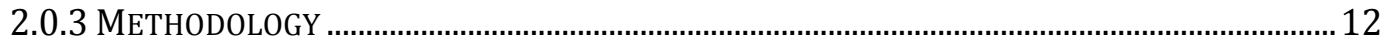

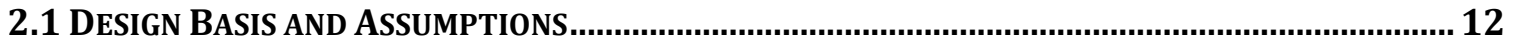

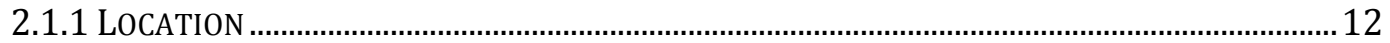

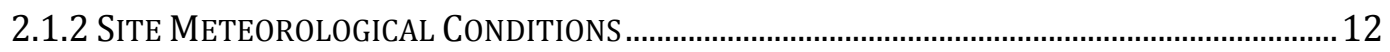

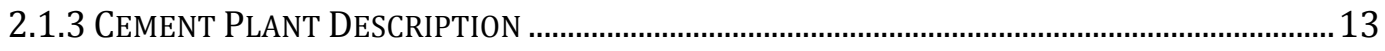

2.1.4 FLUE GAS CONDITIONS ............................................................................................ 13 


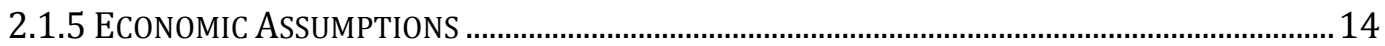

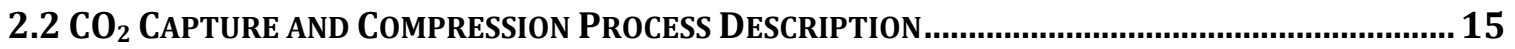

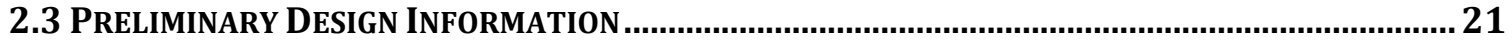

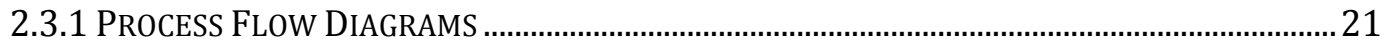

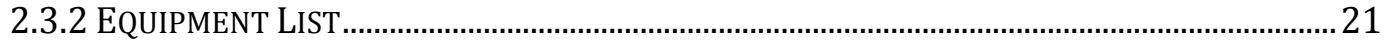

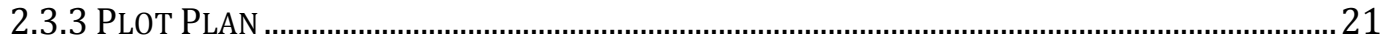

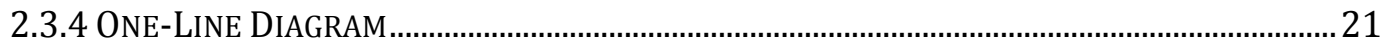

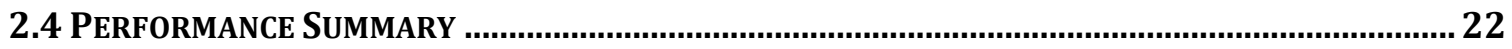

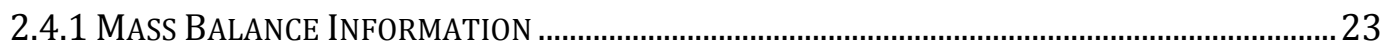

2.4.2 ENERGY BALANCE INFORMATION.................................................................................... 24

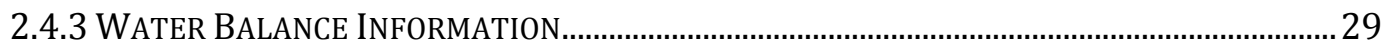

2.5 CoSTS

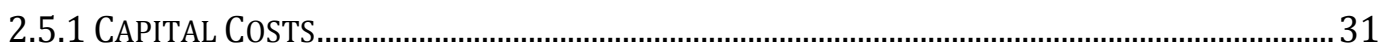

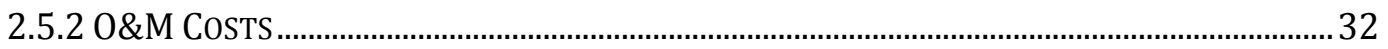

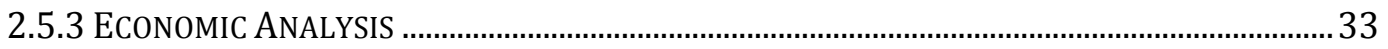

2.6 CONCLUSION

CHAPTER 3 - TRANSPORTATION

3.0 THRALL-AAGARD FIELD

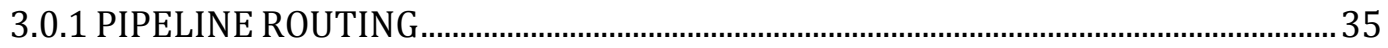

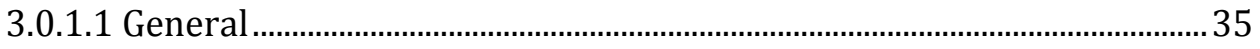

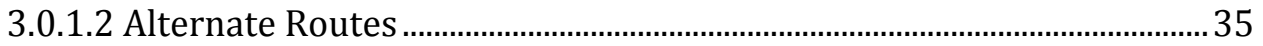

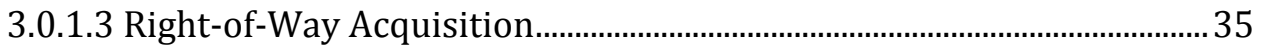

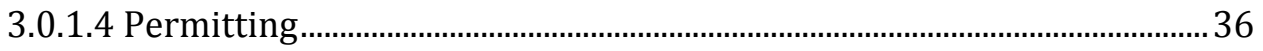

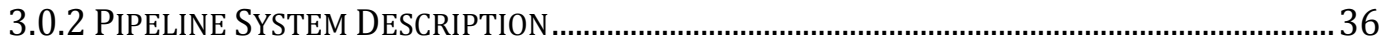

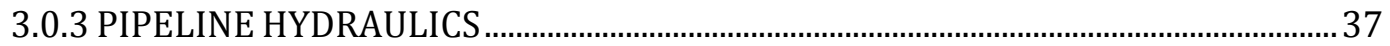

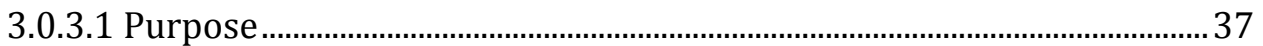

3.0.3.2 Pipeline Routing.............................................................................................. 37

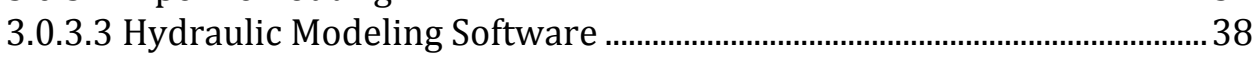

3.0.3.4 Hydraulic Design Basis - Pressure Requirements......................................38

3.0.3.5 Hydraulic Design Basis - Capacity Requirements ...................................... 38

3.0.3.6 Hydraulic Design Basis - Fluid Temperatures ............................................ 38

3.0.3.7 Hydraulic Design Basis - Carbon Dioxide Composition Analysis .........39

3.0.3.8 Hydraulic Design Basis - Assumed Mechanical and Thermodynamic

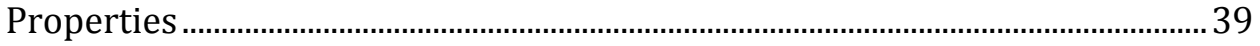

3.0.3.9 Hydraulic Design Basis - Elevation Profile .................................................... 40

3.0.3.10 Hydraulic Design Basis - Surge Pressure ..................................................... 40

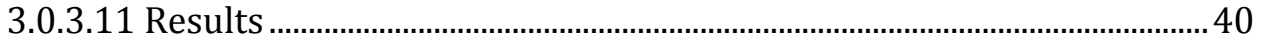

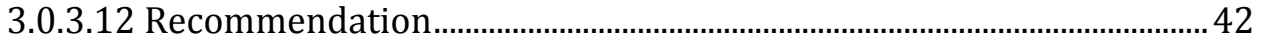

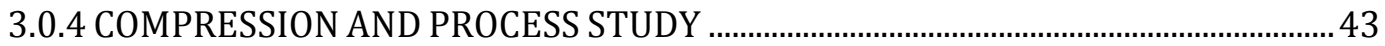

3.0.4.1 General Facility Description ......................................................................... 43

3.0.5 RECIPROCATING AND CENTRIFUGAL COMPRESSOR COMPARISON STUDY .............................. 43

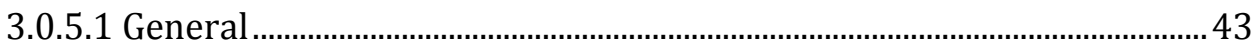

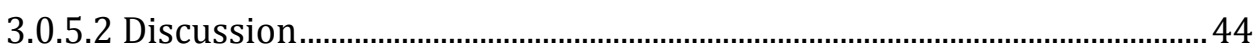

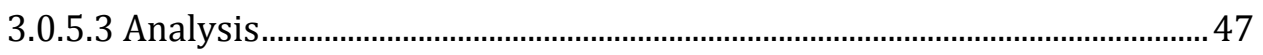

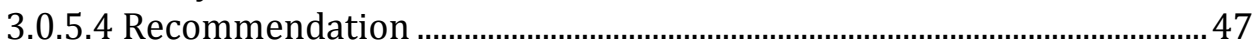

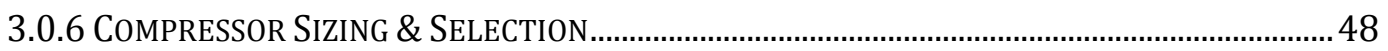

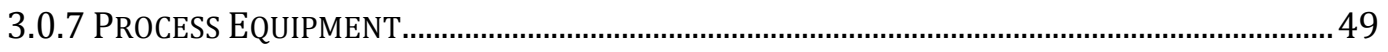

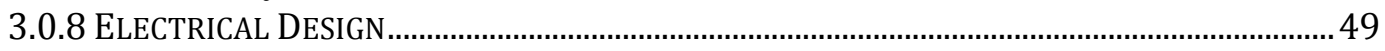




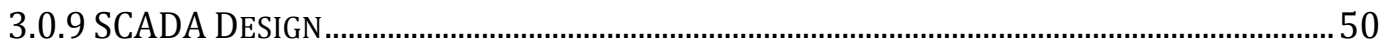

3.0.10 CATHODIC PROTECTION AND AC MITIGATION ……………............................................. 51

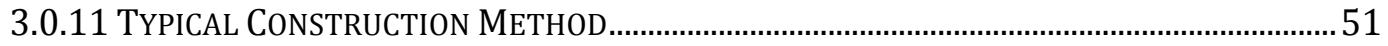

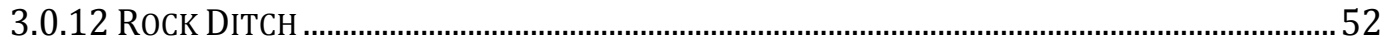

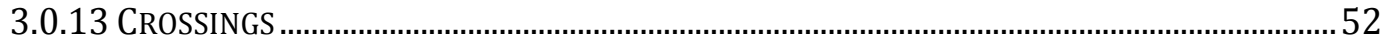

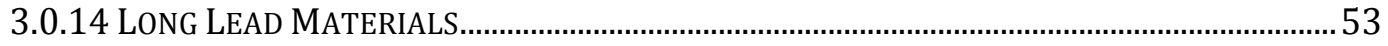

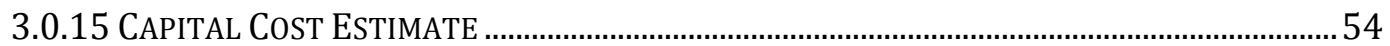

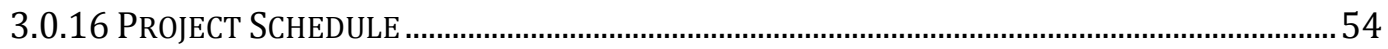

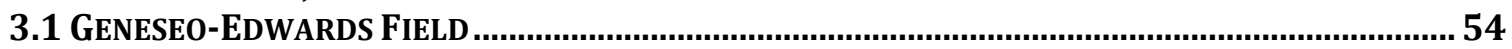

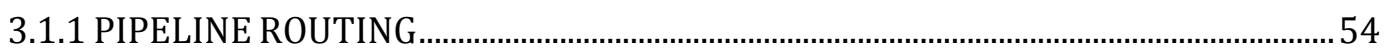

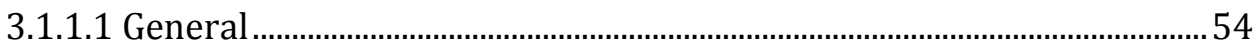

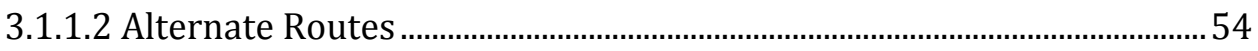

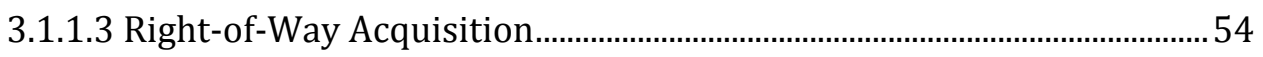

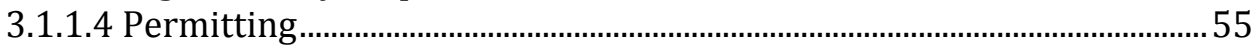

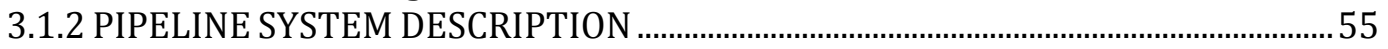

3.1.3 PIPELINE HYDRAULICS................................................................................................. 56

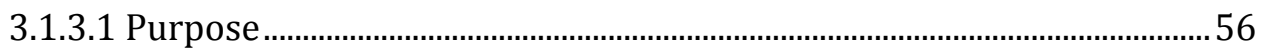

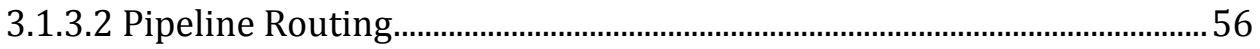

3.1.3.3 Hydraulic Modeling Software ...................................................................56

3.1.3.4 Hydraulic Design Basis - Pressure Requirements.....................................57

3.1.3.5 Hydraulic Design Basis - Capacity Requirements ....................................57

3.1.3.6 Hydraulic Design Basis - Fluid Temperatures ..........................................57

3.1.3.7 Hydraulic Design Basis - Carbon Dioxide Composition Analysis ........58

3.1.3.8 Hydraulic Design Basis - Assumed Mechanical and Thermodynamic

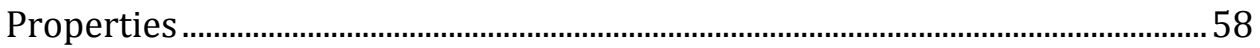

3.1.3.9 Hydraulic Design Basis - Elevation Profile ..................................................58

3.1.3.10 Hydraulic Design Basis - Surge Pressure....................................................59

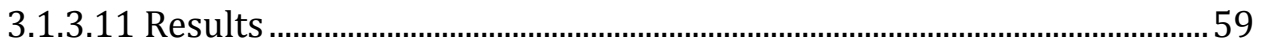

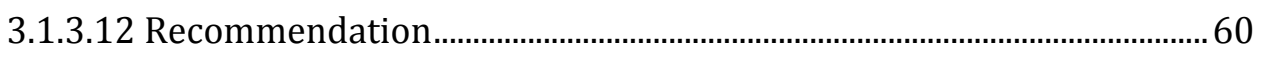

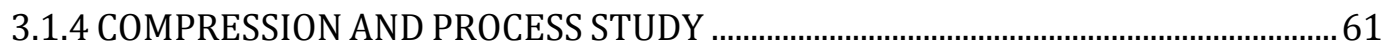

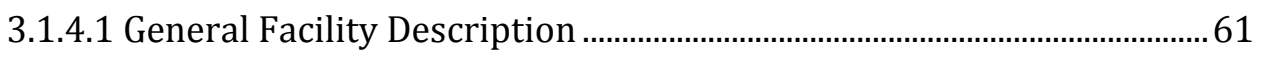

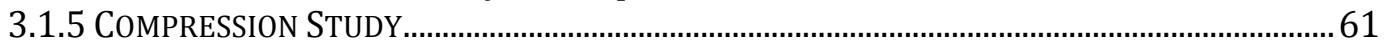

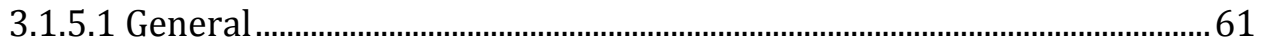

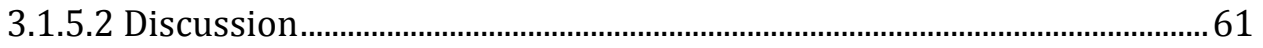

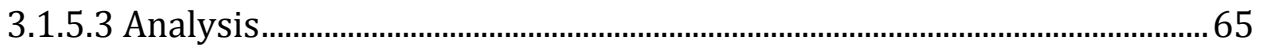

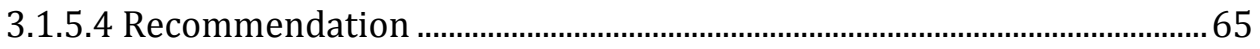

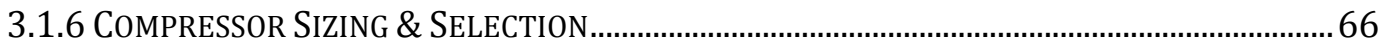

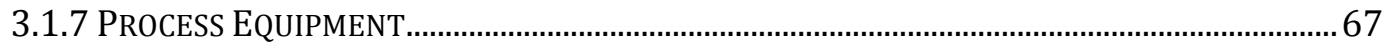

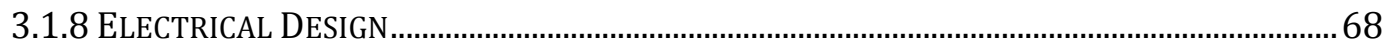

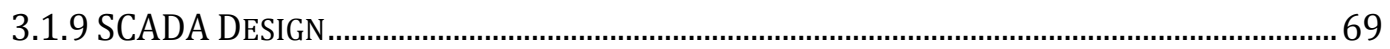

3.1.10 CATHODIC PROTECTION AND AC MITIGATION .................................................................. 70

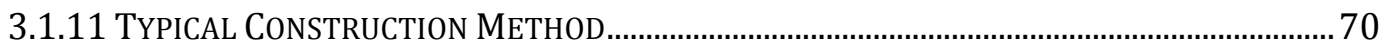

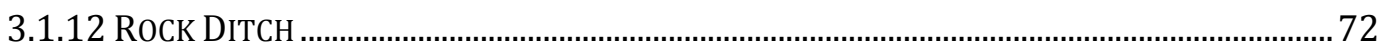

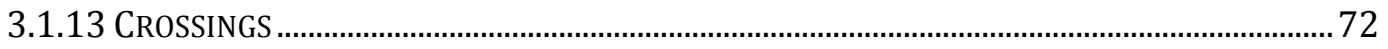

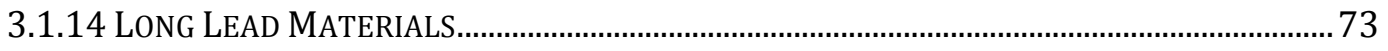

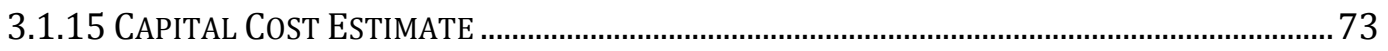

3.1.16 PROJECT SCHEDULE ..................................................................................................

CHAPTER 4 - RESERVOIR MODELING AND SIMULATION 
4.0 ThRALl-AAGARD FIELD - DEEP SALINE SEQUESTRATION ANALYSIS …....................................... 74

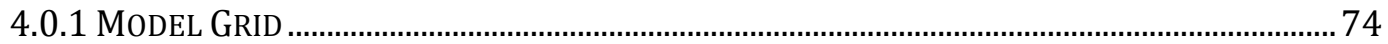

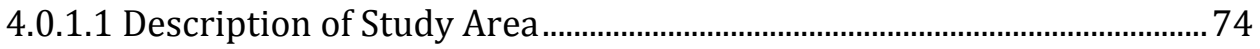

4.0.1.2 Model Grid Development ............................................................................ 75

4.0.1.3 Grid Conversion for TOUGH2 and PFloTran Simulator ............................77

4.0.2 Flow Model: Two-DimEnSIONAL RAdIAL $\mathrm{CO}_{2}$ InJECTION TEST .......................................78

4.0.2.1 Descriptions of TOUGH2 Simulator, Equations of State (EOS)

Algorithms, and Conceptual Model .........................................................................78

4.0.2.2 Vertical/Horizontal $\mathrm{CO}_{2}$ Plume Extension Associated with Time Scale

. .80

4.0.2.3 Convective Mixing due to Density Instability and Injectivity Changes

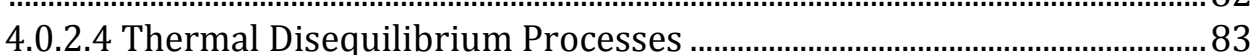

4.0.3 Flow MODEL: PFLOTRAN 3D $\mathrm{CO}_{2}$ INJECTION TEST IN THRALL-AAGARD SALINE

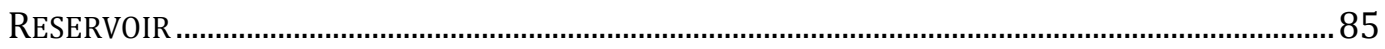

4.0.3.1 Descriptions of PFLOTRAN Simulator, Grid Generation, and

Formation Parameters Assessment ...................................................................... 85

4.0.3.2 Horizontal and Vertical $\mathrm{CO}_{2}$ Plume Migration ............................................ 87

4.0.3.3 Fluid Properties and $\mathrm{CO}_{2}$ Distribution Between Phases.......................... 93

4.0.4 Dynamic Flow Model: 3D $\mathrm{CO}_{2}$ InJECTION TEST In Thrall-AagARd SALINE

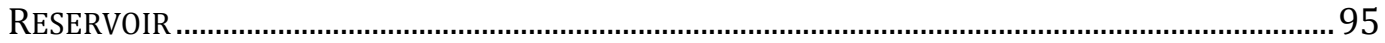

4.0.4.1 Descriptions of Model Grid and Workflow................................................ 95

4.0.4.2 Simulation Results ........................................................................................... 97

4.1 GENESEO-EDWARD FIELD - CoMbINED DEEP SALINE AND EOR SEQUESTRATION SiMULATION

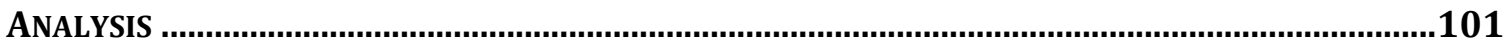

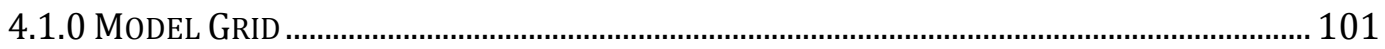

4.1.1.1 Description of Study Area and Data Processing................................... 101

4.1.1.2 Structural Grid, Property Model, and Volumetric Calculation........... 103

4.1.2 Flow Model Simulation ANalysis of Combined EOR and DeEP Saline

SEQUESTRATION IN THRALL-AAGARD RESERVOIRS ................................................................. 117

4.1.2.1 Descriptions of Model Grid and Workflow............................................... 117

4.1.2.2 Simulation Results ..................................................................................... 124

CHAPTER 5 - EOR WITH SEQUESTRATION ANALYSIS

5.0 GENESEO-EDWARdS $\mathrm{CO}_{2}$ ENHANCEd OIL RECOVERY PRoJECT ............................................128

5.0.1 DESCRIPTION OF STUDY AREA - REGIONAL SETTING …................................................... 128

5.0.2 $\mathrm{CO}_{2}$ SOURCE AND PIPELINE PLAN .............................................................................. 131

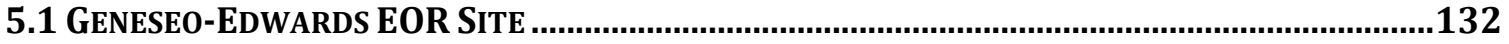

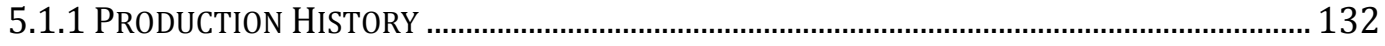

5.1.2 LONG-TERM IMPLICATIONS ..................................................................................... 134

5.2 PRE-MOdELING PRELIMINARY GRAVITY-STABLE FEASIBILTIY STUDY ....................................136

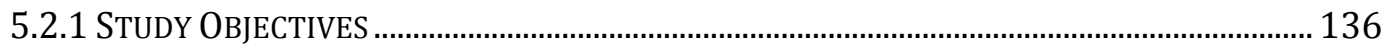

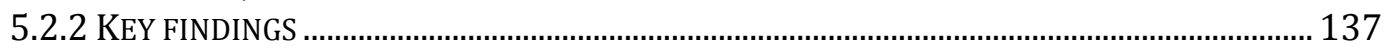

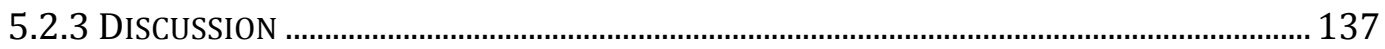

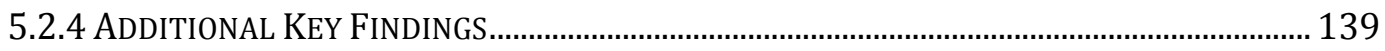

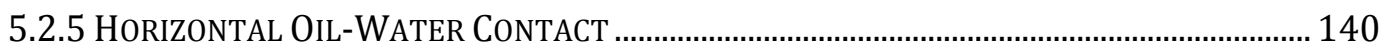

5.2.6 OPERATIONS PLAN BASED ON KEG RIVER ANALOGUES.................................................... 142

5.3 CHARACTERIZATION AND SIMULATION OVERVIEW .....................................................................147

5.3.1 CHARACTERIZATION-SIMULATION TEAM AND WORKFLOW ............................................. 147 
5.3.2 DATA GATHERING AND PROCESSING …....................................................................... 147

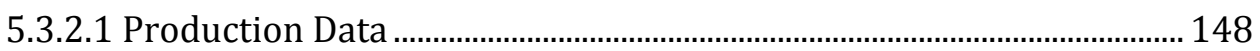

5.3.2.2 Geologic and Petrophysical Data ............................................................ 149

5.3.2.3 Reservoir Data and Fluid Analysis .......................................................... 150

5.3.3 ESTIMATING PROPERTIES WITH Minimal DATA ........................................................... 154

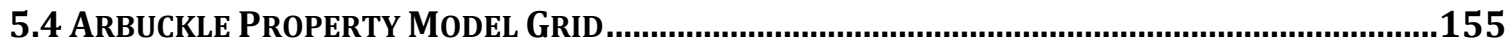

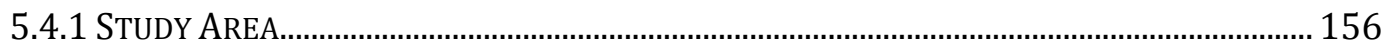

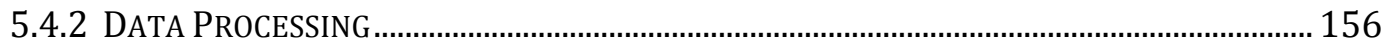

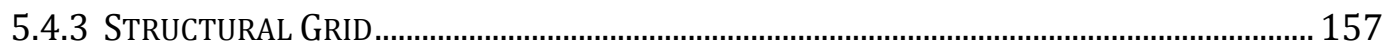

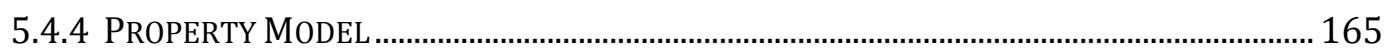

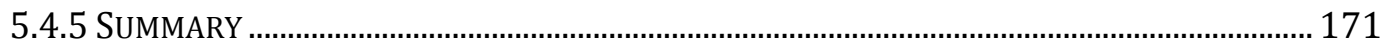

5.5 SIMULATION OF GRAVITY-STABLE $\mathrm{CO}_{2}$ INJECTION FOR EOR AND SEQUESTRATION .................172

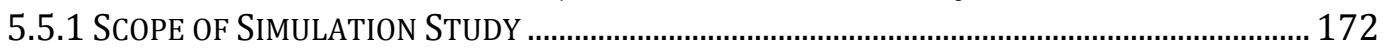

5.5.2 Simulation Model PARAMETERS AND HistORY MATCH ................................................ 172

5.5.2.1 Static Model Grid ................................................................................ 173

5.5.2.2 Equation of State...................................................................................... 174

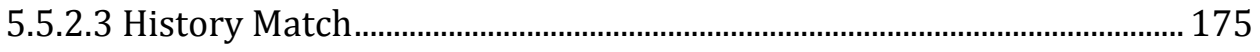

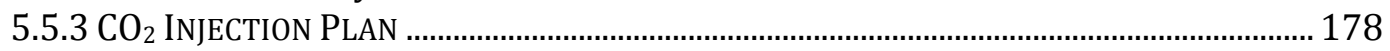

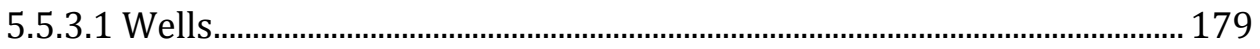

5.5.3.2 Well Pressures ................................................................................................ 180

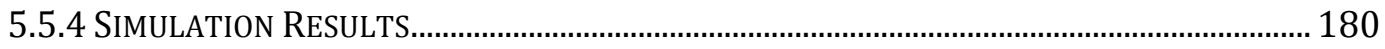

5.5.4.1 Discussion of North Dome Results......................................................... 180

5.5.4.2 Discussion of South Dome Results............................................................. 186

5.5.4.3 Quantification of Displaced Oil................................................................ 188

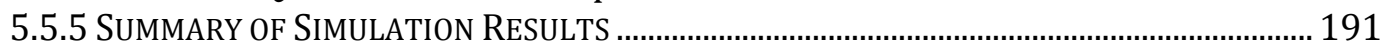

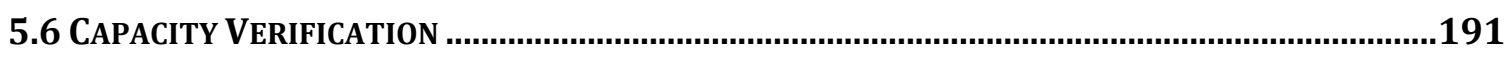

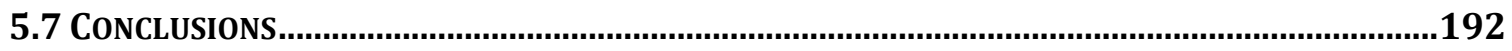

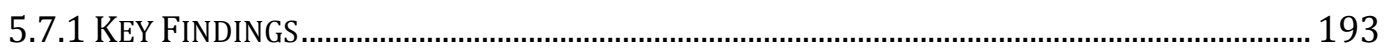

5.7.2 ADDITIONAL WORK ................................................................................................. 194

CHAPTER 6 - RISK ASSESSMENT ………

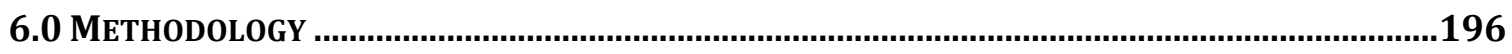

6.1 TECHNICAL RISK RESULTS AND DISCUSSION ..............................................................................199

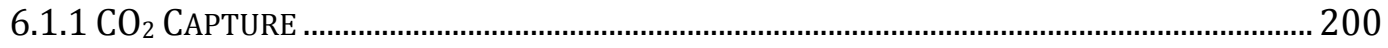

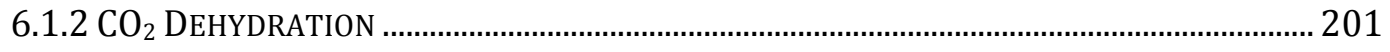

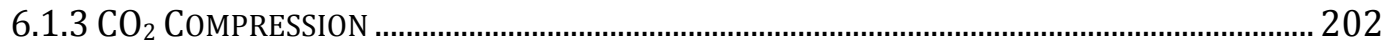

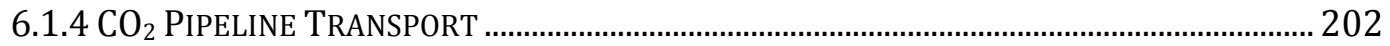

6.1.5 $\mathrm{CO}_{2}$ ENHANCED OIL RECOVERY (EOR) ………................................................................ 204

6.1.6 $\mathrm{CO}_{2}$ DEEP SALINE AQUIFER (DSA) SEQUESTRATION ...................................................... 209

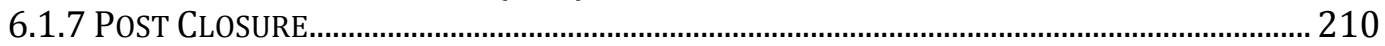

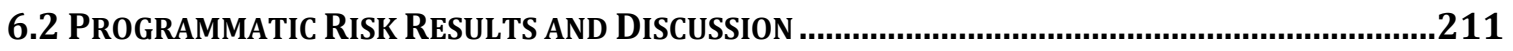

6.2.1 SECURING STRATEGIC PARTNERS FOR EOR OPERATION AND COST SHARE FUNDING....... 211

6.2.2 ACQUIRING CONTIGUOUS LEASEHOLD INTERESTS FOR INJECTION SITES............................ 211

6.2.3 SECURING DOE FUNDING SUPPORT............................................................................ 211

6.2.4 POTENTIAL CONSTRUCTION DELAYS DUE TO THE NEED FOR AN EIS RATHER THAN AN EA

2.5 MANAGING/COORDINATING MULTIPLE PARTNERS IN THE PROJECT

6.2.6 COST ESCALATION.......................................................................................................... 211

6.2.7 OIL PRICE FLUCTUATION........................................................................................... 212 
6.2.8 $\mathrm{CO}_{2}$ QUALITY

$6.2 .9 \mathrm{CO}_{2}$ SUPPLY INTERRUPTION.

6.2.10 BOREHOLE REPLUGGING AND REMEDIATION..

6.2.11 OIL RECOVERY

6.2.12 LONG-TERM LIABILITY FOR SEQUESTERED $\mathrm{CO}_{2}$

6.2.13 DEEP SALINE AQUIFER (DSA) SEQUESTRATION

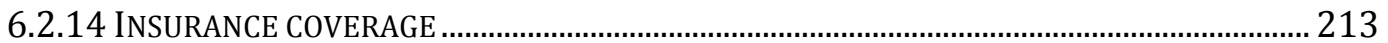

6.2.15 ENGINEERING, PROCUREMENT AND CONSTRUCTION …................................................... 213

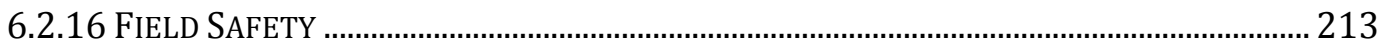

6.2.17 PUBLIC OUTREACH............................................................................................................. 213

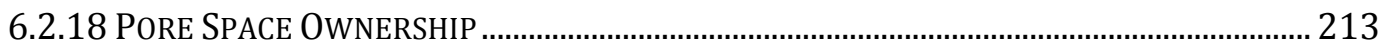

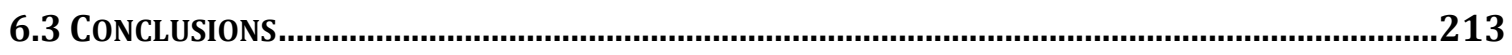

CHAPTER 7 - CONCLUSIONS ……

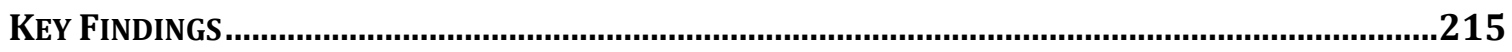

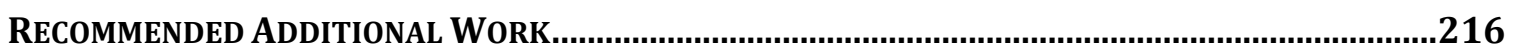

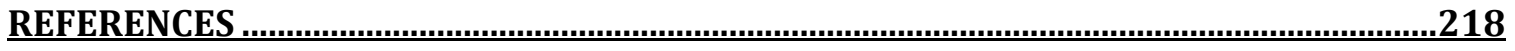

ABBREVIATIONS AND ACRONYMS ………

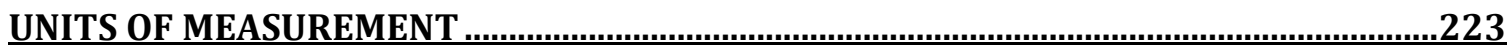




\section{EXECUTIVE SUMMARY}

The overall objective of the Integrated Mid-Continent Carbon Capture, Sequestration and Enhanced Oil Recovery Project (IMCCS Project) was to design an integrated system of large-scale $\mathrm{CO}_{2}$ sources with $\mathrm{CO}_{2}$ capture, geologic sequestration in deep saline formations and in oil field reservoirs with concomitant enhanced oil recovery. The IMCCS Project evaluated fully-commercialized advanced technologies for capture and subsequent sequestration in underground formations. Added-value commercial benefits factored include large-scale enhanced oil recovery (EOR) and optimization of capture technologies, sequestration monitoring technologies and risk assessment protocols for commercial-scale deployment. We investigated the impact of $\mathrm{CO}_{2}$ capture technology on plant operations, economics, and performance. Another major objective was to demonstrate geologic sequestration in multiple geologic horizons ("stacked storage"), including evaluation of costs, operational processes, and technical performance. The IMCCS Project incorporated state-of-the-art monitoring, verification \& accounting (MVA) protocols in its assessment of sequestration in deep saline formations and operating oil and gas fields in Kansas.

The body of work summarized in this report should be considered an initial feasibility study to be followed by additional data gathering, field testing, and more rigorous modeling and simulation study. Results of this project suggest that deep saline sequestration is impractical and uneconomic, without additional (new) financial incentives. However, EOR analysis results of this project are encouraging and suggest a gravity-stable immiscible $\mathrm{CO}_{2}$ EOR flood in select Midwestern oilfields would mobilize oil, form a horizontal oil bank, and could be commercially feasible. However, substantial additional work is needed on three fronts: 1) fill critical fluid property gaps, 2) improve assessments of geophysical and petrophysical properties including residual oil saturation, and 3) gain a better understanding of reservoir "plumbing systems" to insure that a gravity-stable approach could be effective in these reservoirs. 


\section{CHAPTER 1 - Lessons Learned}

\subsection{Introduction}

The purpose of this report is to summarize the approach and results of the project entitled "Integrated Mid-Continent Carbon Capture, Sequestration, and Enhanced Oil Recovery Project," or IMCCS, focusing especially on lessons learned during the brief project.The IMCCS team strove to respond carefully and objectively to a series of opportunities, constraints and criteria that changed multiple times during the course of the project. Regardless, the assembled team made its best effort in responding to the spirit of the the original solicitation and its special goals under auspices of ARRA.

One additional backdrop to this report is that between 2008 and 2010, world oil markets suffered a severe price drop from $\$ 125 /$ barrel down to $\$ 35 /$ barrel in the same period. One particular casualty in this period was the bankruptcy of Semgroup, a privately held entity in Oklahoma, whose loss impacted many oil companies in Kansas and the mid-continent region, and further exacerbated the tight market conditions. The sum of these factors, coupled with legislative uncertainty about carbon cap-and-trade and other policy options led the private equity markets in the oil industry to retreat. Financing options for large capital projects were scarce, and the DOE solicitation "Recovery Act: Carbon Capture and Sequestration from Industrial Sources and Innovative Concepts for Beneficial CO2 Use" came at a time when it was perhaps the only option for credible backing of a commercial-scale opportunity. Many financial advisors recommended that we proceed with entrepreneurial-type ideas with long-term financing contingent upon the successful outcome of our Phase-II proposal. That strategy is what we tried to implement during the course of this project.

The remainder of this chapter breaks down each section of our project by function and highlights the key "Lessons Learned":

- Overall Project Scoping

- $\mathrm{CO}_{2}$ Capture

- $\mathrm{CO}_{2}$ Transport

- $\mathrm{CO}_{2}$ Enhanced Oil Recovery

- $\mathrm{CO}_{2}$ Deep Saline Sequestration

- $\mathrm{CO}_{2}$ Risk Assessment

- Commercial Viability

\subsection{Overall Scoping}

The original Department of Energy solicitation DE-FOA-0000015 stated an ultimate goal to capture and sequester at least 1-million metric tons per year of industrial-sourced carbon dioxide $\left(\mathrm{CO}_{2}\right)$ for either carbon sequestration (CCS) or enhanced oil recovery (EOR) purposes while utilizing new technologies to 'push-the-envelope' on latest $\mathrm{CO}_{2}$ capture, transport, injection and MVA capabilities in the marketplace. The IMCCS team started its effort from a base EOR project involving capture and injection of 880,000 tons 
$\mathrm{CO}_{2}$ per year from Coffeyville Resource's Nitrogen Fertilizer facility. Our leadership team believed that to maximize the chance of commercial sustainability, we should strive to a) be opportunistic with new (even unfinanced) sources of $\mathrm{CO}_{2}$, and b) seek to expand the sequestration potential beyond EOR to include CCS and possibly $\mathrm{CO}_{2}$ enhanced coalbed methane recovery. Towards this goal, we negotiated an additional teaming arrangement with Ash Grove Cement Company, the University of North Dakota, Neumann Systems Group and Black \& Veatch Corporation to include a 1-million tonper-year cement kiln capture project that could possibly deliver a breakthrough in lowcost but high purity $\mathrm{CO}_{2}$ and was likely to lead to new development of coal-bed methane fields nearby that showed promise of using a blended 50\%-pure $\mathrm{CO}_{2}$ stream. During the course of the 5-month program, we also added a project involving gravity-stable $\mathrm{CO}_{2}$ injection utilizing $\mathrm{CO}_{2}$ sourced from Kansas Ethanol, LLC and their ethanol plant nearby. This "sub-project" was designed in collaboration with Epic Consulting, a division of Baker Hughes Canada, to extend the total industrial-sourced $\mathrm{CO}_{2}$ volume to approximately 1-million tons per year. The risk of adding these sub-projects was that they were vetted rather quickly compared to the analysis of our base $\mathrm{CO}_{2} \mathrm{EOR}$ project. More importantly, these projects were not yet financed. However, they did help our DOE project effort more closely match the overall volumetric and technical advancement criteria associated with the original solicitation.

The IMCCS project team worked diligently to execute all goals of the "Phase-I" ICCS project, in collaboration with NETL. The final technical report and each sub-phase report are now published as part of the end-of-project deliverables. This chapter summarizes the key lessons learned and highlights issues for future project teams to consider in evaluating such an effort.

\section{$\mathrm{CO}_{2}$ Capture}

The IMCCS team identified and negotiated three industrial $\mathrm{CO}_{2}$ sources, each with different technological requirements for separation and capture of $\mathrm{CO}_{2}$ :

\subsubsection{Nitrogen Fertilizer Facility}

- The existing 99\% high-purity $\mathrm{CO}_{2}$ emission from the Coffeyville site is readily available (untreated) with only limited dehydration is required for pipeline transport. The delivery $\mathrm{CO}_{2}$ (inlet( pressure is $2 \mathrm{psi}$ at $60^{\circ} \mathrm{F}$.

- The pet-coke gasifiers at Coffeyville emit a higher ratio of $\mathrm{CO}_{2}$ than traditional gas powered ammonia facilities which may provide the facility a competitive incentive to sequester the $\mathrm{CO}_{2}$, depending on possible future legislation.

\subsubsection{Ethanol Facility}

- Due to variations in the ethanol fermentation process, the variability in purity of the existing $\mathrm{CO}_{2}$ emissions ranged between $91 \%$ and $98 \%$ over a single 18 -hour test period. While this variation may be further minimized through leak reductions, the $\mathrm{CO}_{2}$ emission stream will require 
oxygen extraction techniques and dehydration to make the stream achieve the minimum specification for EOR injection. The delivery $\mathrm{CO}_{2}$ inlet pressure is 14 psi at $60^{\circ} \mathrm{F}$.

\subsubsection{Cement Kiln Facility}

- The existing quality of $\mathrm{CO}_{2}$ emissions from the Ash Grove cement kiln was approximately $25 \%$ pure. The required process to filter, scrub and concentrate $\mathrm{CO}_{2}$ using a state-of-the-art amine-based process would require a large-scale effort (although less complex than a typical power plant application). Capital investment for a commercial scale effort was estimated to require $\$ 300$ - $\$ 600$ million, plus fixed and variable operating costs for the $\mathrm{CO}_{2}$ capture of between $\$ 6-10$ per ton.

- Breakthrough amine-based technology was explored by using a design by the Neumann Systems Group, currently configured in a pilot power plant facility in Colorado. However, the configuration would still require a very large capital investment and the cement kiln lacks the boiler heat needed to exploit this particular technology fully. The total capital required on this effort was still estimated to be at least $\$ 250$ million, and would result in at least a $\$ 35-\$ 70$ per ton of capital costs in a best-case scenario.

- Due to the unlikely prospect that our team could finance a commercial-scale $\mathrm{CO}_{2}$ capture project for the cement kiln (in the absence of a $\mathrm{CO}_{2}$ emission tax or other such regulatory mandate), we decided to suspend the effort to capture the $\mathrm{CO}_{2}$ from the cement kiln.

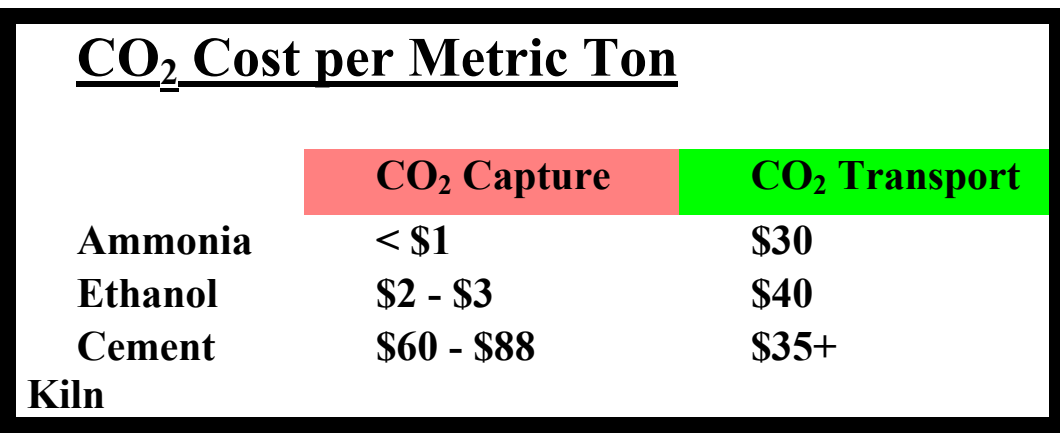

\section{$1.3 \mathrm{CO}_{2}$ Transport}

The multiple options for $\mathrm{CO} 2$ capture require different facilities for compression and different lengths of pipeline for transport after separation and capture. These different requirements are summarized with "bullet lists" in the following subsections.

\subsubsection{Nitrogen Fertilizer Facility}

- Estimated pipeline distance for Phase-I is 108 miles (174 kilometers). 
- Existing oilfields and $100 \%$ access via existing right of way is expected.

- Estimated 8" steel pipeline and compression capital costs are at least $\$ 116$ million.

- Multi-stage compression requirements were estimated as high as 16,500 horsepower for a $40,000 \mathrm{mcf} /$ day load of $\mathrm{CO}_{2}$. Due to the flow rate, the design team recommends centrifugal compressors. The cost estimates include specifications for redundancy, SCADA, cathodic protection and leak detection. Refer to design report for further details.

- Due to the relatively shallow depths and warm reservoir temperatures, an alternative to extend the pipeline an additional 100 miles (161 kilometers) is also considered in the commercial viability section to potentially exploit additional oilfields for EOR.

\subsubsection{Ethanol Facility}

- Estimated pipeline distance from Kansas Ethanol is 15 miles (24 kilometers).

- Existing oilfields and $100 \%$ access via existing right of way is expected

- Estimated 4" steel pipeline and compression capital costs are at least $\$ 30$ million.

- Minimum multi-stage compression requirements were estimated to be 4,500 horsepower for a $8,000 \mathrm{mcf} /$ day load of $\mathrm{CO}_{2}$. Due to the low flow rate and efficiency level, the design team recommends reciprocating compressors and an oxygen removal unit capable of limiting $\mathrm{O}_{2}$ levels to 10 parts per million by consuming $48 \mathrm{mcf} /$ day of natural gas. The cost estimates include specifications for redundancy, SCADA, cathodic protection and leak detection. Readers are referred to the complete design report for further details.

\subsubsection{Cement Kiln Facility}

- Estimated distance from Ash Grove to oilfield interconnect is at least 40 miles (64 kilometers).

- Existing oilfields and $100 \%$ access via existing right of way is expected.

- Estimated 8" steel pipeline and compression capital costs are at least $\$ 90$ million.

- Multi-stage compression requirements were predicted to be similar to the Coffeyville $\mathrm{CO}_{2}$ load, but would depend on the distance to potential interconnect destinations. Due to the high cost of $\mathrm{CO}_{2}$ capture, the project team elected to not complete the compression analysis. 


\section{$1.4 \mathrm{CO}_{2}$ Enhanced Oil Recovery}

\subsubsection{Prairie Hills (Deep Bartlesville EOR)}

- Based on our technical analysis, temperatures in the Bartlesville sands oilfields of Greenwood County are too high and the reservoirs too shallow to provide an effective basis for a miscible $\mathrm{CO}_{2} \mathrm{EOR}$ flood. An estimated average working pressure range of 200 psi was insufficient as the basis for continuing $\mathrm{CO}_{2} \mathrm{EOR}$ investment. Additional analysis is needed to consider alternative tertiary recovery techniques.

- We reexamined non-Arbuckle oilfields in eastern Kansas and Oklahoma that are deeper than 3,000 feet and exhibit good waterflood histories. There are a number of oilfields in the vicinity of the Wellington field (Sumner County) that together comprise as much as 12 to 30 million barrels of EOR targeted oil recovery potential. However, they are small, dispersed, and logistically impractical to flood. Without a DOE grant or similar incentives or support to reduce financial risks of continuing investigation, projects in these fields are not viable at this time.

\subsubsection{KEGE Energy (Geneseo Edwards Gravity Stable Flood)}

- Based on our initial analysis, a 120-foot oil column at a depth of 3,100 feet may produce up to 6 million barrels over 7 to 12 years via an immiscible gravity-stable flood technique (utilizing a $\mathrm{CO}_{2}$ gas-cap at the top of the zone, moving the oil downward) in two primary Geneseo Edwards oilfields analyzed.

- A simulation model developed by Epic Consulting shows a utilization rate of $1.6 \mathrm{mcf}$ of $\mathrm{CO}_{2}$ purchased per barrel of oil recovered via the gravity-stable flood technique, which is significantly better than traditional piston-drive EOR projects

- Additional 3D seismic analysis and pressure testing is essential to evaluate the fluid dynamics and confirm the vertical and horizontal connectivity prior to any commercial-scale project implementation.

\section{5 $\mathrm{CO}_{2}$ Deep Saline Sequestration}

\subsubsection{Arbuckle (below Deep Bartlesville EOR)}

- The project team conducted preliminary model simulations of $\mathrm{CO}_{2}$ storage in the Arbuckle beneath Thrall-Aagard over three, twenty and 50+ year periods. Results suggest that injected $\mathrm{CO}_{2}$ would dissolve in the in situ brine and eventually exsolve to gaseous phase; plume migration extends to the west field boundary after 15 years. 
- Results also suggest that salt precipitation (sodium chloride) is likely to occur after 2 years of $\mathrm{CO}_{2}$ injection and would require freshwater mitigation techniques

- The commercial viability of $\mathrm{CO}_{2}$ sequestration was predicted to be a net loss, and is not viable for financing by investors.

\subsubsection{Arbuckle (below Geneseo Edwards Gravity Stable Flood)}

- The project team also conducted preliminary model simulations of $\mathrm{CO}_{2}$ storage in the Arbuckle beneath Geneseo-Edwards over three, twenty and $50+$ year periods. Similar results suggest that $\mathrm{CO}_{2}$ would dissolve in reservoir brine and eventually exsolve as gas. Plume migration here would extend past the dome structure after 9 years.

- Likewise, commercial viability of $\mathrm{CO}_{2}$ sequestration was predicted to be a net loss, and could not be financed by investors.

\section{6 $\mathrm{CO}_{2}$ Risk Assessment}

The overall risk assessment of the project is very closely tied to the commercial viability of the project. The project team suggests that the critical factors are:

- Certainty of a high-purity industrial sourced $\mathrm{CO}_{2}$ supply, delivered at a market-sensitive economic cost, that does not undermine the profits of an EOR-project.

- Certainty of federal, state and local regulations impacting taxes, permitting, MVA, ownership rights (e.g. pore-space), and environmental indemnities.

- Oil field characteristics that indicate a strong likelihood that $\mathrm{CO}_{2}$ enhanced oil recovery per acre is likely at efficient $\mathrm{CO}_{2}$ utilization rates, and without extensive risk of wellbore integrity failure.

- Access to investment capital with financial backing based on a macro-view that oil price volatility will not undermine the other investment risks in a 10 to 20 -year commercial scale project.

\subsection{Commercial Viability}

\subsubsection{EOR - Enhanced Oil Recovery}

Commercial viability of a $\mathrm{CO}_{2}$ EOR project is still possible if sufficiently-large oilfields with appropriate reservoir characteristics in close proximity to proposed pipeline routes can be identified. After certain oilfields were ranked by our 
engineering team as too risky - due to their relatively high temperatures and shallow depths - alternative (deeper) sites were then investigated. Such fields identified were prospective contingent only on funding to further explore their economic potential. In addition, the oilfield delivered cost of $\mathrm{CO}_{2}$ for $\mathrm{EOR}$ purposes must be substantially reduced to $\$ 15-\$ 20 /$ metric ton to make any EOR initiative commercially viable. If such alternatives can be achieved, then financeable $\mathrm{CO}_{2}$ EOR alternatives would likely reemerge.

\section{Deep Saline Sequestration}

The deep saline sequestration effort was not economically justified based on current anticipated value of eligible US tax credits (maximum $\$ 20$ per ton) and/or VER credits (starting at say $\$ 5$ per ton) in relation to the cost of deep saline sequestration operation. Industry investors associated with the IMCCS team suggested several insurmountable issues:

1) Continued regulatory uncertainty impacting the economic value of credits in the marketplace. IRS guidelines are in draft. Tax credits are due to expire based upon a maximum ceiling. VER credits exemptions may devalue the market's view of credits for several years (assuming a voluntary market to trade credits continues).

2) Continued regulatory uncertainty regarding the permitting of a sequestration well. Concern for pore-space rights. Concern for plume trespass onto adjoining acreage. Unclear stipulation of MVA requirements (e.g. 3D seismic every year vs. alternating years vs. simple surface monitoring techniques). The range of incremental MVA cost expectations from our own industry partners ranged from $\$ 15$ to $\$ 40$ per ton.

3) Opportunity cost of deep saline sequestration is very high when realistic EOR opportunities exist. Best projections showed operating losses of $\$ 20$ to $\$ 55$ per ton (for CCS without any DOE grant). Using $\mathrm{CO}_{2}$ for permanent storage seems economically irrational if mature oilfields with EOR potential are in the vicinity. Options to explore $\mathrm{CO}_{2}$ EOR or "huff-and-puff" or other alternative tertiary techniques seem more likely to be financed by industry partners. In light of the tenuous economics coupled with regulatory concerns, the IMCCS oil company and financing partners were unanimously opposed to funding this deep saline component of the project.

\subsection{Conclusions}

Industrial sources of low-purity $\mathrm{CO}_{2}$ (i.e. $15 \%$ - 30\% pure) such as cement kilns, refineries, power plants, etc. are not economic for a commercial scale $\mathrm{CO}_{2} \mathrm{EOR}$ project at this time. According to this IMCCS study in a "best case" scenario, under idealized conditions, $\mathrm{CO}_{2}$ capture cost alone would be at least $\$ 35$ per metric ton before any cost to transport to any oilfield. We suggest that the cost is more likely to be $\$ 50-\$ 100$ per metric ton, plus transport. Thus, many industrial $\mathrm{CO}_{2}$ emission sources are far too expensive to finance at this time. 
Our IMCCS project had exclusive rights to purchase all the $\mathrm{CO}_{2}$ emissions from Coffeyville Resources, one of the largest industrial sources of the highest-purity $\mathrm{CO}_{2}$ in the United States. Oilfield targets within 120 miles (193 kilometers) from the site were explored and tested and found to possess more risk than traditional-style $\mathrm{CO}_{2}$ floods (i.e. compared to the Permian Basin in west Texas), due to a) generally shallower depths, b) generally warmer reservoir temperatures, (both of which dictate minimum miscibility pressure, or MMP, and the working pressure range), c) less concentrated deposits of oil requiring a more dispersed infrastructure design, d) generally high delivered cost of $\mathrm{CO}_{2}$ of more than $\$ 15$ - \$20 per metric ton (assuming \$70/barrel), and e) many old plugged wells which could contribute to MVA challenges. While each of these problems could be overcome with higher investments (i.e. less overall investor return), the $\sim 50 \%$ level of DOE funding to "de-risk" the project became a mandatory basis for proceeding with the $\mathrm{CO}_{2}$ enhanced oil recovery project. The IMCCS team did acquire contingent equity financing for the $\mathrm{CO}_{2}$ EOR portion of the project, but the project was not selected for Phase-II and thus will not proceed at this time. At a time when market conditions become more favorable, then financeable $\mathrm{CO}_{2} \mathrm{EOR}$ alternatives may reemerge throughout Kansas and Oklahoma.

The gravity-stable $\mathrm{CO}_{2}$ EOR flood opportunity studied by experts from a division of Baker Hughes Canada remains an interesting concept for the Central Kansas Uplift, but it will require additional substantial testing to verify the pressure and containment potential of each oil dome to be explored. Such testing represents a disruption to existing oil producers and thus a large-scale commitment must be in place first, before a meaningful experiment with this technology can be verified in the geology of Kansas.

Our oil industry advisors were unwilling to commit to the deep saline sequestration effort without a large federal subsidy to offset the loss for such a program. The IMCCS team repeatedly confronted opposition regarding lack of definitive CCS legislation, tax incentives, permitting requirements, MVA requirements, pore space rights, leakage $\left(\mathrm{CO}_{2}\right.$ trespass), 50-year indemnity, etc. The lack of profit potential for an investor precluded the deep saline effort, even if $50 \%$ of costs were borne by a NETL cooperative agreement. 


\section{CHAPTER 2 - $\mathrm{CO}_{2}$ Capture}

\subsection{Introduction: CO2 Purity of the IMCCS Sources}

An essential feature of the proposed IMCCS project is its $\mathrm{CO} 2$ capture technology suite. Details about the purity of CO2 from the three IMCCS industrial CO2 sources include:

\section{Nitrogen Fertilizer Facility}

The existing $99 \%$ high-purity $\mathrm{CO}_{2}$ emission from the Coffeyville site is readily available (untreated) with only limited dehydration is required for pipeline transport. The delivery $\mathrm{CO}_{2}$ (inlet ( pressure is 2 psi at $60^{\circ} \mathrm{F}$.

\section{Ethanol Facility}

Due to variations in the ethanol fermentation process, the variability in purity of the existing $\mathrm{CO}_{2}$ emissions ranged between $91 \%$ and $98 \%$ over a single 18 -hour test period.

\section{Cement Kiln Facility}

The existing quality of $\mathrm{CO}_{2}$ emissions from the Ash Grove cement kiln was approximately $25 \%$ pure. The required process to filter, scrub and concentrate $\mathrm{CO}_{2}$ using a state-of-the-art amine-based process would require a large-scale effort (although less complex than a typical power plant application). Breakthrough amine-based technology was explored by using a design by the Neumann Systems Group, currently configured in a pilot power plant facility in Colorado. However, the configuration would still require a very large capital investment and the cement kiln lacks the boiler heat needed to exploit this particular technology fully.

Because the cement kiln is the only $\mathrm{CO} 2$ source requiring advanced separation technology, the remainder of this chapter will focus exclusively on this project component.

\subsubsection{Purpose}

The purpose of this chapter is to provide an overview of the costs and impacts of adding $\mathrm{CO}_{2}$ capture and compression to the Ash Grove cement manufacturing plant in Chanute, Kansas, with the end goal of providing a range of expected values for the cost of captured and compressed $\mathrm{CO}_{2}$ at the cement plant boundary.

\subsubsection{Objectives}

The objectives of this chapter are to provide an overview of the technical implications of adding a commercial-scale, amine-based $\mathrm{CO}_{2}$ capture process to the Ash Grove cement plant and to estimate the cost of $\mathrm{CO}_{2}$ produced from the plant at the plant boundary. Technical implications include the additional equipment (with associated space requirements), power requirements, impact on water requirements, and waste streams from the plant. The cost of $\mathrm{CO}_{2}$ is a function of the capital and operating costs of 
the $\mathrm{CO}_{2}$ plant. To evaluate the expected cost of $\mathrm{CO}_{2}$, the IMCCS team developed a factored cost estimate with an accuracy range of -30 to +40 percent.

\subsubsection{Methodology}

To evaluate the technical implications of adding $\mathrm{CO}_{2}$ capture to the Ash Grove plant, The IMCCS team started with some basic assumptions about the operation of the existing plant, as described in Section 2.2. The information on the cement process and resulting flue gas was provided by the Ash Grove Cement Company. This information was used to develop process flow diagrams, mass balance information, energy balance information, an equipment list, and a plot plan. The mass and energy balance information was used to estimate the sizes of the various pieces of equipment shown in the process flow diagrams. These sizes, along with information on the materials of construction, were tabulated in an equipment list. The equipment list also served as the basis for an electrical one-line diagram and a plot plan. The expected additional electrical loads that the $\mathrm{CO}_{2}$ process will add to the plant were taken into consideration in the energy balance information and the one-line diagram. The equipment list and plot plan were used to develop a capital cost estimate for the $\mathrm{CO}_{2}$ capture process.

After the performance and cost estimates of the $\mathrm{CO}_{2}$ process were developed, a present value cost of $\mathrm{CO}_{2}$ was calculated, which represents the cost at which $\mathrm{CO}_{2}$ would need to be sold to achieve a present value of zero for the project at the given discount rate.

\subsection{Design Basis and Assumptions}

This section presents a design basis for the Ash Grove cement plant (excluding $\mathrm{CO}_{2}$ capture). The costs and impacts of retrofit $\mathrm{CO}_{2}$ capture, presented in Sections 2.4, 2.5, and 2.6, reflect these assumptions.

The two main technologies that are being considered for post-combustion $\mathrm{CO}_{2}$ capture are amine technologies and chilled ammonia. The IMCCS team suggests that amine technologies are closer to commercial scale feasibility and has chosen to use an unimproved MEA as the basis for the design and performance calculations of this study.

As an earlier part of this work, The IMCCS team also evaluated the Neumann Systems NeuStream ${ }^{\mathrm{TM}}$ technology. Although the technology shows promise for reducing the cost and space requirements of $\mathrm{CO}_{2}$ capture systems, the IMCCS team suggests that it is uncertain whether the technology will be commercially available within five years and thus we did not consider it in this current study.

\subsubsection{Location}

The Ash Grove cement plant is located north of Chanute, Kansas, at the intersection of Old US 169 and Ash Grove Road. The main road to the plant is US Highway 169. The site is also accessible by rail.

\subsubsection{Site Meteorological Conditions}

Plant site meteorological assumptions are provided in Table 2-1. The IMCCS team used the performance ambient temperature for most calculations. The cooling equipment was sized on the basis of the 2 percent maximum dry-bulb temperature with its associated 
wet-bulb temperature. The 2 percent maximum is a condition that will only be exceeded 2 percent of the hours during a typical year.

\subsubsection{Cement Plant Description}

The Ash Grove cement plant in Chanute, Kansas, was built more than 100 years ago. The plant produced its first cement in July 1908. The plant had an initial production capacity of 120,000 tons per year. The plant underwent several modifications during the 1960 s to increase capacity to 500,000 tons per year. In 2001, the plant underwent another modernization to increase its annual capacity to 1.5 million tons. The Ash Grove plant is currently the largest cement plant in the state of Kansas; it has a workforce of 138 employees and an estimated annual economic impact in Kansas of more than \$41 million.

The process to produce cement involves combining limestone, clay, and sand in a

Table 2-1

Plant Site Meteorological Basis

Elevation, feet above mean sea level (amsl)

Ambient Pressure, pounds per square inch absolute (psia)

Performance Ambient Temperature, ${ }^{\circ} \mathrm{F}$

2 Percent Dry-Bulb Temperature, ${ }^{\circ} \mathrm{F}$

2 Percent Wet-Bulb Temperature, ${ }^{\circ} \mathrm{F}$
958

14.7

85

91.4

75.3 large rotating furnace known as a kiln. The kiln is a long, rotating steel cylinder sloped slightly downward. The kiln heats the raw materials to approximately $2,500^{\circ} \mathrm{F}$. The heated raw materials react to form a clinker, which is collected at the lower end of the kiln. The

collected clinker is then cooled and ground into what is commonly known as cement.

The kiln can be heated using a variety of fuels. Coal, oil, natural gas, or liquid wastederived fuels can all be used in combination to heat the kiln; therefore, the contaminants in the flue gas can vary depending on the type of fuel being used. $\mathrm{NO}_{\mathrm{x}}$ emissions are controlled by using a low $\mathrm{NO}_{\mathrm{x}}$ burner. Powdered limestone in the raw material helps to neutralize the acid gases (including sulfur) that may have formed in the kiln.

The flue gas exiting the kiln is cooled as it preheats the raw materials in vertical towers before they enter the kiln. The cooled syngas passes through a cyclone to reduce particulate before its pressure is increased in an induced draft fan. The plant typically operates with a raw material mill grinding the material being fed to the cement manufacturing process. When this mill is in operation, the flue gas exiting the fan is combined with gases from the mill, passed through a baghouse, and vented to the atmosphere.

\subsubsection{Flue Gas Conditions}

The information presented in this chapter is based on 90 percent $\mathrm{CO}_{2}$ capture from the full plant capacity. The flue gas conditions, flow rates, and compositions are provided in Table 2-2. 


\begin{tabular}{|c|c|}
\hline \multicolumn{2}{|l|}{$\begin{array}{l}\text { Table } 2-2 \\
\text { Flue Gas Conditions, Rates, and Compositions }\end{array}$} \\
\hline Temperature, ${ }^{\circ} \mathrm{F}$ & 220 \\
\hline Pressure, psia & 14.71 \\
\hline Mass Flow Rate, lb/h & $1,552,520$ \\
\hline Flue Gas Flow Rate, lbmol/h & 51,974 \\
\hline Volumetric Flow Rate, acfm & 429,180 \\
\hline \multicolumn{2}{|l|}{ Flue Gas Composition } \\
\hline Oxygen, lb/h & 166,290 \\
\hline Nitrogen, lb/h & 799,690 \\
\hline $\mathrm{CO}_{2}, \mathrm{lb} / \mathrm{h}$ & 434,540 \\
\hline Moisture, $\mathrm{lb} / \mathrm{h}$ & 149,800 \\
\hline Oxygen, lbmol/h & 4,197 \\
\hline Nitrogen, lbmol/hr & 28,540 \\
\hline $\mathrm{CO}_{2}, \mathrm{lbmol} / \mathrm{h}$ & 9,874 \\
\hline Moisture, $\mathrm{lbmol} / \mathrm{h}$ & 8,315 \\
\hline Oxygen, $\%$ by volume, wet & 10 \\
\hline Nitrogen, $\%$ by volume, wet & 55 \\
\hline $\mathrm{CO}_{2}, \%$ by volume, wet & 19 \\
\hline Moisture, $\%$ by volume & 16 \\
\hline Sulfur Dioxide $\left(\mathrm{SO}_{2}\right)$ Mass Rate, $\mathrm{lb} / \mathrm{h}$ & 1,000 \\
\hline $\mathrm{NO}_{\mathrm{x}}$ Mass Rate, $\mathrm{lb} / \mathrm{h}$ & 1,200 \\
\hline
\end{tabular}

\subsubsection{Economic Assumptions}

The IMCCS team calculated the present value cost of $\mathrm{CO}_{2}$ capture on the basis of the assumed economic criteria as provided in Table 2-3.

The CPI was applied uniformly to plant consumables such as fuel, electricity, and chemicals as well as staff salaries and O\&M contracts. The tax rate was applied to revenues after taking into account depreciation. Although the Owner's cost can vary significantly, the IMCCS team chose 25 percent as a reasonable estimate based on the technology risk and the brownfield site. 


\begin{tabular}{|c|c|}
\hline \multicolumn{2}{|l|}{$\begin{array}{c}\text { Table 2-3 } \\
\text { Economic Assumptions }\end{array}$} \\
\hline Plant life & 20 years \\
\hline $\begin{array}{l}\text { Present worth discount } \\
\text { rate }\end{array}$ & 7.0 percent \\
\hline Capacity factor & 80 percent \\
\hline $\begin{array}{l}\text { Current cost of } \\
\text { electricity }\end{array}$ & $\$ 50 / \mathrm{MWh}$ \\
\hline CPI & 2.5 percent \\
\hline Owner's costs & 25 percent \\
\hline $\begin{array}{l}\text { Fuel for steam } \\
\text { generation }\end{array}$ & Natural gas at $\$ 4.50 / \mathrm{MBtu}$ \\
\hline Depreciation & Straight line over life of the plant \\
\hline Tax rate & 35 percent \\
\hline Gypsum from FGD & Sold at cost \\
\hline
\end{tabular}

\section{2 $\mathrm{CO}_{2}$ Capture and Compression Process Description}

Flue gas from the cement plant stack would be rerouted to the new $\mathrm{CO}_{2}$ recovery process equipment. The flue gas will contain an appreciable amount of $\mathrm{SO}_{2}$, which will degrade the amine that is used to absorb the $\mathrm{CO}_{2}$. The $\mathrm{SO}_{2}$ must be removed upstream of the amine absorber. To do this, the rerouted flue gas enters the flue gas desulfurization (FGD) unit (10-PK-0101) module, where it is contacted in a large tower with a slurry that contains reagent and byproduct solids. The $\mathrm{SO}_{2}$ is absorbed into the slurry and reacts with the calcium to form $\mathrm{CaSO}_{3} \bullet 1 / 2 \mathrm{H}_{2} \mathrm{O}$ and $\mathrm{CaSO}_{4} \bullet 2 \mathrm{H}_{2} \mathrm{O}$. The $\mathrm{SO}_{2}$ reacts with limestone reagent by the following reactions:

$$
\begin{aligned}
& \mathrm{SO}_{2}+\mathrm{CaCO}_{3}+1 / 2 \mathrm{H}_{2} \mathrm{O} \rightarrow \mathrm{CaSO}_{3} \bullet 1 / 2 \mathrm{H}_{2} \mathrm{O}+\mathrm{CO}_{2} \\
& \mathrm{SO}_{2}+\mathrm{CaCO}_{3}+2 \mathrm{H}_{2} \mathrm{O}+1 / 2 \mathrm{O}_{2} \rightarrow \mathrm{CaSO}_{4} \bullet 2 \mathrm{H}_{2} \mathrm{O}+\mathrm{CO}_{2}
\end{aligned}
$$

The flue gas leaving the absorber is saturated with water. Because of the chlorides present in the mist carry-over from the absorber and the pools of low-pH condensate that can develop, the conditions downstream of the absorber are highly corrosive to most materials of construction. Highly corrosion-resistant materials are required for the downstream ductwork.

The reaction products are typically dewatered by a combination of hydrocyclones (or gravity thickeners) and vacuum filters. The resulting filter cake is suitable for landfill disposal. Air is bubbled through the reaction tank and nearly all of the $\mathrm{CaSO}_{3} \bullet 1 / 2 \mathrm{H}_{2} \mathrm{O}$ can be converted to $\mathrm{CaSO}_{4} \cdot 2 \mathrm{H}_{2} \mathrm{O}$, which is commonly known as gypsum. This step is termed "forced oxidation." Dewatered gypsum can be landfilled. The wet FGD 
processes are characterized by high efficiency (greater than 95 percent) and high reagent utilization (95 to 97 percent). The absorbers handle large volumes of abrasive slurries. The overhead flue gas from the FGD is then sent to a blower that feeds the quench column.

Any sulfur left in the flue gas will react with MEA in the downstream amine absorber. This reaction will form heat stable salts that must be removed from the system and replaced with fresh amine. Although $10 \mathrm{ppm}$ sulfur out of the FGD is fairly typical, the allowable concentration of sulfur in the flue gas is subject to economic optimization. $\mathrm{NO}_{\mathrm{x}}$ may also form heat stable salts, and it may be necessary to reduce the $\mathrm{NO}_{\mathrm{x}}$ concentration in the flue gas using selective catalytic reduction. The current cement plant controls $\mathrm{NO}_{\mathrm{x}}$ by using low $\mathrm{NO}_{\mathrm{x}}$ burners. The IMCCS team did not evaluate the $\mathrm{NO}_{\mathrm{x}}$ levels in the flue gas and we did not factor any post-combustion $\mathrm{NO}_{\mathrm{x}}$ controls in this study.

The most commonly applied amine for a $\mathrm{CO}_{2}$ capture system is monoethanolamine (MEA). MEA is a simple alkanolamine with a hydroxyl group and an amine group and has the following chemical structure:

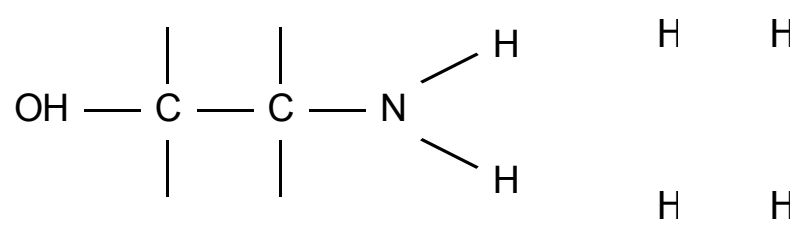

The hydroxyl group reduces the vapor pressure of the MEA and increases its solubility in water. The amine group provides the alkalinity that is required to absorb acid gases. MEA chemically absorbs $\mathrm{CO}_{2}$ from a gas stream to form an amine salt according to the following reaction:

\section{$2 \mathrm{RNH}_{2}+\mathrm{CO}_{2} \leftrightarrow \mathrm{RNHCOONH}_{3} \mathrm{R}$}

Because the product in this reaction has an appreciable vapor pressure, the composition of the equilibrium solution varies with the partial pressure of the $\mathrm{CO}_{2}$. For example, an MEA solution at $77^{\circ} \mathrm{F}$ goes from a $\mathrm{CO}_{2}$ vapor pressure of 0.07 psia to about 0.3 psia as the MEA weight percent goes from 10 percent to 60 percent ${ }^{1}$. The vapor pressure of the product also increases with temperature, so $\mathrm{CO}_{2}$ absorption takes place at a low temperature and stripping takes place at a higher temperature. The stripping process requires significant quantities of low-pressure process steam. In addition to the main reversible reaction with $\mathrm{CO}_{2}$, MEA also undergoes irreversible reactions with sulfur compounds, limiting its effectiveness in treating gas streams with appreciable quantities of these sulfur compounds.

Simple MEA solutions suffer from several operational disadvantages. MEA is a viscous and corrosive liquid that provides relatively limited absorption capacity (mass of $\mathrm{CO}_{2}$ absorbed per mass of solution) and requires a relatively large amount of heat to regenerate the lean solution. MEA also chemically degrades over time by reaction with oxygen and requires the addition of large quantities of replacement amine. Suppliers of

\footnotetext{
${ }^{1}$ Kohl, A. L., Gas Purification, Third Edition, Gulf Publishing Company, 1979.
} 
amine-based $\mathrm{CO}_{2}$ capture systems have applied significant research efforts to developing improved amine formulations that minimize the problems associated with MEA. These proprietary amines include the Mitsubishi Heavy Industries amines marketed under the trade names of KS-1 and KS-2, Fluor's Econamine FG and FG Plus, and Cansolv's (now owned by Shell) DC- $103^{2}$. Some of these improved amines can be used as 30 percent by weight solutions or higher. This aspect alone reduces the required solvent circulation rate substantially. Efforts to develop improved amines with higher absorption capacity, better chemical stability, and improved handling characteristics can be expected to continue and intensify as technology suppliers strive to bring improved $\mathrm{CO}_{2}$ capture systems to the marketplace.

The MEA solution can be very corrosive, particularly if its concentration exceeds 20 percent by weight and if the solution is heavily laden with acid gases. A 20 percent by weight MEA solution at $120^{\circ} \mathrm{F}$ has a $\mathrm{pH}$ of 12 . The corrosive nature of MEA typically requires corrosion-resistant ferrous alloys or nonferrous metals. The high vapor pressure of MEA can cause significant vaporization losses, but this can be minimized via water wash treatment of the purified gas.

Figure 2-1 is a block flow diagram of a typical $\mathrm{CO}_{2}$ removal process using MEA solvent. The $\mathrm{CO}_{2}$ capture plant consists of flue gas preparation in an air quality control system that consists of a wet FGD unit, a quench cooling process, $\mathrm{CO}_{2}$ absorption, $\mathrm{CO}_{2}$ stripping, and $\mathrm{CO}_{2}$ compression with dehydration.

After the flue gas is cleaned of contaminants in the FGD unit, it is routed to the quench water system. The gas is cooled by direct contact cooling with a countercurrent flow of circulating quench water through 24 feet of structured packing within the quench column (10-T-0101). This water removes sensible heat and condenses water vapor in the gas while cooling it from approximately $135^{\circ} \mathrm{F}$ to $128^{\circ} \mathrm{F}$. The flue gas leaves the top of the column and is routed to the amine absorber. The water in the bottom of the column is pumped through its circulation loop at approximately $9,660 \mathrm{gpm}$ by quench water pumps $(10-\mathrm{P}-0101 \mathrm{~A} / \mathrm{B})$ to the quench water cooler $(10-\mathrm{E}-0101)$, where it is cooled to $125^{\circ} \mathrm{F}$. The cooled quench water then flows through the quench water filter (10-U-0101) before either being recycled to the quench column or purged. Water purge from the quench loop is sent to makeup water treatment and is used for the makeup cooling water requirements of the plant.

The cooled flue gas from the quench column passes to the amine absorber (20-T0101). The gas is contacted with an MEA solution in two 21 foot packed beds of the tower, allowing the amine to selectively capture $\mathrm{CO}_{2}$ from the flue gas. The design circulation rate of the MEA solvent (30 percent by weight) is $11,315 \mathrm{gpm}$. The flow is regulated by a controller sensing the level in the amine absorber and a flow valve mounted near the stripper inlet nozzle. The lean amine solvent enters the amine absorber at a temperature of approximately $125^{\circ} \mathrm{F}$.

\footnotetext{
${ }^{2}$ Shell recently purchased the $\mathrm{CO}_{2}$ technology previously marketed by Cansolv. Earlier technical literature references for this system would be found under the Cansolv name.
} 


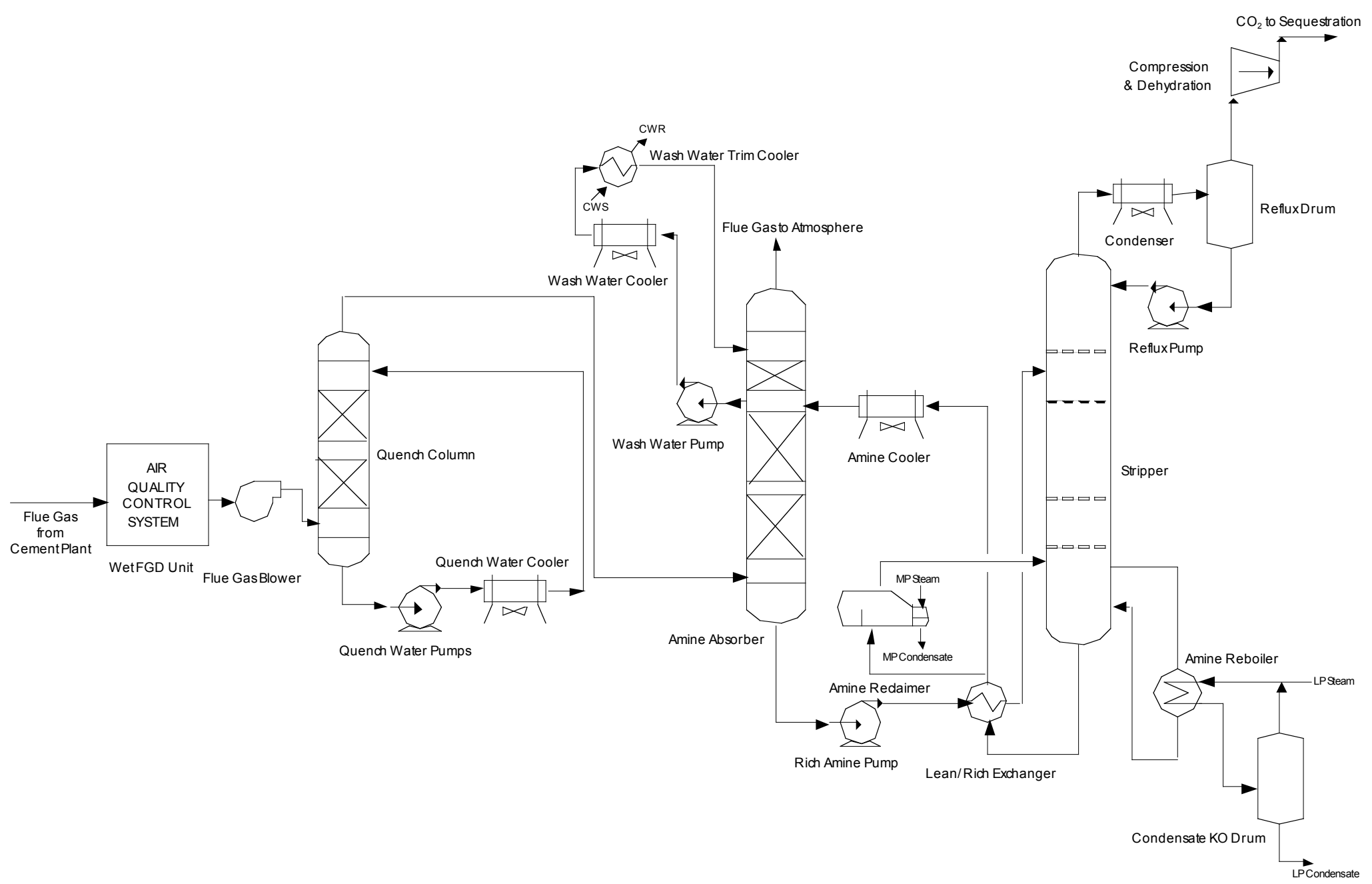

Figure 2-1

MEA Block Flow Diagram 
The flue gas exiting the amine absorber is washed with water to recover any amine compounds and recover water. The flue gas is then discharged from the top of the amine absorber through to the stack and dispersed into the atmosphere. The main component of the water wash loop is the 12 foot packed section to recover amine that is entrained in the overhead flue gas. Recycle wash water is pumped from the amine absorber to the wash water cooler (20-E-106), cooling it down to $125^{\circ} \mathrm{F}$. The trim cooler (20-E-107) further cools the water to $100^{\circ} \mathrm{F}$, before it is returned to the amine absorber.

The rich amine with captured $\mathrm{CO}_{2}$ is sent to the stripper for regeneration. Rich amine is routed through the rich amine pumps $(20-\mathrm{P}-0101 \mathrm{~A} / \mathrm{B})$ to the tubes of the lean/rich exchanger (20-E-0102). The rich solvent is heated in the lean/rich exchanger from approximately $140^{\circ} \mathrm{F}$ to $210^{\circ} \mathrm{F}$ by lean solvent as it flows to the feed tray of the stripper (20-T-0102).

The stripper overhead, at $13 \mathrm{psig}$ and $205^{\circ} \mathrm{F}$, is cooled to $125^{\circ} \mathrm{F}$ by ambient air in the condenser (20-E-0104); the condensed water is subsequently separated from the acid gas in the reflux drum (20-V-0101). The $\mathrm{CO}_{2}$-rich gas leaving the reflux drum is controlled at 11.5 psig through a control valve as it is sent to the compression process. The overhead liquid is pumped out of the reflux drum by the reflux pumps $(20-\mathrm{P}-0103 \mathrm{~A} / \mathrm{B})$ at a rate used to maintain a constant liquid level in the drum as well as a constant flow back to the stripper. Liquid is purged from the pump discharge as needed to maintain the amine concentration. The purge is sent to the makeup water treatment plant.

Lean amine is removed below the bottom tray of the stripper and sent to the amine reboiler (20-E-0105), which uses 50 psig saturated steam to produce stripping steam that is used across 32 trays to strip the $\mathrm{CO}_{2}$ from the solvent. Lean MEA at approximately $259^{\circ} \mathrm{F}$ leaves the bottom of the stripper through the lean amine pumps (20-P-0102A/B) on its way to the amine absorber. A slip stream of 1 to 5 percent of the circulating lean amine will be routed to the amine reclaimer (20-E-0103). MEA degrades over time, decreasing its efficiency for $\mathrm{CO}_{2}$ capture. The amine reclaimer removes degradation products and recovers MEA for reuse. The 150 psig steam generated from the packaged boiler is used as the heat transfer medium for the reclaimer. The lean solvent leaving the pump is cooled first in the shell side of the lean/rich exchanger (20-E-0102) to $188^{\circ} \mathrm{F}$ and then by ambient air in the amine cooler (20-E-0101) to $125^{\circ} \mathrm{F}$. Ten percent of the cooled lean amine is then sent through a set of filters and a carbon bed before combining with the main flow and passing through a flow control valve at the inlet of the absorber. The filters and carbon bed will remove hydrocarbons, corrosion products, and other solids, minimizing any foaming tendency in the stripper/absorber.

$\mathrm{CO}_{2}$ from the stripper is routed to the last steps of compression and dehydration before being sent to sequestration. The compression process consists of four 6-stage, integrally geared compressors (30-C-0101A-D). The four compressors operate in parallel. The first compression stage takes the $\mathrm{CO}_{2}$ from 11.5 psig to 48 psig. $\mathrm{CO}_{2}$ discharged at about $300^{\circ} \mathrm{F}$ is cooled to $125^{\circ} \mathrm{F}$ in the first-stage cooler and then sent to the first-stage knockout drum, where liquids are removed and sent to the makeup water treatment plant. The same step is repeated in the second, third, fourth, and fifth stages. $\mathrm{CO}_{2}$ discharges from the fifth stage at $985 \mathrm{psig}$. It undergoes cooling and water knockout and is then routed to the dehydration section before being compressed one last time to the desired pressure of 2,210 psig. 
At 985 psig, the $\mathrm{CO}_{2}$ stream has a water content of $173 \mathrm{lb}$ water/MMscf. $\mathrm{CO}_{2}$ is dehydrated at this pressure because its water content is at its lowest point. This helps reduce the size of the downstream dehydration system. The water in the $\mathrm{CO}_{2}$ will need to be reduced to a maximum of $30 \mathrm{lb}$ water/MMscf through dehydration with molecular sieve beds. The $\mathrm{CO}_{2}$ dehydrators (40-V-0101/2/3) contain molecular sieve material that removes water by adsorption. During adsorption, water binds to the sieve material in small pores. When all of the pores become occupied, additional water removal cannot be achieved. The sieve is then regenerated by passing a slip stream of dehydrated, heated $\mathrm{CO}_{2}$ across the sieve to remove the adsorbed water. The regenerated sieve is then placed back into adsorption service. In this process, two beds are in adsorption service and one bed is in regeneration service.

The inlet gas enters from the bottom of the dehydrators, 40-V-0101 and 40-V-0102 (assumed to be in adsorption service). Gas flows upward through the sieve bed where the water is adsorbed and dry gas exits from the top. The gas exiting the dehydrators feeds the dehydrator afterfilter (40-U-0101A/B). Over time, the molecular sieve will begin to degrade and crush, producing small dust particles that could plug downstream equipment. Ten percent of the dry gas from the dehydrators going to the afterfilter is sent to the regeneration gas heater $(40-\mathrm{F}-0101)$ to be heated to approximately $450^{\circ} \mathrm{F}$. The heater is a fuel gas fired heater, and effluent gas is discharged to the heater gas stack (40-S-0101). The hot regeneration gas flows downward through 40-V-0103 to remove the adsorbed water and is then cooled in the regeneration gas cooler (40-E-0101) to $125^{\circ} \mathrm{F}$. Water is condensed from the gas and separated in the regeneration gas knockout drum $(40-\mathrm{V}-$ 0104). The condensed water is routed to the makeup water treatment plant. The water saturated regeneration gas is then recompressed in the regeneration gas compressor and sent back to the beds that are in adsorption mode. The dehydrator cycle time is 24 hours, with 12 hours for adsorption and 12 hours for regeneration.

Dry $\mathrm{CO}_{2}$ is then routed back to the compression section, where the last compression stage compresses the $\mathrm{CO}_{2}$ to 2,210 psig, which is suitable for transportation in a $\mathrm{CO}_{2}$ pipeline. The high-pressure $\mathrm{CO}_{2}$ is then cooled to $125^{\circ} \mathrm{F}$ and sent to the pipeline.

Fresh amine is stored in the amine storage tank (50-TK-0101). This makeup amine is pumped by the amine makeup pump (50-P-0102) to the suction of the rich amine pump when needed. Various drains of amine are collected in the amine sump (50-V-0101). Collected amine can then be pumped back to the rich amine pump suction by the amine sump pump (50-P-0101).

Cooling water return from all users at an approximate temperature of $120^{\circ} \mathrm{F}$ is routed to the cooling water tower $(50-\mathrm{W}-0101)$. The cooling tower cools the water to $90^{\circ} \mathrm{F}$.

In general, amine-based $\mathrm{CO}_{2}$ capture is well understood in industrial applications, such as ammonia and hydrogen production. However, commercial-scale $\mathrm{CO}_{2}$ capture for flue gas from a cement kiln has not been demonstrated. The addition of amine-based, postcombustion $\mathrm{CO}_{2}$ capture is not expected to significantly alter the operation of the kiln. The primary gas path modifications (not including the steam, power, and cooling modifications) required for adding $\mathrm{CO}_{2}$ capture to an existing plant would be in the ductwork from the pollution control equipment to the stack.

Because cement plant operations do not have a source of steam, a natural gas fired process boiler must be installed to produce the steam required for stripping the $\mathrm{CO}_{2}$ from the rich amine in the regenerator. Alternatively, the plant could install a larger boiler and 
a back-pressure steam turbine. The boiler would produce superheated steam that could be expanded through a small turbine to the pressure required by the reboiler (approximately $50 \mathrm{psia}$ ). In addition to providing the steam necessary for $\mathrm{CO}_{2}$ capture, this configuration would also provide power for the large electrical loads required for $\mathrm{CO}_{2}$ capture and compression. To simplify the calculations and reduce capital costs, the IMCCS team assumed that steam would be produced in a package boiler and power would be purchased from the grid.

\subsection{Preliminary Design Information}

\subsubsection{Process Flow Diagrams}

The IMCCS team produced preliminary process flow diagrams that show the interconnections between major pieces of equipment. The following process flow diagrams are included in Appendix 2-A:

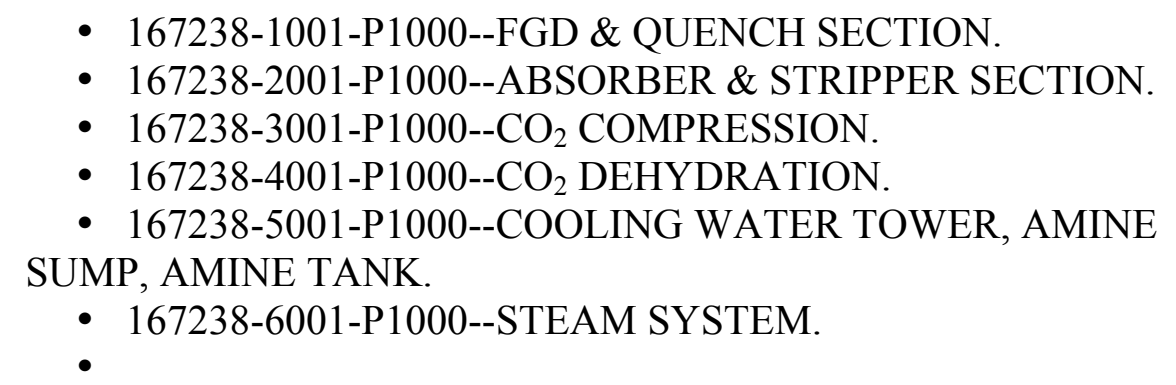

\subsubsection{Equipment List}

The IMCCS team developed an equipment list that is based on the process design and the process flow diagrams listed in Section 2.3.1. The equipment list is provided in Appendix 2-B.

\subsubsection{Plot Plan}

Based on the preliminary design and the equipment list described in Section 2.3.2, the IMCCS team suggests that the $\mathrm{CO}_{2}$ capture and compression equipment will require approximately 4 acres. The most suitable location for the equipment is north of the existing kiln, preheater tower, and raw mill. Some care will be needed to avoid the existing conveyors in that area. Constructability optimization has not been considered as part of this study. A plot plan of the $\mathrm{CO}_{2}$ equipment in relation to the existing cement plant equipment is shown in Appendix 2-C.

\subsubsection{One-Line Diagram}

An electrical one-line diagram of the $\mathrm{CO}_{2}$ capture and compression plant (Drawing ESDSP-167238-E-1001) is included in Appendix 2-D.

The city of Chanute provides electrical power to the Ash Grove cement plant through a $69 \mathrm{kV}$ transmission line. The existing electrical load for the plant during typical operation is $25 \mathrm{MW}$. The electrical power requirement for the $\mathrm{CO}_{2}$ capture and compression system is expected to be approximately $40 \mathrm{MW}$. An auxiliary power transformer must be added to serve this load. To achieve this, the new transformer needs to be fed at $69 \mathrm{kV}$ from the transmission line presently feeding the plant. 
The transformer will be located adjacent to the carbon capture equipment, with an underground circuit that would be installed from the $69 \mathrm{kV}$ transmission line tap point to the new transformer. Only one transformer will be installed, meaning that if the transformer is out of service, the $\mathrm{CO}_{2}$ capture equipment will be unavailable.

The new transformer will be sized to have 25 percent spare capacity, with a top rating of 60 MVA. The transformer will have three windings, the primary winding and two secondary windings and have two different secondary output voltages to accommodate the different voltage requirements of the large motors and the smaller motors. In general, very large motors (5,000 horsepower and above) will be served at 13,800 volts, and motors between 200 and 5,000 hp served at 4160 volts. Therefore, the transformer primary winding would be $69 \mathrm{kV}$, and the two secondary windings would be $13.8 \mathrm{kV}$ and $4.16 \mathrm{kV}$. The transformer would feed two medium voltage switchgear buses that are located adjacent to the new loads. The current rating of the medium voltage buses will depend on the electrical load served from that bus.

A 480 volt motor control center is to be provided to serve motors $200 \mathrm{hp}$ and below. Two step-down transformers will each serve one 480 volt switchgear bus, with each bus serving six motor control centers.

A dedicated dc and essential ac power system will be provided for the capture system. The function of the de power is to provide $125 / 250 \mathrm{VDC}$ to the control and instrumentation system and to provide the normal power source for the essential ac power source.

No emergency generator will be provided.

\subsection{Performance Summary}

A summary of the performance of the Ash Grove cement plant with amine-based capture is presented in Table 2-4. The capture process is removing 90 percent of the $\mathrm{CO}_{2}$ from the lime kiln flue gas, but the additional $\mathrm{CO}_{2}$ produced by the $\mathrm{CO}_{2}$ stripping equipment results in a net effective capture of 67 percent. The performance data are for $85^{\circ} \mathrm{F}$ ambient conditions with the raw mill running. The IMCCS team did not calculate performance for the plant when the raw mill is off. 
Table 2-4

Performance Summary of the Ash Grove Cement Plant with $\mathrm{CO}_{2}$ Capture

$\mathrm{CO}_{2}$ in lime kiln flue gas, tons per hour (tph)

$\mathrm{CO}_{2}$ from new steam generator and molecular sieve heater, tph

74

Total $\mathrm{CO}_{2}$, tph

Lime kiln flue gas to $\mathrm{CO}_{2}$ capture, percent

$\mathrm{CO}_{2}$ captured, tph

$\mathrm{CO}_{2}$ to atmosphere, tph

Net power for $\mathrm{CO}_{2}$ capture, compression, and air cooling, $\mathrm{MW}$

Wet cooling tower duty, MBtu/h

Air cooling duty, MBtu/h

Net additional cooling duty, MBtu/h

Water condensed from flue gas and $\mathrm{CO}_{2}$, gallons per minute (gpm)

Additional makeup water, gpm

\subsubsection{Mass Balance Information}

Before the flue gas enters the amine scrubbing unit, its temperature must be approximately $125^{\circ} \mathrm{F}$ and the $\mathrm{SO}_{2}$ and nitrogen dioxide $\left(\mathrm{NO}_{2}\right)$ contaminants need to be minimized. On the basis of the information provided, the IMCCS team suggests that a wet FGD unit will be required to reduce the $\mathrm{SO}_{2}$ concentration in the flue gas to about 10 ppmv. The temperature of the flue gas exiting the wet FGD will need to be cooled in a direct contact cooler before being passed to the amine column. The direct contact cooler will also remove particulates, fluorides, and chlorides from the flue gas.

The IMCCS team estimated gas path information including flow rates, compositions, temperatures, and pressures as the flue gas passes through the $\mathrm{CO}_{2}$ removal equipment. Pertinent stream information is provided in Table 2-5. A full material balance is provided in Appendix 2-E. 
Table 2-5

Gas Path Stream Information for 90 Percent $\mathrm{CO}_{2}$ Capture

\begin{tabular}{|c|c|c|c|c|}
\hline Medium & & $\begin{array}{l}\quad \text { Raw } \\
\text { Flue } \\
\text { Gas }\end{array}$ & $\begin{array}{l}\text { Polished Flue } \\
\text { Gas }\end{array}$ & Flue Gas \\
\hline From & & Preheater & Cooler & $\begin{array}{l}\text { Amine } \\
\text { Column }\end{array}$ \\
\hline To & & $\begin{array}{l}\text { Wet } \\
\text { FGD }\end{array}$ & $\begin{array}{l}\text { Amine } \\
\text { Column }\end{array}$ & Atmosphere \\
\hline Mole-flow & $\mathrm{h}^{\mathrm{lbmol} /}$ & 51,974 & 50,264 & 39,949 \\
\hline Mass-flow & $\mathrm{klb} / \mathrm{h}$ & 1,553 & 1,521 & 1,104 \\
\hline $\begin{array}{l}\text { Volume- } \\
\text { flow }\end{array}$ & ${ }_{d}$ MMscf & 473 & 458 & 364 \\
\hline Pressure & psia & 14.7 & 16.1 & 15.0 \\
\hline $\mathrm{e}^{\text {Temperatur }}$ & ${ }^{\mathrm{o}} \mathrm{F}$ & 220 & 128 & 125 \\
\hline \multicolumn{5}{|c|}{ Composition } \\
\hline $\mathrm{N}_{2}$ & $\%$ mole & 55 & 57 & 71 \\
\hline $\mathrm{CO}_{2}$ & $\%$ mole & 19 & 20 & 3 \\
\hline $\mathrm{O}_{2}$ & $\%$ mole & 10 & 10 & 13 \\
\hline $\mathrm{H}_{2} \mathrm{O}$ & $\%$ mole & 16 & 13 & 13 \\
\hline $\mathrm{SO}_{2}+\mathrm{SO}_{3}$ & $\%$ mole & 0.03 & 0.00 & 0.00 \\
\hline
\end{tabular}

\subsubsection{Energy Balance Information}

The addition of $\mathrm{CO}_{2}$ capture will require steam heating and will increase the total electric load of the plant.

Heat duties required for amine regeneration from the reboiler and reclaimer, respectively, are the most significant demand on medium- and low-pressure steam. The boiler package generates $937,602 \mathrm{lb} / \mathrm{h}$ of superheated $150 \mathrm{psig}$ steam, which is desuperheated for medium-pressure saturated steam use. A portion of the steam generated is let down to $50 \mathrm{psig}$ for low-pressure saturated steam users. Condensate from process heating is collected in a condensate drum and is sent back to the boiler package. Steam from the condensate drum is condensed in an air cooler and returned to the system to reduce required makeup water. Table 2-6 summarizes the process requirements for the medium- and low-pressure steam systems. 
Table 2-6

Steam System Requirements

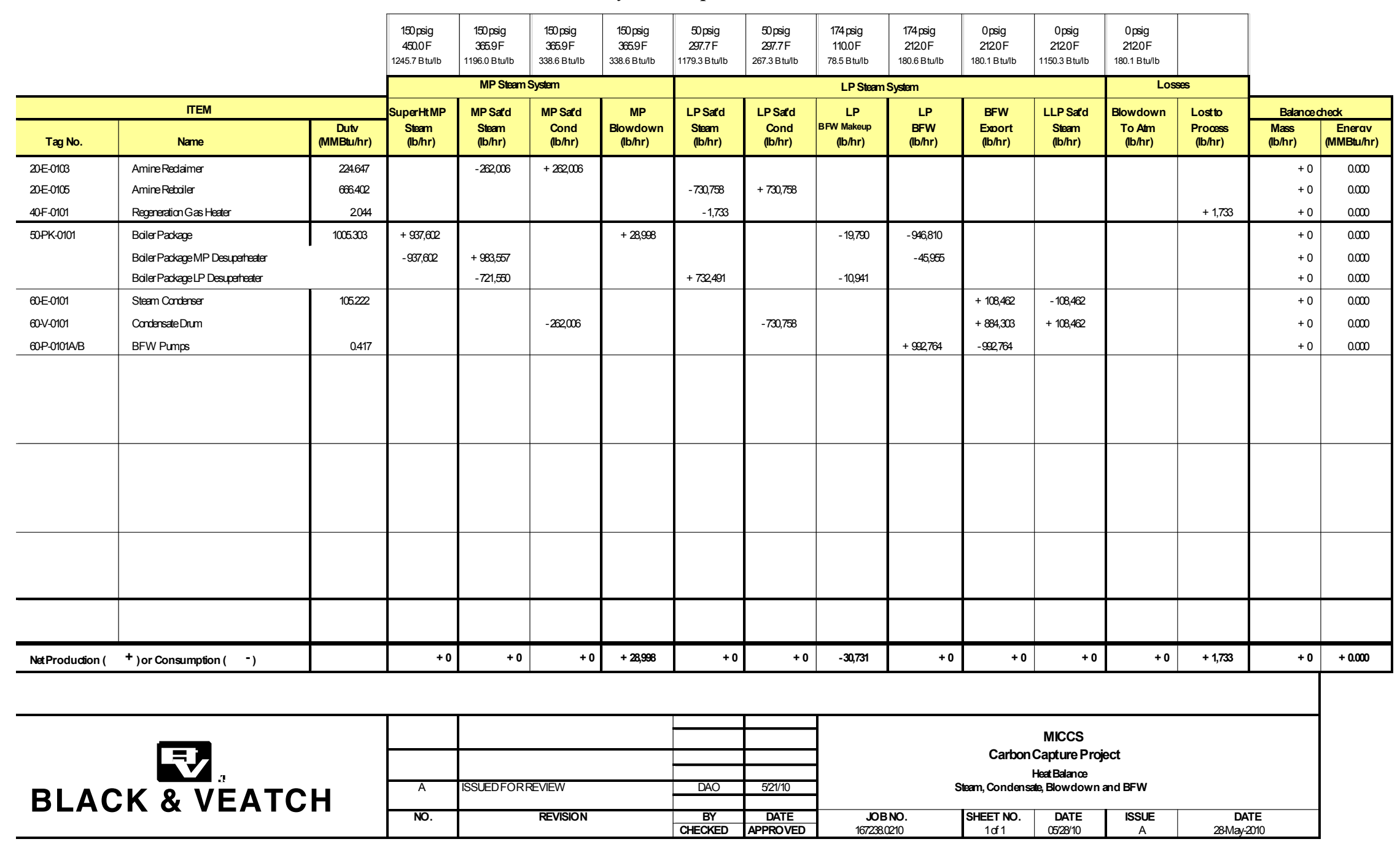


The electric load is most significantly affected by $\mathrm{CO}_{2}$ compression. Compression increases the pressure of the $\mathrm{CO}_{2}$ stream from about 12 to 2,210 psig. There are four compressors in parallel, each with six stages of compression. Between each stage of compression is common air cooling. The total motor load for $\mathrm{CO}_{2}$ compression is 32,000 hp. The next most significant demand on electric power is the amine system, which requires 5,065 hp to power the air cooler motors and pumps. Table 2-7 lists the expected electrical loads of the $\mathrm{CO}_{2}$ capture process.

\begin{tabular}{|c|c|c|c|}
\hline \multicolumn{4}{|c|}{$\begin{array}{l}\text { Table } 2-7 \\
\text { Process Electrical Load Summary }\end{array}$} \\
\hline Tag No. & Equipment Name & $\begin{array}{l}\text { Conn } \\
\text { ected }\end{array}$ & $\begin{array}{l}\text { Opera } \\
\text { ting }\end{array}$ \\
\hline \multicolumn{4}{|c|}{ Compressors } \\
\hline $\begin{array}{l}\text { 10-B- } \\
0101 \mathrm{~A} \mathrm{M}\end{array}$ & Flue Gas Blower & $\begin{array}{l}5,50 \\
0 \mathrm{hp}\end{array}$ & $\begin{array}{l}4,64 \\
1 \mathrm{hp}\end{array}$ \\
\hline $\begin{array}{r}\text { 10-B- } \\
0101 \mathrm{~B} \mathrm{M}\end{array}$ & Flue Gas Blower & $\begin{array}{l}5,50 \\
0 \mathrm{hp}\end{array}$ & \\
\hline $\begin{array}{l}\text { 30-C-0101 } \\
\text { A-D M }\end{array}$ & $\mathrm{CO}_{2}$ Compressor Stage 1 & & $\begin{array}{l}6,43 \\
6 \mathrm{hp}\end{array}$ \\
\hline $\begin{array}{l}30-\mathrm{C}-0101 \\
\text { A-D M }\end{array}$ & $\mathrm{CO}_{2}$ Compressor Stage 2 & & $\begin{array}{l}6,45 \\
6 \mathrm{hp}\end{array}$ \\
\hline $\begin{array}{l}30-\mathrm{C}-0101 \\
\text { A-D M }\end{array}$ & $\mathrm{CO}_{2}$ Compressor Stage 3 & & $\begin{array}{l}5,77 \\
6 \mathrm{hp}\end{array}$ \\
\hline $\begin{array}{l}\text { 30-C-0101 } \\
\text { A-D M }\end{array}$ & $\mathrm{CO}_{2}$ Compressor Stage 4 & & $\begin{array}{l}5,97 \\
6 \mathrm{hp}\end{array}$ \\
\hline $\begin{array}{l}30-C-0101 \\
\text { A-D M }\end{array}$ & $\mathrm{CO}_{2}$ Compressor Stage 5 & & hp 2652 \\
\hline $\begin{array}{l}\text { 30-C-0101 } \\
\text { A-D M }\end{array}$ & $\mathrm{CO}_{2}$ Compressor Stage 6 & $\begin{array}{l}32,0 \\
00 \mathrm{hp}\end{array}$ & $\begin{array}{l}4,37 \\
6 \mathrm{hp}\end{array}$ \\
\hline$M^{40-C-0101}$ & $\begin{array}{l}\text { Regeneration Gas } \\
\text { Compressor }\end{array}$ & hp 20 & hp 19.6 \\
\hline \multicolumn{4}{|l|}{ Pumps } \\
\hline $\mathrm{AM}^{10-\mathrm{P}-0101}$ & Quench Water Pump & $\mathrm{hp}^{600}$ & $\mathrm{hp} 598$ \\
\hline $\mathrm{BM}^{10-\mathrm{P}-0101}$ & Quench Water Pump & hp 600 & \\
\hline $\mathrm{AM}^{20-\mathrm{P}-0101}$ & Rich Amine Pump & hp 800 & hp 735 \\
\hline $\mathrm{BM}^{20-\mathrm{P}-0101}$ & Rich Amine Pump & hp 800 & \\
\hline $\mathrm{AM}^{20-\mathrm{P}-0102}$ & Lean Amine Pump & $0 \mathrm{hp}$ & $8 \mathrm{hp}$ \\
\hline
\end{tabular}




\begin{tabular}{|c|c|c|c|}
\hline \multicolumn{4}{|c|}{$\begin{array}{l}\text { Table 2-7 (Continued) } \\
\text { Process Electrical Load Summary }\end{array}$} \\
\hline Tag No. & Equipment Name & $\begin{array}{l}\text { Conn } \\
\text { ected }\end{array}$ & $\begin{array}{l}\text { Opera } \\
\text { ting }\end{array}$ \\
\hline 20-P-0102 & Lean Amine Pump & 1,25 & \\
\hline AM $^{20-\mathrm{P}-0103}$ & Reflux Pump & hp 25 & $\mathrm{hp} 21$ \\
\hline $\mathrm{BM}^{20-\mathrm{P}-0103}$ & Reflux Pump & 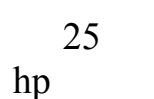 & \\
\hline $\mathrm{AM}^{20-\mathrm{P}-0104}$ & Wash Water Pump & $\mathrm{hp}{ }^{600}$ & hp 513 \\
\hline $\mathrm{BM}^{20-\mathrm{P}-0104}$ & Wash Water Pump & hp 600 & \\
\hline$M^{50-\mathrm{P}-0101}$ & Amine Sump Pump & $5 \mathrm{hp}$ & $4 \mathrm{hp}$ \\
\hline$M^{50-P-0102}$ & Amine Makeup Pump & & 16 \\
\hline 50-P-0103 & Cooling Water Circulation & 400 & 377 \\
\hline $\mathrm{AM}$ & Pump & hp & hp \\
\hline $\mathrm{BM}^{50-\mathrm{P}-0103}$ & $\begin{array}{l}\text { Cooling Water Circulation } \\
\text { Pump }\end{array}$ & hp 400 & \\
\hline \multicolumn{4}{|c|}{ Pumps (continued) } \\
\hline $\mathrm{AM}^{60-\mathrm{P}-0101}$ & Boiler Feedwater Pump & hp 350 & $\mathrm{hp}^{313}$ \\
\hline $\mathrm{BM}^{60-\mathrm{P}-0101}$ & Boiler Feedwater Pump & hp 350 & \\
\hline \multicolumn{4}{|c|}{ Air Coolers } \\
\hline $10-\mathrm{E}-0101$ & $\begin{array}{l}\text { Quench Water Cooler - } 14 \\
\text { Motors } \\
(40 \mathrm{hp})\end{array}$ & hp 560 & $\mathrm{hp}^{475}$ \\
\hline 20-E-0101 & $\begin{array}{l}\text { Amine Cooler }-40 \text { Motors } \\
(40 \mathrm{hp})\end{array}$ & $\begin{array}{l}1,60 \\
0 \mathrm{hp}\end{array}$ & $\begin{array}{l}1,34 \\
4 \mathrm{hp}\end{array}$ \\
\hline 20-E-0104 & $\begin{array}{l}\text { Condenser - } 16 \text { Motors (40 } \\
\text { hp) }\end{array}$ & hp 640 & hp 539 \\
\hline 20-E-0106 & $\begin{array}{l}\text { Wash Water Cooler - } 24 \\
\text { Motors } \\
(40 \mathrm{hp})\end{array}$ & hp 960 & hp 775 \\
\hline 30-E-0101 & $\begin{array}{l}\text { First-Stage Cooler }-10 \\
\text { Motors (40 hp) }\end{array}$ & hp 400 & hp 311 \\
\hline 30-E-0102 & $\begin{array}{l}\text { Second-Stage Cooler }-8 \\
\text { Motors } \\
(30 \mathrm{hp})\end{array}$ & hp 240 & hp 229 \\
\hline
\end{tabular}




\begin{tabular}{|c|c|c|c|}
\hline \multicolumn{4}{|c|}{$\begin{array}{l}\text { Table 2-7 (Continued) } \\
\text { Process Electrical Load Summary }\end{array}$} \\
\hline Tag No. & Equipment Name & $\begin{array}{l}\text { Conn } \\
\text { ected }\end{array}$ & $\begin{array}{l}\text { Opera } \\
\text { ting }\end{array}$ \\
\hline 30-E-0103 & $\begin{array}{l}\text { Third-Stage Cooler }-6 \\
\text { Motors (30 hp) }\end{array}$ & hp 180 & hp 166 \\
\hline 30-E-0104 & $\begin{array}{l}\text { Fourth-Stage Cooler }-6 \\
\text { Motors } \\
(25 \mathrm{hp})\end{array}$ & hp 150 & hp 142 \\
\hline 30-E-0105 & $\begin{array}{l}\text { Fifth-Stage Cooler }-4 \\
\text { Motors (30 hp) }\end{array}$ & hp 120 & hp 103 \\
\hline 30-E-0106 & $\begin{array}{l}\text { Sixth-Stage Cooler }-4 \\
\text { Motors (40 hp) }\end{array}$ & hp 160 & hp 122 \\
\hline 40-E-0101 & $\begin{array}{l}\text { Regeneration Gas Cooler }-2 \\
\text { Motors } \\
(5 \mathrm{hp})\end{array}$ & $\mathrm{hp}$ & hp 7.4 \\
\hline \multirow[t]{3}{*}{$60-E-0101$} & $\begin{array}{l}\text { Steam Condenser }-6 \text { Motors } \\
(40 \mathrm{hp})\end{array}$ & $\mathrm{hp} 240$ & $\mathrm{hp} 205$ \\
\hline & Total Motor Load & $\begin{array}{l}56,355 \\
\mathrm{hp}\end{array}$ & $\begin{array}{l}44,446 \\
\mathrm{hp}\end{array}$ \\
\hline & $\begin{array}{l}\text { Total Process Electrical } \\
\text { Load }\end{array}$ & $\begin{array}{l}56,3 \\
55 \mathrm{hp}\end{array}$ & $\begin{aligned} 44,4 \\
46 \mathrm{hp}\end{aligned}$ \\
\hline
\end{tabular}




\subsubsection{Water Balance Information}

The addition of $\mathrm{CO}_{2}$ capture will affect the existing plant water mass balance and treatment equipment. Primary impacts are as follows:

- Overall increase in heat rejection load and evaporative cooling capacity

- Redistribution of existing heat rejection load sources

- Treatment of process waste streams:

Quench purge

Amine system purge water

Water from compressor knockout drums

Water from dehydration system

- Additional raw water treatment

- Increased wastewater disposal from cooling tower blowdown

Because raw water to the site is limited to about $200 \mathrm{gpm}$, air cooling and condensate generated from cooling the flue gas minimize the amount of makeup water derived from the raw source. Without air cooling, approximately 1,800 gpm of additional raw water would be required. Air cooling and condensate from the flue gas will reduce the raw water demand to about 172 gpm.

An overall water management diagram for the $\mathrm{CO}_{2}$ capture process is shown on Figure 2-2. Raw river water will need to be treated with lime softening clarification before being used in the cooling tower, boiler package, and process. Process waste streams will also undergo a treatment step before being reused. Effluent water from demineralized water treatment and the boiler blowdown lift station will supplement makeup water to the cooling tower. The amine system will not require makeup water. Condensate from the wash water loop on the absorber will generate water, which will be reused in the amine system. A purge water stream from the stripper reflux drum containing water, some $\mathrm{CO}_{2}$, and other impurities will be treated and reused in the process.

The amine reclaimer will be flushed periodically with a caustic solution and will contain minimal water. It is recommended that this effluent be disposed of at an offsite facility. Associated disposal costs will be dependent on the waste stream's hazardous classification and have not been included in the O\&M impact costs.

On the basis of the additional cooling duty required, the IMCCS team suggests that two to four cooling tower cells would be required at design conditions. The expected cooling duty is about $115 \mathrm{MBtu} / \mathrm{h}$ for cooling water to the wash water trim cooler to the amine absorber. All other process cooling will be air-cooled.

Blowdown from the cooling tower is approximately $52 \mathrm{gpm}$ and is expected to be discharged to a nearby 5 acre evaporation pond. Intake and discharge permits will need to be reviewed and revised as necessary before any changes are made. If disposal to a pond is not permitted, partial wastewater recovery or zero liquid discharge may need to be considered. 


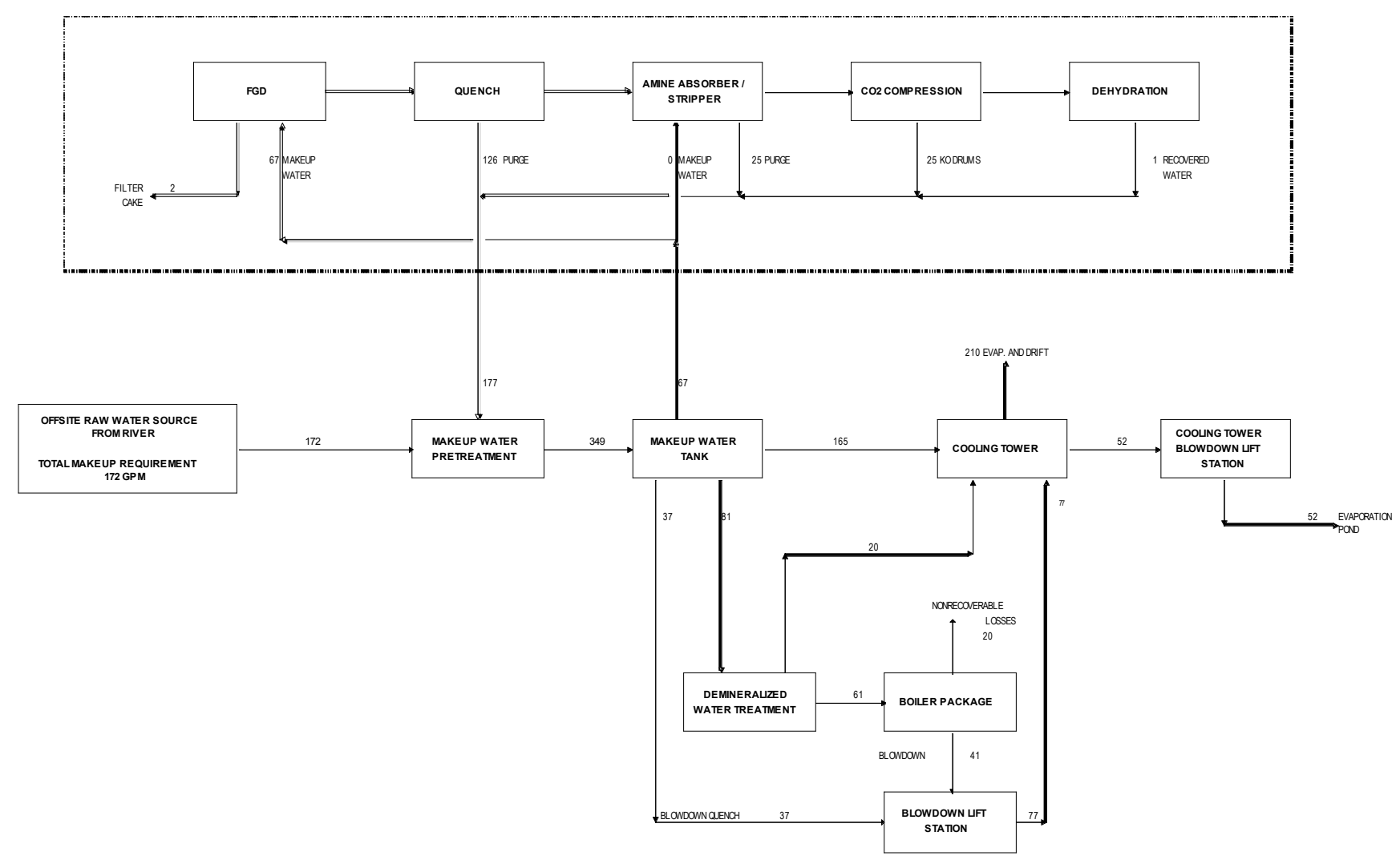

Notes:
1. Hows are in gallons per minute (GPM).

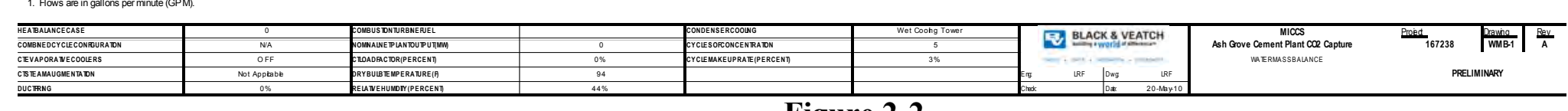

Figure 2-2

Water Mass Balance 


\subsection{Costs}

The capital expenditures required for retrofitting the Ash Grove cement plant with $\mathrm{CO}_{2}$ capture and compression systems will be significant. This section provides an orderof-magnitude overnight capital cost for 90 percent $\mathrm{CO}_{2}$ capture.

\subsubsection{Capital Costs}

The IMCCS team developed a +40/-30 percent EPC factored cost estimate for 90 percent $\mathrm{CO}_{2}$ capture equipment and installation, based on current location-specific cost considerations for the Ash Grove cement plant in Chanute, Kansas. The overnight (first quarter 2010 US dollars) cost is for all furnished and installed major equipment and bulks within the new unit boundary (550 feet by 550 feet).

Field costs include all piperack and interconnecting pipe, electrical and instrumentation cable, and trays. Many cost allowances were included for undefined, but probable elements of cost such as drains and vents, unloading/loading stations, $\mathrm{CO}_{2}$ discharge metering, utility piping and stations, site preparation with a minor allowance for demolition/relocation, a new DCS in a shared structure, a new main substation connected to the grid complete with switchgear, transformers, motor control centers, and catalyst and chemicals.

This estimate was prepared using AspenTech Capital Cost Estimator (CCE - V7.1), which is consistent with AACE International Class 4 guidance.

Process equipment costs were developed in CCE or by using other internal information based on the sized process equipment list. Considerations included capacities, design temperature and pressure, materials of construction, and other costimpacting information developed in the process design. Equipment costs in CCE were comparable to recent project costs or data of IMCCS industry partners.

$\mathrm{CCE}$ estimates the components required within the equipment envelope, such as foundations, piping, instruments, or insulation. Additionally, CCE uses specified or internally developed electrical and control systems criteria from the process equipment. It includes a library to size and price the electrical equipment. The unit costs in CCE's library are conceptually comparable to current industry standards, which allows the estimator to focus more on scope identification and less on pricing.

The direct field costs from CCE for the equipment and all components within the equipment envelope were compared with internally-developed factors to ensure consistency and reasonableness of all estimated process unit costs.

Scope components were added to the estimate for the balance-of-plant costs such as sitework, metering, interconnecting pipe and piperacks, buildings, and initial fill. The source for this scope includes the plot plan and equipment arrangement drawings and confirmed extensive assumptions provided by members of the IMCCS project team.

A single common labor rate of $\$ 65$ was included in the direct labor costs, which includes burden and benefits, temporary construction, and other field labor markups. Costs were estimated separately for freight, construction equipment, and scaffolding, which are included in the field indirects. A construction field labor productivity adjustment of 5 percent was added as a location adjustment.

Significant exclusions for this estimate include the following: 
- Escalation beyond first quarter 2010.

- Future expansion and capacity.

- Offsite haul or access roads and bridges.

- Owner's costs.

Table 2-8 presents a breakdown of the expected total installed cost between direct and indirect costs.

Table 2-8

Capital Cost for 90 Percent $\mathrm{CO}_{2}$ Capture Equipment and Installation

\begin{tabular}{|l|l|}
\hline Direct Costs, \$ million & 271 \\
Indirect Costs, \$ million & 108 \\
\hline Total Installed Cost, \$ million & 379 \\
\hline
\end{tabular}

\subsubsection{O\&M Costs}

Estimated O\&M costs for the $\mathrm{CO}_{2}$ equipment include solvent replacement, water treatment, additional staff, and maintenance materials and contracts. A significant unknown in the amine-based operating cost estimate is the amine degradation and, therefore, the amount of replacement amine that would be required. Table 2-9 provides estimates of the O\&M costs based on an estimated low rate of amine degradation, an estimated high rate of amine degradation, and the average of the two. Costs for fuel, makeup power, and the disposal of waste products are excluded. 
Table 2-9

O\&M Costs for 90 Percent $\mathrm{CO}_{2}$ Capture (\$ million 2010 US)

\begin{tabular}{|c|c|c|c|}
\hline & Low & High & $e^{\text {Averag }}$ \\
\hline \multicolumn{4}{|l|}{ Fixed } \\
\hline Number of Staff & 15 & 15 & 15 \\
\hline Staff Costs, \$ million/yr & 1.8 & 1.8 & 1.8 \\
\hline Other Fixed Costs, \$ million/yr & 0.5 & 0.5 & 0.5 \\
\hline Total Fixed O\&M Costs, \$ million/yr & 2.3 & 2.3 & 2.3 \\
\hline \multicolumn{4}{|l|}{ Variable } \\
\hline $\begin{array}{l}\text { Maintenance Materials and } \\
\text { Contracts, } \$ \text { million/yr }\end{array}$ & 3.0 & 3.0 & 3.0 \\
\hline $\begin{array}{l}\text { Non-solvent Chemicals and } \\
\text { Consumables, \$ million/yr }\end{array}$ & 1.2 & 2.2 & 1.7 \\
\hline Amine Solvent Cost, \$million/yr & 1.0 & 5.0 & 3.0 \\
\hline $\begin{array}{l}\text { Total Variable O\&M Costs, } \$ \\
\text { million/yr }\end{array}$ & 5.2 & 10.2 & 7.7 \\
\hline Total O\&M Costs, \$million/yr & 7.5 & 12.5 & 10.0 \\
\hline
\end{tabular}

\subsubsection{Economic Analysis}

Present value costs of $\mathrm{CO}_{2}$ capture are provided in Table 2-10. The present value cost was determined by taking the net present value of the capital and O\&M costs over a 20 year time period and solving for the required selling price of $\mathrm{CO}_{2}$ that gives a break-even net present value. To set boundaries on the price of $\mathrm{CO}_{2}$, the IMCCS team calculated the low $\mathrm{CO}_{2}$ price using the low capital cost (estimated at -30 percent) with the low O\&M cost estimate and the high $\mathrm{CO}_{2}$ price using the high capital cost (estimated at +40 percent) with the high O\&M cost estimate. The capital costs listed in this section include 25 percent for Owner's costs.

Table 2-10

Low and High Present Value Costs of $\mathrm{CO}_{2}$

\begin{tabular}{|l|l|l|}
\hline & Low & High \\
\hline Capacity Factor, percent & 80 & 80 \\
Overnight Capital Cost, \$million & 332 & 663 \\
Current Cost of Natural Gas, & 4.50 & 4.50 \\
\$/MBtu & 50 & 50 \\
Current Busbar Cost, \$/MWh & 5.2 & 10.2 \\
Current O\&M Cost, \$million/year & 60 & 88 \\
\hline Present Value Price of $\mathrm{CO}_{2}, \$$ ton & 60 \\
\hline
\end{tabular}




\subsection{Conclusion}

The Ash Grove $\mathrm{CO}_{2}$ capture plant operating at 80 percent capacity factor and capturing 90 percent of the $\mathrm{CO}_{2}$ generated would capture approximately 1.4 million tons (1.27 million tonnes) per year. We suggest that the primary technology concern with adding $\mathrm{CO}_{2}$ capture to the Ash Grove plant is that amine-based $\mathrm{CO}_{2}$ scrubbing technology has not yet been demonstrated at the proposed scale. Because this technology has not been demonstrated at scale in the cement manufacturing industry, there is a scaleup risk associated with implementing amine-based, post-combustion $\mathrm{CO}_{2}$ capture in its current state of development. However, given the smaller scale of the cement plant when compared to most power plants, and the fact that significant modifications would be required to the steam cycle to integrate $\mathrm{CO}_{2}$ capture into a conventional power plant, this could represent a good opportunity for a commercial-scale demonstration of an aminebased technology. We also suggest that improvements and optimizations will be forthcoming from current and future development work, and that large-scale amine-based capture systems will be commercially available in about 5 years.

The cement plant would require significant modification to add $\mathrm{CO}_{2}$ capture and compression. In addition to the $\mathrm{CO}_{2}$ equipment, a package boiler would be needed to provide the steam required for stripping. Flue gas emissions control equipment would need to be added to reduce the sulfur compounds and possibly the $\mathrm{NO}_{\mathrm{x}}$ in the flue gas to a level where they would not produce excessive heat stable salts by reaction with the amine. The IMCCS team suggests that additional water treatment equipment would be needed to treat the raw water and the wastewater from the system.

At this time, the capital and operating costs are extremely high. However, opportunities exist to reduce these costs somewhat as the process and solvents are improved. Based on the assumptions described in this chapter and the upper and lower limits to the capital and O\&M cost estimates, the IMCCS team suggests that the $\mathrm{CO}_{2}$ produced in this system would have to be sold for between $\$ 60$ and $\$ 88$ per ton in order to produce a break-even net present value for the project. Even for the low value of $\mathrm{CO}_{2}$, we do not believe that the cost would be competitive in future $\mathrm{CO}_{2}$ markets. 


\section{CHAPTER 3 - Transportation}

\subsection{Thrall-Aagard Field}

\subsubsection{PIPELINE ROUTING}

\subsubsection{General}

Refer to the Drawings Section of this report, Appendix 3-A, Drawing Numbers 2703-M-001 to 02703-M-007 for Overview Maps of the proposed Thrall-Aagard pipeline route. Refer to Drawing Numbers 2703-M-101 to 02703-M-125 for the Alignment Sheets showing detailed sections of land ownership, environmental restrictions, plan view, ground profile, general material specifications, etc.

The pipeline will originate at the Coffeyville Resources Fertilizer Plant (CVR) and generally traverse in a north-westerly direction paralleling existing pipeline corridors for 59 miles (95 kilometers). It will then traverse 49 miles ( 79 kilometers) in a north-easterly direction following existing pipeline corridors where it will terminate at the ThrallAagard Oil Field (TAF).

\subsubsection{Alternate Routes}

While selecting the route for the CVR-TAF pipeline, two substantially alternate routes were considered. The first alternate route followed existing pipeline corridors in a north-easterly direction from Coffeyville, and then turned in a north-westerly direction at approximately Mile Post 56, towards the Thrall-Aagard Oil Field. This route was approximately the same distance at the proposed route. This northern route was not selected due to the higher percentage of cultivated land use and a higher population density than the proposed route.

The second alternate route followed over-head power line corridors, and was more direct than the proposed route or the northern alternate route. This alternate was approximately 8 miles (13 kilometers) shorter than the proposed route. Since this route paralleled over-head power lines, additional cathodic protection measures would be required to protect the pipeline from alternating currents $(\mathrm{AC})$, such as a zinc ribbon. This would add unnecessary cost, complexity, and safety concerns to the project.

In addition to the above analysis, the proposed route also provides better opportunity to expand the carbon dioxide supply to other oil fields in Kansas and Oklahoma, such as the El Dorado Field.

\subsubsection{Right-of-Way Acquisition}

A desktop review of the pipeline right-of-way indicates that $100 \%$ of the right-ofway is private. The right-of-way includes mostly cultivated and prairie lands. This study includes estimated costs for obtaining easements from the private land owners to install the proposed pipeline. The precise number of land owners and parcels was not determined during this study. Only the creek crossings, roads, highways, etc. are not privately owned, and come under state and federal guidelines. 
Disturbance would occur within a 75-foot wide temporary ROW construction corridor. This width should be sufficient to accommodate construction in most areas. However, additional construction space would be required if another pipeline must be crossed, to temporarily store pipe and equipment, and/or to accommodate construction requirements for a certain area (e.g., road and river crossings, steep slopes).

New access roads would not be required for the project during construction. Construction access would be via the pipeline ROW and existing regional access roads. However, during construction it may be determined that additional access is needed.

\subsubsection{Permitting}

Numerous Federal, State and County permits will be required for the construction of the CVR-TAF Pipeline.

For example, some of the permits required under Federal jurisdiction shall be National Environmental Policy Act (NEPA), Corps of Engineers Nationwide Permit, United States Fish and Wildlife Services. Some of the permits required under the State of Kansas jurisdiction shall be Department of Health and Environment, (Air Quality, Water Discharge, General), National Historic Preservation Act, Wildlife and Parks, Kansas Highway Department. Some of the permits required under the County jurisdiction shall be Road and Bridge Departments. Only permits required for construction have been included within this estimate, therefore the NEPA permit, COE, etc. have been excluded from this budget.

\subsubsection{Pipeline System Description}

The purpose of the CVR-TAF Pipeline is to transport compressed high-purity $\mathrm{CO}_{2}$ via a 8" steel intra-state pipeline from the Coffeyville Resources Fertilizer Plant to the Thrall-Aagard Oil Field for both sequestration and enhanced oil recovery purposes.

The pipeline will be designed, constructed and operated in accordance to Title 49, Part 195, "Transportation of Hazardous Liquids by Pipeline" - Department of Transportation, rules and regulations.

The pipeline will be composed of 8.625" O.D., 0.500" wall thickness, API 5L, PSL2, Electric Resistance Welded (ERW) steel line pipe, coated with 14-16 mils of Fusion Bond Epoxy for external corrosion protection. The pipeline will be designed to be operated at a Maximum Operating Pressure of 2,800 PSIG, with an ANSI 1500 flange rating.

All road, railroad and creek crossing pipes will be manufactured to Seamless line pipe specifications instead of ERW to further mitigate fracture propagation.

Carbon Dioxide must be compressed to approximately 2,548 PSIG at the Coffeyville Resources Fertilizer Plant in order to deliver it to the Thrall-Aagard Oil Field at 1,400 PSIG. These operating pressures were utilized to provide a reasonable margin between the operating pressures in the pipeline and the critical pressure of carbon dioxide, which is approximately 1,100 PSIA at $50^{\circ} \mathrm{F}$. Operating at pressures above the critical pressure ensures that the carbon dioxide is transported in the dense phase and that no phase changes occur in the pipeline system. Transporting carbon dioxide in dense-phase is the most efficient means of transportation since it allows for smaller pipeline sizes at high flow rates. 
Isolation Block Valves will be strategically located in the pipeline system, as shown in Table 3-1 to isolate the pipeline and blow the Carbon Dioxide down in case of an emergency.

Table 3-1 CVR-TAF Estimated Isolation Block Valves

\begin{tabular}{|l|l|l|}
\hline No. & Pipeline Station & Mile Post \\
\hline 1 & $115+00$ & MP 2.18 \\
\hline 2 & $215+00$ & MP 4.07 \\
\hline 3 & $505+00$ & MP 9.56 \\
\hline 4 & $1095+00$ & MP 20.74 \\
\hline 5 & $1590+00$ & MP 30.11 \\
\hline 6 & $2055+00$ & MP 38.92 \\
\hline 7 & $2640+00$ & MP 50.00 \\
\hline 8 & $2790+00$ & MP 54.55 \\
\hline 9 & $2880+00$ & MP 59.47 \\
\hline 10 & $3140+00$ & MP 69.98 \\
\hline 11 & $3695+00$ & MP 74.62 \\
\hline 12 & $3940+00$ & MP 75.76 \\
\hline 13 & $4000+00$ & MP 79.55 \\
\hline 14 & $4200+00$ & MP 89.11 \\
\hline 15 & $4705+00$ & MP 95.08 \\
\hline 16 & $5020+00$ & MP 96.21 \\
\hline 17 & $5080+00$ & MP 100.47 \\
\hline 18 & $5305+00$ & \\
\hline
\end{tabular}

Crack arrestor will be installed at every half mile ( 0.8 kilometers) on the steel pipeline to mitigate fracture propagation. It is anticipated that Clock Springs, or similar product, will be utilized as crack arrestors. This type of product has been successfully utilized as crack arrestors on existing carbon dioxide pipelines.

The pipeline will be designed and constructed to accommodate intelligent pigs. Pig launcher and receiver will be installed into the system.

\subsubsection{PIPELINE HYDRAULICS}

\subsubsection{Purpose}

The purpose of this pipeline hydraulic calculation was to analyze the predicted performance of the Coffeyville Resources Nitrogen Fertilizer Plant to Thrall-Aagard oil field (CVR-TAF) carbon dioxide pipeline under various operating scenarios. In general, the results from the hydraulic calculation include resulting pressures, resulting temperatures, resulting velocities, and line size confirmation. Hydraulic scenarios were completed for three potential line sizes.

\subsubsection{Pipeline Routing}

The scope of the hydraulic study was limited to the preferred route. This route heads in a north-westerly direction from Coffeyville and turns north-east at approximately Mile Post 58 towards the Thrall-Aagard oil field. The preferred route is approximately 108.2 miles (174 kilometers) in length. The carbon dioxide delivery point 
at the Thrall-Aagard Oil field is located at the north-west corner of Section 31, Township 23S, Range 10E.

\subsubsection{Hydraulic Modeling Software}

PIPEPHASE Version 9.4 was used to model the hydraulics of the carbon dioxide pipeline. This software has the capability of predicting the mechanical and thermodynamic properties of dense-phase carbon dioxide and can model steady-state carbon dioxide flow in pipeline networks.

\subsubsection{Hydraulic Design Basis - Pressure Requirements}

For this hydraulic study, the delivery pressure at the Thrall-Aagard oil field was fixed at 1,400 PSIG. This pressure was utilized to provide a reasonable margin between the operating pressures in the pipeline and the critical pressure of carbon dioxide, which is approximately 1,100 PSIA at $50^{\circ} \mathrm{F}$. Operating at pressures above the critical pressure ensures that the carbon dioxide is transported in the dense phase and that no phase changes occur within the pipeline.

At the Thrall-Aagard oil field, a pressure reduction valve will be installed to reduce the pressure of the carbon dioxide from the 1400 PSIG to the well head injection pressure of approximately 1,100 PSIG.

The carbon dioxide pipeline will be designed and constructed per CFR 49 Part 195 "Transportation of Hazardous Liquids by Pipeline." A design factor (F) of 0.72 was used for allowable stress calculations and determination of the Maximum Operating Pressure (MOP). Based on the hydraulic results, an appropriate ANSI rating for the pipeline was selected.

\subsubsection{Hydraulic Design Basis - Capacity Requirements}

The baseline capacity for the pipeline design is 40 MMSCFD. This corresponds to the maximum anticipated carbon dioxide availability from the Coffeyville Resources Nitrogen Fertilizer Plant at its current configuration. Initial hydraulic runs were also completed to confirm that the selected line size is capable of additional capacity, with the addition of intermediate pump stations.

\subsubsection{Hydraulic Design Basis - Fluid Temperatures}

It is anticipated that the carbon dioxide discharge temperature from the originating compressor / pump station at Coffeyville will be a maximum of $120^{\circ} \mathrm{F}$. Therefore, the design temperature for the pipeline system was selected to be $130^{\circ} \mathrm{F}$.

In the hydraulic model, an ambient ground temperature of $50^{\circ} \mathrm{F}$ was selected based on research of soil temperatures published by the USDA. The USDA has published maps of soil temperature regimes for the contiguous United States (http://soils.usda.gov/use/thematic/temp_regimes.html). Based on this map, the project area is located near the boundary of the Mesic and Thermic soil temperature regimes. The Mesic soil regime is defined as having a mean annual soil temperature between $8^{\circ} \mathrm{C}$ $\left(46.4^{\circ} \mathrm{F}\right)$ and $15^{\circ} \mathrm{C}\left(59.0^{\circ} \mathrm{F}\right)$. The Thermic soil regime is defined as having a mean annual soil temperature between $15^{\circ} \mathrm{C}\left(59.0^{\circ} \mathrm{F}\right)$ and $22^{\circ} \mathrm{C}\left(71.6^{\circ} \mathrm{F}\right)$. Since the project 
area is on the boundary of these two regimes, the mean annual soil temperature was assumed to be $15^{\circ} \mathrm{C}\left(59.0^{\circ} \mathrm{F}\right)$.

Using the mean annual soil temperature and anticipated depth of burial, the amplitude of seasonal soil temperature change can be determined. For dry soil at a burial depth of 4 feet, the amplitude of seasonal temperature change is approximately $\pm 10^{\circ} \mathrm{F}$ (http://www.geo4va.vt.edu/A1/A1.htm). Therefore, the lowest anticipated soil temperature is approximately $50^{\circ} \mathrm{F}$, which was taken as the ambient soil temperature in the hydraulic model.

\subsubsection{Hydraulic Design Basis - Carbon Dioxide Composition Analysis}

The anticipated composition of fluid stream was provided by Coffeyville Resources Nitrogen Fertilizer Plant and is included as Appendix 3-A to this report. These compositions were modified to reflect the dehydration process needed to meet the dehydrated carbon dioxide specification of $10 \mathrm{lb} \mathrm{H2O} /$ MMSCFD allowable. The below composition (Table 3-2) corresponds to the fluid stream anticipated in the pipeline, which was used in the hydraulic model.

Table 3-2 CVR-TAF Pipeline Compositional Analysis

\begin{tabular}{|l|l|}
\hline Component & Mole Fraction \\
\hline $\mathrm{N} 2$ & 0.000000 \\
\hline $\mathrm{CO}_{2}$ & 0.998890 \\
\hline $\mathrm{H} 2 \mathrm{O}$ & 0.000211 \\
\hline $\mathrm{AR}$ & 0.000040 \\
\hline $\mathrm{CO}$ & 0.000100 \\
\hline $\mathrm{COS}$ & 0.000020 \\
\hline $\mathrm{O} 2$ & 0.000000 \\
\hline $\mathrm{H} 2$ & 0.000700 \\
\hline $\mathrm{CH} 4$ & 0.000040 \\
\hline TOTAL & $\mathbf{1 . 0 0 0 0 0 0}$ \\
\hline
\end{tabular}

\subsubsection{Hydraulic Design Basis - Assumed Mechanical and Thermodynamic Properties}

The table below (Table 3-3) contains the mechanical and thermodynamic parameters that were assumed in the hydraulic model of the carbon dioxide pipeline. The parameters were selected based on various published charts and tables, and project specific requirements. 
Table 3-3 Assumed Mechanical and Thermodynamic Parameters

\begin{tabular}{|l|l|}
\hline Design Parameter & Value \\
\hline Steel Absolute Roughness & $0.00360 \mathrm{IN}$ \\
\hline Flow Efficiency Factor & 95.00 PERCENT \\
\hline Steel Heat Conductivity & $26.500 \mathrm{BTU} / \mathrm{HR}-\mathrm{FT}-{ }^{\circ} \mathrm{F}$ \\
\hline Soil Heat Conductivity & $0.960 \mathrm{BTU} / \mathrm{HR}-\mathrm{FT}-{ }^{\circ} \mathrm{F}$ \\
\hline Ground Temperature & $50^{\circ} \mathrm{F}$ \\
\hline Burial Depth & $48.0 \mathrm{IN}$ (4 FT) \\
\hline Pressure Drop Correlation & BEGGS-BRILL WITH MOODY FRICTION \\
& FACTOR \\
\hline Bulk Modulus of Pipe & $30,000,000$ PSI \\
\hline Bulk Modulus of $\mathrm{CO}_{2}$ & 22,888 PSI \\
\hline
\end{tabular}

\subsubsection{Hydraulic Design Basis - Elevation Profile}

The elevation profile utilized in the hydraulic model was created from available digital elevation models (DEM's) for the project area. The same elevation profile can be found on the attached Alignment Sheet drawings. No field survey data was gathered to create the pipeline elevation profile.

\subsubsection{Hydraulic Design Basis - Surge Pressure}

Surge pressure, also known as water hammer, is the result of a rapid increase in pressure which occurs when the liquid velocity is suddenly changed in a closed piping system. Per CFR 49 Part 195, temporary pressure excursions must be limited to less than $110 \%$ of the design pressure. Surge pressure in dense-phase carbon dioxide pipelines is not well documented; therefore, the standard surge pressure equations were used in the hydraulic model, with appropriate substitutions for liquid density and bulk modulus. The bulk modulus of a fluid is the ratio of the pressure stress to the volumetric strain. The bulk modulus of carbon dioxide was estimated from property tables, calculated by considering the change in density corresponding to a change in pressure.

Surge pressures in dense phase carbon dioxide pipelines are not as great as that in water pipelines, due to the compressibility of the fluid. This is evident in the bulk modulus of carbon dioxide compared to the bulk modulus of water.

\subsubsection{Results}

This section summarizes the results obtained from the hydraulic modeling of the carbon dioxide pipeline. Table 3-4 defines the parameters for the various hydraulic cases. 
Table 3-4 Hydraulic Case Definitions

\begin{tabular}{|c|c|c|c|}
\hline Parameter & Case 1 - 8” & Case 2 - 10" & Case 3 - 12" \\
\hline Volumetric Flowrate & 40 MMSCFD & 40 MMSCFD & $40 \mathrm{MMSCFD}$ \\
\hline Mass Flowrate & $193,124 \mathrm{lb} / \mathrm{hr}$ & $193,124 \mathrm{lb} / \mathrm{hr}$ & $193,124 \mathrm{lb} / \mathrm{hr}$ \\
\hline $\begin{array}{l}\text { Pipeline Outer } \\
\text { Diameter }\end{array}$ & $8.625 "$ & $10.750 "$ & $12.750 "$ \\
\hline $\begin{array}{l}\text { Pipeline Wall } \\
\text { Thickness }\end{array}$ & $0.500 "$ & $0.438^{\prime \prime}$ & $0.375^{\prime \prime}$ \\
\hline Corrosion Allowance & $1 / 8 "(0.125 ")$ & $1 / 8 "(0.125 ")$ & $1 / 8 "(0.125 ")$ \\
\hline $\begin{array}{l}\text { Effective Wall } \\
\text { Thickness }\end{array}$ & $0.375 "$ & $0.313 "$ & $0.250 "$ \\
\hline Pipeline Grade & $\mathrm{X}-65$ & $\mathrm{X}-65$ & X-65 \\
\hline Design Factor & 0.72 & 0.72 & 0.72 \\
\hline Required System MOP & 2,800 PSIG & 2,100 PSIG & 1,800 PSIG \\
\hline Pipe MOP & 4,069 PSIG & 2,725 PSIG & 1,835 PSIG \\
\hline ANSI Class & ANSI 1500 & ANSI 900 & ANSI 900 \\
\hline ANSI Rating at $130^{\circ} \mathrm{F}$ & 3,606 PSIG & 2,161 PSIG & 2,161 PSIG \\
\hline
\end{tabular}

The resulting operating pressures and maximum surge pressures are summarized in Table 3-5. Hydraulic charts, showing the ground elevation, pressure, and surge pressure, have also been completed and are included as Appendix 3-B to this report.

Table 3-5 Pipeline Pressure Results

\begin{tabular}{|l|l|l|l|}
\hline Parameter & Case 1 - 8” & Case 2 - 10" & Case 3 - 12" \\
\hline CVR Discharge & 2,548 PSIG & 1,878 PSIG & 1,726 PSIG \\
\hline Mile Post 10 & 2,427 PSIG & 1,831 PSIG & 1,694 PSIG \\
\hline Mile Post 20 & 2,308 PSIG & 1,774 PSIG & 1,652 PSIG \\
\hline Mile Post 30 & 2,267 PSIG & 1,792 PSIG & 1,684 PSIG \\
\hline Mile Post 40 & 2,063 PSIG & 1,650 PSIG & 1,555 PSIG \\
\hline Mile Post 50 & 1,960 PSIG & 1,607 PSIG & 1,527 PSIG \\
\hline Mile Post 60 & 1,730 PSIG & 1,439 PSIG & 1,373 PSIG \\
\hline Mile Post 70 & 1,656 PSIG & 1,425 PSIG & 1,373 PSIG \\
\hline Mile Post 80 & 1,594 PSIG & 1,423 PSIG & 1,384 PSIG \\
\hline Mile Post 90 & 1,642 PSIG & 1,530 PSIG & 1,505 PSIG \\
\hline Mile Post 100 & 1,510 PSIG & 1,459 PSIG & 1,448 PSIG \\
\hline TAF Delivery & 1,400 PSIG & 1,400 PSIG & 1,400 PSIG \\
\hline \hline Min Pipeline Pressure & 1,385 PSIG & 1,381 PSIG & 1,348 PSIG \\
\hline Max Pipeline Pressure & 2,546 PSIG & 1,878 PSIG & 1,728 PSIG \\
\hline Max Surge Pressure & 2,599 PSIG & 1,923 PSIG & 1,761 PSIG \\
\hline
\end{tabular}

The resulting temperatures are summarized in the table below (Table 3-6). 
Table 3-6 Pipeline Temperature Results

\begin{tabular}{|l|l|l|l|}
\hline Parameter & Case 1 - 8” & Case 2 - 10” & Case 3 - 12” \\
\hline CVR Discharge & $120^{\circ} \mathrm{F}$ & $120^{\circ} \mathrm{F}$ & $120^{\circ} \mathrm{F}$ \\
\hline Mile Post 10 & $79^{\circ} \mathrm{F}$ & $84^{\circ} \mathrm{F}$ & $86^{\circ} \mathrm{F}$ \\
\hline Mile Post 20 & $61^{\circ} \mathrm{F}$ & $64^{\circ} \mathrm{F}$ & $65^{\circ} \mathrm{F}$ \\
\hline Mile Post 30 & $54^{\circ} \mathrm{F}$ & $56^{\circ} \mathrm{F}$ & $56^{\circ} \mathrm{F}$ \\
\hline Mile Post 40 & $51^{\circ} \mathrm{F}$ & $51^{\circ} \mathrm{F}$ & $52^{\circ} \mathrm{F}$ \\
\hline Mile Post 50 & $50^{\circ} \mathrm{F}$ & $50^{\circ} \mathrm{F}$ & $50^{\circ} \mathrm{F}$ \\
\hline Mile Post 60 & $49^{\circ} \mathrm{F}$ & $49^{\circ} \mathrm{F}$ & $49^{\circ} \mathrm{F}$ \\
\hline Mile Post 70 & $50^{\circ} \mathrm{F}$ & $50^{\circ} \mathrm{F}$ & $50^{\circ} \mathrm{F}$ \\
\hline Mile Post 80 & $50^{\circ} \mathrm{F}$ & $50^{\circ} \mathrm{F}$ & $50^{\circ} \mathrm{F}$ \\
\hline Mile Post 90 & $51^{\circ} \mathrm{F}$ & $51^{\circ} \mathrm{F}$ & $51^{\circ} \mathrm{F}$ \\
\hline Mile Post 100 & $50^{\circ} \mathrm{F}$ & $50^{\circ} \mathrm{F}$ & $50^{\circ} \mathrm{F}$ \\
\hline TAF Delivery & $50^{\circ} \mathrm{F}$ & $50^{\circ} \mathrm{F}$ & $50^{\circ} \mathrm{F}$ \\
\hline
\end{tabular}

The resulting velocities are summarized in the table below (Table 3-7). Results for pipeline segment inlet velocity are reported in feet per second (fps).

Table 3-7 Pipeline Velocity Results

\begin{tabular}{|l|l|l|l|}
\hline Parameter & Case 1 - 8” & Case 2 - 10” & Case 3 - 12” \\
\hline CVR to MP 10 & $3.14 \mathrm{fps}$ & $2.69 \mathrm{fps}$ & $1.99 \mathrm{fps}$ \\
\hline MP 10 to MP 20 & $3.07 \mathrm{fps}$ & $1.93 \mathrm{fps}$ & $1.33 \mathrm{fps}$ \\
\hline MP 20 to MP 30 & $2.93 \mathrm{fps}$ & $1.81 \mathrm{fps}$ & $1.23 \mathrm{fps}$ \\
\hline MP 30 to MP 40 & $2.88 \mathrm{fps}$ & $1.76 \mathrm{fps}$ & $1.20 \mathrm{fps}$ \\
\hline MP 40 to MP 50 & $2.87 \mathrm{fps}$ & $1.75 \mathrm{fps}$ & $1.19 \mathrm{fps}$ \\
\hline MP 50 to MP 60 & $2.88 \mathrm{fps}$ & $1.74 \mathrm{fps}$ & $1.19 \mathrm{fps}$ \\
\hline MP 60 to MP 70 & $2.90 \mathrm{fps}$ & $1.75 \mathrm{fps}$ & $1.19 \mathrm{fps}$ \\
\hline MP 70 to MP 80 & $2.92 \mathrm{fps}$ & $1.76 \mathrm{fps}$ & $1.19 \mathrm{fps}$ \\
\hline MP 80 to MP 90 & $2.93 \mathrm{fps}$ & $1.76 \mathrm{fps}$ & $1.19 \mathrm{fps}$ \\
\hline MP 90 to MP 100 & $2.93 \mathrm{fps}$ & $1.76 \mathrm{fps}$ & $1.19 \mathrm{fps}$ \\
\hline MP 100 to TAF & $2.94 \mathrm{fps}$ & $1.76 \mathrm{fps}$ & $1.19 \mathrm{fps}$ \\
\hline
\end{tabular}

\subsubsection{Recommendation}

Based on the hydraulic results, it is recommended that 8 " 0.500 " Wall Thickness, Grade X-65 pipe be utilized for the CVR-TAF pipeline. This corresponds to the hydraulic results from Case 1 in the above tables. The operating pressures for this case are within common operating pressures of other existing carbon dioxide pipelines.

Cost metrics (dollar per inch-mile for pipeline and dollar per horsepower for stations) were applied to the various pipeline and station scenarios, and it was determined that the additional cost to install the larger diameter pipeline was not offset by the reduced horsepower requirement. The below table (Table 3-8) summarizes this cost comparison. This method will give an approximate, order of magnitude, cost difference for the various options. A detailed cost estimate has been created for the recommended 8 " option (Case 1) and is included in Appendix 3-C of this report. 
Table 3-8 Pipeline Cost Comparison

\begin{tabular}{|l|l|c|c|}
\hline Parameter & Case 1 - 8” & Case 2 - 10” & Case 3 - 12” \\
\hline Pipeline Metric & $\$ 35,000 /$ in-mi & $\$ 35,000 /$ in-mi & $\$ 35,000 /$ in-mi \\
\hline Pipeline Diameter & $8.625 \%$ & $10.75 \%$ & $12.75 \%$ \\
\hline Pipeline Length & $\begin{array}{c}108 \text { miles }(174 \\
\text { kilometers) }\end{array}$ & $\begin{array}{c}108 \text { miles }(174 \\
\text { kilometers) }\end{array}$ & $\begin{array}{c}108 \text { miles (174 } \\
\text { kilometers) }\end{array}$ \\
\hline Station Metric & $\$ 3,000$ per BHP & $\$ 3,000$ per BHP & $\$ 3,000$ per BHP \\
\hline Differential BHP & 503 BHP & 302 BHP & 225 BHP \\
\hline $\begin{array}{c}\text { Approx Differential } \\
\text { cost }\end{array}$ & Baseline & $\$ 7,400,000$ & $\$ 14,760,00$ \\
\hline
\end{tabular}

Note that the above listed horsepower requirements do not include the horsepower of the blower or the initial compression to 1,400 PSIG, since these are the same for all three scenarios.

Additional preliminary hydraulic cases were completed to confirm that the 8 " pipeline would be capable of additional capacity at a future date. It was confirmed that the 8" pipeline could transport 80 MMSCFD, with the addition of two intermediate booster stations, at Mile Post 36 and Mile Post 72.

\subsubsection{COMPRESSION AND PROCESS STUDY}

\subsubsection{General Facility Description}

Prior to delivery of the carbon dioxide to the Thrall-Aagard Oil Field, the raw vapor stream off of the Coffeyville Resources amine plant will need to be processed to facilitate miscibility with the crude oil and boosted to pipeline pressure to allow the purified carbon dioxide stream to be transported as a supercritical fluid rather than in the vapor phase, minimizing both pipeline diameter and horsepower requirements, as well as providing the necessary pressure for injection in the oil reservoir. The compression and processing facilities on the CVR-TAF pipeline will require compression and pumping equipment to take the raw carbon dioxide stream from approximately 2 psig to the required pipeline discharge pressure of 2,548 PSIG and dehydration to take the water content to a concentration of less than $200 \mathrm{ppm}$. Three blower compressors will be installed near the ammonia plant process unit within the Coffeyville plant, and will transport the carbon dioxide through a 24" HDPE conduit to the proposed compressor site. At the proposed compressor site, an integrated centrifugal compressor / pump package will be installed. Inter-stage coolers and dehydration equipment will also be installed. For more detail, see the Process Flow Diagram, 02703-F-001. Controls and operation of the CVR compression facilities will be located in a common, pre-engineered, electrical Power Distribution Center ("PDC") located on-site with the specified compression and processing equipment. A process flow diagram and conceptual site layout have been provided in the drawings section of this report.

\subsubsection{Reciprocating and Centrifugal Compressor Comparison Study}

\subsubsection{General}

Transportation of dense phase carbon dioxide is growing application in the oil and gas industry and incorporates three primary compression technologies: reciprocating 
compressors, centrifugal compressors, and recently integrally geared solutions. Prior to selection of the specified compression equipment for this application, a study was completed to compare these technologies, including their associated annual and 9-year operation and maintenance costs.

\subsubsection{Discussion}

Reciprocating compressors consist of one or more cylinders, each with a piston or plunger which displaces a positive volume of gas with each stroke. Centrifugal compressors consist of a rotating element, typically an impeller or bladed rotor, which accelerates the gas as it passes through the compressor, converting the velocity head into static pressure. Both types of compressors are available in single and multi-stage configurations. Centrifugal compressors approximate a constant head-variable volume machine, while reciprocating compressors approximate a constant volume-variable head machine.

In general, the advantages of a centrifugal compressor over a reciprocating unit are:

- Typically lower installed costs

- Typically lower maintenance costs

- Greater continuity of service and reliability

- Less operating attention

- Greater volume capacity for the footprint

In general, the advantages of a reciprocating compressor over a centrifugal unit are:

- Better flexibility in capacity and pressure range

- Higher compressor efficiencies, lower power costs

- Ability to deliver higher pressures

- Ability to handle smaller volumes

- Less sensitive to changes in composition and density

The following provides a comparison of key design criteria for reciprocating and centrifugal compressor packages based upon standard manufacturer designs and materials.

\section{Capacity}

- Reciprocating - Reciprocating compressors are positive displacement machines, therefore, their capacity is determined by cylinder size, the number of throws, or locations on the crankcase where a cylinder can be attached, and driver speed. Capacity may be controlled via speed control, clearances on a cylinder (i.e. addition of fixed or variable volume pockets), cylinder end deactivation, and system recycle. Turndown on a reciprocating compressor can be high as $80-90 \%$.

- Centrifugal - Centrifugal compressors can be sized for an inlet flow capacities as low as 500 acfm upto 400,000 acfm in a single body, and is 
limited by the choke point, or point at which the flow through any part of the compressor nears a velocity of Mach 1 . Unlike a reciprocating compressor where minimum flow is solely a function of compressor geometry and speed, the minimum flow for a centrifugal compressor is limited by surge, which is a function of not only compressor geometry and speed, but also aerodynamic gas conditions and system resistance. Turndown on a centrifugal compressor can be as high as $40-50 \%$.

\section{$\underline{\text { Suction Pressure }}$}

- Reciprocating - Reciprocating compressors can take suction pressures as low as atmospheric, or even a slight vacuum. In vacuum applications, precautions must be taken to prevent atmospheric air from leaking into the cylinder through the piston rod packing.

- Centrifugal - Centrifugal compressors are suitable for service with subatmospheric inlet pressures with special seals and buffering designs to prevent atmospheric air from being drawn into the compressor.

\section{Discharge Pressure}

- Reciprocating - Reciprocating compressors are suitable for discharge pressures up to approximately 12,000 psi.

- Centrifugal - Centrifugal compressors are suitable for discharge pressures up to $1,450 \mathrm{psi}$ with a horizontally split case design and up to 15,000 psi for radially split designs.

\section{Discharge Temperatures}

- Reciprocating - Reciprocating compressors discharge limits will depend upon the application and the seal material selected. API 618 limits the discharge temperature in hydrogen rich applications to $275^{\circ} \mathrm{F}$ and for natural gas service to $350{ }^{\circ} \mathrm{F}$. Most standard manufacturer designs will limit the discharge temperature on each stage to $300{ }^{\circ} \mathrm{F}$.

- Centrifugal - Centrifugal compressors discharge temperature limits are based upon the compressor design and typically range from 400 to $450{ }^{\circ} \mathrm{F}$. Higher discharge temperatures are available with special design considerations.

\section{Compression Ratio}

- Reciprocating - The compression ratio on each stage of a reciprocating compressor is limited by the resulting discharge temperature and piston rod load. Typical compression ratios range from 1.2 to 4.0 per compression stage.

- Centrifugal - The compression ratio limit for centrifugal compressors is a function of the process fluid physical properties, including molecular weight 
and compressibility, as well as the compressor speed, stage geometry, and total number of stages.

\section{Efficiency}

- Reciprocating - Reciprocating compressor efficiency is affected by compression ratio, the respective cylinder's ratio of valve flow area to main bore diameter, and piston speed. Reciprocating compressors typically follow a very characteristic adiabatic curve. High speed reciprocating compressors (900 to $1800 \mathrm{rpm}$ ) typically have an adiabatic efficiency of approximately $82 \%$. Lower speed reciprocating compressors (300 to $700 \mathrm{rpm}$ ) typically have an adiabatic efficiency of approximately $85 \%$.

- Centrifugal - Centrifugal compressor efficiency is typically reported as polytropic rather than adiabatic and are heavily dependant upon inlet volume. Typical polytropic efficiencies range from $60 \%$ at $100-500$ inlet acfm to as high as $85 \%$ at 7,500 acfm or greater. Average reported polytropic efficiencies are however between $70-75 \%$ at the 7,500 acfm or more inlet flow rate.

\section{$\underline{\text { Reliability }}$}

- Reciprocating - Reciprocating compressor reliability is far less than that of centrifugal compressors. Reciprocating units have many more moving parts incorporating more wear and require more frequent replacement. Wear life of seals and valves are significantly effected by the cleanliness of the process fluid and tend to have much longer operational life with process gas free of liquids and debris.

- Centrifugal - Centrifugal compressor reliability approached $98 \%$ to $99 \%$ with proper routine maintenance.

\section{Maintenance Intervals}

- Reciprocating - Maintenance intervals for reciprocating compressors vary significantly with the application. Seal and valve maintenance intervals may be as short as a few months and as long as 3-5 years, depending upon the cleanliness of the process gas. Major overhauls may be required every 10 years or more.

- Centrifugal - Centrifugal compressors designed per API 617, are required to be designed for a minimum 5-year uninterruptable service life. In clean gas service, centrifugal compressors may operate continuously for 10years or more without major maintenance requirements.

\section{Capital \& Operating Costs}

- Reciprocating - Generally, a reciprocating compressor will have a lower base package cost but overall higher installed and operating cost than centrifugal compressors. 
- Centrifugal - Centrifugal compressors have more complex geometry than a reciprocating compressor and therefore typically have a higher up front capital cost, but have fewer moving parts resulting in lower operating costs.

Integrally geared compressors are gaining popularity in carbon dioxide service, however are not as proven as their reciprocating and centrifugal counterparts.

Integrally geared packages incorporate a bull gear and up to six (6) high speed pinions, each with one or more centrifugal compressors mounted on the pinion shaft. Optimal impeller speed and the ability to inter-cool compression phases provide much higher efficiencies than typical centrifugal compression units and typically incorporate very high reliabilities.

\subsubsection{Analysis}

At the Coffeyville Resources compression facility, the 40 MMSCFD carbon dioxide feed stream will be supplied at the suction to the selected compression package at approximately $10 \mathrm{PSIG}$ and $110^{\circ} \mathrm{F}$, equating to an inlet flow rate of approximately 18,120 acfm.

With a required 2,548 PSIG discharge pressure, the total horsepower requirement can be optimized by utilizing compression to take the raw $\mathrm{CO}_{2}$ feed stream to approximately 1,400 PSIG and then utilizing a centrifugal pump to boost the discharge stream from 1,400 PSIG to pipeline pressure at 2,548 PSIG. This would require the selected compression package to provide a compression ratio of approximately 140 , therefore, a multi-stage unit will be required. Multi-stage reciprocating compressors are normally considered for inlet volumes between 1 and 9,000 acfm, so to accommodate the $18,120 \mathrm{acfm}$ feed rate, multiple multi-stage reciprocating compressors would be required. Multi-stage centrifugal compressors are normally considered for inlet volumes between 500 and 200,000 inlet acfm, but are limited to the total developed head available in a single unit. Therefore, a multi-stage, mult-unit compressor configuration will be required for the CVR application.

\subsubsection{Recommendation}

Although, either compressor type may be considered for the CVR compression application, a centrifugal compressor / centrifugal pump integrated package is recommended for the CVR compression facility.

An integrated solution will allow multiple centrifugal compressors as well as a centrifugal pump to be packaged together on a common skid utilizing a single driver with multiple gear boxes. A centrifugal compressor / pump package will provide lower initial costs as well as lower overall long term maintenance costs than multiple reciprocating units. It will also minimize the overall electrical construction requirements, reducing the number of 4160V SSRV's and 500KV cable. In addition, it is also anticipated that the source gas from the facility will be provided at a consistent rate and composition, and therefore the flexibility of capacity and pressure provided in a reciprocating compressor will not be required. The longer duration between maintenance periods of the centrifugal compressor will also allow for these activities to be better coordinated with the plant turnaround period. Information for this analysis was derived from reliable and publicly 
available sources ${ }^{3}$.

\subsubsection{Compressor Sizing \& Selection}

Several compressor configurations were evaluated as part of the desktop study. Viable configuration options, both with and without redundancy in the design, have been summarized in tables 3-9 and 3-10 below and on the following page:

Table 3-9 CVR Compression Facility Compression Configuration Option - No Redundancy

\begin{tabular}{|c|c|c|c|}
\hline $\begin{array}{l}\text { Option } \\
\text { No. }\end{array}$ & Configuration & $\begin{array}{l}\text { Total } \\
\text { bhp }\end{array}$ & $\begin{array}{c}\text { Total } \\
\text { Capital Cost }\end{array}$ \\
\hline $1 \mathrm{a}$ & $\begin{array}{l}\text { Two (2) 50\% Recip + One (1) 100\% Centrif. } \\
\text { Pump }\end{array}$ & 14,656 & $\$ 17,798,000$ \\
\hline $2 \mathrm{a}$ & $\begin{array}{l}\text { One (1) 100\% Centrif. + One (1) 100\% Centrif. } \\
\text { Pump }\end{array}$ & 15,000 & $\$ 11,000,000$ \\
\hline $3 a$ & $\begin{array}{l}\text { One (1) } 100 \% \text { Int. Gear + One (1) } 100 \% \text { Centrif. } \\
\text { Pump }\end{array}$ & 15,000 & $\$ 13,000,000$ \\
\hline $4 a$ & $\begin{array}{l}\text { Three (3) 33\% Recip. + One (1) 100\% Centrif. } \\
\text { Pump }\end{array}$ & 13,027 & $\$ 6,798,000$ \\
\hline $5 a$ & $\begin{array}{l}\text { Two (2) 50\% LP Recip + Two (2) 50\% HP } \\
\text { Recip } \\
\quad \text { Plus.....One (1) } 100 \% \text { Centrif. Pump }\end{array}$ & 12,502 & $\$ 7,798,000$ \\
\hline $6 a$ & $\begin{array}{l}\text { Seven (7) LP Screw + Two (2) 50\% HP Recip } \\
\text { Plus.....One (1) } 100 \% \text { Centrif. Pump }\end{array}$ & 17,430 & $\$ 11,148,000$ \\
\hline
\end{tabular}

Table 3-10 CVR Compression Facility Compression Configuration Option - With Redundancy

\begin{tabular}{|c|c|c|c|}
\hline $\begin{array}{l}\text { Option } \\
\text { No. }\end{array}$ & Configuration & $\begin{array}{l}\text { Total } \\
\text { bhp }\end{array}$ & $\begin{array}{c}\text { Total } \\
\text { Capital Cost }\end{array}$ \\
\hline $1 \mathrm{~b}$ & $\begin{array}{l}\text { Three (3) 50\% Recip + Two (2) 100\% Centrif. } \\
\text { Pump }\end{array}$ & 22,562 & $\$ 27,096,000$ \\
\hline $2 b$ & $\begin{array}{l}\text { Two (2) 100\% Centrif. + Two (2) } 100 \% \text { Centrif. } \\
\text { Pump }\end{array}$ & 30,000 & $\$ 22,000,000$ \\
\hline $3 b$ & $\begin{array}{l}\text { Two (2) } 100 \% \text { Int. Gear + Two (2) } 100 \% \\
\text { Centrif. Pump }\end{array}$ & 30,000 & $\$ 26,000,000$ \\
\hline $4 b$ & $\begin{array}{l}\text { Four (4) 33\% Recip. + Two (2) 100\% Centrif. } \\
\text { Pump }\end{array}$ & 18,140 & $\$ 9,596,000$ \\
\hline $5 b$ & $\begin{array}{l}\text { Three (3) 50\% LP Recip + Three (3) 50\% HP } \\
\text { Recip } \\
\text { Plus.....Two (2) } 100 \% \text { Centrif. Pump }\end{array}$ & 19,331 & $\$ 12,096,000$ \\
\hline $6 b$ & $\begin{array}{l}\text { Eight (8) LP Screw + Three (3) 50\% HP Recip } \\
\text { Plus.... Two (2) } 100 \% \text { Centrif. Pump }\end{array}$ & 22,973 & $\$ 14,996,000$ \\
\hline
\end{tabular}

\footnotetext{
${ }^{3}$ GPSA Engineering Data Book, Twelfth Edition, 2004

John M. Campbell, CO2 Surface Facilities, Version \#PF81-P-03-02-06
} 
Based upon discussions with Blue Source, LLC., Option \#2a was selected for the CVR compression facility. This provides for three blowers that will feed a single integrated centrifugal skid package comprised of three (3) multi-stage centrifugal compressors paired with a single centrifugal pump with a single $4160 \mathrm{~V}, 15,000 \mathrm{hp}$, electric motor. The integrated centrifugal package will include a separate scrubber / cooler skid incorporating both inter-stage and aftercoolers. The use of forced draft fin-fan coolers would be anticipated, adding an auxiliary load of approximately $100 \mathrm{hp}$.

Typical operations and maintenance costs for this package would run approximately $\$ 65,000$ / year.

\subsubsection{Process Equipment \\ Dehydration Unit}

Water vapor from the raw carbon dioxide feed stream would be removed utilizing a single tri-ethylene glycol (TEG) dehydration skid package comprised of a gas fired 3.5 MMBTU / Hr re-boiler and 60" diameter contactor tower.

The initial fill for start-up of the system is anticipated to require approximately 300 gallons of TEG and has been included in the capital costs provided with this study. Annual TEG losses are estimated at less than 1\%, excluding upset conditions, with estimated annual operating costs of $\$ 300,000$.

\subsubsection{Electrical Design}

Power for the CVR compression and processing facilities are anticipated to be available from the Coffeyville Refinery sub-station located approximately $250 \mathrm{ft}$. NE of the proposed CVR compression facility site. Brining power to the CVR compression facility will require construction of an overhead $13.8 \mathrm{KV}$ power line between the CVR substation and compressor site and will terminate at a new $13.8 \mathrm{KV} / 4160 \mathrm{~V}$ transformer before stepping down to $4160 \mathrm{~V}$ to feed the main switchgear for the compression facility. $4160 \mathrm{~V} / 3$-Phase power shall be used as the secondary service, with additional transformation down to $480 \mathrm{~V} / 3$-Phase and $208 \mathrm{~V} / 120 \mathrm{~V}$ for auxiliary equipment and lighting. All power and controls for the new facility would be incorporated into a preengineered metal power distribution center, including a $4160 \mathrm{~V}$ cutler-hammer, or equivalent, switchgear, $4160 \mathrm{~V}$ solid state reduced voltage starter, $480 \mathrm{~V}$ motor control center, Programmable Logic Controller, and miscellaneous power and lighting equipment.

Table 3-11 below summarizes the overall electric loads and estimate annual cost at the CVR compression facility. The electric rate of $\$ 0.0732 / \mathrm{KW}-\mathrm{HR}$ used is the average commercial electric rate paid in the state of Kansas in 2009 (Report No.: DOE/EIA0226). 
Table 3-11 CVR Facility Annual Electric Loads and Costs

\begin{tabular}{|l|c|c|c|}
\hline Description & $\begin{array}{c}\text { Number } \\
\text { of Units }\end{array}$ & $\begin{array}{c}\text { BHP } \\
\text { Each }\end{array}$ & $\begin{array}{c}\text { Total } \\
\text { BHP }\end{array}$ \\
\hline Blower, GD Suitorbuild 8000 & 3.0 & $500 \mathrm{BHP}$ & $1,500 \mathrm{BHP}$ \\
\hline $\begin{array}{c}\text { API Centrifugal Compressor / } \\
\text { Pump }\end{array}$ & 1.0 & $\begin{array}{c}15,000 \\
\text { BHP }\end{array}$ & $15,000 \mathrm{BHP}$ \\
\hline Intercoolers and Aftercoolers & 1.0 & $100 \mathrm{BHP}$ & $100 \mathrm{BHP}$ \\
\hline TEG Dehydration Package & 1.0 & $15 \mathrm{BHP}$ & $15 \mathrm{BHP}$ \\
\hline \hline TOTAL BHP & & & $\mathbf{1 6 , 6 1 5} \mathbf{B H P}$ \\
\hline TOTAL KW-HR/YR & & & $\begin{array}{c}103,108,000 \mathrm{KW}- \\
\mathrm{HR} / \mathrm{YR}\end{array}$ \\
\hline COST PER KW-HR & & & $\$ 0.0732 / \mathrm{KW}-\mathrm{HR}$ \\
\hline \hline ANNUAL COST & & & $\mathbf{\$ 7 , 5 4 8 , 0 0 0}$ \\
\hline
\end{tabular}

\subsubsection{SCADA Design}

The Supervisory Control And Data Acquisition (SCADA) system on the CVR-TAF pipeline will consist of four main components which are the 1) Programmable Logic Controllers (PLC) to be located at all the station and valve sites connected to the instruments, 2) Operator Interface and data collection system which is the SCADA software, 3) Leak detection system, and 4) Communications system which will tie all the parts together.

The communication system will be composed of an armored fiber optic cable installed in the most appropriate method adjacent to the pipeline. The cable could be installed in the same ditch as the pipeline, direct buried, in duct strapped to the pipe at crossings, or plowed into the ground. The SCADA system which communicates through a fiber optic cable will have a very high uptime and the capability for fast and reliable communication between the stations and the main line valves. These features will enable the fast integrated control system to automatically operate more safety.

The PLC at each compressor and main line valve site will be a GE 90-30 or company approved equal and will be housed inside a small building to enable support personnel to program and maintain them in inclement weather.

The SCADA software will have a primary system installed at the primary control center on one end of the pipeline and there will be a backup SCADA host at the facility at the other end of the pipeline. Costs for SCADA vendor services were also included. SCADA vendor services include project management, design specification documents, SCADA communications programming, SCADA screen programming, factory tests, installation onsite, onsite tuning of the software, commissioning tests, operations and the maintenance manual, training support for operators and technicians.

The Leak Detection System will communicate with each station to analyze the pipeline for leaks and report to the SCADA software for operator notification. Leak Detection vendor services were also included. Leak Detection vendor services include project management, design specification documents, communications programming, graphical user interface screen programming, factory tests, installation onsite, tuning of the software, commissioning tests, operations and the maintenance manual, training 
support for operators and technicians.

\subsubsection{Cathodic Protection and AC Mitigation}

Cathodic protection of the 8" steel pipeline system will be accomplished using an impressed current system with either deep-well and/or surface anode ground beds. In order to quantify the soil resistivity in the area, a soil investigation will be required once the pipeline has been installed. The cathodic protection system will be designed accordingly depending upon the soil resistivity. The system will consist of either highsilicon cast iron anodes set in deep wells and/or or treated graphite surface anodes. The quantity and dimension of the deep well anodes and/or surface ground beds will be determined during detailed design of the cathodic protection system. Either system will be powered by a rectifier which will also be sized during detailed design of the cathodic protection system.

Alternate Current (AC) mitigation will be required where pipelines are in close proximity to overhead power lines. AC mitigation will be accomplished using zinc anode ribbon buried alongside the pipeline system. In order to determine the amount of zinc ribbon required for $\mathrm{AC}$ mitigation a soil investigation will be required during detailed design to quantify the soil resistivity in the areas of concern. Based on the soil resistivity, proximity and voltage of overhead power lines, and the operating lifespan of the project, the AC mitigation system will be designed to protect the pipeline system from stray currents imposed by overhead power lines.

\subsubsection{Typical Construction Method}

Standard pipeline construction procedures and BMPs would be followed during construction. The centerline of the ROW would be staked prior to construction. The following discussion provides a brief overview of the construction process.

All equipment and vehicular access into the pipeline project would be confined to existing roads and the established ROW corridor. No major reconstruction or rerouting

of these roads is intended.

The following are the general steps in the construction process:

- Surveying and staking of the ROW

- Right-of-way (ROW) clearing and grading, topsoil stockpiling

- Ditching

- Pipe stringing, and bending

- Pipe welding

- Pipe Jeeping

- Pipe lowering in

- Backfilling of trench

- Testing of pipeline and facilities

- Clean up and revegetation

All construction materials would be hauled to the job site by truck, as needed, and strung along the ROW as they arrive. Pipe would be strung in such a manner as to cause the least interference with the normal use of the land crossed by the ROW. The construction ROW would be limited to a 75-foot width. As a general rule (except for 
steep slope areas), clearing would be limited to 75 feet: 55 feet on the working side and 20 feet on the stockpile side of the trench. Grading of the entire ROW would occur only in areas where equipment access is not possible without ROW clearing. The top 6 inches of topsoil would be removed and stockpiled off of the trench line and any areas to be graded. Top soils would be stockpiled separately from trench spoils.

Construction or routine maintenance activities will not be allowed during periods when soil is too wet to adequately support construction equipment. If such equipment creates surface ruts in excess of 6 inches deep, the construction supervisor would deem that soil conditions are too wet to adequately support construction equipment. Construction activities would not be allowed until soil conditions improve. The pipeline trench would be excavated using a wheel trencher, or a track-hoe excavator. The wheel trencher pulverizes the soil as the trenching progresses, stacking the spoil in a pile along the side of the trench. In the event weather conditions warrant, the spoil pile can be worked by driving a tracked dozer over the spoil and working it with the blade, breaking up frozen soils. Breaking up the frozen soils would mitigate the issue of the ditch settling. A small mound of soil (6-10 inches high) would be placed on top of the trench line to accommodate minor settling.

A wheel trencher or track hoe would be used to dig a trench to an average depth of 60 inches, stacking the dirt beside the ditch. After the pipe is placed in the ditch a motor grader or caterpillar would be used to push the dirt back into the trench. The fill on the trench would then be tamped into place with the grader wheels, leaving a berm of 6 to 10 inches to accommodate settling. Disturbance of the topsoil within the ROW would be kept to a minimum. In areas of excessively steep hillsides, or to provide a smooth approach to a cut or gully, as well as at stream bank crossings and at established work stations, some blading may be required to provide a safe and suitable working area for the equipment and workers. When this occurs the top 6 inches of soil would be stockpiled on the side of the ROW and spread back over the area from which it was taken, after the final grading. Before seeding any disturbed areas, the ROW would be restored to its original form, slope, contour, and soil density to the extent practicable.

\subsubsection{Rock Ditch}

Throughout the course of the pipeline construction, solid rock may be encountered during the excavation. When the rock cannot be excavated with the typical track hoe, additional equipment or blasting may be required. In these areas, construction cost will increase due to the additional equipment and slower installation productivity. Typically, an additional cost for installation is added for every foot of rock ditch encountered. A construction contractor, who has installed pipelines in the project area, estimated that there will be significant amounts of rock encountered on the CVR-TAF pipeline route. In the cost estimate, it was assumed that $45 \%$ of the total route would be considered rock ditch, as recommended by the contractor. The precise amount of rock cannot be determined until construction of the pipeline.

\subsubsection{Crossings}

A detailed review of the required pipeline crossings was completed. The locations where the proposed route crossed an Interstate, Highway, State Road, Other Paved Roads, Dirt Roads, Railroads, Lakes, Rivers, and creeks were identified. The below table (Table 3-12) summarizes the number of each type of crossings, as well as the estimated 
total length of each type of crossing.

Table 3-12 KE-GE Road, Railroad, and Waterway Crossing Tally

\begin{tabular}{|l|c|c|}
\hline TYPE & $\begin{array}{c}\text { TOTAL NO. } \\
\text { CROSSINGS }\end{array}$ & $\begin{array}{c}\text { TOTAL } \\
\text { LENGTH }\end{array}$ \\
\hline Interstate & 0 & $0 \mathrm{ft}$ \\
\hline Highway / State Rd & 5 & $500 \mathrm{ft}$ \\
\hline Other Paved Road & 17 & $1,275 \mathrm{ft}$ \\
\hline Dirt Road & 64 & $3,200 \mathrm{ft}$ \\
\hline Railroad & 6 & $600 \mathrm{ft}$ \\
\hline Lake/ River & 4 & $800 \mathrm{ft}$ \\
\hline Creek & 37 & $1,380 \mathrm{ft}$ \\
\hline \hline TOTAL & 133 & $\mathbf{7 , 7 5 5} \mathbf{f t}$ \\
\hline
\end{tabular}

In general, it is proposed that paved roads or railroads that require a crossing length of 100 feet or greater, be crossed using a Horizontal Directional Drill (HDD). It is proposed that paved roads or railroads that require a crossing length of 100 feet or less, be crossed using an un-cased slick bore. It is proposed that all dirt roads be open cut. Regarding waterway crossings, $t$ is proposed that waterways that require a crossing length of 100 feet or greater, be crossed using a Horizontal Directional Drill (HDD). It is proposed that waterways that require a crossing length of 100 feet or less, be crossed using an un-cased slick bore.

During the detailed design portion of the project, each crossing would need to be analyzed on a site specific basis, and a detailed crossing plan and profile be developed.

\subsubsection{Long Lead Materials}

Most of the materials required for the construction of the CVR-TAF Pipeline Project are considered long lead items. Long lead items are described as items that are not in stock at the time of purchase. These items include the compressors, pumps, dehydration process equipment, valves, actuators, steel pipe, materials for the launchers and receivers and their fabrications, and other miscellaneous fittings. Deliveries are based on budgetary quotes for material received on August 1, 2010.

Budgetary bids have been received from vendors for the blower compressors, with an anticipated delivery of 14-16 weeks after receipt of order.

Budgetary bids have been received from vendors for the integrated centrifugal compressor / pump package, with an anticipated delivery of 60 weeks after receipt of order.

Budgetary bids have been received from vendors for the dehydration process equipment, with an anticipated delivery of 25 weeks after receipt of order.

Budgetary bids have been received from vendors for the 8 " steel line pipe and ANSI 1500 valves and required actuators for the pig launchers/receivers. Anticipated delivery of valves and actuators is 12-26 weeks after receipt of order (ARO).

Budgetary bids have been received from vendors for the steel line pipe. Line pipe will be mill rolled and coated with FBE coating. Anticipated delivery of the line pipe is 20-30 weeks after receipt of order (ARO). Line pipe will be mill rolled and coated with FBE coating. 
Budgetary bids have been received from vendors for the launchers and receivers. Anticipated delivery is 12-14 weeks after purchase orders have been issued. Lead times include material procurement, fabrication and testing and shipping.

Budgetary bids have also been received from vendors for bends for the piggable pipeline systems. Deliveries are anticipated to be 2-3 weeks ARO.

\subsubsection{Capital Cost Estimate}

See the attached Appendix 3-C - Pipeline Estimate prepared for the CVR-TAF Pipeline Systems. See also Appendix 3-D - Estimate Basis Memorandum for more information regarding the estimate.

\subsubsection{Project Schedule}

See Appendix 3-E - Project Schedule prepared for the CVR-TAF Pipeline Systems.

\subsection{Geneseo-Edwards Field}

\subsubsection{PIPELINE ROUTING}

\subsubsection{General}

Refer to Appendix 3-G - Feasibility Drawings of this report, Drawing Number 2702-M-001 "Kansas Ethanol LLC Plant to the Geneseo-Edwards Oil Field - Overview Sheet 1 of 1." Refer to Drawing Numbers 2702-M-101 to 02702-M-104 for the Alignment Sheets showing detailed sections of land ownership, environmental restrictions, plan view, ground profile, general material specifications, etc.

The pipeline will originate at the Kansas Ethanol LLC (KE) Plant and generally traverse in a Northerly direction paralleling existing pipeline corridors for 14 miles ( 23 kilometers). It will then traverse 1.77 miles ( 2.8 kilometers) in a South Easterly direction following existing roads and pipeline corridors where it will terminate at the GeneseoEdwards (GE) Oil Field.

\subsubsection{Alternate Routes}

While selecting the route for the KE-GE pipeline, it was important that existing right of ways be utilized to the greatest extent possible. The pipeline corridor that was selected provides a relatively direct route, without approaching the populated areas of Lyons, Kansas, which is located approximately 1.5 miles (2.4 kilometers) to the west of the route. An alternate existing corridor was available; however, it passes through much more populated areas, and was therefore eliminated.

\subsubsection{Right-of-Way Acquisition}

A desktop review of the pipeline right-of-way indicates that $100 \%$ of the right-ofway is private. The right-of-way includes mostly cultivated and prairie lands. This study includes estimated costs for obtaining easements from the private land owners to install the proposed pipeline. The precise number of land owners and parcels was not 
determined during this study. Only the creek crossings, roads, highways, etc. are not privately owned, and come under state and federal guidelines.

Disturbance would occur within a 75-foot wide temporary ROW construction corridor. This width should be sufficient to accommodate construction in most areas. However, additional construction space would be required if another pipeline must be crossed, to temporarily store pipe and equipment, and/or to accommodate construction requirements for a certain area (e.g., road and river crossings, steep slopes).

New access roads would not be required for the project during construction. Construction access would be via the pipeline ROW and existing regional access roads. However, during construction it may be determined that additional access is needed.

\subsubsection{Permitting}

Numerous Federal, State and County permits will be required for the construction of the KE-GE Pipeline.

For example, some of the permits required under Federal jurisdiction shall be National Environmental Policy Act (NEPA), Corps of Engineers Nationwide Permit, United States Fish and Wildlife Services. Some of the permits required under the State of Kansas jurisdiction shall be Department of Health and Environment, (Air Quality, Water Discharge, General), National Historic Preservation Act, Wildlife and Parks, Kansas Highway Department. Some of the permits required under the County jurisdiction shall be Road and Bridge Departments. Only permits required for construction have been included within this estimate, therefore the NEPA permit, COE, etc. have been excluded from this budget.

\subsubsection{PIPELINE SYSTEM DESCRIPTION}

The purpose of the KE-GE Pipeline is to transport compressed high-purity $\mathrm{CO}_{2}$ via a 4" steel intra-state pipeline from the Kansas Ethanol LLC Plant to the GeneseoEdwards Oil Field for both sequestration and enhanced oil recovery purposes.

The pipeline will be designed, constructed and operated in accordance to Title 49, Part 195, "Transportation of Hazardous Liquids by Pipeline" - Department of Transportation, rules and regulations.

The pipeline will be composed of 4.5" O.D., 0.237" wall thickness, API 5L, PSL2, Electric Resistance Welded (ERW) steel line pipe, coated with 14-16 mils of Fusion Bond Epoxy for external corrosion protection. The pipeline will be designed to be operated at a Maximum Operating Pressure of 1,700 PSIG, with an ANSI 900 flange rating.

All road, railroad and creek crossing pipes will be manufactured to Seamless line pipe specifications instead of ERW to further mitigate fracture propagation.

Carbon Dioxide must be compressed to 1,587 PSIG at the Kansas Ethanol LLC Plant in order to deliver it to the Geneseo-Edwards Oil Field at 1,400 PSIG. These operating pressures were utilized to provide a reasonable margin between the operating pressures in the pipeline and the critical pressure of carbon dioxide, which is approximately 1,100 PSIA at $50^{\circ} \mathrm{F}$. Operating at pressures above the critical pressure ensures that the carbon dioxide is transported in the dense phase and that no phase changes occur in the pipeline system. Transporting carbon dioxide in dense-phase is 
the most efficient means of transportation since it allows for smaller pipeline sizes at high flow rates.

Isolation Block Valves will be strategically located in the pipeline system, as shown in Table 3-13 to isolate the pipeline and blow the Carbon Dioxide down in case of an emergency.

Table 3-13 KE-GE Estimated Isolation Block Valves

\begin{tabular}{|l|l|l|}
\hline No. & Pipeline Station & Mile Post \\
\hline 1 & $80+00$ & MP 1.52 \\
\hline 2 & $90+00$ & MP 1.70 \\
\hline 3 & $380+00$ & MP 7.20 \\
\hline 4 & $540+00$ & MP 10.23 \\
\hline
\end{tabular}

Crack arrestor will be installed at every half mile ( 0.8 kilometers) on the steel pipeline to mitigate fracture propagation. It is anticipated that Clock Springs, or similar product, will be utilized as crack arrestors. This type of product has been successfully utilized as crack arrestors on existing carbon dioxide pipelines.

The pipeline will be designed and constructed to accommodate intelligent pigs. Pig launcher and receiver will be installed into the system.

\subsubsection{Pipeline Hydraulics}

\subsubsection{Purpose}

The purpose of this pipeline hydraulic calculation was to analyze the predicted performance of the Kansas Ethanol to Geneseo-Edwards oil field (KE-GE) carbon dioxide pipeline under various operating scenarios. In general, the results from the hydraulic calculation include resulting pressures, resulting temperatures, resulting velocities, and line size confirmation. Hydraulic scenarios were completed for three potential line sizes.

\subsubsection{Pipeline Routing}

The scope of the hydraulic study was limited to the preferred route. This route heads in a north-easterly direction from the Kansas Ethanol facility and turns north at approximately Mile Post 2. The pipeline route continues north and is located approximately one (1) mile (1.6 kilometers) east of the city of Lyons, Kansas. The preferred route is approximately 15.8 miles ( 25 kilometers) in length. The carbon dioxide delivery point at the Geneseo-Edwards oil field is located at the center of Section 24, Township 18S, Range 8W.

\subsubsection{Hydraulic Modeling Software}

PIPEPHASE Version 9.4 was used to model the hydraulics of the carbon dioxide pipeline. This software has the capability of predicting the mechanical and thermodynamic properties of dense-phase carbon dioxide and can model steady-state carbon dioxide flow in pipeline networks. 


\subsubsection{Hydraulic Design Basis - Pressure Requirements}

For this hydraulic study, the delivery pressure at the Geneseo-Edwards oil field was fixed at 1,400 PSIG. This pressure was utilized to provide a reasonable margin between the operating pressures in the pipeline and the critical pressure of carbon dioxide, which is approximately 1,100 PSIA at $50^{\circ} \mathrm{F}$. Operating at pressures above the critical pressure ensures that the carbon dioxide is transported in the dense phase and that no phase changes occur in the pipeline system. Transporting carbon dioxide in dense-phase is the most efficient means of transportation since it allows for smaller pipeline sizes at high flowrates.

At the Geneseo-Edwards oil field, a pressure reduction valve will be installed to reduce the pressure of the carbon dioxide from the 1,400 PSIG to the well head injection pressure of approximately 1,100 PSIG.

The carbon dioxide pipeline will be designed and constructed per CFR 49 Part 195 "Transportation of Hazardous Liquids by Pipeline." A design factor (F) of 0.72 was used for allowable stress calculations and determination of the Maximum Operating Pressure (MOP). Based on the hydraulic results, an appropriate ANSI rating for the pipeline was selected.

\subsubsection{Hydraulic Design Basis - Capacity Requirements}

The baseline capacity for the pipeline design is 8 MMSCFD. This corresponds to the maximum anticipated carbon dioxide availability from the Kansas Ethanol Facility. No allowance for future capacity was considered.

\subsubsection{Hydraulic Design Basis - Fluid Temperatures}

It is anticipated that the carbon dioxide discharge temperature from the originating compressor / pump station at Kansas Ethanol will be a maximum of $120^{\circ} \mathrm{F}$. Therefore, the design temperature for the pipeline system was selected to be $130^{\circ} \mathrm{F}$.

In the hydraulic model, an ambient ground temperature of $50^{\circ} \mathrm{F}$ was selected based on research of soil temperatures published by the USDA. The USDA has published maps of soil temperature regimes for the contiguous United States (http://soils.usda.gov/use/thematic/temp_regimes.html). Based on this map, the project area is located near the boundary of the Mesic and Thermic soil temperature regimes. The Mesic soil regime is defined as having a mean annual soil temperature between $8{ }^{\circ} \mathrm{C}$ $\left(46.4{ }^{\circ} \mathrm{F}\right)$ and $15^{\circ} \mathrm{C}\left(59.0^{\circ} \mathrm{F}\right)$. The Thermic soil regime is defined as having a mean annual soil temperature between $15^{\circ} \mathrm{C}\left(59.0^{\circ} \mathrm{F}\right)$ and $22^{\circ} \mathrm{C}\left(71.6^{\circ} \mathrm{F}\right)$. Since the project area is on the boundary of these two regimes, the mean annual soil temperature was assumed to be $15^{\circ} \mathrm{C}\left(59.0^{\circ} \mathrm{F}\right)$.

Using the mean annual soil temperature and anticipated depth of burial, the amplitude of seasonal soil temperature change can be determined. For dry soil at a burial depth of 4 feet, the amplitude of seasonal temperature change is approximately $\pm 10^{\circ} \mathrm{F}$ (http://www.geo4va.vt.edu/A1/A1.htm). Therefore, the lowest anticipated soil temperature is approximately $50^{\circ} \mathrm{F}$, which was taken as the ambient soil temperature in the hydraulic model. 


\subsubsection{Hydraulic Design Basis - Carbon Dioxide Composition Analysis}

Kansas Ethanol provided the anticipated compositions of fluid stream. Note that the composition dated October 24, 2009 was utilized and is included as Appendix 3-B to this report. It was assumed that the mole percentage not accounted for in the provided composition was Nitrogen. This composition was modified to reflect the dehydration process needed to meet the dehydrated carbon dioxide specification of $10 \mathrm{lb} \mathrm{H} 2 \mathrm{O}$ / MMSCFD allowable. The below composition (Table 3-14) corresponds to the fluid stream anticipated in the pipeline, which was used in the hydraulic model.

Table 3-14 KE-GE Pipeline Compositional Analysis

\begin{tabular}{|l|l|}
\hline Component & Mole Fraction \\
\hline $\mathrm{N} 2$ & 0.085482 \\
\hline $\mathrm{CO}_{2}$ & 0.905110 \\
\hline $\mathrm{H}_{2} \mathrm{O}$ & 0.000210 \\
\hline $\mathrm{AR}$ & 0.000000 \\
\hline $\mathrm{CO}$ & 0.000000 \\
\hline $\mathrm{COS}$ & 0.000000 \\
\hline $\mathrm{O}_{2}$ & 0.009198 \\
\hline $\mathrm{H}_{2}$ & 0.000000 \\
\hline $\mathrm{CH}_{4}$ & 0.000000 \\
\hline TOTAL & $\mathbf{1 . 0 0 0 0 0 0}$ \\
\hline
\end{tabular}

\subsubsection{Hydraulic Design Basis - Assumed Mechanical and Thermodynamic Properties}

The table below (Table 3-15) contains the mechanical and thermodynamic parameters that were assumed in the hydraulic model of the carbon dioxide pipeline. The parameters were selected based on various published charts and tables, and project specific requirements.

Table 3-15 Assumed Mechanical and Thermodynamic Parameters

\begin{tabular}{|l|l|}
\hline Design Parameter & Value \\
\hline Steel Absolute Roughness & 0.00360 IN \\
\hline Flow Efficiency Factor & 95.00 PERCENT \\
\hline Steel Heat Conductivity & 26.500 BTU/HR-FT- ${ }^{\circ} \mathrm{F}$ \\
\hline Soil Heat Conductivity & 0.960 BTU/HR-FT- ${ }^{\circ} \mathrm{F}$ \\
\hline Ground Temperature & $50^{\circ} \mathrm{F}$ \\
\hline Burial Depth & 48.0 IN $(4$ FT) \\
\hline Pressure Drop Correlation & BEGGS-BRILL WITH MOODY FRICTION FACTOR \\
\hline Bulk Modulus of Pipe & $30,000,000$ PSI \\
\hline Bulk Modulus of $\mathrm{CO}_{2}$ & 22,888 PSI \\
\hline
\end{tabular}

\subsubsection{Hydraulic Design Basis - Elevation Profile}

The elevation profile utilized in the hydraulic model was created from available digital elevation models (DEM's) for the project area. The same elevation profile can be 
found on the attached Alignment Sheet drawings. No field survey data was gathered to create the pipeline elevation profile.

\subsubsection{Hydraulic Design Basis - Surge Pressure}

Surge pressure, also known as water hammer, is the result of a rapid increase in pressure which occurs when the liquid velocity is suddenly changed in a closed piping system. Per CFR 49 Part 195, temporary pressure excursions must be limited to less than $110 \%$ of the design pressure. Surge pressure in dense-phase carbon dioxide pipelines is not well documented; therefore, the standard surge pressure equations were used in the hydraulic model, with appropriate substitutions for liquid density and bulk modulus. The bulk modulus of a fluid is the ratio of the pressure stress to the volumetric strain. The bulk modulus of carbon dioxide was estimated from property tables, calculated by considering the change in density corresponding to a change in pressure.

Surge pressures in dense phase carbon dioxide pipelines are not as great as that in water pipelines, due to the compressibility of the fluid. This is evident in the bulk modulus of carbon dioxide compared to the bulk modulus of water.

\subsubsection{Results}

This section summarizes the results obtained from the hydraulic modeling of the carbon dioxide pipeline. Table 3-16 defines the parameters for the various hydraulic cases.

\section{Table 3-16 Hydraulic Case Definitions}

\begin{tabular}{|c|c|c|c|}
\hline Parameter & Case 1 - 6" & Case 2 - 4" & Case 3 - 3" \\
\hline Volumetric Flowrate & 8 MMSCFD & 8 MMSCFD & 8 MMSCFD \\
\hline Mass Flowrate & $37,355 \mathrm{lb} / \mathrm{hr}$ & $37,355 \mathrm{lb} / \mathrm{hr}$ & $37,355 \mathrm{lb} / \mathrm{hr}$ \\
\hline Pipeline Outer Diameter & $6.625 "$ & $4.500 "$ & $3.500 "$ \\
\hline Pipeline Wall Thickness & $0.280 "$ & $0.237 ”$ & $0.216 "$ \\
\hline Corrosion Allowance & $1 / 8 "(0.125 ”)$ & $1 / 8 "(0.125 ")$ & $1 / 8 "(0.125 ")$ \\
\hline Effective Wall Thickness & 0.155 & $0.112 "$ & $0.091 "$ \\
\hline Pipeline Grade & $\mathrm{X}-52$ & $\mathrm{X}-52$ & $\mathrm{X}-60$ \\
\hline Design Factor & 0.72 & 0.72 & 0.72 \\
\hline Required System MOP & 1,600 PSIG & 1,700 PSIG & 2,100 PSIG \\
\hline Pipe MOP & 1,751 PSIG & 1,863 PSIG & 2,246 PSIG \\
\hline ANSI Class & ANSI 900 & ANSI 900 & ANSI 900 \\
\hline ANSI Rating at $130^{\circ} \mathrm{F}$ & 2,161 PSIG & 2,161 PSIG & 2,161 PSIG \\
\hline
\end{tabular}

The resulting operating pressures and maximum surge pressures are summarized in Table 3-17. Hydraulic charts, showing the ground elevation, pressure, and surge pressure, have also been completed and are included as Appendix 3-C to this report. 
Table 3-17 Pipeline Pressure Results

\begin{tabular}{|l|l|l|l|}
\hline Parameter & Case 1 - 6" & Case 2 - 4” & Case 3 - 3" \\
\hline KE Discharge & 1,433 PSIG & 1,587 PSIG & 2,032 PSIG \\
\hline GE Delivery & 1,400 PSIG & 1,400 PSIG & 1,400 PSIG \\
\hline \hline Min Pipeline Pressure & 1,379 PSIG & 1,391 PSIG & 1,400 PSIG \\
\hline Max Pipeline Pressure & 1,433 PSIG & 1,587 PSIG & 2,032 PSIG \\
\hline Max Surge Pressure & 1,482 PSIG & 1,680 PSIG & 2,142 PSIG \\
\hline
\end{tabular}

The resulting temperatures are summarized in the table below (Table 3-18).

Table 3-18 Pipeline Temperature Results

\begin{tabular}{|l|l|l|l|}
\hline Parameter & Case 1 - 6” & Case 2 - 4” & Case 3 - 3" \\
\hline KE Discharge & $120^{\circ} \mathrm{F}$ & $120^{\circ} \mathrm{F}$ & $120^{\circ} \mathrm{F}$ \\
\hline GE Delivery & $51^{\circ} \mathrm{F}$ & $51^{\circ} \mathrm{F}$ & $49^{\circ} \mathrm{F}$ \\
\hline
\end{tabular}

The resulting velocities are summarized in the table below (Table 3-19). Results for pipeline segment inlet velocity are reported in feet per second (fps).

\section{Table 3-19 Pipeline Velocity Results}

\begin{tabular}{|l|l|l|l|}
\hline Parameter & Case 1 - 6” & Case 2 - 4” & Case 3 - 3" \\
\hline KE Discharge & $2.93 \mathrm{fps}$ & $5.57 \mathrm{fps}$ & $6.59 \mathrm{fps}$ \\
\hline GE Delivery & $0.87 \mathrm{fps}$ & $1.97 \mathrm{fps}$ & $3.36 \mathrm{fps}$ \\
\hline
\end{tabular}

\subsubsection{Recommendation}

Based on the hydraulic results, it is recommended that 4" $\mathrm{x} 0.237$ " Wall Thickness, Grade X-52 pipe be utilized for the KE-GE pipeline. This corresponds to the hydraulic results from Case 2 in the above tables. The operating pressures for this case are within common operating pressures of other existing carbon dioxide pipelines.

Cost metrics (dollar per inch-mile for pipeline and dollar per horsepower for stations) were applied to the various pipeline and station scenarios, and it was determined that the additional cost to install the larger diameter pipeline was not offset by the reduced horsepower requirement. However, since the cost difference between the 3" and 4" options are minimal, it is recommended that the 4" pipe be selected. The below table (Table 3-20) summarizes this cost comparison. This method will give an approximate, order of magnitude, cost difference for the various options. A detailed cost estimate has been created for the recommended 4" option (Case 2) and is included as Appendix 3-H of this report. 
Table 3-20 Pipeline Cost Comparison

\begin{tabular}{|c|c|c|c|}
\hline Parameter & Case 1 - 6" & Case 2 - 4" & Case 3 - 3" \\
\hline Pipeline Metric & $\$ 35,000 /$ in-mi & $\$ 35,000 /$ in-mi & $\$ 35,000 /$ in-mi \\
\hline Pipeline Diameter & $6.625 ”$ & $4.500 ”$ & $3.500 "$ \\
\hline Pipeline Length & $\begin{array}{l}15 \text { miles ( } 24 \\
\text { kilometers) }\end{array}$ & $\begin{array}{l}15 \text { miles ( } 24 \\
\text { kilometers) }\end{array}$ & $\begin{array}{l}115 \text { miles (185 } \\
\text { kilometers) }\end{array}$ \\
\hline Station Metric & $\$ 3,000$ per BHP & $\$ 3,000$ per BHP & $\$ 3,000$ per $\mathrm{BHP}$ \\
\hline Differential BHP & 9 BHP & $41 \mathrm{BHP}$ & $95 \mathrm{BHP}$ \\
\hline $\begin{array}{l}\text { Approx Differential } \\
\text { Cost }\end{array}$ & $\$ 1,380,000$ & $\$ 360,000$ & Baseline \\
\hline
\end{tabular}

Note that the above listed horsepower requirements are differential, and do not include the additional horsepower requirements that would be the same for all three scenarios.

\subsubsection{COMPRESSION AND PROCESS STUDY}

\subsubsection{General Facility Description}

Prior to delivery of the carbon dioxide to the Geneseo-Edwards Oil Field, the raw vapor stream off of the Kansas Ethanol plant will need to be processed to facilitate miscibility with the crude oil and boosted to pipeline pressure to allow the purified carbon dioxide stream to be transported as a supercritical fluid rather than in the vapor phase, minimizing both pipeline diameter and horsepower requirements, as well as providing the necessary pressure for injection in the oil reservoir. The compression and processing facilities on the KE-GE pipeline will require compression to take the raw carbon dioxide stream from approximately atmospheric (13.8 psia) pressure to the required pipeline discharge pressure of 1,587 PSIG, an Oxygen Removal Unit ("ORU") to remove oxygen from the raw feed stream to a desired concentration of less than 10 ppm, and dehydration to take the water content to a concentration of less than $75 \mathrm{ppm}$. Controls and operation of the KE compression facilities will be located in a common, pre-engineered, electrical Power Distribution Center ("PDC") located on-site with the specified compression and processing equipment. A process flow diagram and conceptual site layout have been provided in the drawings section of this report.

\subsubsection{Compression Study}

\subsubsection{General}

Transportation of dense phase carbon dioxide is growing application in the oil and gas industry and incorporates three primary compression technologies: reciprocating compressors, centrifugal compressors, and recently, integrally geared solutions. Prior to selection of the specified compression equipment for this application, a study was completed to compare these technologies, including their associated annual and 9-year operation and maintenance costs.

\subsubsection{Discussion}

Reciprocating compressors consist of one or more cylinders, each with a piston or plunger which displaces a positive volume of gas with each stroke. Centrifugal compressors consist of a rotating element, typically an impeller or bladed rotor, which 
accelerates the gas as it passes through the compressor, converting the velocity head into static pressure. Both types of compressors are available in single and multi-stage configurations. Centrifugal compressors approximate a constant head-variable volume machine, while reciprocating compressors approximate a constant volume-variable head machine.

In general, the advantages of a centrifugal compressor over a reciprocating unit are:

- Typically lower installed costs

- Typically lower maintenance costs

- Greater continuity of service and reliability

- Less operating attention

- Greater volume capacity for the footprint

In general, the advantages of a reciprocating compressor over a centrifugal unit are:

- Better flexibility in capacity and pressure range

- Higher compressor efficiencies, lower power costs

- Ability to deliver higher pressures

- Ability to handle smaller volumes

- Less sensitive to changes in composition and density

The following provides a comparison of key design criteria for reciprocating and centrifugal compressor packages based upon standard manufacturer designs and materials.

\section{Capacity}

- Reciprocating - Reciprocating compressors are positive displacement machines, therefore, their capacity is determined by cylinder size, the number of throws, or locations on the crankcase where a cylinder can be attached, and driver speed. Capacity may be controlled via speed control, clearances on a cylinder (i.e. addition of fixed or variable volume pockets), cylinder end deactivation, and system recycle. Turndown on a reciprocating compressor can be high as $80-90 \%$.

- Centrifugal - Centrifugal compressors can be sized for an inlet flow capacities as low as $500 \mathrm{acfm}$ up to $400,000 \mathrm{acfm}$ in a single body, and is limited by the choke point, or point at which the flow through any part of the compressor nears a velocity of Mach 1. Unlike a reciprocating compressor where minimum flow is solely a function of compressor geometry and speed, the minimum flow for a centrifugal compressor is limited by surge, which is a function of not only compressor geometry and speed, but also aerodynamic gas conditions and system resistance. Turndown on a centrifugal compressor can be as high as $40-50 \%$. 


\section{Suction Pressure}

- Reciprocating - Reciprocating compressors can take suction pressures as low as atmospheric, or even a slight vacuum. In vacuum applications, precautions must be taken to prevent atmospheric air from leaking into the cylinder through the piston rod packing.

- Centrifugal - Centrifugal compressors are suitable for service with subatmospheric inlet pressures with special seals and buffering designs to prevent atmospheric air from being drawn into the compressor.

\section{Discharge Pressure}

- Reciprocating - Reciprocating compressors are suitable for discharge pressures up to approximately $12,000 \mathrm{psi}$.

- Centrifugal - Centrifugal compressors are suitable for discharge pressures up to $1,450 \mathrm{psi}$ with a horizontally split case design and up to 15,000 psi for radially split designs.

\section{Discharge Temperatures}

- Reciprocating - Reciprocating compressors discharge limits will depend upon the application and the seal material selected. API 618 limits the discharge temperature in hydrogen rich applications to $275^{\circ} \mathrm{F}$ and for natural gas service to $350{ }^{\circ} \mathrm{F}$. Most standard manufacturer designs will limit the discharge temperature on each stage to $300{ }^{\circ} \mathrm{F}$. Inter-coolers and after-coolers are often used between stages and at the compressor discharge to improve efficiencies and meet required design temperatures of downstream equipment.

- Centrifugal - Centrifugal compressors discharge temperature limits are based upon the compressor design and typically range from 400 to $450{ }^{\circ} \mathrm{F}$. Higher discharge temperatures are available with special design considerations. Inter-coolers and after-coolers are often used between stages and at the compressor discharge to improve efficiencies and meet required design temperatures of downstream equipment.

\section{Compression Ratio}

- Reciprocating - The compression ratio on each stage of a reciprocating compressor is limited by the resulting discharge temperature and piston rod load. Typical compression ratios range from 1.2 to 4.0 per compression stage.

- Centrifugal - The compression ratio limit for centrifugal compressors is a function of the process fluid physical properties, including molecular weight and compressibility, as well as the compressor speed, stage geometry, and total number of stages. 


\section{Efficiency}

- Reciprocating - Reciprocating compressor efficiency is affected by compression ratio, the respective cylinder's ratio of valve flow area to main bore diameter, and piston speed. Reciprocating compressors typically follow a very characteristic adiabatic curve. High speed reciprocating compressors (900 to $1800 \mathrm{rpm}$ ) typically have an adiabatic efficiency of approximately $82 \%$. Lower speed reciprocating compressors (300 to $700 \mathrm{rpm}$ ) typically have an adiabatic efficiency of approximately $85 \%$.

- Centrifugal - Centrifugal compressor efficiency is typically reported as polytropic rather than adiabatic and are heavily dependant upon inlet volume. Typical polytropic efficiencies range from $60 \%$ at $100-500$ inlet acfm to as high as $85 \%$ at 7,500 acfm or greater. Average reported polytropic efficiencies are however between $70-75 \%$ at the 7,500 acfm or more inlet flow rate.

\section{$\underline{\text { Reliability }}$}

- Reciprocating - Reciprocating compressor reliability is far less than that of centrifugal compressors. Reciprocating units have many more moving parts incorporating more wear and require more frequent replacement. Wear life of seals and valves are significantly affected by the cleanliness of the process fluid and tend to have much longer operational life with process gas free of liquids and debris.

- Centrifugal - Centrifugal compressor reliability approached $98 \%$ to $99 \%$ with proper routine maintenance.

\section{Maintenance Intervals}

- Reciprocating - Maintenance intervals for reciprocating compressors vary significantly with the application. Seal and valve maintenance intervals may be as short as a few months and as long as 3-5 years, depending upon the cleanliness of the process gas. Major overhauls may be required every 10 years or more.

- Centrifugal - Centrifugal compressors designed per API 617, are required to be designed for a minimum 5-year uninterruptable service life. In clean gas service, centrifugal compressors may operate continuously for 10years or more without major maintenance requirements.

\section{Capital \& Operating Costs}

- Reciprocating - Generally, a reciprocating compressor will have a lower base package cost but overall higher installed and operating cost than centrifugal compressors. 
- Centrifugal - Centrifugal compressors have more complex geometry than a reciprocating compressor and therefore typically have a higher up front capital cost, but have fewer moving parts resulting in lower operating costs.

Integrally geared compressors are gaining popularity in carbon dioxide service, however are not as proven as their reciprocating and centrifugal counterparts. Integrally geared packages incorporate a bull gear and up to six (6) high speed pinions, each with one or more centrifugal compressors mounted on the pinion shaft. Optimal impeller speed and the ability to inter-cool compression phases provide much higher efficiencies than typical centrifugal compression units and typically incorporate very high reliabilities.

\subsubsection{Analysis}

At the Kansas Ethanol compression facility, the 8 MMSCFD carbon dioxide feed stream will be supplied at the suction to the selected compression package at approximately 13.8 PSIA and $58{ }^{\circ} \mathrm{F}$, equating to an inlet flow rate of approximately 5,895 acfm. With a required 1,587 PSIG discharge pressure, the selected compression package will need to provide a compression ratio of approximately 116 , therefore, a multi-stage unit will be required. Multi-stage reciprocating compressors are normally considered for inlet volumes between 1 and 9,000 acfm. Multi-stage centrifugal compressors are normally considered for inlet volumes between 500 and 200,000 inlet acfm. Therefore, either a reciprocating or centrifugal compressor could be considered for the KE application.

Efficiencies of multi-stage reciprocating compressors are heavily dependent on speed. High speed reciprocating compressors (900 to $1800 \mathrm{rpm}$ ) typically have an efficiency of approximately $82 \%$. Lower speed reciprocating compressors (300 to 700 rpm) typically have an efficiency of approximately $85 \%$. Due to the high gas density of carbon dioxide (resulting from its high molecular weight), slow rotation and piston speeds are usually recommended in reciprocating compressors. Recent experience has shown efficiencies of reciprocating compressors in carbon dioxide service to be below $75 \%$.

Efficiencies of multi-stage centrifugal compressors are heavily dependant on inlet volume. Centrifugal compressors typically have lower efficiencies at inlet volumes below 7,500 acfm than reciprocating units, primarily due to the geometric design required to develop the higher head at the lower flow.

\subsubsection{Recommendation}

Although, either compressor type may be considered for the KE compression application, the 5,895 acfm inlet flow rate is at the lower end of the centrifugal compressor service range and therefore requires a very small impeller resulting in a lower overall efficiency than that of the reciprocating compressor, therefore, a reciprocating compressor is recommended for the KE compression facility. 


\subsubsection{Compressor Sizing \& Selection}

Several compressor configurations were evaluated as part of the desktop study. Viable configuration options, both with and without redundancy in the design, have been summarized in tables 3-21 and 3-22 below and on the following page:

Table 3-21 Kansas Ethanol Compression Facility Compression Configuration Option - No Redundancy

\begin{tabular}{|c|l|r|r|}
\hline $\begin{array}{c}\text { Option } \\
\text { No. }\end{array}$ & Configuration & $\begin{array}{c}\text { Total } \\
\text { bhp }\end{array}$ & \multicolumn{1}{c|}{$\begin{array}{c}\text { Total } \\
\text { Capital Cost }\end{array}$} \\
\hline 1a & Two (2) $50 \%$ Recips. & 2,720 & $\$ 3,500,000$ \\
\hline 2a & One (1) $100 \%$ Recips. & 2,680 & $\$ 3,750,000$ \\
\hline & One (1) $100 \%$ Low Pressure Recips, plus... & & \\
3a & One (1) $100 \%$ High Pressure Recips & 2,421 & $\$ 2,900,000$ \\
\hline & $\begin{array}{l}\text { Two (2) } 50 \% \text { Low Pressure Screw Compressors, plus.. } \\
\text { 4a }\end{array}$ & & \\
& One (1) $100 \%$ HP Recips & 4,236 & $\$ 2,550,000$ \\
\hline
\end{tabular}

Table 3-22 Kansas Ethanol Compression Facility Compression Configuration Option With Redundancy

\begin{tabular}{|c|c|c|c|}
\hline $\begin{array}{c}\text { Total } \\
\text { No. Units } \\
\end{array}$ & Configuration & $\begin{array}{l}\text { Total } \\
\text { bhp }\end{array}$ & Total \$ \\
\hline $1 b$ & Three (3) $50 \%$ Recips. & 4,080 & $\$ 5,250,000$ \\
\hline $2 b$ & Two (2) $100 \%$ Recips. & 5,360 & $\$ 7,500,000$ \\
\hline $3 b$ & $\begin{array}{l}\text { Two (2) } 100 \% \text { Low Pressure Recips., plus.. } \\
\text { Two (2) } 100 \% \text { High Pressure Recip }\end{array}$ & 4,842 & $\$ 5,800,000$ \\
\hline $4 b$ & $\begin{array}{l}\text { Three (3) 50\% Low Pressure Screw Comrpessors, plus.. } \\
\text { Two (2) } 100 \% \text { High Pressure Recips }\end{array}$ & 6,972 & $\$ 4,250,000$ \\
\hline
\end{tabular}

Based upon discussions with Blue Source, LLC., Option \#1b was selected for the KE compression facility. This provides three (3) 50\% capacity GE FS-706, 6-Stage reciprocating compressors, or equivalent, with $4160 \mathrm{~V}, 1,360 \mathrm{hp}$ electric motors, operating in parallel with one another and provides a single $50 \%$ capacity unit for backup to facilitate the required maintenance schedule associated with the selected reciprocating compressor package. Each compressor package would include scrubbers on each stage and both inter-stage and after coolers. The use of forced draft fin-fan coolers would be anticipated, adding an auxiliary load of approximately $30 \mathrm{hp}$.

Typical maintenance for these units will incorporate routine inspections and checks every 6 months with annual maintenance and extended checks that may include checking main, connecting rod, and crankshaft thrust bearings, inspection of valves, replacement of packing, etc. A copy of the manufacturer's recommended maintenance guide has been provided in Attachment 4 - Compressor Maintenance Information. Typical operations and maintenance costs for these units would run approximately $\$ 80,000$ / year. Properly maintained, this unit should operate 10 -years or more without a major rebuild, but should one become necessary, the estimated cost to do so would be approximately $\$ 200,000$ / overhaul. 


\subsubsection{Process Equipment}

Oxygen Removal Unit

The oxygen removal system for the KE compression and processing facility is based on the catalytic combustion of oxygen. Since the raw carbon dioxide feed stream does not contain any hydrocarbons to "burn" the oxygen, the stream will need to be seeded with natural gas. The amount of natural gas will need to be approximately twice the stoichiometric ratio with the excess being used to ensure the complete combustion of the oxygen. Therefore, if the stream contains $1 \%$ oxygen it will need to have natural gas injected to a concentration of approximately $1 \%$. Based upon the anticipated feed stream composition, it is estimated the approximately $48,000 \mathrm{SCF}$ of natural gas will be required to remove the oxygen to less than $10 \mathrm{ppm}$ for $8 \mathrm{MMSCFD}$ of carbon dioxide. A process flow diagram and high level description of the process is provided on the following page (Figure 3-1).

\section{Figure 3-1 Oxygen Removal Unit (“ORU”) Process Flow Diagram}

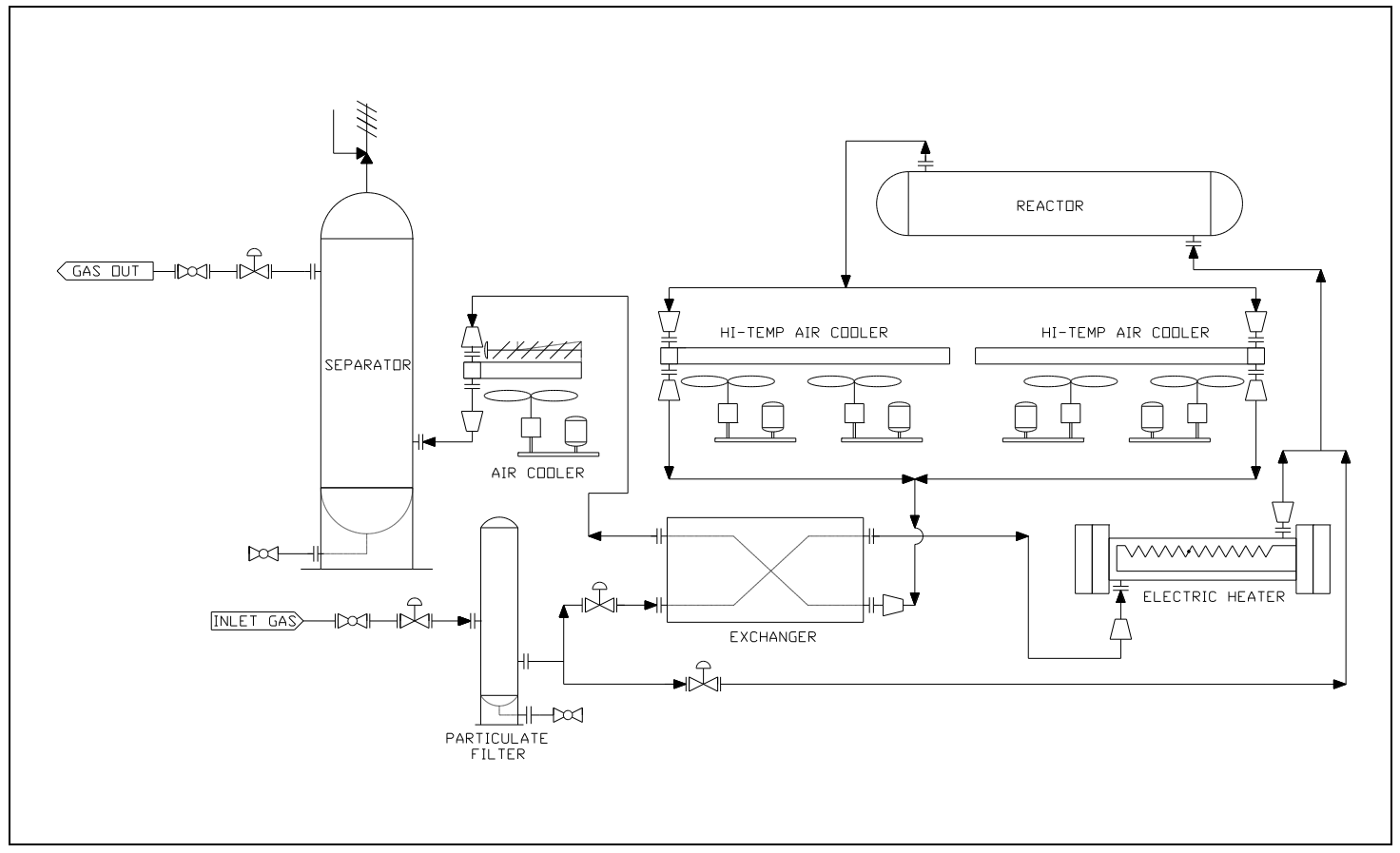

The inlet gas is introduced into a particulate filter after liquids separation. The removal of fine particulates prevents the clogging of the catalyst. The gas goes through a heat exchanger where the gas is heated to the required reaction temperature during steady state operation. There is a cool gas bypass to allow for the control of the temperature going to the reactor. During startup, the electric heater is used to heat the gas to the required reaction temperature. The heater can also be used continuously when there is not enough oxygen to maintain inlet reactor temperatures. The reactor contains the catalyst and is designed to have 
sufficient volume of catalyst necessary to "burn" the amount of oxygen required. This system does not require the high temperature coolers that are shown in the figure above. The gas flows through the heat exchanger where it is cooled and is then introduced into the final air cooler. Condensed water is removed in a separator and the gas exits the system.

This process utilizes a platinum based catalyst with a life expectancy of 5-7 years. Replacement catalyst costs will be dependant upon the price of platinum at the time of replacement, with credit for the remaining platinum in the base charge credited to the purchase of the replacement catalyst. Preliminary discussions with the ORU manufacturers suggested replacement costs can be expected to be approximately $50 \%$ of the original catalyst costs.

In this system, the resulting gas stream will have a residual amount of hydrocarbons. The exact amount can be minimized by reducing the natural gas feed in the feed stream to the minimum required to meet the outlet oxygen specification. Through detailed design, a system that varies the natural gas flow rate into the raw $\mathrm{CO}_{2}$ stream can be developed.

\section{Dehydration Unit}

Water vapor from the raw carbon dioxide feed stream would be removed utilizing a single tri-ethylene glycol (TEG) dehydration skid package comprised of a gas fired 125 MBTU / Hr re-boiler and 24" diameter contactor tower.

The initial fill for start-up of the system is anticipated to require approximately 150 gallons of TEG and has been included in the capital costs provided with this study. Annual TEG losses are estimated at less than 1\% excluding upset conditions with estimated annual operating costs of $\$ 175,000$.

\subsubsection{Electrical Design}

Power for the KE compression and processing facilities are anticipated to be available from the existing Kansas Ethanol plant. $4160 \mathrm{~V} / 3$-Phase power shall be used as the secondary service, with additional transformation down to 480V / 3-Phase and 208V / $120 \mathrm{~V}$ for auxiliary equipment and lighting. All power and controls for the new facility would be incorporated into a pre-engineered metal power distribution center, including a $4160 \mathrm{~V}$ cutler-hammer, or equivalent, switchgear, $4160 \mathrm{~V}$ solid state reduced voltage starter, $480 \mathrm{~V}$ motor control center, Programmable Logic Controller, and miscellaneous power and lighting equipment.

Table 3-23 below summarizes the overall electric loads and estimate annual cost at the $\mathrm{KE}$ compression facility. The electric rate of $\$ 0.0732 / \mathrm{KW}-\mathrm{HR}$ used is the average commercial electric rate paid in the state of Kansas in 2009 (Report No.: DOE/EIA0226). 
Table 3-23 KE Facility Annual Electric Loads and Costs

\begin{tabular}{|l|c|c|c|}
\hline Description & $\begin{array}{c}\text { Number } \\
\text { of Units }\end{array}$ & $\begin{array}{c}\text { BHP } \\
\text { Each }\end{array}$ & $\begin{array}{c}\text { Total } \\
\text { BHPP }\end{array}$ \\
\hline $\begin{array}{c}\text { Compressor, Reciprocating, GE FS- } \\
\text { 706, 6-Stage }\end{array}$ & 2.0 & $\begin{array}{c}1,360 \\
\text { BHP }\end{array}$ & $2,720 \mathrm{BHP}$ \\
\hline Inter-coolers and After-coolers & 2.0 & $\begin{array}{c}30 \\
\text { BHP }\end{array}$ & $60 \mathrm{BHP}$ \\
\hline $\begin{array}{c}\text { Oxygen Removal Unit, 8 MMscfd, } \\
\text { 3\% Maximum O2 }\end{array}$ & 1.0 & $\begin{array}{c}15 \\
\text { BHP }\end{array}$ & $15 \mathrm{BHP}$ \\
\hline TEG Dehydration Package & 1.0 & $\begin{array}{c}5 \\
\mathrm{BHP}\end{array}$ & $5 \mathrm{BHP}$ \\
\hline \hline TOTAL & & & $\mathbf{2 , 8 0 0} \mathbf{B H P}$ \\
\hline TOTAL KW-HR/YR & & & $\begin{array}{c}17,376,000 \\
\mathrm{KW}-\mathrm{HR} / \mathrm{YR}\end{array}$ \\
\hline COST PER KW-HR & & & $\begin{array}{c}\mathbf{\$} 0.0732 / \mathrm{KW}- \\
\mathrm{HR}\end{array}$ \\
\hline \hline ANNUAL COST & & & $\mathbf{\$ 1 , 2 7 2 , 0 0 0}$ \\
\hline
\end{tabular}

\subsubsection{SCADA Design}

The Supervisory Control And Data Acquisition (SCADA) system on the KE-GE pipeline will consist of four main components which are the 1) Programmable Logic Controllers (PLC) to be located at all the station and valve sites connected to the instruments, 2) Operator Interface and data collection system which is the SCADA software, 3) Leak detection system, and 4) Communications system which will tie all the parts together.

The communication system will be composed of an armored fiber optic cable installed in the most appropriate method adjacent to the pipeline. The cable could be installed in the same ditch as the pipeline, direct buried, in duct strapped to the pipe at crossings, or plowed into the ground. The SCADA system which communicates through a fiber optic cable will have a very high uptime and the capability for fast and reliable communication between the stations and the main line valves. These features will enable the fast integrated control system to automatically operate more safety.

The PLC at each compressor and main line valve site will be a GE 90-30 or company approved equal and will be housed inside a small building to enable support personnel to program and maintain them in inclement weather.

The SCADA software will have a primary system installed at the primary control center on one end of the pipeline and there will be a backup SCADA host at the facility at the other end of the pipeline. Costs for SCADA vendor services were also included. SCADA vendor services include project management, design specification documents, SCADA communications programming, SCADA screen programming, factory tests, installation onsite, onsite tuning of the software, commissioning tests, operations and the maintenance manual, training support for operators and technicians. 
The Leak Detection System will communicate with each station to analyze the pipeline for leaks and report to the SCADA software for operator notification. Leak Detection vendor services were also included. Leak Detection vendor services include project management, design specification documents, communications programming, graphical user interface screen programming, factory tests, installation onsite, tuning of the software, commissioning tests, operations and the maintenance manual, training support for operators and technicians.

\subsubsection{Cathodic Protection and AC Mitigation}

Cathodic protection of the 4" steel pipeline system will be accomplished using an impressed current system with either deep-well and/or surface anode ground beds. In order to quantify the soil resistivity in the area, a soil investigation will be required once the pipeline has been installed. The cathodic protection system will be designed accordingly depending upon the soil resistivity. The system will consist of either highsilicon cast iron anodes set in deep wells and/or or treated graphite surface anodes. The quantity and dimension of the deep well anodes and/or surface ground beds will be determined during detailed design of the cathodic protection system. Either system will be powered by a rectifier which will also be sized during detailed design of the cathodic protection system.

Alternate Current $(\mathrm{AC})$ mitigation will be required where pipelines are in close proximity to overhead power lines. AC mitigation will be accomplished using zinc anode ribbon buried alongside the pipeline system. In order to determine the amount of zinc ribbon required for $\mathrm{AC}$ mitigation a soil investigation will be required during detailed design to quantify the soil resistivity in the areas of concern. Based on the soil resistivity, proximity and voltage of overhead power lines, and the operating lifespan of the project, the AC mitigation system will be designed to protect the pipeline system from stray currents imposed by overhead power lines

\subsubsection{Typical Construction Method}

Standard pipeline construction procedures and BMP's would be followed during construction. The centerline of the ROW would be staked prior to construction. The following discussion provides a brief overview of the construction process.

All equipment and vehicular access into the pipeline project would be confined to existing roads and the established ROW corridor. No major reconstruction or rerouting of these roads is intended. 
The following are the general steps in the construction process:

- Surveying and staking of the ROW

- Right-of-way (ROW) clearing and grading, topsoil stockpiling

- Ditching

- Pipe stringing, and bending

- Pipe welding

- Pipe Jeeping

- Pipe lowering in

- Backfilling of trench

- Testing of pipeline and facilities

- Clean up and revegetation

All construction materials would be hauled to the job site by truck, as needed, and strung along the ROW as they arrive. Pipe would be strung in such a manner as to cause the least interference with the normal use of the land crossed by the ROW. The construction ROW would be limited to a 75-foot width. As a general rule (except for steep slope areas), clearing would be limited to 75 feet: 55 feet on the working side and 20 feet on the stockpile side of the trench. Grading of the entire ROW would occur only in areas where equipment access is not possible without ROW clearing. The top 6 inches of topsoil would be removed and stockpiled off of the trench line and any areas to be graded. Top soils would be stockpiled separately from trench spoils.

Construction or routine maintenance activities will not be allowed during periods when soil is too wet to adequately support construction equipment. If such equipment creates surface ruts in excess of 6 inches deep, the construction supervisor would deem that soil conditions are too wet to adequately support construction equipment.

Construction activities would not be allowed until soil conditions improve. The pipeline trench would be excavated using a wheel trencher, or a track-hoe excavator. The wheel trencher pulverizes the soil as the trenching progresses, stacking the spoil in a pile along the side of the trench. In the event weather conditions warrant, the spoil pile can be worked by driving a tracked dozer over the spoil and working it with the blade, breaking up frozen soils. Breaking up the frozen soils would mitigate the issue of the ditch settling. A small mound of soil (6-10 inches high) would be placed on top of the trench line to accommodate minor settling.

A wheel trencher or track hoe would be used to dig a trench to an average depth of 60 inches, stacking the dirt beside the ditch. After the pipe is placed in the ditch a motor grader or caterpillar would be used to push the dirt back into the trench. The fill on the trench would then be tamped into place with the grader wheels, leaving a berm of 6 to 10 inches to accommodate settling. Disturbance of the topsoil within the ROW would be kept to a minimum. In areas of excessively steep hillsides, or to provide a smooth approach to a cut or gully, as well as at stream bank crossings and at established work 
stations, some blading may be required to provide a safe and suitable working area for the equipment and workers. When this occurs the top 6 inches of soil would be stockpiled on the side of the ROW and spread back over the area from which it was taken, after the final grading. Before seeding any disturbed areas, the ROW would be restored to its original form, slope, contour, and soil density to the extent practicable.

\subsubsection{Rock Ditch}

Throughout the course of the pipeline construction, solid rock may be encountered during the excavation. When the rock cannot be excavated with the typical track hoe, additional equipment or blasting may be required. In these areas, construction cost will increase due to the additional equipment and slower installation productivity. Typically, an additional cost for installation is added for every foot of rock ditch encountered. A construction contractor, who has installed pipelines in the project area, estimated that there will be minimal amounts of rock encountered on the KE-GE pipeline route. In the cost estimate, it was assumed that $5 \%$ of the total route would be considered rock ditch. The precise amount of rock cannot be determined until construction of the pipeline.

\subsubsection{Crossings}

A detailed review of the required pipeline crossings was completed. The locations where the proposed route crossed an Interstate, Highway, State Road, Other Paved Roads, Dirt Roads, Railroads, Lakes, Rivers, and creeks were identified. The below table (Table 3-24) summarizes the number of each type of crossings, as well as the estimated total length of each type of crossing.

Table 3-24 KE-GE Road, Railroad, and Waterway Crossing Tally

\begin{tabular}{|l|c|c|}
\hline TYPE & $\begin{array}{c}\text { TOTAL NO. } \\
\text { CROSSINGS }\end{array}$ & $\begin{array}{c}\text { TOTAL } \\
\text { LENGTH }\end{array}$ \\
\hline Interstate & 0 & $0 \mathrm{ft}$ \\
\hline Highway / State Rd & 1 & $100 \mathrm{ft}$ \\
\hline Other Paved Road & 2 & $150 \mathrm{ft}$ \\
\hline Dirt Road & 19 & $950 \mathrm{ft}$ \\
\hline Railroad & 2 & $200 \mathrm{ft}$ \\
\hline Lake/ River & 1 & $100 \mathrm{ft}$ \\
\hline Creek & 1 & $25 \mathrm{ft}$ \\
\hline \hline TOTAL & $\mathbf{2 6}$ & $\mathbf{1 , 5 2 5} \mathbf{f t}$ \\
\hline
\end{tabular}

In general, it is proposed that paved roads or railroads that require a crossing length of 100 feet or greater, be crossed using a Horizontal Directional Drill (HDD). It is proposed that paved roads or railroads that require a crossing length of 100 feet or less, be crossed using an un-cased slick bore. It is proposed that all dirt roads be open cut. Regarding waterway crossings, $t$ is proposed that waterways that require a crossing length of 100 feet or greater, be crossed using a Horizontal Directional Drill (HDD). It is proposed that waterways that require a crossing length of 100 feet or less, be crossed using an un-cased slick bore. 
During the detailed design portion of the project, each crossing would need to be analyzed on a site specific basis, and a detailed crossing plan and profile be developed.

\subsubsection{Long Lead Materials}

Most of the materials required for the construction of the KE-GE Pipeline Project are considered long lead items. Long lead items are described as items that are not in stock at the time of purchase. These items include the compressors, pumps, dehydration process equipment, oxygen removal process equipment, valves, actuators, steel pipe, materials for the launchers and receivers and their fabrications, and other miscellaneous fittings. Deliveries are based on budgetary quotes for material received on August 1, 2010.

Budgetary bids have been received from vendors for the compressors, with an anticipated delivery of 26 weeks after receipt of order.

Budgetary bids have been received from vendors for the dehydration process equipment, with an anticipated delivery of 15 weeks after receipt of order.

Budgetary bids have been received from vendors for the oxygen removal process equipment, with an anticipated delivery of 26 weeks after receipt of order.

Budgetary bids have been received from vendors for the ANSI 900 valves and required actuators for the pig launchers/receivers. Anticipated delivery of valves and actuators is 12-26 weeks after receipt of order (ARO).

Budgetary bids have been received from vendors for the steel line pipe. Line pipe will be mill rolled and coated with FBE coating. Anticipated delivery of the line pipe is 20-30 weeks after receipt of order (ARO). Line pipe will be mill rolled and coated with FBE coating.

Budgetary bids have been received from vendors for the launchers and receivers. Anticipated delivery is $12-14$ weeks after purchase orders have been issued. Lead times include material procurement, fabrication and testing and shipping.

Budgetary bids have also been received from vendors for bends for the piggable pipeline systems. Deliveries are anticipated to be 2-3 weeks ARO.

\subsubsection{Capital Cost Estimate}

See the attached Appendix 3-I - Pipeline Estimate prepared for the KE-GE Pipeline Systems. See also Appendix 3-J - Estimate Basis Memorandum for more information regarding the estimate.

\subsubsection{Project Schedule}

See Appendix 3-K - Project Schedule prepared for the KE-GE Pipeline Systems. 


\section{CHAPTER 4 - Reservoir Modeling and Simulation}

\subsection{Thrall-Aagard Field - Deep Saline Sequestration Analysis}

\subsubsection{Model Grid \\ 4.0.1.1 Description of Study Area}

The Thrall-Aagard site for the $\mathrm{CO}_{2}$ enhanced oil recovery and deep saline aquifer sequestration project is located in the northern half of the Thrall-Aagard oil field. The IMCCS team developed a geologic model of the field and conducting numerical simulations to demonstrate and evaluate the potential for long-term secure and safe storage of $\mathrm{CO}_{2}$ within a saline aquifer. For this goal, the IMCCS team focused on developing a site-specific geologic model to better understand and design $\mathrm{CO}_{2}$ storage, specifically targeted to Cambrian-Ordovician Arbuckle Formation at the Thrall-Aagard site. Simulation of deep saline aquifer sequestration of $\mathrm{CO}_{2}$ in the Thrall-Aagard included injection of up to 100,000 metric tons $\mathrm{CO}_{2}$ per year with a maximum twentyyear injection period.

Geographic location of the study area in the Thrall-Aagard field is illustrated in Figure 4-1. Stratigraphic, petrophysical, and geophysical data used for building the geologic model of the Thrall-Aagard deep saline aquifer were provided by industry partners as well as public databases. However, less information is available for the deep saline formations than for the relatively shallow oil reservoirs targeted for the demonstration of $\mathrm{CO}_{2}$ EOR operation. Currently, there are only a limited number of formation tops available for the Arbuckle and overlying formations due to previous lack of economic interest in this area. No wells directly penetrate the Precambrian Granite have been found within the study area. In detail, there exist only 6 wells containing the top picks for the Granite (basement rock) regionally, and we used these six data points to interpolate the top horizon of the Granite within the model area based on the assumption of a monocline structure identified in the Arbuckle Formation. These data were assembled and processed into an information database for the geologic model development and numerical simulation. We suggest a relatively large uncertainty for many aspects of the deep saline $\mathrm{CO}_{2}$ sequestration project, primarily due to the paucity of data including stratigraphic, petrophysical, hydraulic, and geochemical properties of the intended target formation and caprock. 


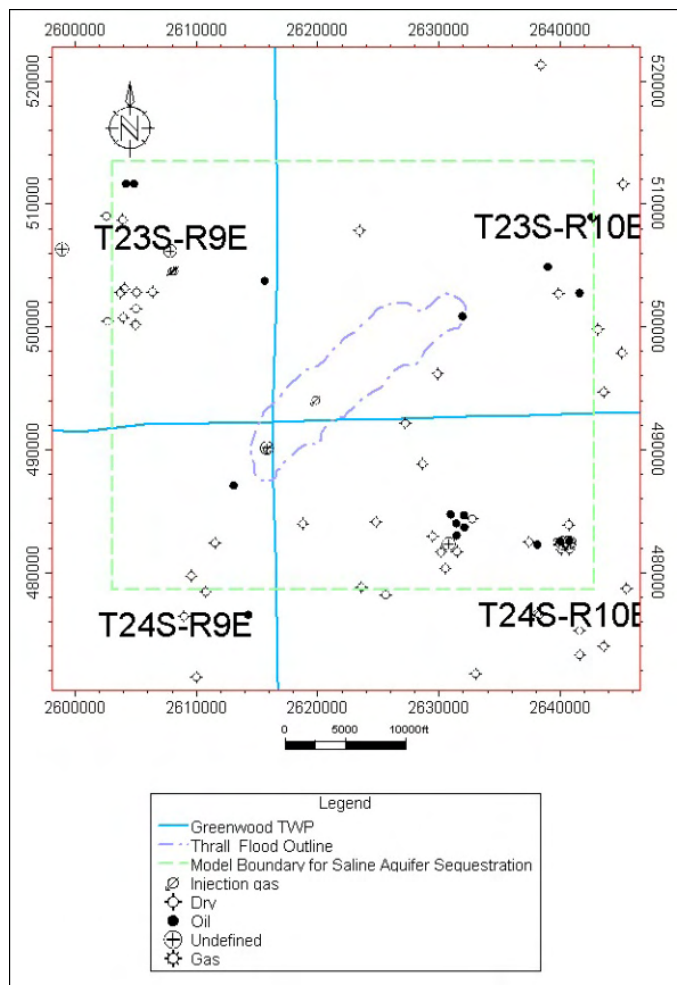

Figure 4-1. Location of the study area and wells containing top picks of the Viola, Simpson, Arbuckle, and Granite Formations.

The Arbuckle Formation is an upper member of the lower unit of the Ozark plateau aquifer system [Carr et al., 2005]. Mineralogically, the Arbuckle formation primarily consists of shallow-shelf dolomites with locally-contained siliceous minerals and exhibits enhanced porosity and permeability due to the repeated prolonged subaerial exposure and extensive karst processes before subsequent burial [Cansler and Carr, 2001]. Economically, the Arbuckle Formation is a major oil producing formation in Kansas as well as oil field by-products disposal (produced water), which implies a potential for $\mathrm{CO} 2$ sequestration. Carr et al. [2005] suggest that the Arbuckle formation is underpressurized due to the extensive hydraulic connectivity to the recharge surface at the Ozark plateau, approximately 200 miles (322 kilometers) to the east of the Thrall-Aagard site. Overlying the Arbuckle is the Simpson Formation, which is composed of green shales and minor amounts of interbedded carbonates and sandstone [McClellan, 1930; Walters, 1958]. Overlying the Simpson is the Ordovician Viola Formation, a series of limestone and dolomite, which is slightly less porous and permeable than the Arbuckle rock.

\subsubsection{Model Grid Development}

The Petrel ${ }^{\mathrm{TM}}$ software package, a 3-D integrated reservoir modeling tool from Schlumberger, was used for the geologic model and associated grid. First, a static geologic model was established based on the available formation tops tied to isochore data. The resulting structural model within the model boundary is shown in Figure 4-2. The model domain is approximately $6.76 \mathrm{~km}$ by $5.79 \mathrm{~km}$ ( 4.2 miles by 3.6 miles) in the $\mathrm{x}$ 
and y directions, respectively (Figure 4-1). The present model contains three geologic formations starting with the Viola Formation at the top, the Simpson Formation in the middle, and the Arbuckle Formation at the bottom (Figure 4-2). Although the Simpson Formation is believed to act as the primary caprock above the Arbuckle formation, its lateral continuity and integrity as a seal is questionable given the available data at the proposed site. Therefore, we included two overlying formations, and then, set the top of the Viola Formation (secondary cap rock) as a no flow boundary to represent the bottom of the Mississippian Kinderhook shale as the uppermost confinement of the model domain.

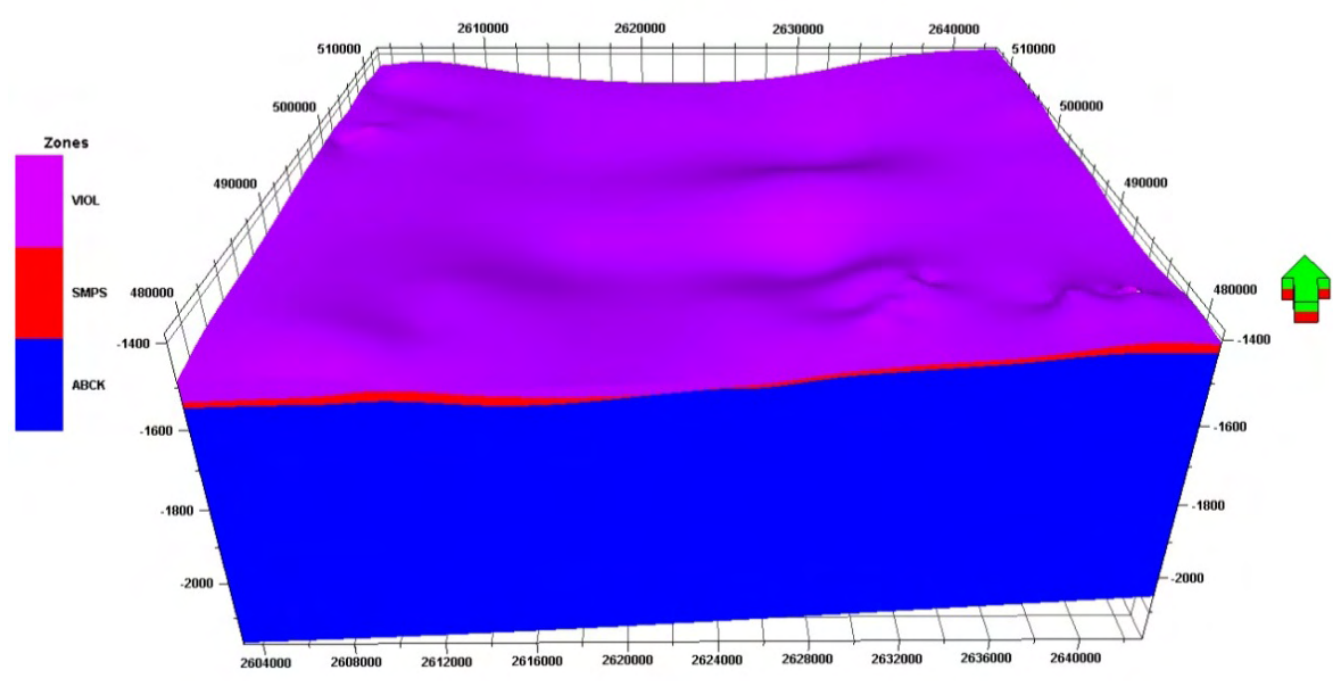

Figure 4-2. Model grid for deep saline $\mathrm{CO}_{2}$ sequestration in Thrall-Aagard field. Vertical exaggeration is $10 x$.

Each cell is equally spaced with a size of $91 \mathrm{~m}(300 \mathrm{ft})$ in the $\mathrm{x}$ and $\mathrm{y}$ directions. The subdivision of the three formations of interest into 20 and 3 layers was performed for the target and two overlying formations, respectively, according to the equal volume fraction. Consequently, the model grid consists of a total of 123,136 cells $(74 \times 64 \times 26)$. This static model exhibits the Arbuckle Formation as slightly dipping upward to east with a gradient of less than 0.01. The average thickness of Arbuckle Formation within the model area is found to be approximately $188 \mathrm{~m}(618 \mathrm{ft})$.

Having established the 3-D structural model of the geologic formations, geologic properties such as porosity and permeability values were assigned to the model. However, due to the lack of directly-available data and large lateral distances between the measurements, we assumed homogeneity in the petrophysical properties in each formation for this generalized scoping study. Based on the available porosity logs existing outside of the model domain, average porosity values for each formation were determined and used for the uniform porosity values for each formation. Average porosity values of $0.06,0.01$, and 0.08 were uniformly assigned to the Viola, Simpson, and Arbuckle Formations, respectively. Although the porosity of the Arbuckle is less than values commonly found in oil reservoirs $(0.1 \sim 0.2)$, we used this lower average value for the Arbuckle porosity in order to be more conservative in terms of $\mathrm{CO}_{2}$ storage. 


\subsubsection{Grid Conversion for TOUGH2 and PFloTran Simulator}

Two different simulators were utilized for the flow simulation work. For 2-D numerical simulation of $\mathrm{CO}_{2}$ injection in the deep saline aquifer, we used TOUGH2 [Pruess et al., 1999], a general-purpose numerical simulator for multiphase, multicomponent fluid and heat flow in porous and fractured media. Detailed descriptions of TOUGH2 simulation and the predicted model results are described in Section 4.1 of this chapter. For the 3-D model, we utilized PFloTran, a massively parallel subsurface multiphase, multi-component reactive transport flow simulator based on the PETSc, SAMRAI and MPI packages [Lu and Lichtner, 2006]. PFloTran's capabilities have been adopted to demonstrate the various flow and transport processes in relation to subsurface contaminant and geological CO2 sequestration [Hammond et al., 2007]. The detailed application of the PFloTran simulator is described in Section 3 of this chapter.

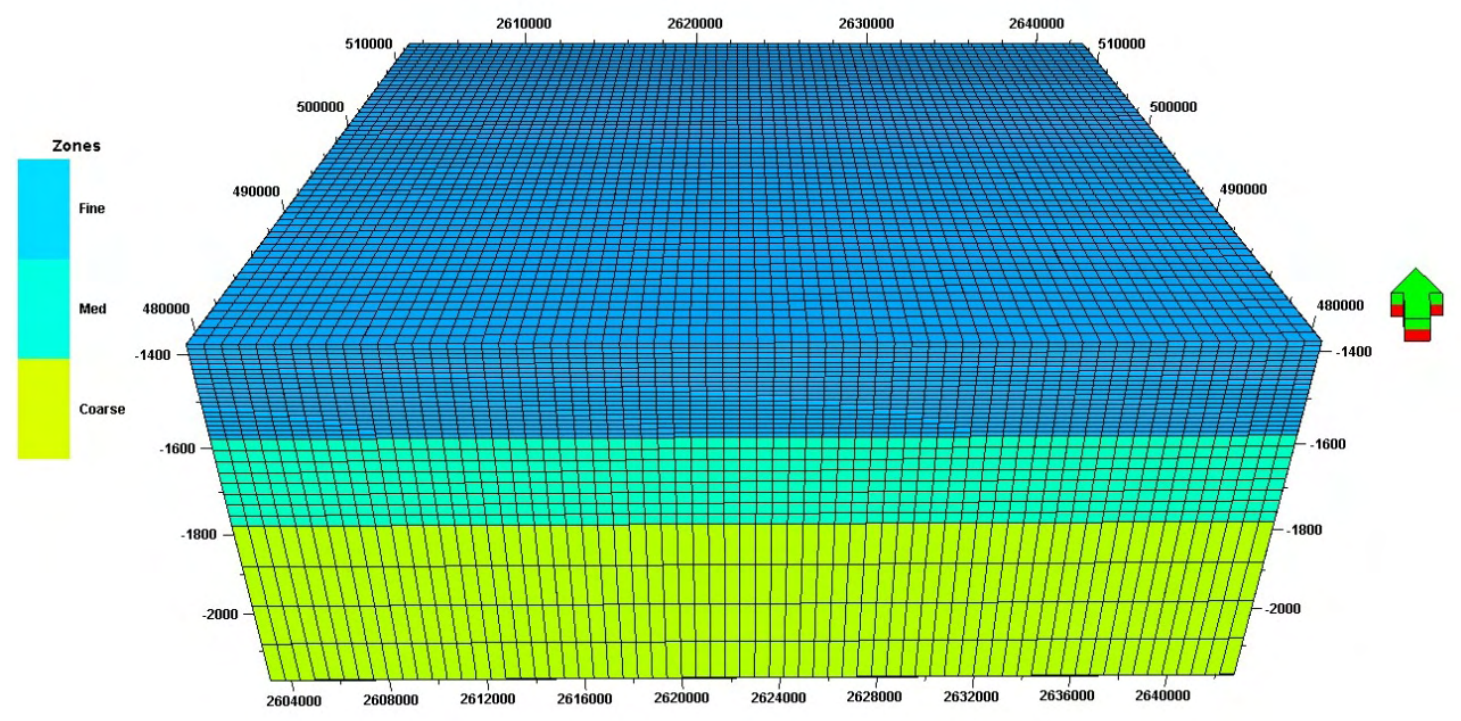

Figure 4-3. Orthogonal grid setting implemented for PFloTran simulator with the location of proposed $\mathrm{CO}_{2}$ injection well. Vertical exaggeration is $10 x$.

Since PFloTran can only run using an orthogonal grid model, we conducted a grid conversion and remapped the porosity distribution into a new orthogonal grid by a volume-weighted averaging methods to preserve the overall volume between the two grids. The new orthogonal grid setting consists of two different vertical zones (fine and coarse grid) depending on the required cell resolution to maintain the structural geometry while minimizing the total number of cells in the model domain (Figure 4-3). The fine-

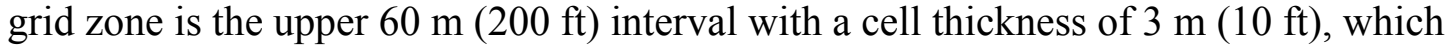
covers the vertical range from the top of the Viola formation to the top horizon of the

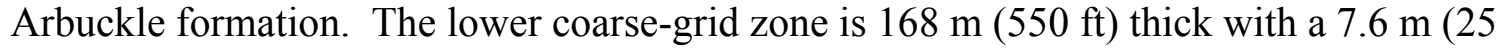
$\mathrm{ft}$ ) cell thickness, representing the Arbuckle formation below the Simpson-Arbuckle contact horizon. The proposed $\mathrm{CO}_{2}$ injection well will be placed approximately $1,220 \mathrm{~m}$ $(4,000 \mathrm{ft})$ southwest from the center of model domain or the center of $\mathrm{CO}_{2} \mathrm{EOR}$ area

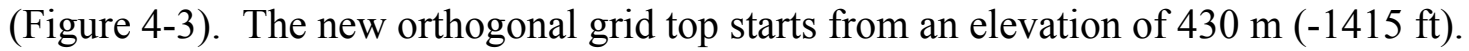


Each cell size has been maintained with the same horizontal cell dimension such as $91 \mathrm{~m}$ by $91 \mathrm{~m}(300 \mathrm{ft} \times 300 \mathrm{ft})$ in the $\mathrm{x}$ and $\mathrm{y}$ directions. Note that due to the refinement in the cell thickness, the total number of cells was increased to $198,912(74 \times 64 \times 42)$ from 123,136. Figure 4-4 illustrates the updated porosity distribution mapped onto the orthogonal grid setting after the volume-weighting method for the PFloTran simulator.

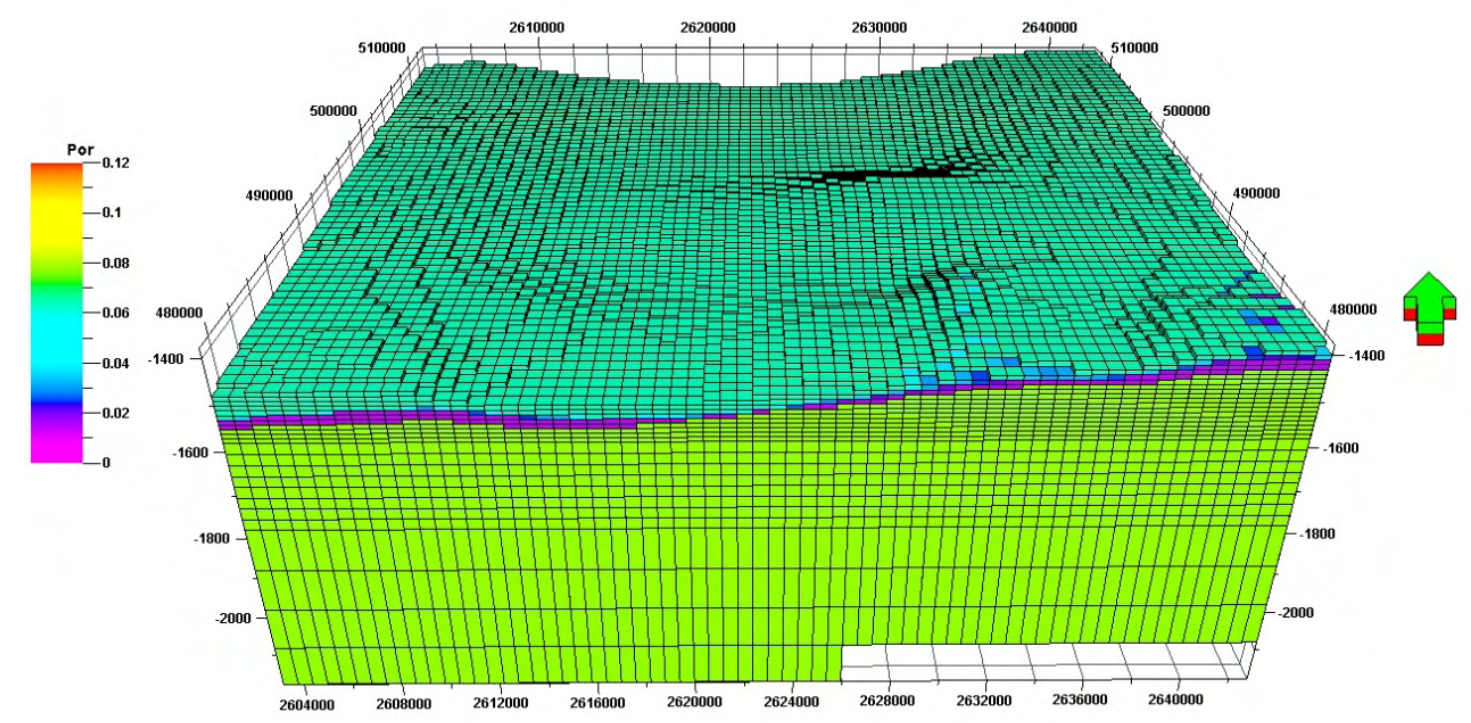

Figure 4-4. Porosity distribution in the orthogonal grid setting for the PFloTran simulator. Vertical exaggeration is 10x.

\subsubsection{Flow Model: Two-Dimensional Radial $\mathrm{CO}_{2}$ Injection Test}

\subsubsection{Descriptions of TOUGH2 Simulator, Equations of State (EOS) Algorithms, and Conceptual Model}

The potential $\mathrm{CO}_{2}$ plume migration and associated heat/drying-out processes were investigated by simulating $\mathrm{CO}_{2}$ injection into a 2-D radially-symmetric domain (Figure 45). The maximum radial extent of this model is $5 \mathrm{~km}$ with logarithmic increase of lateral distance and the formation thickness is $182.9 \mathrm{~m}$ divided with 30 layers. In the model, the pressure, temperature, $\mathrm{NaCl}$ concentration, and $\mathrm{CO}_{2}$-saturation are respectively assigned as 6.89 to $8.39 \mathrm{MPa}, 41.7{ }^{\circ} \mathrm{C}, 15 \%$ of $\mathrm{NaCl}$ mass fraction, with zero $\mathrm{CO}_{2}$ saturation, which represent the current in situ condition of the Arbuckle formation. Two scenarios were developed with different injection rates. In the first scenario, supercritical-phase $\mathrm{CO}_{2}$ is injected at the constant rate of 0.05 million metric tons per year during three years in the injection well, which partially penetrates the $24.4 \mathrm{~m}$ thickness in the bottom of the Arbuckle formation. In the latter one, the injection rate is increased twice. The right-side boundary is assumed as the Dirichlet boundary where thermophysical properties on this boundary remain constant during simulation. The detailed model parameters including the initial/boundary conditions are given in Figure 4-5. 


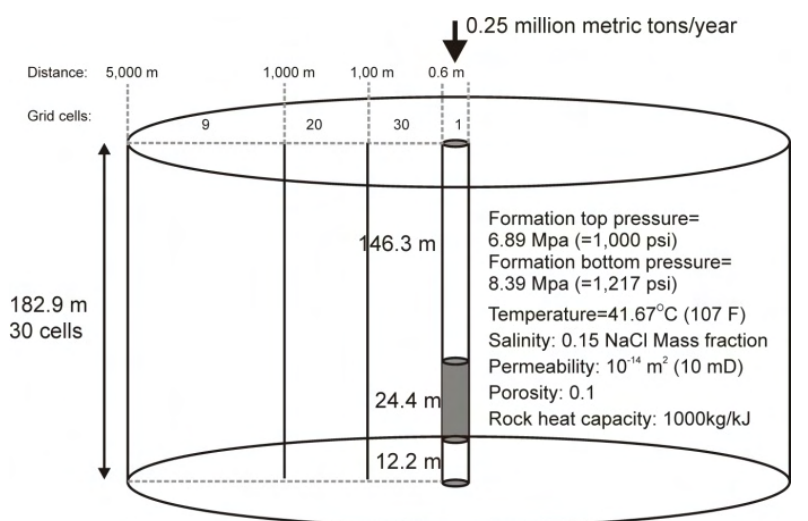

Figure 4-5. 2D radial model representing the Arbuckle formation under the Thrall-Aagard reservoir.

Our numerical simulation of $\mathrm{CO}_{2}$ sequestration potential in the Arbuckle formation with TOUGH2 [Pruess et al., 1999] included application of an equation of state package called ECO2N [Pruess, 2005]. ECO2N is designed to treat two-phase (liquid, gas) transport including three-component [water, salt $(\mathrm{NaCl})$, supercritical-phase $\mathrm{CO}_{2}$ ] systems in suitable pressure and temperature regimes $\left(10^{\circ} \mathrm{C} \leq \mathrm{T} \leq 110^{\circ} \mathrm{C}, \mathrm{P} \leq 60 \mathrm{MPa}\right.$, salinity up to full halite saturation) for $\mathrm{CO}_{2}$ sequestration processes. In TOUGH2/ECO2N, the properties of supercritical-phase $\mathrm{CO}_{2}$ are calculated from the correlations developed by Altunin [1975] and the water properties are obtained from IFC [1967]. Mutual partitioning between supercritical-phase $\mathrm{CO}_{2}$ and water are calculated with Spycher et al. [2003]. In addition, to account for the heat disequilibrium processes during $\mathrm{CO}_{2}$ injection, the enthalpy $\left(H_{m i x}\right)$ of the $\mathrm{CO}_{2}$-laden fluid is calculated by adding the heat of $\mathrm{CO}_{2}$ dissolution to the ideal mixing equation of the supercritical-phase $\mathrm{CO}_{2}$ and brine, which is a similar approach implemented in the ECO2N module within TOUGH2 [Battistelli et al., 1997; Pruess, 2005].
$H_{\text {mix }}=\left(1-X_{\mathrm{CO}_{2}}\right) \mathrm{H}_{b}+X_{\mathrm{CO}_{2}}\left(\mathrm{H}_{\mathrm{CO}_{2}}+\Delta H_{\text {sol }}\right)$.

Here, $\mathrm{H}_{\mathrm{CO}_{2}}$ [Altunin, 1975] and $\mathrm{H}_{b}$ [Pruess, 2005] are the enthalpy of supercritical-phase $\mathrm{CO}_{2}$ and brine, respectively. $\mathrm{X}_{\mathrm{CO}_{2}}$ is the dissolved $\mathrm{CO}_{2}$ mass fraction in brine [Spycher et al., 2003] and $\Delta H_{\text {sol }}$ is the heat of $\mathrm{CO}_{2}$ dissolution [Battistelli et al., 1997]. Similarly, the enthalpy state of the supercritical-phase $\mathrm{CO}_{2}\left(H_{s c}\right)$ due to water vaporization is calculated with the following equation:

$$
H_{s c}=\left(1-Y_{\mathrm{H}_{2} \mathrm{O}}\right) \mathrm{H}_{\mathrm{CO}_{2}}+Y_{\mathrm{H}_{2} \mathrm{O}}\left(\mathrm{H}_{b}+\Delta \mathrm{H}_{\text {vap }}\right) . \quad \text { (Eq. 2) }
$$

Here, $Y_{\mathrm{H}_{2} \mathrm{O}}$ is the mass fraction of water in the supercritical-phase $\mathrm{CO}_{2}$, calculated from Spycher et al. [2003] and $\Delta H_{\text {vap }}$ is heat of water vaporization [Wagner and Prub, 2002]. Both Eq. 1 and 2 completely describe the thermal changes resulting from $\mathrm{CO}_{2}$ dissolution into brine and water vaporization into supercritical-phase $\mathrm{CO}_{2}$.

The changes to brine density caused by varying $\mathrm{CO}_{2}$ concentration were predicted by Garcia [2001]. Finally, the relative permeability and capillary pressure developed by Corey [1954] and van Genuchten [1980] were used without considering the hysteretic effects. 


\subsubsection{Vertical/Horizontal $\mathrm{CO}_{2}$ Plume Extension Associated with Time Scale}

Results from two injection scenarios ( 0.05 and 0.10 million metric tons per year) are presented at Figures 4-6a-c and 4-6d, respectively. The injected $\mathrm{CO}_{2}$ in the Arbuckle formation has a strong tendency of vertical migration, mainly because the reservoir pressure is low resulting in the smaller $\mathrm{CO}_{2}$ density. The measurement of bottom-hole pressure in the field indicates that the range of reservoir pressure was 6.89 to $8.39 \mathrm{MPa}$ from reservoir top to bottom, indicating that the pressure condition of top of the Arbuckle formation is smaller than the critical pressure (7.1 MPa). Consequently, the injected $\mathrm{CO}_{2}$ is potentially stored as gas phase at the top of Arbuckle formation.
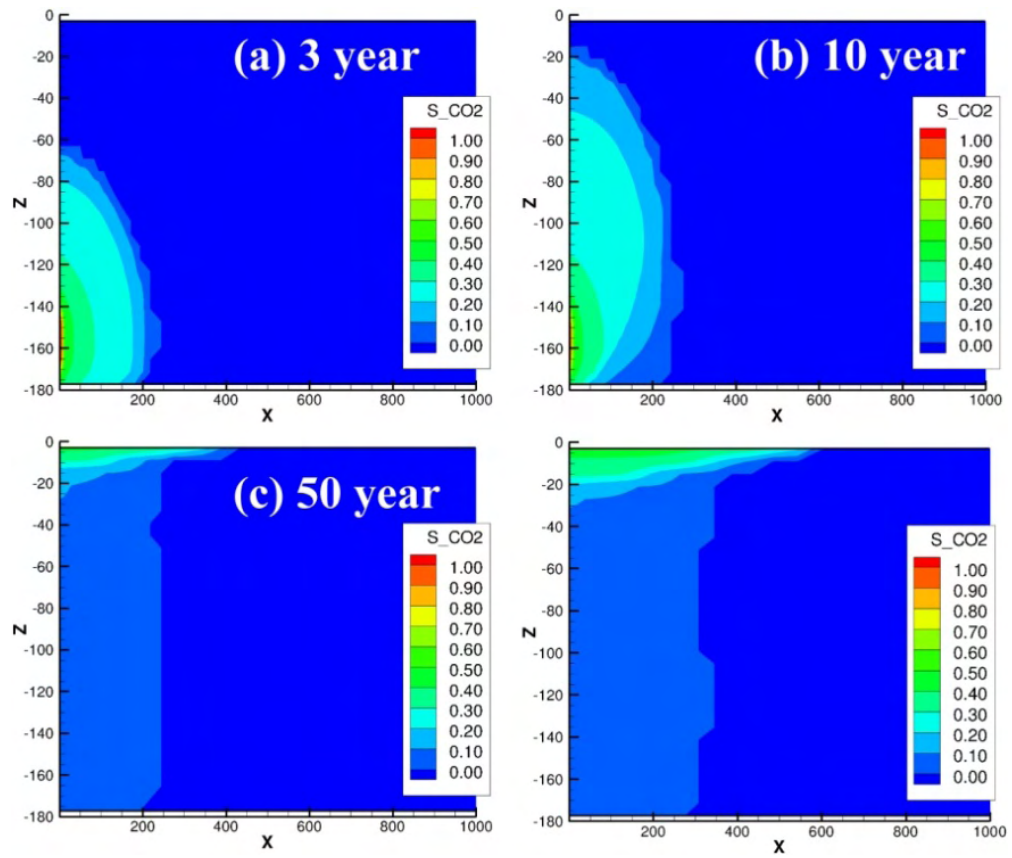

Figure 4-6. Distributions of $\mathrm{CO}_{2}$ plume saturation: (a), (b), and (c) represent the scenarios with 0.05 million metric tons of $\mathrm{CO}_{2}$ injection during 3 years, and (d) shows the 0.10 million metric tons of $\mathrm{CO}_{2}$ injection during 3 years.

Due to a strong buoyant condition, the front of $\mathrm{CO}_{2}$ plume in the small injection scenario migrates vertically after 10 years (Figure 4-6b) and reaches $20 \mathrm{~m}$ less distance under the top of the Arbuckle formation. Within 50 years, all $\mathrm{CO}_{2}$ is hydrostratigraphically trapped under the caprock (Figure 4-6c). In the larger injection scenarios, the shape of $\mathrm{CO}_{2}$ plume is simply the same but extends longer laterally (Figure 4-6d).

Geographically, the outcrop of the Arbuckle formation appears at the Ozark dome, Missouri State, indicating that the calculated regional gradient of the Arbuckle formation was less than 0.01 but the local gradient could be greater. Therefore, a $\mathrm{CO}_{2}$ plume, after reaching the top of the Arbuckle formation, is likely to migrate slowly towards the Ozark dome. However, simulation results suggest that the dipping effect is minimal. The 
radius of the $\mathrm{CO}_{2}$ plume after 50 years is approximately $400 \mathrm{~m}$ and $600 \mathrm{~m}$ in the small and larger injection scenarios, respectively.

Historically, the Arbuckle formation was the major disposal formation of produced brines from oil-fields under vacuuming condition, indicating that the wellhead pressure is typically larger than formation pressure [Carr et al., 2005]. Since the reservoir pressure is low, the concern of injection-induced pressure would likely not be significant for operating commercial scale $\mathrm{CO}_{2}$ disposal in the Arbuckle formation. However, this underpressured condition could potentially result in relatively reduced density of injected $\mathrm{CO}_{2}$, and correspondingly, may reduce capacity and increase the distance of $\mathrm{CO}_{2}$ plume migration under the caprock. Therefore, in these simulations, we investigated the possible range of $\mathrm{CO}_{2}$ densities and its phase state (Figures 4-7a-f). During the injection period in the small injection scenario, the range of $\mathrm{CO}_{2}$ densities within the plume is approximately from $300 \mathrm{~kg} / \mathrm{m}^{3}$ and $700 \mathrm{~kg} / \mathrm{m}^{3}$ (Figure 4-7a), and all $\mathrm{CO}_{2}$ existed as supercritical fluid (Figure 4-7d) because injection activity increased reservoir pressure above the critical pressure. However, within 50 years, the built-up pressure due to the injection activity reached hydrostatic pressure. As such, the rate of pressure dissipation was rapid in the Arbuckle formation since this formation is hydrologically connected to open surface, the Ozark Plateau aquifer system in Missouri. Consequently, the range of $\mathrm{CO}_{2}$ densities radically dropped. After 50 years, the predicted $\mathrm{CO}_{2}$ density was 200 $\mathrm{kg} / \mathrm{m}^{3}$ at top and $300 \mathrm{~kg} / \mathrm{m}^{3}$ at bottom, respectively (Figure 4-7b). In the larger injection scenario, the pressure built-up was larger, resulting that the distribution of $\mathrm{CO}_{2}$ density was increased over $700 \mathrm{~kg} / \mathrm{m}^{3}$ adjacent to the injection well (Figures 4-7c).
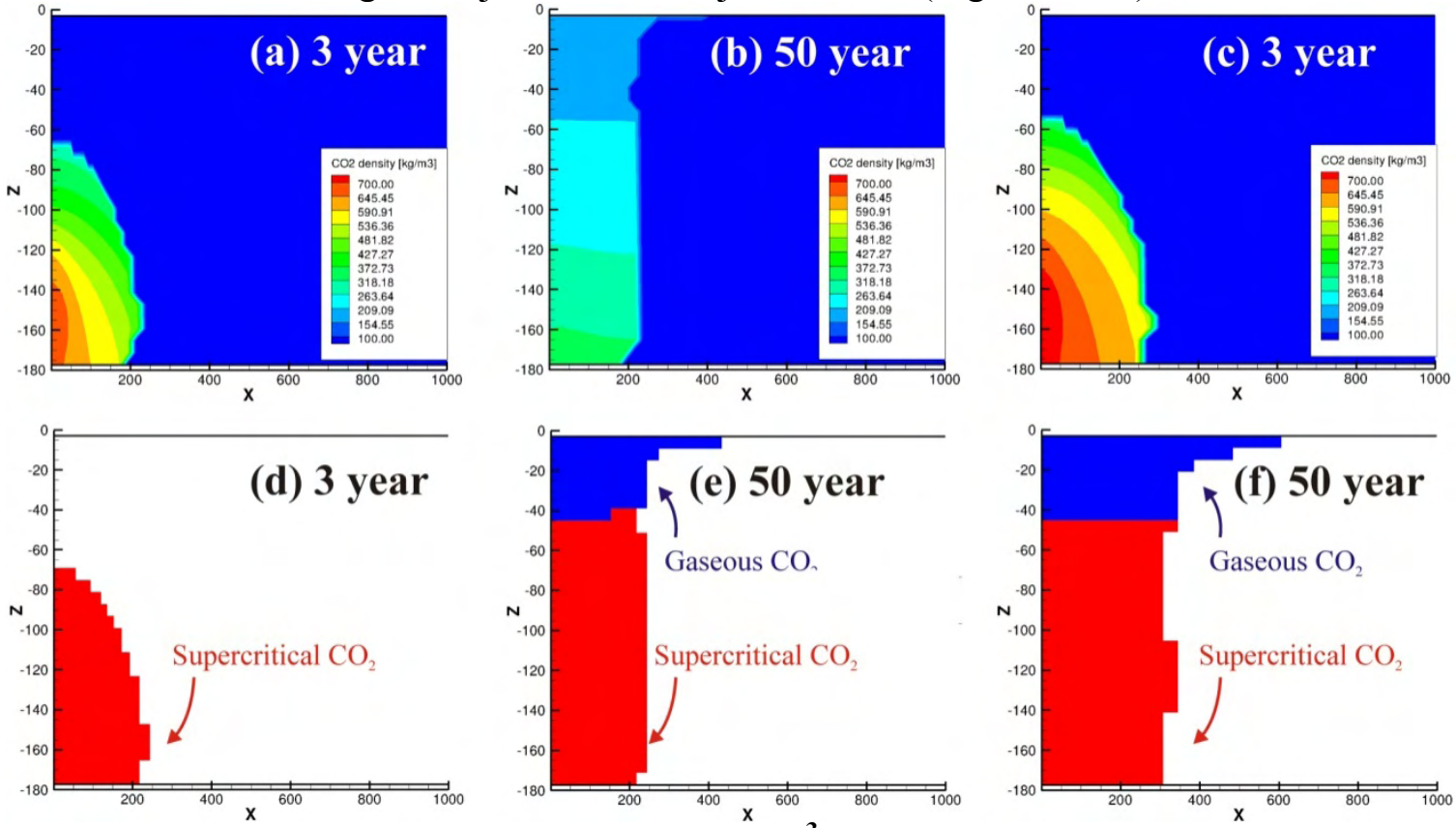

Figure 4-7. Distribution of $\mathrm{CO}_{2}$ density $\left(\mathrm{kg} / \mathrm{m}^{3}\right)$ shown in (a), (b), and (c). Both (a) and (b) represent the small injection scenario and (c) is from the larger injection scenario. States of fluid phase shown in (d), (e), and (f). Both (d) and (e) represent the small injection scenario and (f) is from the larger injection scenario.

Figures 4-7d-f shows the distribution of $\mathrm{CO}_{2}$ phase state. $\mathrm{CO}_{2}$ stays as supercritical fluid during injection period (Figure 4-3d). However, since the pressure dissipation rate 
is rapid in the Arbuckle formation, soon $\mathrm{CO}_{2}$ stays as gaseous phase under the caprock in both scenarios (Figures 4-7e and 4-7f).
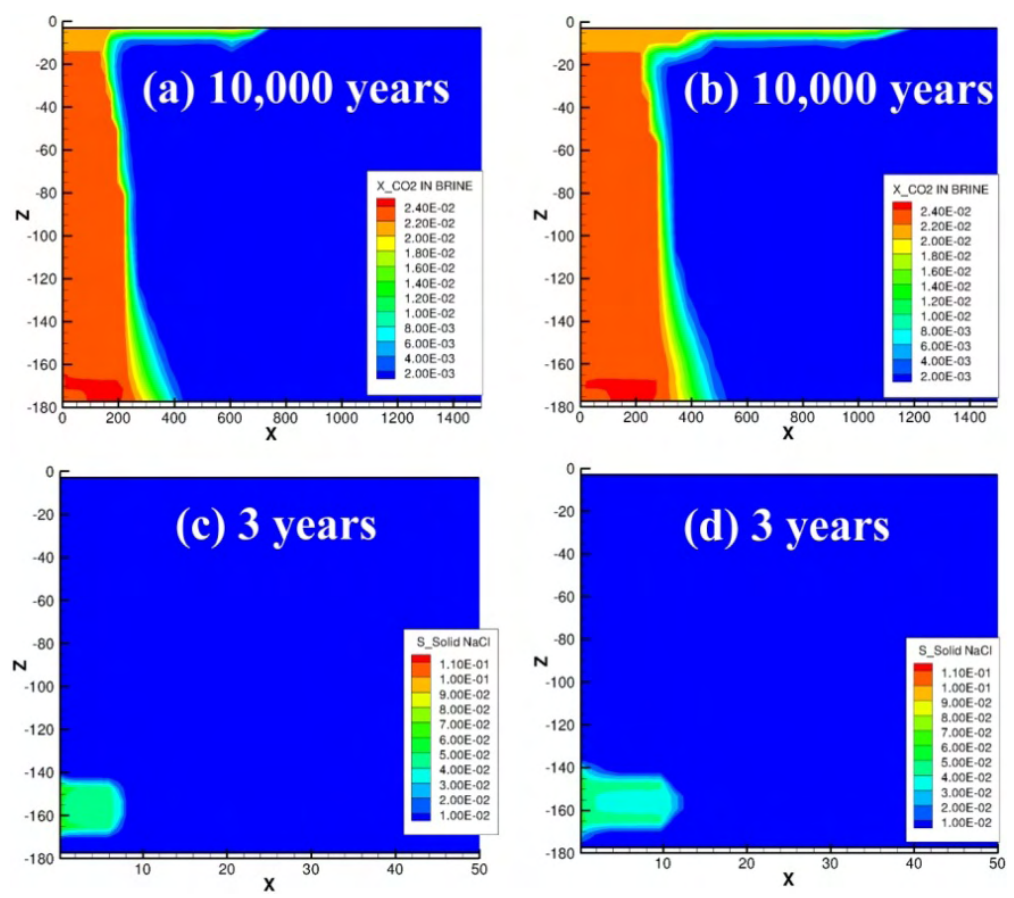

Figure 4-8. Distribution of dissolved $\mathrm{CO}_{2}$ mass fraction in (a) and (b) and $\mathrm{NaCl}$ solid saturation (c) and (d). Both (a) and (c) represent the small injection scenario and both (b) and (d) represent the larger injection scenario.

\subsubsection{Convective Mixing due to Density Instability and Injectivity Changes}

Density of $\mathrm{CO}_{2}$-dissolved brine becomes greater as more $\mathrm{CO}_{2}$ dissolves. For example, Garcia [2001] suggested that the density of CO2-dissolved brine could be as much as $2-3 \%$ greater than surrounding brine. Consequently, CO2-dissolved brine will sink and create density instability resulting in convective transport mixing after several hundred years [Ennis-King and Paterson, 2005; 2007; Xu et al., 2006; Yang and Gu, 2006]. In this generalized scoping study, we investigated the potential of convective mixing and associated time scales applicable to the Arbuckle formation. The time scale of convective mixing is closely related to the mass-transfer processes between $\mathrm{CO}_{2}$ and brine.

In the Arbuckle formation, the solubility of supercritical $\mathrm{CO}_{2}$ is small since it is underpressured. Furthermore, solubility of gaseous $\mathrm{CO}_{2}$ is even smaller. Consequently, less $\mathrm{CO}_{2}$ dissolves into brine, and this causes a slower process of convective mixing. In both scenarios, we predicted that on-set convection did not occur even after 10,000 years, suggesting that the potential for the convective mixing is extremely slow in this formation.

Drying-out processes due to brine evaporation at the vicinity of injection well can cause $\mathrm{NaCl}$ solid to be precipitated and potentially reduce porosity/permeability [Andre et al., 2007; Giorgis et al., 2007; Pruess and Muller, 2009]. In this work, the mutual 
solubility consideration was evaluated with the approach developed by Spycher and Pruess [2003], and we estimated the amount of $\mathrm{NaCl}$ precipitation during the injection period (Figures 4-8c and 4-8d). Simulation results showed that $\mathrm{NaCl}$ solid saturation was 0.07 after 3 years of $\mathrm{CO}_{2}$ injection. Because the initial porosity of model was $0.1, \mathrm{NaCl}$ solid is precipitated in more than half of pore volume. In addition, the radial extent of $\mathrm{NaCl}$ solid precipitation was approximately $8 \mathrm{~m}$ in the small injection scenario but extended to over $10 \mathrm{~m}$ in the large injection scenario. Recently, Pruess and Moller [2009] suggested that pore clogging due to salt precipitation could be prevented by injecting freshwater and displacing saline brine prior to the $\mathrm{CO}_{2}$ injection. If freshwater is present in the vicinity of injection well, water vaporization into supercritical $\mathrm{CO}_{2}$ will not precipitate $\mathrm{NaCl}$ solid and, consequently, will not reduce the injectivity of the injection well. In practice, as suggested by previous researchers, freshwater injection is suggested to prevent such injectivity reduction prior to $\mathrm{CO}_{2}$ injection.

\subsubsection{Thermal Disequilibrium Processes}

Injection of $\mathrm{CO}_{2}$ may perturb subsurface temperatures, leading to a dynamic temperature system in the storage formation and adjacent seal strata. In most cases, the individual effects from wellbore dynamics, solvation reactions, and phase changes are incremental, but collectively these relevant processes may cause temperature changes compared to ambient conditions. In this work, we evaluated several potential nonisothermal effects resulting from $\mathrm{CO}_{2}$ injection activity. These include the JouleThomson cooling effects, exothermic $\mathrm{CO}_{2}$ dissolution, and heat changes associated with concomitant water vaporization.

The spatial distribution of temperature altered by Joule-Thomson cooling, water vaporization, and exothermic $\mathrm{CO}_{2}$ dissolution is plotted in Figures 4-9a-c representing the small injection scenario. As compressed $\mathrm{CO}_{2}$ flows from the injection well into the targeted formation, the forced pressure field dissipates. Due to pressure reduction, the $\mathrm{CO}_{2}$ entering the reservoir formation experiences Joule-Thomson cooling by adiabatic expansion. Simulation results suggest that the zone where Joule-Thomson cooling dominates appears between 0 to $70 \mathrm{~m}$; reservoir temperature becomes cooler than its initial temperature $\left(41.67^{\circ} \mathrm{C}\right)$. At the same time, water vaporization cools the reservoir fluid temperature in this zone since this process is endothermic. Interestingly, this process locally occurs distance between 10 to $40 \mathrm{~m}$ and shows the direction dependency, indicating that water vaporization was significant to the direction of the $\mathrm{CO}_{2}$ plume front. Finally, from 70 to $100 \mathrm{~m}, \mathrm{CO}_{2}$ dissolution into brine is the major mass-transfer mechanism, and the associated heat effects govern the temperature profile. Since this process is exothermic, the resulting fluid temperature is slightly higher than the reservoir temperature $\left(41.67^{\circ} \mathrm{C}\right)$. In Figure $4-9 \mathrm{~d}$, the larger injection scenario is plotted, showing that thermal disturbance becomes larger. 

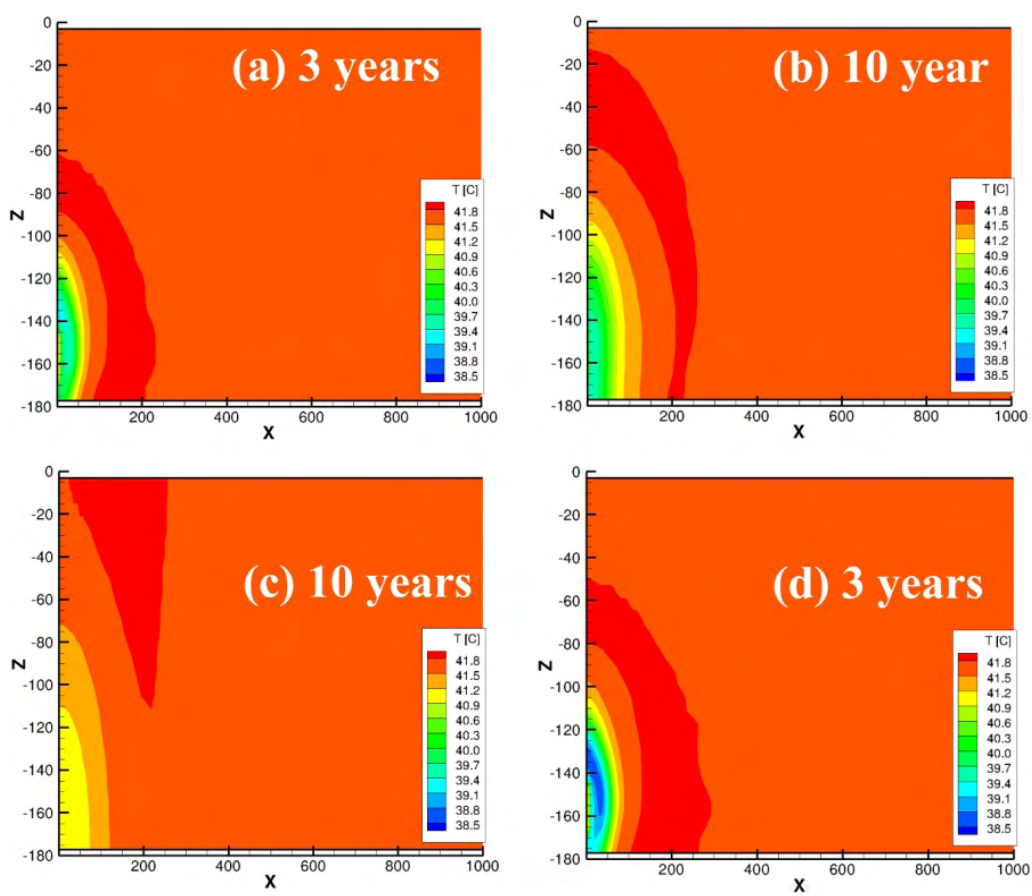

Figure 4-9. Thermal disequilibrium processes caused by $\mathrm{CO}_{2}$ injection: Distributions of $\mathrm{CO}_{2}$ plume saturation: (a), (b), and (c) represent the small injection scenario, and (d) shows the larger injection scenario.

Based on our understanding of non-isothermal processes, there can be certain changes in the subsurface temperature caused by $\mathrm{CO} 2$ sequestration. Recently, Hurter et al. [2007] suggested using a distributed temperature-sensing system in a CO2 sequestration test, which successfully monitored the dynamic changes of temperature during injection and production operations in oil fields [Brown et al., 2004; Lanier et al., 2003]. This distributed temperature sensing system was applied to the CO2SINK project in Germany where $\mathrm{CO} 2$ was injected into a saline aquifer with an anticlinal structure [Forster, 2006]. Although the definite cause observed in temperature signal is still being investigated, the distributed temperature sensing system successfully measured the largest temperature increase $\left(\Delta 25^{\circ} \mathrm{C}\right)$ close to the injection wellhead during the injection period [Giese et al., 2009 ] while the temperature increase within the injection zone was about $\Delta 5-10^{\circ} \mathrm{C}$. In summary, $\mathrm{CO}_{2}$ injection into the Arbuckle formation are expected to disturb the temperature regimes in the target formations, and such temperature changes could be detected by installation of temperature sensors in injection and observation wells. 


\subsubsection{Flow Model: PFLOTRAN 3D $\mathrm{CO}_{2}$ Injection Test in Thrall-Aagard Saline Reservoir}

\subsubsection{Descriptions of PFLOTRAN Simulator, Grid Generation, and Formation Parameters Assessment}

Section 4.0 detailed the procedures and methodology of grid construction and conversion. Figure 4-10 showed the converted grid with porosity distribution to illustrate the equivalence of the conversion. For sake of multi-processor simulations, we utilized the PFOTRAN simulator for all 3-D simulations. As briefly described in the previous section, PFLOTRAN qA developed by Los Alamos National Laboratory under the support of the DOE SCiDAC (Scientific Discovery through Advanced Computing) program. It is a massively parallel, subsurface multiphase, multi-component reactive flow transport simulator. Its parallel efficiency has been demonstrated on various platforms, ranging from desktop-class workstations to supercomputing clusters.

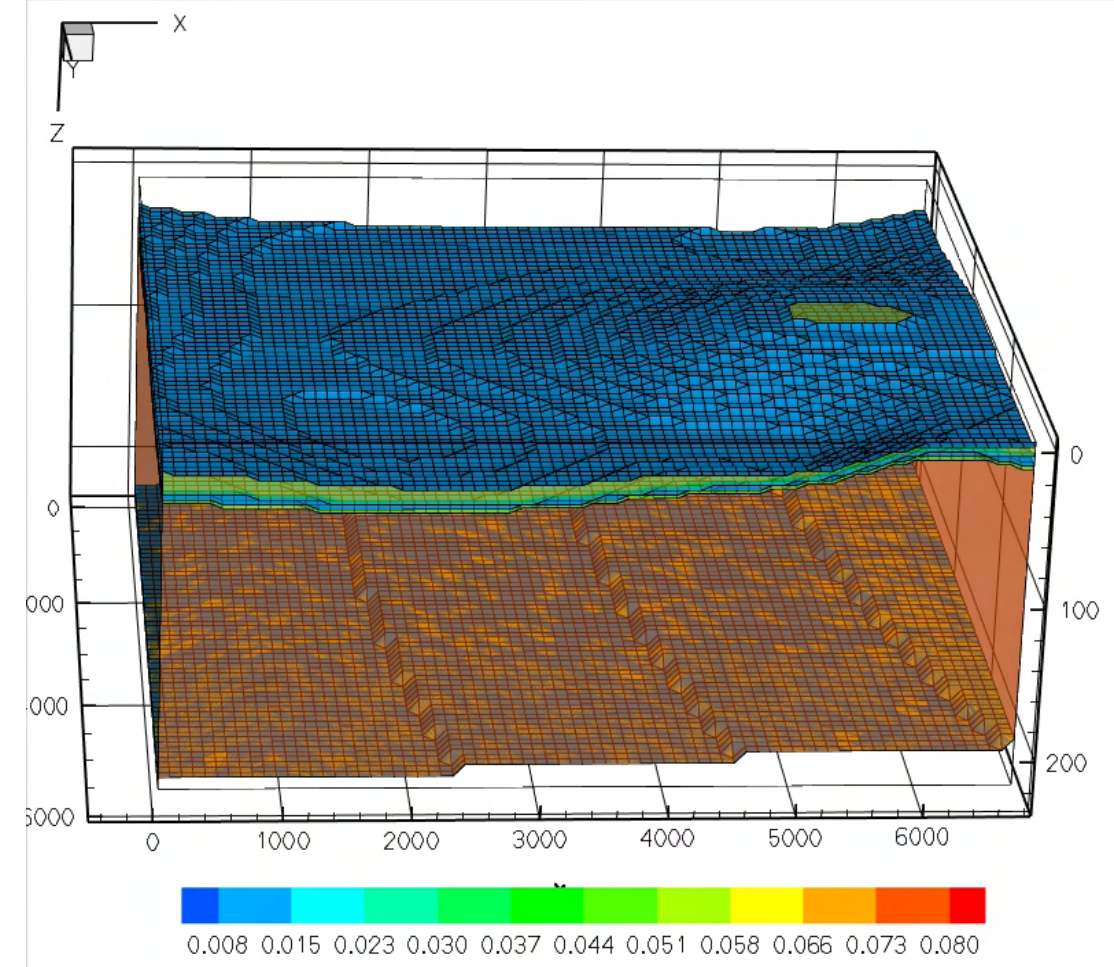

Figure 4-10. Reconstructed structured orthogonal grid contoured with porosity.

The porosity distribution is illustrated in Figure 4-10 for this homogeneous model, which clearly shows the distinct geologic layers (i.e. Viola, Simpson and Arbuckle Formations). For simplicity, the porosity values were assumed to be $0.06,0.01$ and 0.08 for these 3 formations, respectively. Likewise, permeability values were assumed to be $100,0.1$ and $10 \mathrm{mD}$ for the 3 formations, respectively, each with an unisotropic ratio of 10. The formation properties are summarized in Table 4-1. The relative permeability and 
capillary pressure values have not been determined. The van Genuchten [1980] model was

$$
p_{c}=\frac{1}{\alpha}\left(s_{e}^{-1 / m}-1\right)^{1 / n}
$$

adapted to evaluate capillary pressure, Pc, with . Relative permeability was evaluated with formulas implemented by [Doughty, 2007]:

$$
\begin{gathered}
k_{r w}=s_{e}^{1 / 2}\left[1-\left(1-s_{e}^{1 / m}\right)^{m}\right]^{2} \quad \text { (Eq. 4) } \\
k_{r g}=\left(1-s_{e}\right)^{1 / 2}\left[1-\left(1-s_{e}^{1 / m}\right)^{m}\right]^{2}
\end{gathered}
$$

No hysteresis effects were considered for capillary pressure or relative permeability. Parameters of Eqs (1-3) and are listed in Table 4-1 as well.

Table 4-1. 4 Formation properties (Formations were ordered from top to bottom)

\begin{tabular}{lllllll}
\hline Formation & porosity & permeability & Swir & Sgir & $\alpha$ & $\mathrm{m}$ \\
\hline Viola & 0.06 & 10 & 0.25 & 0.1 & 0.001 & 0.75 \\
Simpson & 0.01 & 0.1 & 0.25 & 0.1 & 0.001 & 0.75 \\
Arbuckle & 0.08 & 100 & 0.25 & 0.1 & 0.001 & 0.75 \\
\hline
\end{tabular}

Initially, the saline reservoir was set at hydrostatic conditions with the top pressure and temperature at $6.893 \mathrm{MPa}$ and $40^{\circ} \mathrm{C}$, respectively. The salinity and geothermal gradient were assigned at $1 \mathrm{~m} / \mathrm{kg} \mathrm{H}_{2} \mathrm{O}$ and $0.025^{\circ} \mathrm{C} / \mathrm{m}$, respectively. Constant hydrostatic

\begin{tabular}{|c|c|c|}
\hline Scenario & Total injection rate (metric tons per yr) & Injection period $(\mathrm{yr})$ \\
\hline 1 & 100,000 & 3 \\
\hline 2 & 100,000 & 20 \\
\hline 3 & 50,000 & 3 \\
\hline 4 & 50,000 & 20 \\
\hline
\end{tabular}
pressure was assigned as the boundary condition for all 4 surrounding sides.

Table 4-2. 4 injection scenarios.

Four injection scenarios were simulated with each scenario differing in injection rate and period (Table 4-2). The injection point was designed to be located in grid cell $(25,39,39)$ (counting from east to west, north to south and top to bottom) with the center coordinates at $(2241 \mathrm{~m}, 3520 \mathrm{~m}, 202 \mathrm{~m})$. At this location, the top of the Arbuckle Formation is deeper than surrounding regions (basin shaped). It could be expected that the gaseous $\mathrm{CO}_{2}$ plume will migrate in both the east and west directions though the dip on the east is greater resulting in preferential $\mathrm{CO}_{2}$ migration in this direction. 

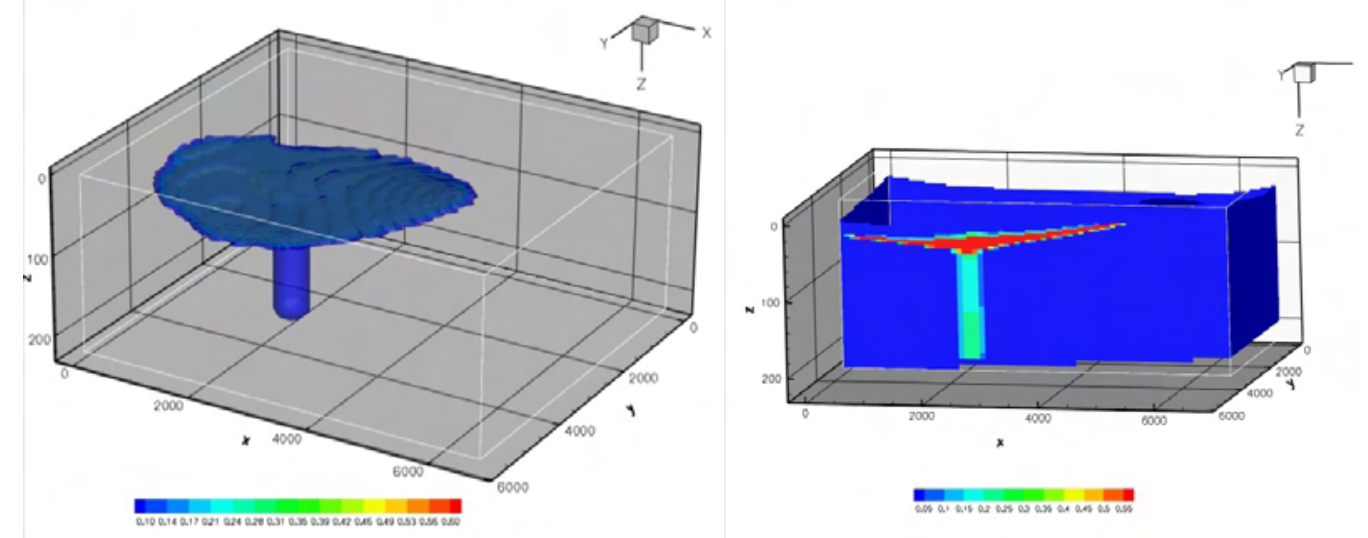

(a)

(b)

Figure 4-11. $\mathrm{CO}_{2}$ saturation profiles at year 15 of Scenario 2: (a) isosurface with $\mathrm{Sg}=\mathbf{0 . 0 1}$ and (b) $\mathrm{x}-\mathrm{z}$ plane slice through injection point

\subsubsection{Horizontal and Vertical $\mathrm{CO}_{2}$ Plume Migration}

The simulation period was 50 years after the cessation of $\mathrm{CO}_{2}$ injection. Among the 4 scenarios, the total injection amount of $\mathrm{CO}_{2}$ for the second scenario was the highest. Numerical simulations of Scenario 2 indicate that the $\mathrm{CO}_{2}$ plume reached the west boundary of the computational domain during 15 th year of injection, as shown in Figure 4-11. As described in the previous section, the injection point is located closer to the west boundary. Though the $\mathrm{CO}_{2}$ plume migrated farther to the east, it still reached the west boundary due to the large injection amount. Simulations beyond 15 years for Scenario 2 were not meaningful since the total mass of injected $\mathrm{CO}_{2}$ could not be maintained; the simulation on Scenario 2 was terminated at 15 years. 


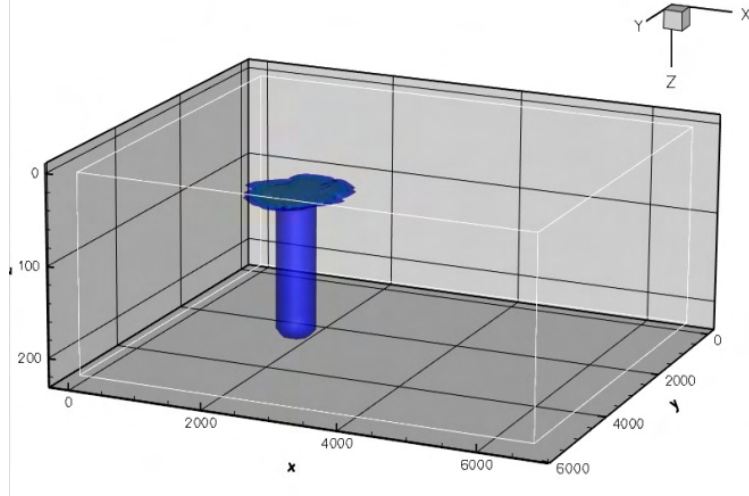

0.100 .140 .170 .210 .240 .280 .310 .350 .390 .420 .450 .490 .530 .550 .50

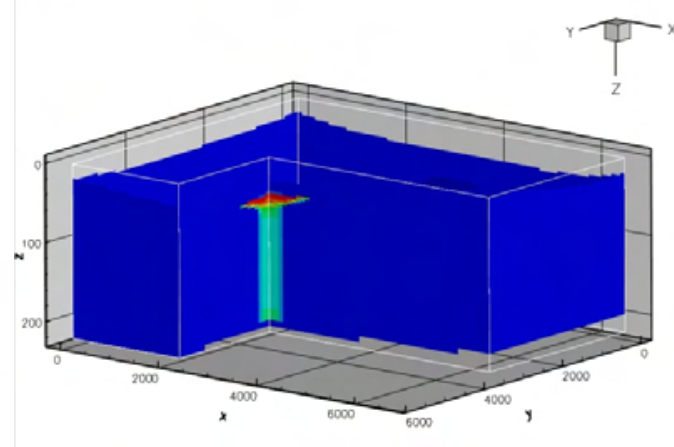

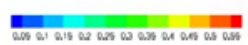

(a)

(b)
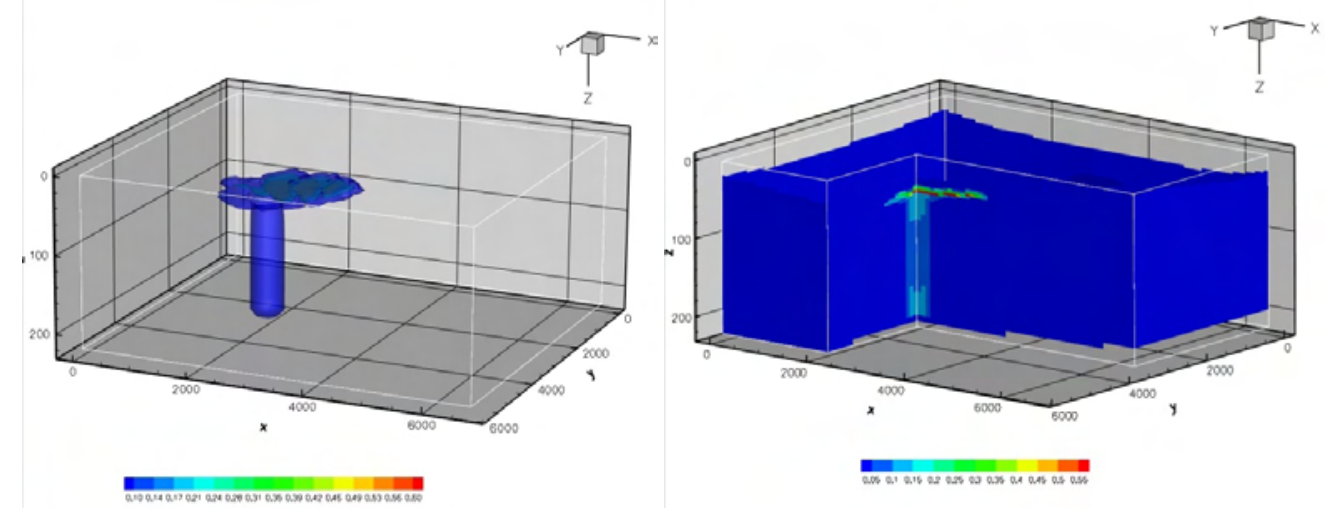

(c)

(d)

Figure 4-12. $\mathrm{CO}_{2}$ saturation profiles of Scenario 1: (a) isosurface with $\mathrm{Sg}=0.01$ at year 3, (b) slice through injection point at year 3, (c) isosurface with $\mathrm{Sg}=0.01$ at year 50 , and (d) slice through injection point at year 50. 

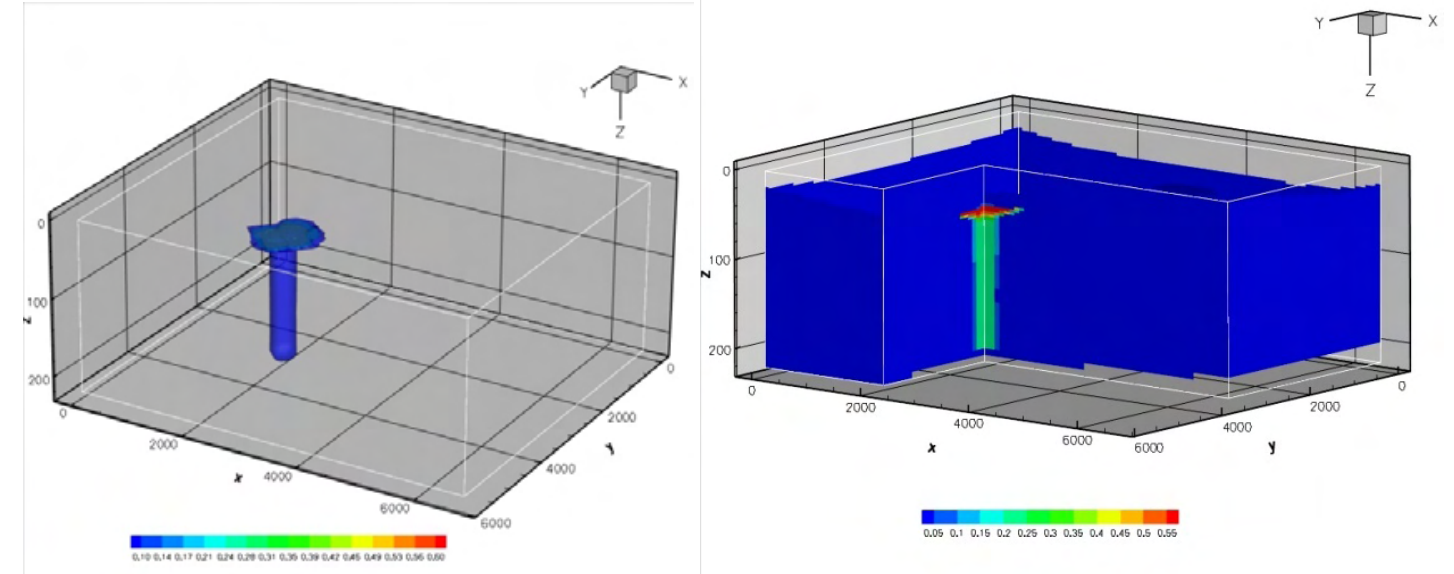

a)

b)
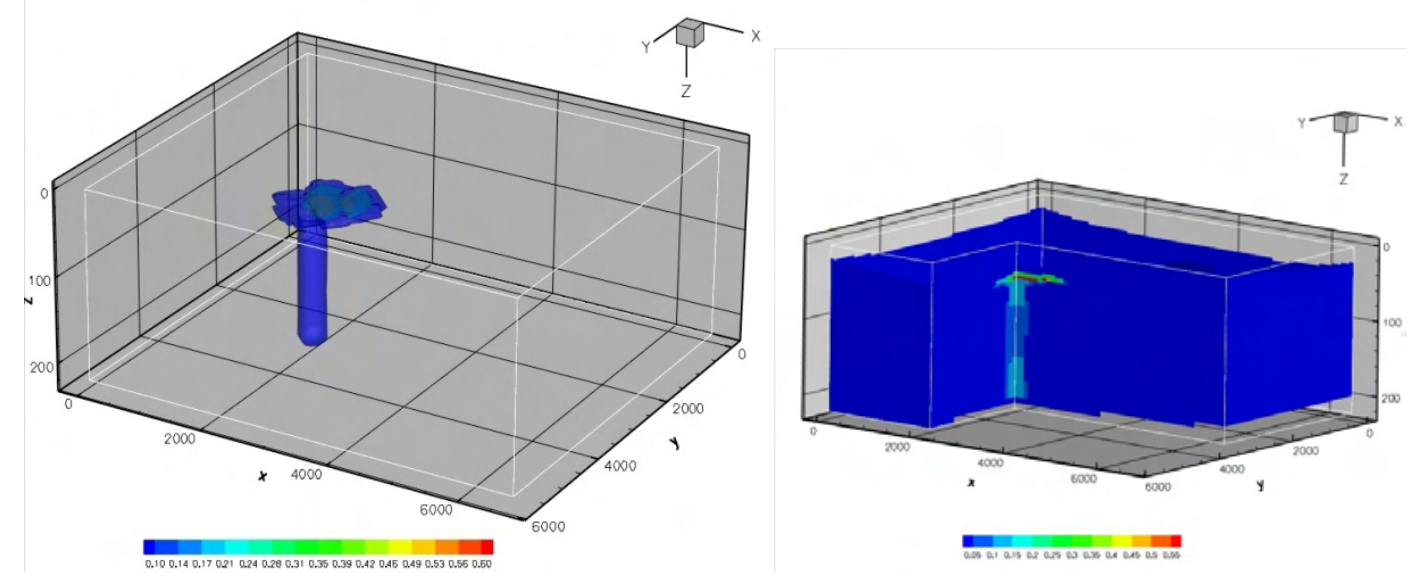

c)

d)

Figure 4-13. $\mathrm{CO}_{2}$ saturation profiles of Scenario 3: (a) isosurface with $\mathrm{Sg}=0.01$ at Year 3, (b) slice through injection point at year 3, (c) isosurface with $\mathrm{Sg}=0.01$ at year 50, and (d) slice through injection point at year 50.

Simulations on Scenarios 1, 3 and 4 were conducted for a total of 100 years, slightly longer than the planned period. Figure 4-12 to Figure 4-14 show the saturation profiles at the end of each injection period ( 3 years for Scenarios 1 and 3 and 20 years for Scenario 4 ) and the end of each simulation period (53 years for Scenarios 1 and 3 and 20 years for Scenario 4). 

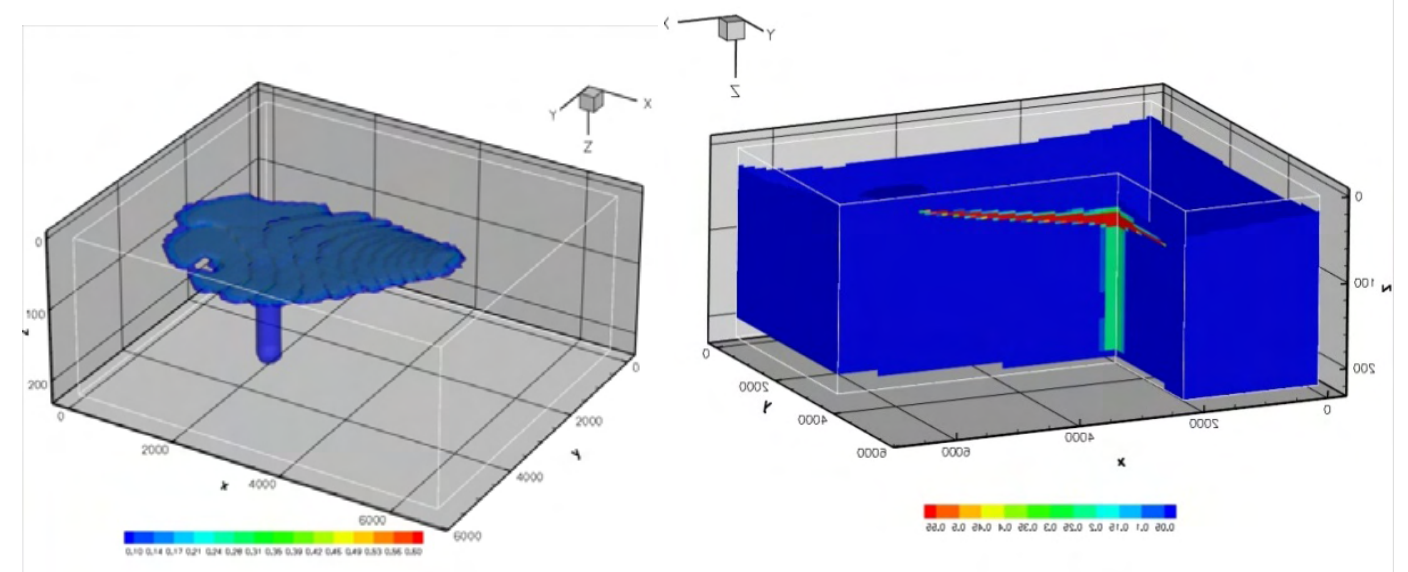

(a)

(b)
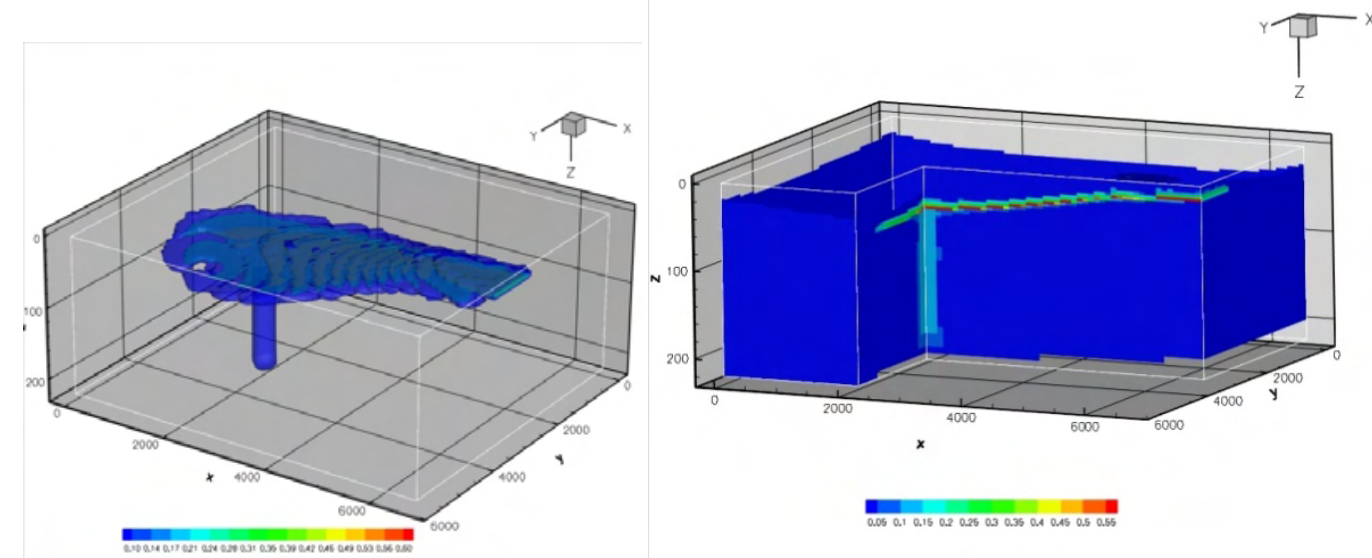

(c)

(d)

Figure 4-14. $\mathrm{CO}_{2}$ saturation profiles of Scenario 4: (a) isosurface with $\mathrm{S}_{\mathrm{g}}=0.01$ at year 3, (b) slice through injection point at year 3 , (c) isosurface with $S_{g}=0.01$ at year 50, and (d) slice through injection point at year 50.

In all 4 simulations, the plume of $\mathrm{SC} /$ gaseous $\mathrm{CO}_{2}$ migrated greater than $152 \mathrm{~m}(500$ feet) from the injection point and reached the top of the Arbuckle Formation within 2 years. The increased $\mathrm{CO}_{2}$ mobility was increased because of the relatively high permeability and greater density contrast between the $\mathrm{SC} /$ gaseous $\mathrm{CO}_{2}$ and the formation fluid. After each plume reached the top of the Arbuckle Formation, further upward migration was impeded by the low permeable Simpson Formation caprock; horizontal plume migration dominates. Driven by buoyancy, the $\mathrm{SC} /$ gaseous plume spreads beneath the Simpson Formation caprock and forms thin layers only occupying several $(<3)$ vertical grid blocks. Figure 4-15 showed that the fast buoyancy-driven migration has two distinct stages: 1) within 2 years, the plume reaches the top of the Arbuckle Formation and; 2) while the plume spreads horizontally, the depth to the top of the plume continuously decreases because of the dip of the Arbuckle Formation. Because of the 
non-zero irreducible gas saturation, there are small amounts of $\mathrm{CO}_{2}$ remaining in the deeper section of the Arbuckle Formation that form cylinder-shaped plumes, showing the migration path of injected $\mathrm{CO}_{2}$.

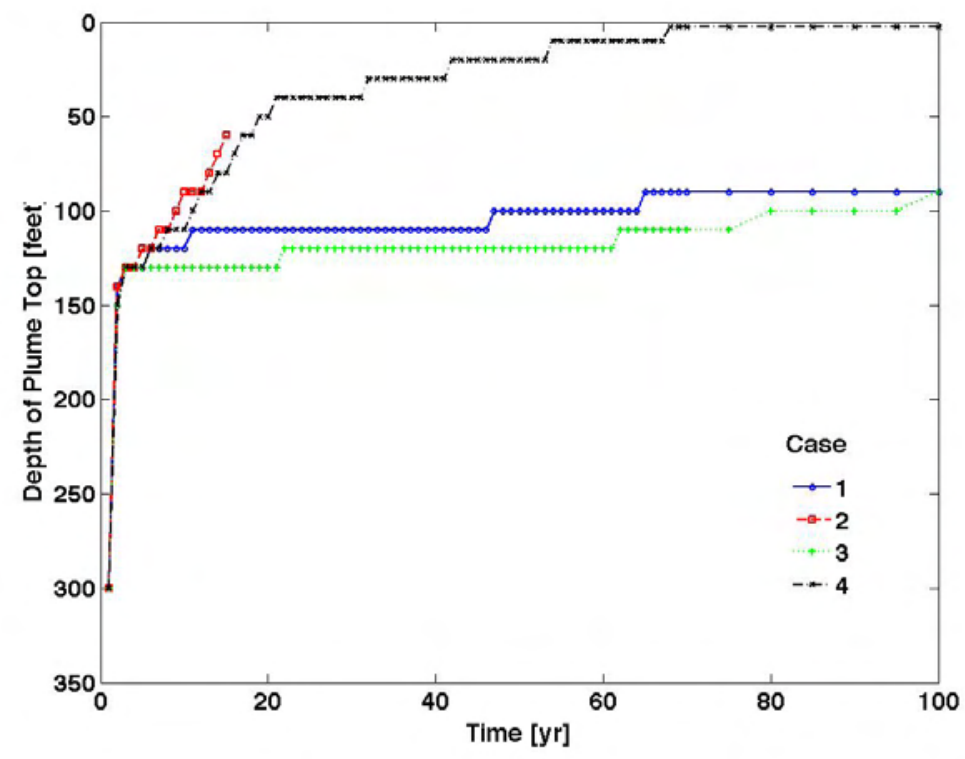

Figure 4-15. Depth of plume top.

Figure 4-16 is the area of review for the 4 different scenarios, showing the horizontal area (NOT volume) of each SC/gaseous plume. The plume of the 2 scenarios with smaller total injection quantities (Scenarios 1 and 3) were almost stabilized after 60 years because of residual trapping (non-zero $\mathrm{S}_{\text {gir }}$, in this study) and dissolution effects (discussed in the next section). The 2 scenarios with larger total injection quantities continued to spread throughout the entire simulation period finally reaching the side boundary. Future investigations should probably exploit larger domains to assess migration of larger amounts of $\mathrm{CO}_{2}$. 


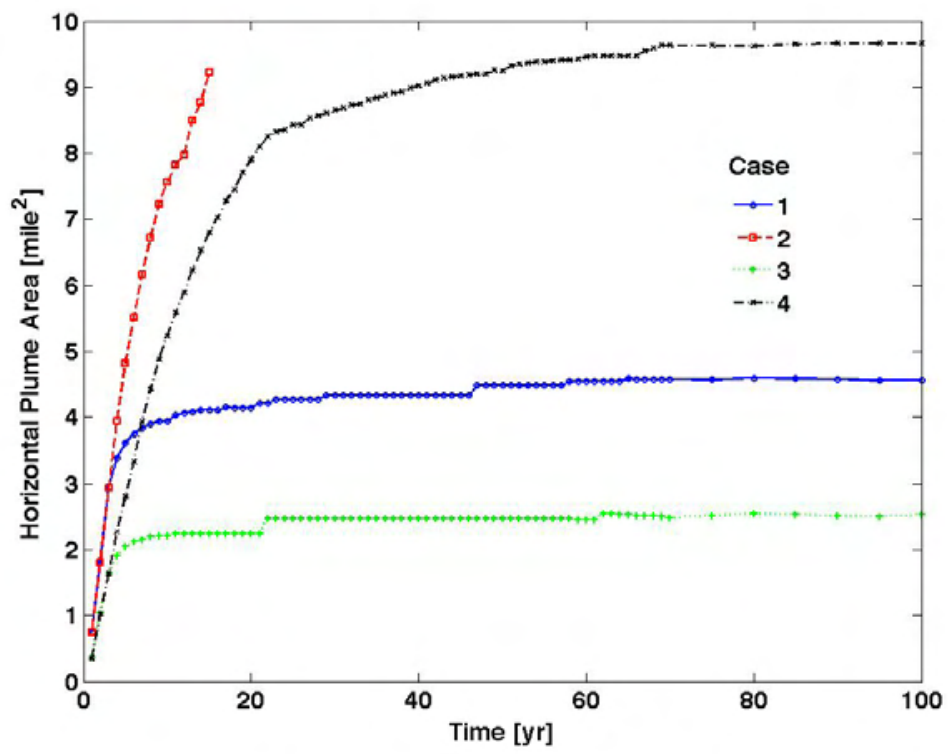

Figure 4-16. Area of review of SC/gaseous plume.

Figure 4-17 shows the length of the plume in the $x$ direction (east-west direction); the $\mathrm{x}$-coordinate represents the greatest distance of the plume from the injection point, eastward is the positive direction. As discussed in Section 4.1, the plumes spread toward the west and east side simultaneously with the east side the dominant direction of migration. The plume in Scenario 4 ceased westward migration shortly after the injection stopped and subsequently reached the east boundary at approximately 32 years from the initiation of injection.

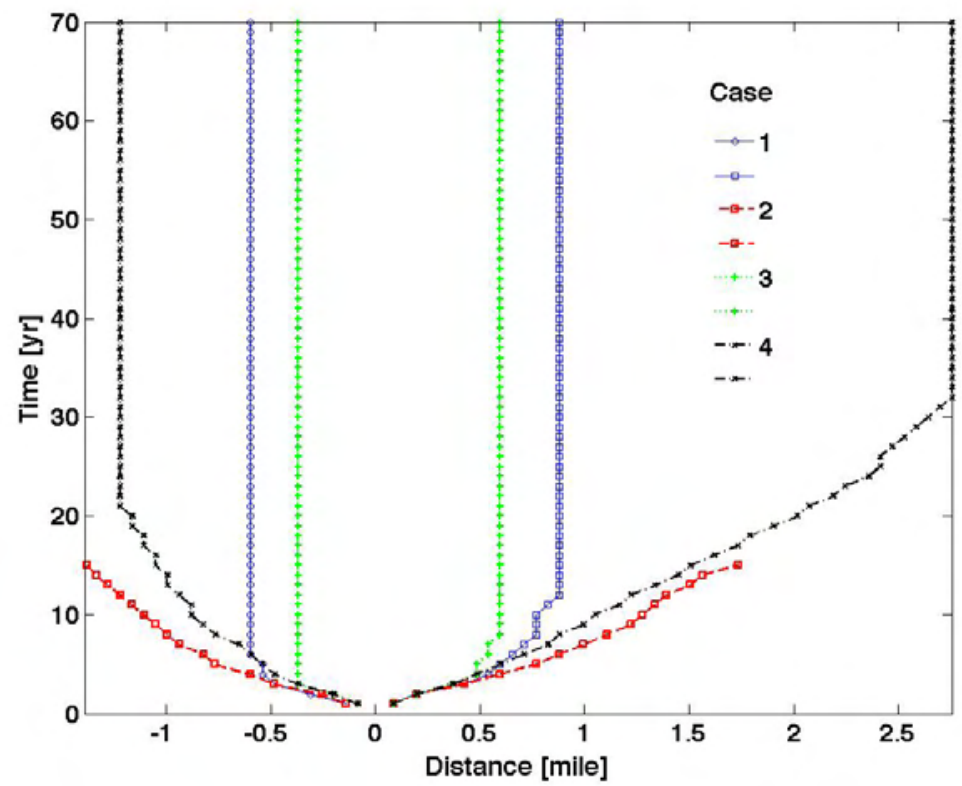

Figure 4-17. Spreading distance in the west-east direction. 
Within the simulation period of all 4 scenarios, there was no noticeable penetration of the $\mathrm{SC}$ /gaseous phase $\mathrm{CO}_{2}$ plume into and through the Simpson Formation caprock.

These results confirm the caprock integrity and its hydrostratigraphic trapping efficiency.
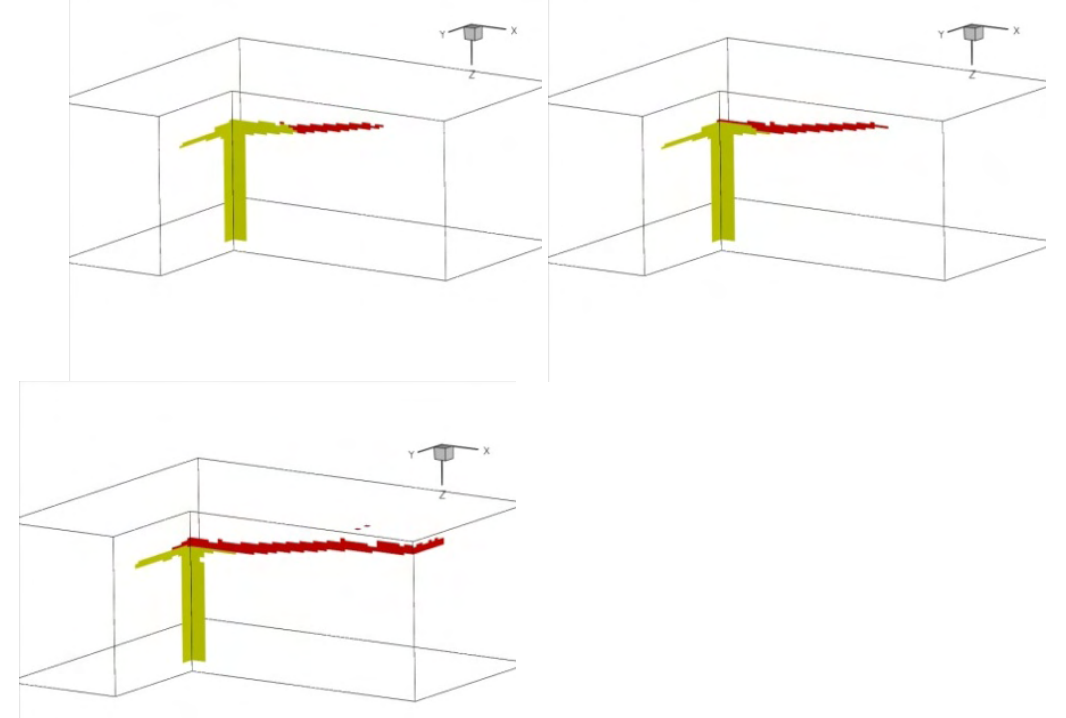
a) Year 20
b) Year 25
c) Year 70

Figure 4-18. $\mathrm{CO}_{2}$ phase state in Scenario 4. Darker color indicates gaseous state. Lighter color indicates SC state.

\subsubsection{Fluid Properties and $\mathrm{CO}_{2}$ Distribution Between Phases}

As discussed in previous 2D simulations, the pressure at the injection point is always above the $\mathrm{CO}_{2}$ critical pressure $\left(\mathrm{P}_{\mathrm{c}}\right)$. At the formation top immediately above the injection point, the pressure is greater than $\mathrm{P}_{\mathrm{c}}$ only during the injection period, due to pressure build-up induced by injection. Shortly after the well shut-in, the pressure at the formation top begins to drop below the $\mathrm{P}_{\mathrm{c}}$. Figure 4-18 showed the phase state of the $\mathrm{CO}_{2}$ plume in Scenario 4. At year 25 of the simulation period, the pressure at the formation top is already lower than the $\mathrm{P}_{\mathrm{c}}$. While the plume spreads along the formation top, more $\mathrm{CO}_{2}$ exists in the gas phase. Figure 4-19 showed the pressure-time evolution at the injection point as well as the formation top; both are consistent with previous simulation results. 


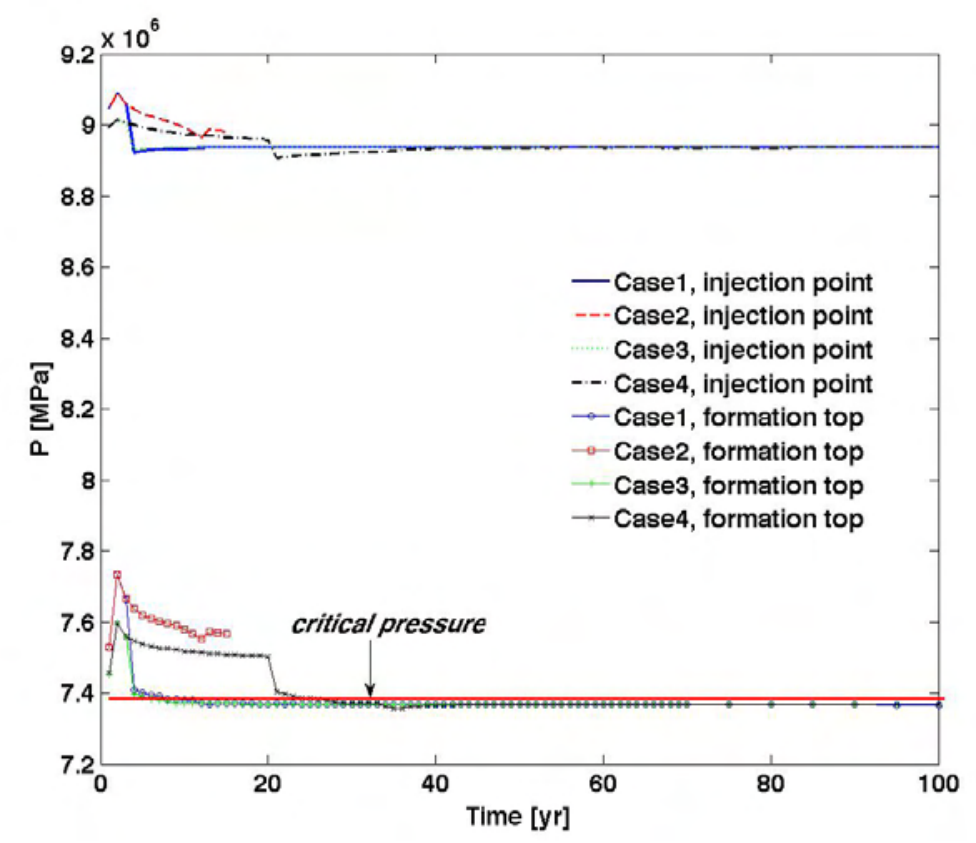

Figure 4-19. Pressure at the injection point and Arbuckle Formation top above the injection point.

Since PFLOTRAN assumes local thermodynamic equilibrium, the injected $\mathrm{CO}_{2}$ continuously dissolves into the formation brine while it migrates. In this study, the amount of dissolved $\mathrm{CO}_{2}$ is greater than that existing in the $\mathrm{SC}$ /gaseous phase because of the long migration distance of the $\mathrm{CO}_{2}$ plume and the large volume of grid cells, as shown in Figure 4-20. The total amount of $\mathrm{CO}_{2}$ begins to drop at approximately year 32 of the simulation because the plume reaches the boundary at this time.

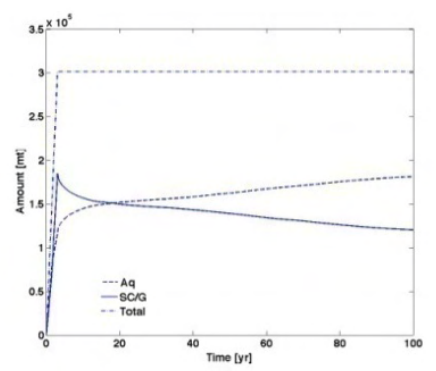

(a)

(b)

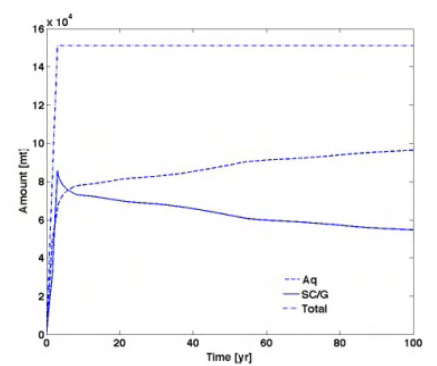

(c)

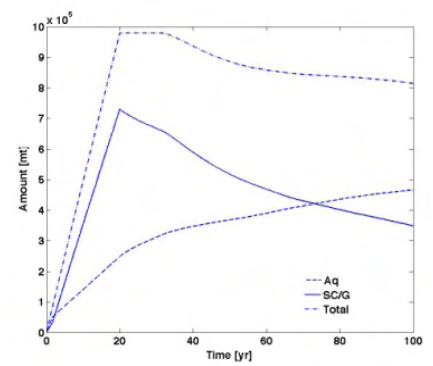

Figure 4-20. $\mathrm{CO}_{2}$ distribution in $\mathrm{SC} /$ gaseous phase and aqueous phase. 


\subsubsection{Dynamic Flow Model: 3D $\mathrm{CO}_{2}$ Injection Test in Thrall-Aagard Saline Reservoir}

\subsubsection{Descriptions of Model Grid and Workflow}

Simulation analyses described in previous sections of this chapter utilized the TOUGH2 and PFloTran simulators. However, all oil reservoir simulations, described in sections to follow, utilized the Eclipse 300 simulator. Thus, for sake of facilitating comparison of deep saline reservoir simulation results to oil reservoir simulation results (e.g., to check consistency), we also developed 3-D models of the deep saline reservoir option in the Eclipse 300 simulator. This generalized modeling study was based primarily on a model grid that included reservoir structural and property information of the saline reservoir. Figure 4-21 shows the static model (grid) that covers an area of 2,600 square $\mathrm{km}(1,000$ square miles). On the other hand, the gridded area in the figure represents the dynamic simulation model.

The dynamic simulation work in this study has been carried out by making use of the $\mathrm{CO}_{2}$ storage feature of the Eclipse 300 simulator. It has been specifically designed for the modeling $\mathrm{CO}_{2}$ storage in subsurface formations and was added to the simulator in the 2006 commercial release. It allows the fluids in the pore space be modeled in two phases: a $\mathrm{CO}_{2}$-rich phase (labeled gas phase), an $\mathrm{H}_{2} \mathrm{O}$-rich phase (labeled liquid phase) and a separate solid phase (salt contents). Additional information about these features are provided by the Technical Description ECLIPSE manual. 


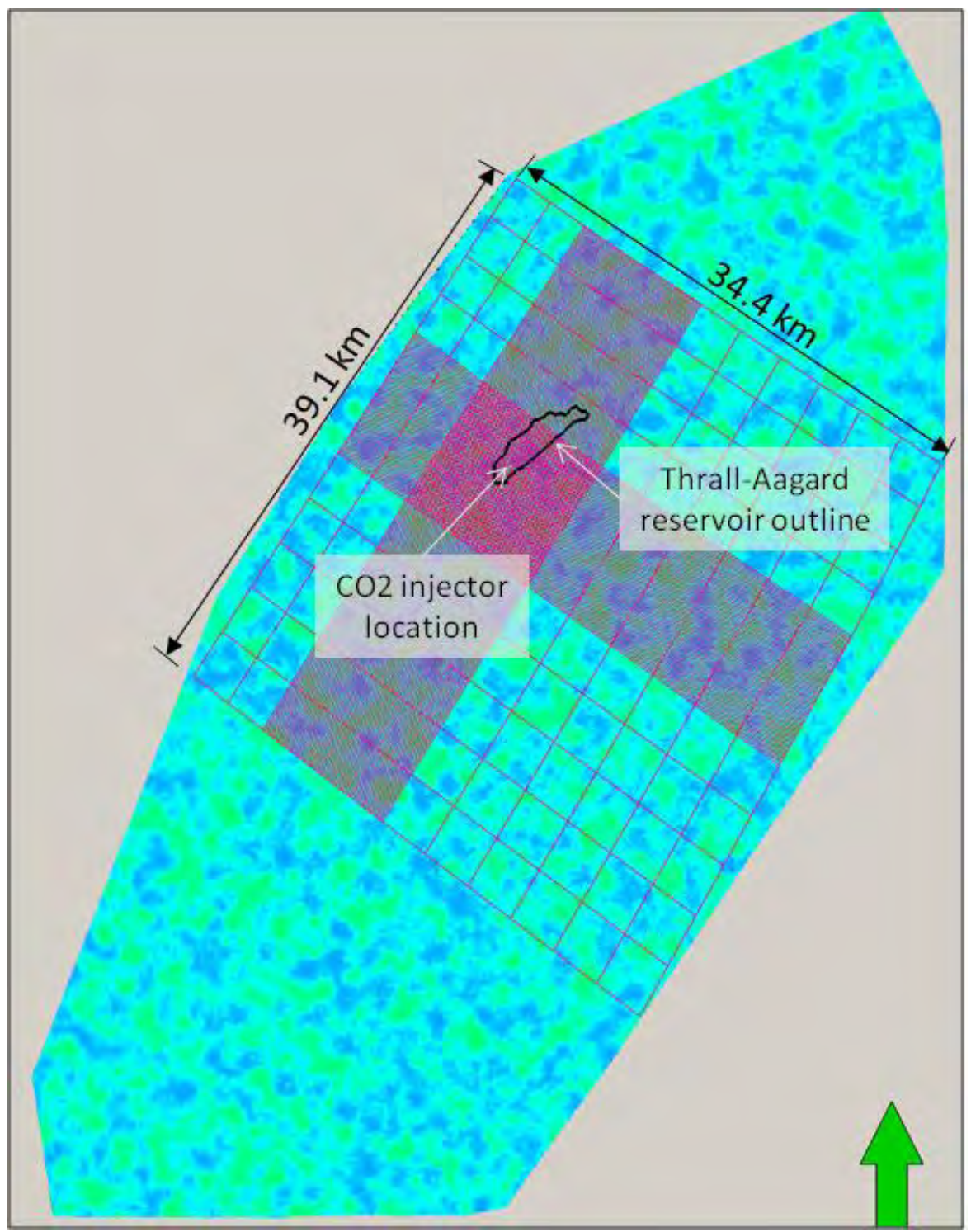

Figure 4-21. Eastern Kansas Arbuckle saline reservoir model

Saline reservoir model for $\mathrm{CO}_{2}$ storage simulation typically covers an extended area ( $>100$ square kilometers) in order to ensure the pressure pulse caused by the injection is not overly restricted by the model boundary. In this case, a model grid with over 20 million cells and covering a vast area (2,600 square kilometers) has been prepared. The first step in a typical $\mathrm{CO}_{2}$ storage modeling workflow is to prepare a suitable simulation grid. A number of gridding schemes for dynamic simulation were tested to determine the optimum areal extent as well as the grid spacing. The grid prepared as a result of this process is large enough to simulate the movements of the pressure pulse and sufficiently fine in the area expected to be eventually covered by the $\mathrm{CO}_{2}$ plume. Figure 4-21 shows the grid for simulation (gridded area in the figure) cover an area of 1350 square $\mathrm{km}$ (520 square miles). The fine grid area is populated with $145 \mathrm{~m}$ by $145 \mathrm{~m}$ (476ft by $476 \mathrm{ft}$ ) grid and dimensions of the largest grid cells are $3,000 \mathrm{~m}$ by $3,000 \mathrm{~m}(10,000 \mathrm{ft}$ by $10,000 \mathrm{ft})$. 
The following are the assumed input values in this model:

1. Reservoir temperature $=49^{\circ} \mathrm{C}\left(120^{\circ} \mathrm{F}\right)$

2. $\quad$ Reservoir pressure $=8.3 \mathrm{MPa}(1,200 \mathrm{psia})$

3. Water salinity $=30,000 \mathrm{ppm}$

The salinity data can be used to determine the initial water and salt mole fraction values as illustrated in Table 4-3.

Table 4-3. Salt content in water

\begin{tabular}{clcl}
\hline & Proportion by weight & $\begin{array}{c}\text { Molecular } \\
\text { weight }\end{array}$ & Proportion by mole \\
\hline $\begin{array}{c}\text { Water } \\
\text { Sodium }\end{array}$ & 1 & 18.01 & 0.9908 \\
Chloride & 0.03 (or $30,000 \mathrm{ppm})$ & 58.44 & 0.0092 \\
\hline
\end{tabular}

\subsubsection{Simulation Results}

Simulations were performed for two different scenarios, one for a 3-year $\mathrm{CO}_{2}$ injection period and the other for a 20-year injection period. In each case, 50,000 tons of $\mathrm{CO}_{2}$ are assumed to be available for storage each year. Figure 4-22 shows the location of the injection well in the model relative to the grid. The well penetrates the reservoir model at about $860 \mathrm{~m}(2,810 \mathrm{ft})$ below ground and, at normal hydrostatic gradient, the reservoir pressure at the depth is estimated to be $8.3 \mathrm{MPa}(1,200 \mathrm{psia}) . \mathrm{CO}_{2}$ at this pressure level is likely to be in gaseous phase and in order to increase the likelihood of injecting the $\mathrm{CO}_{2}$ as a supercritical fluid; the model well is completed in the lower part of the reservoir penetration as shown in Figure 4-22.

Two reservoir property scenarios have been performed:

- High permeability case: average permeability $=100 \mathrm{md}$

- Low permeability case: average permeability $=10 \mathrm{md}$ 


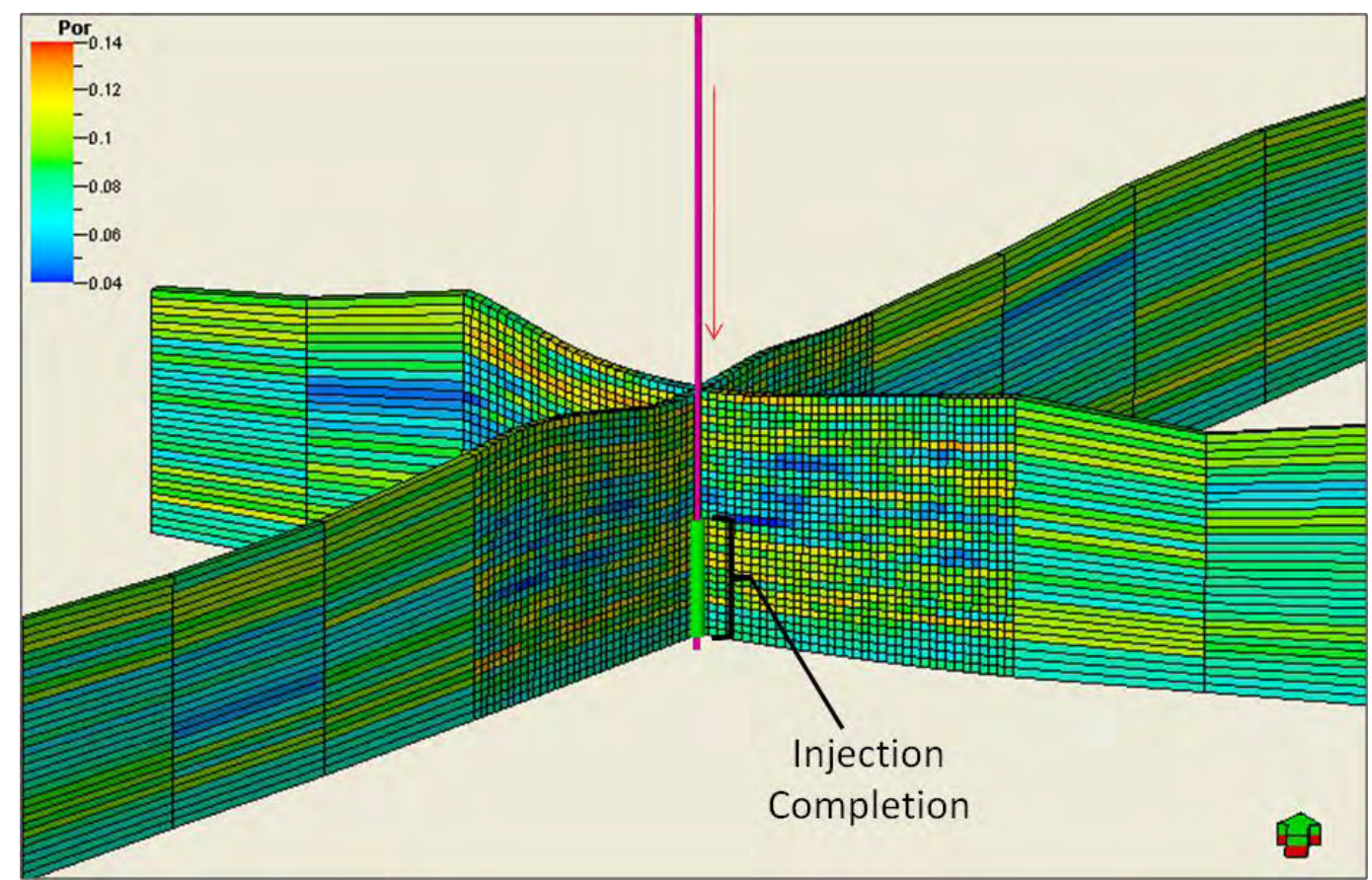

Figure 4-22. $\mathrm{CO}_{2}$ injection well completion in the model

Figure 4-23 and Figure 4-24 show the plume growth in the high permeability cases. In these cases, the $\mathrm{CO}_{2}$ tends travel upward to the top of the Arbuckle structure very rapidly. This is attributed to the relatively low pressure required to deliver the $\mathrm{CO}_{2}$ into the formation and, therefore, resulting in much of this $\mathrm{CO}_{2}$ in gaseous phase as indicated by the low density there.

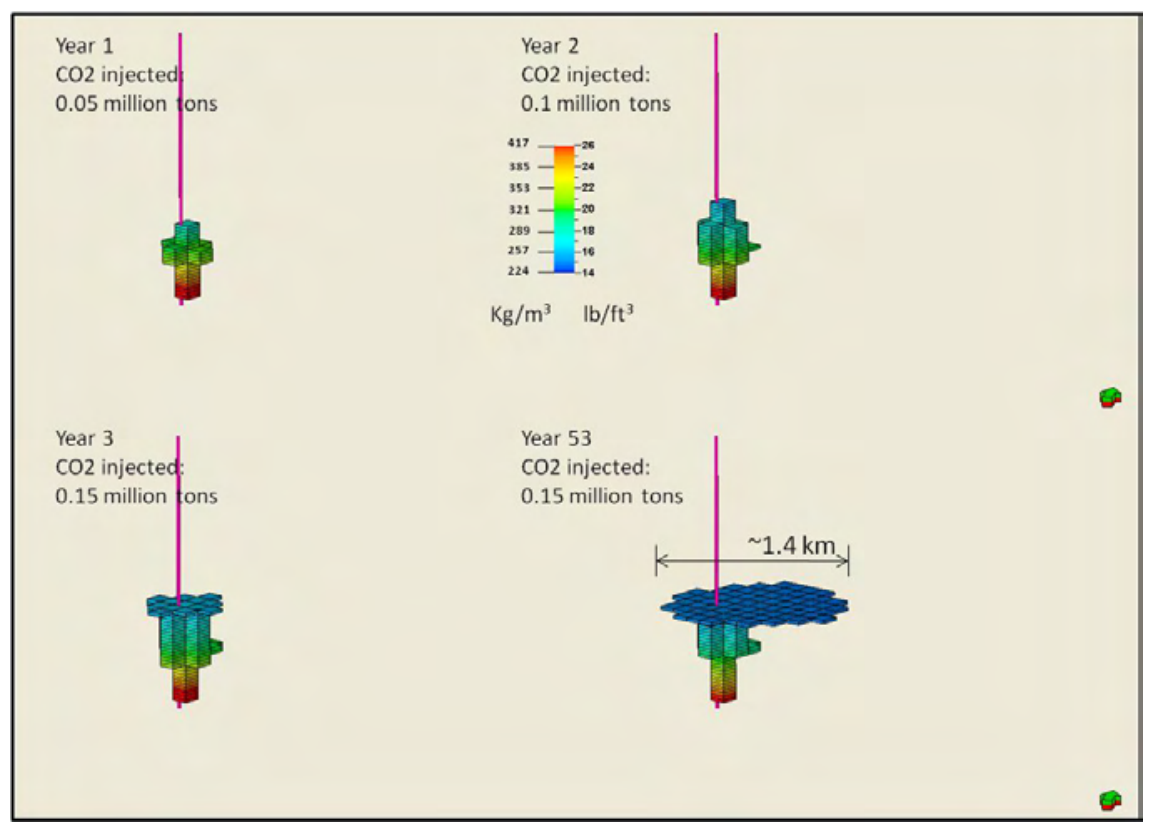

Figure 4-23. Simulated plume growth - high permeability/3-year injection case. 


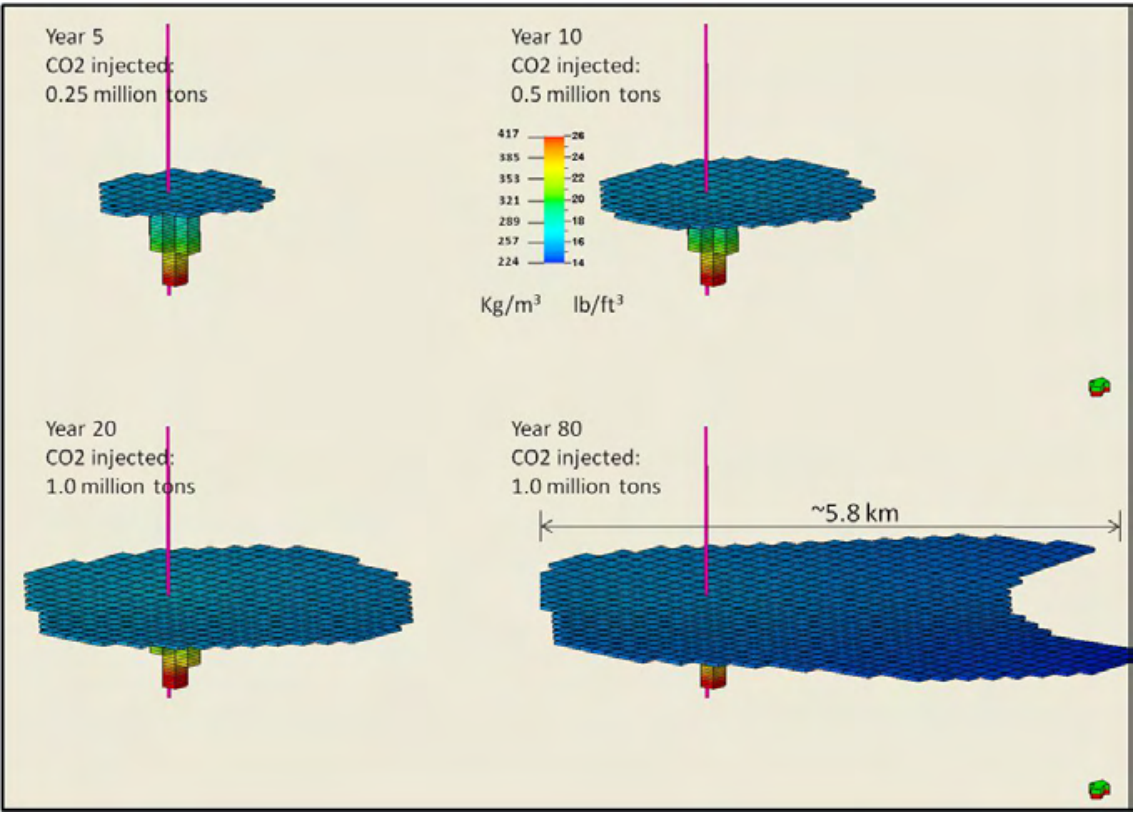

Figure 4-24. Simulated plume growth - high permeability/20-year injection case.

On the other hand, Figure 4-25 and Figure 4-26 show the corresponding plume growth in the low permeability cases. It can be noted that the $\mathrm{CO}_{2}$ in these cases has a higher tendency to accumulate near the injection completion and thus leading much smaller plume. The overall growths in plume size in these cases are also summarized in Figure 427.

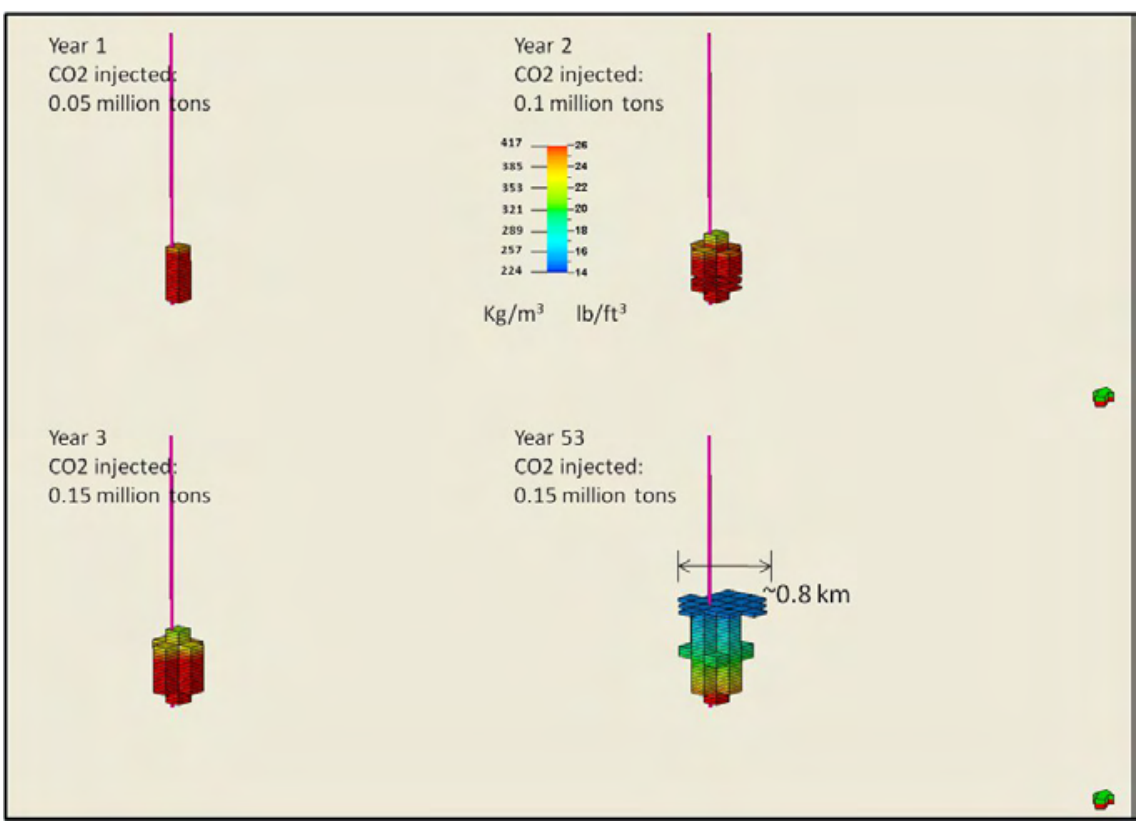

Figure 4-25. Simulated plume growth - low permeability/3-year injection case 


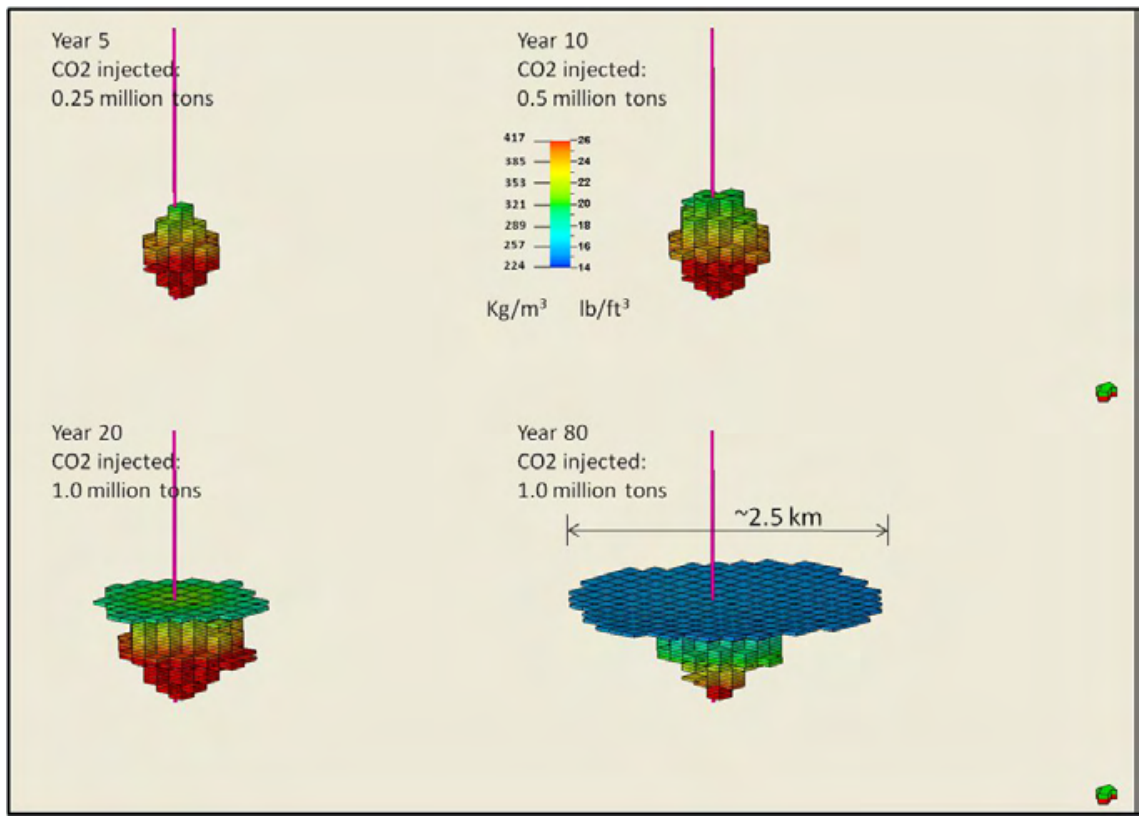

Figure 4-26. Simulated plume growth - low permeability/20-year injection case

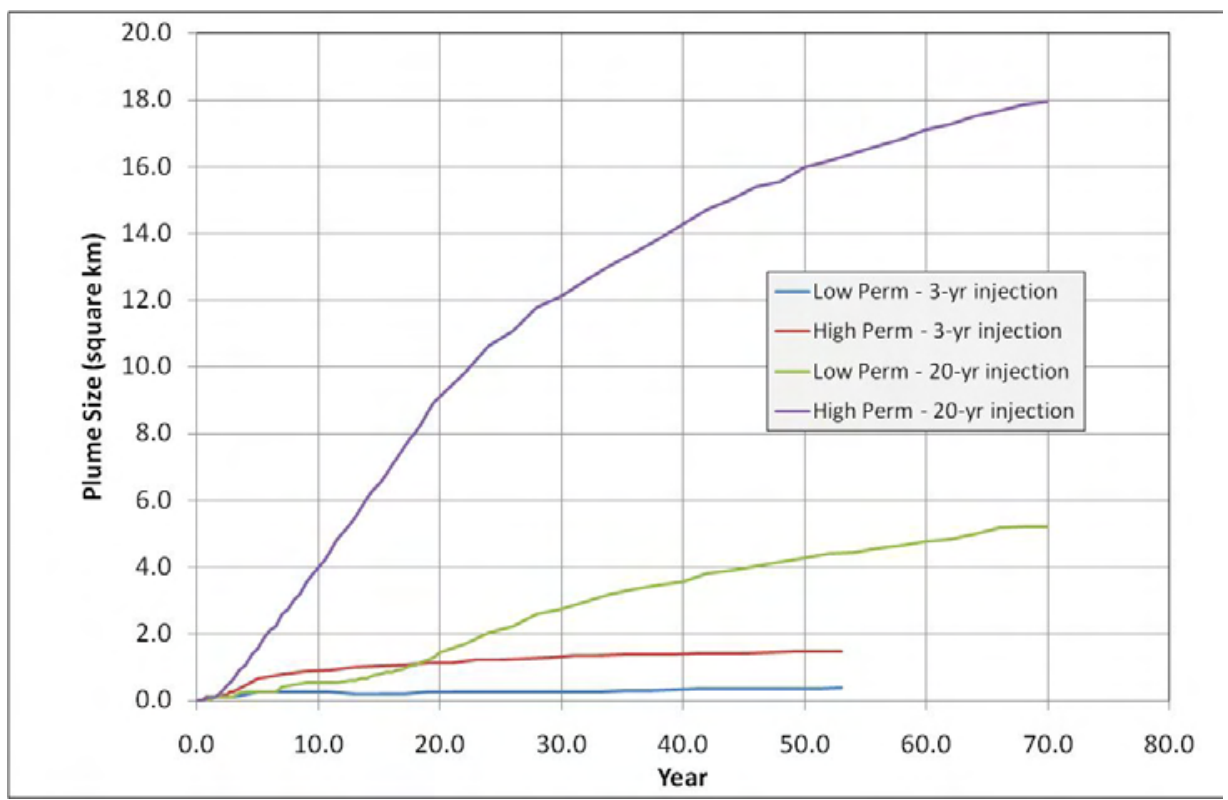

Figure 4-27. Plume size and growth rate versus time 


\subsection{Geneseo-Edward Field - Combined Deep Saline and EOR Sequestration Simulation Analysis}

\subsubsection{Model Grid}

\subsubsection{Description of Study Area and Data Processing}

The study area for the deep saline model analysis was extended well past the EOR injection site in the Geneseo Edwards. The boundary for this model was selected to encompass the entirety of the Geneseo-Edwards structural high (Figure 4-28). This size model allowed any size dynamic model to be selected out of the completed property model as need dictated. The property model covers most of T17S-R8W, T18S-R8W, and T19S-R8W; and partially covers T16S-R8W, T17S-R7W, T18S-R7W, and T19S-R7W.

Data for the model was exported from a Petra database provided by industry partners and all well locations, well tops, cultural polygons, and structural grids were imported to Petrel. The well logs received were porosity logs based on neutron curves calibrated to core data. All well locations and tops were verified by the IMCCS team and erroneous data points were eliminated from the data set. Well tops not used in the model are listed in Table 4-4. Additionally, tops picked by IMCCS geologists were added to the data set. Those tops added to the data set are listed in Table 4-5. 


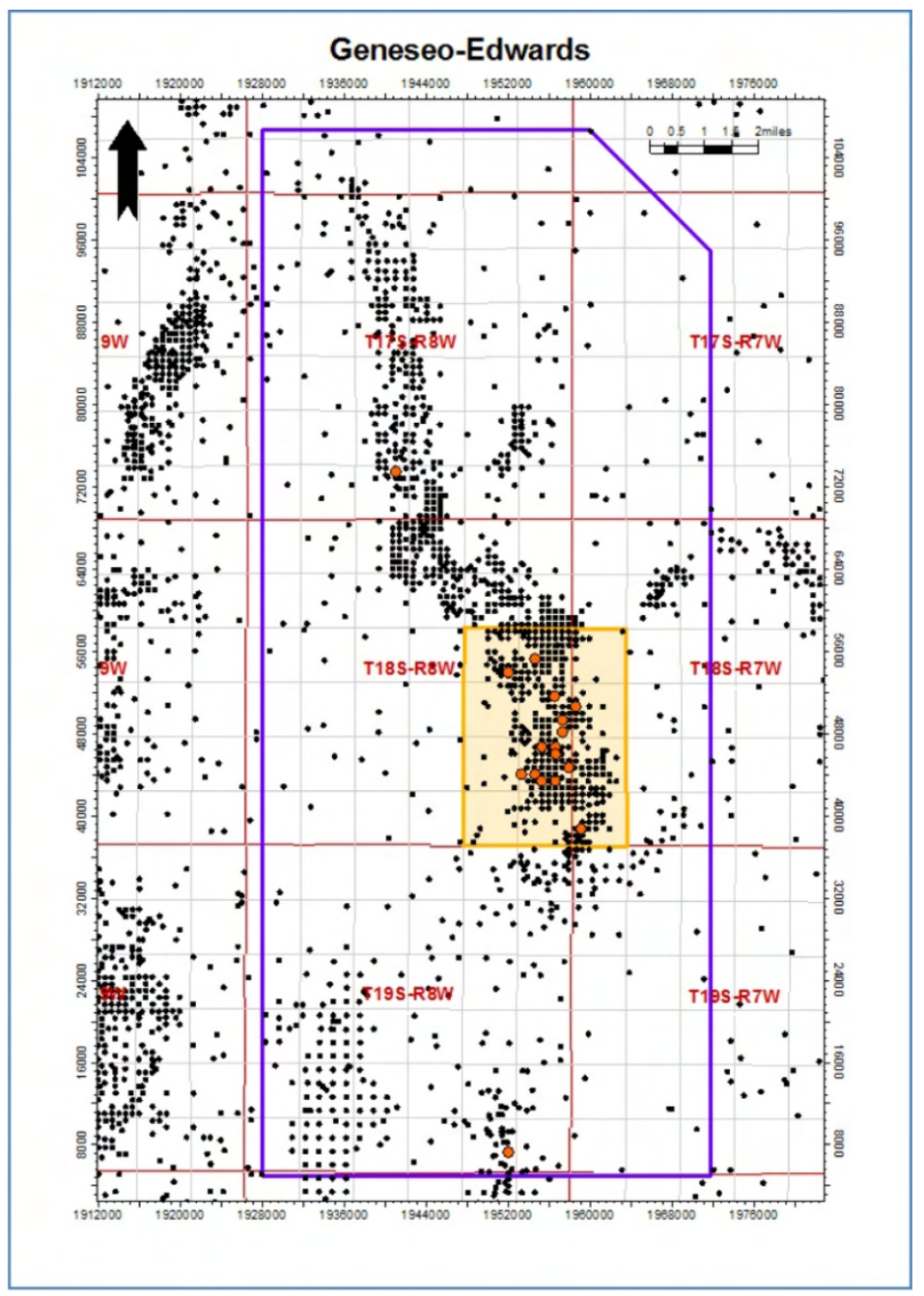

Figure 4-28. Geneseo-Edwards location map. Black dots are the well locations. Orange dots are wells with data. The purple boundary is the property model boundary and the orange boundary is the dynamic model boundary. 
Table 4-4. Tops received from $\mathrm{CAP-CO2}$ and not used in the Geneseo-Edwards structural model. Tops are either too high or too low when compared to adjacent tops and are removed from surface calculation.

\begin{tabular}{|c|c|c|c|c|c|c|}
\hline & UWI(API) & Surface & MD & UWI(API) & Surface & MD \\
\hline & 1505301006 & Arbuckle & 3147 & 15053013670000 & Arbuckle & 3616 \\
\hline & 1505302215 & Arbuckle & 560 & 15053013680000 & Arbuckle & 3290 \\
\hline & 1505319183 & Arbuckle & 3178 & 15053350840000 & Arbuckle & 3134 \\
\hline & 1515903930 & Arbuckle & 3273 & 15159000490000 & Arbuckle & 3251 \\
\hline & 1515905570 & Arbuckle & 4251 & 15159006100000 & Arbuckle & 3295 \\
\hline & 1515905843 & Arbuckle & 4322 & 15159017820000 & Arbuckle & 3228 \\
\hline & 1515906284 & Arbuckle & 2534 & 15159062460000 & Arbuckle & 3336 \\
\hline & 1515920414 & Arbuckle & 4383 & 15159062560000 & Arbuckle & 3253 \\
\hline & 1515920896 & Arbuckle & 3309 & 15159216180000 & Arbuckle & 3247 \\
\hline 00 & 150530026400 & Arbuckle & 3354 & 15159218150000 & Arbuckle & 3158 \\
\hline 00 & 150530079000 & Arbuckle & 3186 & 15159703510000 & Arbuckle & 3174 \\
\hline 00 & 150530079500 & Arbuckle & 3217 & K-1006513568 & PRECAMBRIAN & 3425 \\
\hline 00 & 150530080500 & Arbuckle & 3186 & & & \\
\hline
\end{tabular}

Table 4-5. Tops not initially received form CAP-CO2 and added to the Geneseo-Edwards structural model.

\begin{tabular}{lll}
\hline UWI(API) & Surface & MD \\
\hline 15159204730000 & Arbuckle-31 & 3346.47 \\
15159204730000 & Arbuckle-19 & 3439.76 \\
15159204730000 & Arbuckle-10 & 3630.2 \\
15159204730000 & Arbuckle-4 & 3800.74 \\
15159204730000 & Arbuckle-1 & 3957.47 \\
\hline
\end{tabular}

\subsubsection{Structural Grid, Property Model, and Volumetric Calculation}

The structural grid is based on the Arbuckle top surface. The well top control for the area of interest suggests that a normal fault with about $300 \mathrm{ft}(91.44 \mathrm{~m})$ of displacement exists on the west side of the structure. This fault located in the model by identifying the inflection on the Arbuckle and Arbuckle 19 surfaces and extrapolated though the entire Arbuckle Formation.

The final stratigraphic horizons used in the model were the result of several iterations due to data inconsistency. Both the Arbuckle and Precambrian tops are erosional surfaces and have the most control across the region. The top of the Arbuckle was created first from Petra grids and well tops (Figure 4-29). 


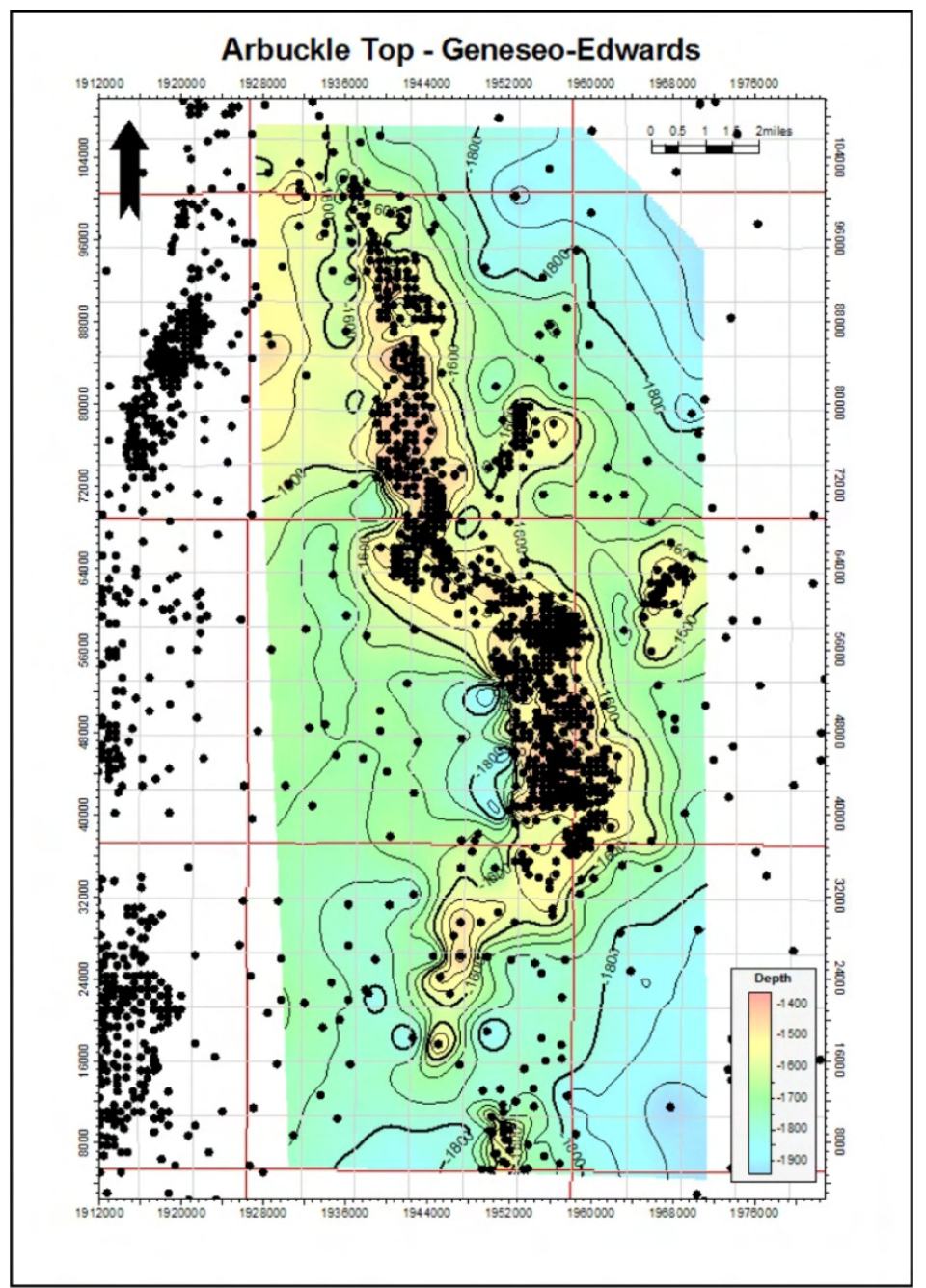

Figure 4-29. Arbuckle top surface for the Geneseo-Edwards model. Black dots are well top control points used in the model. Contour interval $25 \mathrm{ft}(7.62 \mathrm{~m})$.

The Arbuckle-19 horizon was created by isochore from the Arbuckle top; however, because the data were only in the area of interest, all areas outside the well control were heavily smoothed to remove artifact highs and lows inherited from the Arbuckle top surface (Figure 4-30). 


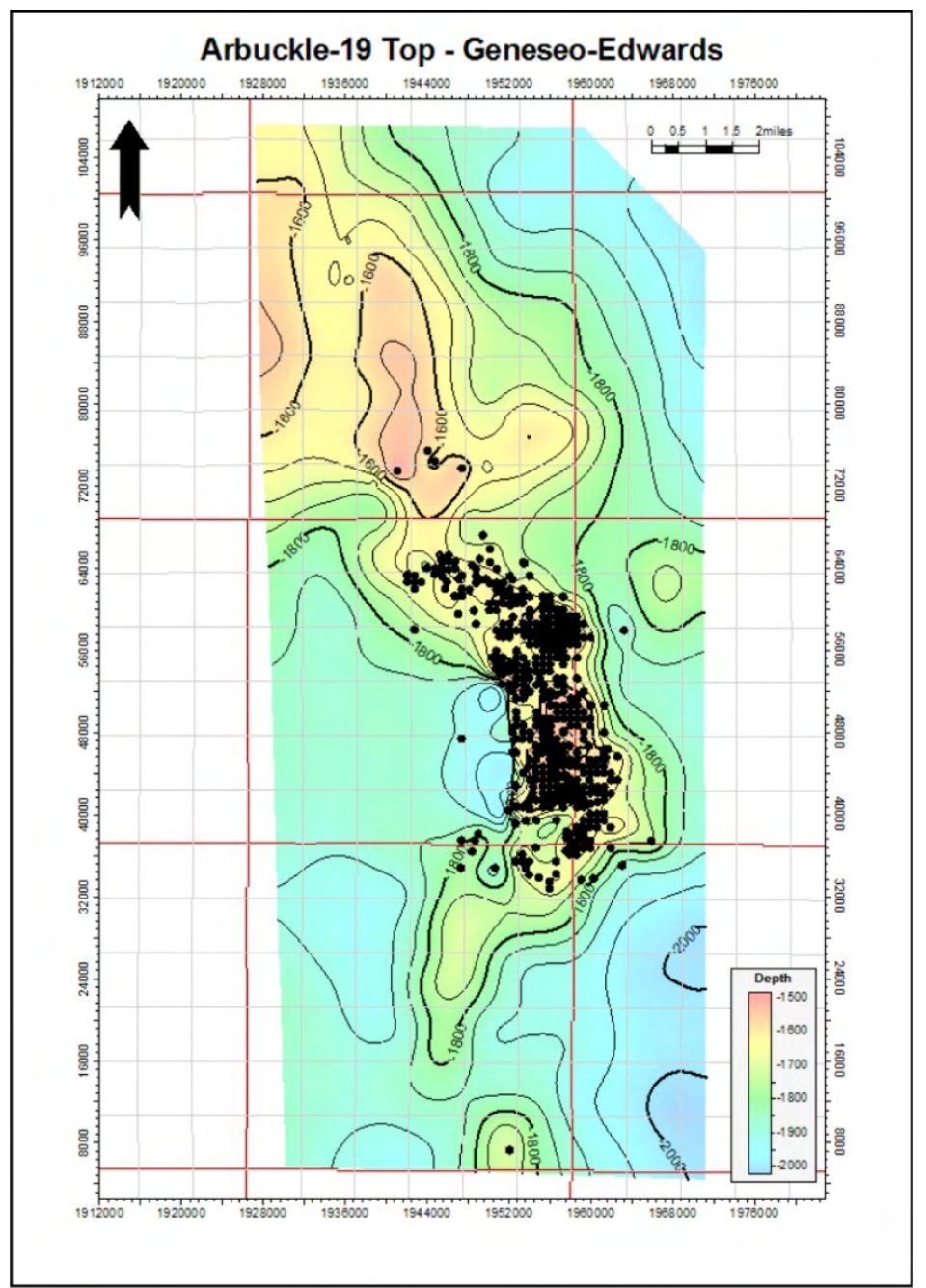

Figure 4-30. Arbuckle-19 surface for the Geneseo-Edwards model. Black dots

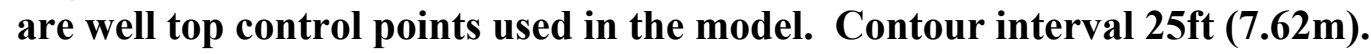

This method isochore and smoothing ensures that the data is honored and reduces structural errors for the other horizons that were built from the Arbuckle isochore. The Arbuckle-31 structural surface was built by isochore up from Arbuckle-19 (Figure 4-31). The Arbuckle-10, 4, 1 surfaces and the Precambrian surface were built by isochore down (Figures 4-32, 4-33, 4-34 and 4-35 respectively). 


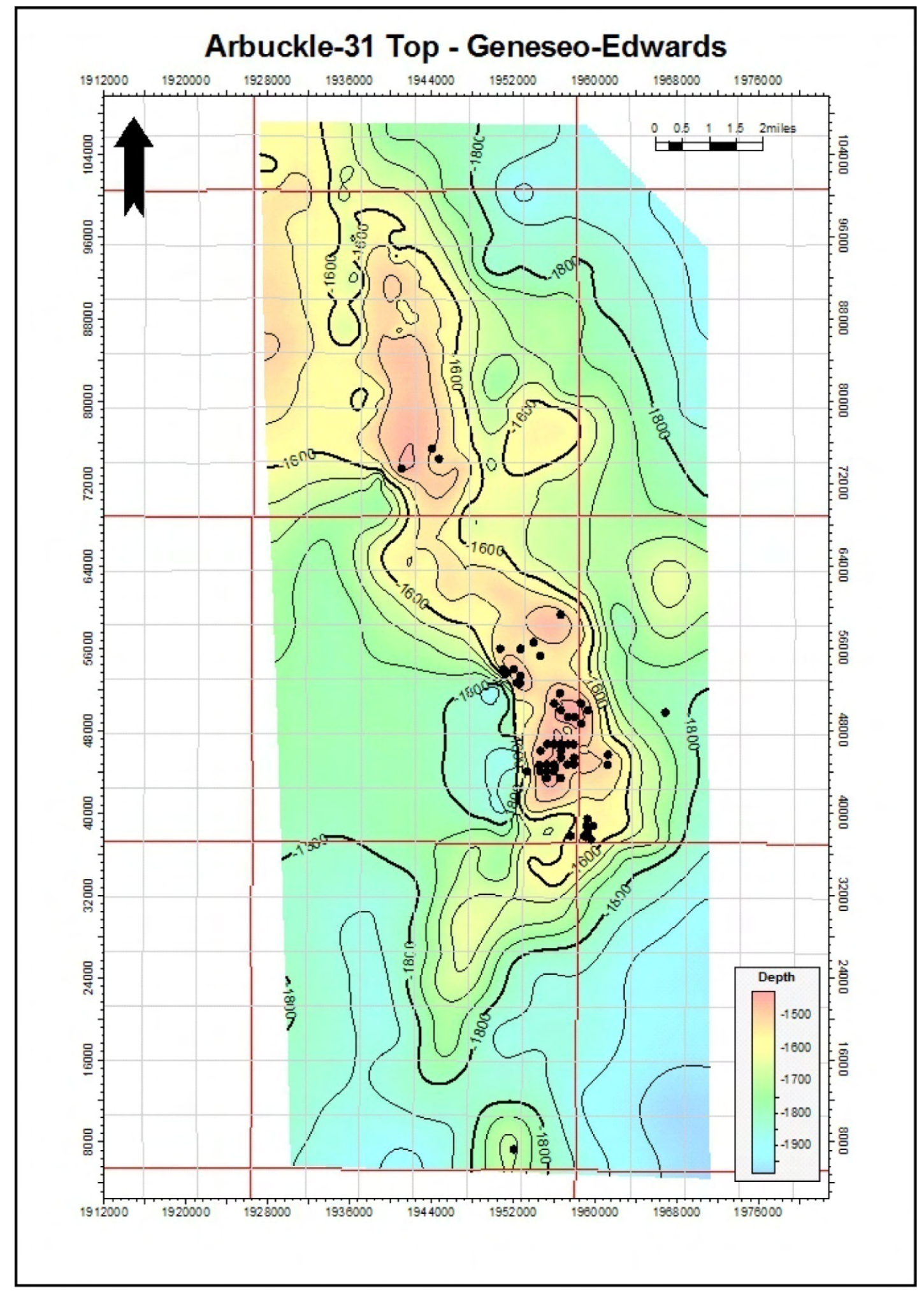

Figure 4-31. Arbuckle-31 surface for the Geneseo-Edwards model. Black dots are well top .control points used in the model. Contour interval $25 \mathrm{ft}(7.62 \mathrm{~m})$. 


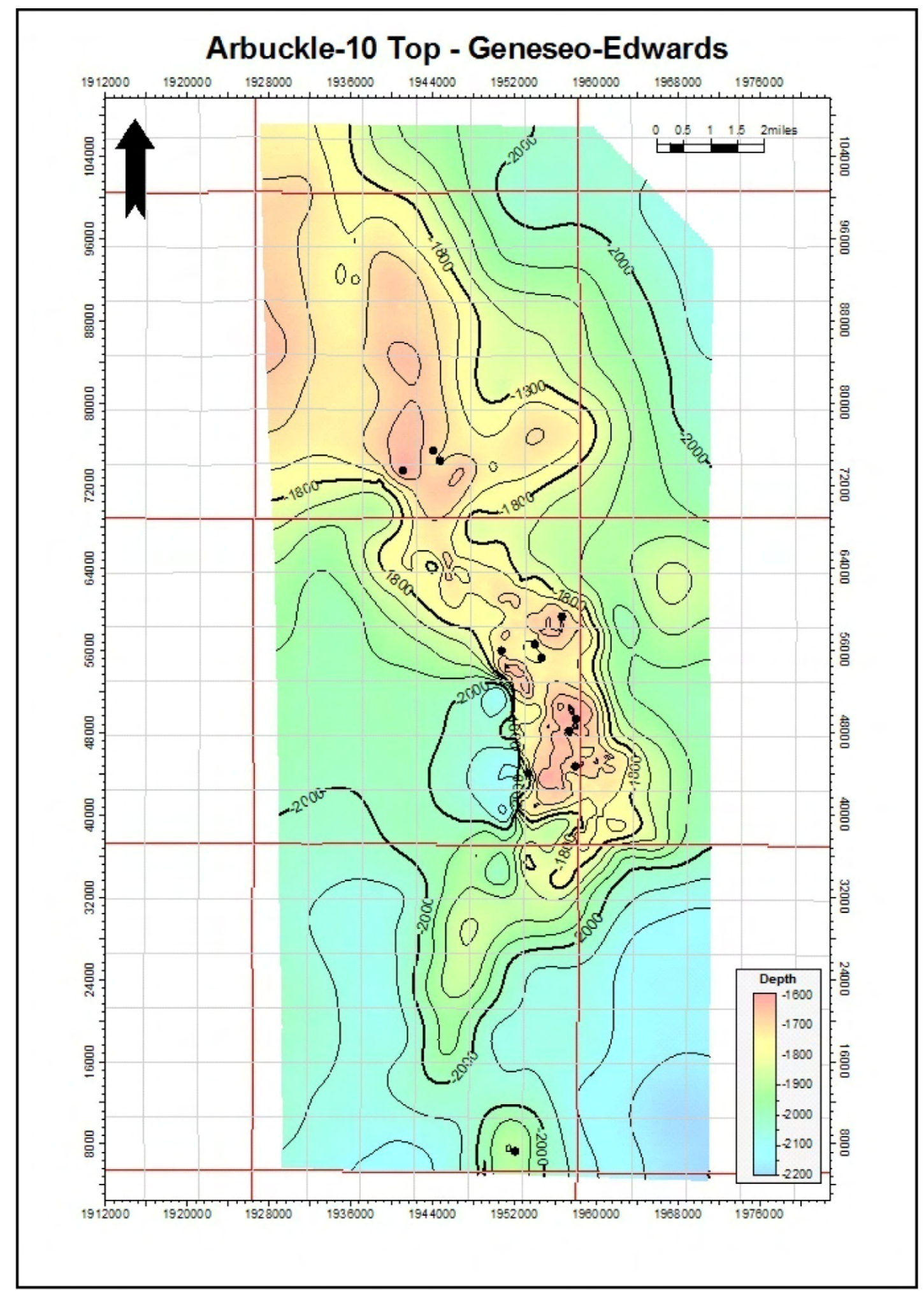

Figure 4-32. Arbuckle-10 surface for the Geneseo-Edwards model. Black dots are well top control points used in the model. Contour interval $25 \mathrm{ft}(7.62 \mathrm{~m})$. 


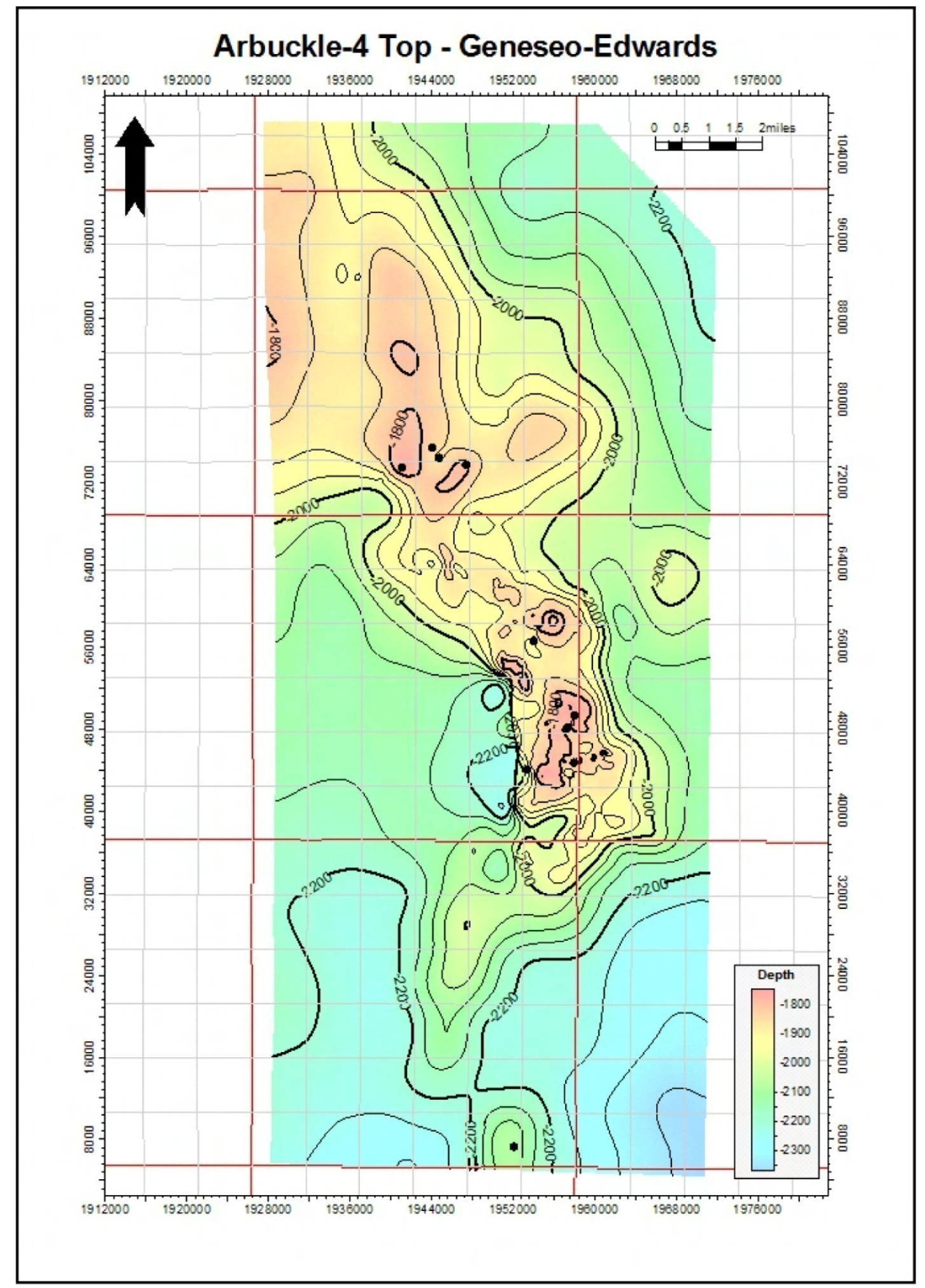

Figure 4-33. Arbuckle-4 surface for the Geneseo-Edwards model. Black dots are well top control points used in the model. Contour interval $25 \mathrm{ft}(7.62 \mathrm{~m})$. 


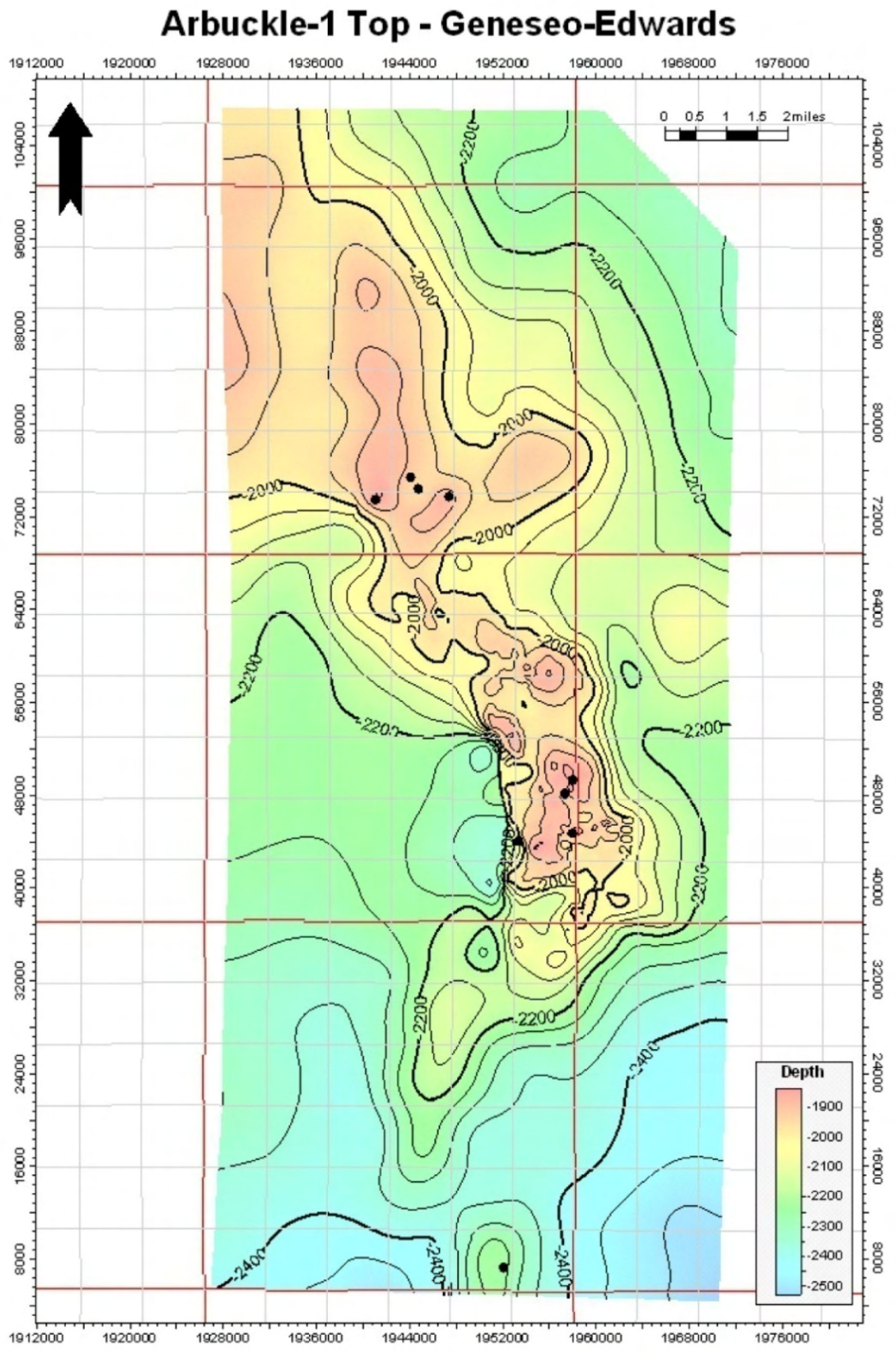

Figure 4-34. Arbuckle-1 surface for the Geneseo-Edwards model. Black dots are well top control points used in the model. Contour interval $25 \mathrm{ft}(\mathbf{7 . 6 2 \mathrm { m }})$. 


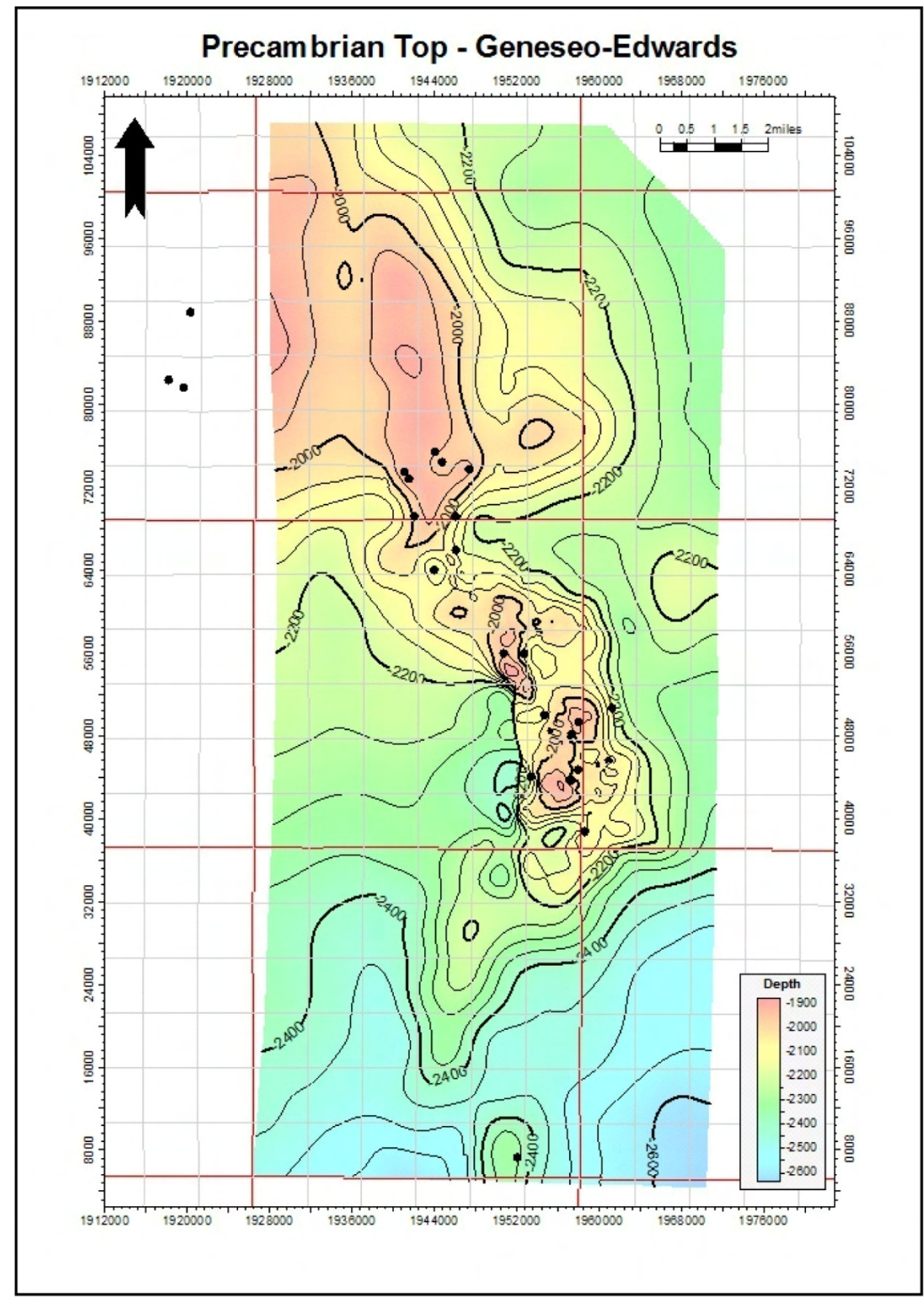

Figure 4-35. Precambrian surface for the Geneseo-Edwards model. Black dots are well top control points used in the model. Contour interval $25 \mathrm{ft}(7.62 \mathrm{~m})$.

Two significant unconformities exist in the stratigraphic column. First, there is a disconformity at the top of the Arbuckle that erodes into the top of the Arbuckle-31 zone. 
Second, there is a nonconformity at the top of the Precambrian basement that has resulted in an absence of the Arbuckle 1 zone to the north. Figures 4-36a and 4-36b show EastWest and North-South cross sections of the zones through the southern structural high of the Geneseo-Edwards, the location of the dynamic model.

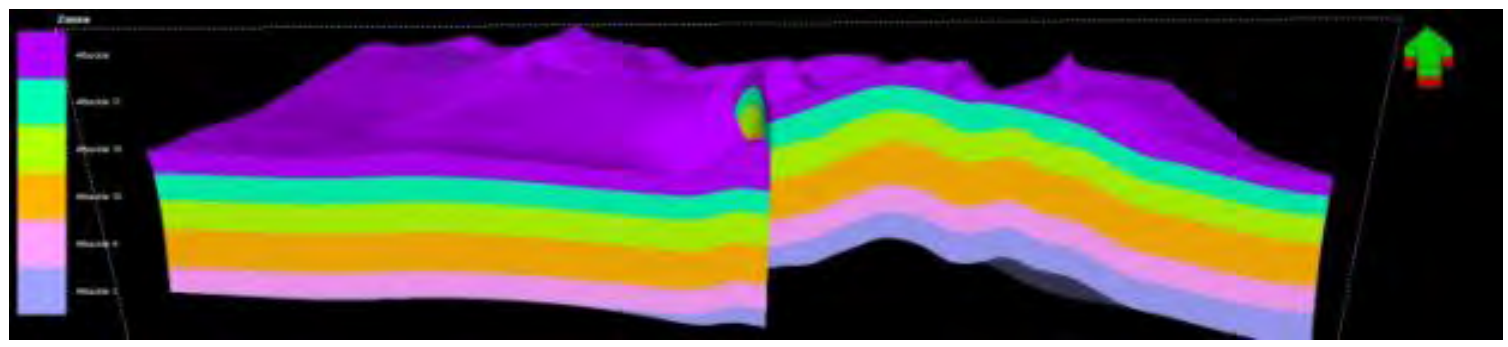

(a)

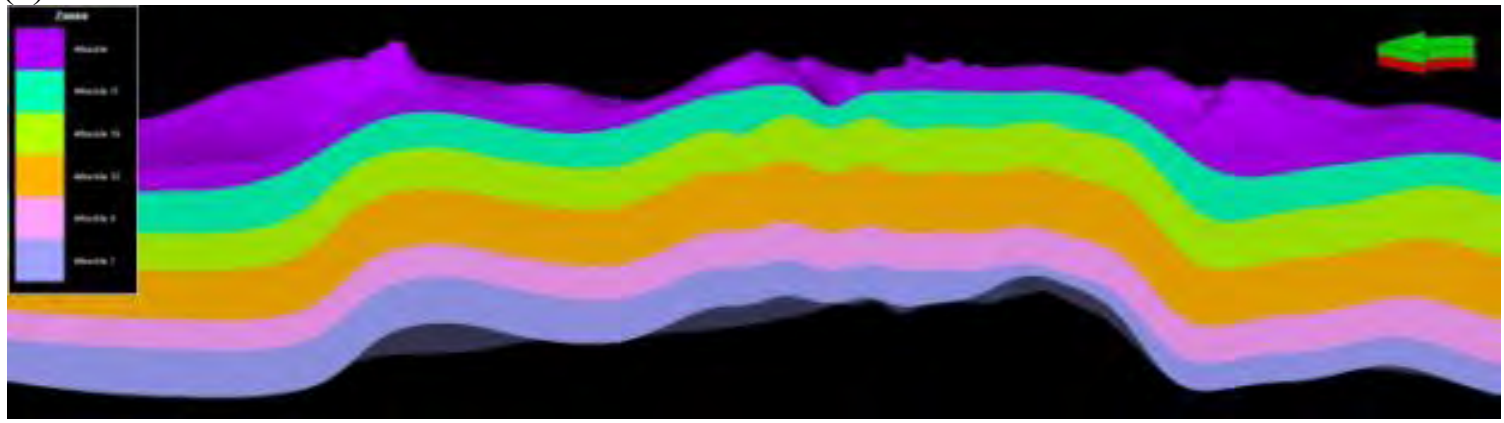

(b)

Figure 4-36 (a) East-West cross section through the zones for the southern structure and the dynamic model area. Note fault cut in the middle of the section and (b) North-South cross section through the zones for the southern structure and the dynamic model area

The size of the study area dictated that a $300 \mathrm{ft}$ by $300 \mathrm{ft}(91.44 \mathrm{~m}$ by $91.44 \mathrm{~m})$ cell horizontal cell size was the smallest possible for the structural model, creating 49,494 2D cells for the model area. Layering of the zones was tied to the distribution of data. Above the Arbuckle-19 there were more well logs and a $5 \mathrm{ft}$ cell height was selected. Below the Arbuckle-19, a 10ft cell size was selected. For the entire modeled area a total of 6,335,232 cells were created with 146 in the i-direction, 339 in the j-direction, and 128 in the k-direction.

The porosity curves calculated from neutron logs were upscaled to the structural grid using the arithmetic averaging method. The locations of the data wells were rather far apart and geostatistical methods to analyze the data was found to be questionable. To better fit the geological conceptual model, the default Petrel settings for distribution were used; $5000 \mathrm{ft}(1524 \mathrm{~m})$ for the major range, $5000 \mathrm{ft}(1524 \mathrm{~m})$ for the minor range, and 10ft $(3.05 \mathrm{~m})$ for the vertical range. Figures $4-37 \mathrm{a}$ and $4-37 \mathrm{~b}$ show east-west and north-south cross sections of the porosity through the southern structural high of the GeneseoEdwards, the location of the dynamic model. Figure 4-38 is the histogram comparing the distribution of well log (red), upscaled (green), and 3D grid (blue). 


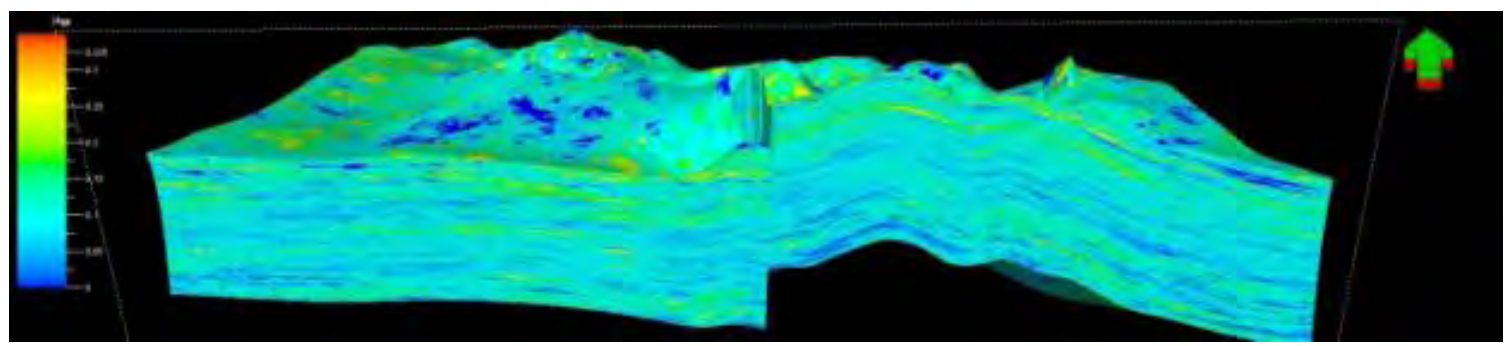

(a)

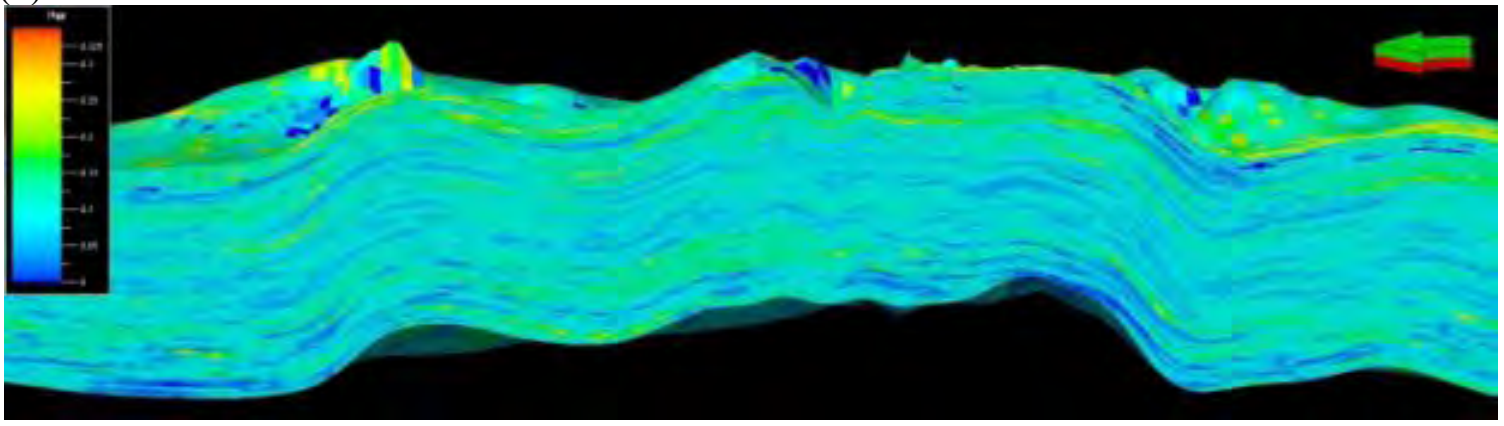

(b)

Figure 4-37. (a) East-West cross section of porosity through the dynamic model area. Note fault cut in the middle of the section and North-South cross section of porosity through the dynamic model area. 


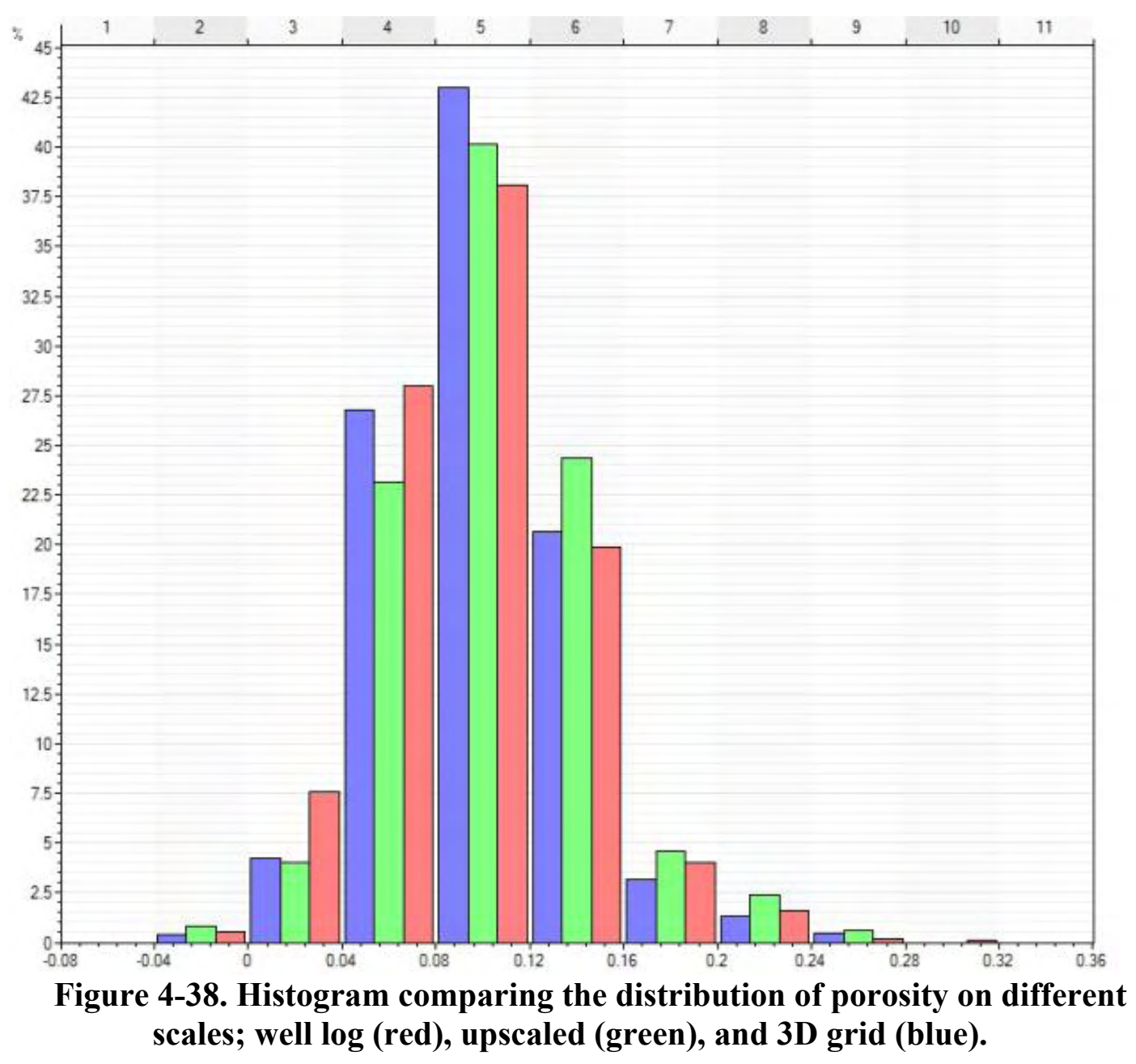

The porosity and permeability core data from two wells were used to make correlations to input to permeability into the property model. Four porosity/permeability trend lines were created from the data by modifying the range of data (Figure 4-39). The blue trend line used all the data provided from CAP-CO2 and other industry partners. The blank permeabilities were estimated with a trend line equation:

$$
k_{\text {blue }}=1778154.23 \phi^{5.66}, R^{2}=0.65
$$

Where $\mathrm{K}$ is permeability and $\Phi$ is porosity. Removing the estimated permeability values (green) the trend line equation is:

$$
k_{\text {green }}=275904.63 \phi^{4.31}, R^{2}=0.47
$$

To get a better fit to the upper cloud of data, porosity bins were established to average the porosity and permeability for all data. Using all of the data, including the permeability estimates, the bins were 0.02 porosity units (red). The data without the estimates were binned in 0.03 porosity units (yellow). In both cases the averaged data for the bins better fits a power function with an $\mathrm{R}^{2}$ value greater than 90 . The trend line equations are:

$$
\begin{aligned}
& k_{\text {red }}=1688910.48 \phi^{4.59}, R^{2}=0.909 \\
& k_{\text {yellow }}=173272.82 \phi^{3.29}, R^{2}=0.91
\end{aligned}
$$




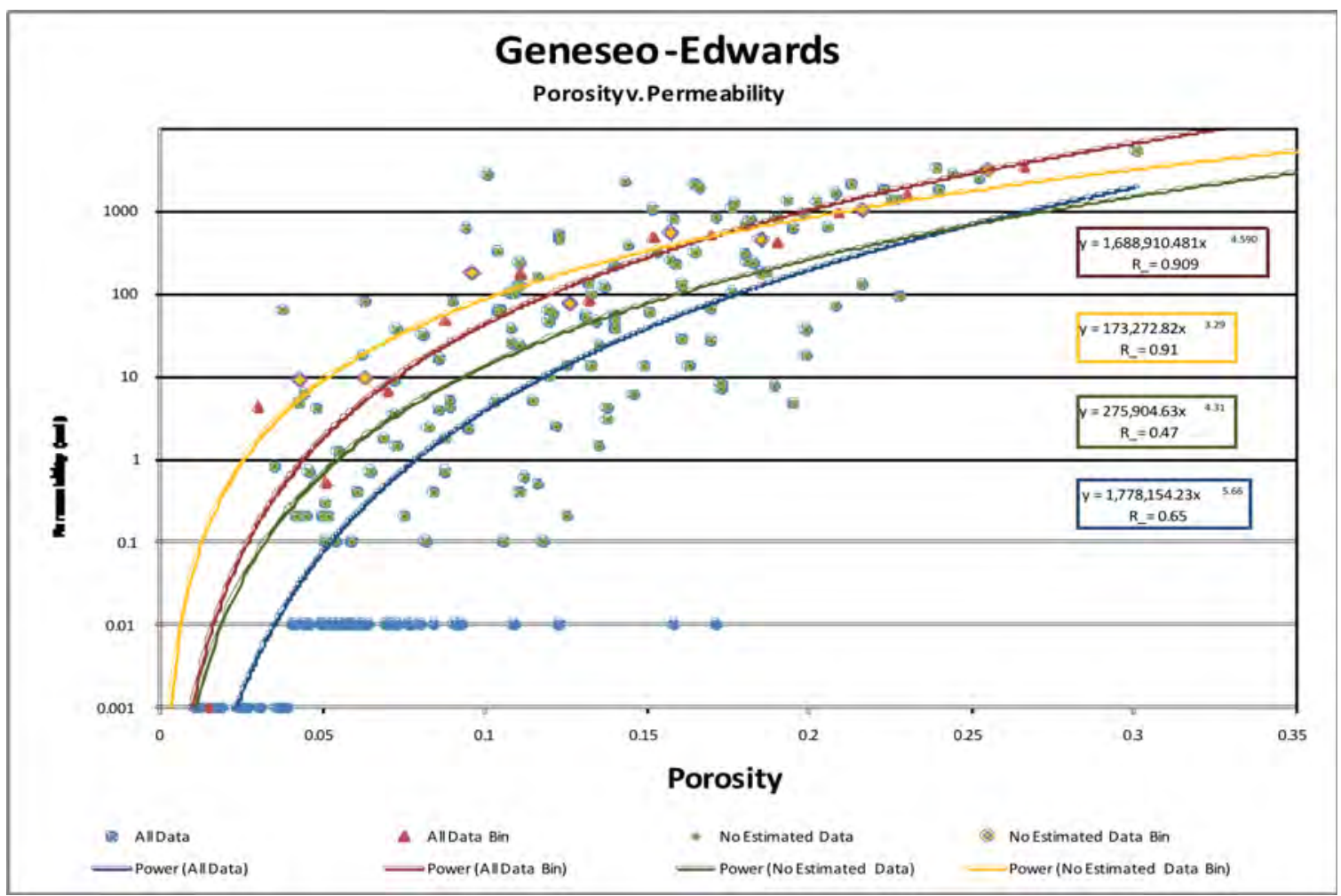

Figure 4-39. Cross-plot of porosity and permeability core data for the GeneseoEdwards. Blue dots are for all core data and estimated data. Green dots are all core data with no estimated data. Red dots are the binned porosity and permeability averages for all core data and estimated data. Yellow dots are the binned porosity and permeability averages for all core data with no estimated data. Trend lines are in corresponding colors to the data.

The sets with no estimated values were selected to be propagated in the model to eliminate potential estimation error. The binned set is used as a high permeability case, while the correlation for the raw data is the low permeability case. Using the previously mentioned power function, the distributed porosity was used to create the high and low permeability properties. The distributed permeabilities are shown in cross sections in figures 4-40a-d. Figures 4-41a and 4-41b are the histograms for the low and high permeability distributions. 


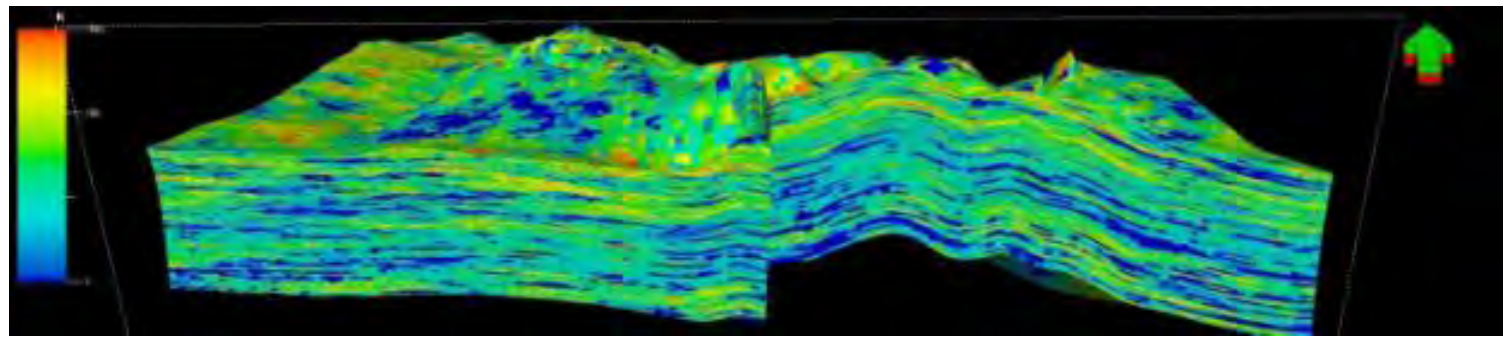

(a)

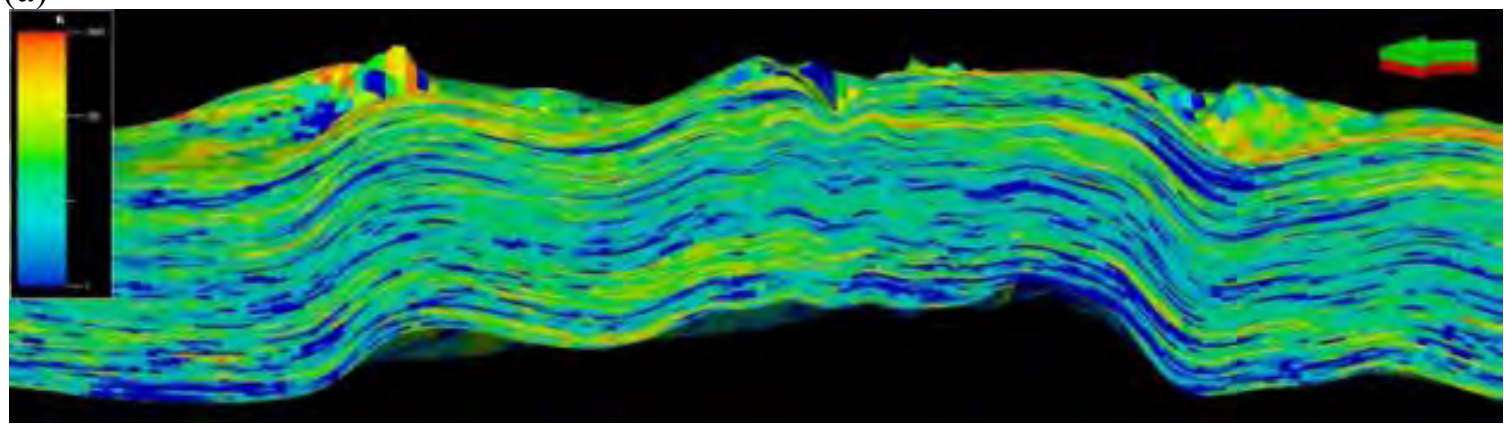

(b)

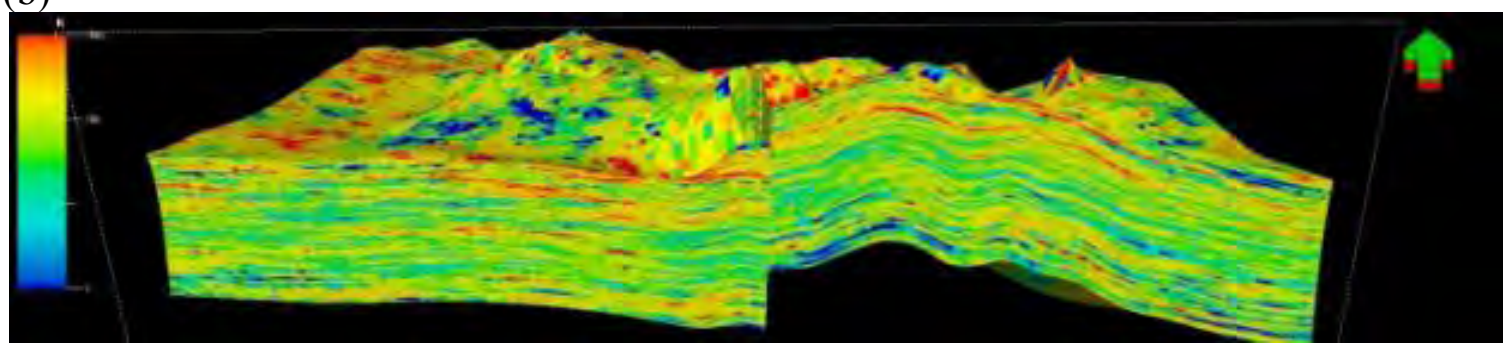

(c)

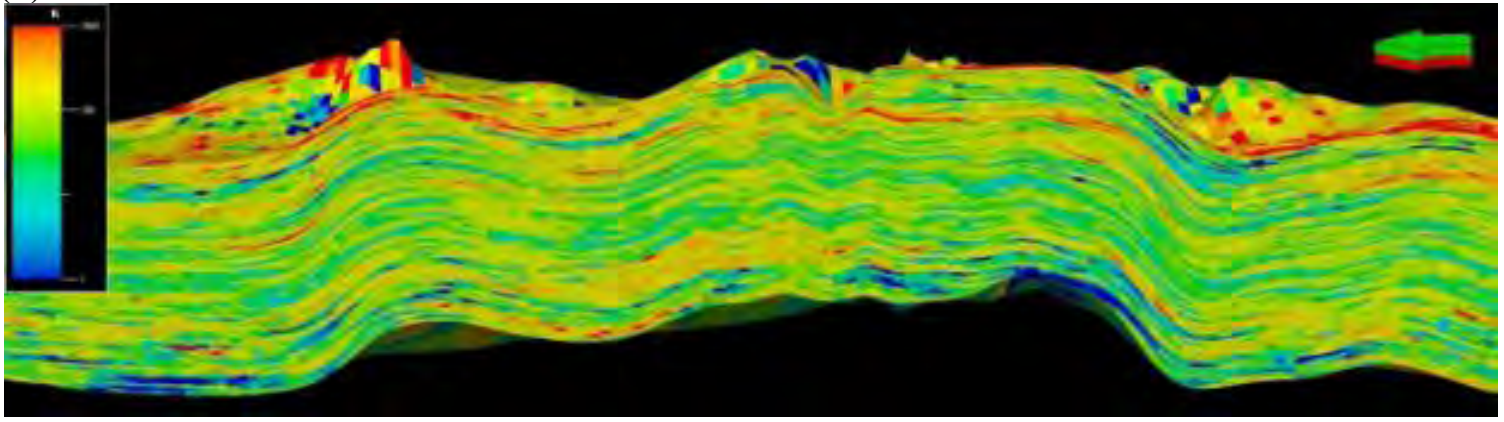

(d)

Figure 4-40. (a) East-West cross section of low permeability through the dynamic model area. Note fault cut in the middle of the section, (b) North-South cross section of low permeability through the dynamic model area, (c) East-West cross section of high permeability through the dynamic model area. Note fault cut in the middle of the section, and (d) North-South cross section of high permeability through the dynamic model area. 


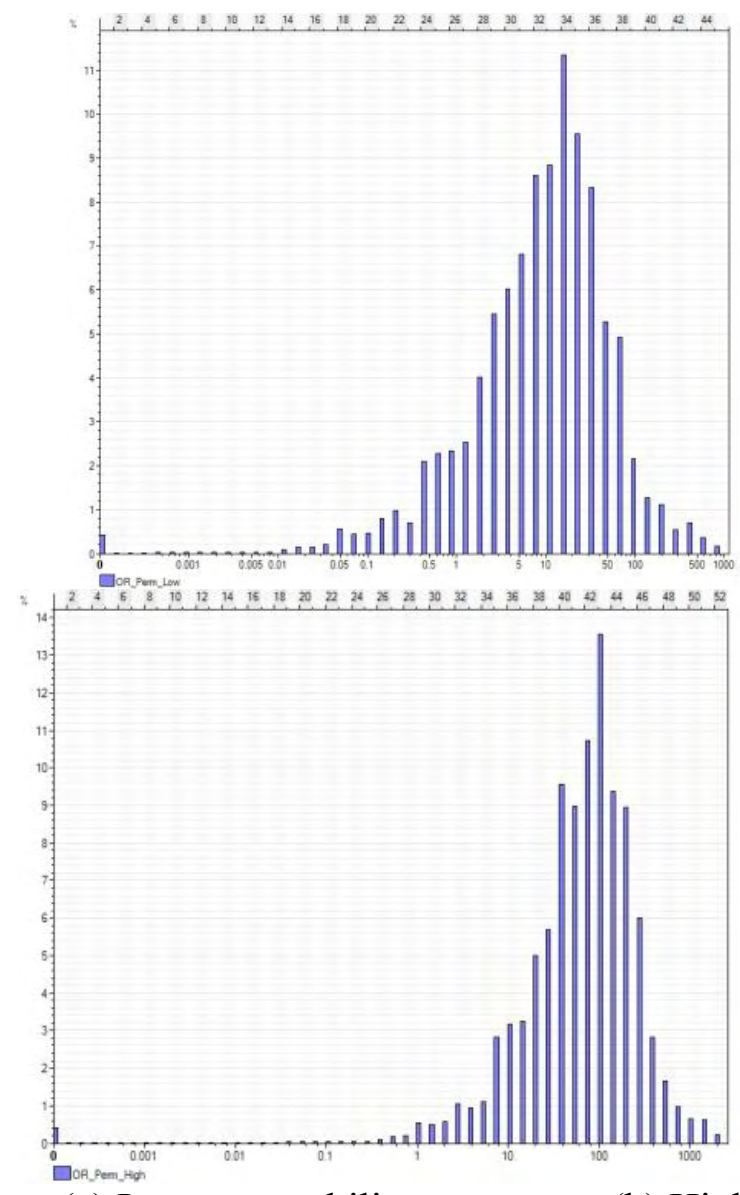

$\begin{array}{ll}\text { (a) Low permeability } & \text { (b) High permeability }\end{array}$

Figure 4-41. Histogram of permeability distribution for 3D grid.

Water saturation was created by using the oil water contact (OWC) of $-1500 \mathrm{ft}$ TVDSS provided by CAP-CO2 and other industry partners. An estimated water saturation of $30 \%$ was used above the OWC. This value was used to initialize the dynamic model. Table 4-6 contains the maximum, minimum, and mean values for each of the properties.

Table 4-6. Minimum, maximum, and mean values for porosity, low permeability, high permeability, and water saturation.

\begin{tabular}{llll}
\hline Property & Minimum & Maximum & Mean \\
\hline Porosity & 0.000 & 0.260 & 0.098 \\
Low Permeability (md) & $0^{*}$ & 830 & 25 \\
High Permeability (md) & $0^{*}$ & 2059 & 121 \\
Water Saturation & 0.3 & 1.0 & --- \\
\hline
\end{tabular}

*Note: values are significantly close to zero and are products of the porositypermeability transform.

Using the distributed porosity, water saturation, and an oil formation volume factor of $1.06 \mathrm{RB} / \mathrm{STB}\left(0.169 \mathrm{~m}^{3} / \mathrm{m}^{3}\right)$, a volume calculation was created for the property model. For the area of the dynamic model the pore volume is $130 \mathrm{MMbbl}\left(20.7 \times 10^{6} \mathrm{~m}^{3}\right)$ with a 
hydrocarbon pore volume of $88 \mathrm{MMbbl}\left(14.0 \times 10^{6} \mathrm{~m}^{3}\right)$ and about $40 \mathrm{MMbbl}(6.4 \mathrm{x}$ $\left.10^{6} \mathrm{~m}^{3}\right)$ of recoverable oil is present. The Arbuckle and Arbuckle- 31 zones contain the entire hydrocarbon amount. These numbers will require validation through dynamic modeling. Table 4-7 contains a listing of the volumetrics by zone.

Table 4-7. Volumetric calculation of STOIIP and Recoverable oil for the dynamic model area.

\begin{tabular}{|c|c|c|c|c|c|c|}
\hline \multirow{2}{*}{ Zone } & \multirow{2}{*}{$\begin{array}{l}\text { Bulk } \\
\text { volume } \\
\text { (MMbbl) }\end{array}$} & \multicolumn{2}{|c|}{ Net volume Pore } & \multirow{2}{*}{$\begin{array}{l}\text { HCPV oil } \\
\text { (MMbbl) }\end{array}$} & STOI & \multirow{2}{*}{$\begin{array}{l}\text { Recoverable } \\
\text { oil (MMbbl) }\end{array}$} \\
\hline & & (MMbbl) & (MMbbl) & & (MMbbl) & \\
\hline Arbuckle & 776 & 776 & 95 & 65 & 61 & 29 \\
\hline Arbuckle 31 & 322 & 322 & 35 & 23 & 22 & 10 \\
\hline $\begin{array}{l}\text { Arbuckle } \\
19^{*}\end{array}$ & 0 & 0 & 0 & 0 & 0 & 0 \\
\hline $\begin{array}{l}\text { Arbuckle } \\
10^{*}\end{array}$ & 0 & 0 & 0 & 0 & 0 & 0 \\
\hline Arbuckle 4* & 0 & 0 & 0 & 0 & 0 & 0 \\
\hline Arbuckle $1^{*}$ & 0 & 0 & 0 & 0 & 0 & 0 \\
\hline Total & 1098 & 1098 & 130 & 88 & 83 & 40 \\
\hline
\end{tabular}

*Note: zone below oil water contact and no calculation for hydrocarbon was conducted.

Finally, using well tops, surface grids, core data, and well log data provided by industry partners and CAP-CO2, structural and property models were created for dynamic simulation of the Geneseo-Edwards Field. The distribution of porosity was used to calculate permeability based upon power function transforms for the two different cases. The final model results in a hydrocarbon pore volume of $88 \mathrm{MMbbl}(14.0 \mathrm{x}$ $\left.10^{6} \mathrm{~m}^{3}\right)$ and approximately $40 \mathrm{MMbbl}\left(6.4 \times 10^{6} \mathrm{~m}^{3}\right)$ of recoverable hydrocarbons.

\subsubsection{Flow Model Simulation Analysis of Combined EOR and Deep Saline Sequestration in Thrall-Aagard Reservoirs}

\subsubsection{Descriptions of Model Grid and Workflow}

This portion of the IMCCS conceptual study accesses the feasibility of the storage of $\mathrm{CO}_{2}$ generated by a nearby ethanol plant and evaluates the feasibility of using the $\mathrm{CO}_{2}$ for EOR (enhanced oil recovery) purposes. For this, a model covering the isolated Arbuckle domes in the Geneseo-Edwards Field is used. The field has been in production since 1935 with a total of 5.4 million $\mathrm{m}^{3}$ (33.7 million barrels) of oil recovered to date. The very strong bottom aquifer allows the production to proceed without the implementation of any secondary recovery process (e.g. water injection). 


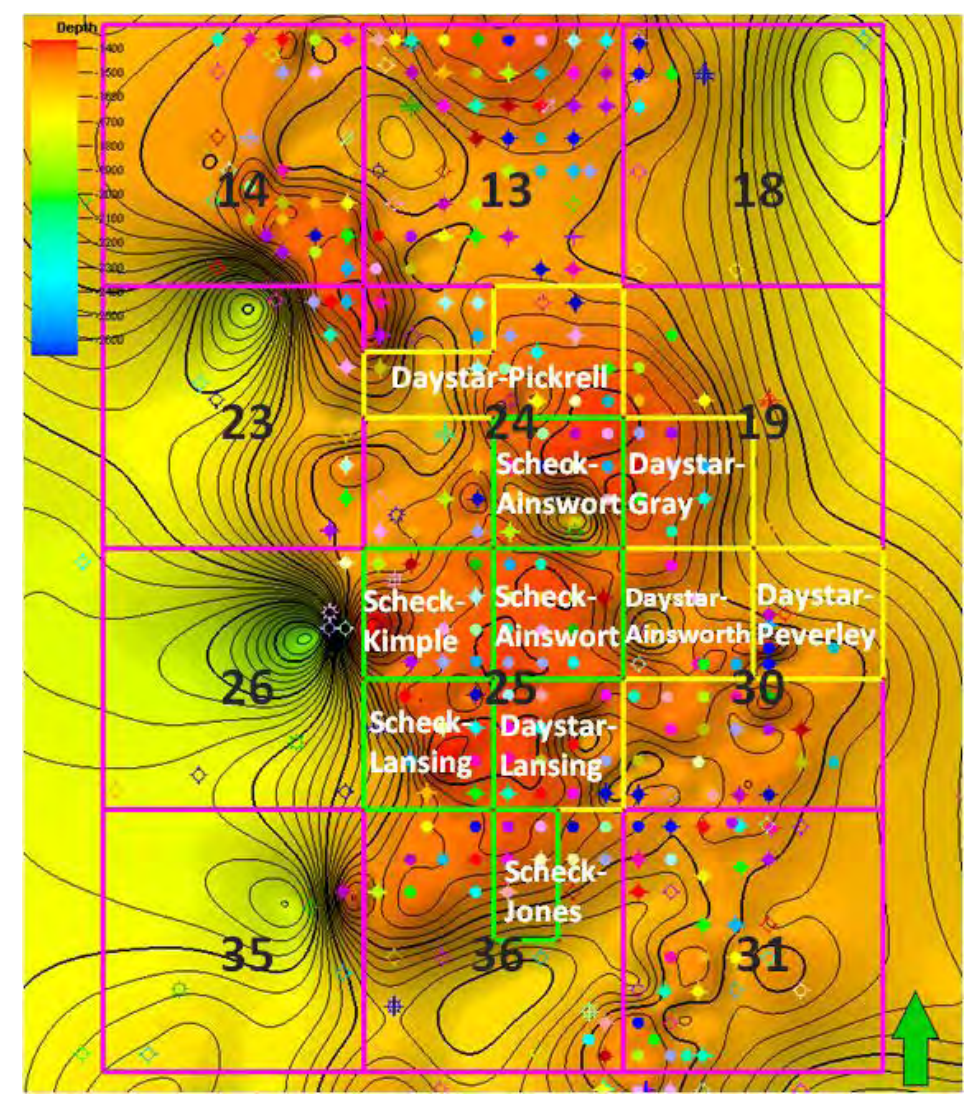

Figure 4-42. Geneseo-Edwards model area.

The simulation model area in this study covers a 12-section area most of which operated by Daystar Oil and Scheck Oil (see Figure 4-42). A total of 152 wells can be found in this area with 3.9 million $\mathrm{m}^{3}$ (24.8 million barrels) of oil recovered in the 75 year history.

The following are the data available for the dynamic simulation work:

- Static model (grid) providing reservoir structural and property information

- PVT data of an oil sample collected in a neighboring field

- Annual oil production rates by lease areas

- Barrel test data of some individual wells provided by Daystar Oil and Scheck Oil 


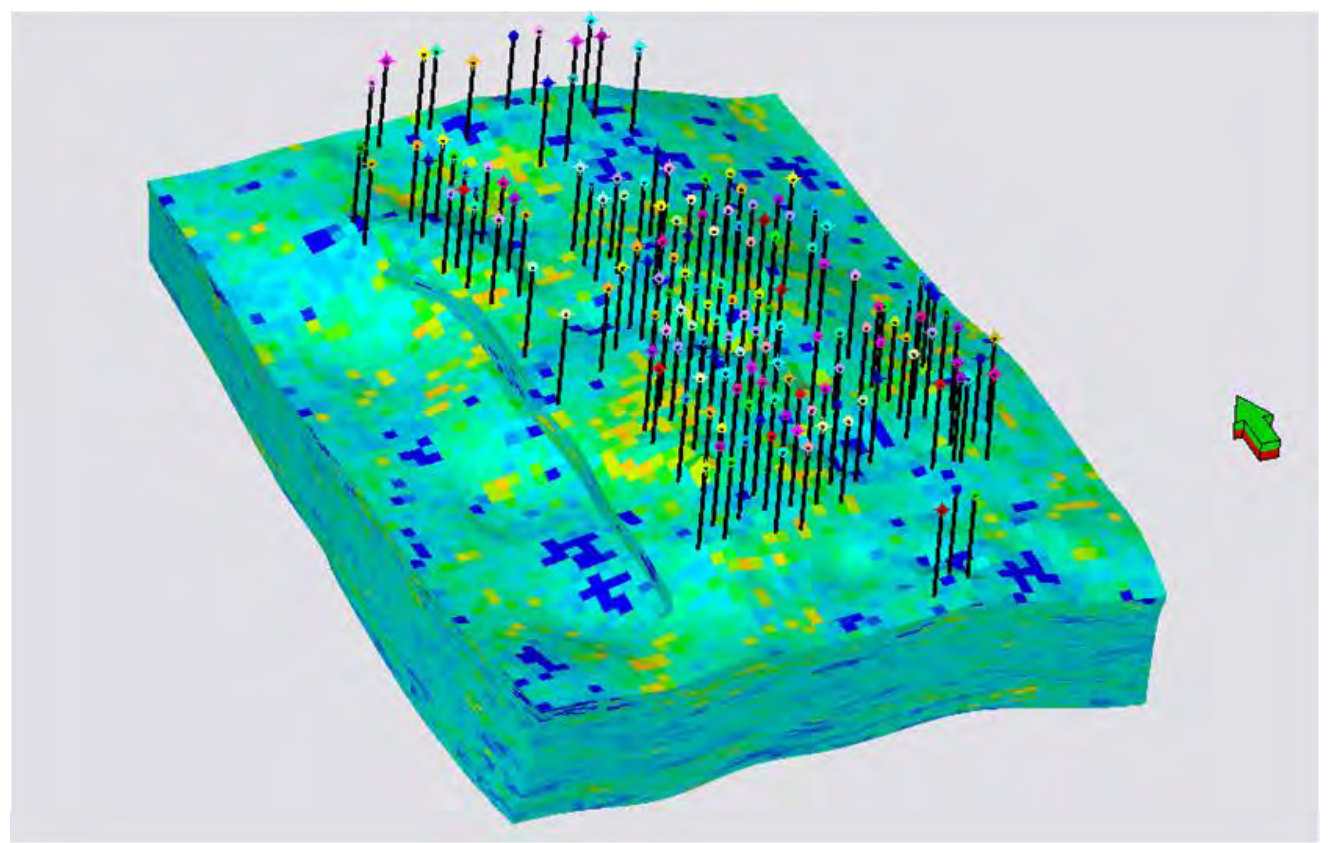

Figure 4-43 The simulation model.

The dynamic simulation model (see Figure 4-43) was extracted from the static model grid with $91 \mathrm{~m} \times 91 \mathrm{~m}(300 \mathrm{ft} \times 300 \mathrm{ft})$ grid cells and 87 layers each averaging $3 \mathrm{~m}(10 \mathrm{ft})$ in thickness. With the initial oil-water contact estimated to be at $458 \mathrm{~m}(1,503 \mathrm{ft})$ subsea, most of these layers cover the underlying saline aquifer. The $\mathrm{CO}_{2}$ injected into the saline aquifer is expected to rise and eventually enters the swept oil zone from below. This phenomenon is included in the simulation with this integrated model.

An EOS (equation-of-state) for the Eclipse model was provided by University of Kansas and is based on a 33.3 API surface oil sample collected from a neighboring field (Ogallah Unit). On the other hand, the oil produced in the Geneseo-Edwards Field is closer to 37 API and this was achieved by slightly adjusting the EOS. The EOS was incorporated into the simulation model after mixing in a small amount of gas $\left(21.4 \mathrm{~m}^{3} / \mathrm{m}^{3}\right.$ or $120 \mathrm{scf} / \mathrm{stb}$ ) numerically. This gave the resulting fluid a saturation pressure of $4.2 \mathrm{MPa}$ $(610 \mathrm{psia})$ at the average reservoir temperature of $47^{\circ} \mathrm{C}\left(117^{\circ} \mathrm{F}\right)$ as shown in Figure 4-44. With this, the model was initializes with initial water saturation shown in Figure 4-45 and estimates a total of 13.57 million $\mathrm{m}^{3}$ (85.4 million barrels) of oil initially in place. 


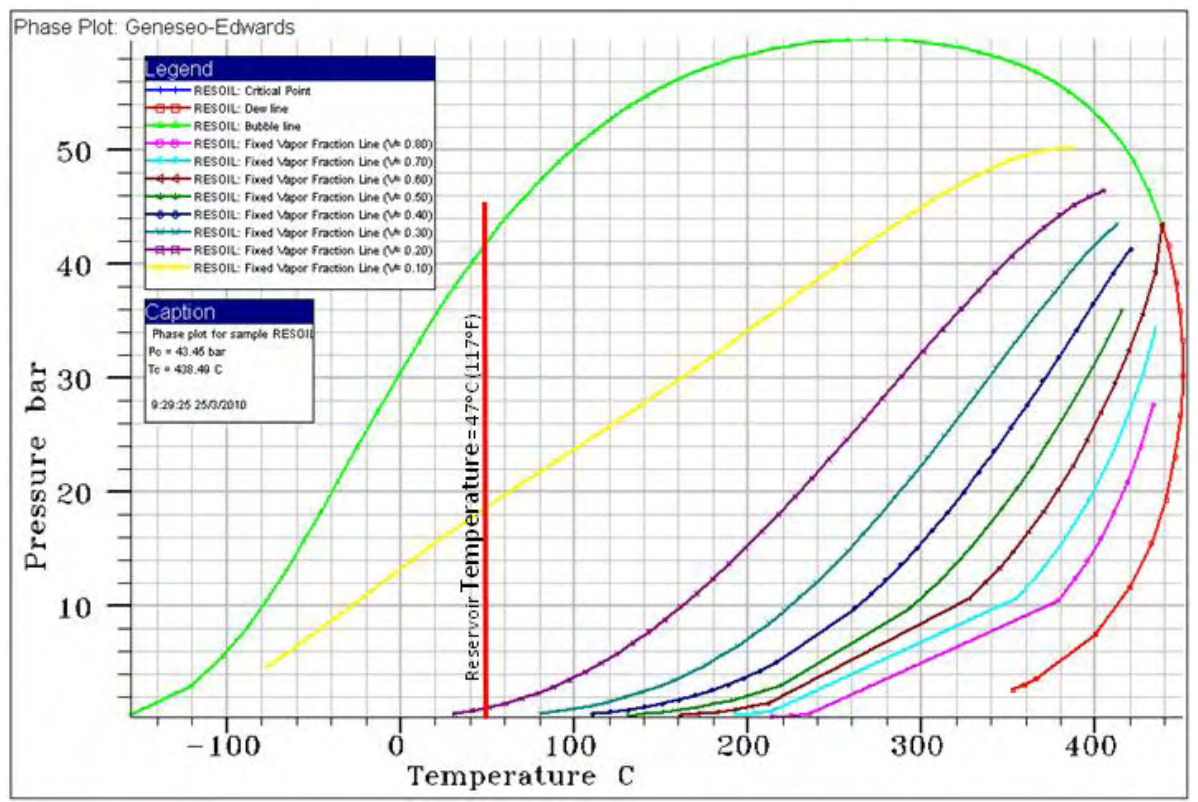

Figure 4-44. Model fluid phase diagram

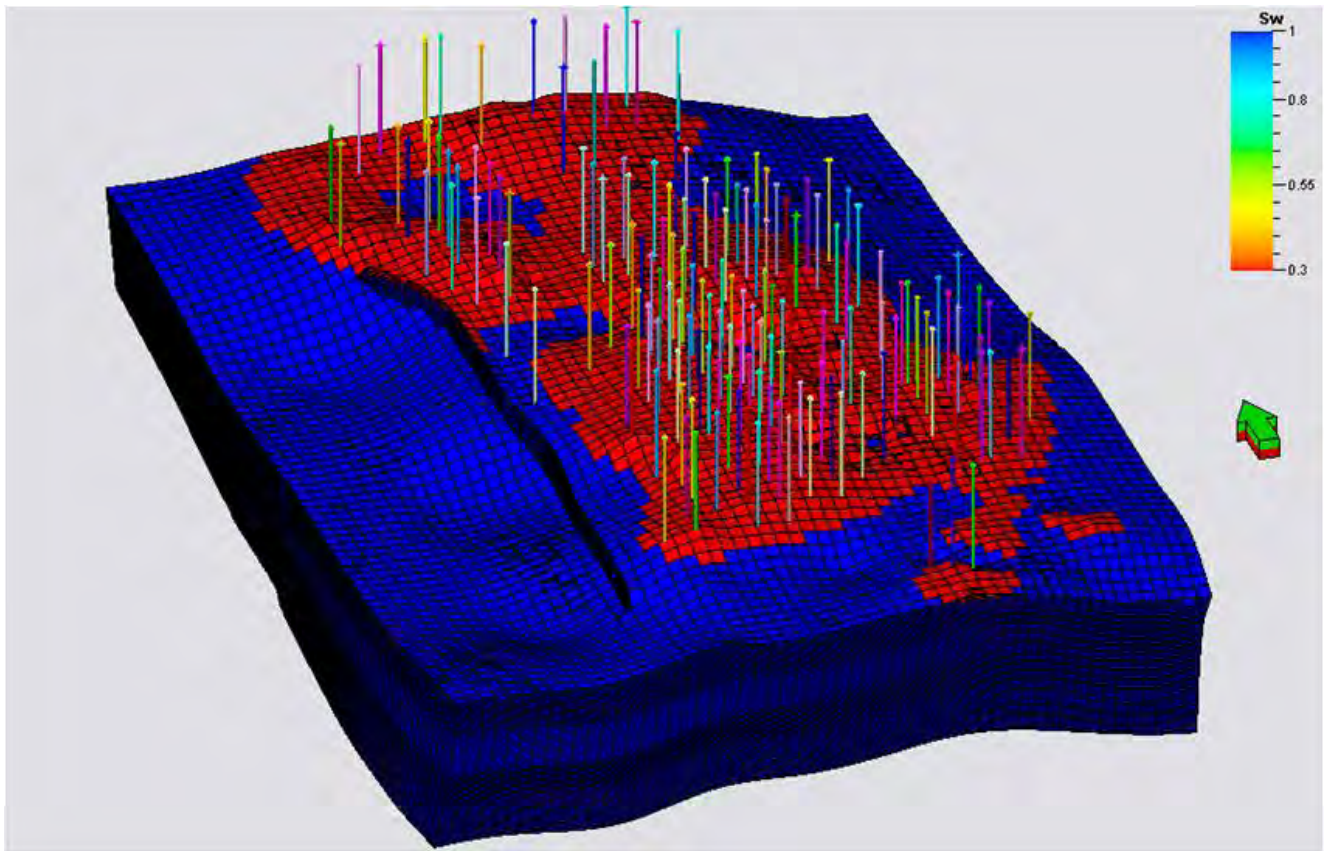

Figure 4-45. Initial water distribution

As previously mentioned, the field had been in operation for the past 75 years and only sketchy production data are available. These include annual oil production figures by lease area and barrel tests of individual wells provided by Daystar Oil and Scheck Oil. It is evident that the reservoir is subject to a strong aquifer support during the substantial amount of primary oil recovery with a relatively stable reservoir pressure. With these in mind, analytical aquifers have been attached to the side and to the bottom of the model as extensions to the water body within the model. 
Well completion and production information (annual oil production rates by lease) was incorporated (see Figure 4-46) once the initial model setup was complete. This was then followed by adjustments of certain model parameters in order to calibrate it to the historical production data. This process is commonly known as history matching. In this case, the model was made to match the general historical trends in water cut measurements during the barrel tests of the wells in the Daystar and Scheck leases. Model parameters (oil-water contact depth, residual oil saturation and analytical aquifer volumes) were adjusted within reasonable ranges.

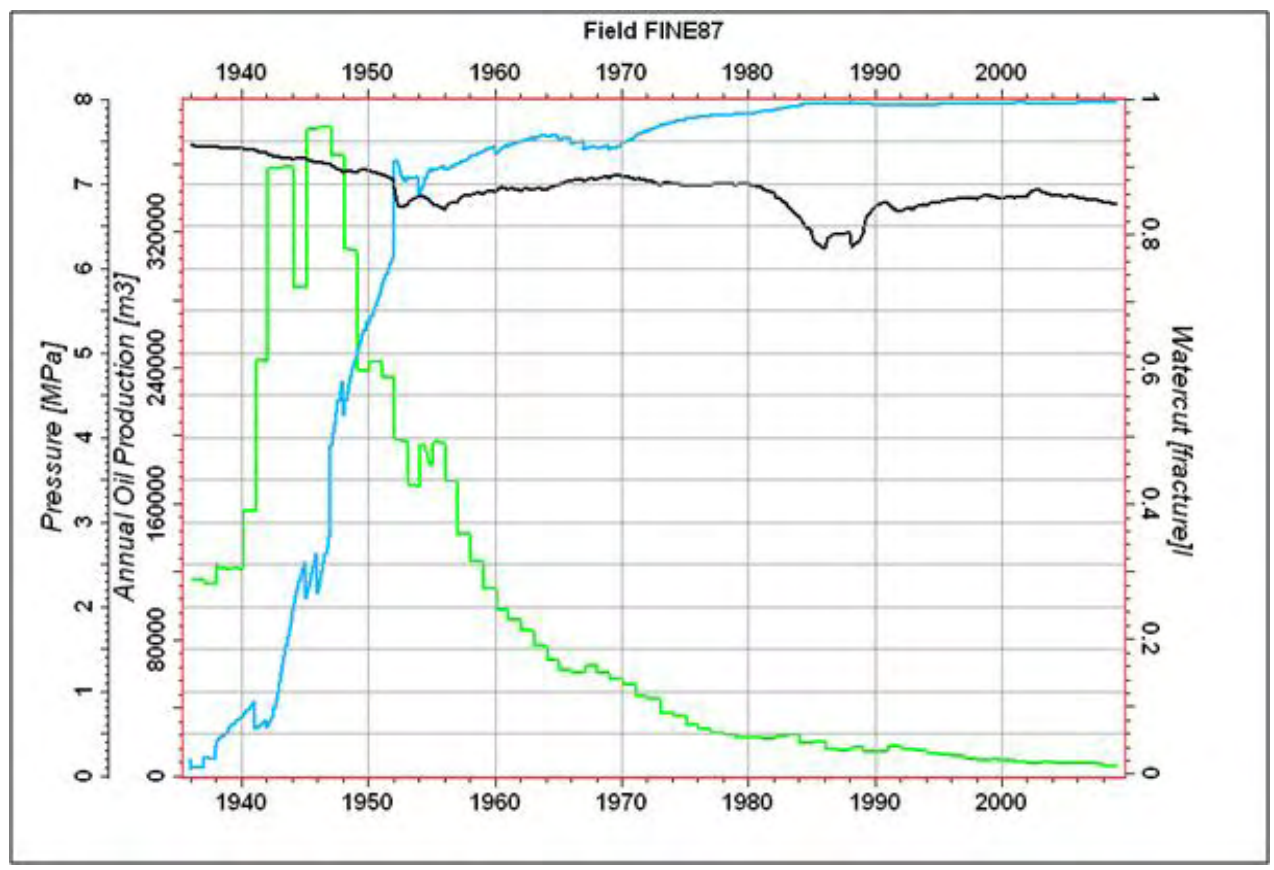

Figure 4-46. Production and pressure profiles.

Once a satisfactory match (see Figure 4-47) was achieved, the model could be used for simulating the effects of $\mathrm{CO}_{2}$ injection in both the sweep oil zone (EOR) and the underlying saline aquifer (sequestration). It should be noted that the model calibration process is generally a non-unique one particularly when sparse field observations are sparse such as in this case. This typically necessitates an uncertainty analysis to evaluate the range of possible outcomes given the lack of data.

Figure 4-47 shows water breakthrough occurred rapidly and consistently throughout the field in the fifties and the sixties. This was caused by the encroaching water from the saline aquifer that also allowed the production to take place without significant observable reservoir pressure declines. Production in recent years has been associated with approximately $99 \%$ water cut levels indicating that vast majority of the oil produced came exclusively from the swept oil zone. The model is able to mimic these trends with the strong analytical aquifers attached. Once the simulation of the historical production has been completed, the model can be used to estimate the present day fluid (oil and water) distributions and Figure 4-48 shows three-dimensional water saturation distributions determined by the model at various points in time during the 75 -year recovery process. 


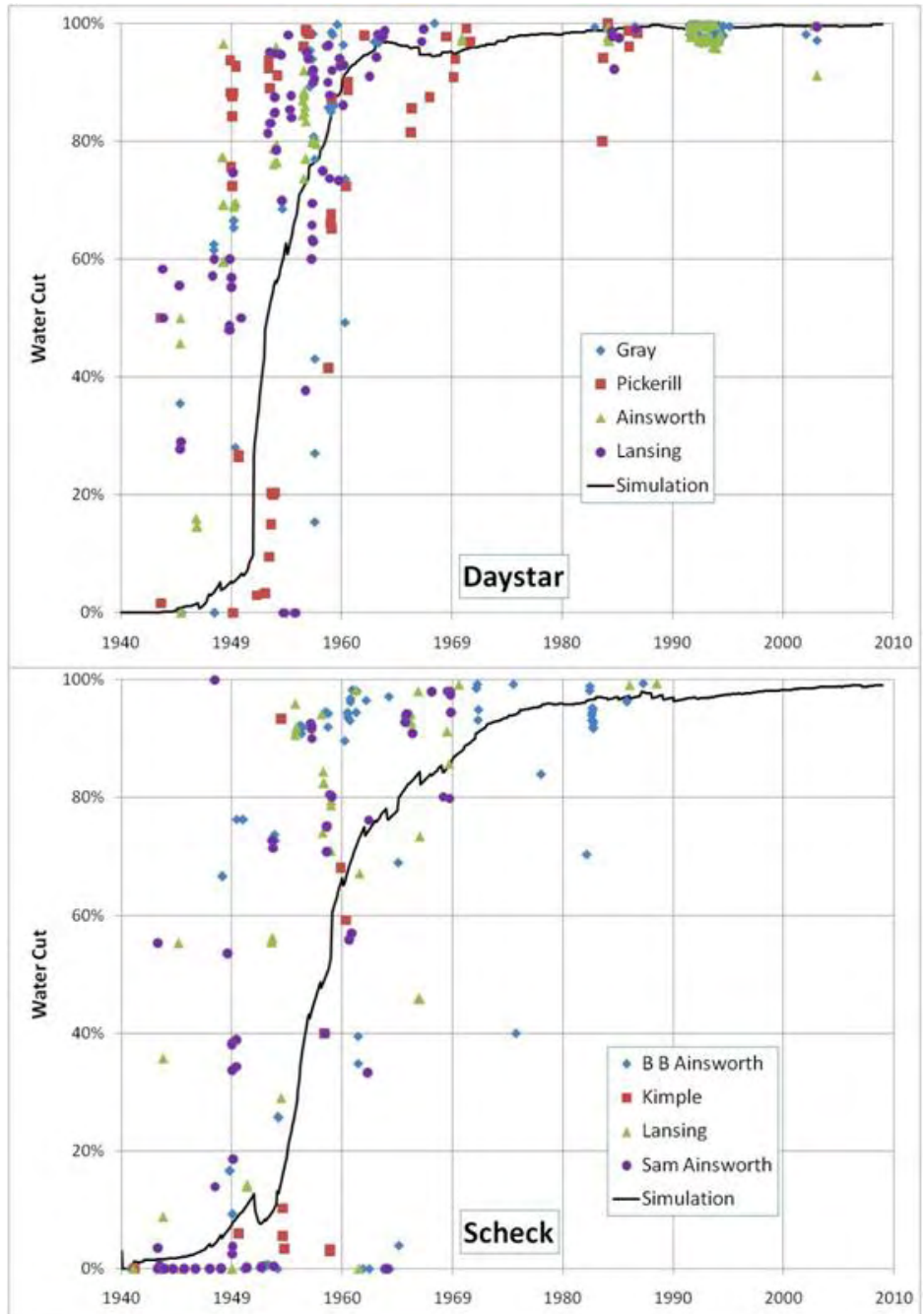

Figure 4-47. Barrel test water and calibrated model water cut profiles. 


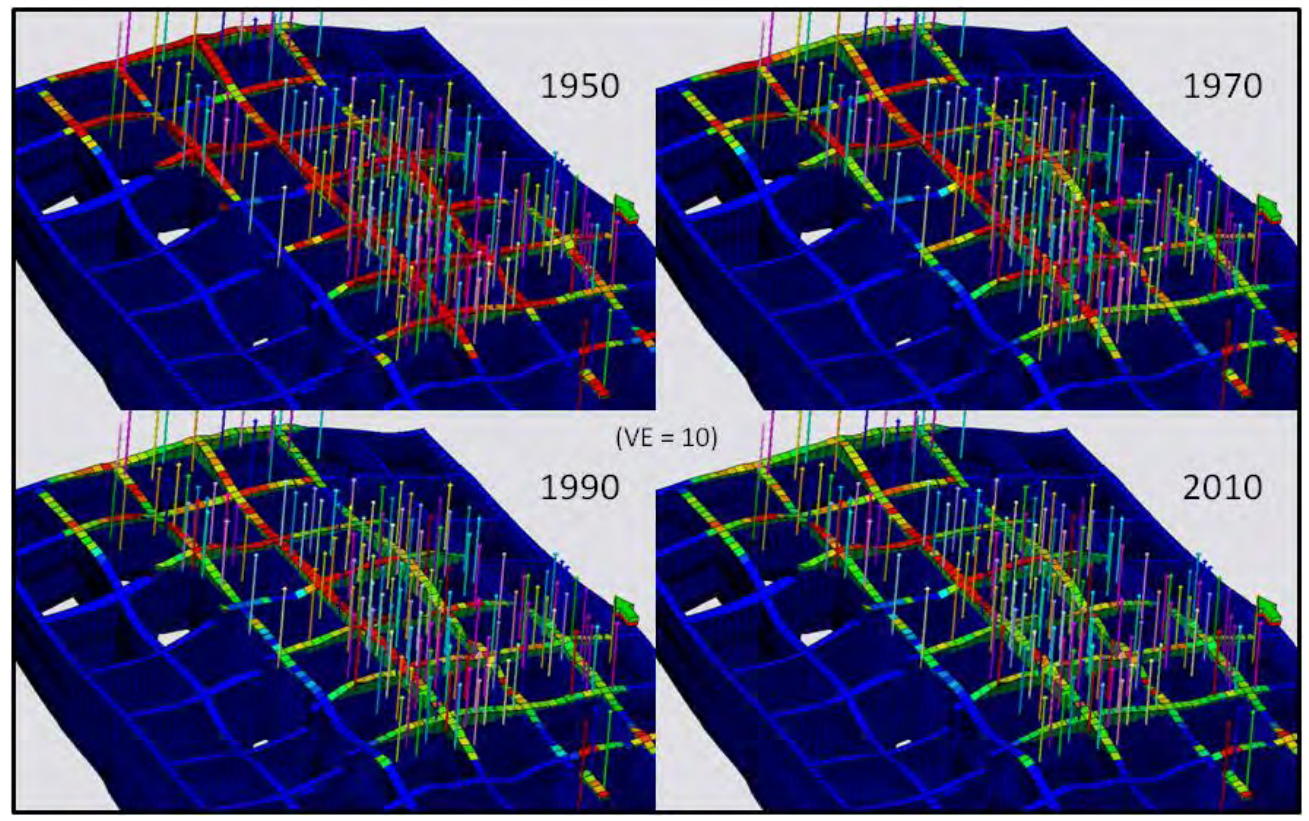

Figure 4-48. Aquifer encroachment progress shown with model generated water saturation distributions.

$\mathrm{CO}_{2}$ injection processes simulated with the calibrated model involve two wells close to the center of the North Dome, one completed near the top of the Arbuckle formation and the other in the saline aquifer underneath (see Figure 4-49).

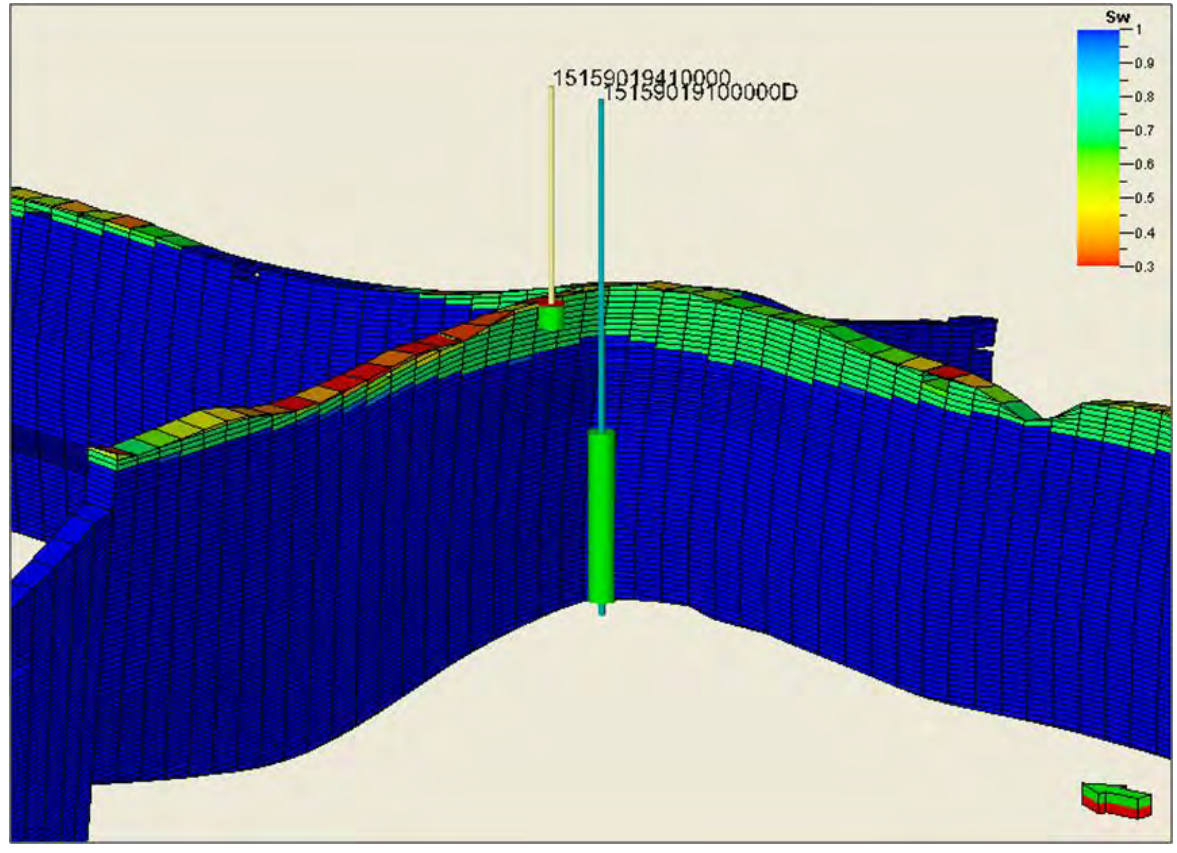

Figure 4-49. $\mathrm{CO}_{2}$ injection well completions in the model. 


\subsubsection{Simulation Results}

A total of 150,000 tons of $\mathrm{CO}_{2}$ is assumed to be available from the ethanol plant annually. Two-third of this is injected into the upper part of the North Dome for EOR and the rest sequestrated in the saline aquifer. Two injection cases have been performed to simulate the $\mathrm{CO}_{2}$ plume development as a result, one for a 3-year injection period and the other for a 20-year injection period. All currently producing wells are assumed to maintain existing productions and the simulation continues for another 50 years in each of these cases to predict the post-injection plume movements.

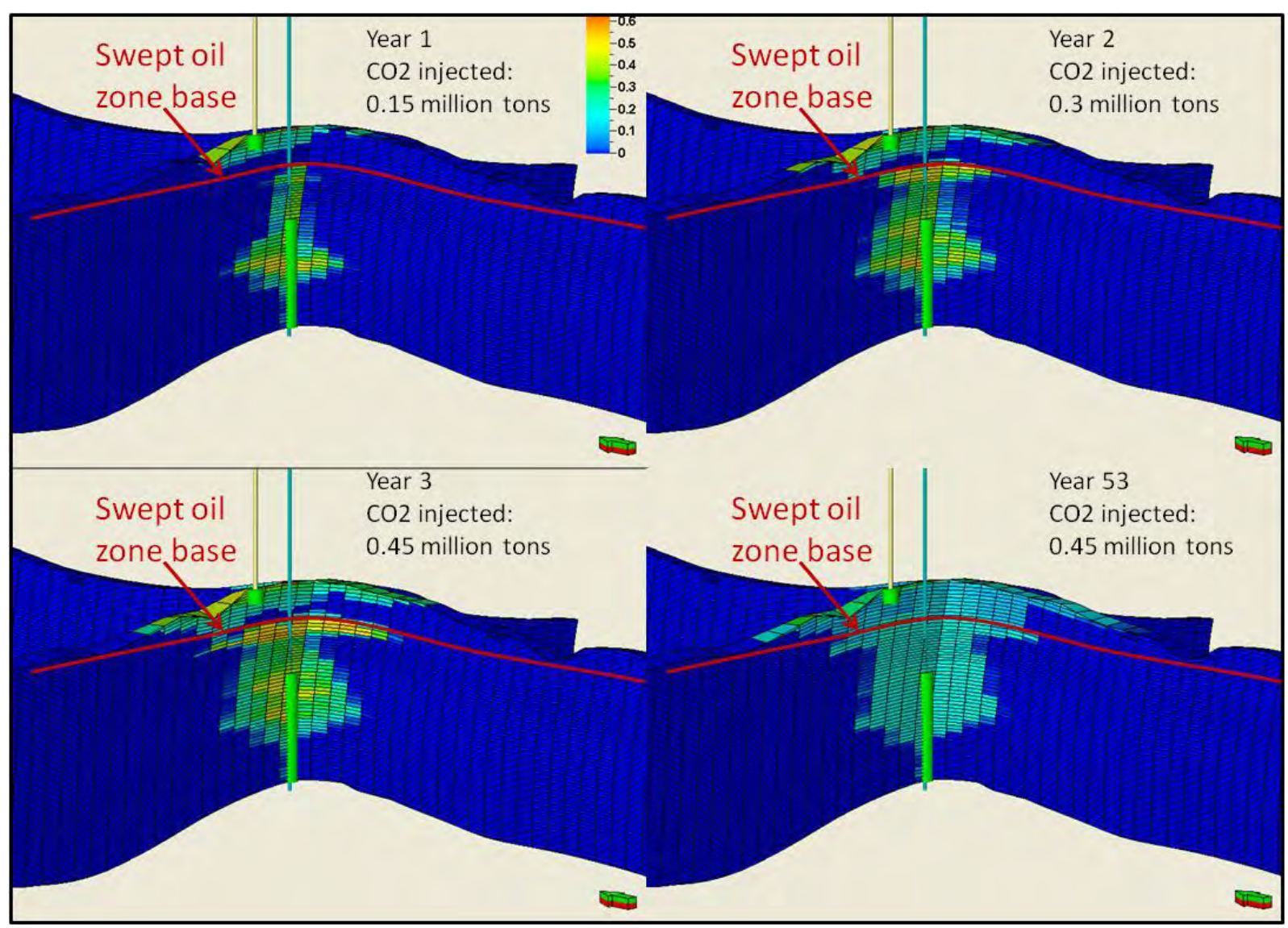

Figure 4-50. Predicted $\mathrm{CO}_{2}$ saturation distributions (3-year injection case)

Figure 4-50 shows predicted $\mathrm{CO}_{2}$ saturation distributions at four points in time in the 3 -year injection case. It shows that the injected $\mathrm{CO}_{2}$ quickly reaches the base of the swept oil zone where it stays and accumulates for a period of time before further penetrating upward. This phenomenon only occurs during the injection of $\mathrm{CO}_{2}$. Figure 4-51 shows the overall plume development with predicted pressure distribution within it. The figure shows the injected $\mathrm{CO}_{2}$ injection to be total contained within the dome structure. 


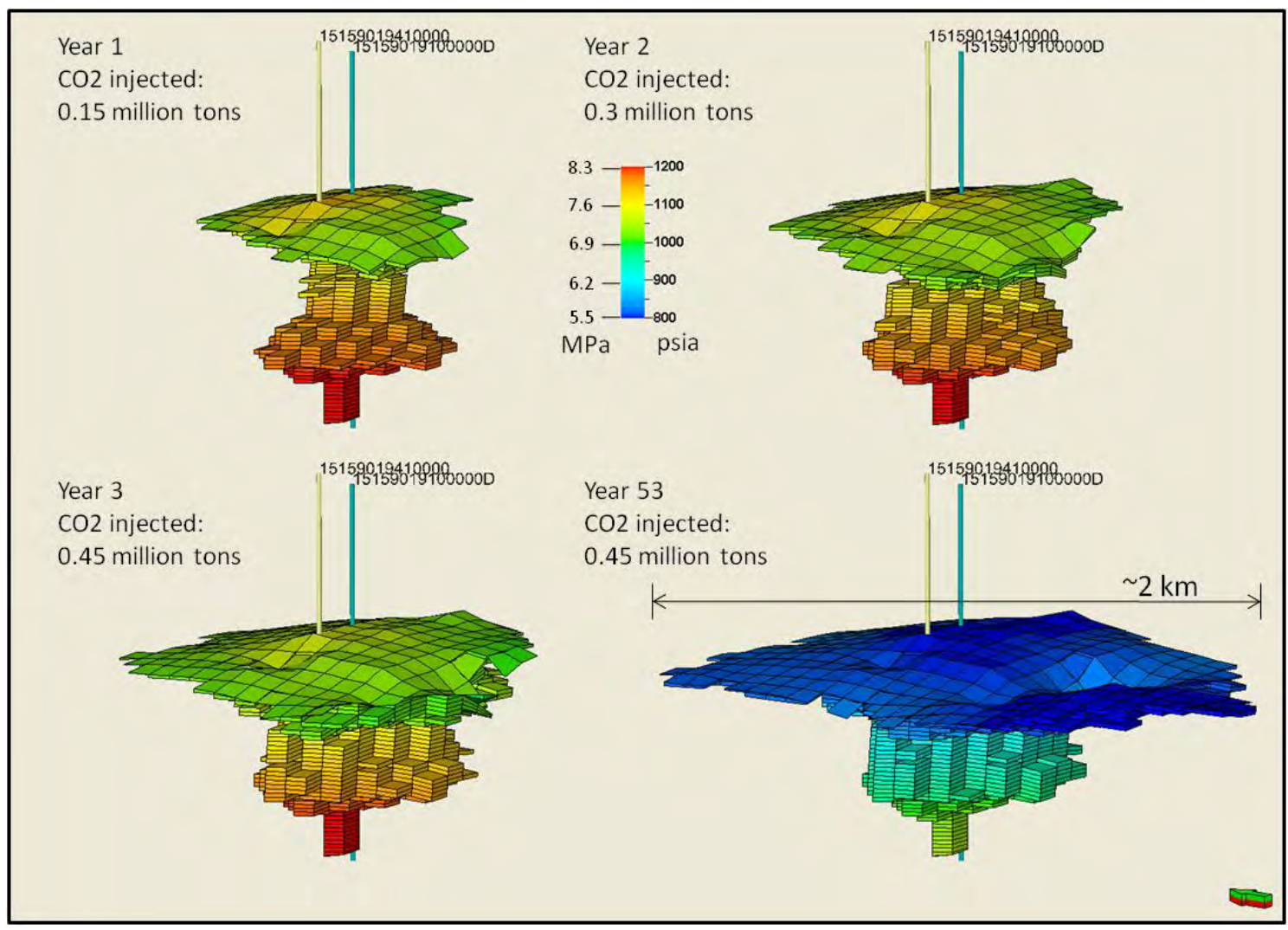

Figure 4-51. Predicted plume growth with pressure distributions (3-year $\mathrm{CO}_{2}$ injection case)

Pressure in the swept oil zone is expected to be lower than in the aquifer due to the ongoing production activities. This leads to substantially lower density levels (see Figure 4-52) and the $\mathrm{CO}_{2}$ is likely to be in gaseous phase. 


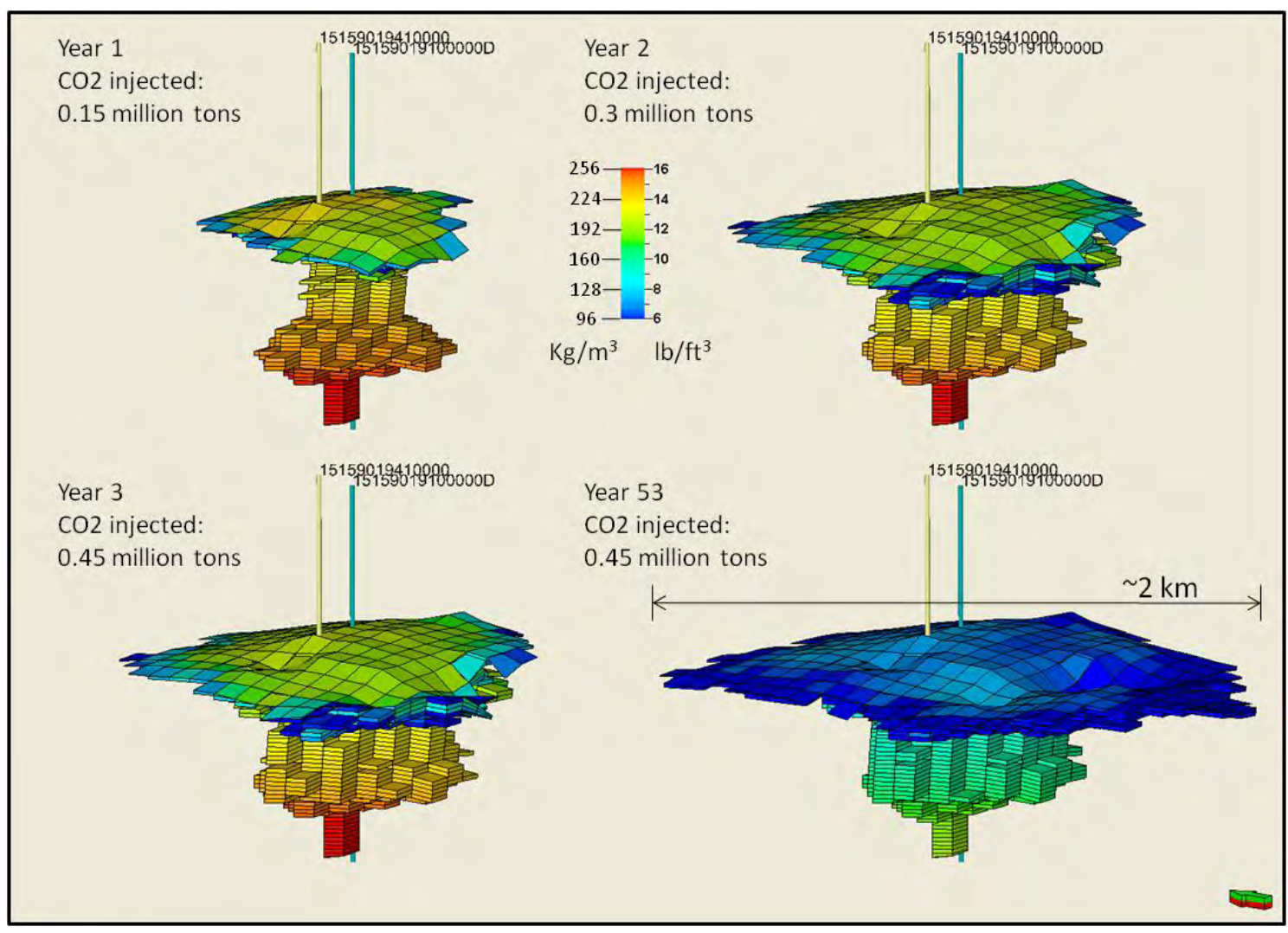

Figure 4-52 - Predicted plume growth with $\mathrm{CO}_{2}$ density distributions (3-year $\mathrm{CO}_{2}$ injection case)

On the other hand, Figure 4-53 the progress of the $\mathrm{CO}_{2}$ plume in the 20-year injection case. It shows the migration of $\mathrm{CO}_{2}$ beyond the structure to begin after 9 years of injection. Figure 4-54 shows the overall production profiles predicted by the conceptual model. The decline in oil production is predicted to be somewhat slowed down during the $\mathrm{CO}_{2}$ injection. However, the model also predicts a fairly rapidly breakthrough of $\mathrm{CO}_{2}$ at the producers largely due to the sub-miscible injection. 


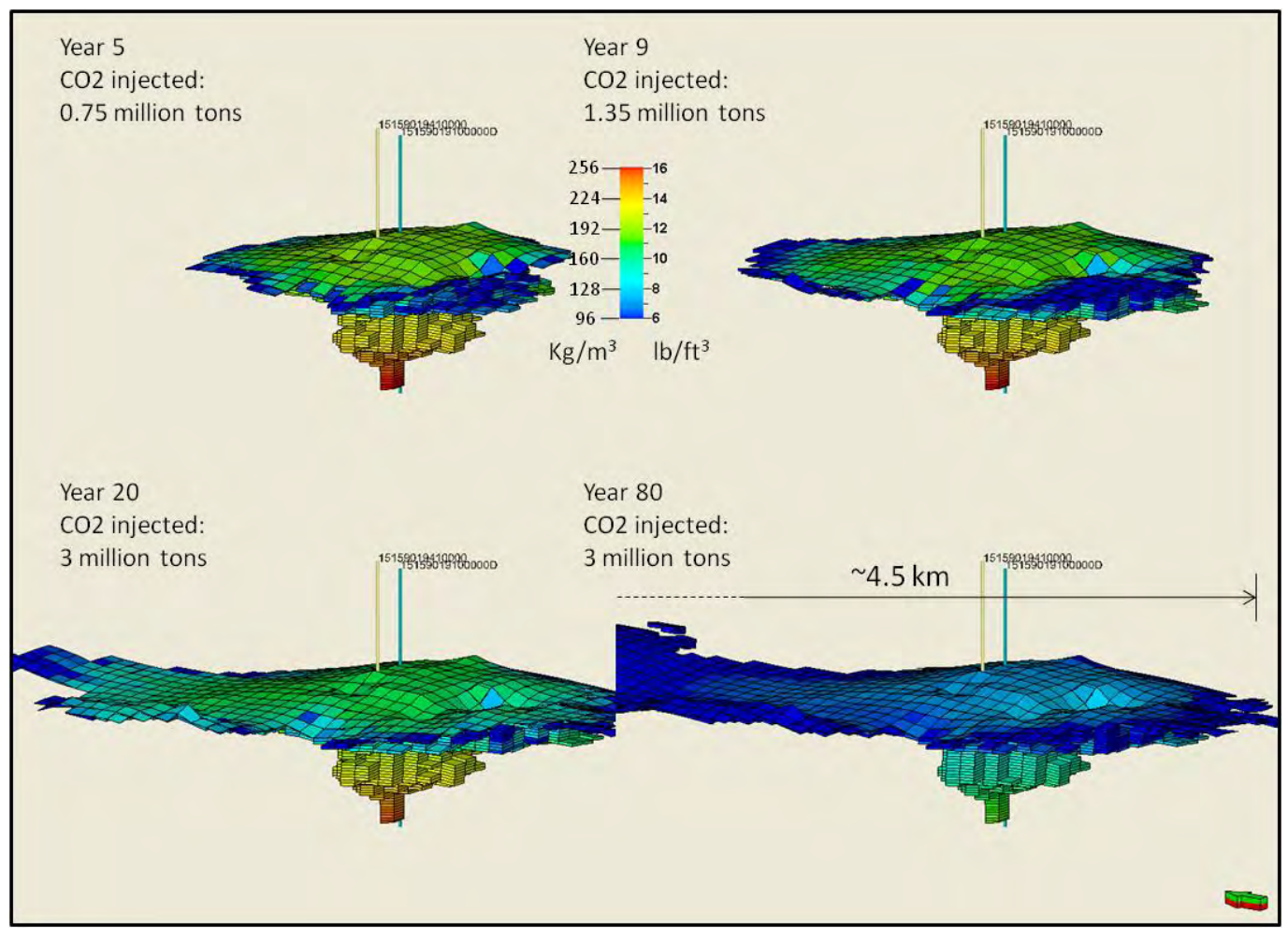

Figure 4-53. Predicted plume growth with $\mathrm{CO}_{2}$ density distributions (20-year $\mathrm{CO}_{2}$ injection case).

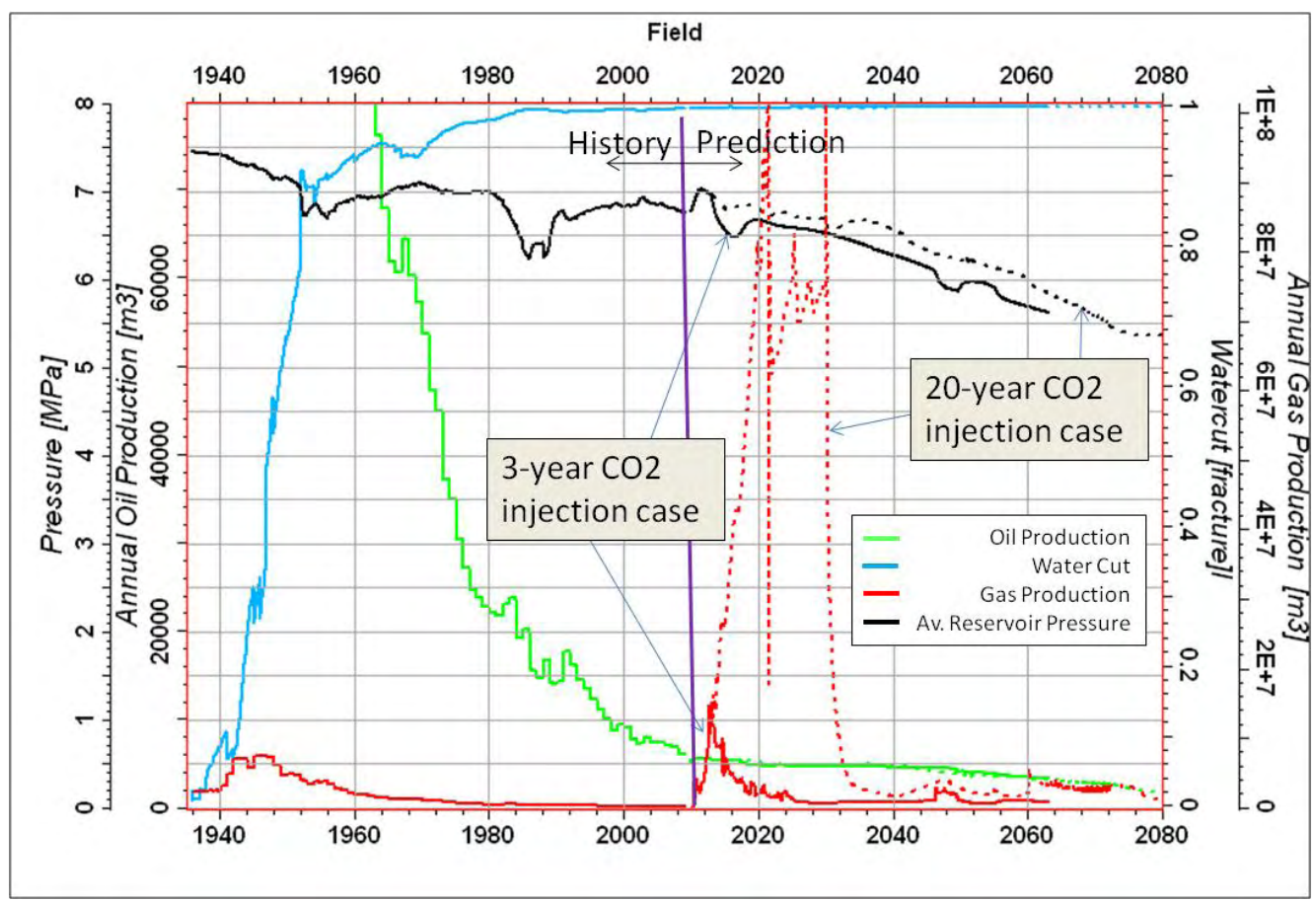

Figure 4-54. Predicted production profiles. 


\section{CHAPTER 5 - EOR with Sequestration Analysis}

\subsection{Geneseo-Edwards $\mathrm{CO}_{2}$ Enhanced Oil Recovery Project}

\subsubsection{Description of Study Area - Regional Setting}

The Geneseo-Edwards project area is situated on the eastern edge of the Central Kansas Uplift (CKU), a prominent structural feature that separates the Salina basin from the Hugoton Embayment of the Anadarko Basin (Figure 5-1). The CKU is predominately post-Mississippian, pre-Pennsylvanian structure formed during the development of the Anadarko basin and the Ancestral Rockies. In places, Precambrian granite is exposed beneath Pennsylvanian on the CKU and younger strata subcrop beneath the pre-Pennsylvanian unconformity away from the CKU (Figure 5-2).

Cambrian-Ordovician-aged Arbuckle strata, the target oil producing zone in the GeneseoEdwards project, subcrops beneath the Pennsylvanian in the project area as it does over much of the CKU.

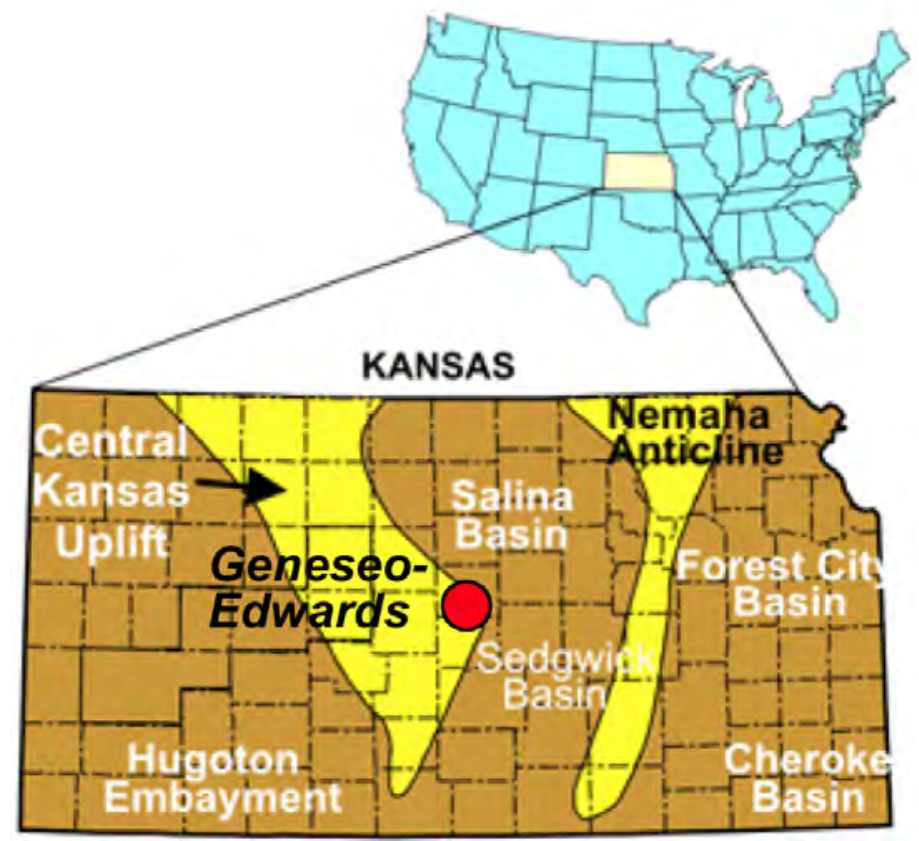

Figure 5-1. Location of Geneseo-Edwards Project and major geologic structural features in Kansas. Modified after [Byrnes et al., 2003]. 


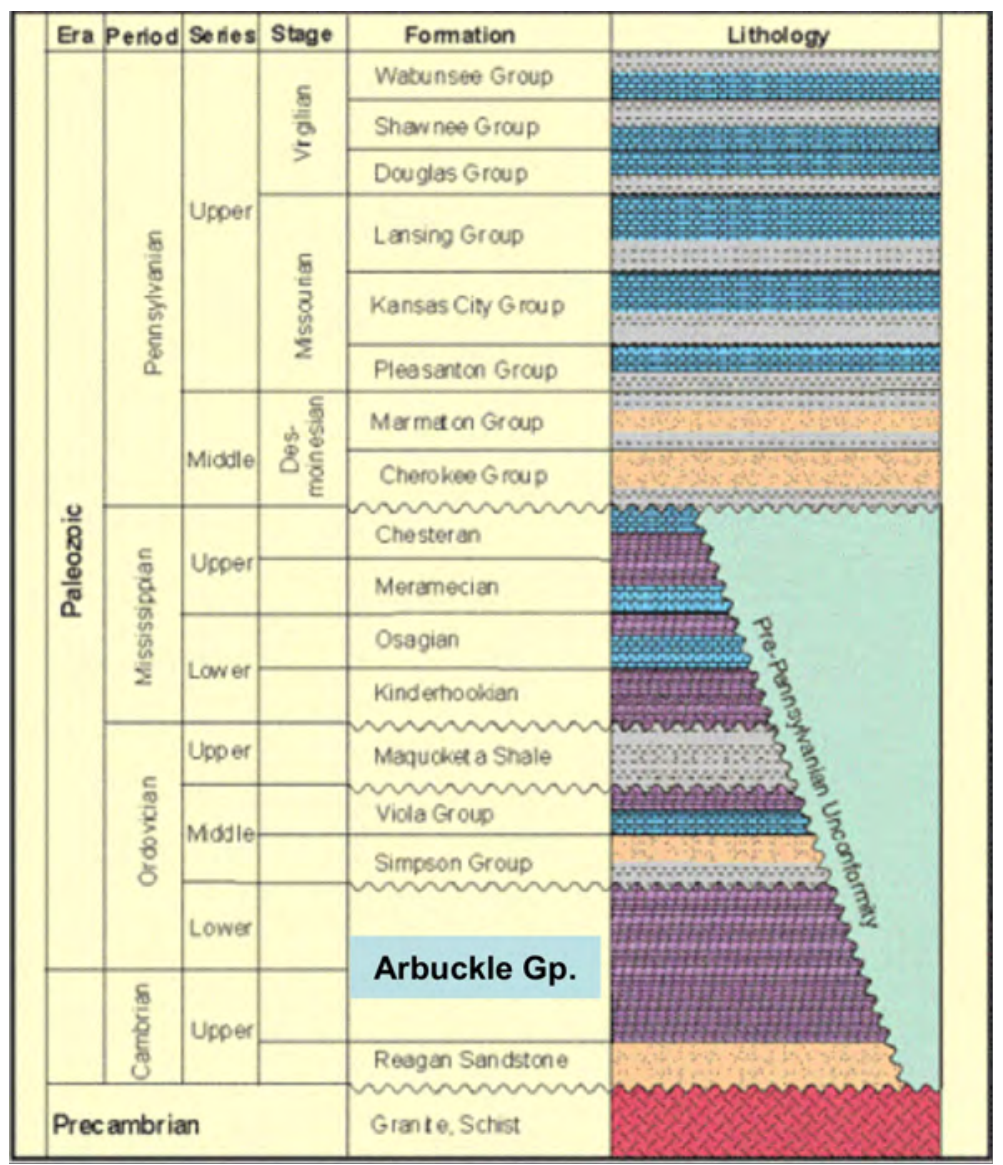

Figure 5-2. Central Kansas stratigraphy (After Cansler and Carr, 2001)

The Arbuckle is the most prolific oil producing strata in Kansas, having produced approximately $37 \%$ of the 6.3 Billion barrels (BBO) of production through 2000 (Figure $5-3$ ). Of the $2.3 \mathrm{BBO}$ cumulative oil in 2000, approximately $1.6 \mathrm{BBO}$ had come from Arbuckle fields on the CKU. Figure 5-4 is a structure map on top of the Arbuckle that show the distribution of oil production from that strata. Most of the high producing fields are on the CKU as illustrated in Figure 5-5. The Geneseo-Edwards project area includes some of the more prolific production in the region.

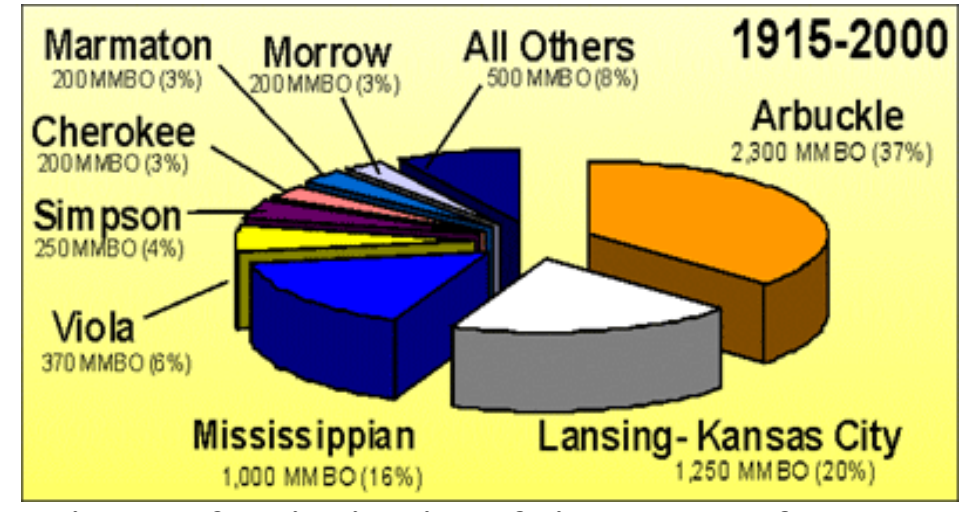

Figure 5-3. Distribution of oil recovered from Kansas reservoirs (Byrnes etal., 2003). 


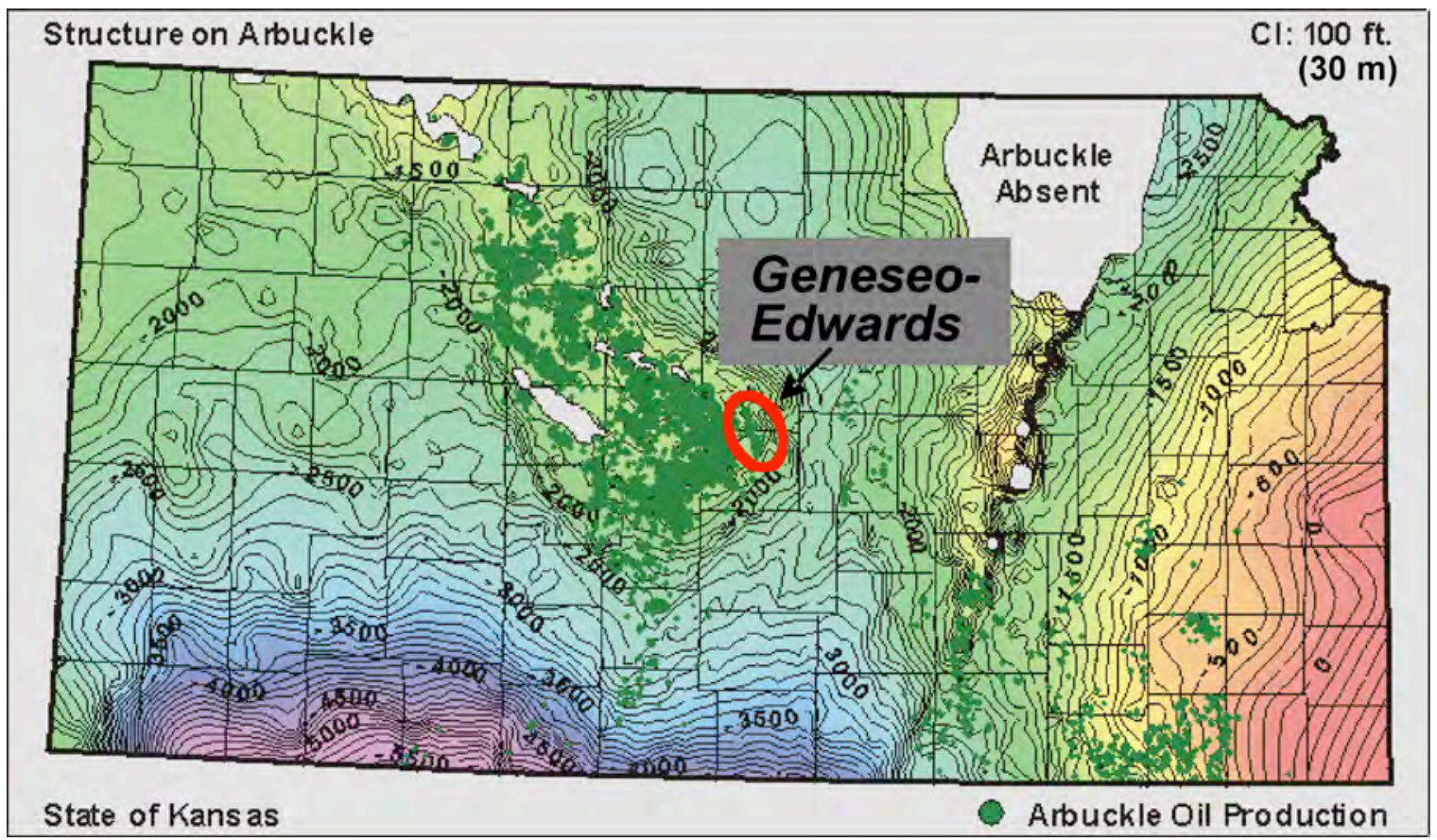

Figure 5-4. Structure map on top of the Arbuckle Group. Arbuckle fields are dark green. (Gerlach 1998), http://www.kgs.ku.edu/DPA/Plays/ProdMaps/arbk_oil.html)

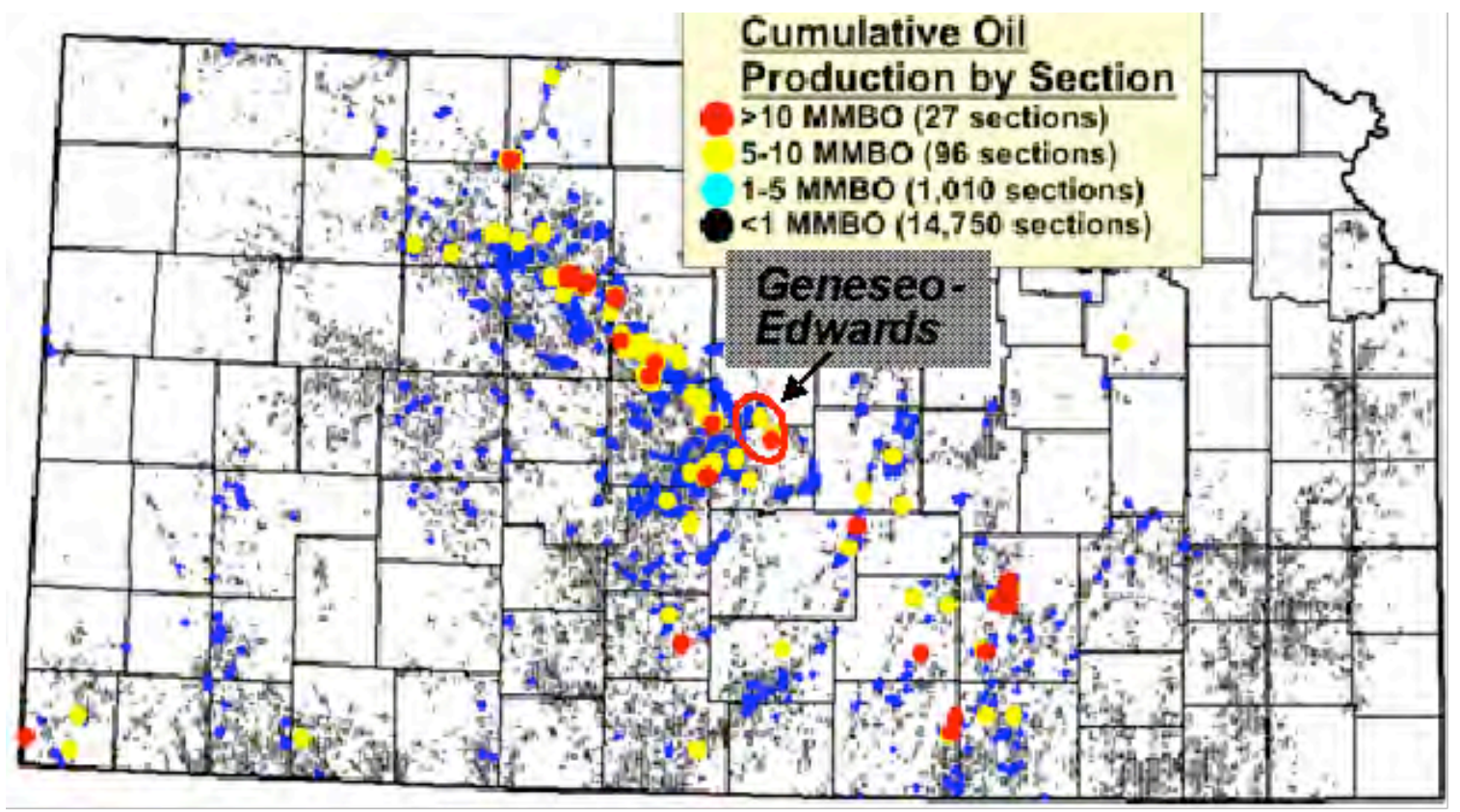

Figure 5-5. Quality of Arbuckle oil production illustrated by cumulative oil per square-mile sections (Gerlach, 1998).

Arbuckle reservoirs are fracture-controlled karstic reservoirs with porosity and permeability influenced by basement structural patterns and subaerial exposure. Subaerial weathering 
and secondary solution significantly enhanced porosity and permeability and created petroleum reservoirs in these strata (Walters 1958, Merriam 1963, Adler 1971, Franseen 1994, Steinhauff et al. 1998, Franseen et al. 2003, and 2004). Reservoir qualities were modified by karst processes during prolonged and repeated subaerial exposure that began after Arbuckle deposition and continued in some areas until the Pennsylvanian (Franseen, et al., 1995). The regional and stratigraphic extent of subaerial exposure and karstification in the Arbuckle was influenced by regional patterns of uplift and subsidence (Newell et al., 1987). The CKU, including the Geneseo-Edwards project area were more heavily karsted than downdip regions where younger strata cover the Arbuckle.

Oil migrated north from the source, the Woodford shale, in the deep Anadarko Basin, and into the prominent southeast northwest trending Central Kansas Uplift where it filled Arbuckle structures to the spill point (Walters, 1958) (Figure 5-6). Downdip fields filled with gas due to gravity separation and oil continued updip to fill karsted and faulted dome-like structures, including the Geneseo and Edwards fields (cross section F-G).
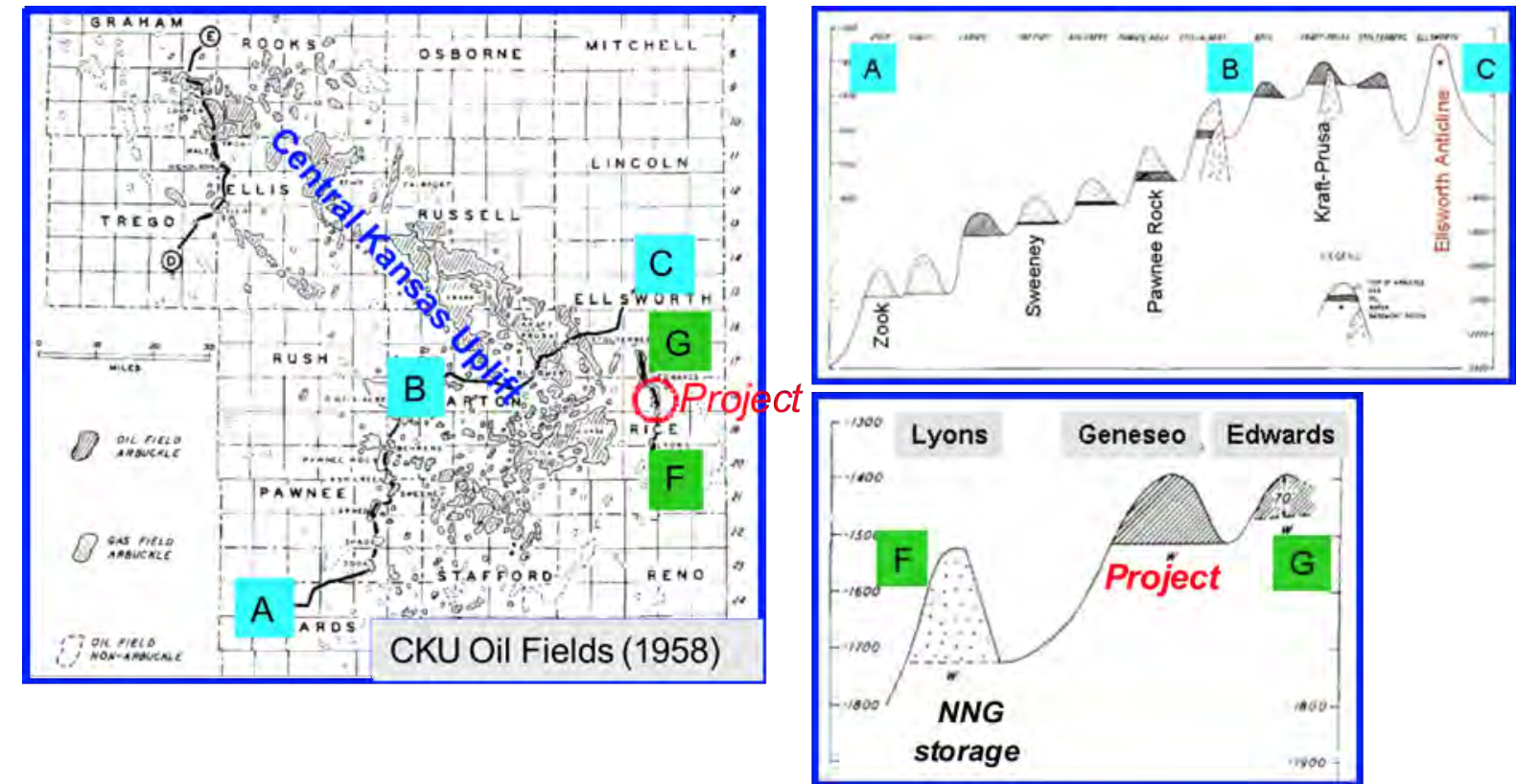

Figure 5-6. CKU oilfields in 1958 in map and cross section view. Cross-hatched patterns indicate oil fields and stippled pattern indicates gas fields.

\subsection{2 $\mathrm{CO}_{2}$ Source and Pipeline Plan}

The source of $\mathrm{CO}_{2}$ for the proposed project is the 40-million-gallon-per-year ethanol plant located 2 miles (3.2 kilometers) south of Lyons, Kansas, owned and operated by Kansas Ethanol. An average of $7.5 \mathrm{mmcfd}$ of ninety-six $\% \mathrm{CO}_{2}$ would be captured and compressed onsite to approximately 1600 psia and delivered by 16 miles (26 kilometers) of 4.5 inch OD steel pipeline to the project area at approximately 1400 psia. Fourteen of the 16 miles (26 kilometers) is on existing pipeline ROW corridors. A separation, capture and recycling system is part of the operations design plan. 


\subsection{Geneseo-Edwards EOR Site}

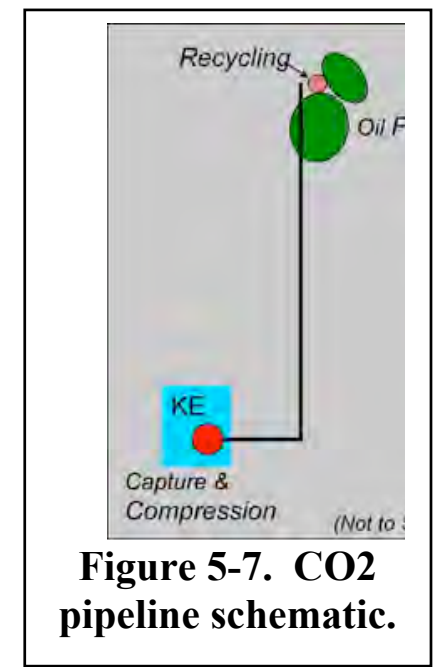

The Geneseo-Edwards project site for EOR concurrent $\mathrm{CO}_{2}$ sequestration is in the southern part of the 14-mile (23 kilometer) long, 1-1/2 mile (2.4 kilometer) wide GeneseoEdwards field (Figure 5-7). The field is an active oil field situated in a gently rolling agricultural landscape comprised mostly of grasslands used for cattle grazing.

The field is a series of eight domed structures forming a narrow, faulted anticline. The project site encompasses the two southernmost domes (Figures 5-8 and 5-9). Project site leases have produced 30 million barrels of oil since 1936, 34\% of field's 89 million barrels of cumulative oil production. Nearly all production has come from the upper part of the $600 \mathrm{ft}$-thick CambrianOrdovician Arbuckle Group. The two project domes have approximately 120 feet of structural closure and $120-\mathrm{ft}$ original oil column at the apex. The drive mechanism is a strong bottom-water aquifer, bottom hole pressure is 1100 psi, and pressure has not been depleted by production. The current production rate for the 60 remaining active wells in the project area averages approximately 3 $\mathrm{BOPD} /$ well and $98 \%$ of the fluid produced is saltwater, which is disposed by injection into the lower Arbuckle, off structure, in Class II disposal wells. The lower Arbuckle has very high injectivity, with one well in the area accepting as much as 10,000 BWPD on a vacuum. (Matt Osborne, Daystar Petroleum, personal communication).

\subsubsection{Production History}

Initial production in the project are was established in 1936 with a flurry of activity that spread to a total of 23 wells on 10 leases in the area shown in Figure 5-9. Production peaked in 1942 following significant expansion in development in the two prior years (Figure 5-10). Cumulative production for the area was 33.7 mmbo through 2009 with an estimate $85-90 \%$ of the oil having come from the Arbuckle. The balance of the oil is from the shallower Simpson and Lansing and Kansas City Groups. The two domes where the project is focused are estimated to have produced a combined $30.2 \mathrm{mmbo}$, of which $26.3 \mathrm{mmbo}(87 \%)$ is estimated to have been produced from the Arbuckle. Production data was compiled from the Kansas Geological Survey database and publicly historical hard copy vendor data. 


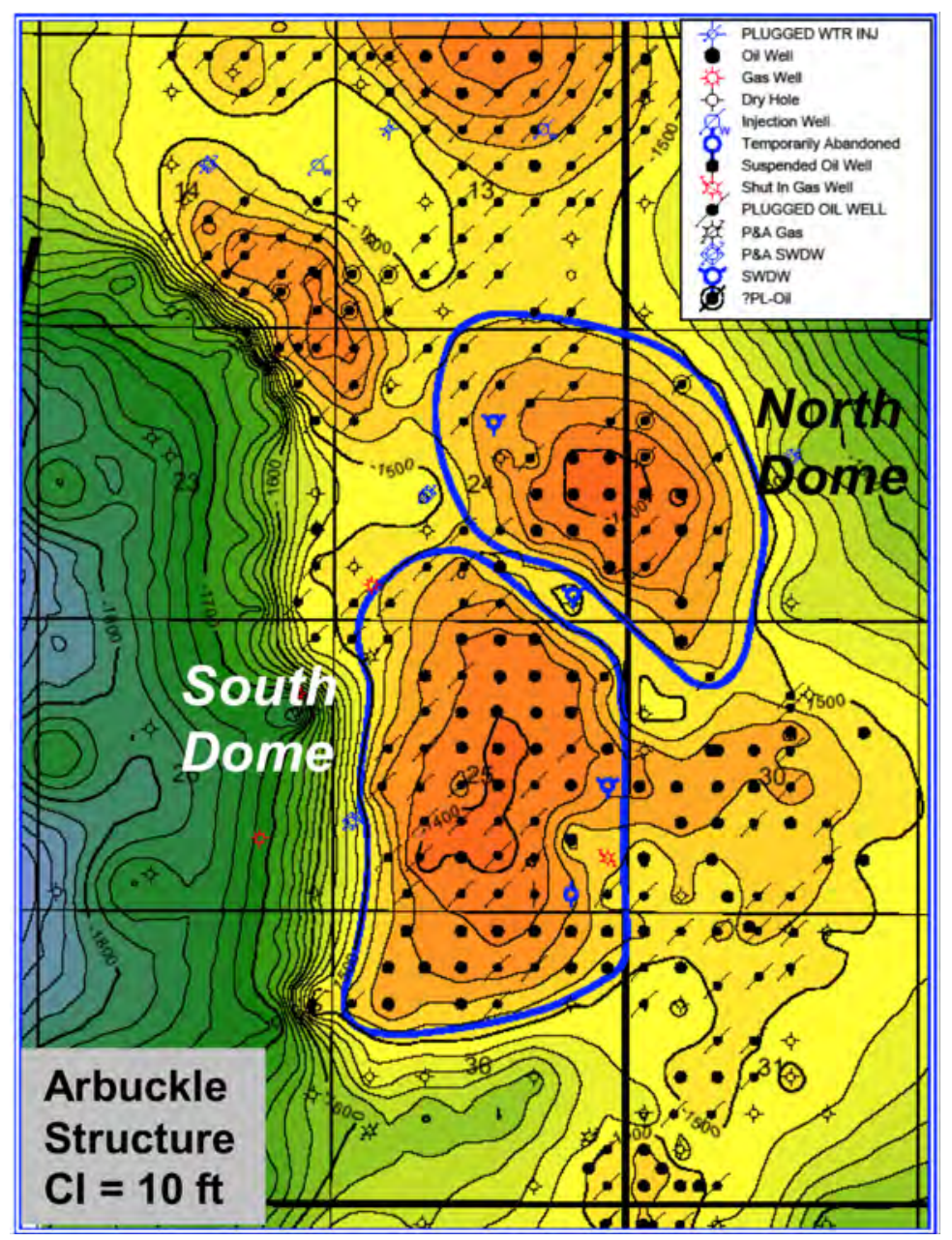

Figure 5-9. Arbuckle structure map in two-dome proposed Phase II project area. Proposed EOR project areas are outlined.

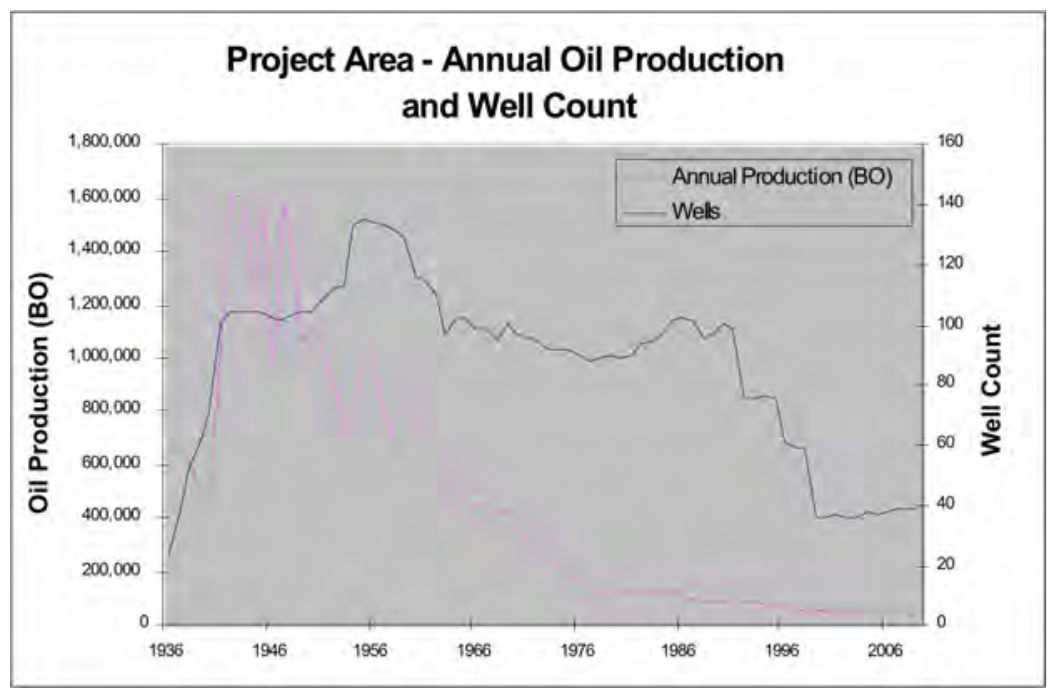

Figure 5-10. Annual production and well count for area shown in Figure 5-9. 


\subsubsection{Long-Term Implications}

The proposed southern Geneseo-Edwards project is considered a proof-of-concept for developing a commercial market for much larger volumes of $\mathrm{CO}_{2}$, and what could become a very large-scale $\mathrm{CO}_{2} \mathrm{EOR} /$ sequestration play. Based on preliminary modeling, discussed in Section 5.2, the project will use 3.5 years of $\mathrm{CO}_{2}$ from the nearby ethanol plant (15 months to fill the smaller of the two domes and 27 months to fill the larger of the domes, shown in Figure 5-9) and produce 6 mmbo over a 10-12 year period. The proposed project plans to inject the $\mathrm{CO}_{2}$ in the southern two of eight domes in the Geneseo-Edwards field. Should this project prove to be successful, an additional 12 mmbo could be recovered from the other six domes in the field, utilizing another 6.3 years supply of $\mathrm{CO}_{2}$ from the ethanol plant and permanently storing an additional 0.9 million tonnes $\mathrm{CO}_{2}$.

The overarching project plan contemplates securing additional sources of anthropogenic $\mathrm{CO}_{2}$ and expanding to nearby fields (Figure 5-11). To be considered are extending a pipeline from Coffeyville Resources Fertilizer or aggregating $\mathrm{CO}_{2}$ from ethanol plants in the Kansas-Nebraska region and bring that $\mathrm{CO}_{2}$ to the Central Kansas

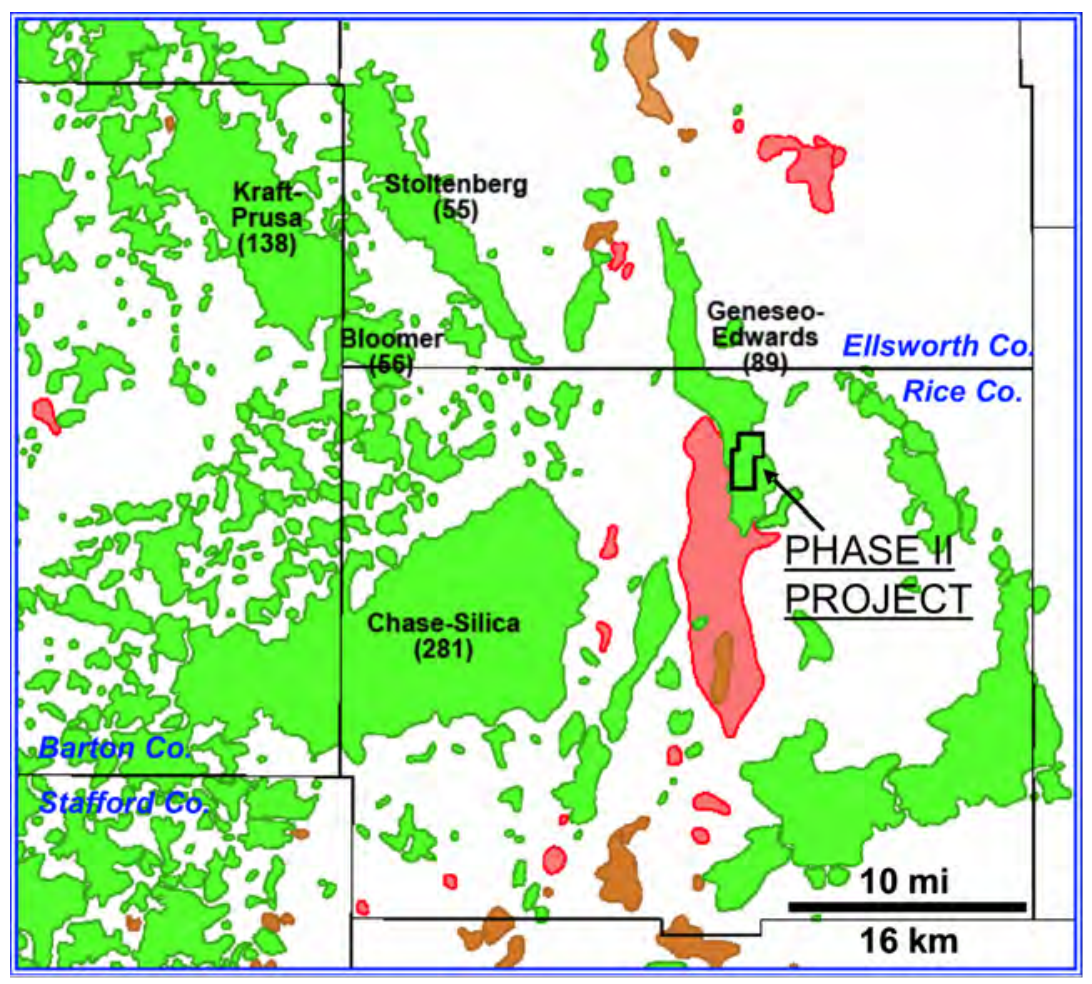

Uplift. Table 5-1 illustrates theoretical oil recovery and $\mathrm{CO}_{2}$ stored from GeneseoEdwards and nearby Arbuckle fields applying results from a preliminary engineering study conducted by CAP $\mathrm{CO} 2$ and Epic Consulting, a division of Baker-Hughes Canada. From that study, the $\mathrm{CO}_{2}$ utilization is $1.6 \mathrm{mcf}$ purchased/BO recovered and the oil recovery factor works out to be $23 \%$ of cumulative oil

produced. It is estimated that $87 \%$ of the oil produced in the project area is from the Arbuckle and the balance from other zones, mostly the Lansing-Kansas City. To be conservative, an $80 \%$ factor is used on the other fields.

Figure 5-11. Geneseo-Edwards and other Arbuckle fields in the Phase II project area and cumulative production (million $\mathrm{BO}$ ). 


\begin{tabular}{|c|c|c|c|c|c|c|}
\hline & & & & & & \\
\hline & \multicolumn{3}{|c|}{ Cumulative Oil (mmbo) } & \multicolumn{2}{|c|}{$\mathrm{CO} 2$ stored } & \multirow[b]{2}{*}{$\begin{array}{c}\text { Ethanol } \\
\text { plant } \\
\text { years }\end{array}$} \\
\hline & Gross & Arbuckle & $\begin{array}{l}\text { CO2 } \\
\text { EOR }\end{array}$ & mmcf & $\begin{array}{l}\text { Million } \\
\text { Tonnes }\end{array}$ & \\
\hline DOE Project & 30.2 & 26.3 & 6.1 & 9,613 & 0.50 & 3.5 \\
\hline Balance Geneseo-Edwards & 59.2 & 47.4 & 11.0 & 17,311 & 0.90 & 6.3 \\
\hline Stoltenberg & 55.1 & 44.1 & 10.2 & 16,112 & 0.84 & 5.9 \\
\hline Bloomer & 55.8 & 44.6 & 10.4 & 16,316 & 0.85 & 6.0 \\
\hline Kraft-Prusa & 137.8 & 110.2 & 25.6 & 40,294 & 2.09 & 14.7 \\
\hline \multirow[t]{2}{*}{ Chase-Silica } & 280.6 & 224.5 & 52.1 & 82,050 & 4.26 & 30.0 \\
\hline & 618.7 & 497.1 & $\overline{115.3}$ & 181,695 & 9.4 & 66.4 \\
\hline
\end{tabular}

Table 5-1. Theoretical recovery and $\mathrm{CO}_{2}$ stored from Geneseo-Edwards and nearby Arbuckle fields. Production from public database: http://www.kgs.ku.edu/PRS/petroDB.html

Although the ethanol plant is adequate to supply $\mathrm{CO}_{2}$ for the Geneseo-Edwards and process that field over a 10 -year period, if successful at proving the concept, it is evident that just the other Arbuckle fields in the immediate vicinity are a sufficiently large enough market for a commercial pipeline the size of which would bring in $\mathrm{CO}_{2}$ from Coffeyville Resources Nitrogen Fertilizer plant $(40 \mathrm{mmcfd})$. Fields in Figure 5-11 and Table 5-1 would require 12 years of CVR supply and they combine for approximate $31 \%$ of the Arbuckle production on the CKU. In addition to the Arbuckle, the Lansing-Kansas City has $\mathrm{CO}_{2}$ EOR potential for horizontal, piston-style displacement in depleted waterfloods, particularly in the Hall-Gurney and Trapp fields located 40 miles (64 kilometers) to the northwest. Those fields and those in Table 5-1 and Figure 5-11 are listed as potential targets (Figure 5-12) in a DOE-sponsored White Paper report (2010). 


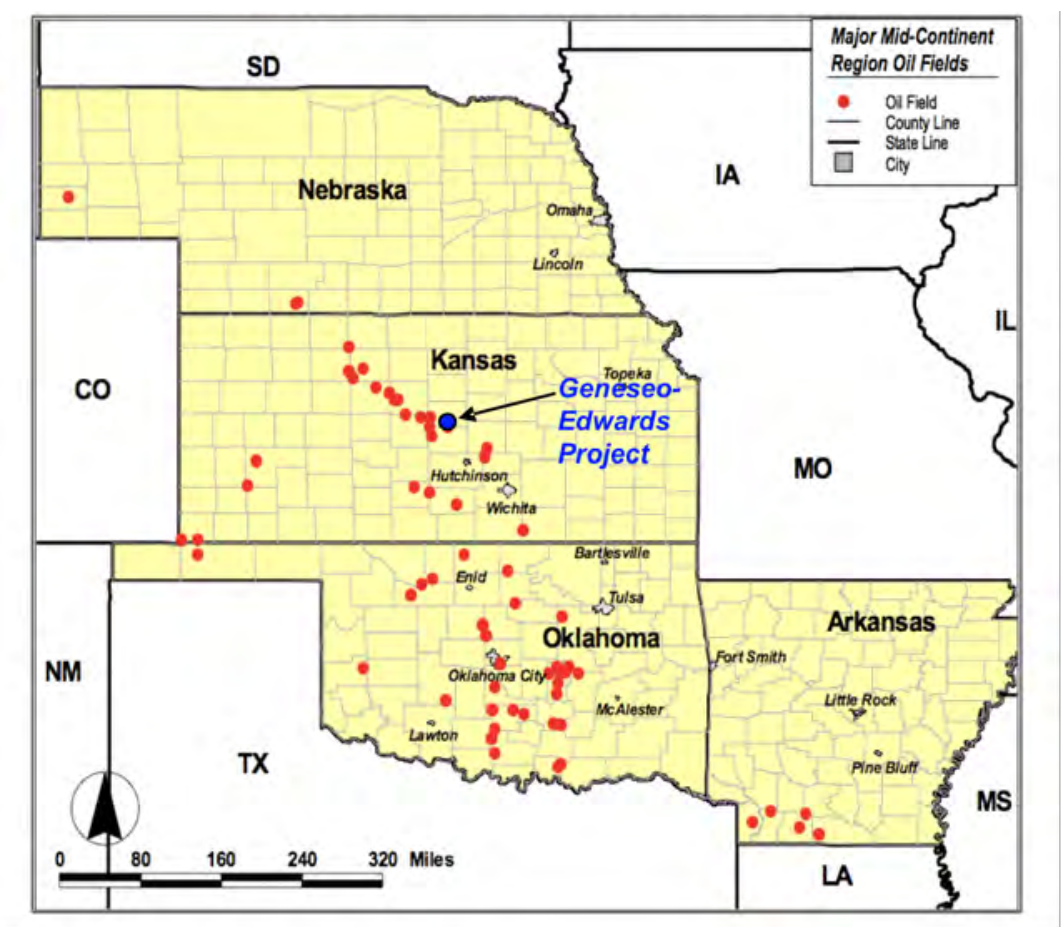

Figure 5-12. Large fields amenable to $\mathrm{CO}_{2}$ EOR based on ARI White Paper. (modified from ARI, 2010).

\subsection{Pre-modeling Preliminary Gravity-Stable Feasibiltiy Study}

\subsubsection{Study Objectives}

EPIC Consultants, Calgary, a division of Baker-Hughes Canada, was selected to work with $\mathrm{CAP} \mathrm{CO} 2$ technical staff to conduct a preliminary engineering study for a potential gravity-stable $\mathrm{CO}_{2} \mathrm{EOR}$ project because of their experience in gravity-stable $\mathrm{CO}_{2}$ flood projects in Canada. The full EPIC report is available in their March 2010 report, Geneseo-Edwards Arbuckle Immiscible CO2 Feasibility Study. The key objectives of the study were to address the following:

1. Estimate the efficiency of near-miscible effects. Reservoir pressure is fixed at $1100 \mathrm{psi}$ and average MMP is $1389 \mathrm{psi}$.

2. Determine whether the flood could be operated in the $\mathrm{CO}_{2}$ super-critical state

3. Evaluate the effectiveness of the bottom water drive for consistency in oil/water contact movement, in order to determine whether gravity-stable process is feasible

4. Basic volumetric and material balance engineering

5. Estimate residual oil saturation

6. Provide a preliminary forecast of $\mathrm{CO}_{2}$ injectivity and overall requirements

7. Recommend a preliminary operational plan

8. Provide a preliminary flowstream forecast 


\subsubsection{Key findings}

Key finding from EPIC report are shown in Figure 5-13, below:

Present volumes were calculated at $-1510 \mathrm{ft}$ subsea oil-water-contact with three dome boundary polygons restricting some lower oil in the area

\begin{tabular}{|c|c|}
\hline $\begin{array}{c}\text { OOIP, original oil in } \\
\text { place, within 3 dome } \\
\text { boundaries (MMbbls) }\end{array}$ & $\begin{array}{c}\text { ROIP, current oil in place } \\
\text { (MMbbls) }\end{array}$ \\
\hline 66 & 38 \\
\hline
\end{tabular}

- The proposed process will be a near miscible process with an MMP value of $\sim 1350$ psi, calculated by slim -tube tests and confirmed with correllations .

- Using correlations, the following results on residual saturation were found:

\begin{tabular}{|c|c|c|}
\hline $\begin{array}{c}\mathrm{S}_{\text {orw, residual oil }} \\
\text { saturation after } \\
\text { waterdrive }\end{array}$ & $\mathrm{S}_{\text {orm }} / \mathrm{S}_{\text {orw }}$ & $\begin{array}{c}\mathrm{S}_{\text {orm, residual oil }} \\
\text { saturation afternear } \\
\text { miscibleflood }\end{array}$ \\
\hline 0.38 & 0.46 & 0.175 \\
\hline
\end{tabular}

Figure 5-13. Key findings 1, copied from Epic Consulting Services (written communication) report.

\subsubsection{Discussion}

The EPIC report included three domes, two of which were evaluated and included in this IMCCS study. Current water saturation was based on their internal proprietary algorithm (ResWorks ver.2008c@) that is based on empirical data (Stoain, 1996). Inputs are basic reservoir data including porosity $(11 \%)$, average permeability $(900 \mathrm{md})$, and initial water saturation (30\%), and rock type (carbonate). EPIC's estimated Sorw $=$ $38.1 \%$ is very close to CAP CO2's estimated Sorw $=38.9 \%$, based on material balance, and also consistent with reservoir simulation (Sorw $=36 \%$ ) in a 3D model by Schlumberger (Figure 5-14). 


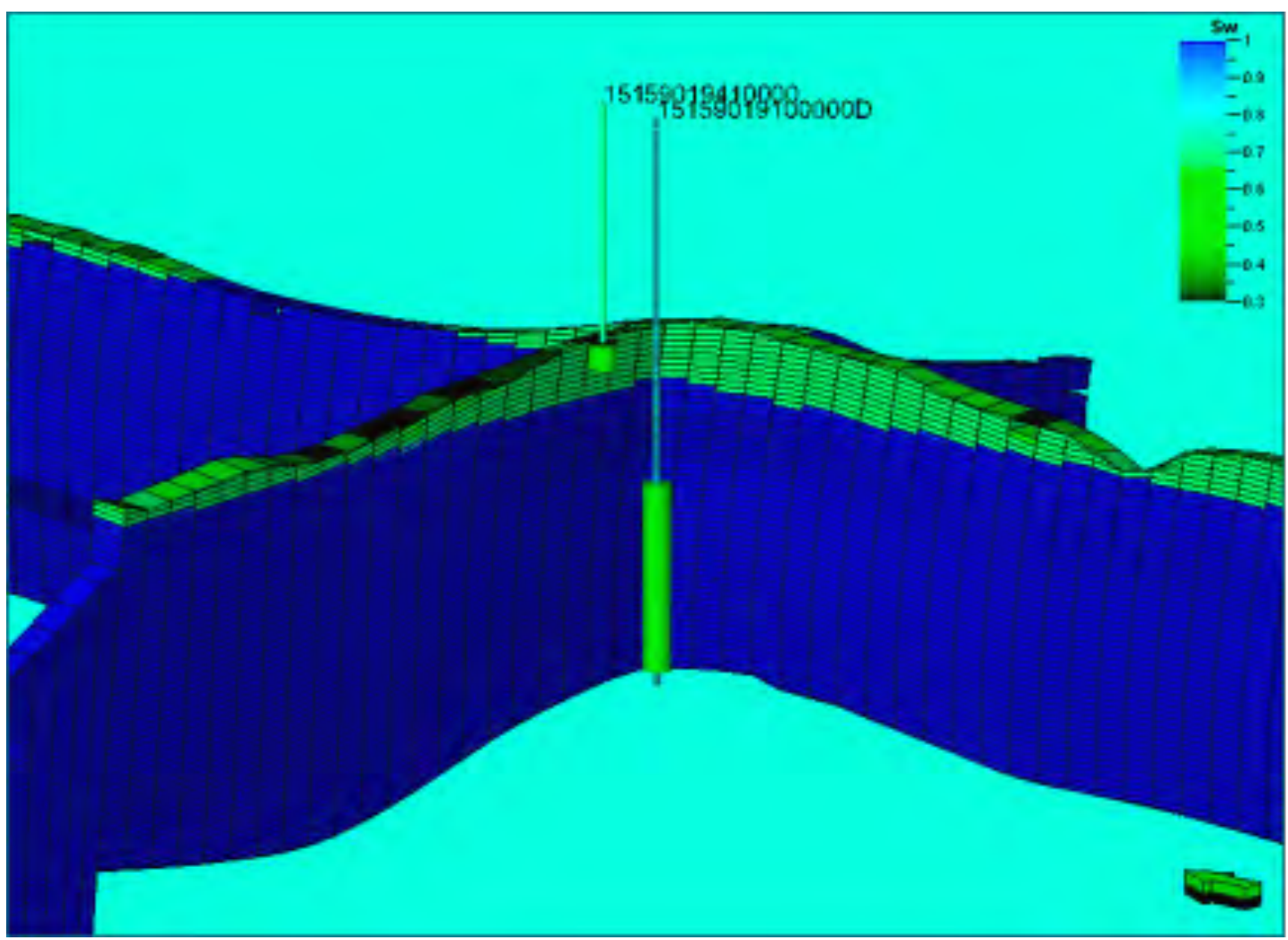

Figure 5-14. Present water saturation in 3D cellular model from numerical simulation performed by project partner Schlumberger Data and Consulting Services. Average water saturation is $64 \%$ (Sorw $=36 \%)$.

The ratio of residual oil to immiscible $\mathrm{CO}_{2}$ (Sorm) to Sorw was calculated using the Exxon/Lange solubility correlation in SPE 35425 (Lange, 1998; Teletzke, 2005). The Lange algorithm is based on empirical correlations and inputs are oil properties and reservoir conditions. Results for two oils sampled, one from each dome, show little variation in Sorm (Table 5-2.). Lange correlations would have predicted an MMP of 1338.5 , very close to the lower of the two MMP's.

\begin{tabular}{|l|l|l|}
\hline & $\underline{M}(1356 \mathrm{MMP})$ & $\underline{M}(1421 \mathrm{MMP})$ \\
\hline ägas & 1.79 & 1.79 \\
\hline äoil $_{\text {oil }}$ & 6.54 & 6.55 \\
\hline äoil - ägas & 4.76 & 4.77 \\
\hline Sorm $_{\text {Sorw }}$ & 0.46 & 0.46 \\
\hline Sorm (\%) & 17.54 & 17.59 \\
\hline
\end{tabular}

Table 5-2. Miscibility calculation results

Theoretical Sorm can only be attained in laboratory conditions and the efficiency of the sweep in a gravity-stable flood is, in part, a function of coning, or how consistently horizontal can the $\mathrm{CO}_{2}$ gas cap / oil-water contact can be maintained (Patel, 1994). The 
degree of coning is a judgment call. Based on a study of the movement of the oil/water contact through production history, EPIC estimates the coning factor (Ev, coning) to be 0.6. That is, the sweep efficiency is $60 \%$, and $60 \%$ of the oil between Sorw and Sorm could be recovered. The last factor in estimating overall recovery is the sweep efficiency of the "waterflooding" or by the active water drive. The average for the three domes investigated was calculated to be 0.917 . Calculation steps for estimating recovery from $\mathrm{CO}_{2}$ are given below:

Recovery Factor after flooding (water drive) $=\mathrm{RF}=\mathrm{E}_{\mathrm{d}} * \mathrm{E}_{\mathrm{v}}$

$\mathrm{E}_{\mathrm{V}}$ is the only value a reservoir engineer can change

$\mathrm{E}_{\mathrm{D}}=($ Soi - Sorw $) /$ Soi $=(0.7-0.381) / 0.7=0.456$

$\mathrm{Ev}=\mathrm{RF} / \mathrm{E}_{\mathrm{D}}=0.418 / 0.456=0.917$

Recovery Factor after $\mathrm{CO}_{2}$ Flood $=\mathrm{RF}=\mathrm{E}_{\mathrm{d}} * \mathrm{E}_{\mathrm{v}}$

$\mathrm{E}_{\mathrm{D}}=($ Sorw - Sorm $) /$ Sorw $=(0.381-0.175) / 0.381=0.54$

$\mathrm{Ev}$, coning $=0.6$

$\mathrm{RF}, \mathrm{CO} 2=\mathrm{E}_{\mathrm{d}} * \mathrm{E}_{\mathrm{v}} * \mathrm{E}_{\mathrm{V} \text {,coning }}=0.54 * 0.917 * 0.6=0.30$

\subsubsection{Additional Key Findings}

Additional key findings from EPIC report are shown in Figure 5-15, below:

- Water Drive Performance

- The gravity viscous number indicates that the flow is gravity dominated.

- The 1-D model of vertical flood assumes volumetric sweep efficiency, $E_{v}$ $=60 \%$ for coning.

- The OWC analysis concluded that more analysis of the water level is needed to analyze waterdrive recovery factor as separate domes, and that due to the high $E_{v}$, there may be a higher OOIP than originally recognized

- Target volumes for this vertical miscible flood calculated from a $-1510 \mathrm{ft}$ subsea oil-water-contact, within three dome boundary polygons.

\begin{tabular}{|c|c|c|}
\hline Target Oil & Fraction of OOIP & Fraction of ROIP \\
\hline 11.3 MMbbls & $17 \%$ & $30 \%$ \\
\hline
\end{tabular}

- 6 field wide injectors are recommended for maximum solvent injection into the Geneseo-Arbuckle Field

- More monitoring, measurement, and simulation studies are highly recommended in this field before confident reservoir management can be obtained.

Figure 5-15. Additional key findings, copied from Epic March 2010 report. 


\subsubsection{Horizontal Oil-Water Contact}

The single-most critical assumption is that the southern Geneseo-Edwards domes can be effectively processed by gravity-stable methods. For this to occur, it is imperative that a $\mathrm{CO}_{2}$ gas cap can be built downward while maintaining a relatively flat gas/water-oil contact. Evidence for being able to do so:

- Oil water contact stayed relatively flat as it moved upward during the 80-year production history - documented by CAP CO2 and detailed by EPIC consulting.

- Many cases where wells completed deep into the Arbuckle went to water, but when plugged back to shallower depths, returned to water-free oil or very low water cuts.

- Density and viscosity differences between $\mathrm{CO}_{2}$ and oil and water are very large indicating high potential for gravity drainage (see EPIC report).

- The Lyons gas storage, located 6 miles (10 kilometers) southwest of the project areas operated by Northern Natural Gas (NNG) has similar geologic domed setting. It is rumored to have a strong bottom-water drive that moves up and down vertically during the gas storage cycles. NNG has not yet agreed to meet with us to discuss the reservoir dynamics.

There is contradictory data, however. Mullins and Ireland (1967) reported in SPE \#1963 that the Arbuckle was stratified in the Northern Geneseo-Edwards field on Conoco Leases, 5 miles ( 8 kilometers) northwest of the proposed project. They reported deepening watered-out wells and encountering high oil cuts in deeper horizons separated by impermeable layers from the watered out zones above.

CAP CO2 and EPIC analyzed well production, oil-water ratios, and perforation depth histories through time in approximately 30 wells in the two dome project area. We compared oil-water ratios through time at specified perforation intervals and well records showing recompletions higher in the section of the 120-foot oil column. Elevations of the oil-water contact were evaluated in 3D (Figure 5-16) and 2D cross sections (Figure 5-17). Oil-water contacts appear to have moved vertically in a relatively consistent, horizontal fashion. An exception is along the edges, which is consistent with Keg River $\mathrm{CO}_{2}$ gravity-stable floods in Canada. This is consistent with the history-matched simulation model over the same period (Figure 5-18). In the simulation the oil/water contact was relatively uniform and exhibited no coning effects. 


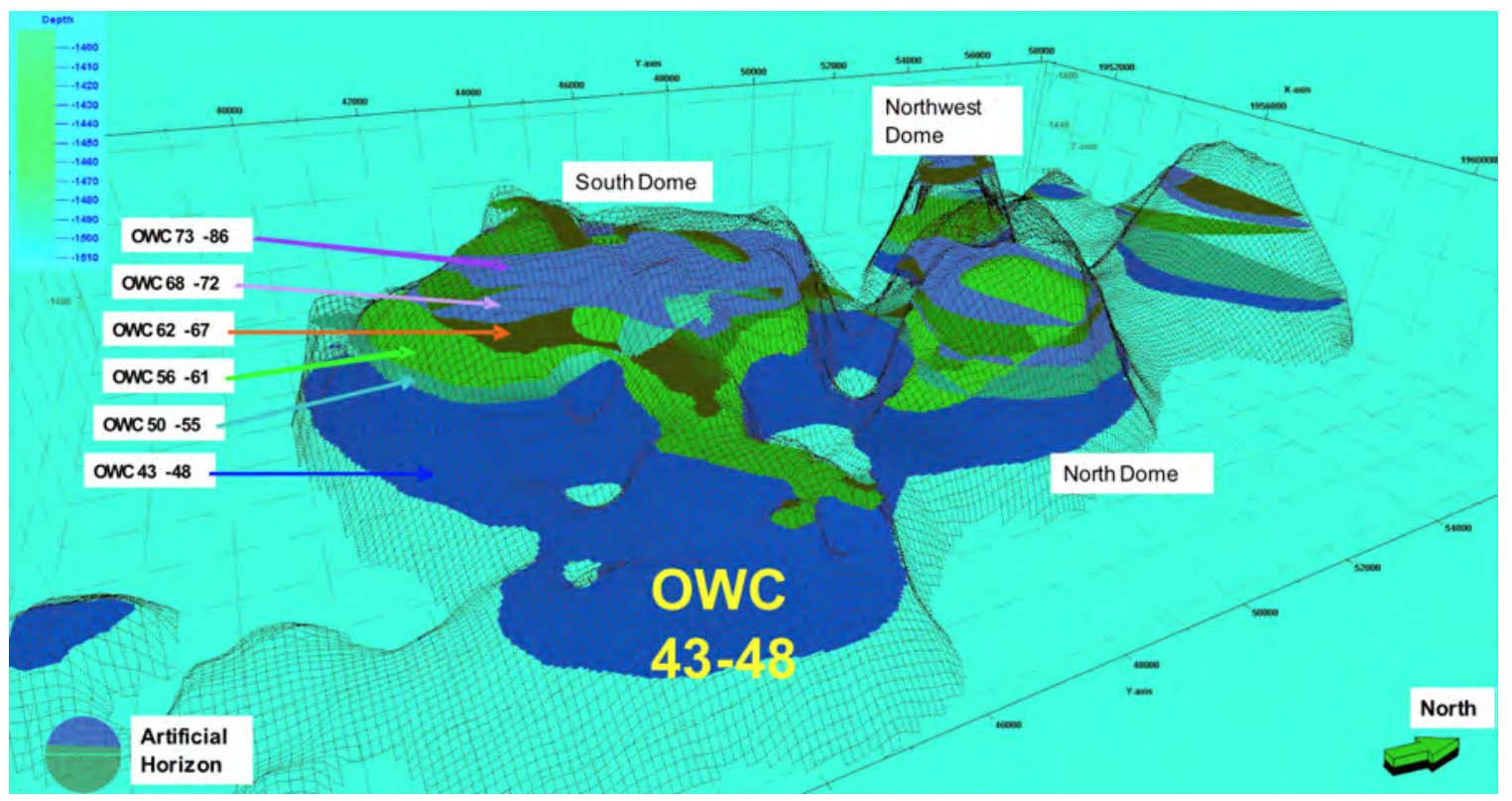

Figure 5-16. Oil-water contact changes through time in $3 D$.

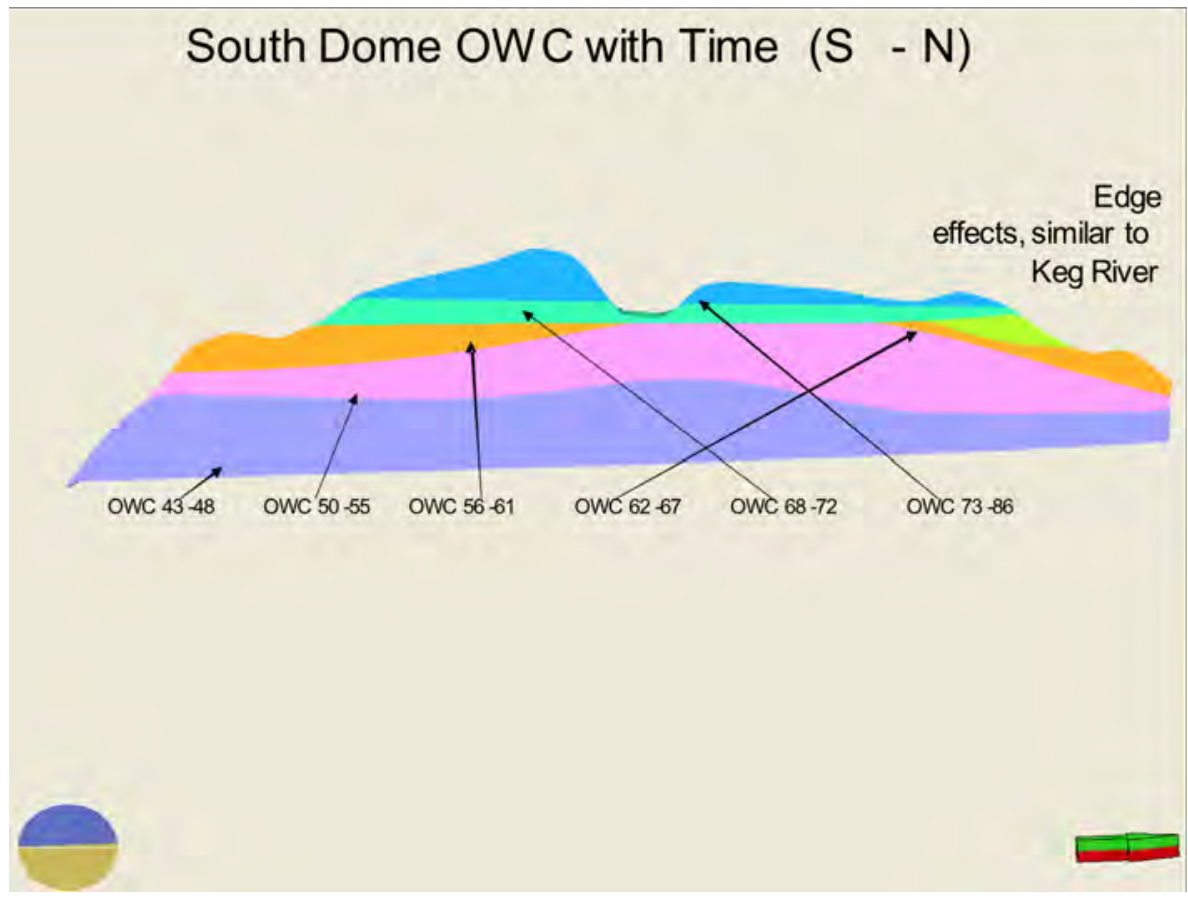

Figure 5-17. Oil-water contact changes through time in $2 D$ in the South Dome. 


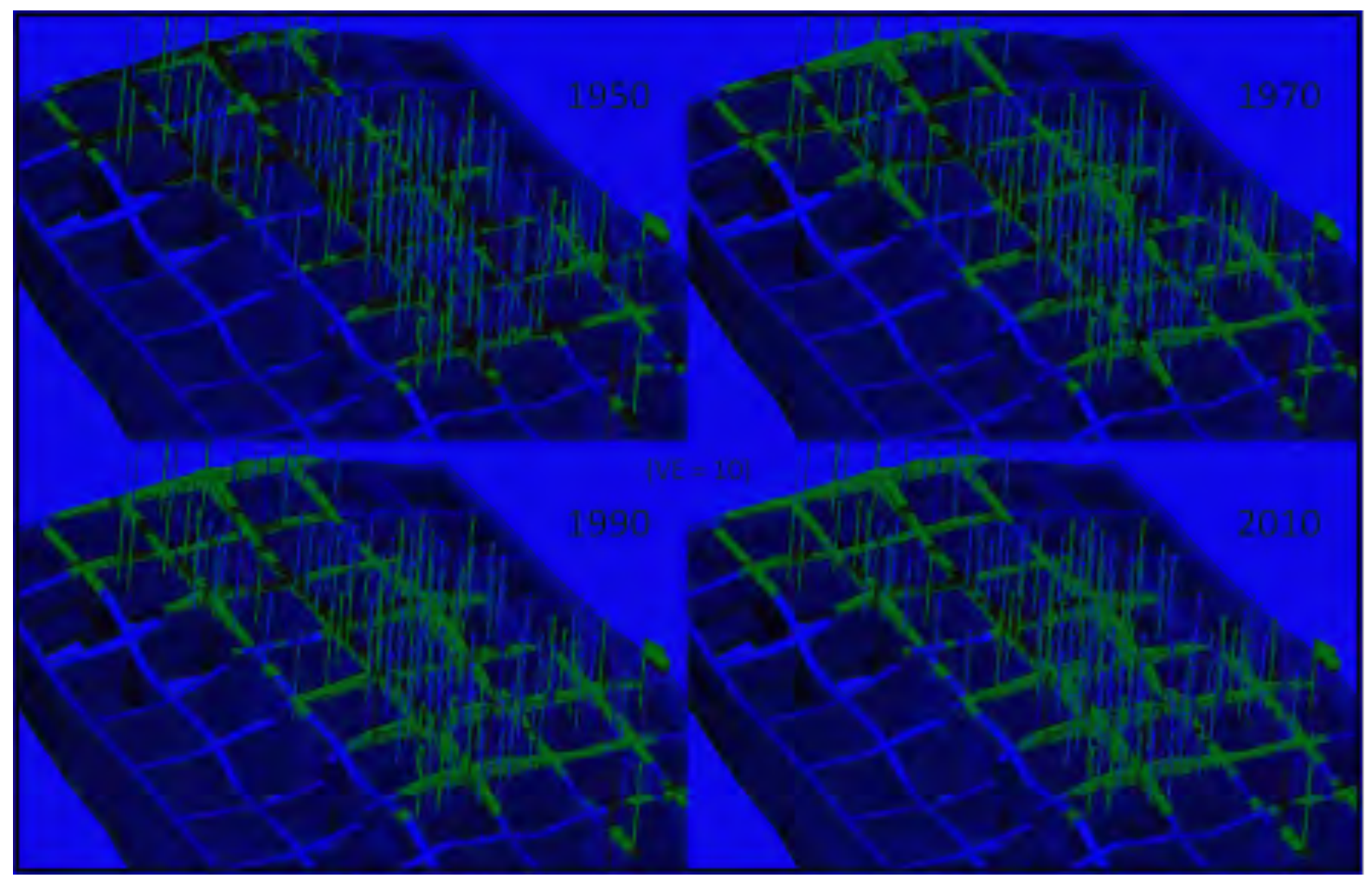

Figure 5-18. Water saturation (Sw) in Geneseo-Edwards simulation model from initial to present. Cooler colors are higher $\mathrm{Sw}($ blue $=\mathbf{1 0 0 \%})$

\subsubsection{Operations Plan Based on Keg River Analogues}

In Alberta, Canada alone, there have been 68 miscible floods as of 2005.54 of these pools are on production and the majority of these floods are in carbonate rock and are vertical floods. In a typical hydrocarbon miscible flood, slug size proportions include 10$15 \%$ solvent followed by $100 \%$ chase gas. Generally, the reservoir is designed with a $30-$ $45 \mathrm{ft}$ solvent bank. In the Geneseo-Edwards field, nearly pure $\mathrm{CO}_{2}$ is to be injected into the reservoir with no chase gas, establishing a $\sim 15-25 \mathrm{ft}$ oil bank, with a $\sim 100 \mathrm{ft}$ solvent bank. Later in the Alberta miscible floods, water is injected into the bottom aquifer to control the voidage replacement ratio (VRR), water oil contact (WOC), and the pressure. As well, later in the miscible flood, horizontal and multilateral wells are considered for economic optimization in offset vertical wells to limit the "sandwich" losses.

In the Keg River A pool, an analogue vertical flood which started solvent injection in 1969, a uniform pressure was maintained. This gas injection continued without significant breakthrough until 1985, a period of approximately 15 years. The miscible flood continued for another 18 years, until 2003, when the flood was abandoned. During this time the oil decline showed a harmonic and rapid decline as the oil sandwich became thinner. In the Keg River B pool, the hydrocarbon miscible flood started and brokethrough in 1986, much faster than the A pool. The differences in heterogeneity play the 
most important role. The Keg River pools have a $\mathrm{RF}_{\mathrm{CO} 2}=10-20 \%$, while the Nisku pools have a $\mathrm{RF}_{\mathrm{CO} 2}=20-30 \%$.

Based on the analysis of the Arbuckle reservoir, material balance, correlations with empirically derived relationships, and with Canadian analogs, the projected $\mathrm{CO}_{2} \mathrm{EOR}$ target oil is shown in Table 5-3. North and South Domes are projected to recover 6.1 mmbo from oil displaced by a gas cap to subsea datum of -1486, assuming a coning factor of $60 \%$.

\section{Target Volume Sensitivities (Mbbls)}

Varying Ev, volumetric sweep efficiency, with cumulative target oil.

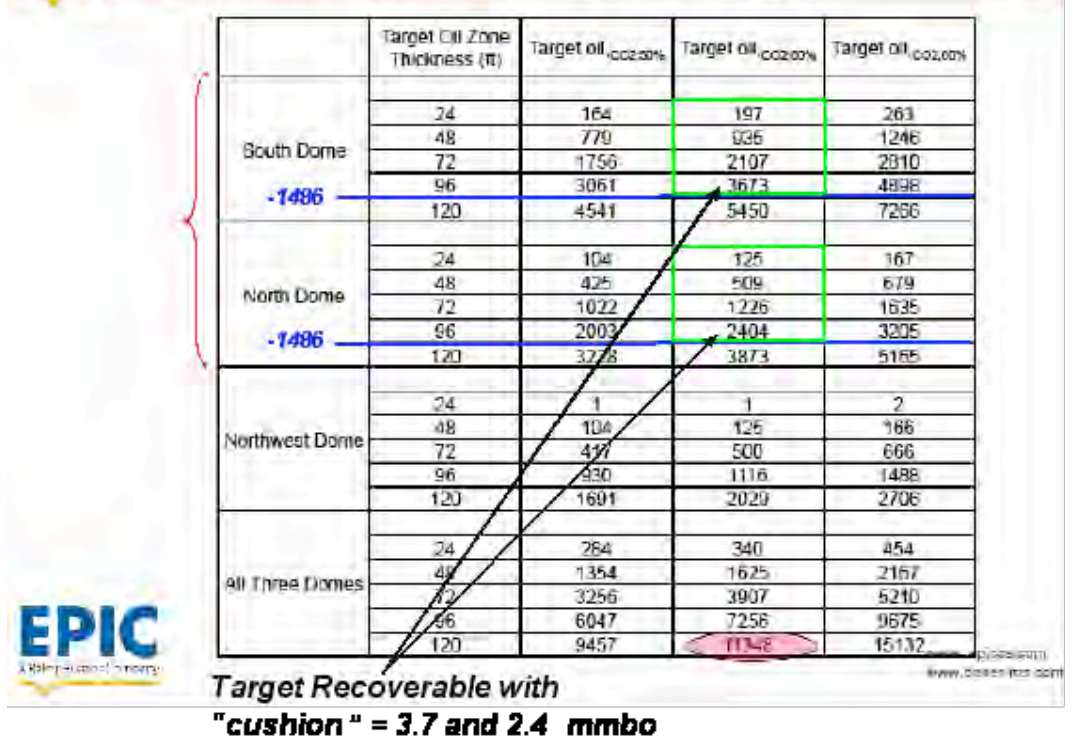

Table 5-3. Estimated oil recovery for three domes analyzed.

$\mathrm{CO}_{2}$ will be injected in a supercritical state at approximate BHP of 1100 psi (19). 
Critical Pressure $=72.9 \mathrm{~atm}$

Critical Temperature $=31.1$ celcius

Current Reservoir Pressure $=74.8 \mathrm{~atm}$

Current Reservoir Temperature $=47.2$ celcius

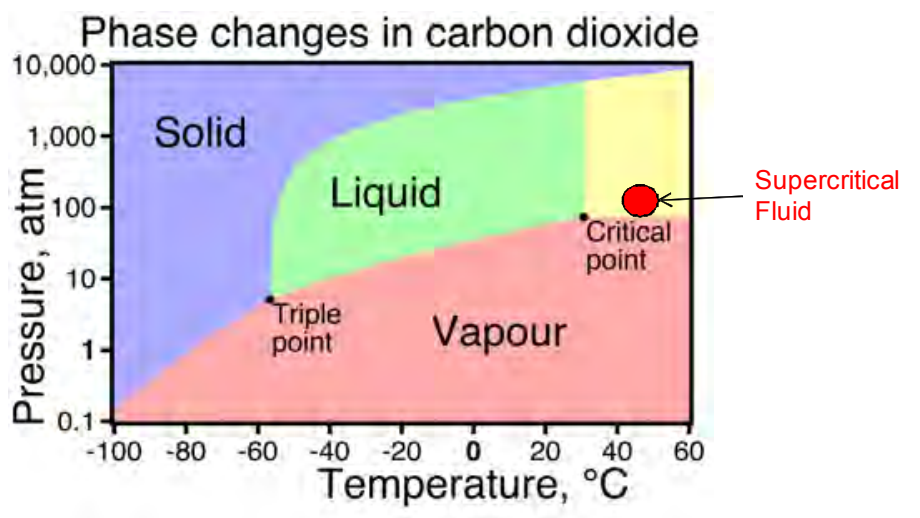

Figure 5-19. Phase diagram showing anticipated conditions in target reservoir.

Figure 5-20 provides a 3D view of the project area.

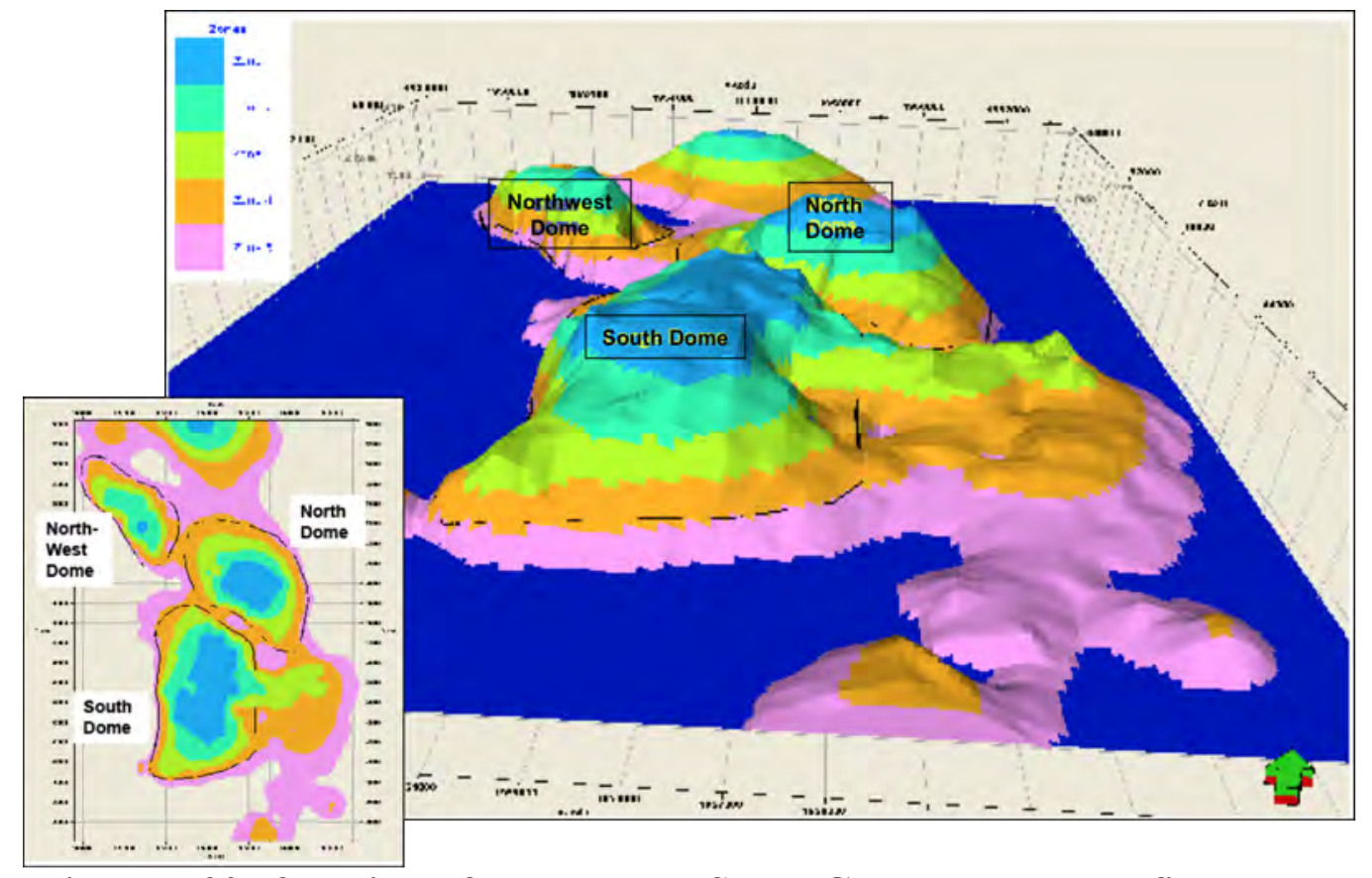

Figure 5-20. 3-D view of three domes South Geneseo-Edwards field. North and South domes are main targets in project. Domes are zoned into 5 layers, each $24 \mathrm{ft}$ thick, for volumetric analysis. 
EPIC recommends not exceeding $1.25 \mathrm{mmcfd}$ per injection well, 6 wells to use the entire $\mathrm{CO}_{2}$ volume of $7.5 \mathrm{mmcfd}$. Planned procedure is to fill one dome then the other to approximately -1486 and then withdraw fluids from a 24 foot cushion below the gas cap $(-1486$ to -1510$)$. The possible development plan is illustrated in Figure 5-21.

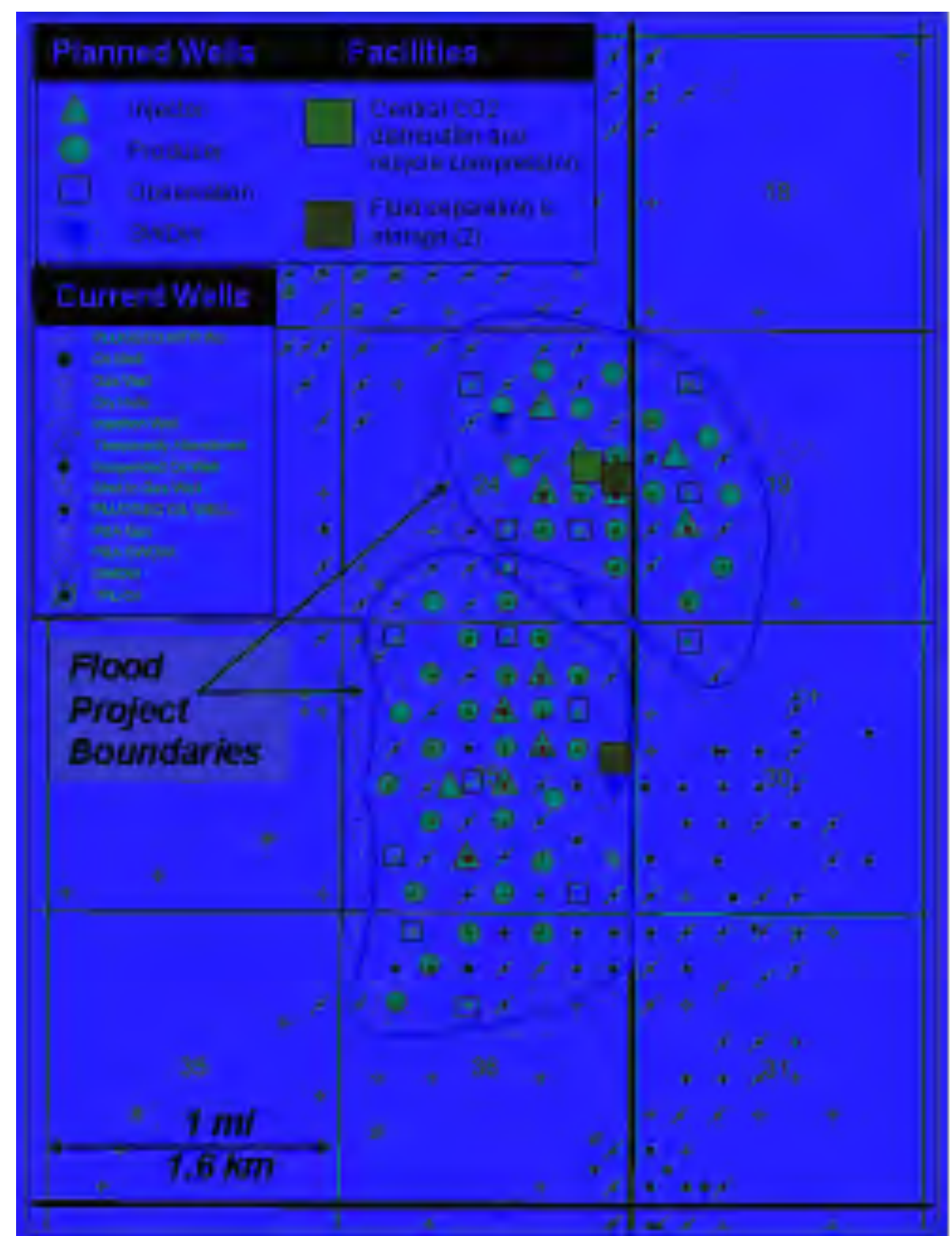

Figure 5-21. Preliminary well plan for a gravity-stable $\mathrm{CO}_{2} \mathrm{EOR}$ project in southern Geneseo-Edwards field.

Below is a possible development and operational scenario for a gravity-stable $\mathrm{CO}_{2}$ EOR project in the southern Geneseo-Edwards area. $\mathrm{CO}_{2}$ volumes required and are estimates by EPIC Consulting.

1. Fill North Dome to approximately -1486 subsea with $\mathrm{CO}_{2}$ 
- 1.25 years at $7.5 \mathrm{mmcfd}$

- 100-foot gas cap and 25-ft oil column at base of gas cap

2. Produce North Dome from perforations below oil column

- Approx. 10-yrs to economic limit

- Recycle $\mathrm{CO}_{2}$ back into gas cap

3. Fill South Dome to approximately -1486 subsea with $\mathrm{CO}_{2}$

- Begin after North Dome is filled

- 2.25 years at $7.5 \mathrm{mmcfd}$

- 100-foot gas cap and 25-ft oil column at base of gas cap

4. Produce from perforations below oil column

- Approx. 11-yrs to economic limit

- Recycle $\mathrm{CO}_{2}$ back into gas cap

Project life-cycle is illustrated in Figures 5-22 and 5-23. $\mathrm{CO}_{2}$ utilization, recycle, and oil recovered are based on EPIC's study.

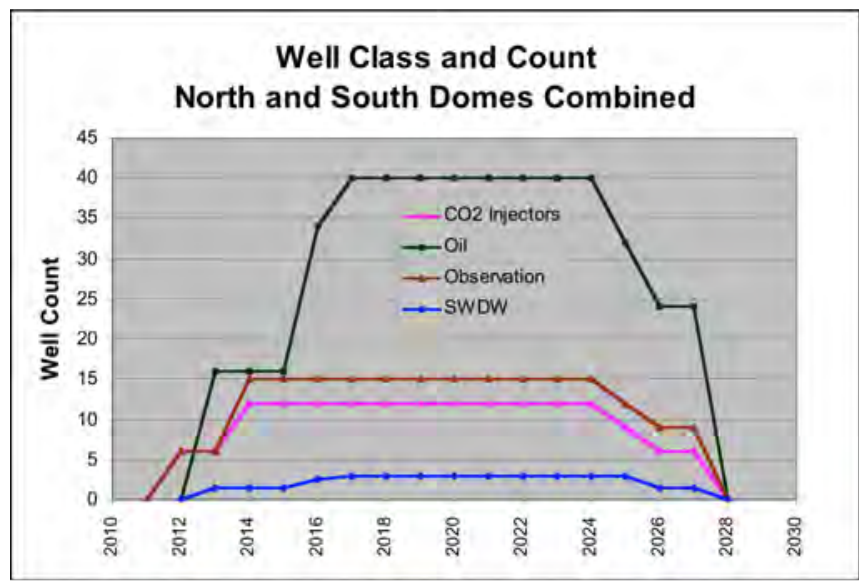

Figure 5-22. Well counts by well class during Geneseo-Edwards project life.

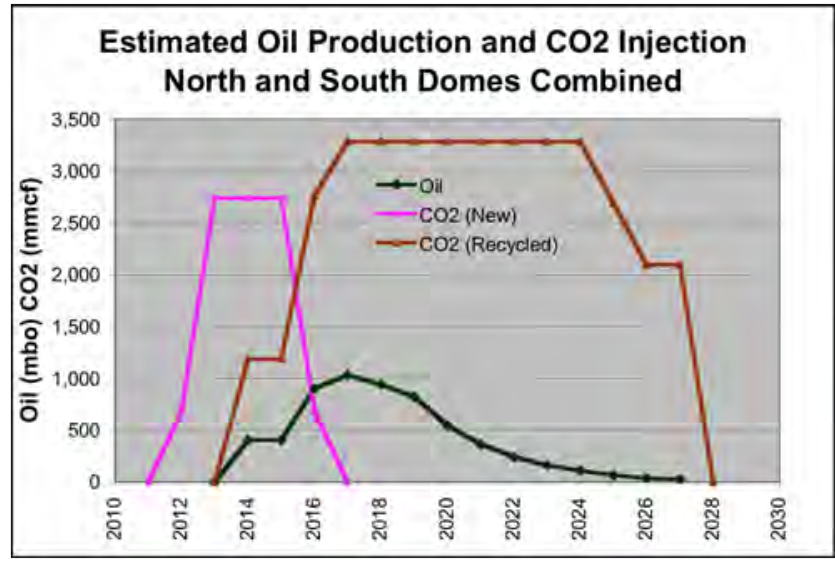

Figure 5-23. Forecast flowstreams for Geneseo-Edwards project life. 


\subsection{Characterization and Simulation Overview}

\subsubsection{Characterization-Simulation Team and Workflow}

Reservoir characterization and simulation was a team effort with the co-authors of this report and technical aspects of the project. The basic workflow is provided in Figure 524. IMCCS researcher Dubois managed the data compilation, acquisition gap-filling data, much of the data analysis and processing and analysis, developed initial 2-D geologic framework in Petra ${ }^{\mathrm{TM}}$, built the property data set at the well scale, and coordinated the overall characterization-simulation process. IMCCS researcher Belobraydic built the 3-D geologic and property static model (grid) in Petrel ${ }^{\mathrm{TM}}$. IMCCS researchers Wang and Waggoner developed input parameters, calibrated the static model through history matching production, and performed reservoir simulations with Eclipse $^{\mathrm{TM}}$.

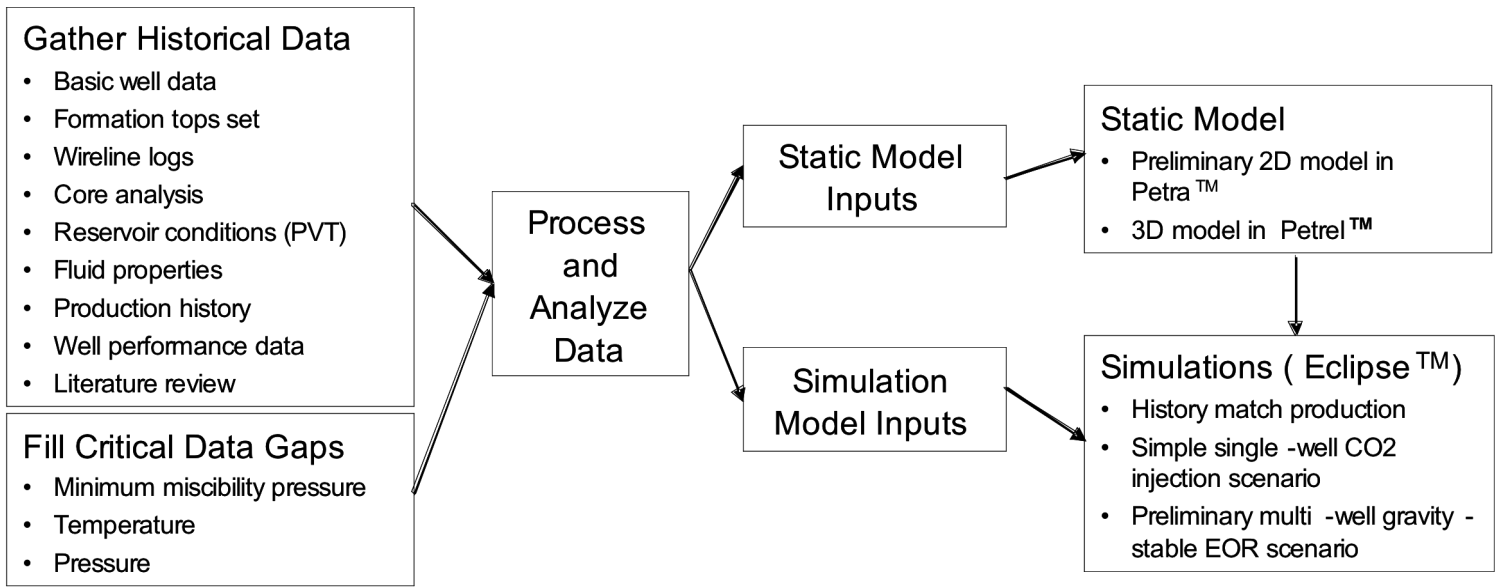

Figure 5-24. Basic workflow for Geneseo-Edwards reservoir characterization and simulation.

\subsubsection{Data Gathering and Processing}

It is a challenge to accurately characterize mature oil and gas reservoirs due to paucity of data. That is the case for the southern Geneseo-Edwards field discovered in the mid1930 's and with most wells drilled prior to the mid 1950's. The timing of drilling, premodern well logs, the type of completions, mainly openhole, and the vintage of the development contribute to the lack of high quality reservoir data. Because the leases have changed hands multiple times since initial development by Conoco, there has been a substantial loss of production and other data that would be useful in documenting reservoir dynamics. The fact that the production data available through public records includes only oil at the lease scale on a monthly basis, exacerbates the problem. We have worked with existing data from public and private sources, operator files, and limited published work, and then filled in data gaps. Not all data gaps, most notably engineering data for developing an Equation of State, were able to be filled in the short, 7-month time frame for the project. Despite the circumstances, we feel that the static model (grid) is a reasonable representation of the target reservoir. Periodic well production tests provided by the operators, Daystar and Scheck, enabled us to estimate fluid production through time. A reasonable history match to present day was attained by numerical 3D reservoir 
simulation and reservoir response to $\mathrm{CO}_{2}$ injection predicted by simulations also appear to be within the expected range.

\subsubsection{Production Data}

Monthly oil production data was compiled from public digital and hard-copy sources under contract by IMCCS researcher Doug Beene, a production data specialist. Post1966 data is from online public records at the Kansas Geological Survey (http://www.kgs.ku.edu/Magellan/Field/ index.html). Pre-1967 data is from various hard-copy and microfiche sources. Oil Production is reported on a lease-scale with multiple wells going into the same tanks and the combined monthly production is reported. Water production is not required and water production data are not available from public databases.

Although individual well production data for oil and water are not publicly available, sporadic well tests for 41 individual wells were captured from operator well files (Figure 5-25). On average, 10 tests were available per well, giving snapshots of production rates and oil-water ratios through time at a given location and depth, providing sufficient data to map the oil-water contact in three dimensions through time. Figure 5-26 illustrates the movement of the oil-water contact through time in a crossplot. Typically, wells in the 1940's were completed for water-free oil production in open hole completions from the top of the Arbuckle, say at -1420 subsea) to as deep as -1490 . Through time, as watercuts increased, the wells were plugged back to shallower and shallower depths when water production

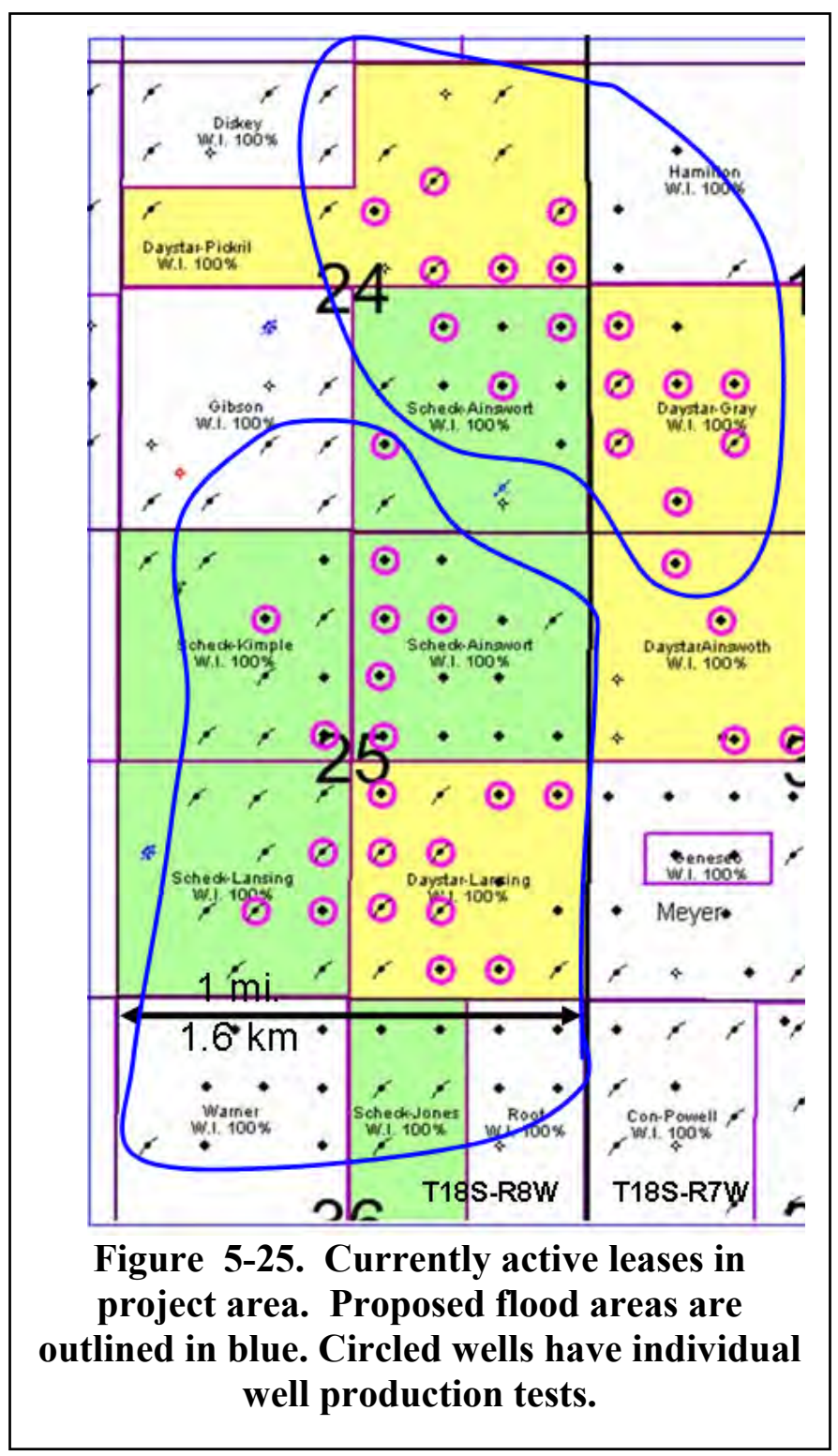
became an issue. 


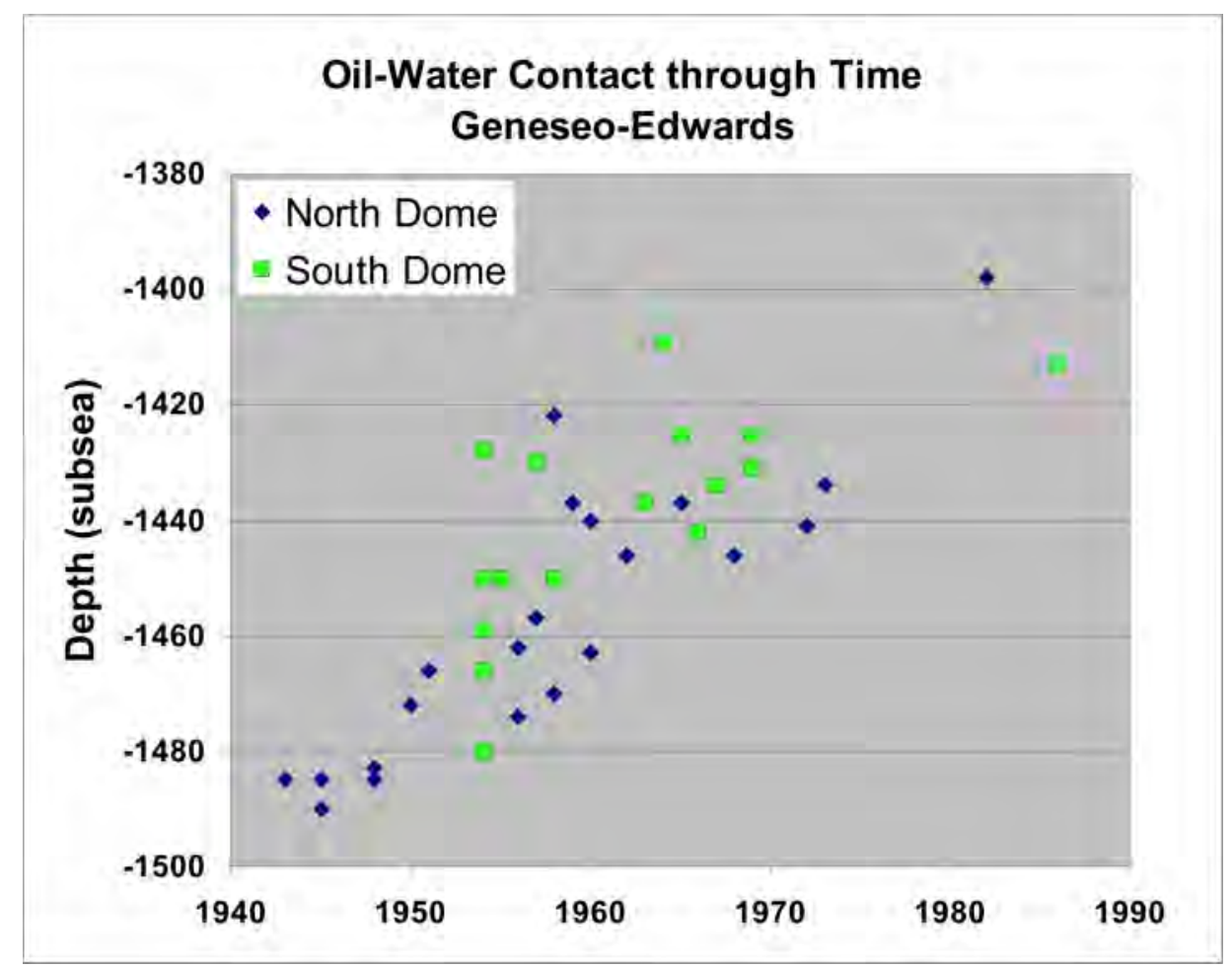

Figure 5-26. Approximate oil-water contact through time based on water cuts and perforation interval in project area.

\subsubsection{Geologic and Petrophysical Data}

Basic well header information, including location, operator name, lease name, well number, and datum elevation is from the online public database at the Kansas Geological Survey (http://www.kgs.ku.edu/Magellan/Qualified/index.html). All wells are vertical wells. Operator formation tops are from completion cards at the Kansas Geological Society library, Wichita, Kansas. A consulting geologist, Robert O'Dell of Wichita, Kansas, joined the IMCCS team and gathered well data, picked formation tops, reviewed operator files, and completed other basic data-gathering tasks. An electric-log based formation tops set was developed including more than half of the 321 wells in the 12 section area and surrounding the two-domed project (Figure 5-27). The 600-foot-thick Arbuckle was subdivided into up to six zones in 53 wells having the deepest penetration into the Arbuckle. Three databases and private operator files were searched for wireline logs, the Kansas Geological Survey, Kansas Geological Society Library, and MJ Systems. Wireline logs from fifteen wells were digitized for more detailed analysis. Logs were selected on the basis of depth of penetration into the Arbuckle and quality of the curves. One is a density-neutron porosity and dual induction log and the rest were uncalibrated gamma ray-neutron logs. Cores and conventional core analysis data was available for two wells (Figure 5-27). 


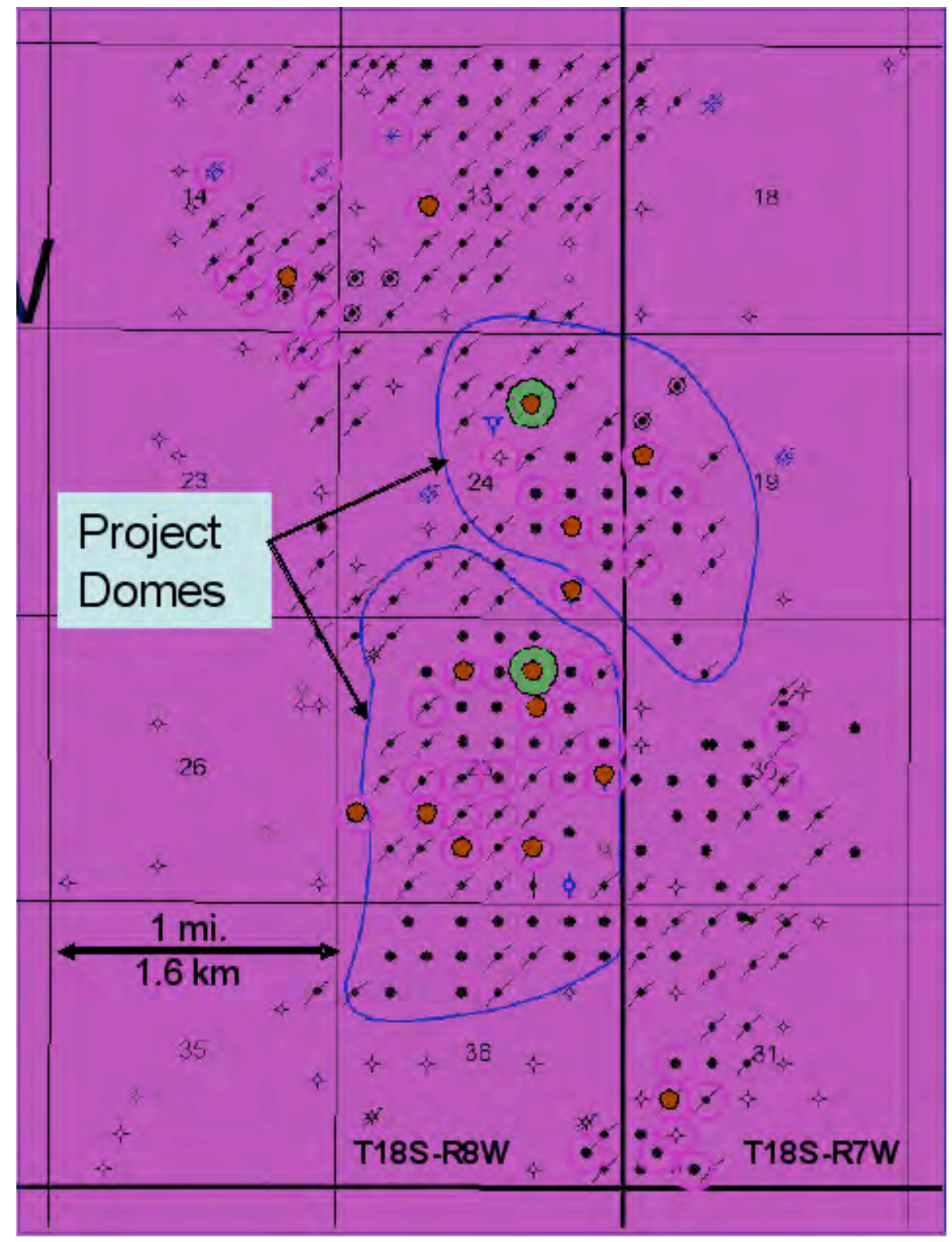

Figure 5-27. Wells and data coverage in the project area. Log or sample tops were available for $95 \%$ of the 321 wells. Fifty-three had wireline logs and were deep enough penetrations to subdivide the Arbuckle (circled wells). Logs were digitized in 15 wells (brown dots). Two cored wells are highlighted in green.

\subsubsection{Reservoir Data and Fluid Analysis}

At the start of the project many fundamental reservoir and fluid properties were not known. Many of these data gaps were filled by field and lab measurements, although significant gaps remain. BHT and BHP data were gathered on three wells in the GeneseoEdwards project area by Trilobite Testing, Inc. Three wells were selected (Figure 5-28) by the following criteria: open in the Arbuckle only, inactive or shut-in for more than 30days, static fluid level, open casing with no casing leaks. BHP-BHT pressure bomb was 
lowered into the wells as deep as possible. The intent was to get the tool to actual TD of the wells, but obstructions in the bottom of each well prevented reaching actual TD, but close.

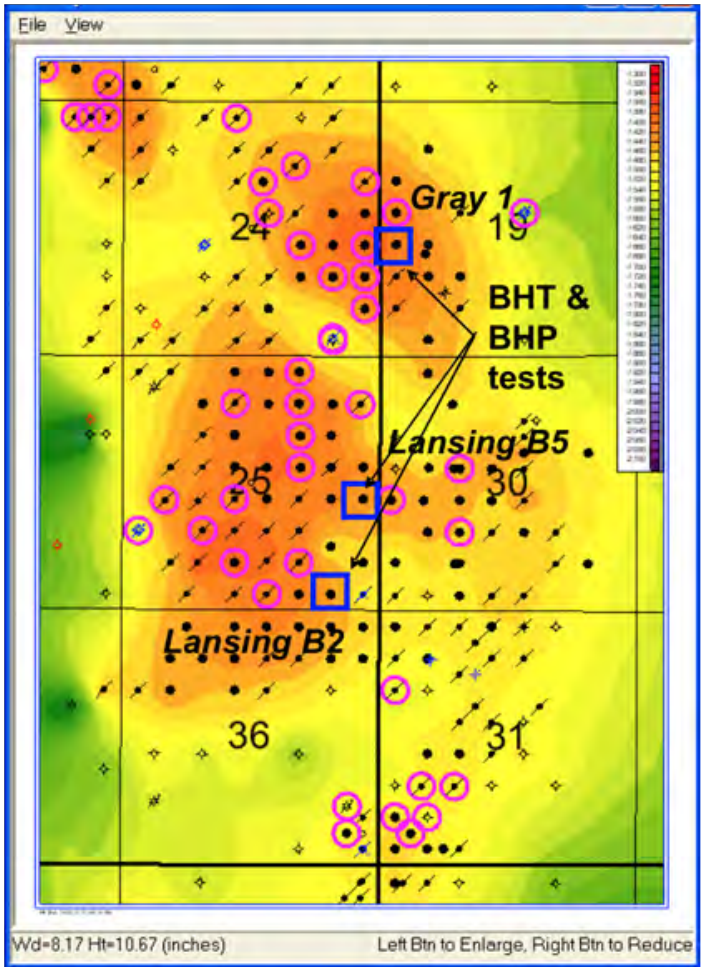

Figure 5-28. Wells selected for BHT and BHP measurements in GeneseoEdwards area.

Sufficient depth was reached to establish temperature and pressures and gradients to extrapolate to the Arbuckle interval:

$\mathrm{BHT}=117$ degrees $\mathrm{F}$ at $3200 \mathrm{ft}$ with gradient of 0.02 degrees per foot.

$\mathrm{BHP}=1080$ psi @ $3200 \mathrm{ft}$ with gradient of 0.43 psi per foot.

Table 5-4 summarizes the three tests. Post analysis discovered that the Lansing B2 was open in the Simpson, a zone that has been produced in the well and others around it and the pressure likely reflects the lower pressured Simpson sandstone. 


\begin{tabular}{|c|c|c|c|c|}
\hline Well & $\begin{array}{l}\text { Arbuckle } \\
\text { Depth }\end{array}$ & $\begin{array}{l}\text { Well } \\
\text { TD }\end{array}$ & $\begin{array}{l}\text { Sample } \\
\text { Depth }\end{array}$ & $\begin{array}{l}\text { BHP } \\
\text { (psig) }\end{array}$ \\
\hline $\begin{array}{l}\text { Gray } 1 \\
\text { API } 151590173\end{array}$ & 3098 & 3176 & 3171 & 960 \\
\hline $\begin{array}{l}\text { Lansing B2 } \\
\text { API } 151590192\end{array}$ & 3163 & $\begin{array}{l}3178 \text { (OTD) } \\
>3210 \text { (DDTD }\end{array}$ & 3210 & 656 \\
\hline $\begin{array}{l}\text { Lansing B5 } \\
\text { API } 151591903\end{array}$ & 3160 & $\begin{array}{l}3970 \text { (OTD) } \\
4029 \text { (DDTD) }\end{array}$ & 2866 & 952 \\
\hline & $\begin{array}{l}\text { Top of Arb } \\
\text { Base of Ar }\end{array}$ & $\begin{array}{l}\text { kle } \\
\text { Ickle }\end{array}$ & $\begin{array}{l}3160 \\
3706\end{array}$ & $\begin{array}{l}1078^{*} \\
1311^{*}\end{array}$ \\
\hline
\end{tabular}

Table 5-4. Summary of BHP and BHT tests in Geneseo-Edwards

Crude oil samples were collected from two wells in the Geneseo-Edwards for compositional and MMP analysis (Figure 5-29). Wells were selected by the following criteria: producing from the Arbuckle only and no casing leaks. Oil was sampled at the wellhead by Daystar Petroleum field personnel from the bleeder valve into clean, sealable plastic containers, transported to JACAM Chemicals where samples were transferred to airtight containers suitable for shipping hazardous materials. Oils were shipped to SCAL, Inc. lab in Midland Texas. MMP analysis was performed by SCAL, Inc. using sand packed slim tube and industry-accepted practices. MMP for the two samples was 1356 and 1421 psi at 117 degrees (Figures 5-30 and 5-31).

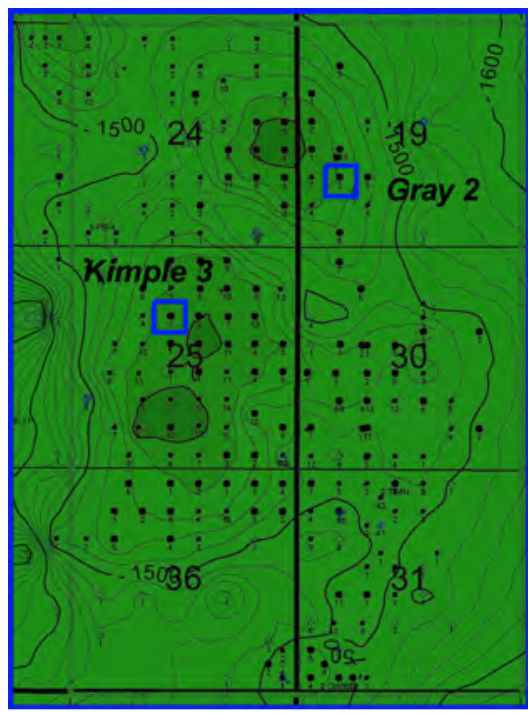

Figure 5-29. Crude oil analysis performed on oils from two wells in GeneseoEdwards field. 


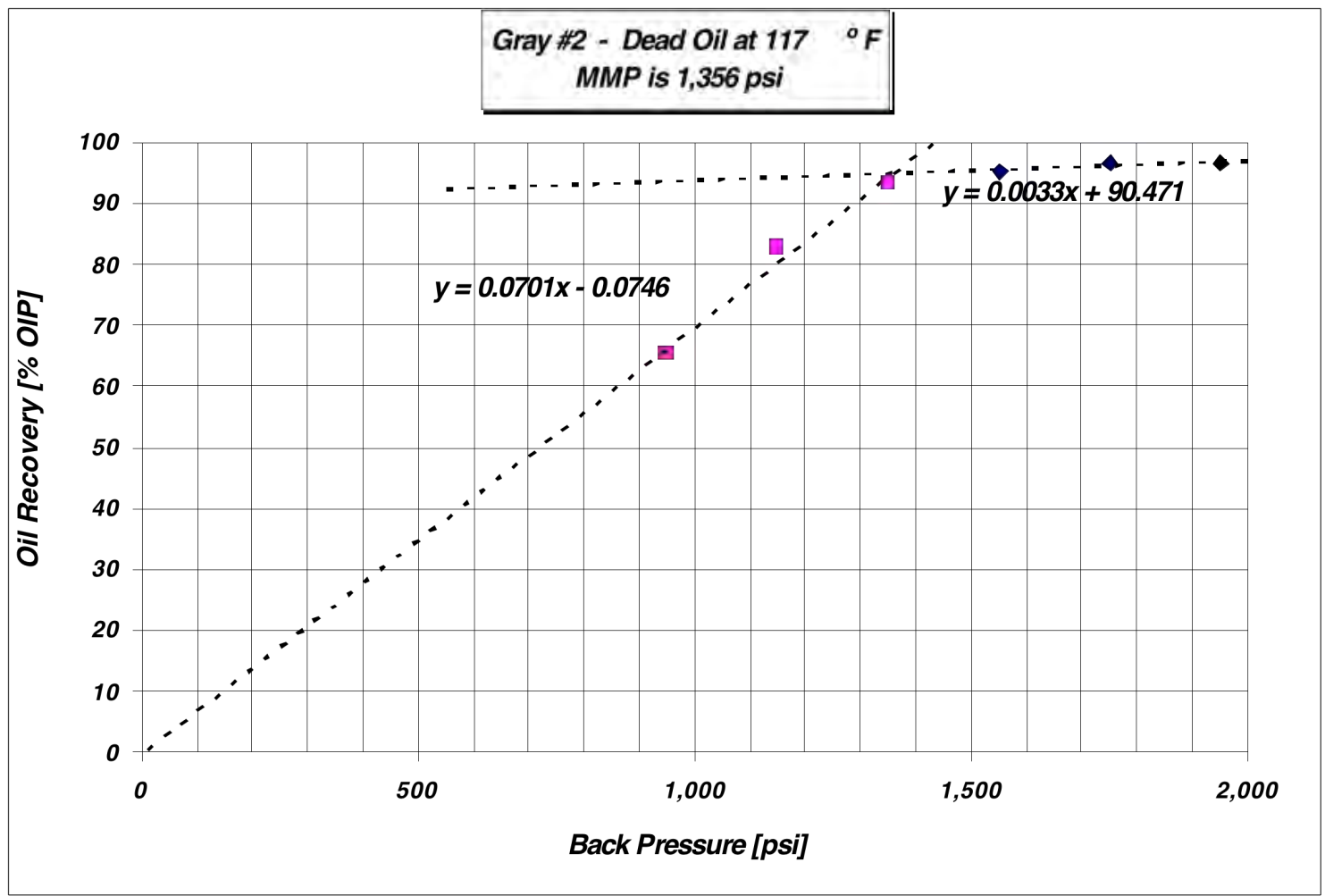

Figure 5-30. MMP for Gray \#2 well is 1,356 psi @ 117 F

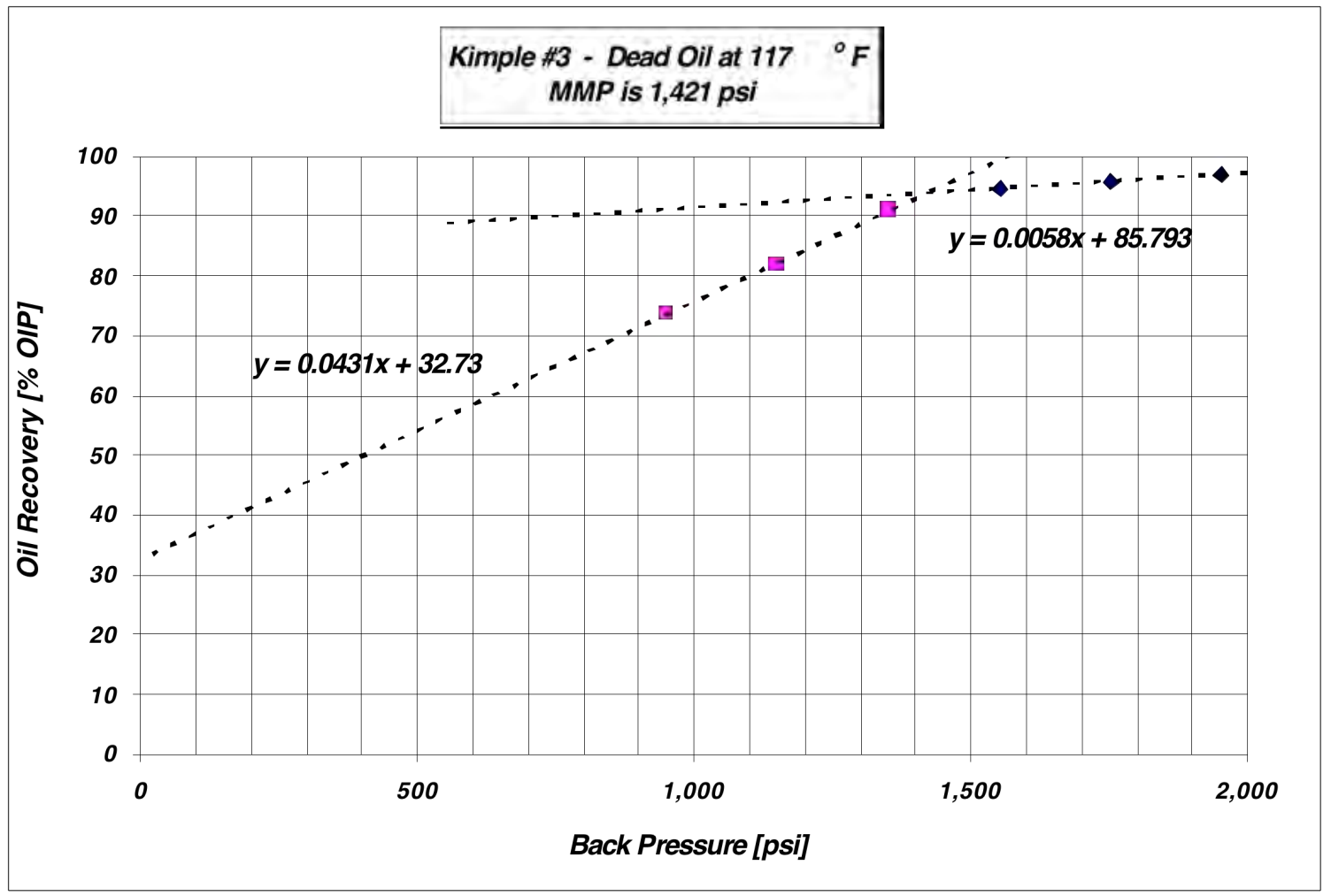

Figure 5-31. MMP for Kimble \#3 well is 1,421 psi @ 117 F 
Basic crude oil properties are summarized in Table 5-5.

\begin{tabular}{l|c|c|c|c|}
\cline { 2 - 5 } & \multicolumn{2}{c|}{ Temperature (F) \#2 } & \multicolumn{2}{c|}{ Kimple \#3 } \\
\cline { 2 - 5 } & 70 & 117 & 70 & 117 \\
\cline { 2 - 5 } Min. Misc. Pres. (psi) & & 1,356 & & 1,421 \\
Density - SI (gm/cc) & 0.835 & 0.819 & 0.84142 & 0.8304 \\
Spec Grav - MA (ideal) (gm/cc) & 0.7808 & & 0.8161 & \\
Vapor Pressure & 7.2 & & 4.73 & \\
API gravity & 37.9 & 41.3 & 36.7 & 38.9 \\
Viscosity (cp) & 6.7 & 3.3 & 8.87 & 3.08 \\
Paraffin (\%) & 1.4 & & 3.86 & \\
Asphaltines (\%) & 0.52 & & 0.52 & \\
\cline { 2 - 5 } & \multicolumn{2}{c}{ SI - SCAL, Inc. } \\
\cline { 2 - 5 } & MA - Mitchell Analytical
\end{tabular}

Table 5-5. Summary of crude oil properties, South Geneseo-Edwards field.

\subsubsection{Estimating Properties with Minimal Data}

Building a basic property model was hindered by shallow Arbuckle penetrations, a paucity of modern open-hole logs, and core analysis data. Only on wells in the project area with relatively deep penetration into the Arbuckle have neutron-density porosity and induction electric $\operatorname{logs}$, forcing the need to utilize uncalibrated neutron-gamma ray logs run in both the open hole and cased hole portions of the wells in the project area. Neutron curves were painstakingly calibrated to the single well with neutron-density porosity and to wells with core porosity to obtain digital porosity profiles at half-foot intervals in 15 wells. Figure 5-32 shows the core plug porosity compared to calibrated neutron curves. Much of the difference between core porosity and calibrated neutron porosity are due to the scale at which the measurements are made, inches (cm's) a few feet $(0.5 \mathrm{~m})$. Permeabilities were estimated using porosity-peremability transforms more fully described in Section 5.4.4. 


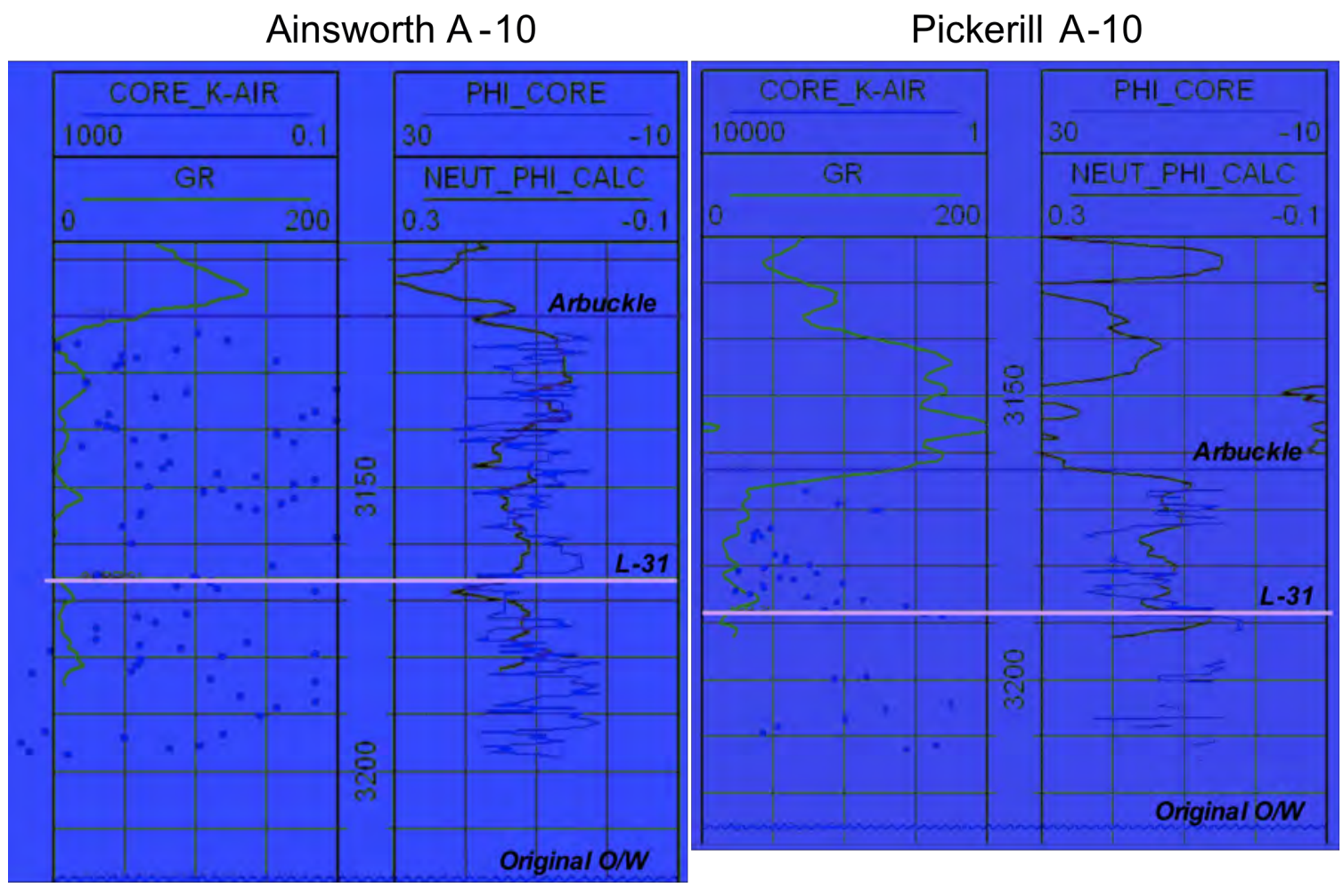

Figure 5-32 Wireline log calibrated neutron porosity and core analysis data from Ainsworth A-10 (South Dome) and Pickerill A-10 (North Dome). Formation tops include the top of the Arbuckel and layer 31, an informal correlation point within the Arbuckle, and the approximate original oil-water contact $(\mathrm{O} / \mathrm{W})$.

Intial water saturation is problematic becuase of the age of the production, established in the mid-1930's. A search of literature and private operator files di not yield any clues. The initial water saturation is estimated as $30 \%$ on the basis of material balance analysis using a formation volume factor (FVF) of 1.1, average porsoity of $11.5 \%$, and oil-water contact subsea depth -1500 . Neither original gas-oil-ratio nor FVF have been found in literature nor in operator files. It is hightly unlikely thet the FVF is any higher than 1.1 because there is no record of casing head gas production and current production is accompaniued by minimal amount of gas that is too small to measure. Avergae porosity is derived from core and very limited wireline logs. The original oil-water contact is based on prodcution tests. Because of the high permeability, the transition zone is very likley to be very narrow, thus using a single saturation value is probably satisfactory until cappillary pressure data can be aquired and better estimates made.

\subsection{Arbuckle Property Model Grid}

The southern part of the Geneseo-Edwards structure was selected for a potential EOR and $\mathrm{CO}_{2}$ sequestration project by IMCCS. The property model for the Geneseo-Edwards 
was created to provide the initial conditions in Petrel 2009.1.1 $1^{4}$ for the start of the dynamic simulation model and to give basic volumetrics of initial oil in place. Using well data for structure and physical properties the resulting model calculates $88 \mathrm{MMbbl}$ $\left(14.0 \times 10^{6} \mathrm{~m}^{3}\right)$ of oil initially in place for the dynamic model area.

\subsubsection{Study Area}

The study area for the property model was extended well past the EOR injection site in the Geneseo Edwards. The boundary for the property model was selected to encompass the entirety of the Geneseo-Edwards structural high (Figure 5-33). This size model allowed any size dynamic model to be selected out of the completed property model as need dictated. The property model covers most of T17S-R8W, T18S-R8W, and T19SR8W; and partially covers T16S-R8W, T17S-R7W, T18S-R7W, and T19S-R7W.

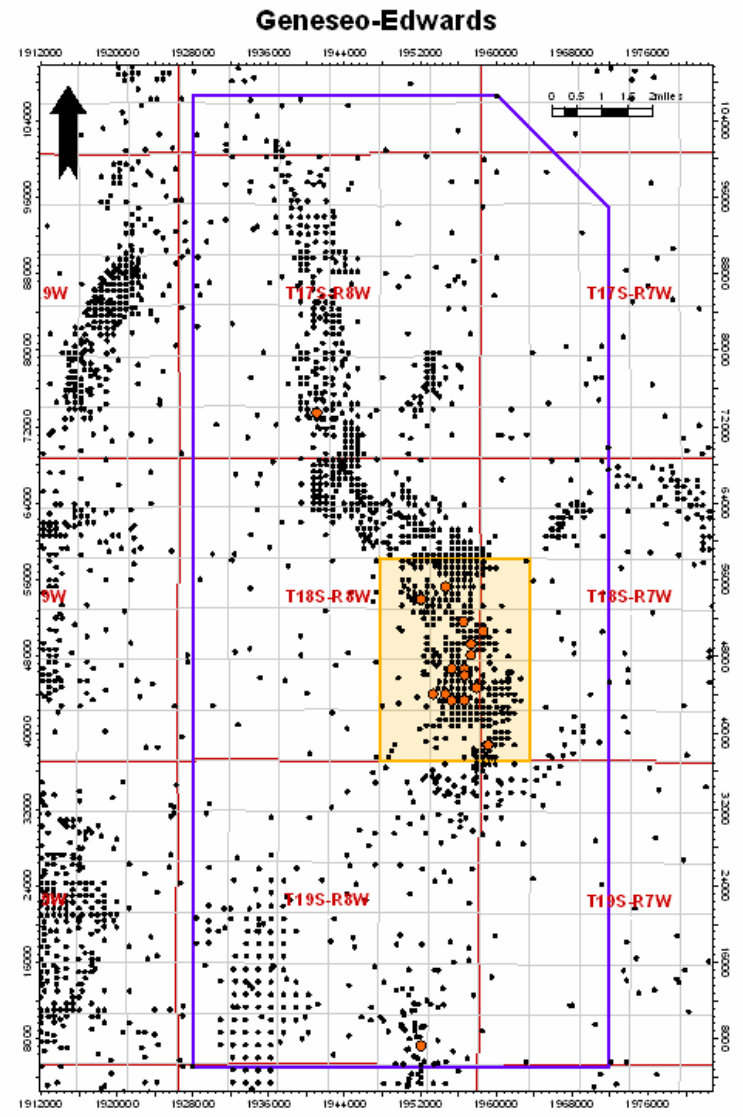

Figure 5-33. Geneseo-Edwards location map. Black dots are the well locations. Orange dots are wells with data. The purple boundary is the property model boundary and the orange boundary is the dynamic model boundary.

\subsubsection{Data Processing}

Data for the model was exported from the Petra database provided by CAP CO2 and other industry partners, and all well locations, well tops, cultural polygons, and structural grids were imported to Petrel. The well logs received were porosity logs based on

${ }^{4}$ mark of Schlumberger 
neutron curves calibrated to core data. All well locations and tops were verified by IMCCS researchers and erroneous data points were eliminated from the data set.

\subsubsection{Structural Grid}

The structural grid is based on the Arbuckle top surface (Figure 5-34) is based on tops in approximately 1100 wells in the area covered by the color-filled contours. The well top control for the area of interest suggests that a normal fault with about $300 \mathrm{ft}$ $(91.44 \mathrm{~m})$ of displacement exists on the west side of the structure. This fault located in the model by identifying the inflection on the Arbuckle and Arbuckle 19 surfaces and extrapolated though the entire Arbuckle Formation.

The final stratigraphic horizons used in the model were the result of several iterations due to data inconsistency. Both the Arbuckle and Precambrian tops are erosional surfaces and have the most control across the region. The top of the Arbuckle was created first from Petra grids and well tops (Figure 5-34). The Arbuckle-19 horizon was created by isochore from the Arbuckle top; however, because the data were only in the area of interest, all areas outside the well control were heavily smoothed to remove artifact highs and lows inherited from the Arbuckle top surface (Figure 5-35). This method isochore and smoothing ensures that the data is honored and reduces structural errors for the other horizons that were built from the Arbuckle isochore. The Arbuckle31 structural surface was built by isochore up from Arbuckle-19 (Figure 5-36). The Arbuckle-10, 4, 1 surfaces and the Precambrian surface were built by isochore down (Figures 5-37, 5-38, 5-39 and 5-40 respectively). 


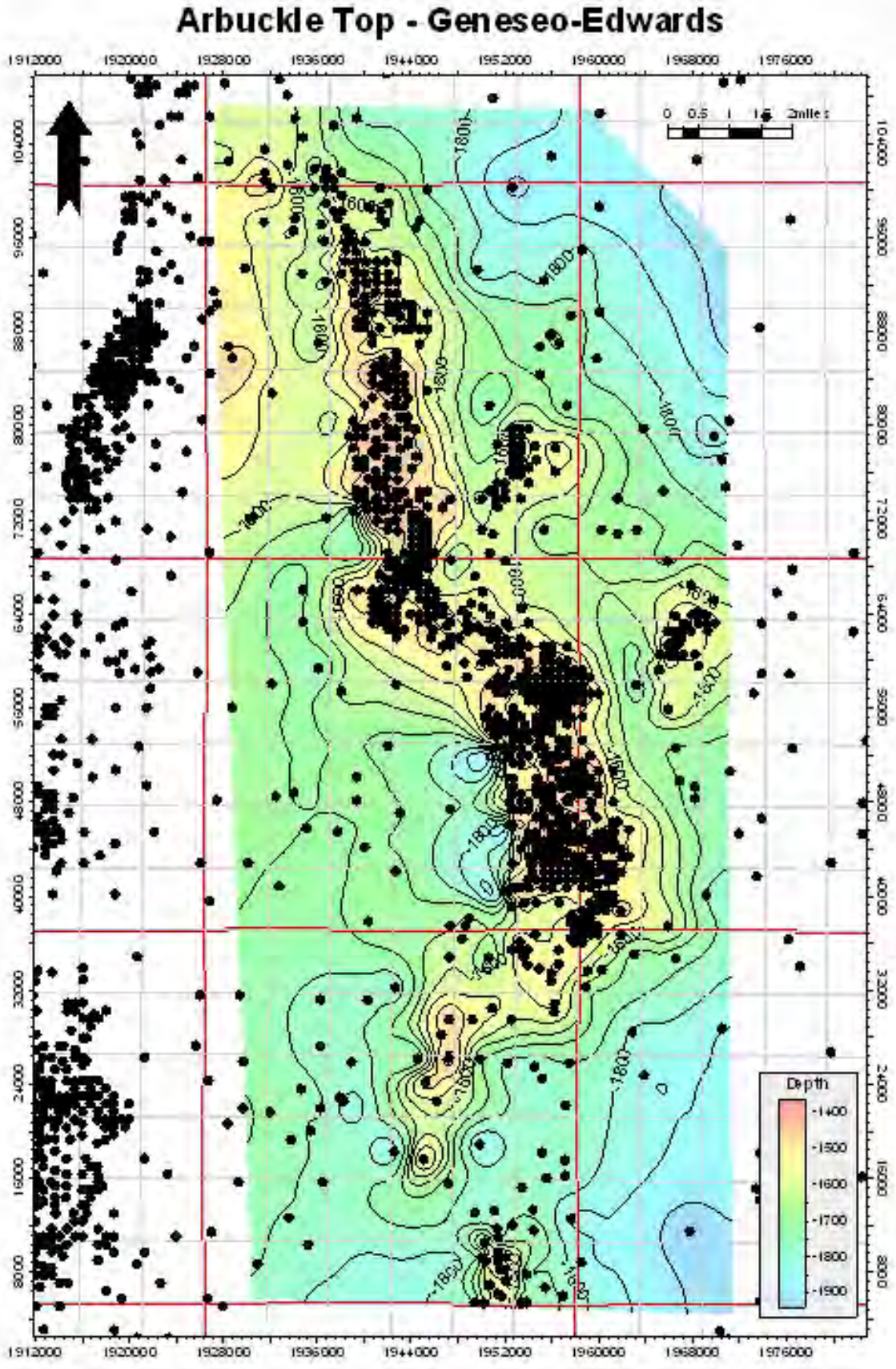

Figure 5-34. Arbuckle top surface for the Geneseo-Edwards model. Black dots are well top control points used in the model. Contour interval $25 \mathrm{ft}(\mathbf{7 . 6 2 \mathrm { m }})$. 


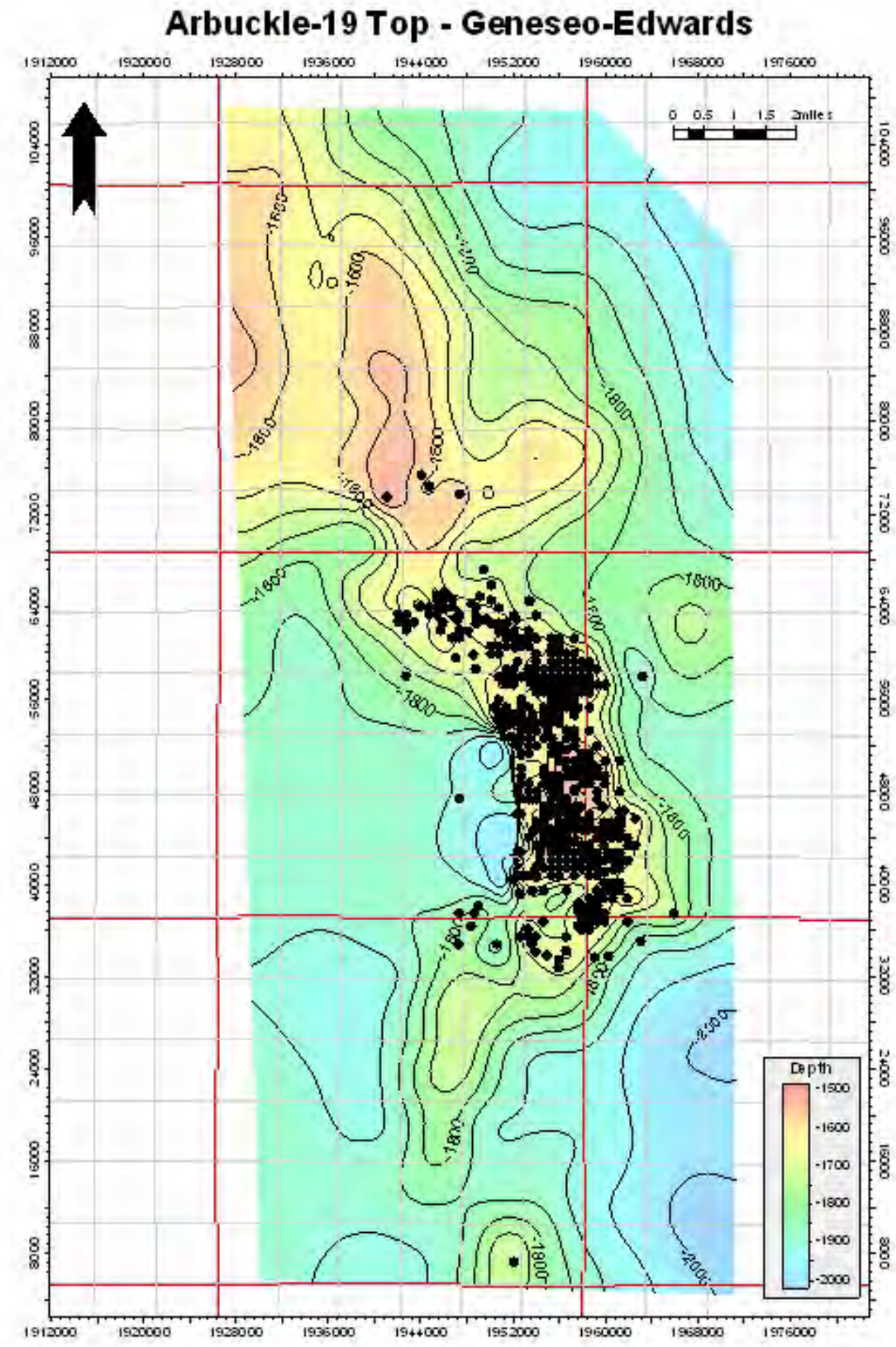

Figure 5-35. Arbuckle-19 surface for the Geneseo-Edwards model. Black dots are well top control points used in the model. Contour interval $25 \mathrm{ft}(\mathbf{7 . 6 2 m})$. 


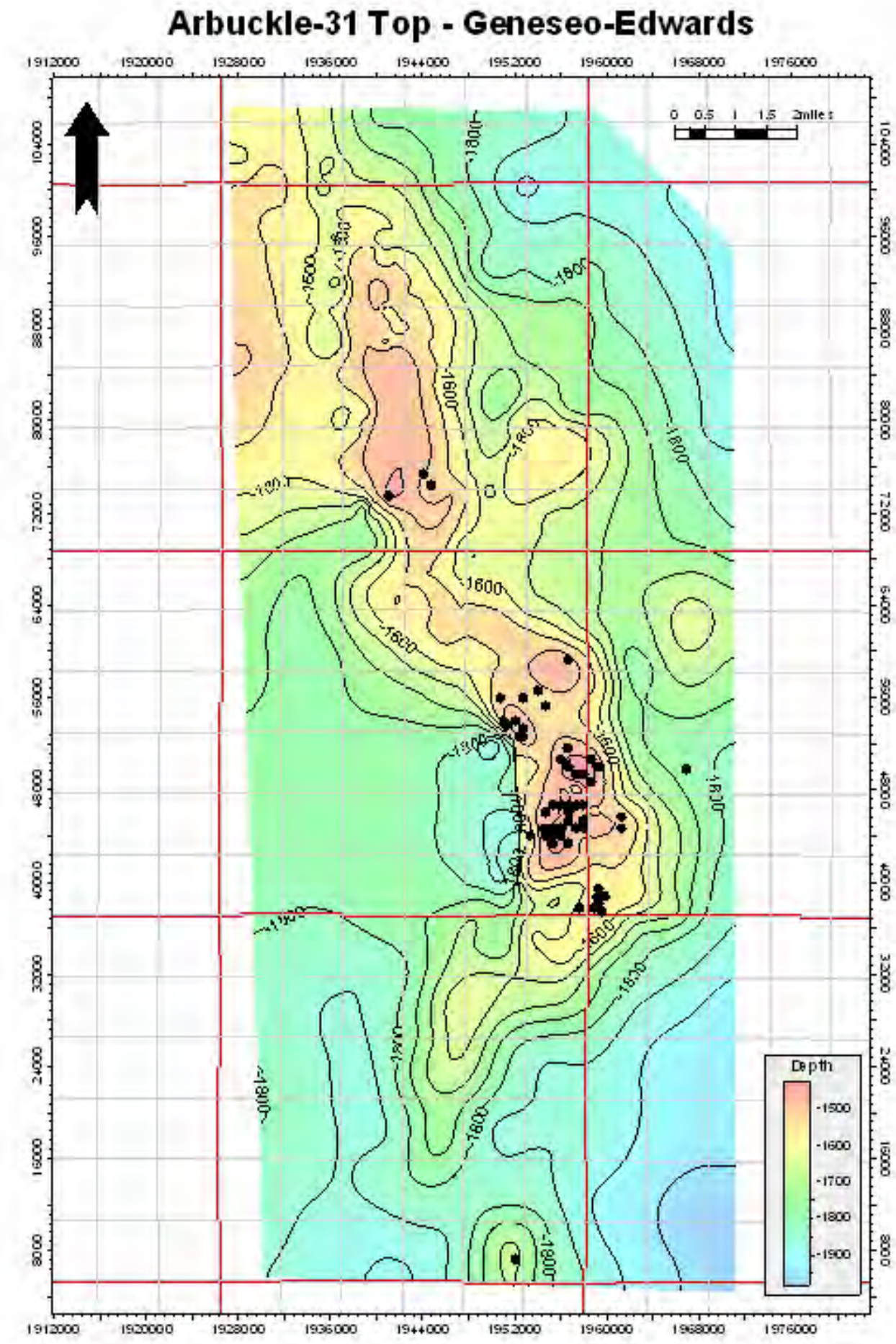

Figure 36. Arbuckle- 31 surface for the Geneseo-Edwards model. Black dots are well top control points used in the model. Contour interval $25 \mathrm{ft}(7.62 \mathrm{~m})$. 


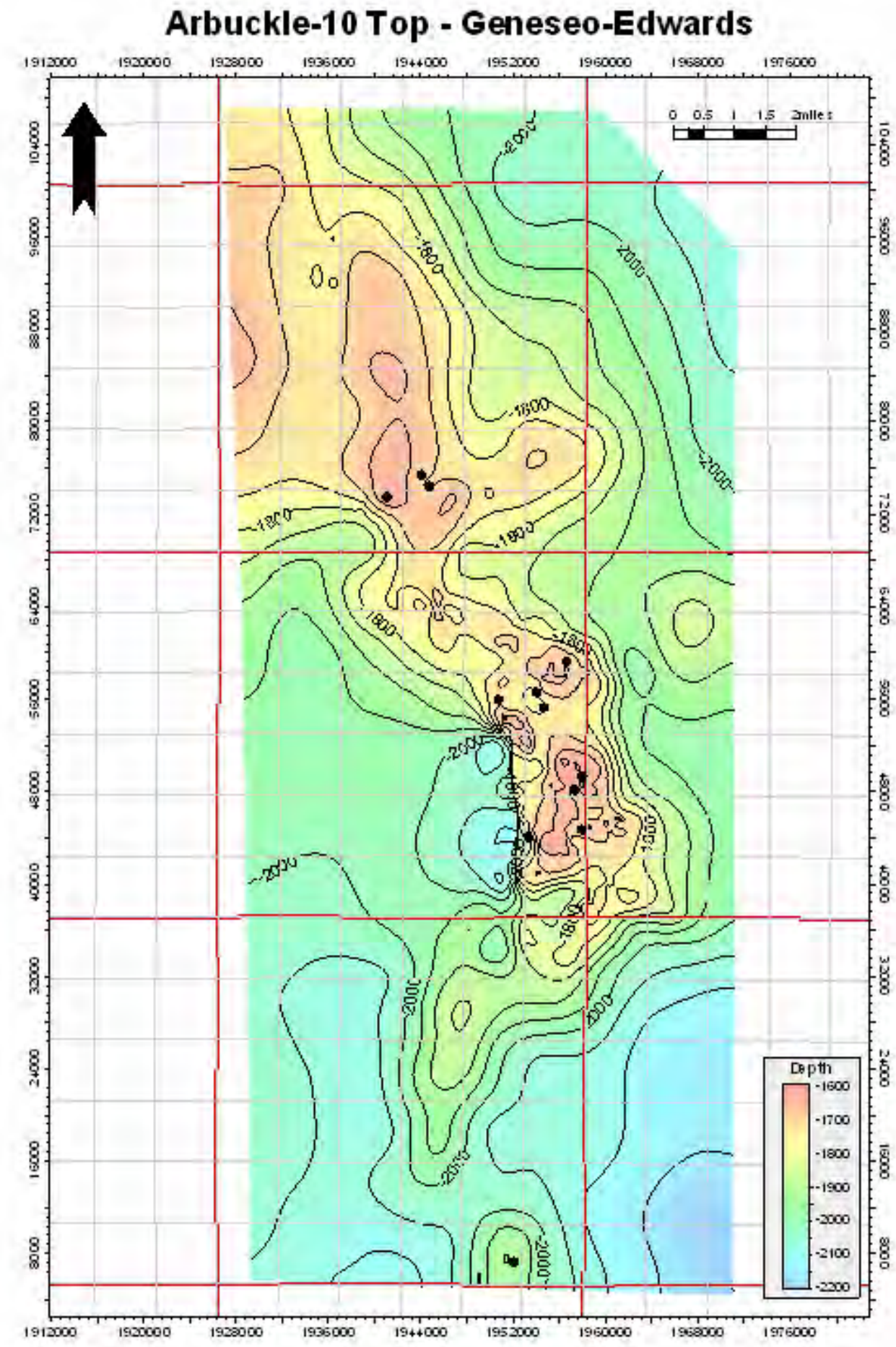

Figure 5-37. Arbuckle-10 surface for the Geneseo-Edwards model. Black dots are well top control points used in the model. Contour interval $25 \mathrm{ft}(\mathbf{7 . 6 2} \mathrm{m})$. 


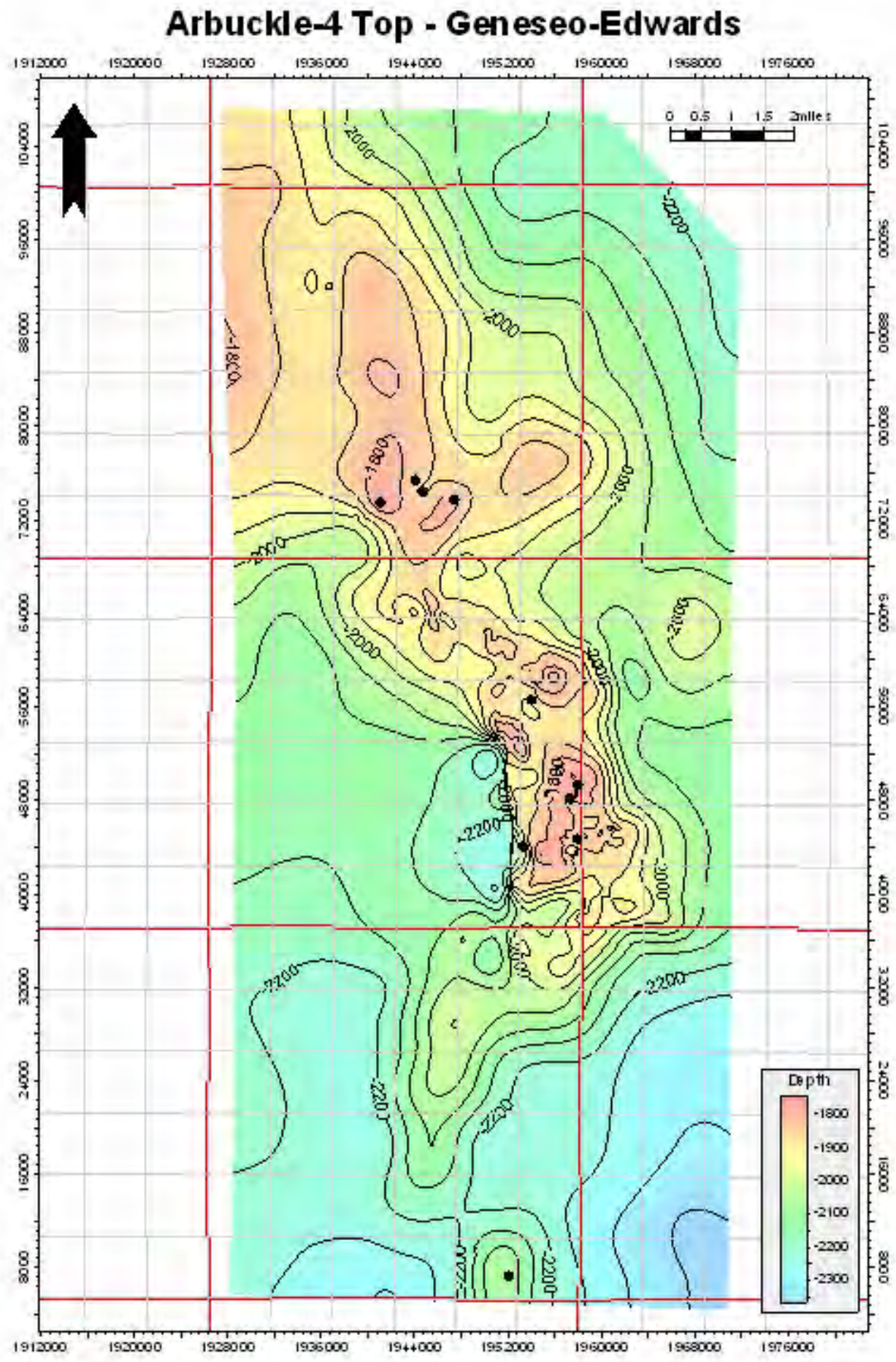

Figure 5-38. Arbuckle-4 surface for the Geneseo-Edwards model. Black dots are well top control points used in the model. Contour interval $25 \mathrm{ft}(\mathbf{7 . 6 2 m})$. 
Arbuckle-1 Top - Geneseo-Edwards

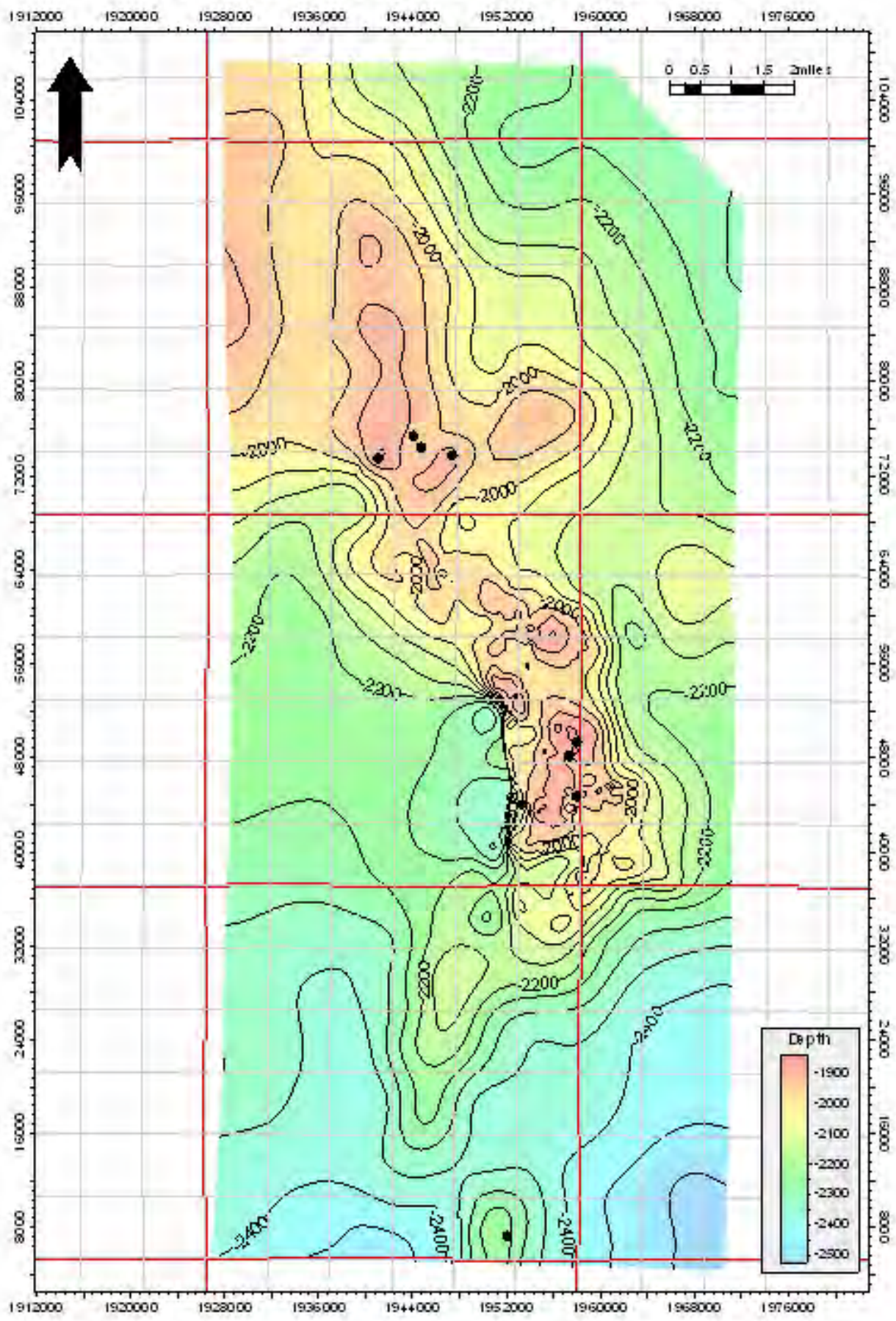

Figure 5-39. Arbuckle-1 surface for the Geneseo-Edwards model. Black dots are well top control points used in the model. Contour interval $25 \mathrm{ft}(7.62 \mathrm{~m})$. 


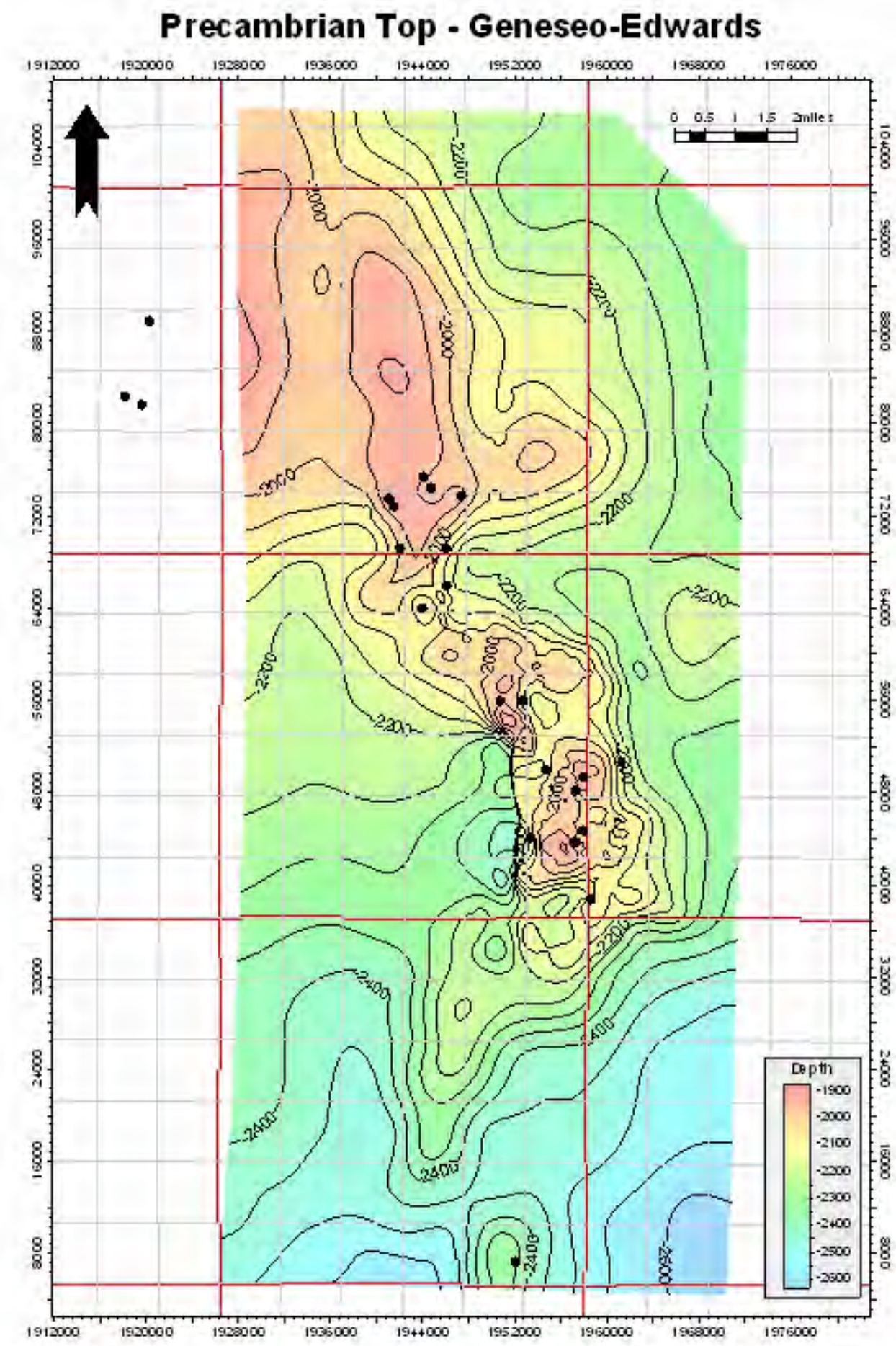

Figure 5-40. Precambrian surface for the Geneseo-Edwards model. Black dots are well top control points used in the model. Contour interval $25 \mathrm{ft}(\mathbf{7 . 6 2 \mathrm { m } ) \text { . }}$

Two significant unconformities exist in the stratigraphic column. First, there is a disconformity at the top of the Arbuckle that erodes into the top of the Arbuckle-31 zone. 
Second, there is a nonconformity at the top of the Precambrian basement that has resulted in an absence of the Arbuckle 1 zone to the north. Figures 5-41 and 5-42 show East-West and North-South cross sections of the zones through the southern structural high of the Geneseo-Edwards, the location of the dynamic model.

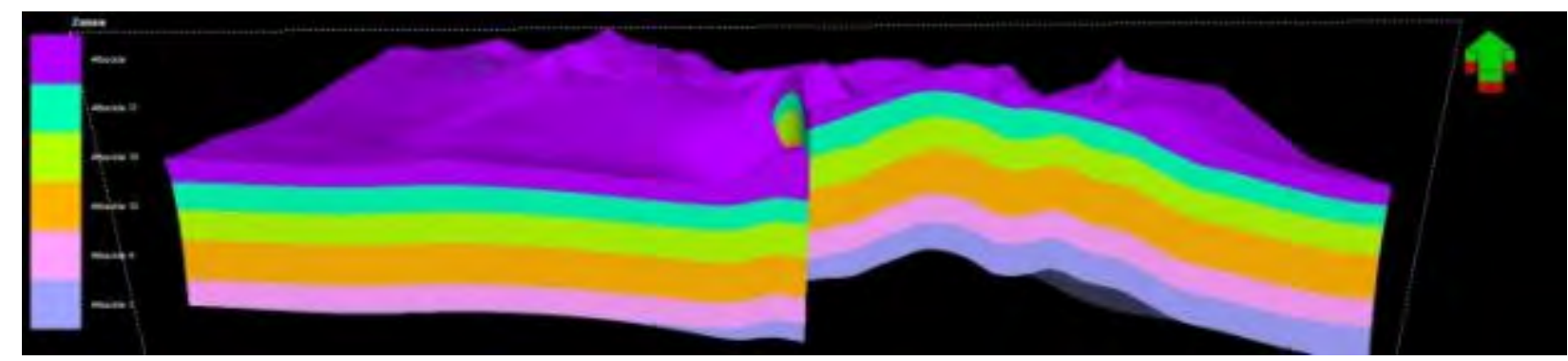

Figure 5-41. East-West cross section through the zones for the southern structure and the dynamic model area. Note fault cut in the middle of the section.

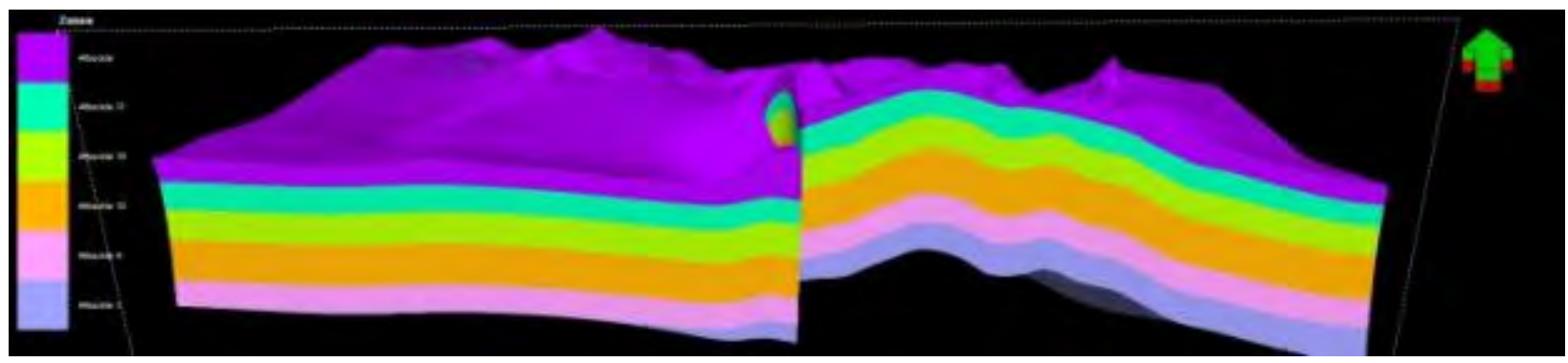

Figure 5-42. North-South cross section through the zones for the southern structure and the dynamic model area.

The size of the study area dictated that a $300 \mathrm{ft}$ by $300 \mathrm{ft}(91.44 \mathrm{~m}$ by $91.44 \mathrm{~m})$ cell horizontal cell size was the smallest possible for the structural model, creating 49,494 2D cells for the model area. Layering of the zones was tied to the distribution of data. Above the Arbuckle-19 there were more well logs and a $5 \mathrm{ft}$ cell height was selected. Below the Arbuckle-19, a 10ft cell size was selected. For the entire modeled area a total of 6,335,232 cells were created with 146 in the i-direction, 339 in the j-direction, and 128 in the k-direction.

\subsubsection{Property Model}

The porosity curves calculated from neutron logs were upscaled to the structural grid using the arithmetic averaging method. The location of the data wells were rather far apart and geostatistical methods to analyze the data was found to be questionable. To better fit the geological conceptual model, the default Petrel settings for distribution were used; $5000 \mathrm{ft}(1524 \mathrm{~m})$ for the major range, $5000 \mathrm{ft}(1524 \mathrm{~m})$ for the minor range, and $10 \mathrm{ft}$ $(3.05 \mathrm{~m})$ for the vertical range. Figures 5-43 and 5-44 show east-west and north-south cross sections of the porosity through the southern structural high of the GeneseoEdwards, the location of the dynamic model. Figure 5-45 is the histogram comparing the distribution of well log (red), upscaled (green), and 3D grid (blue). 


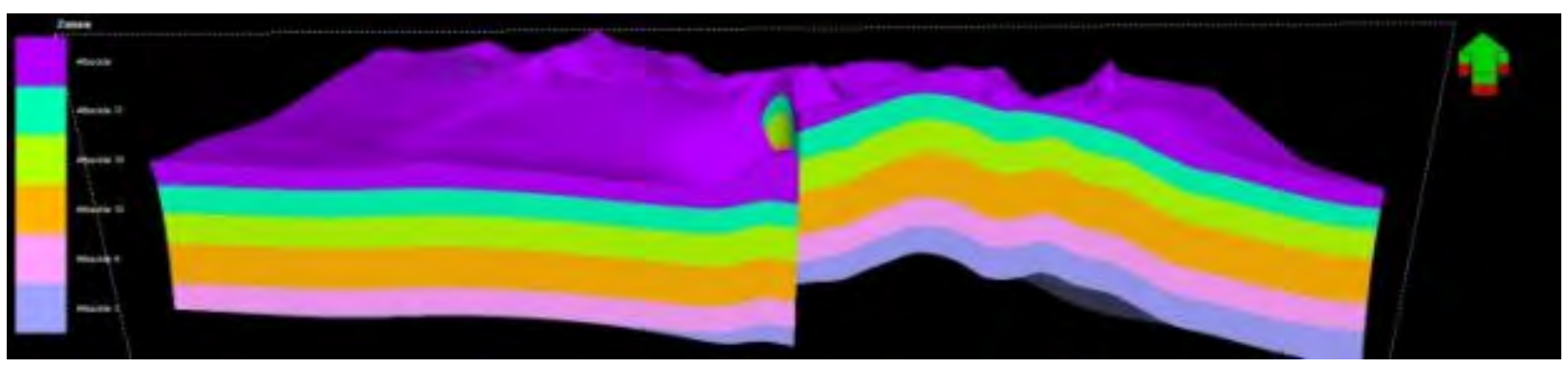

Figure 5-43. East-West cross section of porosity through the dynamic model area. Note fault cut in the middle of the section.

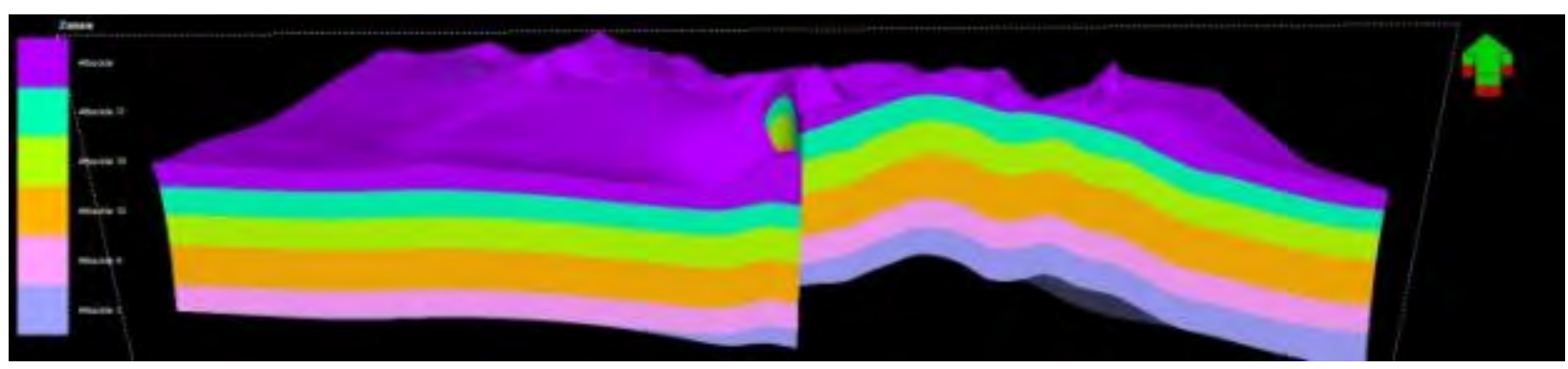

Figure 5-44. North-South cross section of porosity through the dynamic model area.

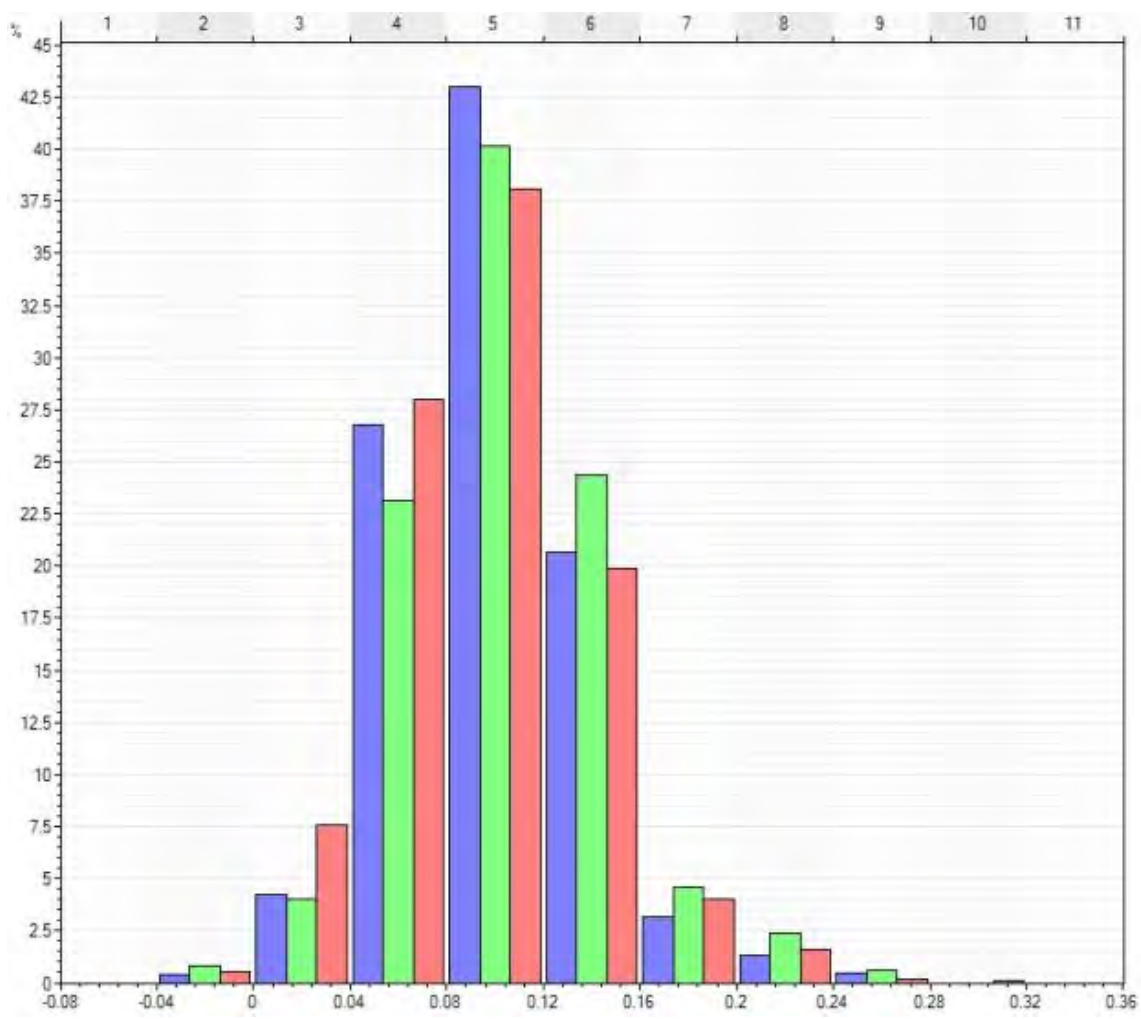

Figure 5-45. Histogram comparing the distribution of porosity on different scales; well log (red), upscaled (green), and 3D grid (blue). 
The porosity and permeability core data from two wells were used to make correlations to input to permeability into the property model. Four porosity/permeability trend lines were created from the data by modifying the range of data (Figure 5-46). The blue trend line used all the data provided from CAP CO2. The blank permeabilities were estimated by CAP-CO2 and the trend line equation:

$\mathrm{K}_{\text {blue }}=1778154.23 *$ porosity $^{\wedge} 5.66$

$\mathrm{R}^{2}=0.65$

Where $\mathrm{K}$ is permeability and $\Phi$ is porosity. Removing the estimated permeability values (green) the trend line equation is:

$\mathrm{K}_{\text {green }}=275904.63 *$ porosity $^{\wedge} 4.31$

$\mathrm{R}^{2}=0.47$

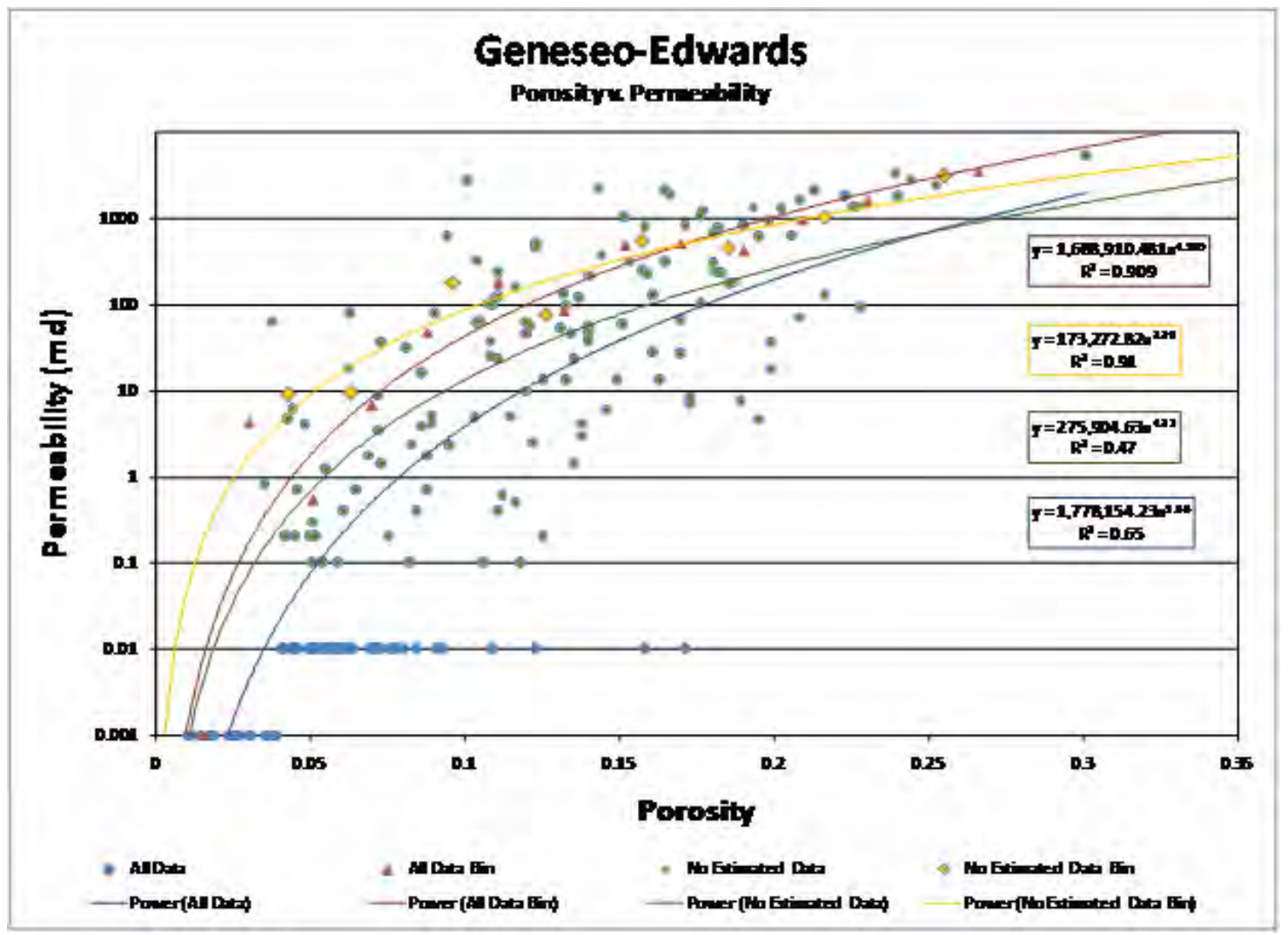

Figure 5-46. Cross-plot of porosity and permeability core data for the GeneseoEdwards. Blue dots are for all core data and estimated data. Green dots are all core data with no estimated data. Red dots are the binned porosity and permeability averages for all core data and estimated data. Yellow dots are the binned porosity and permeability averages for all core data with no estimated data. Trend lines are in corresponding colors to the data.

To achieve a better fit to the upper cloud of data, porosity bins were established to average the porosity and permeability for all data. Using all of the data, including the permeability estimates, the bins were 0.02 porosity units (red). The data without the 
estimates were binned in 0.03 porosity units (yellow). In both cases the averaged data for the bins better fits a power function with an $\mathrm{R}^{2}$ value greater than 90 . The trend line equations are:

$$
\begin{aligned}
& \mathrm{K}_{\text {red }}=16788910.48 * \text { porosity }^{\wedge} 4.59 \\
& \mathrm{R}^{2}=0.909 \\
& \mathrm{~K}_{\text {yellow }}=173272.82 * \text { porosity }^{\wedge} 3.29 \\
& \mathrm{R}^{2}=0.91
\end{aligned}
$$

The sets with no estimated values were propagated in the model to eliminate potential estimation error. The binned set is used as a high permeability case, while the correlation for the raw data is the low permeability case. Using the previously mentioned power function, the distributed porosity was used to create the high and low permeability properties. The distributed permeabilities are shown in cross sections in Figures 5-47a-d. Figure 5-48 and 5-49 are the histograms for the low and high permeability distributions.

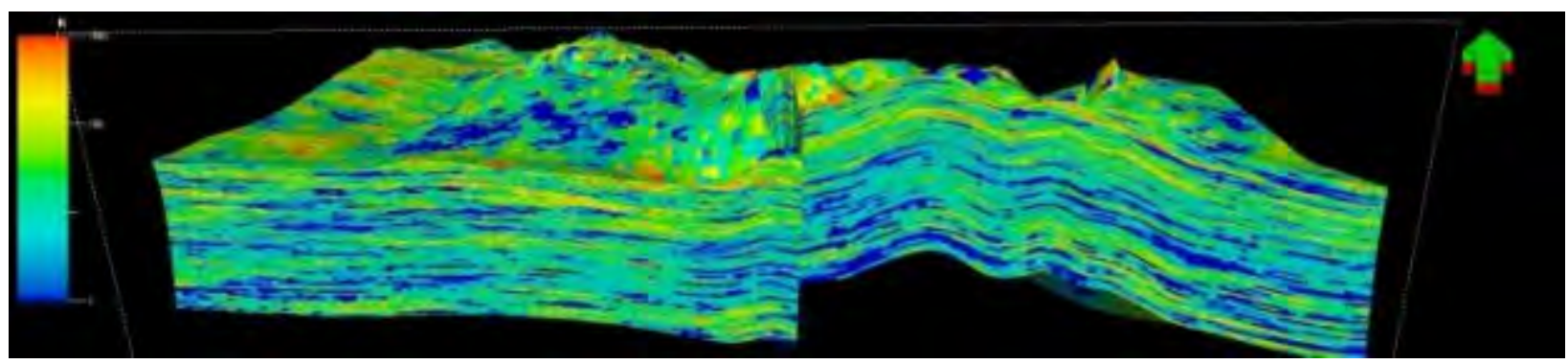

Figure 5-47a. East-West cross section of low permeability through the dynamic model area. Note fault cut in the middle of the section.

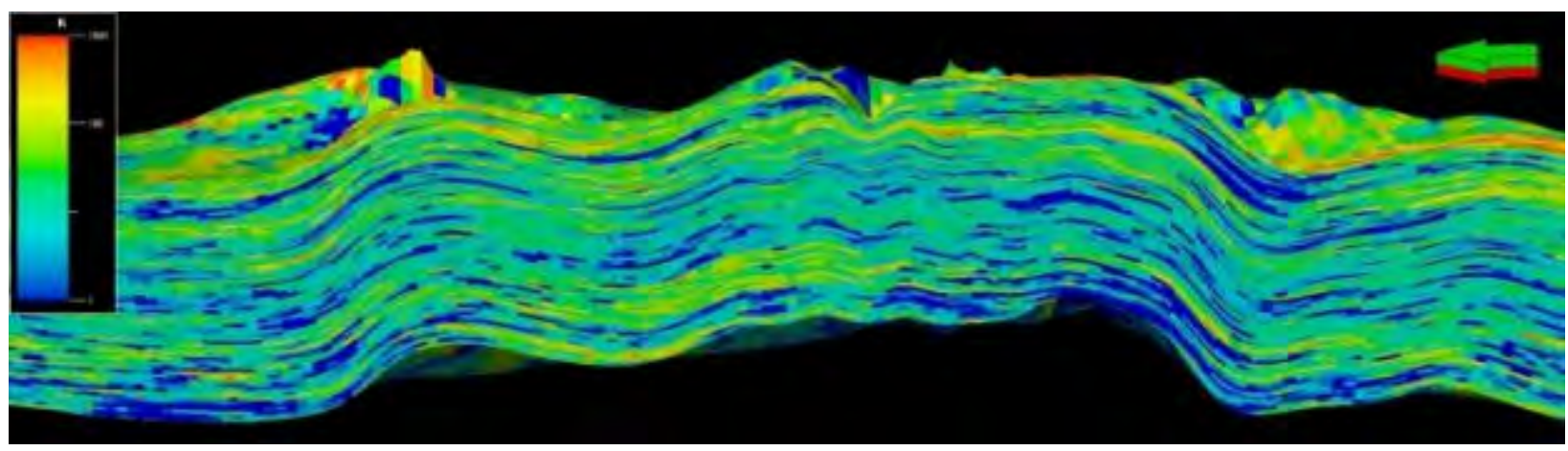

Figure 5-47b. North-South cross section of low permeability through the dynamic model area. 


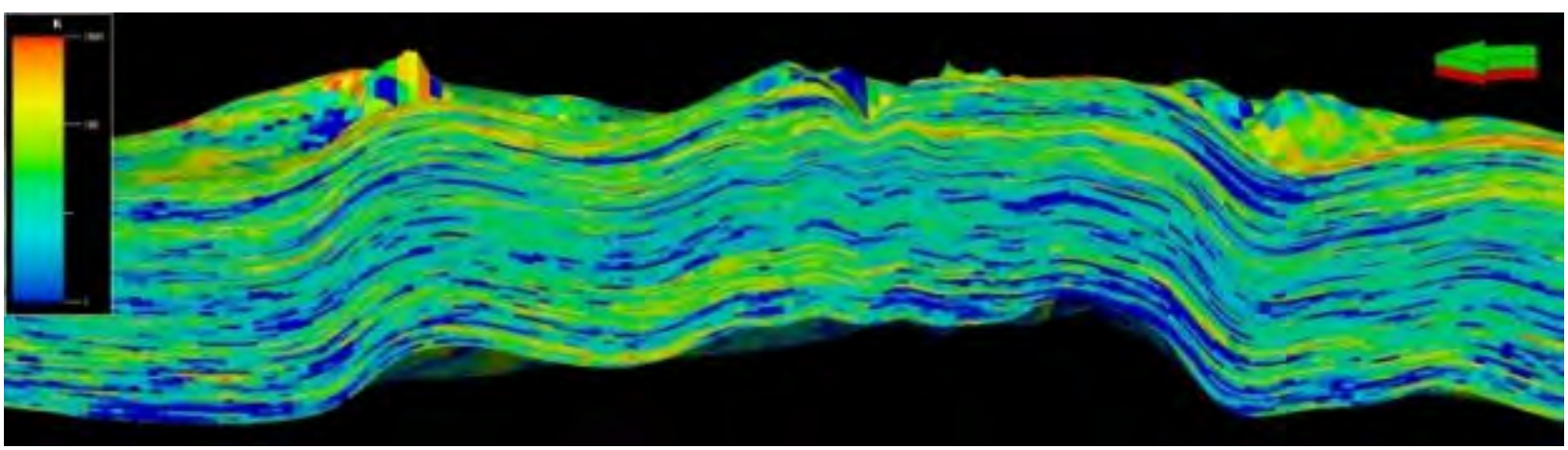

Figure 5-47c. East-West cross section of high permeability through the dynamic model area. Note fault cut in the middle of the section.

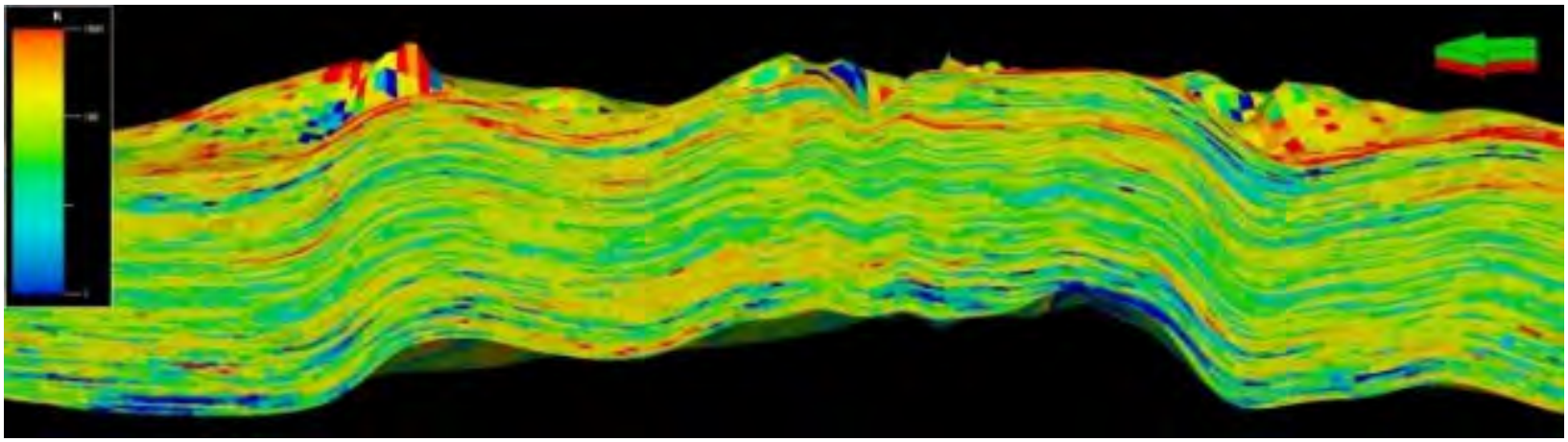

Figure 5-47d. North-South cross section of high permeability through the dynamic model area. 


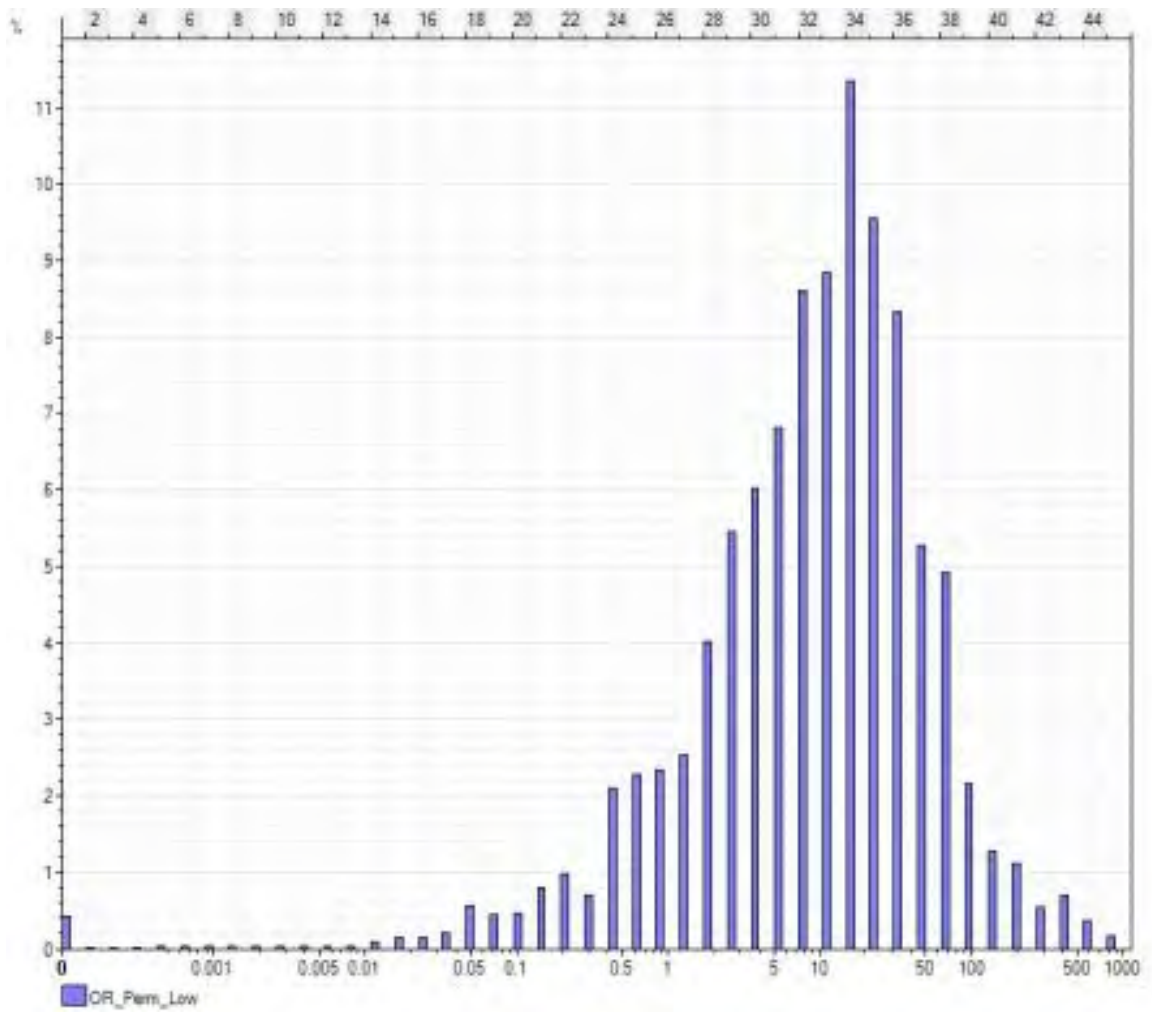

Figure 5-48. Histogram of low permeability distribution for 3D grid.

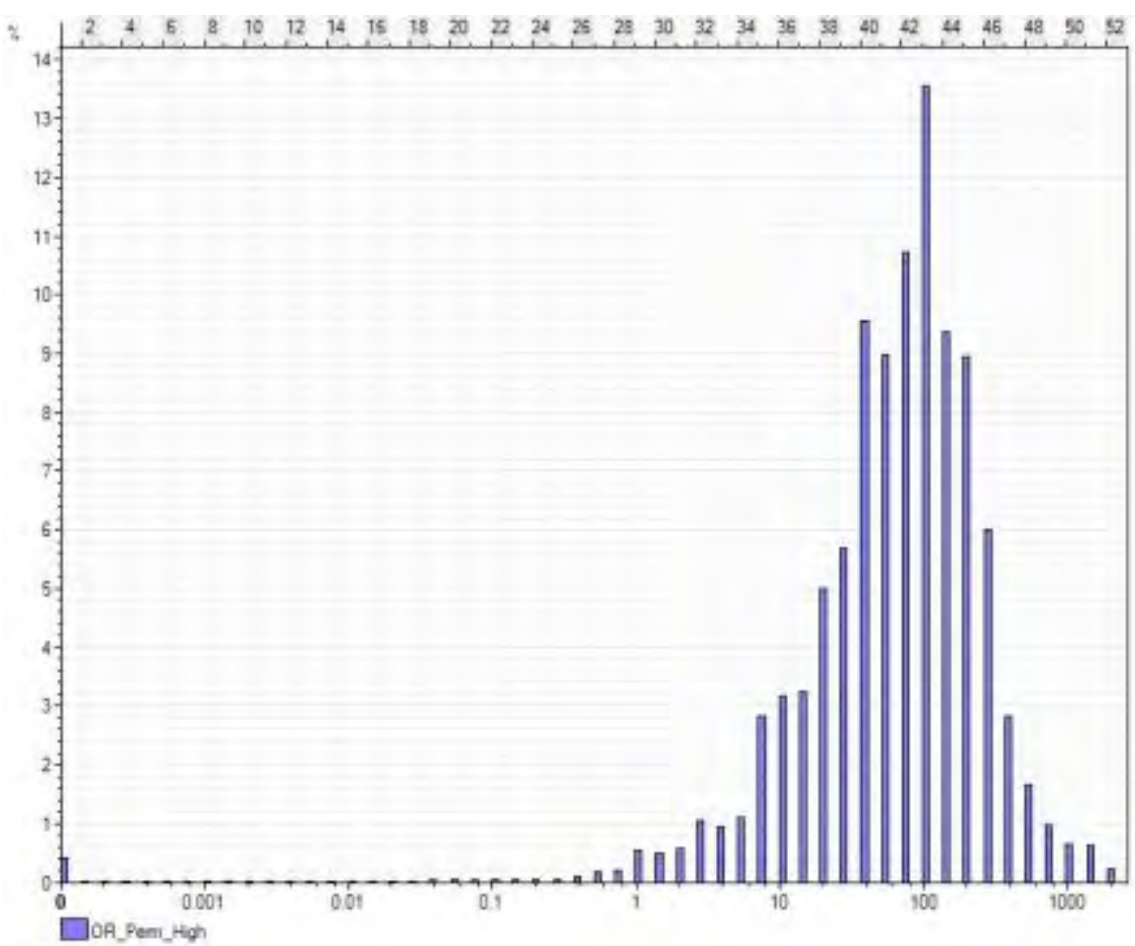

Figure 5-49. Histogram of high permeability distribution for 3D grid. 
Water saturation was created by using the oil water contact (OWC) of $-1500 \mathrm{ft}$ TVDSS provided by CAP-CO2. An estimated water saturation of $30 \%$ was used above the OWC. This value was used to initialize the dynamic model. Table 5-6 contains the maximum, minimum, and mean values for each of the properties.

\begin{tabular}{|l|l|l|l|}
\hline Property & Minimum & Maximum & Mean \\
\hline Porosity & 0.000 & 0.260 & 0.098 \\
\hline Low Permeability (md) & $0^{*}$ & 830 & 25 \\
\hline High Permeability (md) & $0^{*}$ & 2059 & 121 \\
\hline Water Saturation & 0.3 & 1.0 & --- \\
\hline
\end{tabular}

*Note: values are significantly close to zero and are products of the porosity-permeability transform.

Table 5-6. Minimum, maximum, and mean values for porosity, low permeability, high permeability, and water saturation.

\section{Volumetric calculations}

Using the distributed porosity, water saturation, and an oil formation volume factor of $1.06 \mathrm{RB} / \mathrm{STB}\left(0.169 \mathrm{~m}^{3} / \mathrm{m}^{3}\right)$, a volume calculation was created for the property model. For the area of the dynamic model the pore volume is $130 \mathrm{MMbbl}\left(20.7 \times 10^{6} \mathrm{~m}^{3}\right)$ with a hydrocarbon pore volume of $88 \mathrm{MMbbl}\left(14.0 \times 10^{6} \mathrm{~m}^{3}\right)$ and about $40 \mathrm{MMbbl}(6.4 \mathrm{x}$ $10^{6} \mathrm{~m}^{3}$ ) of recoverable oil is present. The Arbuckle and Arbuckle-31 zones contain the entire hydrocarbon amount. These numbers will require validation through dynamic modeling. Table 5-7 contains a listing of the volumetrics by zone.

\begin{tabular}{|l|c|c|c|c|c|c|}
\hline Zone & $\begin{array}{c}\text { Bulk } \\
\text { volume } \\
\text { (MMbbl) }\end{array}$ & $\begin{array}{c}\text { Net } \\
\text { volume } \\
\text { (MMbbl) }\end{array}$ & $\begin{array}{c}\text { Pore } \\
\text { volume } \\
\text { (MMbbl) }\end{array}$ & $\begin{array}{c}\text { HCPV oil } \\
\text { (MMbbl) }\end{array}$ & $\begin{array}{c}\text { STOIIP } \\
\text { (MMbbl) }\end{array}$ & $\begin{array}{c}\text { Recoverable } \\
\text { oil (MMbbl) }\end{array}$ \\
\hline Arbuckle & 776 & 776 & 95 & 65 & 61 & 29 \\
\hline Arbuckle 31 & 322 & 322 & 35 & 23 & 22 & 10 \\
\hline Arbuckle 19* & 0 & 0 & 0 & 0 & 0 & 0 \\
\hline Arbuckle 10* & 0 & 0 & 0 & 0 & 0 & 0 \\
\hline Arbuckle 4* & 0 & 0 & 0 & 0 & 0 & 0 \\
\hline Arbuckle 1* & 0 & 0 & 0 & & 0 & 0 \\
\hline Total & & & $\mathbf{1 3 0}$ & $\mathbf{8 8}$ & $\mathbf{8 3}$ & $\mathbf{4 0}$ \\
\hline
\end{tabular}

*Note: zone below oil water contact and no calculation for hydrocarbon was conducted.

Table 5-7. Volumetric calculation of STOIIP and Recoverable oil for the dynamic model area.

\subsubsection{Summary}

Using well tops, surface grids, core data, and well log data provided by CAP-CO2, structural and property models were created for dynamic simulation of the GeneseoEdwards Field. The distribution of porosity was used to calculate permeability based upon power function transforms for the two different cases. The final model results in a hydrocarbon pore volume of $88 \mathrm{MMbbl}\left(14.0 \times 10^{6} \mathrm{~m}^{3}\right)$ and approximately $40 \mathrm{MMbbl}$ $\left(6.4 \times 10^{6} \mathrm{~m}^{3}\right)$ of recoverable hydrocarbons. 


\subsection{Simulation of Gravity-Stable $\mathrm{CO}_{2}$ Injection for EOR and Sequestration}

\subsubsection{Scope of Simulation Study}

The $\mathrm{CO}_{2}$ Injection Simulation task sought to model the injection of $\mathrm{CO}_{2}$ into a mature oil reservoir for the dual purpose of $\mathrm{CO}_{2}$ storage and mobilization of remain oil. This exercise was a preliminary simulation of the development and injection scenario outlined in Section 5.5.3. Optimization of well placement, trajectory, injection rates that could improve $\mathrm{CO}_{2}$ storage and oil sweep were not applied in this initial simulation. The primary objective is to fill the two domes with $\mathrm{CO}_{2}$ using a fixed maximum rate of 7,500 Mscf/d, and then observe the volume of oil displaced and where the displaced oil bank forms.

\subsubsection{Simulation Model Parameters and History Match}

The reservoir consists of two structurally high domes with closure on all sides. The North Dome is smaller and simpler, while the South Dome is more laterally extensive. The southern Geneseo-Edwards has been in production since 1935 with a total of 5.4 million $\mathrm{m}^{3}$ (33.7 million barrels) of oil recovered to date from the modeled area (Figure 5-50). A strong bottom drive aquifer has maintained the average reservoir pressure very well over the life of the field, even in the absence of active water injection.

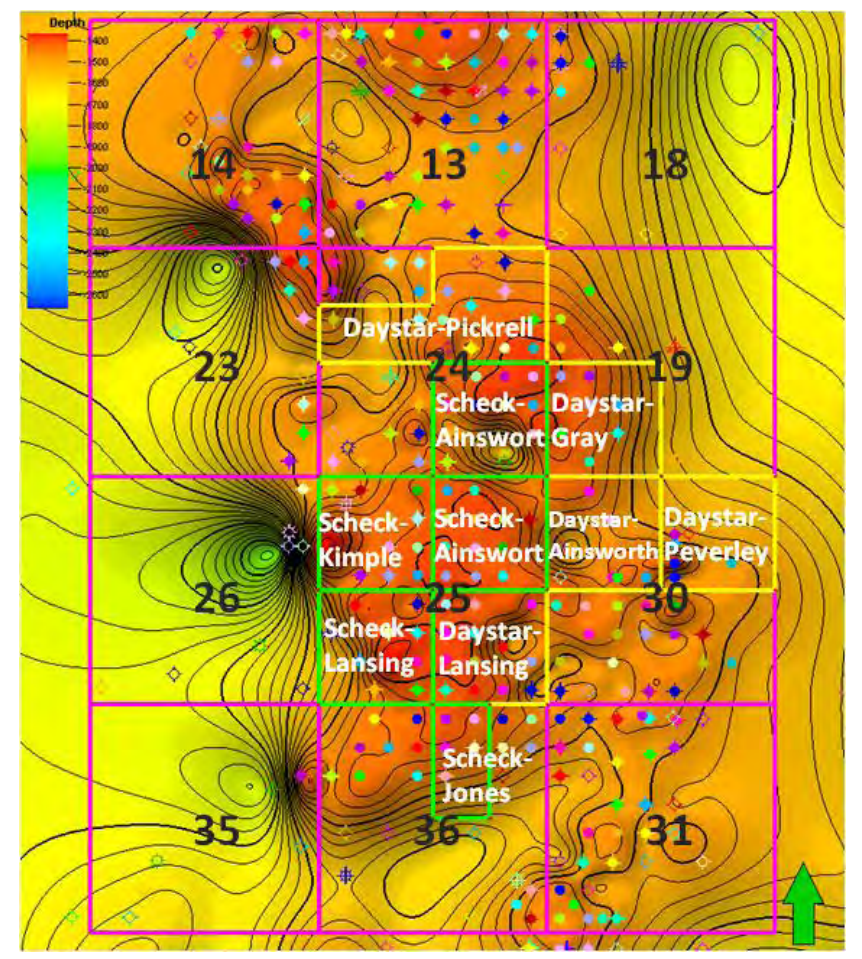

Figure 5-50. Geneseo-Edwards model area with operator and lease names. 
The simulation model area in this study covers a 12-section area most of which operated by Daystar Oil and Scheck Oil (see Figure 5-50). A total of 152 wells can be found in this area with 3.9 million $\mathrm{m}^{3}$ (24.8 million barrels) of oil recovered in the 75 year history. The following are the data available for the dynamic simulation work:

- Static model grid providing reservoir structural and property information

- PVT data of an oil sample collected in a neighboring field

- Annual oil production rates by lease areas

- Barrel test data of some individual wells provided by Daystar Oil and Scheck Oil

\subsubsection{Static Model Grid}

The dynamic simulation model (see Figure 5-51) was extracted from the static model grid with $91 \mathrm{~m} \times 91 \mathrm{~m}(300 \mathrm{ft} \times 300 \mathrm{ft})$ grid cells and 87 layers each averaging $3 \mathrm{~m}(10 \mathrm{ft})$ in thickness. With the initial oil-water contact estimated to be at $458 \mathrm{~m}(1,503 \mathrm{ft})$ subsea, most of these layers cover the underlying saline aquifer. The $\mathrm{CO}_{2}$ injected into the saline aquifer is expected to rise and eventually enters the swept oil zone from below. This phenomenon is included in the simulation with this integrated model.

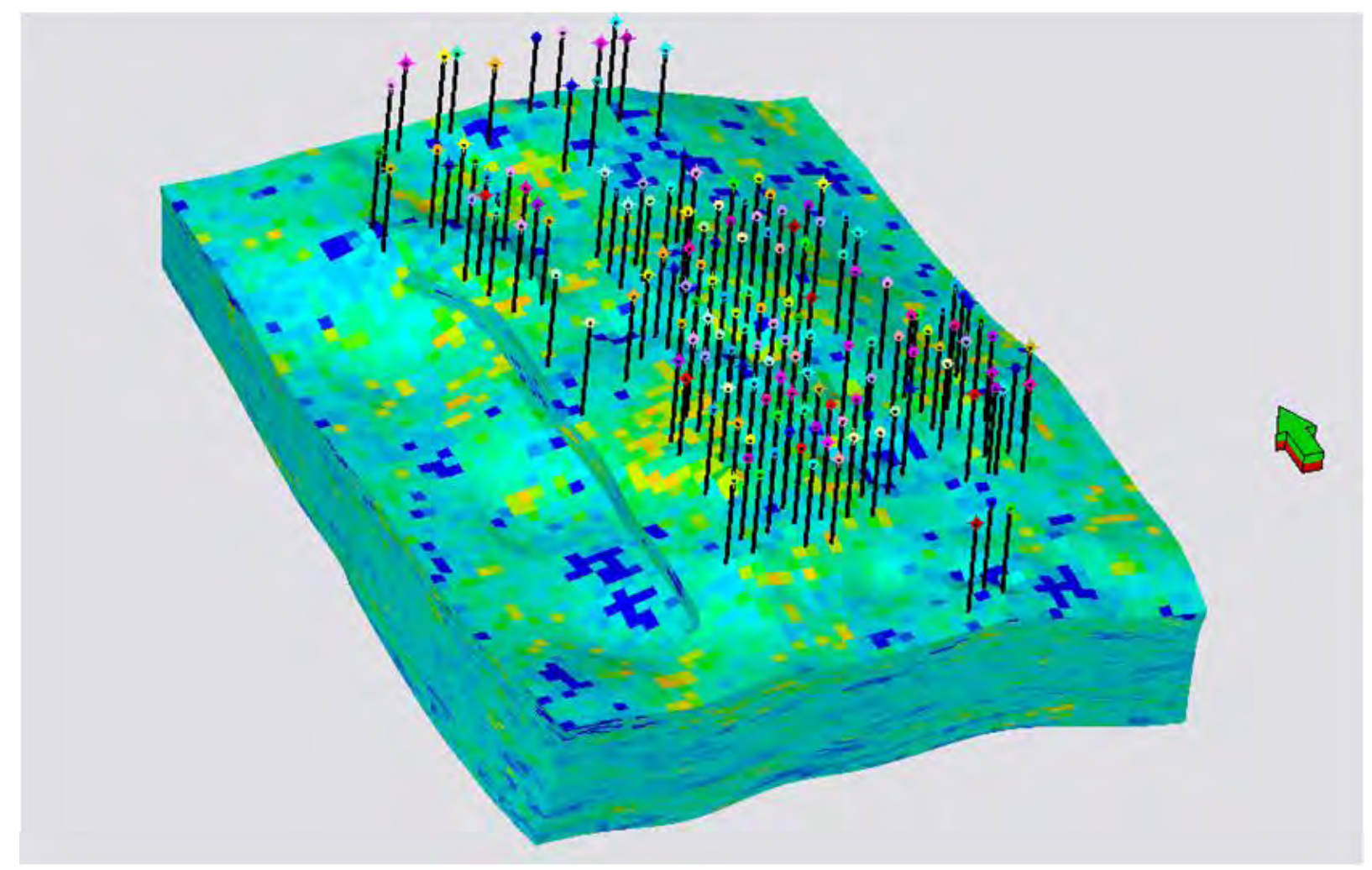

Figure 5-51. The simulation model 


\subsubsection{Equation of State}

An EOS (equation-of-state) for the Eclipse 300 model was provided by University of Kansas and is based on a 33.3 API surface oil sample from a neighboring field, the Ogallah Unit (http://www.torp.ku.edu/research/Tsau_2a.pdf). On the other hand, the oil produced in the Geneseo-Edwards Field is closer to 37 API and this was achieved by slightly adjusting the EOS. The EOS was incorporated into the simulation model after mixing in a small amount of gas $\left(21.4 \mathrm{~m}^{3} / \mathrm{m}^{3}\right.$ or $\left.120 \mathrm{scf} / \mathrm{stb}\right)$. This gave the numerical fluid a saturation pressure of $4.2 \mathrm{MPa}(610 \mathrm{psia})$ at the average reservoir temperature of $47^{\circ} \mathrm{C}\left(117^{\circ} \mathrm{F}\right)$ as shown in Figure 5-52. With this, the model was initializes with initial water saturation shown in Figure 5-53 and estimates a total of 13.57 million cubic meters (85.4 million barrels) of oil initially in place.

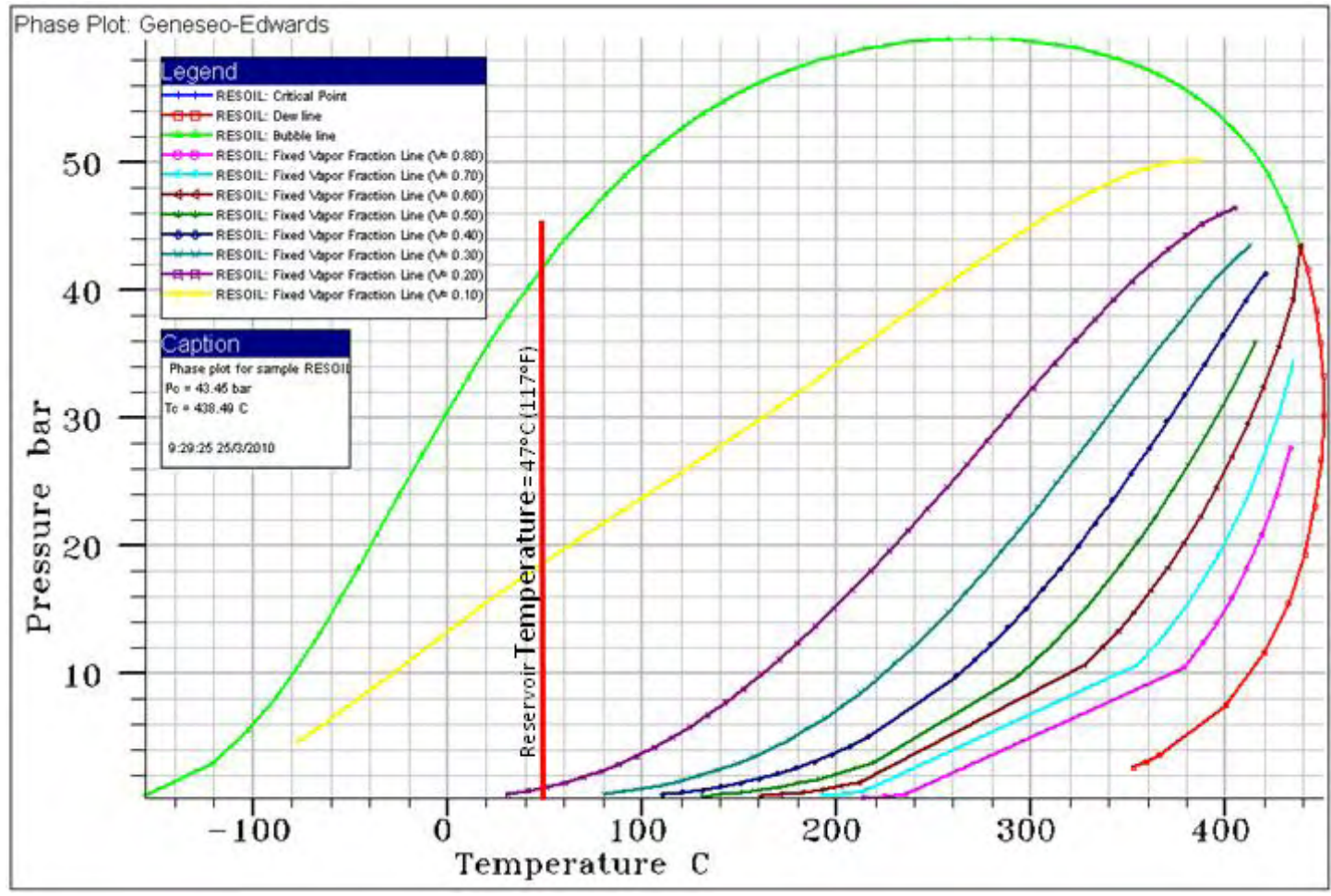

Figure 5-52. Model fluid phase diagram 


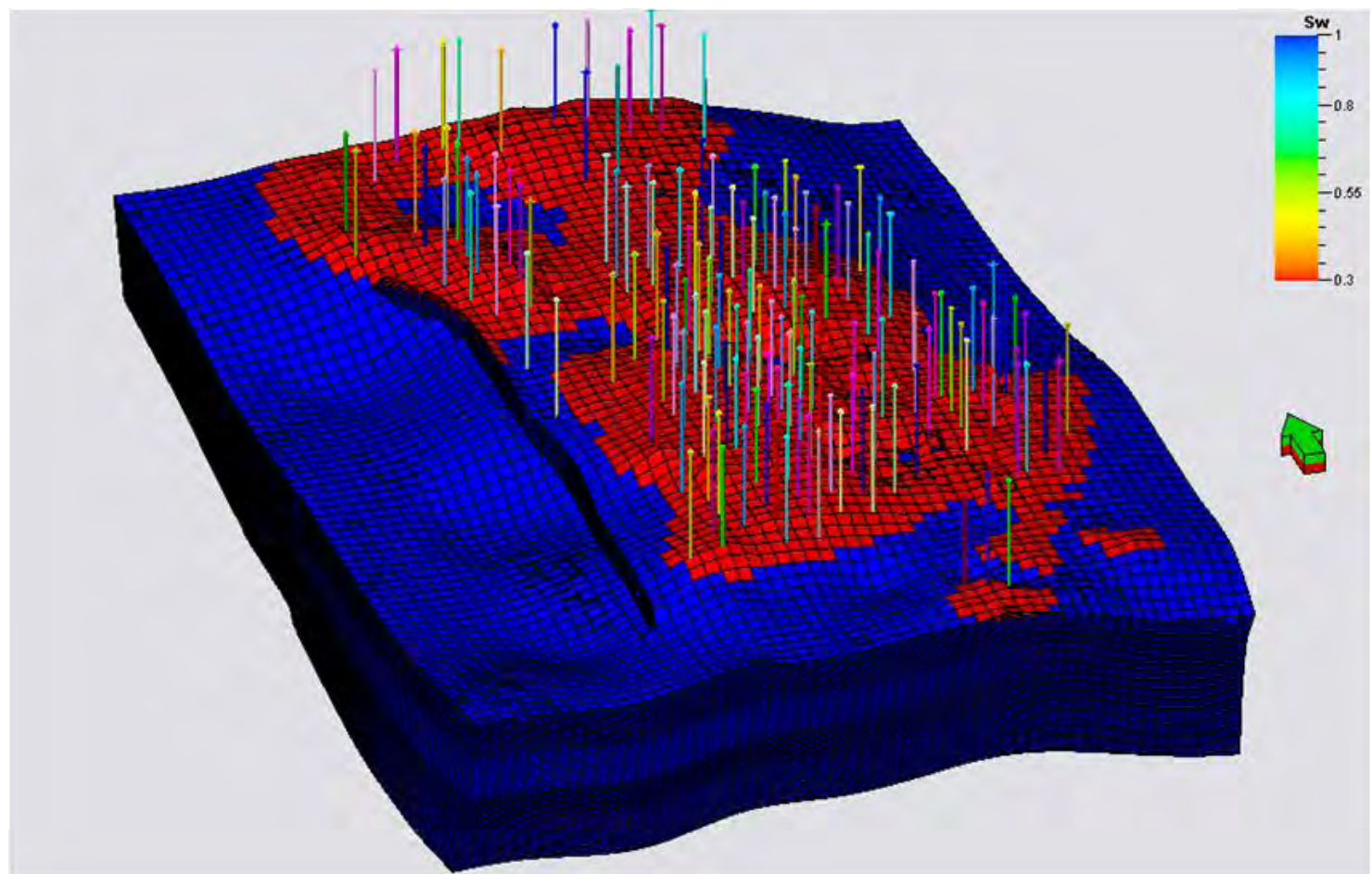

Figure 5-53. Initial water distribution

\subsubsection{History Match}

As previously mentioned, the field had been in operation for the past 75 years and only sketchy production data are available. These include annual oil production figures by lease area and barrel tests of individual wells provided by Daystar Oil and Scheck Oil. It is evidenced that the reservoir is subject to a strong aquifer support during the substantial amount of primary oil recovery with a relatively stable reservoir pressure. With these in mind, analytical aquifers have been attached to the side and to the bottom of the model as extensions to the water body within the model.

Well completion and production information (annual oil production rates by lease) was incorporated (see Figure 5-4) once the initial model setup was complete. This was then followed by adjustments of certain model parameters in order to calibrate it to the historical production data. This process is commonly known as history matching. In this case, the model was made to match the general historical trends in water cut measurements during the barrel tests of the wells in the Daystar and Scheck leases. Model parameters (oil-water contact depth, residual oil saturation and analytical aquifer volumes) were adjusted within reasonable ranges. 


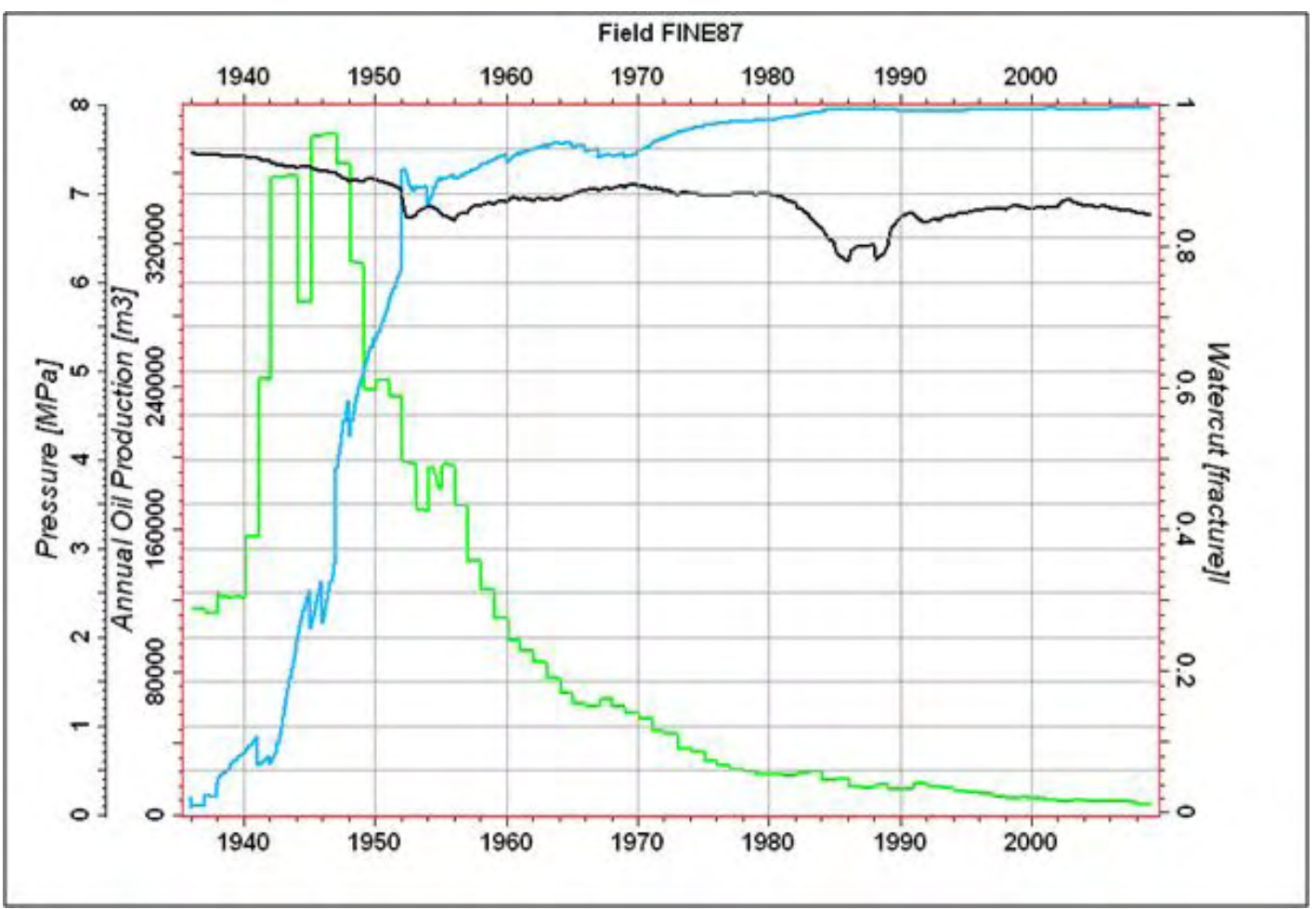

Figure 5-54. Production and pressure profiles

Once a satisfactory match (see Figure 5-55) was achieved, the model could be used for simulating the effects of $\mathrm{CO}_{2}$ injection in both the sweep oil zone (EOR) and the underlying saline aquifer (sequestration). It should be noted that the model calibration process is generally a non-unique one particularly when sparse field observations are sparse such as in this case. This typically necessitates an uncertainty analysis to evaluate the range of possible outcomes given the lack of data. 


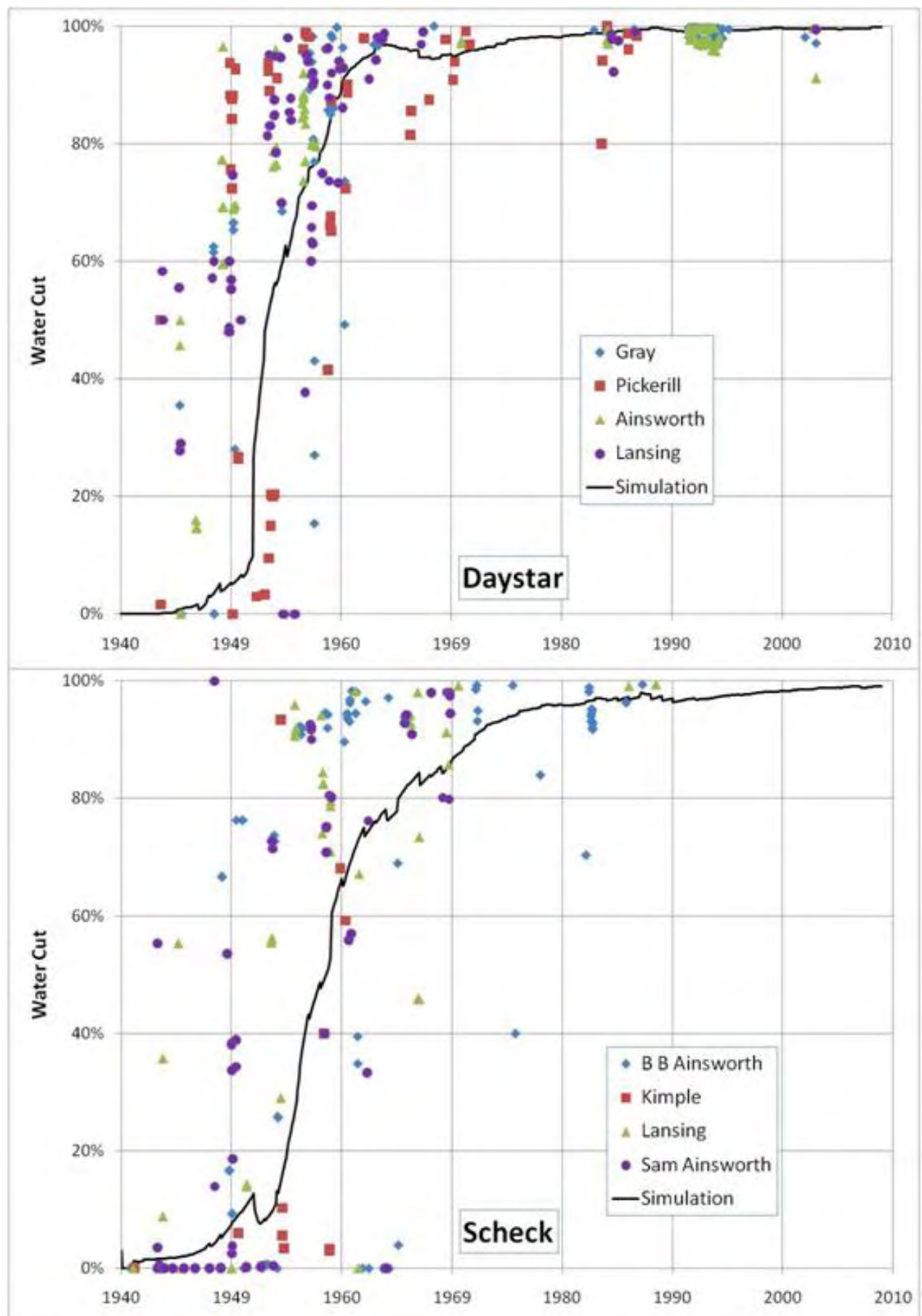

Figure 5-55. Barrel test water and calibrated model water cut profiles.

Figure 5-55 shows water breakthrough occurred rapidly and consistently throughout the field in the fifties and the sixties. This was caused by the encroaching water from the saline aquifer that allowed the production to take place without significant observable reservoir pressure declines. Production in recent years has been associated with approximately $99 \%$ water cut levels indicating that vast majority of the oil produced came exclusively from the swept oil zone. The model is able to mimic these trends with the strong analytical aquifers attached. Once the simulation of the historical production 
has been completed, the model the present day fluid (oil and water) distributions and 56 shows three-dimensional water saturation distributions determined by the model at various points during the 75 -year recovery process.

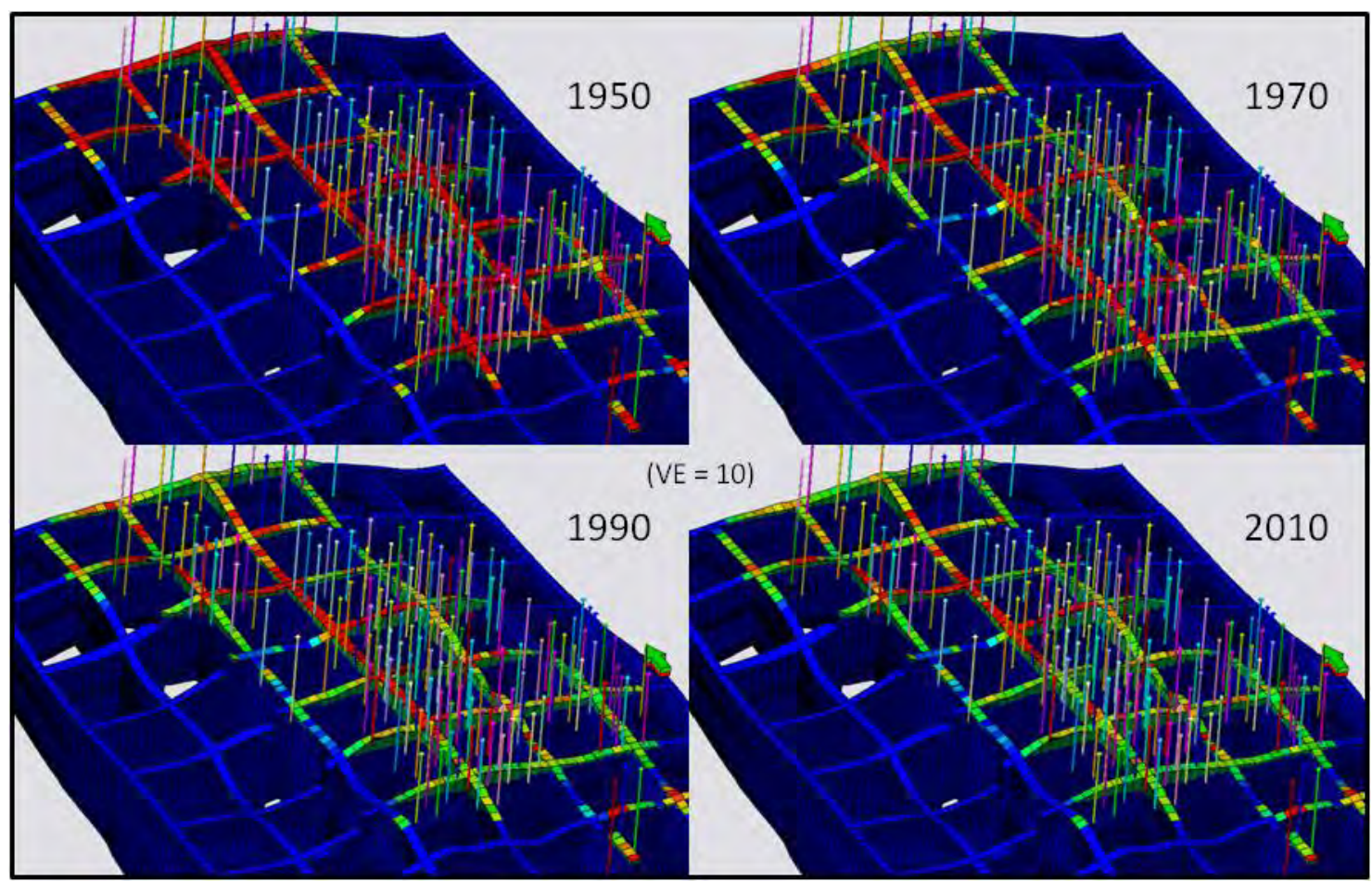

Figure 5-56. Aquifer encroachment progress shown with model generated water saturation distributions.

\subsection{3 $\mathrm{CO}_{2}$ Injection Plan}

$\mathrm{CO}_{2}$ injection processes simulated with the calibrated model involves $\mathrm{CO}_{2}$ injected into the two domes, one at a time, at a fixed maximum rate of 7,500 Mscf/d, the output from the Kansas Ethanol facility at Lyons, Kansas. A group of six wells in the North Dome and six wells in the South Dome receive the $\mathrm{CO}_{2}$, with the North Dome injection starting on 1 Jan 2012 and the South Dome injection starting after the North Dome is filled (Figure 5-57). Injection stops when the South Dome is filled. In both cases, filled is defined as injecting $\mathrm{CO}_{2}$ from the top of the reservoir down to a subsea depth of $-1,486$ $\mathrm{ft} \mathrm{TVD}$, although in neither case is the fill uniform or necessarily complete. Further study is needed to optimize the injection by adjusting well locations and configurations, perforation zones, and injection rate for each well. 


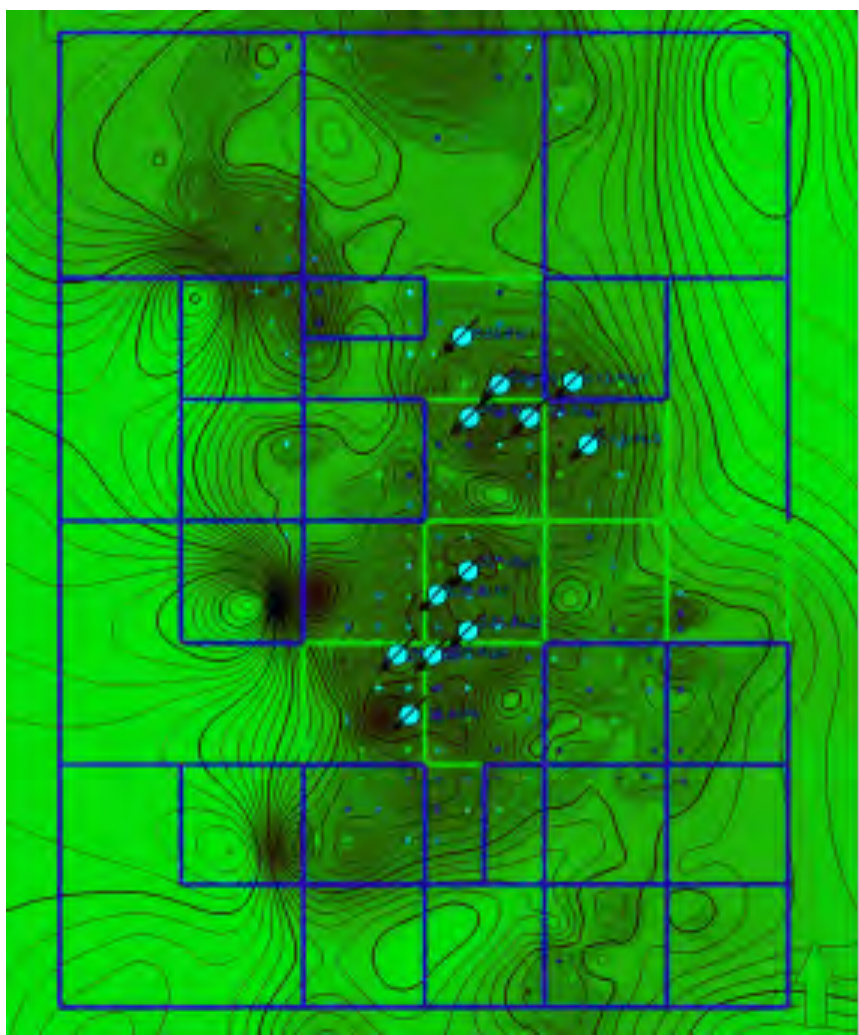

Figure 5-57. Arbuckle structure map showing location of 12 simulated injections wells, six injectors for each dome structure.

\subsubsection{Wells}

The wells used in this study occupy the same location as existing oil production wells. These simulation runs are a restart of the 74-year history match simulation run that ended 1 Jan 2010. Wells continue their group production rates with a BHP limit of 200 psia from 1 Jan 2010 until all production wells are shut on 1 Jan 2012. At this point, the six $\mathrm{CO}_{2}$ injection wells in the North Dome start injecting with a target rate of 7,500 Mscf/d for the whole group and a BHP limit of 1,700 psia. A guide rate was used to inject more of this group rate to the wells toward the east side of the North Dome, and perforations were limited to about the top 3 layers, or about $20 \mathrm{ft}$, below the top of the reservoir. Simulated injection continued in the North Dome until 1 July 2014, for an injection period of 2.5 years. At this point, $\mathrm{CO}_{2}$ has pushed below the subsea depth $-1,486 \mathrm{ft}$ depth in several parts of the dome, but has not reached it in others. There was not time in this brief study to optimize the injected $\mathrm{CO}_{2}$ volume, so it is likely that a longer $\mathrm{CO}_{2}$ injection period would be permissible.

At simulation timestep 1 July 2014, the six $\mathrm{CO}_{2}$ injection wells in the South Dome start injecting with a target rate of 7,500 Mscf/d for the whole group and a BHP limit of 1,700 psia. Again, a guide rate and selective perforating were used to balance the injection, but the South Dome was considered to be filled after 2.5 years of injection. 
The simulation stopped on 1 Jan 2017. Oil production from the "oil leg" beneath the $\mathrm{CO}_{2}$ gas cap was not modeled in this simulation.

\subsubsection{Well Pressures}

While all injection wells were given a BHP limit of 1,700 psia, the maximum BHP observed is on the order of about 1,400 psia (Figure 5-58). This suggests that there is sufficient injectivity to increase the injection rate in the future, or even to reduce the perforation lengths further to achieve a more uniform filling. Additionally, it also suggests that this rate of $\mathrm{CO}_{2}$ can be injected in fewer wells to reduce well conversion costs, although this would be detrimental to the uniformity of fill. Further study should investigate this balance between cost and fill.

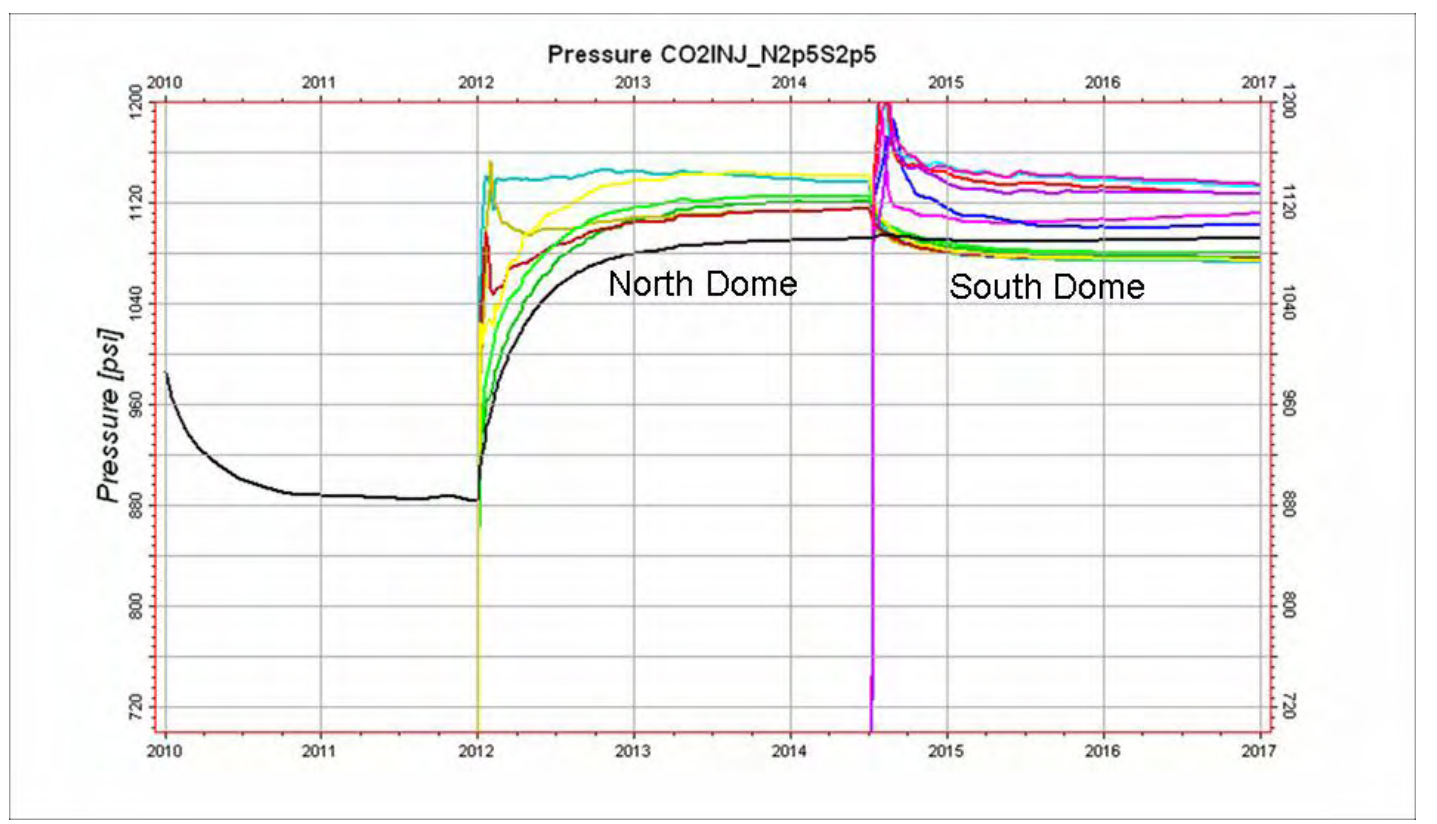

Figure 5-58. Pressure through time at each injection well. Black is average model pressure. Colored are two sets of six injection wells, one set per dome. South dome pressure profile extended for the 2.5 years where injection was switched to South Dome.

\subsubsection{Simulation Results}

\subsubsection{Discussion of North Dome Results}

Figure 5-59 shows the predicted size of the $\mathrm{CO}_{2}$ plume after each dome has received 0.4 million tons of $\mathrm{CO}_{2}$ (7,500 Mscf/d for 2.5 years $\approx 0.4$ million tons). The upper left panel shows cross sections through the North Dome, the upper right panel shows cross sections through the South Dome, and the lower panel shows the complete plume in both the North and South Domes. In all these figures, only cells with $\mathrm{CO}_{2}$ saturation greater than zero are shown, and the color scale indicates the $\mathrm{CO}_{2}$ saturation from 0.0 to about 
0.45. Also shown on the top two panels is the reddish-brown semi-transparent surface at subsea $-1,486 \mathrm{ft}$ TVD. Since these views are from above that surface, cells below subsea $-1,486 \mathrm{ft}$ TVDSS are shaded. This gives a visual indication of where the injected $\mathrm{CO}_{2}$ has filled the dome and where additional volume could be stored.

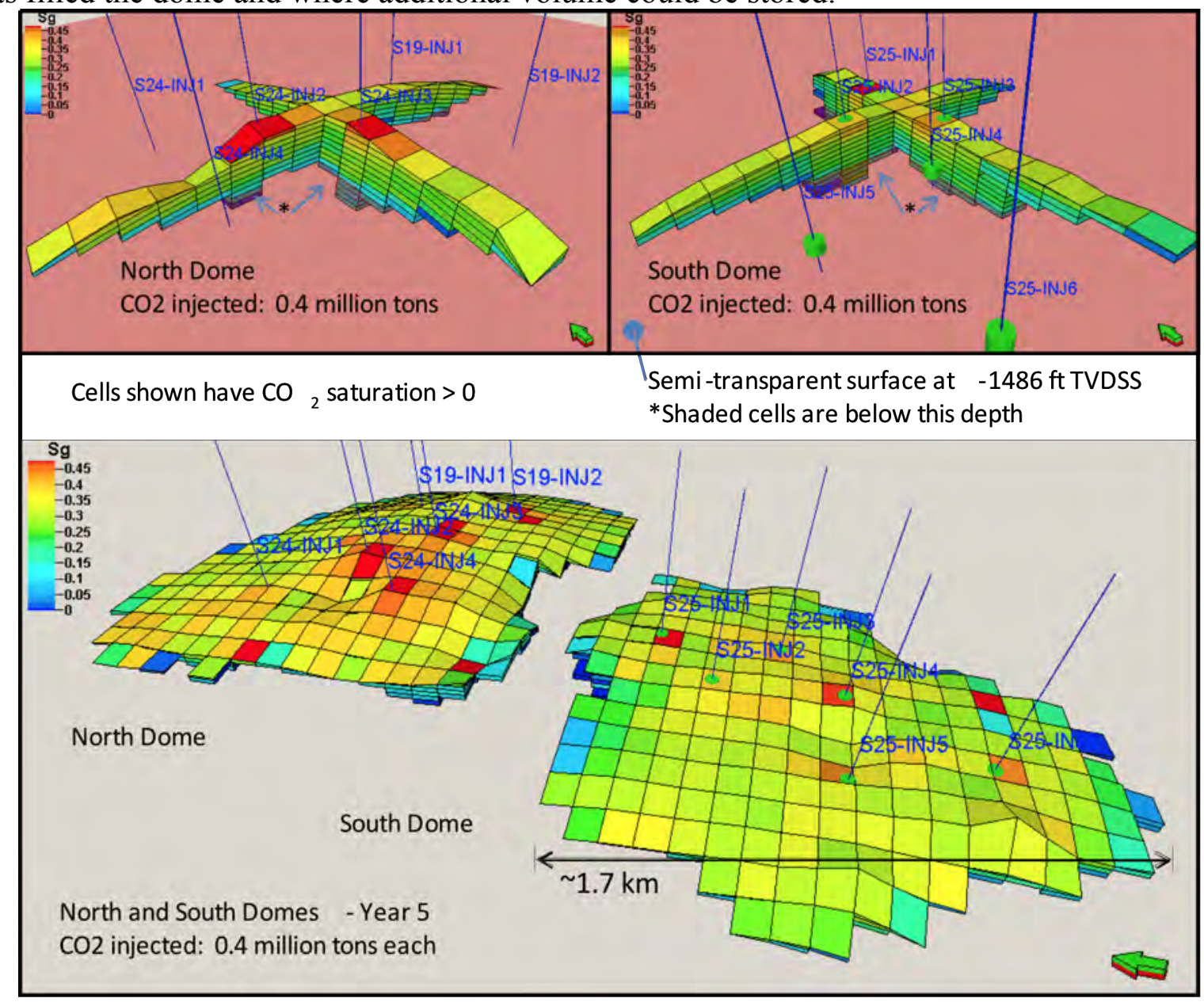

Figure 5-59. Predicted plume size ( $\mathrm{CO}_{2}$ injection case).

Figures 5-60 and 5-61 show the growth of the $\mathrm{CO}_{2}$ plume in the North Dome and South Dome, respectively, in 0.5 year steps. The plume grows both laterally and vertically, with more vertical growth in the cells below the injection wells and fairly consistent lateral growth in all directions. 


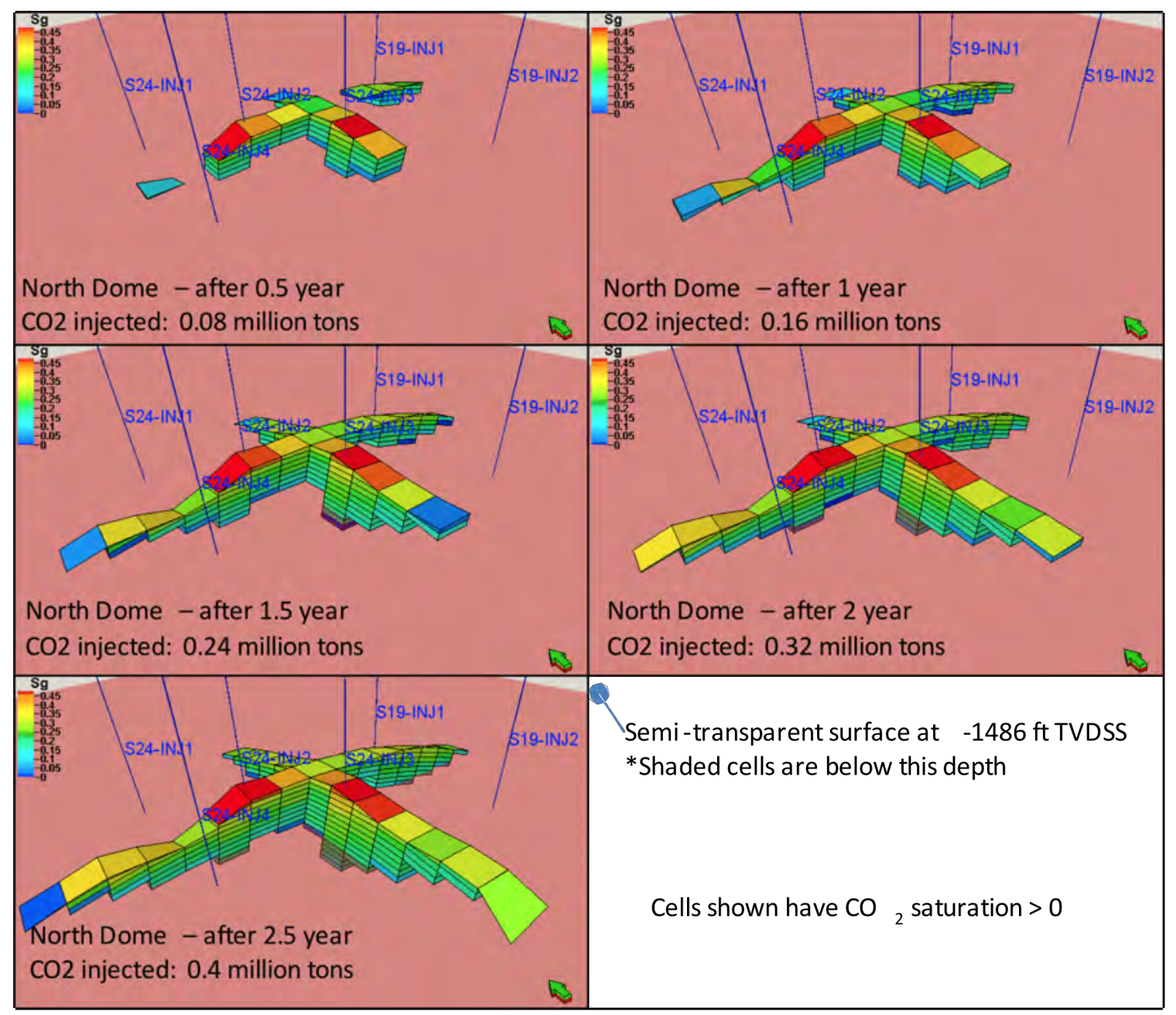

Figure 5-60. Predicted plume growth in the North Dome $\left(\mathrm{CO}_{2}\right.$ injection case). 


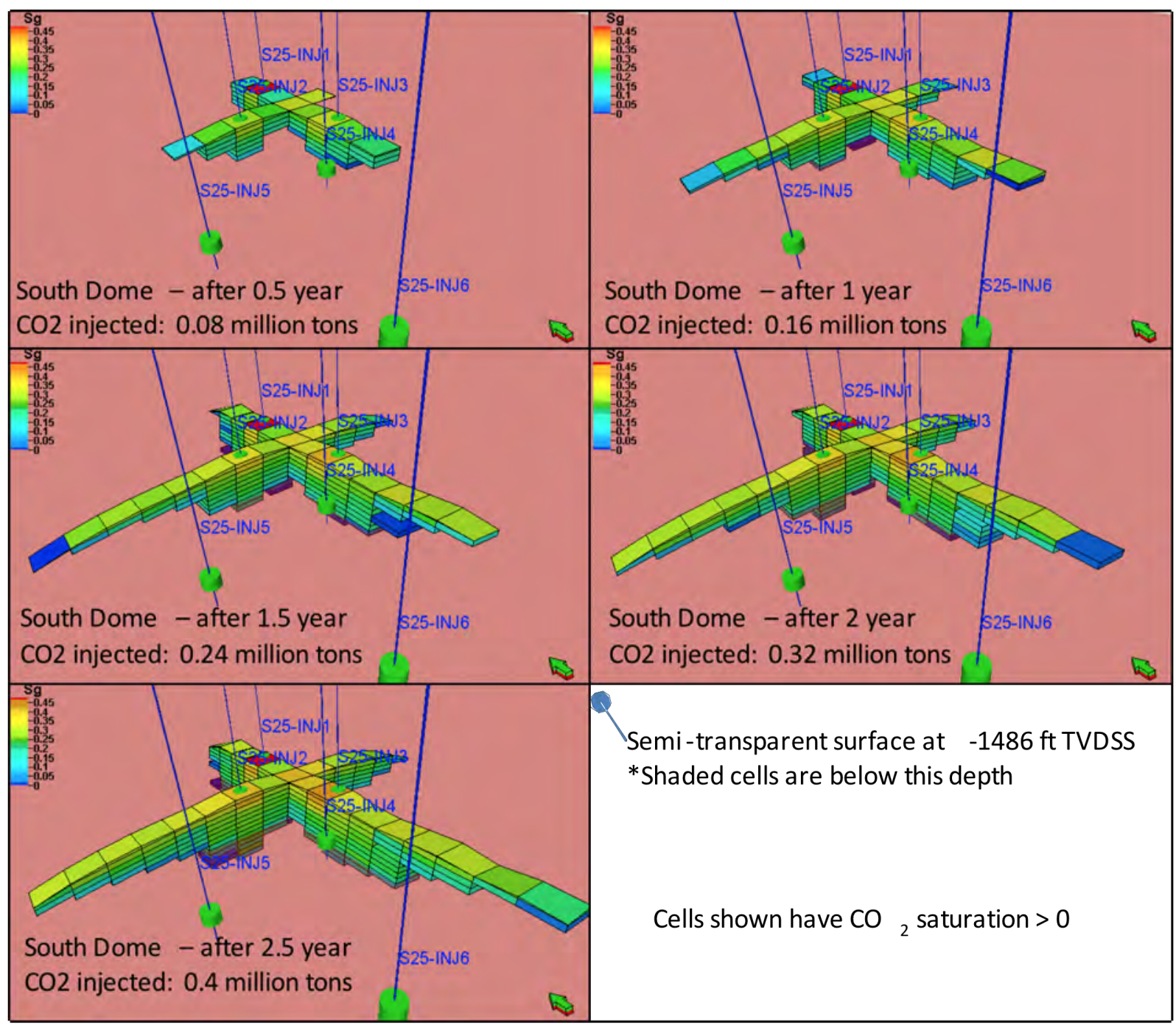

Figure 5-61. Predicted plume growth in the South Dome $\left(\mathrm{CO}_{2}\right.$ injection case).

Figures 5-62 and 5-63 show the oil saturation and water saturation, respectively, in the North Dome in 0.5 year steps, starting with the initial state before $\mathrm{CO}_{2}$ is injected. As expected, initially high oil saturations at the crest are reduced significantly, and this oil displacement can be seen to extend laterally with time. Vertical oil displacement can also be seen by the downward movement of yellow regions. This is interpreted as an oil bank that consists of both the initial mobile oil at the top (attic oil) and the initially residual oil that is mobilized after swelling. This 'yellow' oil bank accumulates at the base as an 'orange' oil leg between the fill depth and the oil water contact. The 'orange' coloration actually comes from viewing what are 'yellow' cells through the semi-transparent reddish surface. The water saturation figures in Figure 5-63 show similar displacement characteristics generally leading to a lower water saturation in the $\mathrm{CO}_{2}$ filled dome. 


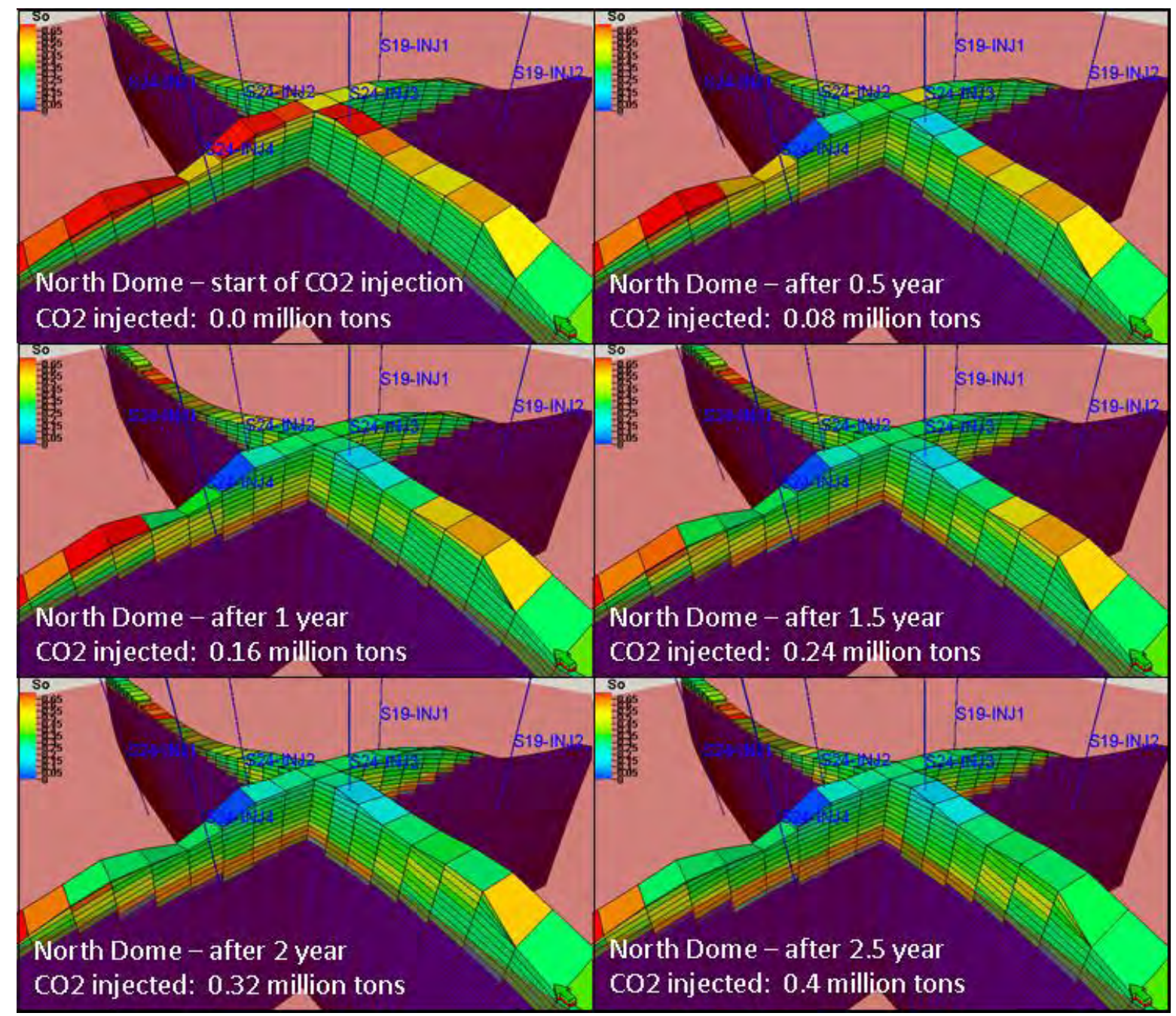

Figure 5-62. Predicted oil saturation in the North Dome ( $\mathrm{CO}_{2}$ injection case). 


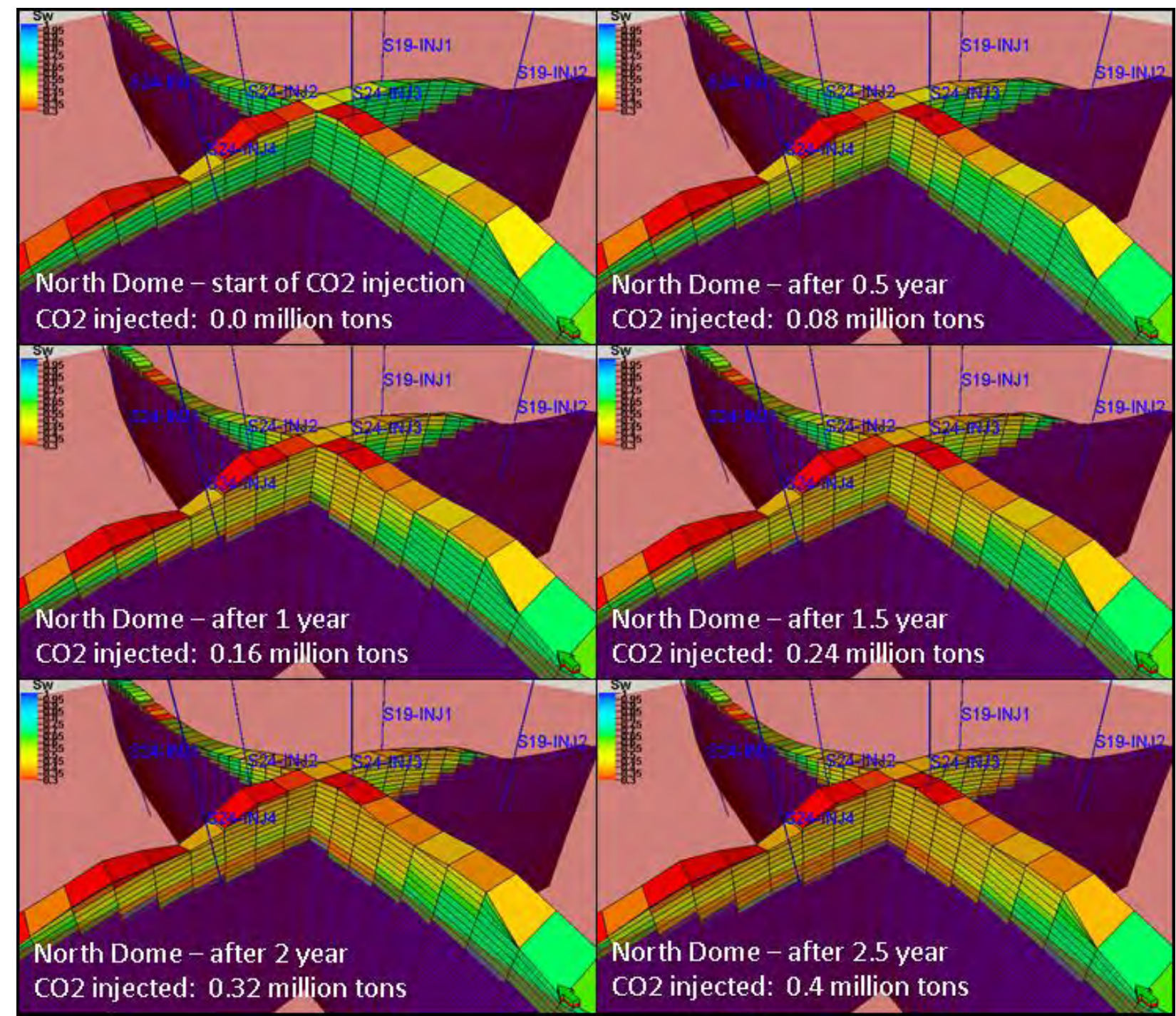

Figure 5-63. Predicted water saturation in the North Dome $\left(\mathrm{CO}_{2}\right.$ injection case $)$

Figure 5-64 shows the oil and water saturation sections in the North Dome before injection, at the end of injection, and then after a 2.5 year quiet period. The top two sets of figures come directly from Figures 5-62 and 5-63, so the focus here is on the continued redistribution of fluids after $\mathrm{CO}_{2}$ injection stops. During this 2.5 year period, there is no injection or production in this North Dome, although there may be some pressure influence from the $\mathrm{CO}_{2}$ injection going on in the adjacent South Dome. So, while there is not a barrier between the domes, Fig. 5-59 shows that the $\mathrm{CO}_{2}$ plumes do not overlap, so the continued movement of fluid in the North Dome can be interpreted as gravity-driven equilibration. 


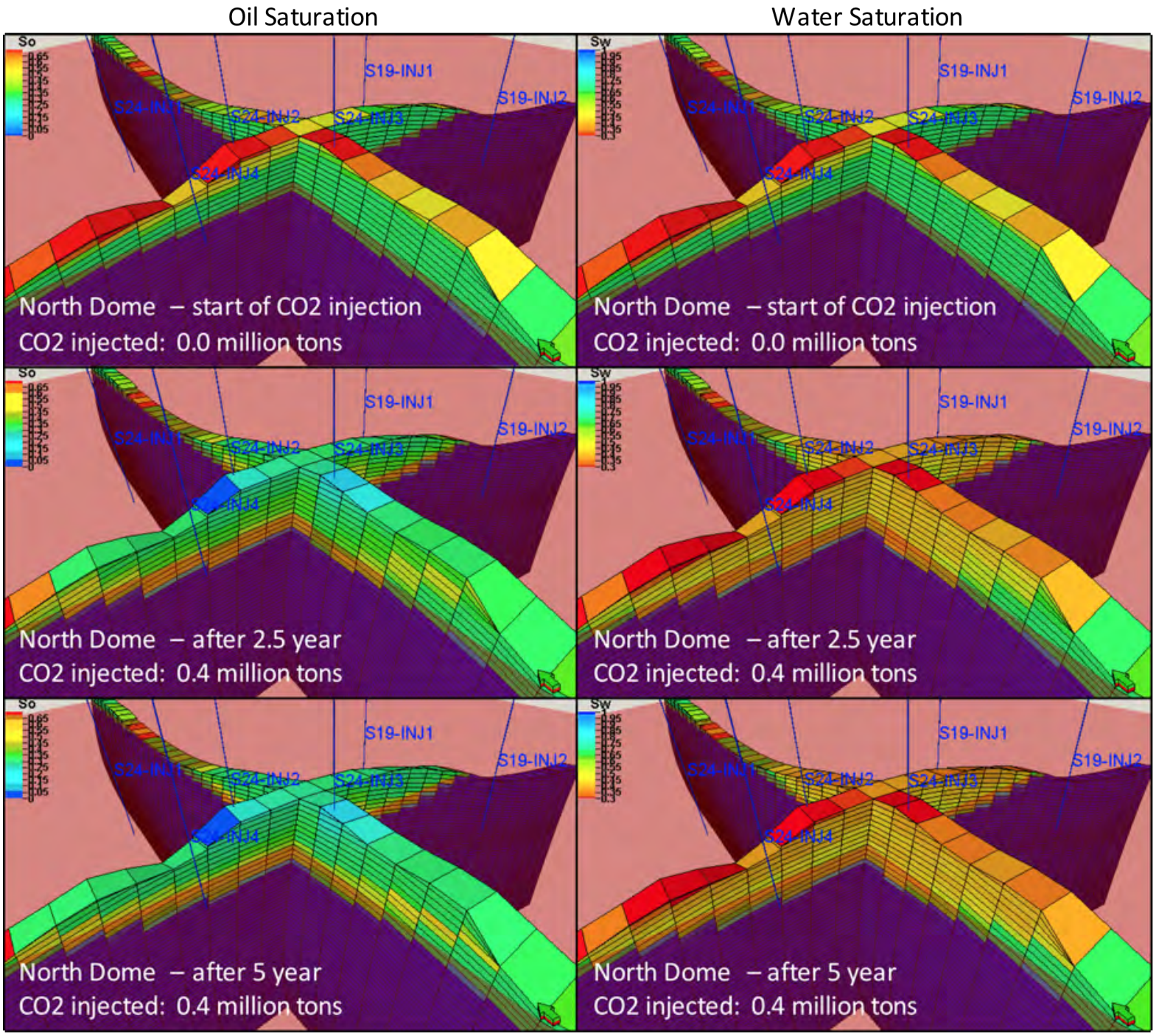

Figure 5-64. Predicted oil (left) and water (right) saturation in the North Dome $\left(\mathrm{CO}_{2}\right.$ injection case).

Movement of oil was seen in Figure 5-62 as the downward movement of 'yellow' cells. This is seen here in Figure 5-64 most clearly on the lower right arm of the oil saturation figures. It can also be seen that a thin 'yellow' layer appears on top of the 'orange' cells, indicating that some of the oil is coming back up above the fill depth. Given time and complete gravity stabilization (perhaps 50 to 100 years), a sharp interface between the $\mathrm{CO}_{2}$, oil, and water phases will develop, and with the amount of $\mathrm{CO}_{2}$ injected in this simulation, that stabilized $\mathrm{CO}_{2}$ and oil interface would certainly be above the subsea $-1,486 \mathrm{ft}$ TVD surface.

\subsubsection{Discussion of South Dome Results}

Figures 5-65 and 5-66 show the oil saturation and water saturation, respectively, in the South Dome at 0.5 year steps. These figures show the same movement of displaced oil as 
seen in the North Dome, although there doesn't appear to be as much mobile attic oil in the model initially. At the end of this 2.5 year $\mathrm{CO}_{2}$ injection period, oil is still moving downward, but in this case there is not an observation period after injection stops that allow gravity stabilization to be observed.

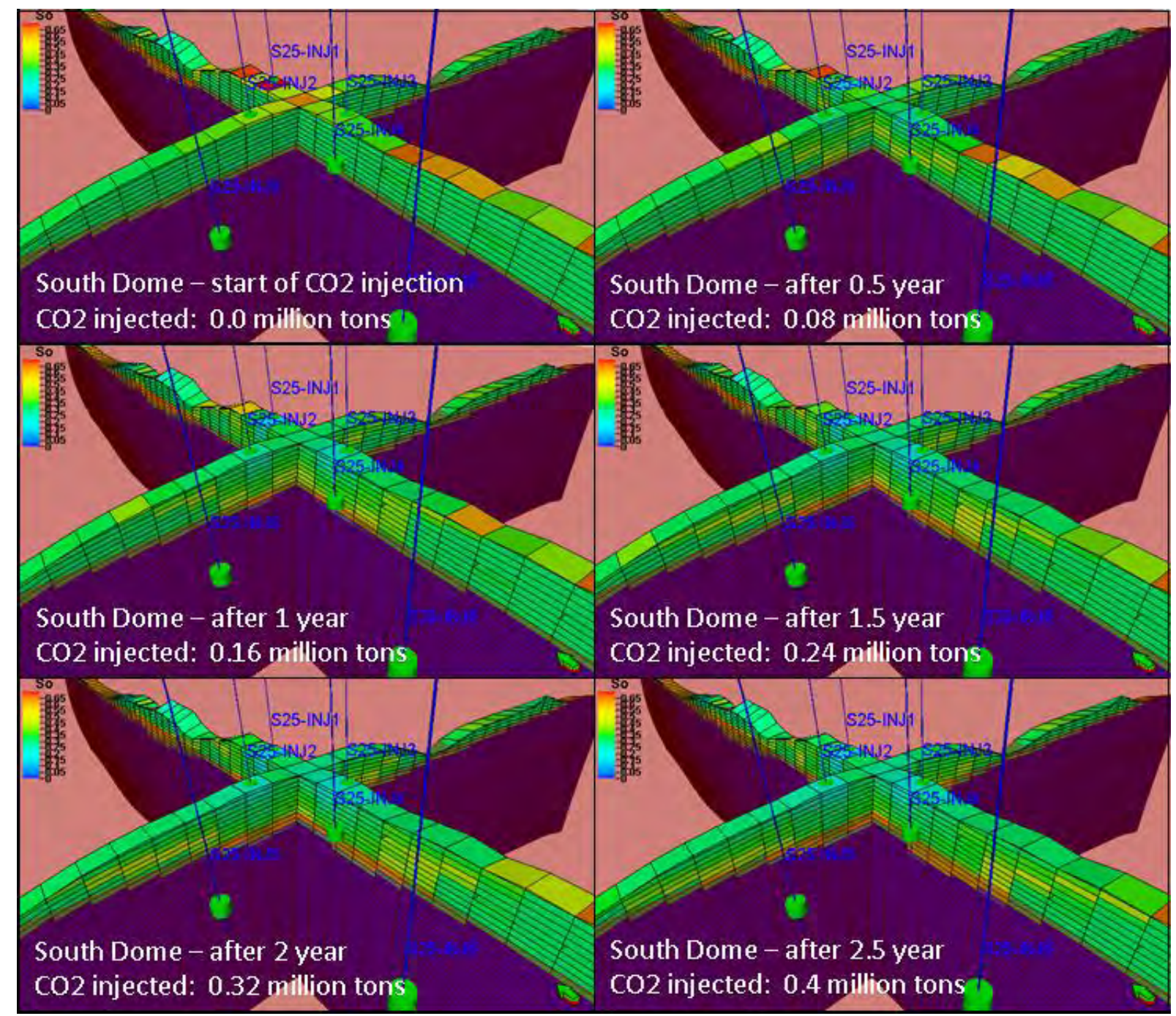

Figure 5-65. Predicted oil saturation in the South Dome $\left(\mathrm{CO}_{2}\right.$ injection case). 


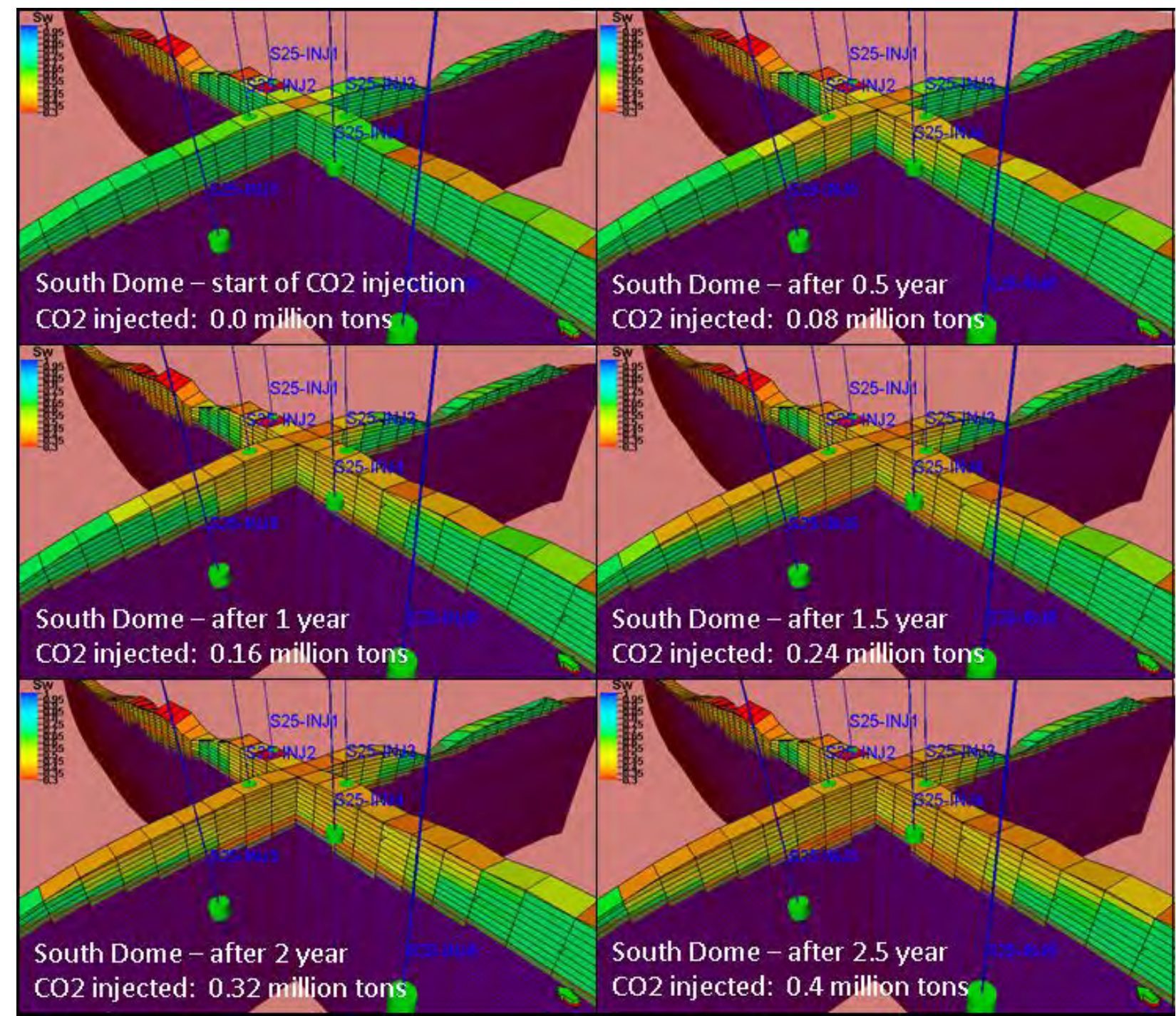

Figure 5-66. Predicted water saturation in the South Dome $\left(\mathrm{CO}_{2}\right.$ injection case $)$

\subsubsection{Quantification of Displaced Oil}

Figure 5-67 shows the change in oil volume for each cell in the model, between the start and end of $\mathrm{CO}_{2}$ injection in the North Dome (top left) and the South Dome (bottom right). The color scale indicates that red colors are a net gain in oil volume (as seen in the oil leg below subsea -1,486 ft TVD surface and purple and blue colors are a net loss in oil volume (as seen at the crest of the structure). Again, the North and South Domes show much the same behavior, although in the cross sections shown, there appears to be more oil displaced in the North Dome than the South Dome. 


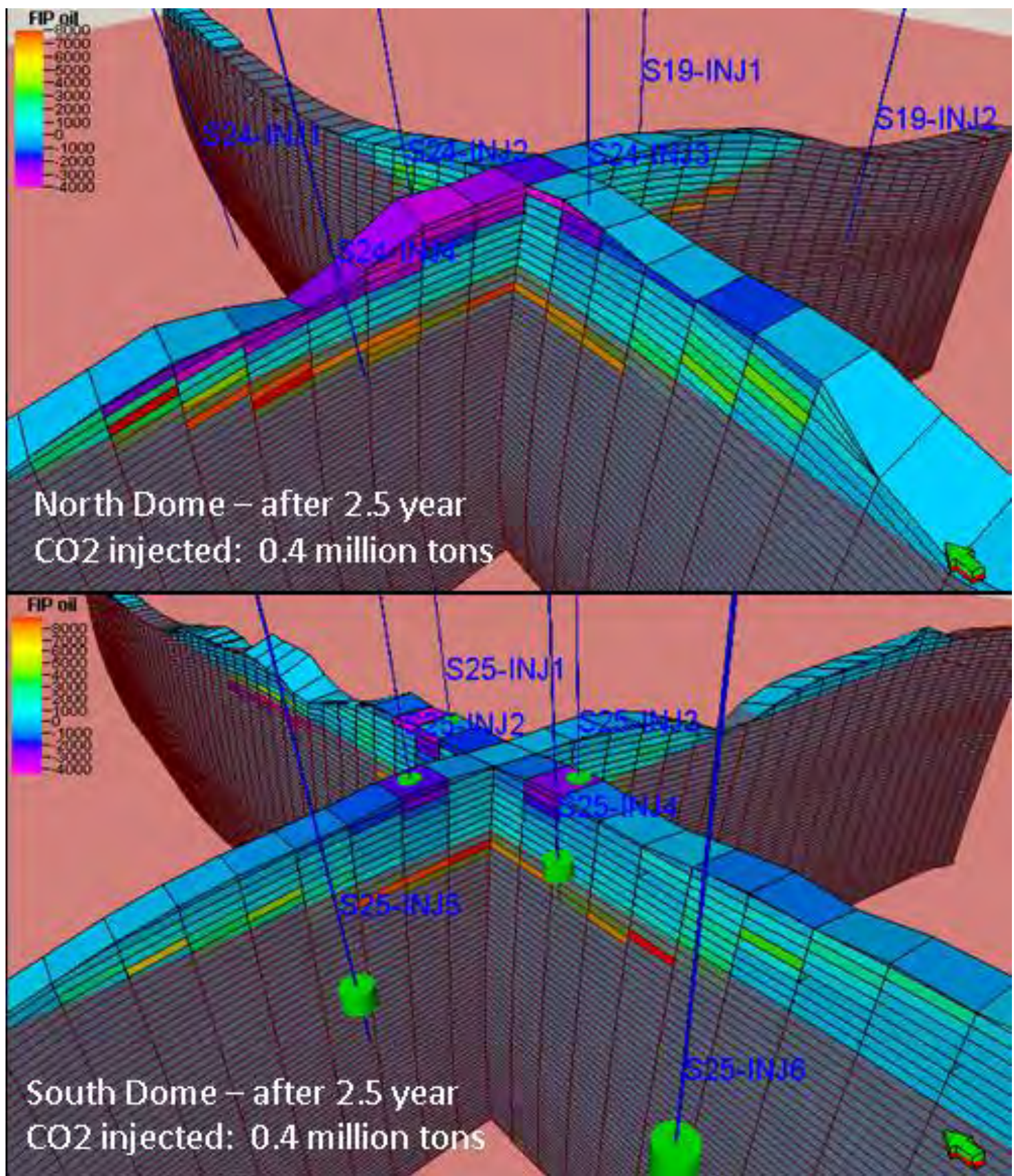

Figure 5-67. Predicted change in oil volume in the North Dome (top) and South Dome (bottom) $\left(\mathrm{CO}_{2}\right.$ injection case). Volume is in barrels of oil per cell.

Table 5-8 provides a summary of oil volumes and changes in the model. The North Dome and South Dome areas are confined to the intersection of the top reservoir horizon with the subsea $-1,486 \mathrm{ft}$ TVD surface. There is certainly oil in the model outside these dome areas, but the intent here is to focus on oil displaced by $\mathrm{CO}_{2}$ as the direct result of $\mathrm{CO}_{2}$ injection. 


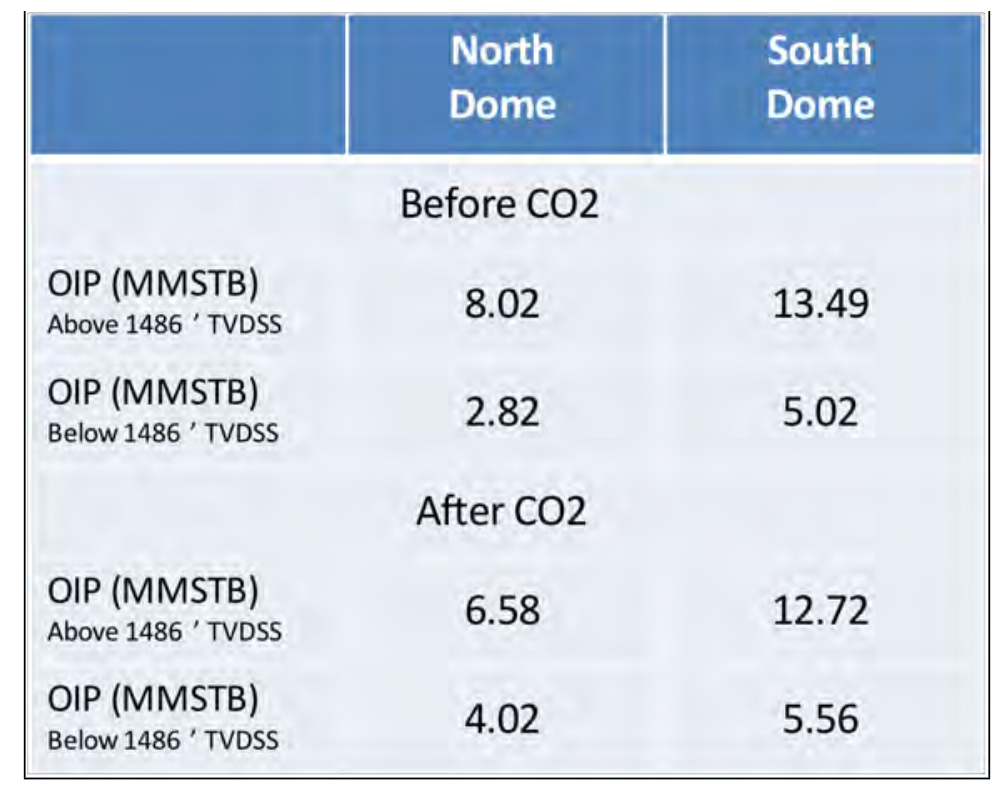

Table 5-8. Summary of oil in place before and after $\mathrm{CO}_{2}$ injection.

The volume of oil in the North Dome before $\mathrm{CO}_{2}$ injection was $10.84 \mathrm{MM}$ STB. After $\mathrm{CO}_{2}$ injection, there was $10.60 \mathrm{MM} \mathrm{STB}$, indicating a loss of 0.24 MM STB. This oil is not 'lost', but is in fact just displaced out of the tightly defined North Dome area. Strictly speaking, this 'lost' volume can be considered part of the oil volume below subsea 1,486 ft TVD surface since most of the area outside the North and South Domes are below this depth.

Before $\mathrm{CO}_{2}$ injection, there were 8.02 MM STB above the fill depth and $2.82 \mathrm{MM}$ STB below. After $\mathrm{CO}_{2}$ injection, the oil volume above decreases by $1.44 \mathrm{MM}$ STB to 6.58 MM STB, and the oil volume below increases by 1.2 MM STB to 4.02 MM STB. Again, the important number is the 1.44 MM STB that has been displaced out of the North Dome above subsea -1,486 ft TVD surface, and realize that the actual volume of oil mobilized by the $\mathrm{CO}_{2}$ is greater than this. As the oil saturation results illustrated, not all of the oil bank made it to the fill depth, so should not be counted as displaced out of the dome.

The situation in the South Dome is similar, but with only 0.77 MM STB displaced out of the dome, even though there is initially more oil in the dome. This supports the observations that the displacement in the South Dome is not as efficient as in the North Dome. This may simply be a lack of initially mobile attic oil (as observed), or indicate that not enough $\mathrm{CO}_{2}$ was injected to displace the oil fully out of the dome. With the laterally larger area, the South Dome is a bigger challenge, and may require more injection wells with a larger footprint. 


\subsubsection{Summary of Simulation Results}

Results of this study should be considered a 'quick look,' figuratively speaking, and as such the conclusions must be taken cautiously. However, some specific salient conclusions may help direct the future direction of $\mathrm{CO}_{2}$ injection in this and other Midwestern reservoirs:

1. The two domed structures are capable of storing significant quantities of $\mathrm{CO}_{2}$. At the specified rate, the reservoir can be a $\mathrm{CO}_{2}$ storage site for at least 5 years, and probably longer, although additional study is needed to quantify this extension.

2. During the $\mathrm{CO}_{2}$ injection process, oil is displaced out of the crest of the dome and accumulated above the water. Oil production wells completed in this zone should be able to produce some of this oil, but the proximity of the thin oil leg to both the water below and $\mathrm{CO}_{2}$ above will make it a challenge to avoid coning problems. If oil production is an objective, gravity stabilization following $\mathrm{CO}_{2}$ injection will form a more well defined oil leg, but further study will be needed to determine whether that would occur effectively within a reasonable period of time.

3. The modeling of this $\mathrm{CO}_{2}$ injection process has taken a conservative view of oil property changes in response to the $\mathrm{CO}_{2}$, primarily because there isn't data available to directly quantify the changes. In some cases, the oil will become considerably leaner on contact with $\mathrm{CO}_{2}$, and there could be a reduction in residual oil saturation. Without the means to quantify these effects, the decision was made to err on the side of caution instead of overstating the recovery potential. With the model indicating almost $22 \mathrm{MM} \mathrm{STB}$ of oil in both domes combined, there is the possibility that with proper characterization of the $\mathrm{CO}_{2} /$ oil interaction, a significant volume of oil could be mobilized and made available for production.

\subsection{Capacity Verification}

In the hypothetical gravity-stable $\mathrm{CO}_{2} \mathrm{EOR}$ project, $\mathrm{CO}_{2}$ is injected into two domes until they are filled to a subsea depth of -1486 . Two studies completed, a preliminary engineering study by EPIC and a "first look" simulation study by Schlumberger have differing volumetric results (Table 5-9). The EPIC study is based on correlations with empirical data while the Schlumberger simulates the base-case hypothetical plan using a static model grid developed from well information. Combined, they project 0.5 to 0.8 million metric tons of $\mathrm{CO}_{2}$ would be stored over a 3.5 to 5 year injection period, utilizing the entire volume of $\mathrm{CO}_{2}$ available from the Lyons ethanol plant. If the balance of the Geneseo-Edwards field was flooded in a similar fashion, the volume stored would nearly triple. Schlumberger's simulation projects the same amount of $\mathrm{CO}_{2}$ will be stored by the project in both domes, despite the North Dome having only $56 \%$ of the pore space that the South Dome has. According to their observations the South Dome does not fill nearly 
as efficiently as the North Dome because of reservoir heterogeneity and irregularities in the dome shape with respect to the injectors.

\begin{tabular}{llc|c|}
\multicolumn{1}{c}{} & \multicolumn{1}{c}{ North Dome } & \multicolumn{1}{c}{ South Dome } \\
\cline { 2 - 3 } Analogues & Billion $\mathrm{ft}^{\wedge} 3$ & 3.42 & 6.16 \\
& Billion $\mathrm{m}^{\wedge} 3$ & 0.096 & 0.174 \\
& Million Tons & 0.20 & 0.36 \\
& Million Metric Tons & 0.18 & 0.32 \\
& Months Supply & 15 & 27 \\
\cline { 3 - 3 } Simulation & Billion $\mathrm{ft}^{\wedge} 3$ & 6.82 & 6.82 \\
& Billion $\mathrm{m}^{\wedge} 3$ & 0.194 & 0.194 \\
& Million Tons & 0.40 & 0.40 \\
& Million Metric Tons & 0.36 & 0.36 \\
& Months Supply & 30 & 30 \\
& &
\end{tabular}

Table 5-9. Estimated $\mathrm{CO}_{2}$ stored in hypothetical gravity-stable CO2 EOR project

The simulation study projects more $\mathrm{CO}_{2}$ stored than the EPIC study in both domes. Some, but not all can be explained by 1) variations in pore volume - the Schlumberger model has slightly higher porosity, and 2) some $\mathrm{CO}_{2}$ is stored below the subsea datum of -1486 in the Schlumberger model. Projected $\mathrm{CO}_{2}$ saturations above -1486 in both domes would average $28 \%$ according to the EPIC study (Table 5-10), while they vary between domes in the Schlumberger study. Average $\mathrm{CO}_{2}$ saturation was not harvested from the Schlumberger simulation, however, a discernable difference in saturation profiles is notable in Figure 5-59. North dome saturations appear to average around 35\% while in the less efficient south dome they appear to average closer to $25 \%$

\begin{tabular}{l|c|c|}
\multicolumn{1}{c}{ Million STB } & North Dome & \multicolumn{1}{c}{ South Dome } \\
\cline { 2 - 3 } Pore Volume (STB) & 19.0 & 33.8 \\
CO2 Stored (STB) & 5.27 & 9.49 \\
CO2 Saturation \%) & 0.28 & 0.28 \\
\cline { 2 - 3 }
\end{tabular}

Table 5-10. Volumetric $\mathrm{CO}_{2}$ statistics for hypothetical flood based on Canadian analogues and empirical correlations. Abbreviation STB = Stock Tank Barrels. One STB $=0.16 \mathrm{~m}^{\wedge} 3$.

\subsection{Conclusions}

The body of work summarized in this chapter and report should be considered an initial feasibility study to be followed by additional data gathering, field testing, more rigorous modeling and simulation study. Results of the studies are encouraging and suggest a gravity-stable immiscible $\mathrm{CO}_{2}$ EOR flood in the Arbuckle would mobilize oil, form a horizontal oil bank, and could be commercially feasible. However, substantial 
additional work is needed on three fronts: 1) fill critical fluid property gaps, 2) improve the static model grid geometry and petrophysical properties including residual oil saturation, and 3) gain a better understanding of the reservoir "plumbing system" to insure that a gravity-stable approach could be effective.

\subsubsection{Key Findings}

The objective of the study detailed in this chapter was to evaluate the potential for a gravity-stable EOR project in the Arbuckle given that the reservoir has a relatively thick oil column, the producing mechanism is a strong bottom-water drive, and evidence that the oil-water contact moved vertically in a fairly uniform manner, leaving behind sufficient residual oil to be targeted for EOR. Key findings include the following:

1. Significant residual oil remains in the water-swept portion of the reservoir. Residual oil saturation (Sorw) is approximately $38.9 \%$ established by material balance, assuming original saturation is $70 \%$, average porosity is $11.5 \%$, and a FVF of 1.1. EPIC's estimated Sorw to be $38.9 \%$ based on reservoir and oil properties, and history-matched reservoir simulation by Schlumberger yielded an average Sorw $=36 \%$.

2. It appears likely that that a $\mathrm{CO}_{2}$ gas cap can be built downward while maintaining a relatively flat gas/water-oil contact. A study of oil-water contacts in 32 wells suggests strongly that the oil-water contact stayed relatively flat as it moved upward during the 80-year production history. Reservoir simulations indicate that a $\mathrm{CO}_{2}$ gas cap with a fairly uniform gas/oil contact can be built downward.

3. Successful Keg River gravity-stable miscible floods (Canada) may be analogs to the Arbuckle of the Central Kansas Uplift.

4. The EPIC preliminary feasibility study, based on correlations with empirically derived data and equations, and comparisons with analogs, suggests that 6.1 million barrels of oil could be recoverable by EOR in the two-dome project.

5. The Schlumberger reservoir simulation study demonstrates that oil is mobilized by $\mathrm{CO}_{2}$ in a gravity-stable process. However, the amount of oil mobilized is a fraction of that predicted to be recoverable by the EPIC study. Significant improvements in the oil mobilized by optimizing the simulation for improved sweep efficiency.

The above results should be utilized with caution. Many caveats and shortcomings have been discussed throughout the report and are summarized below:

1. Residual oil saturation is based on an assumed initial oil saturation of $70 \%$ and FVF of 1.1. Neither of these variables are known. 
2. A published paper (Mullins and Ireland, 1967) on the Arbuckle reservoir 5 miles (8 kilometers) northwest of the proposed project suggests the reservoir is layered. This would negatively impact the potential for gravity-stable EOR process if it is the case in the project area.

3. The simulation model is based on a static model grid built from a sparse petrophysical data set. Critical fluid properties and the equation of state (EOS) for the crude oil were estimated.

\subsubsection{Additional Work}

The current study achieved some progress towards answering fundamental questions and provides encouragement for further evaluation. The final answers will not be known until the concept is tested by large-scale $\mathrm{CO}_{2}$ injection, but there are a number of data to yet be collected, analyzed and incorporated in the model, and field testing that could help to elucidate the fluid dynamics of the reservoir system and reduce major risk factors due to current uncertainties:

Fill critical fluid property for well-constrained EOS and other parameters:

-Laboratory flash liberation tests (CCE)

-Laboratory differential liberation tests (DL, CVD)

-Viscosity versus pressure at reservoir temperature

. Swelling tests

-Additional MMPs

. Oil composition from downhole samples above bubble point

-Gas sample and composition

Improve the static model grid geometry

- Make another search for wireline logs and incorporate

-Acquire initial 3-D seismic survey and incorporate

-Improve layering and identify potential barriers in core

Improve the static model grid petrophysical properties:

-Obtain additional conventional and special core analysis from existing cores, including in situ properties, capillary pressure data, rock mechanical data for fracture pressure of reservoir and seal

-Run modern openhole logs in existing wells with long open hole sections and wells re-entered and deepened for reservoir tests, and incorporate petrophysical data and layering

.Obtain current Sorw from open hole logs

Gain a better understanding of the reservoir "plumbing system" in particular continuity in vertical permeability:

.Further analysis for movement of oil-water contact including correlating well production tests to current layered reservoir model, particularly in areas where there are anomalies what otherwise appears to be a relatively uniform pattern of upward movement. 
-Investigate the data behind the Mullins and Ireland (1967) paper and production records since the paper was written to validate or refute the paper's findings.

-Analyze several cores available at the Kansas Geological Survey core storage facility paying particular attention to potential vertical barriers and correlate to wireline logs.

-Design and perform multiple well tests, including pulse tests and tracer surveys, to measure vertical permeability at varying scales.

-Research and deploy other methods for characterizing reservoir-scale permeability in three dimensions.

Multiple iterations of reservoir characterization, modeling and simulation will be required before one can predict reservoir behavior with confidence. The current understanding of past reservoir behavior, comparison with successful analogs, and current reservoir models all suggest that gravity-stable immiscible $\mathrm{CO}_{2}$ EOR could be successful. Additional work could bolster the case sufficiently to justify moving forward to a commercial-scale development project. 


\section{Chapter 6 - Risk Assessment}

\subsection{Methodology}

A qualitative risk assessment was performed during Phase I of the IMCCS Project. To accomplish this, a risk assessment working group was formed. Table 6-1 shows the individuals making up the risk assessment working group and their areas of focus.

Table 6-1. Risk Assessment Working Group

\begin{tabular}{|l|l|}
\hline Name & Area of Focus \\
\hline Jim Lepinski & Co-lead, subsurface, surface and programmatic \\
\hline Bruce Letellier & Co-lead, subsurface and HSE risks \\
\hline Phil Stauffer & Subsurface risks and HSE risks \\
\hline Brian McPherson & Subsurface risks (especially deep saline \\
\hline Marty Dubois & Subsurface risk (especially EOR) \\
\hline Chris D'Acosta & Financial and local legislation/regulation risks \\
\hline Ray Hattenbach & Dehydration, compression and pipeline risks \\
\hline Mahesh Gundappa & Verification risks \\
\hline Mike Moore & Federal legislation/regulation risks \\
\hline Jon Erickson & Programmatic risks \\
\hline Bob Kolb & Programmatic risks \\
\hline Andrew Duguid & Borehole and monitoring risks \\
\hline Ken Hnottavange- & Subsurface and programmatic risks \\
\hline Neal Drawas & Liability and insurance risks \\
\hline Brandon Pavlish & CO capture risks \\
\hline Gina Rau & Health, safety and environmental risks \\
\hline Pete Fote & Proiect management and EPC risks \\
\hline John Mavor & Surface and programmatic risks \\
\hline
\end{tabular}

Comprehensive lists of programmatic and technical risks, including descriptions and relevance, were prepared by the IMCCS team. These lists were reviewed by members of the risk assessment working group. Project specific information was added to the lists. Risks were then ranked on a scale of 1 to 5 according to probability of occurrence and severity of impact. Tentative risk prevention and mitigation steps were developed and listed. 
The comprehensive lists of risks are divided into Geologic Sequestration Technical Risks (an expanded version of the Quintessa FEPs list) and Surface \& Programmatic Risks. The risks are broken into the following categories:

Geologic Sequestration Technical Risks (see Appendix 6-A)

0.0 Assessment Basis

1.0 External Factors

$2.0 \quad \mathrm{CO}_{2}$ Storage

3.0 $\quad \mathrm{CO}_{2}$ Properties, Interactions \& Transport

4.0 Geosphere

5.0 Boreholes

6.0 Near-Surface Environment

7.0 Impacts

$\underline{\text { Surface and Programmatic Risks (see Appendix 6-B) }}$

8.0 Economic Risks

9.0 Permitting Risks

10.0 External Risks

11.0 Project Management Risks

12.0 Engineering Risks

13.0 Procurement Risks

14.0 Construction Risks

15.0 Commissioning and Startup Risks

16.0 Field Safety Risks

17.0 Legal Risks

$18.0 \mathrm{CO}_{2}$ Capture Risks

19.0 Dehydration Risks

20.0 Compression Risks

21.0 Pipeline Risks

22.0 On-Site Facilities Risks

23.0 Monitoring Risks

Each risk is assigned a risk factor of 1 to 5 for probability of failure $(\mathrm{P})$ and severity of failure $(\mathrm{S})$. The risk priority number is the product of $\mathrm{P} \times \mathrm{S}$ and therefore ranges from 1 to 25. The definition of risk factors for probability and severity are shown in Tables 6-2 and 6-3. 
Table 6-2. Risk Factors for Probability of Failure

\begin{tabular}{|c|l|c|}
\hline 1 & Improbable & $<1 \%$ chance of occurring* \\
\hline 2 & Unlikely & $1-10 \%$ chance of occurring* \\
\hline 3 & Possible & $\begin{array}{c}11-50 \% \text { chance of } \\
\text { occurring* }\end{array}$ \\
\hline 4 & Likely & $51-75 \%$ chance of occurring \\
\hline 5 & Probable & $>75 \%$ chance of occurring* \\
\hline
\end{tabular}

*From beginning of project to 50 years after injection stops. 
Table 6-3. Risk Factors for Severity of Failure

\begin{tabular}{|c|c|c|c|c|c|}
\hline & & $\begin{array}{l}\text { Health \& } \\
\text { Safety }\end{array}$ & $\begin{array}{r}\text { Financial } \\
\text { Liability (\$) }\end{array}$ & Environment & $\begin{array}{l}\text { Industry } \\
\text { Viability }\end{array}$ \\
\hline 1 & Light & $\begin{array}{l}\quad \text { Minor } \\
\text { injury or } \\
\text { illness, first } \\
\text { aid }\end{array}$ & $<\$ 50 \mathrm{k}$ & $\begin{array}{l}\quad \text { Discharge }< \\
\text { reporting thresholds. } \\
\text { Hazmat spill }<100 \text { liters. } \\
\text { Produced water } \\
\text { spill }<50 \text { barrels. }\end{array}$ & $\begin{array}{l}\quad \text { Project lost } \\
\text { time }>1 \text { day. } \\
\text { Moving vehicle } \\
\text { citation. }\end{array}$ \\
\hline 2 & Moderate & $\begin{array}{l}\quad \text { Temporary } \\
\text { disability, } \\
\text { Hospital to } 1 \\
\text { day. Lost days } \\
\text { 1-100 }\end{array}$ & $\$ 50-500 \mathrm{k}$ & $\begin{array}{l}\quad \text { Discharge }> \\
\text { reporting thresholds. } \\
\text { Hazmat } \\
\text { spill }<1000 \text { liters. } \\
\text { Produced water } \\
\text { spill }<100 \text { barrels. }\end{array}$ & $\begin{array}{l}\quad \text { Project lost } \\
\text { time }>1 \text { week. } \\
\text { Regulatory notice } \\
\text { without fine. Local } \\
\text { allegations of } \\
\text { unethical practice } \\
\text { or mismanagement. }\end{array}$ \\
\hline 3 & Serious & $\begin{array}{l}\quad \text { Permanent } \\
\text { disability. } \\
\text { Lost days } \\
>100 \text {. } \\
\text { Intensive care } \\
>1 \text { day. }\end{array}$ & $\$ 500 \mathrm{k}-5 \mathrm{M}$ & $\begin{array}{l}\quad \text { Discharge causes } \\
\text { area evacuation or } \\
\text { wildlife loss. Hazmat } \\
\text { spill }<10 \mathrm{k} \text { liters. } \\
\text { Produced water } \\
\text { spill }<500 \text { barrels. }\end{array}$ & $\begin{array}{l}\quad \text { Project lost } \\
\text { time }>1 \text { month. } \\
\text { Permit suspension. } \\
\text { Majority local } \\
\text { opposition or } \\
\text { substantial negative } \\
\text { local media } \\
\text { coverage. }\end{array}$ \\
\hline 4 & Major & Fatality & $\$ 5 \mathrm{M}-50 \mathrm{M}$ & $\begin{array}{l}\quad \text { Uncontrolled } \\
\text { release of radioactive } \\
\text { material. Hazmat spill } \\
>10 \mathrm{k} \text {. Produced water } \\
\text { spill }>500 \text { barrels. }\end{array}$ & $\begin{array}{l}\quad \text { Project lost } \\
\text { time }>1 \text { year. } \\
\text { International media } \\
\text { coverage of law } \\
\text { violations, } \\
\text { questionable ethical } \\
\text { practices, or } \\
\text { mismanagement }\end{array}$ \\
\hline 5 & Catastrophic & $\begin{array}{l}\text { Multi- } \\
\text { fatality }\end{array}$ & $>\$ 50 \mathrm{M}$ & Multi-Catastrophic & $\begin{array}{l}\text { Negative public } \\
\text { experience results } \\
\text { in legal ban on } \\
\text { similar projects. }\end{array}$ \\
\hline
\end{tabular}

Special attention was given to wellbore risks in the T-A field. A database of plugged and abandoned wells in the T-A was compiled by Dr. Martin Dubois of CAP CO2 and analyzed by Dr. Andrew Duguid of Schlumberger Carbon Services. The analysis was then reviewed by members of the risk assessment working group. The results of the analysis can be found in Appendix 6-C.

\subsection{Technical Risk Results and Discussion}

Some of the more significant technical risks that were identified based on project specific information and ranking of risks are as follows. 
Thrall-Aagard (T-A) Field

- Narrow operating pressure range between MMP and fracture pressure

- $\mathrm{CO}_{2}$ leakage through 457 existing boreholes

- Potential broken seal/reservoir damage from explosive fracturing and hydraulic fracturing

- Potential leakage making it difficult to pressurize the reservoir

- Low pressure (3.4 MPa [500 psi]) thief zone (Douglas Sandstone) above reservoir

- Long time for equilibration of pressurized reservoir

- Up-dip migration of $\mathrm{CO}_{2}$ in DSA monocline

Geneseo-Edwards (G-E) Field

- $\mathrm{CO}_{2}$ leakage through 117 existing boreholes

- Non-uniform gravity stable $\mathrm{CO}_{2}$ flood in G-E

- Bottom hole pressure closeness to $\mathrm{CO}_{2}$ supercritical pressure in G-E

- High minimum miscible pressure (MMP) in G-E

- $\mathrm{H}_{2} \mathrm{~S}$ in Arbuckle water in G-E

- Difficulty of monitoring stacked plumes (EOR and DSA) in G-E field

Deep Bartlesville (DB) Fields

- $\mathrm{CO}_{2}$ leakage through existing boreholes

- Located below or near sensitive groundwater area

- Located adjacent to or near the Humboldt fault zone

- Located in more populated area

Wellington Field

- $\mathrm{CO}_{2}$ leakage through $134+$ existing boreholes

- Located below or near sensitive groundwater area

$\underline{\text { Kansas Ethanol LLC (KE) Plant }}$

- Flow rate fluctuation and inconsistent oxygen content $\mathrm{CO}_{2}$ flow stream due to batch-type fermentation.

- Performance of the first-of-a-kind oxygen removal unit for ${\mathrm{KE} \mathrm{CO}_{2}}$ stream

Ash Grove Cement (AGC) Plant

- Performance of the first-of-a-kind $\mathrm{CO}_{2}$ capture unit for the Ash Grove Cement (AGC) plant

\subsection{1 $\mathrm{CO}_{2}$ Capture}

Coffeyville Resources Nitrogen Fertilizer LLC (CVR)

CVR generates a concentrated stream of $\mathrm{CO}_{2}$ as a by-product in the production of ammonia. A Selexol system is used to recover the $\mathrm{CO}_{2}$ from syngas. The Selexol system started up in July 2000 and has demonstrated high reliability. High plant availability is achieved because CVR has a spare gasifier. $\mathrm{CO}_{2}$ quality is very consistent and is guaranteed by CVR. Therefore risks are relatively low.

Kansas Ethanol LLC (KE)

$\mathrm{KE}$ generates a concentrated $\mathrm{CO}_{2}$ stream in the fermenting process of ethanol production. Overall plant availability is high, but $\mathrm{CO}_{2}$ flow rate fluctuates and quality may be inconsistent due to the batch-type process of fermentation. It may be necessary for $\mathrm{KE}$ to perform a demonstration test to prove that it can consistently meet the $\mathrm{CO}_{2}$ 
specification for the IMCCS project. Fluctuation in flow rate may impact dehydration and compressor performance.

Analyses of the $\mathrm{KE} \mathrm{CO}_{2}$ stream indicate the oxygen content is in the range of 0.4 to $1.3 \%$. The pipeline specification requires oxygen to be less than $30 \mathrm{ppm}$. A catalytic combustion system has been proposed to remove the oxygen by combusting it with natural gas (injected at twice the stoichiometric amount of oxygen to be combusted) in the presence of a platinum catalyst. An electric heater is used for startup and when oxygen content is insufficient to provide sufficient heat for the catalytic reactor. As a first-of-a-kind application, there could be scale-up, operational and maintenance problems with this unit which may be intensified due to fluctuating flow rate and inconsistent oxygen content of the $\mathrm{CO}_{2}$ stream coming from the batch type fermentation process.

\section{$\underline{\text { Ash Grove Cement (AGC) } \mathrm{CO}_{2} \text { Capture }}$}

$\mathrm{CO}_{2}$ capture for cement plants has not been commercially demonstrated yet. Some cement plants are looking at capturing the $\mathrm{CO}_{2}$ in the form of solid carbonates or bicarbonates. For this project, the group initially evaluated recovering the $\mathrm{CO}_{2}$ from cement plant flue gas using a skid-mounted amine-based acid gas removal unit with conventional adsorption tower and stripper. However, the economics didn't look favorable. As an alternative, the group looked at a skid-mounted, high-surface-areacontact unit that offered a potential $40-50 \%$ savings in capital cost. This unit has been used for SOx removal at a power plant on a $20 \mathrm{MW}$ scale but the $\mathrm{CO}_{2}$ capture version has not been demonstrated beyond a bench scale. Again, the economics did not come out favorable due to the small scale. In addition, technical risks associated with first-of-akind and scale-up can be significant. After thorough study, it was concluded that these $\mathrm{CO}_{2}$ capture units were not financeable or commercially viable at this time. This could change if legislation provided greater economic incentives for $\mathrm{CO}_{2}$ capture.

\subsection{2 $\mathrm{CO}_{2}$ Dehydration}

CVR Dehydration Unit

A tri-ethylene glycol (TEG) dehydration unit will be installed at CVR to remove moisture from the $\mathrm{CO}_{2}$ stream. These units are used regularly in industry and generally operate well. The most common problems are: upset conditions; foaming in the contactor; buildup of liquid or solid contaminants in recycled glycol; contactor plugging due to fouling; reboiler tube, heat exchanger or pump seal failure due to fouling; corrosion; and thermal or oxidation degradation of the glycol. The unit at CVR should operate well.

KE Dehydration Unit

A tri-ethylene glycol (TEG) dehydration unit will also be installed at KE to remove moisture from the $\mathrm{CO}_{2}$ steam. However due to the batch-type $\mathrm{CO}_{2}$ generation at $\mathrm{KE}$, the dehydration unit could be subjected to fluctuating $\mathrm{CO}_{2}$ flow rates, and oxygen and organic contaminants in the $\mathrm{CO}_{2}$ stream. This could lead to some of the problems listed in the paragraph above. 


\subsection{3 $\mathrm{CO}_{2}$ Compression}

\section{CVR Compression Unit}

The $\mathrm{CO}_{2}$ at $\mathrm{CVR}$ will be compressed from 0.01 to $0.5 \mathrm{MPa}$ (2 to $75 \mathrm{psig}$ ) in a stainless steel blower. It is then dehydrated to less than $508 \mathrm{~kg} \mathrm{H}_{2} \mathrm{O} /$ million $\mathrm{Nm}^{3}\left(30 \mathrm{lbs} \mathrm{H}_{2} \mathrm{O}\right.$ per million standard cubic feet) using a conventional glycol unit. The dry $\mathrm{CO}_{2}$ is then compressed from (0.5 to $9.7 \mathrm{MPa}$ (75 to $1400 \mathrm{psig}$ ) in a centrifugal compressor and from 9.7 to $18.3 \mathrm{MPa}\left(1400\right.$ to $2650 \mathrm{psig}$ in a centrifugal pump at $49^{\circ} \mathrm{C}\left(120^{\circ} \mathrm{F}\right)$. These units are well proven in industry.

KE Compression Unit

The $\mathrm{CO}_{2}$ stream at $\mathrm{KE}$ will be compressed from -0.005 to $10.9 \mathrm{MPa}(-0.7$ psig to 1587 psig) using three multi-stage reciprocating compressors. A major concern is the fluctuating flow rate of $\mathrm{CO}_{2}$ coming from the batch-type fermentation process. Reciprocating compressors have a high turndown ration but overall efficiency will be lost due to fluctuating flow rates rather than steady state operation.

\subsection{4 $\mathrm{CO}_{2}$ Pipeline Transport}

Two pipelines are planned for this project. A $0.2 \mathrm{~m}$ (8-inch) diameter pipeline will transport $\mathrm{CO}_{2}$ from the CVR site to the Deep Bartlesville fields in Cowley or Wellington field in Sumner County, $\mathrm{KS}$, and a $0.1 \mathrm{~m}$ (4-inch) diameter, pipeline will transport $\mathrm{CO}_{2}$ from the KE site to the Geneseo-Edwards field in Rice County, KS.

The pipelines will use existing pipeline corridors (private land). Blue Source will oversee permitting. Experienced contractors will be used to design, construct and operate the pipelines. The pipelines will be designed, constructed and operated in compliance with Title 49 CFR Part 195, "Transportation of Hazardous Liquids by Pipeline" Department of Transportation, rules and regulations.

The pipelines will be buried $1.2 \mathrm{~m}(4 \mathrm{ft})$ underground $(1.8 \mathrm{~m}[6 \mathrm{ft}]$ under river, road and railroad crossings). River, road and railroad crossings will be bored under rather than trenched.

Sensitive receptor areas (schools, prisons, hospitals, etc.) will be avoided. Sensitive environmental areas will be avoided or bored under. All surface facilities outside of the plant sites will be fenced off to prevent unauthorized access.

The pipelines will be constructed of new ERW pipe. Seamless pipe will be used in all sensitive areas such as crossings. All valves and fittings will be inspected for defects and checked for proper use. Block valves will be located at appropriate locations along the pipelines for emergency shut off. Appropriate access points will be available for maintenance. Room for booster pump stations will be reserved along the pipeline to allow for future expansion.

Cathodic protection and external coating will be employed to protect against external corrosion. Very-dry, $\mathrm{H}_{2} \mathrm{~S}$-free $\mathrm{CO}_{2}$ will be used to protect against internal corrosion.

Supervisory control and data collection (SCADA) will be installed. Plant and field operations will have both SCADA and telephone communication links. Computational pipeline monitoring leak detection system will be installed. Nominations (agreement on $\mathrm{CO}_{2}$ supply and demand) will occur on a daily basis to maintain constant line and delivery pressure. 
Crack arrestors will be installed to minimize propagating cracks. Certified welders will be used on pipe welding. All welds will be x-rayed and replaced if necessary. Pipelines will pass visual inspection for defects and hydrostatic testing. Appropriate back fill will be used to avoid damaging the pipelines during burial.

The top $0.15 \mathrm{~m}$ of top soil will be saved during construction and spread back over the area from which it was taken after the final grading. Before seeding any disturbed areas, the ROW will be restored to its original form, slope, contour, and soil density to the extent practicable.

The pipelines will operate at least $2 \mathrm{MPa}$ (300 psig) above $\mathrm{CO}_{2}$ supercritical pressure to prevent two-phase flow. Pressure will not exceed $80 \%$ of design operating pressure. Standardized operating procedures will be used for pressuring/depressuring the pipelines.

Regular ROW inspection/maintenance, markings, one-call system and field supervision will be used to prevent third-party excavation damage to the pipelines. Asbuilt drawings and maps will be retained for the entire pipelines.

Appropriate field safety guidelines (OSHA) will be followed during construction and operation. All construction and operating personnel will receive training prior to working on the pipelines. DOT pipeline safety regulations will be followed in operation and maintenance of the pipelines. The pipelines will use inline inspection systems (smart pigs) and will be repaired as necessary. The frequency of pipeline inspections will be monitored and increased if any issues arise that require attention. A pipeline integrity management system will be implemented for high consequence areas (if any).

\section{$\underline{\text { KE to G-E Pipeline }}$}

The KE to G-E pipeline is $102 \mathrm{~mm}$ (4 inches) in inside diameter, $26 \mathrm{~km}$ (16 miles) long and follows existing pipeline corridors. The capacity of the pipeline is 214,000 $\mathrm{Nm}^{3} / \mathrm{d}$ (8 million scfd) of $\mathrm{CO}_{2}$. It will operate between (9.7- 10.9 MPa (1400-1587 psig), which is above the supercritical pressure of $\mathrm{CO}_{2}$. Four block valves will divide the pipeline into five sections. Over $85 \%$ of the pipeline right-of-way is on agricultural/cultivated crop land, about $5 \%$ is on wooded land and $10 \%$ is on rangeland. Over $88 \%$ of the pipeline right-of-way is flat land. The pipeline crosses: 1 highway, 2 paved roads, 19 dirt road, 2 railroads, 1 river and 1 creek. There is no designated critical habitat or occurrence within 5 miles ( 8 kilometers) of the pipeline for any special status wildlife species. Based on information gathered in the pipeline feasibility study and Environmental Information Volume, there does not appear to be any significant risk associated with this pipeline.

\section{CVR to T-A Pipeline}

A feasibility study was completed for a pipeline from CVR to T-A. This proposed pipeline is $203 \mathrm{~mm}$ ( 8 inches) in inside diameter, $177 \mathrm{~km}$ (110 miles) long and follows existing pipeline corridors. The capacity of the pipeline is 1.07 million $\mathrm{Nm}^{3} / \mathrm{d}$ (40 million scfd) of $\mathrm{CO}_{2}$. It is designed to operate between 9.7-18.3 MPa (1400-2650 psig), which is above the supercritical pressure of $\mathrm{CO}_{2}$. Eighteen block valves divide the pipeline into 19 sections. Approximately $78 \%$ of the pipeline right-of-way is on rangeland, $10 \%$ is on wooded land, $10 \%$ is on agricultural/cultivated crop land, $1 \%$ is on residential land and $1 \%$ is on industrial/commercial land. Approximately $42 \%$ of the pipeline right-of-way is on flat land, $40 \%$ is gently sloping, $15 \%$ is moderately sloping, $4 \%$ is strongly sloping and $2 \%$ is steep to very steep. The pipeline crosses 5 highways, 17 paved roads, 64 dirt roads, 6 railroads, 4 rivers and 37 creeks. The pipeline intersects with, or comes close to, 
several critical habitats, including five mussel species, the Eastern spotted skunk, the greater prairie chicken, the American burying beetle, the Topeka shiner. Based on the information gathered in the pipeline feasibility study and Environmental Information Volume, the CVR to T-A Pipeline has greater risks than the KE to G-E pipeline, but none of these risks appear insurmountable.

\section{CVR to DB Pipeline}

The proposed CVR to DB pipeline would be similar in size, length and capacity to the CVR to T-A pipeline. The pipeline route would follow existing pipeline corridors as much as possible.

CVR to Wellington Pipeline

The CVR to Wellington pipeline would be the same size and capacity as the CVR to T-A pipeline, but the length would be approximately $193 \mathrm{~km}$ (120 miles) instead of 177 $\mathrm{km}$ (110 miles). The pipeline route would follow existing pipeline corridors as much as possible.

\subsection{5 $\mathrm{CO}_{2}$ Enhanced Oil Recovery (EOR)}

$\mathrm{CO}_{2}$ EOR injection is proposed to take place in the Deep Bartlesville (DB) fields or Wellington field and Geneseo-Edwards (G-E) field respectively. The EOR injection sites will be designed, constructed and operated, in compliance with Kansas Corporation Commission rules and regulations for enhanced oil recovery (82-3-100 through 82-3908). OSHA safety guidelines will be followed. All construction and operating personnel will receive training prior to working on site.

In the design phase, the EOR sites will be fully characterized and the following plans will be prepared:

- Existing well replugging plan

- Drilling and injection plan

- Closure plan

- EOR facility safety plan

- $\mathrm{CO}_{2}$ storage verification plan

Geneseo-Edwards (G-E) Field EOR

The G-E field is a mature oil field with approximately 247 existing wells (117 wells in the two domes covered by the project). Prior to operation, the three wells penetrating into the Arbuckle reservoir will be replugged. These wells and others will be monitored for $\mathrm{CO}_{2}$ leakage and remedial action will be taken if necessary. Several wells will be reconditioned or reactivated for use in EOR.

A gravity-stable, near miscible $\mathrm{CO}_{2}$ flood will be used for EOR in the G-E field. Supercritical or dense-phase $\mathrm{CO}_{2}$ will be injected into the top of an oil-filled dome with $37 \mathrm{~m}$ (120 ft) of closure. The $\mathrm{CO}_{2}$ cap will push the residual oil downward. Oil production wells will collect the mobilized oil through perforations lower in the reservoir and recycle the associated $\mathrm{CO}_{2}$. If the gravity stable flood becomes non-uniform, it may be necessary to decrease the $\mathrm{CO}_{2}$ injection rate per well and/or add more vertical or horizontal injection wells.

The existing bottom-hole pressure in the top of the dome(s) in the G-E field is close to the $\mathrm{CO}_{2}$ supercritical pressure. It will not be possible to increase the pressure of the Arbuckle formation. The $\mathrm{CO}_{2}$ will be injected as a supercritical fluid, but it may revert to 
a dense-phase gas in the top of the dome. This is not expected to create a problem for the gravity stable flood nor the long term retention of $\mathrm{CO}_{2}$ within the dome.

The minimum miscible pressure for the residual oil in the G-E field is significantly higher than the existing bottom-hole pressure in the top of the dome. The $\mathrm{CO}_{2}$ will be injected at near the minimum miscible pressure. This has been taken into account in calculating the expected oil yield.

The Arbuckle water produced with oil has been reported to be highly corrosive and containing $\mathrm{H}_{2} \mathrm{~S}$. Water samples will be taken from the Arbuckle and analyzed for corrosiveness and appropriate materials of construction will be selected for systems that will handle the water and gases produced with the Arbuckle oil. Produced water will be reinjected back into the Arbuckle formation. It will be important to maintain tight seals and monitor for $\mathrm{H}_{2} \mathrm{~S}$ as well as $\mathrm{CO}_{2}$.

There is a fault on the west side of the G-E field with approximately $91 \mathrm{~m}$ (300 feet) of vertical displacement. It is believed that this fault is not active and does not penetrate the caprock. It will be further characterized and included in simulation modeling.

Deep Bartlesville Fields (Rainbow Bend Field and others) EOR

The Deep Bartlesville Fields, in Cowley County, KS, are mature oil fields with some existing wells. The integrity of the seals has been proven over time. $\mathrm{CO}_{2}$ leakage from existing wells represents a potential risk, however, prior to operation, a detailed borehole and replugging plan will be prepared. Wells that are at risk for leaking will be replugged. Prior to $\mathrm{CO}_{2}$ injection, the field will be pressured in stages over 3-6 months by injecting water. This should help in detecting any leaks. The replugged wells and other wells will be monitored for leakage and remedial action will be taken as necessary. Some wells will be reconditioned or reactivated for use in EOR.

The Deep Bartlesville oil reservoirs are discontinuous fluvial channel sandstone up to $15 \mathrm{~m}$ thick. They are totally surrounded by shale overlain by multiple additional seals and sinks. Thus they are essentially "bottles". The injection depths range from 914 to $1006 \mathrm{~m}(3,000$ to 3,300 ft). The minimum miscible pressure (MMP) is approximately $11 \mathrm{MPa}$. The maximum injection pressure, (or fracture pressure minus $0.34 \mathrm{MPa}$ ) is approximately $15 \mathrm{MPa}$. This gives a working pressure range of approximately $4 \mathrm{MPa}$. Over pressuring the reservoirs will be prevented by producing oil, water and gas to compensate for the volume of $\mathrm{CO}_{2}$ injected.

The reservoirs are in a of sensitive groundwater area along the Arkansas River. Monitoring or observation wells will be used to monitor $\mathrm{CO}_{2}$ levels in sinks located above the primary seal to detect any $\mathrm{CO}_{2}$ leakage before it comes in contact with groundwater. Procedures will be in place to prevent/mitigate any $\mathrm{CO}_{2}$ contamination of groundwater or surface water, including extraction of $\mathrm{CO}_{2}$ from a leaky reservoir and injecting it into another sealed reservoir if necessary. There are multiple small isolated reservoirs in the area for combined enhanced oil recovery and $\mathrm{CO}_{2}$ sequestration. This should be a lower risk compared to one large reservoir.

The Humboldt fault zone is located adjacent to some of the Deep Bartlesville oil reservoirs. The fault zone is relatively stable in this area. 3-D seismic will be used to characterize the fault zone and the oil reservoirs. $\mathrm{CO}_{2}$ injection will be kept away from the fault zone and will be controlled to prevent over pressuring. Monitoring and modeling will be used to track $\mathrm{CO}_{2}$ migration. 


\section{Wellington Field EOR}

The Wellington Filed is located two miles (3.2 kilometers) Northwest of Wellington, KS in Sumner County. The oil reservoir is in Mississippian Chat (chert and dolomite). It is $1113 \mathrm{~m}(3650 \mathrm{ft})$ deep, $20.7 \mathrm{~km}^{2}\left(8 \mathrm{mi}^{2}\right)$ in lateral area, $6 \mathrm{~m}(20 \mathrm{ft})$ thick, and has $30 \%$ porosity, $6 \mathrm{MPa}(1750 \mathrm{psi})$ pressure and $49^{\circ} \mathrm{C}\left(120^{\circ} \mathrm{F}\right)$ temperature. The caprock (primary seal) is Pennsylvanian shale with a thickness of around $18 \mathrm{~m}(60)$ feet. A secondary seal consists of a 61-91 m (200-300 ft) evaporite formation located below the shallow fresh water aquifer. The Arbuckle deep saline aquifer is located at a depth of 1250 to $1554 \mathrm{~m}$ (4100 to $5100 \mathrm{ft}$ ). It is separated from the Mississippian Chat oil reservoir by Chattanooga shale.

Wellington is a mature oil field that has been in existence over 80 years. Cumulative oil production has been 20.5 million barrels with over half coming from secondary water flooding. The field is unitized and owned by BEREXCO. It has over 134 existing wells. 44 are active wells. The field currently produces $138 \mathrm{bpd}$ of $42^{\circ}$ API gravity oil along with 10,000 bpd of water.

The Wellington field appears to be a very good candidate for $\mathrm{CO}_{2} \mathrm{EOR}$. The formation pressure is sufficiently above the $\mathrm{CO}_{2}$ supercritical pressure. The high API gravity of the crude oil indicates that the minimum miscible pressure should be lower than the Thrall-Aagard or Geneseo-Edwards fields. The greater depth should allow a higher maximum pressure. Thus the range of working pressure should be sufficient. The fact that more oil was produced with secondary water flooding than with primary oil production suggests that the tertiary $\mathrm{CO}_{2}$ flooding will also be successful.

A current DOE program is underway at the Wellington Field. A 3-D seismic survey was completed in April 2010. High resolution gravity/magnetic survey and a 2-D seismic survey are scheduled for June 2010. Field data will be inputted into computer simulation to optimize $\mathrm{CO}_{2}$ EOR operation. A typical 5-spot pattern is planned for the piston-type $\mathrm{CO}_{2}$ EOR operation. A risk assessment of existing wells will be performed to determine how many are likely to fail (leak) over time. The effects of any sealing or transmitting faults will also be addressed. Characterization and risk assessment of potential $\mathrm{CO}_{2}$ leakage pathways (wells, faults and fractures) located within $16 \mathrm{~km}(10 \mathrm{miles})$ of the field will be performed. It is estimated that the Mississippian Chat oil reservoir can hold approximately 25 million tonnes of $\mathrm{CO}_{2}$. Additional $\mathrm{CO}_{2}$ could be sequestered in the Arbuckle deep saline aquifer below the oil reservoir.

The primary risk that exists for environmental, health and safety issues related to the Wellington EOR site is wellbore leakage through degraded casings. Secondary risks include potential leakage through faults or fractures.

The proposed site is a mature oil field operated for over 80 years with many existing wells throughout the field. Depending upon the condition of the casings at the time of drilling, these wells could serve as fast migration pathways from the reservoir to the surface. Many of the existing wells have been plugged and abandoned and the procedures used may have varied over the years due to a range of regulations imposed on the cap/abandonment procedure occurring over the 80 years of operation. Therefore, these wells serve as potential conduits for free-phase $\mathrm{CO}_{2}$ movement from the reservoir to the surface. 
In addition to known wells located near the proposed injection site, there are possibly unknown wells located within the area that were not properly recorded. Such wells must be considered in any analysis to show what impact they might have on the overall risks of the project. If risks from unknown wells are small, they can be ignored. However, if these risks are high, some effort must be made to use monitoring or exploration to reduce uncertainty in these risk drivers. Risk associated with existing wells can be managed by selectively replugging and sealing those wells that are determined to be of concern after completing a quantitative risk analysis such as presented by Pawar et al. (2009).

Risks from leaking wells include (1) environmental impact to overlying groundwater systems (acidification of these systems), (2) $\mathrm{CO}_{2}$ asphyxiation hazard close to the well, and (3) local plant, and soil bacterial stress in the overlying environment.

Induced seismicity could be an issue if the reservoir were to be over pressured. However, in an EOR operation, increased pressure from injection of $\mathrm{CO}_{2}$ is partially or fully compensated for by production of oil, water and gas. The relatively small volume of $\mathrm{CO}_{2}$ injection is not expected to cause anything more than microseismicity.

The Pennsylvanian shale caprock or primary seal is $18+\mathrm{m}$ thick. If the caprock is fractured, $\mathrm{CO}_{2}$ could leak to overlying formations. However a 61-91 m thick evaporite formation is located between the primary seal and the shallow fresh water aquifer and should pose a formidable barrier to $\mathrm{CO}_{2}$, keeping it away from the fresh water aquifer.

Slate Creek flows across the Southwestern edge of the Wellington Field. This creek feeds into the Arkansas River and is therefore included as part of the sensitive receptor vulnerable to $\mathrm{CO}_{2}$ intrusion. Appropriate safeguards and monitoring would be needed to assure that $\mathrm{CO}_{2}$ does not contaminate the water in Slate Creek.

Preliminary review of population density data suggests that the Wellington field are is sparsely populated with a population density of approximately 1 person per square mile (1 person per 2.6 square kilometers).

Additional concerns that may be resolved with a more detailed information survey include the following:

- Proximity to nearest seismic fault fracture and migration potential of the injected $\mathrm{CO}_{2}$ plume. The Humboldt fault zone is located approximately 8 miles (13 kilometers) east of the injection site. There are some closer minor faults located on either side of the injection site.

- Previous water floods may have activated microfaults/fissures and/or damaged caprock integrity. Management history unknown at this time.

- Seal integrity and uniformity of overburden throughout the Wellington region uncertain.

- Modeling of geomechanical attributes of the stress field. Induced stresses are present from historical depletion. Possible thermal gradients during injection may induce localized tensile stresses on a previously "exercised" field.

\section{Thrall Aagard (T-A) Field EOR}

The IMCCS Project originally planned to inject $\mathrm{CO}_{2}$ into the T-A (and other adjacent fields) for enhanced oil recovery. However, after significant study it was concluded that the T-A field was too shallow for $\mathrm{CO}_{2}$ EOR. This resulted in insufficient working pressure range (1.5 $\mathrm{MPa}[215 \mathrm{psi}]$ ). Working pressure range is equal to maximum bottom hole injection 
pressure (10.8 $\mathrm{MPa}$ [1560 psi] or fracture pressure minus $0.34 \mathrm{MPa}$ [50 psi] at T-A) minus minimum miscibility pressure $\left(9.3 \mathrm{MPa}[1345 \mathrm{psi}]\right.$ at $43^{\circ} \mathrm{C}\left[110^{\circ} \mathrm{F}\right]$ at $\left.\mathrm{T}-\mathrm{A}\right)$.

In addition, it was most likely that the $\mathrm{T}$-A field could not operate at a high enough pressure to achieve miscible $\mathrm{CO}_{2}$ EOR. The reservoir pressure would have to operate significantly higher than original bottom hole pressure. And finally, the field has over 457 existing wells that could eventually leak through degraded casings.

This section is included for purpose of completeness to document the work that was done on the T-A field. Special attention was given to wellbore risks in the T-A field. A database of plugged and abandoned wells in the T-A was compiled by Dr. Martin Dubois of CAP $\mathrm{CO} 2$ and analyzed by Dr. Andrew Duguid of Schlumberger Carbon Services. The analysis was then reviewed by members of the risk assessment working group. This analysis can be found in Appendix 6-C.

The T-A field is a mature oil field with approximately 457 existing wells. Some of the early wells have been fractured with nitroglycerin while later wells were hydrofractured to improve permeability. $\mathrm{CO}_{2}$ leakage from existing wells represents the most significant risk for the T-A field. Prior to operation, a detailed replugging plan would be prepared. Three plugs are standard: one at the Bartlesville Sandstone at $671 \mathrm{~m}$

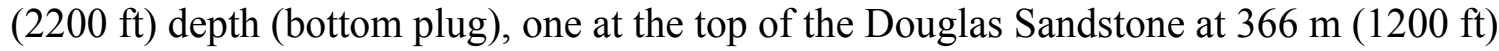
depth (middle plug) and from $67 \mathrm{~m}$ (220 ft) to the surface (top plug). Wells which didn't meet this standard would be replugged. Prior to $\mathrm{CO}_{2}$ injection, the field would be pressured in stages up to 8.3-9.7 MPa (1200-1400 psig) over 3-6 months by injecting water. This would help in detecting any leaks. The replugged wells and other wells would be monitored for leakage and remedial action would be taken as necessary. Several wells would be reconditioned or reactivated for use in EOR.

The Bartlesville oil reservoir, in the T-A field, is discontinuous fluvial channel sandstone up to $30 \mathrm{~m}$ thick $\times 6.4 \mathrm{~km}$ long $\times 1.3 \mathrm{~km}$ wide $(100 \mathrm{ft}$ thick $\times 4$ miles $(6.4$ kilometers) long and 0.8 miles (1.3 kilometers) wide). It is totally surrounded (top, bottom and sides) by a Middle Pennsylvanian Cherokee shale (61 m [200 ft] above and $30 \mathrm{~m}[100 \mathrm{ft}]$ below). Multiple addition seals and sinks occur above the Cherokee shale.

Water flooding indicates the Bartlesville oil reservoir is essentially a "bottle" surrounded by shale. Well records indicate the reservoir has been pressured up to 11.7 $\mathrm{MPa}$ (1700 psig). The current bottom-hole pressure is $5.9 \mathrm{MPa}$ ( $850 \mathrm{psig}$ ). The minimum miscible pressure for the residual oil is $9.3 \mathrm{MPa}(1345 \mathrm{psig})$. The plan was to pressurize the reservoir to $9.7 \mathrm{MPa}$ (1400 psig) in order to maintain the $\mathrm{CO}_{2}$ in supercritical form, make it miscible with the residual oil and stay below the formation fracture gradient. Any leaks through existing wells or lateral leaks would make it difficult to pressurize the reservoir, therefore special attention would be given in the drilling and injection plan to prevent or minimize leakage.

The Douglas Sandstone is a 15-24 m (50-80 ft) thick, highly-permeable, salineaquifer, low pressure (3.4 MPa [500 psig]) thief zone located 152-183 m (500-600 ft) above the Bartlesville oil reservoir in the T-A field. Any leaky borehole would act as a conduit for passing $\mathrm{CO}_{2}$ from the oil reservoir to the thief zone. Observation wells would be used to monitor $\mathrm{CO}_{2}$ content in the thief zone and remedial action would be taken to locate and stop any $\mathrm{CO}_{2}$ leakage that may occur.

After discontinuing $\mathrm{CO}_{2}$ injection into the Bartlesville oil reservoir, it would be necessary to decrease the pressure from $9.7 \mathrm{MPa}$ (1400 psig) back to the pre-injection pressure of $5.9 \mathrm{MPa}(850 \mathrm{psig})$. This could be accelerated by recovering $\mathrm{CO}_{2}$ from the 
reservoir for use in EOR operations in other nearby oil fields, injecting the $\mathrm{CO}_{2}$ into the Douglas Sandstone, or injecting the $\mathrm{CO}_{2}$ into the Arbuckle formation. A closure plan would be prepared and implemented to select the best alternative.

\subsection{6 $\mathrm{CO}_{2}$ Deep Saline Aquifer (DSA) Sequestration}

It was originally planned that $\mathrm{CO}_{2}$ DSA sequestration would be included in Phase 2 of the IMCCS project. However, it was determined that under current market conditions, there is insufficient economic incentive to justify $\mathrm{CO}_{2}$ DSA sequestration and this portion of the project was dropped from Phase 2. $\mathrm{CO}_{2} \mathrm{DSA}$ sequestration could become feasible in the future if appropriate legislation is enacted to incentivize $\mathrm{CO}_{2}$ sequestration and the IMCCS project could add this portion back into the project if this happens. This section is included for completeness to indicate the work done on DSA risk assessment.

The original plan was to inject $\mathrm{CO}_{2}$ into the Arbuckle DSA below the G-E and/or T-A fields. These are mature oil fields and the footprints of the deep saline $\mathrm{CO}_{2}$ plumes was not expected to exceed the boundaries of the leased EOR surface area above them. In both cases, $\mathrm{CO}_{2}$ would be injected into the bottom of the Arbuckle formation - a 183 $\mathrm{m}(600 \mathrm{ft})$ thick, porous-dolomite, with multiple stacked seals and sinks above it. The integrity of the vertical seals have been demonstrated by the presence of hydrocarbons in and above the Arbuckle formation.

Sufficient $\mathrm{CO}_{2}$ would be injected into the DSA to enable 3-D seismic monitoring of the plumes ( $\mathrm{Up}$ to 50,000 tonnes per year or 150,000 tonnes total over a 3-year period for $\mathrm{G}-\mathrm{E}$ and up to 100,000 tonnes per year or 300,000 tonnes total over a 3-year period for T-A).

In the Design sub phase, the operators were to complete a full characterization of the site(s) including:

- Generalized stratigraphic column of the geologic formations encountered, supported with geophysical logs

- Geologic, geomechanic, geochemical, hydrogeologic and reservoir evaluation

- Assessment of regional and local faults and other structural or stratigraphic features

- Estimate of $\mathrm{CO}_{2}$ storage capacity based on modeling

- Estimate of plume footprint over time based on modeling

- Identification of any petroleum or water resources that may be impacted

- Assessment of existing wells, and other man-made surface structures and activities within one-mile (1.6 kilometers) outside of the storage facility boundary

- Isopach maps of the $\mathrm{CO}_{2}$ storage reservoir and adjacent confining layers

- Structural and stratigraphic cross sections of the reservoir at the site(s)

- Detailed monitoring plan for soil, useable water, and the first porous zone immediately above the $\mathrm{CO}_{2}$ reservoir's confining layer

- Saline fluid flow map of the storage reservoir showing local and regional fluid flow directions

In addition, the following plans were to be prepared: 
- Replugging plan for existing wells that penetrate the DSA

- Drilling and injection plan (number and type of wells, maximum injection rate, pressure, etc.)

- Closure plan (including: pressure existing before and expected at the end of $\mathrm{CO}_{2}$ injection, predicted time for equilibration, estimated ultimate extent of the $\mathrm{CO}_{2}$ plume, and procedure for monitoring the plume)

- $\mathrm{CO}_{2}$ storage facility safety plan (facilities security, public safety, public notification procedures, emergency response and contingency plans for leaks or loss of containment, contact information for emergency response contractors, interface with county emergency management, monitoring plan to ensure containment of $\mathrm{CO}_{2}$ vertically and horizontally, safety plan updating schedule).

- $\mathrm{CO}_{2}$ storage verification plan (monitoring and documentation procedures)

The DSA injection sites were to be designed, constructed, operated, and closed in compliance with Kansas Corporation Commission regulations for carbon dioxide storage facilities (82-3-1100 through 82-3-1120 effective as of February 26, 2010). OSHA safety guidelines will be followed. All construction and operating personnel will receive training prior to working on site.

The risks associated with $\mathrm{CO}_{2}$ DSA sequestration included:

Leakage of $\mathrm{CO}_{2}$ through existing boreholes - This is not as severe a problem compared to EOR operation the T-A field because there are only about 4 wells in the area that penetrate through the caprock to the Arbuckle. The risks for DSA and EOR in the G-E field are comparable because the oil reservoir is in the Arbuckle formation.

Up-dip migration of $\mathrm{CO}_{2}$ in the T-A - The top of the Arbuckle under the T-A field is a gently

dipping monocline. There was not sufficient characterization work completed to determine if there were up-dip traps to secure the $\mathrm{CO}_{2}$ long-term. However, after simulation modeling, it was determined that due to the low volume of $\mathrm{CO}_{2}$ to be injected and the very gentle dip, the $\mathrm{CO}_{2}$ migration would gradually stop after about 60 years.

$\mathrm{H}_{2} \mathrm{~S}$ stripping in the Arbuckle - Preliminary information indicates that the Arbuckle fluids contain $\mathrm{H}_{2} \mathrm{~S}$. Free $\mathrm{CO}_{2}$ could strip the $\mathrm{H} 2 \mathrm{~S}$ and causing it to flow with the $\mathrm{CO}_{2}$ if a leak developed. Therefore it would be necessary to monitor for $\mathrm{H} 2 \mathrm{~S}$ as well as $\mathrm{CO}_{2}$.

Transformation of $\mathrm{CO}_{2}$ from supercritical to gas phase - The Arbuckle formation below the T-A field is sufficiently shallow that injected $\mathrm{CO}_{2}$ would transform from supercritical phase to gas phase as it migrated away from the injection well. This could cool the surrounding area, significantly increase the volume of $\mathrm{CO}_{2}$ stored, accelerate migration of the $\mathrm{CO}_{2}$ and increase stripping of any $\mathrm{H}_{2} \mathrm{~S}$.

\subsubsection{Post Closure}

At the end of $\mathrm{CO}_{2}$ EOR injection, the operator will follow Kansas Corporation Commission regulations for plugging and abandonment of wells, removal of surface equipment, site remediation and safety.

All necessary records, including those needed for verification of long-term storage of $\mathrm{CO}_{2}$, will be maintained for the duration of time required by law. 
It is anticipated that the owner/operator of the EOR field(s), will take on all liabilities associated with the $\mathrm{CO}_{2}$ storage until legislation establishes an appropriate mechanism for transferring long-term liability.

\subsection{Programmatic Risk Results and Discussion}

Based on ranking and project specific information, the following significant programmatic risks/issues have been identified. Under each issue, we have summarized the proposed strategies to prevent the occurrence or minimize the impact of the risk.

6.2.1 Securing strategic partners for EOR operation and cost share funding

Strategic partner agreements should be in place prior to finalizing the Phase 2 Agreement. A backup list of potential strategic partners has been developed in case any current partners should bail out. Note that the strategic partner(s) selected for the enhanced oil recovery may determine the final EOR site selected.

\subsubsection{Acquiring contiguous leasehold interests for injection sites}

Leaseholds should be in place prior to finalizing the Phase 2 Agreement. Compulsory unitization rules allow the operator to receive a Kansas Corporation Commission order with at least $63 \%$ interest. The process takes approximately 6 months. There are multiple oilfields in Cowley, Sumner and Rice Counties suitable for EOR. Lease acquisition is tied to current (declining) production levels; therefore there is motivation to sell to avoid lease termination.

\subsubsection{Securing DOE funding support}

We intend to comply with all of DOE requirements for obtaining and maintaining funding for this project.

\subsubsection{Potential construction delays due to the need for an EIS rather than an EA}

With the possibility that an EIS may be required, we have taken the conservative approach to include a 12 month Design sub-phase and sufficient funds in the budget to cover an EIS. If an EIS is required, we may also begin the EIS process as soon as possible after selection notification to gain three additional months (assuming an EIS may take 15 months to complete). While we have allocated 12 months for the Construction sub-phase beginning in October 2011, it is possible that construction can be compressed into six months with work beginning in April 2012 if necessary due to permitting delays or long-lead times on equipment.

\subsection{Managing/coordinating multiple partners in the project}

The project partners have been successfully working together throughout Phase 1 . Phase 2 will use a similar organization structure consisting of a cross-functional management group, multiple working groups, well defined scopes of work and budgets, secure website, regular conference calls and meetings, and reporting system to keep the project on schedule, within budget and on target.

\subsubsection{Cost escalation}

Efforts have been made to get quotes and proposals covering major scopes of work for the project. Vendor quotes will be negotiated and subject to competitive bidding. Suitable escalation factors have been included and identified within the budget. Most of the capital budget will be expended in the first half of the project, thus escalation should be less than if the spending occurred in the last half. Long lead items, such as compressors, will be committed early. 


\subsubsection{Oil Price Fluctuation}

Crude oil prices are unpredictable and subject to periods of high volatility. The price of $\mathrm{CO}_{2}$ will be tied to crude oil price to allow the supplier and user to share in the risks and rewards associated with fluctuating oil prices. The project is commercially viable with average WTI crude oil prices above $\$ 75 /$ barrel over the 5-year term.

\subsection{8 $\mathrm{CO}_{2}$ quality}

The project will require that Kansas Ethanol conduct a sufficiently long performance test to prove that it can consistently produce on-spec $\mathrm{CO}_{2}$. The project will require Kansas Ethanol to guarantee $\mathrm{CO}_{2}$ quality. Coffeyville Resources Nitrogen Fertilizer has already demonstrated it can consistently meet the $\mathrm{CO}_{2}$ specification and is willing to guarantee it.

\subsection{9 $\mathrm{CO}_{2}$ supply interruption}

Coffeyville Resource Nitrogen Fertilizer has a backup gasifier on site to maintain high plant availability. $\mathrm{CO}_{2}$ is paid based upon $75 \%$ of available supply, no supply: no liability to pay. If suppliers are unable to provide reliable $\mathrm{CO}_{2}$ supply, they forfeit reliability incentives that would otherwise be paid in year four. After initial four years of $\mathrm{CO}_{2}$ injection, water-alternating-gas (WAG) techniques can minimize affects of $\mathrm{CO}_{2}$ downtime. Eventually, $\mathrm{CO}_{2}$ recycling will exceed fresh $\mathrm{CO}_{2}$, this will minimize the impact of a temporary interruption in fresh $\mathrm{CO}_{2}$ supply. There are several other ethanol plants in the area of the Geneseo-Edwards field that could ultimately replace or supplement Kansas Ethanol $\mathrm{CO}_{2}$ supply.

\subsubsection{Borehole replugging and remediation}

We plan to replug any wells that have a risk of leaking before injecting $\mathrm{CO}_{2}$. By switching the injection site away from the Thrall-Aagard field, the amount of borehole replugging and remediation will be significantly less. We will increase the pressure of the Bartlesville oil reservoirs with water and check for leakage before injecting any $\mathrm{CO}_{2}$. Kansas Corporation Commission may offer assistance for locating and plugging abandoned wells. Lease purchases are conditioned on plugging details (with claw back for new discoveries of poorly plugged wells).

\subsubsection{Oil recovery}

Strong empirical results from water flooding during the past 50 years indicate that recovery of $12.5 \%$ of original oil in place (OOIP) with $\mathrm{CO}_{2}$ EOR is achievable. Oil reservoirs will be thoroughly modeled and engineered to optimize well pattern, well spacing and oil recovery. Injection and production performance will be monitored and modeled and well pattern and spacing will be modified if necessary to optimize oil recovery.

\subsubsection{Long-term liability for sequestered $\mathrm{CO}_{2}$}

$\mathrm{CO}_{2}$ injection sites will be fully characterized and modeled to identify trapping mechanisms to hold $\mathrm{CO}_{2}$ in place long-term. Site closure plans will be submitted to Kansas Corporation Commission as part of the permitting process for $\mathrm{CO}_{2}$ sequestration. Verification of $\mathrm{CO}_{2}$ sequestration will be done by an independent third party.

\subsubsection{Deep saline aquifer (DSA) sequestration}

Without new legislation, DSA sequestration is uneconomic. Regulations for DSA permitting, operation and closure are more onerous and less defined than those for EOR, resulting in higher costs and greater liabilities. The current plan is to operate under the 
EOR umbrella during the 5-year term of the project with the option to expand into DSA sequestration in the future if the economic hurdles can be overcome.

\subsubsection{Insurance coverage}

Insurance coverage may be available for EOR operation but may not be available for DSA sequestration. Insurance coverage would address short-term liability including physical damage, machinery breakdown, business interruption (advanced loss of profits), third-party liability and environmental liabilities.

\subsubsection{Engineering, Procurement and Construction}

The project will work with competent, experienced firms to provide engineering, procurement and construction services. Design review meetings will be conducted by a cross-functional team of experts. As-built drawings will be reviewed for accuracy and completeness. Equipment and infrastructure will be inspected and tested before being placed into service. Budgets and schedules will be closely tracked and managed by experienced project managers.

\subsubsection{Field Safety}

A Health, Safety, Environment and Security (HSES) Plan and an Emergency Response Plan will be developed and implemented during the Design sub-phase. Personnel will receive HSES training before working in the field. The project will maintain compliance will all OSHA and State safety regulations including regular HSES training meetings, emergency response drills and safety audits. The project will mark and regularly inspect pipelines, use a one-call system, and supervise third-party excavation activities to prevent excavation damage to pipelines. Surface facilities will be fenced in and protected from public access. HSES incidents will be appropriately tracked and documented. The Emergency Response Plan will be regularly updated and integrated with the local community emergency response plan and public outreach and education program.

\subsubsection{Public Outreach}

The public outreach program will follow the NETL/DOE best practices manual. By focusing on EOR, it is believed that less public concern will be generated than with DSA sequestration. The oil industry and local residents have a long-term successful working relationship at the potential injection sites.

\subsubsection{Pore Space Ownership}

Pore space ownership is a significant issue in $\mathrm{CO}_{2}$ deep saline aquifer sequestration but has not been an issue in $\mathrm{CO}_{2}$ EOR. One of the reasons IMCCS has focused on EOR for Phase 2 is that regulations on pore space ownership have not been adopted in the State of Kansas. IMCCS will monitor developments in poor space ownership regulations and will need to comply with State of Kansas regulations when and if they are adopted.

\subsection{Conclusions}

The qualitative risk assessment on Phase I of the IMCCS project identified a comprehensive list of technical and programmatic risks associated with $\mathrm{CO}_{2}$ capture, dehydration, compression, pipeline transportation, enhanced oil recovery and deep saline aquifer injection. The risks have been analyzed and ranked relative to site-specific conditions. Tentative risk prevention and mitigation steps have been developed for each risk. 
The two suppliers of $\mathrm{CO}_{2}$ for the project already generate concentrated $\mathrm{CO}_{2}$ as a byproduct of ammonia and ethanol production. The $\mathrm{CO}_{2}$ capture at $\mathrm{CVR}$ is well proven and performing well on a continuous basis. The $\mathrm{CO}_{2}$ capture at Kansas Ethanol tends to be variable in quality and flowrate due to the batch-type nature of fermentation. This may have a negative impact on $\mathrm{CO}_{2}$ dehydration and compression performance. It may be necessary to install a surge tank at Kansas Ethanol to steady out $\mathrm{CO}_{2}$ quality and flowrate and a performance test should be conducted to confirm that Kansas Ethanol can consistently meet $\mathrm{CO}_{2}$ quality specification.

The two pipelines in the project will be installed along existing pipeline corridors. There does not appear to be any site-specific conditions that would result in above normal risks compared to other existing $\mathrm{CO}_{2}$ pipelines. As long as the pipelines are installed and operated in accordance with US Department of Transportation regulations (Title 49 CFR Part 195), the pipelines should be able to operate safely.

Several mature oil fields were evaluated for enhanced oil recovery. The Thrall-Aagard Field appeared to have the highest technical risks due to shallow depth and high concentration of existing wells. The Deep Bartlesville Fields have better reservoir conditions due to depth and fewer well penetrations, but are located in a sensitive groundwater area of the Arkansas River and near the Humboldt fault zone, requiring greater precautions and more intensive monitoring. The Geneseo-Edwards Field requires gravity-stable $\mathrm{CO}_{2}$ flooding which is more difficult to control. It reportedly has hydrogen sulfide in the Arbuckle formation that may require additional corrosion control in production wells and recycling systems. And there is a small fault on the west side of the field that will need to be characterized and monitored. The Wellington Field in Southern $\mathrm{KS}$ appears to be well suited for $\mathrm{CO}_{2} \mathrm{EOR}$ and may have the lowest risks. There are existing wells in the field, but significantly fewer than the Thrall-Aagard field. The field is near a sensitive groundwater area and eight miles (13 kilometers) away from the Humboldt fault zone. 


\section{Chapter 7 - Conclusions}

Results of this project should be considered an initial feasibility study to be followed by additional data gathering, field testing, and more rigorous modeling and simulation study. Analyses suggest that deep saline sequestration is impractical and uneconomic, without additional (new) financial incentives. However, EOR analysis results of this project are encouraging and suggest a gravity-stable immiscible $\mathrm{CO}_{2}$ EOR flood in select Midwestern oilfields would mobilize oil, form a horizontal oil bank, and could be commercially feasible. However, substantial additional work is needed on three fronts: 1) fill critical fluid property gaps, 2) improve assessments of geophysical and petrophysical properties including residual oil saturation, and 3) gain a better understanding of reservoir "plumbing systems" to insure that a gravity-stable approach could be effective in these reservoirs.

\section{Key Findings}

The objective of the study detailed in this chapter was to evaluate the potential for a gravity-stable EOR project in the Arbuckle given that the reservoir has a relatively thick oil column, the producing mechanism is a strong bottom-water drive, and evidence that the oil-water contact moved vertically in a fairly uniform manner, leaving behind sufficient residual oil to be targeted for EOR. Key findings include the following:

1. Significant residual oil remains in the water-swept portion of the reservoir. Residual oil saturation (Sorw) is approximately 38.9\% established by material balance, assuming original saturation is $70 \%$, average porosity is $11.5 \%$, and a FVF of 1.1. EPIC's estimated Sorw to be $38.9 \%$ based on reservoir and oil properties, and history-matched reservoir simulation by Schlumberger yielded an average Sorw $=36 \%$.

2. It appears likely that that a $\mathrm{CO}_{2}$ gas cap can be built downward while maintaining a relatively flat gas/water-oil contact. A study of oil-water contacts in 32 wells suggests strongly that the oil-water contact stayed relatively flat as it moved upward during the 80-year production history. Reservoir simulations indicate that a $\mathrm{CO}_{2}$ gas cap with a fairly uniform gas/oil contact can be built downward.

3. Successful Keg River gravity-stable miscible floods (Canada) may be analogs to the Arbuckle of the Central Kansas Uplift.

4. The EPIC preliminary feasibility study, based on correlations with empirically derived data and equations, and comparisons with analogs, suggests that 6.1 million barrels of oil could be recoverable by EOR in the two-dome project. 
5. The Schlumberger reservoir simulation study demonstrates that oil is mobilized by $\mathrm{CO}_{2}$ in a gravity-stable process. However, the amount of oil mobilized is a fraction of that predicted to be recoverable by the EPIC study. Significant improvements in the oil mobilized by optimizing the simulation for improved sweep efficiency.

The above results should be utilized with caution. Many caveats and shortcomings have been discussed throughout the report and are summarized below:

1. Residual oil saturation is based on an assumed initial oil saturation of $70 \%$ and FVF of 1.1. Neither of these variables are known.

2. A published paper (Mullins and Ireland, 1967) on the Arbuckle reservoir 5 miles ( 8 kilometers) northwest of the proposed project suggests the reservoir is layered. This would negatively impact the potential for gravity-stable EOR process if it is the case in the project area.

3. The simulation model is based on a static model grid built from a sparse petrophysical data set. Critical fluid properties and the equation of state (EOS) for the crude oil were estimated.

\section{Recommended Additional Work}

The current study achieved some progress towards answering fundamental questions and provides encouragement for further evaluation. The final answers will not be known until the concept is tested by large-scale $\mathrm{CO}_{2}$ injection, but there are a number of data to yet be collected, analyzed and incorporated in the model, and field testing that could help to elucidate the fluid dynamics of the reservoir system and reduce major risk factors due to current uncertainties:

Fill critical fluid property for well-constrained EOS and other parameters:

-Laboratory flash liberation tests (CCE)

-Laboratory differential liberation tests (DL, CVD)

-Viscosity versus pressure at reservoir temperature

-Swelling tests

-Additional MMPs

- Oil composition from downhole samples above bubble point

-Gas sample and composition

Improve the static model grid geometry

-Make another search for wireline logs and incorporate

-Acquire initial 3-D seismic survey and incorporate

-Improve layering and identify potential barriers in core

Improve the static model grid petrophysical properties: 
- Obtain additional conventional and special core analysis from existing cores, including in situ properties, capillary pressure data, rock mechanical data for fracture pressure of reservoir and seal

-Run modern openhole logs in existing wells with long open hole sections and wells re-entered and deepened for reservoir tests, and incorporate petrophysical data and layering

.Obtain current Sorw from open hole logs

Gain a better understanding of the reservoir "plumbing system" in particular continuity in vertical permeability:

-Further analysis for movement of oil-water contact including correlating well production tests to current layered reservoir model, particularly in areas where there are anomalies what otherwise appears to be a relatively uniform pattern of upward movement.

-Investigate the data behind the Mullins and Ireland (1967) paper and production records since the paper was written to validate or refute the paper's findings.

-Analyze several cores available at the Kansas Geological Survey core storage facility paying particular attention to potential vertical barriers and correlate to wireline logs.

-Design and perform multiple well tests, including pulse tests and tracer surveys, to measure vertical permeability at varying scales.

-Research and deploy other methods for characterizing reservoir-scale permeability in three dimensions.

Multiple iterations of reservoir characterization, modeling and simulation will be required before one can predict reservoir behavior with confidence. The current understanding of past reservoir behavior, comparison with successful analogs, and current reservoir models all suggest that gravity-stable immiscible $\mathrm{CO}_{2} \mathrm{EOR}$ could be successful. Additional work could bolster the case sufficiently to justify moving forward to a commercial-scale development project. 


\section{References}

Adler, F.J., (1971), Future petroleum provinces of the mid-continent, region 7: in Future Petroleum Provinces of the United States-Their Geology and Potential: AAPG Memoir $15,985-1120$.

Altunin, V. V. (1975), Thermophysical Properties of Carbon Dioxides, Publishing house of Standards, Moscow.

Andre, L., et al. (2007), Numerical modeing of fluid-rock chemical interactions at the supercrtical CO2-liquid interface during $\mathrm{CO} 2$ injection into a carbonate reservoir, the Dogger aquifer (Paris basin, France), Energy Conversion and Management, 48(6), 17821797.

ARI, (2010), White Paper: U.S. Oil Production Potential from Accelerated Deployment of Carbon Capture and Storage, prepared by Advanced Resources International for the Natural Resources Defense Council, March 10, 2010, 56.

Battistelli, A., et al. (1997), The simulator TOUGH2/EWASG for modeling geothermal reservoirs with brines and non-condensible gas, Geothermics 26(4), 437-464.

Brown, G., et al. (2004), Monitoring alternating CO2 and water injection and its effect on production in carbonate reservoir using permanent fibre-optic distributed temperature systems, paper presented at SPE Annual Technical Conference and Exhibition, Houston, Texas, 26-29 September, 2004.

Byrnes, A.P., et al. (2003), The Role of Moldic Porosity in Paleozoic Kansas Reservoirs and the Association of Original Depositional Facies and Early Diagenesis With Reservoir Properties, Kansas Geological Survey Open-file Report 2003-32, http://www.kgs.ku.edu/PRS/publication/2003/ofr2003-32/index.html

Cansler, J. R., and T. R. Carr (2001), Paleogeomorphology of the sub-Pennsylvanian unconformity of the Arbuckle Group (Cambrian-Lower Ordovician): Kansas Geological Survey, Open-file Report 2001-55.

Carr, T. R., et al. (2005), Use of relational databases to evaluate regional petroleum accumulation, groundwater flow, and CO2 sequestration in Kansas, AAPG Bulletin, $89(12), 1607-1627$.

Corey, A. T. (1954), The interrelation between gas and oil relative permeabilities, Producers Monthly, 38-41. 
Doughty, C. (2007), Modeling geologic storage of carbon dioxide: Comparison of nonhysteretic and hysteretic characteristic curves, Energy Conversion $\backslash \&$ Management, 48, 1768--1781.

Ennis-King, J., and L. Paterson (2005), Role of convection mixing in the long-term storage of carbon dioxide in deep saline formations, Society of Petroleum Engineers Journal, 10(3), 349-356.

Ennis-King, J., and L. Paterson (2007), Coupling of geochemical reactions and convective mixing in the long-term geological storage of carbon dioxide, International Journal of Greenhouse Gas Control, 1, 86-93.

Franseen, E. K., (1994), Facies and porosity relationships of Arbuckle strata--Initial observations from two cores, Rice and Rush counties, Kansas: Kansas Geological Survey, Open-file Report 94-53, 34.

Franseen, E.K., et al. (1995), Technical Proposal: Depositional, structural, and diagenetic controls on fractured reservoirs, Arbuckle Group, Kansas: Kansas Geological Survey through the University of Kansas Center for Research, Inc., 74.

Franseen, E. K., et al. (2003), Geologic controls on variable character of Arbuckle reservoirs in Kansas--An emerging picture: Kansas Geological Survey, Open-file Report 2003-59, 30.

Franseen, E. K., et al. (2004), The geology of Kansas: Arbuckle Group, Kansas Geological Survey, Current Research in Earth Sciences, Bulletin 250, part 2.

Forster, A., et al. (2006), Baseline characterization of CO2SINK geological storage site at Ketzin, Germany, Environmental Geosciences, 13(3), 145-161.

Garcia, J. E. (2001), Density of aqueous solutions of CO2, 8 pp, Lawrence Berkeley National Laboratory.

Gerlach, P.M., (1998), Kansas Oil Production Maps, in Kansas Digital Petroleum Atlas, Kansas Geological Survey, http://www.kgs.ku.edu/DPA/Plays/ProdMaps/arbk_oil.html

Giese, R., et al. (2009 ), Monitoring at the CO2SINK site: A concept integrating geohysics, geochemistry, and microbiology, Energy Procedia, 1(1), 2251-2259.

Giorgis, T., et al. (2007), 2D modeling of salt precipitation during the injection of dry $\mathrm{CO} 2$ in a depleted gas reservoir, Energy Conversion and Management, 48(6), 1816-1826.

Hammond, G. P., et al. (2007), Subsurface multiphase flow and multicomponent reactive transport modeling using high-performance computing. 
Hurter, S., et al. (2007), Thermal signature of free-phase CO2 in porous rocks: Detectability of $\mathrm{CO} 2$ by temperature logging, paper presented at Offshore Europe, Scotland, U.K., 4-7 September.

IFC (1967), A formulation of the Thermodynamic Properties of Ordinary Water Substances, International Formulation Committee, Dusseldorf, Germany.

Lange, E., (1998), Correlation and Predictioni of Residual Oil saturation for GasInjection-Enhanced Oil-Recovery Process. SPPE Evaluation and Engineering.

Lanier, G. H., et al. (2003), Brunei field trial of a fibre optic distributed temperature sensor (DTS) system in a $1000 \mathrm{~m}$ open hole horizontal oil producer, paper presented at SPE Annual Technical Conference and Exhibition, Denver, Colorado, 5-8 October, 2003.

Lu, C., and P. C. Lichtner (2006), Numerical Investigation of CO\$2\$ Sequestration in Geologic Media Using the Massively Parallel Computer Code PFLOTRAN, Copenhagen, Denmark, June.

McClellan, H. W. (1930), Subsurface distribution of pre-Mississippian rocks of Kansas and Oklahoma, Bull. Amer. Assoc. Petrol. Geol, 14(12), 1535-1556.

Merriam, D. F., (1963), The geologic history of Kansas: Kansas Geological Survey, Bulletin 162, 317.

Mullins, C.A., and W.C. Ireland (1967), Additional Arbuckle Reserves Developed Below Original Completion Depth in Stratified Reservoir, Society of Petroleum Engineers, SPE 1963,6 .

Newell, K.D., et al. (1987), Stratigraphic and Spatial Distribution of Oil and Gas Production in Kansas: Kansas Geological Survey, Subsurface Geology Series 9, 86.

Patel, R. (1994). The Application of Fluid Injection to Mitigate Coning. SPE 69th Annual Technical Conference and Exhibition. New Orleans: Society of Petroleum Engineers.

Pawar R. J., et al. (2009), Numerical Simulation of $\mathrm{CO}_{2}$ Leakage through Abandoned Wells: Model for an Abandoned Site with Observed Gas Migration in Alberta, Canada, Energy Procedia, 1(1), 3625-3632.

Pruess, K., et al. (1999), TOUGH2 user's guide, version 2.0, 198 pp, Lawrence Berkeley National Laboratory.

Pruess, K. (2005), TOUGH2 fluid property module for mixtures of water, $\mathrm{NaCl}$, and CO2, 66 pp, Lawrence Berkeley National Laboratory.

Pruess, K., and N. Muller (2009), Formation dry-out from CO2 injection into saline aquifers: 1. Effect of solids precipitation and their migration, Water Resources Research. 
Spycher, N., et al. (2003), CO2-H2O mixtures in the geological sequestration of CO2. I. Assessment and calculation of mutual solubilities from 12 to $100 \mathrm{C}$ and up to $600 \mathrm{bar}$, Geochimica Cosmochimica Acta, 67(16), 3015-3031.

Steinhauff, M., et al. (1998), Arbuckle reservoirs in central Kansas--Relative importance of depositional facies, early diagenesis and unconformity karst processes on reservoir properties: Kansas Geological Survey, Open-file Report 98-55.

Stoain, E. (1996). Determination of Natural Gas Recovery Factors. The Journal of Canadian Petroleum Technology , 115-128.

Teletzke, G. (2005). Methodology for Miscible Gas injection EOR Screening. SPE International Improved Oi lRecovery Conference (pp. 2,3,9,10). Kuala Lumpur: Society of Petroleum Engineers.

Van Genuchten, M. T. (1980), A closed-form equation for predicting the hydraulic conductivity of unsaturated soils, Soil Science Society of American Journal, 44, 892-898.

Wagner, W., and A. Prub (2002), The IAPWS formulation 1995 for the thermodynamic properties of ordinary water substance for general and scientific use, Journal of Physical and Chemical Reference Data, 31(2), 387-535.

Walters, R. F. (1958), Differential entrapment of oil and gas in Arbuckle dolomite of central Kansas, AAPG bulletin, 42(9), 2133?2173.

$\mathrm{Xu}, \mathrm{X}$., et al. (2006), Convective stability analysis of the long-term storage of carbon dioxide in deep saline aquifers, Advances in Water Resources, 29, 397-407.

Yang, C., and Y. Gu (2006), Accelerated mass transfer of CO2 in reservoir brine due to density-driven natural convection at high pressures and elevated temperatures, Ind. Eng. Chem. Res., 45, 2430-2436. 
Appendix $\square$ A

$\square$ Process Flow Diagrams

Appendix 2-1 


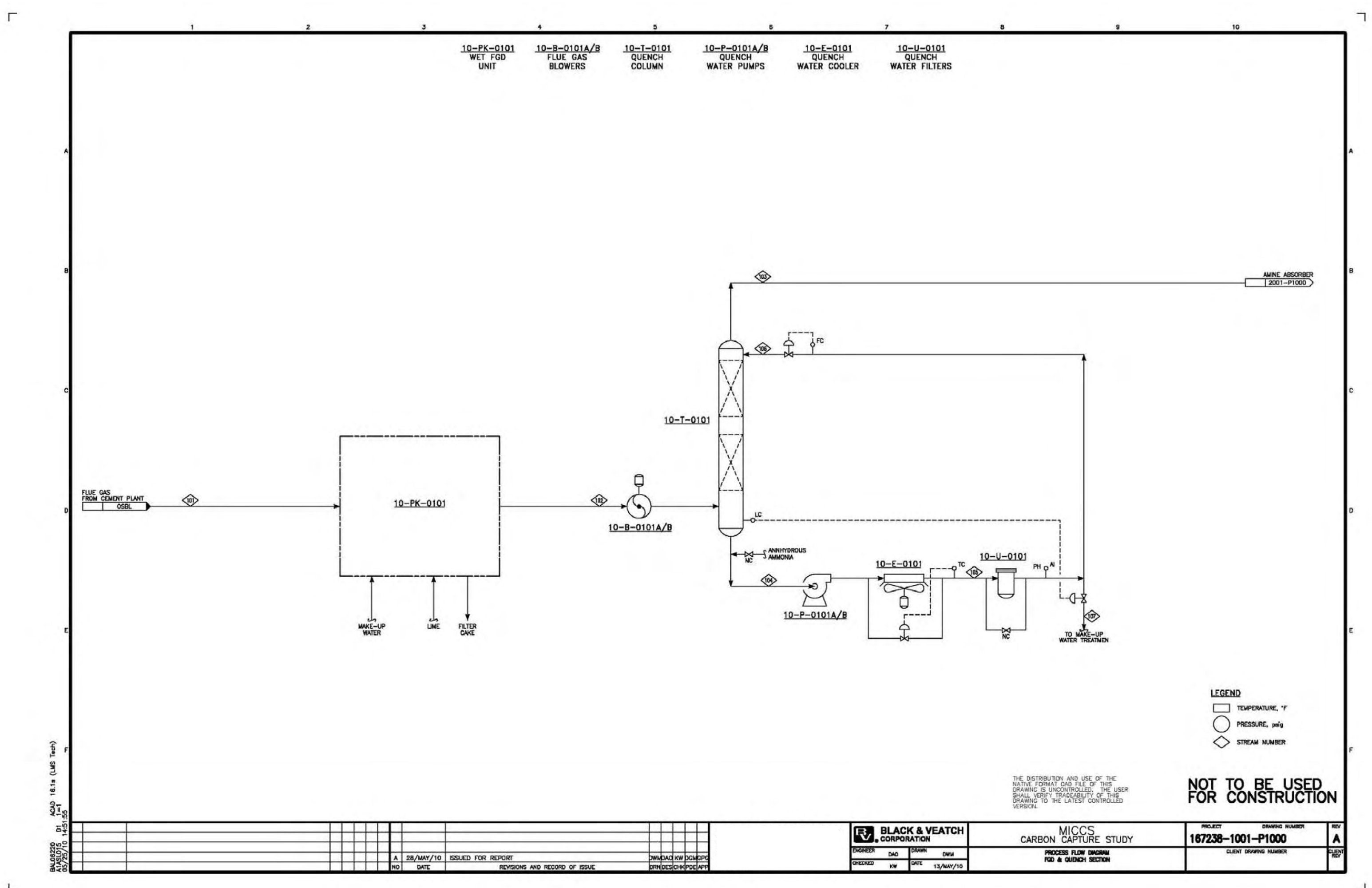




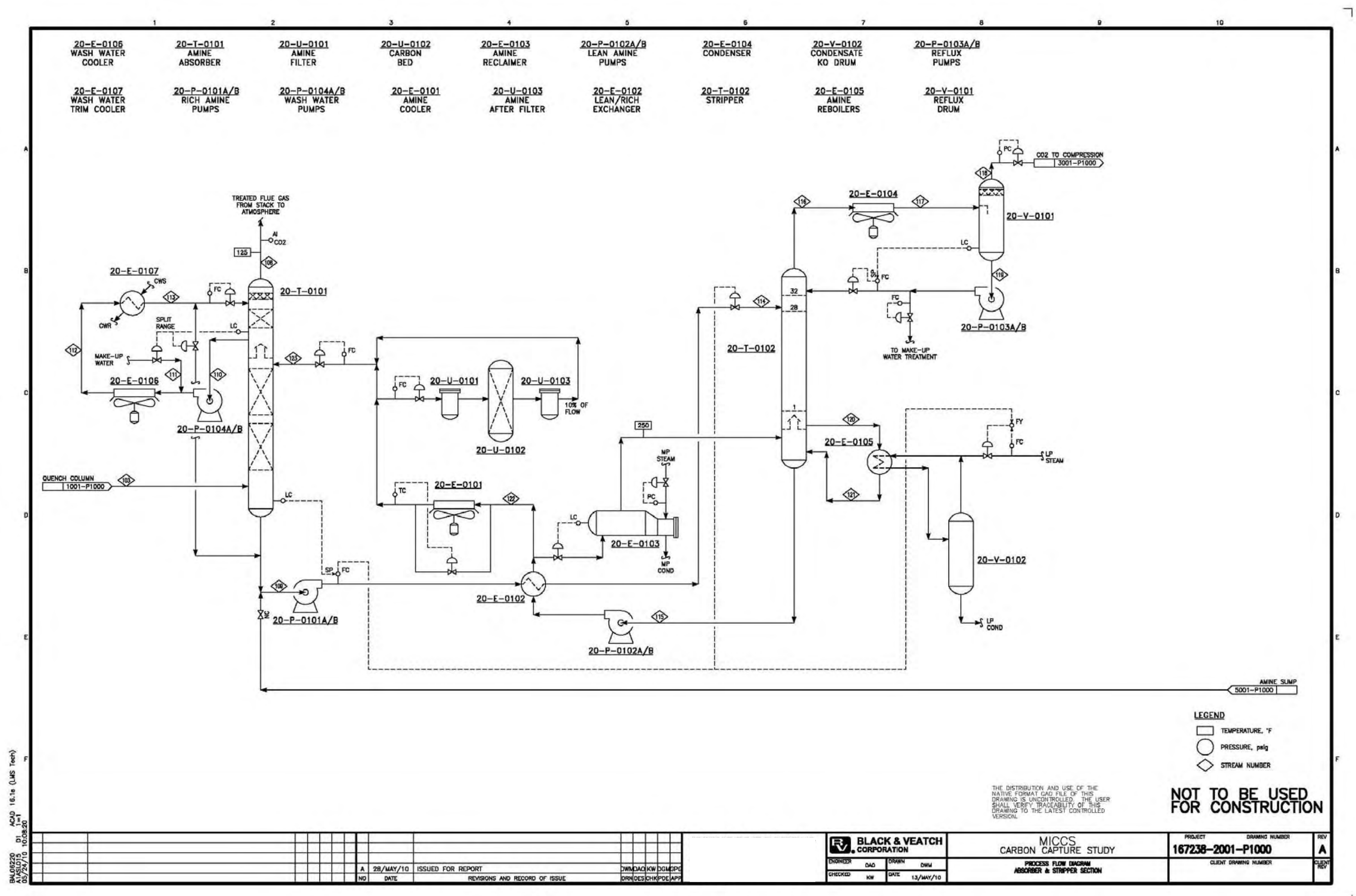




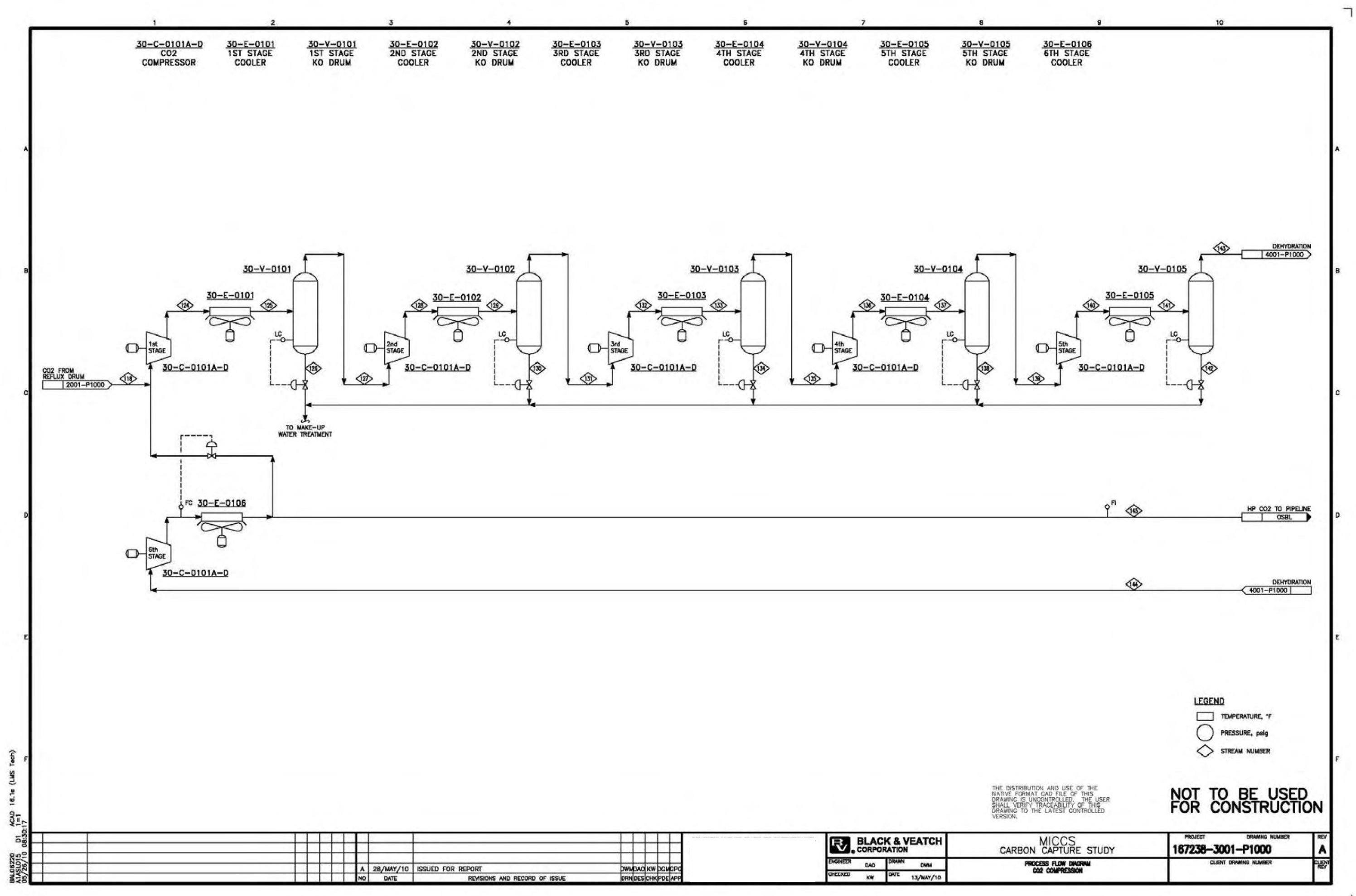




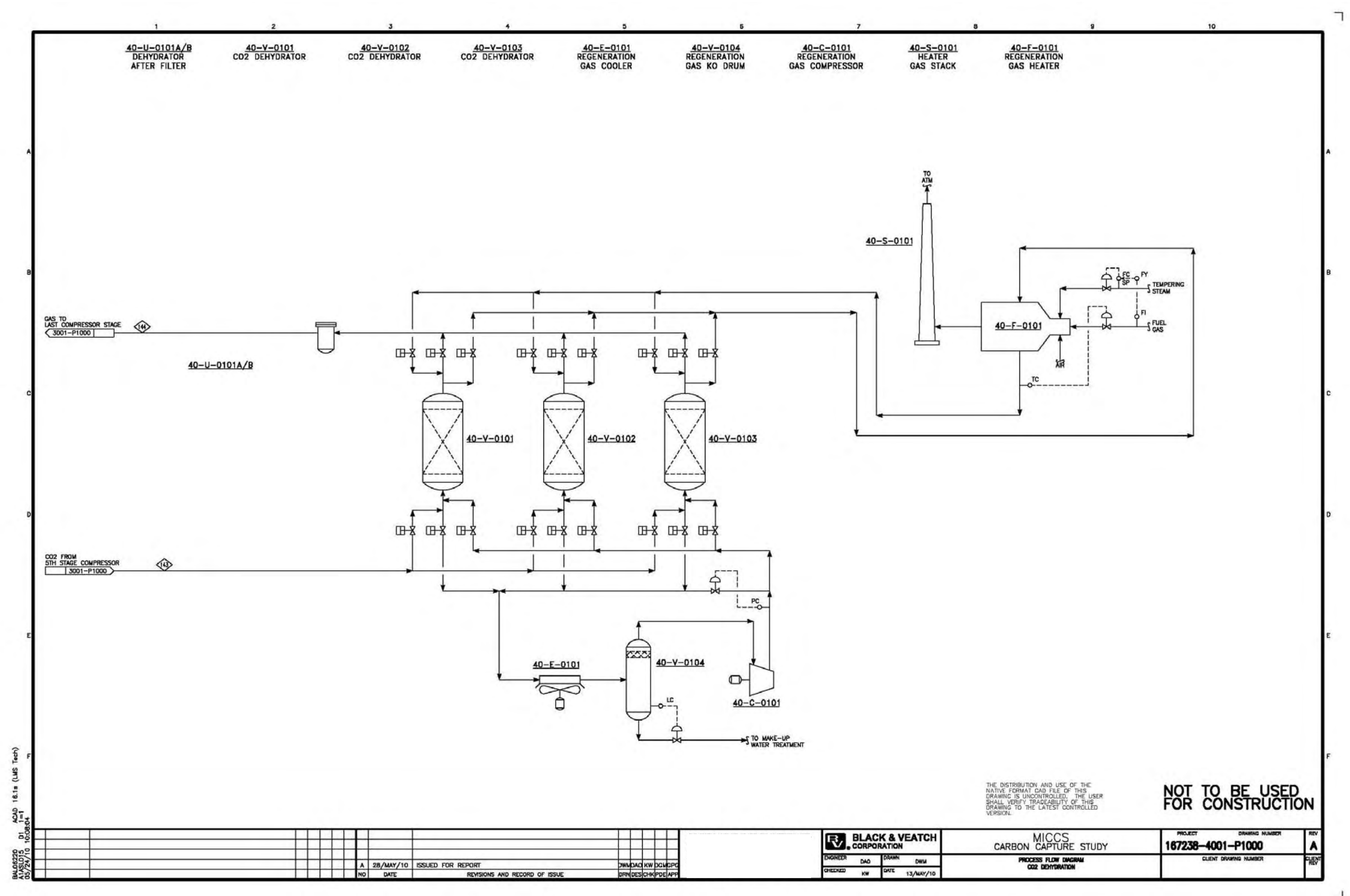




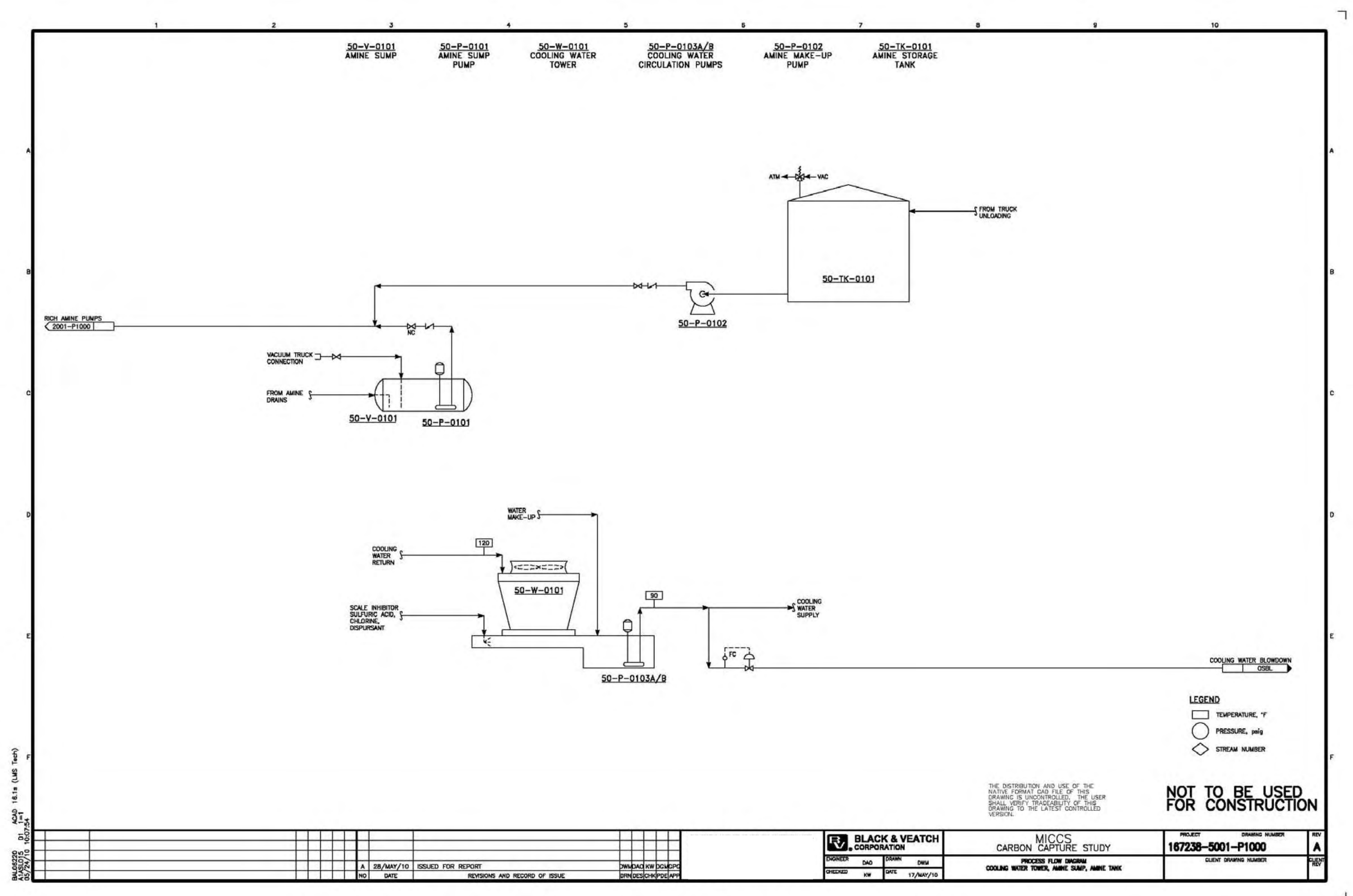




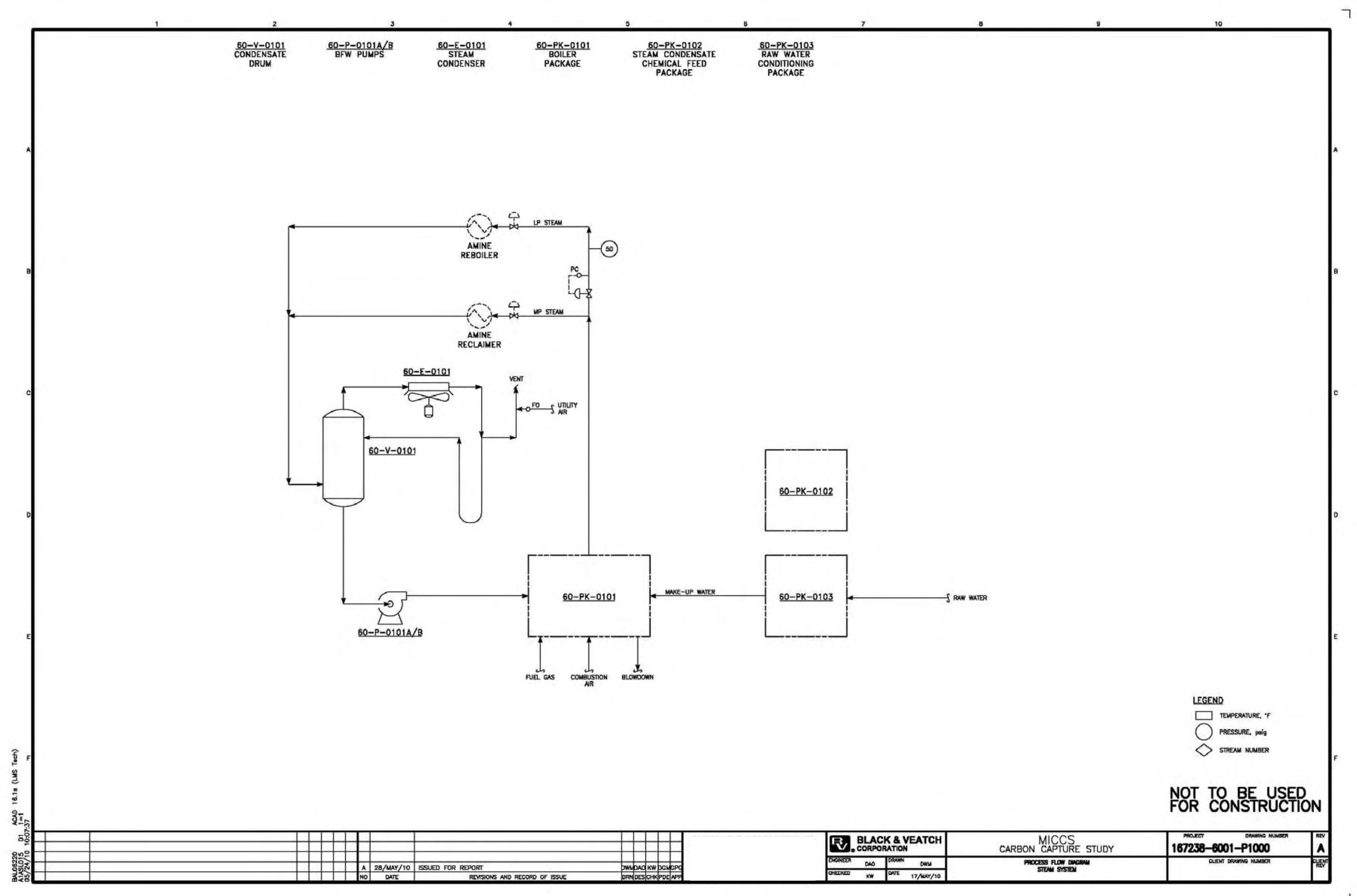


Appendix 2-B

Equipment List 


\begin{tabular}{|c|c|c|c|c|c|c|c|c|c|c|c|}
\hline \multirow[b]{2}{*}{ Tag Number } & \multirow[b]{2}{*}{ Service } & \multirow[b]{2}{*}{ Qty } & \multirow[b]{2}{*}{ Type } & \multicolumn{2}{|c|}{ Size } & \multicolumn{2}{|c|}{ Electrical } & \multicolumn{2}{|c|}{ Mech. Design } & \multirow[b]{2}{*}{ Material } & \multirow[b]{2}{*}{ Notes } \\
\hline & & & & Parameter 1 & Parameter 2 & $\begin{array}{l}\text { Oper. } \\
\text { (HP) }\end{array}$ & $\begin{array}{c}\text { Conn. } \\
\text { (HP) }\end{array}$ & $\begin{array}{c}\text { Pres } \\
\text { [psig] }\end{array}$ & $\begin{array}{c}\text { Temp } \\
(\mathrm{F})\end{array}$ & & \\
\hline \multicolumn{12}{|c|}{ FURNACES, FIRED HEATERS AND STACK } \\
\hline 40-S-0101 & Heater Gas Stack & 1 & & $327,406 \mathrm{ft} 3 / \mathrm{h}$ & & & & 50 & 750 & cs & \\
\hline \multicolumn{12}{|l|}{ EXCHANGERS } \\
\hline 10-E-0101 & Quench Water Cooler & 1 & Air Cooler & $71.580 \mathrm{MMBtu} / \mathrm{h}$ & $\begin{array}{c}33,370 \mathrm{ft2} \\
\text { (Bare Tube Area) }\end{array}$ & 475 & 560 & 130 & 190 & CS & $\begin{array}{l}7 \text { Bays }\left(15^{\prime}-10^{\prime \prime} \times 40^{\prime}-0 " \text { each) }\right. \\
14 \text { Fans total with } 40 \text { hp Motors }\end{array}$ \\
\hline 20-E-0101 & Amine Cooler & 1 & Air Cooler & $337.021 \mathrm{MMBtu} / \mathrm{h}$ & $\begin{array}{c}94,717 \mathrm{ft} 2 \\
\text { (Bare Tube Area) }\end{array}$ & 1,344 & 1,600 & 130 & 240 & CS-HC & $\begin{array}{l}20 \text { Bays }\left(15^{\prime}-7 " \times 40^{\prime}-0 " \text { each }\right) \\
40 \text { Fans total with } 40 \text { hp Motors }\end{array}$ \\
\hline 20-E-0102 & Lean/Rich Exchanger & 1 & Plate \& Frame & 368.287 MMBtu/h & $68,564 \mathrm{ft} 2$ & & & $\begin{array}{l}90 \\
130\end{array}$ & $\begin{array}{l}260 \\
310\end{array}$ & $\begin{array}{l}\text { CS-HC } \\
316 L S S\end{array}$ & \\
\hline 20-E-0103 & Amine Reclaimer & 1 & $\begin{array}{l}\text { Shell side } \\
\text { Tube side }\end{array}$ & $224.650 \mathrm{MMBtu} / \mathrm{h}$ & $52,611 \mathrm{ft} 2$ & & & $\begin{array}{l}130 \\
175\end{array}$ & $\begin{array}{l}240 \\
420\end{array}$ & $\begin{array}{l}\text { CS-HC } \\
316 \mathrm{LSS}\end{array}$ & \\
\hline $20-E-0104$ & Condenser & 1 & Air Cooler & $154.626 \mathrm{MMBtu} / \mathrm{h}$ & $\begin{array}{c}37,907 \mathrm{ft} 2 \\
\text { (Bare Tube Area) }\end{array}$ & 539 & 640 & 50 & 255 & 316 LSS & $\begin{array}{l}8 \text { Bays }\left(15^{\prime}-7 " \times 40^{\prime}-0 \text { " each }\right) \\
16 \text { Fans total with } 40 \text { hp Motors }\end{array}$ \\
\hline 20-E-0105 & Amine Reboilers & 1 & $\begin{array}{l}\text { Shell side } \\
\text { Tube side }\end{array}$ & $666.402 \mathrm{MMBtu} / \mathrm{h}$ & $168,385 \mathrm{ft} 2$ & & & $\begin{array}{l}50 \\
75\end{array}$ & $\begin{array}{l}310 \\
350\end{array}$ & $\begin{array}{l}\text { CS-HC } \\
316 \mathrm{LSS}\end{array}$ & \\
\hline $20-E-0106$ & Wash Water Cooler & 1 & Air Cooler & 121.287 MMBtu/h & $\begin{array}{c}59,154 \mathrm{ft} 2 \\
\text { (Bare Tube Area) }\end{array}$ & 775 & 960 & 75 & 200 & cs & $\begin{array}{l}13 \text { Bays }\left(15^{\prime}-0 " \text { × } 40^{\prime}-0 \text { " each }\right) \\
24 \text { Fans total with } 40 \text { hp Motors }\end{array}$ \\
\hline $20-E-0107$ & Wash Water Trim Cooler & 1 & $\begin{array}{l}\text { Shell side } \\
\text { Tube side }\end{array}$ & $126.515 \mathrm{MMBtu} / \mathrm{h}$ & $44,374 \mathrm{ft} 2$ & & & $\begin{array}{r}75 \\
125\end{array}$ & $\begin{array}{l}175 \\
175\end{array}$ & $\begin{array}{c}\text { CS } \\
\text { CS-HC }\end{array}$ & \\
\hline 30-E-0101 & 1st Stage Cooler & 1 & Air Cooler & $25.330 \mathrm{MMBt} / \mathrm{h}$ & $\begin{array}{c}21,895 \mathrm{ft} 2 \\
\text { (Bare Tube Area) }\end{array}$ & 311 & 400 & 75 & 350 & $304 \mathrm{SS}$ & $\begin{array}{l}5 \text { Bays }\left(14^{\prime}-6 " \text { x } \times 40^{\prime}-0 \text { " each) }\right. \\
10 \text { Fans total with } 40 \text { hp Motors }\end{array}$ \\
\hline $30-E-0102$ & 2nd Stage Cooler & 1 & Air Cooler & $21.278 \mathrm{MMBtu} / \mathrm{h}$ & $\begin{array}{c}15,901 \mathrm{ft} 2 \\
\text { (Bare Tube Area) }\end{array}$ & 229 & 240 & 140 & 350 & $304 \mathrm{SS}$ & $\begin{array}{l}4 \text { Bays }\left(13^{\prime}-2 " \times 40^{\prime}-0 " \text { each }\right) \\
8 \text { Fans total with } 30 \text { hp Motors }\end{array}$ \\
\hline 30-E-0103 & 3rd Stage Cooler & 1 & Air Cooler & $19.481 \mathrm{MMBtu} / \mathrm{h}$ & $\begin{array}{c}11,518 \mathrm{ft} 2 \\
\text { (Bare Tube Area) }\end{array}$ & 166 & 180 & 285 & 350 & $304 \mathrm{SS}$ & $\begin{array}{l}3 \text { Bays }\left(12^{\prime}-7 " \text { × } \times 40^{\prime}-0 \text { " each) }\right. \\
6 \text { Fans total with } 30 \text { hp Motors }\end{array}$ \\
\hline $30-E-0104$ & 4th Stage Cooler & 1 & Air Cooler & $20.743 \mathrm{MMBt} / \mathrm{h}$ & $\begin{array}{c}10,205 \mathrm{ft} 2 \\
\text { (Bare Tube Area) }\end{array}$ & 142 & 150 & 680 & 350 & $3045 s$ & $\begin{array}{l}3 \text { Bays }\left(11^{\prime}-4^{\prime \prime} \times 40^{\prime}-00^{\prime \prime} \text { each) }\right. \\
6 \text { Fans total with } 25 \text { hp Motors }\end{array}$ \\
\hline
\end{tabular}




\begin{tabular}{|c|c|c|c|c|c|c|c|c|c|c|c|}
\hline \multirow[b]{2}{*}{ Tag Number } & \multirow[b]{2}{*}{ Service } & \multirow[b]{2}{*}{ aty } & \multirow[b]{2}{*}{ Type } & \multicolumn{2}{|c|}{ Size } & \multicolumn{2}{|c|}{ Electrical } & \multicolumn{2}{|c|}{ Mech. Design } & \multirow[b]{2}{*}{ Material } & \multirow[b]{2}{*}{ Notes } \\
\hline & & & & Parameter 1 & Parameter 2 & $\begin{array}{l}\text { Oper. } \\
\text { (HP) }\end{array}$ & $\begin{array}{c}\text { Conn. } \\
\text { (HP) }\end{array}$ & $\begin{array}{c}\text { Pres } \\
\text { [psig] }\end{array}$ & $\begin{array}{c}\text { Temp } \\
(\mathrm{F})\end{array}$ & & \\
\hline 30-E-0106 & 6th Stage Cooler & 1 & Air Cooler & $37.196 \mathrm{MMBtu} / \mathrm{h}$ & $\begin{array}{c}8,564 \mathrm{ft} 2 \\
\text { (Bare Tube Area) }\end{array}$ & 122 & 160 & 2435 & 330 & $3045 S$ & $\begin{array}{l}2 \text { Bays }\left(14^{\prime}-2 " \text { x } 40^{\prime}-0 " \text { each }\right) \\
4 \text { Fans total with } 40 \text { hp Motors }\end{array}$ \\
\hline 40-E-0101 & Regeneration Gas Cooler & 1 & Air Cooler & $1.802 \mathrm{MMBtu} / \mathrm{h}$ & $\begin{array}{c}491 \mathrm{ft} 2 \\
\text { (Bare Tube Area) }\end{array}$ & 7.4 & 10 & 1070 & 300 & 304SS & $\begin{array}{l}1 \text { Bay }\left(4^{\prime}-6 " \text { × } 15^{\prime}-0 " \text { each) }\right. \\
2 \text { Fans total with } 5 \text { hp Motors }\end{array}$ \\
\hline 50-W-0101 & Cooling Water Tower & 1 & & $126.005 \mathrm{MMBtu} / \mathrm{h}$ & $8,436 \mathrm{gpm}$ & & & & & cs & $\begin{array}{l}\text { Cooling water supply temperature }=90 \mathrm{~F} \\
\text { cooling water return temperature }=120 \mathrm{~F} \\
\text { Air wet bulb temperature }=76 \mathrm{~F}\end{array}$ \\
\hline 60-E-0101 & Steam Condenser & 1 & $\begin{array}{l}\text { Shell side } \\
\text { Tube side }\end{array}$ & $107.558 \mathrm{MMBtu} / \mathrm{h}$ & $14,412 \mathrm{ft} 2$ & 205 & 240 & 50 & 265 & cs & $\begin{array}{l}3 \text { Bays }\left(15^{\prime}-11^{\prime \prime} \times 40^{\prime}-0 \text { " each) }\right. \\
6 \text { Fans total with } 40 \text { hp Motors }\end{array}$ \\
\hline \multicolumn{12}{|l|}{ TOWERS } \\
\hline 10-Т-0101 & Quench Column & 1 & Vertical & 372 in ID & 50'-0" T/T & & & 50 & 195 & cs & \\
\hline 10-T-0101-P & Quench Column Packing & 1 & Structured & 288 in depth & $3 Y_{\text {size }}^{\text {Packing }}$ & & & 50 & 195 & 316 LSS & \\
\hline 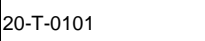 & Amine Absorber & 1 & Vertical & 414 in ID & $84^{\prime}-6 "$ T/T & & & 50 & 220 & CS-HIC & \\
\hline 20-T-0101-P & Amine Absorber Packing & 1 & Structured & 504 in depth & $\begin{array}{l}\text { PYacking } \\
\text { size }\end{array}$ & & & 50 & 220 & 316 LSS & $\begin{array}{l}\text { Water wash packing: } 3 Y \text { structured packing, } 144 \text { in } \\
\text { depth }\end{array}$ \\
\hline 20-Т-0102 & Stripper & 1 & Vertical & 312 in ID & 74'-0" T/T & & & 50 & 310 & CS-HIC & \\
\hline 20-T-0102-T & Stripper Trays & 1 & Valve & 20 Trays & 4-Pass Trays & & & 50 & 310 & 316LSS & \\
\hline \multicolumn{12}{|c|}{ VESSELS, DRUMS AND TANKS } \\
\hline 20-V-0101 & Reflux Drum & 1 & Vertical & 132 in ID & $20^{\prime}-6^{\prime \prime} T / T$ & & & 50 & 180 & $304 S S$ & \\
\hline $20-\mathrm{V}-0102$ & Condensate KO Drum & 1 & Vertical & 54 in ID & 13'-6" T/T & & & 175 & 420 & cS & \\
\hline $30-\mathrm{V}-0101$ & 1st Stage Drum & 1 & Vertical & 114 in ID & $16^{\prime}-6 " \mathrm{~T} / \mathrm{T}$ & & & 75 & 175 & $304 S S$ & \\
\hline $30-\mathrm{V}-0102$ & 2nd Stage Drum & 1 & Vertical & 90 in ID & 14'-6" T/T & & & 140 & 175 & $3045 S$ & \\
\hline $30-\mathrm{V}-0103$ & 3rd Stage Drum & 1 & Vertical & 78 in ID & $13^{\prime}-0 " \mathrm{~T} / \mathrm{T}$ & & & 285 & 175 & $304 S S$ & \\
\hline 30-V-0104 & 4th Stage Drum & 1 & Vertical & 78 in ID & $12-6 " \mathrm{~T} / \mathrm{T}$ & & & 680 & 175 & $304 S S$ & \\
\hline 30-V-0105 & 5th Stage Drum & 1 & Vertical & 78 in ID & $12^{\prime}-6 " \mathrm{~T} / \mathrm{T}$ & & & 1085 & 175 & $304 S S$ & \\
\hline $40-\mathrm{V}-0101 / 0102 / 0103$ & CO2 Dehydrators & 1 & Vertical & 84 in ID & $31^{\prime}-0 " \mathrm{~T} / \mathrm{T}$ & & & 1100 & 500 & cs & Molecular Sieve Dehydration Beds \\
\hline $40-V-0104$ & Regeneration Gas KO Drum & 1 & Vertical & 24 in ID & 8'-6" T/T & & & 1070 & 175 & $304 S S$ & \\
\hline 50-TK-0101 & Amine Storage Tank & 1 & Vertical & 456 in ID & $38^{\prime}-0 " \mathrm{~T} / \mathrm{T}$ & & & 50 & & CS-HC & \\
\hline $50-\mathrm{V}-0101$ & Amine Sump & 1 & Horizontal & 156 in ID & 52'-0" T/T & & & 100 & 400 & CS-HC & \\
\hline 60-V-0101 & Condensate Drum & 1 & Vertical & 108 in ID & 27'-9" T/T & & & 175 & 420 & cs & \\
\hline
\end{tabular}




\begin{tabular}{|c|c|c|c|c|c|c|c|c|c|c|c|}
\hline \multirow[b]{2}{*}{ Tag Number } & \multirow[b]{2}{*}{ Service } & \multirow[b]{2}{*}{ Qty } & \multirow[b]{2}{*}{ Type } & \multicolumn{2}{|r|}{ Size } & \multicolumn{2}{|c|}{ Electrical } & \multicolumn{2}{|c|}{ Mech. Design } & \multirow[b]{2}{*}{ Material } & \multirow[b]{2}{*}{ Notes } \\
\hline & & & & Parameter 1 & Parameter 2 & $\begin{array}{l}\text { Oper. } \\
\text { (HP) }\end{array}$ & $\begin{array}{l}\text { Conn. } \\
\text { (HP) }\end{array}$ & 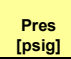 & $\begin{array}{c}\text { Temp } \\
(\mathrm{F})\end{array}$ & & \\
\hline \multicolumn{12}{|c|}{ PUMPS, COMPRESSORS, BLOWERS AND DRIVERS } \\
\hline 10-B-0101A/B & Flue Gas Blowers & 2 & Centrifugal & 538.650 MMSCFD & $2.04 \mathrm{psi} \mathrm{dP}$ & & 5,500 & 50 & 195 & cs & \\
\hline 30-C-0101A-D & $\mathrm{CO} 2$ Compressor Stage 1 & 4 & Centrifugal & 24.038 MMSCFD & $\begin{array}{|ll|}\text { Suction: } 12 & \text { psig } \\
\text { Discharge: } 48 & \text { psig }\end{array}$ & 1,609 & & 75 & 350 & cs & $\begin{array}{l}\text { 6-Stage Compressor - Motor Size 8,000 HP } \\
4 \text { CO2 } 2 \text { Compressors are operting in parallel }\end{array}$ \\
\hline 30-C-0101A-D & CO2 Compressor Stage 2 & 4 & Centrifugal & 23.099 MMSCFD & $\begin{array}{|ll|}\text { Suction: } 38 & \text { psig } \\
\text { Discharge: } 114 & \text { psig }\end{array}$ & 1,614 & & 140 & 350 & CS & $\begin{array}{l}\text { 6-Stage Compressor - Motor Size 8,000 HP } \\
4 \text { CO2 Compressors are operting in parallel }\end{array}$ \\
\hline 30-C-0101A-D & $\mathrm{CO} 2$ Compressor Stage 3 & 4 & Centrifugal & 22.623 MMSCFD & \begin{tabular}{|ll} 
Suction: 104 & psig \\
Discharge: 256 & psig \\
\end{tabular} & 1,444 & & 285 & 350 & cs & $\begin{array}{l}\text { 6-Stage Compressor - Motor Size 8,000 HP } \\
4 \text { CO2 Compressors are operting in parallel }\end{array}$ \\
\hline 30-C-0101A-D & CO2 Compressor Stage 4 & 4 & Centrifugal & 22.419 MMSCFD & \begin{tabular}{|ll} 
Suction: 246 & psig \\
Discharge: 619 & psig \\
\end{tabular} & 1,494 & & 680 & 350 & CS & $\begin{array}{l}\text {-Stage Compressor - Motor Size 8,000 } \mathrm{HP} \\
4 \mathrm{CO} 2 \text { Compressors are operting in parallel }\end{array}$ \\
\hline 30-C-0101A-D & CO2 Compressor Stage 5 & 4 & Centrifugal & 22.325 MMSCFD & \begin{tabular}{|ll} 
Suction: 609 & psig \\
Discharge: 985 & psig \\
\end{tabular} & 663 & & 1085 & 265 & cs & $\begin{array}{l}\text { 6-Stage Compressor - Motor Size 8,000 } \mathrm{HP} \\
4 \mathrm{CO} 2 \text { Compressors are operting in parallel }\end{array}$ \\
\hline 30-C-0101A-D & CO2 Compressor Stage 6 & 4 & Centrifugal & 22.230 MMSCFD & \begin{tabular}{|ll} 
Suction: 955 & psig \\
Discharge: 2210 & psig \\
\end{tabular} & 1,094 & & 2435 & 330 & CS & $\begin{array}{l}\text { 6-Stage Compressor - Motor Size 8,000 HP } \\
4 \text { CO2 Compressors are operting in parallel }\end{array}$ \\
\hline 40-C-0101 & $\begin{array}{l}\text { Regeneration Gas } \\
\text { Compressor }\end{array}$ & 1 & Centrifugal & 8.918 MMSCFD & $\begin{array}{|ll|}\text { Suction: } 955 & \text { psig } \\
\text { Discharge: } 996 & \text { psig } \\
\end{array}$ & 19.6 & 20 & 1100 & 185 & CS & \\
\hline $10-P-0101 \mathrm{~A} / \mathrm{B}$ & Quench Water Pumps & 2 & Centrifugal & $10,484 \mathrm{gpm}$ & $73 \mathrm{psi} d P$ & 598 & 600 & & 190 & $A-8$ & \\
\hline $20-P-0101 \mathrm{~A} / \mathrm{B}$ & Rich Amine Pumps & 2 & Centrifugal & $12,138 \mathrm{gpm}$ & $78 \mathrm{psidP}$ & 735 & 800 & & 190 & $A-8$ & \\
\hline $20-\mathrm{P}-0102 \mathrm{~A} / \mathrm{B}$ & Lean Amine Pumps & 2 & Centrifugal & $12,482 \mathrm{gpm}$ & 115 psi dP & 1,118 & 1,250 & & 310 & $A-8$ & \\
\hline $20-P-0103 A / B$ & Reflux Pumps & 2 & Centrifugal & $281 \mathrm{gpm}$ & $60 \mathrm{psidP}$ & 21 & 25 & & 180 & $A-8$ & \\
\hline $20-P-0104 A / B$ & Wash Water Pumps & 2 & Centrifugal & $10,367 \mathrm{gpm}$ & $63 \mathrm{psidP}$ & 513 & 600 & & 200 & $A-8$ & \\
\hline 50-P-0101 & Amine Sump Pump & 1 & Centrifugal & $125 \mathrm{gpm}$ & $27 \mathrm{psi} d \mathrm{P}$ & 4 & 5 & & 150 & A-8 & \\
\hline 50-P-0102 & Amine Makeup Pump & 1 & Centrifugal & $509 \mathrm{gpm}$ & $33 \mathrm{psidP}$ & 16 & 20 & & 150 & $\mathrm{~S}-8$ & \\
\hline 50-P-0103A/B & $\begin{array}{l}\text { Cooling Water Circulation } \\
\text { Pumps }\end{array}$ & 2 & Centrifugal & $8,436 \mathrm{gpm}$ & $57 \mathrm{psidP}$ & 377 & 400 & & 170 & $S-5$ & \\
\hline $60-P-0101 A / B$ & BFW Pumps & 2 & Centrifugal & 2,246 gpm & $171 \mathrm{psidP}$ & 313 & 350 & & 265 & S-4 & \\
\hline \multicolumn{12}{|c|}{ SPECIAL EQUIPMENT } \\
\hline 10-U-0101 & Quench Water Filter & 1 & Vertical & $10,446 \mathrm{gpm}$ & Cartridge Filter & & & 130 & 190 & $304 \mathrm{SS}$ & \\
\hline 10-PK-0101 & Wet FGD Unit & 1 & Packaged & $430,000 \mathrm{ft} 3 / \mathrm{h}$ & & & & 50 & 270 & & \\
\hline 20-U-0102 & Carbon Bed & 1 & Vertical & 228 in ID & $166^{\prime}-0 " \mathrm{~T} / \mathrm{T}$ & & & 130 & 240 & CS-HC & \\
\hline 20-U-0103 & Amine After Filter & 1 & Vertical & $1,244 \mathrm{gpm}$ & Cartridge Fitter & & & 130 & 240 & CS-HC & \\
\hline $40-U-0101 \mathrm{~A} / \mathrm{B}$ & Dehydration After Filters & 2 & Vertical & 88.920 MMSCFD & Cartridge Filter & & & 1075 & 175 & CS & \\
\hline 60-PK-0101 & Boiler Package & 1 & Packaged & 1,002.290 MMBTU/hr & & & & 175 & 420 & CS & 150\# Steam, 1,012,314 lb/hr \\
\hline 60-PK-0102 & $\begin{array}{l}\begin{array}{l}\text { Steam Condensate } \\
\text { Chemical Feed Package }\end{array} \\
\end{array}$ & 1 & Packaged & $17,323 \mathrm{ft} 3 / \mathrm{h}$ & & & & & & & \\
\hline 60-PK-0103 & $\begin{array}{l}\text { Raw Water Conditioning } \\
\text { Package }\end{array}$ & 1 & Packaged & $1,553 \mathrm{ft} 3 / \mathrm{h}$ & & & & & & & \\
\hline
\end{tabular}


l

Appendix 2-C

Plot Plan of $\mathrm{CO}_{2}$ Equipment Location Relative to Existing Cement Plant 


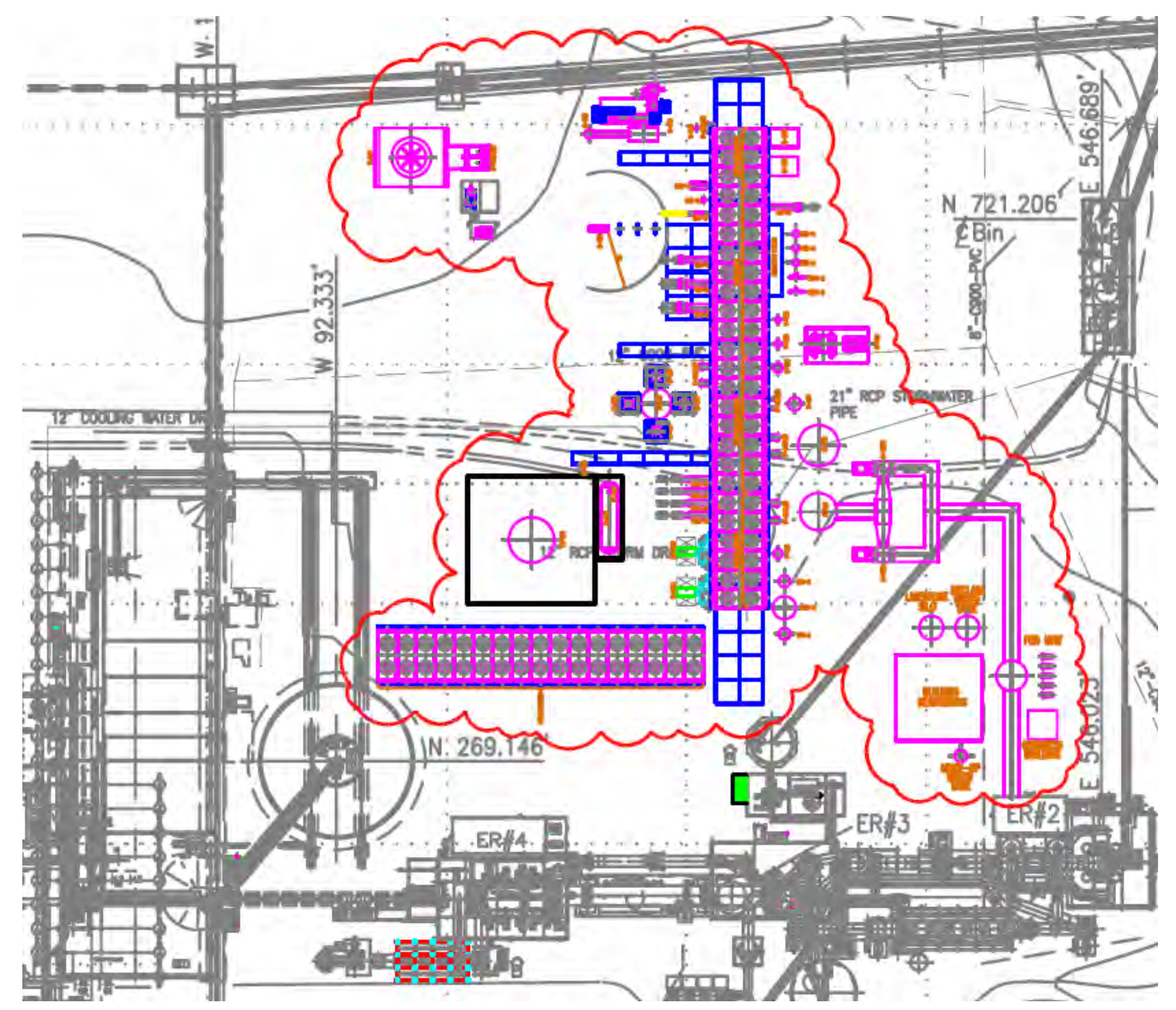


Appendix 2-D

One-Line Diagram 


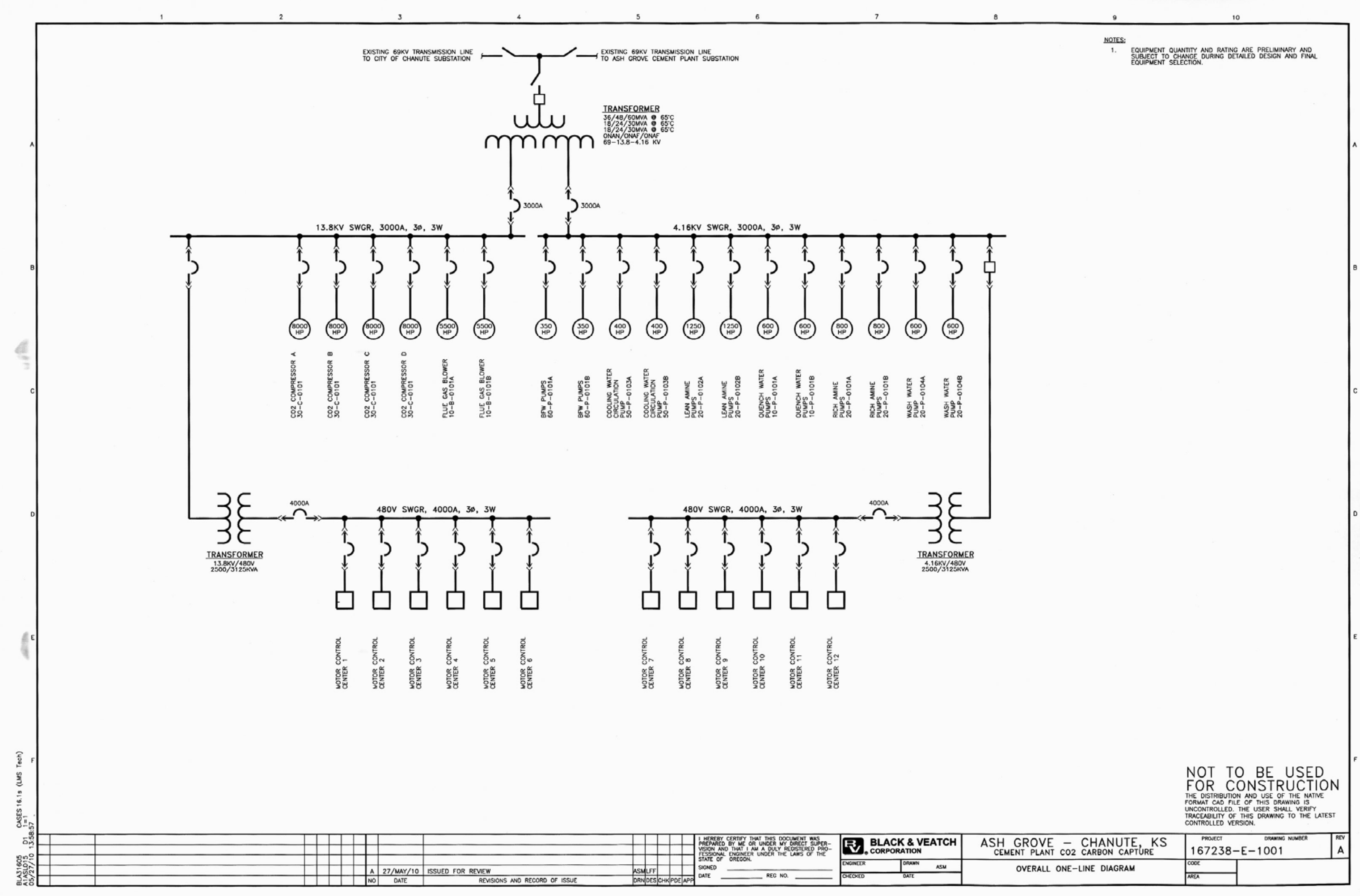


Appendix 2-E

Heat and Material Balance Data 


\section{Material Balance}

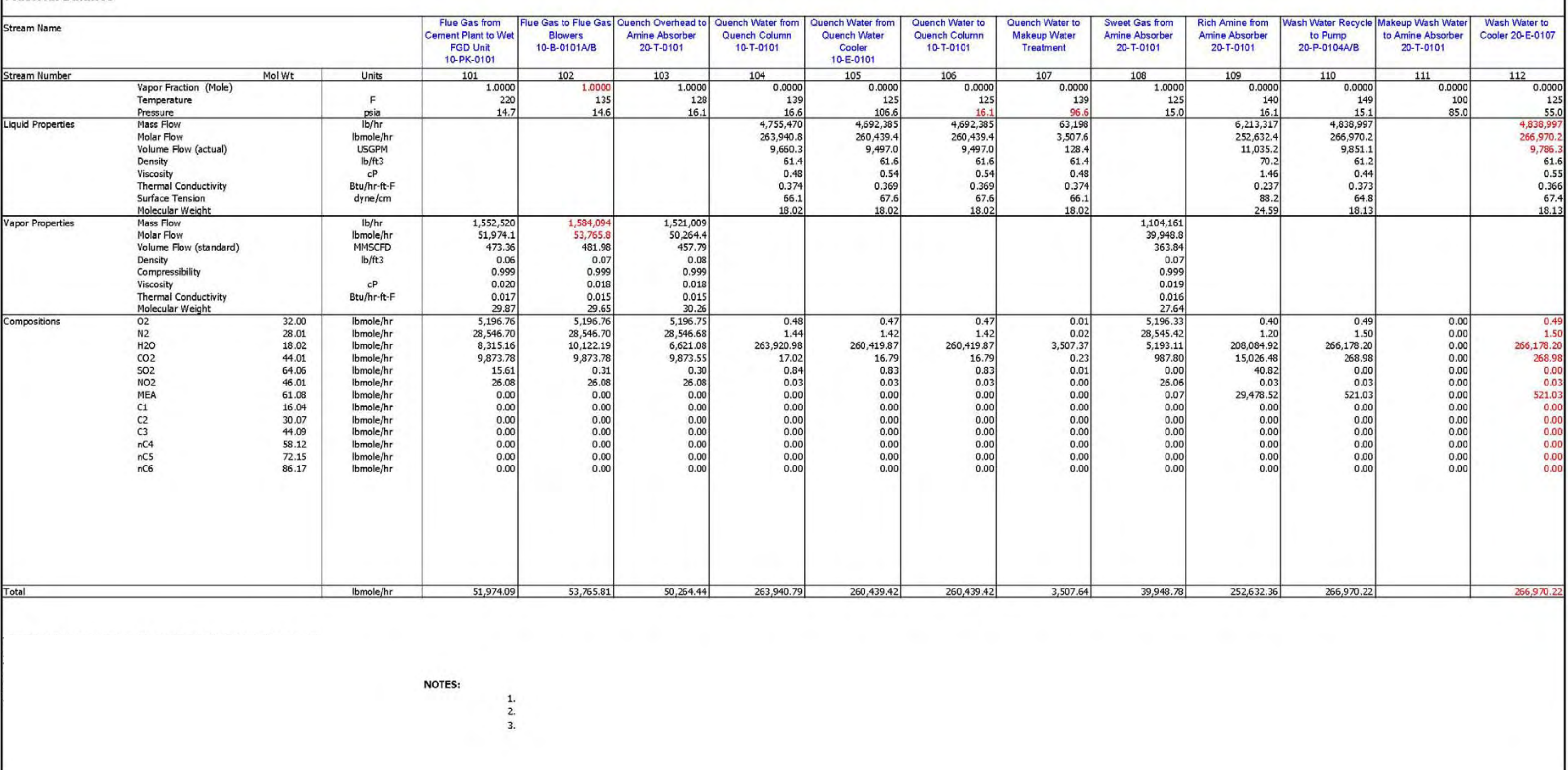




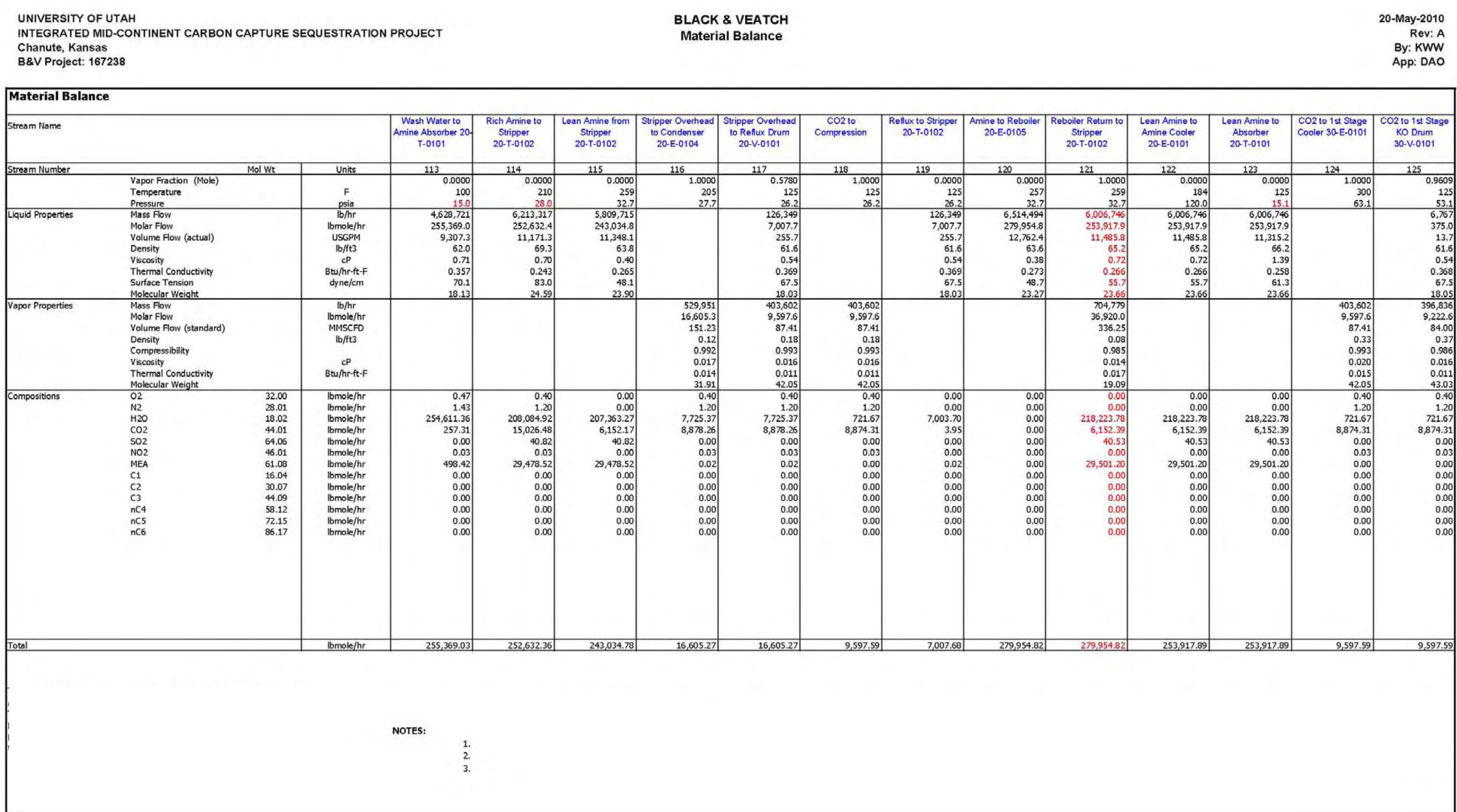


Material Balance

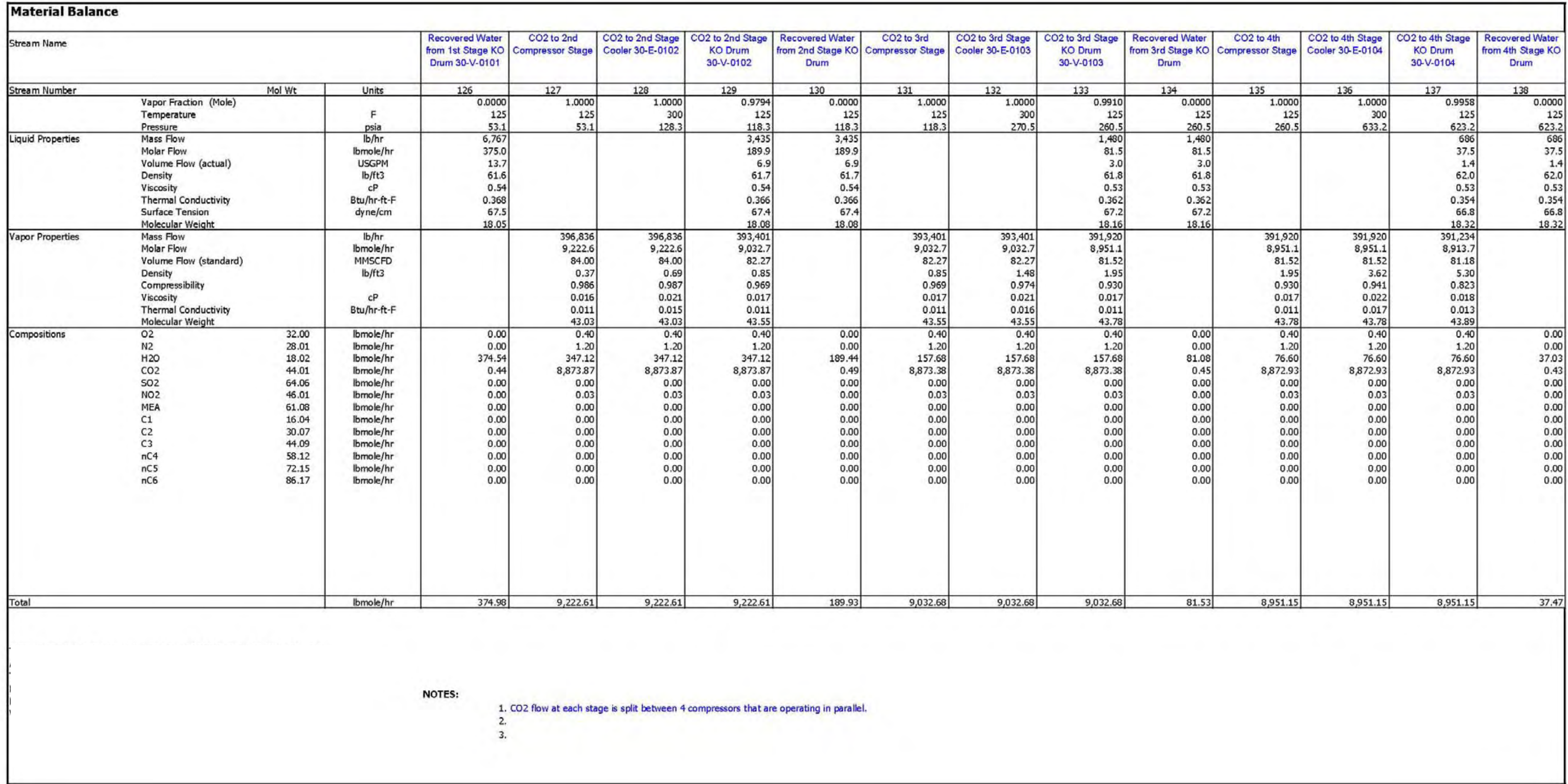


University of Utah

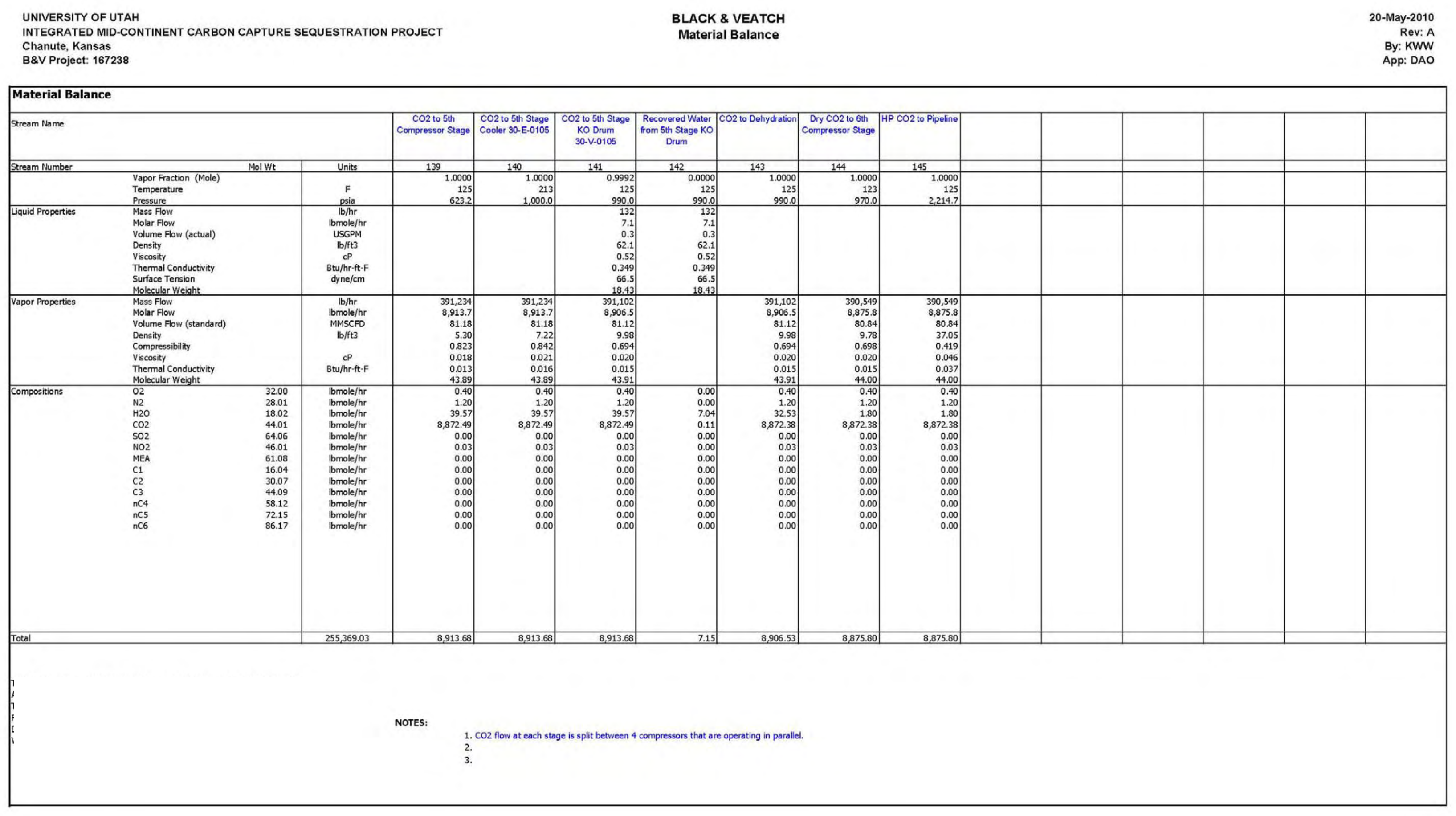

167238-0000-P1100

Printed 27-May-2010

Appendix 2-20 
APPENDIX 3-A

FEASIBILITY DRAWINGS

THRALL-AAGARD FIELD

Appendix 3-1 


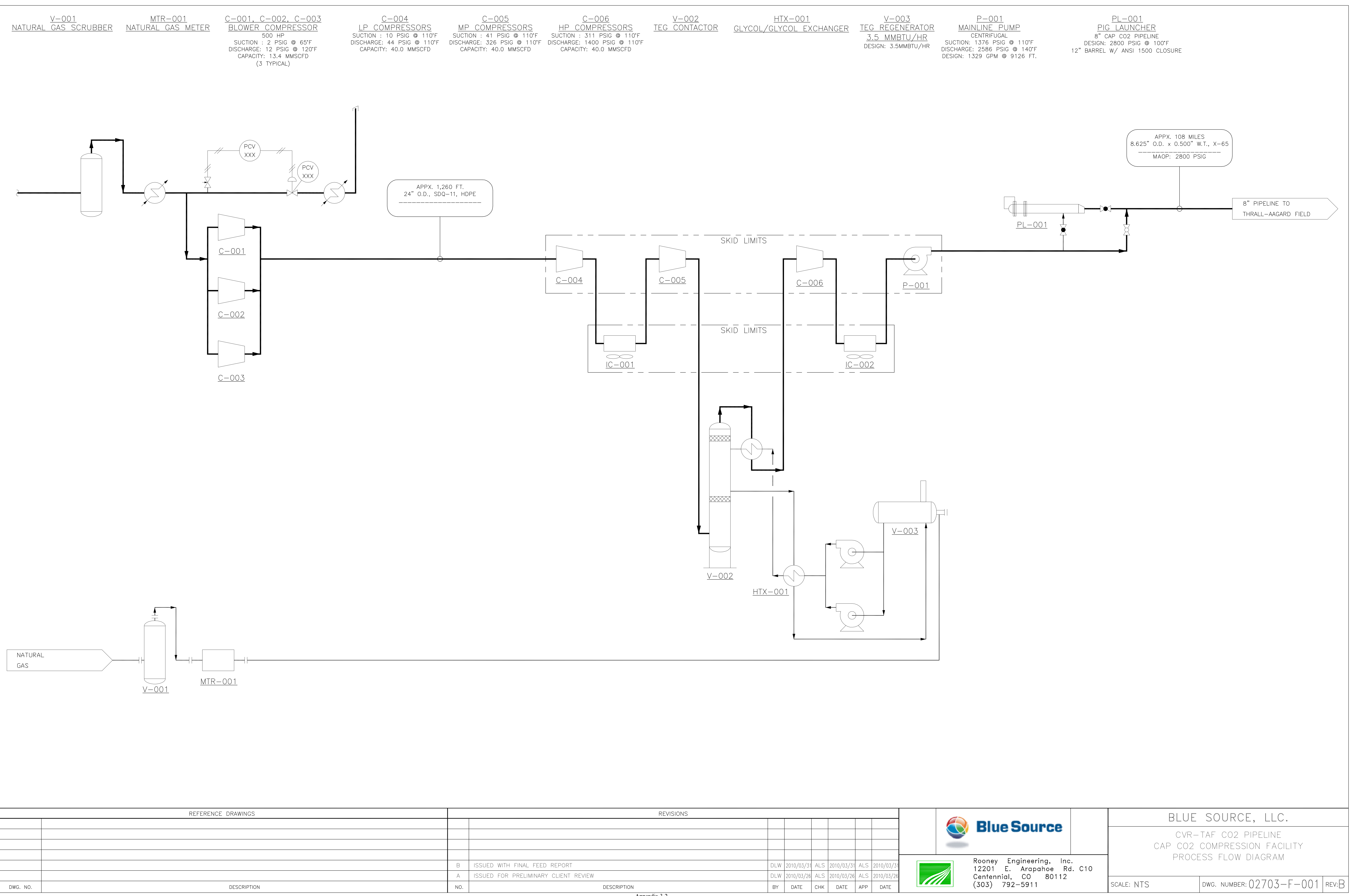




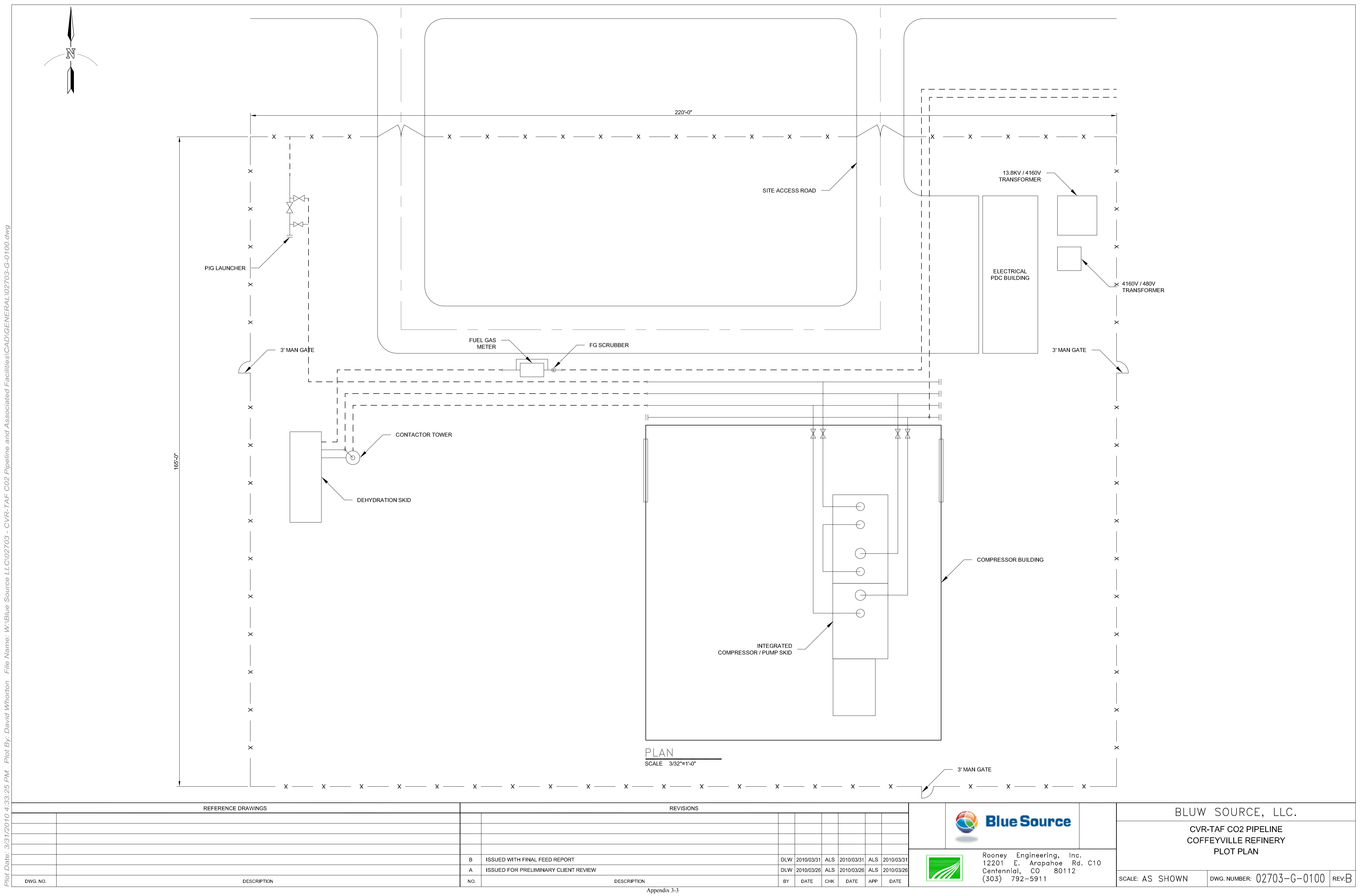




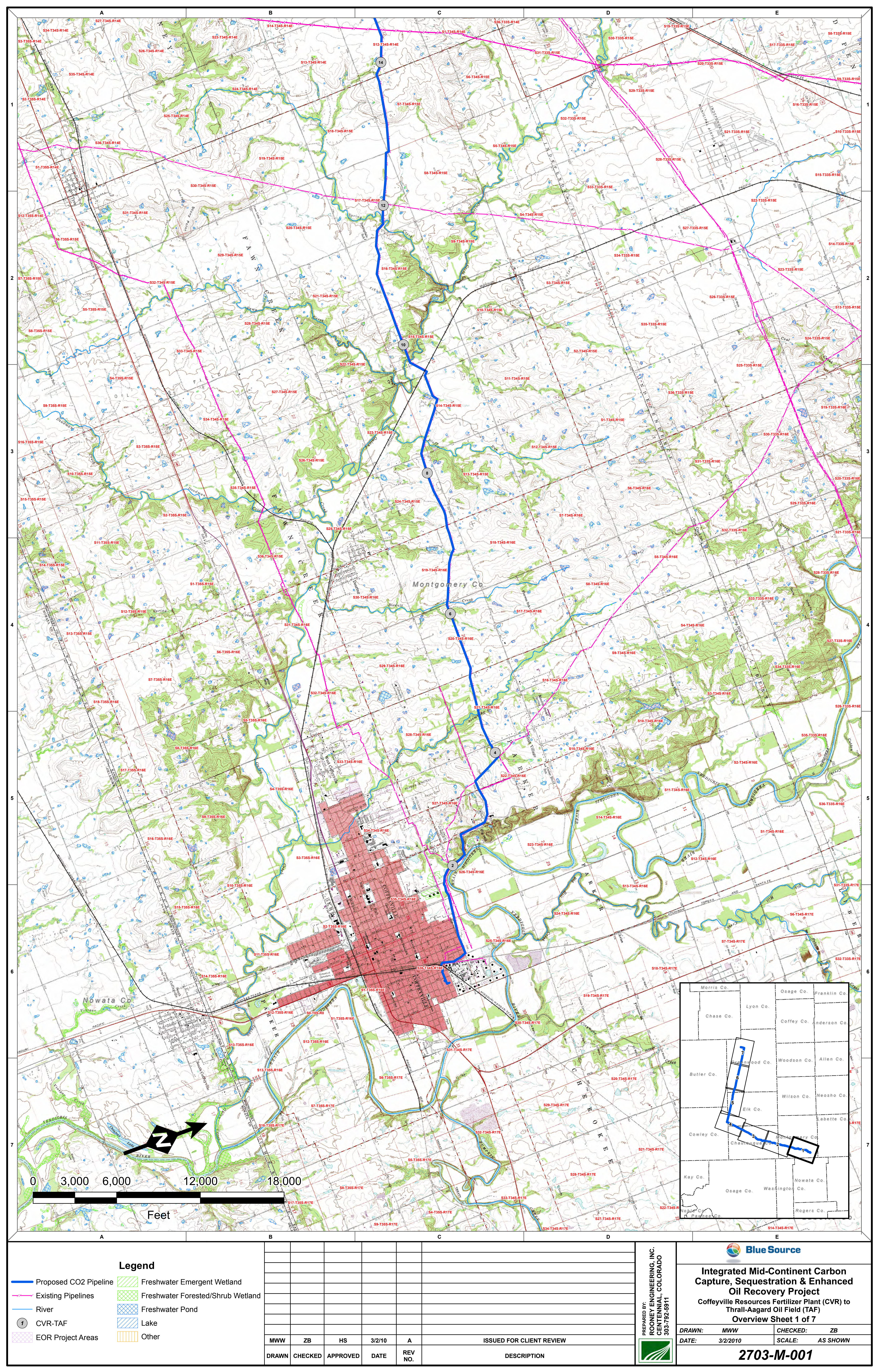




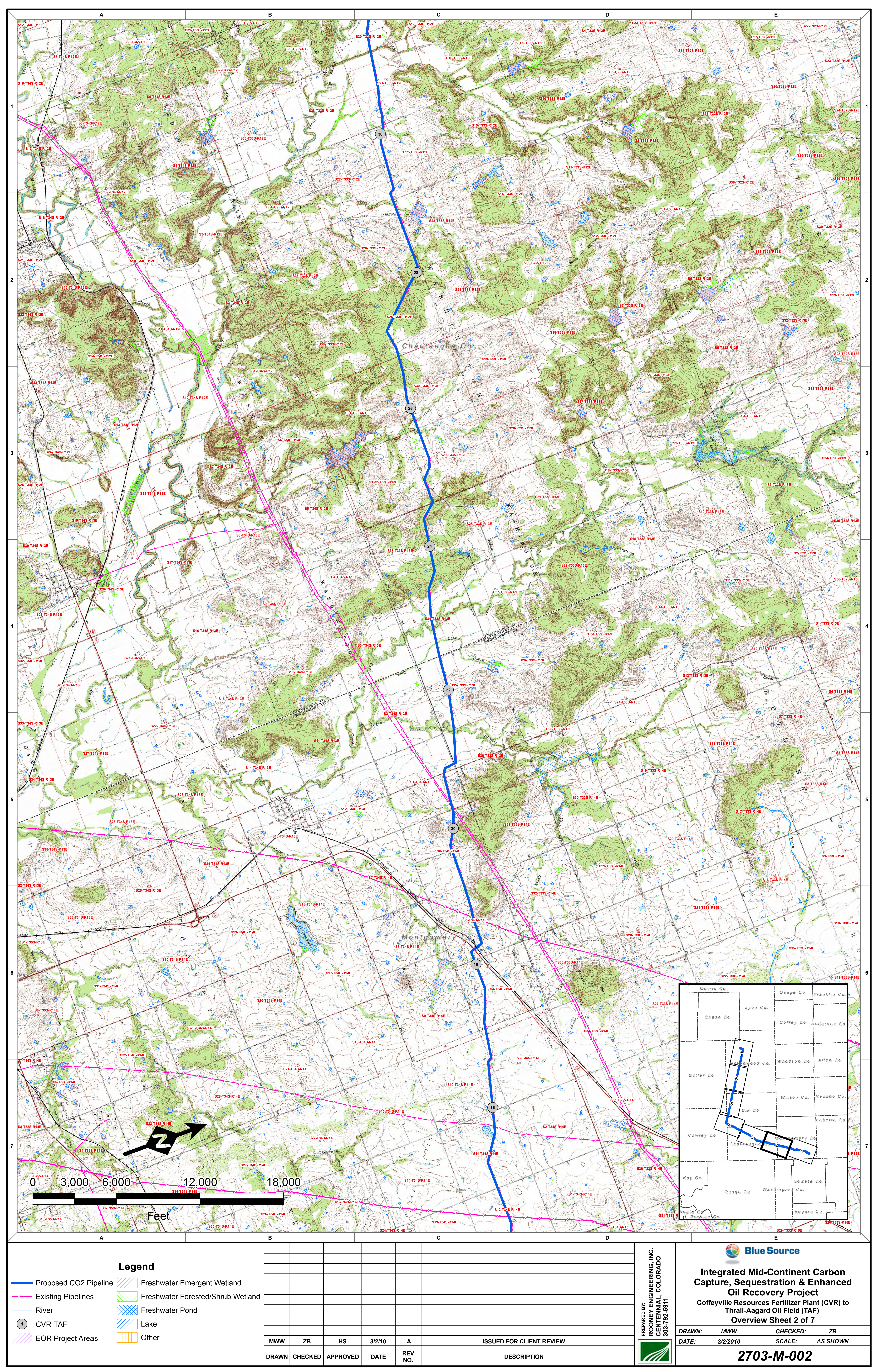




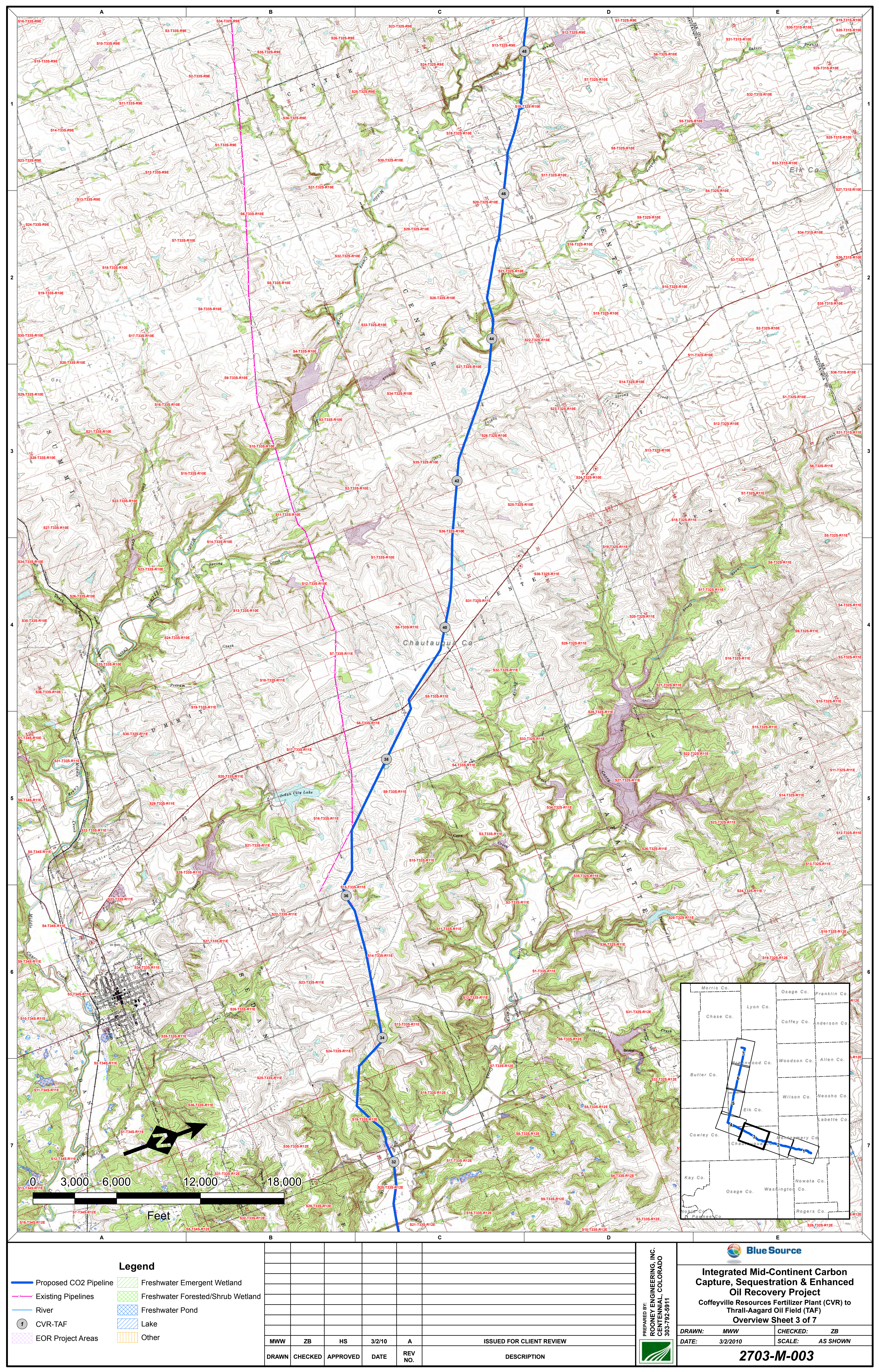




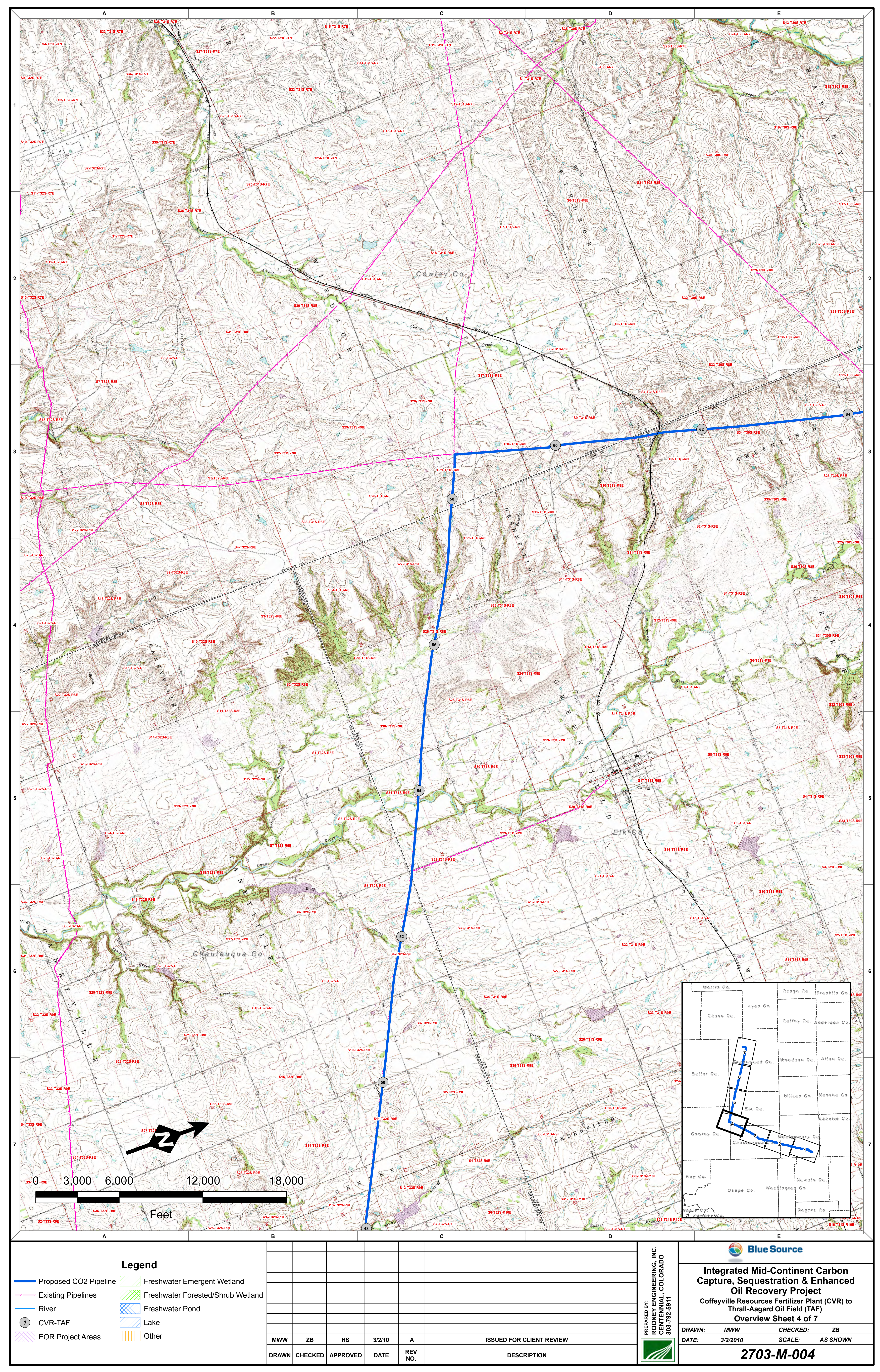




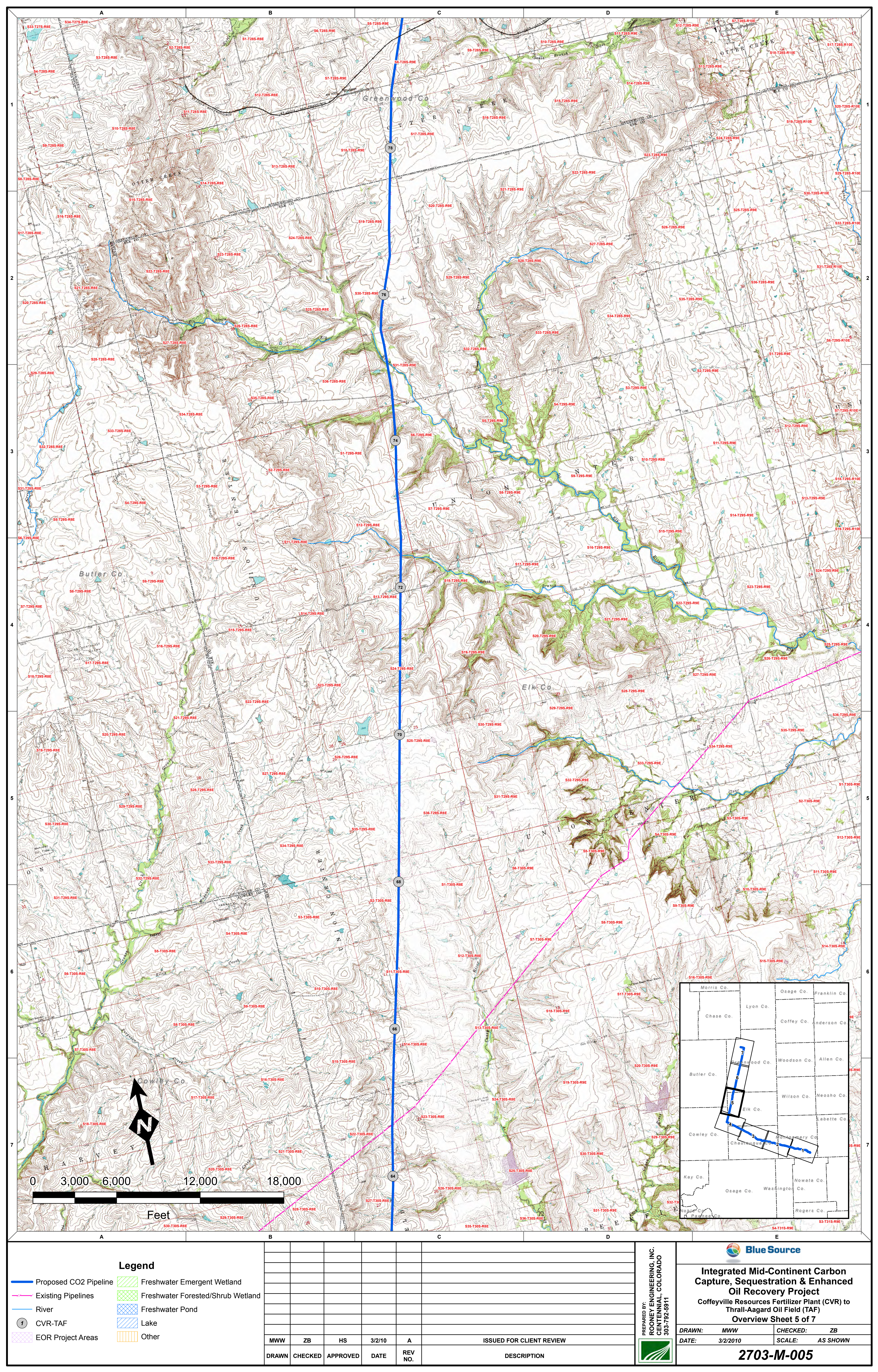




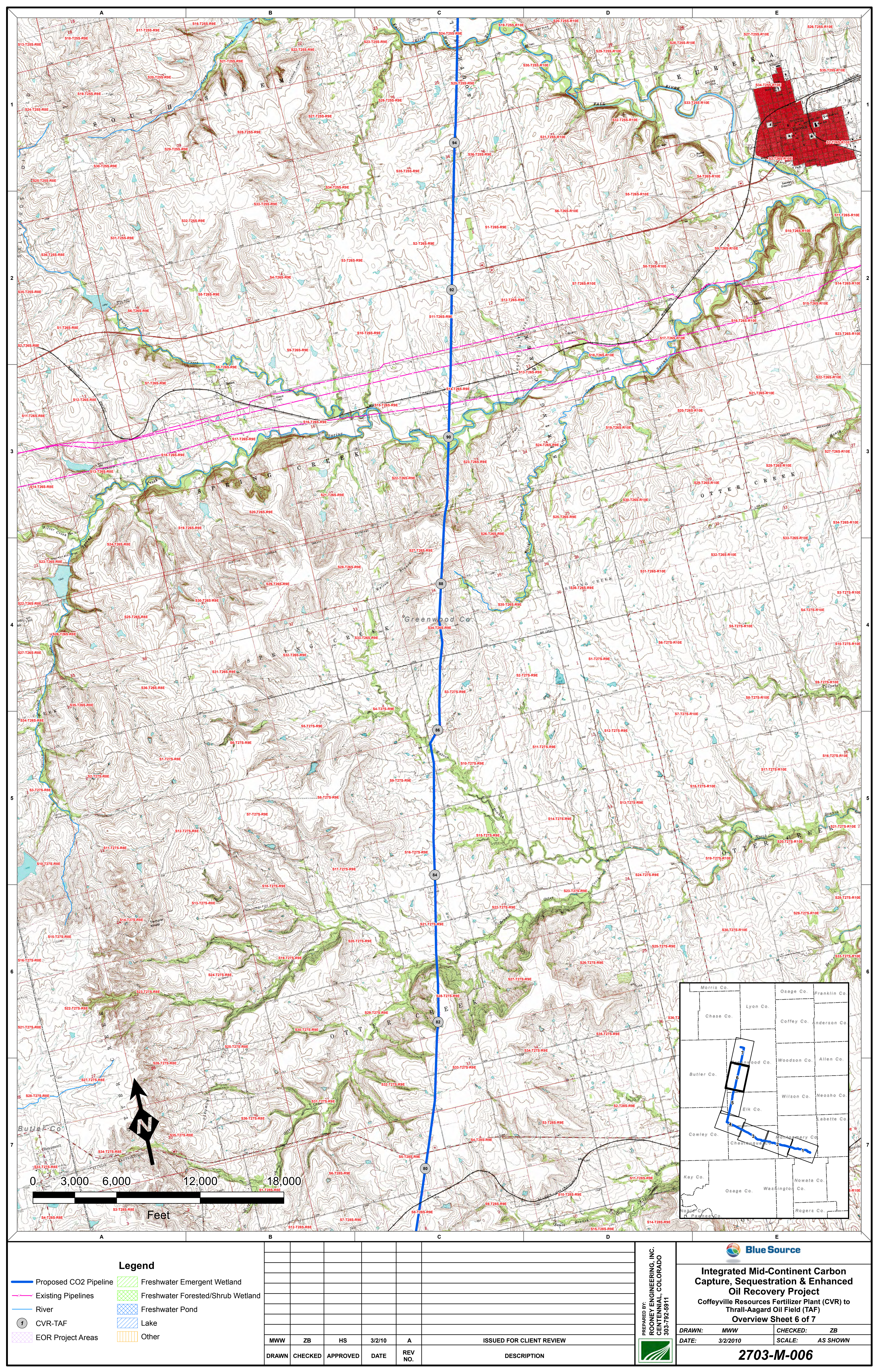




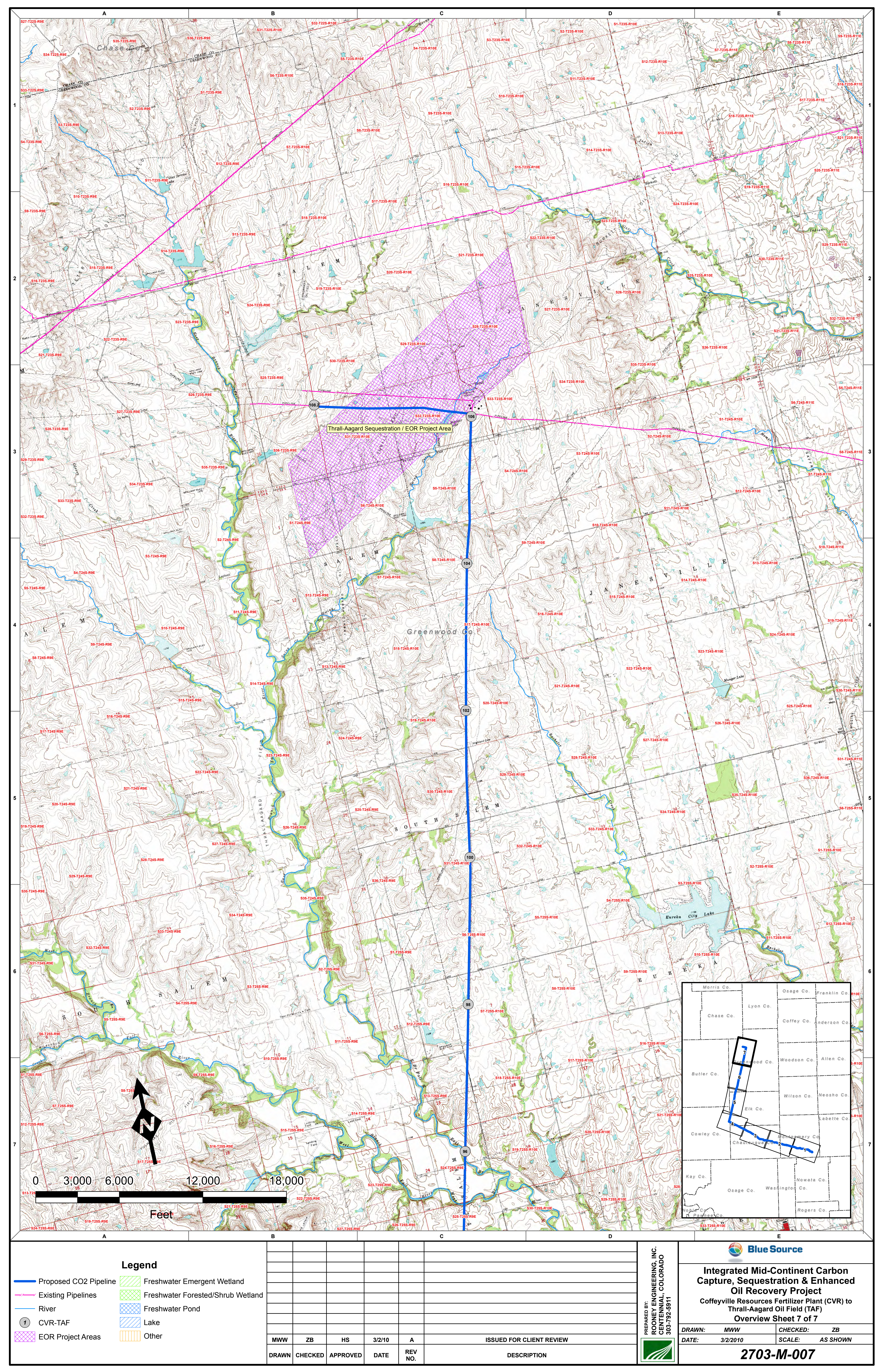




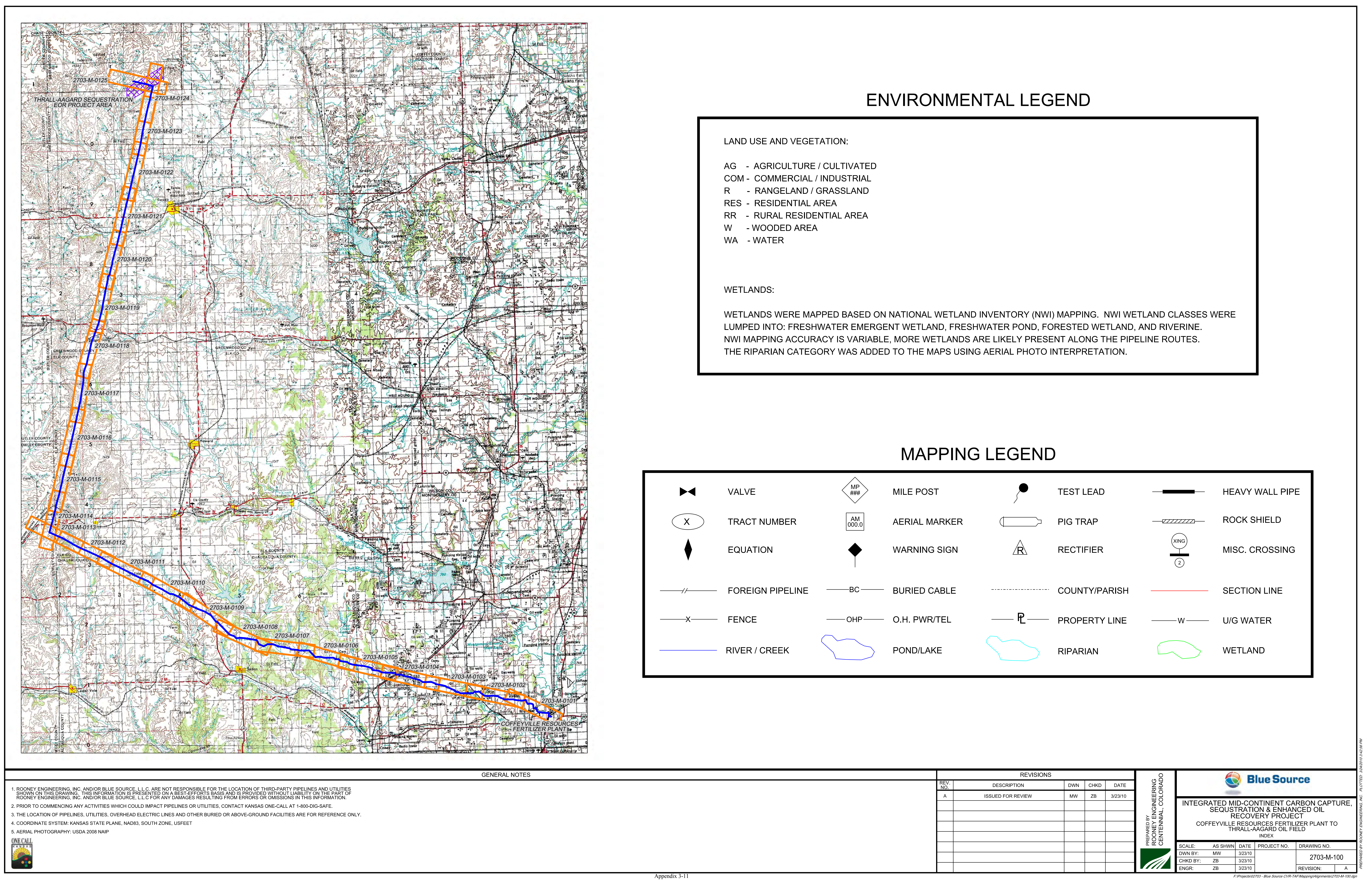




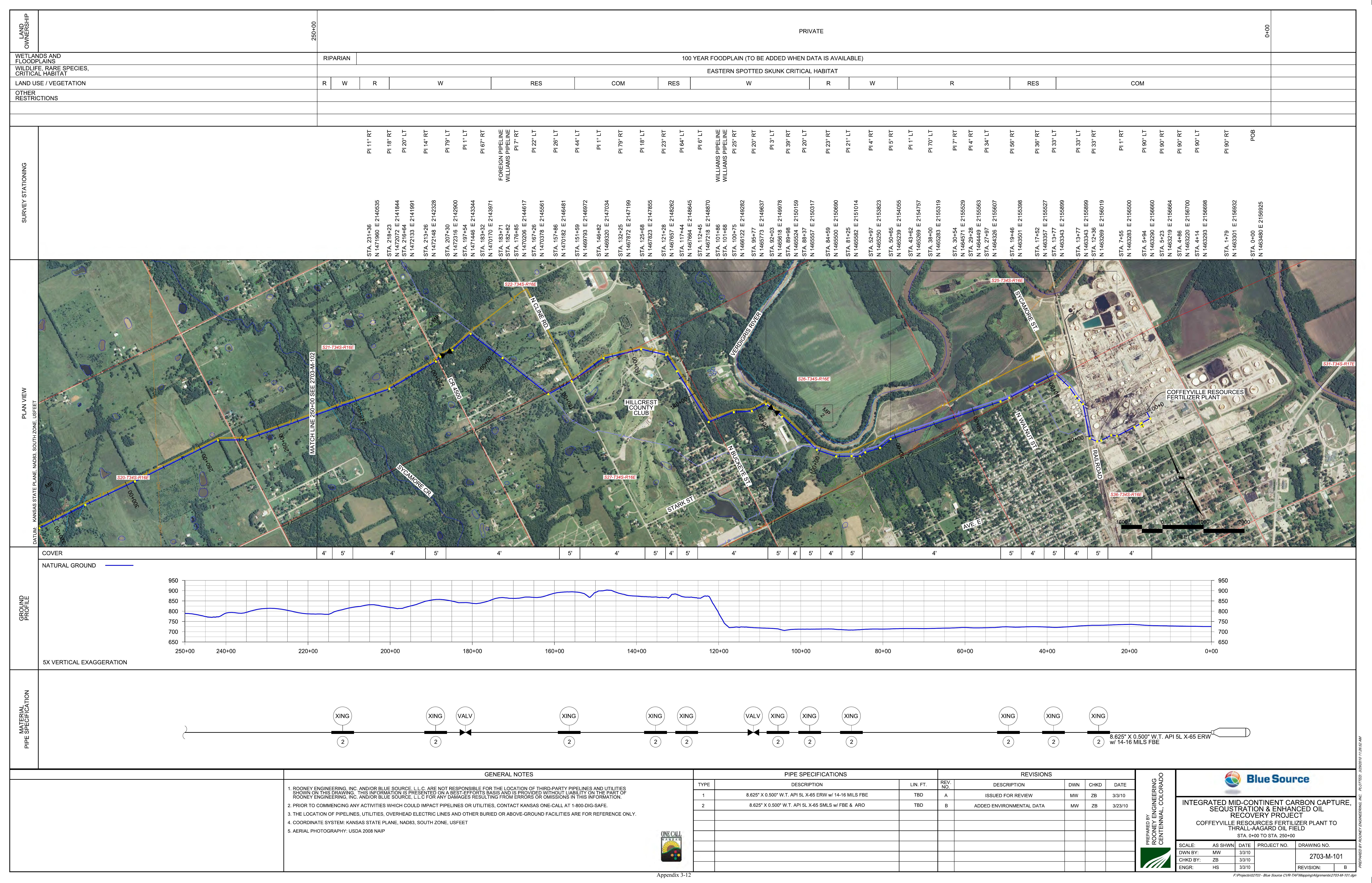




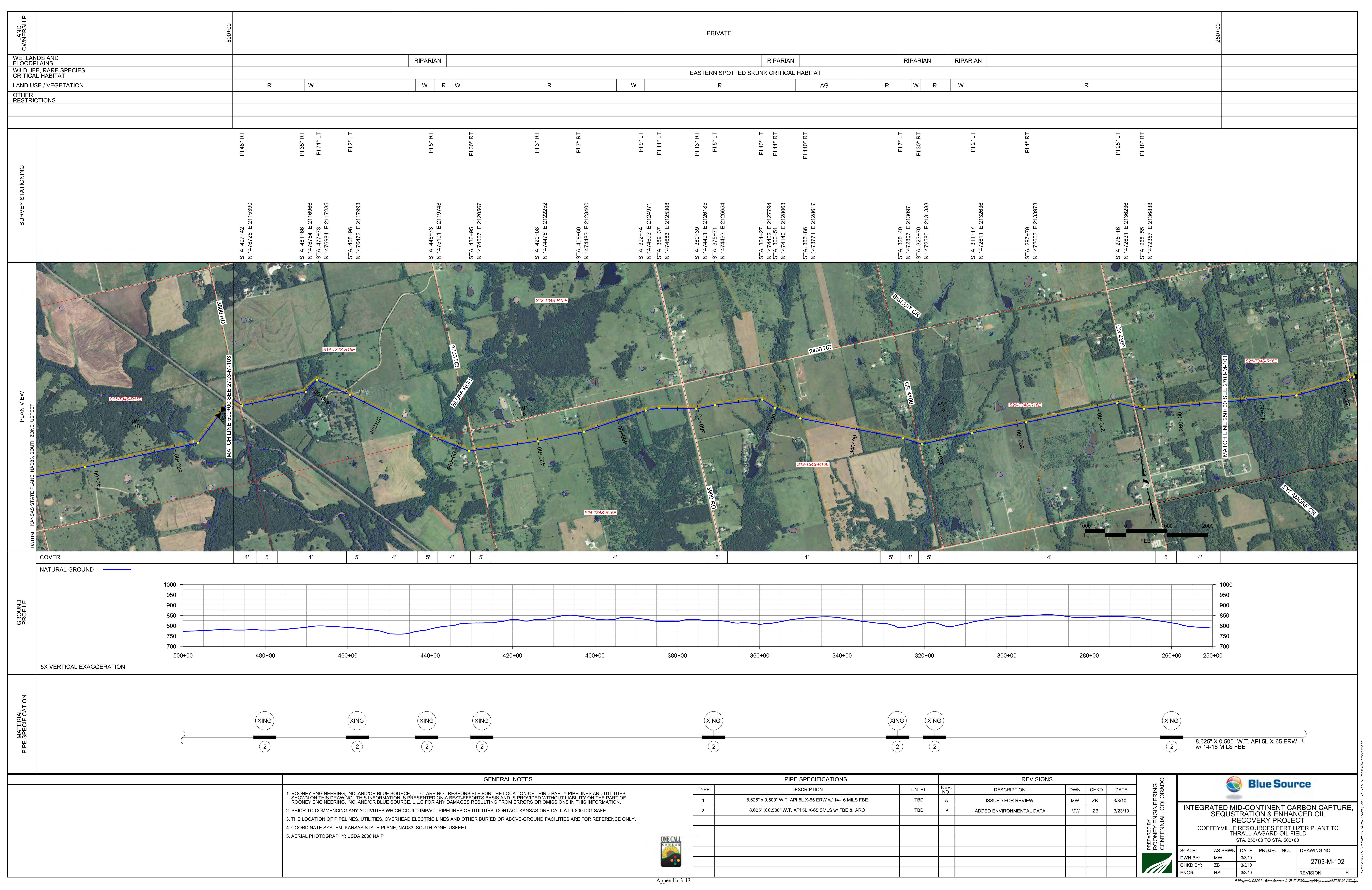




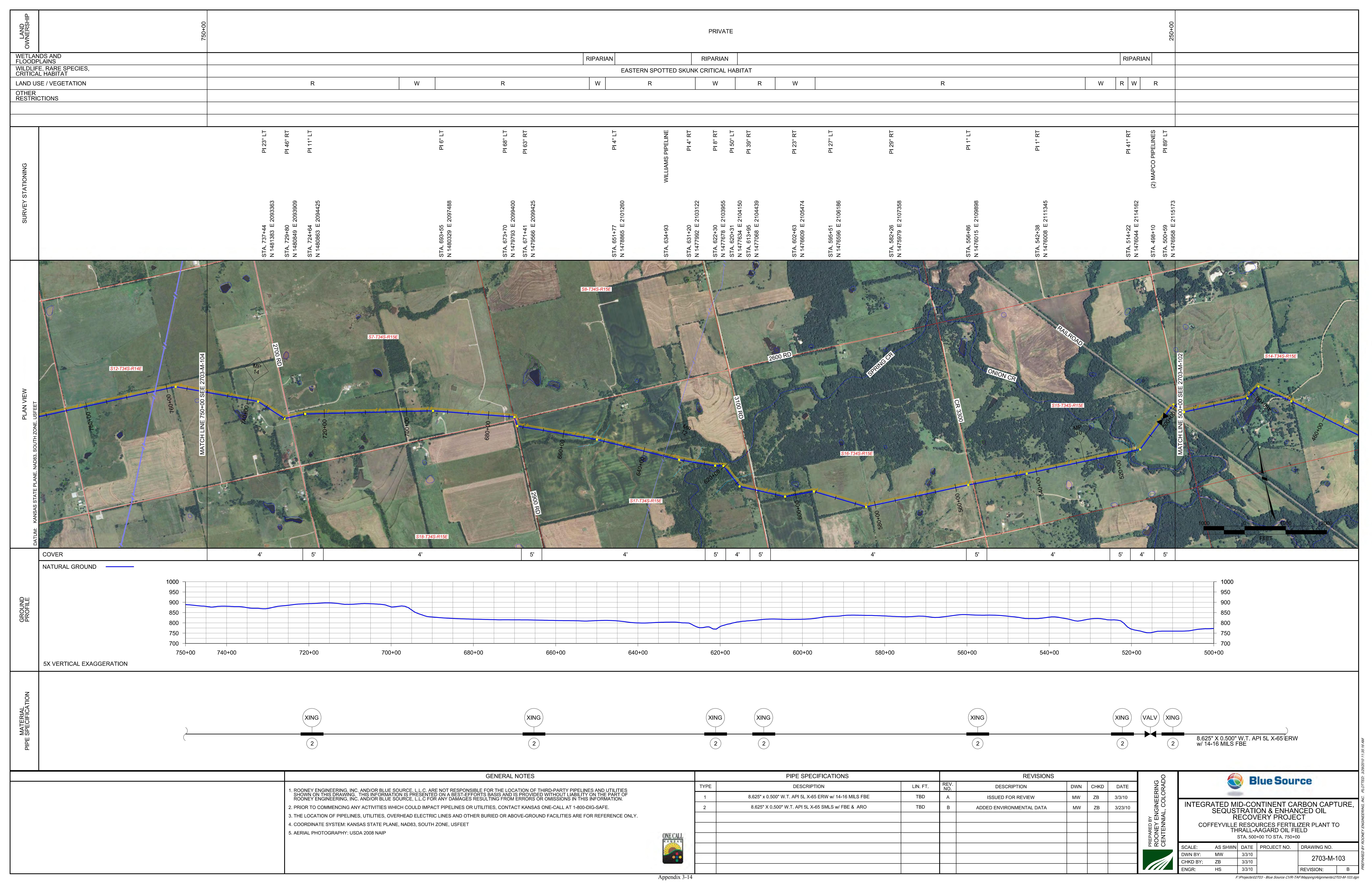




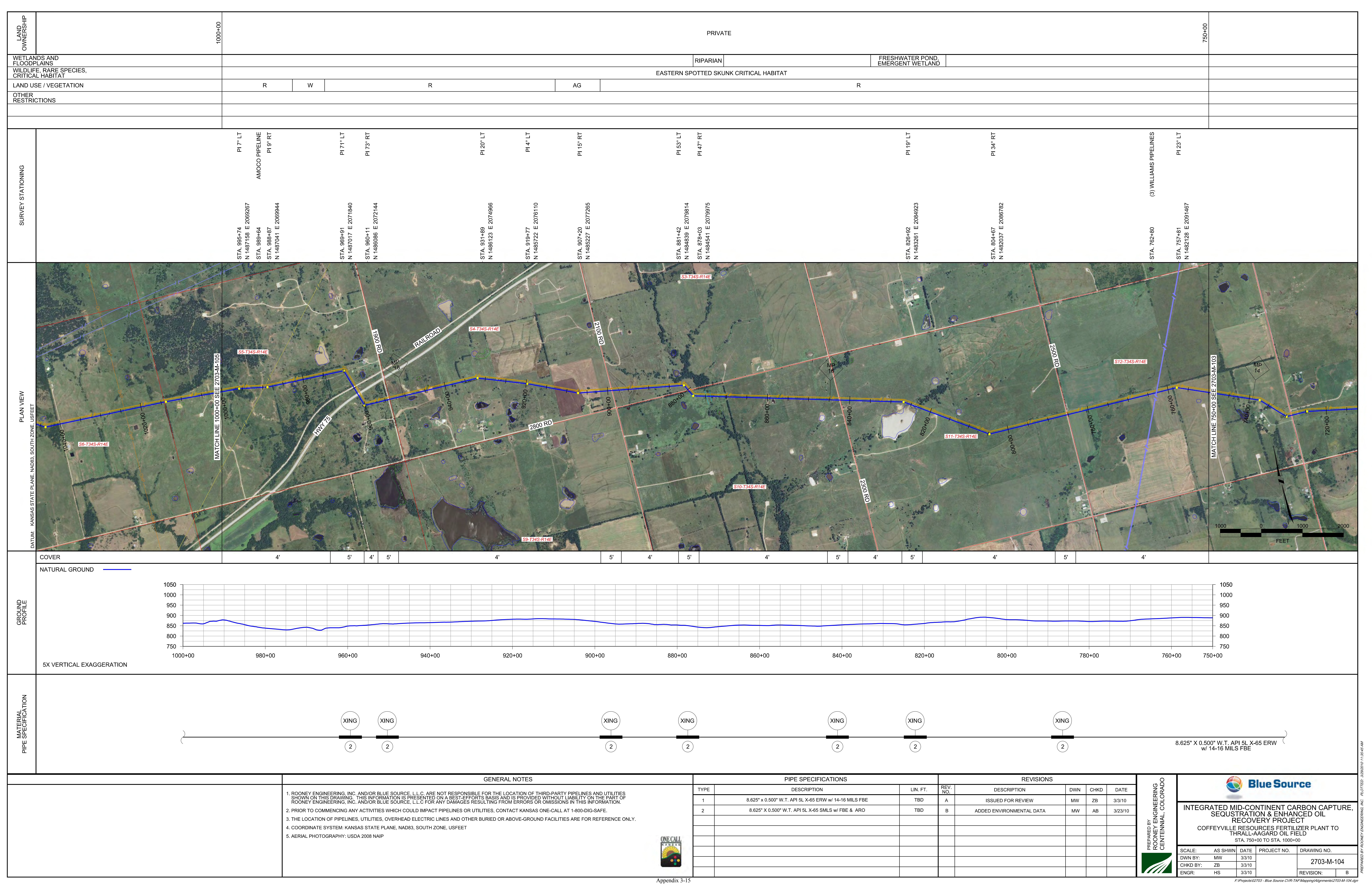




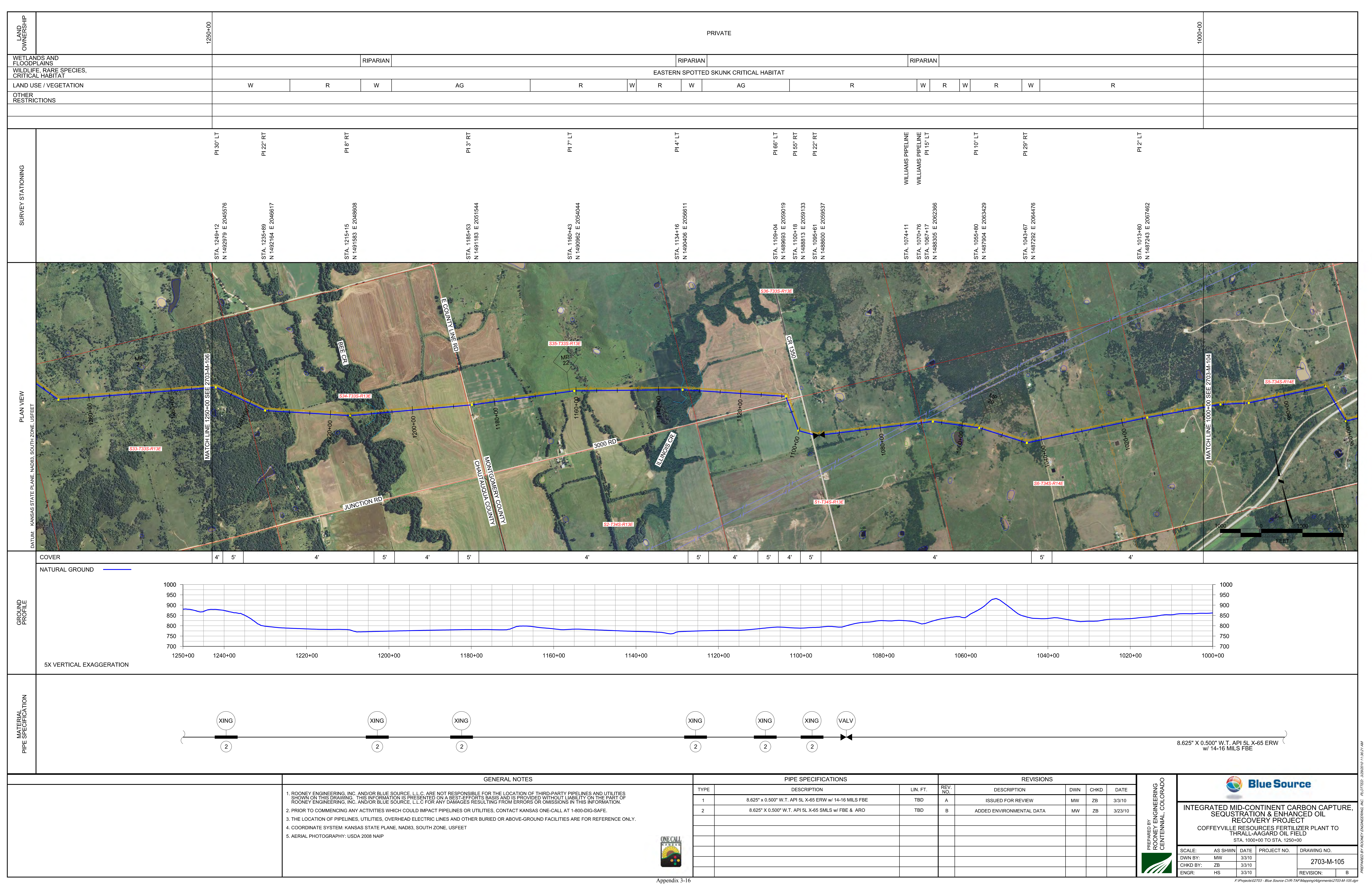




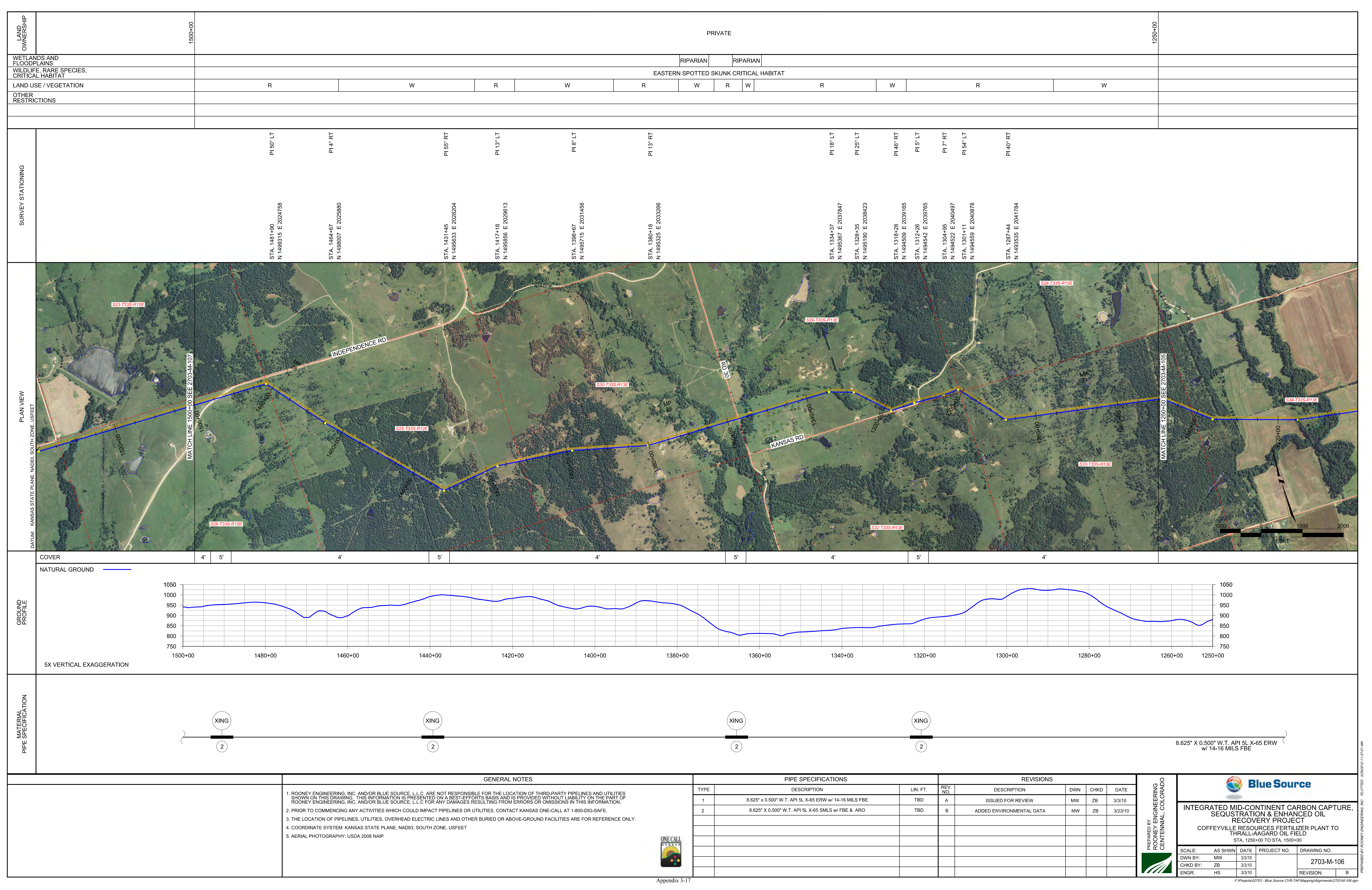




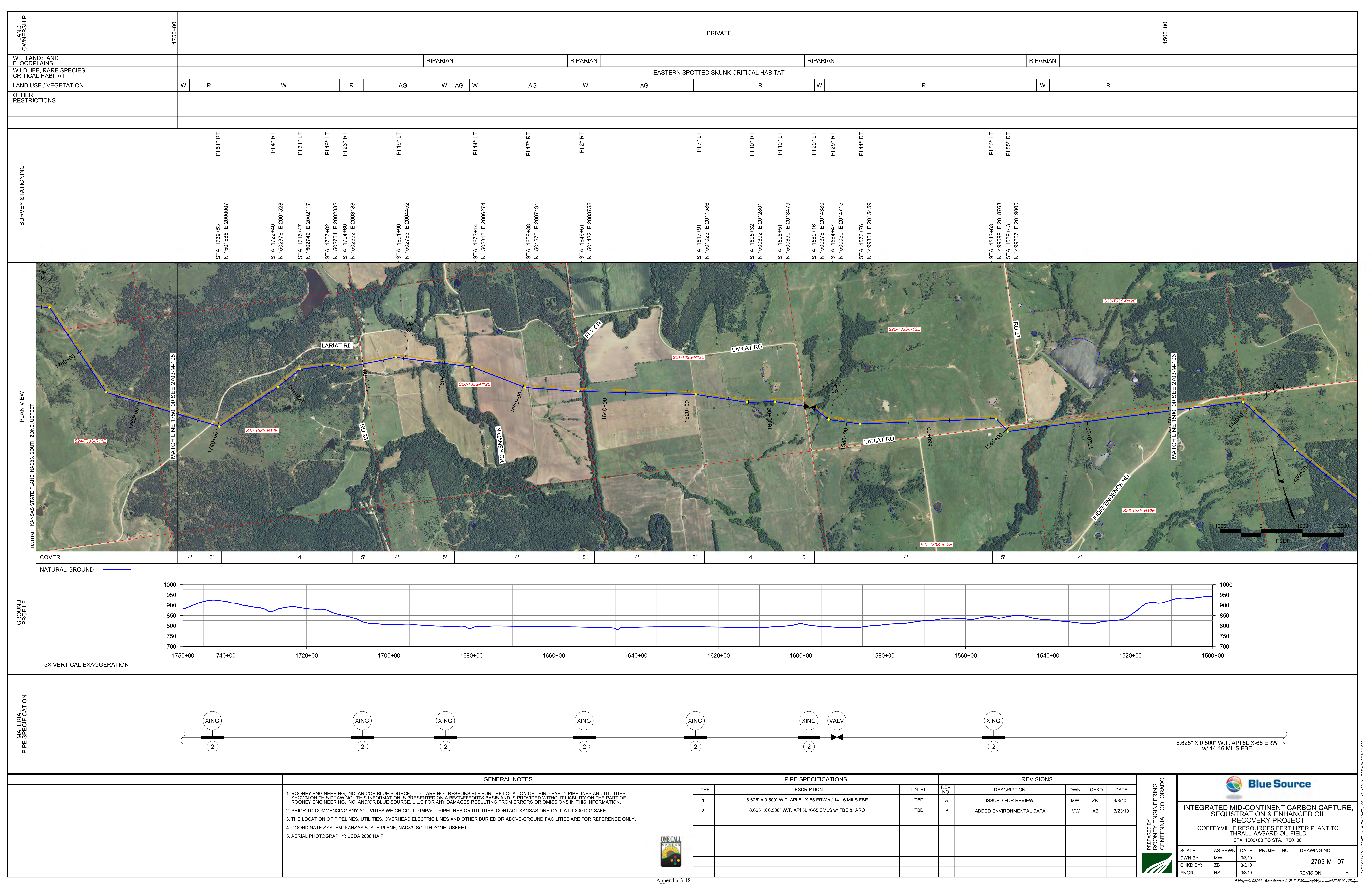




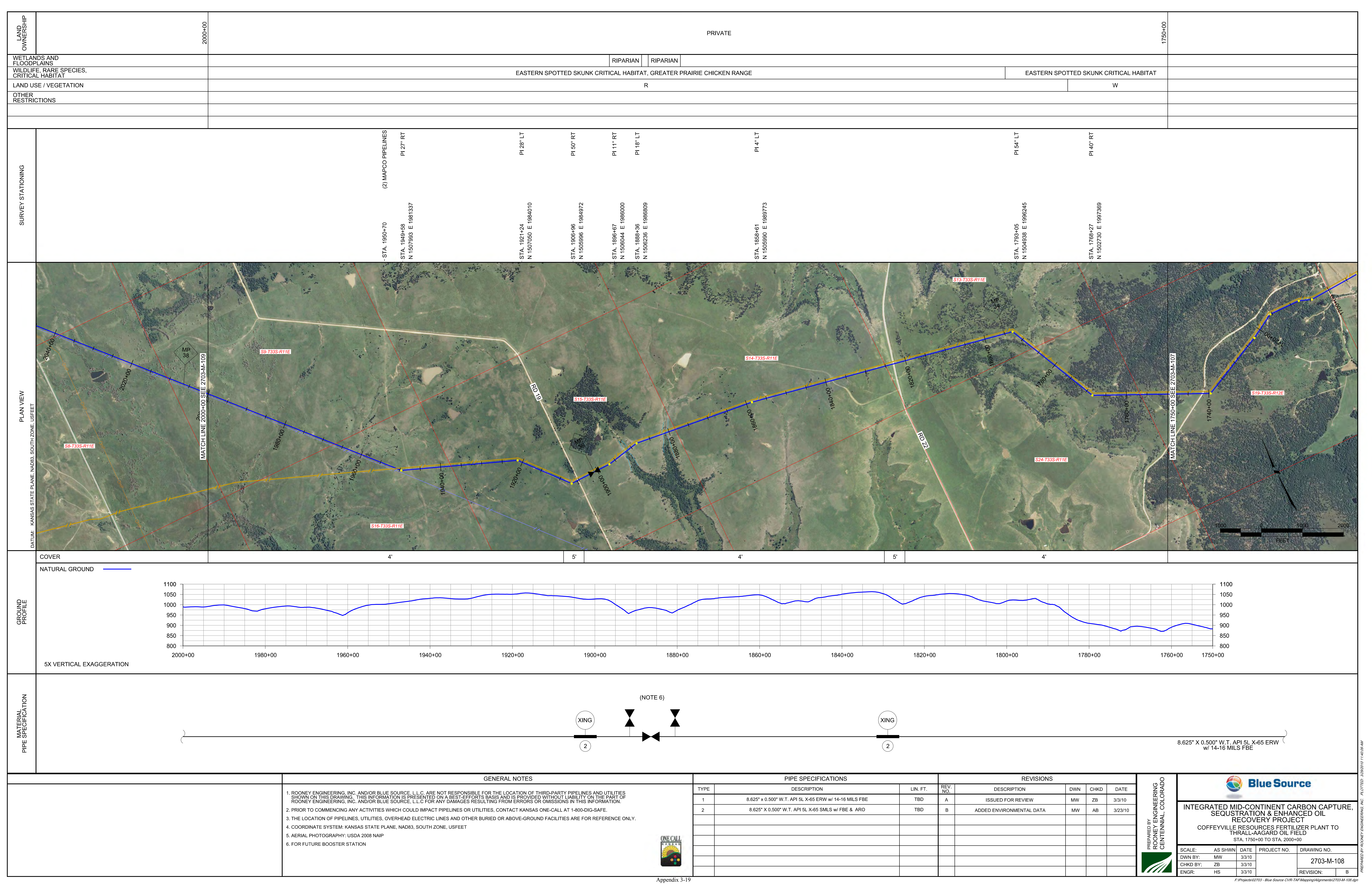




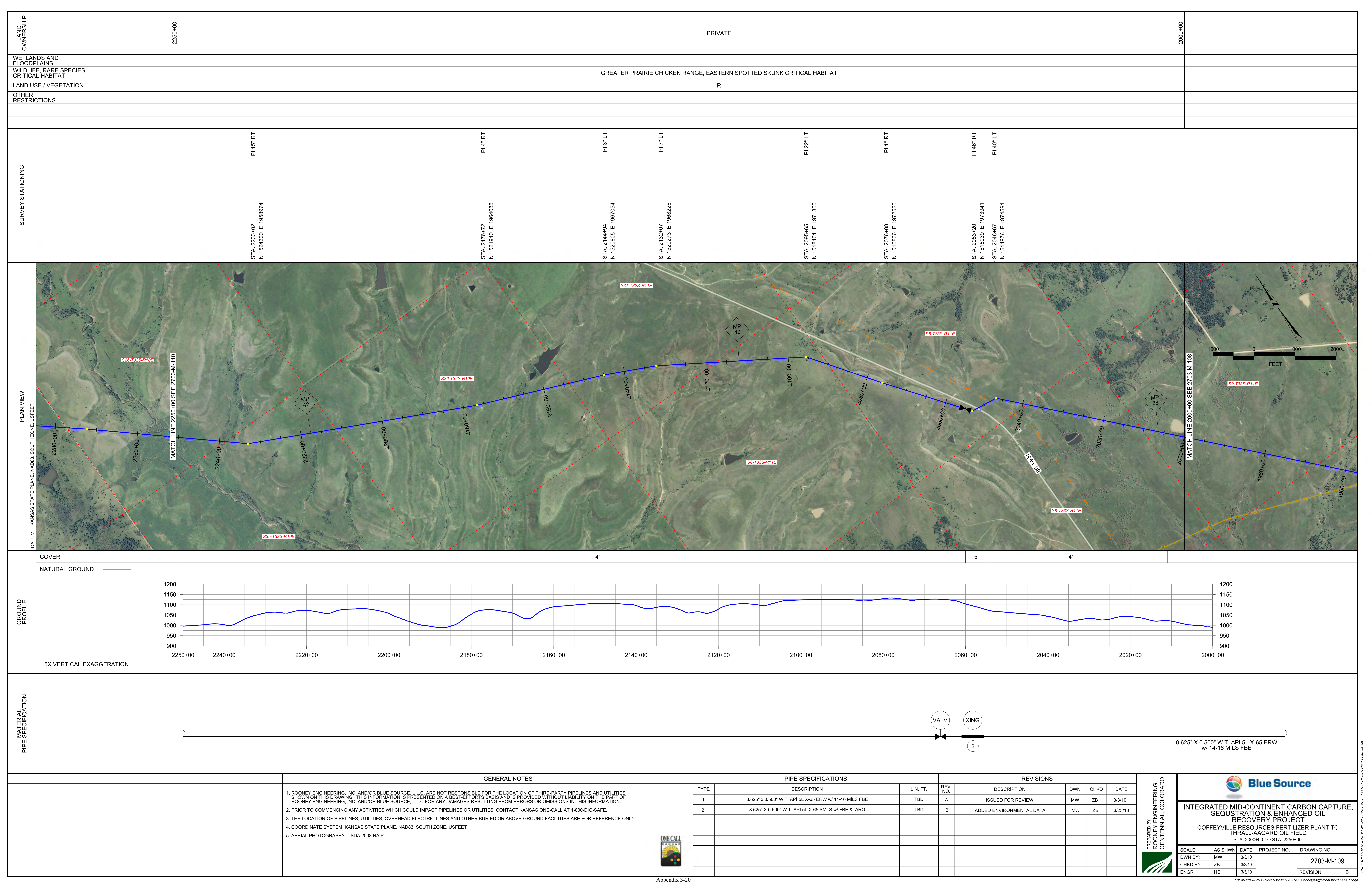




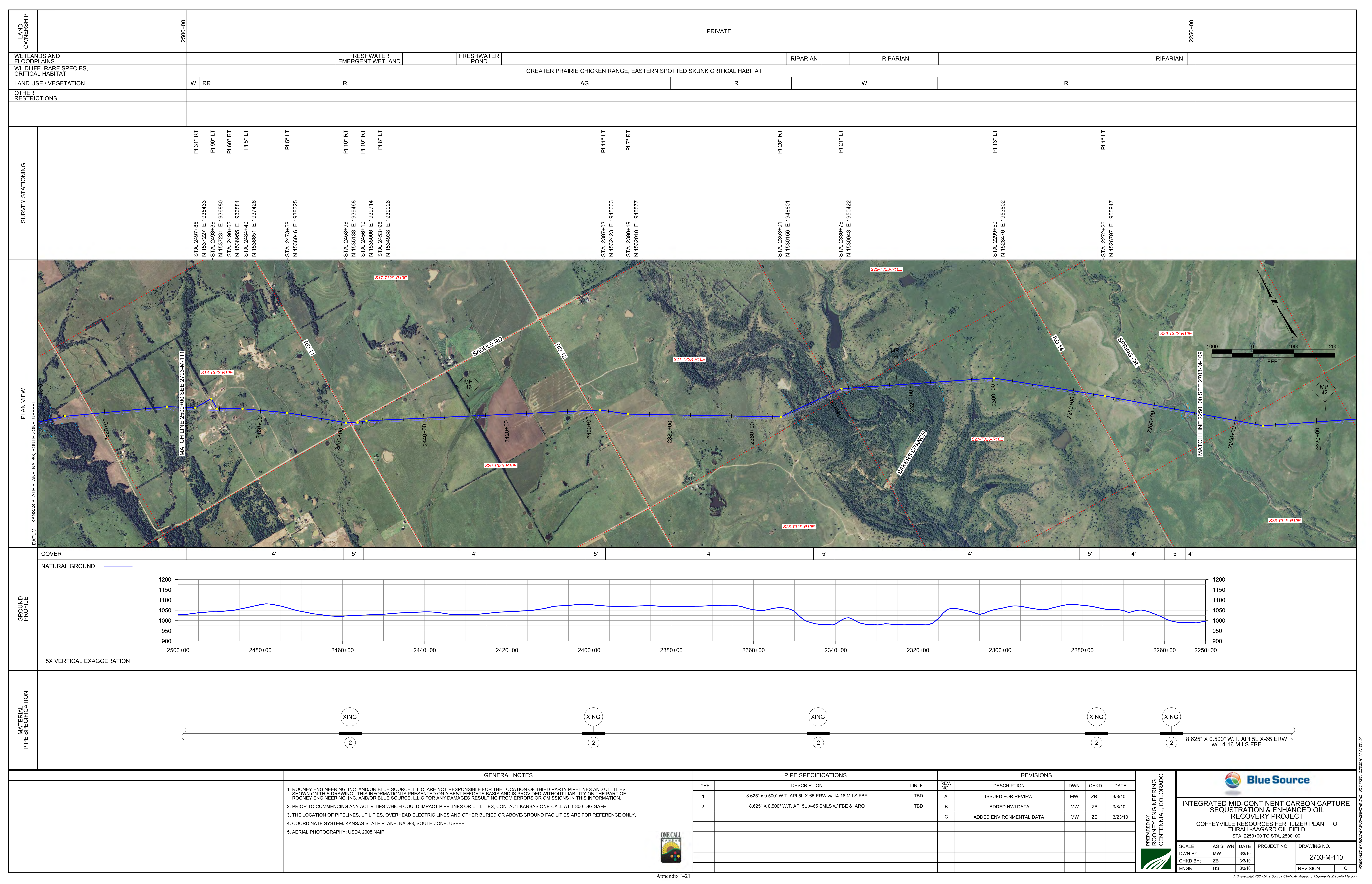




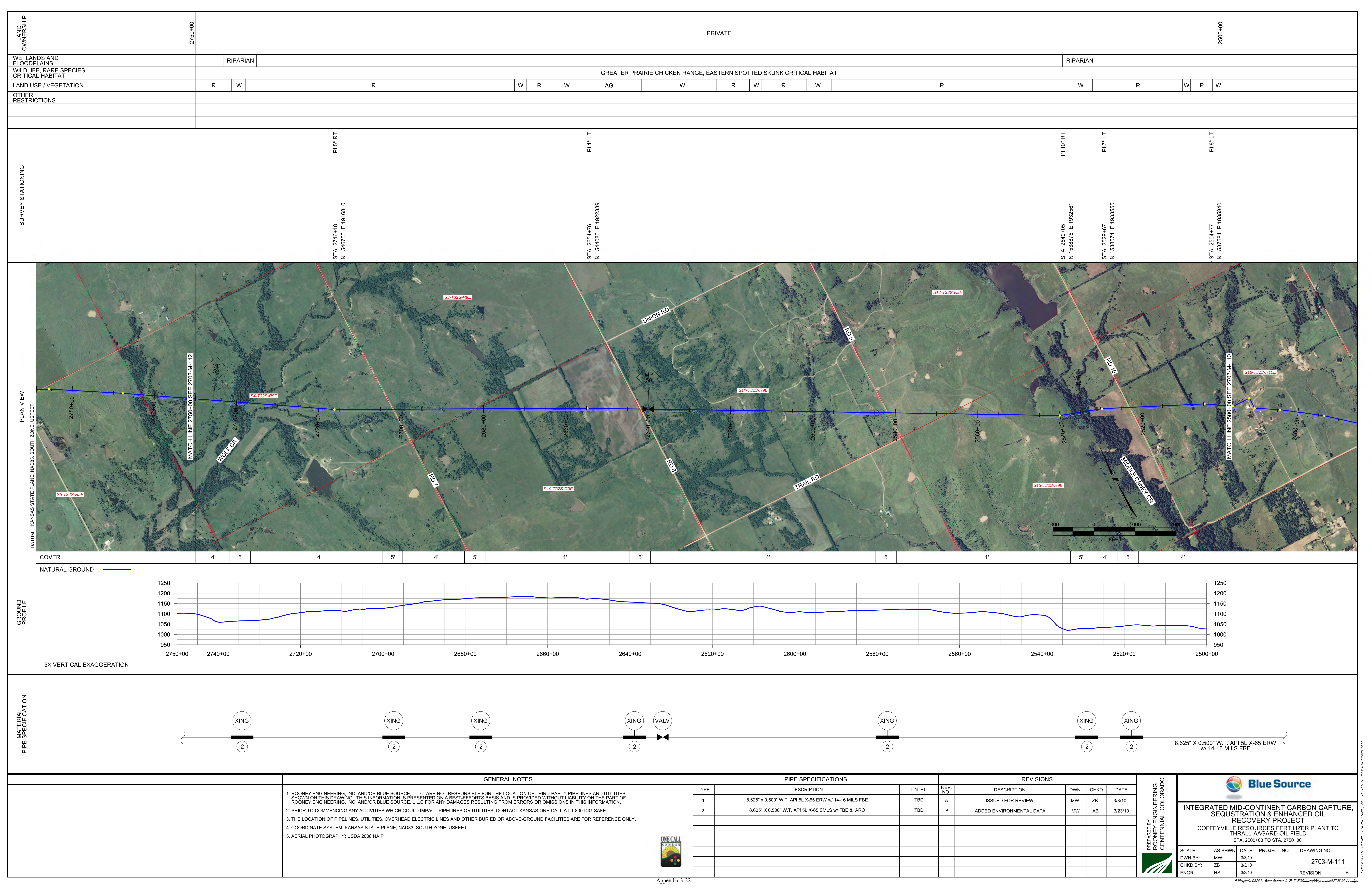




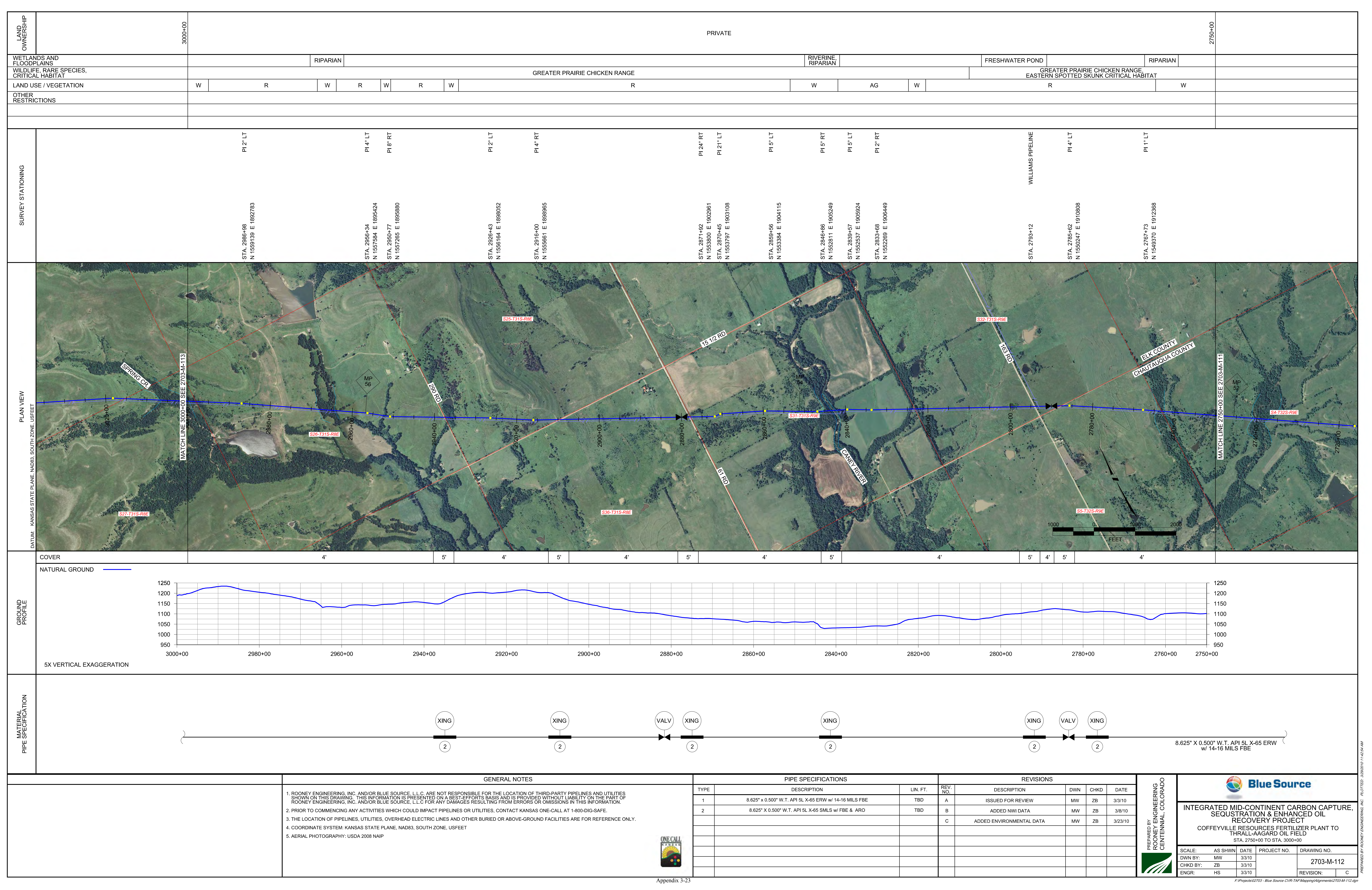




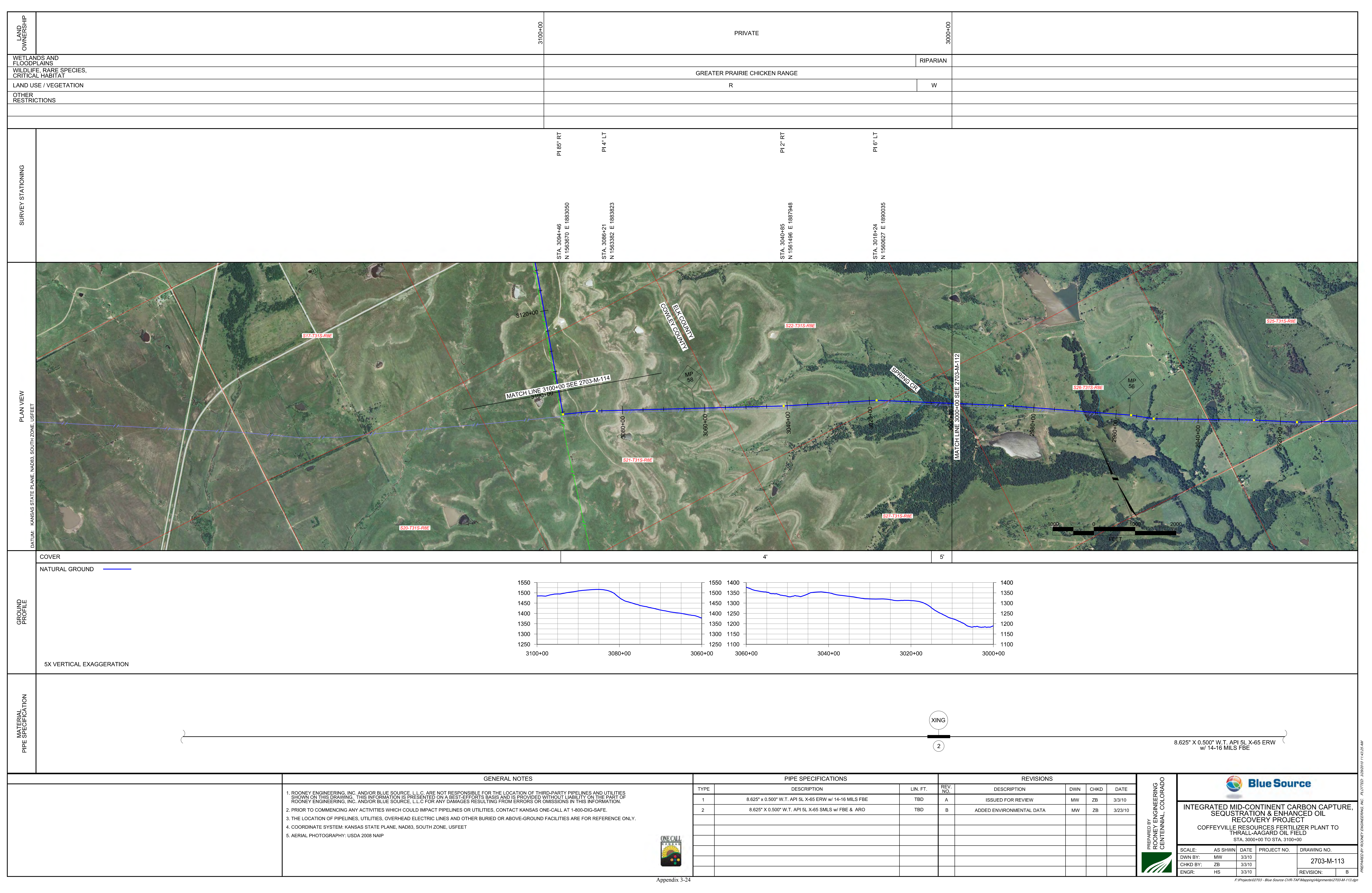




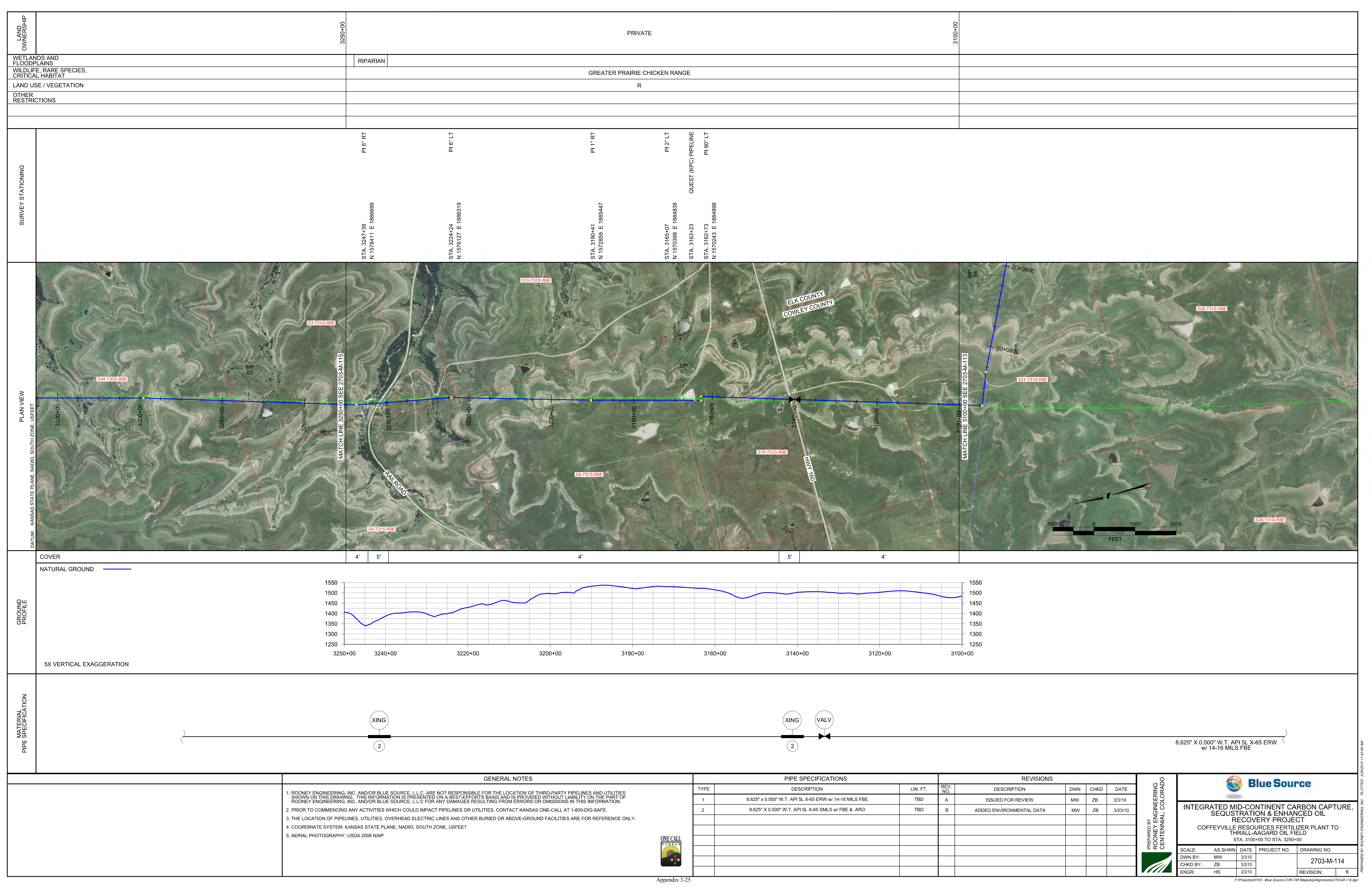




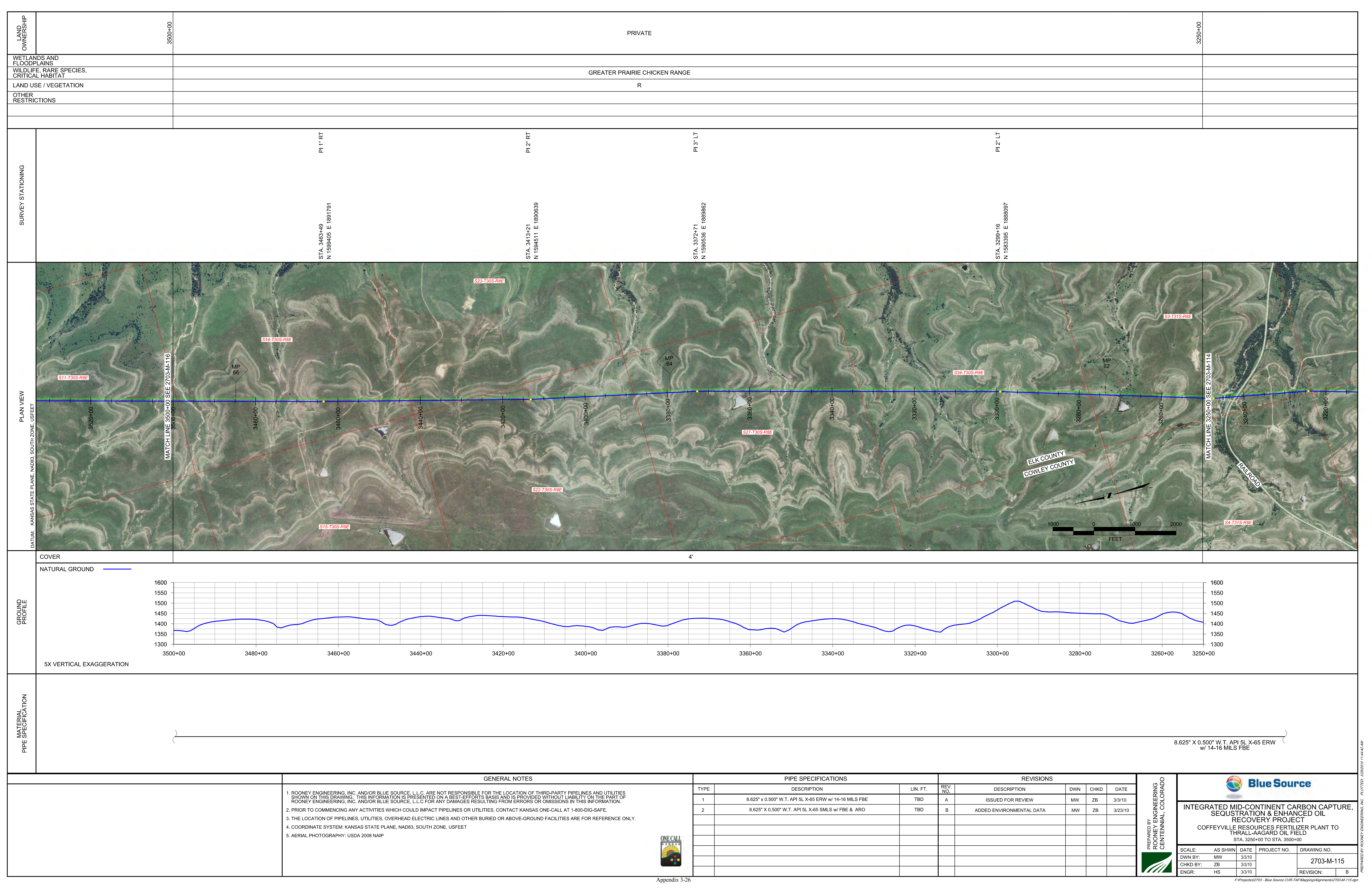




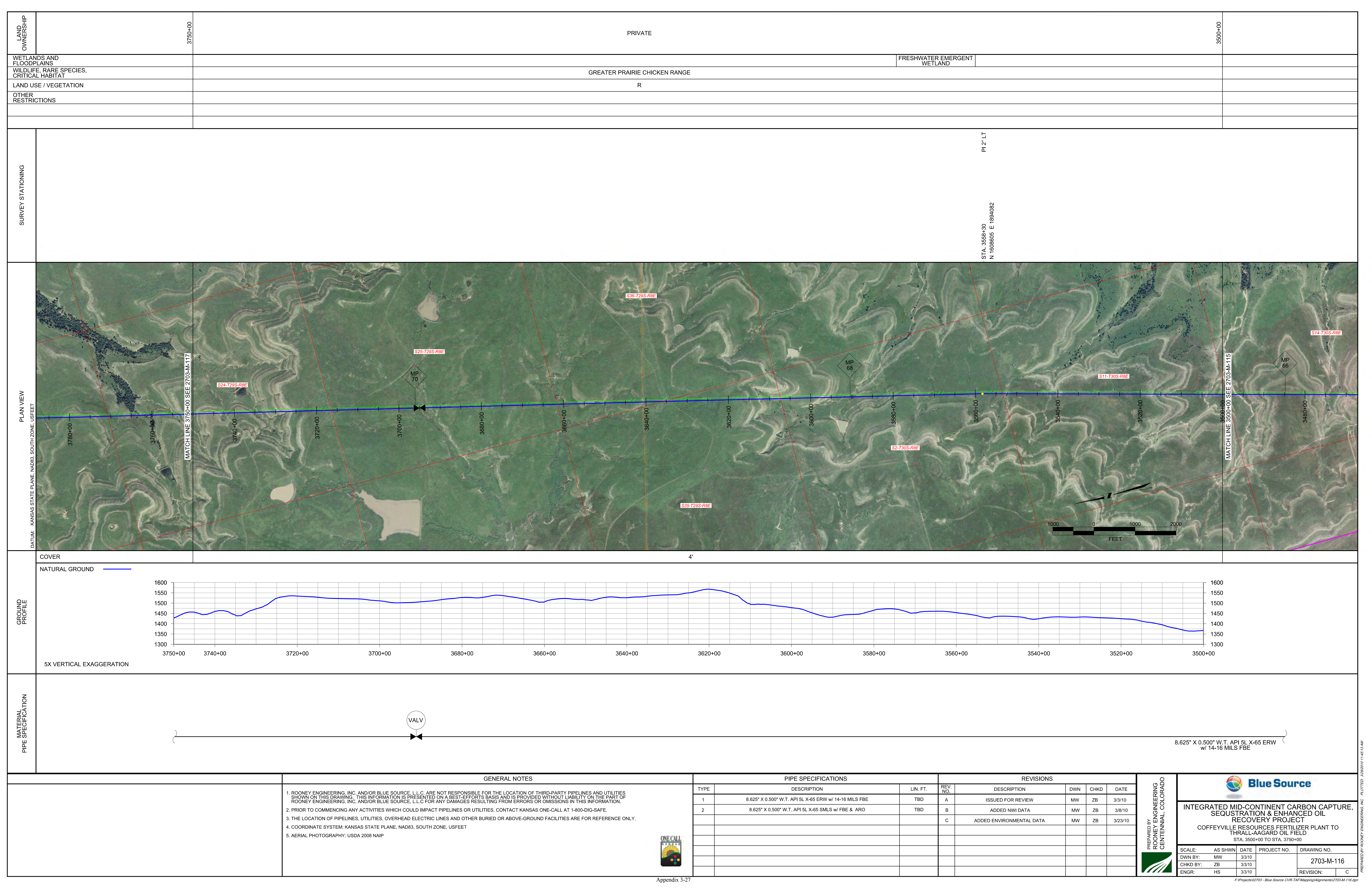




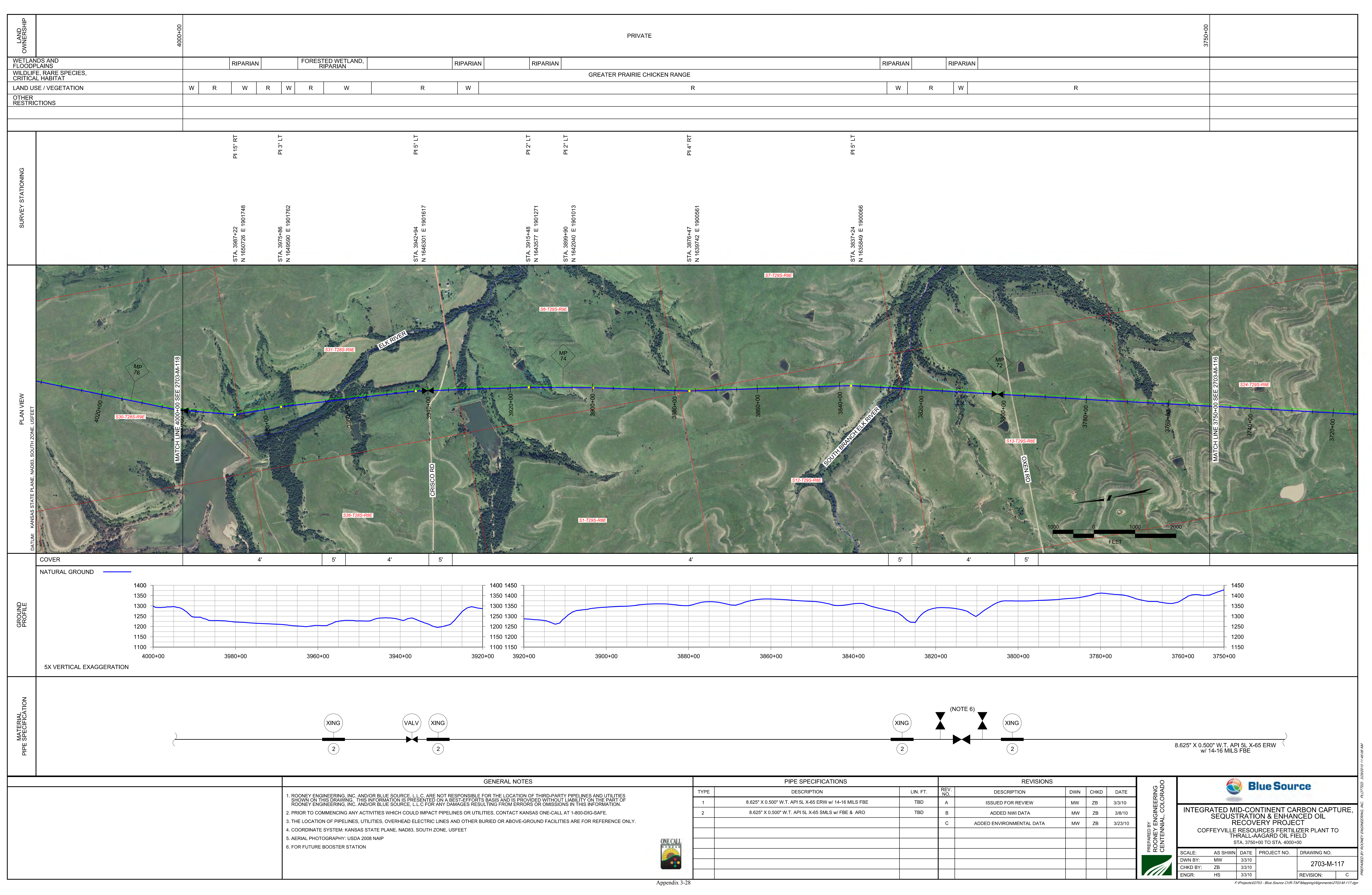




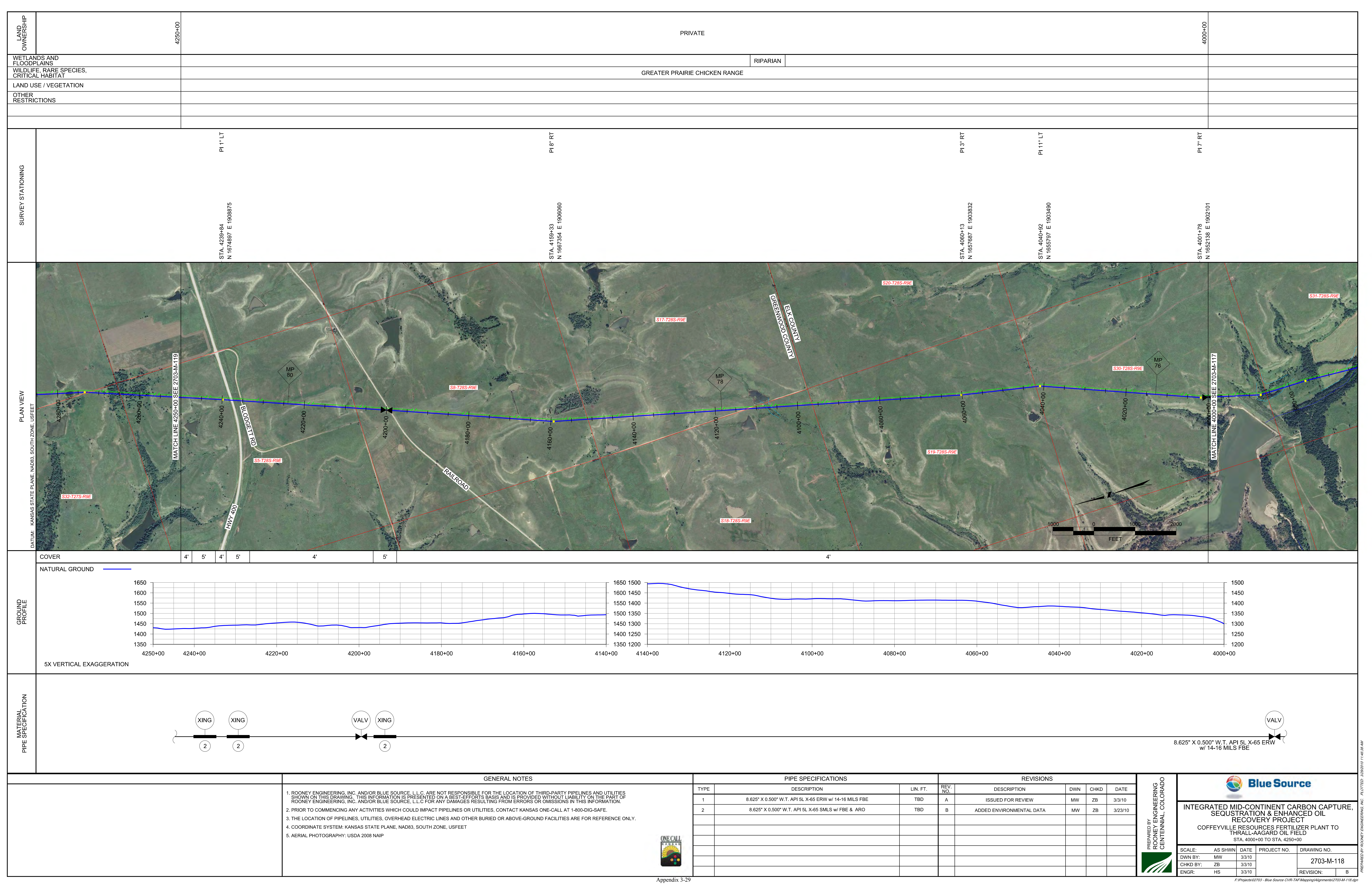




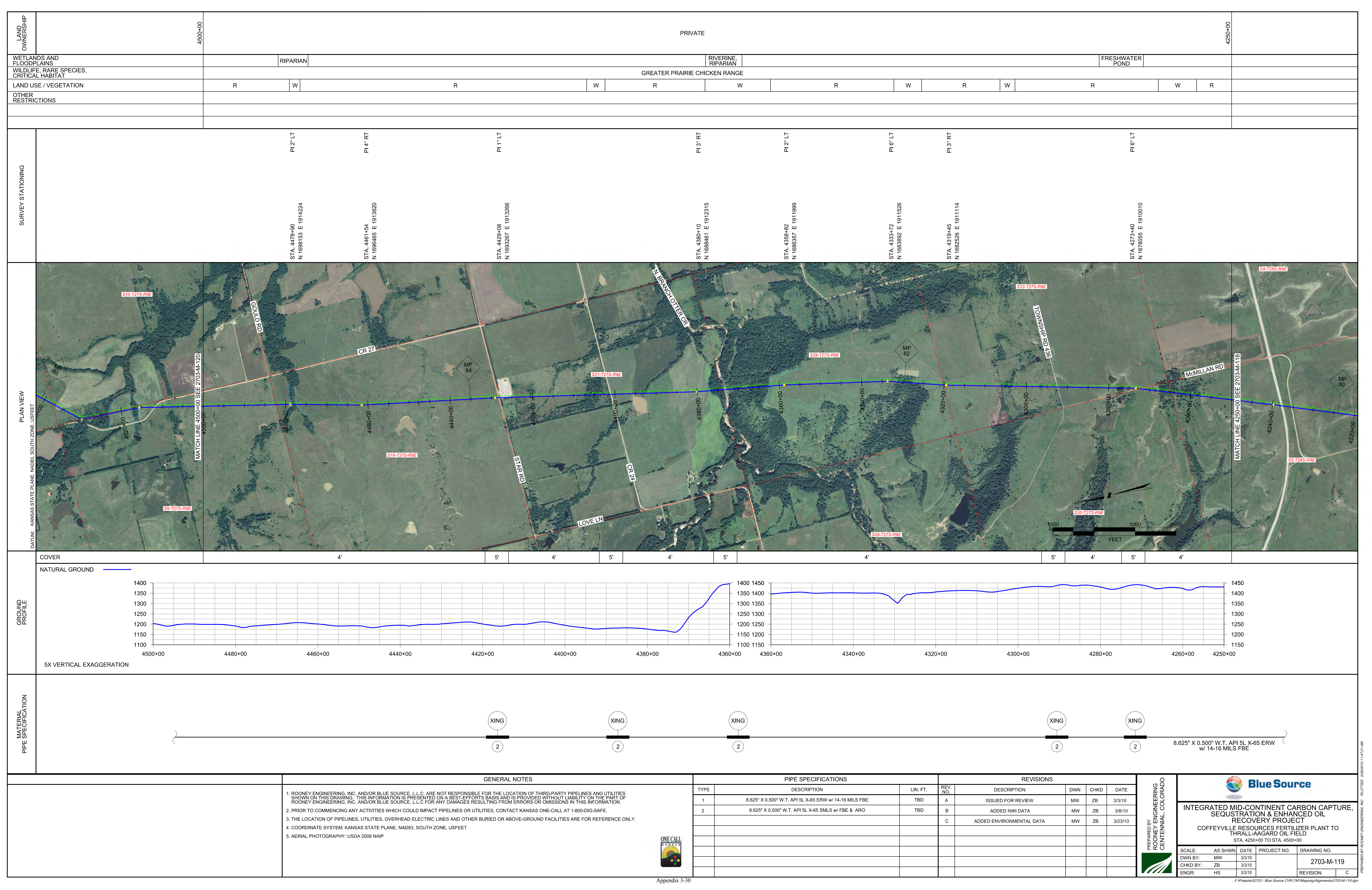




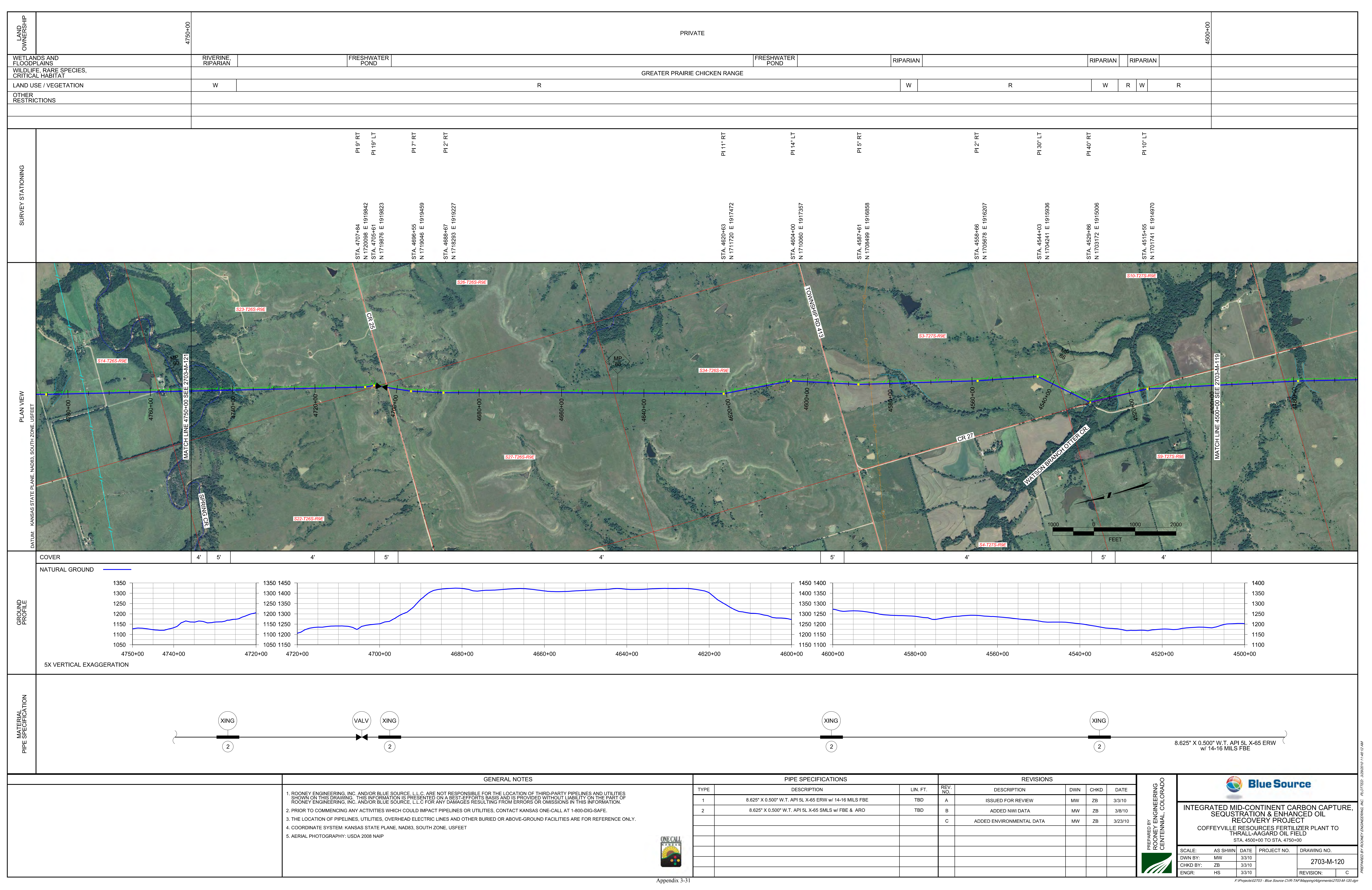




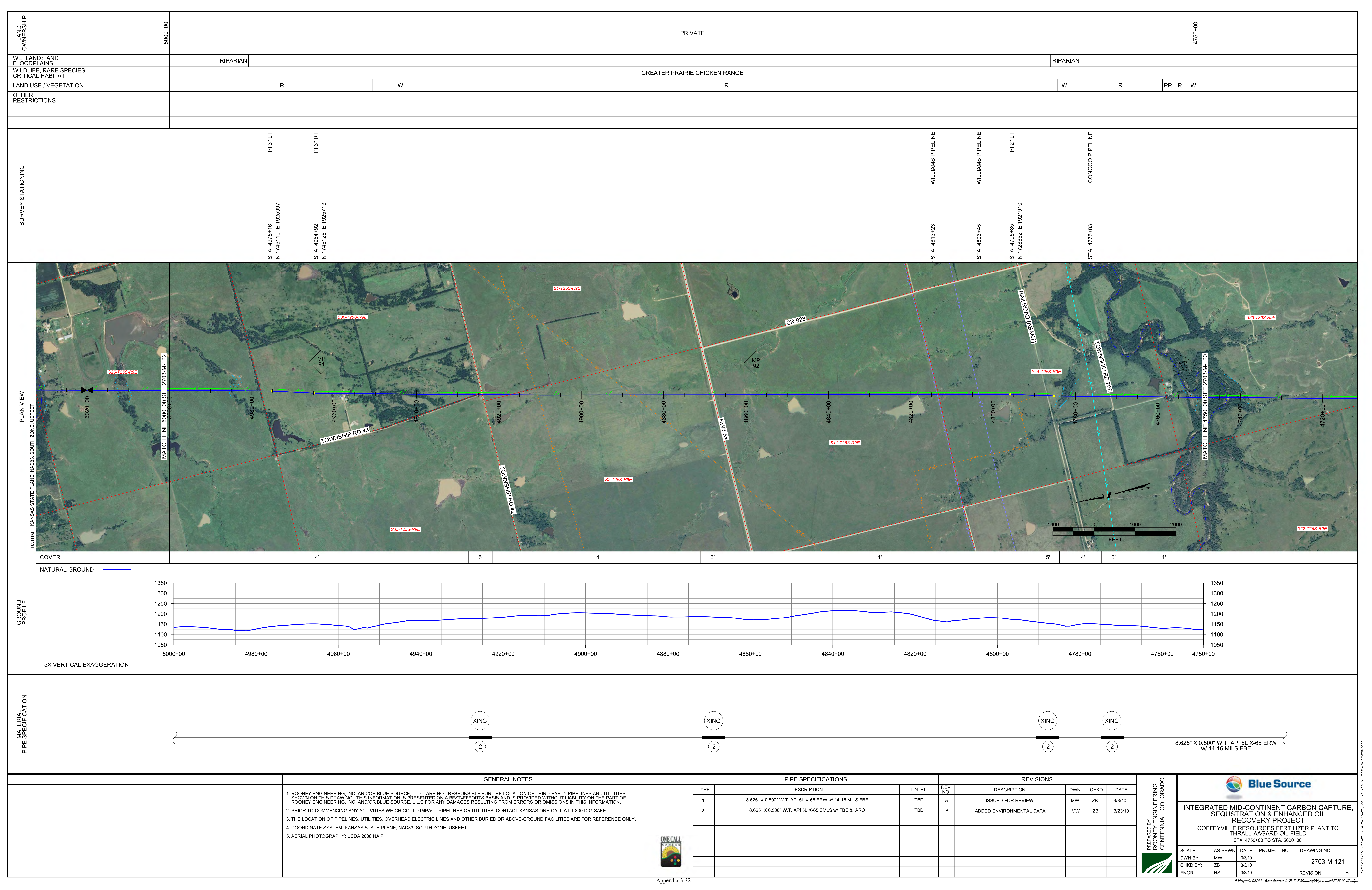




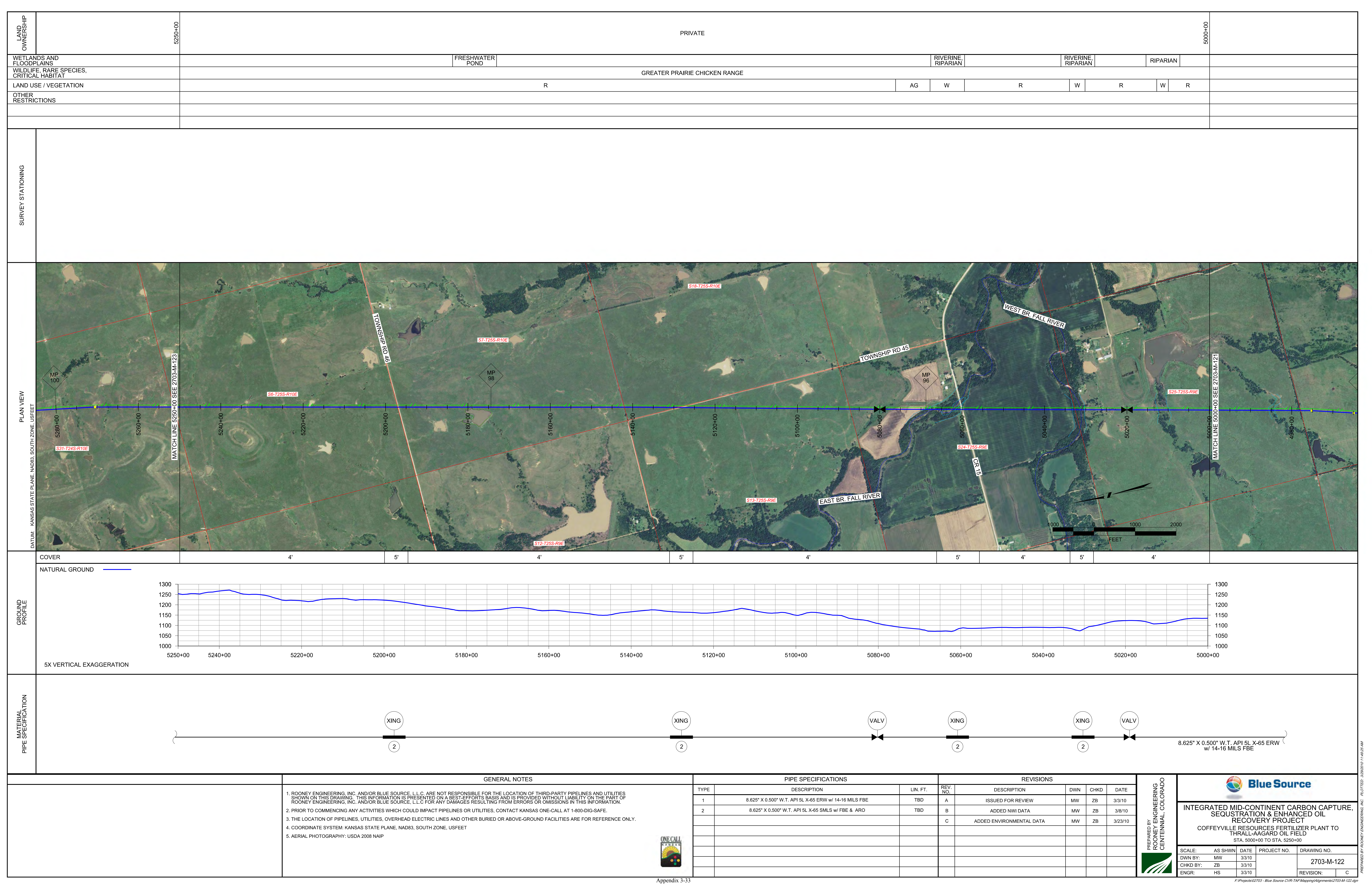




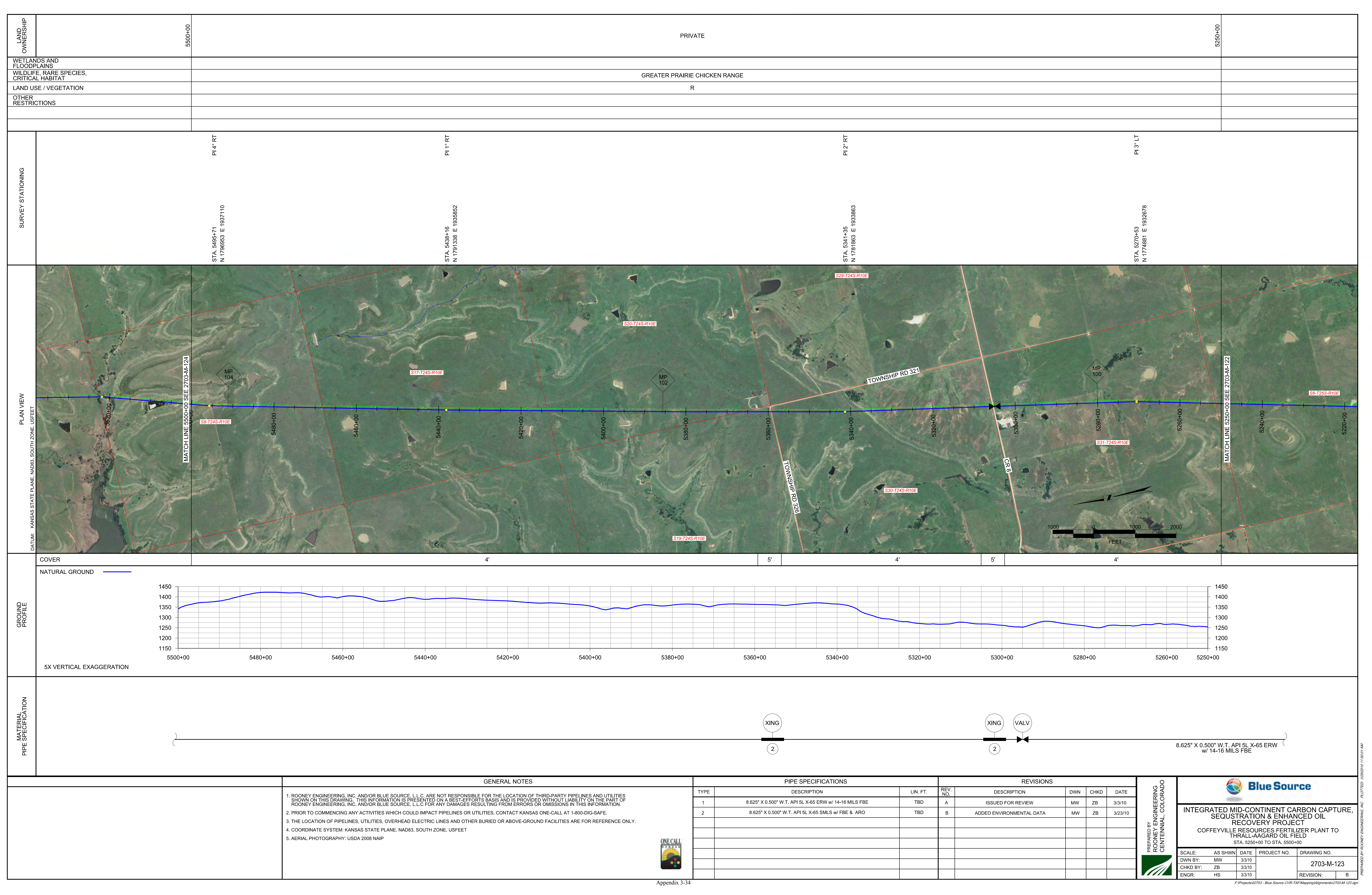




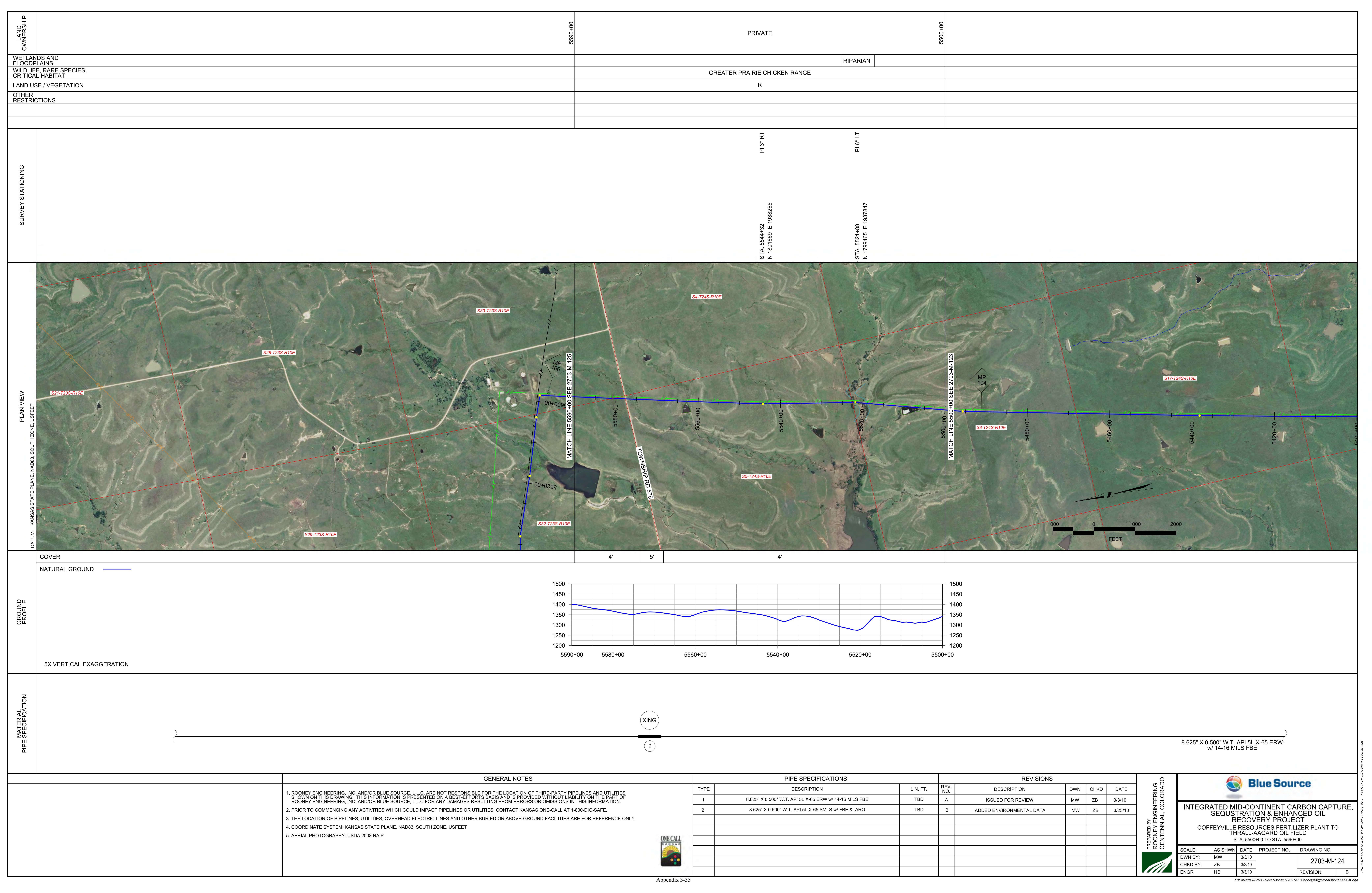




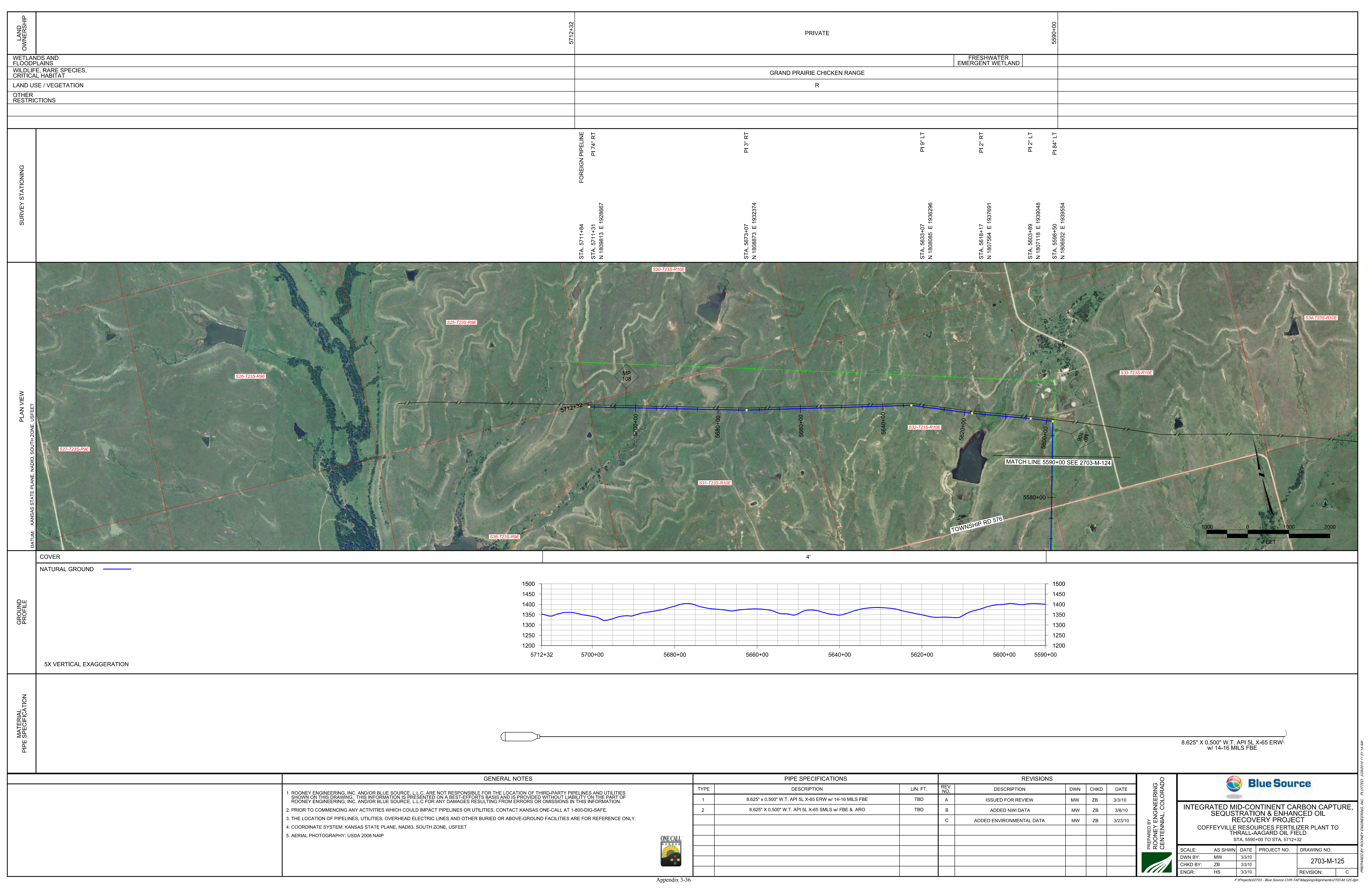


APPENDIX 3-B

COFFEYVILLE RESOURCE FERTILIZER PLANT

$\mathrm{CO}_{2}$ COMPOSITIONAL ANALYSIS

THRALL-AAGARD FIELD 


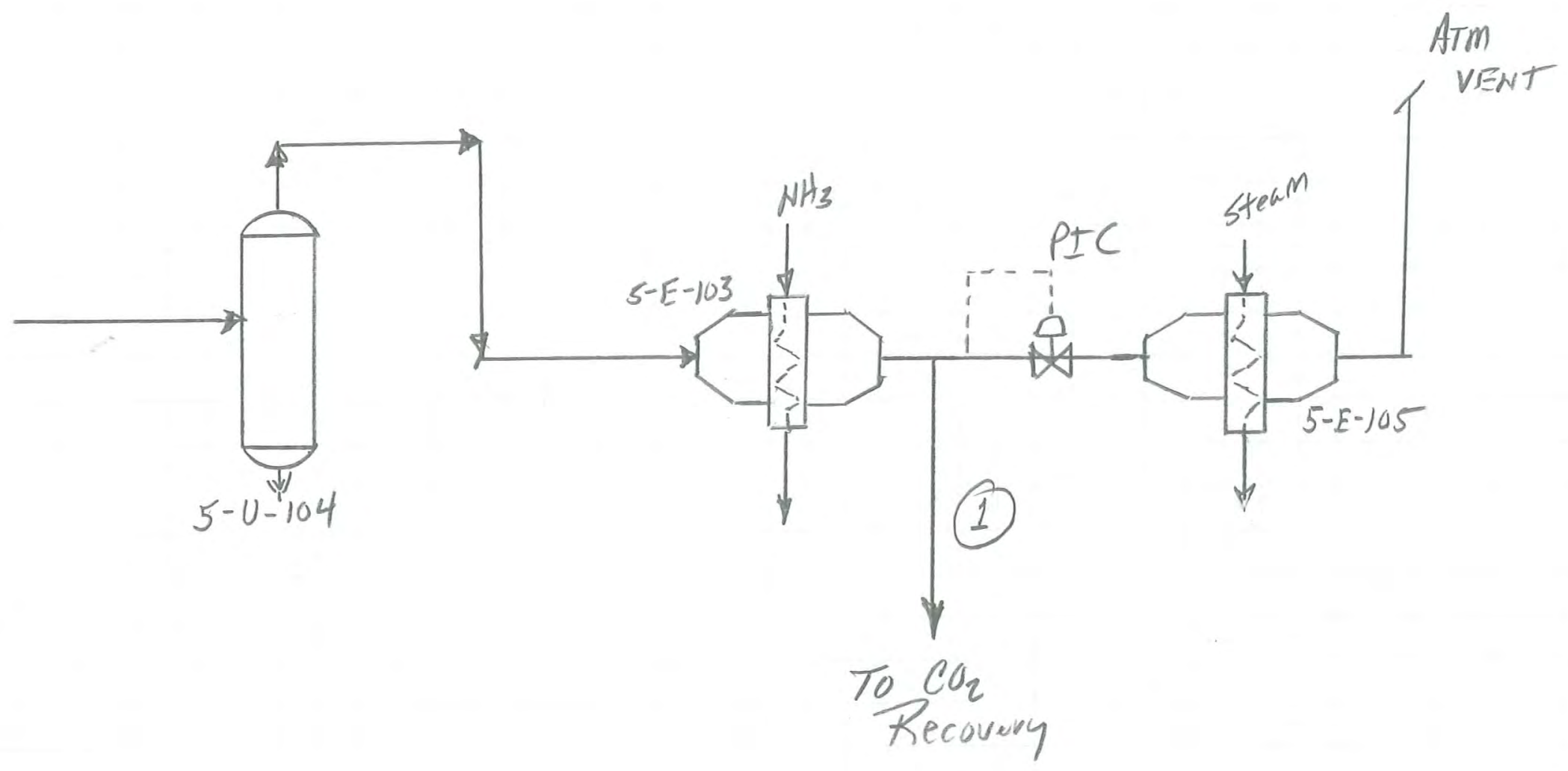

(1) Proposed take off location for $C A P C C_{2}, \angle L C$.

Changes:

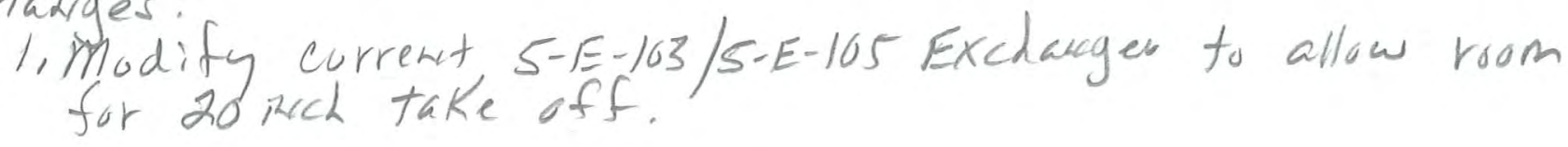

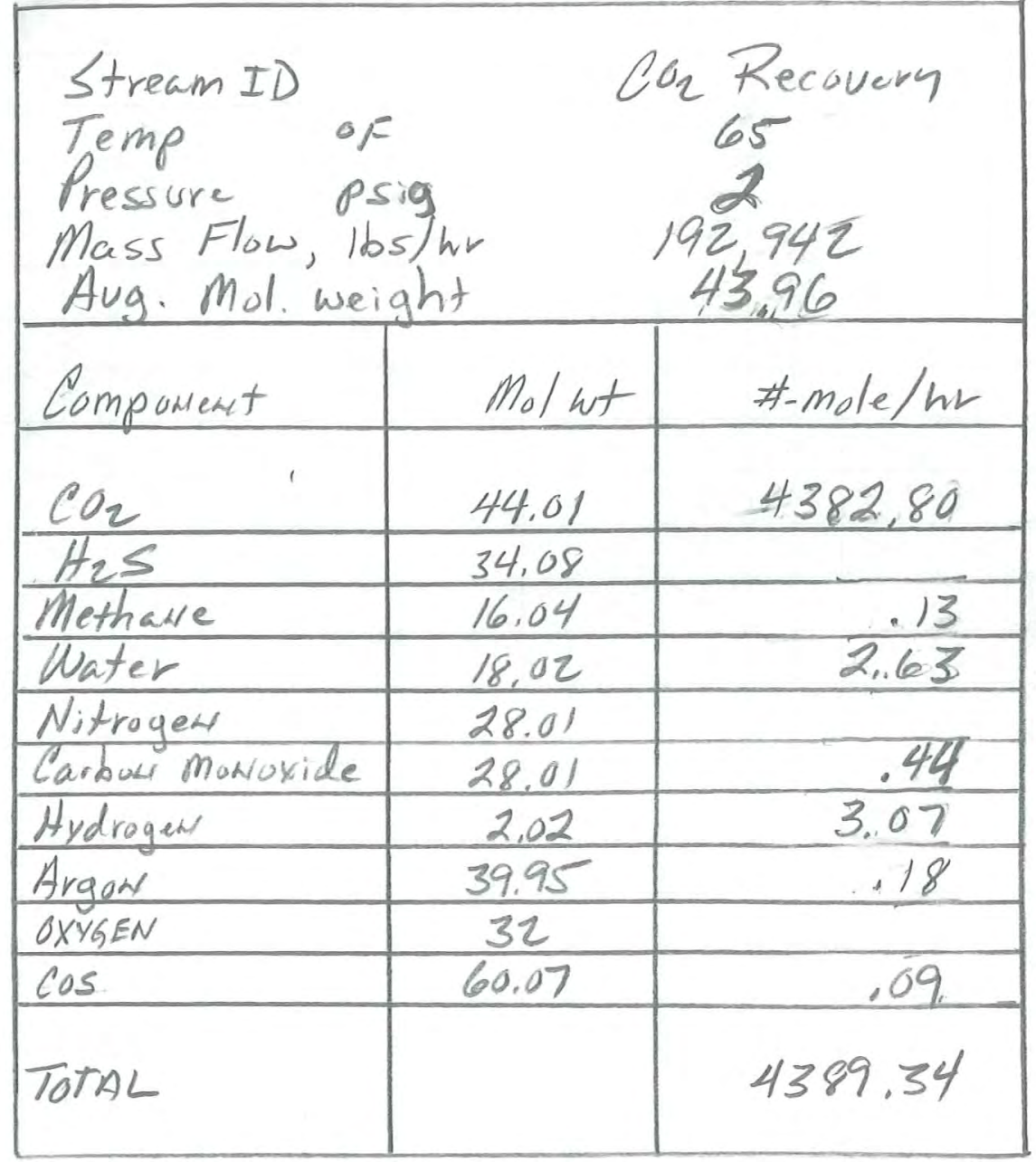
2. Install PIC value to hold back pressure of 2 p sig
upstream of $5-E-105$, 


\section{APPENDIX 3-C}

\section{PIPELINE HYDRAULIC CHARTS}

\section{THRALL-AAGARD FIELD}




\section{CVR-TAF Pipeline}

8" x 0.500" WT Grade X-65 Pipeline at 40 MMSCFD - No Booster Stations

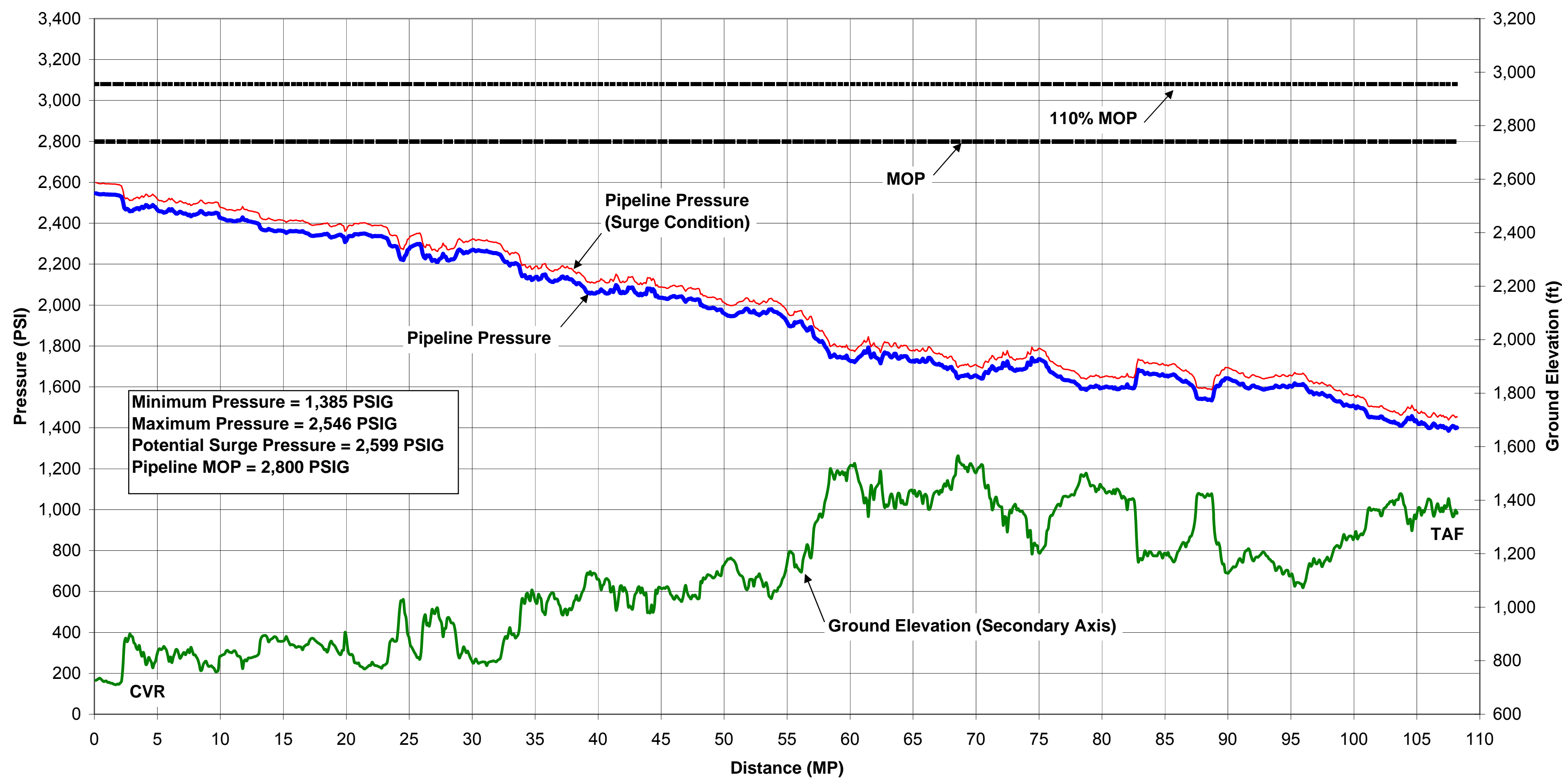




\section{CVR-TAF Pipeline}

10" x 0.438" WT Grade X-65 Pipeline at 40 MMSCFD - No Booster Stations

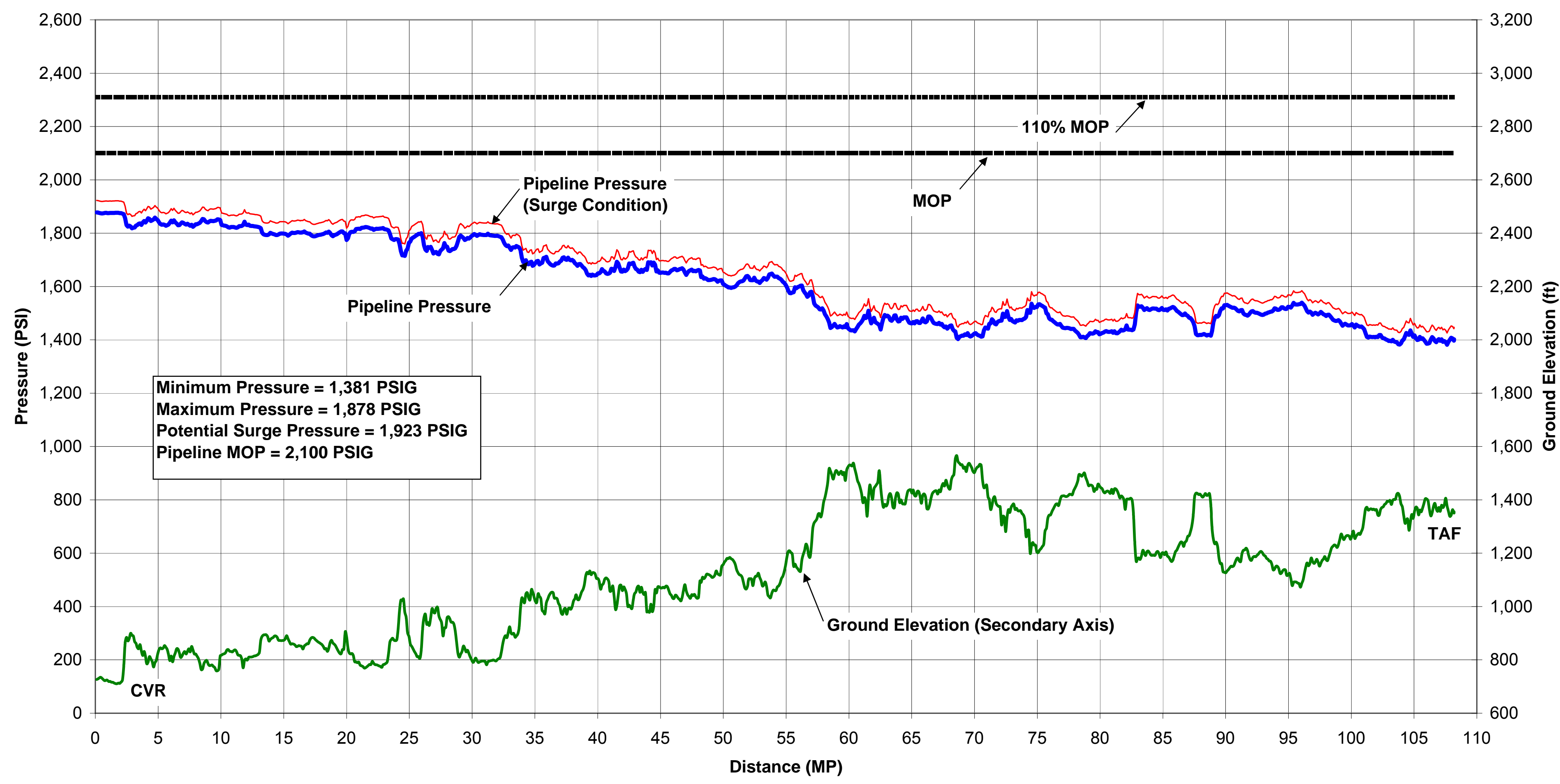




\section{CVR-TAF Pipeline}

12" x 0.375" WT Grade X-65 Pipeline at 40 MMSCFD - No Booster Stations

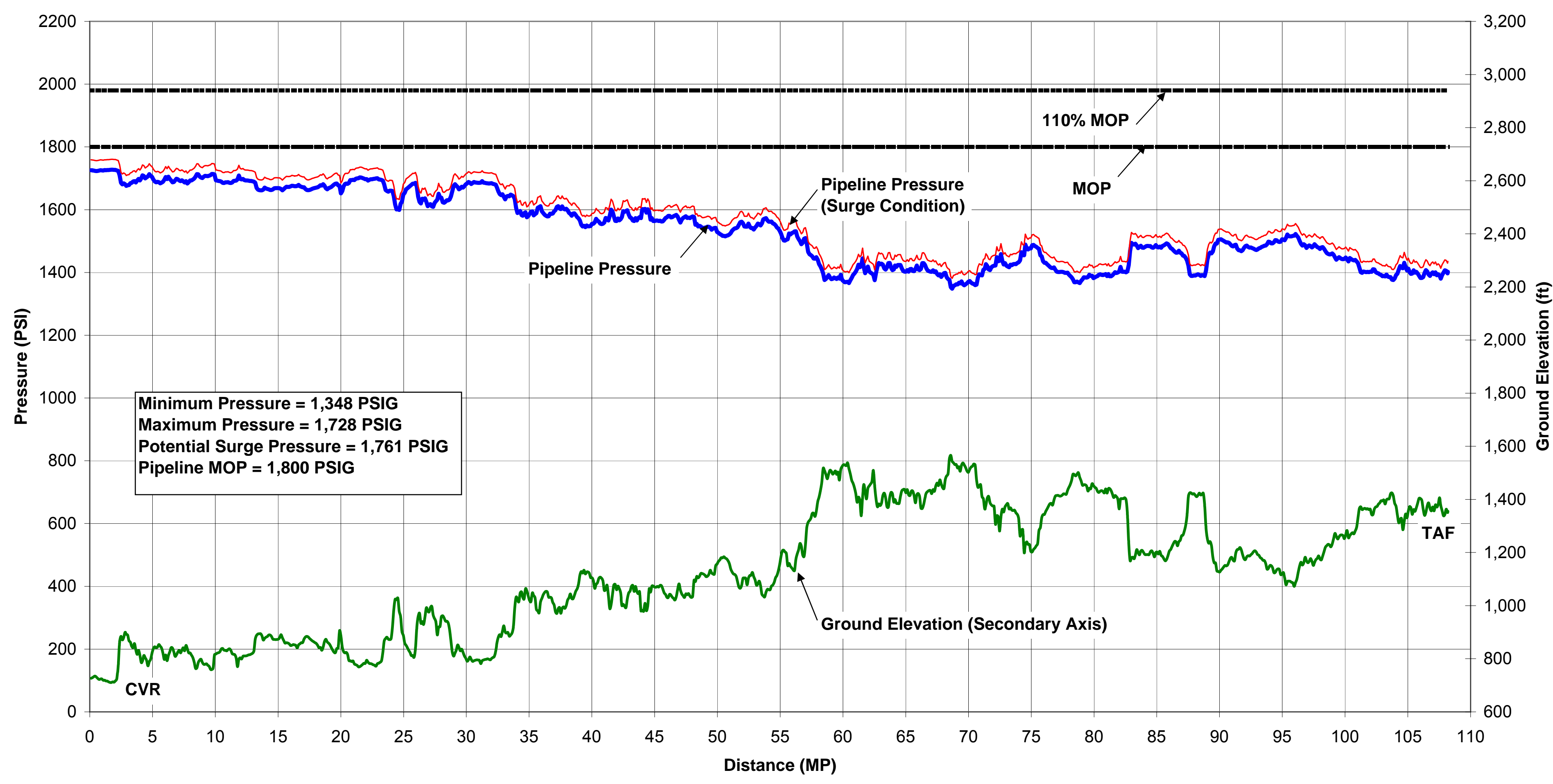




\section{APPENDIX 3-D}

\section{PIPELINE ESTIMATE}

THRALL-AAGARD FIELD 


\title{
Blue Source
}

\section{INTEGRATED MID-CONTINENT CARBON CAPTURE, SEQUESTRATION \& ENHANCED OIL RECOVERY PROJECT}

\author{
Coffeyville Resources Nitrogen Fertilizer Plant (CVR) to \\ Thrall-Aagard Oil Field (TAF)
}

\section{ESTIMATE BASIS MEMORANDUM}

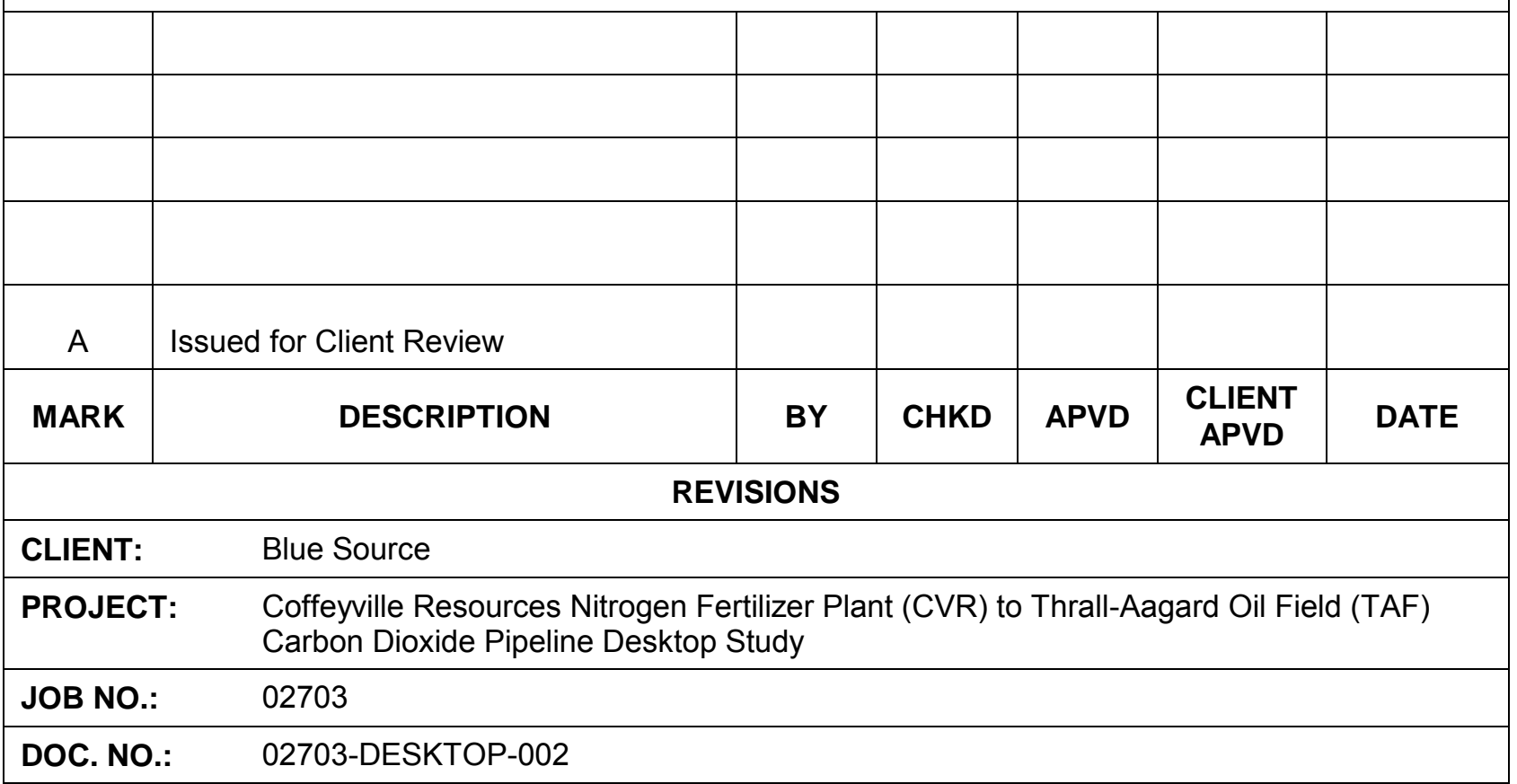




\begin{tabular}{|c|c|c|c|}
\hline Date: & $3 / 26 / 2010$ & DIPFINF SVSTFMS FSTIMATF RASIS & Doc. No.: 02703-DESKTOP-002 \\
\hline Rev: & A & PITELIIVE STSIEIVIS ESIIIVIA IIE DADIS & \begin{tabular}{r|l} 
Page: & 2 of 9 \\
\end{tabular} \\
\hline
\end{tabular}

TABLE OF CONTENTS

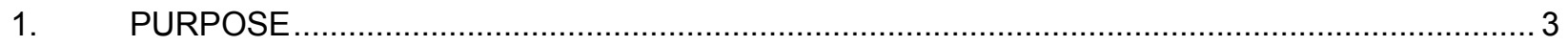

2. SCOPE

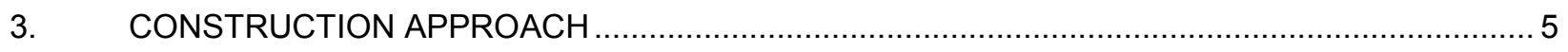

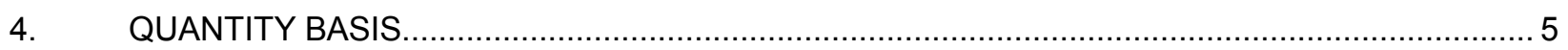

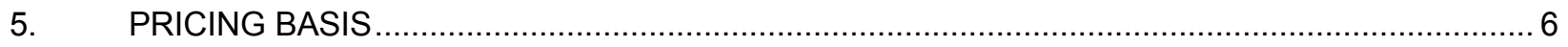

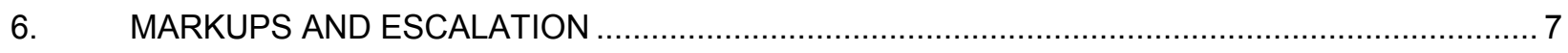

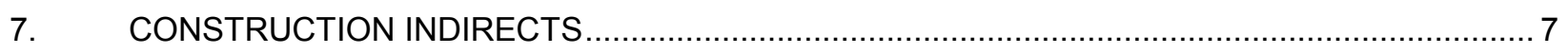

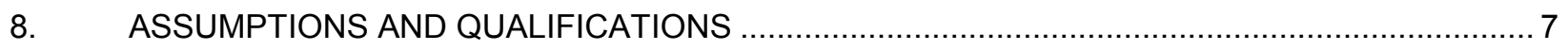

9. ATTACHED CONSTRUCTION CONTRACTOR BUDGETARY PROPOSAL .............................. $\underline{9}$ 


\begin{tabular}{|c|c|c|c|}
\hline Date: & $3 / 26 / 2010$ & \multirow{2}{*}{ PIPELINE SYSTEMS ESTIMATE BASIS } & Doc. No.: 02703-DESKTOP-002 \\
\hline Rev: & A & & \begin{tabular}{r|l|} 
Page: & 3 of 9 \\
\end{tabular} \\
\hline
\end{tabular}

\section{PURPOSE}

This estimate was prepared to provide budgetary cost information to design and construct the Coffeyville Resources Fertilizer Plant (CVR) to the Thrall-Aagard Oil Field (TAF) pipeline.

The CVR-TAF pipeline is a 108.2 mile, 8.625 inch in diameter steel pipeline to transport $\mathrm{CO} 2$ from the Coffeyville Resources Fertilizer Plant (CVR) to the Thrall-Aagard Oil Field (TAF). A 15,000 BHP compression facility is proposed at the pipeline origination. A fiber optic communication system is proposed to facilitate the Supervisory Control and Data Acquisition (SCADA) system.

This estimate is comparable to an Association for the Advancement of Cost Engineering (AACE) Class 2 Estimate, with an expected accuracy range of $+30 \% /-15 \%$. A Class 2 estimate corresponds with $30 \%$ to $70 \%$ project definition, using primarily deterministic methodology. (See AACE Recommended Practice No. 17R-97 "Cost Estimate Classification Systems.")

The capital expenditure cost estimate addresses the pipeline systems, compression facility, and communication systems and includes material, engineering, procurement assistance, procurement inspection, right-of-way acquisition, right-of-way damages, cathodic protection, construction permitting, construction costs, construction management, survey, x-ray, construction inspection, commissioning, and start-up portions of the project.

\section{SCOPE}

The purpose of the CVR-TAF Pipeline is to transport compressed high-purity carbon dioxide via a 4" steel intra-state pipeline from the Coffeyville Resources Fertilizer Plant to the Thrall-Aagard Oil Field for both sequestration and enhanced oil recovery purposes.

The pipeline will be designed, constructed and operated in accordance to Title 49, Part 195, "Transportation of Hazardous Liquids by Pipeline," the Department Of Transportation rules and regulations.

The pipeline will be composed of approximately 108.2 miles of 8.625" O.D., 0.500 " wall thickness, API5L, PSL2, Electric Resistance Welded (ERW) steel line pipe, coated with 14-16 mils of Fusion Bond Epoxy for corrosion protection. The pipeline will be designed to be operated at a Maximum Operating Pressure of 2,800 PSIG, with an ANSI 1500 flange rating.

All road, railroad and creek crossing pipes will be manufactured to Seamless line pipe specifications instead of ERW to further mitigate fracture propagation.

Carbon Dioxide must be compressed to approximately 2,548 PSIG at the Coffeyville Resources Fertilizer Plant in order to deliver it to the Thrall-Aagard Oil Field at 1,400 PSIG. These operating pressures were utilized to provide a reasonable margin between the operating pressures in the pipeline and the critical pressure of carbon dioxide, which is approximately $1,100 \mathrm{PSIA}$ at $50^{\circ} \mathrm{F}$. Operating at pressures above the critical pressure ensures that the carbon dioxide is transported in the dense phase and that no phase changes occur in the pipeline system. Transporting carbon dioxide in dense-phase is the most efficient means of transportation since it allows for smaller pipeline sizes at high flow rates.

Eighteen (18) Isolation Block Valves will be strategically located in the pipeline system to isolate the pipeline and blow the Carbon Dioxide down in case of an emergency. Valve connections for two future pipeline booster stations will be located at Mile Post 36 and Mile Post 72.

Crack arrestor will be installed at every half mile on the 8.625" O.D. Steel Pipeline to mitigate fracture propagation. Clock Spring type crack arrestors were used in the cost estimate. 


\begin{tabular}{|c|c|c|c|}
\hline Date: & $3 / 26 / 2010$ & PIPFI INE SVSTFMS ESTIMATF RASIS & Doc. No.: 02703-DESKTOP-002 \\
\hline Rev: & A & PITELIIVE SYSIEIVIS ES IIVIAAIE BASIS & \begin{tabular}{c|c|} 
Page: & 4 of 9 \\
\end{tabular} \\
\hline
\end{tabular}

The pipeline will be designed and constructed to accommodate intelligent pigs. Pig launcher and receiver will be installed into the system

The Engineering, procurement assistance, procurement inspection, right-of-way acquisition, right-of-way damages, cathodic protection, construction permitting, construction costs, construction management, survey, x-ray, construction inspection, commissioning, and start-up portions of the project involve the following work which was included in the estimate (see estimated quantities in the Capital Cost Estimate spreadsheet):

- Detailed Engineering for the project to include project calculations, P\&ID Drawings, PFD Drawings, Piping Drawings, Alignment Sheet Drawings, Material Sheet Drawings, Road and Creek Crossing Detail Drawings, Ditch Detail Drawings, and project specifications.

- Procurement support for the project to include providing quotation packages, technical evaluation and recommendation, material inspection services, and material expediting.

- Construction Management, including progress tracking, contractor communication, construction inspection, survey, and x-ray.

- Surveyors to stake construction work areas and pipeline centerline. Surveyors shall gather required as-built information throughout the duration of construction.

- NDE (X-Ray) including material and labor to x-ray the entire circumference of $100 \%$ of all girth welds.

- Assemble Job Books and prepare As Built Drawings.

The construction of the above pipeline involves the following work which was included in the estimate (see estimated quantities in the Capital Cost Estimate spreadsheet):

a) Mobilize to job site - located near Coffeyville, Kansas.

b) Train all personnel in site safety and environmental requirements.

c) Notify all underground utility and service providers, and abide by all their requirements.

d) Company shall provide survey subcontractor. Surveyors will stake construction work areas and pipeline centerline. Surveyors shall gather the required as-built information throughout the duration of construction.

e) Company will provide 75' wide construction work area for the construction of the pipeline and 300' $x$ 300' work area on each side of each crossing.

f) Company will provide one lay down yard for the project, strategically located for construction.

g) Line pipe shall be delivered to the right-of-way by trucks - Contractor shall string pipe onto the right-of-way from the stringing trucks

h) Access, clear and grade right-of-way to enable the crews to access and work on the right-of-way.

i) Topsoil separation, storage and replacement of the ditch line and spoil in all construction areas.

j) Install 8" buried (with risers) isolation block valves and valves for future booster stations.

k) Perform field bending, align and weld pipe - Company will provide welding procedures.

I) Install Company provided Clock Spring, Crack Arrestors (CS-130-04) which are 12" wide, 12 wraps each. Two Clock Springs will be installed next to each other. Clock Spring Crack Arrestors will be installed every $1 / 2$ mile on the pipeline for a total of 30 locations (install two clock springs next to each other) 


\begin{tabular}{|l|l|l|l|}
\hline Date: & $3 / 26 / 2010$ & \multirow{2}{*}{ PIPELINE SYSTEMS ESTIMATE BASIS } & \multicolumn{2}{|c|}{ Doc. No.: 02703-DESKTOP-002 } \\
\cline { 1 - 2 } \cline { 4 - 4 } & & Page: & 5 of 9 \\
\hline
\end{tabular}

m) Company shall provide NDE (X-Ray) subcontractor - who will provide material and labor to x-ray the entire circumference of $100 \%$ of all girth welds.

n) Apply Two (2) part Epoxy or Shrink Sleeves to the girth welds.

o) Holiday test (Jeep) the FBE steel coated pipe. Contractor to supply patch sticks for the repair of the FBE.

p) Ditch along the Right-of-way

q) Contractor to provide equipment to pad and shade all pipe - Pad and shade with 6" (bottom of pipe) and 6" (above the pipe) of $3 / 4$ " minus material.

r) Install fiber optic armored cable, hand-holes and pull boxes.

s) Total pipe cover shall be 48" minimum. Cover at road crossings shall be 60 " minimum.

t) Install pipeline Company supplied markers.

u) Install Company supplied cathodic protection test stations. Contractor to provide all wires and cad welds necessary for the installation of the test stations.

v) Prepare hydrostatic test plan for the pipelines and submit to engineer for approval, run air swab, cleaning and gauging pigs (only soft pigs will be run in the HDPE lined pipelines), fill and dispose of test water, provide and fill the pipelines with clean water, successfully hydrostatically test the pipelines for a minimum of 8 hours and dispose of water. Contractor to provide all required pigs.

w) Company will acquire permits for acquiring and disposing hydrostatic test water. Source and disposal site for the Hydro water will be within 50 miles of the job site.

x) The 8" steel pipelines will be tested to $125 \%$ of MOP - minimum test pressure shall be 3500 PSIG

y) Continuous clean up of right-of-way to the satisfaction of Company and landowner, make all necessary permanent repairs to gates and fences.

z) Required re-seeding and re-vegetation will be by Company.

aa) Demobilize from job site.

\section{CONSTRUCTION APPROACH}

It was assumed that the Right Of Way areas would be accessible to the contractor's equipment at all times during construction, and that the contractor would not have to compete for space to place spoils, pipeline materials or working crews.

\section{QUANTITY BASIS}

Pipe quantities were measured from preliminary routing from aerial photography, as shown on the preliminary Alignment Sheet Drawings.

Large diameter valve quantities were estimated based on the quantities shown on the preliminary Alignment Sheet Drawings.

Pig trap assembly quantities were estimated based on the quantities shown on the preliminary Alignment Sheet Drawings.

Quantity for all other material and construction quantities were estimated from Rooney Engineering's experience with similar pipeline systems, and from construction contractor input. 


\begin{tabular}{|l|l|l|l|l|}
\hline Date: & $3 / 26 / 2010$ & \multirow{2}{*}{ PIPELINE SYSTEMS ESTIMATE BASIS } & \multicolumn{2}{|c|}{ Doc. No.: 02703-DESKTOP-002 } \\
\cline { 1 - 1 } \cline { 4 - 5 } & & & \multicolumn{2}{|c|}{ Page: 6 of 9} \\
\hline
\end{tabular}

A centrifugal compressor / pump package was selected from GE at $100 \%$ of the design flowrate. No redundancy was selected based on the high reliability and low expected maintenance of centrifugal compressors.

\section{PRICING BASIS}

The pricing for material in this estimate was derived from budgetary quotation pricing. Construction pricing is based on budgetary quotes provided by a contractor with experience in construction similar to that required for this project. The following items were priced based on budgetary quotations from vendors or were estimated based on a scale factor applied to quotations to adjust for the current scope of work. If multiple quotations were received, pricing was normalized and averaged.

\section{Pipeline}

- Steel Line Pipe and Fusion Bond Epoxy (FBE) Coating - Current budgetary quotations were received from Edgen Murray and McJunkin Red Man.

- Abrasive Resistant Outer (ARO) Line Pipe Coatings - Pricing from other recent projects was utilized.

- Valves and Actuators - Current budgetary quotations were received from Cameron.

- Pipeline Fittings and Flanges - Current budgetary quotations were received from Edgen Murray and McJunkin Red Man.

- Fabricated Assemblies (Pig Traps) - Current budgetary quotations were received from Sagebrush and PECO.

- Miscellaneous Materials (e.g. Clock Springs, Cathodic Test Stations, Shrink Sleeves, Pipeline Markers) - Current budgetary quotations were received from Hoff Company.

- Pipeline Construction and Site Construction (e.g. Road Bores, Cathodic Test Station Installation) and associated materials (e.g. Hay Bales, Silt Fence). - A site specific construction budgetary estimate was received from Jomax, who has completed many projects in and around Kansas.

\section{Compression Facility}

- Compressor Packages - Current budgetary quotations were received from Exterran, UE Compression, and GE Oil and Gas.

- Pump Packages - Current budgetary quotations were received from Sulzer and GE Oil and Gas.

- Dehydration Package - Current budgetary quotations were received from QB Johnson and Exterran.

- Scrubbers - Pricing from other recent projects was utilized.

- Orifice Meter - Pricing from other recent projects was utilized.

- Compressor Building - Recent cost per square foot pricing from Tri-State Insulation was utilized.

- Flow Control Valves - Pricing from other recent projects was utilized.

- Switchgear, Motor Control Center, Transformers, Control Switches and Lighting, Power and Control Building - Recent pricing from DM Consulting was utilized.

- Compressor Station Construction - Budgetary estimates for facility construction was received from Holloman Construction and LE Bell Construction.

\section{SCADA and Fiber Optic}

- SCADA Material, Licenses, and Vendor Services - Pricing from other recent projects was utilized. 


\begin{tabular}{|c|c|c|c|}
\hline Date: & $3 / 26 / 2010$ & \multirow{2}{*}{ PIPELINE SYSTEMS ESTIMATE BASIS } & \multirow{2}{*}{ Doc. No.: 02703-DESKTOP-002 } \\
\hline Rev: & $A$ & & \\
\hline
\end{tabular}

- Fiber Optic Installation - Pricing from other recent projects was utilized.

- Fiber Optic Material - Pricing from other recent projects was utilized.

6. MARKUPS and ESCALATION

Taxes $-5.98 \%$ sales tax included on all materials. No tax included on labor.

Material Escalation - No material escalation was included, vendors quoted for late summer 2010 delivery. Construction Escalation - No construction escalation is included, assume late summer 2010 construction. G\&A - Included in cost estimate.

Construction Bond $-3 \%$ of total construction estimate

Contingency - $15 \%$ contingency included in each line item

\section{CONSTRUCTION INDIRECTS}

All construction indirect costs are included in construction labor unit prices.

\section{8. $\quad$ ASSUMPTIONS AND QUALIFICATIONS}

\section{Pipeline}

- Estimate includes construction permitting only. Costs for National Environmental Policy Act (NEPA) Review, Studies to Support the NEPA Process, COE Nationwide \#12 Permit, Clean Water Act, Section 401 Consultations, U.S. Fish and Wildlife Service Consultations, Endangered Species Act are not included in this budget.

- Estimate includes (3) month license of PipePhase Hydraulic Modeling Software.

- Estimate assumes $75^{\prime}$ wide construction work area and 300' x 300' temporary work areas at all crossings.

- Estimate assumes construction working six (6) days per week for ten (10) hours per day.

- Assumes source and disposal site for the Hydro water will be within 50 miles of the job site.

- $2.5 \%$ wastage assumed for pipe and piping components.

- Construction is in loose, dry soil.

- $45 \%$ Rock Ditch was included based on contractor input for the project area.

- Pricing reflects 3D fittings for a piggable system.

- Concrete foundation construction included in estimate.

- Silt fencing was included for the perimeter of all anticipated temporary work areas only.

- Contractor will be non-union.

- Mitigation measures and landowner requirements are unknown at this time.

- Estimate includes MFL /Caliper Tool - Smart Pig

- Estimate includes Cathodic Protection (Impressed Current).

- Estimate includes costs for Right of Way revegetation.

- Unforeseen conditions are not included in the estimate. 


\begin{tabular}{|l|l|l|l|}
\hline Date: & $3 / 26 / 2010$ & \multirow{2}{*}{ PIPELINE SYSTEMS ESTIMATE BASIS } & \multicolumn{2}{|c|}{ Doc. No.: 02703-DESKTOP-002 } \\
\cline { 1 - 2 } \cline { 4 - 4 } & & Page: & 8 of 9 \\
\hline
\end{tabular}

- Capital Cost Estimate includes the units and quantities shown in the estimate.

\section{Compression Facility}

- Assume compressor station site is grass roots, relatively level field with minimal grading, grubbing and clearing required. No trees or existing infrastructure required to be removed.

- Assumes one centrifugal compressor train, consisting of a motor, gear box, a single stage Low Pressure Centrifugal Compressor (MCL753), a two stage Mid Pressure Centrifugal Compressor (2BCL456), a two stage High Pressure Centrifugal Compressor (2BCL454), and a single stage Centrifugal Pump. A separate Inter-cooler and scrubber skid package was not included in the base package, and has been added.

- Estimate includes $8 \%$ of the capital expenditure of the compressors/pumps for initial spares, as recommended by GE.

- Estimate includes one (1) compressor building for the compressors.

- Estimate includes one (1) 3.5 MMBTU/Hr TEG Dehydration Skid w/ 60" O.D. Contactor Tower.

- Estimate includes scrubber and orifice metering for dehydration re-boiler fuel gas

Fiber Optic and SCADA

- SCADA electrical construction contractor labor not included since wiring up the PLCs would be done by site contractor along with instruments.

- The PLC at each compressor and main line valve site will be a GE 90-30 or company approved equal and will be housed inside a small building to enable support personnel to program and maintain them in inclement weather.

- The SCADA software will have a primary system installed at the primary control center on one end of the pipeline and there will be a backup SCADA host at the facility at the other end of the pipeline. Costs for SCADA vendor services were also included. SCADA vendor services include project management, design specification documents, SCADA communications programming, SCADA screen programming, factory tests, installation onsite, onsite tuning of the software, commissioning tests, operations and the maintenance manual, training support for operators and technicians.

- The Leak Detection System will communicate with each station to analyze the pipeline for leaks and report to the SCADA software for operator notification. Leak Detection vendor services were also included. Leak Detection vendor services include project management, design specification documents, communications programming, graphical user interface screen programming, factory tests, installation onsite, tuning of the software, commissioning tests, operations and the maintenance manual, training support for operators and technicians. 
Coffeyville Resources Nitrogen Fertilizer Plant to Thrall-Aagard Oil Field

\begin{tabular}{|l|l|l|}
\hline Date: & $3 / 26 / 2010$ & \multirow{2}{*}{ PIPELINE SYSTEMS ESTIMATE BASIS } \\
\cline { 1 - 2 } Rev: & A & \\
\cline { 1 - 2 }
\end{tabular}

Rev:
$3 / 26 / 2010$

PIPELINE SYSTEMS ESTIMATE BASIS
Doc. No.: 02703-DESKTOP-002

Page: 9 of 9

\section{ATTACHED CONSTRUCTION CONTRACTOR BUDGETARY PROPOSAL}

See attached contractor budgetary proposal that was utilized in preparing the capital cost estimate. 
APPENDIX 3-E

ESTIMATE BASIS MEMORANDUM

THRALL-AAGARD FIELD

Appendix 3-53 


\section{CVR-TAF Desktop FEED Capital Cost Estimate}

Montgomery, Chautauqua, Elk, Cowley, and Greenwood Counties, Kansas

Date: March 26, 2010

\section{CAPITAL COST ESTIMATE SUMMARY}

\begin{tabular}{|l|lr|}
\hline \multicolumn{1}{|c|}{ Cost Description } & \multicolumn{2}{c|}{ Total Cost } \\
\hline Pipeline & \multicolumn{2}{c|}{} \\
\hline Materials & $\$$ & $37,992,000$ \\
\hline Construction & $\$$ & $26,015,000$ \\
\hline ROW Acquisition, Damages and Revegetation & $\$$ & $7,120,000$ \\
\hline Cathodic Protection & $\$$ & 92,000 \\
\hline Construction Permitting & $\$$ & 32,000 \\
\hline Property Plats & $\$$ & $1,083,000$ \\
\hline Engineering Survey and Procurement Inspection & $\$$ & 634,000 \\
\hline Engineering \& Procurement Assistance & $\$$ & $1,453,000$ \\
\hline Construction Administration & $\$$ & $1,372,000$ \\
\hline Construction Inspection, Surveying and X-Ray & $\$$ & $6,841,000$ \\
\hline \hline & $\mathbf{8 2 , 6 3 4 , 0 0 0}$ \\
\hline Fiber Optic and SCADA & $\$$ & $2,745,000$ \\
\hline SCADA and Fiber Optic Materials & $\$$ & 249,000 \\
\hline SCADA Engineering Hours/Expenses & $\$$ & 466,000 \\
\hline SCADA Vendor Labor & $\$$ & $1,314,000$ \\
\hline Fiber Optic Construction Labor & $\$, 774,000$ \\
\hline \hline Total Fiber Optic and SCADA Cost & $\$$ & $20,472,000$ \\
\hline Compressor I Pump Station & & $3,891,000$ \\
\hline Equipment and Materials & $\$$ & - \\
\hline Construction & $\$$ & 685,000 \\
\hline Land and ROW Total Compressor I Pump Cost & $\$$ & $1,194,000$ \\
\hline Environmental and Permitting & $\$$ & $\mathbf{2 6 , 5 4 8 , 0 0 0}$ \\
\hline Engineering Design & $\$$ & \\
\hline Construction Administration & $\$$ & \\
\hline \hline & & \\
\hline
\end{tabular}




\section{INTEGRATED MID-CONTINENT CARBON CAPTURE, SEQUESTRATION \& ENHANCED OIL RECOVERY PROJECT Coffeyville Resources Fertilizer Plant (CVR) to the Thrall-Aagard Oil Field (TAF) \\ Capital Cost Estimate - 108.2 Miles of 8" Pipeline \\ Blue Source LLC}

Date: March 26, 2010

\begin{tabular}{|c|c|c|c|c|c|c|c|}
\hline \multirow{2}{*}{ LINE PIPE, COATING, \& FREIGHT } & Qty. & Unit & & Unit Cost & & Total Cost & \% of Total \\
\hline & & & & & & & \\
\hline Steel & & & & & & & \\
\hline $8.625^{\prime \prime}, 0.500 "$ w.t., API 5L, X-65, PSL2, ERW Line Pipe, DRL, coated 14 -16 mils of FBE & 574,967 & $\mathrm{ft.}$. & $\$$ & 50.23 & $\$$ & $28,880,600$ & \\
\hline $8.625 ", 0.500 "$ w.t., API $5 \mathrm{~L}, \mathrm{X}-65$, PSL2, SMLS Line Pipe, DRL, coated $14-16$ mils of FBE & 8,143 & ft. & $\$$ & 47.48 & $\$$ & 386,600 & \\
\hline 8.625" ARO Coating - Road Crossings & 8,143 & $\mathrm{ft.}$. & $\$$ & 11.30 & $\$$ & 92,000 & \\
\hline FOB (Included in Unit Prices Above) & 0 & ea & $\$$ & - & $\$$ & - & \\
\hline Line Pipe Contingency & $15 \%$ & & & & $\$$ & 4.403880 & \\
\hline & & & & & & & \\
\hline Subtotal - Pipe \& Coating & & & & & $\$$ & $33,763,000$ & $40.86 \%$ \\
\hline
\end{tabular}

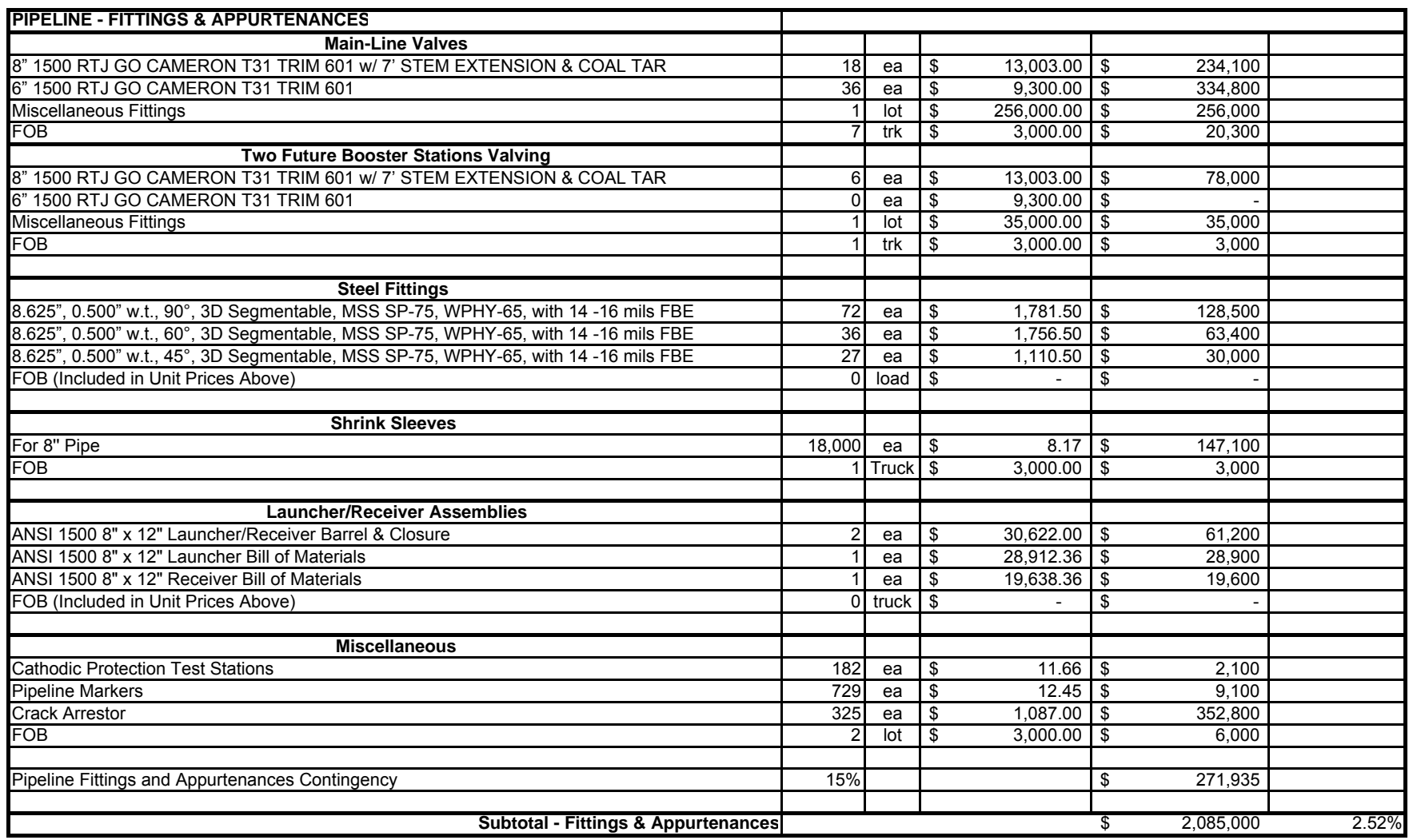




\section{INTEGRATED MID-CONTINENT CARBON CAPTURE, SEQUESTRATION \& ENHANCED OIL RECOVERY PROJECT \\ Coffeyville Resources Fertilizer Plant (CVR) to the Thrall-Aagard Oil Field (TAF) \\ Capital Cost Estimate - 108.2 Miles of 8" Pipeline \\ Blue Source LLC}

Date: March 26, 2010

\begin{tabular}{|c|c|c|c|c|}
\hline Qty. & Unit & Unit Cost & Total Cost & $\%$ of Total \\
\hline
\end{tabular}

PIPELINE - CONSTRUCTION

\begin{tabular}{c} 
Pipeline Construction \\
\hline Mobilization / Demobilization to Construct 8" Carbon Dioxide Pipeline
\end{tabular}

nstallation of pipe per lineal foot (Rural)

Installation of pipe per lineal foot (Town)

8" Open Cut Crossing - No Casing

8" Bored Crossing - No Casing

8" HDD Crossing - No Casing

8" ANSI 1500 Pig Launchers/Receivers with supports

nstall 8" Buried Valve - with Risers

Install 8" Valving for Future Booster Stations

Install Cathodic Test Station

Install Silt Fence

Install Hay Bale

16" Foreign Pipeline Crossing

Install Foam Ditch Breaker (Ditch Plugs)

Fences - Remove 75' existing fences, install temporary for construction and replace

nstall Crack Arrestor

Rock Ditch (Assumed at $45 \%$ of Route)

ROW Clearing - Timber (Estimated from Aerial Photography)

Hot Bends Installed

8" MFL /Caliper Tool - Smart Pig

Pipeline Construction Contingency

Subtotal - Construction

\begin{tabular}{|c|c|c|c|c|c|c|}
\hline 1 & LS & $\$$ & $137,000.00$ & $\$$ & 137,000 & \\
\hline 552,816 & $\mathrm{ft}$ & $\$$ & 20.00 & $\$$ & $11,056,300$ & \\
\hline 18,480 & $\mathrm{ft}$ & $\$$ & 80.00 & $\$$ & $1,478,400$ & \\
\hline 3,200 & $\mathrm{ft}$ & $\$$ & 90.00 & $\$$ & 288,000 & \\
\hline 3,755 & $\mathrm{ft}$ & $\$$ & 90.00 & $\$$ & 338,000 & \\
\hline 800 & $\mathrm{ft}$ & $\$$ & 110.00 & $\$$ & 88,000 & \\
\hline 2 & LS & $\$$ & $28,000.00$ & $\$$ & 56,000 & \\
\hline 18 & ea & $\$$ & $18,000.00$ & $\$$ & 324,000 & \\
\hline 2 & ea & $\$$ & $18,000.00$ & $\$$ & 36,000 & \\
\hline 182 & ea & $\$$ & $2,000.00$ & $\$$ & 364,000 & \\
\hline 319,200 & $\mathrm{ft}$ & $\$$ & 7.50 & $\$$ & $2,394,000$ & \\
\hline 1,200 & ea & $\$$ & 20.00 & $\$$ & 24,000 & \\
\hline 108 & ea & $\$$ & $2,000.00$ & $\$$ & 216,000 & \\
\hline 200 & ea & $\$$ & $1,200.00$ & $\$$ & 240,000 & \\
\hline 433 & ea & $\$$ & $1,400.00$ & $\$$ & 606,200 & \\
\hline 325 & ea & $\$$ & 200.00 & $\$$ & 64,900 & \\
\hline 257,083 & $\mathrm{ft}$ & $\$$ & 12.00 & $\$$ & $3,085,000$ & \\
\hline 42,470 & $\mathrm{ft}$ & $\$$ & 20.00 & $\$$ & 849,400 & \\
\hline 135 & ea & $\$$ & 500.00 & $\$$ & 67,600 & \\
\hline 1 & LS & $\$$ & 25000000 & $\$$ & 250000 & \\
\hline & & & & & & \\
\hline $15 \%$ & & & & $\$$ & $3,294,420$ & \\
\hline
\end{tabular}

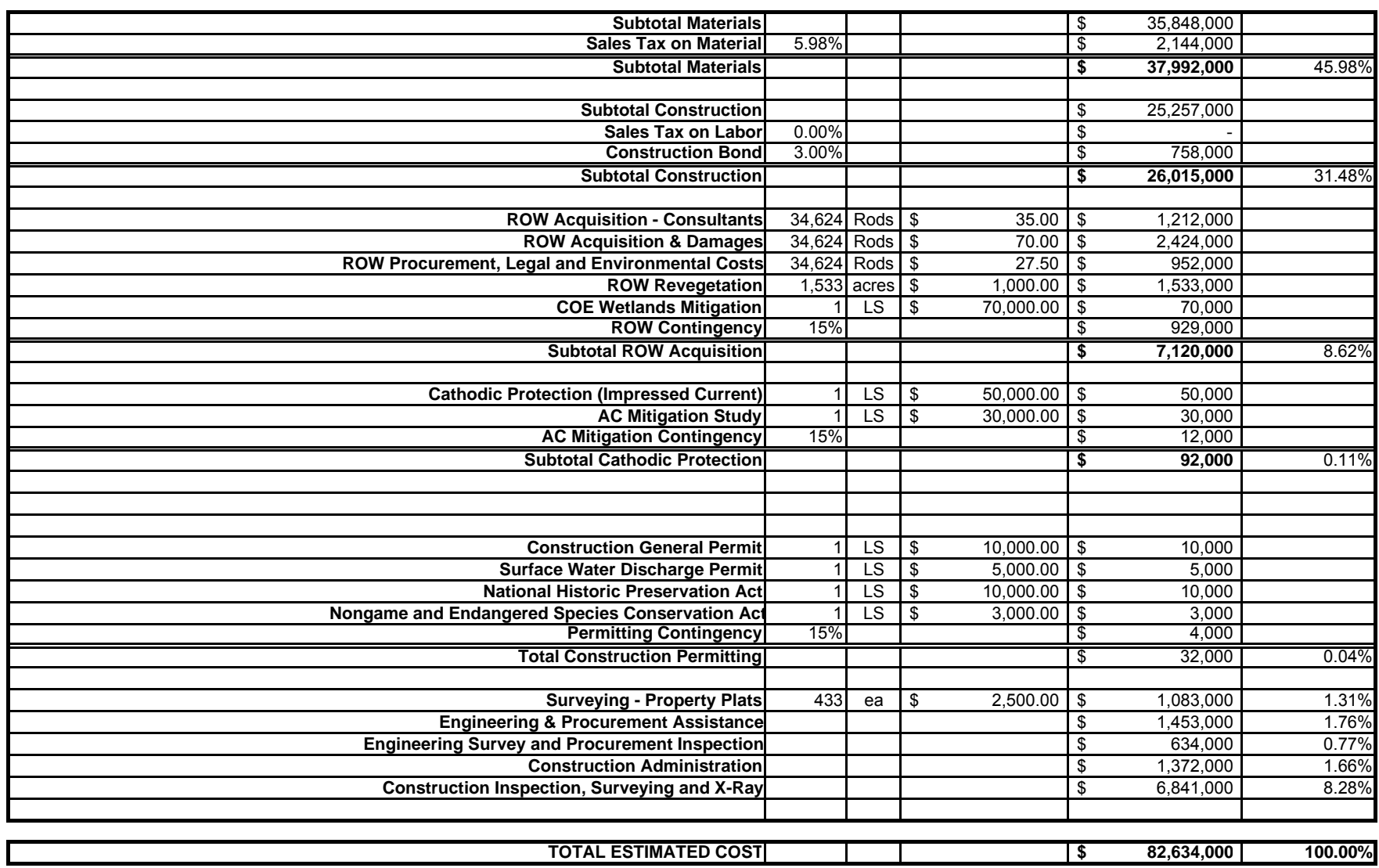

Appendix 3-56 
INTEGRATED MID-CONTINENT CARBON CAPTURE, SEQUESTRATION \&

ENHANCED OIL RECOVERY PROJECT

-Aagard Oil Field (TAF)

Detailed Engineering and Procurement Assistanace

Date: March 26, 2010

\begin{tabular}{|c|c|c|c|c|c|c|c|c|c|c|c|c|c|c|c|c|c|c|c|c|c|c|c|c|c|}
\hline INDIVIDUAL & TITLE & 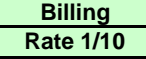 & $\begin{array}{l}\frac{S_{\text {Billing }}}{\text { Rate 8110 }} \\
\end{array}$ & $\frac{1}{1-\text { Jul-10 }}$ & $\frac{2}{8-\mathrm{Jul}-10}$ & $\frac{3}{15-J u l-10}$ & $\frac{4}{22-J u l-10}$ & $\frac{5}{29-J u l-10}$ & 5-Aug-10 & \begin{tabular}{|l}
7 \\
$12-$ Aug-10 \\
\end{tabular} & $\frac{8}{19-\text { Aug-10 }}$ & $\frac{-9}{26-A u g-10}$ & $\frac{10}{2-\text { Sep }-10}$ & $9-11-10$ & $\frac{12}{16-\operatorname{sep}-10}$ & \begin{tabular}{|l|}
$23-$ Sep-10 \\
\end{tabular} & $\begin{array}{l}14 \\
30-5 e p-10 \\
\end{array}$ & $\frac{15}{7-\text { oct-10 }}$ & $\frac{16}{14-O c t-10}$ & \begin{tabular}{|c|}
$17-0 c t-10$ \\
\end{tabular} & $\frac{18}{8-\text { oct-10 }}$ & \begin{tabular}{|l|} 
4-Nov-10 \\
\end{tabular} & $\frac{20}{1-N o v-10}$ & $\frac{21}{18 \text {-Nov-10 }}$ & $\frac{-22}{5-\mathrm{Nov}-10}$ \\
\hline $\begin{array}{l}\text { PROJECT MANAGEMENT } \\
\text { Henrick Sarkissian }\end{array}$ & Principal & & $\begin{array}{l}7.0 \% \\
\$ 161.57 \\
\end{array}$ & 40 & 40 & 40 & 40 & 40 & 40 & 40 & 40 & 40 & 40 & 40 & 40 & 40 & 40 & 40 & 40 & 40 & 40 & & & 40 & 40 \\
\hline & \begin{tabular}{|l|} 
Principal \\
Offic Doropol
\end{tabular} & $\frac{\$ 151.00}{\$ 400}$ & 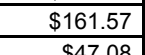 & $\frac{0}{20}$ & 0 & $\frac{0}{20}$ & 0 & 0 & 0 & $\frac{0}{20}$ & $\frac{0}{30}$ & $\frac{0}{20}$ & 0 & $\frac{0}{20}$ & 0 & 0 & 0 & $\frac{0}{20}$ & & 0 & & & 0 & $\frac{0}{19}$ & 0 \\
\hline $\begin{array}{l}\text { Office Personnnel } \\
\text { Accounting Personnel }\end{array}$ & $\begin{array}{l}\text { Office eersonnel } \\
\text { Cost Accountant }\end{array}$ & $\frac{\$ 44.00}{\$ 64.00}$ & $\$ 4.78 .48$ & $\frac{20}{4}$ & $\frac{20}{4}$ & $\frac{20}{4}$ & $\frac{20}{4}$ & \begin{tabular}{r|r}
20 \\
4
\end{tabular} & $\frac{20}{4}$ & $\frac{20}{4}$ & $\frac{20}{4}$ & $\frac{20}{4}$ & $\frac{20}{4}$ & $\frac{20}{4}$ & $\frac{20}{4}$ & $\frac{20}{4}$ & $\frac{20}{4}$ & $\frac{20}{4}$ & $\frac{20}{4}$ & $\frac{20}{4}$ & $\frac{20}{4}$ & 20 & $\frac{20}{4}$ & $\frac{40}{4}$ & 40 \\
\hline & & & & & & & & & & & & & & & & & & & & & & & & & \\
\hline $\begin{array}{l}\text { Subtotal Man-Hours } \\
\text { Subtotal }\end{array}$ & & & & $\frac{64}{\$ 7,176}$ & $\begin{aligned} 64 \\
\$ 7,176 \\
\end{aligned}$ & $\begin{array}{rl}64 & 64 \\
\$ 7,176 & \end{array}$ & $\begin{array}{r}67,176 \\
\$ 176\end{array}$ & $\begin{array}{r}64 \\
\$ 7,176 \\
\end{array}$ & \begin{tabular}{r|r|}
64 & 6768 \\
\end{tabular} & $\begin{aligned} 64 \\
\$ 7,678 \\
\end{aligned}$ & $\begin{aligned} 64,678 \\
\$ 7.678\end{aligned}$ & $\begin{array}{r}64 \\
\$ 7,678 \\
\end{array}$ & \begin{tabular}{r|r|}
64 & 4678 \\
7767 &
\end{tabular} & $\begin{array}{r}64 \\
\$ 7.678 \\
\end{array}$ & $\begin{aligned} 64 \\
\$ 7.678 \\
\end{aligned}$ & \begin{tabular}{r|}
64 \\
$\$ 7.678$ \\
\end{tabular} & \begin{tabular}{r|r|}
64648 \\
$\$ 77678$
\end{tabular} & $\frac{64}{87678}$ & $\frac{64}{87,678}$ & $\begin{array}{rl}64 & 64 \\
\$ 7.678 & \end{array}$ & $\begin{aligned} 64 \\
77.678 \\
\end{aligned}$ & $\begin{aligned} 64 \\
97.678 \\
\end{aligned}$ & \begin{tabular}{r|r|}
64 & \\
$\$ 77678$ &
\end{tabular} & $\frac{84}{58,620}$ & $\frac{84}{88.620}$ \\
\hline $\begin{array}{l}\text { PROJECT ENGINEERING } \\
\end{array}$ & & & & & & & & & & & & & & & & & & & & & & & & & \\
\hline Lachary Bauer & $\begin{array}{l}\text { Sentor r reject Engineer } \\
\text { Project Engineer }\end{array}$ & $\$ \$ \$ 116.00$ & $\begin{array}{l}\$ 1924.47 \\
\$ 124.12\end{array}$ & $\frac{40}{40}$ & $\frac{40}{40}$ & 40 & $\frac{40}{40}$ & $\frac{40}{40}$ & $\frac{40}{40}$ & $\frac{40}{40}$ & $\frac{40}{40}$ & $\frac{40}{40}$ & $\frac{40}{40}$ & $\frac{40}{40}$ & $\frac{40}{40}$ & $\frac{40}{40}$ & $\frac{40}{40}$ & $\frac{40}{n}$ & 40 & $\frac{40}{40}$ & $\frac{40}{40}$ & $\begin{array}{ll}40 \\
40\end{array}$ & $\begin{array}{ll}40 \\
40\end{array}$ & $\begin{array}{ll}40 \\
40\end{array}$ & $\frac{40}{40}$ \\
\hline Brian Techau & Project Engineer & $\$ 1116.00$ & $\$ 124.12$ & $\frac{40}{40}$ & 40 & 40 & 40 & 40 & 40 & 40 & 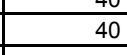 & 40 & 40 & 40 & 40 & 40 & 40 & 40 & 40 & 40 & 40 & 40 & 40 & 40 & 40 \\
\hline $\begin{array}{l}\text { Subtotal Man-Hours } \\
\text { Subtotals }\end{array}$ & & & & $\frac{120}{91420}$ & $\frac{120}{41200}$ & $\frac{120}{914420}$ & $\begin{aligned} 120 \\
914.420 \\
-12\end{aligned}$ & 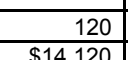 & \begin{tabular}{r|r|}
120 \\
51188
\end{tabular} & $\frac{120}{815108}$ & $\begin{aligned} 120 \\
815108 \\
\end{aligned}$ & $\begin{aligned} 120 \\
915108\end{aligned}$ & $\begin{aligned} 120 \\
\$ 15108 \\
\end{aligned}$ & $\begin{aligned} 120 \\
815108\end{aligned}$ & $\begin{array}{r}120 \\
5188\end{array}$ & $\begin{aligned} 120 \\
\$ 15108\end{aligned}$ & \begin{tabular}{r|r|}
120 \\
15118 \\
\end{tabular} & $\frac{120}{81508}$ & $\begin{array}{r}120 \\
\$ 15108 \\
-1510\end{array}$ & $\begin{array}{r}120 \\
15108 \\
-15108\end{array}$ & $\frac{120}{15108}$ & $\begin{aligned} 120 \\
15108 \\
\end{aligned}$ & \begin{tabular}{r|r|}
120 \\
15108 \\
\end{tabular} & $\begin{aligned} 120 \\
85108\end{aligned}$ & $\frac{120}{15108}$ \\
\hline ROJECT DESIGN & & & & & & & & & & & & & & & & & & & & & & & & & \\
\hline ike Wager & $\begin{array}{l}\text { Designer } \\
\text { Desiner- }\end{array}$ & $\$ \$ 91.00$ & $\frac{\$ 97.37}{99737}$ & $\frac{40}{40}$ & $\frac{40}{40}$ & $\frac{40}{40}$ & $\frac{40}{40}$ & $\frac{40}{40}$ & $\frac{40}{40}$ & $\frac{40}{40}$ & $\frac{40}{40}$ & $\frac{40}{40}$ & 40 & 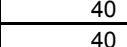 & $\frac{40}{40}$ & $\frac{40}{40}$ & $\frac{40}{40}$ & 40 & 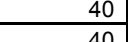 & 4 & -2 & 40 & 40 & 40 & $\frac{40}{40}$ \\
\hline Chuck Haas & Designer & $\$ 91.00$ & 997.37 & 40 & 40 & 40 & 40 & 40 & 40 & 40 & 40 & 40 & 40 & 40 & 40 & 40 & 40 & 40 & 40 & 40 & 40 & 40 & 40 & 40 & 40 \\
\hline $\begin{array}{l}\text { Subtotal Man-Hours } \\
\end{array}$ & & & & $\frac{120}{\sin 020}$ & 120 & $\frac{120}{91020}$ & $\begin{array}{r}120 \\
9102020 \\
\end{array}$ & 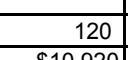 & 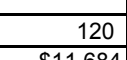 & $\frac{120}{911099}$ & $\frac{120}{91601}$ & $\frac{120}{91109}$ & $\frac{120}{911601}$ & $\frac{120}{91602}$ & 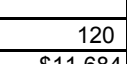 & $\frac{120}{911601}$ & $\begin{aligned} 120 \\
91601 \\
91601\end{aligned}$ & $\frac{120}{9160}$ & 120 & $\frac{120}{110204}$ & $\frac{120}{91102}$ & $\frac{120}{9169 t}$ & $\begin{aligned} 120 \\
91691\end{aligned}$ & $\frac{120}{9169}$ & $\frac{120}{1120}$ \\
\hline BTOTAL ROONEY ENGINEERING & (HOURS) & & & 304 & $.0 \mathrm{hrs}$ & 304.0 hrs & $304.0 \mathrm{hrs} / \mathrm{L}$. & 0 hrs & $.0 \mathrm{hrs}$ & 304.0 hrs & $304.0 \mathrm{hrs}$ & 304.0 hrs & 304.0 hrs & .0 hrs & $304.0 \mathrm{hrs}$ & 304.0 hrs & 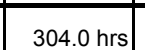 & $304.0 \mathrm{hrs}=\mathrm{F}$ & $304.0 \mathrm{hrs}$ & $304.0 \mathrm{hrs}$ & $304.0 \mathrm{H}$ & 304.0 hrs & 304.0 rrs & & 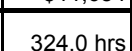 \\
\hline UBTOTAL ROONEY ENGINEERING & (Cost) & & & $\$ 32,216$ & $\$ 32,216$ & $\$ 32,216$ & $\$ 32,216$ & $\$ 32,216$ & $\$ 34,471$ & $\$ 34,471$ & $\$ 34,471$ & $\$ 34,471$ & $\$ 34,471$ & $\$ 34,471$ & $\$ 34,471$ & $\$ 34,471$ & $\$ 34,471$ & $\$ 34,471$ & $\$ 34,471$ & $\$ 34,471$ & $\$ 34,471$ & $\$ 34,471$ & $\$ 34,471$ & $\$ 35,413$ & $\$ 35,4$ \\
\hline
\end{tabular}

DETAILED ENGINEERING AND PROCUREMENT - Subcontractors and Expenses

\begin{tabular}{|c|c|c|c|c|c|c|c|c|c|c|c|c|c|c|c|c|c|c|c|c|c|c|c|c|c|}
\hline INDIVIDUAL & TITLE & $\begin{array}{l}\text { Biling } \\
\text { Rate 1/10 } \\
\end{array}$ & \begin{tabular}{|l} 
Billing \\
Rate 8/10 \\
\end{tabular} & 1-Jul-10 & 8-Jul-10 & 15-Jul-10 & 22-Jul-10 & 29-Jul-10 & 5-Aug-10 & 12-Aug-10 & \begin{tabular}{|l|l|}
$19-$ Aug-10 \\
\end{tabular} & 26-Aug-10 & 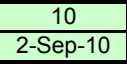 & 9-Sep-10 & $\frac{16-\text { Sep-10 }}{16}$ & 23-Sep-10 & $30-$ Sep-10 & 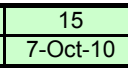 & $\frac{10}{14-\mathrm{Oct}-10}$ & 21-Oct-10 & $\frac{18}{8-0 c t-10}$ & $\frac{1 \mathrm{~s}-10}{4-\text { Nov-10 }}$ & 11-Nov-10 & 18-Nov-10 & 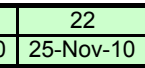 \\
\hline SUBCONTRACT ENGINEERING & & & & & & & & & & & & & & & & & & & & & & & & & \\
\hline & & $\begin{array}{r}\text { Ra } \\
\text { REIC }\end{array}$ & $\begin{array}{l}\text { tes } \\
\text { cost }\end{array}$ & & & & & & & & & & & & & & & & & & & & & & \\
\hline Mark Madden & $\begin{array}{l}\text { Senior Project Engineer } \\
\text { Catrofidi Protection }\end{array}$ & $\$ 121.00$ & $\$ 129.47$ & & & $\frac{40}{40}$ & $\frac{40}{40}$ & $\frac{40}{0}$ & $\frac{40}{0}$ & & $\frac{40}{0}$ & $\frac{40}{0}$ & $\frac{0}{40}$ & $\frac{0}{40}$ & $\frac{0}{40}$ & & $\frac{0}{0}$ & & $\frac{40}{40}$ & $\frac{40}{40}$ & $\frac{40}{40}$ & & & & \\
\hline Bruce Craig / Metcorr & Cathodic Protection & $\$ 200.00$ & $\$ 214.00$ & & & $\frac{40}{0}$ & $\frac{40}{0}$ & $\frac{0}{0}$ & $\frac{0}{0}$ & $\frac{0}{0}$ & $\frac{0}{0}$ & $\frac{0}{0}$ & $\frac{40}{0}$ & $\frac{40}{0}$ & $\frac{40}{0}$ & & $\frac{0}{0}$ & $\frac{0}{0}$ & $\frac{40}{0}$ & $\frac{40}{0}$ & $\frac{40}{0}$ & 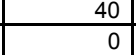 & & $\frac{0}{0}$ & \\
\hline $\begin{array}{r}\text { Subtotal Man-Hours } \\
\text { Subtotal } \\
\end{array}$ & & & & $\begin{array}{c}0 \\
0 \\
0\end{array}$ & & $\begin{array}{r}80 \\
\$ 12,840 \\
\end{array}$ & $\begin{array}{r}80 \\
12,840 \\
\end{array}$ & $\begin{array}{r}40 \\
\$ 4,840 \\
\end{array}$ & $\begin{array}{r}40 \\
\$ 5,179 \\
\end{array}$ & $\overline{\$ 0}$ & $\begin{array}{r}40 \\
55,179 \\
\end{array}$ & $\begin{array}{r}40 \\
5,179 \\
\end{array}$ & $\begin{array}{r}40 \\
8,560 \\
\end{array}$ & $\begin{array}{c}40 \\
8.560 \\
\end{array}$ & $\begin{array}{r}40 \\
8,560 \\
\end{array}$ & & $\frac{0}{\$ 0}$ & $\frac{0}{50}$ & $\begin{array}{r}80 \\
13,739 \\
\end{array}$ & $\frac{80}{13,739}$ & $\begin{array}{r}80 \\
\$ 13,739 \\
\end{array}$ & $\begin{array}{r}80 \\
\$ 13,739 \\
\end{array}$ & $\frac{0}{80}$ & $\frac{0}{80}$ & 0 \\
\hline $\begin{array}{l}\text { EXPENSES } \\
\text { Denver Office Travel Expenses }\end{array}$ & & & & $\$ 3,000$ & $\$ 3,000$ & $\$ 3,00 \mathrm{c}$ & $\$ 3,000$ & $\$ 3,000$ & $\$ 3,000$ & $\$ 3,000$ & $\$ 3,000$ & $\$ \$ 0$ & so & $\$ 0$ & 93,000 & $\$ 0$ & $\$ 3,000$ & $\$ 0$ & $\$ 3,000$ & $\$ 0$ & $\$ 0$ & $\$ 3,000$ & $s_{0}$ & 50 & 3,000 \\
\hline $\begin{array}{l}\text { Denver Office Expenses } \\
\text { Mines }\end{array}$ & & & & $\$ 200$ & $\$ 200$ & $\$ 200$ & $\$ 2000$ & $\$ 200$ & $\$ 200$ & $\$ 200$ & $\$ 200$ & & $\$ 200$ & $\$ 200$ & & $\$ 200$ & $\$ 200$ & & $\$ 200$ & $\$ 200$ & $\$ 200$ & $\$ 200$ & & & 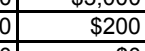 \\
\hline $\begin{array}{l}\text { Misc. } \\
\text { Hydraulic Software } \\
\end{array}$ & & & & $\$ 10,000$ & $\frac{86}{86}$ & $\frac{\$ 0}{\$ 0}$ & $\begin{array}{l}\$ 0 \\
\$ \$ 0 \\
\end{array}$ & $\frac{50}{\$ 0}$ & $\frac{\$ 0}{\$ 0}$ & $\frac{50}{50}$ & $\frac{24}{\frac{20}{4}}$ & $\frac{\$ 0}{\$ 0}$ & $\frac{\$ 0}{s 0}$ & $\begin{array}{l}\$ 0 \\
\$ 0 \\
\end{array}$ & $\frac{\$ 0}{\$ 0}$ & $\frac{\$ 0}{\$ 0}$ & $\frac{\$ 0}{\$ 0}$ & 然0 & $\frac{s c}{s c}$ & $\frac{\$ 0}{\$ 0}$ & $\frac{\$ 0}{\$ 0}$ & $\frac{\$ 0}{90}$ & $\frac{\$ 0}{\$ 0}$ & $\begin{array}{l}\text { sol } \\
\text { so } \\
\end{array}$ & $\begin{array}{l}\$ 0 \\
\$ 80 \\
\end{array}$ \\
\hline Subtotal S & & & & $\$ 13,200$ & $\$ 3,200$ & $\$ 3,200$ & $\$ 3,200$ & $\$ 3,200$ & $\$ 3,200$ & $\$ 3,200$ & $\$ 3,200$ & $\$ 200$ & $\$ 200$ & $\$ 200$ & $\$ 3,200$ & $\$ 200$ & $\$ 3,200$ & $\$ 200$ & $\$ 3,200$ & $\$ 200$ & $\$ 200$ & $\$ 3,200$ & $\$ 200$ & $\$ 200$ & $\$ 3,200$ \\
\hline SUBTOTAL SUBCONTRACTORS AND & EXPENSES (HOURS) & & & $0.0 \mathrm{hrs}$ & $0.0 \mathrm{hrs}$ & $80.0 \mathrm{hrs}$ & $80.0 \mathrm{hrs}$ & $40.0 \mathrm{hrs}$ & $40.0 \mathrm{hrs}$ & $0.0 \mathrm{hrs}$ & $40.0 \mathrm{hrs}$ & $40.0 \mathrm{hrs}$ & $40.0 \mathrm{hrs}$ & $40.0 \mathrm{hrs}$ & $40.0 \mathrm{hrs}$ & $0.0 \mathrm{hrs}$ & $0.0 \mathrm{hrs}$ & $0.0 \mathrm{hrs}$ & $80.0 \mathrm{hrs}$ & $80.0 \mathrm{hrs}$ & $80.0 \mathrm{hrs}$ & $80.0 \mathrm{hrs}$ & $0.0 \mathrm{hrs}$ & $0.0 \mathrm{hrs}$ & \\
\hline SUBTOTAL SUBCONTRACTORS AND & EXPENSES (COST) & & & $\$ 13,200$ & $\$ 3,200$ & $\$ 16,040$ & $\$ 16,040$ & $\$ 8,040$ & $\$ 8,379$ & $\$ 3,200$ & $\$ 8,379$ & $\$ 5,379$ & $\$ 8,760$ & $\$ 8,760$ & $\$ 11,760$ & $\$ 200$ & $\$ 3,200$ & $\$ 200$ & $\$ 16,939$ & $\$ 13,939$ & $\$ 13,939$ & $\$ 16,939$ & $\$ 200$ & $\$ 200$ & $\$ 3,200$ \\
\hline PROJECT TOTAL (HOURS) & & & & $304.0 \mathrm{hrs}$ & $304.0 \mathrm{hrs}$ & $384.0 \mathrm{hrs}$ & $384.0 \mathrm{hrs}$ & $344.0 \mathrm{hrs}$ & $344.0 \mathrm{hrs}$ & $304.0 \mathrm{hrs}$ & $344.0 \mathrm{hrs}$ & \begin{tabular}{|l|l|}
$344.0 \mathrm{hrs}$ \\
\end{tabular} & $344.0 \mathrm{hrs}$ & 344.0 hrs & $344.0 \mathrm{hrs}$ & $304.0 \mathrm{hrs}$ & $304.0 \mathrm{hrs}$ & $304.0 \mathrm{hrs}$ & $384.0 \mathrm{hrs}$ & 384.0 hrs & $384.0 \mathrm{hrs}$ & $384.0 \mathrm{hrs} \mid$ & & $324.0 \mathrm{hrs} \mid$ & 324.0 \\
\hline $\begin{array}{l}\text { PROJECT TOTAL (COST) } \\
\end{array}$ & & & & $\$ 45,416$ & $\$ 35,416$ & $\$ 48,256$ & $\$ 48,256$ & $\$ 40,256$ & $\$ 42,850$ & $\$ 37,671$ & $\$ 42,850$ & 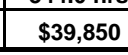 & $\$ \$ 43,231$ & $\$ 43,231$ & \begin{tabular}{|l|l}
446,231 \\
\end{tabular} & $\$ 34,671$ & \begin{tabular}{|l|l}
$\$ 37,671$ \\
\end{tabular} & $\$ 34,671$ & 551,410 & $\$ 48,410$ & \begin{tabular}{|l|l}
48,410 \\
\end{tabular} & $\$ 551,410$ & $\$ 34,671$ & $\$ 35,613$ & \begin{tabular}{|l|l|}
$\$ 38,613$ \\
\end{tabular} \\
\hline
\end{tabular}




\begin{tabular}{|c|c|c|c|c|c|c|c|c|c|c|c|c|c|c|c|c|c|c|}
\hline INDIVIDUAL & TITLE & $\begin{array}{l}\frac{1}{\text { Billing }} \\
\text { Rate 1/10 }\end{array}$ & $\frac{23}{2-\text { Dec- } 10}$ & $\begin{array}{l}24 \\
\text { 9-Dec-10 } \\
\end{array}$ & $\frac{25}{16-\operatorname{Dec}-10}$ & $\frac{26}{23-\mathrm{Dec}-10}$ & $\frac{27}{30-\text { Dec-10 }}$ & $\frac{28}{6-\text {-an-11 }}$ & $\frac{29}{13-\operatorname{Jan}-11}$ & $\frac{30}{20-\operatorname{Jan}-11}$ & \begin{tabular}{|l|}
31 \\
27-Jan-11
\end{tabular} & $\frac{32}{3-\text {-eb-11 }}$ & $\frac{33}{10-\mathrm{Feb}-11}$ & $\frac{34}{17-\text { Feb-11 }}$ & $\frac{35}{24-\text { Feb-11 }}$ & $\frac{36}{3-M a r-11}$ & \begin{tabular}{|l|}
10 -Mar-11 \\
\end{tabular} & $\frac{38}{17-\text { Mar-11 }}$ \\
\hline $\begin{array}{l}\text { ROJECT MANAGEMENT } \\
\text { tenrick Sarkisisan }\end{array}$ & 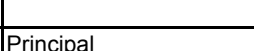 & $\$ 15100$ & 40 & 40 & 40 & 40 & 40 & 40 & & 40 & & 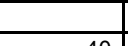 & 40 & 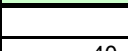 & 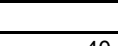 & Pln & 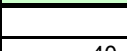 & \\
\hline ther & Principal & $\$ 151.00$ & 0 & $\frac{40}{0}$ & $\frac{40}{0}$ & $\frac{40}{0}$ & $\frac{40}{0}$ & $\frac{40}{0}$ & $\frac{40}{0}$ & $\frac{40}{0}$ & $\frac{40}{0}$ & $\frac{40}{0}$ & $\frac{40}{0}$ & $\frac{40}{0}$ & $\frac{40}{0}$ & $\frac{40}{0}$ & $\frac{40}{0}$ & $\frac{0}{0}$ \\
\hline $\begin{array}{l}\text { Sffice Personnel } \\
\text { cccountina Personnel }\end{array}$ & $\begin{array}{l}\text { Office Personnel } \\
\text { CostAccountant }\end{array}$ & $\begin{array}{l}\$ 44.00 \\
\$ 64.00\end{array}$ & \begin{tabular}{c|c}
40 \\
4
\end{tabular} & $\frac{40}{4}$ & $\frac{20}{4}$ & $\frac{20}{4}$ & $\frac{20}{4}$ & $\frac{20}{4}$ & $\frac{20}{4}$ & $\frac{20}{4}$ & $\frac{20}{4}$ & 20 & $\frac{20}{4}$ & $\frac{20}{4}$ & $\frac{20}{4}$ & $\frac{20}{4}$ & $\frac{20}{4}$ & $\frac{0}{0}$ \\
\hline & & & & & & & & & & & & & & & & & & \\
\hline $\begin{array}{l}\text { Subtotal Man-Huors } \\
\text { Subtotal } \$ \\
\end{array}$ & & & $\begin{array}{r}84,620 \\
\end{array}$ & 884 & $\$ 67,678$ & $\begin{array}{r}64,678 \\
\$ 7\end{array}$ & $\begin{array}{r}64 \\
\$ 7,678\end{array}$ & $\begin{array}{l}64 \\
\$ 97,678\end{array}$ & $\frac{64}{97,678}$ & \begin{tabular}{r|r|}
57678 \\
\end{tabular} & $\begin{array}{r}67,678 \\
\$ 1768\end{array}$ & \begin{tabular}{r|r|}
57,678 \\
\end{tabular} & $\frac{64}{87,678}$ & $\frac{64}{87,678}$ & $\frac{64}{87,678}$ & $\begin{array}{r}64 \\
87,678 \\
-10\end{array}$ & $\begin{array}{r}64,678 \\
\$ 7,678\end{array}$ & $\frac{0}{\$ 0}$ \\
\hline PROJECT ENGINEERING & & & & & & & & & & & & 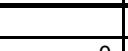 & & E & ב & E & ב & \\
\hline $\begin{array}{l}\text { Quinn Bailiey } \\
\text { achary Bauer }\end{array}$ & $\begin{array}{l}\text { Senior r roject Engineer } \\
\text { Proiect nnaineer }\end{array}$ & $\frac{\$ 111.00}{\$ 11600}$ & $\frac{40}{40}$ & $\frac{40}{40}$ & $\frac{0}{0}$ & $\frac{0}{0}$ & $\frac{0}{0}$ & $\frac{0}{0}$ & $\frac{0}{0}$ & $\begin{array}{ll}0 \\
0\end{array}$ & $\frac{0}{0}$ & $\frac{0}{0}$ & $\frac{0}{0}$ & 0 & $\frac{0}{n}$ & 0 & $\frac{0}{0}$ & 0 \\
\hline rian Techau & Project Engineer & $\$ 116.00$ & 40 & 40 & 40 & 40 & 40 & 40 & 40 & 40 & 40 & 40 & 40 & 40 & 40 & 40 & 40 & \\
\hline $\begin{array}{l}\text { Subtotal Man-Hours } \\
\end{array}$ & & & 120 & 120 & 40 & 40 & 40 & 40 & 40 & 40 & 40 & 40 & 40 & 40 & 40 & 40 & 40 & 0 \\
\hline Subtotals $\mathrm{S}$ & & & $\$ 15,108$ & $\$ 15,108$ & $\frac{54,965}{5}$ & $\$ 4,965$ & $\$ 4,965$ & $\overline{\$ 44,965}$ & $\$ 4,965$ & S4,965 & $\begin{array}{l}54,965 \\
\end{array}$ & $\$ 4,965$ & 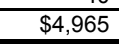 & $\begin{array}{l}54,965 \\
\end{array}$ & 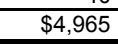 & $\$ 44,965$ & $\$ 4,965$ & \$0 \\
\hline $\begin{array}{l}\text { PROJECT DESIGN } \\
\text { Mike Waer }\end{array}$ & Designer & $\$ 9100$ & 40 & 40 & 0 & 0 & 0 & 0 & 0 & 0 & 0 & 0 & 0 & & & & 0 & \\
\hline Roxanne Burridge & Designer & $\$ 91.00$ & 40 & 40 & 0 & 0 & 0 & 0 & 0 & 0 & 0 & 0 & 0 & 0 & & & 0 & 0 \\
\hline uck Haas & Designer & $\$ 991.00$ & 40 & 40 & 0 & 0 & 0 & 0 & 0 & 0 & 0 & 0 & 0 & 0 & 0 & 0 & 0 & 0 \\
\hline $\begin{array}{l}\text { Subtotal Man-Hours } \\
\end{array}$ & & & 120 & 120 & 0 & 0 & 0 & 0 & 0 & 0 & 0 & 0 & 0 & 0 & 0 & 0 & 0 & 0 \\
\hline TOTA R & HOUPS: & & 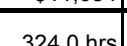 & 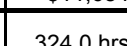 & $\overline{O p r s}$ & 040 hro & $10 \mathrm{hrcs}$ & 1040 hro & $40 \mathrm{pros}$ & o pras & 1040 hres & Ohrot & 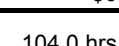 & $10 \mathrm{hrcs}$ & & $40 \mathrm{hr}$ & $240 \mathrm{pres}$ & Su \\
\hline BTOTAL ROONEY ENGINEERING & Cost) & & $\$ 35,413$ & $\$ 35,413$ & $\$ 12,643$ & \begin{tabular}{|l}
$\$ 12,643$ \\
\end{tabular} & \begin{tabular}{|l|l}
12,643 \\
\end{tabular} & $\$ 12,643$ & $\$ 12,643$ & $\$ 12,643$ & $\$ \$ 12,643$ & $\$ 12.643$ & $\$ 12,643$ & $\$ 12,643$ & $\$ 12,643,>>20$ & $\$ 12,643$ & $\$ 12,643$ & $\$ 0$ \\
\hline
\end{tabular}

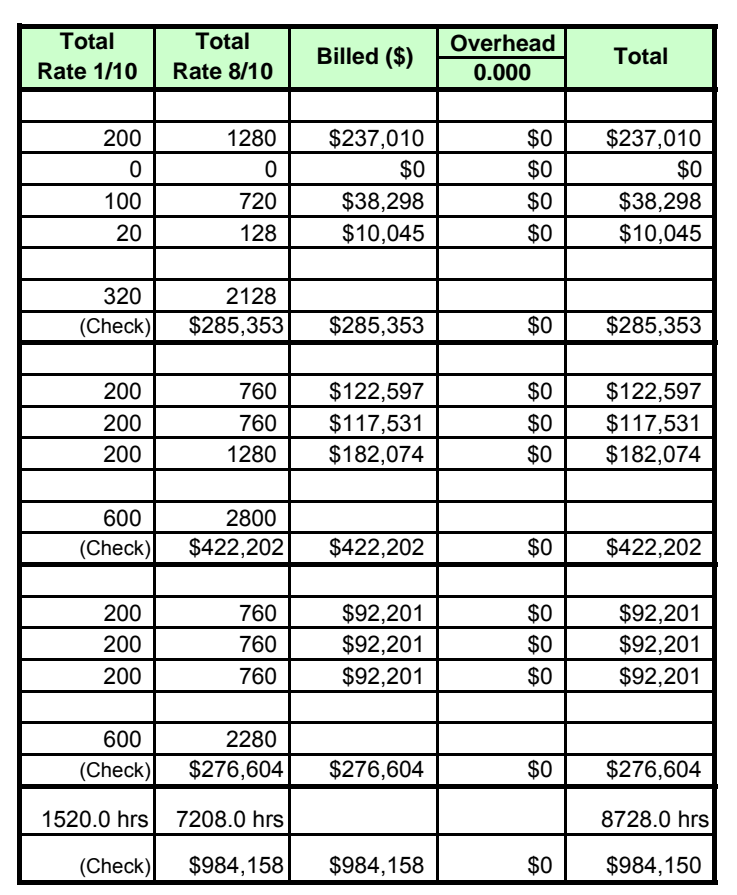

DETAILED ENGINEERING AND PROCUREMENT - Subcontractors an

\begin{tabular}{|c|c|c|c|c|c|c|c|c|c|c|c|c|c|c|c|c|c|c|}
\hline $\begin{array}{c}\text { INDIVIDUAL } \\
\end{array}$ & TITLE & $\begin{array}{l}\frac{B}{\text { Biling }} \\
\text { Rate 1/10 }\end{array}$ & $\frac{23}{2-\operatorname{Dec}-10}$ & $\frac{24-10}{9-D e c-10}$ & $\frac{25}{16-\text {-ec-10 }}$ & $\frac{26}{23-\text { Dec-10 }}$ & $\frac{2 l}{30-D e c-10}$ & $\frac{28}{6-\mathrm{Jan}-11}$ & $\frac{29}{13-\mathrm{Jan}-11}$ & $\frac{30}{20-\operatorname{Jan}-11}$ & $\frac{31}{27-\operatorname{san}-11}$ & $\frac{32}{3-F e b-11}$ & $\frac{33}{10-\mathrm{Feb}-11}$ & \begin{tabular}{|l}
34 \\
$17-$-eb-11 \\
\end{tabular} & $\frac{35}{24-F e b-11}$ & $\frac{36}{3-\text { Mar-11 }}$ & $\frac{37}{10-\text { Mar-11 }}$ & $\begin{array}{ll}38 \\
17-\text { Mar-11 } \\
\end{array}$ \\
\hline SUBCONTRACT ENGINEERING & & & & & & & & & & & & & & & & & & \\
\hline & & REI & & & & & & & & & & & & & & & & \\
\hline Mark Madden & Senior Project Engineer & $\$ 1211.00$ & 0 & & & 0 & 0 & 0 & 0 & 0 & 0 & 0 & 0 & 0 & 0 & 0 & 0 & 0 \\
\hline Bruce Craig / Metcorr & Cathodic Protection & $\$ 200.00$ & & & $\frac{0}{0}$ & $\frac{0}{0}$ & $\frac{0}{0}$ & $\frac{40}{0}$ & $\frac{40}{0}$ & $\frac{40}{0}$ & $\frac{40}{0}$ & $\frac{0}{0}$ & $\frac{0}{0}$ & $\frac{0}{0}$ & $\frac{0}{0}$ & $\frac{0}{0}$ & $\frac{0}{0}$ & $\frac{0}{0}$ \\
\hline $\begin{array}{l}\text { Subtotal Man-Hours } \\
\text { Subtotal } \$\end{array}$ & & & $\frac{80}{\$ 0}$ & $\$ 0$ & $\frac{0}{80}$ & $\frac{0}{80}$ & 0 & $\begin{array}{r}40 \\
8560 \\
-1500\end{array}$ & $\frac{40}{8850}$ & $\frac{40}{88500}$ & $\frac{40}{88500}$ & $\frac{0}{80}$ & $\frac{0}{80}$ & $\frac{0}{80}$ & $\frac{0}{80}$ & $\frac{0}{90}$ & $\frac{0}{90}$ & $\frac{0}{\$ 0}$ \\
\hline $\begin{array}{l}\text { EXPENSES } \\
\text { Denver Offece Travel Exnenses }\end{array}$ & & & & & & & & & & & & & & & & & & \\
\hline $\begin{array}{l}\text { Denver Office Trave Expenses } \\
\text { Denver Office Expenses }\end{array}$ & & & $\frac{\$ 0}{\$ 200}$ & $\frac{\$ 3,000}{\$ 10,000}$ & $\frac{\$ 3,000}{\$ 100}$ & $\frac{\$ 0}{\$ 100}$ & $\frac{50}{80}$ & $\frac{\$ 3,000}{\$ 0}$ & $\frac{\$ 0}{\$ 0}$ & $\frac{\$ 0}{\$ 0}$ & $\$ 3,000$ & $\frac{\$ 0}{\$ 0}$ & $\frac{\$ 0}{\$ 0}$ & $\$ 3,000$ & $\frac{\$ 0}{\$ 0}$ & $\frac{\$ 3,000}{80}$ & $\$ C$ & $\frac{\$ 0}{\$ 0}$ \\
\hline Misc. & & & $\frac{\$ C}{S c}$ & $\frac{80}{80}$ & $\begin{array}{l}50 \\
0\end{array}$ & $\$ 10$ & $\frac{\$ 0}{90}$ & $\frac{86}{86}$ & $\frac{\$ c}{s c}$ & $\frac{90}{90}$ & $\$ \$ 0$ & $\frac{\$ 0}{90}$ & $\frac{\$ 0}{80}$ & $\frac{S 0}{80}$ & 匆 & $\frac{90}{90}$ & $\frac{\$ 0}{\$ 0}$ & $\$ 0$ \\
\hline & & & & & & & & & & & & & & & & & & \\
\hline Subtotal $\$$ & & & $\$ 200$ & $\$ 13,000$ & $\$ 3,100$ & $\$ 100$ & s0 & $\$ 3,000$ & so & $\$ 0$ & $\$ 3,000$ & $\$ 0$ & so & $\$ 33,000$ & so & $\$ 3,000$ & \$0 & So \\
\hline SUBTOTAL SUBCONTRACTORS AND & EXPENSES (HOURS) & & $0.0 \mathrm{hrs}$ & $0.0 \mathrm{hrs}$ & $0.0 \mathrm{hrs}$ & $0.0 \mathrm{hrs}$ & $0.0 \mathrm{hrs}$ & $40.0 \mathrm{hrs}$ & $40.0 \mathrm{hrs}$ & $40.0 \mathrm{hrs}$ & $40.0 \mathrm{hrs} / \mathrm{r}$ & $0.0 \mathrm{hrs}$ & $0.0 \mathrm{hrs}$ & $0.0 \mathrm{hrs}$ & $0.0 \mathrm{hrs}$ & $0.0 \mathrm{hrs}$ & $0.0 \mathrm{hrs}$ & $0.0 \mathrm{hrs}$ \\
\hline SUBTOTAL SUBCONTRACTORS AND & EXPENSES (COST) & & $\$ 200$ & $\$ 13,000$ & $\$ 3,100$ & $\$ 100$ & $s_{0}$ & $\$ 11,560$ & $\$ 8,560$ & $\$ 8,560$ & $\$ 11,560$ & so & $\$ 0$ & $\$ 3,000$ & $\$ 0$ & $\$ 3,000$ & $\$ 0$ & $\$ 0$ \\
\hline ОJЕСТ TOTAL & & & $324.0 \mathrm{hrs}$ & $324.0 \mathrm{hrs}$ & $104.0 \mathrm{hrs}$ & $104.0 \mathrm{hrs}$ & $4.0 \mathrm{hrs}$ & $144.0 \mathrm{hrs}$ & $144.0 \mathrm{hrs}$ & $144.0 \mathrm{hrs}$ & $\begin{array}{l}144.0 \mathrm{hrs} \\
\end{array}$ & $104.0 \mathrm{hrs}$ & $1.0 \mathrm{hrs}$ & $104.0 \mathrm{hrs}$ & & $04.0 \mathrm{hrs}$ & $104.0 \mathrm{hrs}$ & $0.0 \mathrm{hrs}$ \\
\hline PROJECT TOTAL (COST) & & & $\begin{array}{l}35,613 \\
\end{array}$ & $\begin{array}{lll}48,413 \\
\end{array}$ & $\$ 15,743$ & $\$ 12,743$ & $\$ 12,643$ & $\$ 24,203$ & $\$ 21,203$ & $\begin{array}{lll}\$ 21,203 \\
\end{array}$ & $\$ 24,203$ & $\$ 12,643$ & $\$ 12,643$ & $\$ 15,643$ & $\$ 12,643$ & $\$ 15,643$ & $\$ 12,643$ & -1 \\
\hline
\end{tabular}

\begin{tabular}{|c|c|c|c|c|}
\hline $\begin{array}{l}\text { Total } \\
\text { Rate al110 }\end{array}$ & $\begin{array}{l}\text { Total } \\
\text { Rete } 810\end{array}$ & Billed (\$) & $\begin{array}{l}\text { Overhead } \\
0.150\end{array}$ & Total \\
\hline & & & & \\
\hline & 280 & & & \\
\hline 80 & 440 & $\begin{array}{l}\$ s 0,1712 \\
\$ 110,160\end{array}$ & $\begin{array}{l}\$ 1,010,524 \\
\$\end{array}$ & $\begin{array}{l}\$ 20,36,684 \\
\$ 120\end{array}$ \\
\hline 200 & 720 & & & \\
\hline & $\$ 160,932$ & $\$ \$ 160,932$ & $\$ 24,410$ & $\$ 185,071$ \\
\hline & & $\frac{\$ 5,7,000}{\$ 1,400}$ & $\frac{\$ 8,550}{\$ 2,220}$ & $\$ 65,550$ \\
\hline & & $\begin{aligned} S 0 \\
\$ \$ 10,000\end{aligned}$ & $\begin{array}{r}\$ 0 \\
\$ 1,500\end{array}$ & $\begin{array}{r}50 \\
511,500\end{array}$ \\
\hline (Check) & $\$ 81,800$ & $\$ 81,800$ & $\$ 12,270$ & $\$ 994,070$ \\
\hline $760.0 \mathrm{hrs}$ & $160.0 \mathrm{hrs}$ & & & $920.0 \mathrm{hrs}$ \\
\hline (Check) & $\$ 242,732$ & $\$ 242,732$ & $\$ 36,410$ & $\$ 279,140$ \\
\hline $7812.0 \mathrm{hrs}$ & $1836.0 \mathrm{hrs}$ & & & $9648.0 \mathrm{hrs}$ \\
\hline (Check) & $\$ 1,226,890$ & $\$ 1,226,890$ & $\$ 36,410$ & $\$ 1,263,290$ \\
\hline
\end{tabular}


INTEGRATED MID-CONTINENT CARBON CAPTURE, SEQUESTRATION \&

ENHANCED OIL RECOVERY PROJECT

Coffeyville Resources Fertilizer Plant (CVR) to the Thrall-Aagard Oil Field (TAF)

Construction Administration and As-Built

Blue Source LLC

Date: March 26, 2010

CONSTRUCTION ADMINISTRATION AND AS BUILT - Rooney Engineering Direct Labor

INDIVIDUA

TITLE

\begin{tabular}{l} 
PROJECT MANAGEM \\
Henrick Sarkissian \\
\hline Other \\
\hline
\end{tabular}

\begin{tabular}{|l|l|}
\hline & \\
\hline Ther & Principal \\
\hline Oice Personnel & Principal \\
\hline
\end{tabular}

\begin{tabular}{|l|l|}
\hline frice Personnel & Principal \\
\hline cofice Personne & Cost Accounta \\
\hline & \\
\hline
\end{tabular}

\begin{aligned} & Cost Accountant \\ & \hline Subtotal Man-Hours \\ & \hline Subtotal S \end{aligned}

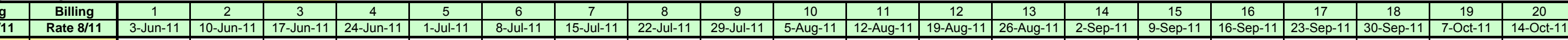

PROJECT ENGINEERING

\begin{tabular}{|l|l|l}
\hline inn Bailey & Senior Project Engineer \\
\hline
\end{tabular}

Zachary Bauer

Subtotal Man-How

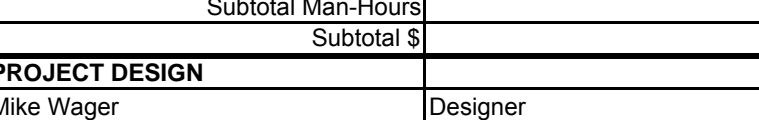

\begin{tabular}{|l|l|l}
\hline Mike Wager & Design \\
\hline Chuck Haas & Designer \\
\hline
\end{tabular}

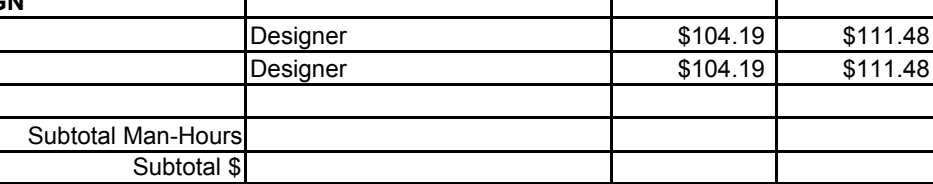

SUBTOTAL ROONEY ENGINEERING (HOURS

SUBTOTAL ROONEY ENGINEERING (COST)

CONSTRUCTION ADMINISTRATION AND AS BUILT - Subcontractors and Expenses

INDIVIDUA

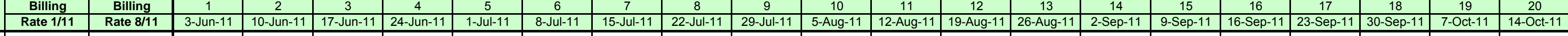

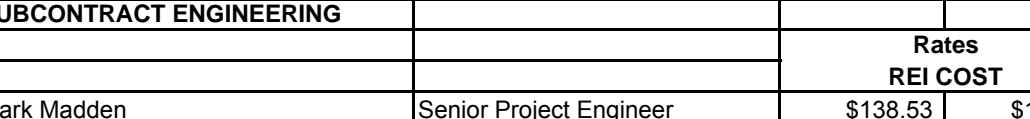

Senior Project Engines
Cathodic Protection Subtotal Man-Hours

(1)

Renver Office Travel Expenses
Denver Office Expenses

Subtotal \$

-

$+2$

SUBTOTAL SUBCONTRACTORS AND EXPENSES (HOURS)

SUBTOTAL SUBCONTRACTORS AND EXPENSES (COST)

PROJECT TOTAL (HOURS)

PROJJECT TOTALL(HOURS)
PROJECT TOTAL (COST) 
INTEGRATED MID-CONTINENT CARBON CAPTURE, SEQUEST

ENHANCED OIL RECOVERY PROJECT

Coffeyville Resources Fertilizer Plant (CVR) to the Thrall-Aagarc

Construction Administration and As-Built

Blue Source LLC
Date: March 26, 2010

CONSTRUCTION ADMIIISTRATION AND AS BUILT - Rooney Engine

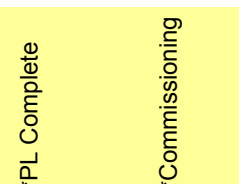

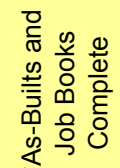
INDIVIDUAL TITLE \begin{tabular}{|c|c|c|}
\hline Billing & \\
\hline Rate 1111 & $21-0$ \\
\hline 7011 & \\
\hline
\end{tabular}

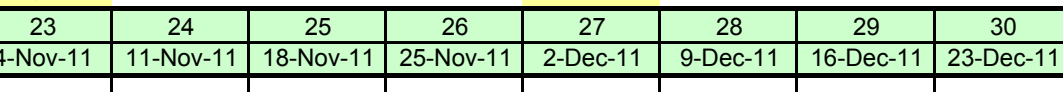

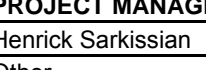

\begin{tabular}{l} 
Other \\
\hline Office Personnel \\
Accounting Personnel
\end{tabular}

\begin{tabular}{|l}
\hline Principal \\
\hline Principal \\
\hline Coss Accolng
\end{tabular}

(20) \begin{tabular}{|c|c|}
\hline $7.0 \%$ \\
\hline 172.8 \\
\hline
\end{tabular}
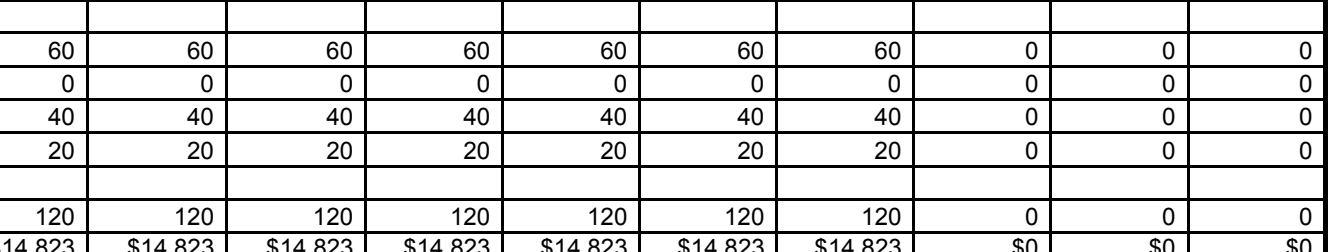

Subtol \begin{tabular}{l} 
Office Personnel \\
Cost Accountant \\
\hline
\end{tabular} \begin{tabular}{|r|}
\hline$\$ 172.88$ \\
\hline$\$ 50.38$ \\
\hline$\$ 73.27$ \\
\hline
\end{tabular} \begin{tabular}{r|r|r|r|r|r|r}
120 & 120 & 120 & 120 & 120 & 120 & 120 \\
\hline$\$ 14,823$ & $\$ 14,823$ & $\$ 14,823$ & $\$ 14,823$ & $\$ 14,823$ & $\$ 14,823$ & $\$ 14,823$ \\
\hline
\end{tabular}

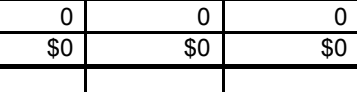

\begin{tabular}{|l|l}
\hline RujECr NGINEERING & Senior Project Engineer \\
\hline Quinn Bailey &
\end{tabular}

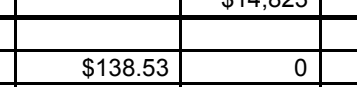

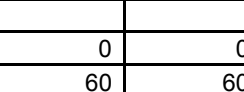

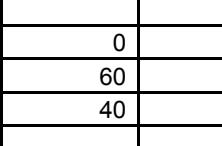

Subtotal Man-Hour
Subtotal Project Engineer

\begin{tabular}{r|r|r|r|r|}
\hline 0 & 0 & 0 & 0 & 0 \\
\hline 60 & 60 & 0 & 0 & 0 \\
\hline 40 & 40 & 0 & 0 & 0 \\
\hline & & & & \\
\hline
\end{tabular}

\begin{tabular}{l} 
PROJJCT DESIGN \\
\hline Mike Wager \\
\hline Chuck Haas
\end{tabular} \begin{tabular}{l} 
Designer \\
Designer \\
\hline
\end{tabular} Subtotal Man-Hours esigner \begin{tabular}{|r|r|r|r|r|r|r|r|r|r|}
100 & 100 & 100 & 100 & 100 & 100 & 100 & 0 & 0 & \\
$\$ \$ 14,210$ & $\$ 14,210$ & $\$ 14,210$ & $\$ 14,210$ & $\$ 14,210$ & $\$ 14,210$ & $\$ 14,210$ & $\$ 0$ & $\$ 0$ & $\$ 0$ \\
\hline
\end{tabular} \begin{tabular}{l}
\hline SUBTOTAL ROONEY ENGINEERING (HOURS) \\
\hline SUBTOTAL ROONEY ENGINEERING (COST) \\
\hline
\end{tabular} \begin{tabular}{|r|r|r|r|r|r|r|r|r|r|}
\hline & $\$ 104.19$ & 40 & 40 & 40 & 40 & 40 & 40 & 40 \\
\hline & $\$ 104.19$ & 40 & 40 & 40 & 40 & 40 & 40 & 40 &
\end{tabular} \begin{tabular}{r|r|r|r|}
80 & 80 & 80 & 80 \\
\hline 918 & $\$ 8,918$ & $\$ 8,918$ & $\$ 8,91$ \\
\hline
\end{tabular} \begin{tabular}{r|r|r|r|}
\hline & 80 & 80 & 80 \\
\hline 98,918 & $\$ 8,918$ & $\$ 8,918$ \\
\hline
\end{tabular}

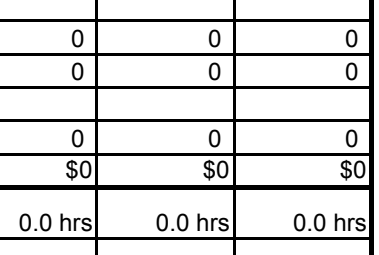
CONSTRUCTION ADMINISTRATION AND AS BUILT - Subcontractors

\begin{tabular}{|l|l|l|l|l|l|l|l|l|l|}
\hline TITE & & \\
\hline
\end{tabular}
SUBCONTRA TE

TILE

\begin{tabular}{l} 
Mark Madden \\
Bruce Craig / Metcorr \\
\hline
\end{tabular} \begin{tabular}{|l|}
\hline Senior Project Engine \\
\hline Cathodic Protection \\
\hline
\end{tabular}

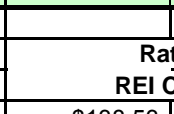

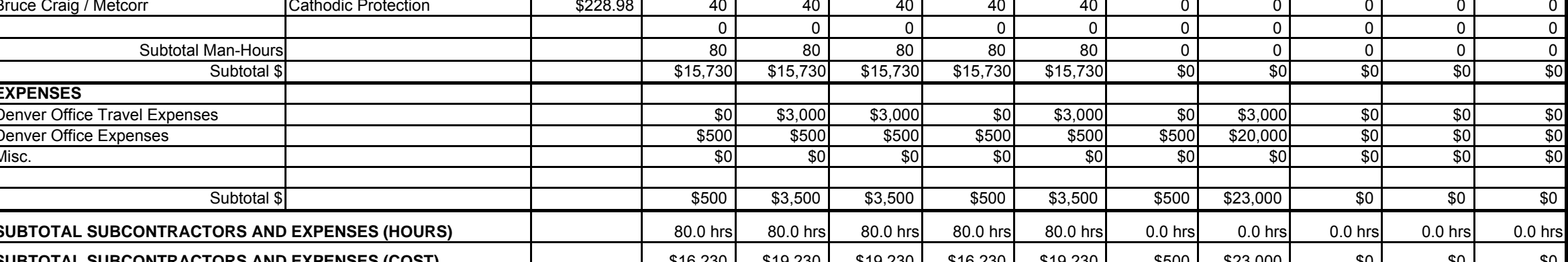

SUBTOTAL SUBCONTRACTORS AND EXPENSES (HOUR \begin{tabular}{|c|c|c|c|c|c|c|}
\hline $80.0 \mathrm{hrs}$ & $80.0 \mathrm{hrs}$ & $80.0 \mathrm{hrs}$ & $80.0 \mathrm{hrs}$ & $80.0 \mathrm{hrs}$ & $0.0 \mathrm{hrs}$ & $0.0 \mathrm{~h}$ \\
\hline 516230 & $\$ 19230$ & & & & & \\
\hline
\end{tabular}

\begin{tabular}{|c|c|c|c|c|}
\hline $\begin{array}{c}\text { Total } \\
\text { Rate } 1 / 11\end{array}$ & $\begin{array}{l}\text { Total } \\
\text { Rate } 8111\end{array}$ & Billed (\$) & $\begin{array}{c}\text { Overhead } \\
0.000\end{array}$ & Total \\
\hline 540 & 1080 & $\$ 293,135$ & $\$ 0$ & $\$ 293,135$ \\
\hline$\frac{0}{360}$ & $\frac{0}{720}$ & $\begin{array}{r}\$ \$ 0 \\
\$ 56.945\end{array}$ & $\frac{\$ 0}{90}$ & $\begin{array}{r}\$ 0 \\
5560.5\end{array}$ \\
\hline$\frac{360}{180}$ & $\frac{720}{360}$ & $\begin{array}{l}\$ 560,945 \\
\$ 41,414\end{array}$ & $\$ 0$ & $\begin{array}{l}\$ 56,9,45 \\
\$ 44,144\end{array}$ \\
\hline 1080 & 2160 & & & \\
\hline check & $\$ 391,494$ & $\$ 391,494$ & so & $\$ 391,494$ \\
\hline 0 & 0 & $\$ 0$ & $\$ 0$ & \\
\hline 540 & 1080 & $\$ 225,190$ & $\$ 0$ & $\$ 225,190$ \\
\hline 360 & 720 & $\$ 150,127$ & $\$ 0$ & $\$ 150,127$ \\
\hline 900 & 1800 & & & \\
\hline Check & $\$ 375,317$ & $\$ 375,317$ & $\$ 0$ & $\$ 375,317$ \\
\hline 180 & 540 & $\$ 78,952$ & $\$ 0$ & $\$ 78,952$ \\
\hline & 440 & $\$ 49,051$ & $\$ 0$ & $\$ 49,051$ \\
\hline 180 & 980 & & & \\
\hline & $\$ 128,003$ & $\$ 128,003$ & $\$ 0$ & $\$ 128,003$ \\
\hline $2160.0 \mathrm{hrs}$ & $4940.0 \mathrm{hrs}$ & & & $7100.0 \mathrm{hrs}$ \\
\hline (Check) & $\$ 894,813$ & $\$ 894,813$ & $\$ 0$ & $\$ 894,810$ \\
\hline
\end{tabular}

\begin{tabular}{|c|c|c|c|c|}
\hline \begin{tabular}{|c|} 
Total \\
Rate $1 / 11$ \\
\end{tabular} & $\begin{array}{c}\text { Total } \\
\text { Rate } 8 / 11\end{array}$ & Billed (\$) & $\frac{c^{\frac{\text { Overhead }}{0.150}}}{0.0}$ & Total \\
\hline & & & & \\
\hline 120 & 280 & $\$ 58,128$ & $\$ 8,719$ & $\$ 66,848$ \\
\hline 120 & 280 & $\$ 96,080$ & $\$ 14,412$ & $\$ 110,492$ \\
\hline 240 & 560 & & & \\
\hline (Check) & $\$ 154,208$ & $\begin{array}{l}\$ 154,208 \\
\end{array}$ & $\$ 23,131$ & $\$ 177,340$ \\
\hline & & $\$ 72,000$ & $\$ 10,800$ & $\$ 82,800$ \\
\hline & & $\frac{\$ \$ \$ 33,000}{\$ 0}$ & $\begin{array}{r}\$ 4,950 \\
\$ 0\end{array}$ & $\begin{array}{r}\$ 37,950 \\
\$ 0\end{array}$ \\
\hline (Check) & $\$ 105,000$ & $\$ 105,000$ & $\$ 15,750$ & $\$ 120,750$ \\
\hline $400.0 \mathrm{hrs}$ & $400.0 \mathrm{hrs}$ & & & $800.0 \mathrm{hrs}$ \\
\hline (Check) & $\$ 259,208$ & $\$ 259,208$ & $\$ 38,881$ & $\$ 298,080$ \\
\hline $0.0 \mathrm{hrs}$ & $3340.0 \mathrm{hrs}$ & & & $7900.0 \mathrm{hrs}$ \\
\hline (Check) & $\$ 1,154,022$ & $\$ 1,154,022$ & $\$ 38,881$ & $\$ 1,192,890$ \\
\hline
\end{tabular}


INTEGRATED MID-CONTINENT CARBON CAPTURE, SEQUESTRATION \&

ENHANCED OIL RECOVERY PROJECT

Coffeyville Resources Fertilizer Plant (CVR) to the Thrall-Aagard Oil Field (TAF)

Inspection, Survey and X-Ray

Blue Source LLC

Date: March 26, 2010

Procurement Inspection

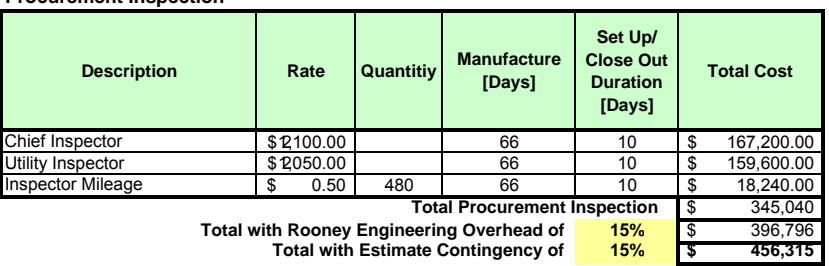

\begin{tabular}{|c|c|c|c|c|c|}
\hline Description & Rate & Quantitiy & $\begin{array}{c}\text { Construction } \\
\text { Duration } \\
\text { [Days] }\end{array}$ & $\begin{array}{c}\text { Set Up/ } \\
\text { Close Out } \\
\text { Duration } \\
\text { [Days] }\end{array}$ & Total Cost \\
\hline Chief Inspector & $\$ 2,100.00$ & & 123 & 20 & $314,600.00$ \\
\hline Chief Welding Inspector & $\$ 6050.00$ & & 123 & 15 & $869,400.00$ \\
\hline Welding Inspector & $\$ 5000.00$ & & 123 & 15 & $828,000.00$ \\
\hline Environmental Inspector & $\$ 950.00$ & 2 & 123 & 15 & $262,200.00$ \\
\hline \multirow[t]{4}{*}{ Inspector Mileage } & $\begin{array}{ll}\$ & 0.50 \\
\end{array}$ & 1920 & 123 & 15 & $132,480.00$ \\
\hline & \multirow{2}{*}{\multicolumn{4}{|c|}{$\begin{array}{r}\text { Total Construction Inspection } \\
\text { ith Rooney Engineering Overhead of }\end{array}$}} & $2,406,680$ \\
\hline & \multirow{2}{*}{\multicolumn{3}{|c|}{$\begin{array}{r}\text { Total with Rooney Engineering Overhead of } \\
\text { Total with Estimate Contingency of }\end{array}$}} & $15 \%$ & $2,767,682$ \\
\hline & & & & $15 \%$ & $3,182,834$ \\
\hline
\end{tabular}

\begin{tabular}{|c|c|c|c|c|c|}
\hline Description & $\begin{array}{l}\text { Rate } \\
\text { [\$/day] }\end{array}$ & $\begin{array}{c}\text { Quantitiy } \\
\text { [ea] }\end{array}$ & $\begin{array}{c}\text { Construction } \\
\text { Duration } \\
\text { [Days] }\end{array}$ & $\begin{array}{c}\text { Set Upl } \\
\text { Close Out } \\
\text { Duration } \\
\text { [Days] }\end{array}$ & Total Cost \\
\hline 2 Man Survey Crew (\#1) & $\$ 991.67$ & 1 & 55 & 3 & $57,516.67$ \\
\hline 2 Man Survey Crew (\#2) & $\$ 991.67$ & 0 & 0 & 0 & $\$$ \\
\hline GPS Survey Equipment (\#1) & $\$ 650.00$ & 1 & 55 & 3 & $37,700.00$ \\
\hline GPS Survey Equipment (\#2) & $\$ 650.00$ & 0 & 0 & 0 & - \\
\hline Survey Truck (\#1) & $\$ 450.00$ & 1 & 55 & 3 & $26,100.00$ \\
\hline Survey Truck (\#2) & $\$ 450.00$ & 0 & 0 & 0 & - \\
\hline Per Diem (\#1) & $\$ 110.00$ & 2 & 55 & 3 & $12,760.00$ \\
\hline Per Diem (\#2) & $\$ 110.00$ & 0 & 0 & 0 & $\$$ \\
\hline \multicolumn{5}{|c|}{$\begin{array}{cc} & \text { Total Route Survey } \\
\text { Total with Rooney Engineering Overhead of } 15 \%\end{array}$} & 134,077 \\
\hline \multicolumn{5}{|c|}{$\begin{aligned} \text { Total with Rooney Engineering Overhead of } & 15 \% \\
\text { Total with Estimate Contingency of } & 15 \%\end{aligned}$} & $\begin{array}{l}154,188 \\
\mathbf{1 7 7 , 3 1 6}\end{array}$ \\
\hline
\end{tabular}
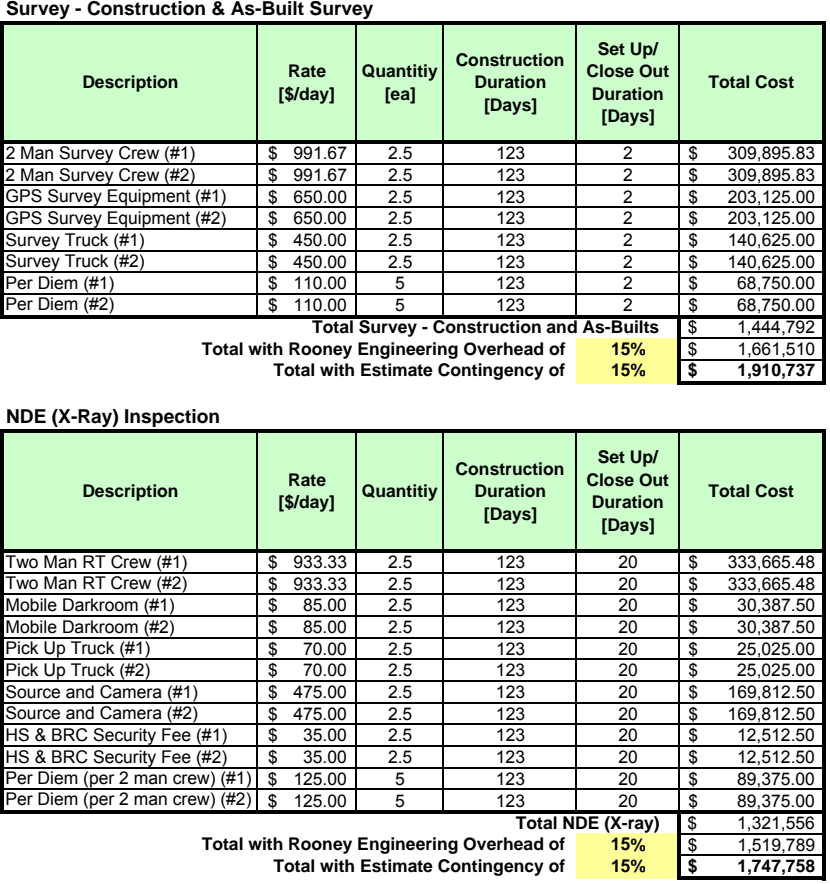

Engineering Survey and Procurement Inspection $\$$

Construction Inspection, Surveying and X-Ray \begin{tabular}{|rr}
\hline & $6,841,329$ \\
\cline { 3 - 4 } &
\end{tabular} 
INTEGRATED MID-CONTINENT CARBON CAPTURE, SEQUESTRATION \&

ENHANCED OIL RECOVERY PROJECT

Coffeyville Resources Fertilizer Plant (CVR) to the Thrall-Aagard Oil Field (TAF)

Material Quote Summary

Blue Source LLC

Dated: March 26, 2010

Pipeline Materal Bid Summary

\begin{tabular}{|c|c|c|c|}
\hline Type & Analysis & Material Description & Cost \\
\hline \multirow[t]{3}{*}{ 3D Bends } & Average & 8", $0.500 "$ w.t., 90 Degree, 3D, MSS SP-75, WPHY-65, Segmentable Fitting, coated with $14-16$ mils of FBE & $\$ 1,781.50$ \\
\hline & Average & 8", $0.500 "$ w.t., 60 Degree, 3D, MSS SP-75, WPHY-65, Segmentable Fitting, coated with $14-16$ mils of FBE & $\$ 1,756.50$ \\
\hline & Average & $8 ", 0.500 "$ w.t., 90 Degree, 3D, MSS SP-75, WPHY-65, Segmentable Fitting, coated with 14-16 mils of FBE & $\$ 1,110.50$ \\
\hline \multirow{2}{*}{ Line Pipe } & Average & 8.625" OD, 0.500" w.t., ERW, API 5L, PSL2, Grade X-65, DRL, BEW, Coated with 14-16 mils of FBE & $\$ 50.23$ \\
\hline & Average & 8.625" OD, 0.500" w.t., SMLS, API 5L, PSL2, Grade X-65, DRL, BEW, Coated with 14-16 mils of FBE & $\$ 47.48$ \\
\hline Launcher/Receiver & Average & $\begin{array}{l}\text { 8" x 12" - ANSI } 1500 \text { Launcher/Reciever, Barrel and Closure (Yale } 500 \text { or equivalent) Only, Traps to } \\
\text { accommodate instrumented pigs, conventional pigs and typical pipeline inspection tools. }\end{array}$ & $\$ 30,622.00$ \\
\hline Pig Launcher - Bill of Material & Edgen - Murray & 8" x 12" Pig Launcher Bill of Materials & $\$ 28,912.36$ \\
\hline \multirow[t]{2}{*}{ Pig Launcher - Bill of Material } & Edgen - Murray & 8" x 12 " Pig Receiver Bill of Materials & $\$ 19,638.36$ \\
\hline & & & \\
\hline \multirow{2}{*}{ Valves } & Cameron & 8" 1500 RTJ GO CAMERON T31 TRIM 601 w/ 7' STEM EXTENSION \& COAL TAR & $\$ 13,003.00$ \\
\hline & & 6" 1500 RTJ GO CAMERON T31 TRIM 601 & $\$ 9,300.00$ \\
\hline & & & \\
\hline
\end{tabular}


INTEGRATED MID-CONTINENT CARBON CAPTURE, SEQUESTRATION \&

ENHANCED OIL RECOVERY PROJECT

Coffeyville Resources Fertilizer Plant (CVR) to the Thrall-Aagard Oil Field (TAF)

Blue Source LLC

Date: March 26, 2010

Road, Railroad, and Waterway Crossing List

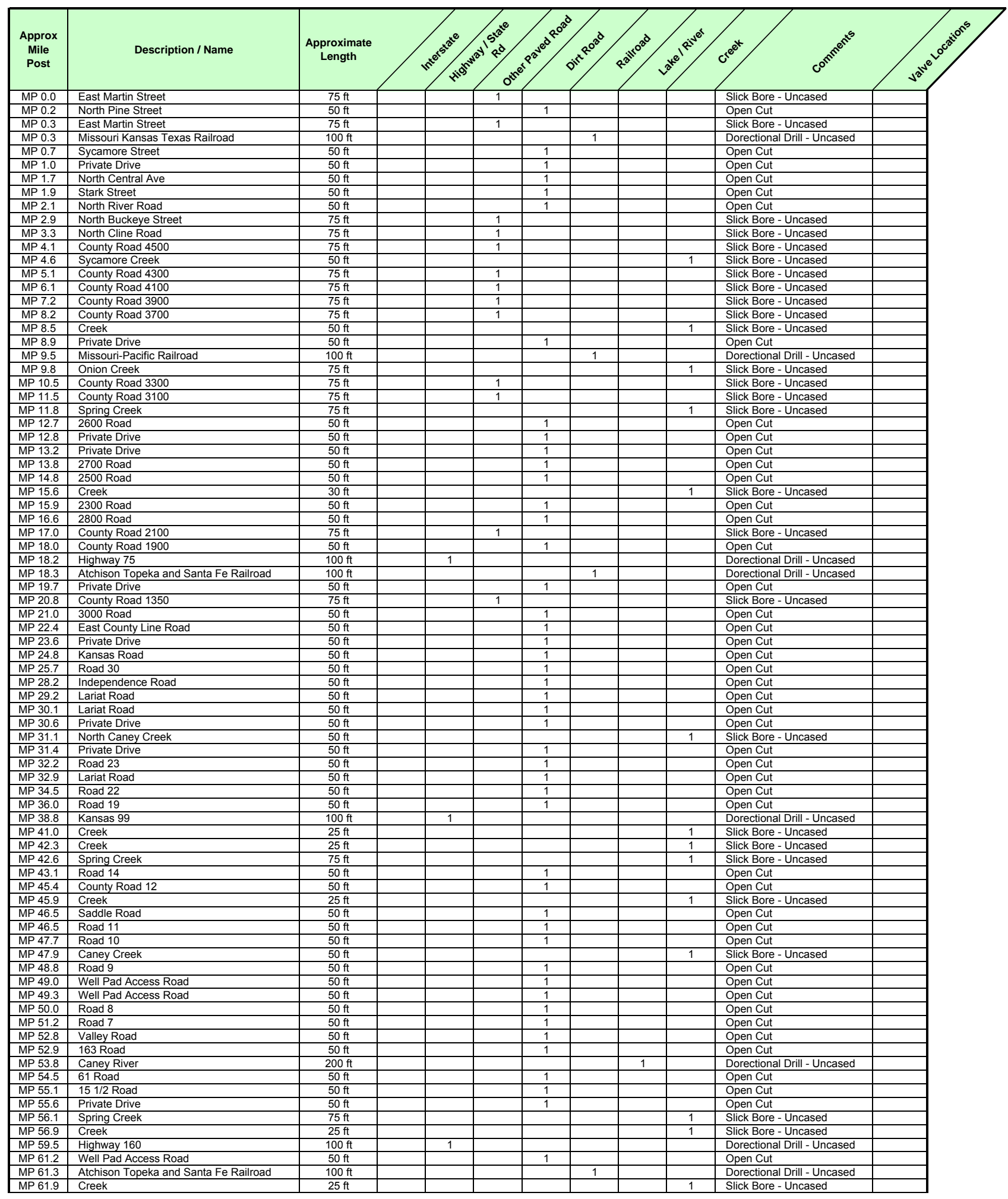


INTEGRATED MID-CONTINENT CARBON CAPTURE, SEQUESTRATION \&

ENHANCED OIL RECOVERY PROJECT

Coffeyville Resources Fertilizer Plant (CVR) to the Thrall-Aagard Oil Field (TAF)

Blue Source LLC

Date: March 26, 2010

Road, Railroad, and Waterway Crossing List

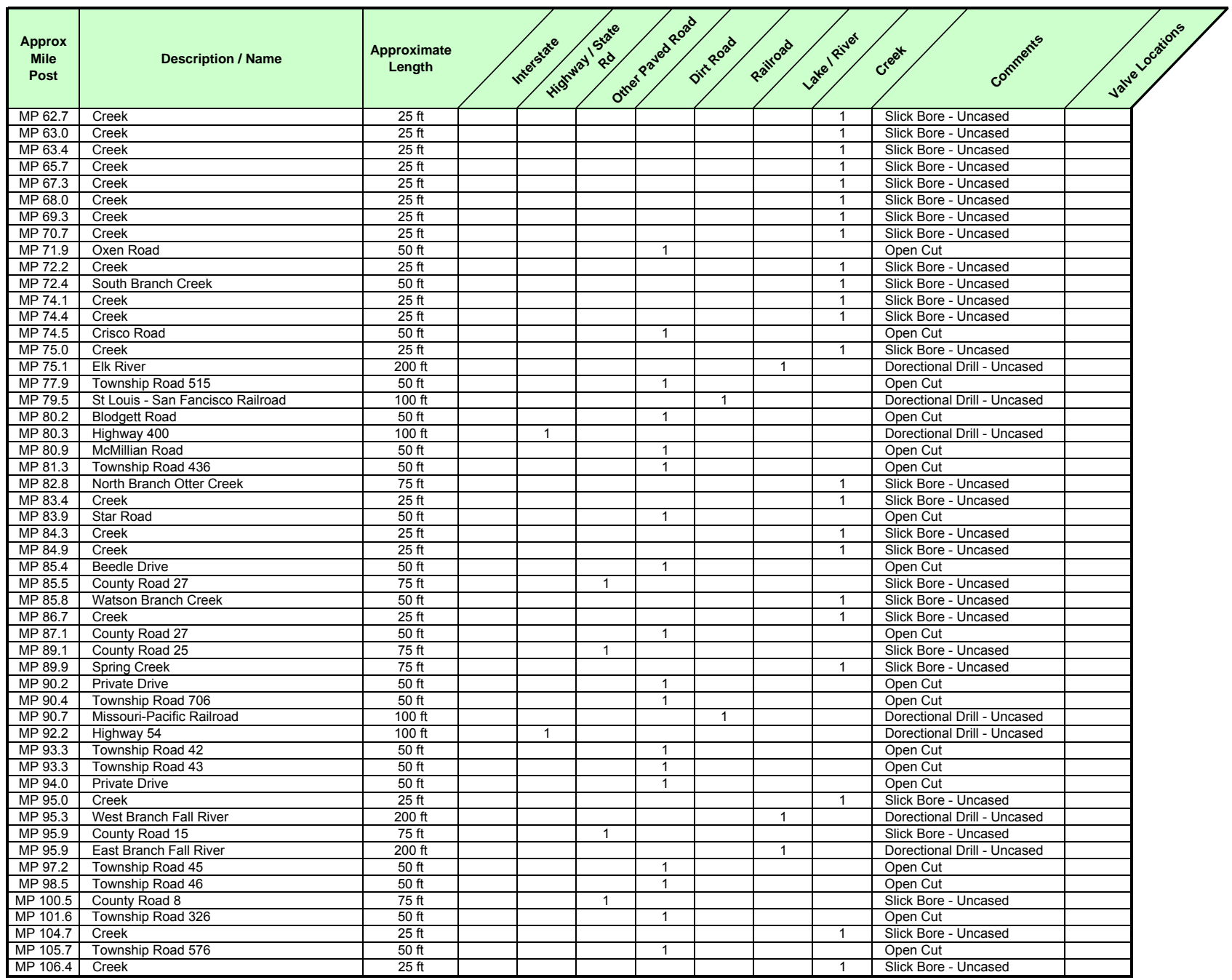

\section{Crossing Summary}

\begin{tabular}{|l|c|c|c|c|c|}
\hline \multicolumn{1}{|c|}{ TYPE } & $\begin{array}{c}\text { TOTAL NO. } \\
\text { CROSSINGS }\end{array}$ & $\begin{array}{c}\text { TOTAL } \\
\text { LENGTH }\end{array}$ & $\begin{array}{c}\text { W.A. } \\
\text { Length }\end{array}$ & $\begin{array}{c}\text { W.A. } \\
\text { Width }\end{array}$ & W.A. Dimensions \\
\hline Interstate & 0 & $0 \mathrm{ft}$ & $300 \mathrm{ft}$ & $300 \mathrm{ft}$ & 0 sq.ft. \\
\hline Highway / State Rd & 5 & $500 \mathrm{ft}$ & $300 \mathrm{ft}$ & $300 \mathrm{ft}$ & 900,000 sq.ft. \\
\hline Other Paved Road & 17 & $1,275 \mathrm{ft}$ & $300 \mathrm{ft}$ & $300 \mathrm{ft}$ & $3,060,000$ sq.ft. \\
\hline Dirt Road & 64 & $3,200 \mathrm{ft}$ & $300 \mathrm{ft}$ & $300 \mathrm{ft}$ & $11,520,000$ sq.ft. \\
\hline Railroad & 6 & $600 \mathrm{ft}$ & $300 \mathrm{ft}$ & $300 \mathrm{ft}$ & $1,080,000$ sq.ft. \\
\hline Lake / River & 4 & $800 \mathrm{ft}$ & $300 \mathrm{ft}$ & $300 \mathrm{ft}$ & 720,000 sq.ft. \\
\hline Creek & 37 & $1,380 \mathrm{ft}$ & $300 \mathrm{ft}$ & $300 \mathrm{ft}$ & $6,660,000$ sq.ft. \\
\hline TOTAL & 133 & $\mathbf{7 , 7 5 5} \mathrm{ft}$ & $\mathbf{N} / \mathrm{A}$ & $\mathbf{N} / \mathbf{A}$ & $\mathbf{2 3 , 9 4 0 , 0 0 0}$ sq.ft. \\
\hline
\end{tabular}

Total Crossing Work Areas $=\quad 549.6$ acres

Pipeline ROW Disturbance $=\quad 983.6$ acres

Total Disturbance $=1533.2$ acres 
INTEGRATED MID-CONTINENT CARBON CAPTURE, SEQUESTRATION \&

ENHANCED OIL RECOVERY PROJECT

Coffeyville Resources Fertilizer Plant (CVR) to the Thrall-Aagard Oil Field (TAF)

Blue Source LLC

Date: March 29, 2010

\section{FEED ESTIMATE FOR SCADA SYSTEM}

CLIENT: BLUE SOURCE

PROJECT CVR-TAF

DESCRIPTION: 108.2 MILES OF CO2 PIPELINE FROM THE COFFEYVILLE TO THRALL-AAGARD OIL FIELD

DATE

29-Mar-10

Estimate Overview:

This estimate is for a SCADA and Leak Detection system for a $\mathrm{CO} 2$ pipeline with main stations on either end of the pipeline and block valves sites along the pipeline as required. Each site would have a PLC and installed in a small building. The main control center site would house the primary SCADA and Leak Detection Computers which would communicate via fiber to the other sites. The other end of the pipeline would have a backup control center which would also contain the secondary SCADA and Leak Detection computers. A fiber optic cable would be installed along the pipeline and would be configured in a ring configuration for improved reliability.

SCADA Materials

\begin{tabular}{|l|r|rr|rr|}
\cline { 2 - 6 } \multicolumn{1}{c|}{} & Quantity & \multicolumn{1}{c|}{ Unit Price } & \multicolumn{1}{c|}{ Extension } \\
\hline Origination Station & 1 & $\$$ & $196,500.00$ & $\$$ & $196,500.00$ \\
\hline Terminal Station & 1 & $\$$ & $176,700.00$ & $\$$ & $176,700.00$ \\
\hline Block Valve Stations & 1 & $\$$ & $927,000.00$ & $\$$ & $927,000.00$ \\
\hline Fiber Optic Cable & 1 & $\$$ & $951,944.00$ & $\$$ & $951,944.00$ \\
\hline & & & & \\
\hline \hline & & & Subtotal & $\$$ & $\mathbf{2 , 2 5 2 , 1 4 4 . 0 0}$ \\
\hline & \multicolumn{2}{|c|}{ Sales Tax on Material (5.98\%) } & $\$$ & $134,700.00$ \\
\hline \hline
\end{tabular}

SCADA Engineering Hours/Expenses

\begin{tabular}{|l|r|rr|rr|}
\cline { 2 - 5 } \multicolumn{1}{c|}{} & \multicolumn{1}{c|}{ Hours } & \multicolumn{2}{c|}{ Unit Price } & \multicolumn{2}{c|}{ Extension } \\
\hline Sr Project Engineer - SCADA & 1604 & $\$$ & 121.00 & $\$$ & $194,084.00$ \\
\hline Sr Designer & 104 & $\$$ & 91.00 & $\$$ & $9,464.00$ \\
\hline Travel Expenses & 1 & $\$$ & $13,130.00$ & $\$$ & $13,130.00$ \\
\hline & & & & & \\
\hline \hline & & Subtotal & $\$$ & $\mathbf{2 4 9 , 0 0 0}$ \\
\hline
\end{tabular}

SCADA Vendor Labor

\begin{tabular}{|l|r|r|rr|}
\cline { 2 - 5 } \multicolumn{1}{c|}{} & Quantity & \multicolumn{1}{c|}{ Unit Price } & \multicolumn{2}{c|}{ Extension } \\
\hline SCADA, PLC, Leak Detection Services & 1 & $\$ 405,000.00$ & $\$$ & $405,000.00$ \\
\hline \hline & & & & $\mathbf{4 6 6 , 0 0 0}$ \\
\hline
\end{tabular}

Fiber Optic Construction Labor

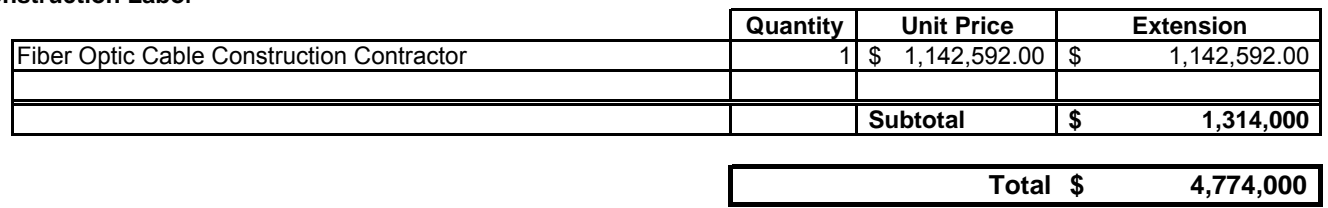

Notes:

Assumed Estimate Contingency $\quad 15.0 \%$

1) SCADA electrical construction contractor labor not included since wiring up the PLCs would be done by site contractor along with instruments

2) Fiber optic labor assumes moderately difficult ground conditions which raises cable installation cost moderately

3) PLC MCC building is included at the terminal station

4) Instrumentation not included here. 
INTEGRATED MID-CONTINENT CARBON CAPTURE, SEQUESTRATION \&

ENHANCED OIL RECOVERY PROJECT

Coffeyville Resources Fertilizer Plant (CVR) to the Thrall-Aagard Oil Field (TAF)

Blue Source LLC

Date: March 29, 2010

STATIONS ON EITHER END OF PIPELINE

Materials

ORIGINATION STATION

TERMINAI

\begin{tabular}{|l|r|rr|rr|}
\multicolumn{1}{c|}{} & \multicolumn{1}{c|}{ Quantity } & \multicolumn{2}{c|}{ Unit Price } & \multicolumn{1}{c|}{ Extension } \\
\cline { 2 - 5 } \multicolumn{1}{c|}{ PLC, w Cabinet } & 1 & $\$ 40,000.00$ & $\$$ & $40,000.00$ \\
\hline SCADA Software Licenses & 1 & $\$ 35,000.00$ & $\$$ & $35,000.00$ \\
\hline Backup communications components & 1 & $\$$ & $10,000.00$ & $\$$ & $10,000.00$ \\
\hline SCADA Server, Rack, Printer, etc & 1 & $\$$ & $20,000.00$ & $\$$ & $20,000.00$ \\
\hline Leak Detection Server & 1 & $\$$ & $5,000.00$ & $\$$ & $5,000.00$ \\
\hline Leak Detection Software Licenses (note 2) & 1 & $\$$ & $60,000.00$ & $\$$ & $60,000.00$ \\
\hline UPS & 1 & $\$$ & $5,000.00$ & $\$$ & $5,000.00$ \\
\hline Fiber Media Converter & 1 & $\$$ & $1,500.00$ & $\$$ & $1,500.00$ \\
\hline Communications Equipment for backup communications & 1 & $\$$ & $5,000.00$ & $\$$ & $5,000.00$ \\
\hline Misc & 1 & $\$$ & $15,000.00$ & $\$$ & $15,000.00$ \\
\hline \hline & & & Subtotal & $\$$ & $\mathbf{1 9 6 , 5 0 0 . 0 0}$ \\
\hline
\end{tabular}

\begin{tabular}{|c|c|c|c|c|c|c|}
\hline \multirow[b]{2}{*}{ TERMINAL } & \multirow[b]{2}{*}{ PLC, w Cabinet } & \multirow{2}{*}{\begin{tabular}{r|} 
Quantity \\
1
\end{tabular}} & \multicolumn{2}{|c|}{ Unit Price } & \multicolumn{2}{|c|}{ Extension } \\
\hline & & & $\$$ & $40,000.00$ & $\$$ & $40,000.00$ \\
\hline \multirow[t]{11}{*}{ STATION } & PLC-MCC Building & 1 & $\$$ & $65,000.00$ & $\$$ & $65,000.00$ \\
\hline & SCADA Software Licenses & 1 & $\$$ & $7,000.00$ & $\$$ & $7,000.00$ \\
\hline & Backup communications components & 1 & $\$$ & $10,000.00$ & $\$$ & $10,000.00$ \\
\hline & SCADA Computer, Rack & 1 & $\$$ & $10,000.00$ & $\$$ & $10,000.00$ \\
\hline & Leak Detection Computer & 1 & $\$$ & $5,000.00$ & $\$$ & $5,000.00$ \\
\hline & \begin{tabular}{|l|} 
Leak Detection Software Licenses \\
\end{tabular} & 1 & $\$$ & $15,000.00$ & $\$$ & $15,000.00$ \\
\hline & UPS & 1 & $\$$ & $5,000.00$ & $\$$ & $5,000.00$ \\
\hline & Fiber Media Converter & 1 & $\$$ & $3,200.00$ & $\$$ & $3,200.00$ \\
\hline & Communications Equipment for backup communications & 1 & $\$$ & $1,500.00$ & $\$$ & $1,500.00$ \\
\hline & Misc & 1 & $\$$ & $15,000.00$ & $\$$ & $15,000.00$ \\
\hline & & & \multicolumn{2}{|c|}{ Subtotal } & $\$$ & $176,700.00$ \\
\hline
\end{tabular}

VENDOR SERVICES

\begin{tabular}{|c|c|c|c|c|c|}
\hline & & & & \multicolumn{2}{|c|}{ Extension } \\
\hline SCADA Vendor Services for Origination Station (note 6) & 1 & $\$$ & $175,000.00$ & $\$$ & $175,000.00$ \\
\hline SCADA Vendor services for Terminal Station & 1 & $\$$ & $10,000.00$ & $\$$ & $10,000.00$ \\
\hline SCADA Vendor Travel Expenses & 1 & $\$$ & $30,000.00$ & $\$$ & $30,000.00$ \\
\hline PLC Programming for two PLCs & 2 & $\$$ & $50,000.00$ & $\$$ & $100,000.00$ \\
\hline PLC Programmer Travel Expenses & 1 & $\$$ & $15,000.00$ & $\$$ & $15,000.00$ \\
\hline Leak Detection System services for Origination Station & 1 & $\$$ & $60,000.00$ & $\$$ & $60,000.00$ \\
\hline Leak Detection System services for Terminal Station & 1 & $\$$ & $5,000.00$ & $\$$ & $5,000.00$ \\
\hline \multirow[t]{3}{*}{ Leak Detection Vendor Travel Expenses } & 1 & $\$$ & $10,000.00$ & $\$$ & $10,000.00$ \\
\hline & & & & $\$$ & - \\
\hline & & & ototal & $\$$ & $\overline{4405,000.00}$ \\
\hline
\end{tabular}

Notes:

1) Assumes fiber optic communications.

3) PLC MCC building is included at the terminal station

3) Assumes Wonderware class SCADA software

4) Assuming $120 \mathrm{VAC}$ is available at both stations

5) Instrumentation not included here.

6) SCADA vendor services include project management, design specification documents, SCADA communications programming, SCADA screen programming, factory tests, installation onsite, onsite tuning of the software, commissioning tests, operations and the maintenance manual, training support for operators and technicians

7) Leak Detection vendor services include project management, design specification documents, communications programming, graphical user interface screen programming, factory tests, installation onsite, tuning of the software, commissioning tests, operations and the maintenance manual, training support for operators and technicians 
INTEGRATED MID-CONTINENT CARBON CAPTURE, SEQUESTRATION \&

ENHANCED OIL RECOVERY PROJECT

Coffeyville Resources Fertilizer Plant (CVR) to the Thrall-Aagard Oil Field (TAF)

Blue Source LLC

Date: March 29, 2010

\section{BLOCK VALVE STATIONS}

Materials

\begin{tabular}{|l|r|rr|rr|}
\cline { 2 - 5 } \multicolumn{1}{c|}{} & Quantity & \multicolumn{2}{c|}{ Unit Price } & \multicolumn{2}{c|}{ Extension } \\
\hline PLC, w Cabinet & 18 & $\$ 15,000.00$ & $\$$ & $270,000.00$ \\
\hline PLC Building & 18 & $\$$ & $30,000.00$ & $\$$ & $540,000.00$ \\
\hline Fiber media converter & 18 & $\$ 1,500.00$ & $\$$ & $27,000.00$ \\
\hline Misc & 18 & $\$$ & $5,000.00$ & $\$$ & $90,000.00$ \\
\hline \hline & & Subtotal & $\$$ & $\mathbf{9 2 7 , 0 0 0 . 0 0}$ \\
\hline
\end{tabular}

Services

\begin{tabular}{|c|c|c|c|}
\hline & Quantity & Unit Price & Extension \\
\hline PLC Programming & 18 & $\$ 3,000.00$ & $54,000.00$ \\
\hline PLC Programmer Travel Expenses & 18 & $1,000.00$ & $18,000.00$ \\
\hline Misc & 18 & $2,000.00$ & $36,000.00$ \\
\hline & & Subtotal & $108,000.00$ \\
\hline
\end{tabular}

Notes:

1 PLC building is recommended due to the difficulty of maintaining PLC in winter conditions. 
INTEGRATED MID-CONTINENT CARBON CAPTURE, SEQUESTRATION \&

ENHANCED OIL RECOVERY PROJECT

Coffeyville Resources Fertilizer Plant (CVR) to the Thrall-Aagard Oil Field (TAF)

Blue Source LLC

Date: March 29, 2010

FIBER OPTICS

Materials

\begin{tabular}{|c|c|c|c|c|c|c|}
\hline & Quantity & Units & \multicolumn{2}{|c|}{ Unit Price } & \multicolumn{2}{|c|}{ Extension } \\
\hline 12 Strand Single Mode Armored Outside Plant Cable & 571,296 & $\mathrm{ft}$ & $\$$ & 1.50 & $\$$ & $856,944.00$ \\
\hline Fiber troublshooting instument & 1 & LS & \$ & $35,000.00$ & $\$$ & $35,000.00$ \\
\hline Misc Hand Holes, etc & 3 & LS & \$ & $20,000.00$ & \$ & $60,000.00$ \\
\hline & & & & total & \$ & $951,944.00$ \\
\hline
\end{tabular}

Labor - Installation Contractor

\begin{tabular}{|c|c|c|c|c|}
\hline & Quantity & Units & Unit Price & Extension \\
\hline Contractor Labor for installation and testing & 571,296 & $\mathrm{ft}$ & $\$ \quad 2.00$ & $\$ 1,142,592.00$ \\
\hline & & & & $\$$ \\
\hline & & & Subtotal & $\$ 1,142,592.00$ \\
\hline
\end{tabular}

Notes: 
INTEGRATED MID-CONTINENT CARBON CAPTURE, SEQUESTRATION \&

ENHANCED OIL RECOVERY PROJECT

Coffeyville Resources Fertilizer Plant (CVR) to the Thrall-Aagard Oil Field (TAF)

Blue Source LLC

Date: March 26, 2010

SCADA PROJECT - ESTIMATE OF I\&E ENGINEERING TASKS

\begin{tabular}{|c|c|c|c|c|c|c|c|c|c|c|c|c|c|c|c|c|c|c|c|}
\hline & & \multirow[b]{2}{*}{$\begin{array}{c}\bar{\Phi} \\
\sum_{2}^{0} \\
\text { Rates: }\end{array}$} & \multicolumn{4}{|c|}{ Project Management } & \multicolumn{5}{|c|}{ TRAVEL \& MISC EXPENSES } & \multicolumn{6}{|c|}{ Engineering } & \multirow[b]{2}{*}{ 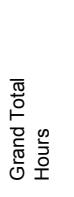 } & \multirow[b]{2}{*}{ 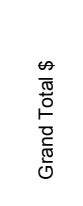 } \\
\hline TASK \# & TASKS & & 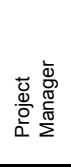 & 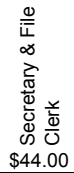 & 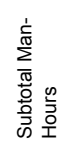 & 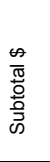 & 菢 & 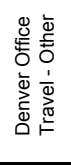 & 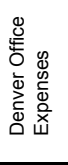 & $\begin{array}{l}\dot{0} \\
\dot{m} \\
\dot{m}\end{array}$ & 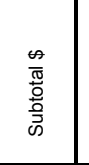 & 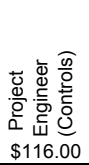 & 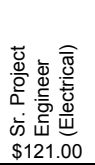 & 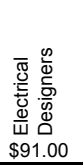 & 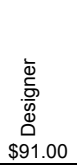 & 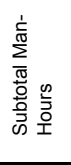 & 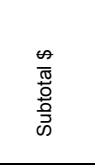 & & \\
\hline 1 & Initial Site visit & & & & 0 & $\$ 0$ & 1,920 & & & & $\$ 1,920$ & & 30 & & & 30 & 3,630 & 30 & 5,550 \\
\hline 2 & & & & & 0 & $\$ 0$ & & & & & $\$ 0$ & & & & & 0 & 0 & 0 & 0 \\
\hline 3 & & & & & 0 & $\$ 0$ & & & & & $\$ 0$ & & & & & 0 & 0 & 0 & 0 \\
\hline 4 & Assist with Project Budget preparation & & & & 0 & $\$ 0$ & & & & & $\$ 0$ & & 24 & & & 24 & 2,904 & 24 & 2,904 \\
\hline 5 & & & & & 0 & $\$ 0$ & & & & & $\$ 0$ & & & & & 0 & 0 & 0 & 0 \\
\hline 6 & $\begin{array}{l}\text { SCADA SPECIFICATION, RFQ, CONTRACT OVERSIGHT, DESIGN } \\
\text { APPROVAL, FACTORY TEST, SITE TEST }\end{array}$ & & & & 0 & $\$ 0$ & & & 300 & & $\$ 300$ & & 400 & & & 400 & 48,400 & 350 & 48,700 \\
\hline 7 & & & & & 0 & $\$ 0$ & & & & & $\$ 0$ & & & & & 0 & 0 & 0 & 0 \\
\hline & $\begin{array}{l}\text { LEAK DETECTION SYSTEM SPECIFICATION, RFQ, CONTRACT } \\
\text { OVERSIGHT, DESIGN APPROVAL, FACTORY TEST, SITE TEST }\end{array}$ & & & & 0 & $\$ 0$ & & & 200 & & $\$ 200$ & & 300 & & & 300 & 36,300 & 250 & 36,500 \\
\hline 1 & & & & & 0 & $\$ 0$ & & & & & $\$ 0$ & & & & & 0 & 0 & 0 & 0 \\
\hline 2 & Fiber Optic Design, RFQ & & & & 0 & $\$ 0$ & & & & & \$o & & 120 & & & 120 & 14,520 & 120 & 14,520 \\
\hline 3 & & & & & 0 & $\$ 0$ & & & & & $\$ 0$ & & & & & 0 & 0 & 0 & 0 \\
\hline 4 & Fiber Optic Construction Spec, RFQ, Contract Oversight & & & & 0 & $\$ 0$ & & & & & $\$ 0$ & & 100 & & & 100 & 12,100 & 100 & 12,100 \\
\hline 5 & & & & & 0 & $\$ 0$ & & & & & $\$ 0$ & & & & & 0 & 0 & 0 & 0 \\
\hline 6 & & & & & 0 & $\$ 0$ & & & & & $\$ 0$ & & & & & 0 & 0 & 0 & 0 \\
\hline 7 & & & & & 0 & $\$ 0$ & & & & & $\$ 0$ & & & & & 0 & 0 & 0 & 0 \\
\hline 8 & & & & & 0 & $\$ 0$ & & & & & $\$ 0$ & & & & & 0 & 0 & 0 & 0 \\
\hline 9 & & & & & 0 & $\$ 0$ & & & & & $\$ 0$ & & & & & 0 & 0 & 0 & 0 \\
\hline 10 & & & & & 0 & $\$ 0$ & & & & & \$0 & & & & & 0 & 0 & 0 & 0 \\
\hline 11 & & & & & 0 & $\$ 0$ & & & & & $\$ 0$ & & & & & 0 & 0 & 0 & 0 \\
\hline 12 & Weekly Conference Calls & & & & 0 & $\$ 0$ & & & & & $\$ 0$ & & 30 & & & 30 & 3,630 & 30 & 3,630 \\
\hline 13 & & & & & 0 & $\$ 0$ & & & & & $\$ 0$ & & & & & 0 & 0 & 0 & 0 \\
\hline 14 & Construction Inspection Trip (X 5) & & & & 0 & $\$ 0$ & 5,950 & & & & $\$ 5,950$ & & 200 & & & 200 & 24,200 & 200 & 30,150 \\
\hline 15 & Testing Trips ( $x 4)$ & & & & 0 & $\$ 0$ & 4,760 & & & & $\$ 4,760$ & & 160 & & & 160 & 19,360 & 160 & 24,120 \\
\hline 16 & & & & & 0 & $\$ 0$ & & & & & $\$ 0$ & & & & & 0 & 0 & 0 & 0 \\
\hline$\frac{10}{17}$ & & & & & 0 & $\$ 0$ & & & & & $\$ 0$ & & & & & 0 & 0 & 0 & 0 \\
\hline 18 & As Built Electrical Drawings & & & & 0 & $\$ 0$ & & & & & $\$ 0$ & & 80 & 100 & & 180 & 18,780 & 180 & 18,780 \\
\hline 19 & I\&E Job Book & & & & 0 & $\$ 0$ & & & & & $\$ 0$ & & 40 & 4 & & 44 & 5,204 & 44 & 5,204 \\
\hline 20 & & & & & 0 & $\$ 0$ & & & & & $\$ 0$ & & & & & 0 & 0 & 0 & 0 \\
\hline$\frac{21}{21}$ & Assist with SCADA \& Leak Detection Tuning & & & & 0 & $\$ 0$ & & & & & $\$ 0$ & & 120 & & & 120 & 14,520 & 120 & 14,520 \\
\hline 22 & & & & & 0 & $\$ 0$ & & & & & $\$ 0$ & & & & & 0 & 0 & 0 & 0 \\
\hline 23 & & & & & 0 & $\$ 0$ & & & & & $\$ 0$ & & & & & 0 & 0 & 0 & 0 \\
\hline 24 & & & & & 0 & $\$ 0$ & & & & & $\$ 0$ & & & & & 0 & 0 & 0 & 0 \\
\hline 25 & & & & & & $\$ 0$ & & & & & & & & & & 24 & 0 & & \\
\hline 26 & & & & 0 & 0 & $\$ 0$ & 0 & & 0 & & $\$ 0$ & & & 0 & 0 & 0 & 0 & 0 & 0 \\
\hline 27 & & & 0 & 0 & 0 & $\$ 0$ & 0 & & 0 & 0 & $\$ 0$ & 0 & 0 & 0 & 0 & 0 & 0 & 0 & 0 \\
\hline & & Hours & 0 & 0 & 0 & $\$ 0$ & $\frac{0}{12,630}$ & & 500 & 0 & $\frac{\varphi 0}{13,130}$ & $\frac{0}{0}$ & 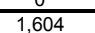 & 104 & 0 & 1,732 & 203,548 & 1,608 & \\
\hline & & Cost (\$) & 0 & 0 & $\$ 0$ & & 12,630 & 0 & 500 & 0 & 13,130 & 0 & 194,084 & 9,464 & 0 & & 203,548 & & 216,678 \\
\hline
\end{tabular}




\section{BLUE SOURCE, LLC. \\ CVR-TAF CO2 PIPELINE PROJECT \\ COFFEYVILLE COMPRESSION FACILITY \\ TIER III - CAPITAL COST ESTIMATE}

Client: Blue Source, LLC.

Project: CVR-TAF CO2 Pipeline Project

System: Coffeyville Compression Facility

Scope: Ref. Blue Source RFP for Kansas CO2 Pipeline Study, Doc. RPH-12-29-09.

Description: Engineering, Design \& Construction of low pressure booster facilities to take waste gas off of the Coffeyville Refinery Amine Plant vent stack and transport it approximately 1,300 ft. via a new 24", SDR-32.5 high density polyethylene (HDPE) pipeline to a new BS/CVR compression facility located in the SW NE of Section 36, T34S, R16E, where the CO2 mix stream is processed for use in Enhanced Oil Recover and taken from the vapor phase to the supercritical phase and boosted to pipeline pressure for transportation to the Thrall Aagard Field delivery point located in NW NW of Section 31, T24S, R10E.

\section{COMPRESSION FACILITIES}

ENGINEERING \& DESIGN

BS/CVR COMPRESSION FACILITIES

\section{LAND \& RIGHT-OF-WAY}

BS/CVR COMPRESSION FACILITIES

ENVIRONMENTAL \& PERMITTING

BS/CVR COMPRESSION FACILITIES

EQUIPMENT \& MATERIALS

BS/CVR COMPRESSION FACILITIES

FREIGHT @ 8\%

TAXES @ 5.98\%

CONSTRUCTION SERVICES

BS/CVR COMPRESSION FACILITIES

CONSTRUCTION

BS/CVR COMPRESSION FACILITIES

BOND @ 3\%

$\$ 985,000$

$\$ 984,538$

$\$ 0$




\section{BLUE SOURCE, LLC. CVR-TAF CO2 PIPELINE PROJECT \\ COFFEYVILLE COMPRESSION FACILITY TIER III - CAPITAL COST ESTIMATE}

Client: Blue Source, LLC.

Project: CVR-TAF CO2 PIpelıne Project

system: Cofteyville Compressıon racility

Scope: Ref. Blue Source RFP for Kansas CO2 Pipeline Study, Doc. RPH-12-29-09.

Description: Engineering, Design \& Construction of low pressure booster facilities to take waste gas off of the Coffeyville Refinery Amine Plant vent stack and transport it approximately 1,300 ft. via a new 24", SDR-32.5 high density polyethylene (HDPE) pipeline to a new BS/CVR compression facility located in the SW NE of Section 36, T34S, R16E, where the CO2 mix stream is processed for use in Enhanced Oil Recover and taken from the vapor phase to the supercritical phase and boosted to pipeline pressure for transportation to the Thrall Aagard Field delivery point located in NW NW of Section 31, T24S, R10E.

\begin{tabular}{|c|c|c|c|c|}
\hline \multirow{2}{*}{$\frac{\text { BSICVR COMPRESSION FACILITIES }}{\text { LAND \& RIGHT-OF-WAY (BY OTHERS) }}$} & \multicolumn{3}{|c|}{ Station Horsepower: 15,000 BHP } & \multirow{2}{*}{$\frac{\% \text { Total }}{0.0 \%}$} \\
\hline & & & $\$ 0$ & \\
\hline ENVIRONMENTAL \& PERMITTING (BY OTHERS) & & & $\$ 5,000$ & $0.0 \%$ \\
\hline MATERIALS \& EQUIPMENT & & & $\$ 15,553,000$ & $58.6 \%$ \\
\hline \multirow[t]{5}{*}{ CONSTRUCTION } & & & $\$ 3,297,505$ & $12.4 \%$ \\
\hline & Land, Permitting, Materials \& Construction Sul & b-Total: & $\$ 18,855,505$ & $71.0 \%$ \\
\hline & Freight on Materials \& Equipment @ & $8 \%$ & $\$ 1,244,240$ & \\
\hline & Taxes@_. & $5.98 \%$ & $\$ 1,004,475$ & \\
\hline & \multicolumn{2}{|c|}{ Land, Permitting, Materials \& Construction Total: } & $\$ 21,104,219$ & $79.5 \%$ \\
\hline ENGINEERING \& DESIGN & & & $\$ 836,120$ & $3.1 \%$ \\
\hline GEOTECHNICAL INVESTIGATIONS & & & $\$ 20,000$ & $0.1 \%$ \\
\hline CONSTRUCTION MANAGEMENT & & & $\$ 723,540$ & $2.7 \%$ \\
\hline SURVEY (INCL W/ CONSTRUCTION COSTS) & & $0.0 \%$ & $\$ 0$ & $0.0 \%$ \\
\hline INSPECTION SERVICES & 240 Man-Days @ & $100 \%$ & $\$ 264,000$ & $1.0 \%$ \\
\hline NON-DESTRUCTIVE EXAMINATION & 30 Crew-Days @ & $100 \%$ & $\$ 51,000$ & $0.2 \%$ \\
\hline \multirow[t]{5}{*}{ LEGAL (BY OTHERS) } & & & $\$ 0$ & $0.0 \%$ \\
\hline & \multicolumn{2}{|c|}{ Engineering \& Contract Services Sub-Total: } & $\$ 1,894,660$ & $7.1 \%$ \\
\hline & \multicolumn{2}{|c|}{ Compression Facilities Sub-Total: } & $\$ 22,998,879$ & \\
\hline & \multicolumn{2}{|c|}{ Contingency @ 15\% } & $\$ 3,449,832$ & $13.0 \%$ \\
\hline & \multicolumn{2}{|l|}{ Construction Performance Bond @ 3\% } & $\$ 98,925$ & $0.4 \%$ \\
\hline \$/BHP: $\quad \$ 1,770$ & \multicolumn{3}{|c|}{ COMPRESSION FACILITIES TOTAL: } & $100.0 \%$ \\
\hline
\end{tabular}


Blue Source, LLC.

CVR-TAF CO2 Pipeline Project

Coffeyville Compression Facility

\section{Project Estimate Worksheet}

LAND \& RIGHT-OF-WAY

100. BS/CVR COMPRESSOR STATION

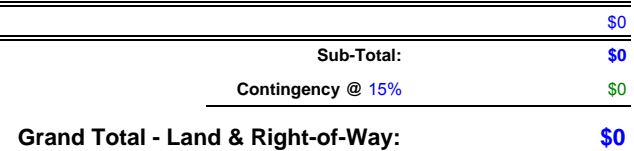

Cost Code

Qty

Units

Unit Rate

Sub-Total Price

Estimate Supplier

100. BS/CVR COMPRESSOR STATION

101. Acquisition \& Damages

01 Land \& Property Appraisals

02 Land Acquisition Costs

Sub-To

0 Weeks $\$ 2,500$

03 Property Expense 
Blue Source, LLC.

CVR-TAF CO2 Pipeline Project

Coffeyville Compression Facility

\section{Project Estimate Worksheet}

ENVIRIONMENTAL \& PERMITTING SUPPORT

100. BS/CVR COMPRESSOR STATION

\begin{tabular}{rr} 
& $\$ 5,000$ \\
\hline Sub-Total: & $\$ 5,000$ \\
ency @ 15\% & $\$ 750$ \\
\hline
\end{tabular}

Grand Total - Environmental \& Permitting Support:

$\$ 5,750$

Description

Cost Code

Qty

Units

Unit Rate

Sub-Total Price

Estimate Supplie

100. BS/CVR COMPRESSOR STATION

101. Permitting Assistance

01 Air Permitting Support \& Acquisition Costs

101.01

LS

$\$ 5,000$

102. Storm Water Monitoring

01 TBD

102.01

LS $\$ 0$

$\$ 5,000$

LWR Consultants 
Blue Source, LLC.

CVR-TAF CO2 Pipeline Project

Coffeyville Compression Facility
MATERIALS \& EQUIPMENT

100. MECHANICAL EQUIPMENT \& MATERIALS

200. ELECTRICAL \& INSTRUMENTATION EQUIPMENT \& MATERIALS
$\$ 14,463,000$

$\$ 1,090,000$

Sub-Total:

Freight @ 8\%

Taxes@6\%

$\$ 1,004,475$

Contingency @ 15\%

$\$ 2,670,257$

Grand Total - Materials \& Equipment:

$\$ 20,471,972$

\section{Project Estimate Worksheet}

Cost Code

Description

100. MECHANICAL EQUIPMENT \& MATERIALS

101. Pipe, Fittings \& Materials

01 Pipe, Various Diameters \& Coatings

02 24-Inch, SDR-11, High Density Polyethylene

03 Fittings, Various Diameters

102. Scrubbers / Filters / Separators

01 Scrubber, 2-Phase, Vertical, 8.625" O.D. x 4'-0" S/S, ASME Sect. VIII, Div. 1, 285 psi @ -20/1C

103. Compression Equipment

01 API Centrifugal Compressor / API Centrifugal Pump, Integrated Package, 15,000 bhp Total

01 API Centrifugal Compressor / API Centrifugal Pump,

03 Compressor, Blower, GD Suitorbuild 8000 or Equal, 500 HP, $4160 \mathrm{~V}$ Inv. Duty Electric Drive

104. Processing Equipment

01 TEG Dehydration Package, 3.5 MMBTU/ Hr Reboiler, 60" Contactor Column

101.01

101.02
Estimate Supplier

Units Unit Rate Sub-Total Price

$\$ 14,463,000$

Pipe_Lot2

24_HDPE_SDR11

Fitting_Lot3

Sub-Total:

$\$ 20,000$

$\$ 20,000$

\section{$\$ 40,000$}

$\$ 40,000 \quad$ REI - Estimated

$\$ 89,813$ Fergeson

01 Scrubber_Vertical $8 \times 48$

$\begin{array}{cc}2 & \text { LOT } \\ 1,386 & \text { LF } \\ 2 & \text { LOT }\end{array}$

$\$ 15,000$

$\$ 5,749 \quad$ Midco Fabricators

103.01 Comp_Cent_15000HP

103.02 Spares

Comp_Blower_500HP

EA $\$ 5,749$

$11,000,000$

GE - Est

$\$ 600,000$ UE Compression - Est.

104.01 Dehy_TEG3.5

$\$ 880,000$

$\$ 200,000$

$\$ 1,100,000$

QB Johnson

105. Compressor Building

01 Compressor Building, 75' W x 80' L x 15' Eve Hght, Ovhd Door, Fixed Louvers, 5 Ton Bridge C

106. Block Valves \& SDV's

01 Valves, Various Sizes \& Type

Comp_Bldg $75 \times 80 \times 15$

$\$ 1,100,000$

$\$ 361,444$

REI - Estimated

106.01 Valve_Lot4

$\$ 250,000 \quad$ REI - Estimated

107. Metering

01 Meter, Ultrasonic, Krohne Model UFM3030, 8" 150\# ANSI, RFFE, w/ Local Indication \& Signal

02 Orifice Meter, 2" ANSI 150 RFFE, Simplex w/ Flow Cond. \& Skid Mounted Metal Building

\subsection{1}

\section{ButT150}

108.01

4C60AS

01 Valve, Check, 4" ANSI 600 RFFE, Swing, API-6D

109. Sump Tank

01 Sump Tank, 3,000 Gallon, Double Wall Fiberglass w/ Turbine Enclosure, Leak Monitor, Brine

110. Pipe Supports

01 Pipe Support, 20" Pipe, EZ-Line Model CSB-20 w/Shim Blocks, Pipe Clamp \& Baseplate

02 Pipe Support, 12" Pipe, EZ-Line Model CSB-12 w/Shim Blocks, Pipe Clamp \& Baseplate

02 Pipe Support, 12" Pipe, EZ-Line Model CSB-12 W/Shim Blocks, Pipe Clamp \& Basepl

04 Pipe Support, 4" Pipe, EZ-Line Model CSB-4 w/Shim Blocks, Pipe Clamp \& Baseplate
109.01

\subsection{1}

110.02

110.03
Sump_3000

\section{CSB-20}

CSB-12

CSB-08

CSB-04
\$18,934 Trailblazer Controls

$\$ 23,214 \quad$ JW Measurement

\$2,968 REI - Estimated

$\$ 17,808 \quad$ Palmer Mfct - 11.17 .09

$\$ 12,126 \quad$ EZ-Line - 2009

$\$ 19,334 \quad$ EZ-Line - 2009

$\$ 7,123$ REI - Estimated

REI - Estimated

$\begin{array}{cc}201.01 & \\ 201.02 & \text { PI } \\ 201.03 & \text { TI } \\ 201.04 & \text { PSHH } \\ 201.05 & \text { LSHH_1 } \\ 201.06 & \text { LG } \\ 201.07 & \text { PIT } \\ 201.08 & \text { TT } \\ 201.09 & \text { LIT-1 } \\ 201.10 & \text { LSHH_2 } \\ 201.11 & \text { CO2_DET } \\ 201.12 & \text { FIRE_EYE } \\ & \text { VT }\end{array}$

201.12

11 Fire Eye, Class 1 / Div 1 Rated

202. Switchgear / Motor Starters \& MCC's

01 Switchgear, $4160 \mathrm{~V}$ w/ Vacuum Circuit Breaker \& 4160V Solid State Reduced Voltage Starter

03 Motor Control Center, $480 \mathrm{~V}$

203. Transformers

01 Transformer, 4160V / 480V, Padmount, Oil Filled, 500 KVA, Nema 3R, 65 deg. C Rise

02 Transformer, 13.8KV / 4160V, Padmount, Oil Filled, 5000 KVA

204. UPS / Power Supply Equipment

01 Unitized Distribution Substation

02 UPS, Rack Mounted, Bypass Switch, 7 KVA

205. Control Switches \& Lighting

01 Lighting Subpanel, 120V, 1Ph

02 Yard Lighting, 1000 Watt w/40' Aluminum Pole

206. Power \& Control Buildings

01 Building, Pre-Fab Metal, 13'x60', HVAC, w/ Access Platforms \& Stairs

207. PLC Equipment \& Controls

01 PLC \& DIO Panel \& Equipment, Incl. Programming \& Commissioning

208. Consumables

01 Electrical \& Instrumentation Consumables (Compressor Station)
202.01

202.02

202.03

203.01

203.02

204.01

204.02

205.01

205.02

206.01

PDC_13X60MED

207.01

PLC_Lot2

PLCLot2

4160_Switchgear

Soft_Start 1

$$
\begin{aligned}
& \text { UDS } \\
& \text { UPS }
\end{aligned}
$$

LGHT_Sub Pane

LGHT1000
208.01
500KVA TRN 4160.480 5000KVA_TRN138.4160

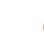

6

EA

$\$ 4,240$

EA $\$ 260,760$

$\$ 0$

$\$ 74,200$

$\$ 184,440$

$\$ 368,880$

Sub-Total: $\quad \$ 1,090,000$

$\$ 119$

$\$ 185$
$\$ 425$

$\$ 1,180$

$\$ 1,963$

$\$ 2,650$

$\$ 4,637$

$\$ 1,272$

$\$ 1,272$

$\$ 357$

$\$ 556 \quad$ Applied Control Equip.

$\$ 425$
$\$ 1,180$

$\$ 1,963$

$\$ 13,082$

$\$ 10,600$
$\$ 4,637$

$\$ 4,637$

$\$ 2,544$

$\$ 2,544$

$\$ 2,400$

Applied Control Equip.

REI - Estimated

Applied Control Equip.

Applied Control Equip.

Rosemount, Inc.

Applied Control Equip.

Applied Control Equip.

REI - Estimated

REI - Estimated

REI - Estimated

$\$ 106,000 \quad$ DM Consulting - Est.

$\$ 54,000 \quad$ REl Estimated

$\$ 59,625 \quad$ DM Consulting - Est.

$\$ 18,020 \quad$ DM Consulting - Est.

$\$ 132,500 \quad$ DM Consulting - Est.

$\$ 10,600 \quad$ DM Consulting - Est

$\$ 9,540$ DM Consulting - Est.

$\$ 636$ DM Consulting - Est

$\$ 25,440 \quad$ DM Consulting - Est.

60,760 REI - Estimated

\$0 Included w/ SCADA 
Blue Source, LLC.

CVR-TAF CO2 Pipeline Project

Coffeyville Compression Facility

\section{Project Estimate Worksheet}

CONSTRUCTION

100. BS/CVR COMPRESSOR STATION

Contingency @ 15\%

$\$ 494,626$

Grand Total - Construction:

$\$ 3,792,130$

Description

Cost Code

Qty

Units

Unit Rate Sub-Total Price

Estimate Supplier

100. BS/CVR COMPRESSOR STATION

101. BS/CVR Blower Facilities
01 Blower Facility Construction

102. 24-Inch LP HDPE Pipeline Construction

01 24-Inch HDPE Pipeline

103. Compressor Station Construction (Civil / Mechanical / Electrical)

01 Compressor Station Construction

\subsection{1}

102.01

103.01

104.01

105.01

105.02

106.01

01 Station Rock Materials

107. Pre-Commission / Commissioning / Start-Up Services

01 E\&I Contractor Support

02 Mechanical Contractor Support

03 Solid State Reduced Voltage Starters Technician

04 Compression - Controls Technician

05 Compression - Service Specialist / Supervisor
107.01

107.01

107.02
107.03

107.03

107.04
Station Rock

L Sub-Total: $\$ 3,297,505$

$\$ 3,297,505$

REI - Estimated

$\$ 25$

$\$ 32,500 \quad$ Fergeson

1,300 FT

0

$\$ 2,207,900$

REI - Estimated

1 LS

$\$ 19,205$

$\$ 19,205$

ESC, Inc.

$\$ 50,000$

$\begin{array}{rr}\$ 100,000 & \text { REI - Estimated } \\ \$ 70,000 & \text { REI - Estimated }\end{array}$

$\begin{array}{lll}2 & \text { LS } & \$ 50,000 \\ 2 & \text { LS } & \$ 35,000\end{array}$

$\$ 70,000$

1 LS

$\$ 10,100$

$\$ 10,100$

REI - Estimated

\section{$\$ 8,000$}

$\$ 10,000$

$\$ 2,300$ 


\section{APPENDIX 3-F \\ PROJECT SCHEDULE \\ THRALL-AAGARD FIELD}

Appendix 3-76 


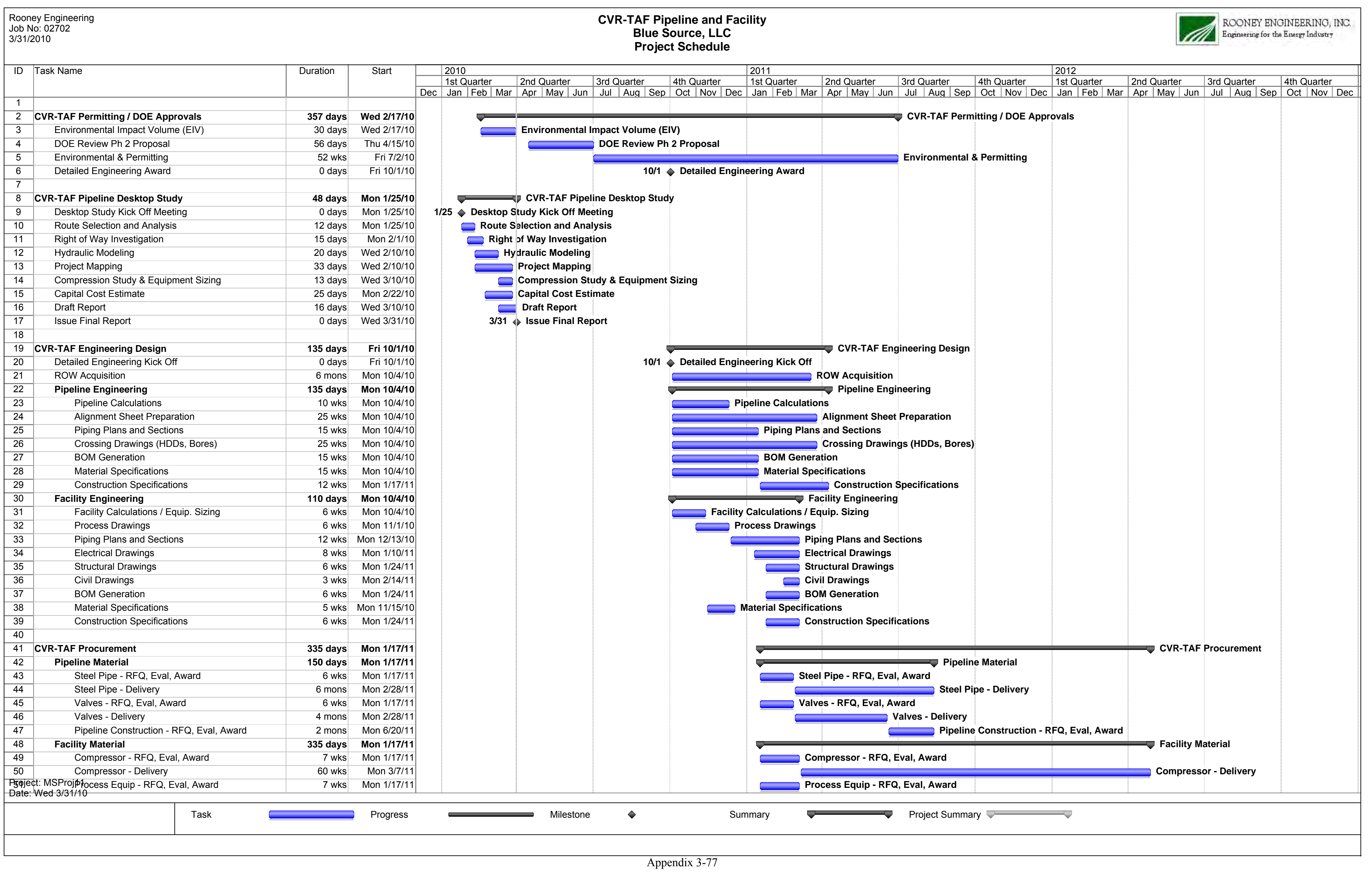




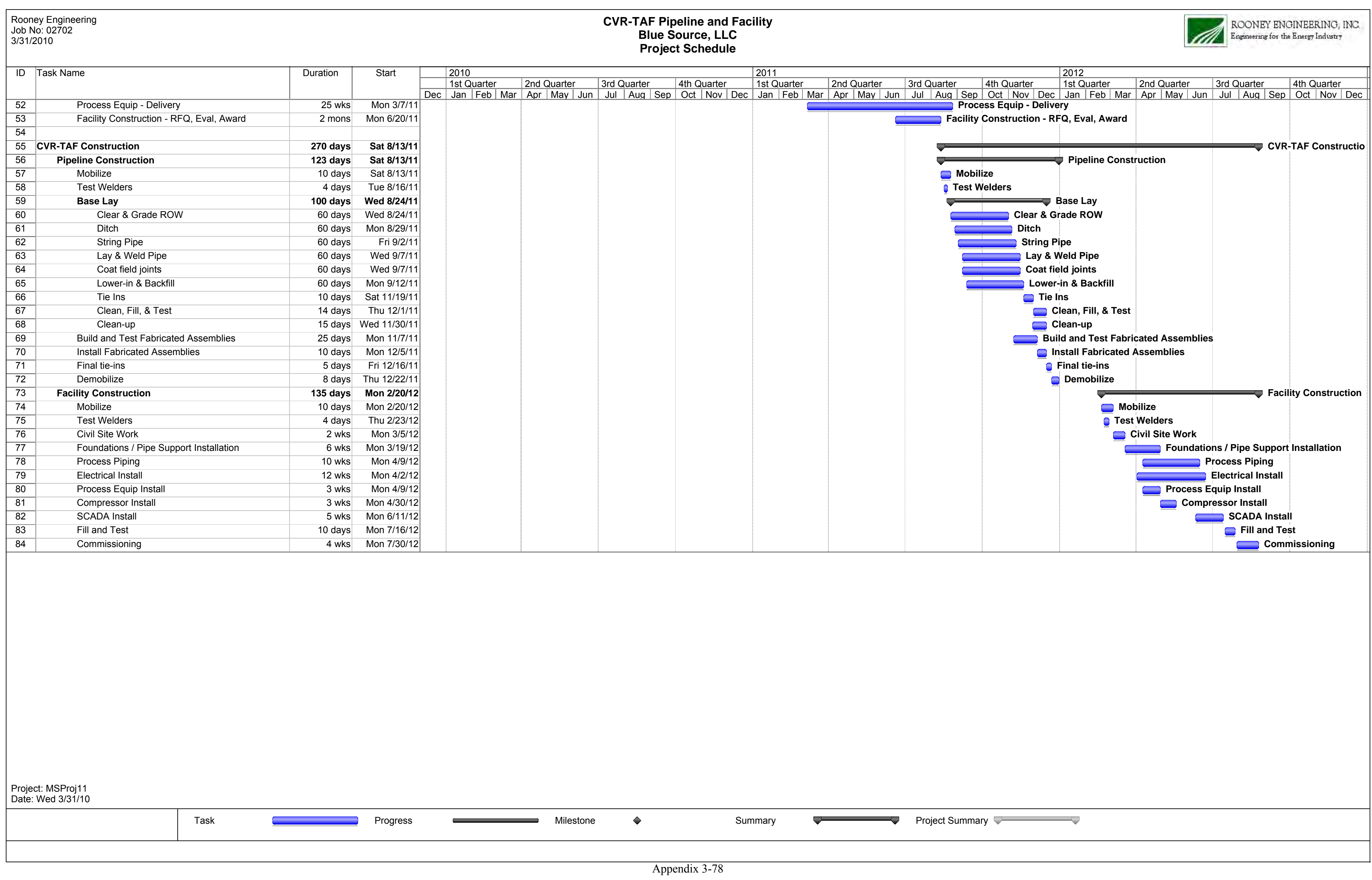




\section{APPENDIX 3-G \\ FEASIBILITY DRAWINGS \\ GENESEO-EDWARDS FIELD}

Appendix 3-79 


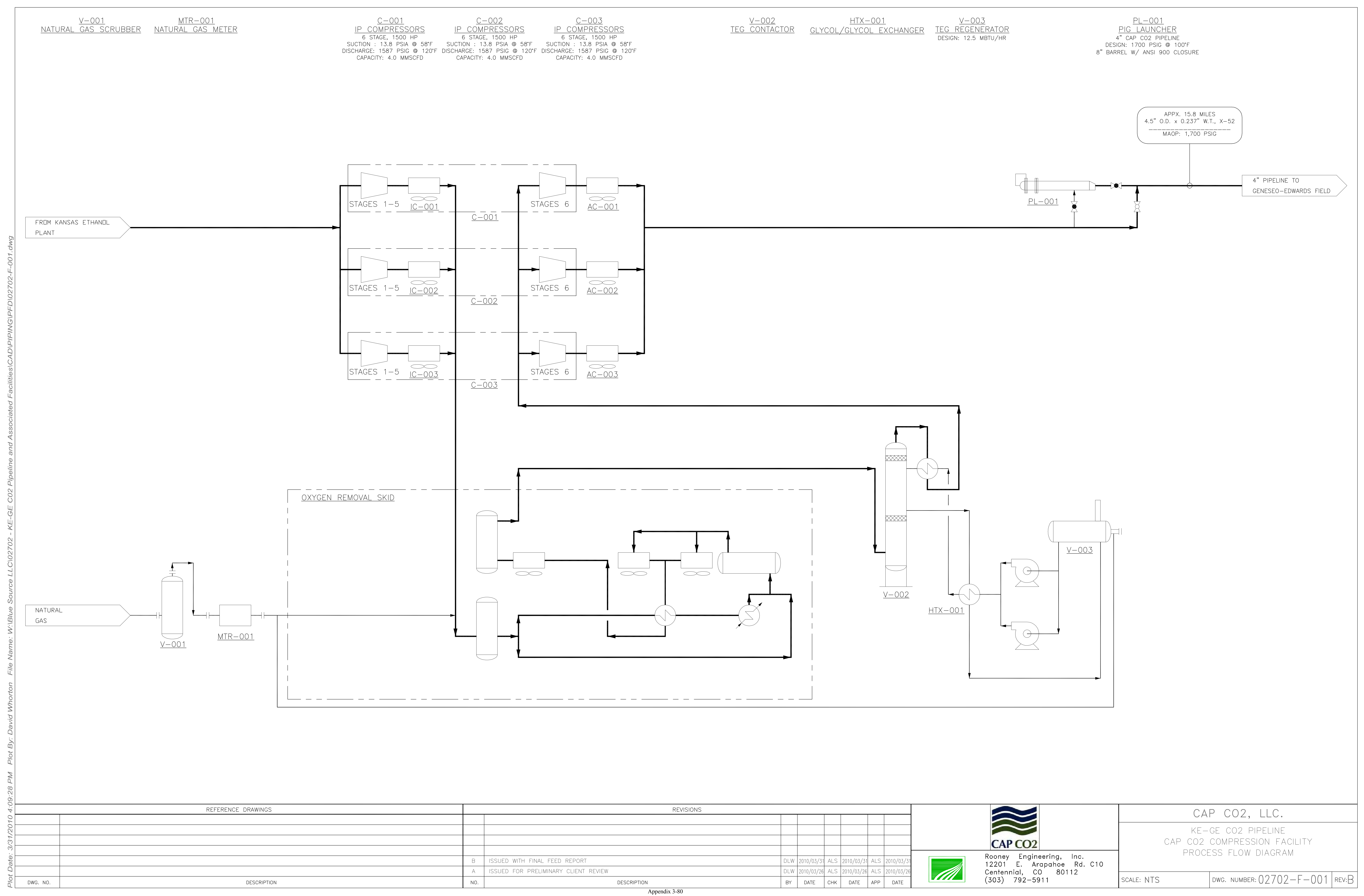




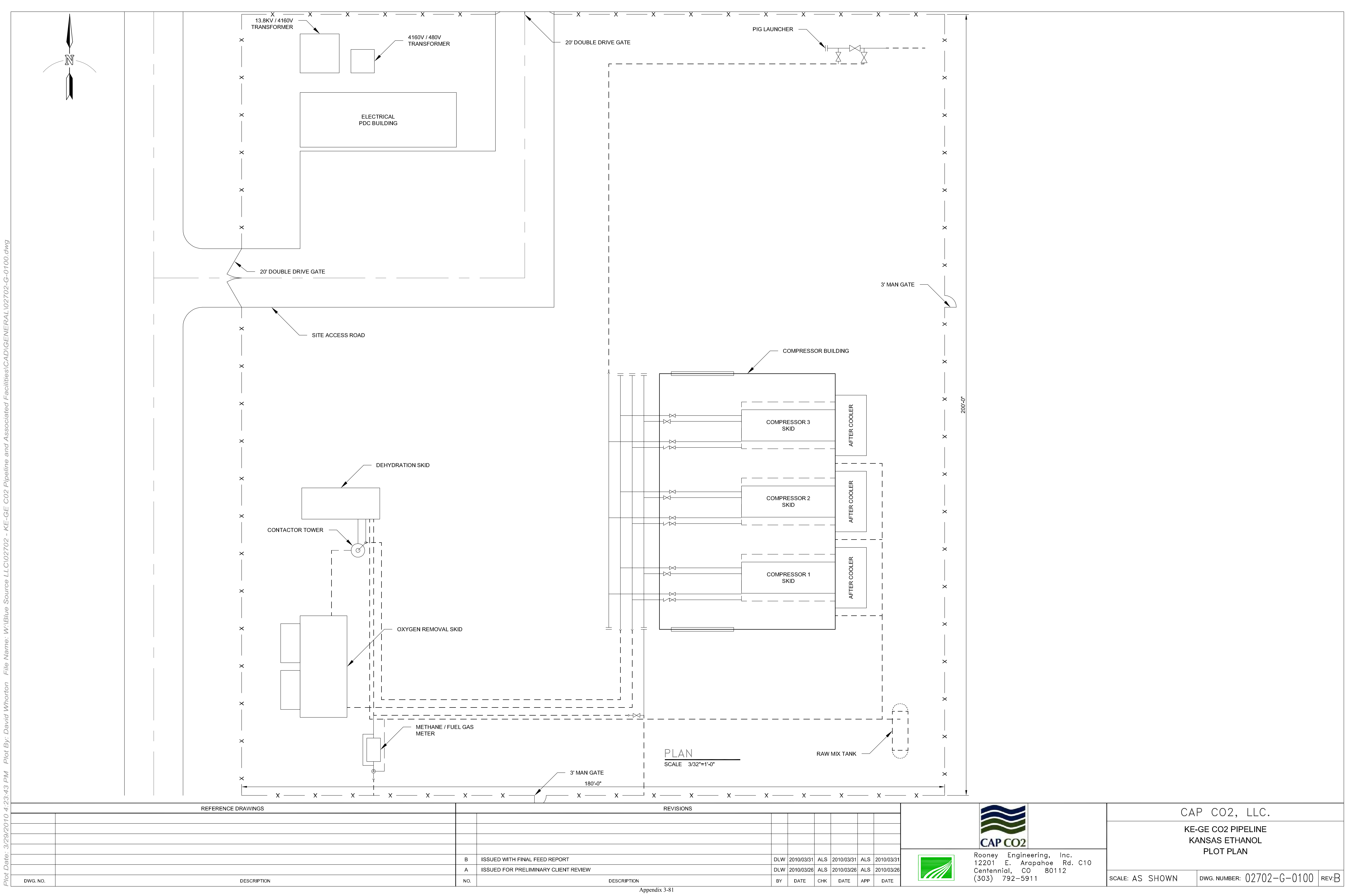




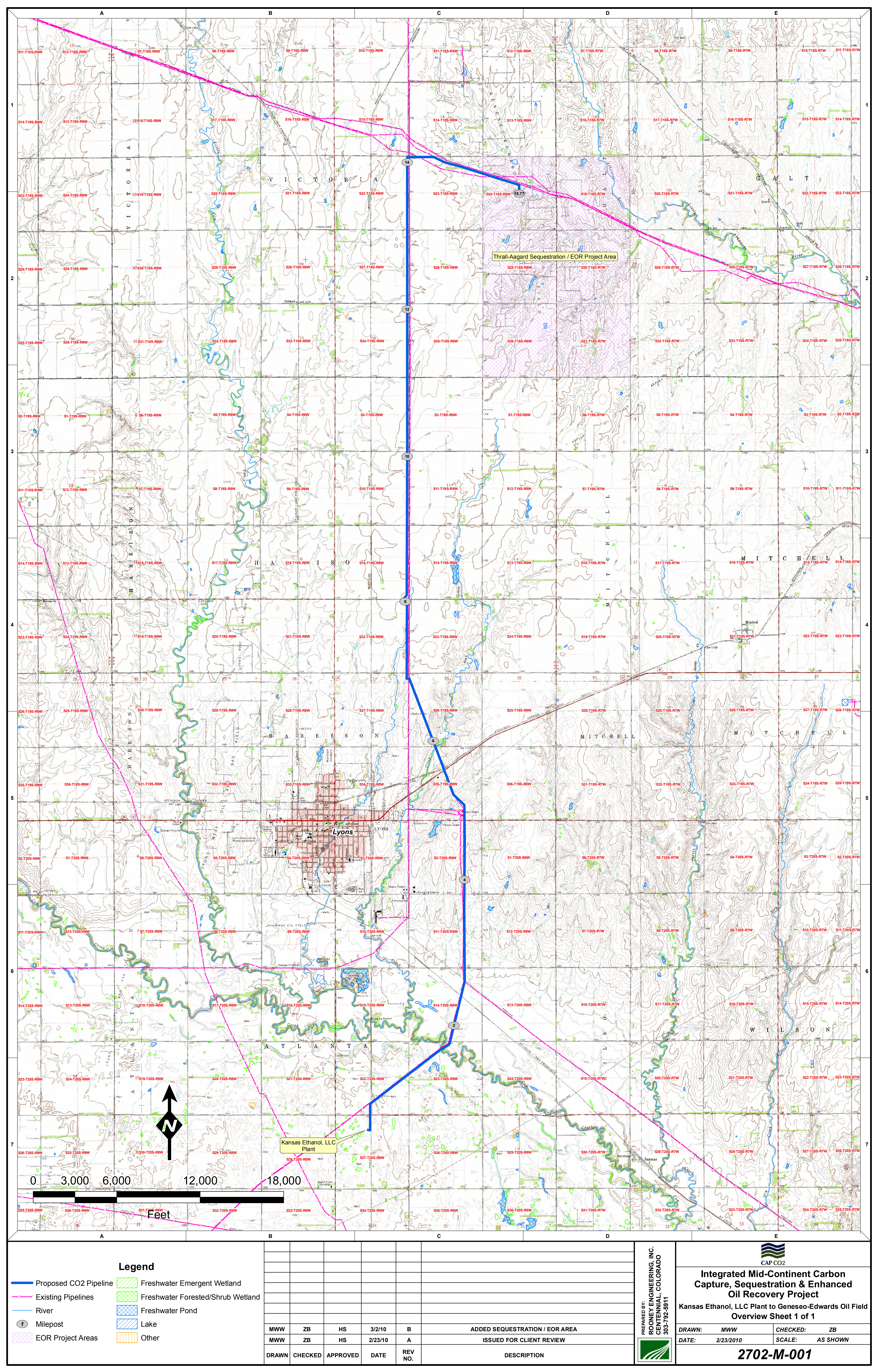




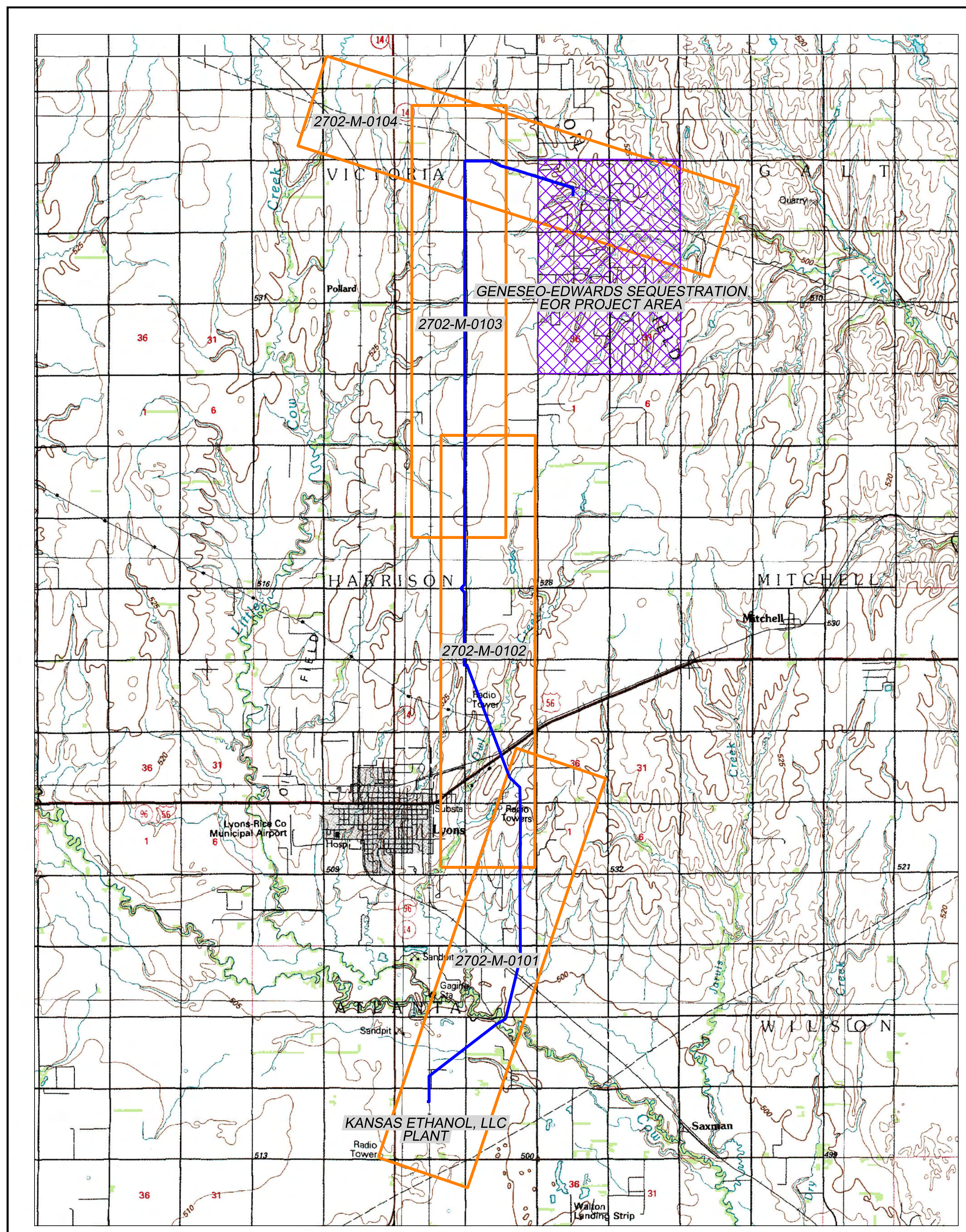

LAND USE AND VEGETATION

AG - AGRICULTURE/ CULTIVATED

COM - COMMERCIAL / INDUSTRIA

R - RANGELAND / GRASSLAND

RES - RESIDENTIAL AREA

RR - RURAL RESIDENTIAL AREA

WA - WATER

WETLANDS:

WETLANDS WERE MAPPED BASED ON NATIONAL WETLAND INVENTORY (NWI) MAPPING. NWI WETLAND CLASSES WERE NWI THE RIPARIAN CATEGORY WAS ADDED TO THE MAPS USING AERIAL PHOTO INTERPRETATION.

MAPPING LEGEND

\begin{tabular}{|c|c|c|c|c|c|c|c|}
\hline 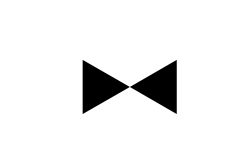 & VALVE & 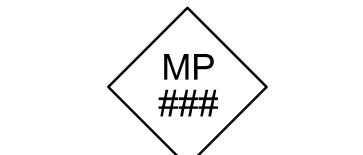 & MILE POST & $\bullet$ & TEST LEAD & 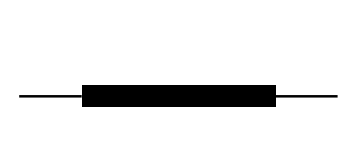 & HEAVY WALL PIPE \\
\hline$x$ & TRACT NUMBER & $\begin{array}{c}\mathrm{AM} \\
0000.0\end{array}$ & AERIAL MARKER & > & PIG TRAP & - & ROCK SHIELD \\
\hline 1 & EQUATION & & WARNING SIGN & R & RECTIFIER & $\frac{(x \mathrm{No})}{\rho}$ & MISC. CROSSING \\
\hline & FOREIGN PIPELINE & & BURIED CABLE & & COUNTY/PARISH & 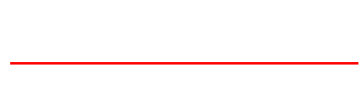 & SECTION LINE \\
\hline$-x$ & FENCE & -OHP- & O.H. PWR/TEL & R & PROPERTY LINE & $w$ & U/G WATER \\
\hline & RIVER / CREEK & & POND/LAKE & & RIPARIAN & & WETLAND \\
\hline
\end{tabular}




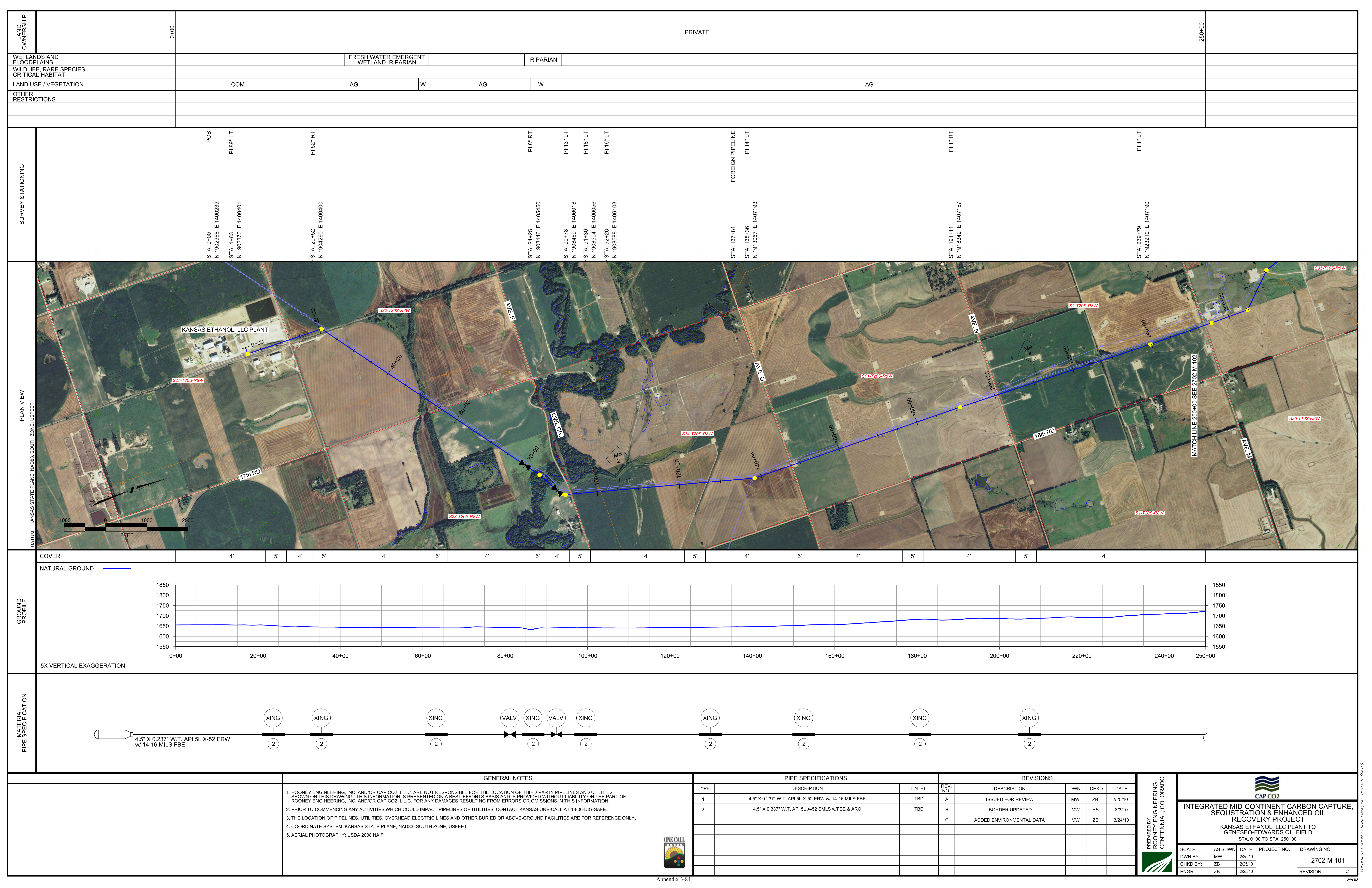









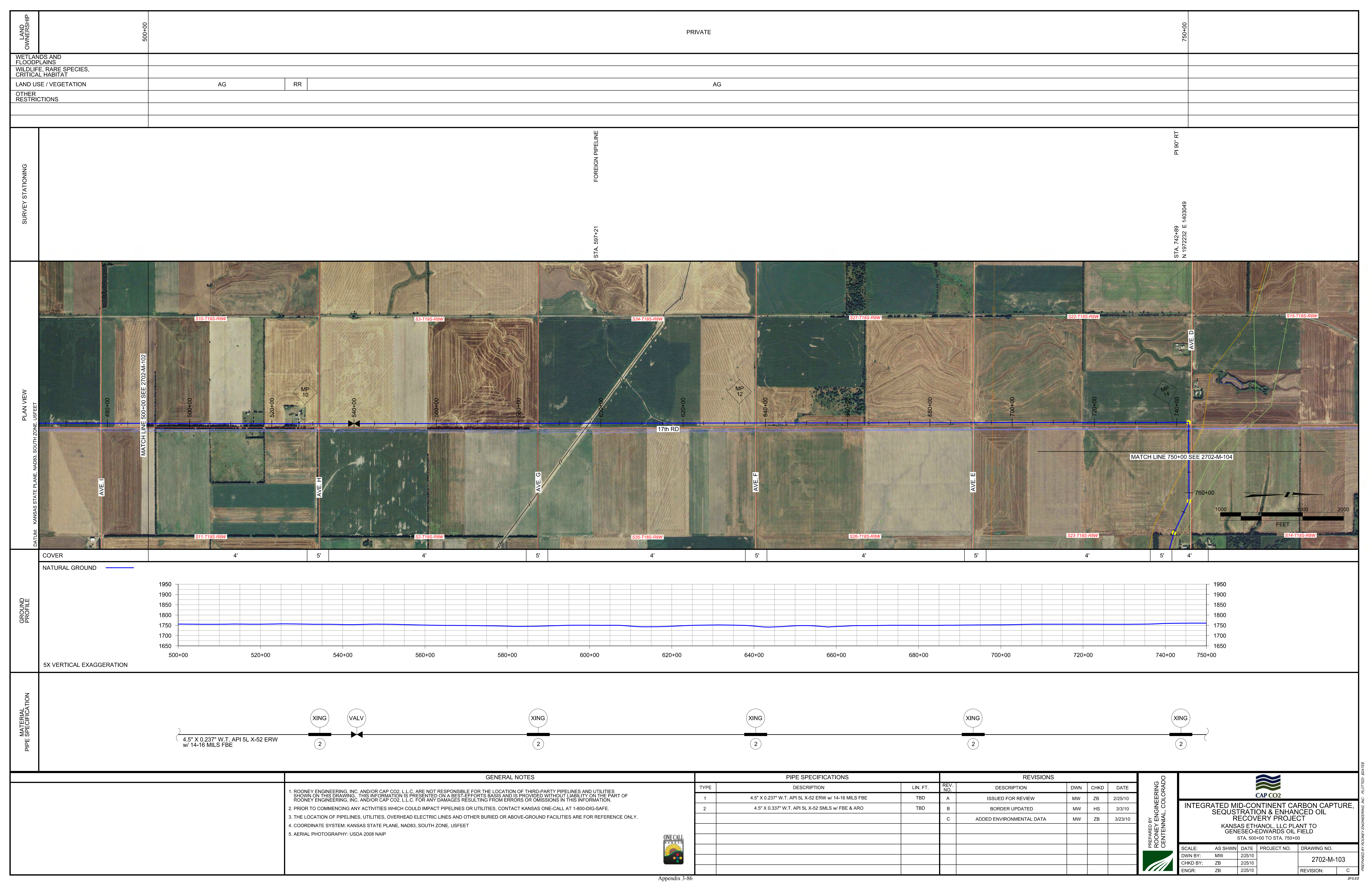




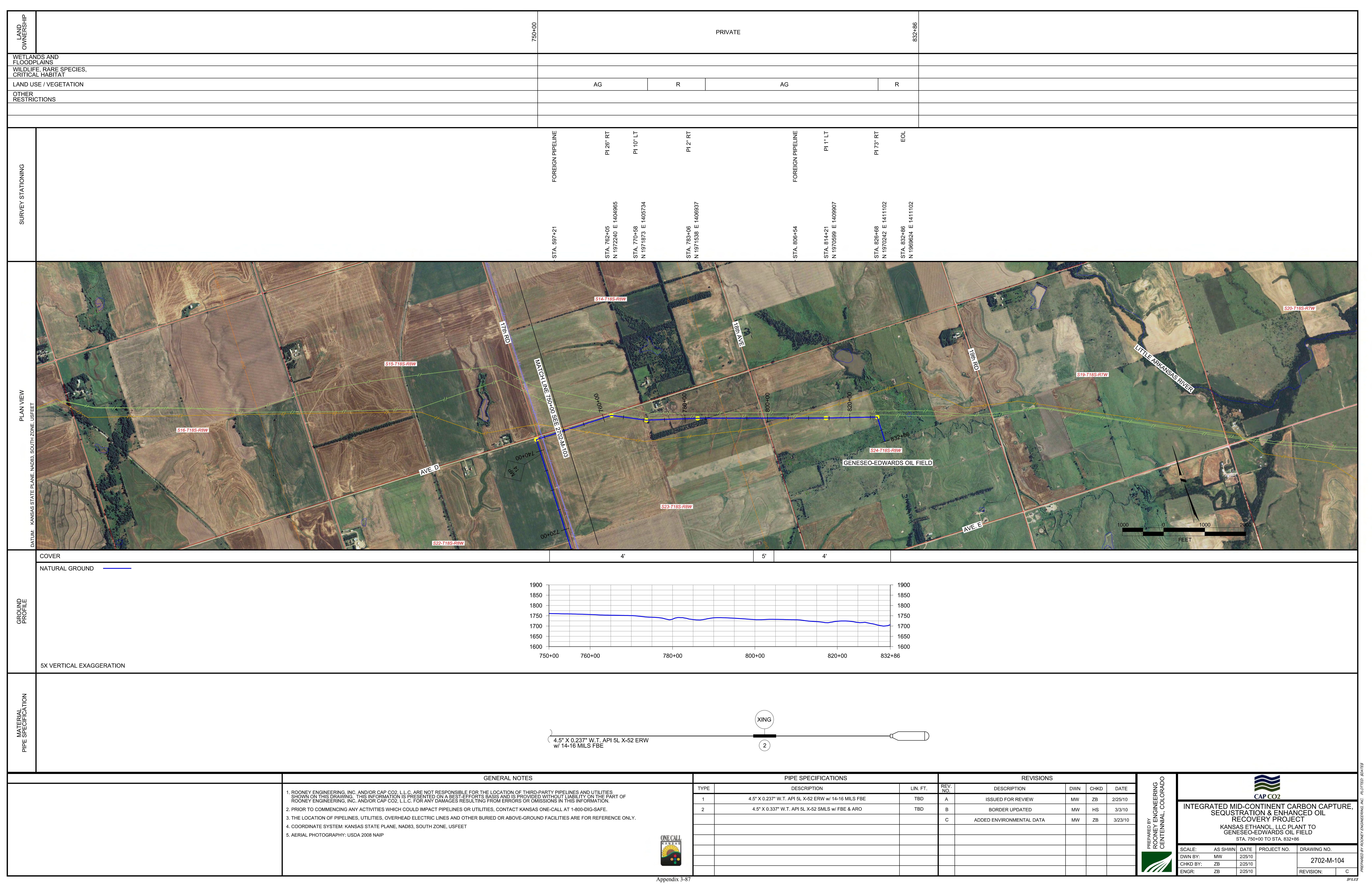




\section{APPENDIX 3-H}

KANSAS ETHANOL PLANT

$\mathrm{CO}_{2}$ COMPOSITIONAL ANALYSIS

\section{GENESEO-EDWARDS FIELD}

Appendix 3-88 


\begin{tabular}{|c|c|c|c|c|c|}
\hline \multicolumn{6}{|c|}{$\begin{array}{l}\text { Kansas Ethanol, LLC : Lyons, Kansas Ethanol Plant } \\
\text { Test Results Summary - Fermentation Scrubber @ } 60 \text { gpm water, } 0.8 \text { gph chemica (10/24/2009) }\end{array}$} \\
\hline Start Time & $20: 20$ & $21: 50$ & $23: 10$ & Average & \multirow{8}{*}{$\begin{array}{l}\text { Permit } \\
\text { Limits }\end{array}$} \\
\hline Stop Time & $21: 20$ & $22: 50$ & $0: 10$ & & \\
\hline Stack Temp ( F) & 59 & 58 & 58 & 58 & \\
\hline Stack Flow (dscfm) & 1,026 & 6,989 & 6,685 & 6,900 & \\
\hline $\mathrm{O}_{2}(\% \vee d)$ & 0.9 & 0.9 & 0.9 & 0.9 & \\
\hline $\mathrm{CO}_{2}(\% \vee \mathrm{d})$ & 88.9 & 88.9 & 88.9 & 88.9 & \\
\hline $\mathrm{H}_{2} \mathrm{O}(\% v w)$ & 18 & 17 & 17 & 1.8 & \\
\hline \multicolumn{5}{|l|}{ Emission Data } & \\
\hline TVOC (ppmvd as $\mathrm{C}_{3} \mathrm{H}_{8}$ ) & 44.6 & 50.4 & 63.5 & 52.8 & \\
\hline TVOC (lb/hr as $\left.\mathrm{C}_{3} \mathrm{H}_{3}\right)$ & 3.9 & 4.3 & 5.2 & 4.5 & \\
\hline TVOC (tons/year as $\mathrm{C}_{3} \mathrm{H}_{8}$ ) & 16.9 & 19.0 & 23.0 & 19.6 & \\
\hline Acetaldehyde (lb/hr) & 0.47 & 1.15 & 2.03 & 1.22 & \\
\hline Acetaldehyde (tons/year) & 2.07 & 5.05 & 8.87 & 5.33 & \\
\hline Acrolein ( $\mathrm{b} \mathrm{b} / \mathrm{hr}$ ) & 0.005 & 0.005 & 0.005 & 0.005 & \\
\hline Acrolein (tons/year) & 0.02 & 0.02 & 0.02 & 0.02 & \\
\hline Methanol (lb/hr) & 0.005 & 0005 & 0.005 & 0.005 & \\
\hline Methanol (tonsiyear) & 0.02 & 0.02 & 0.02 & 0.02 & \\
\hline Formaldehyde ( $\mathrm{b} / \mathrm{hr})$ & 0.003 & 0.004 & 0.005 & 0.004 & \\
\hline Formaldehyde (tons/year) & 0.01 & 0.02 & 0.02 & 0.02 & \\
\hline Ethanol (Ib/hr) & 0004 & 0.004 & 0.004 & 0.004 & \\
\hline Ethanol (tonsiyear) & 0.02 & 0.02 & 0.02 & 0.02 & \\
\hline Total HAPS (Ib/hr) & 0.49 & 117 & 2.04 & 1.23 & \\
\hline Total HAPS (tons/year) & 2.13 & 5.11 & 8.93 & 5.39 & \\
\hline \multicolumn{6}{|c|}{ RTO, Package Boiler, Fermentation Scrubber* \& DDGS Cyclone Combined } \\
\hline TVOC (tons/year as $\mathrm{C}_{3} \mathrm{H}_{8}$ ) & *. & -- & - & 42.68 & 73.2 \\
\hline Total HAPs (tons/year) & $\cdots$ & -- & $-\cdot$ & 8.0 & 11.5 \\
\hline
\end{tabular}

Table 4.11: Test Results Summary - Fermentation Scrubber, Condition 2 


\section{APPENDIX 3-I \\ PIPELINE HYDRAULIC CHARTS GENESEO-EDWARDS FIELD}




\section{KE-GE Pipeline}

3" x 0.216" WT Grade X-60 Pipeline at 8 MMSCFD

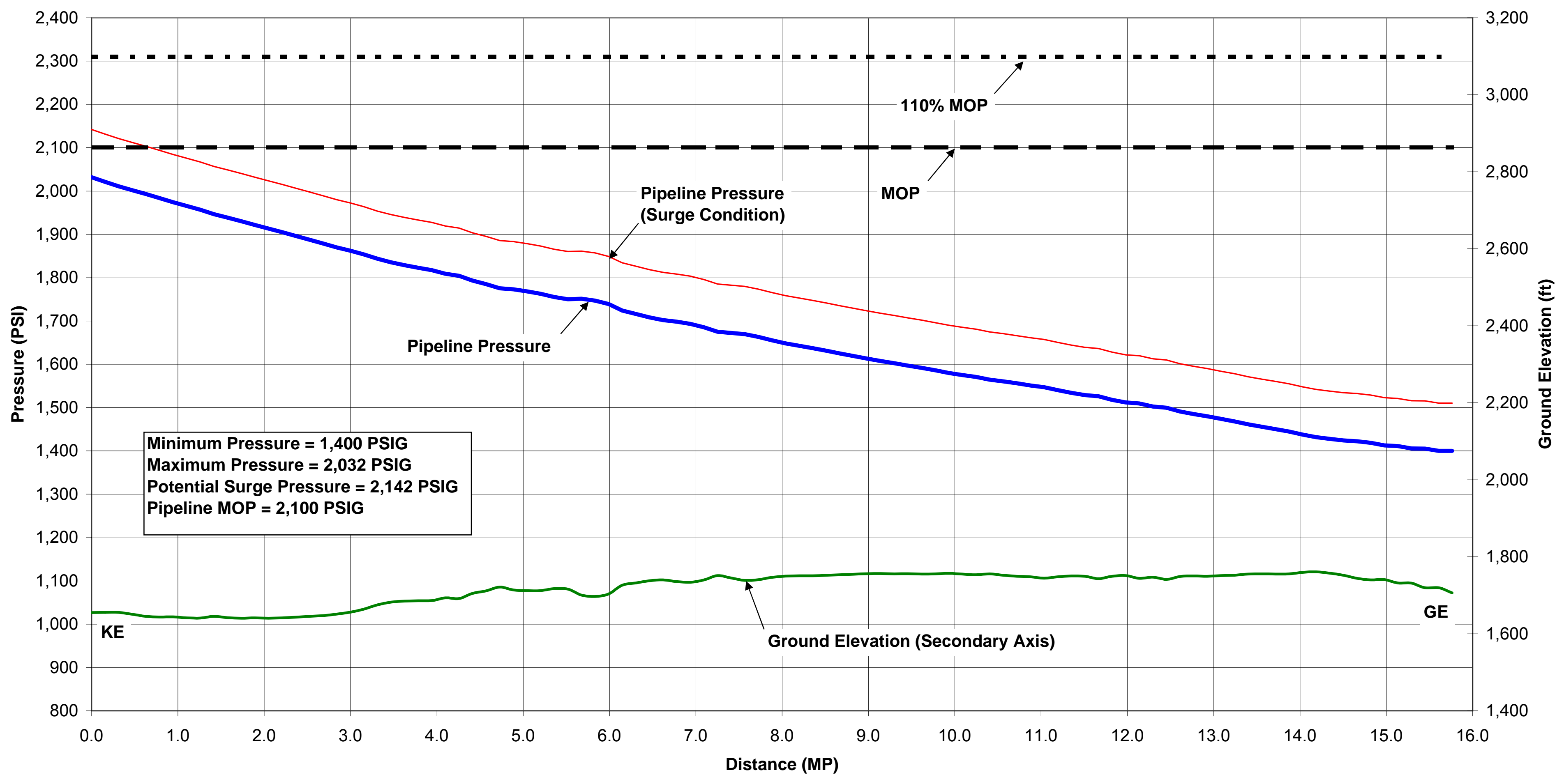




\section{KE-GE Pipeline}

4" x 0.237" WT Grade X-52 Pipeline at 8 MMSCFD

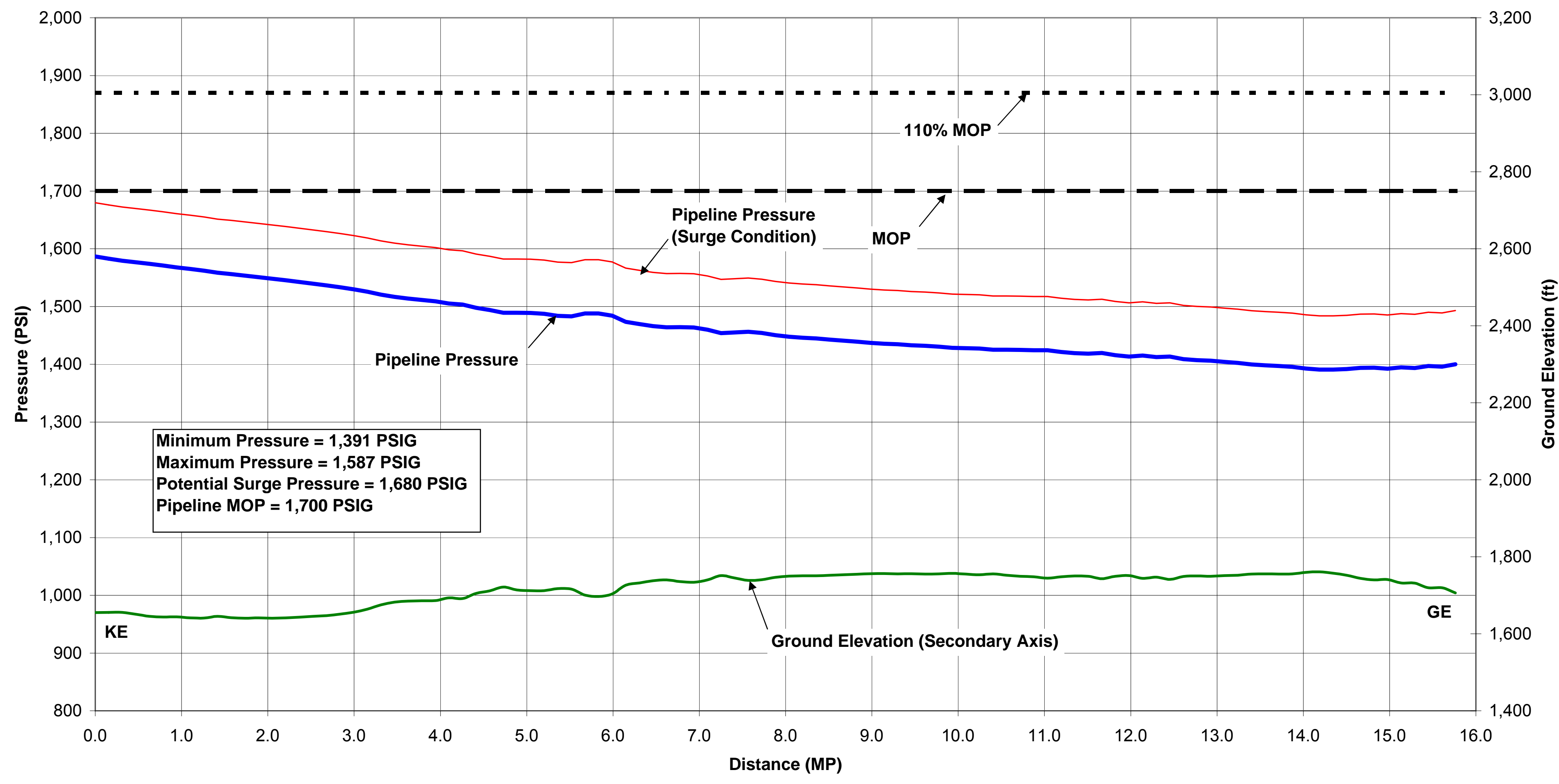




\section{KE-GE Pipeline}

6" x 0.280" WT Grade X-52 Pipeline at 8 MMSCFD

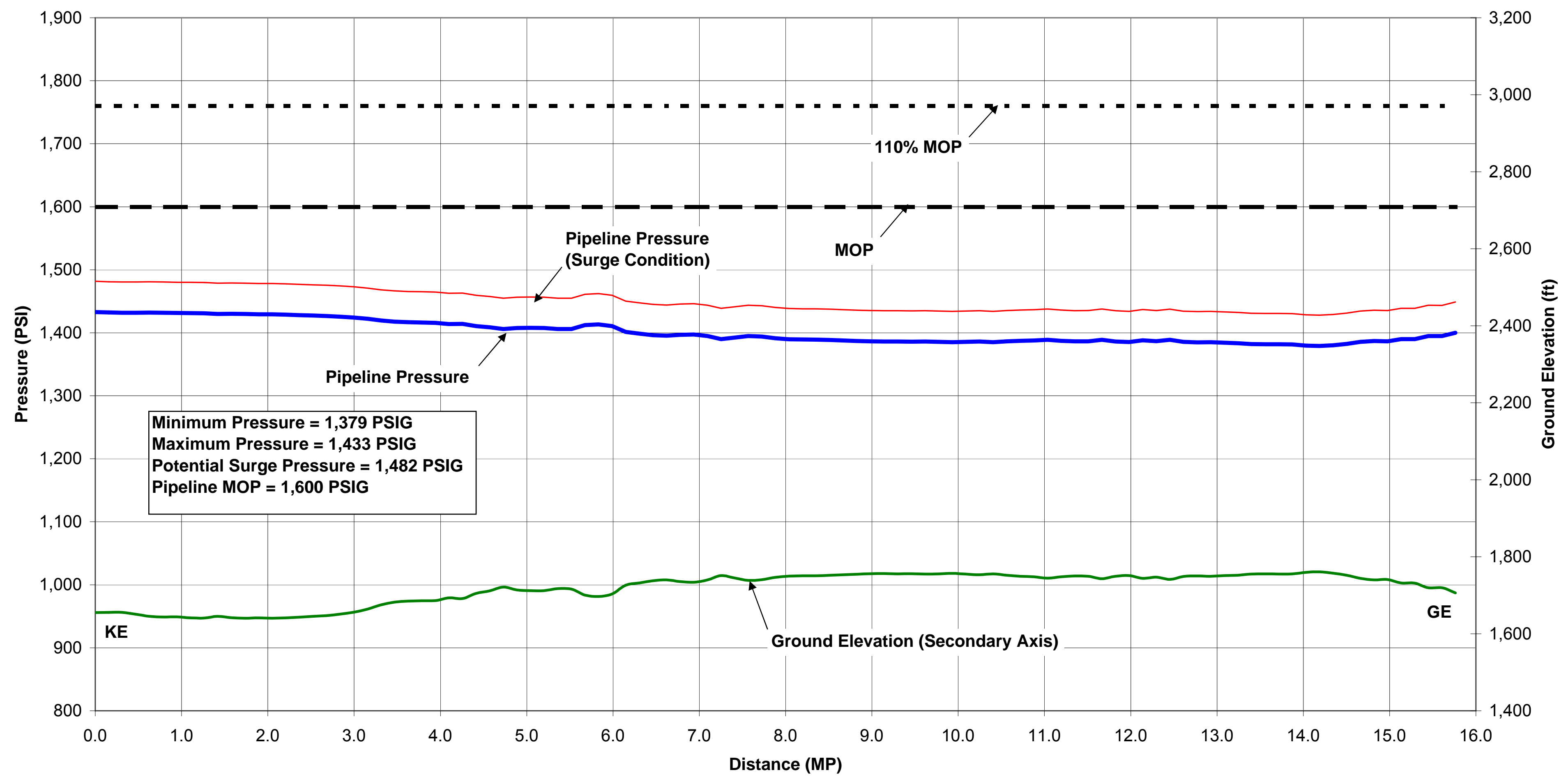


APPENDIX 3-J

PIPELINE ESTIMATE

GENESEO-EDWARDS FIELD 


\title{
Blue Source
}

\section{INTEGRATED MID-CONTINENT CARBON CAPTURE, SEQUESTRATION \& ENHANCED OIL RECOVERY PROJECT}

\author{
Kansas Ethanol LLC Plant (KE) to Geneseo-Edwards (GE) Oil Field \\ RICE COUNTY, KANSAS
}

\section{ESTIMATE BASIS MEMORANDUM}

\begin{tabular}{|c|c|c|c|c|c|c|c|}
\hline & & & & & & & \\
\hline & & & & & & & \\
\hline & & & & & & & \\
\hline & & & & & & & \\
\hline B & & vised per Client Comment & & & & & $4 / 6 / 2010$ \\
\hline A & & ued for Client Review & & & & & $3 / 31 / 10$ \\
\hline MARK & & DESCRIPTION & BY & CHKD & APVD & $\begin{array}{c}\text { CLIENT } \\
\text { APVD }\end{array}$ & DATE \\
\hline & & & IONS & & & & \\
\hline CLIENT: & & Blue Source & & & & & \\
\hline PROJEC & & Kansas Ethanol LLC Pl & enese & Edwards & GE) Oil F & & \\
\hline & & Carbon Dioxide Pipeline & & & randum & & \\
\hline JOB NO. & & 02702 & & & & & \\
\hline DOC. NC & & 02702-DESKTOP-002 & & & & & \\
\hline
\end{tabular}


Kansas Ethanol LLC Plant to Geneseo-Edwards Oil Field

ROONEY ENGINEERING, INC.

Engineering for the Energy Industry

\begin{tabular}{|l|l|l|l|}
\hline Date: & $4 / 6 / 2010$ & \multirow{2}{*}{ PIPELINE SYSTEMS ESTIMATE BASIS } & \multicolumn{2}{|c|}{ Doc. No.: 02702-DESKTOP-002 } \\
\cline { 1 - 2 } Rev: & $\mathrm{B}$ & & \multicolumn{2}{|c|}{ Page: 2 of 10} \\
\hline
\end{tabular}

TABLE OF CONTENTS

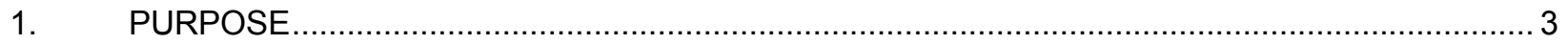

2. SCOPE

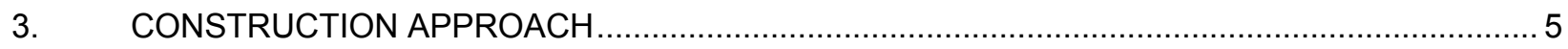

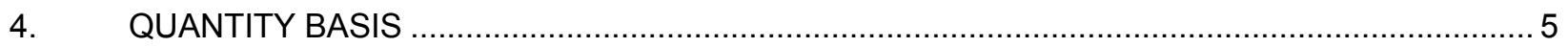

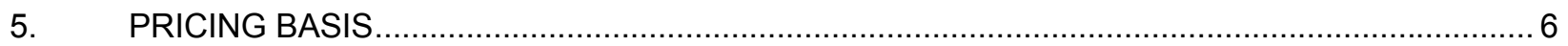

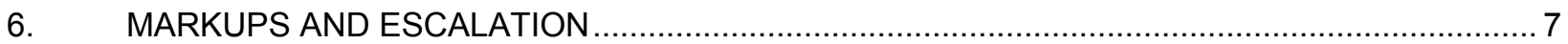

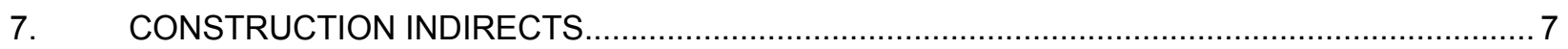

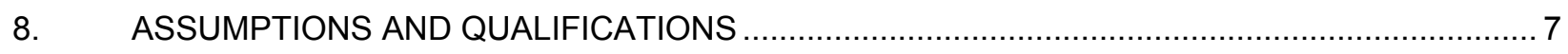

9. ATTACHED VENDOR BUDGETARY PROPOSALS ........................................................ 9

10. ATTACHED CONSTRUCTION CONTRACTOR BUDGETARY PROPOSAL ........................... 10 


\begin{tabular}{|l|l|l|l|l|}
\hline Date: & $4 / 6 / 2010$ & \multirow{2}{*}{ PIPELINE SYSTEMS ESTIMATE BASIS } & \multicolumn{2}{|c|}{ Doc. No.: 02702-DESKTOP-002 } \\
\cline { 1 - 1 } \cline { 4 - 5 } & & & Page: & 3 of 10 \\
\hline
\end{tabular}

1. PURPOSE

This estimate was prepared to provide budgetary cost information to design and construct the Kansas Ethanol, LLC Plant (KE) to the Geneseo-Edwards Oil Field (GE) pipeline.

The KE-GE pipeline is a 15.8 mile, 4.5 inch in diameter steel pipeline to transport $\mathrm{CO}_{2}$ from the Kansas Ethanol, LLC Plant (KE), located outside Lyons, Kansas to the Geneseo-Edwards Oil Field (GE) . A 4,500 BHP compression facility is proposed at the pipe line origination. A fiber optic communication system is proposed to facilitate the Supervisory Control and Data Acquisition (SCADA) system.

This estimate is comparable to an Association for the Advancement of Cost Engineering (AACE) Class 2 Estimate, with an expected accuracy range of $+30 \% /-15 \%$. A Class 2 estimate corresponds with $30 \%$ to $70 \%$ project definition, using primarily determi nistic methodology. (See AACE Recommended Practice No. 17R-97 "Cost Estimate Classification Systems.")

The capital expenditure cost estimate addresses the pipeline systems, compression facility, and communication systems and includes material, engineer ing, procurement assi stance, procurement inspection, right-of-way acquisition, right-of-way damages, cathodic protection, construction permitting, construction costs, construction management, survey, x-ray, construction inspection, commissioning, and start-up portions of the project.

\section{SCOPE}

The purpose of the KE-GE Pipeline is to transport compressed high-purity carbon dioxide via a 4" steel intra-state pipeline from the Kansas Ethanol LLC Plant to the Geneseo-Edwards Oil Field for both sequestration and enhanced oil recovery purposes.

The pipeline will be designed, constructed and operated in accordance to Title 49, Part 195, "Transportation of Hazardous Liquids by Pipeline," the Department Of Transportation rules and regulations.

The pipeline will be composed of approximately 15.8 miles of 4.5" O.D., 0.237" wall thickness, API5L, PSL2, Electric Resistance Welded (ERW) steel line pipe, coated with 14-16 mils of Fusion Bond Epoxy for corrosion protection. The pipeline will be designed to be operated at a Maximum Operating Pressure of 1,700 PSIG, with an ANSI 900 flange rating.

All road, railroad and creek crossing pipes will be $m$ anufactured to Seamless line pipe specifications instead of ERW to further mitigate fracture propagation.

Carbon Dioxide must be compressed to 1,587 PSIG at the Kansas Ethanol LLC Plant in order to deliver it to the Geneseo-Edwards Oil Field at 1,400 PSIG. This pressure was utilized for a reasonable margin between the operating pressures in the pipeline and the critical pressure of carbon dioxide, which is approximately $1,100 \mathrm{PSIA}$ at $50^{\circ} \mathrm{F}$. Operating at pressu res above the critical pressure ensures that the carbon dioxide is transported in the dense phase and that no phase changes occur in the pipeline system. Transporting carbon dioxide in dense-phase is the most efficient means of transportation since it allows for smaller pipeline sizes at high flow rates.

Four (4) Isolation Block Valves will be strategically located in the pipeline system to isolate the pipeline and blow the Carbon Dioxide down in case of an emergency.

Crack arrestor will be installed at every half mile on the 4.5" O.D. Steel Pipeline to mitigate fracture propagation. Clock Spring type crack arrestors were used in the cost estimate. 


\begin{tabular}{|l|l|l|r|l|}
\hline Date: & $4 / 6 / 2010$ & \multirow{2}{*}{ PIPELINE SYSTEMS ESTIMATE BASIS } & \multicolumn{2}{|c|}{ Doc. No.: 02702-DESKTOP-002 } \\
\cline { 1 - 1 } \cline { 4 - 4 } & & & Page: & 4 of 10 \\
\hline
\end{tabular}

The pipeline will be designed and constructed to accommodate intelligent pigs. Pig launcher and receiver will be installed into the system

The Engineering, procurement assist ance, procurement inspection, right -of-way acquisition, right-of-way damages, cathodic protection, construction permitti ng, construction costs, construction management, survey, $x$-ray, construction inspection, commissioning, and start-up portions of the project involve the following work which was included in the estimate (see estimated quantities in the Capital Cost Estimate spreadsheet):

- Detailed Engineering for the project to include proj ect calculations, P\&ID Drawings, PFD Drawings, Piping Drawings, Alignment Sheet Drawings, Ma terial Sheet Drawings, Road and Creek Crossing Detail Drawings, Ditch Detail Drawings, and project specifications.

- Procurement support for the project to include pr oviding quotation packages, technical evaluation and recommendation, material inspection services, and material expediting.

- Construction Management, including progress tracki ng, contractor communication, construction inspection, survey, and x-ray.

- Surveyors to stake construction work areas and pipe line centerline. Surveyors shall gather required as-built information throughout the duration of construction.

- NDE (X-Ray) including material and labor to x-ray the entire circumference of $100 \%$ of all girth welds.

- Assemble Job Books and prepare As Built Drawings.

The construction of the above pipeline involves the following work which was included in the estimate (see estimated quantities in the Capital Cost Estimate spreadsheet):

a) Mobilize to job site - located near Lyons, Kansas.

b) Train all personnel in site safety and environmental requirements.

c) Notify all underground utility and service providers, and abide by all their requirements.

d) Company shall provide survey subcontractor. Surveyors will stake construction work areas and pipeline centerline. Surveyors shall gather $\mathrm{t}$ he required as-built information throughout the duration of construction.

e) Company will provide $75^{\prime}$ ' wide construction wo rk area for the construction of the pipeline and 300 ' x 300' work area on each side of each crossing.

f) Company will provide one lay down yard for the project, strategically located for construction.

g) Line pipe shall be deliv ered to the right-of-way by trucks - Cont ractor shall st ring pipe ont o the right-of-way from the stringing trucks

h) Access, clear and grade right-of-way to enable the crews to access and work on the right-of-way.

i) Topsoil separation, storage and replacement of the ditch line and spoil in all construction areas.

j) Install 4" buried (with risers) isolation block valves

k) Perform field bending, align and weld pipe - Company will provide welding procedures. 


\begin{tabular}{|l|l|l|l|l|}
\hline Date: & $4 / 6 / 2010$ & \multirow{2}{*}{ PIPELINE SYSTEMS ESTIMATE BASIS } & \multicolumn{2}{|c|}{ Doc. No.: 02702-DESKTOP-002 } \\
\cline { 1 - 1 } \cline { 4 - 5 } & & & Page: & 5 of 10 \\
\hline
\end{tabular}

I) Install Company provided Clock Spring, Cra ck Arrestors (CS-130-04) which are 12" wide, 12 wraps each. Two Clock Springs will be installed next to each other. Clock Spring Crack Arrestors will be installed every $1 / 2$ mile on the pipe line for a total of 30 locations (install two clock springs next to each other)

m) Company shall provide NDE (X-R ay) subcontractor - who will prov ide material and labor to x-ray the entire circumference of $100 \%$ of all girth welds.

n) Apply Two (2) part Epoxy or Shrink Sleeves to the girth welds.

o) Holiday test (Jeep) the FBE steel coated pipe. Contractor to supply patch sticks for the repair of the FBE.

p) Ditch along the Right-of-way

q) Contractor to provide equipment to pad and shade all pipe - Pad and shade with 6" (bottom of pipe) and 6" (above the pipe) of $3 / 4$ " minus material.

r) Install fiber optic armored cable, hand-holes and pull boxes.

s) Total pipe cover shall be 48 " minimum. Cover at road crossings shall be 60 " minimum.

t) Install pipeline Company supplied markers.

u) Install Company supplied cathodic protection test stations. Contractor to provide all wires and cad welds necessary for the installation of the test stations.

v) Prepare hydrostatic test plan for the pipelines and submit to engineer for approval, run air swab, cleaning and gauging pigs (only soft pigs will be run in the HDPE lined pipelines), fill and dispose of test water, provide and fill the pipelines with clean water, successfully hy drostatically test the pipelines for a minimum of 8 hours and dispose of water. Contractor to provide all required pigs.

w) Company will acquire permits for acquiring and disposing hydrostatic test water. Source and disposal site for the Hydro water will be within 50 miles of the job site.

x) The 4" steel pipelines will be tested to $125 \%$ of MOP - minimum test pressure shall be 2125 PSIG

y) Continuous clean up of right-of-way to the satisfaction of Company and landowner, make all necessary permanent repairs to gates and fences.

z) Required re-seeding and re-vegetation will be by Company.

aa) Demobilize from job site.

\section{CONSTRUCTION APPROACH}

It was assumed that the Right Of Way areas would be accessible to the contractor's equipment at all times during construction, and that $t$ he contractor would not have to compete for space to place spoils, pipeline materials or working crews.

\section{QUANTITY BASIS}

Pipe quantities were measured from preliminary routing from aerial photography, as shown on the preliminary Alignment Sheet Drawings. 


\begin{tabular}{|c|c|c|c|}
\hline Date: & $4 / 6 / 2010$ & \multirow{2}{*}{ PIPELINE SYSTEMS ESTIMATE BASIS } & \multirow{2}{*}{ Doc. No.: 02702-DESKTOP-002 } \\
\hline Rev: & $B$ & & \\
\hline
\end{tabular}

Large diameter valve quantities were estimated Alignment Sheet Drawings.

based on the quantities shown on the preliminary

Pig trap assembly quantities were estimated based on the quantities shown on the preliminary Alignment Sheet Drawings.

Quantity for all other material and construction quant ities were estimated from Rooney Engineering's experience with similar pipeline systems, and from construction contractor input.

Three (3) reciprocating compressors were selected, each designed to $50 \%$ of the total design flowrate, therefore giving a total redundancy of $50 \%$.

\section{PRICING BASIS}

The pricing for material in this estimate was derived from budgetary quotation pricing. Construction pricing is based on budgetary quotes provided by a contractor with experience in construction similar to that required for this project. The following items were priced based on budgetary quotations from vendors or were estimated based on a scale factor applied to quotations to adjust for the current scope of work. If multiple quotations were received, pricing was normalized and averaged.

\section{Pipeline}

- Steel Line Pipe and Fusion Bond Epoxy (FBE) C oating - Current budgetary quotations were received from Edgen Murray and McJunkin Red Man.

- Abrasive Resistant Outer (ARO) Line Pipe Coatings - Rooney Engineering Estimated.

- Valves and Actuators - Current budgetary quotations were received from Cameron.

- Pipeline Fittings and Flanges - Current budgetary quot ations were received from Edgen Murray and McJunkin Red Man.

- Fabricated Assemblies (Pig Traps) - Current budget ary quotations were received from Sagebrush and PECO.

- Miscellaneous Materials (e.g. Clock Springs, Cathodic Test Stations, Shrink Sleeves, Pipeline Markers) - Current budgetary quotations were received from Hoff Company.

- Pipeline Construction and Site Construction (e.g. Road Bores, Cathodic Test Station Installation) and associated materials (e.g. Hay Bales, Silt Fence). - A site specif ic construction budgetary estimate was received from Jomax, who has completed many projects in and around Kansas.

\section{Compression Facility}

- Compressor Packages - Current budgetary quotati ons were received from Exterran, UE Compression, and GE Oil and Gas.

- Dehydration Package - Current budgetary quotations were received from QB Johnson and Exterran.

- Oxygen Removal Package - Current budgetary pric ing was received from BCCK Engineers and Newpoint Gas, LP..

- Scrubbers - Pricing from other recent projects was utilized.Orifice Meter - Pricing from other recent projects was utilized.Compressor Building - Recent pricing costs per square foot from Tri-State Insulating was utilized. 


\begin{tabular}{|l|l|l|l|l|}
\hline Date: & $4 / 6 / 2010$ & \multirow{2}{*}{ PIPELINE SYSTEMS ESTIMATE BASIS } & \multicolumn{2}{|c|}{ Doc. No.: 02702-DESKTOP-002 } \\
\cline { 1 - 1 } \cline { 4 - 5 } & & & Page: & 7 of 10 \\
\hline
\end{tabular}

- Flow Control Valves - Pricing from other rec ent projects was utilized.Switchgear, Motor Control Center, Transformers, Control Switches and Light ing, Power and Control Building - Pricing from other recent projects was utilized.Compressor Station Construction - Budgetary estimates for facility construction was received from Holloman Construction and LE Bell Construction.

\section{SCADA and Fiber Optic}

- SCADA Material, Licenses, and Vendor Services - Pricing from other recent projects was utilized.

- Fiber Optic Installation - Pricing from other recent projects was utilized.

- Fiber Optic Material - Pricing from other recent projects was utilized.

\section{MARKUPS and ESCALATION}

Taxes $-5.98 \%$ sales tax included on all materials. No tax included on labor.

Material Escalation - No material escalation was included, vendors quoted for late summer 2010 delivery. Construction Escalation - No construction escalation is included, assume late summer 2010 construction. G\&A - Included in cost estimate.

Construction Bond $-3 \%$ of total construction estimate

Contingency $-15 \%$ contingency included in each line item

\section{CONSTRUCTION INDIRECTS}

All construction indirect costs are included in construction labor unit prices.

\section{ASSUMPTIONS AND QUALIFICATIONS}

\section{Pipeline}

- Estimate includes construction permitting only. Co sts for National Environmental Policy Act (NEPA) Review, Studies to Support the NEPA Process, COE Nationwide \#12 Permit, Clean Water Act, Section 401 Consultations, U.S. Fish and Wildlif e Service Consultations, Endangered Species Act are not included in this budget.

- Estimate includes (3) month license of PipePhase Hydraulic Modeling Software.

- Estimate assumes $75^{\prime}$ wide construction work ar ea and 300' x 300' temporary work areas at all crossings.

- Estimate assumes construction working six (6) days per week for ten (10) hours per day.

- Assumes source and disposal site for the Hydro water will be within 50 miles of the job site.

- $2.5 \%$ wastage assumed for pipe and piping components.

- Construction is in loose, dry soil.

- $5 \%$ Rock Ditch was included based on contractor input for the project area.

- Pricing reflects 3D fittings for a piggable system.

- Concrete foundation construction included in estimate.

- Silt fencing was included for the perimeter of all anticipated temporary work areas only. 


\begin{tabular}{|l|l|l|l|l|}
\hline Date: & $4 / 6 / 2010$ & \multirow{2}{*}{ PIPELINE SYSTEMS ESTIMATE BASIS } & \multicolumn{2}{|c|}{ Doc. No.: 02702-DESKTOP-002 } \\
\cline { 1 - 1 } \cline { 4 - 5 } & & & Page: & 8 of 10 \\
\hline
\end{tabular}

- Contractor will be non-union.

- Mitigation measures and landowner requirements are unknown at this time.

- Estimate includes MFL /Caliper Tool - Smart Pig

- Estimate includes Cathodic Protection (Impressed Current).

- Estimate includes costs for Right of Way revegetation.

- Unforeseen conditions are not included in the estimate.

- Capital Cost Estimate includes the units and quantities shown in the estimate.

\section{Compression Facility}

- Estimate excludes appraisal and acquisition of 180'x 200' property adjacent to Kansas Ethanol plant. Assumed to be provided by Others.

- Assume compressor station site is grass roots, relatively level field with minimal grading, grubbing and clearing required. No trees or existing infrastructure required to be removed.

- Assumes three reciprocating compressors, each siz ed at $50 \%$ of the total design flowrate. No centrifugal pumps are required or included at this location.

- Estimate includes $2.5 \%$ of the capital expenditure of the compressors for initial spares, as recommended by GE.

- Estimate includes one (1) compressor building for all three compressors.

- Estimate includes one (1) TEG Dehydration Package, 125,000 BTU/ Hr Reboiler, 24" x 25', 8-Tray Contactor Column.

- Estimate includes scrubber and orifice metering for dehydration re-boiler fuel gas

Fiber Optic and SCADA

- SCADA electrical construction contractor labor not included since wiring up the PLCs would be done by site contractor along with instruments.

- The PLC at each compressor and main line valve site will be a GE 90-30 or company approved equal and will be housed inside a small building to enable support personnel to program and maintain them in inclement weather.

- The SCADA software will have a primary system in stalled at the primary control center on one end of the pipeline and there will be a backup SCADA host at the facility at the other end of the pipeline. Costs for SCADA vendor services were also included. SCADA vendor services include project management, design specification documents, SCADA communications programming, SCADA screen programming, factory tests, installation ons ite, onsite tuning of $t$ he software, commissioning tests, operations and the maintenance manual, training support for operators and technicians.

- The Leak Detection System will communicate with each station to analyze the pipeline for leaks and report to the SCADA software for operator notification. Leak Detect ion vendor services were also included. Leak Detection vendor services in clude project management, design specification documents, communications programming, graphica I user interface screen programming, factory tests, installation onsite, $t$ uning of the software, commissi oning tests, operations and the maintenance manual, training support for operators and technicians. 
Kansas Ethanol LLC Plant to Geneseo-Edwards Oil Field

ROONEY ENGINEERING, INC.

Engineering for the Energy Industry

\begin{tabular}{|l|l|l|l|}
\hline Date: & $4 / 6 / 2010$ & \multirow{2}{*}{ PIPELINE SYSTEMS ESTIMATE BASIS } & \multicolumn{2}{|c|}{ Doc. No.: 02702-DESKTOP-002 } \\
\cline { 1 - 2 } \cline { 4 - 5 } & & Page: & 9 of 10 \\
\hline
\end{tabular}

\section{ATTACHED VENDOR BUDGETARY PROPOSALS}

See attached vendor budgetary quotes that were utilized in preparing the capital cost estimate. 
Kansas Ethanol LLC Plant to Geneseo-Edwards Oil Field

ROONEY ENGINEERING, INC.

Engineering for the Energy Industry

\begin{tabular}{|l|l|l|l|}
\hline Date: & $4 / 6 / 2010$ & \multirow{2}{*}{ PIPELINE SYSTEMS ESTIMATE BASIS } & \multicolumn{2}{|c|}{ Doc. No.: 02702-DESKTOP-002 } \\
\cline { 1 - 1 } \cline { 4 - 4 } & & & \multicolumn{2}{|c|}{ Page: 10 of 10} \\
\hline
\end{tabular}

10. ATTACHED CONSTRUCTION CONTRACTOR BUDGETARY PROPOSAL

See attached contractor budgetary proposal that was utilized in preparing the capital cost estimate. 


\section{APPENDIX 3-K}

\section{ESTIMATE BASIS MEMORANDUM GENESEO-EDWARDS FIELD}




\section{KE-GE Desktop FEED Capital Cost Estimate}

Rice County, Kansas

Date: March 31, 2010

CAPITAL COST ESTIMATE SUMMARY

\begin{tabular}{|c|c|c|}
\hline Cost Description & & \\
\hline \multicolumn{3}{|l|}{ Pipeline } \\
\hline Materials & $\$$ & $1,327,000$ \\
\hline Construction & $\$$ & $2,836,000$ \\
\hline ROW Acquisition, Damages and Revegetation & $\$$ & $1,070,000$ \\
\hline Cathodic Protection & $\$$ & 92,000 \\
\hline Construction Permitting & $\$$ & 32,000 \\
\hline Property Plats & $\$$ & 158,000 \\
\hline Engineering \& Procurement Assistance & $\$$ & 635,000 \\
\hline Engineering Survey and Procurement Inspection & $\$$ & 235,000 \\
\hline Construction Administration & $\$$ & 742,000 \\
\hline Construction Inspection, Surveying and X-Ray & $\$$ & $1,682,000$ \\
\hline $\begin{array}{ll} & \text { Total Pipeline Cost } \\
\end{array}$ & 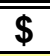 & $8,8,809,000$ \\
\hline \multicolumn{3}{|l|}{ Fiber Optic and SCADA } \\
\hline SCADA and Fiber Optic Materials & $\$$ & 913,000 \\
\hline SCADA Engineering Hours/Expenses & $\$$ & 162,000 \\
\hline SCADA Vendor Labor & $\$$ & 380,000 \\
\hline Fiber Optic Construction Labor & $\$$ & 192,000 \\
\hline $\begin{array}{lc}\text { Total Fiber Optic and SCADA Cost } \\
\end{array}$ & 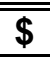 & $1,1,647,000$ \\
\hline \multicolumn{3}{|l|}{ Compressor I Pump Station } \\
\hline Equipment and Materials & $\$$ & $13,644,000$ \\
\hline Construction & $\$$ & $4,181,000$ \\
\hline Land and ROW & $\$$ & \\
\hline Environmental and Permitting & $\$$ & 6,000 \\
\hline Engineering Design & $\$$ & 799,000 \\
\hline Construction Administration & $\$$ & $1,035,000$ \\
\hline $\begin{array}{lc}\text { Total Compressor I Pump Cost } \\
\end{array}$ & $\$$ & $19,665,000$ \\
\hline
\end{tabular}


INTEGRATED MID-CONTINENT CARBON CAPTURE, SEQUESTRATION \&

ENHANCED OIL RECOVERY PROJECT

Kansas Ethanol LLC Plant (KE) to Geneseo-Edwards (GE) Oil Field

Capital Cost Estimate - 15.8 Miles of 4" Pipeline

Blue Source LLC

Date: March 31, 2010

\begin{tabular}{|c|c|c|c|c|c|c|c|}
\hline IINE PIPF COATING \& EREIGHT & Qty. & Unit & \multicolumn{2}{|r|}{ Unit Cost } & \multicolumn{2}{|r|}{ Total Cost } & \% of Total \\
\hline 4.5", 0.237" w.t., API 5L, X-52, PSL2, ERW Line Pipe, DRL, coated $14-16$ mils of FBE & 83,406 & $\mathrm{ft}$ & $\$$ & 9.61 & $\$$ & 801,500 & \\
\hline 4.5", 0.337" w.t., API 5L, X-52, PSL2, SMLS Line Pipe, DRL, coated $14-16$ mils of FBE & 1,645 & $\mathrm{ft}$ & $\$$ & 20.16 & $\$$ & 33,200 & \\
\hline Line Pipe Contingency & $15 \%$ & & & & $\$$ & 126660 & \\
\hline & & & & & & & \\
\hline
\end{tabular}

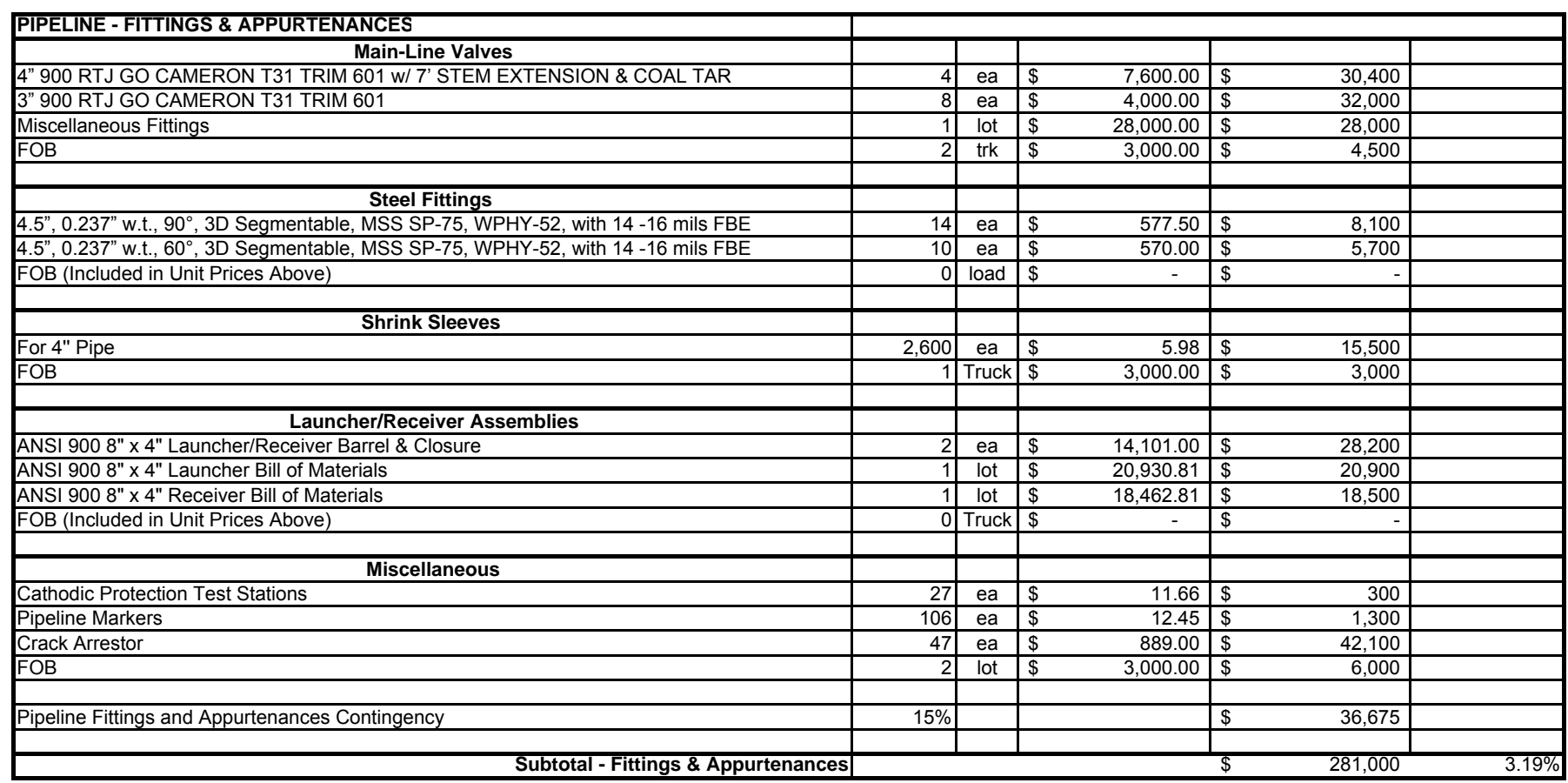




\author{
INTEGRATED MID-CONTINENT CARBON CAPTURE, SEQUESTRATION \& \\ ENHANCED OIL RECOVERY PROJECT \\ Kansas Ethanol LLC Plant (KE) to Geneseo-Edwards (GE) Oil Field \\ Capital Cost Estimate - 15.8 Miles of 4" Pipeline \\ Blue Source LLC \\ Date: March 31, 2010
}

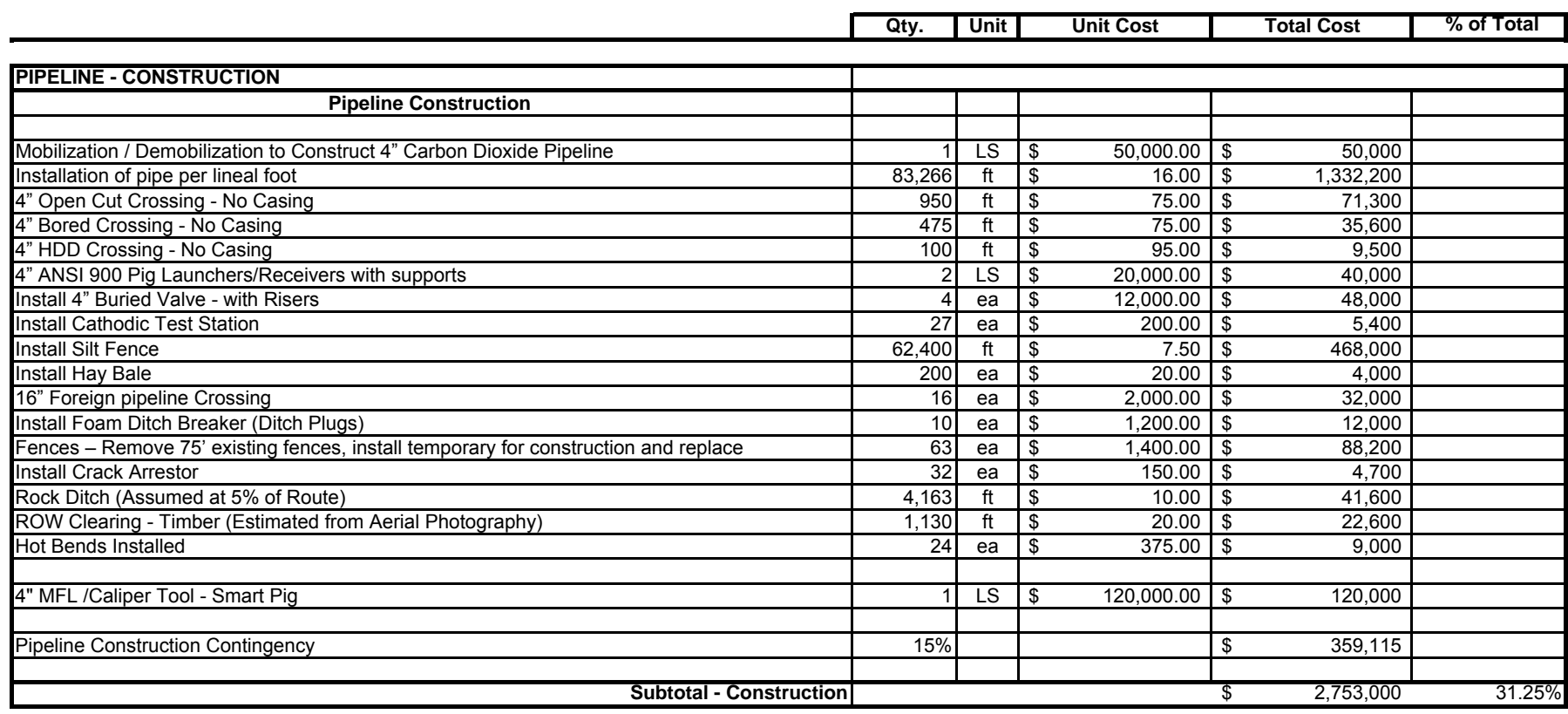

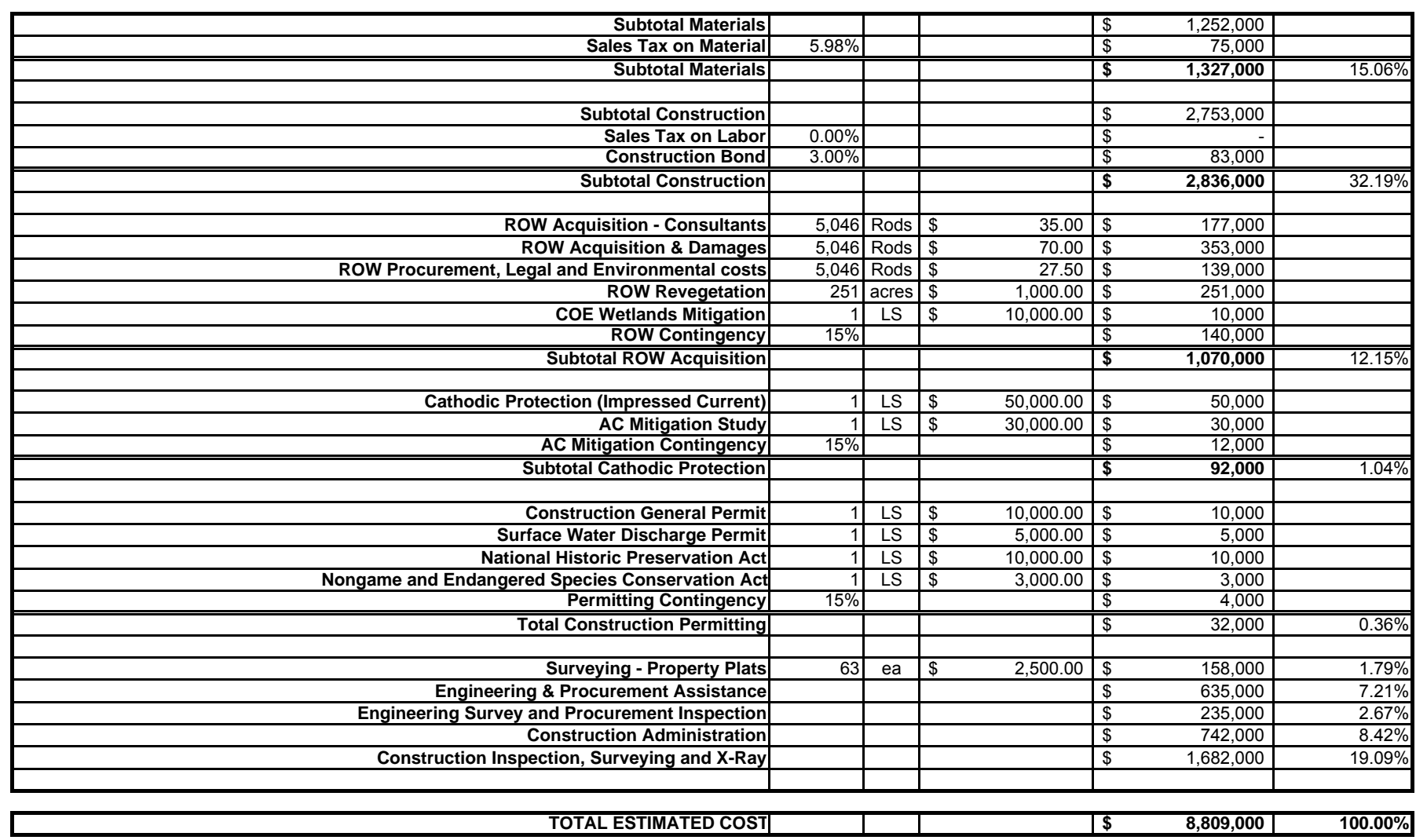


INTEGRATED MID-CONTINENT CARBON CAPTURE, SEQUESTRATION \&

ENHANCED OIL RECOVERY PROJECT

Kansas Ethanol LLC Plant (KE) to Geneseo-Edwards (GE) Oil Field

Detailed Engineering and Procurement Assistanace

Blue Source LLC

DETAILED ENGINEERING AND PROCUREMENT - Rooney Engineering Direct Labor

\begin{tabular}{|c|c|c|c|c|c|c|c|c|c|c|c|c|c|c|c|c|c|c|c|c|c|c|c|}
\hline INDIVIDUAL & TITLE & $\begin{array}{l}\frac{\text { Biling }}{\text { Rate } 1 / 10} \\
\end{array}$ & $\begin{array}{l}\frac{1}{\text { Billing }} \\
\text { Rate } 8110 \\
\end{array}$ & $\frac{1}{1 \text {-Jul-10 }}$ & $\frac{2}{8-J u l-10}$ & $\frac{3}{15-\mathrm{Jul}-10}$ & $\frac{4}{22-J u l-10}$ & $\frac{5}{29-J u l-10}$ & \begin{tabular}{|c|}
6 \\
5 -Aug-10 \\
\end{tabular} & \begin{tabular}{|l|} 
\\
$12-$ Aug-10 \\
\end{tabular} & $\frac{8}{19-A u g-10}$ & \begin{tabular}{|c|}
9 \\
$26-A u g-10$ \\
\end{tabular} & \begin{tabular}{|c|}
10 \\
$2-S e p-10$ \\
\end{tabular} & $\frac{11}{9-S e p-10}$ & \begin{tabular}{|c|}
12 \\
$16-$ Sep-10 \\
\end{tabular} & $\frac{13}{23-\text { Sep-10 }}$ & \begin{tabular}{|c|}
14 \\
$30-S e p-10$ \\
\end{tabular} & \begin{tabular}{|c|}
15 \\
$7-0 c t-10$ \\
\end{tabular} & $\frac{16}{14-\text { Oct-10 }}$ & \begin{tabular}{|c|}
17 \\
$21-$ Oct-10 \\
\end{tabular} & \begin{tabular}{|l|}
18 \\
28 -Oct-10 \\
\end{tabular} & $\frac{19}{4-\text { Nov-10 }}$ & $\frac{20}{11-\text { Nov-10 }}$ \\
\hline $\begin{array}{l}\text { PROJECT MANAGEMENT } \\
\text { Henrick Sarkissian }\end{array}$ & |Principal & & $\begin{array}{l}7.0 \% \\
\$ 161.57 \\
\end{array}$ & & & & & & & & 40 & 40 & 40 & 40 & 40 & 40 & 40 & 20 & & 20 & & & \\
\hline Dther & \begin{tabular}{|l|l|} 
Principal \\
\end{tabular} & $\$ 151.00$ & $\$ 161.57$ & $\frac{0}{0}$ & 0 & 0 & 0 & 0 & 0 & 0 & 0 & 0 & 0 & 0 & 0 & 0 & 0 & $\frac{0}{0}$ & $\frac{0}{0}$ & 0 & $\frac{0}{0}$ & 0 & \\
\hline Dffice Personnel & \begin{tabular}{|l|l|} 
Office Personnel \\
\end{tabular} & \begin{tabular}{ll|l}
$\$ 44.00$ \\
6400
\end{tabular} & \begin{tabular}{|l|l|l|l}
$\$ 47.08$ \\
$\$ 68.48$
\end{tabular} & 20 & 20 & $\frac{20}{4}$ & $\frac{20}{4}$ & 20 & 20 & 20 & 20 & 20 & 20 & 20 & 20 & 20 & 20 & 20 & 20 & 20 & 20 & 20 & 20 \\
\hline Accounting Personnel & Cost Accountant & $\$ 64.00$ & & & & & & & 4 & 4 & 4 & 4 & 4 & & 4 & 4 & 4 & 4 & 4 & 4 & 4 & 4 & \\
\hline $\begin{array}{l}\text { Subtotal Man-Hours } \\
\end{array}$ & & & & 64 & 64 & 64 & 64 & 64 & 64 & 64 & 64 & 64 & 64 & 64 & 64 & 64 & 64 & 44 & 44 & 44 & 44 & 44 & \\
\hline $\begin{array}{l}\text { Subtotal } \$ \\
\text { DIFCT ENGINEFPING }\end{array}$ & & & & $\$ 7,176$ & $\$ 7,176$ & $\$ 7,176$ & $\$ 7,176$ & $\$ 7,176$ & $\$ 7,678$ & $\$ 7,678$ & $\$ 7,678$ & $\$ 7,678$ & $\$ 7,678$ & $\$ 7,678$ & $\$ 7,678$ & $\$ 7,678 \mathrm{G}$ & $\$ 7,678$ & $\$ 4,447$ & $\$ 4,447$ & $\$ 4,447$ & $\$ 4,447$ & $\$ 4,447$ & $\$ 4,447$ \\
\hline Quinn Bailey & Senior Project Engineer & $\$ 121.00$ & $\$ 129.47$ & 40 & 40 & 40 & 40 & 40 & 40 & 40 & 40 & 40 & 40 & 40 & 40 & 40 & 40 & 0 & & 0 & 0 & & \\
\hline Zachary Bauer & \begin{tabular}{|l} 
Project Engineer \\
\end{tabular} & & $\$ 124.12$ & 40 & 40 & 50 & 40 & 40 & 40 & 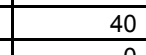 & 50 & 40 & 40 & 40 & 40 & 40 & 40 & 40 & 40 & $\frac{40}{10}$ & 40 & $\frac{40}{2}$ & \\
\hline Brian Techau & Project Engineer & $\begin{array}{l}116.00 \\
\end{array}$ & $\$ 124.12$ & 0 & 0 & 0 & 0 & 0 & 0 & 0 & 0 & 0 & 0 & 0 & 0 & 0 & 0 & 0 & 0 & 0 & 0 & 0 & \\
\hline Subtotal Man-Hours & & & & 80 & 80 & 90 & 80 & 80 & 80 & 80 & 90 & 80 & 80 & 80 & 80 & 80 & 80 & 40 & 40 & 40 & 40 & 40 & \\
\hline Subtotal & & & & $\$ 9,480$ & $\$ 9,480$ & $\$ 10,640$ & $\$ 9,480$ & $\$ 9,480$ & $\$ 10,144$ & $\$ 10,144$ & $\$ 11,385$ & $\$ 10,144$ & $\$ 10,144$ & $\$ 10,144$ & $\$ 10,144$ & $\$ 10,144$ & $\$ 10,144$ & $\$ 4,965$ & $\$ 4,965$ & $\$ 4,965$ & $\$ 4,965$ & $\$ 4,965$ & $\$ 44,965$ \\
\hline JECT DESIGN & & & & & & 510 & 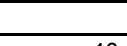 & 50 & & & 10 & & $0 \Omega$ & $\bar{E}$ & & $\overline{5}$ & & & & & & & \\
\hline $\begin{array}{l}\text { Mike Wager } \\
\text { Roxanne Burridge }\end{array}$ & \begin{tabular}{|l} 
Designer \\
Desinger
\end{tabular} & $\frac{\$ 91.00}{\$ 91.00}$ & $\begin{array}{l}977.37 \\
997.37 \\
\end{array}$ & $\frac{40}{0}$ & $\frac{40}{0}$ & $\frac{40}{0}$ & $\frac{40}{0}$ & $\begin{aligned} 40 \\
0\end{aligned}$ & $\frac{40}{0}$ & $\frac{40}{0}$ & $\frac{40}{0}$ & $\frac{40}{0}$ & $\frac{40}{0}$ & $\frac{40}{0}$ & $\frac{40}{0}$ & $\frac{40}{0}$ & & $\frac{0}{0}$ & 0 & $\frac{0}{0}$ & $\frac{0}{0}$ & $\frac{0}{0}$ & \\
\hline Chuck Haas & \begin{tabular}{|l} 
Designer \\
Desing
\end{tabular} & $\$ 991.00$ & $\$ 97.37$ & 40 & 40 & 40 & 40 & 40 & 40 & 0 & 0 & 0 & 0 & 0 & 0 & 0 & 0 & 0 & 0 & 0 & 0 & 0 & \\
\hline Subtotal Man-Hours & & & & 80 & 80 & 80 & 80 & 80 & 80 & 40 & 40 & 40 & 40 & 40 & 40 & 40 & & & & 0 & 0 & & \\
\hline Subtotal $\$$ & & & & $\$ 7,280$ & $\$ 7,280$ & $\$ 7,280$ & $\$ 7,280$ & $\$ 7,280$ & $\$ 87,790$ & $\$ 3,895$ & $\begin{array}{l}43,895 \\
\end{array}$ & $\$ 3,895$ & $\$ 3,895$ & $\$ 3,895$ & $\$ 3,895$ & $\$ 3,895$ & $\$ 0$ & $\$ 0$ & & $\frac{4}{\$ C}$ & $\frac{9}{50}$ & & \\
\hline TOTAL ROONEY EN & oURS) & & & $224.0 \mathrm{hrs}$ & $224.0 \mathrm{hrs}$ & $234.0 \mathrm{hrs}$ & $224.0 \mathrm{hrs}$ & $224.0 \mathrm{hrs}$ & $224.0 \mathrm{hrs}$ & $184.0 \mathrm{hrs}$ & $194.0 \mathrm{hrs}$ & $184.0 \mathrm{hrs}$ & $184.0 \mathrm{hrs}$ & $184.0 \mathrm{hrs}$ & $184.0 \mathrm{hrs}$ & $184.0 \mathrm{hrs}$ & $144.0 \mathrm{hrs}$ & $84.0 \mathrm{hrs}$ & $84.0 \mathrm{hr}$ & $4.0 \mathrm{hrs}$ & $84.0 \mathrm{hrs}$ & $84.0 \mathrm{hrs}$ & \\
\hline & & & & & & & & & & & & & & & & & & & & & & & \\
\hline
\end{tabular}

DETAILED ENGINEERING AND PROCUREMENT - SUbcontractors and EXpenses

\begin{tabular}{|c|c|c|c|c|c|c|c|c|c|c|c|c|c|c|c|c|c|c|c|c|c|c|c|}
\hline INDIVIDUAL & TITLE & $\begin{array}{l}\text { Biling } \\
\text { Rate 1/10 }\end{array}$ & $\begin{array}{l}\text { Biling } \\
\text { Rate 8/10 }\end{array}$ & $\frac{1}{1-\mathrm{Jul}-10}$ & $\frac{2}{8-J u l-10}$ & $\frac{3}{15-J u l-10}$ & $\frac{4}{22-J u l-10}$ & $\frac{5}{29-J u l-10}$ & \begin{tabular}{|c|}
6 \\
5 -Aug-10 \\
\end{tabular} & \begin{tabular}{|l|} 
12-Aug-10 \\
\end{tabular} & \begin{tabular}{|l|} 
\\
$19-A u g-10$ \\
\end{tabular} & $\frac{9}{26-\text { Aug-10 }}$ & $\frac{10}{2-\text { Sep-10 }}$ & \begin{tabular}{|l|}
11 \\
$9-$ Sep-10 \\
\end{tabular} & $\frac{12}{16-\text { Sep-10 }}$ & \begin{tabular}{|c|}
13 \\
$23-S e p-10$ \\
\end{tabular} & \begin{tabular}{|c|}
14 \\
$30-$ Sep-10 \\
\end{tabular} & $\frac{15}{7-0 c t-10}$ & $\frac{16}{14-\text { Oct-10 }}$ & $\frac{17}{21-\text { oct-10 }}$ & \begin{tabular}{|c|}
18 \\
$28-O c t-10$ \\
\end{tabular} & $\frac{19}{4-\text { Nov-10 }}$ & \begin{tabular}{|l|} 
11-Nov-10 \\
\end{tabular} \\
\hline SUBCONTRACT ENGINEERING & & & 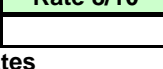 & & & & & & & & & & & & & & & & & & & & \\
\hline & & & 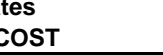 & & & & & & & & & & & & & & & & & & & & \\
\hline $\begin{array}{l}\text { Mark Madden } \\
\text { Bruce Criaj/ Metcorr }\end{array}$ & $\begin{array}{l}\text { Senior Project Engineer } \\
\text { Cathodic }\end{array}$ & $\begin{array}{l}\$ 121.00 \\
\$ 2000\end{array}$ & \begin{tabular}{|l|}
$\$ 129.47$ \\
$\$ 21400$
\end{tabular} & $\frac{0}{0}$ & $\frac{0}{0}$ & $\frac{40}{40}-30$ & $\frac{40}{40}$ & 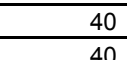 & $\begin{array}{l}40 \\
40\end{array}$ & $\frac{0}{40}$ & 0 & 0 & 0 & $\frac{0}{0}$ & $\frac{0}{0}$ & 0 & \begin{tabular}{c|c}
0 \\
40
\end{tabular} & $\frac{0}{0}$ & $\frac{0}{0}$ & $\frac{0}{0}$ & $\frac{0}{0}$ & $\frac{0}{0}$ & 0 \\
\hline Subtotal Man-Hours & & & & $\frac{0}{0}$ & 0 & $\begin{array}{r}0 \\
80 \\
\end{array}$ & $\begin{array}{r}0 \\
80\end{array}$ & $\begin{array}{r}0 \\
80\end{array}$ & $\begin{array}{r}40 \\
80 \\
8\end{array}$ & $\begin{array}{r}40 \\
40 \\
\end{array}$ & $\frac{0}{0}$ & $\frac{0}{0}$ & $\begin{array}{l}0 \\
0\end{array}$ & $\frac{0}{0}$ & 0 & 0 & $\begin{array}{r}0 \\
40 \\
\end{array}$ & 0 & 0 & $\frac{0}{0}$ & $\frac{0}{0}$ & $\frac{0}{0}$ & \\
\hline Subtotal $\$$ & & & & $\$ 0$ & $\frac{50}{50}$ & $\$ 12,840$ & $\$ 12,84 \mathrm{C}$ & $\$ 12,840$ & $\$ 13,739$ & $\$ 8,560$ & $\$ 0$ & 90 & so & 90 & so & $\$ 0$ & $\$ 8,560$ & $\$ 0$ & $\$ 0$ & $\$ 0$ & $\$ 0$ & 90 & \\
\hline $\begin{array}{l}\text { EXPENESS } \\
\text { Denver Office Travel Expenses }\end{array}$ & & & & 93000 & $\$ 3,000$ & $\$ 3000$ & $\$ 3000$ & 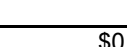 & $50>>$ & 50 & $500>0$ & $900>>$ & $\$ 0$ & $500>>1$ & $\$ 3000$ & 80 & $\$ 3000$ & $500>0$ & $\$ 3000$ & si & $\$ 0$ & $\$ 3000$ & \\
\hline Denver Office Expenses & & & & $\frac{0,200}{\$ 200}$ & $\frac{900}{\$ 200}$ & $\frac{9,000}{\$ 200}$ & $\frac{D, 000}{\$ 200}$ & $\$ 200$ & $\frac{\$ 0}{\$ 200}$ & $\$ 200$ & $\frac{\$ 0}{\$ 200}$ & $\frac{\$ 0}{\$ 200}$ & $\frac{\$ 0}{\$ 200}$ & $\frac{\$ 0}{\$ 200}$ & 95,000 & $\frac{20}{2200}$ & $\frac{\$, 300}{\$ 100}$ & $\frac{\$ 0}{\$ 100}$ & $\frac{\$, 300}{\$ 100}$ & $\frac{\$ 0}{\$ 100}$ & $\frac{\$ 0}{\$ 100}$ & $\frac{\$, 300}{\$ 100}$ & $\$ 1$ \\
\hline $\begin{array}{l}\text { Misc. } \\
\text { Hydraulic Software. }\end{array}$ & & & & $\frac{\$ 0}{\$ 10}$ & $\frac{\$ 0}{\$ 0}$ & 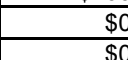 & $\frac{\$ 1}{\$ C}$ & $\begin{array}{l}\$ 0 \\
\$ 0\end{array}$ & $\frac{\$ 0}{\$ 0}$ & $\frac{50}{90}$ & $\frac{50}{\$ 50}$ & $\frac{50}{\$ 0}$ & $\frac{50}{90}$ & $\frac{50}{\$ 0}$ & $\frac{50}{90}$ & $\frac{50}{90}$ & 50 & $\$ 0$ & $\frac{50}{60}$ & $\frac{\$ 0}{90}$ & $\$ 0$ & $\frac{50}{90}$ & \\
\hline Subtotal \$ & & & & $\$ 13200$ & $\$ 3,200$ & $\$ 3,200$ & $\$ 3200$ & $\$ 200$ & $\$ 200$ & $\$ 200$ & $\$ 200$ & $\$ 200$ & $\$ 200$ & $\$ 200$ & $\$ 8.000$ & $\$ 200$ & $\$ 3,100$ & $\$ 100$ & $\$ 3,100$ & $\$ 100$ & $\$ 100$ & $\$ 3,100$ & $\$ 100$ \\
\hline BTOTAL SUBCONTRACTORS AND & IPENSES & & & $0.0 \mathrm{hrs}$ & $0.0 \mathrm{hrs}$ & $80.0 \mathrm{hrs}$ & $80.0 \mathrm{hrs}$ & 80.0 hrs & $800 \mathrm{hrs}$ & $400 \mathrm{hrs}$ & $0.0 \mathrm{hrs}$ & $0.0 \mathrm{hrs}$ & $0.0 \mathrm{hrs}$ & $0.0 \mathrm{hrs}$ & $0.0 \mathrm{hrs}$ & $0.0 \mathrm{hrs}$ & $400 \mathrm{hrs}$ & $0.0 \mathrm{hrs}$ & $0.0 \mathrm{hrs}$ & $0.0 \mathrm{hrs}$ & $0.0 \mathrm{hrs}$ & $00 \mathrm{prcs}$ & \\
\hline SUBTOTAL SUBCONTRACTORS AND & EXPENSES (COST) & & & $\$ 13,200$ & $\$ 3,200$ & $\$ 16,040$ & $\$ 16,040$ & $\$ 13,040$ & $\$ 13,939$ & $\$ 8,760$ & $\$ 200$ & $\$ 200$ & $\$ 200$ & $\$ 200$ & $\$ 8,000$ & $\$ 200$ & $\$ 11,660$ & $\$ 100$ & $\$ 3,100$ & $\$ 100$ & $\$ 100$ & $\$ 3,100$ & $\$ 100$ \\
\hline
\end{tabular}

UBTOTAL SUBCONTRACTORS AND EXPENSES ( $C O S$

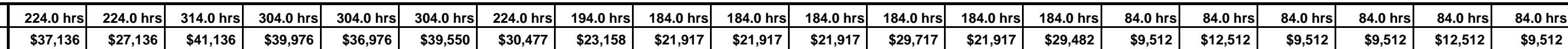

\begin{tabular}{l} 
PROJECT TOTAL (HOURS) \\
\hline PROJECT TOTAL (COST) \\
\hline COST
\end{tabular} 
INTEGRATED MID-CONTINENT CARBON CAPTURE, SEQUESTI

ENHANCED OIL RECOVERY PROJECT

Kansas Ethanol LLC Plant (KE) to Geneseo-Edwards (GE) Oil F

Detailed Engineering and Procurement Assistanace

Blue Source LLC

DETAILED ENGINEERING AND PROCUREMENT - Rooney Engineerin

\begin{tabular}{|c|c|c|c|c|c|c|c|c|c|c|c|c|c|}
\hline INDIVIDUAL & TITLE & \begin{tabular}{|l|} 
Billing \\
Rate 1/10 \\
\end{tabular} & $\frac{21}{18 \text {-Nov-10 }}$ & \begin{tabular}{|l|l|}
25 -Nov-1 \\
\end{tabular} & & $\frac{23}{2-\text { Dec- }-1}$ & & $\frac{24}{9-D e C-11}$ & & $\frac{25}{16-\mathrm{Dec}-1}$ & & $\frac{26}{23-\operatorname{Dec}-16}$ & $\frac{27}{30-\text {-ec-10 }}$ \\
\hline PROJECT MANAGEMENT & & & & & & & & & & & & & \\
\hline Henrick Sarkissian & Principal & $\$ 151.00$ & 20 & 2 & & & & $\overline{2}$ & & & & 20 & 0 \\
\hline Other & Principal & $\$ 151.00$ & 0 & $z$ & & & & & & & & $c$ & 0 \\
\hline Office Personnel & Office Personnel & $\$ 44.00$ & 20 & 2 & & 2 & & 2 & & & & 26 & \\
\hline Accounting Personnel & Cost Accountant & $\$ 64.00$ & & & & & & & & & & & 0 \\
\hline Subtotal Man-Hours & & & 44 & 4 & & & & 4 & & & & & 0 \\
\hline Subtotal $\mathrm{S}$ & & & $\$ 4,447$ & $\$ 4,44$ & & $\$ 4,4.4$ & & $\$ 4,44$ & & $\$ 4,44$ & & $\$ 4,447$ & $\$ 0$ \\
\hline $\begin{array}{l}\text { PROJECT ENGINEERING } \\
\text { Piving Baley }\end{array}$ & & & & & & & & & & & & & \\
\hline $\begin{array}{l}\text { Quinn Bailey } \\
\text { Zachary Bauer }\end{array}$ & $\begin{array}{l}\text { SSnior Project Engineer } \\
\text { Project Engineer }\end{array}$ & $\$ \$ \$ 116.00$ & $\frac{0}{40}$ & 4 & & & & 4 & & & & $\frac{1}{4 c}$ & $\begin{array}{ll}0 \\
0\end{array}$ \\
\hline Brian Techau & Project Engineer & $\$ 116.00$ & 0 & 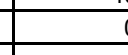 & & 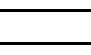 & & 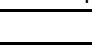 & & 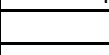 & & c & 0 \\
\hline Subtotal Man-Hours & & & 40 & 4 & & & & 4 & & & & 4 & 0 \\
\hline Subtotal \$ & & & $\$ 4,965$ & $\$ 4,96$. & & 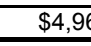 & & $\$ 4,96$ & & $\frac{94,96}{3}$ & & $\$ 4,964$ & 50 \\
\hline $\begin{array}{l}\text { PROJECT DESIGN } \\
\text { Mike Wagar }\end{array}$ & Designer & $\$ 9100$ & 0 & 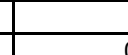 & & & & & & & & & \\
\hline $\begin{array}{l}\text { Mike Wager } \\
\text { Roxanne Burridge }\end{array}$ & Designer & $\$ 91.00$ & $\frac{0}{0}$ & - & & & & - & & & & c & 0 \\
\hline Chuck Haas & Designer & $\$ 91.00$ & 0 & I & & & & 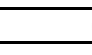 & & & & c & 0 \\
\hline Subtotal Man-Hours & & & 0 & t & & & & 7 & & & & $\mathrm{c}$ & 0 \\
\hline Subtotal \$ & & & & & & & & & & & & $\$$ & $\$ 0$ \\
\hline \multirow{2}{*}{\multicolumn{2}{|c|}{$\begin{array}{l}\text { SUBTOTAL ROONEY ENGINEERING (HOURS) } \\
\text { SUBTOTAL ROONEY ENGINEERING (COST) }\end{array}$}} & & $84.0 \mathrm{hrs}$ & $84.0 \mathrm{~h}$ & & 84.01 & & $340 \mathrm{~h}-2>$ & & $84.0 \mathrm{~h} \quad \mathrm{C}$ & & $84.0 \mathrm{hr}$ & $0.0 \mathrm{hrs}$ \\
\hline & & & $\$ 9,412$ & $\$ 9.41$ & & $\$ 9,4$ & & $\$ 9,41$ & & $\$ 9,41$ & & $\$ 9,412$ & \\
\hline
\end{tabular}

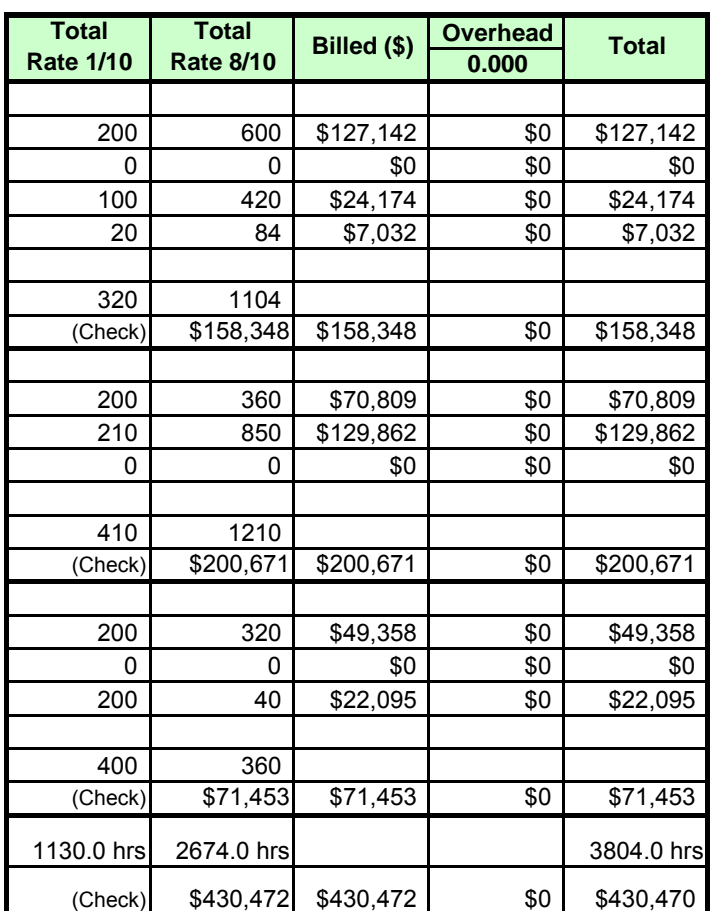

DETAILED ENGINEERING AND PROCUREMENT - Subcontractors ant

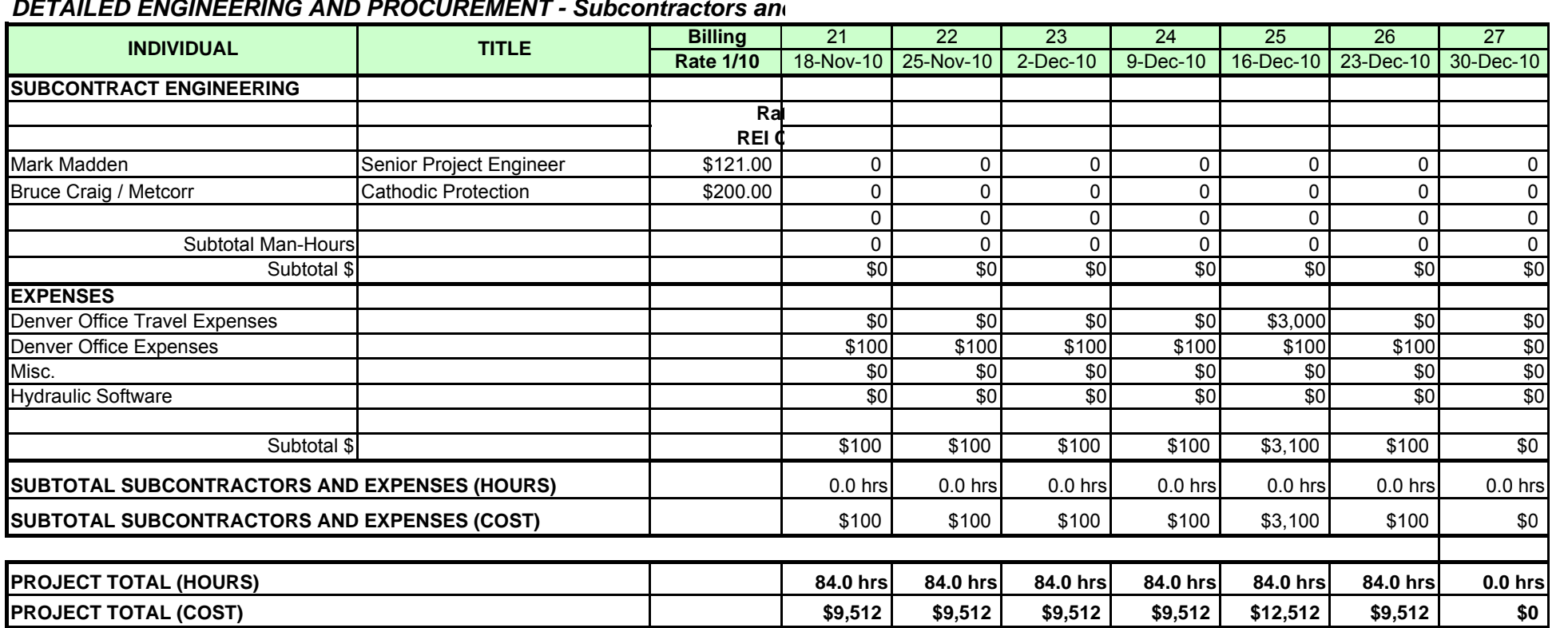

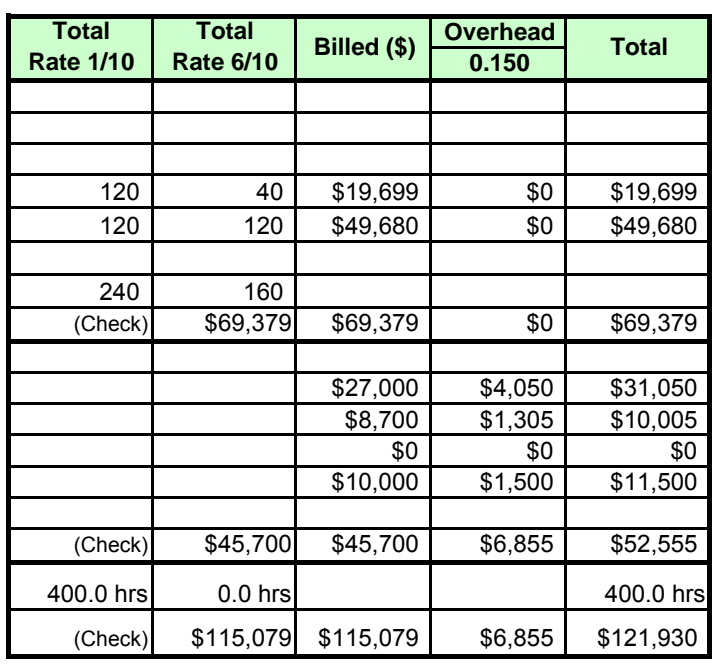

PROJECT TOTAL (HOURS)
PROJECT TOTAL (COST) 
INTEGRATED MID-CONTINENT CARBON CAPTURE, SEQUESTRATION \&

ENHANCED OIL RECOVERY PROJECT

Kansas Ethanol LLC Plant (KE) to Geneseo-Edwards (GE) Oil Field

Construction Administration and As-Built

Blue Source LLC

CONSTRUCTION ADMINISTRATION AND AS BUILT - Rooney Engineering Direct Labor

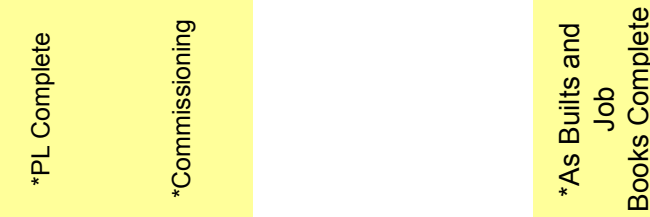

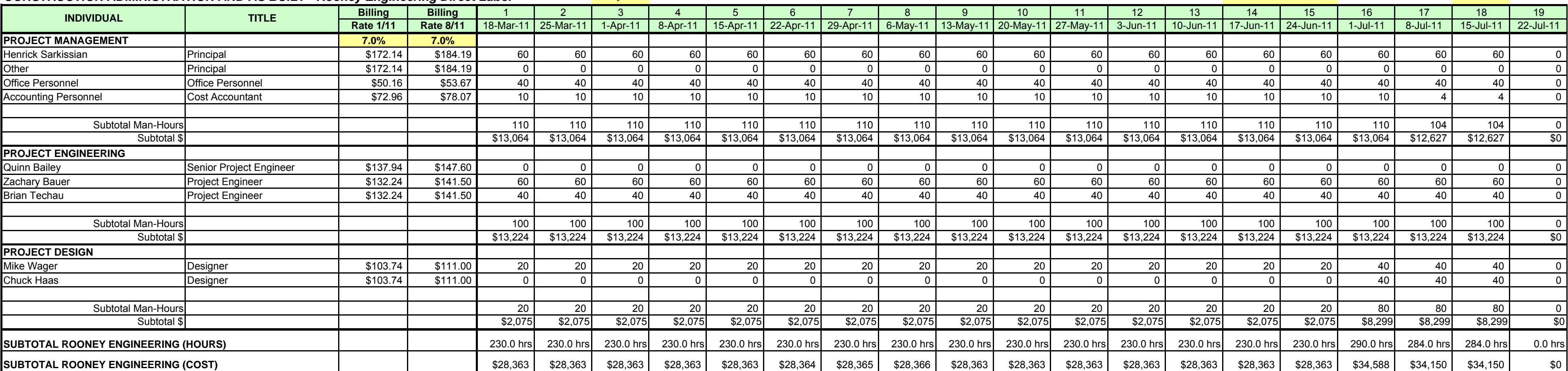

CONSTRUCTION ADMINISTRATION AND AS BUILT - Subcontractors and Expenses

INDIVIDUAL \begin{tabular}{l|c|c|c|}
\multirow{2}{*}{ TITLE } & Billing & Billing & \\
\cline { 2 - 4 } & Rate 1/11 & Rate 8/11 & 18. \\
\hline
\end{tabular}

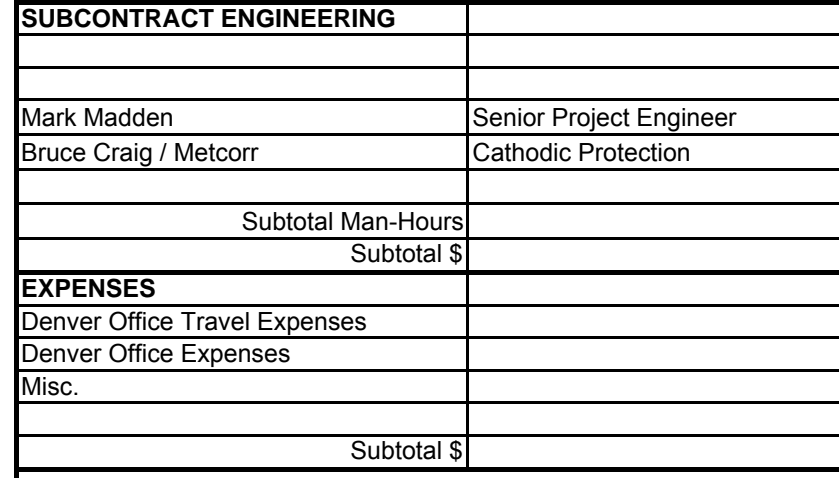

SUBTOTAL SUBCONTRACTORS AND EXPENSES (HOURS)

Rates
REICOST
$\$ 137.94$

\begin{tabular}{|l|l|l|l}
$\$ 228.00$ & $\$ 243.96$ \\
\hline
\end{tabular}

SURTOTAL SUBCONTRACTORS AND EXPENSES (COST)

\begin{tabular}{|l|l|l|}
\hline PROJECT TOTAL (HOURS) & \\
\hline
\end{tabular}

PROJECT TOTAL (COST) 
INTEGRATED MID-CONTINENT CARBON CAPTURE, SEQUEST

ENHANCED OIL RECOVERY PROJECT

Kansas Ethanol LLC Plant (KE) to Geneseo-Edwards (GE) Oil

Construction Administration and As-Buil

Blue Source LLC

CONSTRUCTION ADMINISTRATION AND AS BUILT - Rooney Engine

\begin{tabular}{|c|c|c|c|}
\hline INDIVIDUAL & TITLE & $\begin{array}{c}\frac{\text { Billing }}{\text { Rate 1/11 }} \\
\end{array}$ & $\frac{20}{29-J u l-11}$ \\
\hline PROJECT MANAGEMENT & & $7.0 \%$ & \\
\hline Tenrick Sarkissian & \begin{tabular}{|l|l} 
Principal \\
\end{tabular} & $\$ 172.14$ & \\
\hline ther & $\begin{array}{l}\text { Principal } \\
\end{array}$ & $\begin{array}{l}172.14 \\
\end{array}$ & \\
\hline office Personnel & Office Personnel & $\$ 50.16$ & \\
\hline Accounting Personnel & Cost Accountant & $\$ 72.96$ & \\
\hline Subtotal Man-Hours & & & \\
\hline Subtotal $\$$ & & & \\
\hline ROJECT ENGINEERING & & & \\
\hline Quinn Bailey & Senior Project Engineer & $\$ 137.94$ & \\
\hline $\begin{array}{l}\text { Zachary Bauer } \\
\text { arian Techau }\end{array}$ & $\frac{\frac{\text { Project Engineer }}{\text { Proiect Eninineer }}}{}$ & 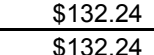 & $\frac{0}{0}$ \\
\hline & & & \\
\hline $\begin{array}{c}\text { Subtotal Man--Hours } \\
\text { Subtotal }\end{array}$ & & & $\frac{0}{\$ 0}$ \\
\hline RROJECT DESIGN & & & \\
\hline Mike Wager & $\begin{array}{l}\text { Designer } \\
\text { Desimar }\end{array}$ & $\begin{array}{ll}\$ 103.74 \\
\$ \$ 10374\end{array}$ & $\frac{0}{0}$ \\
\hline Shuck Haas & Designer & $\$ 103.74$ & \\
\hline $\begin{array}{c}\text { Subtotal Man-Hours } \\
\text { Subtotal } \$ \\
\end{array}$ & & & \\
\hline उTOTAL ROONEY ENGINEERING & 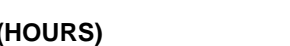 & & $0.0 \mathrm{hr}$ \\
\hline & & & \\
\hline
\end{tabular}

\begin{tabular}{l|l|l|l|}
\hline CONSTRUCTION ADMINISTRATION AND AS BUILT - Subcontractors \\
\hline Billing & 20 \\
\cline { 2 - 4 }
\end{tabular}

\begin{tabular}{|c|c|c|c|}
\hline INDIVIDUAL & TITLE & $\begin{array}{c}\text { Billing } \\
\text { Rate 1/11 } \\
\end{array}$ & $\frac{20}{29-J u-11}$ \\
\hline \multicolumn{4}{|l|}{ SUBCONTRACT ENGINEERING } \\
\hline & & $\begin{array}{c}\text { Ri } \\
\text { REI }\end{array}$ & \\
\hline Mark Madden & Senior Project Engineer & $\$ 137.94$ & 0 \\
\hline Bruce Craig / Metcorr & Cathodic Protection & $\$ 228.00$ & \\
\hline Subtotal Man-Hours & & & $\frac{0}{0}$ \\
\hline Subtotal \$ & & & \\
\hline \begin{tabular}{|l} 
Denver Office Travel Expenses \\
Denyor Office Fromsec \\
\end{tabular} & & & \\
\hline $\begin{array}{l}\text { Denver Office Expenses } \\
\text { Misc. }\end{array}$ & & & \\
\hline Subtotal \$ & & & $\$ 0$ \\
\hline SUBTOTAL SUBCONTRACTORS AND & EXPENSES (HOURS) & & $0.0 \mathrm{hrs}$ \\
\hline SUBTOTAL SUBCONTRACTORS AND & $s(\cos T)$ & & $\$ 0$ \\
\hline
\end{tabular}

PROJECT TOTAL (HOURS)

$+\frac{1}{1+3}$
CII EOONEY ENGINEERING, INC
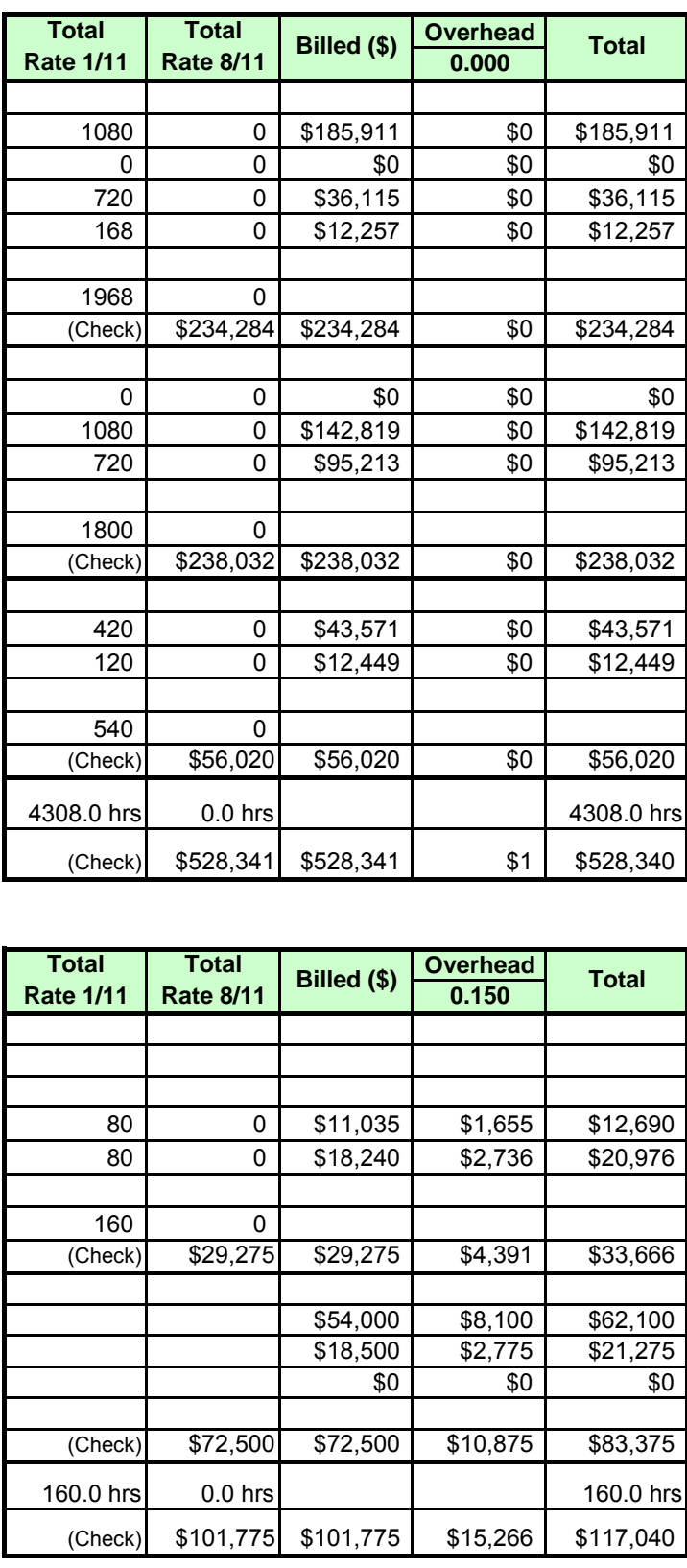

\begin{tabular}{|r|r|r|r|r|}
\hline $4468.0 \mathrm{hrs}$ & $0.0 \mathrm{hrs}$ & & & $4468.0 \mathrm{hrs}$ \\
\hline (Check) & $\$ 630,116$ & $\$ 630,116$ & $\$ 15,267$ & $\$ 645,380$ \\
\hline
\end{tabular} 
INTEGRATED MID-CONTINENT CARBON CAPTURE, SEQUESTRATION \& ENHANCED OIL RECOVERY PROJECT

Kansas Ethanol LLC Plant (KE) to Geneseo-Edwards (GE) Oil Field

Inspection, Surveying and X-Ray

Blue Source LLC

Date: March 31, 2010

Procurement Inspection

\begin{tabular}{|c|c|c|c|c|c|}
\hline Description & Rate & Quantitiy & $\begin{array}{c}\text { Manufacture } \\
\text { [Days] }\end{array}$ & $\begin{array}{c}\text { Set Upl } \\
\text { Close Out } \\
\text { Duration } \\
\text { [Days] }\end{array}$ & Total \\
\hline Chief Inspector & $\$ 2100.00$ & & 20 & 10 & 66,000 \\
\hline Utility Inspector & $\$ 2,050.00$ & & 20 & 10 & 63,000 \\
\hline Inspector Mileage & $\$ \quad 0.50$ & 480 & 20 & 10 & 7,200 \\
\hline \multirow{2}{*}{\multicolumn{5}{|c|}{$\begin{array}{l}\text { Total Procurement Inspection } \\
\text { Engineering Overhead of } 15 \%\end{array}$}} & 136,200 \\
\hline & $\begin{array}{l}\text { th Roone } \\
\text { Total wi }\end{array}$ & $\begin{array}{l}\text { Engineerin } \\
\text { Estimate C }\end{array}$ & $\begin{array}{l}\text { g Overhead of } \\
\text { ontingency of }\end{array}$ & $\begin{array}{l}15 \% \\
15 \%\end{array}$ & $\begin{array}{l}156,630 \\
\mathbf{1 8 0 , 1 2 5}\end{array}$ \\
\hline
\end{tabular}

Construction Inspection

\begin{tabular}{|c|c|c|c|c|c|}
\hline Description & Rate & Quantitiy & $\begin{array}{l}\text { Construction } \\
\text { Duration } \\
\text { [Days] }\end{array}$ & $\begin{array}{l}\text { Set Upl } \\
\text { Close Out } \\
\text { Duration } \\
\text { [Days] }\end{array}$ & Total \\
\hline Chief Inspector & $\$ 11,100.00$ & & 67 & 20 & 95,700 \\
\hline Chief Welding Inspector & $\$ 3050.00$ & & 67 & 15 & 258,300 \\
\hline Welding Inspector & $\$ B 000.00$ & & 67 & 10 & 231,000 \\
\hline Environmental Inspector & $\$ 950.00$ & 1 & 67 & 10 & 73,150 \\
\hline \begin{tabular}{|l|} 
Inspector Mileage \\
\end{tabular} & $\begin{array}{ll}\$ & 0.50 \\
\end{array}$ & 960 & 67 & 15 & 39,360 \\
\hline \multirow{3}{*}{ Total } & & & Construction & nspection & 697,510 \\
\hline & \multirow{2}{*}{\multicolumn{3}{|c|}{$\begin{array}{l}\text { vith Rooney Engineering Overhead of } \\
\text { Total with Estimate Contingency of }\end{array}$}} & $15 \%$ & 802,137 \\
\hline & & & & $15 \%$ & 922,457 \\
\hline
\end{tabular}

Note that above inspectors will be responsible for all aspects of contractor's activities from mobilization to

\begin{tabular}{|c|c|c|c|c|c|c|}
\hline Description & $\begin{array}{l}\text { Rate } \\
\text { [\$/day] }\end{array}$ & $\begin{array}{c}\text { Quantitiy } \\
\text { [ea] }\end{array}$ & $\begin{array}{c}\text { Construction } \\
\text { Duration } \\
\text { [Days] }\end{array}$ & $\begin{array}{c}\text { Set Upl } \\
\text { Close Out } \\
\text { Duration } \\
\text { [Days] }\end{array}$ & & rotal \\
\hline 2 Man Survey Crew (\#1) & $\$ \$ 991.67$ & 1 & 15 & 3 & $\$$ & 17,850 \\
\hline 2 Man Survey Crew (\#2) & $\$ 991.67$ & 0 & 0 & 0 & $\$$ & \\
\hline GPS Survey Equipment (\#1) & $\$ \quad 650.00$ & 1 & 15 & 3 & $\$$ & 11,700 \\
\hline GPS Survey Equipment (\#2) & \begin{tabular}{|l|l|}
$\$ 650.00$ \\
\end{tabular} & 0 & 0 & 0 & $\$$ & \\
\hline Survey Truck (\#1) & $\$ \quad 450.00$ & 1 & 15 & 3 & $\$$ & 8,100 \\
\hline \begin{tabular}{|l} 
Survey Truck (\#2) \\
\end{tabular} & $\begin{array}{l}\$ \quad 450.00 \\
\end{array}$ & 0 & 0 & 0 & $\$$ & \\
\hline Per Diem (\#1) & \begin{tabular}{|l|l|}
$\$ 110.00$ \\
\end{tabular} & 2 & 15 & 3 & $\$$ & 3,960 \\
\hline Per Diem (\#2) & $\$ 110.00$ & 0 & 0 & 0 & $\$$ & \\
\hline \multicolumn{5}{|c|}{$\begin{array}{c}\text { Total Route Survey } \\
\text { O Overhead of }\end{array}$} & $\$$ & 41,610 \\
\hline & $\begin{array}{l}\text { ith Roone } \\
\text { Total wi }\end{array}$ & Engineer & $\begin{array}{l}\text { g Overhead of } \\
\text { ontingency of }\end{array}$ & $\begin{array}{l}15 \% \\
15 \%\end{array}$ & \begin{tabular}{|l}
$\$$ \\
$\$$
\end{tabular} & $\begin{array}{l}47,852 \\
55,029\end{array}$ \\
\hline
\end{tabular}

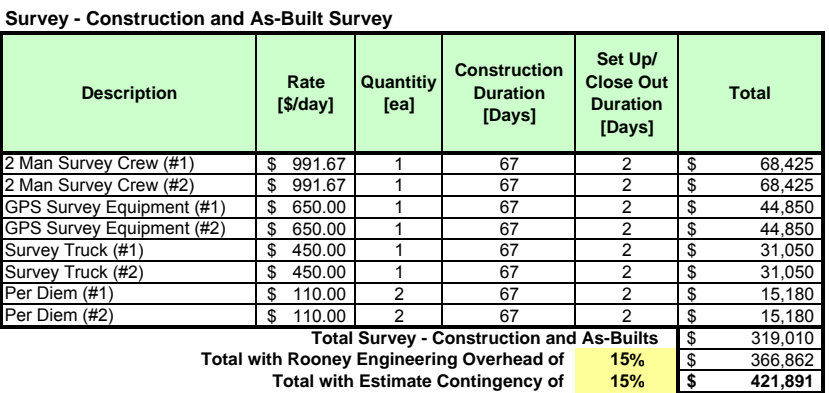

NDE (X-Ray) Inspection

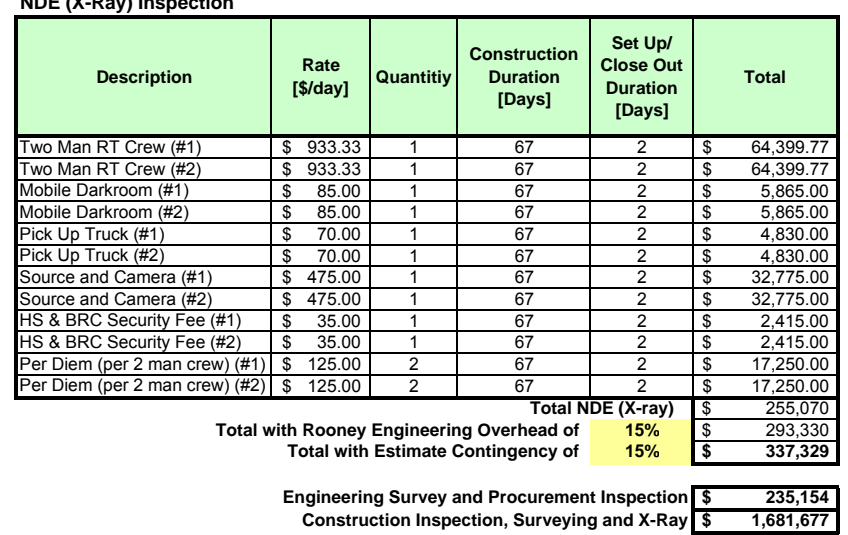


INTEGRATED MID-CONTINENT CARBON CAPTURE, SEQUESTRATION \&

ENHANCED OIL RECOVERY PROJECT

Kansas Ethanol LLC Plant (KE) to Geneseo-Edwards (GE) Oil Field

Material Quote Summary

Blue Source LLC

Date: March 31, 2010

Pipeline Materal Bid Summary

\begin{tabular}{|c|c|c|c|}
\hline Type & Analysis & Material Description & Cost \\
\hline 3D Bends & Average & 4", 0.337 " w.t., 90 Degree, 3D, MSS SP-75, WPHY-52, Segmentable Fitting, coated with 14-16 mils of FBE & $\$ 577.50$ \\
\hline & Average & 4", 0.337 " w.t., 60 Degree, 3D, MSS SP-75, WPHY-52, Segmentable Fitting, coated with $14-16$ mils of FBE & $\$ 570.00$ \\
\hline Line Pipe & Average & 4.5" OD, 0.237" w.t., ERW, API 5L, PSL2, Grade X-52, DRL, BEW, Coated with 14-16 mils of FBE & $\$ 9.61$ \\
\hline & Average & 4.5" OD, 0.337" w.t., SMLS, API 5L, PSL2, Grade X-52, DRL, BEW, Coated with $14-16$ mils of FBE & $\$ 20.16$ \\
\hline Launcher/Receiver & Average & $\begin{array}{l}\text { 4" - ANSI } 900 \text { Launcher/Reciever, Barrel and Closure (Yale } 500 \text { or equivalent) Only, Traps to accommodate } \\
\text { instrumented pigs, conventional pigs and typical pipeline inspection tools. }\end{array}$ & $\$ 14,101.00$ \\
\hline Pig Launcher - Bill of Material & Edgen - Murray & 4" Pig Launcher Bill of Materials & $\$ 20,930.81$ \\
\hline Pig Launcher - Bill of Material & Edgen - Murray & 4" Pig Receiver Bill of Materials & $\$ 18,462.81$ \\
\hline Valves & Cameron & 4" 900 RTJ GO CAMERON T31 TRIM 601 w/7' STEM EXTENSION \& COAL TAR & $\$ 7.600 .00$ \\
\hline & & 3" 900 RTJ GO CAMERON T31 TRIM 601 & $\$ 4,000.00$ \\
\hline
\end{tabular}


INTEGRATED MID-CONTINENT CARBON CAPTURE, SEQUESTRATION \&

ENHANCED OIL RECOVERY PROJECT

Kansas Ethanol LLC Plant (KE) to Geneseo-Edwards (GE) Oil Field

Blue Source LLC

Date: March 31, 2010

Road, Railroad, and Waterway Crossing List

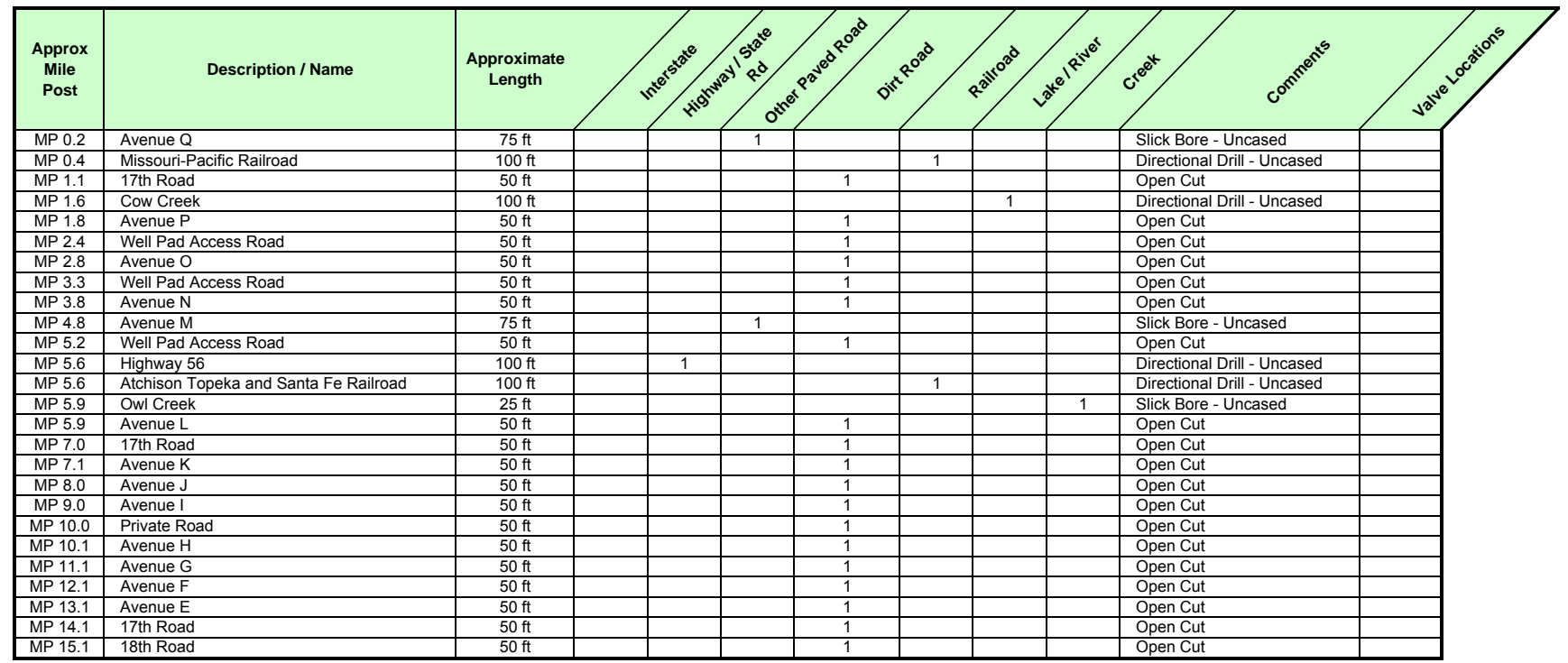

Crossing Summary

\begin{tabular}{|l|c|c|c|c|c|}
\hline \multicolumn{1}{|c|}{ TYPE } & $\begin{array}{c}\text { TOTAL NO. } \\
\text { CROSSINGS }\end{array}$ & $\begin{array}{c}\text { TOTAL } \\
\text { LENGTH }\end{array}$ & $\begin{array}{c}\text { W.A. } \\
\text { Length }\end{array}$ & $\begin{array}{c}\text { W.A. } \\
\text { Width }\end{array}$ & W.A. Dimensions \\
\hline Interstate & 0 & $0 \mathrm{ft}$ & $300 \mathrm{ft}$ & $300 \mathrm{ft}$ & 0 sq.ft. \\
\hline Highway / State Rd & 1 & $100 \mathrm{ft}$ & $300 \mathrm{ft}$ & $300 \mathrm{ft}$ & 180,000 sq.ft. \\
\hline Other Paved Road & 2 & $150 \mathrm{ft}$ & $300 \mathrm{ft}$ & $300 \mathrm{ft}$ & $360,000 \mathrm{sq} . \mathrm{ft}$ \\
\hline Dirt Road & 19 & $950 \mathrm{ft}$ & $300 \mathrm{ft}$ & $300 \mathrm{ft}$ & $3,420,000$ sq.ft. \\
\hline Railroad & 2 & $200 \mathrm{ft}$ & $300 \mathrm{ft}$ & $300 \mathrm{ft}$ & 360,000 sq.ft. \\
\hline Lake / River & 1 & $100 \mathrm{ft}$ & $300 \mathrm{ft}$ & $300 \mathrm{ft}$ & 180,000 sq.ft. \\
\hline Creek & 1 & $25 \mathrm{ft}$ & $300 \mathrm{ft}$ & $300 \mathrm{ft}$ & 180,000 sq.ft. \\
\hline TOTAL & $\mathbf{2 6}$ & $\mathbf{1 , 5 2 5 \mathrm { ft }}$ & $\mathbf{N} / \mathrm{A}$ & $\mathbf{N} / \mathbf{A}$ & $\mathbf{4 , 6 8 0 , 0 0 0}$ sq.ft. \\
\hline
\end{tabular}

Total Crossing Work Areas $=\quad 107.4$ acres

Pipeline ROW Disturbance $=\quad 143.6$ acres

Total Disturbance $=251.1$ acres 
INTEGRATED MID-CONTINENT CARBON CAPTURE, SEQUESTRATION \&

ENHANCED OIL RECOVERY PROJECT

Kansas Ethanol LLC Plant (KE) to Geneseo-Edwards (GE) Oil Field

Blue Source LLC

Date: March 31, 2010

\section{FEED ESTIMATE FOR SCADA SYSTEM}

CLIENT: BLUE SOURCE

PROJECT KE-GE

DESCRIPTION: 15.8 MILES OF CO2 PIPELINE FROM THE KANSAS ETHANOL PLANT TO GENESEO-EDWARDS FIELD

DATE

29-Mar-10

Estimate Overview:

This estimate is for a SCADA and Leak Detection system for a $\mathrm{CO} 2$ pipeline with main stations on either end of the pipeline and block valves sites along the pipeline as required. Each site would have a PLC and installed in a small building. The main control center site would house the primary SCADA and Leak Detection Computers which would communicate via fiber to the other sites. The other end of the pipeline would have a backup control center which would also contain the secondary SCADA and Leak Detection computers. A fiber optic cable would be installed along the pipeline and would be configured in a ring configuration for improved reliability.

SCADA Materials

\begin{tabular}{|c|c|c|c|c|c|}
\hline & Quantity & $\$$ & $5,000.00$ & \multicolumn{2}{|c|}{ Extension } \\
\hline Origination Station & 1 & $\$$ & $186,500.00$ & $\$$ & $186,500.00$ \\
\hline Terminal Station & 1 & $\$$ & $176,700.00$ & $\$$ & $176,700.00$ \\
\hline Block Valve Stations & 1 & $\$$ & $206,000.00$ & $\$$ & $206,000.00$ \\
\hline Fiber Optic Cable & & $\$$ & $180,136.00$ & $\$$ & $180,136.00$ \\
\hline & & & total & st & $749,336.00$ \\
\hline & ales Tax on & $\mathrm{Ma}$ & rial (5.98\%) & $\$$ & $44,800.00$ \\
\hline & & & total & $\$$ & 913,000 \\
\hline
\end{tabular}

SCADA Engineering Hours/Expenses

\begin{tabular}{|l|r|rr|rr|}
\cline { 2 - 6 } \multicolumn{1}{c|}{} & \multicolumn{1}{c|}{ Hours } & \multicolumn{2}{c|}{ Unit Price } & \multicolumn{2}{c|}{ Extension } \\
\hline Sr Project Engineer - SCADA & 1056 & $\$$ & 121.00 & $\$$ & $127,776.00$ \\
\hline Sr Designer & 54 & $\$$ & 91.00 & $\$$ & $4,914.00$ \\
\hline Travel Expenses & 1 & $\$$ & $8,370.00$ & $\$$ & $8,370.00$ \\
\hline & & & & \\
\hline \hline & & Subtotal & $\mathbf{\$}$ & $\mathbf{1 6 2 , 0 0 0}$ \\
\hline
\end{tabular}

SCADA Vendor Labor

\begin{tabular}{|l|r|r|rr|}
\cline { 2 - 5 } \multicolumn{1}{c|}{} & Quantity & \multicolumn{1}{c|}{ Unit Price } & \multicolumn{1}{c|}{ Extension } \\
\hline SCADA, PLC, Leak Detection Services & 1 & $\$ 330,000.00$ & $\$ 330,000.00$ \\
\hline \hline & & & \\
\hline
\end{tabular}

Fiber Optic Construction Labor

\begin{tabular}{|c|c|c|c|c|}
\hline \multirow[b]{2}{*}{ Fiber Optic Cable Construction Contractor } & Quantity & Unit Price & \multicolumn{2}{|c|}{ Extension } \\
\hline & & $\$ 166,848.00$ & $\$$ & $166,848.00$ \\
\hline & & Subtotal & $\$$ & 192,000 \\
\hline
\end{tabular}

Notes:

Assumed Estimate Contingency $\quad 15.0 \%$

1) SCADA electrical construction contractor labor not included since wiring up the PLCs would be done by site contractor along with instruments

2) Fiber optic labor assumes moderately difficult ground conditions which raises cable installation cost moderately

3) PLC MCC building is included at the terminal station

4) Instrumentation not included here. 
INTEGRATED MID-CONTINENT CARBON CAPTURE, SEQUESTRATION \&

ENHANCED OIL RECOVERY PROJECT

Kansas Ethanol LLC Plant (KE) to Geneseo-Edwards (GE) Oil Field

Blue Source LLC

Date: March 31, 2010

STATIONS ON EITHER END OF PIPELINE

Materials

ORIGINATION

STATION

STATION

\begin{tabular}{|l|r|rr|rr|}
\cline { 2 - 5 } \multicolumn{1}{c|}{} & \multicolumn{2}{c|}{ Quantity } & \multicolumn{2}{c|}{ Unit Price } & \multicolumn{2}{c|}{ Extension } \\
\hline PLC, w Cabinet & 1 & $\$$ & $40,000.00$ & $\$$ & $40,000.00$ \\
\hline SCADA Software Licenses & 1 & $\$ 25,000.00$ & $\$$ & $25,000.00$ \\
\hline Backup communications components & 1 & $\$$ & $10,000.00$ & $\$$ & $10,000.00$ \\
\hline SCADA Server, Rack, Printer, etc & 1 & $\$$ & $20,000.00$ & $\$$ & $20,000.00$ \\
\hline Leak Detection Server & 1 & $\$$ & $5,000.00$ & $\$$ & $5,000.00$ \\
\hline Leak Detection Software Licenses (note 2) & 1 & $\$$ & $60,000.00$ & $\$$ & $60,000.00$ \\
\hline UPS & 1 & $\$$ & $5,000.00$ & $\$$ & $5,000.00$ \\
\hline Fiber Media Converter & 1 & $\$$ & $1,500.00$ & $\$$ & $1,500.00$ \\
\hline Communications Equipment for backup communications & 1 & $\$$ & $5,000.00$ & $\$$ & $5,000.00$ \\
\hline Misc & 1 & $\$$ & $15,000.00$ & $\$$ & $15,000.00$ \\
\hline \hline & & & Subtotal & $\$$ & $\mathbf{1 8 6 , 5 0 0 . 0 0}$ \\
\hline
\end{tabular}

\begin{tabular}{|c|c|c|c|c|}
\hline & & Quantity & Unit Price & Extension \\
\hline TERMINAL & PLC, w Cabinet & 1 & $\$ \quad 40,000.00$ & $40,000.00$ \\
\hline \multirow{11}{*}{ STATION } & PLC-MCC Building & 1 & $65,000.00$ & $65,000.00$ \\
\hline & SCADA Software Licenses & 1 & $7,000.00$ & $7,000.00$ \\
\hline & Backup communications components & 1 & $10,000.00$ & $10,000.00$ \\
\hline & SCADA Computer, Rack & 1 & $10,000.00$ & $10,000.00$ \\
\hline & Leak Detection Computer & 1 & $5,000.00$ & $5,000.00$ \\
\hline & \begin{tabular}{|l|} 
Leak Detection Software Licenses \\
\end{tabular} & 1 & $15,000.00$ & $15,000.00$ \\
\hline & UPS & 1 & $5,000.00$ & $5,000.00$ \\
\hline & Fiber Media Converter & 1 & $3,200.00$ & $3,200.00$ \\
\hline & Communications Equipment for backup communications & 1 & $1,500.00$ & $1,500.00$ \\
\hline & Misc & 1 & $\$ \quad 15,000.00$ & $15,000.00$ \\
\hline & & & Subtotal & $176,700.00$ \\
\hline
\end{tabular}

VENDOR SERVICES

\begin{tabular}{|c|c|c|c|c|c|}
\hline & Quantity & \multicolumn{2}{|c|}{ Unit Price } & \multicolumn{2}{|c|}{ Extension } \\
\hline SCADA Vendor Services for Origination Station (note 6) & 1 & \$ & $100,000.00$ & $\$$ & $100,000.00$ \\
\hline SCADA Vendor services for Terminal Station & 1 & $\$$ & $10,000.00$ & $\$$ & $10,000.00$ \\
\hline SCADA Vendor Travel Expenses & 1 & $\$$ & $30,000.00$ & $\$$ & $30,000.00$ \\
\hline PLC Programming for two PLCs & 2 & $\$$ & $50,000.00$ & $\$$ & $100,000.00$ \\
\hline PLC Programmer Travel Expenses & 1 & $\$$ & $15,000.00$ & $\$$ & $15,000.00$ \\
\hline Leak Detection System services for Origination Station & 1 & $\$$ & $60,000.00$ & $\$$ & $60,000.00$ \\
\hline Leak Detection System services for Terminal Station & 1 & $\$$ & $5,000.00$ & $\$$ & $5,000.00$ \\
\hline \multirow[t]{3}{*}{ Leak Detection Vendor Travel Expenses } & 1 & $\$$ & $10,000.00$ & $\$$ & $10,000.00$ \\
\hline & & & & $\$$ & - \\
\hline & & & btotal & $\$$ & $330,000.00$ \\
\hline
\end{tabular}

Notes:

1) Assumes fiber optic communications.

3) PLC MCC building is included at the terminal station

3) Assumes Wonderware class SCADA software

4) Assuming 120 VAC is available at both stations

5) Instrumentation not included here.

6) SCADA vendor services include project management, design specification documents, SCADA communications programming, SCADA screen programming, factory tests, installation onsite, onsite tuning of the software, commissioning tests, operations and the maintenance manual, training support for operators and technicians.

7) Leak Detection vendor services include project management, design specification documents, communications programming, graphical user interface screen programming, factory tests, installation onsite, tuning of the software, commissioning tests, operations and the maintenance manual, training support for operators and technicians. 
INTEGRATED MID-CONTINENT CARBON CAPTURE, SEQUESTRATION \&

ENHANCED OIL RECOVERY PROJECT

Kansas Ethanol LLC Plant (KE) to Geneseo-Edwards (GE) Oil Field

Blue Source LLC

Date: March 31, 2010

\section{BLOCK VALVE STATIONS}

Materials

\begin{tabular}{|c|c|c|c|c|c|}
\hline & Quantity & & Init Price & & Extension \\
\hline PLC, w Cabinet & 4 & $\$$ & $15,000.00$ & $\$$ & $60,000.00$ \\
\hline PLC Building & 4 & $\$$ & $30,000.00$ & $\$$ & $120,000.00$ \\
\hline Fiber Media Converter & 4 & $\$$ & $1,500.00$ & $\$$ & $6,000.00$ \\
\hline Misc & 4 & $\$$ & $5,000.00$ & $\$$ & $20,000.00$ \\
\hline & & \multicolumn{2}{|c|}{ Subtotal } & $\overline{\$}$ & $206,000.00$ \\
\hline
\end{tabular}

Services

\begin{tabular}{|c|c|c|c|c|c|}
\hline & Quantity & \multicolumn{2}{|c|}{ Unit Price } & \multicolumn{2}{|c|}{ Extension } \\
\hline PLC Programming & 4 & $\$$ & $5,000.00$ & $\$$ & $20,000.00$ \\
\hline PLC Programmer Travel Expenses & 4 & $\$$ & $2,000.00$ & $\$$ & $8,000.00$ \\
\hline Misc & 4 & $\$$ & $2,000.00$ & $\$$ & $8,000.00$ \\
\hline & & & total & $\$$ & $36,000.00$ \\
\hline
\end{tabular}

Notes:

1 PLC building is recommended due to the difficulty of maintaining PLC in winter conditions. 
INTEGRATED MID-CONTINENT CARBON CAPTURE, SEQUESTRATION \&

ENHANCED OIL RECOVERY PROJECT

Kansas Ethanol LLC Plant (KE) to Geneseo-Edwards (GE) Oil Field

Blue Source LLC

Date: March 31, 2010

FIBER OPTICS

Materials

\begin{tabular}{|c|c|c|c|c|c|c|}
\hline & Quantity & Units & \multicolumn{2}{|c|}{ Unit Price } & \multicolumn{2}{|r|}{ Extension } \\
\hline 12 Strand Single Mode Armored Outside Plant Cable & 83,424 & $\mathrm{ft}$ & $\$$ & 1.50 & & $125,136.00$ \\
\hline Fiber Troubleshooting instrument & 1 & LS & $\$$ & $35,000.00$ & $\$$ & $35,000.00$ \\
\hline Misc Hand Holes, etc & 1 & LS & $\$$ & $20,000.00$ & $\$$ & $20,000.00$ \\
\hline & & & & ototal & & $180,136.00$ \\
\hline
\end{tabular}

Labor - Installation Contractor

\begin{tabular}{|c|c|c|c|c|c|}
\hline & Quantity & Units & Unit Price & & Extension \\
\hline Contractor Labor for installation and testing & 83,424 & $\mathrm{ft}$ & $\$ 2.00$ & $\$$ & $166,848.00$ \\
\hline & & & & $\$$ & - \\
\hline & & & Subtotal & $\$$ & $166,848.00$ \\
\hline
\end{tabular}


INTEGRATED MID-CONTINENT CARBON CAPTURE, SEQUESTRATION \&

ENHANCED OIL RECOVERY PROJECT

Kansas Ethanol LLC Plant (KE) to Geneseo-Edwards (GE) Oil Field

Blue Source LLC

Date: March 31, 2010

SCADA PROJECT - ESTIMATE OF I\&E ENGINEERING TASKS

\begin{tabular}{|c|c|c|c|c|c|c|c|c|c|c|c|c|c|c|c|c|c|c|c|}
\hline \multirow[b]{2}{*}{ TASK \# } & \multirow[b]{2}{*}{ TASKS } & \multirow[b]{2}{*}{$\begin{array}{l} \\
\bar{\Phi} \\
\sum_{2} \\
\text { Rates: }\end{array}$} & \multicolumn{4}{|c|}{ Project Management } & \multicolumn{5}{|c|}{ TRAVEL \& MISC EXPENSES } & \multicolumn{6}{|c|}{ Engineering } & \multirow[b]{2}{*}{ 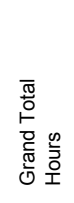 } & \multirow[b]{2}{*}{ 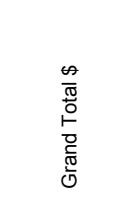 } \\
\hline & & & 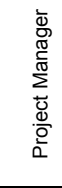 & 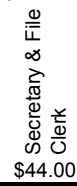 & 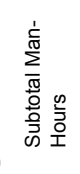 & 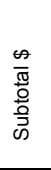 & 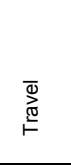 & 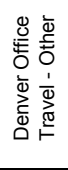 & 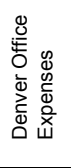 & $\begin{array}{l}\dot{0} \\
\dot{m} \\
\dot{\omega n}\end{array}$ & 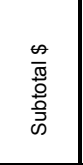 & 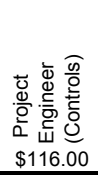 & 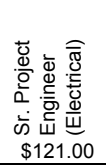 & 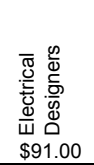 & 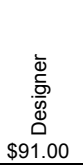 & 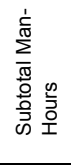 & 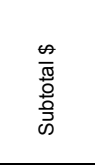 & & \\
\hline 1 & Initial Site visit & & & & 0 & $\$ 0$ & 1,920 & & & & $\$ 1,920$ & & 30 & & & 30 & 3,630 & 30 & 5,550 \\
\hline 2 & & & & & 0 & $\$ 0$ & & & & & $\$ 0$ & & & & & 0 & 0 & 0 & 0 \\
\hline 3 & & & & & 0 & $\$ 0$ & & & & & $\$ 0$ & & & & & 0 & 0 & 0 & 0 \\
\hline 4 & Assist with Project Budget preparation & & & & 0 & $\$ 0$ & & & & & $\$ 0$ & & 24 & & & 24 & 2,904 & 24 & 2,904 \\
\hline 5 & & & & & 0 & $\$ 0$ & & & & & $\$ 0$ & & & & & 0 & 0 & 0 & 0 \\
\hline 6 & $\begin{array}{l}\text { SCADA SPECIFICATION, RFQ, CONTRACT OVERSIGHT, DESIGN } \\
\text { APPROVAL, FACTORY TEST, SITE TEST }\end{array}$ & & & & 0 & $\$ 0$ & & & 300 & & $\$ 300$ & & 300 & & & 300 & 36,300 & 350 & 36,600 \\
\hline 7 & & & & & 0 & $\$ 0$ & & & & & $\$ 0$ & & & & & 0 & 0 & 0 & 0 \\
\hline & $\begin{array}{l}\text { LEAK DETECTION SYSTEM SPECIFICATION, RFQ, CONTRACT } \\
\text { OVERSIGHT, DESIGN APPROVAL, FACTORY TEST, SITE TEST }\end{array}$ & & & & 0 & $\$ 0$ & & & 200 & & $\$ 200$ & & 200 & & & 200 & 24,200 & 250 & 24,400 \\
\hline 1 & & & & & 0 & $\$ 0$ & & & & & $\$ 0$ & & & & & 0 & 0 & 0 & 0 \\
\hline 2 & Fiber Optic Design, RFQ & & & & 0 & $\$ 0$ & & & & & $\$ 0$ & & 60 & & & 60 & 7,260 & 60 & 7,260 \\
\hline 3 & & & & & 0 & $\$ 0$ & & & & & $\$ 0$ & & & & & 0 & 0 & 0 & 0 \\
\hline 4 & Fiber Optic Construction Spec, RFQ, Contract Oversight & & & & 0 & $\$ 0$ & & & & & $\$ 0$ & & 80 & & & 80 & 9,680 & 80 & 9,680 \\
\hline 5 & & & & & 0 & $\$ 0$ & & & & & $\$ 0$ & & & & & 0 & 0 & 0 & 0 \\
\hline 6 & & & & & 0 & $\$ 0$ & & & & & $\$ 0$ & & & & & 0 & 0 & 0 & 0 \\
\hline 7 & & & & & 0 & $\$ 0$ & & & & & $\$ 0$ & & & & & 0 & 0 & 0 & 0 \\
\hline 8 & & & & & 0 & $\$ 0$ & & & & & $\$ 0$ & & & & & 0 & 0 & 0 & 0 \\
\hline 9 & & & & & 0 & $\$ 0$ & & & & & $\$ 0$ & & & & & 0 & 0 & 0 & 0 \\
\hline 10 & & & & & 0 & $\$ 0$ & & & & & $\$ 0$ & & & & & 0 & 0 & 0 & 0 \\
\hline 11 & & & & & 0 & $\$ 0$ & & & & & $\$ 0$ & & & & & 0 & 0 & 0 & 0 \\
\hline 12 & Weekly Conference Calls & & & & 0 & $\$ 0$ & & & & & $\$ 0$ & & 30 & & & 30 & 3,630 & 30 & 3,630 \\
\hline 13 & & & & & 0 & $\$ 0$ & & & & & $\$ 0$ & & & & & 0 & 0 & 0 & 0 \\
\hline 14 & Construction Inspection Trip (X 3) & & & & 0 & $\$ 0$ & 3,570 & & & & $\$ 3,570$ & & 120 & & & 120 & 14,520 & 120 & 18,090 \\
\hline 15 & Testing Trips ( $\mathrm{x} 2$ ) & & & & 0 & $\$ 0$ & 2,380 & & & & $\$ 2,380$ & & 80 & & & 80 & 9,680 & 80 & 12,060 \\
\hline 16 & & & & & 0 & $\$ 0$ & & & & & $\$ 0$ & & & & & 0 & 0 & 0 & 0 \\
\hline 17 & & & & & 0 & $\$ 0$ & & & & & $\$ 0$ & & & & & 0 & 0 & 0 & 0 \\
\hline 18 & As Built Electrical Drawings & & & & 0 & $\$ 0$ & & & & & $\$ 0$ & & 40 & 50 & & 90 & 9,390 & 90 & 9,390 \\
\hline 19 & I\&E Job Book & & & & 0 & $\$ 0$ & & & & & $\$ 0$ & & 32 & 4 & & 36 & 4,236 & 36 & 4,236 \\
\hline 20 & & & & & 0 & $\$ 0$ & & & & & $\$ 0$ & & & & & 0 & 0 & 0 & 0 \\
\hline 21 & Assist with SCADA \& Leak Detection Tuning & & & & 0 & $\$ 0$ & & & & & $\$ 0$ & & 60 & & & 60 & 7,260 & 60 & 7,260 \\
\hline 22 & & & & & 0 & $\$ 0$ & & & & & $\$ 0$ & & & & & 0 & 0 & 0 & 0 \\
\hline 23 & & & & & 0 & $\$ 0$ & & & & & $\$ 0$ & & & & & 0 & 0 & 0 & 0 \\
\hline 24 & & & & & 0 & $\$ 0$ & & & & & $\$ 0$ & & & & & 0 & 0 & 0 & 0 \\
\hline 25 & & & & & & $\$ 0$ & & & & & & & & & & 24 & 0 & & \\
\hline 26 & & & & 0 & 0 & $\$ 0$ & 0 & & 0 & & $\$ 0$ & & & 0 & 0 & 0 & 0 & 0 & 0 \\
\hline 27 & & & 0 & 0 & 0 & $\$ 0$ & 0 & & 0 & 0 & $\$ 0$ & 0 & 0 & 0 & 0 & 0 & 0 & 0 & 0 \\
\hline & & Hours & 0 & 0 & 0 & $\$ 0$ & 7,870 & 0 & 500 & 0 & 8,370 & 0 & 1,056 & 54 & 0 & 1,134 & 132,690 & 1,210 & \\
\hline & & Cost (\$) & 0 & 0 & $\$ 0$ & & 7,870 & 0 & 500 & 0 & 8,370 & 0 & 127,776 & 4,914 & 0 & & 132,690 & & 141,060 \\
\hline & & Back check & & & & & & & & & 8,370 & & & & & & 132,69 & & $\begin{array}{l}\$ 141,060 \\
\$ 141,060\end{array}$ \\
\hline & & & & & & & & & & & & & & & & Withou & Expenses $=$ & & $\$ 132,690$ \\
\hline Not Inclu & & & & & & & & & & & & & & & & & xpenses $=$ & & $\$ 8,370$ \\
\hline
\end{tabular}


BLUE SOURCE, LLC.

KE - GE CO2 PIPELINE PROJECT

CAP CO2 KANSAS ETHANOL COMPRESSION FACILITY

TIER III - CAPITAL COST ESTIMATE

Client: Blue Source, LLC.

Project: KE-GE CO2 Pipeline Project

System: Kansas Ethanol Compression Facility

Scope: Ref. Blue Source RFP for Kansas CO2 Pipeline Study, Doc. RPH-12-29-09.

Description: Engineering, Design, and Construction of a new CAP CO2 compression facility at the Kansas Ethanol, Lyons, KS plant located in the NE NW of Section

27, T20S, R8W, for the purpose of recovering waste gases off of the Ethanol Plant and processing the high concentration $\mathrm{CO} 2$ mix stream for use in

Enhanced Oil Recover and boosting the purified stream pressure for transportation as a supercritical phase fluid via pipeline to the Geneseo Edwards Field delivery point located in the center of Section 24, T18S, R8W.

\section{COMPRESSION FACILITIES}

ENGINEERING \& DESIGN

LAND \& RIGHT-OF-WAY

ENVIRONMENTAL \& PERMITTING

EQUIPMENT \& MATERIALS

$\$ 13,644,000$

$\$ 11,920,900$

FREIGHT @ 8\%

$\$ 953,672$

TAXES @ 5.98\%

$\$ 769,899$

CONSTRUCTION SERVICES

CONSTRUCTION

BOND @ 3\% 


\section{BLUE SOURCE, LLC. \\ KE - GE CO2 PIPELINE PROJECT \\ CAP CO2 KANSAS ETHANOL COMPRESSION FACILITY \\ TIER III - CAPITAL COST ESTIMATE}

Client: Blue Source, LLC

Project: KE-GE CO2 PIpelıne Project

system: Kansas tthanol Compression racillty

Scope: Ref. Blue Source RFP for Kansas CO2 Pipeline Study, Doc. RPH-12-29-09.

Description: Engineering, Design, and Construction of a new CAP CO2 compression facility at the Kansas Ethanol, Lyons, KS plant located in the NE NW of Section $27, \mathrm{~T} 20 \mathrm{~S}, \mathrm{R} 8 \mathrm{~W}$, for the purpose of recovering waste gases off of the Ethanol Plant and processing the high concentration CO2 mix stream for use in Enhanced Oil Recover and boosting the purified stream pressure for transportation as a supercritical phase fluid via pipeline to the Geneseo Edwards Field delivery point located in the center of Section 24, T18S, R8W.

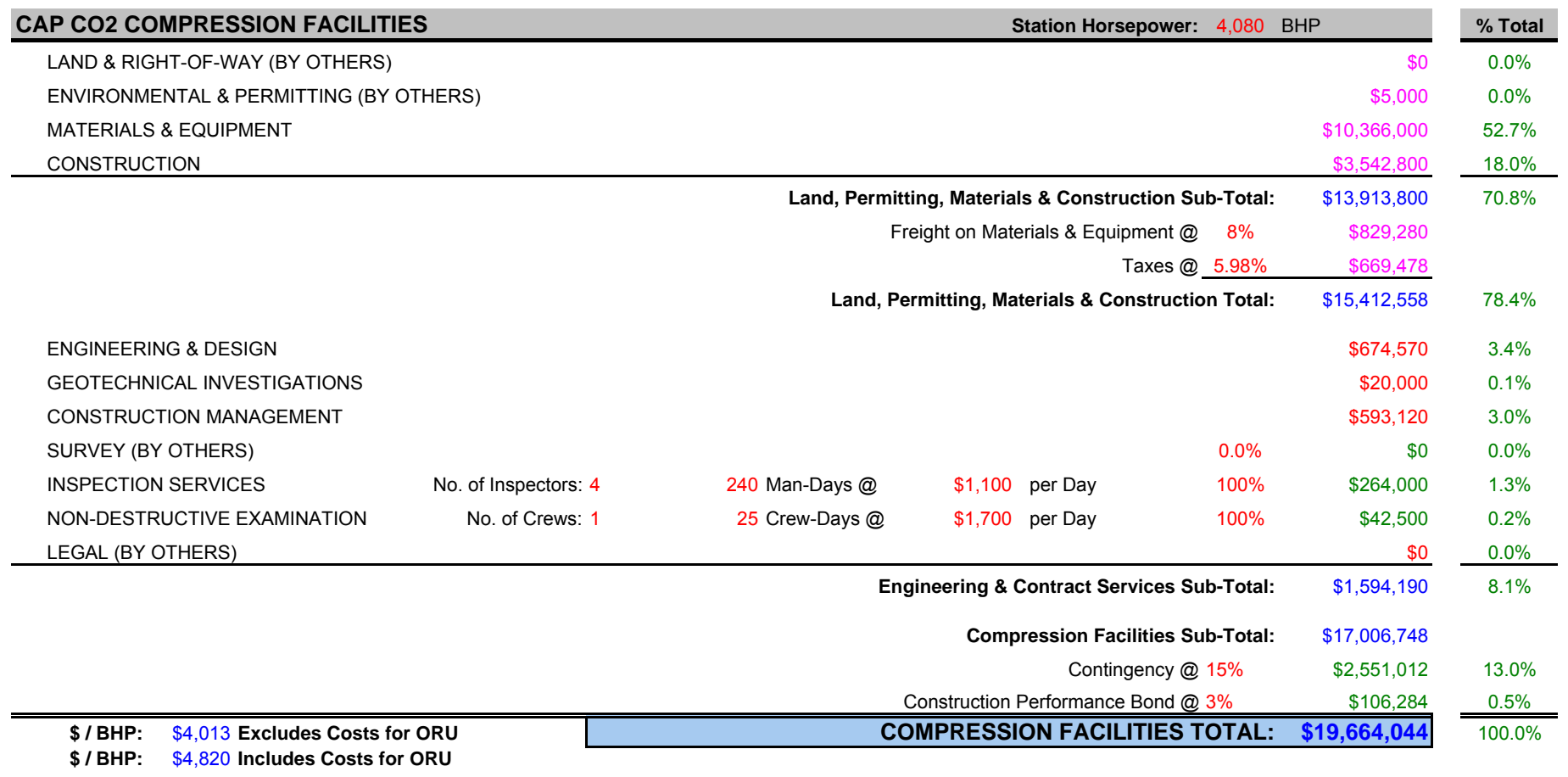


Blue Source, LLC.

KE-GE CO2 Pipeline Project

Kansas Ethanol Compression Facility

\section{Project Estimate Worksheet}

LAND \& RIGHT-OF-WAY

100. CAP CO2 KANSAS ETHANOL COMPRESSOR STATION

\begin{tabular}{rr} 
& $\$ 0$ \\
\hline Sub-Total: & $\$ 0$ \\
Contingency @ 15\% & $\$ 0$ \\
\hline \& Right-of-Way: & $\$ 0$
\end{tabular}

Grand Total - Land \& Right-of-Way:

$\$ 0$
Qty

Units

Unit Rate

Sub-Total Price

Estimate Supplier

Description

Sub-Total:

CAP CO2 KANSAS ETHANOL
101. Acquisition \& Damages

01 Land \& Property Appraisals

02 Land Acquisition Costs

03 Property Expense

$\begin{array}{lll}0 & \text { Weeks } \$ 2,500 \\ 0 & \text { Weeks } & \$ 2500\end{array}$

$\$ 2,500$

$\$ 15,000$

$\$ 0$

$\$ 0$

$\$ 0$ 
Blue Source, LLC.

KE-GE CO2 Pipeline Project

Kansas Ethanol Compression Facility

\section{Project Estimate Worksheet}

ENVIRIONMENTAL \& PERMITTING SUPPORT

100. CAP CO2 KANSAS ETHANOL COMPRESSOR STATION

sub-Totat:

Contingency @ 15\%

$\$ 5,000$

Grand Total - Environmental \& Permitting Support:

$\$ 5,750$

Cost Code

Qty

Units

Unit Rate

Sub-Total Price

Estimate Supplier

100. CAP CO2 KANSAS ETHANOL COMPRESSOR STATION

101. Permitting Assistance

01 Air Permitting Support \& Acquisition Costs

101.01

is

5,000

$\$ 5,000$

LWR Consultants

102. Storm Water Monitoring

01 TBD

102.01

LS $\$ 0$

Air Permit 
Blue Source, LLC.

KE-GE CO2 Pipeline Project

Kansas Ethanol Compression Facility
MATERIALS \& EQUIPMENT

100. MECHANICAL EQUIPMENT \& MATERIALS

200. ELECTRICAL \& INSTRUMENTATION EQUIPMENT \& MATERIALS
$\$ 9,358,000$

$\$ 1,008,000$

Sub-Total:

Freight @ $8 \%$

Taxes@6\%

Contingency @ 15\%

Grand Total - Materials \& Equipment

$13,644,471$

\section{Project Estimate Worksheet}

Cost Code

100. MECHANICAL EQUIPMENT \& MATERIALS

101. Pipe, Fittings \& Materials

01 Pipe, Various Diameters \& Coatings

02 Fittings, Various Diameters

102. Scrubbers / Filters / Separators

01 Scrubber, 2-Phase, Vertical, 8.625" O.D. x 4'-0" S/S, ASME Sect. VIII, Div. 1, 285 psi @ -20/1C 102.01

103. Compression Equipment

01 Compressor, Reciprocating, GE FS-706, 6-Stage, $4160 \mathrm{~V}$ Inv. Duty Electric Drive

02 Compressor Package Spare Parts

104. Processing Equipment

01 Oxygen Removal Unit, 8 MMscfd, 3\% Maximum O2

02 TEG Dehydration Package, 125,000 BTU/ Hr Reboiler, 24" x 25', 8-Tray Contactor Column

105. Metering Equipment

01 Orifice Meter, 2" ANSI 150 RFFE, Simplex w/ Flow Cond. \& Skid Mounted Metal Building

106. Compressor Building

01 Compressor Building, 50' W X 65' L x 15' Eve Hght, Ovhd Door, Fixed Wall Louvers, 5 Ton Bric 106.01

107. Block Valves \& SDV's

01 Valves, Various Sizes \& Type

108. Control Valves \& Regulators

01 Flow Control Valve, Fisher EZ or Comparable, 1" ANSI 150 RFFE

109. Liquid Dump Valves \& Controllers

01 Liquid Dump Valve, 1" Kimray SMT 1400 or Similar, 0.5-Inch Inner Valve

02 Level Controller, Kimray Gen II or Similar, Float Operated, 2" MNPT

110. Check Valves

01 Valve, Check, 4" ANSI 900 RFFE, Piston Type, API-6D
02 Valve, Check, 4" ANSI 300 RFFE, Piston Type, API-6D

111. Relief Valves

01 Pressure Relief Valve, 1" FNPT X 1" FNPT, For Gas Service

112. Sump Tank

01 Sump Tank, 3,000 Gallon, Double Wall Fiberglass w/ Turbine Enclosure, Leak Monitor, Brine

113. Pipe Supports

01 Pipe Support, 6" Pipe, EZ-Line Model CSB-6 w/Shim Blocks, Pipe Clamp \& Baseplate

02 Pipe Support, 4" Pipe, EZ-Line Model CSB-4 w/Shim Blocks, Pipe Clamp \& Baseplate

\section{ELECTRICAL \& INSTRUMENTATION EQUIPMENT \& MATERIALS}

201. Instrumentation

01 Pressure Gauge, 5" Dial, 1/2" MNPT Process Connection, Range: Varies

02 Gauge, Temperature, Range: Varies, w/ Thermowell

03 Switch, Gage Pressure, Range: Varies

04 Switch, Level, 316 SS Media Contacts w/ Relay, 24VDC

05 Gauge, Level, 316 SS Chamber w/ Side Connect Valves, Center-to-Center Dim: Varies

06 Pressure Transmitter, Indicating, "Smart", Range: Varies, Includes 2-Valve Manifold

07 Transmitter, Temperature, "Smart", Range: Varies, w/ Thermowell

08 Transmitter, Level, SABB Radar, Range: Varies w/ RTD Inputs

09 Switch, Level, Range / Length: Varies

10 CO2 Detector, Class $1 /$ Div. 1 Rated

11 Fire Eye, Class $1 /$ Div 1 Rated

12 Vibration Transducer

101.01
101.02
102.01

103.01
103.02

104.01
104.02
105.01

106.01

107.01

108.01

109.01
109.02

110.01

110.01
110.02

Scrubber_Vertical $8 \times 48$

Comp_Recip_1360HP

ORU_8MM

Dehy_TEG125

Comp_Bldg 50×65×15

111.01 1x1PSV_Gas

112.01

113.01

113.02

$\begin{array}{lc}201.01 & \text { PI } \\ 201.02 & \text { TI } \\ 201.03 & \text { PSHH } \\ 201.04 & \text { LSHH_1 } \\ 201.05 & \text { LG } \\ 201.06 & \text { PIT } \\ 201.07 & \text { TT } \\ 201.08 & \text { LIT-1 } \\ 201.09 & \text { LSHH_2 } \\ 201.10 & \text { CO2_DET } \\ 201.11 & \text { FIRE_EYE } \\ 201.12 & \text { VT }\end{array}$

Qty

Units

\section{Pipe_Lot2}

Fitting_Lot3

Spares

2ORF150_JR

Valve_Lot2

FCV_150

1400SMT_0.5

LC

4C90AP

4 C30AP

Unit Rate

Sub-Total Price

$\$ 9,358,000$

Sub-Total:

0.75

$\$ 20,000$

$\$ 15,000$

$\$ 11,250$

REI - Estimated

$\$ 5,749 \quad$ Midco Fabricators

$5,250,000 \quad$ General Electric - Est. $\$ 132,000 \quad$ General Electric - Est.

3,290,000 BCCK Engineers

$\$ 350,000$ QB Johnson

$\$ 7,738 \quad J W$ Measurement

$\$ 195,782 \quad$ Tri-State -11.18 .09$

$\$ 45,000 \quad$ REl - Estimated

\$2,924 Applied Control Equip.

$\$ 315$ RMWH

$\$ 9,540 \quad$ REI - Estimated

$\$ 7,208$ REI - Estimated

$\$ 700 \quad$ REl - Estimated

Sump_3000

CSB-06

CSB-0 04

Switchgear / Motor Starters \& MCC's

01 Switchgear, $4160 \mathrm{~V}$ w/ Vacuum Circuit Breaker \& (3) $4160 \mathrm{~V}$ Solid State Reduced Voltage Start
02 Motor Control Center, 480V

203. Transformers

01 Transformer, 4160V / 480V, Padmount, Oil Filled, 500 KVA, Nema 3R, 65 deg. C Rise

02 Transformer, 13.8KV / 4160V, Padmount, Oil Filled, 5000 KVA

202.01
202.02

4160_Switch

480_MCC

203.01
203.02

5000KVA_TRN138.4160

4. UPS / Power Supply Equipment

01 Unitized Distribution Substation

02 UPS, Rack Mounted, Bypass Switch, 7 KVA

204.0

204.01
204.02

UDS

UPS

205.01 LGHT_Sub Panel

LGHT1000

01 Lighting Subpanel, 120V $1 \mathrm{Ph}$

02 Yard Lighting, 1000 Watt w/40' Aluminum Pole

205.02

206.01 PDC_13X40MED

01 Building, Pre-Fab Metal, 13' $\times 40$ ', HVAC, w/ Access Platforms \& Stairs

207. PLC Equipment \& Controls

01 PLC \& DIO Panel \& Equipment, Incl. Programming \& Commissioning

208. Consumables

01 Electrical \& Instrumentation Consumables (Compressor Station)

207.01

PLC_Lot2

208.01

E\&I_Cons 1

$1.5 \quad$ EA $\quad \$ 229,000$

$\$ 343,500$

\section{$\$ 1,008,000$}

Sub-Total:

$\$ 357$

$\$ 185$

$\$ 425$

$\$ 1,180$

$\$ 1,963$

$\$ 3,271$

$\$ 2,650$

$\$ 4,637$

$\$ 3,848$

$\$ 1,272$

$\$ 300$

$\$ 425$
$\$ 1,180$

$\$ 1,963$

$\$ 13,082$

$\$ 10,600$

$\$ 4,637$
$\$ 3,848$

$\$ 3,848$

$\$ 3,816$
$\$ 900$

- Esimated

7,808 Palmer Mfct - 11.17.09

229

REI - Estimated

REI - Estimated 
Blue Source, LLC.

KE-GE CO2 Pipeline Project

Kansas Ethanol Compression Facility

\section{Project Estimate Worksheet}

CONSTRUCTION

100. CAP CO2 KANSAS ETHANOL COMPRESSOR STATION $\$ 3,542,800$ $\$ 3,542,800$ $\$ 531,420$

Grand Total - Construction:

$\$ 4,074,220$

Cost Code

Qty

Units

Unit Rate Sub-Total Price

Estimate Supplier

100. CAP CO2 KANSAS ETHANOL COMPRESSOR STATION

101. Compressor Station Construction (Civil / Mechanical / Electrical)

01 Compressor Station Construction

LS

Sub-To

$\$ 3,542,800$

102. E\&I Unit Price Adders

01 Megar / High Pot Testing

02 Switchgear Commissioning

3. Station Rock

01 Station Rock Materials

4. Pre-Commission / Commissioning / Start-Up Services

01 E\&I Contractor Support

02 Mechanical Contractor Support

03 Solid State Reduced Voltage Starters Technician

04 Compression - Controls Technician

05 Compression - Service Specialist / Superviso
01

01
02

01

01

01
02
03
04
05
$\$ 3,312,000$

$\$ 50,000$

$(10.000$

$\$ 10,000$

$\$ 8,000$

$\$ 10,000$

$\$ 2,000$

$\$ 2,300$

$\$ 2,000$
$\$ 3,312,000$

REI - Estimated

$\$ 50,000 \quad$ REI - Estimated $\$ 25,000$ REI - Estimated

$\$ 10,000$ REI - Estimated

$\$ 48,000$ REI - Estimated

$\$ 60,000$ REI - Estimated

$\$ 13,800 \quad$ REI - Estimated

$\$ 12,000 \quad$ REI - Estimated
$\$ 12,000$ REI - Estimated 


\section{APPENDIX 3-L \\ PROJECT SCHEDULE \\ GENESEO-EDWARDS FIELD}

Appendix 3-127 


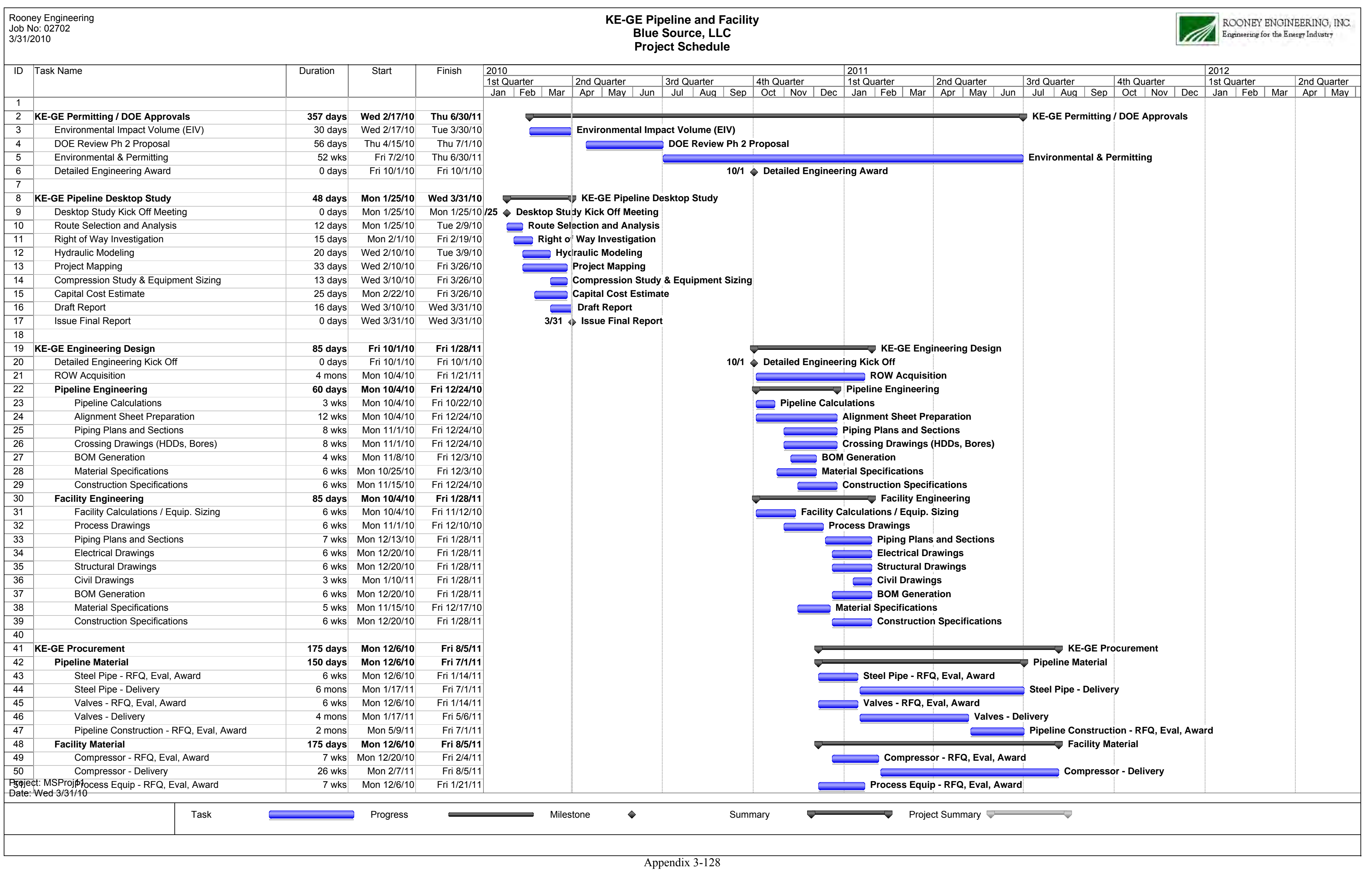




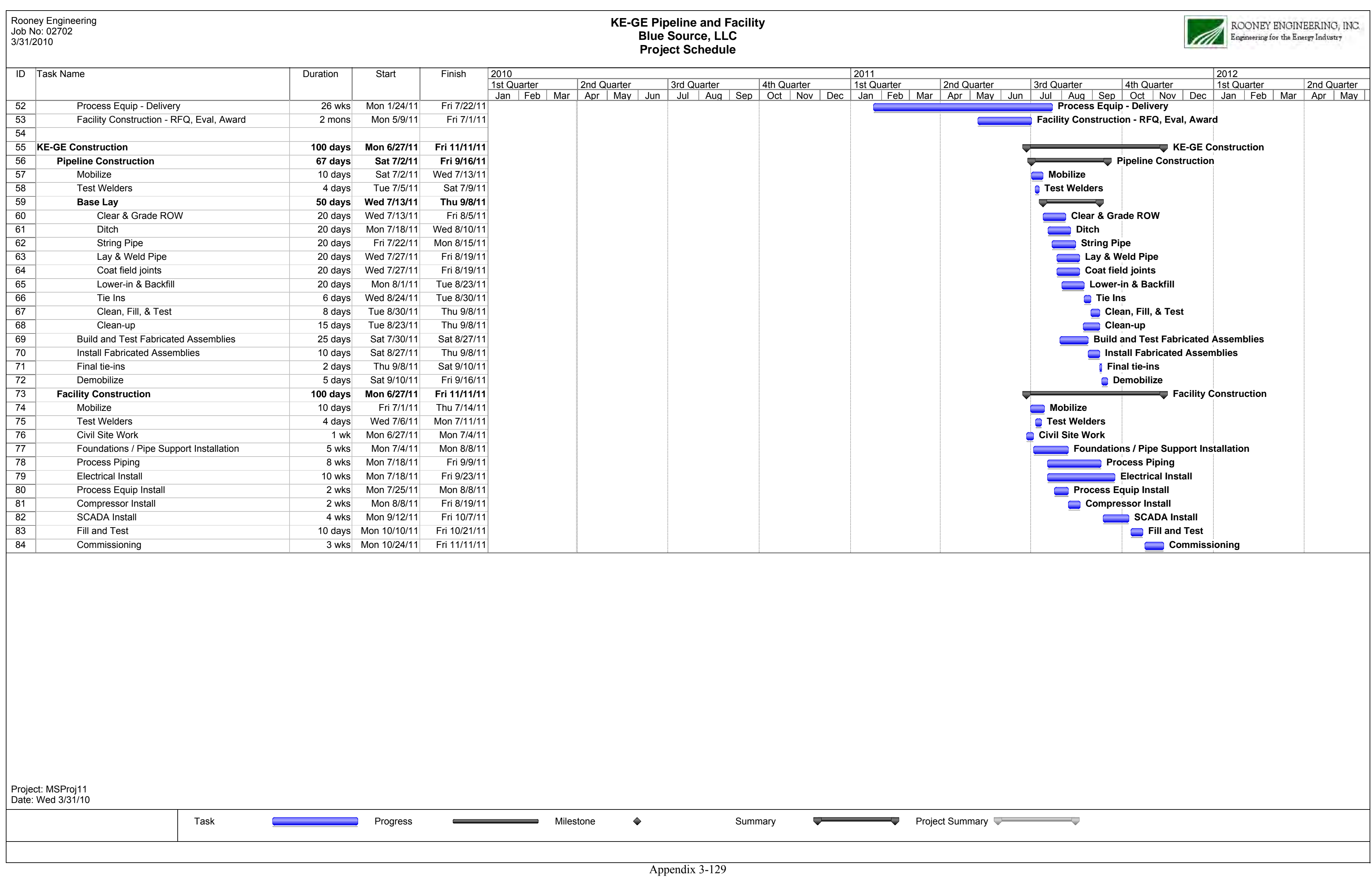




\section{Appendix 6-A}

Geologic Sequestration Technical Risks for the IMCCS Project 


\begin{tabular}{|c|c|c|c|c|c|c|c|c|c|c|c|c|c|}
\hline \multicolumn{6}{|c|}{ CO2 Geologic Sequestration Risks for the IMCCS Project } & \multicolumn{3}{|c|}{ Project Specific Information } & \multicolumn{3}{|c|}{ Risk Ranking } & \multicolumn{2}{|c|}{ Prevention and Mitigation } \\
\hline Line \# & Index No. & Risk Area & Description & Relevance & $\begin{array}{l}\text { Qunitessa } \\
\text { FEP } \\
\text { Category }\end{array}$ & $\begin{array}{l}\text { Individual } \\
\text { Comments }\end{array}$ & $\begin{array}{c}\text { IMCCS Project } \\
\text { Specific Information }\end{array}$ & \begin{tabular}{|c|} 
IMCCS Project \\
Information Gaps \\
or Uncertainties
\end{tabular} & 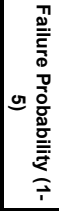 & 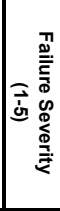 & 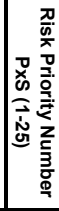 & $\begin{array}{l}\text { Risk Prevention } \\
\text { Steps (Actions } \\
\text { taken to reducee } \\
\text { risk probability) }\end{array}$ & $\begin{array}{c}\text { Risk Mitigation } \\
\text { Steps (Actions taken } \\
\text { to reduce risk } \\
\text { severity) }\end{array}$ \\
\hline 1 & 0.0 .00 .00 . & Assessment Basis & $\begin{array}{l}\text { This category of FEPs determines the } \\
\text { boundary conditions for any assessment, } \\
\text { specifying the spatial and temporal domain } \\
\text { of the system. The Assessment Basis } \\
\text { determines what is being assessed and why, } \\
\text { so that those FEPs that need to be } \\
\text { considered in the analysis can be defined, } \\
\text { and those which can be screened out as } \\
\text { being outside the scope of the assessment } \\
\text { can be identified. }\end{array}$ & & $\begin{array}{l}\text { Quintessa } \\
\text { scope \& } \\
\text { assumptions }\end{array}$ & & & & NA & NA & NA & NA & NA \\
\hline 2 & 0.1 .00 .00 . & $\begin{array}{l}\text { Purpose of the } \\
\text { assessment }\end{array}$ & \begin{tabular}{|l|} 
\\
The purpose of the assessment of geological \\
CO2 sequestration.
\end{tabular} & $\begin{array}{l}\text { The general purpose of an assessment of } \\
\text { geological cO2 sequestration is to determine the } \\
\text { performance of the sequestration system. In any } \\
\text { specific case, however, the purpose of } \\
\text { conducting an assessment may vary from simple } \\
\text { calculations to test initial ideas for sequestration } \\
\text { concepts, to support for an application for } \\
\text { regulatory approval requiring detailed, site- } \\
\text { specific performance assessment against } \\
\text { relevant criteria. The level of complexity and } \\
\text { comprehensiveness will vary according to the } \\
\text { use to which it will be put. Addititionally, the } \\
\text { assessment endpoints of interest may not only } \\
\text { vary in type, depending on the assessment } \\
\text { purpose, but also in the level of rigor required for } \\
\text { compliance demonstration. }\end{array}$ & $\begin{array}{c}\text { Quintessa } \\
\text { scope \& } \\
\text { assumptions }\end{array}$ & & $\begin{array}{l}\text { Site specific qualitative } \\
\text { assessment of } \\
\text { programmatic and } \\
\text { technical risks }\end{array}$ & & NA & NA & NA & NA & NA \\
\hline 3 & 0.2 .00 .00 & $\begin{array}{l}\text { Endpoints of } \\
\text { interest }\end{array}$ & The assessment endpoints of interest. & $\begin{array}{l}\text { The structure and composition of an assessment } \\
\text { will tend to reflect the endpoints that are required } \\
\text { to be assessed. These in turn, will reflect the } \\
\text { criteria that are adopted to judge the overall } \\
\text { performance of the sequestration system. Thus, } \\
\text { for example, an assessment may be constrained } \\
\text { to considering the degree of containment within a } \\
\text { geological feature, alternatively, it may need to } \\
\text { address potential near-surface impacts. } \\
\text { Invariably, a combination of endpoints will be } \\
\text { required. }\end{array}$ & $\begin{array}{c}\text { Quintessa } \\
\text { scope \& } \\
\text { assumptions } \\
\end{array}$ & & $\begin{array}{l}\text { Near surface HSE } \\
\text { impact }\end{array}$ & & NA & NA & NA & NA & NA \\
\hline 4 & 0.3 .00 .00 & $\begin{array}{l}\text { Spatial domain of } \\
\text { interest }\end{array}$ & $\begin{array}{l}\text { The spatial domain of interest in the } \\
\text { assessment. }\end{array}$ & $\begin{array}{l}\text { The spatial domain of interest will be dependent } \\
\text { on the site context, which may vary from generic } \\
\text { assessments to site specific assessments, the } \\
\text { sequestration concept and the endpoints of } \\
\text { interest. The spatial domain will contribute to } \\
\text { determining the information requirements and } \\
\text { modeling capabilities that may be required. }\end{array}$ & \begin{tabular}{|c} 
Quintessa \\
scope \& \\
assumptions
\end{tabular} & & $\begin{array}{l}\text { Compressor sites } \\
\text { Pipeline ROWs } \\
\text { Injection sites }\end{array}$ & & NA & NA & NA & NA & NA \\
\hline
\end{tabular}




\begin{tabular}{|c|c|c|c|c|c|c|c|c|c|c|c|c|c|}
\hline \multicolumn{6}{|c|}{ CO2 Geologic Sequestration Risks for the IMCCS Project } & \multicolumn{3}{|c|}{ Project Specific Information } & \multicolumn{3}{|c|}{ Risk Ranking } & \multicolumn{2}{|c|}{ Prevention and Mitigation } \\
\hline Line \# & Index No. & Risk Area & Description & Relevance & $\begin{array}{l}\text { Qunitessa } \\
\text { FEP } \\
\text { Category }\end{array}$ & $\begin{array}{l}\text { Individual } \\
\text { Comments }\end{array}$ & $\begin{array}{c}\text { IMCCS Project } \\
\text { Specific Information }\end{array}$ & \begin{tabular}{|l} 
IMCCS Project \\
Information Gaps \\
or Uncertainties
\end{tabular} & 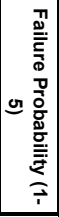 & 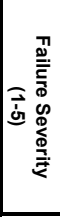 & 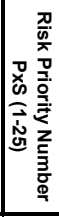 & $\begin{array}{l}\text { Risk Prevention } \\
\text { Steps (Actions } \\
\text { taken to reduce } \\
\text { risk probability) }\end{array}$ & $\begin{array}{l}\text { Risk Mitigation } \\
\text { Steps (Actions taken } \\
\text { to reduce risk } \\
\text { severity) }\end{array}$ \\
\hline 5 & 0.4 .00 .00 & $\begin{array}{c}\text { Timescales of } \\
\text { interest }\end{array}$ & Timescale of interest for the assessment. & $\begin{array}{l}\text { Timescales over which the assessment will be } \\
\text { performed will constrain processes which must } \\
\text { be considered in the assessment. In general } \\
\text { terms there are two timescales of interest for } \\
\text { geological storage of carbon dioxide. Firstly, } \\
\text { there is that over which isolation of carbon } \\
\text { dioxide from the atmosphere is necessary to } \\
\text { mititigate climate change. This timescale is likely } \\
\text { to be in the order of a few hundred years at most. } \\
\text { The second timescale of interest is potentially } \\
\text { much longer and is that pertaining to the } \\
\text { assessment of potential hazard to humans and } \\
\text { the environment. This timescale could be in the } \\
\text { order of thousands to tens of thousands of years. }\end{array}$ & $\begin{array}{c}\text { Quintessa } \\
\text { scope \& } \\
\text { assumptions }\end{array}$ & & $\begin{array}{l}50 \text { years after } \\
\text { injection stops. }\end{array}$ & & NA & NA & NA & NA & NA \\
\hline 6 & 0.5 .00 .00 & $\begin{array}{l}\text { Sequestration } \\
\text { assumptions }\end{array}$ & $\begin{array}{l}\text { High level assumptions concerning the } \\
\text { sequestration system(s) of relevance to the } \\
\text { assessment. For example, the quantity of } \\
\text { cO2 sequestered, the method of injection } \\
\text { and information concerning the assumed } \\
\text { performance of the sequestration system. }\end{array}$ & $\begin{array}{l}\text { Provides a background to the sequestration } \\
\text { technique adopted. Note that more detailed } \\
\text { consideration of the CO2 sequestration system is } \\
\text { provided in subsequent FEP categories. }\end{array}$ & $\begin{array}{l}\text { Quintessa } \\
\text { scope \& } \\
\text { assumptions }\end{array}$ & & $\begin{array}{l}\text { Enhanced oil recovery } \\
\text { and deep saline } \\
\text { aquifer }\end{array}$ & & NA & NA & NA & NA & NA \\
\hline 7 & 0.6 .00 .00 & $\begin{array}{c}\text { Future human } \\
\text { action assumptions }\end{array}$ & $\begin{array}{l}\text { The assumptions made in the assessment } \\
\text { concerning general boundary conditions for } \\
\text { assessing future human action. }\end{array}$ & $\begin{array}{l}\text { For example, it can be expected that human } \\
\text { technology and society will develop over the } \\
\text { timescales of relevance for the assessment of } \\
\text { CO2 sequestration systems, however, this } \\
\text { development is unpredictable. Therefore it may } \\
\text { be necessary to make some assumptions in } \\
\text { order to constrain the range of future human } \\
\text { actions that are considered, such as assuming } \\
\text { that only present-day technologies, or } \\
\text { technologies practiced in the past, will be } \\
\text { considered. }\end{array}$ & $\begin{array}{l}\text { Quintessa } \\
\text { scope \& } \\
\text { assumptions }\end{array}$ & & $\begin{array}{l}\text { Assume little change } \\
\text { in human impact or } \\
\text { technology over the } \\
\text { life of the project }\end{array}$ & & NA & NA & NA & NA & NA \\
\hline 8 & 0.7 .00 .00 & $\begin{array}{l}\text { Legal and } \\
\text { regulatory } \\
\text { framework }\end{array}$ & $\begin{array}{l}\text { The legal and regulatory framework within } \\
\text { which the assessment takes place. }\end{array}$ & $\begin{array}{l}\text { In undertaking an assessment it is vital to } \\
\text { consider the appropriate regulatory framework } \\
\text { requirements. At one extreme these may be } \\
\text { specific, prescriptive quantitative requirements, at } \\
\text { the other they could be non-prescriptive or may } \\
\text { not have been fully developed. } \\
\text { The legal and regulatory framework can shape } \\
\text { various aspects of an assessment, such as the } \\
\text { required assessment endpoints, timescales of } \\
\text { interest and assumptions concerning future } \\
\text { human actions. }\end{array}$ & $\begin{array}{l}\text { Quintessa } \\
\text { scope \& } \\
\text { assumptions } \\
\end{array}$ & & $\begin{array}{l}\text { Legal and regulatory } \\
\text { framework not fully } \\
\text { developed }\end{array}$ & & NA & NA & NA & NA & NA \\
\hline 9 & 0.8.00.00. & $\begin{array}{l}\text { Model and data } \\
\text { issues }\end{array}$ & $\begin{array}{l}\text { General methodological issues affecting the } \\
\text { assessment modeling process and use of } \\
\text { data }\end{array}$ & $\begin{array}{l}\text { Examples of general model and data issues } \\
\text { include the treatment of uncertainty; the method } \\
\text { for handling site specific data; and the } \\
\text { reduction/simplification of models and data. }\end{array}$ & $\begin{array}{l}\text { Quintessa } \\
\text { scope \& } \\
\text { assumptions }\end{array}$ & & $\begin{array}{l}\text { Qualitative risk } \\
\text { assessment - no } \\
\text { modeling }\end{array}$ & & NA & NA & NA & NA & NA \\
\hline
\end{tabular}




\begin{tabular}{|c|c|c|c|c|c|c|c|c|c|c|c|c|c|}
\hline \multicolumn{6}{|c|}{ CO2 Geologic Sequestration Risks for the IMCCS Project } & \multicolumn{3}{|c|}{ Project Specific Information } & \multicolumn{3}{|c|}{ Risk Ranking } & \multicolumn{2}{|c|}{ Prevention and Mitigation } \\
\hline Line \# & Index No. & Risk Area & Description & Relevance & $\begin{array}{l}\text { Qunitessa } \\
\text { FEP } \\
\text { Category }\end{array}$ & $\begin{array}{l}\text { Individual } \\
\text { Comments }\end{array}$ & $\begin{array}{c}\text { IMccs Project } \\
\text { Specific Information }\end{array}$ & \begin{tabular}{|l} 
IMCCS Project \\
Information Gaps \\
or Uncertainties
\end{tabular} & 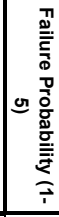 & 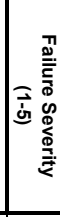 & 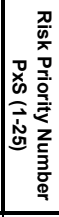 & $\begin{array}{l}\text { Risk Prevention } \\
\text { Steps (Actions } \\
\text { taken to reduce } \\
\text { risk probability) }\end{array}$ & $\begin{array}{l}\text { Risk Mitigation } \\
\text { Steps (Actions taken } \\
\text { to reduce risk } \\
\text { severity) }\end{array}$ \\
\hline 10 & 1.0.00.00. & External Factors & $\begin{array}{l}\text { This category of FEPs describes natural or } \\
\text { human factors that are outside the system } \\
\text { domain. These FEPs are most important in } \\
\text { determining scenarios for the future } \\
\text { evolution of the system, and are often } \\
\text { referred to as EFEPs (External FEPs). Three } \\
\text { classes of FEPs are considered. Geological } \\
\text { Factors and Climatic Factors are concerned } \\
\text { with natural processes and events, whilst } \\
\text { Future Human Actions is concerned with } \\
\text { those human activities that can directly affect } \\
\text { the sequestration system. }\end{array}$ & & $\begin{array}{l}\text { Quintessa } \\
\text { original FEP }\end{array}$ & & & & NA & NA & NA & NA & NA \\
\hline 11 & 1.1.00.00. & Geological factors & $\begin{array}{l}\text { Natural geological processes and events in } \\
\text { the environment outside the system domain } \\
\text { that are relevant to the evolution of the } \\
\text { sequestration system. }\end{array}$ & $\begin{array}{l}\text { Changes in the geological environment outside } \\
\text { the system domain may directly affect the } \\
\text { transport of carbon dioxide within the system. }\end{array}$ & \begin{tabular}{|l} 
Quintessa \\
original FEP
\end{tabular} & & & & NA & NA & NA & NA & NA \\
\hline 12 & 1.1.01.00. & Neotectonics & $\begin{array}{l}\text { Neotectonics is the study of crustal } \\
\text { movements that both occurred in the Earths } \\
\text { recent past and are continuing at the present } \\
\text { day. These movements, which are driven } \\
\text { directly or indirectly yb global plate motions } \\
\text { (tectonics), result in the vertical and } \\
\text { horizontal warping, folding or faulting of the } \\
\text { Earths surface. }\end{array}$ & $\begin{array}{l}\text { Neotectonic events have the potential to cause } \\
\text { sudden changes in the physical properties of } \\
\text { rocks due to stress changes and induced } \\
\text { hydrogeological changes. }\end{array}$ & $\begin{array}{l}\text { Quintessa } \\
\text { original FEP }\end{array}$ & $\begin{array}{l}\text { Neotectonics do } \\
\text { not play a } \\
\text { significant role in } \\
\text { the region. }\end{array}$ & & & 1 & 3 & 3 & NA & NA \\
\hline 13 & 1.1.02.00. & $\begin{array}{l}\text { Volcanic and } \\
\text { magmatic activity }\end{array}$ & $\begin{array}{l}\text { Magma is molten, mobile rock material, } \\
\text { generated below and within the Earth's crust, } \\
\text { which gives rise to igneous rocks when } \\
\text { solidified. A volcano is a vent or fissure in the } \\
\text { Earth's surface through which molten or part- } \\
\text { molten materials (lava) may flow, and ash } \\
\text { and hot gases be expelled. }\end{array}$ & $\begin{array}{l}\text { The high temperatures associated with volcanic } \\
\text { and magmatic activity may result in permanent } \\
\text { changes in the surrounding rocks, either directly, } \\
\text { or through circulating high temperature fluids. } \\
\text { This FEP is relevant to CO2 disposal in areas of } \\
\text { potential magmatic activity, e.g. Japan. } \\
\text { Besides bedrock damage, pressure and } \\
\text { temperature changes due to heating, stress, pr } \\
\text { displacement could affect CO2 density and } \\
\text { solubility , creating the risk of uncontrolled, rapid } \\
\text { migration and escape of stored CO2. } \\
\text { CO2STORE page 69) }\end{array}$ & 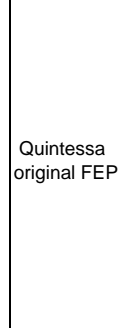 & $\begin{array}{l}\text { No volcanic or } \\
\text { magmatic activity } \\
\text { has been } \\
\text { observed in the } \\
\text { region. }\end{array}$ & & & 1 & 3 & 3 & NA & NA \\
\hline 14 & 1.1.03.00. & Seismicity & $\begin{array}{l}\text { Events and processes related to seismic } \\
\text { events and also the potential for seismic } \\
\text { events. A seismic event is caused by rapid } \\
\text { relative movements within the Earth's crust } \\
\text { usually along existing faults. The } \\
\text { accompanying release of energy may result } \\
\text { in rock movement and/or rupture, e.g. } \\
\text { earthquakes. }\end{array}$ & $\begin{array}{l}\text { Seismic events may result in changes in the } \\
\text { physical properties of rocks due to stress } \\
\text { changes and induced hydrogeological changes. } \\
\text { Seismic events are most common in tectonically } \\
\text { active or volcanically active regions at crustal } \\
\text { plate margins. }\end{array}$ & $\begin{array}{l}\text { Quintessa } \\
\text { original FEP }\end{array}$ & \begin{tabular}{|l|} 
Seismic activity \\
has been \\
associated with \\
the Humboldt fault \\
zone located 25 \\
mi west of the \\
Thrall-Aagard \\
field.
\end{tabular} & \begin{tabular}{|l|} 
Humboldt fault zone is \\
slightly active, mostly \\
in the Northeastern \\
part of Kansas.
\end{tabular} & & 1 & 5 & 5 & NA & $\begin{array}{l}\text { Have emergency } \\
\text { procedures in place } \\
\text { for dealing with } \\
\text { earthquakes. }\end{array}$ \\
\hline
\end{tabular}




\begin{tabular}{|c|c|c|c|c|c|c|c|c|c|c|c|c|c|}
\hline \multicolumn{6}{|c|}{ CO2 Geologic Sequestration Risks for the IMCCS Project } & \multicolumn{3}{|c|}{ Project Specific Information } & \multicolumn{3}{|c|}{ Risk Ranking } & \multicolumn{2}{|c|}{ Prevention and Mitigation } \\
\hline Line \# & Index No. & Risk Area & Description & Relevance & $\begin{array}{l}\text { Qunitessa } \\
\text { FEP } \\
\text { Category }\end{array}$ & $\begin{array}{l}\text { Individual } \\
\text { Comments }\end{array}$ & $\begin{array}{c}\text { IMCCS Project } \\
\text { Specific Information }\end{array}$ & $\begin{array}{c}\text { IMCCS Project } \\
\text { Information Gaps } \\
\text { or Uncertainties }\end{array}$ & 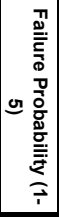 & 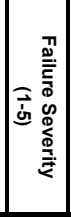 & 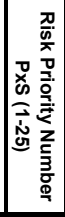 & $\begin{array}{l}\text { Risk Prevention } \\
\text { Steps (Actions } \\
\text { taken to reduce } \\
\text { risk probability) }\end{array}$ & $\begin{array}{c}\text { Risk Mitigation } \\
\text { Steps (Actions taken } \\
\text { to reduce risk } \\
\text { severity) }\end{array}$ \\
\hline 15 & 1.1.03.01. & $\mid \begin{array}{c}\text { Earthquake induced } \\
\text { fractures } \\
\end{array}$ & $\begin{array}{l}\text { Many people are convinced that we want to } \\
\text { avoid seismically-active areas for CO2 } \\
\text { storage. In reality there are very large natural } \\
\text { gas fields associated with some of the } \\
\text { planet's major fault zones. For instance } \\
\text { Indonesia and Malaysia have nay examples, } \\
\text { and so does California. Earthquakes in these } \\
\text { areas have never been associated with } \\
\text { sudden emissions of significant quantities of } \\
\text { naturara gas or oil from deep reservoirs. (CCP } \\
\text { 2009) } \\
\text { Major earthquakes (magnitude } 6 \text { and above) } \\
\text { occur primarily in strong, brittle basement } \\
\text { rock at depths on the order of } 6 \text { miles or } \\
\text { more (although very small earthquakes } \\
\text { occur at depths as shallow as } 2 \text { miles. }\end{array}$ & $\begin{array}{l}\text { Seismic disturbances might cause caprock failure } \\
\text { (Damen 2006). Earthquakes could disrupt } \\
\text { drilling, well operation, and monitoring activities, } \\
\text { and damage surface facilities including the CO2 } \\
\text { source. An earthquake on a fault through the } \\
\text { CO2 plume could create or close an open } \\
\text { pathway. Earthquakes may cause public concern } \\
\text { about the project even if not project related. } \\
\end{array}$ & $\begin{array}{l}\text { Additional } \\
\text { [new] FEP }\end{array}$ & $\begin{array}{l}\text { Very unlikely to be } \\
\text { an issue. }\end{array}$ & \begin{tabular}{l|} 
Humboldt fault zone is \\
25 miles down dip \\
from Thrall Aagard. It \\
is a slightly active \\
strike-slip fault zone \\
trending N-NE with \\
most seismic activity \\
occurring over 100 \\
miles north of Thrall- \\
Aagard field. \\
The Geneseo- \\
Edwards field appears \\
to have one or more \\
deeep 300 ft vertical \\
fault on the West side \\
of the field.
\end{tabular} & \begin{tabular}{|l|} 
Data on seismic \\
activity for the \\
Geneseo-Edwards \\
fault(s).
\end{tabular} & 1 & 5 & 5 & NA & $\begin{array}{l}\text { Have emergency } \\
\text { procedures in place } \\
\text { for dealing with } \\
\text { earthquakes. }\end{array}$ \\
\hline 16 & 1.1.03.02. & $\begin{array}{l}\text { Natural micro- } \\
\text { seismicity }\end{array}$ & $\begin{array}{l}\text { Micro-seismicity consists of very tiny seismic } \\
\text { events often responding to subsurface flfuid } \\
\text { flow and relative pressure changes. All parts } \\
\text { of the earth's crust are in continuous } \\
\text { movement and generate micro-seismic } \\
\text { events, and the analysis of micro-seismicity } \\
\text { offers unique insights into subsurface } \\
\text { properties(CCP 2009). }\end{array}$ & \begin{tabular}{|l|} 
Microseismicity may cause public concern about \\
the project even if not project related, may add \\
noise interfering with microseismic monitoring.
\end{tabular} & $\begin{array}{l}\text { Additional } \\
\text { [new] FEP }\end{array}$ & $\begin{array}{l}\text { Natural } \\
\text { microseismicity } \\
\text { already exists. } \\
\text { Considering } \\
\text { installing passive } \\
\text { microseismic } \\
\text { monitors to } \\
\text { differentiate } \\
\text { between natural } \\
\text { and induced } \\
\text { microseismicity. }\end{array}$ & & & 3 & 2 & 6 & NA & $\begin{array}{l}\text { Install passive } \\
\text { microseismic monitors } \\
\text { to differentiate } \\
\text { between natural and } \\
\text { induced } \\
\text { microseismicity. }\end{array}$ \\
\hline 17 & 1.1.04.00. & $\begin{array}{l}\text { Hydrothermal } \\
\text { activity }\end{array}$ & $\begin{array}{l}\text { Processes associated with high temperature } \\
\text { groundwaters, and hydrothermal alteration of } \\
\text { minerals in the rocks through which the high } \\
\text { temperature groundwater flows. } \\
\text { Hydrothermal activity may be directly } \\
\text { associated with volcanic and magmatic } \\
\text { activity. } \\
\text { Hot springs, geysers and submarine } \\
\text { hydrothermal vents provide evidence of } \\
\text { hydrothermal activity. }\end{array}$ & $\begin{array}{l}\text { Can result in the hydrothermal alteration of rocks } \\
\text { or minerals by the reaction of hot water (and } \\
\text { other fluids) with pre-existing rocks. }\end{array}$ & \begin{tabular}{|l} 
Quintessa \\
original FEP
\end{tabular} & $\begin{array}{l}\text { Thermal gradient } \\
\text { measured in the } \\
\text { two fields do not } \\
\text { indicate any } \\
\text { significant } \\
\text { hydrothermal } \\
\text { activity. }\end{array}$ & & & 1 & 1 & 1 & NA & NA \\
\hline 18 & 1.1.05.00. & $\begin{array}{c}\text { Hydrological and } \\
\text { hydrogeological } \\
\text { response to } \\
\text { geological changes }\end{array}$ & $\begin{array}{l}\text { Processes arising from large-scale } \\
\text { geological changes and could include } \\
\text { changes of fluid boundary conditions due to } \\
\text { the effects of changes of fluid properties of } \\
\text { geological units due to changes in rock } \\
\text { stress or fault movements. }\end{array}$ & $\begin{array}{l}\text { In and below low-permeability geological } \\
\text { formations, hydrogeological conditions may } \\
\text { evolve very slowly and often reflect past } \\
\text { geological conditions, i.e. be in a state of } \\
\text { disequilibrium }\end{array}$ & $\begin{array}{l}\text { Quintessa } \\
\text { original FEP }\end{array}$ & $\begin{array}{l}\text { Very unlikely to be } \\
\text { an issue. }\end{array}$ & \begin{tabular}{|l|} 
These sites are \\
mature oil fields that \\
have been operated \\
for 75 to 80 years. \\
Disequilibrium has not \\
been identified as a \\
problem in these \\
fields.
\end{tabular} & & 1 & 2 & 2 & NA & NA \\
\hline
\end{tabular}




\begin{tabular}{|c|c|c|c|c|c|c|c|c|c|c|c|c|c|}
\hline \multicolumn{6}{|c|}{ CO2 Geologic Sequestration Risks for the IMCCS Project } & \multicolumn{3}{|c|}{ Project Specific Information } & \multicolumn{3}{|c|}{ Risk Ranking } & \multicolumn{2}{|c|}{ Prevention and Mitigation } \\
\hline Line \# & Index No. & Risk Area & Description & Relevance & $\begin{array}{l}\text { Qunitessa } \\
\text { FEP } \\
\text { Category }\end{array}$ & $\begin{array}{l}\text { Individual } \\
\text { Comments }\end{array}$ & $\begin{array}{c}\text { IMCCS Project } \\
\text { Specific Information }\end{array}$ & \begin{tabular}{|c|} 
IMCcS Project \\
Information Gaps \\
or Uncertainties
\end{tabular} & 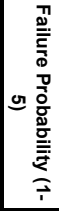 & 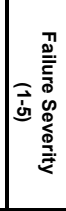 & 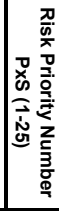 & $\begin{array}{l}\text { Risk Prevention } \\
\text { Steps (Actions } \\
\text { taken to reduce } \\
\text { risk probability) }\end{array}$ & $\begin{array}{l}\text { Risk Mitigation } \\
\text { Steps (Actions taken } \\
\text { to reduce risk } \\
\text { severity) }\end{array}$ \\
\hline 19 & 1.1.06.00. & Large scale erosion & $\begin{array}{l}\text { Processes related to the large scale } \\
\text { (geological) removal of rocks and sediments, } \\
\text { with associated changes in topography and } \\
\text { geoological/hydrogeological conditions of the } \\
\text { system. }\end{array}$ & $\begin{array}{l}\text { Potential to modify the geological and } \\
\text { hydrogeological environment. }\end{array}$ & $\begin{array}{l}\text { Quintessa } \\
\text { original FEP }\end{array}$ & $\begin{array}{l}\text { The pipelines will } \\
\text { follow existing } \\
\text { pipeline corridors } \\
\text { which have } \\
\text { existing for } \\
\text { decades. The } \\
\text { dinjection sites are } \\
\text { existing EOR sites } \\
\text { which have not } \\
\text { experienced large } \\
\text { scale erosion. }\end{array}$ & & & 1 & 1 & 1 & NA & NA \\
\hline 20 & 1.1.07.00. & $\begin{array}{c}\text { Bolide impact } \\
\text { (meteorite impact) }\end{array}$ & $\begin{array}{l}\text { An extraterrestrial body in the 1-10-km size } \\
\text { range, which impacts the earth at high } \\
\text { velocity, explodes upon impact, and creates } \\
\text { a large crater. }\end{array}$ & $\begin{array}{l}\text { A low probability, high consequence event that } \\
\text { has the potential to substantially disrupt the CO2 } \\
\text { storage system. Often screened out on the basis } \\
\text { that the impact of the bolide will greatly exceed } \\
\text { that of the disruption caused to the sequestration } \\
\text { system. }\end{array}$ & $\begin{array}{c}\text { Quintessa } \\
\text { FEP with } \\
\text { additional text }\end{array}$ & $\begin{array}{l}\text { Very unlikely to } \\
\text { occur. }\end{array}$ & & & 1 & 5 & 5 & NA & $\begin{array}{l}\text { Prepare procedures to } \\
\text { shut down and } \\
\text { evacuate site if } \\
\text { warned of imminent } \\
\text { impact. }\end{array}$ \\
\hline 21 & 1.2.00.00. & Climatic factors & $\begin{array}{l}\text { Natural processes and events in the } \\
\text { atmospheric environment that are relevant to } \\
\text { the evolution of the sequestration system. }\end{array}$ & $\begin{array}{l}\text { Changes in climate may directly affect the nature } \\
\text { of any impacts that are incurred if carbon dioxide } \\
\text { returns to the near-surface environment. }\end{array}$ & $\begin{array}{l}\text { Quintessa } \\
\text { original FEP }\end{array}$ & $\begin{array}{l}\text { very unlikely to be } \\
\text { an issue. }\end{array}$ & & & 1 & 1 & 1 & NA & NA \\
\hline 22 & 1.2.01.00. & $\begin{array}{l}\text { Global climate } \\
\text { change }\end{array}$ & $\begin{array}{l}\text { The process of global climate change due to } \\
\text { natural andlor anthropogenic causes. The } \\
\text { last two million years of the Quaternary have } \\
\text { been characterized by glacial/linterglacial } \\
\text { cycling. According to the Milankovitch } \\
\text { Theory, the Quaternary glacialintinglacial } \\
\text { cycles are caused by long-term changes in } \\
\text { seasonal and latitudinal distribution of } \\
\text { incoming solar radiation which are due to the } \\
\text { periodic variations of the Earth's orbit about } \\
\text { the Sun (Milankovitch cycles). } \\
\text { Evidence suggests that the Earth is } \\
\text { presently in a period of global warming (see } \\
\text { the figure below). The anthropogenic release } \\
\text { of gases into the atmosphere may be } \\
\text { increasing the rate of global warming by } \\
\text { enhancing the natural greenhouse effect, a } \\
\text { process by which long wave radiation } \\
\text { emitted from the Earth is trapped in the } \\
\text { atmosphere by greenhouse gases such as } \\
\text { CO2. }\end{array}$ & $\begin{array}{l}\text { Changes in the global climate are likely to impact } \\
\text { the CO2 sequestration system in a number of } \\
\text { ways. For example, through its affect on sea } \\
\text { levels and the local and regional climate. }\end{array}$ & $\begin{array}{l}\text { Quintessa } \\
\text { original FEP }\end{array}$ & $\begin{array}{l}\text { very unlikely to be } \\
\text { an issue. }\end{array}$ & & & 1 & 1 & 1 & NA & NA \\
\hline
\end{tabular}




\begin{tabular}{|c|c|c|c|c|c|c|c|c|c|c|c|c|c|}
\hline \multicolumn{6}{|c|}{ CO2 Geologic Sequestration Risks for the IMCCS Project } & \multicolumn{3}{|c|}{ Project Specific Information } & \multicolumn{3}{|c|}{ Risk Ranking } & \multicolumn{2}{|c|}{ Prevention and Mitigation } \\
\hline Line \# & Index No. & Risk Area & Description & Relevance & $\begin{array}{c}\text { Qunitessa } \\
\text { FEP } \\
\text { Category }\end{array}$ & $\begin{array}{l}\text { Individual } \\
\text { Comments }\end{array}$ & $\begin{array}{c}\text { Imccs Project } \\
\text { Specific Information }\end{array}$ & \begin{tabular}{|c|} 
IMCCS Project \\
Information Gaps \\
or Uncertainties
\end{tabular} & 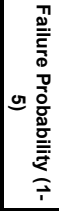 & 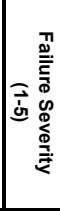 & 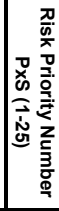 & $\begin{array}{l}\text { Risk Prevention } \\
\text { Steps (Actions } \\
\text { taken to reduce } \\
\text { risk probability) }\end{array}$ & $\begin{array}{l}\text { Risk Mitigation } \\
\text { Steps (Actions taken } \\
\text { to reduce risk } \\
\text { severity) }\end{array}$ \\
\hline 23 & 1.2.02.00. & $\begin{array}{l}\text { Regional and local } \\
\text { climate change }\end{array}$ & 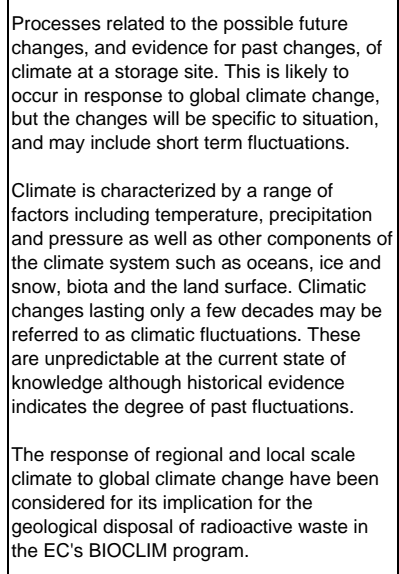 & $\begin{array}{l}\text { Changes in the regional and local climate could } \\
\text { faftect the CO2 sequestration system in a number } \\
\text { of ways. For example, changes in groundwater } \\
\text { recharge could affect regional hydrogeology and } \\
\text { hence the transport of CO2 dissolved in } \\
\text { groundwater. It may also alter the near-surface } \\
\text { environment to which some of the disposed } \mathrm{CO} 2 \\
\text { may migrate. }\end{array}$ & $\begin{array}{l}\text { Quintessa } \\
\text { original FEP }\end{array}$ & $\begin{array}{l}\text { Very unlikely to be } \\
\text { an issue. }\end{array}$ & & & 1 & 1 & 1 & NA & NA \\
\hline 24 & 1.2.03.00. & Sea level change & $\begin{array}{l}\text { Processes related to changes in sea level } \\
\text { which may occur as a result of global } \\
\text { (eustaticy change and/or regional geological } \\
\text { change, e.g. isostatic movements. } \\
\text { The component of sea-level change } \\
\text { involving the interchange of water between } \\
\text { land ice and the sea is referred to as eustatic } \\
\text { change. As ice sheets melt so the ocean } \\
\text { volume increases and sea levels rise. Sea } \\
\text { level at a given location will also be affected } \\
\text { by vertical movement of the land mass, e.g. } \\
\text { depression and rebound due to glacial } \\
\text { loading and unloading, referred to as } \\
\text { isostatic change. }\end{array}$ & $\begin{array}{l}\text { Sea level change may affect the sequestration } \\
\text { system through its impact on the near surface } \\
\text { environment and the regional or local } \\
\text { hydrogeological regime. }\end{array}$ & $\begin{array}{l}\text { Quintessa } \\
\text { original FEP }\end{array}$ & $\begin{array}{l}\text { Very unlikely to be } \\
\text { an issue. }\end{array}$ & & & 1 & 1 & 1 & NA & NA \\
\hline 25 & 1.2.04.00. & Periglacial effects & $\begin{array}{l}\text { Related to the physical processes and } \\
\text { associated landforms in cold but ice-sheet- } \\
\text { free environments. }\end{array}$ & $\begin{array}{l}\text { An important characteristic of periglacial } \\
\text { environments is the seasonal change from winter } \\
\text { freezing to summer thaw with large water } \\
\text { movements and potential for erosion. Frozen sub- } \\
\text { soils are referred to as permafrost. Melt water } \\
\text { from seasonal thaw is unable to percolate } \\
\text { downwards due to permafrost and saturates the } \\
\text { surface materials. Permafrost layers may isolate } \\
\text { the deep hydrogeological regime from surface } \\
\text { hydrology, or flow may be focused at "taliks" } \\
\text { (localized unfrozen zones, e.g. under lakes, large } \\
\text { rivers or at regions of groundwater discharge). }\end{array}$ & $\begin{array}{l}\text { Quintessa } \\
\text { original FEP }\end{array}$ & $\begin{array}{l}\text { Very unlikely to be } \\
\text { an issue. }\end{array}$ & & & 1 & 1 & 1 & NA & NA \\
\hline
\end{tabular}

Appendix 6-7

Quintessa Original FEP: Taken from Quintessa's on-line CO2 FEP database, which is freely accessible at: http://www.quintessa.org/co2fepdb/ 


\begin{tabular}{|c|c|c|c|c|c|c|c|c|c|c|c|c|c|}
\hline \multicolumn{6}{|c|}{ CO2 Geologic Sequestration Risks for the IMCCS Project } & \multicolumn{3}{|c|}{ Project Specific Information } & \multicolumn{3}{|c|}{ Risk Ranking } & \multicolumn{2}{|c|}{ Prevention and Mitigation } \\
\hline Line \# & Index No. & Risk Area & Description & Relevance & $\begin{array}{l}\text { Qunitessa } \\
\text { FEP } \\
\text { Category }\end{array}$ & $\begin{array}{l}\text { Individual } \\
\text { Comments }\end{array}$ & $\begin{array}{c}\text { IMCCS Project } \\
\text { Specific Information }\end{array}$ & \begin{tabular}{|l} 
IMCCS Project \\
Information Gaps \\
or Uncertainties
\end{tabular} & 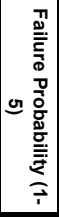 & 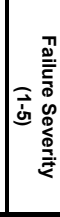 & 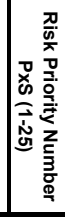 & $\begin{array}{l}\text { Risk Prevention } \\
\text { Steps (Actions } \\
\text { taken to reduce } \\
\text { risk probability) }\end{array}$ & $\begin{array}{c}\text { Risk Mitigation } \\
\text { Steps (Actions taken } \\
\text { to reduce risk } \\
\text { severity) }\end{array}$ \\
\hline 26 & 1.2.05.00. & $\begin{array}{l}\text { Glacial and ice } \\
\text { sheet effects }\end{array}$ & $\begin{array}{l}\text { Processes related to the effects of glaciers } \\
\text { and ice sheets within the region of a storage } \\
\text { site. This is distinct from the effects of large } \\
\text { ice masses on global and regional climate. } \\
\text { The ice sheet and the permafrost beneath } \\
\text { the ice sheet may constitute a barrier to } \\
\text { groundwater flow and to heat loss. If the } \\
\text { basal transmissivity of the till and bedrock } \\
\text { below the ice is low, water r ressures may } \\
\text { rise to levels equaling the ice pressure } \\
\text { inducing the formation of major conduits in } \\
\text { the subglacial material. The central parts of } \\
\text { the ice sheet are likely to be warm-based } \\
\text { and could permit groundwater recharge to } \\
\text { take place. Discharge of groundwater is } \\
\text { likely to take place close to and beyond the } \\
\text { frontal parts of the ice sheet. Excessive } \\
\text { recharge at the margin of the ice sheet could } \\
\text { provide direct recharge of oxidizing water to } \\
\text { considerable depths in conductive fracture } \\
\text { zones. If the permeability an and beyond the } \\
\text { rim of the ice is low, the water pressures } \\
\text { may again build up resulting in } \\
\text { hydroffacturing of the ice or the rock mass. } \\
\text { Ad the ice sheet advances, these induced } \\
\text { fractures may increase their aperture and } \\
\text { deptht due to freezing of subglacial melt } \\
\text { water. }\end{array}$ & \begin{tabular}{|l} 
Erosional processes (abrasion, over deepening) \\
associated with glacial action, especially \\
advancing glaciers and ice sheets, and with \\
glacial melt waters beneath the ice mass and at \\
the margins, can lead to morphological changes \\
in the environment, e.g. U-shaped valleys, \\
hanging valleys, fjords and drumlins. Depositional \\
features associated with glaciers and ice sheets \\
include moraines and eskers. The pressure of \\
the ice mass on the landscape may result in \\
significant hydrogeological effects and even \\
depression of the regional crustal plate.
\end{tabular} & Quintessa & $\begin{array}{l}\text { Very unlikely to be } \\
\text { an issue. }\end{array}$ & & & 1 & 1 & 1 & NA & NA \\
\hline 27 & 1.2.06.00. & $\begin{array}{l}\text { Warm climate } \\
\text { effects }\end{array}$ & $\begin{array}{l}\text { Processes related to warm tropical and } \\
\text { desert climates, including seasonal effects, } \\
\text { and meteorological and geomorphological } \\
\text { effects special to these climates. }\end{array}$ & $\begin{array}{l}\text { Regions with a tropical climate may experience } \\
\text { extreme weather patterns (monsoons, } \\
\text { hurricanes) that could result in flooding, storm } \\
\text { surges, high winds etc. with implications for } \\
\text { erosion and hydrogeology. The high } \\
\text { temperatures and humidity associated with } \\
\text { tropical climates result in rapid biological } \\
\text { degradation and soils are generally thin. In arid } \\
\text { climates, total rainfall, erosion and recharge may } \\
\text { be dominated by infrequent storm events. }\end{array}$ & $\begin{array}{l}\text { Quintessa } \\
\text { original FEP }\end{array}$ & $\begin{array}{l}\text { Very unlikely to be } \\
\text { an issue. }\end{array}$ & & & 1 & 1 & 1 & NA & NA \\
\hline 28 & 1.2.07.00. & $\begin{array}{c}\text { Hydrological and } \\
\text { hydrogeological } \\
\text { response to climate } \\
\text { change }\end{array}$ & $\begin{array}{l}\text { Processes related to changes in hydrology } \\
\text { and hydrogeology, e.g. recharge, sediment } \\
\text { load and seasonality, in response to climate } \\
\text { change in a region. }\end{array}$ & $\begin{array}{l}\text { The hydrology and hydrogeology of a region is } \\
\text { closely coupled to climate. Climate controls the } \\
\text { amount of precipitation and evaporation, } \\
\text { seasonal ice cover, and thus the soil water } \\
\text { balance, extent of soil saturation, surface runoff } \\
\text { and groundwater recharge. Vegetation and } \\
\text { human actions may modify these responses. }\end{array}$ & $\begin{array}{l}\text { Quintessa } \\
\text { original FEP }\end{array}$ & $\begin{array}{l}\text { Very unlikely to be } \\
\text { an issue. }\end{array}$ & & & 1 & 1 & 1 & NA & NA \\
\hline
\end{tabular}




\begin{tabular}{|c|c|c|c|c|c|c|c|c|c|c|c|c|c|}
\hline \multicolumn{6}{|c|}{ CO2 Geologic Sequestration Risks for the IMCCS Project } & \multicolumn{3}{|c|}{ Project Specific Information } & \multicolumn{3}{|c|}{ Risk Ranking } & \multicolumn{2}{|c|}{ Prevention and Mitigation } \\
\hline Line \# & Index No. & Risk Area & Description & Relevance & $\begin{array}{l}\text { Qunitessa } \\
\text { FPP } \\
\text { Category }\end{array}$ & $\begin{array}{l}\text { Individual } \\
\text { Comments }\end{array}$ & $\begin{array}{c}\text { IMCcS Project } \\
\text { Specific Information }\end{array}$ & \begin{tabular}{|c|} 
IMCcS Project \\
Information Gaps \\
or Uncertainties
\end{tabular} & 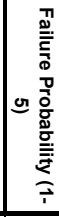 & 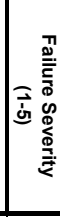 & 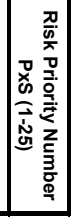 & $\begin{array}{l}\text { Risk Prevention } \\
\text { Steps (Actions } \\
\text { taken to reduce } \\
\text { risk probability) }\end{array}$ & $\begin{array}{c}\text { Risk Mitigation } \\
\text { Steps (Actions taken } \\
\text { to reduce risk } \\
\text { severity) }\end{array}$ \\
\hline 29 & 1.2.08.00. & $\begin{array}{l}\text { Responses to } \\
\text { climate change }\end{array}$ & $\begin{array}{l}\text { The process of global climate change due to } \\
\text { natural andl/or anthropogenic causes. The } \\
\text { last two million years of the Quaternary have } \\
\text { been characterized by glaciallinterglacial } \\
\text { cycling. According to the Milankovitch } \\
\text { Theory, the Quaternary glacialiniterglacial } \\
\text { cycles are caused by long-term changes in } \\
\text { seasonal and latitudinal distribution of } \\
\text { incoming solar radiation which are due to the } \\
\text { periodic variations of the Earth's orbit about } \\
\text { the Sun (Milankovitch cycles). } \\
\text { Evidence suggests that the Earth is } \\
\text { presently in a period of global warming. The } \\
\text { anthropogenic release of gases into the } \\
\text { atmosphere may be increasing the rate of } \\
\text { global warming by enhancing the natural } \\
\text { greenhouse effect, a process by which long } \\
\text { wave radiation emitted from the Earth is } \\
\text { trapped in the atmosphere by greenhouse } \\
\text { gases such as CO2. }\end{array}$ & $\begin{array}{l}\text { Changes in ecology and human behavior in } \\
\text { response to climate change will influence the } \\
\text { relevant FEPs to be considered in the surface } \\
\text { environment as an assessment extends into the } \\
\text { future. }\end{array}$ & \begin{tabular}{|l} 
Quintessa \\
original FEP
\end{tabular} & $\begin{array}{l}\text { Very unlikely to be } \\
\text { an issue. }\end{array}$ & & & 1 & 1 & 1 & NA & NA \\
\hline 30 & 1.3.00.00. & $\begin{array}{l}\text { Future human } \\
\text { actions }\end{array}$ & $\begin{array}{l}\text { Human activities that are relevant to the } \\
\text { evolution of the sequestration system. }\end{array}$ & $\begin{array}{l}\text { Human activities may directly interfere with the } \\
\text { sequestered fluid resulting in immediate or } \\
\text { delayed impacts. }\end{array}$ & $\begin{array}{l}\text { Quintessa } \\
\text { original FEP }\end{array}$ & $\begin{array}{l}\text { Very unlikely to be } \\
\text { an issue. }\end{array}$ & $\begin{array}{l}\text { The injection sites are } \\
\text { very sparsely } \\
\text { populated. There are } \\
\text { no residences within } 1 \\
\text { mile of the Thrall } \\
\text { injection site. }\end{array}$ & \begin{tabular}{|l|} 
Need to confirm \\
population density \\
in and near \\
Geneseo-Edwards \\
injection site.
\end{tabular} & 1 & 1 & 1 & $\begin{array}{l}\text { Clearly mark site } \\
\text { with warnings and } \\
\text { register site as CO2 } \\
\text { storage site with the } \\
\text { State. }\end{array}$ & $\begin{array}{l}\text { Routine site inspection } \\
\text { and/or monitoring. }\end{array}$ \\
\hline 31 & 1.3.01.00. & $\begin{array}{l}\text { Human influences } \\
\text { on climate }\end{array}$ & $\begin{array}{l}\text { Processes related to human activities that } \\
\text { could affect the change of climate either } \\
\text { globally or in a region. }\end{array}$ & $\begin{array}{l}\text { Anthropogenic emissions of 'greenhouse' gases } \\
\text { such as CO2 and CH4 have been implicated as } \\
\text { factors in global warming. One of the primary } \\
\text { aims of CO2 sequestration is to reduce the } \\
\text { quantity of } \mathrm{CO} 2 \text { that is discharged to the } \\
\text { atmosphere. } \\
\text { Regionally, climate can be modified by human } \\
\text { activities such as de-forestation. } \\
\end{array}$ & $\begin{array}{l}\text { Quintessa } \\
\text { original FEP }\end{array}$ & $\begin{array}{l}\text { Very unlikely to be } \\
\text { an issue. }\end{array}$ & & & 1 & 1 & 1 & NA & NA \\
\hline 32 & 1.3.02.00. & $\begin{array}{c}\text { Motivation and } \\
\text { knowledge issues }\end{array}$ & $\begin{array}{l}\text { Events and processes related to the degree } \\
\text { of knowledge of the existence, location } \\
\text { and//or nature of the storage site. Also, } \\
\text { reasons for deliberate interference with, or } \\
\text { intrusion into a CO2 storage site after } \\
\text { closure with complete or incomplete } \\
\text { knowledge. } \\
\text { Knowledge of the sequestration site may be } \\
\text { regained through post-closure airborne, } \\
\text { geophysical or other surface-based non- } \\
\text { intrusive investigation of a sequestration site. } \\
\text { Such investigations might occur after } \\
\text { information of the location of the } \\
\text { sequestration system has been lost and } \\
\text { therefore excludes monitoring of the disposal } \\
\text { system, but includes activities such as } \\
\text { prospecting for geological resources. The } \\
\text { evidence of the sequestration, such as } \\
\text { injection boreholes, may itself prompt } \\
\text { investigation. }\end{array}$ & $\begin{array}{l}\text { Some future human actions could directly impact } \\
\text { upon performance of the storage system. The } \\
\text { following could be distinguished: } \\
\text { - inadvertent actions, which are actions taken } \\
\text { without knowledge or awareness of the storage } \\
\text { site, and } \\
\text { - deliberate actions, which are actions that are } \\
\text { taken with knowledge of the storage systems } \\
\text { existence and location, e.g. deliberate attempts } \\
\text { to retrieve any hydrocarbons (e.g., EOR and } \\
\text { ECBM) associated with the CO2, malicious } \\
\text { intrusion and sabotage. } \\
\text { Intermediate cases, of intrusion with incomplete } \\
\text { knowledge, could also occur. }\end{array}$ & 西 & $\begin{array}{l}\text { Very unlikely to be } \\
\text { an issue. }\end{array}$ & & & 1 & 3 & 3 & $\begin{array}{l}\text { Clearly mark site } \\
\text { with warnings and } \\
\text { register site as } \mathrm{CO} 2 \\
\text { storage site with the } \\
\text { State. }\end{array}$ & $\begin{array}{l}\text { Routine site inspection } \\
\text { and/or monitoring. }\end{array}$ \\
\hline
\end{tabular}

Quintessa Original FEP: Taken from Quintessa's on-line CO2 FEP database, which is freely accessible at: http://www.quintessa.org/co2fepdb/ 


\begin{tabular}{|c|c|c|c|c|c|c|c|c|c|c|c|c|c|}
\hline \multicolumn{6}{|c|}{ CO2 Geologic Sequestration Risks for the IMCCS Project } & \multicolumn{3}{|c|}{ Project Specific Information } & \multicolumn{3}{|c|}{ Risk Ranking } & \multicolumn{2}{|c|}{ Prevention and Mitigation } \\
\hline Line \# & Index No. & Risk Area & Description & Relevance & $\begin{array}{l}\text { Qunitessa } \\
\text { FEP } \\
\text { Category }\end{array}$ & $\begin{array}{l}\text { Individual } \\
\text { Comments }\end{array}$ & $\begin{array}{c}\text { IMccs Project } \\
\text { Specific Information }\end{array}$ & \begin{tabular}{|c|} 
IMCcS Project \\
Information Gaps \\
or Uncertainties
\end{tabular} & 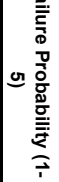 & 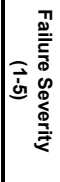 & 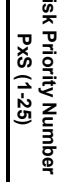 & $\begin{array}{l}\text { Risk Prevention } \\
\text { Steps (Actions } \\
\text { taken to reduce } \\
\text { risk probability) }\end{array}$ & \begin{tabular}{|c|} 
Risk Mitigation \\
Steps (Actions taken \\
to reduce risk \\
severity)
\end{tabular} \\
\hline 33 & 1.3.02.01. & $\begin{array}{l}\text { Inadvertent } \\
\text { interference with or } \\
\text { intrusion into the } \\
\text { CO2 reservoir }\end{array}$ & $\begin{array}{l}\text { Third party inadvertent intrusion or } \\
\text { interference with CO2 reservoir after closure } \\
\text { due to incomplete knowledge. }\end{array}$ & Leakage and damage issues. & $\begin{array}{l}\text { Expansion of } \\
\text { Q FEP }\end{array}$ & $\begin{array}{l}\text { Covered by KCC } \\
\text { CO2 storage } \\
\text { regulations }\end{array}$ & & & 1 & 3 & 3 & \begin{tabular}{|l|} 
Clearly mark site \\
with warnings and \\
register site as $\mathrm{CO} 2$ \\
storage site with the \\
State.
\end{tabular} & $\begin{array}{l}\text { Routine site inspection } \\
\text { and/or monitoring. }\end{array}$ \\
\hline 34 & 1.3.02.02. & $\begin{array}{l}\text { Deliberate } \\
\text { interference with or } \\
\text { intrusion into the } \\
\text { CO2 reservoir }\end{array}$ & \begin{tabular}{|l|} 
Third party deliberate intrusion or \\
interference with CO2 reservoir after closure \\
to recover hydrocarbons (e.g. EOR and \\
ECBMM) or malicious intrusion and sabotage.
\end{tabular} & Leakage and damage issues. & $\begin{array}{l}\text { Expansion of } \\
\text { Q FEP }\end{array}$ & $\begin{array}{l}\text { Covered by KCC } \\
\text { CO2 storage } \\
\text { regulations }\end{array}$ & & & 1 & 3 & 3 & \begin{tabular}{|l|} 
Clearly mark site \\
with warnings and \\
register site as $\mathrm{CO} 2$ \\
storage site with the \\
State.
\end{tabular} & $\begin{array}{l}\begin{array}{l}\text { Routine site inspection } \\
\text { and/or monitoring. }\end{array} \\
\end{array}$ \\
\hline 35 & 1.3.03.00. & $\begin{array}{l}\text { Social and } \\
\text { institutional } \\
\text { developments }\end{array}$ & $\begin{array}{l}\text { Events and processes related to changes in } \\
\text { social patterns and degree of local } \\
\text { government, planning and regulation. } \\
\text { Potentially significant social and institutional } \\
\text { developments include: } \\
\text { - changes in planning controls and } \\
\text { environmental legislation; } \\
\text { - demographic change and urban } \\
\text { development; } \\
\text { - changes in land use; } \\
\text { - loss of archives/records, loss/degradation } \\
\text { of societal memory. }\end{array}$ & $\begin{array}{l}\text { Social and institutional developments have the } \\
\text { potential to affect motivation and knowledge } \\
\text { issues, human use of the surface and sub- } \\
\text { surface environments and the type of impacts } \\
\text { that may be considered. }\end{array}$ & $\begin{array}{l}\text { Quintessa } \\
\text { original FEP }\end{array}$ & $\begin{array}{l}\text { Very unlikely to be } \\
\text { an issue. }\end{array}$ & & & 1 & 1 & 1 & \begin{tabular}{|l|} 
Clearly mark site \\
with warnings and \\
register site as $\mathrm{CO} 2$ \\
storage site with the \\
State.
\end{tabular} & $\begin{array}{l}\text { Routine site inspection } \\
\text { and/or monitoring. }\end{array}$ \\
\hline 36 & 1.3.03.01. & $\begin{array}{l}\text { Changes in } \\
\text { planning controls }\end{array}$ & & & $\begin{array}{c}\text { Expansion of } \\
\text { Q FEP }\end{array}$ & $\begin{array}{l}\text { Very unlikely to be } \\
\text { an issue. }\end{array}$ & & & 1 & 1 & 1 & \begin{tabular}{|l|} 
Monitoring zoning \\
announcements. \\
Clearly mark site \\
with warnings and \\
register site as CO22 \\
storage site with the \\
State. \\
\end{tabular} & $\begin{array}{l}\text { Routine site inspection } \\
\text { and/or monitoring. }\end{array}$ \\
\hline 37 & 1.3.03.02. & $\begin{array}{l}\text { Changes in } \\
\text { environmental } \\
\text { legislation }\end{array}$ & & & $\begin{array}{l}\text { Expansion of } \\
\text { Q FEP }\end{array}$ & $\left|\begin{array}{|l}\text { Uncertain. } \\
\text { Changes in } \\
\text { legislation could } \\
\text { impact the project. }\end{array}\right|$ & & & 3 & 1 & 3 & $\begin{array}{l}\text { Monitoring } \\
\text { environmental } \\
\text { legislation. Provide } \\
\text { input to lawmakers. }\end{array}$ & $\begin{array}{l}\text { Monitoring } \\
\text { environmental } \\
\text { legislation. Provide } \\
\text { input to lawmakers. }\end{array}$ \\
\hline 38 & 1.3.03.03. & $\begin{array}{l}\text { Demographic } \\
\text { change and urban } \\
\text { development }\end{array}$ & & & $\begin{array}{l}\text { Expansion of } \\
\text { Q FEP }\end{array}$ & $\begin{array}{l}\text { Very unlikely to be } \\
\text { an issue. }\end{array}$ & $\begin{array}{l}\text { Neither Thrall-Aagard } \\
\text { or Geneseo-Edwards } \\
\text { fields are close to } \\
\text { urban areas. } \\
\text { Urbanization highly } \\
\text { unlikely. }\end{array}$ & & 1 & 1 & 1 & \begin{tabular}{|l|} 
Monitor local \\
demographic \\
changes. Clearly \\
mark site with \\
warnings and \\
register site as $\mathrm{CO} 2$ \\
storage site with the \\
State.
\end{tabular} & $\begin{array}{l}\text { Routine site inspection } \\
\text { and/or monitoring. }\end{array}$ \\
\hline 39 & 1.3.03.04. & $\begin{array}{l}\text { Changes in land } \\
\text { use }\end{array}$ & & & $\begin{array}{c}\text { Expansion of } \\
\text { Q FEP }\end{array}$ & $\begin{array}{l}\text { Very unlikely to be } \\
\text { an issue. }\end{array}$ & $\begin{array}{l}\text { Land currently used } \\
\text { for farming and } \\
\text { ranching. }\end{array}$ & $\begin{array}{l}\text { Check zoning } \\
\text { regulations for } \\
\text { Greenwood and } \\
\text { Rice counties }\end{array}$ & 1 & 1 & 1 & \begin{tabular}{|l|} 
Clearly mark site \\
with warnings and \\
register site as $\mathrm{CO} 2$ \\
storage site with the \\
State. \\
\end{tabular} & \begin{tabular}{|l|}
$\begin{array}{l}\text { Routine site inspection } \\
\text { and/or monitoring. }\end{array}$ \\
\end{tabular} \\
\hline 40 & 1.3.03.05. & $\begin{array}{c}\text { Loss of } \\
\text { archives/records, } \\
\text { loss/degradation of } \\
\text { societal memory }\end{array}$ & & & $\begin{array}{c}\text { Expansion of } \\
\text { Q FEP }\end{array}$ & Unlikely to occur & & & 1 & 1 & 1 & \begin{tabular}{|l|} 
Keep backup \\
documentation at off- \\
site locations. \\
Clearly mark site \\
with warnings and \\
register site as $\mathrm{CO} 2$ \\
storage site with the \\
State.
\end{tabular} & $\begin{array}{l}\text { Routine site inspection } \\
\text { and/or monitoring. }\end{array}$ \\
\hline
\end{tabular}

Appendix 6-10

Quintessa Original FEP: Taken from Quintessa's on-line CO2 FEP database, which is freely accessible at: http://www.quintessa.org/co2fepdb/ 


\begin{tabular}{|c|c|c|c|c|c|c|c|c|c|c|c|c|c|}
\hline \multicolumn{6}{|c|}{ CO2 Geologic Sequestration Risks for the IMCCS Project } & \multicolumn{3}{|c|}{ Project Specific Information } & \multicolumn{3}{|c|}{ Risk Ranking } & \multicolumn{2}{|c|}{ Prevention and Mitigation } \\
\hline Line \# & Index No. & Risk Area & Description & Relevance & $\begin{array}{l}\text { Qunitessa } \\
\text { FEP } \\
\text { Category }\end{array}$ & $\begin{array}{l}\text { Individual } \\
\text { Comments }\end{array}$ & $\begin{array}{c}\text { IMccs Project } \\
\text { Specific Information }\end{array}$ & \begin{tabular}{|c|} 
IMccS Project \\
Information Gaps \\
or Uncertainties
\end{tabular} & 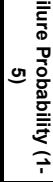 & 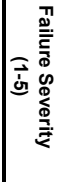 & 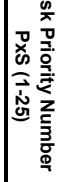 & $\begin{array}{l}\text { Risk Prevention } \\
\text { Steps (Actions } \\
\text { taken to reduce } \\
\text { risk probability) }\end{array}$ & $\begin{array}{l}\text { Risk Mitigation } \\
\text { Steps (Actions taken } \\
\text { to reduce risk } \\
\text { severity) }\end{array}$ \\
\hline 41 & 1.3.04.00. & $\begin{array}{l}\text { Technological } \\
\text { developments }\end{array}$ & $\begin{array}{l}\text { Events and processes related to future } \\
\text { developments in human technology and } \\
\text { changes in the capacity and motivation to } \\
\text { implement technologies. This may include } \\
\text { retrograde developments, e.g. loss of } \\
\text { capacity to implement a technology. }\end{array}$ & $\begin{array}{l}\text { Of interest are those technologies that might } \\
\text { change the capacity of humans to intrude } \\
\text { deliberately or otherwise into a storage site, to } \\
\text { cause changes that would affect the movement } \\
\text { of CO2 and associated contaminants, or that } \\
\text { may otherwise affect the performance and safety } \\
\text { of the sequestration system. Technological } \\
\text { developments are likely but may not be } \\
\text { predictable especially at longer times into the } \\
\text { future. }\end{array}$ & $\begin{array}{l}\text { Quintessa } \\
\text { original FEP }\end{array}$ & $\begin{array}{l}\text { Highly unlikely } \\
\text { during the life of } \\
\text { the project. }\end{array}$ & & & 1 & 1 & 1 & NA & NA \\
\hline 42 & 1.3.04.01. & $\begin{array}{l}\text { New technology } \\
\text { that would replace } \\
\text { the need for CO2 } \\
\text { geologic } \\
\text { sequestration }\end{array}$ & $\begin{array}{l}\text { Shift from fossil fuels toward nuclear, solar } \\
\text { or wind power. Breakthrough in terrestrial } \\
\text { sequestration. Alternative ways of cooling } \\
\text { the earth's atmosphere. }\end{array}$ & $\begin{array}{l}\text { Increased public/permitting resistance, threat to } \\
\text { project cash flow, potential loss of infrastructure } \\
\text { investment, halt in }>\text { failure of monitoring of } \\
\text { already-injected } \mathrm{CO} 2 \ldots\end{array}$ & \begin{tabular}{|l} 
Additional \\
[new] FEP
\end{tabular} & $\begin{array}{l}\text { Highly unlikely } \\
\text { during the life of } \\
\text { the project. }\end{array}$ & & & 1 & 1 & 1 & NA & $\begin{array}{l}\text { Keep abreast of new } \\
\text { technology } \\
\text { developments and } \\
\text { analyze impact on } \\
\text { project. Take } \\
\text { corrective action if } \\
\text { necessary. }\end{array}$ \\
\hline 43 & 1.3.04.02. & $\begin{array}{l}\text { New lower-cost } \\
\text { desalination } \\
\text { technology }\end{array}$ & \begin{tabular}{|l|} 
A low-cost desalination technology could \\
increase the value of deep saline aquifers in \\
desert regions and may limit the use of deep \\
saline aquifers for CO2 geologic \\
sequestration. However, it could also make \\
treatment and disposal of saline water \\
easier.
\end{tabular} & $\begin{array}{l}\text { Possible regulatory proscription of aquifer use, } \\
\text { but also possible benefit if project design } \\
\text { incorporated saline water withdrawals for } \\
\text { pressure management. }\end{array}$ & \begin{tabular}{|l} 
Additional \\
[new] FEP
\end{tabular} & $\begin{array}{l}\text { Very unlikely to be } \\
\text { an issue. }\end{array}$ & $\begin{array}{l}\text { Arbuckle is a Class } 1 \\
\text { hazardous waste } \\
\text { reservoir. }\end{array}$ & & 1 & 1 & 1 & NA & $\begin{array}{l}\text { Keep abreast of new } \\
\text { technology } \\
\text { developments and } \\
\text { analyze impact on } \\
\text { project. Take } \\
\text { corrective action if } \\
\text { necessary. }\end{array}$ \\
\hline 44 & 1.3.04.03. & $\begin{array}{l}\text { Lack of CO2 } \\
\text { capture technology } \\
\text { improvements }\end{array}$ & $\begin{array}{l}\text { Lack of significant improvements in } \mathrm{CO} 2 \\
\text { capture technology could hinder retrofititing } \\
\text { of existing coal-fired power plants and } \\
\text { cement plants and thus limit availability or } \\
\text { increase cost of } \mathrm{CO} 2 \text { for geologic } \\
\text { sequestration. }\end{array}$ & $\begin{array}{l}\text { Threat to project cash flow, potential loss of } \\
\text { infrastructure investment, halt in }>\text { failure of } \\
\text { monitoring of already-injected } \mathrm{CO} 2 \ldots\end{array}$ & $\begin{array}{l}\text { Additional } \\
\text { [new] FEP }\end{array}$ & $\begin{array}{l}\text { Very unlikely to be } \\
\text { an issue. }\end{array}$ & $\begin{array}{l}\text { Fertilizer and ethanol } \\
\text { plants already } \\
\text { concentrate } \mathrm{CO} 2\end{array}$ & & 1 & 1 & 1 & NA & $\begin{array}{l}\text { Keep abreast of new } \\
\text { technology } \\
\text { developments and } \\
\text { analyze impact on } \\
\text { project. Take } \\
\text { corrective action if } \\
\text { necessary. } \\
\end{array}$ \\
\hline 45 & 1.3.05.00. & Drilling activities & \begin{tabular}{|l|} 
Events related to any type of drilling activity \\
in the vicinity of the CO2 sequestration \\
system. These may be taken with or without \\
knowledge of the disposal and may include \\
activities such as: \\
- exploratory and/or exploitation drilling for \\
natural resources; \\
- attempted recovery of residual hydrocarbon \\
resources (e.g., EOR and ECBM); \\
- drilling for water resources; \\
- drilling for site characterization or research; \\
- drilling for further disposal; ; nd \\
- drilling for hydrothermal resources.
\end{tabular} & $\begin{array}{l}\text { Has the potential to disrupt geological features } \\
\text { that provide a barrier to } \mathrm{CO} 2 \text { migration and } \\
\text { provide a relatively quick migration pathway to } \\
\text { the near-surface. }\end{array}$ & $\begin{array}{l}\text { Quintessa } \\
\text { original FEP }\end{array}$ & $\begin{array}{l}\text { Very unlikely to be } \\
\text { an issue. }\end{array}$ & & & 1 & 3 & 3 & $\begin{array}{l}\text { Clearly mark site } \\
\text { with warnings and } \\
\text { register site as } \mathrm{CO} 2 \\
\text { storage site with the } \\
\text { State. }\end{array}$ & $\begin{array}{l}\text { Routine site inspection } \\
\text { and/or monitoring. }\end{array}$ \\
\hline 46 & 1.3.05.01. & $\begin{array}{l}\text { Drilling for water } \\
\text { resources }\end{array}$ & & & $\begin{array}{c}\text { Expansion of } \\
\text { Q FEP }\end{array}$ & $\begin{array}{l}\text { Very unlikely to be } \\
\text { an issue. }\end{array}$ & $\begin{array}{l}\text { Drinkable water } \\
\text { aquifer extends down } \\
\text { to } 200 \text { oft at both sites } \\
\text { but historically there } \\
\text { hasn't been enough } \\
\text { water for windmills to } \\
\text { fill stock troughs. All } \\
\text { drinkable water } \\
\text { currently comes from } \\
\text { surface water. }\end{array}$ & & 1 & 3 & 3 & $\begin{array}{l}\text { Clearly mark site } \\
\text { with warnings and } \\
\text { register site as } \mathrm{CO} 2 \\
\text { storage site with the } \\
\text { State. }\end{array}$ & $\begin{array}{l}\text { Routine site inspection } \\
\text { and/or monitoring. }\end{array}$ \\
\hline
\end{tabular}

Quintessa Original FEP: Taken from Quintessa's on-line CO2 FEP database, which is freely accessible at: http://www.quintessa.org/co2fepdb/ 


\begin{tabular}{|c|c|c|c|c|c|c|c|c|c|c|c|c|c|}
\hline \multicolumn{6}{|c|}{ CO2 Geologic Sequestration Risks for the IMCCS Project } & \multicolumn{3}{|c|}{ Project Specific Information } & \multicolumn{3}{|c|}{ Risk Ranking } & \multicolumn{2}{|c|}{ Prevention and Mitigation } \\
\hline Line \# & Index No. & Risk Area & Description & Relevance & $\begin{array}{l}\text { Qunitessa } \\
\text { FEP } \\
\text { Category }\end{array}$ & $\begin{array}{l}\text { Individual } \\
\text { Comments }\end{array}$ & $\begin{array}{c}\text { IMCcS Project } \\
\text { Specific Information }\end{array}$ & $\mid \begin{array}{c}\text { Imccs Project } \\
\text { Information Gaps } \\
\text { or Uncertainties }\end{array}$ & 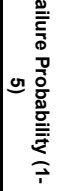 & 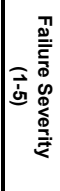 & 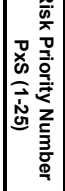 & $\begin{array}{l}\text { Risk Prevention } \\
\text { Steps (Actions } \\
\text { taken to reduce } \\
\text { risk probability) }\end{array}$ & \begin{tabular}{|c|} 
Risk Mitigation \\
Steps (Actions taken \\
to reduce risk \\
severity)
\end{tabular} \\
\hline 47 & 1.3.05.02. & $\begin{array}{l}\text { Drilling for site } \\
\text { characterization or } \\
\text { research }\end{array}$ & & & $\begin{array}{c}\text { Expansion of } \\
\text { Q FEP }\end{array}$ & $\begin{array}{l}\text { Very unlikely to be } \\
\text { an issue. }\end{array}$ & & & 1 & 2 & 2 & $\begin{array}{l}\text { Clearly mark site } \\
\text { with warnings and } \\
\text { register site as } \mathrm{CO} 2 \\
\text { storage site with the } \\
\text { State. }\end{array}$ & $\begin{array}{l}\text { Routine site inspection } \\
\text { and/or monitoring. }\end{array}$ \\
\hline 48 & 1.3.05.03. & $\begin{array}{l}\text { Drilling for further } \\
\text { disposal }\end{array}$ & & & $\begin{array}{c}\text { Expansion of } \\
\text { Q FEP }\end{array}$ & \begin{tabular}{|l} 
Unlikely to be an \\
issue
\end{tabular} & $\begin{array}{l}\text { Disposal would likely } \\
\text { be in the Arbuckle } \\
\text { formation, below any } \\
\text { EOR activity. }\end{array}$ & & 2 & 2 & 4 & $\begin{array}{l}\text { Clearly mark site } \\
\text { with warnings and } \\
\text { register site as } \mathrm{CO} 2 \\
\text { storage site with the } \\
\text { State. }\end{array}$ & $\begin{array}{l}\text { Routine site inspection } \\
\text { and/or monitoring. }\end{array}$ \\
\hline 49 & 1.3.05.04. & $\begin{array}{l}\text { Drilling for } \\
\text { hydrothermal } \\
\text { resources }\end{array}$ & & & $\begin{array}{c}\text { Expansion of } \\
\text { Q FEP }\end{array}$ & $\begin{array}{l}\text { very unlikely to be } \\
\text { an issue. }\end{array}$ & $\begin{array}{l}\text { Hydrothermal } \\
\text { resources are not } \\
\text { significant in the area. }\end{array}$ & & 1 & 3 & 3 & $\begin{array}{l}\text { Clearly mark site } \\
\text { with warnings and } \\
\text { register site as } \mathrm{CO} 2 \\
\text { storage site with the } \\
\text { State. }\end{array}$ & $\begin{array}{l}\text { Routine site inspection } \\
\text { and/or monitoring. }\end{array}$ \\
\hline 50 & 1.3.06.00. & $\begin{array}{c}\text { Mining and other } \\
\text { underground } \\
\text { activities }\end{array}$ & $\begin{array}{l}\text { Events related to any type of mining or } \\
\text { excavation activity carried out in the vicinity } \\
\text { of the storage site. These may be taken with } \\
\text { or without knowledge of the site. } \\
\text { Mining and other excavation activities } \\
\text { include: } \\
\text { - resource mining; } \\
\text { - excavation for industry; } \\
\text { - excavation for storage or disposal; } \\
\text { - excavation for military purposes; } \\
\text { - geothermal energy production; } \\
\text { - injection of liquid wastes and other fluids; } \\
\text { - scientific or archaeological investigation; } \\
\text { - shaft construction, underground } \\
\text { construction and tunneling; } \\
\text { - underground nuclear testing; } \\
\text { - malicious intrusion, sabotage or war; } \\
\text { - recovery of materials associated with CO2 } \\
\text { injection (e.g., EOR and ECBM) }\end{array}$ & $\begin{array}{l}\text { Mining and other underground activities have the } \\
\text { potential to disrupt the geosphere (storage } \\
\text { reservoir, surrounding and overlying rock) and } \\
\text { near-surface environment. They therefore have } \\
\text { the potential to significantly affect the migration } \\
\text { and distribution of sequestered cO2. }\end{array}$ & $\begin{array}{l}\text { Quintessa } \\
\text { original FEP }\end{array}$ & $\begin{array}{l}\text { Very unlikely to be } \\
\text { an issue. }\end{array}$ & & & 1 & 3 & 3 & $\begin{array}{l}\text { Clearly mark site } \\
\text { with warnings and } \\
\text { register site as } \mathrm{CO} 2 \\
\text { storage site with the } \\
\text { State. }\end{array}$ & $\begin{array}{l}\text { Routine site inspection } \\
\text { and/or monitoring. }\end{array}$ \\
\hline 51 & 1.3.06.01. & Resource mining & & & $\begin{array}{c}\text { Expansion of } \\
\text { Q FEP }\end{array}$ & $\begin{array}{l}\text { Very unlikely to be } \\
\text { an issue. }\end{array}$ & $\begin{array}{l}\text { No known mineral } \\
\text { resources other than } \\
\text { oil at sites. }\end{array}$ & & 1 & 3 & 3 & $\begin{array}{l}\text { Clearly mark site } \\
\text { with warnings and } \\
\text { register site as } \mathrm{CO} 2 \\
\text { storage site with the } \\
\text { State. }\end{array}$ & $\begin{array}{l}\text { Routine site inspection } \\
\text { and/or monitoring. }\end{array}$ \\
\hline 52 & 1.3.06.02. & $\begin{array}{l}\text { Excavation for } \\
\text { industry }\end{array}$ & & & $\begin{array}{l}\text { Expansion of } \\
\text { Q FEP }\end{array}$ & $\begin{array}{l}\text { very unlikely to be } \\
\text { an issue. }\end{array}$ & No industries nearby. & & 1 & 3 & 3 & $\begin{array}{l}\text { Clearly mark site } \\
\text { with warnings and } \\
\text { register site as } \mathrm{CO} 2 \\
\text { storage site with the } \\
\text { State. }\end{array}$ & $\begin{array}{l}\text { Routine site inspection } \\
\text { and/or monitoring. }\end{array}$ \\
\hline 53 & 1.3.06.03. & $\begin{array}{c}\text { Excavation for } \\
\text { storage or disposal }\end{array}$ & & & $\begin{array}{c}\text { Expansion of } \\
\text { Q FEP }\end{array}$ & $\begin{array}{l}\text { Very unlikely to be } \\
\text { an issue. }\end{array}$ & No industries nearby. & & 1 & 3 & 3 & \begin{tabular}{|l|} 
Clearly mark site \\
with warnings and \\
register site as $\mathrm{CO} 2$ \\
storage site with the \\
State. \\
\end{tabular} & $\begin{array}{l}\text { Routine site inspection } \\
\text { and/or monitoring. }\end{array}$ \\
\hline 54 & 1.3.06.04. & $\begin{array}{l}\text { Excavation for } \\
\text { military purposes }\end{array}$ & & & $\begin{array}{c}\text { Expansion of } \\
\text { Q FEP }\end{array}$ & $\begin{array}{l}\text { Very unlikely to be } \\
\text { an issue. }\end{array}$ & $\begin{array}{l}\text { No military bases } \\
\text { nearby. }\end{array}$ & & 1 & 3 & 3 & $\begin{array}{l}\text { Clearly mark site } \\
\text { with warnings and } \\
\text { register site as } \mathrm{CO} 2 \\
\text { storage site with the } \\
\text { State. }\end{array}$ & $\begin{array}{l}\text { Routine site inspection } \\
\text { and/or monitoring. }\end{array}$ \\
\hline
\end{tabular}

Appendix 6-12

Quintessa Original FEP: Taken from Quintessa's on-line CO2 FEP database, which is freely accessible at: http://www.quintessa.org/co2fepdb/ 


\begin{tabular}{|c|c|c|c|c|c|c|c|c|c|c|c|c|c|}
\hline \multicolumn{6}{|c|}{ CO2 Geologic Sequestration Risks for the IMCCS Project } & \multicolumn{3}{|c|}{ Project Specific Information } & \multicolumn{3}{|c|}{ Risk Ranking } & \multicolumn{2}{|c|}{ Prevention and Mitigation } \\
\hline Line \# & Index No. & Risk Area & Description & Relevance & $\begin{array}{l}\text { Qunitessa } \\
\text { FEP } \\
\text { Category }\end{array}$ & $\begin{array}{l}\text { Individual } \\
\text { Comments }\end{array}$ & $\begin{array}{c}\text { IMCcs Project } \\
\text { Specific Information }\end{array}$ & \begin{tabular}{|c|} 
IMccs Project \\
Information Gaps \\
or Uncertainties
\end{tabular} & 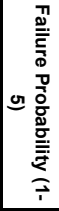 & 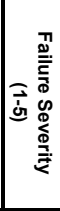 & 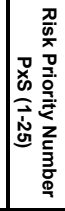 & $\begin{array}{l}\text { Risk Prevention } \\
\text { Steps (Actions } \\
\text { taken to reduce } \\
\text { risk probability) }\end{array}$ & \begin{tabular}{|c|} 
Risk Mitigation \\
Steps (Actions taken \\
to reduce risk \\
severity)
\end{tabular} \\
\hline 55 & 1.3.06.05. & $\begin{array}{c}\text { Geothermal energy } \\
\text { production }\end{array}$ & & & $\begin{array}{c}\text { Expansion of } \\
\text { Q FEP }\end{array}$ & $\begin{array}{l}\text { Very unlikely to be } \\
\text { an issue. }\end{array}$ & $\begin{array}{l}\text { No geothermal } \\
\text { properties identified. }\end{array}$ & & 1 & 3 & 3 & $\begin{array}{l}\text { Clearly mark site } \\
\text { with warnings and } \\
\text { register site as } \mathrm{CO} 2 \\
\text { storage site with the } \\
\text { State. }\end{array}$ & $\begin{array}{l}\text { Routine site inspection } \\
\text { and/or monitoring. }\end{array}$ \\
\hline 56 & 1.3.06.06. & $\begin{array}{l}\text { Injection of liquid } \\
\text { waste and other } \\
\text { fluids }\end{array}$ & & & $\begin{array}{c}\text { Expansion of } \\
\text { Q FEP }\end{array}$ & $\begin{array}{l}\text { Unlikely to be an } \\
\text { issue }\end{array}$ & $\begin{array}{l}\text { No liquid waste } \\
\text { generators nearby } \\
\text { except EOR water } \\
\text { production }\end{array}$ & & 2 & 3 & 6 & \begin{tabular}{|l|} 
Clearly mark site \\
with warnings and \\
register site as $\mathrm{CO} 2$ \\
storage site with the \\
State.
\end{tabular} & \begin{tabular}{|l|}
$\begin{array}{l}\text { Routine site inspection } \\
\text { and/or monitoring. }\end{array}$ \\
\end{tabular} \\
\hline 57 & 1.3.06.07. & $\begin{array}{l}\text { Scientific or } \\
\text { archaeological } \\
\text { investigation }\end{array}$ & & & $\begin{array}{c}\text { Expansion of } \\
\text { Q FEP }\end{array}$ & $\begin{array}{l}\text { Very unlikely to be } \\
\text { an issue. }\end{array}$ & $\begin{array}{l}\text { Mature oil fields. No } \\
\text { archeological sites } \\
\text { identified. }\end{array}$ & $\begin{array}{l}\text { Check Kansas } \\
\text { historical society }\end{array}$ & 1 & 3 & 3 & \begin{tabular}{|l|} 
Clearly mark site \\
with warnings and \\
register site as $\mathrm{CO} 2$ \\
storage site with the \\
State. \\
\end{tabular} & \begin{tabular}{|l|}
$\begin{array}{l}\text { Routine site inspection } \\
\text { and/or monitoring. }\end{array}$ \\
\end{tabular} \\
\hline 58 & 1.3.06.08. & $\begin{array}{l}\text { Shaft construction, } \\
\text { underground } \\
\text { construction and } \\
\text { tunneling; }\end{array}$ & & & $\begin{array}{c}\text { Expansion of } \\
\text { Q FEP }\end{array}$ & $\begin{array}{l}\text { Very unlikely to be } \\
\text { an issue. }\end{array}$ & $\begin{array}{l}\text { Sparsely populated } \\
\text { area. No underground } \\
\text { construction work } \\
\text { planned. }\end{array}$ & & 1 & 3 & 3 & \begin{tabular}{|l} 
Clearly mark site \\
with warnings and \\
register site as $\mathrm{CO} 2$ \\
storage site with the \\
State.
\end{tabular} & \begin{tabular}{|l|}
$\begin{array}{l}\text { Routine site inspection } \\
\text { and/or monitoring. }\end{array}$ \\
\end{tabular} \\
\hline 59 & 1.3.06.09. & $\begin{array}{l}\text { Underground } \\
\text { nuclear testing }\end{array}$ & & & $\begin{array}{c}\text { Expansion of } \\
\text { Q FEP }\end{array}$ & $\begin{array}{l}\text { Very unlikely to be } \\
\text { an issue. }\end{array}$ & $\begin{array}{l}\text { Site not suitable for } \\
\text { nuclear testing. }\end{array}$ & & 1 & 3 & 3 & $\begin{array}{l}\text { Clearly mark site } \\
\text { with warnings and } \\
\text { register site as } \mathrm{CO} 2 \\
\text { storage site with the } \\
\text { State. }\end{array}$ & \begin{tabular}{|l|}
$\begin{array}{l}\text { Routine site inspection } \\
\text { and/or monitoring. }\end{array}$ \\
\end{tabular} \\
\hline 60 & 1.3.06.10. & $\begin{array}{c}\text { Malicious intrusion, } \\
\text { sabotage or war; }\end{array}$ & & & $\begin{array}{c}\text { Expansion of } \\
\text { Q FEP }\end{array}$ & $\begin{array}{l}\text { Very unlikely to be } \\
\text { an issue. }\end{array}$ & \begin{tabular}{|l|} 
Site is sparsely \\
populated and \\
residents have long \\
history of cooperating \\
with oil companies. \\
\end{tabular} & & 1 & 3 & 3 & \begin{tabular}{|l|} 
Clearly mark site \\
with warnings and \\
register site as $\mathrm{CO} 2$ \\
storage site with the \\
State. \\
\end{tabular} & \begin{tabular}{|l|}
$\begin{array}{l}\text { Routine site inspection } \\
\text { and/or monitoring. }\end{array}$ \\
\end{tabular} \\
\hline 61 & 1.3.06.11. & $\begin{array}{c}\text { Recovery of } \\
\text { materials } \\
\text { associated with } \\
\text { CO2 injection (e.g., } \\
\text { EOR and ECBM) }\end{array}$ & & & $\begin{array}{l}\text { Expansion of } \\
\text { Q FEP }\end{array}$ & $\begin{array}{l}\text { EOR part of } \\
\text { project. No coal } \\
\text { seams. }\end{array}$ & \begin{tabular}{|l|} 
Potential for additional \\
EOR recovery if \\
technology improves.
\end{tabular} & & 3 & 3 & 9 & $\begin{array}{l}\text { Clearly mark site } \\
\text { with warnings and } \\
\text { register site as CO2 } \\
\text { storage site with the } \\
\text { State. }\end{array}$ & $\begin{array}{l}\text { Routine site inspection } \\
\text { and/or monitoring. }\end{array}$ \\
\hline 62 & 1.3.07.00. & $\begin{array}{c}\text { Human activities in } \\
\text { the surface } \\
\text { environment }\end{array}$ & $\begin{array}{l}\text { Events and processes related to any type of } \\
\text { human activities that may be carried out in } \\
\text { the surface environment that can potentially } \\
\text { affect the performance of the storage } \\
\text { system, or leakage pathways, excepting } \\
\text { those FEPs related to water management } \\
\text { which are described elsewhere. } \\
\text { Examples include: } \\
\text { - quarrying, trenching; } \\
\text { - excavation for construction; } \\
\text { - residential, industrial, transport and road } \\
\text { construction; } \\
\text { - pollution of surface environment and } \\
\text { groundwater. }\end{array}$ & $\begin{array}{l}\text { Human activities in the surface environment have } \\
\text { the potential to affect } \mathrm{CO} 2 \text { release processes, } \\
\text { should leakage occur. They may also determine } \\
\text { the types of impact to be considered. }\end{array}$ & \begin{tabular}{|l} 
Quintessa \\
original FEP
\end{tabular} & $\begin{array}{l}\text { Very unlikely to be } \\
\text { an issue. }\end{array}$ & & & 1 & 1 & 1 & $\begin{array}{l}\text { Clearly mark site } \\
\text { with warnings and } \\
\text { register site as } \mathrm{CO} 2 \\
\text { storage site with the } \\
\text { State. }\end{array}$ & $\begin{array}{l}\text { Routine site inspection } \\
\text { and/or monitoring. }\end{array}$ \\
\hline 63 & 1.3.07.01. & $\begin{array}{l}\text { Quarrying, } \\
\text { trenching }\end{array}$ & & & $\begin{array}{c}\text { Expansion of } \\
\text { Q FEP }\end{array}$ & $\begin{array}{l}\text { Very unlikely to be } \\
\text { an issue. }\end{array}$ & $\begin{array}{l}\text { No industry near } \\
\text { injection sites }\end{array}$ & & 1 & 1 & 1 & \begin{tabular}{|l|} 
Clearly mark site \\
with warnings and \\
register site as $\mathrm{CO} 2$ \\
storage site with the \\
State.
\end{tabular} & $\begin{array}{l}\text { Routine site inspection } \\
\text { and/or monitoring. }\end{array}$ \\
\hline
\end{tabular}

Quintessa Original FEP: Taken from Quintessa's on-line CO2 FEP database, which is freely accessible at: http://www.quintessa.org/co2fepdb/ 


\begin{tabular}{|c|c|c|c|c|c|c|c|c|c|c|c|c|c|}
\hline \multicolumn{6}{|c|}{ CO2 Geologic Sequestration Risks for the IMCCS Project } & \multicolumn{3}{|c|}{ Project Specific Information } & \multicolumn{3}{|c|}{ Risk Ranking } & \multicolumn{2}{|c|}{ Prevention and Mitigation } \\
\hline Line \# & flindex No. & Risk Area & Description & Relevance & $\begin{array}{l}\text { Qunitessa } \\
\text { FEP } \\
\text { Category }\end{array}$ & $\begin{array}{l}\text { Individual } \\
\text { Comments }\end{array}$ & $\begin{array}{c}\text { IMCCS Project } \\
\text { Specific Information }\end{array}$ & $\begin{array}{c}\text { IMCCS Project } \\
\text { Information Gaps } \\
\text { or Uncertainties }\end{array}$ & 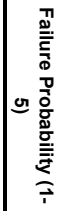 & 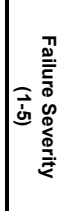 & 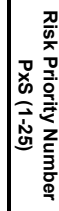 & $\begin{array}{c}\text { Risk Prevention } \\
\text { Steps (Actions } \\
\text { taken to reduce } \\
\text { risk probability) }\end{array}$ & $\begin{array}{l}\text { Risk Mitigation } \\
\text { Steps (Actions taken } \\
\text { to reduce risk } \\
\text { severity) }\end{array}$ \\
\hline 64 & 1.3.07.02. & $\begin{array}{l}\text { Excavation and } \\
\text { construction }\end{array}$ & & & $\begin{array}{l}\text { Expansion of } \\
\text { Q FEP }\end{array}$ & $\begin{array}{l}\text { Very unlikely to be } \\
\text { an issue. }\end{array}$ & $\begin{array}{l}\text { No industry near } \\
\text { injection sites }\end{array}$ & & 1 & 1 & 1 & $\begin{array}{l}\text { Clearly mark site } \\
\text { with warnings and } \\
\text { register site as } \mathrm{CO} 2 \\
\text { storage site with the } \\
\text { State. }\end{array}$ & $\begin{array}{l}\text { Routine site inspection } \\
\text { and/or monitoring. }\end{array}$ \\
\hline 65 & 1.3.07.03. & $\begin{array}{c}\text { Residential, } \\
\text { industrial transport } \\
\text { and road } \\
\text { construction }\end{array}$ & & & $\begin{array}{c}\text { Expansion of } \\
\text { Q FEP }\end{array}$ & $\begin{array}{l}\text { Very unlikely to be } \\
\text { an issue. }\end{array}$ & \begin{tabular}{|l} 
No industry near \\
injection sites
\end{tabular} & & 1 & 1 & 1 & $\begin{array}{l}\text { Clearly mark site } \\
\text { with warnings and } \\
\text { register site as } \mathrm{CO} 2 \\
\text { storage site with the } \\
\text { State. }\end{array}$ & $\begin{array}{l}\text { Routine site inspection } \\
\text { and/or monitoring. }\end{array}$ \\
\hline 66 & 1.3.07.04. & $\begin{array}{c}\text { Pollution of surface } \\
\text { environment }\end{array}$ & & & $\begin{array}{c}\text { Expansion of } \\
\text { Q FEP }\end{array}$ & $\begin{array}{l}\text { Very unlikely to be } \\
\text { an issue. }\end{array}$ & $\begin{array}{l}\text { No industry near } \\
\text { injection sites }\end{array}$ & & 1 & 1 & 1 & $\begin{array}{l}\text { Clearly mark site } \\
\text { with warnings and } \\
\text { register site as } \mathrm{CO} 2 \\
\text { storage site with the } \\
\text { State. }\end{array}$ & $\begin{array}{l}\text { Routine site inspection } \\
\text { and/or monitoring. }\end{array}$ \\
\hline 67 & 1.3.07.05. & $\begin{array}{c}\text { Changes in } \\
\text { groundwater } \\
\text { geochemistry (not } \\
\text { caused by project) }\end{array}$ & $\begin{array}{l}\text { Apart from potential project impacts, waters } \\
\text { in the project area formations above the } \\
\text { reservoir formation could change chemically } \\
\text { (including total dissolved solids) due to } \\
\text { groundwater extraction, climate, } \\
\text { contaminination, or other non-project causes. } \\
\text { This could change their susceptibility to } \\
\text { impact or the requirement for monitoring or } \\
\text { protection. }\end{array}$ & & \begin{tabular}{|l} 
Additional \\
[new] FEP
\end{tabular} & $\begin{array}{l}\text { Very unlikely to be } \\
\text { an issue. }\end{array}$ & $\begin{array}{l}\text { Fresh water sources } \\
\text { are very small volume } \\
\text { not enough for } \\
\text { windmills and stock } \\
\text { tanks at Thrall. }\end{array}$ & & 1 & 2 & 2 & $\begin{array}{l}\text { Characterize } \\
\text { groundwater aquifer. } \\
\text { Conduct baseline } \\
\text { survey of } \\
\text { groundwater } \\
\text { geochemistry. } \\
\text { Monitor third-party } \\
\text { activity in the area. }\end{array}$ & $\begin{array}{l}\text { Monitor groundwater } \\
\text { geochemistry and } \\
\text { determine root cause } \\
\text { of any changes. }\end{array}$ \\
\hline 68 & 1.3.07.06. & $\begin{array}{c}\text { Human activities in } \\
\text { the surface } \\
\text { environment offsite }\end{array}$ & $\begin{array}{l}\text { Above the CO2 plume, humans could incur } \\
\text { risks related to specific activities that take } \\
\text { place in low areas (e.g. farming, pruning, } \\
\text { harvesting, irrigation maintenance) that may } \\
\text { have limited air circulation. }\end{array}$ & & \begin{tabular}{|l} 
Additional \\
[new] FEP
\end{tabular} & $\begin{array}{l}\text { Very unlikely to be } \\
\text { an issue. }\end{array}$ & $\begin{array}{l}\text { There appear to be } \\
\text { few low lying areas in } \\
\text { or near the injection } \\
\text { sites and the sites are } \\
\text { sparsely populated. }\end{array}$ & & 1 & 2 & 2 & $\begin{array}{l}\text { Identify any low lying } \\
\text { areas in or near the } \\
\text { injection sites. Mark } \\
\text { sites with warnings. } \\
\text { Educate local } \\
\text { population on safety } \\
\text { aspects. }\end{array}$ & $\begin{array}{l}\text { Routine site inspection } \\
\text { and/or monitoring. }\end{array}$ \\
\hline 69 & 1.3.08.00. & Water management & $\begin{array}{l}\text { Events and processes related to } \\
\text { groundwater and surface water management } \\
\text { including water extraction, reservoirs, dams, } \\
\text { and river management. } \\
\text { Water is a valuable resource and water } \\
\text { extraction and management schemes } \\
\text { provide increased control over its distribution } \\
\text { and availability through construction of } \\
\text { dams, barrages, canals, pumping stations } \\
\text { and pipelines. Groundwater and surface } \\
\text { water may be extracted for human domestic } \\
\text { use (e.g. drinking water, washing), } \\
\text { agricultural uses (e.g. irigation, animal } \\
\text { consumption) and industrial uses. }\end{array}$ & $\begin{array}{l}\text { Extraction and management of water may affect } \\
\text { the movement of } \mathrm{CO} 2 \text { or associated } \\
\text { contaminants to and in the surface environment. }\end{array}$ & $\begin{array}{l}\text { Quintessa } \\
\text { original FEP }\end{array}$ & $\begin{array}{l}\text { Unlikely to be an } \\
\text { issue. }\end{array}$ & $\begin{array}{l}\text { There is no significiant } \\
\text { surface water in or } \\
\text { near the injection } \\
\text { sites. Drinkable water } \\
\text { aquifer extends down } \\
\text { to } 200 \text { oft at both sites } \\
\text { but historically there } \\
\text { hasn't been enough } \\
\text { water for windmills to } \\
\text { fill stock troughs. }\end{array}$ & & 2 & 3 & 6 & $\begin{array}{l}\text { Characterize surface } \\
\text { water and } \\
\text { groundwater aquifer. } \\
\text { Monitor third-party } \\
\text { activity in the area. }\end{array}$ & $\begin{array}{l}\text { Routine site inspection } \\
\text { and/or monitoring. }\end{array}$ \\
\hline 70 & 1.3.08.01. & Water extraction & & Apr & $\begin{array}{l}\text { Expansion of } \\
\text { Q FEP } \\
\text { dix 6-14 }\end{array}$ & $\begin{array}{l}\text { Unlikely to be an } \\
\text { issue. }\end{array}$ & $\begin{array}{l}\text { There is no significant } \\
\text { surface water in or } \\
\text { near the injection } \\
\text { sites. Drinkable water } \\
\text { aquifer extends down } \\
\text { to } 200 \text { oft tat both sites } \\
\text { but historically there } \\
\text { hasn't been enough } \\
\text { water for windmills to } \\
\text { fill stock troughs. }\end{array}$ & & 2 & 3 & 6 & $\begin{array}{l}\text { Characterize surface } \\
\text { water. Monitor third- } \\
\text { party activity in the } \\
\text { area. }\end{array}$ & $\begin{array}{l}\text { Routine site inspection } \\
\text { and/or monitoring. }\end{array}$ \\
\hline
\end{tabular}

Quintessa Original FEP: Taken from Quintessa's on-line CO2 FEP database, which is freely accessible at: http://www.quintessa.org/co2fepdb/ 


\begin{tabular}{|c|c|c|c|c|c|c|c|c|c|c|c|c|c|}
\hline \multicolumn{6}{|c|}{ CO2 Geologic Sequestration Risks for the IMCCS Project } & \multicolumn{3}{|c|}{ Project Specific Information } & \multicolumn{3}{|c|}{ Risk Ranking } & \multicolumn{2}{|c|}{ Prevention and Mitigation } \\
\hline Line \# & Index No. & Risk Area & Description & Relevance & $\begin{array}{l}\text { Qunitessa } \\
\text { FEP } \\
\text { Category }\end{array}$ & $\begin{array}{l}\text { Individual } \\
\text { Comments }\end{array}$ & $\begin{array}{c}\text { IMCCS Project } \\
\text { Specific Information }\end{array}$ & $\mid \begin{array}{c}\text { ImCcCs Project } \\
\text { Information Gaps } \\
\text { or Uncertainties } \\
\end{array}$ & 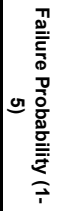 & 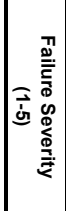 & 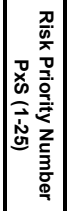 & $\begin{array}{l}\text { Risk Prevention } \\
\text { Steps (Actions } \\
\text { taken to reduce } \\
\text { risk probability) }\end{array}$ & \begin{tabular}{|c|} 
Risk Mitigation \\
Steps (Actions taken \\
to reduce risk \\
severity)
\end{tabular} \\
\hline 71 & 1.3.08.02. & Reservoirs & & & $\begin{array}{c}\text { Expansion of } \\
\text { Q FEP }\end{array}$ & $\begin{array}{l}\text { Very unlikely to be } \\
\text { an issue. }\end{array}$ & $\begin{array}{l}\text { There is no significant } \\
\text { surface water in or } \\
\text { near the injection } \\
\text { sites. }\end{array}$ & & 1 & 3 & 3 & $\begin{array}{l}\text { Characterize surface } \\
\text { water. Monitor third- } \\
\text { party activity in the } \\
\text { area. }\end{array}$ & $\begin{array}{l}\text { Routine site inspection } \\
\text { and/or monitoring. }\end{array}$ \\
\hline 72 & 1.3.08.03. & Dams & & & $\begin{array}{c}\text { Expansion of } \\
\text { Q FEP }\end{array}$ & \begin{tabular}{|l|}
$\begin{array}{l}\text { Very unlikely to be } \\
\text { an issue. }\end{array}$ \\
\end{tabular} & $\begin{array}{l}\text { There is no significant } \\
\text { surface water in or } \\
\text { near the injection } \\
\text { sites. }\end{array}$ & & 1 & 3 & 3 & \begin{tabular}{|l|} 
Characterize surface \\
water. Monitor third- \\
party activity in the \\
area.
\end{tabular} & \begin{tabular}{|l|} 
Routine site inspection \\
and/or monitoring.
\end{tabular} \\
\hline 73 & 1.3.08.04. & River management & & & $\begin{array}{c}\text { Expansion of } \\
\text { Q FEP }\end{array}$ & \begin{tabular}{|l|}
$\begin{array}{l}\text { Very unlikely to be } \\
\text { an issue. }\end{array}$ \\
\end{tabular} & $\begin{array}{l}\text { There is no significant } \\
\text { surface water in or } \\
\text { near the injection } \\
\text { sites. }\end{array}$ & & 1 & 3 & 3 & \begin{tabular}{|l|} 
Characterize surface \\
water. Monitor third- \\
party activity in the \\
area.
\end{tabular} & $\begin{array}{l}\text { Routine site inspection } \\
\text { and/or monitoring. }\end{array}$ \\
\hline 74 & 1.3.09.00. & $\begin{array}{l}\text { CO2 presence } \\
\text { influencing future } \\
\text { operations }\end{array}$ & \begin{tabular}{|l|} 
The presence of injected CO2 may hinder \\
future extractive operations by obscuring \\
seismic traces or by making the driling \\
process more difficult. Conversely, the \\
presence of CO2 locally, might allow for \\
more economic future enhanced oil recovery \\
operations. This FEP assumes that future \\
technical advances might identify useable \\
resources in the vicinity of previous $\mathrm{CO} 2$ \\
injection.
\end{tabular} & $\begin{array}{l}\text { Drilling through a formation filled with } \\
\text { supercritical } \mathrm{CO} 2 \text { might cause 'blowouts' or loss } \\
\text { of } \mathrm{CO} 2 \text { along the wellbore. A CO2 'bubble' will } \\
\text { change the velocity of seismic waves, distorting } \\
\text { the 'image' of the underlying formations, and } \\
\text { reducing confidence in the understanding of this } \\
\text { structure. }\end{array}$ & $\begin{array}{l}\text { Quintessa } \\
\text { original FEP }\end{array}$ & $\begin{array}{l}\text { Very unlikely to be } \\
\text { an issue. }\end{array}$ & $\begin{array}{l}\text { Covered by } \mathrm{KCC} \mathrm{CO2} \\
\text { storage regulations. }\end{array}$ & & 1 & 4 & 4 & $\begin{array}{l}\text { Clearly mark site } \\
\text { with warnings and } \\
\text { register site as } \mathrm{CO} 2 \\
\text { storage site with the } \\
\text { State. }\end{array}$ & $\begin{array}{l}\text { Routine site inspection } \\
\text { and/or monitoring. }\end{array}$ \\
\hline 75 & 1.3.10.00. & $\begin{array}{l}\text { Explosions and } \\
\text { crashes }\end{array}$ & \begin{tabular}{|l|} 
Events related to deliberate or accidental \\
explosions and crashes such as might have \\
some impact on a closed storage site, e.g. \\
underground nuclear testing, an aircraft \\
crash on the site, acts of war, marine \\
collisions or trawler damage to exposed sea- \\
bed structures.
\end{tabular} & $\begin{array}{l}\text { Explosions and crashes are likely to be low } \\
\text { probability events that could have a significant } \\
\text { impact on the performance of the sequestration } \\
\text { system by disrupting the expected evolution of } \\
\text { the system. }\end{array}$ & $\begin{array}{l}\text { Quintessa } \\
\text { original FEP }\end{array}$ & $\begin{array}{l}\text { Very unlikely to be } \\
\text { an issue. }\end{array}$ & $\begin{array}{l}\text { Area is sparsely } \\
\text { populated. }\end{array}$ & & 1 & 5 & 5 & $\begin{array}{l}\text { Avoid high activity } \\
\text { areas in site } \\
\text { selection. }\end{array}$ & $\begin{array}{l}\text { Prepare procedures to } \\
\text { handle emergencies in } \\
\text { and near the sites. }\end{array}$ \\
\hline 76 & 1.3.10.01. & $\begin{array}{l}\text { Accidental } \\
\text { explosions and } \\
\text { crashes }\end{array}$ & & & $\begin{array}{c}\text { Expansion of } \\
\text { Q FEP }\end{array}$ & $\begin{array}{l}\text { Very unlikely to be } \\
\text { an issue. }\end{array}$ & $\begin{array}{l}\text { Area is sparsely } \\
\text { populated. }\end{array}$ & & 1 & 5 & 5 & $\begin{array}{l}\text { Avoid high activity } \\
\text { areas in site } \\
\text { selection. }\end{array}$ & $\begin{array}{l}\text { Prepare procedures to } \\
\text { handle emergencies in } \\
\text { and near the sites. }\end{array}$ \\
\hline 77 & 1.3.10.02. & $\begin{array}{l}\text { Deliberate } \\
\text { explosions and } \\
\text { crashes }\end{array}$ & & & $\begin{array}{c}\text { Expansion of } \\
\text { Q FEP }\end{array}$ & $\begin{array}{l}\text { Very unlikely to be } \\
\text { an issue. }\end{array}$ & $\begin{array}{l}\text { Area is sparsely } \\
\text { populated. }\end{array}$ & & 1 & 5 & 5 & $\begin{array}{l}\text { Avoid high activity } \\
\text { areas in site } \\
\text { selection. }\end{array}$ & $\begin{array}{l}\text { Prepare procedures to } \\
\text { handle emergencies in } \\
\text { and near the sites. }\end{array}$ \\
\hline 78 & 2.0.00.00. & CO2 Storage & $\begin{array}{l}\text { This category of FEPs specifies details of } \\
\text { the sequestration concept under } \\
\text { consideration. It is split into two classes for } \\
\text { the pre- and post-closure periods. }\end{array}$ & & \begin{tabular}{|l} 
Quintessa \\
original FEP
\end{tabular} & & NA & & NA & NA & NA & NA & NA \\
\hline 79 & 2.1.00.00. & Pre-closure & $\begin{array}{l}\text { Details of the sequestration concept, the } \\
\text { fluids injected, and factors for the design, } \\
\text { construction, operation and } \\
\text { decommissioning phases. }\end{array}$ & $\begin{array}{l}\text { The details of the sequestration concept are } \\
\text { fundamental to determining which FEPs in other } \\
\text { categories need to be considered in a given } \\
\text { assessment. Some details of sequestration } \\
\text { operations may affect the post-closure } \\
\text { performance. }\end{array}$ & $\begin{array}{l}\text { Quintessa } \\
\text { original FEP }\end{array}$ & $\begin{array}{l}\text { Unlikely to be an } \\
\text { issue. }\end{array}$ & & & 2 & 3 & 6 & \begin{tabular}{|l|} 
Prepare a post \\
closure plan early in \\
the design process \\
and update as \\
needed over time.
\end{tabular} & $\begin{array}{l}\text { Prepare a post closure } \\
\text { plan early in the } \\
\text { design process and } \\
\text { update as needed } \\
\text { over time. }\end{array}$ \\
\hline 80 & 2.1.01.00. & Storage concept & $\begin{array}{l}\text { Features related to the concept of storage, } \\
\text { such as whether a closure exists } \\
\text { (sequestration in an abandoned oil or gas } \\
\text { field) or whether isolation of } \mathrm{CO} 2 \text { is } \\
\text { dependent upon slow diffusion rates through } \\
\text { an areally extensive open structure (saline } \\
\text { aquifer sequestration). }\end{array}$ & $\begin{array}{l}\text { Different processes will be relevant to different } \\
\text { storage concepts. For example, the rate of CO2 } \\
\text { migration in an open aquifer will be relevant to } \\
\text { safety assessment of saline aquifer storage, but } \\
\text { less relevant to sequestration in a closed } \\
\text { geological structure. }\end{array}$ & $\begin{array}{l}\text { Quintessa } \\
\text { original FEP }\end{array}$ & $\begin{array}{l}\text { Unlikely to be an } \\
\text { issue. }\end{array}$ & & & 2 & 3 & 6 & $\begin{array}{l}\text { Fully characterize } \\
\text { and model the sites } \\
\text { early in the design } \\
\text { phase. }\end{array}$ & $\begin{array}{l}\text { Fully characterize and } \\
\text { model the sites early } \\
\text { in the design phase. }\end{array}$ \\
\hline
\end{tabular}

Appendix 6-15

Quintessa Original FEP: Taken from Quintessa's on-line CO2 FEP database, which is freely accessible at: http://www.quintessa.org/co2fepdb/ 


\begin{tabular}{|c|c|c|c|c|c|c|c|c|c|c|c|c|c|}
\hline \multicolumn{6}{|c|}{ CO2 Geologic Sequestration Risks for the IMCCS Project } & \multicolumn{3}{|c|}{ Project Specific Information } & \multicolumn{3}{|c|}{ Risk Ranking } & \multicolumn{2}{|c|}{ Prevention and Mitigation } \\
\hline Line \# & f Index No. & Risk Area & Description & Relevance & $\begin{array}{l}\text { Qunitessa } \\
\quad \text { FEP } \\
\text { Category }\end{array}$ & $\begin{array}{l}\text { Individual } \\
\text { Comments }\end{array}$ & $\begin{array}{c}\text { IMCCS Project } \\
\text { Specific Information }\end{array}$ & $\begin{array}{c}\text { IMCCS Project } \\
\text { Information Gaps } \\
\text { or Uncertainties }\end{array}$ & 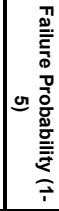 & 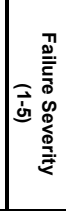 & 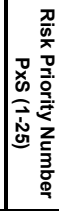 & $\begin{array}{l}\text { Risk Prevention } \\
\text { Steps (Actions } \\
\text { taken to reduce } \\
\text { risk probability) }\end{array}$ & $\begin{array}{l}\text { Risk Mitigation } \\
\text { Steps (Actions taken } \\
\text { to reduce risk } \\
\text { severity) }\end{array}$ \\
\hline 81 & 2.1.02.00. & $\begin{array}{c}\text { CO2 quantities, } \\
\text { injection rate }\end{array}$ & $\begin{array}{l}\text { Features related to the amounts of } \mathrm{CO} 2 \\
\text { injected and their rate of injection into the } \\
\text { storage aquifer/reservoir. }\end{array}$ & $\begin{array}{l}\text { High rates of } \mathrm{CO} 2 \text { injection could have adverse } \\
\text { affects, such as hydrofracturing. } \\
\text { For fast injection rates, displacement of oil/water } \\
\text { will not be efficient during enhanced oil recovery; } \\
\text { instead one will recover CO2; premature break } \\
\text { through is undesirable from an economic } \\
\text { perspective. }\end{array}$ & $\begin{array}{l}\text { Quintessa } \\
\text { original FEP }\end{array}$ & $\begin{array}{l}\text { Unlikely to be an } \\
\text { issue. }\end{array}$ & $\begin{array}{l}\text { Thrall will be } \\
\text { pressured with water } \\
\text { prior to CO2 injection. } \\
\text { if Geneseo-Edwards } \\
\text { exhibits coning, the } \\
\text { injection rate per well } \\
\text { will be cut back and } \\
\text { additional injection } \\
\text { wells will be used. }\end{array}$ & & 2 & 3 & 6 & $\begin{array}{l}\text { Fully characterize } \\
\text { and model the sites } \\
\text { early in the design } \\
\text { phase. Conduct } \\
\text { injectivity tests and } \\
\text { adjust injection plan } \\
\text { appropriately. Avoid } \\
\text { excessive injection } \\
\text { pressures. If } \\
\text { injection pressure is } \\
\text { unacceptably high, } \\
\text { cut back on } \\
\text { individual well } \\
\text { injection rate and } \\
\text { use additional } \\
\text { injection wells. }\end{array}$ & \begin{tabular}{|l} 
Fully characterize and \\
model the sites early \\
in the design phase. \\
Conduct injectivity \\
tests and adjust \\
injection plan \\
appropriately. Avoid \\
excessive injection \\
pressures. If injection \\
pressure is \\
unacceptably high, cut \\
back on individual well \\
injection rate and use \\
additional injection \\
wells.
\end{tabular} \\
\hline 82 & 2.1.03.00. & CO2 composition & 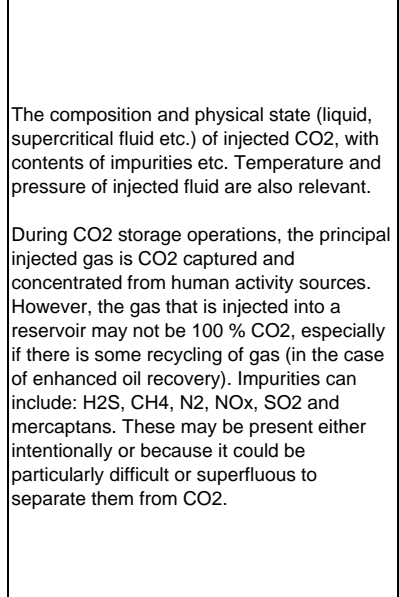 & $\begin{array}{l}\text { The presence of even small amounts of other } \\
\text { gases has a strong effect on the phase behavior } \\
\text { of CO2-dominated gases. High-pressure } \\
\text { equations of state for CO2-dominated gas } \\
\text { mixtures are required to take into account } \\
\text { changes in critical pressures and temperatures } \\
\text { caused by the presence of other gases. } \\
\text { Impurities will reduce the critical temperature } \\
\text { which, in turn, has effects on interfacial tension. } \\
\text { Amongst the possible companion gases, NOx } \\
\text { and SOO2 are particularly relevant because: } \\
\text { - NOx and SO2 are polluting gases that are } \\
\text { generated by the same power plants that } \\
\text { generate massive amounts of CO2 and attract } \\
\text { emission taxes in certain countries (e.g. Italy). } \\
\text { Their injection, in smanller amounts, with CO2 } \\
\text { could therefore help the economics of } \\
\text { sequestration. } \\
\text { Impurities may affect pore water chemistry (pH } \\
\text { and redox conditions, for example) depending on } \\
\text { the impurities involved. Special care is needed } \\
\text { when considering corrosive gases, such as } \mathrm{H} 2 \mathrm{~S} \text {. }\end{array}$ & \begin{tabular}{|l} 
Quintessa \\
original FEP
\end{tabular} & $\begin{array}{l}\text { Unlikely to be an } \\
\text { issue. }\end{array}$ & $\begin{array}{l}\text { CVR CO2 stream } \\
\text { composition is well } \\
\text { documented and } \\
\text { consistent. KE CO2 } \\
\text { stream composition is } \\
\text { poorly documented } \\
\text { and is expected to } \\
\text { fluctuate. }\end{array}$ & $\begin{array}{l}\text { Confirm } \\
\text { composition and } \\
\text { consistency of KE } \\
\text { CO2 stream. }\end{array}$ & 2 & 2 & 4 & \begin{tabular}{|l} 
Set target \\
specifications for \\
CO2 streams. \\
Confirm CO2 stream \\
composition through \\
performance tests \\
and guarantees. \\
Monitor CO2 \\
composition. Provide \\
backup deep saline \\
injection option if \\
CO2 stream doesn't \\
meat specification \\
for EOR or ECBM. \\
Or vent CO2 prior to \\
compression if \\
necessary.
\end{tabular} & $\begin{array}{l}\text { Set target } \\
\text { specifications for CO2 } \\
\text { streams. Confirm CO2 } \\
\text { stream composition } \\
\text { through performance } \\
\text { tests and guarantees. } \\
\text { Monitor CO2 } \\
\text { composition. Provide } \\
\text { backup deep saline } \\
\text { injection option if CO2 } \\
\text { stream doesn't meat } \\
\text { specification for EOR } \\
\text { or ECBM. Or vent } \\
\text { CO2 prior to } \\
\text { compression if } \\
\text { necesssary. }\end{array}$ \\
\hline
\end{tabular}




\begin{tabular}{|c|c|c|c|c|c|c|c|c|c|c|c|c|c|}
\hline \multicolumn{6}{|c|}{ CO2 Geologic Sequestration Risks for the IMCCS Project } & \multicolumn{3}{|c|}{ Project Specific Information } & \multicolumn{3}{|c|}{ Risk Ranking } & \multicolumn{2}{|c|}{ Prevention and Mitigation } \\
\hline Line \# & Index No. & Risk Area & Description & Relevance & $\begin{array}{l}\text { Qunitessa } \\
\text { FEP } \\
\text { Category }\end{array}$ & $\begin{array}{l}\text { Individual } \\
\text { Comments }\end{array}$ & $\begin{array}{c}\text { IMCCS Project } \\
\text { Specific Information }\end{array}$ & $\mid \begin{array}{c}\text { IMccs Project } \\
\text { Information Gaps } \\
\text { or Uncertainties }\end{array}$ & 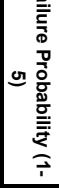 & 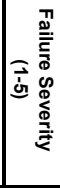 & 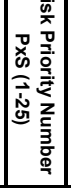 & $\begin{array}{l}\text { Risk Prevention } \\
\text { Steps (Actions } \\
\text { taken to reduce } \\
\text { risk probability) }\end{array}$ & \begin{tabular}{|l|} 
Risk Mitigation \\
Steps (Actions taken \\
to reduce risk \\
severity)
\end{tabular} \\
\hline 83 & 2.1.03.01. & $\begin{array}{l}\mathrm{CO} 2 \text { containing } \\
\text { H2S }\end{array}$ & & & $\begin{array}{c}\text { Expansion of } \\
\text { Q FEP }\end{array}$ & $\begin{array}{l}\text { Very unlikely to } \\
\text { be an issue. }\end{array}$ & \begin{tabular}{l|} 
H2S is very low in \\
CVR or KE CO2 \\
streams but may be \\
present in recycled \\
CO2 streams at EOR \\
operations.
\end{tabular} & \begin{tabular}{|l} 
Confirm H2S \\
levels in Arbuckle \\
oil, water and gas \\
at Genesee- \\
Edwards.
\end{tabular} & 1 & 3 & . & \begin{tabular}{|l|} 
Fully characterize \\
site for subsurface \\
H2S generation. \\
Specify appropriate \\
materials of \\
construction for \\
handling H2S in \\
production wells, \\
disposal wells and \\
CO2 recycle \\
systems. Include \\
H2S in modeling. \\
Monitor for H2S \\
along with CO2 \\
above and below \\
ground. Train \\
operators how to \\
handle H2S safely.
\end{tabular} & $\begin{array}{l}\text { Fully characterize site } \\
\text { for subsurface H2S } \\
\text { generation. Specify } \\
\text { appropriate materials } \\
\text { of construction for } \\
\text { handling H2S in } \\
\text { production wells, } \\
\text { disposal wells and } \\
\text { CO2 recycle systems. } \\
\text { Include H2S in } \\
\text { modeling. Monitor for } \\
\text { H2S along with CO2 } \\
\text { above and below } \\
\text { ground. Train } \\
\text { operators how to } \\
\text { handle H2S safely. }\end{array}$ \\
\hline 84 & 2.1.03.02. & $\begin{array}{l}\mathrm{CO} 2 \text { containing } \\
\text { H2O }\end{array}$ & & $\begin{array}{l}\text { If the water vapor is not removed prior to } \\
\text { compression, the } \mathrm{CO} 2 \text { product will be very } \\
\text { corrosive and the pipeline well head and } \\
\text { borehole would have to be built with much more } \\
\text { expensive materials than carbon steel. }\end{array}$ & $\begin{array}{c}\text { Expansion of } \\
\text { Q FEP }\end{array}$ & $\begin{array}{l}\text { Unlikely to be an } \\
\text { issue. }\end{array}$ & \begin{tabular}{|l|} 
CO2 will be \\
dehydrated to \\
specified levels prior to \\
compression and \\
transportation.
\end{tabular} & & 2 & 3 & (1) & \begin{tabular}{|l|} 
Install CO2 \\
dehydration units. \\
Operate \\
appropriately. \\
Monitor CO2 water \\
content in and out of \\
dehydration. Vent \\
CO2 if dehydration is \\
not working. Keep \\
CO2 pipelines free \\
of water. Specify \\
appropriate \\
materials of \\
construction for \\
production wells and \\
CO2 recycling \\
facilities to handle \\
wet $\mathrm{CO} 2$.
\end{tabular} & \begin{tabular}{|l|} 
\\
Install CO2 \\
dehydration units. \\
Operate appropriately. \\
Monitor CO2 water \\
content in and out of \\
dehydration. Vent \\
CO2 if dehydration is \\
not working. Keep \\
CO2 pipelines free of \\
water. Specify \\
appropriate materials \\
of construction for \\
production wells and \\
CO2 recycling facilities \\
to handle wet CO2.
\end{tabular} \\
\hline 85 & 2.1.03.03. & $\mathrm{CO} 2$ containing $\mathrm{O} 2$ & $\begin{array}{l}\text { EOR and deep saline applications can } \\
\text { tolerate some oxygen (air) in the CO2, but } \\
\text { ECBM can't. }\end{array}$ & & $\begin{array}{l}\text { Expansion of } \\
\text { Q FEP }\end{array}$ & Possible issue. & $\begin{array}{l}\text { Oxygen is very low in } \\
\text { CVR CO2 but may } \\
\text { need to be removed } \\
\text { from KE CO2 prior to } \\
\text { compression and } \\
\text { transport in order to } \\
\text { meet target } \\
\text { specifications. }\end{array}$ & $\begin{array}{l}\text { Confirm O2 } \\
\text { content and } \\
\text { variability in KE } \\
\text { CO2 stream. }\end{array}$ & 3 & 2 & 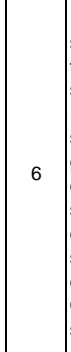 & \begin{tabular}{|l|} 
Install O2 removal \\
system at $\mathrm{KE}$ facility \\
to achieve $\mathrm{CO} 2$ \\
specification. \\
Require $\mathrm{CO} 2$ \\
suppliers to \\
guarantee $\mathrm{O} 2$ \\
content of CO2 \\
stream. Monitor $\mathrm{O} 2$ \\
content in CO2 \\
streams. Take \\
corrective action if \\
O2 exceeds \\
specification.
\end{tabular} & $\begin{array}{l}\text { Monitor O2 content of } \\
\text { CO2 stream. Take } \\
\text { corrective action if } \mathrm{O} 2 \\
\text { exceeds specification: } \\
\text { vent CO2 prior to } \\
\text { compression or inject } \\
\text { off-spec } \mathrm{CO} 2 \text { into } \\
\text { back up deep saline } \\
\text { injection well. }\end{array}$ \\
\hline
\end{tabular}

Appendix 6-17

Quintessa Original FEP: Taken from Quintessa's on-line CO2 FEP database, which is freely accessible at: http://www.quintessa.org/co2fepdb/ 


\begin{tabular}{|c|c|c|c|c|c|c|c|c|c|c|c|c|c|}
\hline \multicolumn{6}{|c|}{ CO2 Geologic Sequestration Risks for the IMCCS Project } & \multicolumn{3}{|c|}{ Project Specific Information } & \multicolumn{3}{|c|}{ Risk Ranking } & \multicolumn{2}{|c|}{ Prevention and Mitigation } \\
\hline Line \# & Index No. & Risk Area & Description & Relevance & $\begin{array}{l}\text { Qunitessa } \\
\text { FEP } \\
\text { Category }\end{array}$ & $\begin{array}{l}\text { Individual } \\
\text { Comments }\end{array}$ & $\begin{array}{c}\text { IMCCS Project } \\
\text { Specific Information }\end{array}$ & $\begin{array}{c}\text { IMCCS Project } \\
\text { Information Gaps } \\
\text { or Uncertainties }\end{array}$ & 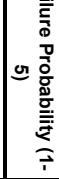 & 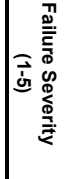 & 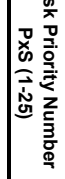 & $\begin{array}{l}\text { Risk Prevention } \\
\text { Steps (Actions } \\
\text { taken to reduce } \\
\text { risk probability) }\end{array}$ & $\begin{array}{l}\text { Risk Mitigation } \\
\text { Steps (Actions taken } \\
\text { to reduce risk } \\
\text { severity) }\end{array}$ \\
\hline 86 & 2.1.03.04. & CO2 containing N2 & & $\begin{array}{l}\text { Nitrogen is undesirable for EOR because it raises } \\
\text { the minimum miscibility pressure of the fluid and } \\
\text { makes the injection process less efficient. } \\
\text { Nitrogen is not a problem in ECBM as a minor } \\
\text { component of CO2. It will lower the partial } \\
\text { pressure of methane and allow more methane to } \\
\text { be released and recovered. }\end{array}$ & $\begin{array}{c}\text { Expansion of } \\
\text { Q FEP }\end{array}$ & $\begin{array}{l}\text { Likely to be an } \\
\text { issue. }\end{array}$ & $\begin{array}{l}\text { Nitrogen is very low in } \\
\text { the CVR CO2 stream, } \\
\text { but may fluctuate in } \\
\text { the KE CO2 stream }\end{array}$ & $\begin{array}{l}\text { Confirm N2 } \\
\text { content and } \\
\text { variability in KE } \\
\text { CO2 stream. Need } \\
\text { to model the } \\
\text { impact of N2 on } \\
\text { MMP at Geneseo- } \\
\text { Edwards. }\end{array}$ & 4 & 2 & 8 & \begin{tabular}{|l} 
Request that KE \\
adjust their \\
operating practices \\
to guarantee \\
minimum N2 content \\
and fluctuation in the \\
CO2 stream. Monitor \\
N2 content in the \\
CO2 stream. Take \\
corrective action if \\
N2 exceeds \\
specifications.
\end{tabular} & $\begin{array}{l}\text { Monitor N2 content of } \\
\text { CO2 stream. Take } \\
\text { corrective action if N2 } \\
\text { exceeds specification: } \\
\text { vent CO2 prior to } \\
\text { compression or inject } \\
\text { off-spec CO2 into } \\
\text { back up deep saline } \\
\text { injection well. }\end{array}$ \\
\hline 87 & 2.1.03.05. & $\begin{array}{l}\text { CO2 containing } \\
\text { NOX }\end{array}$ & & & $\begin{array}{l}\text { Expansion of } \\
\text { Q FEP }\end{array}$ & \begin{tabular}{|l|}
$\begin{array}{l}\text { Very unlikely to be } \\
\text { an issue. }\end{array}$ \\
\end{tabular} & \begin{tabular}{|l|}
$\begin{array}{l}\text { CVR and KE have } \\
\text { very low NOx content } \\
\text { in the CO2 streams. }\end{array}$ \\
\end{tabular} & & 1 & 2 & 2 & NA & NA \\
\hline 88 & 2.1.03.06. & $\begin{array}{l}\text { CO2 containing } \\
\text { SOx }\end{array}$ & & & $\begin{array}{l}\text { Expansion of } \\
\text { Q FEP }\end{array}$ & $\begin{array}{l}\text { Very unlikely to be } \\
\text { an issue. }\end{array}$ & \begin{tabular}{|l}
$\begin{array}{l}\text { CVR and KE have } \\
\text { very low SOx content } \\
\text { in the CO2 streams. }\end{array}$ \\
\end{tabular} & & 1 & 2 & 2 & NA & NA \\
\hline 89 & 2.1.03.07. & $\begin{array}{l}\mathrm{CO} 2 \text { containing } \\
\text { CH4 }\end{array}$ & & & $\begin{array}{l}\text { Expansion of } \\
\text { Q FEP }\end{array}$ & $\begin{array}{l}\text { Unlikely to be an } \\
\text { issue. }\end{array}$ & $\begin{array}{l}\text { CVR and KE have } \\
\text { very lowCH4 content } \\
\text { in the } \mathrm{CO} 2 \text { streams. } \\
\text { However, there could } \\
\text { be high } \mathrm{CH} 4 \text { in the } \\
\text { recycle } \mathrm{CO} 2 \text { stream. }\end{array}$ & & 2 & 2 & 4 & $\begin{array}{l}\text { Monitor for } \mathrm{CH} 4 \\
\text { content in fresh and } \\
\text { recycle CO2 } \\
\text { streams. }\end{array}$ & $\begin{array}{l}\text { Prepare operating } \\
\text { procedures to deal } \\
\text { with high CH4 in the } \\
\text { CO2 stream. }\end{array}$ \\
\hline 90 & 2.1.03.08. & $\begin{array}{l}\text { CO2 containing } \\
\text { mercaptans }\end{array}$ & & $\begin{array}{l}\text { Mercaptans and other malodorous sulfur } \\
\text { compounds are strong smelling and require } \\
\text { additional sealing around the wellhead to capture } \\
\text { fugitive emissions and minimize odors. }\end{array}$ & $\begin{array}{l}\text { Expansion of } \\
\text { Q FEP }\end{array}$ & $\begin{array}{l}\text { Very unlikely to be } \\
\text { an issue. }\end{array}$ & $\begin{array}{l}\text { CVR and KE have } \\
\text { very low mercaptan } \\
\text { content in the CO2 } \\
\text { streams. However, } \\
\text { there could be } \\
\text { mercaptans in the } \\
\text { recycle CO2 stream. }\end{array}$ & & 1 & 3 & 3 & $\begin{array}{l}\text { Monitor for } \\
\text { mercaptans in } \\
\text { production wells. }\end{array}$ & $\begin{array}{l}\text { Prepare operating } \\
\text { procedures to deal } \\
\text { with mercaptans if } \\
\text { they are found in the } \\
\text { CO2. }\end{array}$ \\
\hline 91 & 2.1.03.09. & $\mathrm{CO} 2$ containing $\mathrm{CO}$ & & & $\begin{array}{l}\text { Expansion of } \\
\text { Q FEP }\end{array}$ & Possible issue. & $\begin{array}{l}\text { CVR and KE have } \\
\text { very low CO content in } \\
\text { the CO2 streams. }\end{array}$ & & 3 & 2 & 6 & $\begin{array}{l}\text { Monitor for CO } \\
\text { content in CO2 } \\
\text { streams. }\end{array}$ & \begin{tabular}{|l|} 
Prepare operating \\
procedures to deal \\
with high CO content if \\
found in the $\mathrm{CO} 2$. \\
\end{tabular} \\
\hline 92 & 2.1.03.10 & $\mathrm{CO} 2$ containing $\mathrm{H} 2$ & & $\begin{array}{l}\text { Hydrogen can leak through seals that other } \\
\text { gases can't }\end{array}$ & $\begin{array}{l}\text { Expansion of } \\
\text { Q FEP }\end{array}$ & $\begin{array}{l}\text { Unlikely to be an } \\
\text { issue. }\end{array}$ & $\begin{array}{l}\text { CVR and KE have } \\
\text { very low } \mathrm{H} 2 \text { content in } \\
\text { the } \mathrm{CO} 2 \text { streams. }\end{array}$ & & 2 & 2 & 4 & $\begin{array}{l}\text { Monitor for } \mathrm{H} 2 \\
\text { content in } \mathrm{CO} 2 \\
\text { streams. }\end{array}$ & \begin{tabular}{|l|} 
Prepare operating \\
procedures to deal \\
with high $\mathrm{H} 2$ content if \\
found in the CO2.
\end{tabular} \\
\hline 93 & 2.1.03.10. & $\begin{array}{l}\text { CO2 containing } \\
\text { particulates }\end{array}$ & & & $\begin{array}{l}\text { Expansion of } \\
\text { Q FEP }\end{array}$ & $\begin{array}{l}\text { Very unlikely to be } \\
\text { an issue. }\end{array}$ & $\begin{array}{l}\text { CVR and KE have } \\
\text { very low particulate } \\
\text { content in the CO2 } \\
\text { streams. }\end{array}$ & & 1 & 2 & 2 & \begin{tabular}{|l} 
Monitor for \\
particulate content in \\
CO2 streams.
\end{tabular} & \begin{tabular}{|l|}
$\begin{array}{l}\text { Prepare operating } \\
\text { procedures to deal } \\
\text { with high particulate } \\
\text { content if found in the } \\
\text { CO2. }\end{array}$ \\
\end{tabular} \\
\hline 94 & 2.1.04.00. & $\begin{array}{l}\text { Microbiological } \\
\text { contamination }\end{array}$ & $\begin{array}{l}\text { Microbiological contamination of injected } \\
\text { fluid. Contamination of supercritical CO2 is } \\
\text { considered unlikely due to its being a very } \\
\text { good solvent. However, other fluids may be } \\
\text { injected into the storage site that may be } \\
\text { contaminated with microbes. }\end{array}$ & $\begin{array}{l}\text { The introduction of microbes into the } \\
\text { sequestration system may affect both the } \\
\text { performance of the storage system and the } \\
\text { endpoints considered. }\end{array}$ & $\begin{array}{l}\text { Quintessa } \\
\text { original FEP }\end{array}$ & $\begin{array}{l}\text { Very unlikely to be } \\
\text { an issue. }\end{array}$ & & $\begin{array}{l}\text { Identify any } \\
\text { significant } \\
\text { subsurface } \\
\text { microbial cultures } \\
\text { at the injection } \\
\text { sites. }\end{array}$ & 1 & 1 & 1 & $\begin{array}{l}\text { Monitor for microbial } \\
\text { activity if injection } \\
\text { pressures increase } \\
\text { unexpectedly. Avoid } \\
\text { O2 content in the } \\
\text { CO2 stream. }\end{array}$ & $\begin{array}{l}\text { Use chemical } \\
\text { treatment if necessary } \\
\text { to control microbial } \\
\text { growth. }\end{array}$ \\
\hline
\end{tabular}

Appendix 6-18

Quintessa Original FEP: Taken from Quintessa's on-line CO2 FEP database, which is freely accessible at: http://www.quintessa.org/co2fepdb/ 


\begin{tabular}{|c|c|c|c|c|c|c|c|c|c|c|c|c|c|}
\hline \multicolumn{6}{|c|}{ CO2 Geologic Sequestration Risks for the IMCCS Project } & \multicolumn{3}{|c|}{ Project Specific Information } & \multicolumn{3}{|c|}{ Risk Ranking } & \multicolumn{2}{|c|}{ Prevention and Mitigation } \\
\hline Line \# & Index No. & Risk Area & Description & Relevance & $\begin{array}{l}\text { Qunitessa } \\
\text { FEP } \\
\text { Category }\end{array}$ & $\begin{array}{l}\text { Individual } \\
\text { Comments }\end{array}$ & $\begin{array}{c}\text { IMCCS Project } \\
\text { Specific Information }\end{array}$ & $\mid \begin{array}{c}\text { IMccs Project } \\
\text { Information Gaps } \\
\text { or Uncertainties }\end{array}$ & 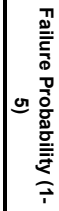 & 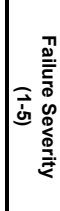 & 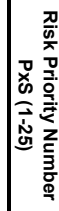 & $\begin{array}{l}\text { Risk Prevention } \\
\text { Steps (Actions } \\
\text { taken to reduce } \\
\text { risk probability) }\end{array}$ & $\begin{array}{l}\text { Risk Mitigation } \\
\text { Steps (Actions taken } \\
\text { to reduce risk } \\
\text { severity) }\end{array}$ \\
\hline 95 & 2.1.05.00. & $\begin{array}{l}\text { Schedule and } \\
\text { planning }\end{array}$ & $\begin{array}{l}\text { Features related to the sequence of events } \\
\text { and activities occurring during storage } \\
\text { system design, CO2 injection and sealing. } \\
\text { This could include enhanced oil recovery } \\
\text { processes. }\end{array}$ & $\begin{array}{l}\text { Relevant events may include phased drilling of } \\
\text { wells and emplacement of CO2, sealing of } \\
\text { boreholes, and monitoring activities to provide } \\
\text { data on the transient behavaio of the system or to } \\
\text { provide input to the final assessment. The } \\
\text { sequence of events and time between events } \\
\text { may have implications for long term performance, } \\
\text { e.g. chemeical and hydraulic changes during a } \\
\text { prolonged injection phase. }\end{array}$ & Quintessa & Possible issue. & $\begin{array}{l}\text { Complex project with } \\
\text { multiple parties and } \\
\text { multiple parts. }\end{array}$ & & 3 & 2 & 6 & $\begin{array}{l}\text { Establish } \\
\text { management } \\
\text { committee and } \\
\text { working groups. } \\
\text { Detailed project } \\
\text { schedule and work } \\
\text { breakdown } \\
\text { structure. Secure } \\
\text { website. Weekly } \\
\text { conference calls. }\end{array}$ & $\begin{array}{l}\text { Establish } \\
\text { management } \\
\text { committee and } \\
\text { working groups. } \\
\text { Detailed project } \\
\text { schedule and work } \\
\text { breakdown structure. } \\
\text { Secure website. } \\
\text { Weekly conference } \\
\text { calls. }\end{array}$ \\
\hline 96 & 2.1.06.00. & $\begin{array}{l}\text { Pre-closure } \\
\text { administrative } \\
\text { control }\end{array}$ & $\begin{array}{l}\text { Features related to measures to control } \\
\text { events at or around the sequestration site } \\
\text { during the design, construction, operation } \\
\text { and decommissioning phases. The type of } \\
\text { administrative control may vary depending } \\
\text { on the stage in the storage system lifetime. }\end{array}$ & $\begin{array}{l}\text { The pre-closure administrative control will } \\
\text { influence the quantity and quality of information } \\
\text { about the sequestration project that is available } \\
\text { post-closure, therefore helping to determine } \\
\text { societal memory. The better the amount and } \\
\text { quality of information available, the lower the } \\
\text { possibility of inadvertent intrusion. }\end{array}$ & $\begin{array}{l}\text { Quintessa } \\
\text { original FEP }\end{array}$ & $\begin{array}{l}\text { Unlikely to be an } \\
\text { issue. }\end{array}$ & $\begin{array}{l}\text { Data management } \\
\text { working group } \\
\text { established. }\end{array}$ & & 2 & 2 & 4 & Data management. & Data management. \\
\hline 97 & 2.1.07.00. & $\begin{array}{l}\text { Pre-closure } \\
\text { monitoring of } \\
\text { storage }\end{array}$ & $\begin{array}{l}\text { Processes related to any monitoring } \\
\text { undertaken during the operational and } \\
\text { closure phase. The extent and requirement } \\
\text { for such monitoring activities may be } \\
\text { determined by issues such as storage } \\
\text { concept, geological setting, regulations, or } \\
\text { public pressure. } \\
\text { A number of monitoring techniques exist } \\
\text { including seismic data, electrical resistance, } \\
\text { soil gas and isotopic characteristics. }\end{array}$ & $\begin{array}{l}\text { Monitoring during the operational phase } \\
\text { contributes towards the amount and quality of } \\
\text { information initially available after closure } \\
\text { concerning the behavior and distribution of } \\
\text { sequestered CO2. }\end{array}$ & $\begin{array}{l}\text { Quintessa } \\
\text { original FEP }\end{array}$ & $\begin{array}{l}\text { Unlikely to be an } \\
\text { issue. }\end{array}$ & $\begin{array}{l}\text { Monitoring working } \\
\text { group established to } \\
\text { prepare and } \\
\text { implement MVA plan. }\end{array}$ & & 2 & 2 & 4 & $\begin{array}{l}\text { Preparation and } \\
\text { implementation of } \\
\text { MVA plan. }\end{array}$ & $\begin{array}{l}\text { Preparation and } \\
\text { implementation of } \\
\text { MVA plan. }\end{array}$ \\
\hline 98 & 2.1.08.00. & Quality control & $\begin{array}{l}\begin{array}{l}\text { Features related to quality control } \\
\text { procedures and tests during the design, and } \\
\text { operation of the storage system. }\end{array} \\
\text { It could be expected that a range of quality } \\
\text { control measures would be applied during } \\
\text { ooperation of the storage system and supply } \\
\text { of } \mathrm{CO} \text { to be sequestered. There may be } \\
\text { specific regulations governing quality control } \\
\text { procedures, objectives and criteria. }\end{array}$ & $\begin{array}{l}\text { The degree of quality control during the design, } \\
\text { construction, operation and decommissioning of } \\
\text { a sequestration system can affect the post- } \\
\text { closure performance by influencing the integrity } \\
\text { of the engineered parts of the system (borehole } \\
\text { seals, for example) and by influencing the } \\
\text { quantity, quality and accuracy of records. }\end{array}$ & $\begin{array}{l}\text { Quintessa } \\
\text { original FEP }\end{array}$ & $\begin{array}{l}\text { Unlikely to be an } \\
\text { issue. }\end{array}$ & $\begin{array}{l}\text { Risk management } \\
\text { working group } \\
\text { established }\end{array}$ & & 2 & 2 & 4 & $\begin{array}{l}\text { Risk management } \\
\text { overseeing quality } \\
\text { control. }\end{array}$ & $\begin{array}{l}\text { Risk management } \\
\text { overseeing quality } \\
\text { control. }\end{array}$ \\
\hline 99 & 2.1.09.00. & $\begin{array}{c}\text { Accidents and } \\
\text { unplanned events }\end{array}$ & 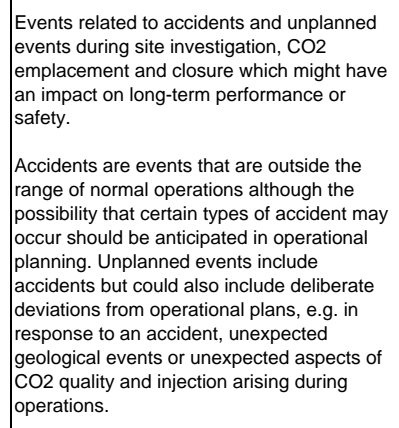 & $\begin{array}{l}\text { Accidents and unplanned events may affect the } \\
\text { post-closure performance of the sequestration } \\
\text { system. One example may be the incomplete } \\
\text { sealing of an injection borehole that may } \\
\text { subsequently provide a pathway for CO2 } \\
\text { migration. }\end{array}$ & 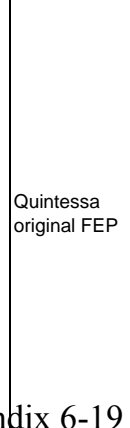 & Possible issue. & $\begin{array}{l}\text { Risk management } \\
\text { working group } \\
\text { established }\end{array}$ & & 3 & 4 & 12 & \begin{tabular}{|l|} 
Implement safety \\
training and \\
standard \\
procedures. Analyze \\
project changes. \\
Document response \\
to accidents and \\
unplanned events.
\end{tabular} & $\begin{array}{l}\text { Implement safety } \\
\text { training and standard } \\
\text { procedures. Analyze } \\
\text { project changes. } \\
\text { Document response to } \\
\text { accidents and } \\
\text { unplanned events. }\end{array}$ \\
\hline
\end{tabular}

Quintessa Original FEP: Taken from Quintessa's on-line CO2 FEP database, which is freely accessible at: http://www.quintessa.org/co2fepdb/ 


\begin{tabular}{|c|c|c|c|c|c|c|c|c|c|c|c|c|c|}
\hline \multicolumn{6}{|c|}{ CO2 Geologic Sequestration Risks for the IMCCS Project } & \multicolumn{3}{|c|}{ Project Specific Information } & \multicolumn{3}{|c|}{ Risk Ranking } & \multicolumn{2}{|c|}{ Prevention and Mitigation } \\
\hline Line \# & Index No. & Risk Area & Description & Relevance & $\begin{array}{l}\text { Qunitessa } \\
\text { FEP } \\
\text { Category }\end{array}$ & $\begin{array}{l}\text { Individual } \\
\text { Comments }\end{array}$ & $\begin{array}{c}\text { IMccs Project } \\
\text { Specific Information }\end{array}$ & \begin{tabular}{|c} 
IMccs Project \\
Information Gaps \\
or Uncertainties
\end{tabular} & 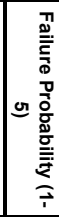 & 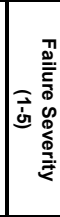 & 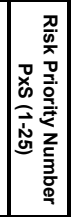 & $\begin{array}{l}\text { Risk Prevention } \\
\text { Steps (Actions } \\
\text { taken to reduce } \\
\text { risk probability) }\end{array}$ & $\begin{array}{l}\text { Risk Mitigation } \\
\text { Steps (Actions taken } \\
\text { to reduce risk } \\
\text { severity) }\end{array}$ \\
\hline 100 & 2.1.1.10.00. & Over pressuring & 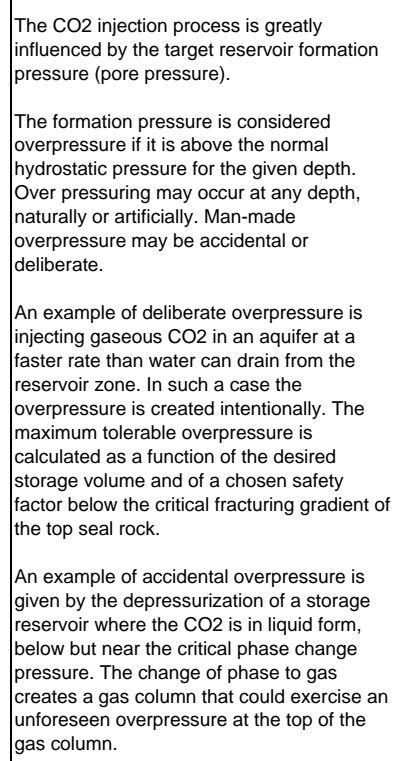 & \begin{tabular}{|l} 
Deliberate or accidental over pressuring during \\
the operational phase will affect the initial \\
geossphere conditions for a post-closure \\
assessment. It has the potential to cause \\
fractures in the sealing formation and hence \\
provide migration pathways for the sequestered \\
cO2.
\end{tabular} & $\begin{array}{l}\text { Quintessa } \\
\text { original FEP }\end{array}$ & $\begin{array}{l}\text { Possible issue } \\
\text { with Bartlesville } \\
\text { Sandstone. }\end{array}$ & \begin{tabular}{|l} 
Bartlesville Sandstone \\
integrity has been \\
demonstrated up to \\
1700 psig with water \\
injection without \\
problems. Maintain \\
injection pressure \\
below $80 \%$ of fracture \\
pressure. \\
Can't overpressure the \\
Arbuckle formation.
\end{tabular} & & 3 & 4 & 12 & \begin{tabular}{|l|} 
Determine fracture \\
pressure. Monitor \\
injection pressure. \\
Maintain injection \\
pressure below $80 \%$ \\
of fracture pressure. \\
Alarm system if \\
injection pressure \\
exceeds $80 \%$ of \\
fracture pressure.
\end{tabular} & $\begin{array}{l}\text { Develop procedures } \\
\text { for handling an over } \\
\text { pressuring situation. } \\
\text { Operator training. }\end{array}$ \\
\hline 101 & 2.1.1.10.01. & $\begin{array}{l}\text { Deliberate over } \\
\text { pressuring }\end{array}$ & $\begin{array}{l}\text { An example of deliberate overpressure is } \\
\text { injecting gaseous CO2 in an aquifer at a } \\
\text { faster rate than water can drain from the } \\
\text { reservoir zone. In such a case the } \\
\text { overpressure is created intentionally. The } \\
\text { maximum tolerable overpressure is } \\
\text { calculated as a function of the desired } \\
\text { storage volume and of a chosen safety } \\
\text { factor below the critical fracturing gradient of } \\
\text { the top seal rock. }\end{array}$ & $\begin{array}{l}\text { Induced fractures in the caprock can be created } \\
\text { by over pressuring the reservoir. Fractures could } \\
\text { be sealed in time by precipitation of newly formed } \\
\text { minerals, but could also be re-opened as a } \\
\text { consequence of new changes in stresses during } \\
\text { storage of } \mathrm{CO} 2 \text {. }\end{array}$ & $\begin{array}{l}\text { Expansion of } \\
\text { Q FEP }\end{array}$ & $\begin{array}{l}\text { Possible issue } \\
\text { with Bartlesville } \\
\text { Sandstone. }\end{array}$ & \begin{tabular}{|l|} 
Bartlesville Sandstone \\
integrity has been \\
demonstrated up to \\
1700 psig with water \\
flood without \\
problems. Maintain \\
injection pressure \\
below $80 \%$ of fracture \\
pressure. \\
Can't overpressure the \\
Arbuckle formation.
\end{tabular} & & 3 & 4 & 12 & \begin{tabular}{l|} 
Determine fracture \\
pressure. Monitor \\
injection pressure. \\
Maintain injection \\
pressure below $80 \%$ \\
of fracture pressure. \\
Alarm system if \\
injection pressure \\
exceeds $80 \%$ of \\
fracture pressure.
\end{tabular} & $\begin{array}{l}\text { Develop procedures } \\
\text { for handling an over } \\
\text { pressuring situation. } \\
\text { Operator training. }\end{array}$ \\
\hline 102 & 2.1.10.02. & $\begin{array}{l}\text { Accidental over } \\
\text { pressuring due to } \\
\text { CO2 phase change }\end{array}$ & $\begin{array}{l}\text { An example of accidental overpressure is } \\
\text { given by the depressurization of a storage } \\
\text { reservoir where the CO2 is in liquid form, } \\
\text { below but near the critical phase change } \\
\text { pressure. The change of phase to gas } \\
\text { creates a gas column that could exercise an } \\
\text { unforeseen overpressure at the top of the } \\
\text { gas column. }\end{array}$ & $\begin{array}{l}\text { Fractures in the caprock can be created by over } \\
\text { pressuring the reservoir. Fractures could be } \\
\text { sealed in time by precipitation of newly formed } \\
\text { minerals, but could also be re-opened as a } \\
\text { consequence of new changes in stresses during } \\
\text { storage of CO2. }\end{array}$ & $\begin{array}{l}\text { Expansion of } \\
\text { Q FEP }\end{array}$ & $\begin{array}{l}\text { Thrall has already } \\
\text { seen this in water } \\
\text { flood and survived } \\
\text { quite well. } \\
\text { Geneseo-Edwards } \\
\text { will not exceed } \\
\text { bottom hole } \\
\text { pressure. }\end{array}$ & \begin{tabular}{|l|} 
Bartlesville Sandstone \\
integrity has been \\
demonstrated up to \\
1700 psig with water \\
flood without \\
problems. Maintain \\
injection pressure \\
below $80 \%$ of fracture \\
pressure.
\end{tabular} & & 3 & 4 & 12 & \begin{tabular}{|l|} 
Bartlesville \\
Sandstone integrity \\
has been \\
demonstrated up to \\
1700 psig with water \\
flood without \\
problems. Maintain \\
injection pressure \\
below $80 \%$ of \\
fracture pressure. \\
\end{tabular} & $\begin{array}{l}\text { Bartlesville Sandstone } \\
\text { integrity has been } \\
\text { demonstrated up to } \\
1700 \text { psig with water } \\
\text { flood without } \\
\text { problems. Maintain } \\
\text { injection pressure } \\
\text { below } 80 \% \text { of fracture } \\
\text { pressure. }\end{array}$ \\
\hline
\end{tabular}

Appendix 6-20

Quintessa Original FEP: Taken from Quintessa's on-line CO2 FEP database, which is freely accessible at: http://www.quintessa.org/co2fepdb/ 


\begin{tabular}{|c|c|c|c|c|c|c|c|c|c|c|c|c|c|}
\hline \multicolumn{6}{|c|}{ CO2 Geologic Sequestration Risks for the IMCCS Project } & \multicolumn{3}{|c|}{ Project Specific Information } & \multicolumn{3}{|c|}{ Risk Ranking } & \multicolumn{2}{|c|}{ Prevention and Mitigation } \\
\hline Line \# & Index No. & Risk Area & Description & Relevance & $\begin{array}{l}\text { Qunitessa } \\
\text { FEP } \\
\text { Category }\end{array}$ & $\begin{array}{l}\text { Individual } \\
\text { Comments }\end{array}$ & $\begin{array}{c}\text { IMCCS Project } \\
\text { Specific Information }\end{array}$ & \begin{tabular}{|c|} 
ImCcCs Project \\
Information Gaps \\
or Uncertainties
\end{tabular} & 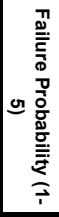 & 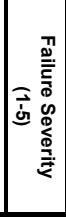 & 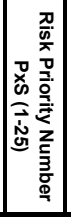 & $\begin{array}{l}\text { Risk Prevention } \\
\text { Steps (Actions } \\
\text { taken to reduce } \\
\text { risk probability) }\end{array}$ & $\begin{array}{l}\text { Risk Mitigation } \\
\text { Steps (Actions taken } \\
\text { to reduce risk } \\
\text { severity) }\end{array}$ \\
\hline 103 & 2.1.10.03. & $\begin{array}{c}\text { Regional-scale over } \\
\text { pressuring }\end{array}$ & & & \begin{tabular}{|l} 
Additional \\
[new] FEP
\end{tabular} & $\begin{array}{l}\text { Very unlikely to be } \\
\text { an issue. }\end{array}$ & $\begin{array}{l}\text { Can't overpressure the } \\
\text { Arbuckle. Bartlesville } \\
\text { Sandstone is locally } \\
\text { isolated. }\end{array}$ & & 1 & 4 & 4 & NA & NA \\
\hline 104 & 2.1.10.04. & $\begin{array}{l}\text { Local-scale over } \\
\text { pressuring }\end{array}$ & & & \begin{tabular}{|l} 
Additional \\
[new] FEP
\end{tabular} & \begin{tabular}{|l|} 
Can't \\
overpressure the \\
Arbuckle
\end{tabular} & \begin{tabular}{|l|} 
Bartlesville Sandstone \\
integrity has been \\
demonstrated up to \\
1700 psig with water \\
flood without \\
problems. Maintain \\
injection pressure \\
below $80 \%$ of fracture \\
pressure.
\end{tabular} & \begin{tabular}{|l} 
Need more detail \\
on the Thrall
\end{tabular} & 2 & 4 & 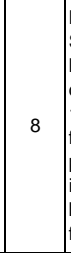 & \begin{tabular}{|l|} 
Bartlesville \\
Sandstone integrity \\
has been \\
demonstrated up to \\
1700 psig with water \\
flood without \\
problems. Maintain \\
injection pressure \\
below $80 \%$ of \\
fracture pressure. \\
\end{tabular} & $\begin{array}{l}\text { Bartlesville Sandstone } \\
\text { integrity has been } \\
\text { demonstrated up to } \\
1700 \text { psig with water } \\
\text { flood without } \\
\text { problems. Maintain } \\
\text { injection pressure } \\
\text { below } 80 \% \text { of fracture } \\
\text { pressure. }\end{array}$ \\
\hline 105 & 2.1.10.05. & $\begin{array}{l}\text { Caprock failure due } \\
\text { to over pressuring }\end{array}$ & $\begin{array}{l}\text { Over pressuring can generate new fractures } \\
\text { or faults in the caprock. Catastrophic failure } \\
\text { (bursting) of the caprock. }\end{array}$ & $\begin{array}{l}\text { CO2 leakage through induced fractures or faults } \\
\text { in caprock. }\end{array}$ & \begin{tabular}{|l} 
Additional \\
[new] FEP
\end{tabular} & Possible issue. & $\begin{array}{l}\text { Bartlesville Sandstone } \\
\text { integrity has been } \\
\text { demonstrated up to } \\
1700 \text { psig with water } \\
\text { flood without } \\
\text { problems. Maintain } \\
\text { injection pressure } \\
\text { below } 80 \% \text { of fracture } \\
\text { pressure. }\end{array}$ & & 3 & 4 & 12 & \begin{tabular}{|l|} 
Bartlesville \\
Sandstone integrity \\
has been \\
demonstrated up to \\
1700 psig with water \\
flood without \\
problems. Maintain \\
injection pressure \\
below $80 \%$ of \\
fracture pressure.
\end{tabular} & $\begin{array}{l}\text { Bartlesville Sandstone } \\
\text { integrity has been } \\
\text { demonstrated up to } \\
1700 \text { psig with water } \\
\text { flood without } \\
\text { problems. Maintain } \\
\text { injection pressure } \\
\text { below } 80 \% \text { of fracture } \\
\text { pressure. }\end{array}$ \\
\hline 106 & 2.1.10.06. & $\begin{array}{c}\text { Caprock failure due } \\
\text { to dilatant shear }\end{array}$ & $\begin{array}{l}\text { Significant fluctuations in reservoir pressure } \\
\text { could cause dilatant shear formation and } \\
\text { fracturing in the caprock. }\end{array}$ & & \begin{tabular}{|l} 
Additional \\
[new] FEP
\end{tabular} & \begin{tabular}{|l|} 
Unlikely to be an \\
issue at Geneseo- \\
Edwards. Could \\
be an issue in the \\
Thrall.
\end{tabular} & & $\begin{array}{l}\text { Not sure of the } \\
\text { physics - need to } \\
\text { document }\end{array}$ & 2 & 4 & 8 & \begin{tabular}{|l} 
Avoid large up-and- \\
down pressure \\
swings
\end{tabular} & $\begin{array}{l}\text { Monitor and control } \\
\text { injection pressure. }\end{array}$ \\
\hline 107 & 2.1.10.07. & $\begin{array}{c}\text { Reactivating } \\
\text { existing faults } \\
\text { and/or fractures in } \\
\text { caprock }\end{array}$ & $\begin{array}{l}\text { Over pressuring can reactivate existing faults } \\
\text { and/or fractures in the caprock. }\end{array}$ & $\begin{array}{l}\mathrm{CO} 2 \text { leakage through reactivated fault or fracture } \\
\text { in caprock. }\end{array}$ & \begin{tabular}{|l} 
Additional \\
[new] FEP
\end{tabular} & \begin{tabular}{|l|} 
Very unlikely to be \\
an issue.
\end{tabular} & \begin{tabular}{|l} 
No faults identified in \\
the Thrall area. Faults \\
in Geneseo-Edwards \\
area are down dip and \\
do not penetrate the \\
seal. In addition, the \\
Arbuckle can't be over \\
pressured.
\end{tabular} & $\begin{array}{l}\text { Confirm that all } \\
\text { faults have been } \\
\text { identified and } \\
\text { properly } \\
\text { characterized. }\end{array}$ & 1 & 4 & 4 & NA & NA \\
\hline 108 & 2.1.10.08. & $\begin{array}{l}\text { Low injection } \\
\text { pressure limit }\end{array}$ & $\begin{array}{l}\text { An artificiallly low injection pressure limit may } \\
\text { require driling additional injection wells, } \\
\text { resulting in the unintended consequence of } \\
\text { creating additional artificial penetrations of } \\
\text { the containment system. (CCP2009) }\end{array}$ & & \begin{tabular}{|l} 
Additional \\
[new] FEP
\end{tabular} & Possible issue. & \begin{tabular}{|l|} 
High CO2 injection \\
rate could lead to non- \\
uniform gravity stable \\
CO2 flooding (coning) \\
in the Geneseo- \\
Edwards domes.
\end{tabular} & & 3 & 2 & 6 & \begin{tabular}{|l|} 
Install multiple CO2 \\
injection wells and/or \\
horizontal injection \\
wells.
\end{tabular} & $\begin{array}{l}\text { If coning occurs, } \\
\text { decrease CO2 } \\
\text { injection rate per well, } \\
\text { add new injection } \\
\text { wells and/or switch } \\
\text { from vertical to } \\
\text { horizontal injection } \\
\text { wells. }\end{array}$ \\
\hline 109 & 2.1.10.09. & $\begin{array}{c}\text { Increase in } \\
\text { pressure leading to } \\
\text { changes in pathway } \\
\text { migration }\end{array}$ & & & \begin{tabular}{|l} 
Additional \\
[new] FEP
\end{tabular} & $\begin{array}{l}\text { Thrall has already } \\
\text { seen this in water } \\
\text { flood and survived } \\
\text { quite well. } \\
\text { Geneseo-Edwards } \\
\text { will not exceed } \\
\text { bottom hole } \\
\text { pressure. }\end{array}$ & $\begin{array}{l}\text { Arbuckle in the Thrall } \\
\text { field is a slightly } \\
\text { dipping monocline. }\end{array}$ & & 3 & 3 & 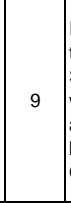 & \begin{tabular}{|l|} 
Increase pressure in \\
the Bartlesville \\
Sandstone using \\
water and identify \\
and eliminate leaks \\
before injecting \\
CO2.
\end{tabular} & $\begin{array}{l}\text { Monitor } \mathrm{CO} 2 \text { plume } \\
\text { and adjust CO2 } \\
\text { injection strategy if } \\
\text { necessary to control } \\
\text { CO2 migration. Could } \\
\text { include recovery of } \\
\text { CO2 and reinjection } \\
\text { elsewhere. }\end{array}$ \\
\hline
\end{tabular}

Appendix 6-21

Quintessa Original FEP: Taken from Quintessa's on-line CO2 FEP database, which is freely accessible at: http://www.quintessa.org/co2fepdb/ 


\begin{tabular}{|c|c|c|c|c|c|c|c|c|c|c|c|c|c|}
\hline \multicolumn{6}{|c|}{ CO2 Geologic Sequestration Risks for the IMCCS Project } & \multicolumn{3}{|c|}{ Project Specific Information } & \multicolumn{3}{|c|}{ Risk Ranking } & \multicolumn{2}{|c|}{ Prevention and Mitigation } \\
\hline Line \# & Index No. & Risk Area & Description & Relevance & $\begin{array}{l}\text { Qunitessa } \\
\text { FPP } \\
\text { Category }\end{array}$ & $\begin{array}{l}\text { Individual } \\
\text { Comments }\end{array}$ & $\begin{array}{c}\text { IMCCS Project } \\
\text { Specific Information }\end{array}$ & \begin{tabular}{|c|} 
IMCCS Project \\
Information Gaps \\
or Uncertainties
\end{tabular} & 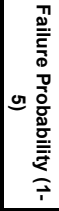 & 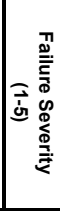 & 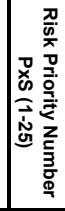 & $\begin{array}{l}\text { Risk Prevention } \\
\text { Steps (Actions } \\
\text { taken to reduce } \\
\text { risk probability) }\end{array}$ & $\begin{array}{l}\text { Risk Mitigation } \\
\text { Steps (Actions taken } \\
\text { to reduce risk } \\
\text { severity) }\end{array}$ \\
\hline 110 & 2.2.00.00. & Post-closure & $\begin{array}{l}\text { Details of post-closure activities associated } \\
\text { with sequestration. }\end{array}$ & $\begin{array}{l}\text { Human activities post-closure may affect the } \\
\text { likelihood of specific impacts being incurred. }\end{array}$ & $\begin{array}{l}\text { Quintessa } \\
\text { original FEP }\end{array}$ & $\begin{array}{l}\text { Very unlikely to be } \\
\text { an issue. }\end{array}$ & $\begin{array}{l}\text { Injection areas are } \\
\text { sparsely populated. }\end{array}$ & & 1 & 3 & 3 & $\begin{array}{l}\text { Clearly mark site } \\
\text { with warnings and } \\
\text { register site as } \mathrm{CO} 2 \\
\text { storage site with the } \\
\text { State. }\end{array}$ & $\begin{array}{l}\text { Routine site inspection } \\
\text { and/or monitoring. }\end{array}$ \\
\hline 111 & 2.2.01.00. & $\begin{array}{l}\text { Post-closure } \\
\text { administrative } \\
\text { control }\end{array}$ & $\begin{array}{l}\text { Administrative control of the sequestration } \\
\text { site after closure of the project. } \\
\text { The administrative control of the post-closure } \\
\text { site may differ from that of the pre-closure } \\
\text { site with subsequent implications for the } \\
\text { resources available for administrative } \\
\text { control, the degree of access and availability } \\
\text { of information etc. }\end{array}$ & $\begin{array}{l}\text { There may be potential for loss of information in } \\
\text { any transfer of administrative control. A lack of } \\
\text { awareness about the details of a } \mathrm{CO} 2 \\
\text { sequestration project could result in inadvertent } \\
\text { disruption in the future. }\end{array}$ & $\begin{array}{l}\text { Quintessa } \\
\text { original FEP }\end{array}$ & \begin{tabular}{|l|} 
Unlikely to be an \\
issue.
\end{tabular} & $\begin{array}{l}\text { Data management } \\
\text { working group } \\
\text { established. }\end{array}$ & & 2 & 3 & 6 & $\begin{array}{l}\text { Implement data } \\
\text { management. Use } \\
\text { multiple back up } \\
\text { sites for data } \\
\text { storage. Clearly } \\
\text { mark site with } \\
\text { warnings and } \\
\text { register site as } \mathrm{CO} 2 \\
\text { storage site with the } \\
\text { State. } \\
\end{array}$ & $\begin{array}{l}\text { Data management. } \\
\text { Routine site inspection } \\
\text { and/or monitoring. } \\
\end{array}$ \\
\hline 112 & 2.2.02.00. & $\begin{array}{l}\text { Post-closure } \\
\text { monitoring of } \\
\text { storage }\end{array}$ & $\begin{array}{l}\text { FEPs related to any monitoring undertaken } \\
\text { during the post-closure phase. This includes } \\
\text { monitoring of parameters related to the long- } \\
\text { term safety and performance. The extent } \\
\text { and requirement for such monitoring } \\
\text { activities may be determined by issues such } \\
\text { as storage concept, geological setting, } \\
\text { regulations, or public pressure. } \\
\text { A number of monitoring techniques exist } \\
\text { including seismic data, electrical resistance, } \\
\text { soil gas and isotopic characteristics. }\end{array}$ & $\begin{array}{l}\text { Post-closure monitoring will provide information } \\
\text { regarding the performance of the sequestration } \\
\text { project and may trigger post-closure remedial } \\
\text { actions, if necessary. }\end{array}$ & $\begin{array}{l}\text { Quintessa } \\
\text { original FEP }\end{array}$ & $\begin{array}{l}\text { Unlikely to be an } \\
\text { issue. }\end{array}$ & & & 2 & 1 & 2 & $\begin{array}{l}\text { Clearly mark site } \\
\text { with warnings and } \\
\text { register site as } \mathrm{CO} 2 \\
\text { storage site with the } \\
\text { State. }\end{array}$ & $\begin{array}{l}\text { Routine site inspection } \\
\text { and/or monitoring. } \\
\text { Prepare procedures } \\
\text { for potential remedial } \\
\text { action. }\end{array}$ \\
\hline 113 & 2.2.03.00. & $\begin{array}{l}\text { Records and } \\
\text { markers (long-term } \\
\text { knowledge } \\
\text { retention) }\end{array}$ & $\begin{array}{l}\text { Features related to the retention of records } \\
\text { of the content and nature of a CO2 storage } \\
\text { site atter closure and also the placing of } \\
\text { permanent markers at or near the site. }\end{array}$ & $\begin{array}{l}\text { It is expected that records will be kept to allow } \\
\text { future generations to recall the existence and } \\
\text { nature of the storage reservoir/aquifer following } \\
\text { closure. }\end{array}$ & $\begin{array}{l}\text { Quintessa } \\
\text { FEP with } \\
\text { additional text }\end{array}$ & $\begin{array}{l}\text { Unlikely to be an } \\
\text { issue. }\end{array}$ & & & 2 & 1 & 2 & $\begin{array}{l}\text { Clearly mark site } \\
\text { with warnings and } \\
\text { register site as } \mathrm{CO} 2 \\
\text { storage site with the } \\
\text { State. }\end{array}$ & $\begin{array}{l}\text { Routine site inspection } \\
\text { and/or monitoring. } \\
\text { Prepare procedures } \\
\text { for potential remedial } \\
\text { action. }\end{array}$ \\
\hline 114 & 2.2.04.00. & Reversibility & $\begin{array}{l}\text { The degree to which the sequestered } \mathrm{CO} 2 \\
\text { could be deliberately removed, if required. } \\
\text { Either as an extreme remedial action, } \\
\text { because the } \mathrm{CO} 2 \text { is required as a resource, } \\
\text { or because its presence is impeding access } \\
\text { to other geological resources. }\end{array}$ & $\begin{array}{l}\text { The degree to which reversibility is considered in } \\
\text { the design of a sequestration system may } \\
\text { influence its long-term performance, by leaving } \\
\text { viable boreholes in-situ after closure, for } \\
\text { example. }\end{array}$ & $\begin{array}{l}\text { Quintessa } \\
\text { original FEP }\end{array}$ & \begin{tabular}{|l|} 
Some $\mathrm{CO} 2$ could \\
be recovered from \\
the Geneseo- \\
Edwards domes \\
and/or the \\
Bartlesville \\
Sandstone. \\
\end{tabular} & $\begin{array}{l}\text { It is likely that } \mathrm{CO} 2 \\
\text { would be removed for } \\
\text { the Bartlesville } \\
\text { Sandstone in order to } \\
\text { achieve pressure } \\
\text { equilibrium faster. }\end{array}$ & & 2 & 3 & 6 & $\begin{array}{l}\text { Maintain good } \\
\text { records and models } \\
\text { on CO2 injection. } \\
\text { Use appropriate } \\
\text { materials of } \\
\text { construction. }\end{array}$ & $\begin{array}{l}\text { Prepare procedures } \\
\text { for removal of } \mathrm{CO} 2 .\end{array}$ \\
\hline 115 & 2.2.05.00. & Remedial actions & $\begin{array}{l}\text { Events and processes related to actions that } \\
\text { might be taken following closure of a storage } \\
\text { site to remedy yroblems that, either, are } \\
\text { associated with its not performing to the } \\
\text { standards required, result from disruption by } \\
\text { some natural event or process, or result from } \\
\text { inadvertent or deliberate damage by human } \\
\text { actions. }\end{array}$ & $\begin{array}{l}\text { The aim of possible future remedial actions will } \\
\text { be to modify the performance and safety of the } \\
\text { CO2 sequestration system. }\end{array}$ & $\begin{array}{l}\text { Quintessa } \\
\text { original FEP }\end{array}$ & Possible issue. & & & 3 & 3 & 9 & $\begin{array}{l}\text { Maintain good } \\
\text { records and models } \\
\text { on CO2 injection. } \\
\text { Use appropriate } \\
\text { materials of } \\
\text { construction. }\end{array}$ & \begin{tabular}{|l} 
Prepare procedures \\
for remediating $\mathrm{CO} 2$ \\
leakage. Monitor for \\
CO2 leakage, \\
Remediate any $\mathrm{CO} 2$ \\
leakage quickly.
\end{tabular} \\
\hline
\end{tabular}




\begin{tabular}{|c|c|c|c|c|c|c|c|c|c|c|c|c|c|}
\hline \multicolumn{6}{|c|}{ CO2 Geologic Sequestration Risks for the IMCCS Project } & \multicolumn{3}{|c|}{ Project Specific Information } & \multicolumn{3}{|c|}{ Risk Ranking } & \multicolumn{2}{|c|}{ Prevention and Mitigation } \\
\hline Line \# & \# Index No. & Risk Area & Description & Relevance & $\begin{array}{l}\text { Qunitessa } \\
\text { FEP } \\
\text { Category }\end{array}$ & $\begin{array}{l}\text { Individual } \\
\text { Comments }\end{array}$ & $\begin{array}{c}\text { IMccs Project } \\
\text { Specific Information }\end{array}$ & \begin{tabular}{|c|} 
IMccs Project \\
Information Gaps \\
or Uncertainties
\end{tabular} & 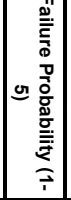 & 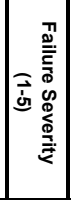 & 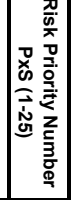 & $\begin{array}{l}\text { Risk Prevention } \\
\text { Steps (Actions } \\
\text { taken to reduce } \\
\text { risk probability) }\end{array}$ & $\begin{array}{l}\text { Risk Mitigation } \\
\text { Steps (Actions taken } \\
\text { to reduce risk } \\
\text { severity) }\end{array}$ \\
\hline 116 & 3.0.00.00 & $\begin{array}{c}\text { CO2 Properties, } \\
\text { Interactions \& } \\
\text { Transport }\end{array}$ & $\begin{array}{l}\text { This category of FEPs is concerned with } \\
\text { those Features, Events and Processes that } \\
\text { are relevant to the fate of the sequestered } \\
\text { fluid. Carbon dioxides properties can vary } \\
\text { greatly between conditions at depth and near } \\
\text { surface, and a wide range of physical and } \\
\text { chemicar reactions can be important. The } \\
\text { category is divided into three classes for the } \\
\text { properties, interactions and transport of } \\
\text { carbon dioxide. }\end{array}$ & & $\begin{array}{l}\text { Quintessa } \\
\text { original FEP }\end{array}$ & & & & NA & NA & NA & NA & NA \\
\hline 117 & 3.1.00.00. & CO2 properties & $\begin{array}{l}\text { The fundamental physical and chemical } \\
\text { properties of carbon dioxide, taking into } \\
\text { account impurities. }\end{array}$ & $\begin{array}{l}\text { Carbon dioxides properties can vary greatly with } \\
\text { pressure, temperature and impurities, and an } \\
\text { understanding of these properties is essential } \\
\text { before the fate of sequestered fluid can be } \\
\text { assessed. }\end{array}$ & $\begin{array}{l}\text { Quintessa } \\
\text { original FEP }\end{array}$ & & & & NA & NA & $\mathrm{NA}$ & NA & NA \\
\hline 118 & 3.1.00.01. & $\begin{array}{l}\text { CO2 properties } \\
\text { changed by } \\
\text { pressure }\end{array}$ & & & $\begin{array}{l}\text { Expansion of } \\
\text { Q FEP }\end{array}$ & $\begin{array}{l}\text { Unlikely to be an } \\
\text { issue. }\end{array}$ & $\begin{array}{l}\text { Potential for } \mathrm{CO} 2 \\
\text { phase change in the } \\
\text { Thrall-Aagard field. } \\
\text { EOR and DSA. }\end{array}$ & & 2 & 3 & 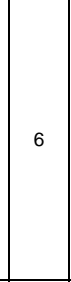 & $\begin{array}{l}\text { Characterize } \\
\text { reservoir pressure } \\
\text { and include in } \\
\text { modeling. } \\
\text { Pressurize the } \\
\text { Bartlesville } \\
\text { Sandstone above } \\
1200 \text { psig with water } \\
\text { before injecting } \\
\text { CO2. }\end{array}$ & $\begin{array}{l}\text { Monitor CO2 plume } \\
\text { and adjust CO2 } \\
\text { injection strategy if } \\
\text { necessary to control } \\
\text { CO2 migration. Could } \\
\text { include recovery of } \\
\text { CO2 and reinjection } \\
\text { elsewhere. }\end{array}$ \\
\hline 119 & 3.1.00.02. & $\begin{array}{l}\text { CO2 properties } \\
\text { changed by } \\
\text { temperature }\end{array}$ & & & $\begin{array}{c}\text { Expansion of } \\
\text { Q FEP }\end{array}$ & $\begin{array}{l}\text { Very unlikely to be } \\
\text { an issue. }\end{array}$ & $\begin{array}{l}\text { Phase change from } \\
\text { supercritical to gas } \\
\text { could lower CO2 } \\
\text { temperature in the } \\
\text { Thrall EOR and DSA. }\end{array}$ & & 1 & 2 & 2 & $\begin{array}{l}\text { Characterize } \\
\text { reservoir } \\
\text { temperature and } \\
\text { include in model. }\end{array}$ & $\begin{array}{l}\text { Monitor BHT. Identify } \\
\text { any irregularities. } \\
\text { Determine root cause. } \\
\text { Modify injection } \\
\text { strategy if necessary. }\end{array}$ \\
\hline 120 & 3.1.00.03. & $\begin{array}{l}\text { CO2 properties } \\
\text { changed by } \\
\text { impurities }\end{array}$ & & & $\begin{array}{c}\text { Expansion of } \\
\text { Q FEP }\end{array}$ & $\begin{array}{l}\text { Unlikely to be an } \\
\text { issue. }\end{array}$ & \begin{tabular}{l|} 
KE CO2 may have O2 \\
and N2 that could \\
impact EOR operation. \\
Recycled CO2 may \\
pickup H2S in the \\
Arbuckle.
\end{tabular} & & 2 & 3 & 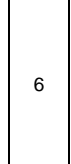 & $\begin{array}{l}\text { Characterize CO2 } \\
\text { composition and } \\
\text { include in modeling. } \\
\text { Monitor CO2 } \\
\text { composition and } \\
\text { maintain within spec. }\end{array}$ & $\begin{array}{l}\text { Vent off-spec } \mathrm{CO} 2 \text { or } \\
\text { inject off-spec } \mathrm{CO} 2 \\
\text { into backup DSA. }\end{array}$ \\
\hline 121 & 3.1 .00 .04 & $\begin{array}{l}\text { CO2 properties } \\
\text { changed by } \\
\text { geochemistry }\end{array}$ & $\begin{array}{l}\text { CO2 properties can change by encountering } \\
\text { different reservoir geochemistry, e.g. } \\
\text { migrating from quartz sand into calcite } \\
\text { cemented sand. }\end{array}$ & & $\begin{array}{l}\text { Additional } \\
\text { [new] FEP }\end{array}$ & $\begin{array}{l}\text { Unlikely to be an } \\
\text { issue. }\end{array}$ & $\begin{array}{l}\text { Arbuckle is a dolomite } \\
\text { and contains H2S. }\end{array}$ & & 2 & 3 & 6 & \begin{tabular}{|l|} 
Characterize \\
reservoir \\
geochemistry and \\
include in modeling.
\end{tabular} & $\begin{array}{l}\text { Take Arbuckle } \\
\text { geochemistry into } \\
\text { consideration in } \\
\text { modeling. }\end{array}$ \\
\hline 122 & 3.1.01.00. & $\begin{array}{c}\text { Physical properties } \\
\text { of } \mathrm{CO} 2\end{array}$ & $\begin{array}{l}\text { Physical properties of } \mathrm{CO} 2 \text { including density, } \\
\text { viscosity, interfacial tension and thermal } \\
\text { conductivity and their dependence on } \\
\text { pressure and temperature. }\end{array}$ & $\begin{array}{l}\text { The physical properties of } \mathrm{CO} 2 \text { determine the } \\
\text { way in which it will behave in the environment } \\
\text { once injected. }\end{array}$ & $\begin{array}{l}\text { Quintessa } \\
\text { original FEP }\end{array}$ & & & & NA & NA & $\mathrm{NA}$ & $\begin{array}{l}\text { Take CO2 physical } \\
\text { properties into } \\
\text { consideration in } \\
\text { modeling. }\end{array}$ & $\begin{array}{l}\text { Take CO2 physical } \\
\text { properties into } \\
\text { consideration in } \\
\text { modeling. }\end{array}$ \\
\hline 123 & 3.1.01.01. & $\mathrm{CO} 2$ density & & & $\begin{array}{l}\text { Expansion of } \\
\text { Q FEP }\end{array}$ & Possible issue. & $\begin{array}{l}\text { CO2 density will be } \\
\text { low due to low } \\
\text { injection pressures. }\end{array}$ & & 3 & 3 & 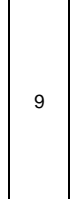 & $\begin{array}{l}\text { Increase pressure in } \\
\text { the Bartlesville } \\
\text { Sandstone using } \\
\text { water before } \\
\text { injecting CO2 for } \\
\text { EOR. Inject CO2 } \\
\text { deep in the Arbuckle } \\
\text { for DSA. }\end{array}$ & $\begin{array}{l}\text { Monitor CO2 plume } \\
\text { and adjust CO2 } \\
\text { injection strategy if } \\
\text { necessary to control } \\
\text { CO2 migration. Could } \\
\text { include recovery of } \\
\text { CO2 and reinjection } \\
\text { elsewhere. }\end{array}$ \\
\hline
\end{tabular}

Appendix 6-23

Quintessa Original FEP: Taken from Quintessa's on-line CO2 FEP database, which is freely accessible at: http://www.quintessa.org/co2fepdb/ 


\begin{tabular}{|c|c|c|c|c|c|c|c|c|c|c|c|c|c|}
\hline \multicolumn{6}{|c|}{ CO2 Geologic Sequestration Risks for the IMCCS Project } & \multicolumn{3}{|c|}{ Project Specific Information } & \multicolumn{3}{|c|}{ Risk Ranking } & \multicolumn{2}{|c|}{ Prevention and Mitigation } \\
\hline Line \# & Index No. & Risk Area & Description & Relevance & $\begin{array}{l}\text { Qunitessa } \\
\text { FEP } \\
\text { Category }\end{array}$ & $\begin{array}{l}\text { Individual } \\
\text { Comments }\end{array}$ & $\begin{array}{c}\text { IMCCS Project } \\
\text { Specific Information }\end{array}$ & $\begin{array}{c}\text { Imccs Project } \\
\text { Information Gaps } \\
\text { or Uncertainties }\end{array}$ & 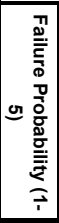 & 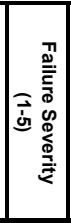 & 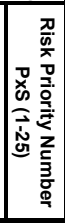 & $\begin{array}{l}\text { Risk Prevention } \\
\text { Steps (Actions } \\
\text { taken to reduce } \\
\text { risk probability) }\end{array}$ & $\begin{array}{l}\text { Risk Mitigation } \\
\text { Steps (Actions taken } \\
\text { to reduce risk } \\
\text { severity) }\end{array}$ \\
\hline 124 & 3.1.01.02. & CO2 viscosity & & & $\begin{array}{l}\text { Expansion of } \\
\text { Q FEP }\end{array}$ & $\begin{array}{l}\text { Unlikely to be an } \\
\text { issue. }\end{array}$ & & \begin{tabular}{|l|} 
Insufficient \\
information to \\
determine impact.
\end{tabular} & 2 & 3 & 6 & $\begin{array}{l}\text { Take CO2 viscosity } \\
\text { into consideration in } \\
\text { modeling. }\end{array}$ & $\begin{array}{l}\text { Take CO2 viscosity } \\
\text { into consideration in } \\
\text { modeling. }\end{array}$ \\
\hline 125 & 3.1.01.03. & $\begin{array}{l}\text { CO2 interfacial } \\
\text { tension }\end{array}$ & & & $\begin{array}{c}\text { Expansion of } \\
\text { Q FEP }\end{array}$ & $\begin{array}{l}\text { Unlikely to be an } \\
\text { issue. }\end{array}$ & & \begin{tabular}{|l|}
$\mid \begin{array}{l}\text { Insufficient } \\
\text { information to } \\
\text { determine impact. }\end{array}$ \\
\end{tabular} & 2 & 3 & 6 & \begin{tabular}{|l|} 
Take CO2 interfacial \\
tension into \\
consideration in \\
modeling.
\end{tabular} & $\begin{array}{l}\mid \begin{array}{l}\text { Take CO2 interfacial } \\
\text { tension into } \\
\text { consideration in } \\
\text { modeling. }\end{array} \\
\end{array}$ \\
\hline 126 & 3.1.01.04. & $\begin{array}{l}\mathrm{CO} 2 \text { thermal } \\
\text { conductivity }\end{array}$ & & & $\begin{array}{c}\text { Expansion of } \\
\text { Q FEP }\end{array}$ & $\begin{array}{l}\text { Very unlikely to be } \\
\text { an issue. }\end{array}$ & & \begin{tabular}{|l|} 
Insufficient \\
information to \\
determine impact.
\end{tabular} & 1 & 3 & 3 & \begin{tabular}{|l|} 
Take CO2 thermal \\
conductivity into \\
consideration in \\
modeling.
\end{tabular} & \begin{tabular}{|l|} 
Take CO2 thermal \\
conductivity into \\
consideration in \\
modeling.
\end{tabular} \\
\hline 127 & 3.1.02.00. & $\begin{array}{l}\text { CO2 phase } \\
\text { behavior }\end{array}$ & $\begin{array}{l}\text { FEPs related to the phase behavior (gas, } \\
\text { liquid, supercritical fluid) of } \mathrm{CO} 2 \text {. The } \\
\text { presence of contaminants in the injected } \\
\text { CO2 (e.g. N2) and gas and hydrocarbons } \\
\text { (e.g., in EOR and ECBM operations) in the } \\
\text { reservoir will affect the phase behavior and } \\
\text { partition of } \mathrm{CO} 2 \text { between different physical } \\
\text { states. } \\
\text { CO2 mixing with other fluids and gases, } \\
\text { leads to modified flow behavior that is not } \\
\text { fully understood (CCP 2009) }\end{array}$ & $\begin{array}{l}\mathrm{CO} 2 \text { phase behavior is a primary consideration } \\
\text { for modeling } \mathrm{CO} 2 \text { migration. }\end{array}$ & $\begin{array}{c}\text { Quintessa } \\
\text { FEP with } \\
\text { additional text }\end{array}$ & Possible issue. & $\begin{array}{l}\text { Potential for } \mathrm{CO} 2 \\
\text { phase change in the } \\
\text { Thrall-Aagard field. } \\
\text { EOR and DSA. }\end{array}$ & & 3 & 3 & 9 & $\begin{array}{l}\text { Take CO2 phase } \\
\text { change behavior into } \\
\text { consideration in } \\
\text { modeling. }\end{array}$ & $\begin{array}{l}\text { Take CO2 phase } \\
\text { change behavior into } \\
\text { consideration in } \\
\text { modeling. }\end{array}$ \\
\hline 128 & 3.1.03.00. & 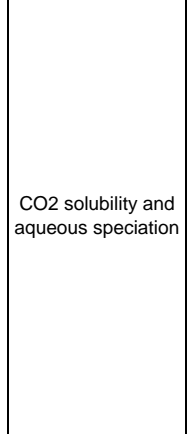 & 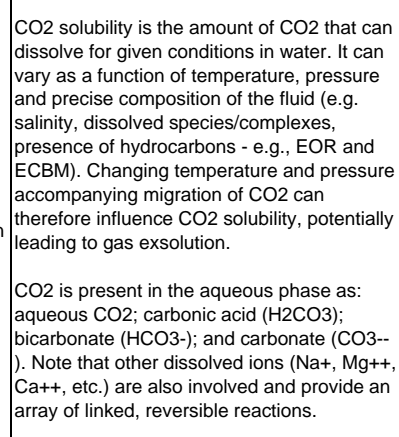 & $\begin{array}{l}\text { CO2 solubility has an impact on the chemical } \\
\text { composition of formation fluids, pressure } \\
\text { distribution, 'sorption' processes, mineral-fluid } \\
\text { reactions and the overall storage capacity of } \\
\text { CO2. Dissolved CO2 may migrate in a different } \\
\text { manner to 'free' supercritical CO2. CO2 solubility } \\
\text { in water and its partition between aqueous, } \\
\text { gaseous, and organic phases controls the } \\
\text { efficiency of diffusive transport and successive } \\
\text { mineral reactions. } \\
\text { The aqueous speciation of dissolved CO2 will } \\
\text { impact upon the mobility of sequestered CO2 } \\
\text { and associated contaminants. }\end{array}$ & $\begin{array}{l}\text { Quintessa } \\
\text { original FEP } \\
\end{array}$ & $\begin{array}{l}\text { Unlikely to be an } \\
\text { issue. }\end{array}$ & & & 2 & 3 & 6 & $\begin{array}{l}\text { Take } \mathrm{CO} 2 \text { solubility } \\
\text { and aqueous } \\
\text { speciation into } \\
\text { consideration in } \\
\text { modeling. }\end{array}$ & $\begin{array}{l}\text { Take CO2 solubility } \\
\text { and aqueous } \\
\text { speciation into } \\
\text { consideration in } \\
\text { modeling. }\end{array}$ \\
\hline 129 & 3.2.00.00. & CO2 interactions & $\begin{array}{l}\text { Potential interactions of carbon dioxide with } \\
\text { solid, liquid or gaseous media. }\end{array}$ & $\begin{array}{l}\text { A wide range of physical and chemical reactions } \\
\text { can be important, and an understanding of these } \\
\text { interactions is essential for the assessment of } \\
\text { potential impacts. }\end{array}$ & $\begin{array}{l}\text { Quintessa } \\
\text { original FEP }\end{array}$ & $\begin{array}{l}\text { Unlikely to be an } \\
\text { issue. }\end{array}$ & & & 2 & 3 & 6 & \begin{tabular}{|l|} 
Take $\mathrm{CO} 2$ physical \\
and chemical \\
interactions into \\
consideration in \\
modeling. \\
\end{tabular} & $\begin{array}{l}\text { Take CO2 physical } \\
\text { and chemical } \\
\text { interactions into } \\
\text { consideration in } \\
\text { modeling. }\end{array}$ \\
\hline
\end{tabular}




\begin{tabular}{|c|c|c|c|c|c|c|c|c|c|c|c|c|c|}
\hline \multicolumn{6}{|c|}{ CO2 Geologic Sequestration Risks for the IMCCS Project } & \multicolumn{3}{|c|}{ Project Specific Information } & \multicolumn{3}{|c|}{ Risk Ranking } & \multicolumn{2}{|c|}{ Prevention and Mitigation } \\
\hline Line \# & Index No. & Risk Area & Description & Relevance & $\begin{array}{l}\text { Qunitessa } \\
\text { FEP } \\
\text { Category }\end{array}$ & $\begin{array}{l}\text { Individual } \\
\text { Comments }\end{array}$ & $\begin{array}{c}\text { IMccs Project } \\
\text { Specific Information }\end{array}$ & $\begin{array}{c}\text { IMCCS Project } \\
\text { Information Gaps } \\
\text { or Uncertainties }\end{array}$ & 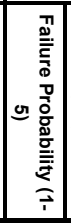 & 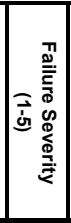 & 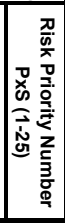 & $\begin{array}{l}\text { Risk Prevention } \\
\text { Steps (Actions } \\
\text { taken to reduce } \\
\text { risk probability) }\end{array}$ & $\begin{array}{l}\text { Risk Mitigation } \\
\text { Steps (Actions taken } \\
\text { to reduce risk } \\
\text { severity) }\end{array}$ \\
\hline 130 & 3.2.01.00. & $\begin{array}{l}\text { Effects of } \\
\text { pressurization of } \\
\text { reservoir on } \\
\text { caprock }\end{array}$ & $\begin{array}{l}\text { A storage reservoir will experience enhanced } \\
\text { pressure due to injection of CO2. This may } \\
\text { exceed original 'natural' pressurization due } \\
\text { to hydrocarbon emplacement } \\
\text { ECOR or } \\
\text { ECBM, for example), or clay mineral } \\
\text { transformations during diagenesis. }\end{array}$ & $\begin{array}{l}\text { 'Over pressuring' of the reservoir may involve } \\
\text { leakage of } \mathrm{CO} 2 \text { through the caprock due to } \\
\text { fracturing or enhanced interactions with } \mathrm{CO} 2 .\end{array}$ & \begin{tabular}{|l} 
Quintessa \\
original FEPP
\end{tabular} & $\begin{array}{l}\text { Unlikely to be an } \\
\text { issue. }\end{array}$ & & & 2 & 3 & 6 & \begin{tabular}{|l|} 
Determine fracture \\
pressure. Monitor \\
injection pressure. \\
Maintain injection \\
pressure below $80 \%$ \\
of fracture pressure. \\
Alarm system if \\
injection pressure \\
exceeds $80 \%$ of \\
fracture pressure.
\end{tabular} & $\begin{array}{l}\text { Develop procedures } \\
\text { for handling an over } \\
\text { pressuring situation. } \\
\text { Operator training. }\end{array}$ \\
\hline 131 & 3.2.02.00. & $\begin{array}{l}\text { Effects of } \\
\text { pressurization on } \\
\text { reservoir fluids }\end{array}$ & $\begin{array}{l}\text { Increased pressurization caused by the } \\
\text { injection of supercritical CO2 will affect the } \\
\text { behavior of other fluids within the reservoir. }\end{array}$ & $\begin{array}{l}\text { The potential importance of increased } \\
\text { pressurization to enhanced oil and gas recovery } \\
\text { indicates that it can modify the mobility of other } \\
\text { flluids in the receiving reservoir. }\end{array}$ & $\begin{array}{l}\text { Quintessa } \\
\text { original FEP }\end{array}$ & $\begin{array}{l}\text { Unlikely to be an } \\
\text { issue. }\end{array}$ & & & 2 & 3 & 6 & \begin{tabular}{|l|} 
Take effects of \\
pressurization on \\
reservoir fluids into \\
consideration in \\
modeling.
\end{tabular} & $\begin{array}{l}\text { Take effects of } \\
\text { pressurization on } \\
\text { reservoir fluids into } \\
\text { consideration in } \\
\text { modeling. }\end{array}$ \\
\hline 132 & 3.2.03.00. & $\begin{array}{l}\text { Interaction with } \\
\text { hydrocarbons }\end{array}$ & $\begin{array}{l}\text { In EOR or ECBM sites, for example, } \\
\text { hydrocarbons could be mobilized by CO2, by } \\
\text { miscible displacement for example, and } \\
\text { transported to the near-surface. This is of } \\
\text { particular relevance if enhanced oil recovery } \\
\text { is an addititional aim of the sequestration } \\
\text { concept. Kolak and Burruss (2003) } \\
\text { demonstrate that polyaromatic hydrocarbons } \\
\text { (PAHs) can be mobilized by sequestration in } \\
\text { deep coal beds. } \\
\text { Sequestered } \mathrm{CO} 2 \text { can also precipitate } \\
\text { asphaltenes from crude oil under certain } \\
\text { conditions of composition, temperature and } \\
\text { pressure. Such precipitation in the vicinity of } \\
\text { injection wells can lead to loss of injectivity } \\
\text { and even plugging of the wells. }\end{array}$ & $\begin{array}{l}\text { Mobilized hydrocarbons may migrate to the near- } \\
\text { surface environment. } \\
\text { Precipitated asphaltenes can clog pores, } \\
\text { reducing permeability and affecting fluid flow } \\
\text { paths. }\end{array}$ & $\begin{array}{l}\text { Quintessa } \\
\text { original FEP }\end{array}$ & $\begin{array}{l}\text { Unlikely to be an } \\
\text { issue. }\end{array}$ & & & 2 & 3 & 6 & $\begin{array}{l}\text { Take CO2 } \\
\text { interactions with } \\
\text { hydrocarbons into } \\
\text { consideration in } \\
\text { modeling. }\end{array}$ & $\begin{array}{l}\text { Take CO2 } \\
\text { interactions with } \\
\text { hydrocarbons into } \\
\text { consideration in } \\
\text { modeling. }\end{array}$ \\
\hline 133 & 3.2.03.01. & EOR attributes & $\begin{array}{l}\text { Technical screening guidelines for CO2 } \\
\text { flooding: recommended (current projects } \\
\text { range) } \\
\text { Crude oil gravity, }{ }^{\circ} \text { API: }>22(27 \text { to } 44) \\
\text { Crude oil viscosity, cp: }<10 \text { ( } 0.3 \text { to } 6) \\
\text { Crude oil composition: High percent of } \mathrm{C}_{5} \text { to } \\
\mathrm{C}_{12} \\
\text { Reservoir oil saturation: }>40(15 \text { to } 70) \\
\text { Type of formation: Relatively thin sandstone } \\
\text { or carbonate unless dipping } \\
\text { Permeability: Not critical if sufficient rates } \\
\text { can be applied } \\
\text { Depth/temperature: For miscible } \\
\text { displacement, depth must be great enough } \\
\text { to allow injection pressures greater than the } \\
\text { MMP, which increase with temperature and } \\
\text { for heavier oils (API 2007). }\end{array}$ & & \begin{tabular}{|} 
Additional \\
[new] FEP
\end{tabular} & $\begin{array}{l}\text { Thrall-Aagard and } \\
\text { Geneseo-Edwards } \\
\text { fields fall within } \\
\text { preferred EOR } \\
\text { attribute } \\
\text { guidelines }\end{array}$ & \begin{tabular}{|l|} 
Crude API : $37-38$ \\
Crude viscosity: $4-8.9$ \\
cp \\
Reservoir Oil \\
Saturation: $34-40 \%$
\end{tabular} & $\begin{array}{l}\text { Fully characterize } \\
\text { all fields for EOR } \\
\text { attributes. }\end{array}$ & 1 & 3 & 3 & $\begin{array}{l}\text { Fully characterize all } \\
\text { fields for EOR } \\
\text { attributes. }\end{array}$ & $\begin{array}{l}\text { Monitor and model } \\
\text { EOR performance. } \\
\text { Identify irregularities. } \\
\text { Determine root cause. } \\
\text { Adjust injection } \\
\text { strategy if necessary. }\end{array}$ \\
\hline
\end{tabular}

Appendix 6-25

Quintessa Original FEP: Taken from Quintessa's on-line CO2 FEP database, which is freely accessible at: http://www.quintessa.org/co2fepdb/ 


\begin{tabular}{|c|c|c|c|c|c|c|c|c|c|c|c|c|c|}
\hline \multicolumn{6}{|c|}{ CO2 Geologic Sequestration Risks for the IMCCS Project } & \multicolumn{3}{|c|}{ Project Specific Information } & \multicolumn{3}{|c|}{ Risk Ranking } & \multicolumn{2}{|c|}{ Prevention and Mitigation } \\
\hline Line \# & Index No. & Risk Area & Description & Relevance & $\begin{array}{c}\text { Qunitessa } \\
\text { FEP } \\
\text { Category }\end{array}$ & $\begin{array}{l}\text { Individual } \\
\text { Comments }\end{array}$ & $\begin{array}{c}\text { IMCCS Project } \\
\text { Specific Information }\end{array}$ & \begin{tabular}{|c|} 
IMccs Project \\
Information Gaps \\
or Uncertainties
\end{tabular} & 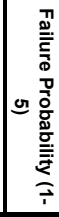 & 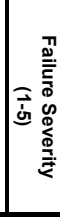 & 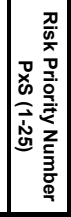 & $\begin{array}{c}\text { Risk Prevention } \\
\text { Steps (Actions } \\
\text { taken to reduce } \\
\text { risk probability) }\end{array}$ & $\begin{array}{c}\text { Risk Mitigation } \\
\text { Steps (Actions taker } \\
\text { to reduce risk } \\
\text { severity) }\end{array}$ \\
\hline 134 & 3.2.03.02. & $\begin{array}{l}\text { EOR reservoir } \\
\text { depth }\end{array}$ & 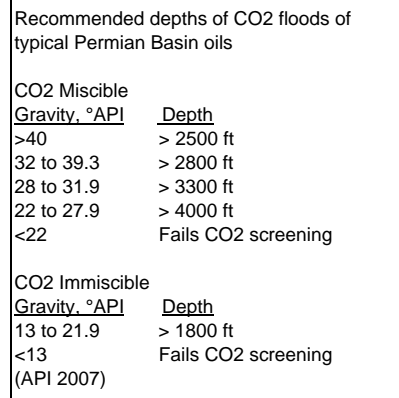 & & \begin{tabular}{|l} 
Additional \\
[new] FEP
\end{tabular} & \begin{tabular}{|l} 
Thrall is shallower \\
than 2800 ft but \\
water floods \\
injected at 1500 \\
psi and our MMP \\
is 1100 psi. We \\
plan to inject at \\
same pressure as \\
water floods.
\end{tabular} & G-E Depth: $3200 \mathrm{ft}$ & & 3 & 3 & 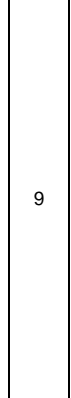 & \begin{tabular}{|l|} 
Increase pressure of \\
Bartlesville \\
Sandstone with \\
water prior to \\
injecting $\mathrm{CO} 2$ to \\
compensate for \\
shallow depth.
\end{tabular} & 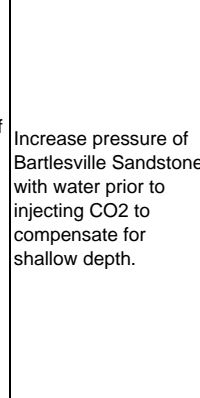 \\
\hline 135 & 3.2.03.03. & Oil recovery & $\begin{array}{l}\text { Typical oil recovery by recovery mechanism } \\
\text { as a function of Original Oil in Place (OOIP) } \\
\text { Primary: } 6 \text { to } 15 \% \text { OOIP } \\
\text { Secondary: } 6 \text { to } 30 \% \text { OOIP } \\
\text { Miscible CO2 EOR: } 8 \text { to } 20 \% \text { OOIP } \\
\text { Remaining: } 8 \text { to } 35 \% \text { OOIP } \\
\text { (API 2007) } \\
\text { Miscible CO2 EOR: } 7-23 \% \text { OOIP } \\
\text { (Immiscible CO2 EOR: } 9 \text { to } 19 \% \% \text { OOIP } \\
\text { (API 2007) }\end{array}$ & & $\begin{array}{l}\text { Additional } \\
\text { [new] FEP }\end{array}$ & $\begin{array}{l}\text { We expect oil } \\
\text { recovery to be in } \\
\text { the economic } \\
\text { range based on } \\
\text { engineering } \\
\text { studies }\end{array}$ & & $\begin{array}{l}\text { Confirm expected } \\
\text { oil recovery from } \\
\text { simulation } \\
\text { modeling. }\end{array}$ & 2 & 3 & 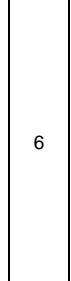 & \begin{tabular}{|l|} 
Model EOR \\
operation and try to \\
optimize oil recovery \\
through reservoir \\
engineering. \\
Operate close to or \\
above MMP if \\
possible,
\end{tabular} & $\begin{array}{l}\text { Adjust } \mathrm{CO} 2 \mathrm{EOR} \\
\text { strategy to improve oil } \\
\text { recovery if necessary. } \\
\text { such as injection } \\
\text { beneath and above G } \\
\text { E reservoir or } \\
\text { adjusting well spacing }\end{array}$ \\
\hline 136 & 3.2.03.04. & $\begin{array}{l}\mathrm{CO} 2 \text { demand per } \\
\text { unit EOR }\end{array}$ & $\begin{array}{l}\text { For field scale miscible } \mathrm{CO} 2 \mathrm{EOR} \text { floods net } \\
\text { (purchased) amount of } \mathrm{CO} 2 \text { required is } \\
\text { estimated to be between } 2.5 \text { to } 11 \mathrm{MCF} / \mathrm{STB} \\
\text { of incremental recovery with an average } \\
\text { value of } 6 \text { to } 7 \text { MCF/STB. For immiscible } \\
\text { flloods, actual incremental oil recovery has } \\
\text { been on the order of } 5 \text { to } 12 \text { MCF?STB (API } \\
\text { 2007). }\end{array}$ & & \begin{tabular}{|}
$\begin{array}{c}\text { Additional } \\
\text { [new] FEP }\end{array}$ \\
\end{tabular} & $\begin{array}{l}\text { Our engineering } \\
\text { studies suggest } \\
\text { that we will be in } \\
\text { the "normal" } \\
\text { range. }\end{array}$ & & $\begin{array}{l}\text { Confirm expected } \\
\text { CO2 demand per } \\
\text { unit of EOR from } \\
\text { simulation } \\
\text { modeling. }\end{array}$ & 2 & 3 & 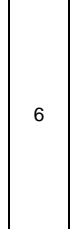 & \begin{tabular}{|l|} 
Model EOR \\
operation and try to \\
optimize CO2 \\
consumption per \\
barrel of oil through \\
reservoir \\
engineering. Monitor \\
CO2 consumption \\
per barrel of oil.
\end{tabular} & $\begin{array}{l}\text { Adjust CO2 EOR } \\
\text { strategy to improve oil } \\
\text { recovery if necessary. } \\
\text { such as injection } \\
\text { beneath and above G } \\
\text { E reservoir or } \\
\text { adjusting well spacing }\end{array}$ \\
\hline 137 & 3.2.03.05. & Viscosity relations & $\begin{array}{l}\text { Because the viscosity of } \mathrm{CO} 2 \text { at reservoir } \\
\text { conditions is much lower than that of most } \\
\text { oils, viscous instability will limit the sweep } \\
\text { efficiency of the displacement and, therefore, } \\
\text { oil recovery (API 2007). }\end{array}$ & $\begin{array}{l}\text { Can lead to adverse hydrodynamic instabilities, } \\
\text { such as fingering, which lead to vertical fluid } \\
\text { stratification and reduced oil recovery (API 2007). }\end{array}$ & $\begin{array}{l}\text { Additional } \\
\text { [new] FEP }\end{array}$ & $\begin{array}{l}\text { Gravity override is } \\
\text { working in our } \\
\text { favor in the Thrall. } \\
\text { Geneseo-Edwards } \\
\text { is a gravity stable } \\
\text { process and we } \\
\text { will take } \\
\text { advantage of the } \\
\text { CO2 buoyancy. }\end{array}$ & & & 2 & 3 & 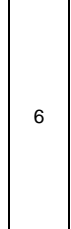 & \begin{tabular}{|l|} 
Model EOR \\
operation and try to \\
optimize $\mathrm{CO} 2$ \\
performance through \\
reservoir \\
engineering.
\end{tabular} & $\begin{array}{l}\text { Adjust } \mathrm{CO} 2 \mathrm{EOR} \\
\text { strategy to improve oi } \\
\text { recovery if necessary. } \\
\text { such as injection } \\
\text { beneath and above G. } \\
\text { E reservoir or } \\
\text { adjusting well spacing }\end{array}$ \\
\hline
\end{tabular}




\begin{tabular}{|c|c|c|c|c|c|c|c|c|c|c|c|c|c|}
\hline \multicolumn{6}{|c|}{ CO2 Geologic Sequestration Risks for the IMCCS Project } & \multicolumn{3}{|c|}{ Project Specific Information } & \multicolumn{3}{|c|}{ Risk Ranking } & \multicolumn{2}{|c|}{ Prevention and Mitigation } \\
\hline Line \# & Index No. & Risk Area & Description & Relevance & $\begin{array}{l}\text { Qunitessa } \\
\text { FEP } \\
\text { Category }\end{array}$ & $\begin{array}{l}\text { Individual } \\
\text { Comments }\end{array}$ & $\begin{array}{c}\text { IMCCS Project } \\
\text { Specific Information }\end{array}$ & $\begin{array}{c}\text { IMCCS Project } \\
\text { Information Gaps } \\
\text { or Uncertainties }\end{array}$ & 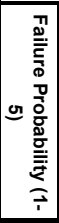 & 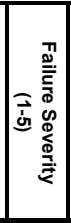 & 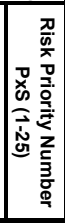 & $\begin{array}{l}\text { Risk Prevention } \\
\text { Steps (Actions } \\
\text { taken to reduce } \\
\text { risk probability) }\end{array}$ & $\begin{array}{c}\text { Risk Mitigation } \\
\text { Steps (Actions taken } \\
\text { to reduce risk } \\
\text { severity) }\end{array}$ \\
\hline 138 & 3.2.03.06. & $\begin{array}{l}\text { Oil reservoir } \\
\text { heterogeneity }\end{array}$ & $\begin{array}{l}\text { Oil reservoir rock is extremely } \\
\text { heterogeneneous, exhibiting zones of high } \\
\text { permeability in close proximity to those of } \\
\text { low permeability. These permeability } \\
\text { differences may be innate, that is caused by } \\
\text { differences in pore structure th the time of } \\
\text { geological deposition, or a product of } \\
\text { fractures, natural or man-made (API 2007) }\end{array}$ & Can decrease efficiency of oil recovery. & \begin{tabular}{|l} 
Additional \\
[new] FEP
\end{tabular} & $\begin{array}{l}\text { Thrall was a great } \\
\text { water flood - } \\
\text { supporting } \\
\text { homogeneity. } \\
\text { Geneseo-Edwards } \\
\text { was a great } \\
\text { bottom-water drive } \\
\text { reservoir - } \\
\text { heterogeneity not } \\
\text { a problem. }\end{array}$ & & & 2 & 3 & 6 & \begin{tabular}{|l|} 
Fully characterize oil \\
reservoir. Take \\
heterogeneity of oil \\
reservoir into EOR \\
modeling and \\
reservoir \\
engineering in order \\
to optimize \\
performance.
\end{tabular} & $\begin{array}{l}\text { Adjust CO2 EOR } \\
\text { strategy to improve oil } \\
\text { recovery if necessary., } \\
\text { such as injection } \\
\text { beneath and above G- } \\
\text { E reservoir or } \\
\text { adjusting well spacing. }\end{array}$ \\
\hline 139 & 3.2.03.07. & $\begin{array}{l}\text { Hydrocarbon } \\
\text { precipitation }\end{array}$ & $\begin{array}{l}\text { Precipitation of asphaltenes or paraffins. } \\
\text { CO2 injection promotes asphaltene } \\
\text { precipitation. Paraffins precipitate when } \\
\text { temperatures are less than } 25^{\circ} \mathrm{C} \text {. }\end{array}$ & $\begin{array}{l}\text { Precipitation of asphaltenes can clog pores, } \\
\text { reducing permeability and affecting fluid flow } \\
\text { paths. It can also cause plugging of boreholes. }\end{array}$ & \begin{tabular}{|} 
Additional \\
[new] FEP
\end{tabular} & \begin{tabular}{|l|} 
Could be a \\
problem, \\
particularly in the \\
Geneseo- \\
Edwards. More \\
study needed. \\
Gravity stable \\
means oil doesn't \\
move very far. \\
Therefore, may \\
not be a problem.
\end{tabular} & & $\begin{array}{l}\text { More study } \\
\text { needed }\end{array}$ & 3 & 3 & 9 & \begin{tabular}{|l|} 
Monitor for \\
asphaltene \\
precipitation. \\
Injection of hot water \\
or steam every \\
couple of months.
\end{tabular} & $\begin{array}{l}\text { Injection of hot water, } \\
\text { steam, hot oil, } \\
\text { deasphalted oil, } \\
\text { solvents or enzymes. }\end{array}$ \\
\hline 140 & 3.2.03.08. & Miscibility & $\begin{array}{l}\text { Flooding a reservoir with } \mathrm{CO} 2 \text { can occur } \\
\text { either miscibly or immiscibly. Miscible CO2 } \\
\text { displacement is only achieved under a } \\
\text { specific combination of conditions, which are } \\
\text { set by four variables : reservoir temperature, } \\
\text { reservoir pressure, injected gas composition, } \\
\text { and oil chemical composition (API 2007). } \\
\text { Miscible displacement is achieved at } \\
\text { pressures above the minimum miscibility } \\
\text { pressure (MMP). If the reservoir pressure is } \\
\text { below the MMP, CO2 can still be injected, } \\
\text { but the efficiency of the enhanced oil } \\
\text { recovery process is adversely impacted. } \\
\text { Typically this does not occur since, after } \\
\text { primary depletion, water flooding operations } \\
\text { commence which restore reservoir pressure } \\
\text { to values above the MMP(API 2007). }\end{array}$ & $\begin{array}{l}\text { Immiscible operation decreases efficiency of } \\
\text { CO2 in recovering oil. }\end{array}$ & \begin{tabular}{|l} 
Additional \\
[new] FEP
\end{tabular} & $\begin{array}{l}\text { Will be miscible in } \\
\text { the Thrall and } \\
\text { near miscible in } \\
\text { Geneseo- } \\
\text { Edwards. }\end{array}$ & & & 3 & 3 & 9 & \begin{tabular}{|l|} 
Try to maintain \\
injection pressures \\
in the miscible or \\
near miscible range. \\
Keep nitrogen \\
content low.
\end{tabular} & $\begin{array}{l}\text { Increase reservoir } \\
\text { pressure. }\end{array}$ \\
\hline 141 & 3.2.03.09. & $\begin{array}{l}\text { Residual oil } \\
\text { saturation }\end{array}$ & $\begin{array}{l}\text { Poor injectivity due to oil presence reduction } \\
\text { of relative permeability to CO2. Unexpected } \\
\text { bottom hole pressure increase. }\end{array}$ & & \begin{tabular}{|l} 
Additional \\
[new] FEP
\end{tabular} & \begin{tabular}{|l|} 
Definitely not a \\
problem based on \\
injectivities in the \\
Thrall water flood \\
and withdrawal \\
rate in Geneseo- \\
Edwards.
\end{tabular} & & & 1 & 3 & 3 & NA & NA \\
\hline 142 & 3.2.03.10. & Breakthrough & $\begin{array}{l}\text { The alternating water and CO2 gas (WAG) } \\
\text { approach is typically applied in CO2 EOR to } \\
\text { minimize CO2 use (as it is purchased) and to } \\
\text { avoid early breakthrough of } \mathrm{CO} 2 \text {. }\end{array}$ & & \begin{tabular}{|l} 
Additional \\
[new] FEP
\end{tabular} & Possible issue. & & & 3 & 3 & 9 & $\begin{array}{l}\text { Optimize reservoir } \\
\text { engineering. }\end{array}$ & $\begin{array}{l}\text { Increase well spacing. } \\
\text { Modify well pattern. }\end{array}$ \\
\hline
\end{tabular}

Appendix 6-27

Quintessa Original FEP: Taken from Quintessa's on-line CO2 FEP database, which is freely accessible at: http://www.quintessa.org/co2fepdb/ 


\begin{tabular}{|c|c|c|c|c|c|c|c|c|c|c|c|c|c|}
\hline \multicolumn{6}{|c|}{ CO2 Geologic Sequestration Risks for the IMCCS Project } & \multicolumn{3}{|c|}{ Project Specific Information } & \multicolumn{3}{|c|}{ Risk Ranking } & \multicolumn{2}{|c|}{ Prevention and Mitigation } \\
\hline Line \# & Index No. & Risk Area & Description & Relevance & $\begin{array}{l}\text { Qunitessa } \\
\text { FEP } \\
\text { Category }\end{array}$ & $\begin{array}{l}\text { Individual } \\
\text { Comments }\end{array}$ & $\begin{array}{c}\text { IMCCS Project } \\
\text { Specific Information }\end{array}$ & \begin{tabular}{|c|} 
IMccs Project \\
Information Gaps \\
or Uncertainties
\end{tabular} & 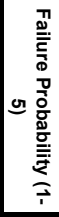 & 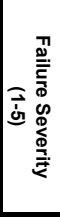 & 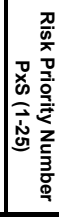 & $\begin{array}{l}\text { Risk Prevention } \\
\text { Steps (Actions } \\
\text { taken to reduce } \\
\text { risk probability) }\end{array}$ & $\begin{array}{l}\text { Risk Mitigation } \\
\text { Steps (Actions taken } \\
\text { to reduce risk } \\
\text { severity) }\end{array}$ \\
\hline 143 & 3.2.03.11. & WAG ratio & $\begin{array}{l}\text { The ratio of water to } \mathrm{CO} 2 \text { (WAG ratio) } \\
\text { injection may need to be adjusted to } \\
\text { optimize EOR performance. Typical WAG } \\
\text { ratios range from 1:1 to 5:1. }\end{array}$ & & \begin{tabular}{|l} 
Additional \\
[new] FEP
\end{tabular} & Possible issue. & $\begin{array}{l}\text { WAG will not be used } \\
\text { in G-E but will be used } \\
\text { in T-A. }\end{array}$ & & 3 & 3 & 9 & $\begin{array}{l}\text { Optimize WAG } \\
\text { through reservoir } \\
\text { engineering and } \\
\text { modeling. }\end{array}$ & $\begin{array}{l}\text { Evaluate WAG } \\
\text { performance based on } \\
\text { projected modeling } \\
\text { and make adjustments } \\
\text { in WAG ratio or well } \\
\text { spacing/pattern as } \\
\text { needed. }\end{array}$ \\
\hline 144 & 3.2.03.12. & $\begin{array}{c}\text { Injection water } \\
\text { quality / attributes / } \\
\text { chemistry }\end{array}$ & & & \begin{tabular}{|l} 
Additional \\
[new] FEP
\end{tabular} & $\begin{array}{l}\text { Not a problem. } \\
\text { Water will be } \\
\text { treated. }\end{array}$ & & $\begin{array}{l}\text { Obtain water } \\
\text { chemistry }\end{array}$ & 1 & 2 & 2 & $\begin{array}{l}\text { Obtain water } \\
\text { chemistry and } \\
\text { compare with } \\
\text { recommended } \\
\text { specification for } \\
\text { WAG. Set up water } \\
\text { treatment facilities to } \\
\text { meet specification. }\end{array}$ & $\begin{array}{l}\text { Monitor water quality } \\
\text { and treat as needed }\end{array}$ \\
\hline 145 & 3.2.03.13. & $\begin{array}{l}\text { Injection water } \\
\text { pressure }\end{array}$ & $\begin{array}{l}\text { Water is denser than } \mathrm{CO} 2 \text {. When changing } \\
\text { from CO2 injection to water injection, a } \\
\text { pressure differential needs to be overcome. } \\
\text { To do so, the water supply header operates } \\
\text { at a pressure in excess of the CO2 supply } \\
\text { header pressure. This allows water to be } \\
\text { throttled into the well, its pressure declining } \\
\text { to the appropriate value once the CO2 is } \\
\text { displaced from the wellbores (API 2007). }\end{array}$ & & $\begin{array}{l}\text { Additional } \\
\text { [new] FEP }\end{array}$ & $\begin{array}{l}\text { Unlikely to be an } \\
\text { issue. }\end{array}$ & Will be managed. & & 2 & 2 & 4 & $\begin{array}{l}\text { Calculate water } \\
\text { pressure needed } \\
\text { based on modeling. } \\
\text { Install sufficient } \\
\text { pumping capacity to } \\
\text { meet water pressure } \\
\text { requirements. }\end{array}$ & $\begin{array}{l}\text { Monitor water } \\
\text { pressure and adjust } \\
\text { pump pressure as } \\
\text { needed. }\end{array}$ \\
\hline 146 & 3.2.03.14. & $\begin{array}{c}\text { Injection and } \\
\text { production well } \\
\text { spacing and pattern }\end{array}$ & $\begin{array}{l}\text { The layout of the injection and production } \\
\text { wells will impact the efficiency of the sweep. }\end{array}$ & & \begin{tabular}{|l} 
Additional \\
[new] FEP
\end{tabular} & Yes & & & 3 & 3 & 9 & $\begin{array}{l}\text { Optimize well } \\
\text { spacing and pattern } \\
\text { based on modeling } \\
\text { and reservoir } \\
\text { engineering. }\end{array}$ & \begin{tabular}{|l} 
Monitor well \\
performance versus \\
model prediction. \\
Adjust model and well \\
spacing and pattern \\
as needed to optimize \\
oil recovery. \\
\end{tabular} \\
\hline 147 & 3.2.03.15. & $\begin{array}{l}\text { Oil attributes } \\
\text { (Oil gravity) }\end{array}$ & $\begin{array}{l}\text { oil API gravity influences minimum miscibility } \\
\text { pressure }\end{array}$ & & \begin{tabular}{|l} 
Additional \\
[new] FEP
\end{tabular} & \begin{tabular}{|l} 
This is high gravity \\
oil
\end{tabular} & y API: 37-38 & & 2 & 3 & 6 & $\begin{array}{l}\text { Fully characterize } \\
\text { crude oil API and } \\
\text { MMP. Take API and } \\
\text { MMP into account in } \\
\text { modeling and } \\
\text { reservoir } \\
\text { engineering. }\end{array}$ & $\begin{array}{l}\text { Monitor API and MMP } \\
\text { during operation. } \\
\text { Make adjustments to } \\
\text { CO2 injection } \\
\text { pressure as needed to } \\
\text { maintain miscible } \\
\text { operation. }\end{array}$ \\
\hline 148 & 3.2.03.16. & $\begin{array}{l}\text { Intermittent CO2 } \\
\text { supply }\end{array}$ & $\begin{array}{l}\text { Intermittent CO2 supply can negatively } \\
\text { impact sweep efficiency. }\end{array}$ & & \begin{tabular}{|l} 
Additional \\
[new] FEP
\end{tabular} & $\begin{array}{l}\text { Should not be a } \\
\text { problem. }\end{array}$ & $\begin{array}{l}\text { Will have plans for } \\
\text { short-term } \\
\text { interruptions - switch } \\
\text { to WAG for example. }\end{array}$ & & 3 & 2 & 6 & \begin{tabular}{|l} 
Maintain daily, \\
weekly and monthly \\
nominations for CO2 \\
supply and demand \\
planning.
\end{tabular} & $\begin{array}{l}2 \begin{array}{l}\text { Use water injection as } \\
\text { a backup for sweep if } \\
\text { necessary. }\end{array} \\
\end{array}$ \\
\hline
\end{tabular}




\begin{tabular}{|c|c|c|c|c|c|c|c|c|c|c|c|c|c|}
\hline \multicolumn{6}{|c|}{ CO2 Geologic Sequestration Risks for the IMCCS Project } & \multicolumn{3}{|c|}{ Project Specific Information } & \multicolumn{3}{|c|}{ Risk Ranking } & \multicolumn{2}{|c|}{ Prevention and Mitigation } \\
\hline Line \# & Index No. & Risk Area & Description & Relevance & $\begin{array}{l}\text { Qunitessa } \\
\quad \text { FEP } \\
\text { Category }\end{array}$ & $\begin{array}{l}\text { Individual } \\
\text { Comments }\end{array}$ & $\begin{array}{c}\text { IMCCS Project } \\
\text { Specific Information }\end{array}$ & \begin{tabular}{|c|} 
IMCcS Project \\
Information Gaps \\
or Uncertainties
\end{tabular} & 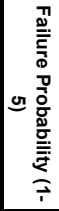 & 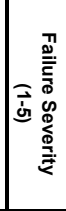 & 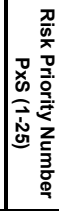 & $\begin{array}{l}\text { Risk Prevention } \\
\text { Steps (Actions } \\
\text { taken to reduce } \\
\text { risk probability) }\end{array}$ & $\begin{array}{l}\text { Risk Mitigation } \\
\text { Steps (Actions taken } \\
\text { to reduce risk } \\
\text { severity) }\end{array}$ \\
\hline 149 & 3.2.04.00. & $\begin{array}{l}\text { Displacement of } \\
\text { saline formation } \\
\quad \text { fluids }\end{array}$ & \begin{tabular}{|l} 
Injection of CO2 into a geologic formation \\
may result in displacement of saline \\
formation fluids into potable water supplies. \\
Limitations on the pressure in a formation \\
(for seal integrity) will mean that existing \\
fluids are displaced/replaced. Displaced \\
flluids are highly likely to be saline. Because \\
the pressure wave created by injection \\
travels much further than the physical CO2 \\
front, displacement of saline formation fluids \\
can occur at locations outside the CO2 \\
storage area. Inter-connection of aquifer \\
systems may enable saline fluids to enter \\
potable water formations. \\
For significant storage to be possible, it is \\
necessary for a significant amount of the \\
native pore space fluid to be displaced from \\
the reservoir over the injection period. This \\
may occur either by production of fluids (oil \\
or gas), by deliberate production of formation \\
water, and/or by migration of fluids into \\
adjacent formations, surface or oceans.
\end{tabular} & $\begin{array}{l}\text { Displaced saline formation fluids may } \\
\text { contaminate near-surface aquifers with } \\
\text { subsequent impacts, such as contamination of } \\
\text { potable water supplies. }\end{array}$ & \begin{tabular}{|c|} 
\\
Quintessa \\
FEP with \\
additional text \\
\end{tabular} & $\begin{array}{l}\text { Not an issue for } \\
\text { EOR because of } \\
\text { water and oil } \\
\text { production. Only } \\
\text { an issue for DSA. } \\
\text { But the volume of } \\
\text { CO2 to be used } \\
\text { for DSA is so } \\
\text { small compared to } \\
\text { the Arbuckle } \\
\text { capacity, it will not } \\
\text { be an issue in this } \\
\text { project. }\end{array}$ & & & 2 & 3 & 6 & $\begin{array}{l}\text { Fully characterize } \\
\text { and model reservoirs } \\
\text { to understand likely } \\
\text { displacement of } \\
\text { saline formation } \\
\text { fluids. Take into } \\
\text { account fluid } \\
\text { displacement in } \\
\text { reservoir } \\
\text { engineering. }\end{array}$ & $\begin{array}{l}\text { Monitor near surface } \\
\text { aquifers for increases } \\
\text { in salinity. Determine } \\
\text { root cause for any } \\
\text { increase in salinity. } \\
\text { Use tracers if } \\
\text { necessary. }\end{array}$ \\
\hline 150 & 3.2.05.00. & $\begin{array}{l}\text { Mechanical } \\
\text { processes and } \\
\text { conditions }\end{array}$ & \begin{tabular}{|l|} 
Features and processes related to the \\
mechanical processes and conditions \\
resulting from the injection of CO2 that affect \\
the rock, boreholes and other engineered \\
features, and the overall mechanical \\
evolution with time. This includes the effects \\
of hydraulic, mechanical and thermal loads \\
imposed on the rock by the injected CO2. \\
Injection of CO2 into a reservoir can cause \\
(directly or indirectly) changes of the \\
geomemechanical properties of the reservoir \\
rock. Direct changes can be due to change \\
of reservoir pressure and temperature (PVT \\
system). Indirect changes (of rock \\
properties) might result from geochemical \\
and mineralogical changes after storage of \\
CO2.
\end{tabular} & $\begin{array}{l}\text { Mechanical changes of the reservoir resulting } \\
\text { from } \mathrm{CO} 2 \text { injection (such as generation of } \\
\text { fractures, reactivation of fractures/faults, changes } \\
\text { of bulk elastic properties and effective reservoir) } \\
\text { could lead to subsidence/uplift (at surface), } \\
\text { induced seismicity, changes in migration } \\
\text { pathways, even burstlleakage of the seal. } \\
\text { Examples of other relevant processes are: } \\
\text { borehole lining colllapse; rock volume changes, } \\
\text { leading to cracking }\end{array}$ & $\begin{array}{c}\text { Quintessa } \\
\text { original FEP }\end{array}$ & $\begin{array}{l}\text { Unlikely to be an } \\
\text { issue. }\end{array}$ & $\begin{array}{l}\text { T-A Bartlesville } \\
\text { Sandstone has } \\
\text { demonstrated } \\
\text { operation at } 1700 \text { psig } \\
\text { with water flooding. } \\
\text { The CO2 EOR will } \\
\text { operate below that. } \\
\text { The G-E can't be } \\
\text { pressurized. Volume } \\
\text { increase from CO2 } \\
\text { injection will be } \\
\text { compensated for by } \\
\text { water/oil production in } \\
\text { EOR. }\end{array}$ & & 2 & 3 & 6 & $\begin{array}{l}\text { Operate below } 80 \% \\
\text { of fracture pressure. }\end{array}$ & $\begin{array}{l}\text { Operate below } 80 \% \text { of } \\
\text { fracture pressure. } \\
\text { Monitor injection } \\
\text { pressure, tiltmeter and } \\
\text { micro-seismicity. }\end{array}$ \\
\hline
\end{tabular}




\begin{tabular}{|c|c|c|c|c|c|c|c|c|c|c|c|c|c|}
\hline \multicolumn{6}{|c|}{ CO2 Geologic Sequestration Risks for the IMCCS Project } & \multicolumn{3}{|c|}{ Project Specific Information } & \multicolumn{3}{|c|}{ Risk Ranking } & \multicolumn{2}{|c|}{ Prevention and Mitigation } \\
\hline Line \# & Index No. & Risk Area & Description & Relevance & $\begin{array}{l}\text { Qunitessa } \\
\text { FEP } \\
\text { Category }\end{array}$ & $\begin{array}{l}\text { Individual } \\
\text { Comments }\end{array}$ & $\begin{array}{c}\text { IMCCS Project } \\
\text { Specific Information }\end{array}$ & $\begin{array}{c}\text { IMCcS Project } \\
\text { Information Gaps } \\
\text { or Uncertainties }\end{array}$ & 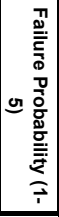 & 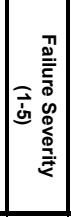 & 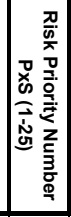 & $\begin{array}{c}\text { Risk Prevention } \\
\text { Steps (Actions } \\
\text { taken to reduce } \\
\text { risk probability) }\end{array}$ & $\begin{array}{c}\text { Risk Mitigation } \\
\text { Steps (Actions taken } \\
\text { to reduce risk } \\
\text { severity) }\end{array}$ \\
\hline 151 & 3.2.06.00. & Induced seismicity & $\begin{array}{l}\text { Injection of CO2 may cause and trigger } \\
\text { seismic events and earthquake hazards } \\
\text { through processes such as reducing friction } \\
\text { at existing faults. This may occur both in } \\
\text { seismically active areas and in areas } \\
\text { characterized by a low background } \\
\text { seismicity (reactivation of ancient fault } \\
\text { planes, changes in the orientation, fluid- } \\
\text { pockets occurrence). This FEP includes } \\
\text { microseismicity. }\end{array}$ & $\begin{array}{l}\text { Seismicity can introduce sudden physical } \\
\text { changes to the sequestration system and may } \\
\text { expose any local population to earthquake } \\
\text { hazards. } \\
\text { Potential effects of reservoir-induced seismicity } \\
\text { (RIS) are damage to the caprock and wells, } \\
\text { which might cause CO2 leakage, and damage to } \\
\text { building and infrastructure (Damen 2006). } \\
\text { In a reservoir that is under high tectonic stresses, } \\
\text { any significant reduction of pressure (pressure } \\
\text { acting between individual rock particles) may } \\
\text { trigger faults. This may lead to upliting or down- } \\
\text { faulting of the surface (Damen 2006). }\end{array}$ & $\begin{array}{c}\text { Quintessa } \\
\text { FEP with } \\
\text { additional text } \\
\end{array}$ & $\begin{array}{l}\text { Unlikely to be an } \\
\text { issue. }\end{array}$ & \begin{tabular}{|l|} 
T-A Bartlesville \\
Sandstone has \\
demonstrated \\
operation at 1700 psig \\
with water flooding. \\
The cO2 EOR will \\
operate below that. \\
The G-E can't be \\
pressurized. Volume \\
increase from CO2 \\
injection will be \\
compensated for by \\
waterloil production in \\
EOR.
\end{tabular} & & 2 & 3 & 6 & $\begin{array}{l}\text { Operate below } 80 \% \\
\text { of fracture pressure. } \\
\text { Volume increase } \\
\text { from CO2 injection } \\
\text { will be compensated } \\
\text { for by water/oil } \\
\text { production in EOR. }\end{array}$ & $\begin{array}{l}\text { Operate below } 80 \% \text { of } \\
\text { fracture pressure. } \\
\text { Monitor injection } \\
\text { pressure, tiltmeter and } \\
\text { micro-seismicity. } \\
\text { Volume increase from } \\
\text { CO2 injection will be } \\
\text { compensated for by } \\
\text { water/oil production in } \\
\text { EOR. }\end{array}$ \\
\hline 152 & 3.2.07.00. & Subsidence or uplift & $\begin{array}{l}\text { Injecting the CO2 may cause acidification of } \\
\text { formation water, leading to mineral } \\
\text { dissolution and subsidence. This is of } \\
\text { particular relevance to shallow storage sites. } \\
\text { Injection of large quantities of } \mathrm{CO} 2 \text { into a } \\
\text { confined aquifer may increase pore pressure } \\
\text { and lift the overlying rocks upwards. }\end{array}$ & $\begin{array}{l}\text { Deformation may affect geological processes and } \\
\text { may result in impacts of concern at the surface. }\end{array}$ & $\begin{array}{l}\text { Quintessa } \\
\text { original FEP }\end{array}$ & $\begin{array}{l}\text { Unlikely to be an } \\
\text { issue. }\end{array}$ & $\begin{array}{l}\text { T-A Bartlesville } \\
\text { Sandstone has } \\
\text { demonstrated } \\
\text { operation at } 1700 \text { psig } \\
\text { with water flooding. } \\
\text { The CO2 EOR will } \\
\text { operate below that. } \\
\text { The G-E can't be } \\
\text { pressurized. Volume } \\
\text { increase from CO2 } \\
\text { injection will be } \\
\text { compensated for by } \\
\text { waterloil production in } \\
\text { EOR. }\end{array}$ & & 2 & 3 & 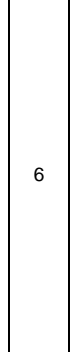 & \begin{tabular}{l|} 
Operate below $80 \%$ \\
of fracture pressure. \\
Volume increase \\
from CO2 injection \\
will be compensated \\
for by water/oil \\
production in EOR.
\end{tabular} & $\begin{array}{l}\text { Operate below } 80 \% \text { of } \\
\text { fracture pressure. } \\
\text { Monitor injection } \\
\text { pressure, tiltmeter and } \\
\text { micro-seismicity. } \\
\text { Volume increase from } \\
\text { CO2 injection will be } \\
\text { compensated for by } \\
\text { water/oil production in } \\
\text { EOR. }\end{array}$ \\
\hline 153 & 3.2.07.01. & Subsidence & \begin{tabular}{|l|} 
Injecting the CO2 may cause acidification of \\
formation water, leading to mineral \\
dissolution and subsidence. This is of \\
particular relevance to shallow storage sites. \\
Chemical compaction or dissolution of the \\
reservoir rock will particularly be a matter of \\
concern in carbonate rocks with high \\
porosity (Damen 2006).
\end{tabular} & $\begin{array}{l}\text { Dissolution of the reservoir rock (chemical } \\
\text { compaction) can lead to the reservoir caving in } \\
\text { under the weight of the overburden formation } \\
\text { (Damen 2006) } \\
\text { Vertical subsidence above large reservoirs could } \\
\text { affect lake levels and shift streams in lowland } \\
\text { areas with low topographic relief. } \\
\text { Subsidence could damage buildings or farmland. }\end{array}$ & $\begin{array}{c}\text { Expansion of } \\
\text { Q FEP }\end{array}$ & $\begin{array}{l}\text { Unlikely to be an } \\
\text { issue. }\end{array}$ & \begin{tabular}{|l|} 
T-A Bartlesville \\
Sandstone has \\
demonstrated \\
operation at 1700 psig \\
with water flooding. \\
The CO2 EOR will \\
operate below that. \\
The G-E can't be \\
pressurized. Volume \\
increase from CO2 \\
injection will be \\
compensated for by \\
waterloil production in \\
EOR.
\end{tabular} & & 2 & 3 & 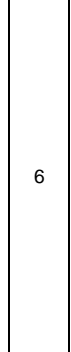 & \begin{tabular}{l|} 
Operate below $80 \%$ \\
of fracture pressure. \\
Volume increase \\
from CO2 injection \\
will be compensated \\
for by water/oil \\
production in EOR.
\end{tabular} & $\begin{array}{l}\text { Monitor surface } \\
\text { change with tiltmeters. } \\
\text { Monitor subsurface } \\
\text { change with } 3 d \\
\text { seismic and/or VSP. } \\
\text { Compare with model. } \\
\text { Identify any } \\
\text { irregularities and take } \\
\text { corrective action if } \\
\text { necessary. }\end{array}$ \\
\hline
\end{tabular}

Appendix 6-30

Quintessa Original FEP: Taken from Quintessa's on-line CO2 FEP database, which is freely accessible at: http://www.quintessa.org/co2fepdb/ 


\begin{tabular}{|c|c|c|c|c|c|c|c|c|c|c|c|c|c|}
\hline \multicolumn{6}{|c|}{ CO2 Geologic Sequestration Risks for the IMCCS Project } & \multicolumn{3}{|c|}{ Project Specific Information } & \multicolumn{3}{|c|}{ Risk Ranking } & \multicolumn{2}{|c|}{$\begin{array}{l}\text { Prevention and Mitigation } \\
\end{array}$} \\
\hline Line \# & Index No. & Risk Area & Description & Relevance & $\begin{array}{l}\text { Qunitessa } \\
\text { FEP } \\
\text { Category }\end{array}$ & $\begin{array}{l}\text { Individual } \\
\text { Comments }\end{array}$ & $\begin{array}{c}\text { IMCCS Project } \\
\text { Specific Information }\end{array}$ & $\begin{array}{c}\text { IMCCS Project } \\
\text { Information Gaps } \\
\text { or Uncertainties }\end{array}$ & 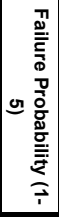 & 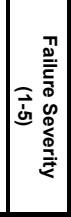 & 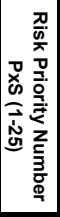 & $\begin{array}{l}\text { Risk Prevention } \\
\text { Steps (Actions } \\
\text { taken to reduce } \\
\text { risk probability) }\end{array}$ & $\begin{array}{l}\text { Risk Mitigation } \\
\text { Steps (Actions taken } \\
\text { to reduce risk } \\
\text { severity) }\end{array}$ \\
\hline 154 & 3.2.07.02. & Uplift & $\begin{array}{l}\text { Injection of large quantities of } \mathrm{CO} 2 \text { into a } \\
\text { confined aquifer may increase pore pressure } \\
\text { and lift the overlying rocks upwards. } \\
\text { It is not envisaged that uplift will take place in } \\
\text { a cO2 reservoir as long as the maximum } \\
\text { storage pressure is kept below the geostatic } \\
\text { pressure (Damen 2006). }\end{array}$ & $\begin{array}{l}\text { Vertical uplift above large reservoirs could affect } \\
\text { lake levels and shift streams in lowland areas } \\
\text { with low topographic relief. } \\
\text { Uplift could damage buildings or farmland. }\end{array}$ & $\begin{array}{c}\text { Expansion of } \\
\text { Q FEP }\end{array}$ & Unlikely to be an & $\begin{array}{l}\text { T-A Bartlesville } \\
\text { Sandstone has } \\
\text { demonstrated } \\
\text { operation at } 1700 \text { psig } \\
\text { with water flooding. } \\
\text { The CO2 EOR will } \\
\text { operate below that. } \\
\text { The G-E can't be } \\
\text { pressurized. Volume } \\
\text { increase from CO2 } \\
\text { injection will be } \\
\text { compensated for by } \\
\text { water/oil production in } \\
\text { EOR. }\end{array}$ & & 2 & 3 & 6 & $\begin{array}{l}\text { Operate below } 80 \% \\
\text { of fracture pressure. } \\
\text { Volume increase } \\
\text { from CO2 injection } \\
\text { will be compensated } \\
\text { for by water/oil } \\
\text { production in EOR. }\end{array}$ & $\begin{array}{l}\text { Operate below } 80 \% \text { of } \\
\text { fracture pressure. } \\
\text { Monitor injection } \\
\text { pressure, tiltmeter and } \\
\text { micro-seismicity. } \\
\text { Volume increase from } \\
\text { CO2 injection will be } \\
\text { compensated for by } \\
\text { water/oil production in } \\
\text { EOR. }\end{array}$ \\
\hline 155 & 3.2.08.00. & $\begin{array}{c}\text { Thermal effects on } \\
\text { the injection point }\end{array}$ & $\begin{array}{l}\text { Temperature of the injected fluid could result } \\
\text { in geological modification of the region } \\
\text { around the point of injection due to thermal } \\
\text { gradients. }\end{array}$ & $\begin{array}{l}\text { These thermal effects could influence the mobility } \\
\text { of the injected CO2 and impurities. }\end{array}$ & $\begin{array}{l}\text { Quintessa } \\
\text { original FEP }\end{array}$ & \begin{tabular}{|l|} 
The volume of \\
CO2 to be injected \\
is relatively small. \\
The CO2 goes \\
could have a \\
localized cooling \\
effect if it goes \\
from supercritical \\
state to a gas due \\
to low pressure.
\end{tabular} & $\begin{array}{l}\text { The cO2 will have a } \\
\text { wellhead temperature } \\
\text { of } 18-20^{\circ} \mathrm{C} \text { and the } \\
\text { BHT is } 47^{\circ} \mathrm{C} \text { at G-E } \\
\text { and } 36^{\circ} \mathrm{C} \text { at T-A. }\end{array}$ & & 2 & 2 & 4 & $\begin{array}{l}\text { Maintain } \mathrm{CO} 2 \\
\text { injection pressure } \\
\text { above the CO2 } \\
\text { supercritical } \\
\text { pressure. }\end{array}$ & $\begin{array}{l}\text { Maintain } \mathrm{CO} 2 \text { injection } \\
\text { pressure above the } \\
\text { CO2 supercritical } \\
\text { pressure. }\end{array}$ \\
\hline 156 & 3.2.09.00. & Water chemistry & $\begin{array}{l}\text { Water phase geochemistry of sequestered } \\
\text { CO2. This includes the solubility trapping of } \\
\text { CO2 in water (HO) to form carbonic acid } \\
\text { (H2CO3). Subsequent ionic trapping of } \\
\text { carbonic acid with hydroxide ions (OH-) } \\
\text { forms icarabbonte ions (HCO3-), which can } \\
\text { react in turn with further hydroxide ions to } \\
\text { form carbonate (CO3). }\end{array}$ & $\begin{array}{l}\text { Modification of the water phase geochemistry } \\
\text { can disturb the equilibria between the water and } \\
\text { solid phase of the reservoir and result in further } \\
\text { geochemical (for example, solid phase } \\
\text { geochemistryy and physical changes with } \\
\text { resulting implications for the long-term } \\
\text { performance of the sequestration system. }\end{array}$ & $\begin{array}{l}\text { Quintessa } \\
\text { original FEP }\end{array}$ & $\begin{array}{l}\text { Reactions are } \\
\text { likely to be slow. }\end{array}$ & & \begin{tabular}{|l|} 
Need more \\
information of \\
water chemistry in \\
Arbuckle and \\
Bartlesville.
\end{tabular} & 2 & 2 & 4 & $\begin{array}{l}\text { Take geochemistry } \\
\text { into account in } \\
\text { modeling and } \\
\text { reservoir } \\
\text { engineering. }\end{array}$ & $\begin{array}{l}\text { Monitor impact on } \\
\text { boreholes and } \\
\text { replug/remediate if } \\
\text { necessary. }\end{array}$ \\
\hline 157 & 3.2.09.01. & $\begin{array}{l}\text { Formation of } \\
\text { carbonic acid } \\
\text { (H2CO3) }\end{array}$ & & & $\begin{array}{c}\text { Expansion of } \\
\text { Q FEP }\end{array}$ & $\begin{array}{l}\text { Reactions are } \\
\text { likely to be slow. }\end{array}$ & & $\begin{array}{l}\text { Need modeling } \\
\text { results }\end{array}$ & 2 & 2 & 4 & \begin{tabular}{|l|} 
Take geochemistry \\
into account in \\
modeling and \\
reservoir \\
engineering. \\
\end{tabular} & $\begin{array}{l}\text { Monitor impact on } \\
\text { boreholes and } \\
\text { replug/remediate if } \\
\text { necessary. }\end{array}$ \\
\hline 158 & 3.2.09.02. & $\begin{array}{l}\text { Formation of } \\
\text { bicarbonate ions } \\
\text { (HCO3-) }\end{array}$ & & & $\begin{array}{c}\text { Expansion of } \\
\text { Q FEP }\end{array}$ & $\begin{array}{l}\text { Reactions are } \\
\text { likely to be slow. }\end{array}$ & & $\begin{array}{l}\text { Need modeling } \\
\text { results }\end{array}$ & 2 & 2 & 4 & $\begin{array}{l}\text { Take geochemistry } \\
\text { into account in } \\
\text { modeling and } \\
\text { reservoir } \\
\text { engineering. }\end{array}$ & $\begin{array}{l}\text { Monitor impact on } \\
\text { boreholes and } \\
\text { replug/remediate if } \\
\text { necessary. }\end{array}$ \\
\hline 159 & 3.2.09.03. & $\begin{array}{c}\text { Formation of } \\
\text { carbonate (CO3) }\end{array}$ & & & $\begin{array}{c}\text { Expansion of } \\
\text { Q FEP }\end{array}$ & $\begin{array}{l}\text { Reactions are } \\
\text { likely to be slow. }\end{array}$ & & $\begin{array}{l}\text { Need modeling } \\
\text { results }\end{array}$ & 2 & 2 & 4 & \begin{tabular}{|l|} 
Take geochemistry \\
into account in \\
modeling and \\
reservoir \\
engineering.
\end{tabular} & $\begin{array}{l}\text { Monitor impact on } \\
\text { boreholes and } \\
\text { replug/remediate if } \\
\text { necessary. }\end{array}$ \\
\hline 160 & 3.2.10.00. & $\begin{array}{l}\text { Interaction of } \mathrm{CO} 2 \\
\text { with chemical } \\
\text { barriers }\end{array}$ & $\begin{array}{l}\text { Chemical barriers (pH, En-pH, ion exchange) } \\
\text { may exist in aquifers to retard the migration } \\
\text { of CO2 from depth. The precipitation of CO2 } \\
\text { bearing solids may result from such } \\
\text { interactions. }\end{array}$ & $\begin{array}{l}\text { Such barriers will affect the rate of migration of } \\
\mathrm{CO} 2 \text { from depth. }\end{array}$ & $\begin{array}{l}\text { Quintessa } \\
\text { original FEP }\end{array}$ & \begin{tabular}{|l|} 
Very unlikely to be \\
an issue.
\end{tabular} & $\begin{array}{l}\text { No chemical barriers } \\
\text { have been identified in } \\
\text { the project area. CO2 } \\
\text { containment is not } \\
\text { dependent on } \\
\text { chemical barriers. }\end{array}$ & & 1 & 3 & 3 & NA & NA \\
\hline
\end{tabular}

Appendix 6-31

Quintessa Original FEP: Taken from Quintessa's on-line CO2 FEP database, which is freely accessible at: http://www.quintessa.org/co2fepdb/ 


\begin{tabular}{|c|c|c|c|c|c|c|c|c|c|c|c|c|c|}
\hline \multicolumn{6}{|c|}{ CO2 Geologic Sequestration Risks for the IMCCS Project } & \multicolumn{3}{|c|}{ Project Specific Information } & \multicolumn{3}{|c|}{ Risk Ranking } & \multicolumn{2}{|c|}{ Prevention and Mitigation } \\
\hline Line \# & Index No. & Risk Area & Description & Relevance & $\begin{array}{l}\text { Qunitessa } \\
\text { FEP } \\
\text { Category }\end{array}$ & $\begin{array}{l}\text { Individual } \\
\text { Comments }\end{array}$ & $\begin{array}{c}\text { IMccs Project } \\
\text { Specific Information }\end{array}$ & $\begin{array}{c}\text { IMCCS Project } \\
\text { Information Gaps } \\
\text { or Uncertainties }\end{array}$ & 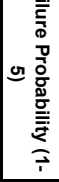 & 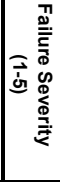 & 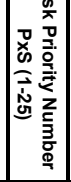 & $\begin{array}{l}\text { Risk Prevention } \\
\text { Steps (Actions } \\
\text { taken to reduce } \\
\text { risk probability) }\end{array}$ & \begin{tabular}{|c|} 
Risk Mitigation \\
Steps (Actions taken \\
to reduce risk \\
severity)
\end{tabular} \\
\hline 161 & 3.2.11.00. & $\begin{array}{l}\text { Sorption and } \\
\text { desorption of } \mathrm{CO} 2 \\
\text { (CO2 interaction } \\
\text { with coal seams) }\end{array}$ & \begin{tabular}{|l|} 
The sorption and desorption of $\mathrm{CO} 2$ on \\
geological materials. Sorption onto coal and \\
the displacement of methane (CH4) is the \\
primary mechanism behind the enhanced \\
coal bed methane recovery (ECBM) method \\
for geological CO2 sequestration.
\end{tabular} & $\begin{array}{l}\text { The rate of sorption and desorption of } \mathrm{CO} 2 \text { on } \\
\text { geological materials affects its mobility and } \\
\text { therefore the performance of the storage system. }\end{array}$ & \begin{tabular}{|} 
Quintessa \\
FEP with \\
additional text
\end{tabular} & $\begin{array}{l}\text { Very unlikely to be } \\
\text { an issue in this } \\
\text { project. Very small } \\
\text { percentage of total } \\
\text { CO2. }\end{array}$ & & & 1 & 2 & 2 & $\begin{array}{l}\text { Take into account in } \\
\text { modeling and } \\
\text { reservoir } \\
\text { engineering. }\end{array}$ & NA \\
\hline 162 & 3.2.11.01. & $\begin{array}{l}\text { Sorption of } \mathrm{CO} 2 \text { on } \\
\text { coal and release of } \\
\text { methane }\end{array}$ & $\begin{array}{l}>2 \mathrm{~mol} \mathrm{CO} 2 \text { adsorbed on coal for every mol } \\
\text { of } \mathrm{CH} 4 \text { desorbed. }\end{array}$ & & $\begin{array}{l}\text { Expansion of } \\
\text { Q FEP }\end{array}$ & $\begin{array}{l}\text { Very unlikely to be } \\
\text { an issue in this } \\
\text { project. Very small } \\
\text { percentage of total } \\
\text { CO2. }\end{array}$ & & & 1 & 2 & 2 & $\begin{array}{l}\text { Take into account in } \\
\text { modeling and } \\
\text { reservoir } \\
\text { engineering. }\end{array}$ & NA \\
\hline 163 & 3.2.11.02. & $\begin{array}{l}\text { Desorption of } \mathrm{CO} 2 \\
\text { from coal or other } \\
\text { solids }\end{array}$ & & & $\begin{array}{l}\text { Expansion of } \\
\text { Q FEP }\end{array}$ & $\begin{array}{l}\text { Very unlikely to } \\
\text { be an issue in this } \\
\text { project. Very small } \\
\text { percentage of total } \\
\mathrm{CO} 2 .\end{array}$ & & & 1 & 3 & 3 & $\begin{array}{l}\text { Take into account in } \\
\text { modeling and } \\
\text { reservoir } \\
\text { engineering. }\end{array}$ & NA \\
\hline 164 & 3.2.11.03. & Coal swelling & \begin{tabular}{|l|} 
The chemical reactions and physical \\
processes that occur during CO2 injection \\
into coal seams and their impact on the \\
integrity of the coal seams are not well \\
understood. One of the reactions is swelling \\
of the coal matrix when injecting CO2. \\
(Damen 2006)
\end{tabular} & \begin{tabular}{|l|} 
Coal seam swelling may cause a reduction in \\
permeability. Swelling might also induce stresses \\
on the overlying and underlying rock strata in non \\
ideal coal seams (thin, low permeability and \\
highly faulted), that could cause faulting and \\
possible migration pathways out of the coal seam \\
(Damen 2006).
\end{tabular} & $\begin{array}{r}\text { Additional } \\
\text { [new] FEP }\end{array}$ & $\begin{array}{l}\text { Very unlikely to be } \\
\text { an issue. }\end{array}$ & $\begin{array}{l}\text { Not doing ECBM in } \\
\text { Phase } 2 \text {. }\end{array}$ & & 1 & 2 & 2 & NA & NA \\
\hline 165 & 3.2.11.04. & $\begin{array}{c}\text { Release of } \\
\text { polyaromatic } \\
\text { hydrocarbons from } \\
\text { coal seams }\end{array}$ & & Toxicity & \begin{tabular}{|l} 
Additional \\
[new] FEP
\end{tabular} & $\begin{array}{l}\text { Very unlikely to be } \\
\text { an issue. }\end{array}$ & $\begin{array}{l}\text { Not doing ECBM in } \\
\text { Phase } 2 \text {. }\end{array}$ & & 1 & 2 & 2 & NA & NA \\
\hline 166 & 3.2.12.00. & $\begin{array}{l}\text { Heavy metal } \\
\text { release }\end{array}$ & $\begin{array}{l}\text { Heavy metal ions may be dissolved in } \\
\text { formation fluids or sorbed on rock/mineral } \\
\text { surfaces. Complexation may occur between } \\
\text { CO2 and heavy metals dissolved in } \\
\text { formation fluids. The influence of dissolved } \\
\text { CO2 on pore water chemistry can also } \\
\text { reduce the pH and change the equilibrium } \\
\text { between sorption/desorption of metals, } \\
\text { thereby resulting in significant release of } \\
\text { these metals. }\end{array}$ & $\begin{array}{l}\text { This process has the potential to release heavy } \\
\text { metals, which may then migrate to the near- } \\
\text { surface environment with resulting impacts of } \\
\text { interest. These heavy metals will also change } \\
\text { pore water chemistry, which could impact on } \\
\text { carbonate complexation. }\end{array}$ & $\begin{array}{l}\text { Quintessa } \\
\text { original FEP }\end{array}$ & \begin{tabular}{|l} 
Heavy metals \\
likely to be an \\
issue only if there \\
is leakage. \\
Leakage is most \\
likely to occur \\
through \\
boreholes.
\end{tabular} & & \begin{tabular}{|l|} 
Need data on \\
heavy metal \\
content of \\
Arbuckle, \\
Bartlesville and \\
Douglas and near \\
surface waters.
\end{tabular} & 3 & 3 & 9 & $\begin{array}{l}\text { Fully characterize } \\
\text { Arbuckle, Bartlesville } \\
\text { and Douglas and } \\
\text { take heavy metals } \\
\text { content into account } \\
\text { in modeling and } \\
\text { monitoring. }\end{array}$ & $\begin{array}{l}\text { Monitor for appropriate } \\
\text { heavy metals in near } \\
\text { surface waters in the } \\
\text { area. }\end{array}$ \\
\hline 167 & 3.2.13.00. & Mineral phase & $\begin{array}{l}\text { Geochemistry of the mineral phase relevant } \\
\text { to sequestered CO2, including ion exchange } \\
\text { and mineral dissolution. }\end{array}$ & $\begin{array}{l}\text { Geochemical reactions between sequestered } \\
\mathrm{CO} 2 \text { and the mineral phase of the storage } \\
\text { system will affect the evolution of the system and } \\
\text { the sorption (and therefore mobility) of the } \mathrm{CO} 2 \text {. }\end{array}$ & $\begin{array}{l}\text { Quintessa } \\
\text { original FEP }\end{array}$ & \begin{tabular}{|l|} 
Not likely to be an \\
issue in this \\
project. Very small \\
percentage of total \\
CO2. Long time \\
frame.
\end{tabular} & & & 1 & 1 & 1 & NA & NA \\
\hline 168 & 3.2.13.01.00 & $\begin{array}{c}\text { Mineral dissolution } \\
\text { and precipitation }\end{array}$ & $\begin{array}{l}\text { The dissolution of minerals due to the } \\
\text { addition of } \mathrm{CO} 2 \text { (an acid gas) to the } \\
\text { geochemistry and precipitation. For example, } \\
\text { the dissolution of albite and precipitation of } \\
\text { calcite modeled for the Sleipner site by Gaus } \\
\text { et al. (2003). }\end{array}$ & $\begin{array}{l}\mathrm{CO} 2 \text { reaction with the host rock will modify: the } \\
\text { porosity and permeability of the reservoir; fluid } \\
\text { flow (direction or velocity); mechanical properties } \\
\text { (e.g. strength); and } \mathrm{CO} \text { storage capacity. }\end{array}$ & $\begin{array}{l}\text { Quintessa } \\
\text { original FEP }\end{array}$ & \begin{tabular}{|l|} 
There is likely to \\
be some mineral \\
dissolution and \\
precipitation \\
associated with \\
CO2 and the \\
Arbuckle dolomite \\
but this is very \\
long term and not \\
likely to pose a \\
risk.
\end{tabular} & & & 2 & 1 & 2 & \begin{tabular}{|} 
Take mineral \\
dissolution and \\
precipitation into \\
account in modeling.
\end{tabular} & $\begin{array}{l}\text { Monitor impact on } \\
\text { boreholes and } \\
\text { replug/remediate if } \\
\text { necessary. }\end{array}$ \\
\hline
\end{tabular}

Appendix 6-32

Quintessa Original FEP: Taken from Quintessa's on-line CO2 FEP database, which is freely accessible at: http://www.quintessa.org/co2fepdb/ 


\begin{tabular}{|c|c|c|c|c|c|c|c|c|c|c|c|c|c|}
\hline \multicolumn{6}{|c|}{ CO2 Geologic Sequestration Risks for the IMCCS Project } & \multicolumn{3}{|c|}{ Project Specific Information } & \multicolumn{3}{|c|}{ Risk Ranking } & \multicolumn{2}{|c|}{ Prevention and Mitigation } \\
\hline Line \# & Index No. & Risk Area & Description & Relevance & $\begin{array}{l}\text { Qunitessa } \\
\text { FEP } \\
\text { Category }\end{array}$ & $\begin{array}{l}\text { Individual } \\
\text { Comments }\end{array}$ & $\begin{array}{c}\text { IMccs Project } \\
\text { Specific Information }\end{array}$ & \begin{tabular}{|c|} 
IMCcS Project \\
Information Gaps \\
or Uncertainties
\end{tabular} & 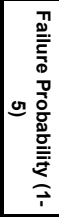 & 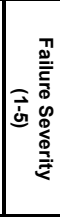 & 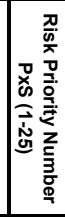 & $\begin{array}{l}\text { Risk Prevention } \\
\text { Steps (Actions } \\
\text { taken to reduce } \\
\text { risk probability) }\end{array}$ & $\begin{array}{l}\text { Risk Mitigation } \\
\text { Steps (Actions taken } \\
\text { to reduce risk } \\
\text { severity) }\end{array}$ \\
\hline 169 & 3.2.13.01.01 & $\begin{array}{c}\text { Mineral dissolution } \\
\text { reservoir }\end{array}$ & \begin{tabular}{|l|} 
Minerals in the reservoir formation (grains or \\
cement) may dissolve. This may locally \\
increase porosity and permeability along the \\
borehole, and/or may lead to mineral \\
reprecipitation that reduces local porosity \\
and permeability.
\end{tabular} & & \begin{tabular}{|} 
Additional \\
[new] FEP
\end{tabular} & Very little risk. & & & 2 & 1 & 2 & \begin{tabular}{|l|} 
Take mineral \\
dissolution and \\
precipitation into \\
account in modeling.
\end{tabular} & $\begin{array}{l}\text { Monitor impact on } \\
\text { boreholes and } \\
\text { replugiremediate if } \\
\text { necessary. }\end{array}$ \\
\hline 170 & 3.2.13.01.02 & \begin{tabular}{|c|}
$\begin{array}{c}\text { Mineral dissolution - } \\
\text { borehole }\end{array}$ \\
\end{tabular} & \begin{tabular}{|l|} 
Minerals in borehole cement or in the \\
reservoir formation next to the borehole \\
(grains and cement) may dissolve. This may \\
locally increase porosity and permeability \\
along the borehole, andlor may lead to \\
mineral reprecipitation that reduces local \\
porosity and permeability.
\end{tabular} & & \begin{tabular}{|}
$\begin{array}{l}\text { Additional } \\
\text { [new] FEP }\end{array}$ \\
\end{tabular} & Very little risk & & & 2 & 1 & 2 & $\begin{array}{l}\text { Take mineral } \\
\text { dissolution and } \\
\text { precipitation into } \\
\text { account in modeling. }\end{array} \mid$ & $\begin{array}{l}\text { Monitor impact on } \\
\text { boreholes and } \\
\text { replugg/remediate if } \\
\text { necessary. }\end{array}$ \\
\hline 171 & 3.2.13.01.03 & $\begin{array}{c}\text { Mineral dissolution } \\
\text { caprock }\end{array}$ & \begin{tabular}{|l|} 
Minerals in the caprock formation may \\
dissolve. This may locally increase porosity \\
and permeability in the caprock and or may \\
lead to mineral reprecipitation that reduces \\
local porosity and permeability. Especially in \\
the caprock, this phenomenon might be \\
localized along a microfracture.
\end{tabular} & & \begin{tabular}{|} 
Additional \\
[new] FEP
\end{tabular} & Very little risk & & & 2 & 1 & 2 & \begin{tabular}{|l|} 
Characterize \\
caprock mineralogy. \\
Take mineral \\
dissolutition and \\
precipitation into \\
account in modeling. \\
\end{tabular} & \begin{tabular}{|l|} 
Monitor for CO2 \\
leakage in sinks above \\
seal. Plug leaks, If \\
necessary, extract \\
CO2 from leaky \\
formation and reinject \\
CO2 into a sealed \\
formation. \\
\end{tabular} \\
\hline 172 & 3.2.13.01.04 & $\begin{array}{c}\text { Precipitation of } \\
\text { carbonate minerals }\end{array}$ & $\begin{array}{l}\text { Calcium carbonate and magnesium } \\
\text { carbonate can be formed when } \mathrm{HCO}_{3} \text { reacts } \\
\text { with } \mathrm{CA}^{2+} \text { or } \mathrm{Mg}^{2+} \text {. }\end{array}$ & $\begin{array}{l}\text { Dry out and salt out may cause reduced porosity } \\
\text { and permeability in the reservoir, especially near } \\
\text { the borehole. }\end{array}$ & $\begin{array}{l}\text { Additional } \\
\text { [new] FEP }\end{array}$ & Very little risk & & & 2 & 1 & 2 & \begin{tabular}{|l|} 
Take mineral \\
precipitation into \\
account in modeling.
\end{tabular} & $\begin{array}{l}\text { Monitor impact near } \\
\text { boreholes. }\end{array}$ \\
\hline 173 & 3.2.13.01.05 & Salt precipitation & $\begin{array}{l}\text { Dry CO2 can pick up moisture from high } \\
\text { salinity brines in the reservoir. This increases } \\
\text { the salinity of the brines. (CCP 2009) }\end{array}$ & $\begin{array}{l}\text { Increased salinity of brines can lead to } \\
\text { precipitation of salt in pore space, which can } \\
\text { decrease reservoir permeability and impair } \\
\text { injection rates of CO2. (CCP 2009) }\end{array}$ & \begin{tabular}{|} 
Additional \\
[new] FEP
\end{tabular} & $\begin{array}{l}\text { Very little risk. Not } \\
\text { likely to be an } \\
\text { issue in the EOR } \\
\text { operations. }\end{array}$ & $\begin{array}{l}\text { No water in the top of } \\
\text { the G-E domes where } \\
\mathrm{CO} 2 \text { will be injected. }\end{array}$ & & 1 & 1 & 1 & $\begin{array}{l}\text { Include brine salinity } \\
\text { and potential for salt } \\
\text { precipitation in } \\
\text { modeling. Control } \\
\text { salinity of water } \\
\text { injected into the } \\
\text { Bartlesville } \\
\text { Sandstone. }\end{array}$ & \begin{tabular}{|l|} 
Monitor salinity in \\
brine. Use fresh water \\
injection to dissolve \\
salt buildup.
\end{tabular} \\
\hline 174 & 3.2.13.01.06 & Scale buildup & $\begin{array}{l}\mathrm{CO} 2 \text { reacts with brine to form hard water } \\
\text { which can lead to scaling in or near a } \\
\text { production well }\end{array}$ & $\begin{array}{l}\text { Scale buildup can cause reduced porosity and } \\
\text { permeability in the reservoir, especially near the } \\
\text { borehole. }\end{array}$ & \begin{tabular}{|} 
Additional \\
[new] FEP
\end{tabular} & $\begin{array}{l}\text { Unlikely to be a } \\
\text { issue. }\end{array}$ & $\begin{array}{l}\text { Will deal with this } \\
\text { using chemicals. }\end{array}$ & & 2 & 1 & 2 & $\begin{array}{l}\text { Monitor brine for } \\
\text { common ions that } \\
\text { cause scale. } \\
\text { Periodically treat } \\
\text { system with } \\
\text { chemicals. } \\
\end{array}$ & $\begin{array}{l}\text { Treat system with } \\
\text { chemicals. }\end{array}$ \\
\hline 175 & 3.2.13.02. & Ion exchange & $\begin{array}{l}\text { The process of exchanging one ion in the } \\
\text { liquid phase for another ion on a charged, } \\
\text { solid substrate. } \\
\text { Injected co2 may perturb ion exchange } \\
\text { equilibria between relevant minerals (such as } \\
\text { sheet silicates) and the pore fluid. Some } \\
\text { cations may be released to the pore fluid and } \\
\text { others fixed as a consequence. }\end{array}$ & $\begin{array}{l}\text { Disturbance of the rock-pore fluid equilibria may } \\
\text { affect the capacity of the rock to store } \mathrm{CO} 2 \text {. }\end{array}$ & \begin{tabular}{|l} 
Quintessa \\
original FEP
\end{tabular} & $\begin{array}{l}\text { Very unlikely to be } \\
\text { an issue. }\end{array}$ & & & 1 & 1 & 1 & $\begin{array}{l}\text { Take ion exchange } \\
\text { into account in } \\
\text { modeling }\end{array}$ & \begin{tabular}{|l|} 
Monitor and model \\
CO2 injection. Identify \\
irregularities. \\
Determine root cause. \\
Modify iniection \\
strategy if necessary.
\end{tabular} \\
\hline 176 & 3.2.13.03. & Desiccation of clay & 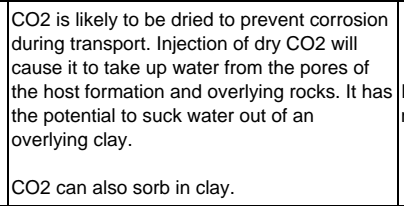 & $\begin{array}{l}\text { If clay dehydrates, it will shrink and crack. This } \\
\text { might aid CO2 migration upwards. }\end{array}$ & $\begin{array}{c}\text { Quintessa } \\
\text { FEP with } \\
\text { additional text }\end{array}$ & $\begin{array}{l}\text { Very unlikely to be } \\
\text { an issue. }\end{array}$ & & $\begin{array}{l}\text { Check clay } \\
\text { content of seals, }\end{array}$ & 1 & 2 & 2 & \begin{tabular}{|l|} 
Characterize seals \\
to evaluate clay \\
content and potential \\
for desiccation. \\
Include in modeling \\
if it appears to be an \\
issue.
\end{tabular} & $\begin{array}{l}\text { Inject water to hydrate } \\
\text { clay. }\end{array}$ \\
\hline
\end{tabular}

Quintessa Original FEP: Taken from Quintessa's on-line CO2 FEP database, which is freely accessible at: http://www.quintessa.org/co2fepdb/ 


\begin{tabular}{|c|c|c|c|c|c|c|c|c|c|c|c|c|c|}
\hline \multicolumn{6}{|c|}{ CO2 Geologic Sequestration Risks for the IMCCS Project } & \multicolumn{3}{|c|}{ Project Specific Information } & \multicolumn{3}{|c|}{ Risk Ranking } & \multicolumn{2}{|c|}{ Prevention and Mitigation } \\
\hline Line \# & Index No. & Risk Area & Description & Relevance & $\begin{array}{l}\text { Qunitessa } \\
\text { FEP } \\
\text { Category }\end{array}$ & $\begin{array}{l}\text { Individual } \\
\text { Comments }\end{array}$ & $\begin{array}{c}\text { IMCCS Project } \\
\text { Specific Information }\end{array}$ & $\begin{array}{c}\text { IMccs Project } \\
\text { Information Gaps } \\
\text { or Uncertainties }\end{array}$ & 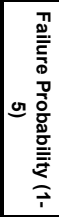 & 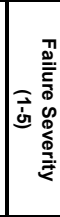 & 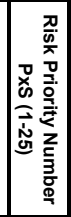 & $\begin{array}{l}\text { Risk Prevention } \\
\text { Steps (Actions } \\
\text { taken to reduce } \\
\text { risk probability) }\end{array}$ & $\begin{array}{l}\text { Risk Mitigation } \\
\text { Steps (Actions taken } \\
\text { to reduce risk } \\
\text { severity) }\end{array}$ \\
\hline 177 & 3.2.14.00. & Gas chemistry & $\begin{array}{l}\text { Gases such as } \mathrm{CO} \text {, methane and } \mathrm{H} 2 \mathrm{~S} \text {, will } \\
\text { occur naturally in the geosphere, either } \\
\text { sorbed onto minerals, dissolved in formation } \\
\text { fluids or as a free gas phase. Gas solubility } \\
\text { will depend upon pressure, temperature and } \\
\text { the salinity of the formation fluid. }\end{array}$ & $\begin{array}{l}\text { Gases naturally present in the geosphere could } \\
\text { affect the behavior of } \mathrm{CO} 2 \text { injected into a storage } \\
\text { reservoir and could accompany } \mathrm{CO} 2 \text { along } \\
\text { potential migration paths. }\end{array}$ & $\begin{array}{l}\text { Quintessa } \\
\text { original FEP }\end{array}$ & $\begin{array}{l}\text { Very unlikely to be } \\
\text { an issue. }\end{array}$ & $\begin{array}{l}\text { G-E and T-A expected } \\
\text { to have little gas } \\
\text { based on historical } \\
\text { production results. } \\
\text { Arbuckle may contain } \\
\text { H2S. }\end{array}$ & $\begin{array}{l}\text { Check for gas in } \\
\text { reservoirs } \\
\text { (particularly H2S) }\end{array}$ & 1 & 3 & 3 & $\begin{array}{l}\text { Check reservoirs for } \\
\text { presence of gases } \\
\text { (particularly H2S). } \\
\text { Include results in } \\
\text { systems design. }\end{array}$ & $\begin{array}{l}\text { Monitor for } \mathrm{H} 2 \mathrm{~S} \text { and } \\
\text { train operators how to } \\
\text { handle } \mathrm{H} 2 \mathrm{~S} \\
\text { appropriately. }\end{array}$ \\
\hline 178 & 3.2.14.01. & $\begin{array}{l}\mathrm{CO} 2 \text { interaction } \\
\text { with free gases in } \\
\text { the reservoir }\end{array}$ & & & 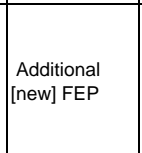 & \begin{tabular}{|l|} 
Very unlikely to be \\
an issue.
\end{tabular} & \begin{tabular}{|l|} 
G-E and T-A expected \\
to have little gas \\
based on historical \\
production results. \\
Arbuckle may contain \\
H2S.
\end{tabular} & $\begin{array}{l}\text { Check for gas in } \\
\text { reservoirs } \\
\text { (particularly H2S) }\end{array}$ & 1 & 3 & 3 & $\begin{array}{l}\text { Check reservoirs for } \\
\text { presence of gases } \\
\text { (particularly H2S). } \\
\text { Include results in } \\
\text { systems design. }\end{array}$ & $\begin{array}{l}\text { Monitor for } \mathrm{H} 2 \mathrm{~S} \text { and } \\
\text { train operators how to } \\
\text { handle H2S } \\
\text { appropriately. }\end{array}$ \\
\hline 179 & 3.2.14.02. & $\begin{array}{c}\text { CO2 interaction } \\
\text { with gases sorbed } \\
\text { on minerals }\end{array}$ & & & \begin{tabular}{|l} 
Additional \\
[new] FEP
\end{tabular} & \begin{tabular}{|l|} 
Very unlikely to be \\
an issue.
\end{tabular} & \begin{tabular}{|l|} 
G-E and T-A expected \\
to have little gas \\
based on historical \\
production results. \\
Arbuckle may contain \\
H2S.
\end{tabular} & \begin{tabular}{|l} 
Check for gas in \\
reservoirs \\
(particularly H2S)
\end{tabular} & 1 & 3 & 3 & $\begin{array}{l}\text { Check reservoirs for } \\
\text { presence of gases } \\
\text { (particularly H2S). } \\
\text { Include results in } \\
\text { systems design. }\end{array}$ & \begin{tabular}{|l} 
Monitor for $\mathrm{H} 2 \mathrm{~S}$ and \\
train operators how to \\
handle H2S \\
appropriately.
\end{tabular} \\
\hline 180 & 3.2.14.03. & $\begin{array}{l}\mathrm{CO} 2 \text { interaction } \\
\text { with gases } \\
\text { dissolved in } \\
\text { formation fluids }\end{array}$ & & & 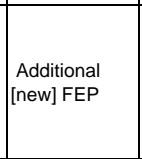 & \begin{tabular}{|l|} 
Very unlikely to be \\
an issue.
\end{tabular} & \begin{tabular}{|l|} 
G-E and T-A expected \\
to have little gas \\
based on historical \\
production results. \\
Arbuckle may contain \\
H2S.
\end{tabular} & $\begin{array}{l}\text { Check for gas in } \\
\text { reservoirs } \\
\text { (particularly H2S) }\end{array}$ & 1 & 3 & 3 & $\begin{array}{l}\text { Check reservoirs for } \\
\text { presence of gases } \\
\text { (particularly H2S). } \\
\text { Include results in } \\
\text { systems design. }\end{array}$ & $\begin{array}{l}\text { Monitor for } \mathrm{H} 2 \mathrm{~S} \text { and } \\
\text { train operators how to } \\
\text { handle } \mathrm{H} 2 \mathrm{~S} \\
\text { appropriately. }\end{array}$ \\
\hline 181 & 3.2.14.04. & $\begin{array}{c}\mathrm{CO} 2 \text { interaction } \\
\text { with gaseous } \\
\text { hydrocarbons in the } \\
\text { reservoir }\end{array}$ & & & \begin{tabular}{|l} 
Additional \\
[new] FEP
\end{tabular} & $\begin{array}{l}\text { Very unlikely to be } \\
\text { an issue. }\end{array}$ & $\begin{array}{l}\text { G-E and T-A expected } \\
\text { to have little or no } \\
\text { hydrocarbon gas } \\
\text { based on historical } \\
\text { production results. }\end{array}$ & $\begin{array}{l}\text { Check for } \\
\text { hydrocarbon } \\
\text { gases in the } \\
\text { reservoirs. }\end{array}$ & 1 & 3 & 3 & $\begin{array}{l}\text { Check reservoirs for } \\
\text { presence of } \\
\text { hydrocarbon gases } \\
\text { Include results in } \\
\text { systems design. }\end{array}$ & $\begin{array}{l}\text { Monitor for } \mathrm{H} 2 \mathrm{~S} \text { and } \\
\text { train operators how to } \\
\text { handle H2S } \\
\text { appropriately. }\end{array}$ \\
\hline 182 & 3.2.15.00. & Gas stripping & \begin{tabular}{|l|} 
CO 2 migration through the reservoir and \\
into the overlying barrier sequence could \\
result in the $\mathrm{CO} 2$ stripping other gases \\
entrained within the sediments. These gases \\
could include radon, methane (CH4) and \\
hydrogen sulphide (H2S).
\end{tabular} & $\begin{array}{l}\text { The presence of other gases in a leaking } \mathrm{CO} 2 \\
\text { gas stream is important in deciding the level of } \\
\text { CO2 leakage that can be tolerated and may } \\
\text { constitute an important hazard. }\end{array}$ & $\begin{array}{l}\text { Quintessa } \\
\text { original FEP }\end{array}$ & $\begin{array}{l}\text { Unlikely to be a } \\
\text { issue. }\end{array}$ & \begin{tabular}{|l|} 
G-E and T-A expected \\
to have little gas \\
based on historical \\
production results. \\
Arbuckle may contain \\
H2S. \\
\end{tabular} & $\begin{array}{l}\text { Check for gas in } \\
\text { reservoirs } \\
\text { (particularly H2S) }\end{array}$ & 2 & 3 & 6 & $\begin{array}{l}\text { Check reservoirs for } \\
\text { presence of gases } \\
\text { (particularly H2S). } \\
\text { Include results in } \\
\text { systems design. }\end{array}$ & \begin{tabular}{|l} 
Monitor for $\mathrm{H} 2 \mathrm{~S}$ and \\
train operators how to \\
handle $\mathrm{H} 2 \mathrm{~S}$ \\
appropriately.
\end{tabular} \\
\hline 183 & 3.2.15.01. & Radon stripping & & & $\begin{array}{c}\text { Expansion of } \\
\text { Q FEP }\end{array}$ & $\begin{array}{l}\text { Very unlikely to be } \\
\text { an issue. }\end{array}$ & & $\begin{array}{l}\text { Check for radon in } \\
\text { reservoirs. }\end{array}$ & 1 & 3 & 3 & \begin{tabular}{|l} 
Check for radon in \\
reservoirs. Include \\
results in modeling \\
and system design if \\
necessary. \\
\end{tabular} & $\begin{array}{l}\text { Monitor for radon and } \\
\text { train operators how to } \\
\text { handle radon } \\
\text { appropriately. }\end{array}$ \\
\hline 184 & 3.2.15.02. & $\begin{array}{l}\text { Methane (CH4) } \\
\text { stripping }\end{array}$ & & & $\begin{array}{c}\text { Expansion of } \\
\text { Q FEP }\end{array}$ & $\begin{array}{l}\text { Very unlikely to be } \\
\text { an issue. }\end{array}$ & \begin{tabular}{|l} 
G-E and T-A expected \\
to have little or no \\
methane based on \\
historical production \\
results.
\end{tabular} & $\begin{array}{l}\text { Check for } \\
\text { methane in } \\
\text { reservoirs. }\end{array}$ & 1 & 3 & 3 & $\begin{array}{l}\text { Check for methane } \\
\text { in reservoirs. Include } \\
\text { results in modeling } \\
\text { and system design if } \\
\text { necessary. }\end{array}$ & $\begin{array}{l}\text { Monitor for methane } \\
\text { and train operators } \\
\text { how to handle } \\
\text { methane } \\
\text { appropriately. }\end{array}$ \\
\hline 185 & 3.2.15.03. & $\begin{array}{l}\text { Hydrogen sulfide } \\
\text { (H2S) stripping }\end{array}$ & & & $\begin{array}{c}\text { Expansion of } \\
\text { Q FEP }\end{array}$ & $\begin{array}{l}\text { Very unlikely to be } \\
\text { an issue. }\end{array}$ & $\begin{array}{l}\text { H2S has been } \\
\text { reported in the } \\
\text { Arbuckle. }\end{array}$ & $\begin{array}{l}\text { Check for H2S in } \\
\text { the reservoirs. }\end{array}$ & 1 & 3 & 3 & $\begin{array}{l}\text { Check for H2S in } \\
\text { reservoirs. Include } \\
\text { results in modeling } \\
\text { and system design if } \\
\text { necessary. }\end{array}$ & $\begin{array}{l}\text { Monitor for } \mathrm{H} 2 \mathrm{~S} \text { and } \\
\text { train operators how to } \\
\text { handle H2S } \\
\text { appropriately. }\end{array}$ \\
\hline
\end{tabular}

Appendix 6-34

Quintessa Original FEP: Taken from Quintessa's on-line CO2 FEP database, which is freely accessible at: http://www.quintessa.org/co2fepdb/ 


\begin{tabular}{|c|c|c|c|c|c|c|c|c|c|c|c|c|c|}
\hline \multicolumn{6}{|c|}{ CO2 Geologic Sequestration Risks for the IMCCS Project } & \multicolumn{3}{|c|}{ Project Specific Information } & \multicolumn{3}{|c|}{ Risk Ranking } & \multicolumn{2}{|c|}{ Prevention and Mitigation } \\
\hline Line \# & Index No. & Risk Area & Description & Relevance & $\begin{array}{l}\text { Qunitessa } \\
\text { FEP } \\
\text { Category }\end{array}$ & $\begin{array}{l}\text { Individual } \\
\text { Comments }\end{array}$ & $\begin{array}{c}\text { IMccs Project } \\
\text { Specific Information }\end{array}$ & \begin{tabular}{|c|} 
IMccS Project \\
Information Gaps \\
or Uncertainties
\end{tabular} & 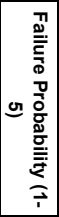 & 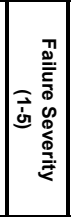 & 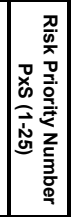 & $\begin{array}{l}\text { Risk Prevention } \\
\text { Steps (Actions } \\
\text { taken to reduce } \\
\text { risk probability) }\end{array}$ & $\begin{array}{l}\text { Risk Mitigation } \\
\text { Steps (Actions taker } \\
\text { to reduce risk } \\
\text { severity) }\end{array}$ \\
\hline 186 & 3.2.16.00. & Gas hydrates & $\begin{array}{l}\text { Gas hydrates are 'ice-like' solids that form at } \\
\text { low temperatures and high pressures. They } \\
\text { are formed of 'cages' of water molecules } \\
\text { surrounding a gas molecule. CO2 can for } \\
\text { hydrates in the presence of water. }\end{array}$ & $\begin{array}{l}\text { Cooling of the reservoir (e.g. by injecting cold } \\
\text { CO2 or through adiabatic expansion) well below } \\
\text { normal in-situ temperatures might stabilize gas } \\
\text { hydratates. Their growth might seal fluid flow } \\
\text { pathways (at least temporarily). } \\
\text { If CO2 is injected below deep water or } \\
\text { permafrost, then rising CO2 might hit the hydrate } \\
\text { stabilitit zone before escaping to the ocean or air, } \\
\text { so hydrates could act as a secondary chemical } \\
\text { barrier. Similarly, storage could be focused on } \\
\text { actively forming CO2 hydrate as a stable, } \\
\text { immobile phase to lock up the CO2 (Koide et al., } \\
\text { 1997). }\end{array}$ & $\begin{array}{l}\text { Quintessa } \\
\text { original FEP } \\
\end{array}$ & $\begin{array}{l}\text { Very unlikely to be } \\
\text { an issue. }\end{array}$ & $\begin{array}{l}\text { G-E Arbuckle could be } \\
\text { cooled locally by CO2 } \\
\text { changing form } \\
\text { subcritical to gas } \\
\text { phase, but the cO2 } \\
\text { volume is relatively } \\
\text { small and not } \\
\text { expected to form gas } \\
\text { hydrates. }\end{array}$ & $\begin{array}{l}\text { Evaluate potential } \\
\text { of hydrate } \\
\text { formation through } \\
\text { modeling. }\end{array}$ & 1 & 1 & 1 & NA & NA \\
\hline 187 & 3.2.16.01. & \begin{tabular}{|c|} 
Gas hydrates \\
formed below deep \\
water
\end{tabular} & & & $\begin{array}{c}\text { Expansion of } \\
\text { Q FEP }\end{array}$ & $\begin{array}{l}\text { Very unlikely to be } \\
\text { an issue. }\end{array}$ & No deep water & & 1 & 1 & 1 & NA & NA \\
\hline 188 & 3.2.16.02. & \begin{tabular}{c|} 
Gas hydrates \\
formed below \\
permafrost
\end{tabular} & & & $\begin{array}{c}\text { Expansion of } \\
\text { Q FEP }\end{array}$ & $\begin{array}{l}\text { Very unlikely to be } \\
\text { an issue. }\end{array}$ & No permafrost & & 1 & 1 & 1 & NA & $\mathrm{N}^{\prime}$ \\
\hline 189 & 3.2.17.00. & Biogeochemistry & $\begin{array}{l}\text { Features and processes related to the } \\
\text { biological/biochemical processes that affect } \\
\text { the CO2, borehole seals and rock/pore fluid, } \\
\text { and the overall biological/biochemical } \\
\text { evolution with time. This includes the effects } \\
\text { of biological//biochemical influences on the } \\
\text { cO2 and engineered components by the } \\
\text { surrounding geology. Microbes exist in the } \\
\text { subsurface and are used in hydrocarbon } \\
\text { operations to improve hydrocarbon recovery } \\
\text { (e.g., in EOR and ECBM operations). } \\
\text { Microbes can also catalyze geochemical } \\
\text { reactions, including methanogenesis, but the } \\
\text { latter reaction is thermodynamically } \\
\text { unfavorable and is unlikely. }\end{array}$ & $\begin{array}{l}\text { Examples of relevant processes are: } \\
\text { - microbial growth; } \\
\text { - microbially/biologically mediated processes; and } \\
\text { - microbial/biological fffects of evolution of redox } \\
\text { (Eh) and acidity/lalkalinity (pH) , etc. } \\
\text { This FEP has probably low relevance to the } \\
\text { safetylffate of CO2. However, CO2 releases may } \\
\text { affect/impact microbe populations being used in } \\
\text { independent hydrocarbon-recovery enhancement } \\
\text { projects. }\end{array}$ & $\begin{array}{l}\text { Quintessa } \\
\text { original FEP }\end{array}$ & $\begin{array}{l}\text { Very unlikely to be } \\
\text { an issue. }\end{array}$ & & $\begin{array}{l}\text { Identify any } \\
\text { significant } \\
\text { subsurface } \\
\text { microbial cultures } \\
\text { at the injection } \\
\text { sites. }\end{array}$ & 1 & 1 & 1 & $\begin{array}{l}\text { Monitor for microbial } \\
\text { activity if injection } \\
\text { pressures increase } \\
\text { unexpectedly. Avoid } \\
\text { O2 content in the } \\
\text { CO2 stream. }\end{array}$ & $\begin{array}{l}\text { Use chemical } \\
\text { treatment if necessary } \\
\text { to control microbial } \\
\text { growth. }\end{array}$ \\
\hline 190 & 3.2.18.00. & Microbial processes & $\begin{array}{l}\text { Microbes can metabolize } \mathrm{CO} 2 \text {, for example, } \\
\text { methanogenic microbes use } \mathrm{H} 2 \text { to reduce } \\
\text { cO2 to methane (CH4), a process called } \\
\text { methanogenesis. These microbes need } \\
\text { anaerobic conditions. }\end{array}$ & $\begin{array}{l}\text { Methanogenesis, if it occurs, could affect the } \\
\text { pressure distribution of } \mathrm{CO} 2 \text {. The fate and impact } \\
\text { of the } \mathrm{CH} 4 \text { produced may be an endpoint of } \\
\text { interest in itself. }\end{array}$ & $\begin{array}{l}\text { Quintessa } \\
\text { original FEP }\end{array}$ & $\begin{array}{l}\text { Very unlikely to be } \\
\text { an issue. }\end{array}$ & & $\begin{array}{l}\text { Identify any } \\
\text { significant } \\
\text { subsurface } \\
\text { microbial cultures } \\
\text { at the injection } \\
\text { sites. }\end{array}$ & 1 & 1 & 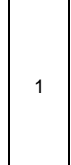 & $\begin{array}{l}\text { Monitor for microbial } \\
\text { activity if injection } \\
\text { pressures increase } \\
\text { unexpectedly. Avoid } \\
\text { O2 content in the } \\
\text { CO2 stream. }\end{array}$ & $\begin{array}{l}\text { Monitor for methane. } \\
\text { Use chemical } \\
\text { treatment if necessary } \\
\text { to control microbial } \\
\text { growth. }\end{array}$ \\
\hline 191 & 3.2.19.00. & $\begin{array}{l}\text { Biomass uptake of } \\
\text { CO2 }\end{array}$ & $\begin{array}{l}\text { If sequestered } \mathrm{CO} 2 \text { migrates to the } \\
\text { biosphere, it can be taken up by microbes, } \\
\text { plants and algae (including phytoplankton). }\end{array}$ & $\begin{array}{l}\text { This mechanism may provide a sink for } \mathrm{CO} 2 \text { that } \\
\text { has migrated from the sequestration system. }\end{array}$ & $\begin{array}{l}\text { Quintessa } \\
\text { original FEP }\end{array}$ & $\begin{array}{l}\text { Very unlikely to be } \\
\text { an issue. }\end{array}$ & $\begin{array}{l}\text { Biomass in the } \\
\text { injection site areas } \\
\text { appear to be minimal. }\end{array}$ & & 1 & 1 & 1 & NA & NA \\
\hline 192 & 3.3.00.00. & $\mathrm{CO} 2$ transport & $\begin{array}{l}\text { Transport processes that may affect } \\
\text { sequestered carbon dioxide and associated } \\
\text { impurities. }\end{array}$ & $\begin{array}{l}\text { An understanding of those processes that could } \\
\text { transport carbon dioxide, and associated } \\
\text { impurities, within the geosphere, near-surface } \\
\text { and surface environments is fundamental to the } \\
\text { assessment of long-term performance and } \\
\text { safety. }\end{array}$ & $\begin{array}{l}\text { Quintessa } \\
\text { original FEP }\end{array}$ & $\begin{array}{l}\text { Very unlikely to be } \\
\text { an issue. }\end{array}$ & & & 1 & 3 & 3 & $\begin{array}{l}\text { Fully characterize } \\
\text { and model the sites } \\
\text { and avoid or } \\
\text { eliminate potential } \\
\text { leaks. }\end{array}$ & $\begin{array}{l}\text { Monitor for } \mathrm{CO} 2 \\
\text { leakage. If necessary, } \\
\text { extract CO2 from } \\
\text { leaky formation and } \\
\text { reinject CO2 into a } \\
\text { sealed formation. }\end{array}$ \\
\hline
\end{tabular}

Appendix 6-35

Quintessa Original FEP: Taken from Quintessa's on-line CO2 FEP database, which is freely accessible at: http://www.quintessa.org/co2fepdb/ 


\begin{tabular}{|c|c|c|c|c|c|c|c|c|c|c|c|c|c|}
\hline \multicolumn{6}{|c|}{ CO2 Geologic Sequestration Risks for the IMCCS Project } & \multicolumn{3}{|c|}{ Project Specific Information } & \multicolumn{3}{|c|}{ Risk Ranking } & \multicolumn{2}{|c|}{ Prevention and Mitigation } \\
\hline Line \# & Index No. & Risk Area & Description & Relevance & $\begin{array}{l}\text { Qunitessa } \\
\text { FEP } \\
\text { Category }\end{array}$ & $\begin{array}{l}\text { Individual } \\
\text { Comments }\end{array}$ & $\begin{array}{c}\text { IMCCS Project } \\
\text { Specific Information }\end{array}$ & \begin{tabular}{|c|} 
IMCCS Project \\
Information Gaps \\
or Uncertainties
\end{tabular} & 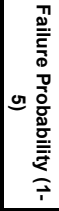 & 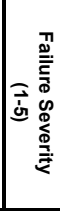 & 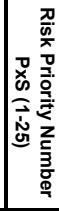 & $\begin{array}{l}\text { Risk Prevention } \\
\text { Steps (Actions } \\
\text { taken to reduce } \\
\text { risk probability) }\end{array}$ & $\begin{array}{c}\text { Risk Mitigation } \\
\text { Steps (Actions taken } \\
\text { to reduce risk } \\
\text { severity) }\end{array}$ \\
\hline 193 & 3.3.01.00. & $\begin{array}{l}\text { Advection of free } \\
\mathrm{CO2}\end{array}$ & $\begin{array}{l}\text { Advection of free CO2 occurs in response to } \\
\text { differences in pressure. The pressure } \\
\text { difference may be due to differences in the } \\
\text { pressure of injected CO2 and formation } \\
\text { pressures. } \\
\text { The rate and direction of advection is } \\
\text { affected by the physical properties of the } \\
\text { rock, such as porosity and permeability. } \\
\text { Advection may also occur though fractures. } \\
\text { Fracture flow will be episodic with high } \\
\text { transport efficiencies. Resealing of fractures } \\
\text { (for example by cementation) will reduce and } \\
\text { ultimately block fluid flow. }\end{array}$ & $\begin{array}{l}\text { Advective flow is a key transport process for } \\
\text { migrating CO2, and associated contaminants, in } \\
\text { the geosphere (reservoir, surrounding and } \\
\text { overlying rock), near-surface and surface } \\
\text { environments. }\end{array}$ & $\begin{array}{l}\text { Quintessa } \\
\text { original FEP }\end{array}$ & $\begin{array}{l}\text { Unlikely to be a } \\
\text { issue. }\end{array}$ & $\begin{array}{l}\text { Oil reservoirs in G-E } \\
\text { and T-A have top and } \\
\text { lateral seals, }\end{array}$ & & 2 & 3 & 6 & $\begin{array}{l}\text { Inject CO2 into } \\
\text { reservoirs that have } \\
\text { top and lateral seals } \\
\text { such as domes at G- } \\
\text { E or "bottles" at T-A. }\end{array}$ & $\begin{array}{l}\text { Monitor CO2 plumes } \\
\text { to make sure they } \\
\text { don't pass beyond spill } \\
\text { points or enter } \\
\text { leakage pathways. If } \\
\text { necessary, extract } \\
\text { CO2 from leaky } \\
\text { formation and reinject } \\
\text { CO2 into a sealed } \\
\text { formation. }\end{array}$ \\
\hline 194 & 3.3.01.01. & $\begin{array}{l}\text { Advection causing } \\
\text { change in } \mathrm{CO} 2 \\
\text { migration direction }\end{array}$ & & & \begin{tabular}{|l} 
Additional \\
[new] FEP
\end{tabular} & $\begin{array}{l}\text { Unlikely to be a } \\
\text { issue. }\end{array}$ & $\begin{array}{l}\text { Oil reservoirs in G-E } \\
\text { and T-A have top and } \\
\text { lateral seals, }\end{array}$ & & 2 & 3 & 6 & $\begin{array}{l}\text { Thoroughly } \\
\text { characterize and } \\
\text { model reservoirs and } \\
\text { include results in } \\
\text { reservoir } \\
\text { engineering. }\end{array}$ & $\begin{array}{l}\text { Monitor CO2 plumes } \\
\text { to make sure they } \\
\text { don't pass beyond spill } \\
\text { points or enter } \\
\text { leakage pathways. If } \\
\text { necessary, extract } \\
\text { CO2 from leaky } \\
\text { formation and reinject } \\
\text { CO2 into a sealed } \\
\text { formation. }\end{array}$ \\
\hline 195 & 3.3.01.02. & $\begin{array}{l}\text { Hydrodynamic } \\
\text { gradients }\end{array}$ & $\begin{array}{l}\text { CO2 migration path diverges from expected } \\
\text { path. Significant } \mathrm{CO} 2 \text { volumes migrate off } \\
\text { structure. }\end{array}$ & & \begin{tabular}{|l} 
Additional \\
[new] FEP
\end{tabular} & $\begin{array}{l}\text { Unlikely to be a } \\
\text { issue. }\end{array}$ & $\begin{array}{l}\text { Oil reservoirs in G-E } \\
\text { and T-A have top and } \\
\text { lateral seals, CO2 } \\
\text { injection for DSA in } \\
\text { the Arbuckle could be } \\
\text { impacted by } \\
\text { hydrodynamic } \\
\text { gradients but the } \\
\text { injected volume will be } \\
\text { very limited and will } \\
\text { ultimately flow upward } \\
\text { and spread out on top } \\
\text { of the formation. }\end{array}$ & & 2 & 2 & 4 & $\begin{array}{l}\text { Thoroughly } \\
\text { characterize and } \\
\text { model reservoirs and } \\
\text { include results in } \\
\text { reservoir } \\
\text { engineering. }\end{array}$ & $\begin{array}{l}\text { Monitor CO2 plumes } \\
\text { to make sure they } \\
\text { don't pass beyond spill } \\
\text { points or enter } \\
\text { aleakage pathways. If } \\
\text { necessary, extract } \\
\text { CO2 from leaky } \\
\text { formation and reinject } \\
\text { CO2 into a sealed } \\
\text { formation. }\end{array}$ \\
\hline 196 & 3.3.01.01. & Fault valving & $\begin{array}{l}\text { Fault valving is a process resulting from } \\
\text { gradual build up of pore pressure due to fluid } \\
\text { generataion, causing the subsequent opening } \\
\text { of a fault along with fluid escape towards } \\
\text { surface. This mechanism has been } \\
\text { recognized as causing earthuakes in many } \\
\text { parts of the world, as a result of hydrocarbon } \\
\text { generation (e.g., in EOR or ECBM } \\
\text { operations) or infiltration of other fluids. }\end{array}$ & $\begin{array}{l}\text { Large releases of pore fluids may occur during } \\
\text { fault valving episodes. }\end{array}$ & $\begin{array}{l}\text { Quintessa } \\
\text { original FEP }\end{array}$ & $\begin{array}{l}\text { Unlikely to be a } \\
\text { issue. }\end{array}$ & $\begin{array}{l}\text { Existing faults in G-E } \\
\text { are stable, down dip } \\
\text { and don't penetrate } \\
\text { the caprock. The } \\
\text { Arbuckle can't be } \\
\text { pressurized in that } \\
\text { area. Faults in T-A are } \\
25 \text { miles away and the } \\
\text { Bartlesville Sandstone } \\
\text { is isolated. }\end{array}$ & & 2 & 4 & 8 & $\begin{array}{l}\text { Don't inject CO2 } \\
\text { near faults. Don't } \\
\text { overpressure the } \\
\text { reservoir near faults. }\end{array}$ & $\begin{array}{l}\text { Monitor micro- } \\
\text { seismicity and CO2 on } \\
\text { surface of faults. If } \\
\text { necessary, extract } \\
\text { CO2 from leaky } \\
\text { formation and reinject } \\
\text { CO2 into a sealed } \\
\text { formation. }\end{array}$ \\
\hline
\end{tabular}




\begin{tabular}{|c|c|c|c|c|c|c|c|c|c|c|c|c|c|}
\hline \multicolumn{6}{|c|}{ CO2 Geologic Sequestration Risks for the IMCCS Project } & \multicolumn{3}{|c|}{ Project Specific Information } & \multicolumn{3}{|c|}{ Risk Ranking } & \multicolumn{2}{|c|}{ Prevention and Mitigation } \\
\hline Line \# & Index No. & Risk Area & Description & Relevance & $\begin{array}{c}\text { Qunitessa } \\
\text { FEP } \\
\text { Category }\end{array}$ & $\begin{array}{l}\text { Individual } \\
\text { Comments }\end{array}$ & $\begin{array}{c}\text { Imccs Project } \\
\text { Specific Information }\end{array}$ & \begin{tabular}{|c|} 
IMCCS Project \\
Information Gaps \\
or Uncertainties
\end{tabular} & 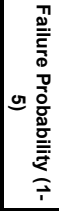 & 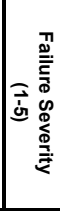 & 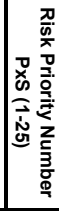 & $\begin{array}{l}\text { Risk Prevention } \\
\text { Steps (Actions } \\
\text { taken to reducee } \\
\text { risk probability) }\end{array}$ & $\begin{array}{l}\text { Risk Mitigation } \\
\text { Steps (Actions taken } \\
\text { to reduce risk } \\
\text { severity) }\end{array}$ \\
\hline 197 & 3.3.01.02. & $\begin{array}{c}\text { CO2 leakage } \\
\text { through an existing } \\
\text { open fault }\end{array}$ & Existing open fault detected or undetected. & $\begin{array}{l}\mathrm{CO} 2 \text { can leak through an open fault into } \\
\text { shallower formations or the surface. }\end{array}$ & \begin{tabular}{|l} 
Additional \\
[new] FEP
\end{tabular} & $\begin{array}{l}\text { Unlikely to be a } \\
\text { issue. }\end{array}$ & $\begin{array}{l}\text { Existing faults in G-E } \\
\text { are stable, down dip } \\
\text { and don't penetrate } \\
\text { the caprock. The } \\
\text { Arbuckle can't be } \\
\text { pressurized in that } \\
\text { area. Faults in T-A are } \\
25 \text { miles away and the } \\
\text { Bartlesville Sandstone } \\
\text { is isolated. }\end{array}$ & & 2 & 4 & 8 & $\begin{array}{l}\text { Don't inject CO2 } \\
\text { near faults. Don't } \\
\text { overpressure the } \\
\text { reservoir near faults. }\end{array}$ & $\begin{array}{l}\text { Monitor micro- } \\
\text { seismicity and } \mathrm{CO} 2 \text { on } \\
\text { surface of faults. If } \\
\text { necessary, extract } \\
\text { CO2 from leaky } \\
\text { formation and reinject } \\
\text { CO2 into a sealed } \\
\text { formation. }\end{array}$ \\
\hline 198 & 3.3.01.03. & $\begin{array}{l}\text { CO2 leakage } \\
\text { through a } \\
\text { reactivated fault }\end{array}$ & $\begin{array}{l}\text { Reactivation of an existing fault due to } \\
\text { pressure buildup from } \mathrm{CO2} \text { injection. }\end{array}$ & $\begin{array}{l}\text { CO2 can leak through a reactivated fault into } \\
\text { shallower formations or the surface. }\end{array}$ & \begin{tabular}{|l} 
Additional \\
[new] FEP
\end{tabular} & $\begin{array}{l}\text { Unlikely to be a } \\
\text { issue. }\end{array}$ & $\begin{array}{l}\text { Existing faults in G-E } \\
\text { are stable, down dip } \\
\text { and don't penetrate } \\
\text { the caprock. The } \\
\text { Arbuckle can't be } \\
\text { pressurized in that } \\
\text { area. Faults in T-A are } \\
25 \text { miles away and the } \\
\text { Bartlesville Sandstone } \\
\text { is isolated. }\end{array}$ & & 2 & 4 & 8 & $\begin{array}{l}\text { Don't inject CO2 } \\
\text { near faults. Don't } \\
\text { overpressure the } \\
\text { reservoir near faults. }\end{array}$ & $\begin{array}{l}\text { Monitor micro- } \\
\text { seismicity and } \mathrm{CO} 2 \text { on } \\
\text { surface of faults. If } \\
\text { necessary, extract } \\
\text { CO2 from leaky } \\
\text { formation and reinject } \\
\text { CO2 into a sealed } \\
\text { formation. }\end{array}$ \\
\hline 199 & 3.3.02.00. & $\begin{array}{l}\text { Buoyancy-driven } \\
\text { flow }\end{array}$ & $\begin{array}{l}\text { Different relative densities of fluids in a } \\
\text { geological system will result in buoyancy- } \\
\text { driven flows as less dense fluids will have a } \\
\text { tendency to flow upwards. The density of } \\
\text { fluids will depend on its temperature and } \\
\text { pressure. }\end{array}$ & $\begin{array}{l}\text { Carbon dioxide can be less dense than water, } \\
\text { which may cause injected CO2 to flow upwards } \\
\text { and accumulate above the water phase below } \\
\text { the caprock of a reservoir. Water with dissolved } \\
\text { CO2 is more dense than water, which can result } \\
\text { in stratification of water bodies into which CO2 } \\
\text { may leak, if conditions are suitable. }\end{array}$ & $\begin{array}{l}\text { Quintessa } \\
\text { original FEP }\end{array}$ & $\begin{array}{l}\text { Buoyancy driven } \\
\text { flow not an issue } \\
\text { with EOR in G-E } \\
\text { and T-A except if } \\
\text { tied to well bore } \\
\text { leakage. May not } \\
\text { be an issue in } \\
\text { DSA due to the } \\
\text { small amount of } \\
\text { CO2 to be } \\
\text { injected. }\end{array}$ & \begin{tabular}{|l|} 
Buoyancy driven flow \\
is helpful for gravity \\
stable flooding in the \\
G-E dome. In G-E \\
DSA, buoyancy driven \\
flow will push CO2 \\
upward into oil \\
reservoir. In T-A, \\
Bartlesville Sandstone \\
is isolated and CO2 \\
will be conventional \\
piston flood. In T-A \\
DSA, buoyancy driven \\
flow will cause CO2 to \\
flow up to top of \\
Arbuckle and spread \\
out until plume is \\
stabilized.
\end{tabular} & & 3 & 2 & 6 & $\begin{array}{l}\text { Ensure integrity of } \\
\text { vertical and lateral } \\
\text { seals. }\end{array}$ & $\begin{array}{l}\text { Monitor and model } \\
\text { CO2 plume. If } \\
\text { necessary, extract } \\
\text { CO2 from leaky } \\
\text { formation and reinject } \\
\text { CO2 into a sealed } \\
\text { formation. }\end{array}$ \\
\hline 200 & 3.3.02.01. & \begin{tabular}{|l} 
CO2 exceeding \\
reservoir spill point
\end{tabular} & $\begin{array}{l}\text { CO2 migrates beyond the reservoir's } \\
\text { structural spill points. }\end{array}$ & & \begin{tabular}{|l} 
Additional \\
[new] FEP
\end{tabular} & Possible issue. & $\begin{array}{l}\text { Applicable to spill } \\
\text { points in G-E domes. }\end{array}$ & & 3 & 3 & 9 & $\begin{array}{l}\text { Stop cO2 injection } \\
\text { before exceeding } \\
\text { spill point in domes. } \\
\text { Switch injection to } \\
\text { other domes. }\end{array}$ & $\begin{array}{l}\text { Monitor and model } \\
\text { CO2 plume and adjust } \\
\text { CO2 injection strategy } \\
\text { if necessary to control } \\
\text { CO2 migration. Could } \\
\text { include recovery of } \\
\text { CO2 and reinjection } \\
\text { elsewhere. }\end{array}$ \\
\hline
\end{tabular}




\begin{tabular}{|c|c|c|c|c|c|c|c|c|c|c|c|c|c|}
\hline \multicolumn{6}{|c|}{ CO2 Geologic Sequestration Risks for the IMCCS Project } & \multicolumn{3}{|c|}{ Project Specific Information } & \multicolumn{3}{|c|}{ Risk Ranking } & \multicolumn{2}{|c|}{ Prevention and Mitigation } \\
\hline Line \# & Index No. & Risk Area & Description & Relevance & $\begin{array}{l}\text { Qunitessa } \\
\text { FEP } \\
\text { Category }\end{array}$ & $\begin{array}{l}\text { Individual } \\
\text { Comments }\end{array}$ & $\begin{array}{c}\text { IMCCS Project } \\
\text { Specific Information }\end{array}$ & \begin{tabular}{|l} 
IMccs Project \\
Information Gaps \\
or Uncertainties
\end{tabular} & 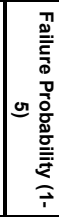 & 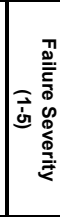 & 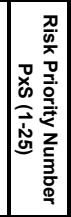 & $\begin{array}{l}\text { Risk Prevention } \\
\text { Steps (Actions } \\
\text { taken to reduce } \\
\text { risk probability) }\end{array}$ & $\begin{array}{l}\text { Risk Mitigation } \\
\text { Steps (Actions taker } \\
\text { to reduce risk } \\
\text { severity) }\end{array}$ \\
\hline 201 & 3.3.02.02. & Lateral $\mathrm{CO} 2$ flow & $\begin{array}{l}\text { CO2 migrates laterally across the reservoir } \\
\text { formation into unintended areas. }\end{array}$ & $\begin{array}{l}\text { May result in migration up a fault, groundwater } \\
\text { contamination, civil suit for trespass, permit } \\
\text { revocation, increased monitoring costs, etc. }\end{array}$ & \begin{tabular}{|l} 
Additional \\
[new] FEP
\end{tabular} & Possible issue. & \begin{tabular}{|l} 
Applicable to T-A \\
DSA. No lateral seals \\
in Arbuckle below T-A.
\end{tabular} & $\begin{array}{l}\text { Need 3-d seismic } \\
\text { to identify potential } \\
\text { traps in top of } \\
\text { Arbuckle at T-A... }\end{array}$ & 3 & 3 & 9 & $\begin{array}{l}\text { Characterize the site } \\
\text { for lateral seals. } \\
\text { Keep CO2 injection } \\
\text { to a minimum if } \\
\text { there are no lateral } \\
\text { seals. }\end{array}$ & $\begin{array}{l}\text { Monitor and model } \\
\text { CO2 plume and adjus } \\
\text { CO2 injection strategy } \\
\text { if necessary to control } \\
\text { CO2 migration. Could } \\
\text { include recovery of } \\
\text { CO2 and reinjection } \\
\text { elsewhere. }\end{array}$ \\
\hline 202 & 3.3.03.00. & $\begin{array}{l}\text { Displacement of } \\
\text { formation fluids }\end{array}$ & $\begin{array}{l}\text { This depends on interfacial tension and } \\
\text { capillary pressure. } \\
\text { Capillary pressure is the pressure difference } \\
\text { existing across the interface separating two } \\
\text { immiscible fluids due to interfacial tension. } \\
\text { The interfacial tension itself is caused by the } \\
\text { imbalance in the molecular forces of } \\
\text { attraction experienced by the molecules at } \\
\text { the surface and is a function of temperature } \\
\text { and pressure. } \\
\text { At a given pressure, increased interfacial } \\
\text { tension values between water and CO2 will } \\
\text { make larger pores accessible to CO2 (this is } \\
\text { only valid for water-wet systems). The } \\
\text { change from a water-wet system to a CO2- } \\
\text { wet system has an effect on capillary forces } \\
\text { (ite. displacement of water by enhanced } \\
\text { pressure versus CO2 injection with less } \\
\text { capillary pressure) and the displacement } \\
\text { capacity (ie.e. as a non-wetting fluid, CO2 will } \\
\text { have less displacement capacity). If the } \\
\text { injection velocity is high, effects of capillary } \\
\text { forces are small. }\end{array}$ & $\begin{array}{l}\text { Interfacial tension and capillary pressure } \\
\text { determine the location of CO2 within the pore } \\
\text { spaces of the reservoir and the displacement } \\
\text { capacity of the reservoir. }\end{array}$ & $\begin{array}{l}\text { Quintessa } \\
\text { original FEP }\end{array}$ & \begin{tabular}{|l|} 
Not an issue with \\
EOR because \\
oil/water \\
production \\
compensate for \\
CO2 injection. Not \\
an issue for DSA \\
in the Arbuckle \\
due to limited \\
amount of \\
injection and \\
under pressured \\
reservoir.
\end{tabular} & & & 1 & 3 & 3 & $\begin{array}{l}\text { Characterize and } \\
\text { model the reservoirs. } \\
\text { Keep CO2 injection } \\
\text { for DSA to a } \\
\text { minimum. }\end{array}$ & $\begin{array}{l}\text { Monitor and model } \\
\text { displacement of } \\
\text { formation fluids. If } \\
\text { necessary, extract } \\
\text { brine and reinjection } \\
\text { elsewhere. }\end{array}$ \\
\hline 203 & 3.3.04.00. & $\begin{array}{l}\text { Dissolution in } \\
\text { formation fluids }\end{array}$ & $\begin{array}{l}\text { The process of dissolution of } \mathrm{CO} 2 \text { in } \\
\text { formation fluids. The rate of dissolution } \\
\text { depends on factors such as the interfacial } \\
\text { area between the } \mathrm{CO} 2 \text { and the formation } \\
\text { fluids and temperature. }\end{array}$ & $\begin{array}{l}\text { Dissolution in formation fluids can be an } \\
\text { important process in determining the period that } \\
\text { free } \mathrm{CO} 2 \text { remains in the reservoir. }\end{array}$ & $\begin{array}{l}\text { Quintessa } \\
\text { original FEP }\end{array}$ & $\begin{array}{l}\text { Not likely to be an } \\
\text { issue. Dissolution } \\
\text { of } \mathrm{CO} 2 \text { takes } \\
\text { thousands of } \\
\text { years. }\end{array}$ & & & 1 & 2 & 2 & $\begin{array}{l}\text { Include dissolution in } \\
\text { model. }\end{array}$ & $\begin{array}{l}\text { Include dissolution in } \\
\text { model. }\end{array}$ \\
\hline 204 & 3.3.04.02. & $\begin{array}{l}\mathrm{CO} 2 \text { exsolution } \\
\text { from water }\end{array}$ & $\begin{array}{l}\text { Long-term risks might result from the } \\
\text { gravitational sinking of dense CO2 saturated } \\
\text { brines; if they come into contact with salt } \\
\text { formations this could lead to a degassing of } \\
\text { the formation water and the ascent of CO2 } \\
\text { outside of the original closed storage } \\
\text { structure. (CO2STORE, page 68) } \\
\text { Exsolution can also occur under significant } \\
\text { (large) changes in pressure or temperature. } \\
\text { The risk of major changes in pressure or } \\
\text { temperature in a deep reservoir is very low. }\end{array}$ & $\begin{array}{l}\text { Displaced brine containing dissolved } \mathrm{CO} 2 \text { flows } \\
\text { to the surface and releases } \mathrm{CO} 2 \text { to the } \\
\text { atmosphere or ocean. }\end{array}$ & \begin{tabular}{|l} 
Additional \\
[new] FEP
\end{tabular} & $\begin{array}{l}\text { Not likely to be an } \\
\text { issue. The amount } \\
\text { of } \mathrm{CO} 2 \text { available } \\
\text { for exsolution is } \\
\text { expected to be } \\
\text { very low. }\end{array}$ & & & 1 & 2 & 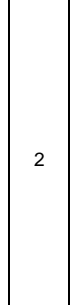 & $\begin{array}{l}\text { Characterize } \\
\text { reservoir. Maintain } \\
\text { integrity of vertical } \\
\text { and lateral seals. } \\
\text { Include } \mathrm{CO} 2 \\
\text { exsolution in } \\
\text { modeling. }\end{array}$ & $\begin{array}{l}\text { Monitor ground water } \\
\text { and surface water } \\
\text { CO2 content. Extract } \\
\text { contaminated water, } \\
\text { remove contaminants } \\
\text { and reinject treated } \\
\text { water and CO2. }\end{array}$ \\
\hline
\end{tabular}

Appendix 6-38

Quintessa Original FEP: Taken from Quintessa's on-line CO2 FEP database, which is freely accessible at: http://www.quintessa.org/co2fepdb/ 


\begin{tabular}{|c|c|c|c|c|c|c|c|c|c|c|c|c|c|}
\hline \multicolumn{6}{|c|}{ CO2 Geologic Sequestration Risks for the IMCCS Project } & \multicolumn{3}{|c|}{ Project Specific Information } & \multicolumn{3}{|c|}{ Risk Ranking } & \multicolumn{2}{|c|}{ Prevention and Mitigation } \\
\hline Line \# & Index No. & Risk Area & Description & Relevance & $\begin{array}{c}\text { Qunitessa } \\
\text { FEP } \\
\text { Category }\end{array}$ & $\begin{array}{l}\text { Individual } \\
\text { Comments }\end{array}$ & $\begin{array}{c}\text { IMCcS Project } \\
\text { Specific Information }\end{array}$ & \begin{tabular}{|c|} 
IMCCS Project \\
Information Gaps \\
or Uncertainties
\end{tabular} & 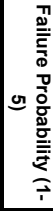 & 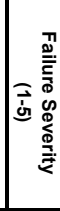 & 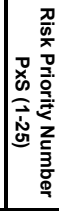 & $\begin{array}{l}\text { Risk Prevention } \\
\text { Steps (Actions } \\
\text { taken to reduce } \\
\text { risk probability) }\end{array}$ & $\begin{array}{c}\text { Risk Mitigation } \\
\text { Steps (Actions taken } \\
\text { to reduce risk } \\
\text { severity) }\end{array}$ \\
\hline 205 & 3.3.05.00. & $\begin{array}{l}\text { Water mediated } \\
\text { transport }\end{array}$ & $\begin{array}{l}\text { Processes related to the transport of CO2, } \\
\text { and associated contaminants, in } \\
\text { groundwater and surface water, including } \\
\text { advection, dispersion and molecular } \\
\text { diffusion. } \\
\text { Advection is the process by which } \\
\text { contaminants are transported by the bulk } \\
\text { movement of the water in which they are } \\
\text { dissolved. Advective groundwater flow can } \\
\text { occur along connected porous regions, such } \\
\text { as fractures and faults. } \\
\text { Dispersion is the collective name for the } \\
\text { consequences of a number of processes } \\
\text { that cause 'spreading-out' of CO2, and } \\
\text { associated contaminants, , issolved in water } \\
\text { in all directions, superimposed on the bulk } \\
\text { movement predicted by a simple advection } \\
\text { model. It results in a spatially distributed } \\
\text { contaminant plume. } \\
\text { Diffusion is the process whereby chemical } \\
\text { species move under the influence of a } \\
\text { chemical potential gradient (usually a } \\
\text { concentration gradient). }\end{array}$ & $\begin{array}{l}\text { The transport of } \mathrm{CO} 2 \text {, and associated } \\
\text { contaminants, within groundwater is likely to be a } \\
\text { key migration process and therefere an important } \\
\text { consideration in determining performance and } \\
\text { safety. } \\
\text { CO2 dissolves in brine at co2/brine interface } \\
\text { and brine transports } \mathrm{CO} \text { out of closure. }\end{array}$ & $\begin{array}{l}\text { Quintessa } \\
\text { original FEP }\end{array}$ & $\begin{array}{l}\text { Not likely to be an } \\
\text { issue. There is } \\
\text { very little } \\
\text { groundwater in the } \\
\text { project areas. }\end{array}$ & & & 2 & 2 & 4 & $\begin{array}{l}\text { Ensure integrity of } \\
\text { vertical and lateral } \\
\text { seals. Monitor wells } \\
\text { for leakage and } \\
\text { repair leaky wells. }\end{array}$ & $\begin{array}{l}\text { Monitor ground water } \\
\text { and surface water } \\
\text { CO2 content. Extract } \\
\text { contaminated water, } \\
\text { remove contaminants } \\
\text { and reinject treated } \\
\text { water and } \mathrm{CO} 2 .\end{array}$ \\
\hline 206 & 3.3.06.00. & $\begin{array}{l}\text { CO2 release } \\
\text { processes }\end{array}$ & $\begin{array}{l}\text { Processes by which } \mathrm{CO} 2 \text { is lost from the } \\
\text { sequestration system. Once in the near- } \\
\text { surface, changes in pressure and } \\
\text { temperature result in the potential for phase } \\
\text { changes and degassing, with resulting } \\
\text { changes in the transport properties of } \\
\text { sequestered CO2. Examples of } \mathrm{CO} 2 \text { release } \\
\text { processes include: } \\
\text { - surface and undersea blowouts; } \\
\text { - cO2 geysers such as Crystal Geyser in } \\
\text { Utah; } \\
\text { - submarine gas release. }\end{array}$ & $\begin{array}{l}\text { The potential for } \mathrm{CO} 2 \text { to be lost from a } \\
\text { sequestration system will determine the } \\
\text { performance of that system. }\end{array}$ & $\begin{array}{l}\text { Quintessa } \\
\text { original FEP }\end{array}$ & Possible issue. & \begin{tabular}{|l} 
Most likely to be tied to \\
wellbore leakage.
\end{tabular} & & 3 & 4 & 12 & $\begin{array}{l}\text { Ensure integrity of } \\
\text { vertical and lateral } \\
\text { seals. }\end{array}$ & $\begin{array}{l}\text { Monitor higher } \\
\text { formations, surface } \\
\text { and wells for CO2 } \\
\text { leakage. Plug leaks. If } \\
\text { necessary, extract } \\
\text { CO2 from leaky } \\
\text { formation and reinject } \\
\text { CO2 into a sealed } \\
\text { formation. }\end{array}$ \\
\hline
\end{tabular}




\begin{tabular}{|c|c|c|c|c|c|c|c|c|c|c|c|c|c|}
\hline \multicolumn{6}{|c|}{ CO2 Geologic Sequestration Risks for the IMCCS Project } & \multicolumn{3}{|c|}{ Project Specific Information } & \multicolumn{3}{|c|}{ Risk Ranking } & \multicolumn{2}{|c|}{ Prevention and Mitigation } \\
\hline Line \# & Index No. & Risk Area & Description & Relevance & $\begin{array}{l}\text { Qunitessa } \\
\text { FEP } \\
\text { Category }\end{array}$ & $\begin{array}{l}\text { Individual } \\
\text { Comments }\end{array}$ & $\begin{array}{c}\text { IMCCS Project } \\
\text { Specific Information }\end{array}$ & \begin{tabular}{|c|} 
IMccs Project \\
Information Gaps \\
or Uncertainties
\end{tabular} & 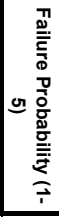 & 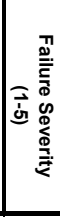 & 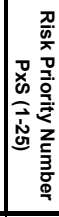 & $\begin{array}{l}\text { Risk Prevention } \\
\text { Steps (Actions } \\
\text { taken to reduce } \\
\text { risk probability) }\end{array}$ & $\begin{array}{l}\text { Risk Mitigation } \\
\text { Steps (Actions taken } \\
\text { to reduce risk } \\
\text { severity) }\end{array}$ \\
\hline 207 & 3.3.06.01. & Limnic eruption & \begin{tabular}{|l|} 
The rapid turnover and degassing of $\mathrm{CO} 2$ \\
from a surface water body. \\
\\
Due to the high solubility of $\mathrm{CO} 2$ in water, a \\
lake can dissolve a volume of CO2 that, in \\
gaseous form, is more than five times its \\
volume. CO2 rich water is denser that pure \\
water which can result in an unstable \\
stratification. A drop in temperature will \\
reduce the solubility of CO2 in water. If the \\
water reaches its solubility limit as a result, \\
bubbles will nucleate. \\
and the bubblew, a chain reaction occurs where \\
and gudden ex-solution of $\mathrm{CO} 2$ can result in a \\
rapid degassing of the water body with an \\
eruption of rising, expanding bubbles. \\
Limnic eruptions can be triggered by events \\
such as landslides that disturb the unstable \\
stratification.
\end{tabular} & $\begin{array}{l}\text { Limnic eruption provides a release mechanism } \\
\text { for CO2, migrating from a storage system to the } \\
\text { atmosphere. } \\
\text { Natural limnic eruption events can be } \\
\text { catastrophic. On the 29th of August 1986, a } \\
\text { massive limnic eruption from Lake Nyos in } \\
\text { Cameroon resulted in } 1800 \text { deaths as the CO2 } \\
\text { smothered local villages. The CO2, which is } \\
\text { volcanic in origin, seeps through the lake bed } \\
\text { sediments and builds up in the lower strata of the } \\
\text { water column. } \\
\text { The Lake Nyos sudden release involved an } \\
\text { estimated 240,000 tonnes of CO2 (Damen 2006) }\end{array}$ & $\begin{array}{l}\text { Quintessa } \\
\text { original FEP }\end{array}$ & $\begin{array}{l}\text { Very unlikely to be } \\
\text { an issue. }\end{array}$ & $\begin{array}{l}\text { No significant surface } \\
\text { water bodies in the } \\
\text { injection area }\end{array}$ & & 1 & 5 & 5 & $\begin{array}{l}\text { Avoid injection under } \\
\text { deep lakes. }\end{array}$ & $\begin{array}{l}\text { Monitor CO2 buildup } \\
\text { in bottom of deep } \\
\text { lakes and use } \\
\text { convection to keep } \\
\text { CO2 content under } \\
\text { control. }\end{array}$ \\
\hline 208 & 3.3.06.02. & Surface blowout & & $\begin{array}{l}\text { Could occur as a well blowout. CO2 shooting } \\
\text { into the atmosphere will rapid mixing with air. } \\
\text { nijury more likely from flying object rather than } \\
\text { CO2 asphyxiation. }\end{array}$ & $\begin{array}{l}\text { Expansion of } \\
\text { Q FEP }\end{array}$ & $\begin{array}{l}\text { Very unlikely to be } \\
\text { an issue. }\end{array}$ & & & 1 & 3 & 3 & $\begin{array}{l}\text { Replug old wells. } \\
\text { Maintain well } \\
\text { integrity. Install } \\
\text { automatic shut off } \\
\text { protection. }\end{array}$ & $\begin{array}{l}\text { Alert any people at } \\
\text { risk. Shutdown and } \\
\text { plug leak. Train } \\
\text { operators and educate } \\
\text { residence on what to } \\
\text { do if a blowout occurs. }\end{array}$ \\
\hline 209 & 3.3.06.03. & Undersea blowout & & & $\begin{array}{c}\text { Expansion of } \\
\text { Q FEP }\end{array}$ & $\begin{array}{l}\text { Very unlikely to be } \\
\text { an issue. }\end{array}$ & & & 1 & 3 & 3 & NA & NA \\
\hline 210 & 3.3.06.04. & CO2 geyser & & & $\begin{array}{c}\text { Expansion of } \\
\text { Q FEP }\end{array}$ & $\begin{array}{l}\text { Very unlikely to be } \\
\text { an issue. }\end{array}$ & & & 1 & 3 & 3 & NA & NA \\
\hline 211 & 3.3.06.05. & $\begin{array}{c}\text { Submarine gas } \\
\text { release }\end{array}$ & & & $\begin{array}{c}\text { Expansion of } \\
\text { Q FEP }\end{array}$ & $\begin{array}{l}\begin{array}{l}\text { Very unlikely to be } \\
\text { an issue. }\end{array} \\
\end{array}$ & & & 1 & 3 & 3 & NA & NA \\
\hline 212 & 3.3.06.06. & $\begin{array}{l}\text { Diffusion through } \\
\text { soil }\end{array}$ & & & \begin{tabular}{|l} 
Additional \\
[new] FEP
\end{tabular} & $\begin{array}{l}\text { Possible if tied to } \\
\text { a leaky well. }\end{array}$ & & & 3 & 2 & 6 & \begin{tabular}{|l|} 
Plug and seal old \\
wells. Increase \\
pressure Bartlesville \\
reservoir with water, \\
check for leaks and \\
fix them prior to \\
injecting $\mathrm{CO} 2$.
\end{tabular} & $\begin{array}{l}\text { Monitor Soil and } \\
\text { atmosphere for } \mathrm{CO} 2 . \\
\text { Plug leaks or } \\
\text { depressurize leaky } \\
\text { reservoir. }\end{array}$ \\
\hline 213 & 3.3.06.07. & $\begin{array}{l}\text { Mud volcano or } \\
\text { mud flow }\end{array}$ & \begin{tabular}{|l|} 
In fine-clastic unconsolidated rocks, \\
suspensions could form and cause mud- \\
volcanism and mud flows. (CO2STORE \\
p.68) \\
Mud diapir could be formed in \\
unconsolidated (plastic, water-rich, under- \\
compacted ) reservoir and overburden strata \\
possibly including the entire reservoir \\
because of the buoyancy of store CO2. \\
(CO2STORE, page 68)
\end{tabular} & CO2 released to the surface in mud flow. & \begin{tabular}{|l} 
Additional \\
[new] FEP
\end{tabular} & $\begin{array}{l}\text { Very unlikely to be } \\
\text { an issue. }\end{array}$ & & & 1 & 3 & 3 & NA & NA \\
\hline
\end{tabular}

Appendix 6-40

Quintessa Original FEP: Taken from Quintessa's on-line CO2 FEP database, which is freely accessible at: http://www.quintessa.org/co2fepdb/ 


\begin{tabular}{|c|c|c|c|c|c|c|c|c|c|c|c|c|c|}
\hline \multicolumn{6}{|c|}{ CO2 Geologic Sequestration Risks for the IMCCS Project } & \multicolumn{3}{|c|}{ Project Specific Information } & \multicolumn{3}{|c|}{ Risk Ranking } & \multicolumn{2}{|c|}{$\begin{array}{l}\text { Prevention and Mitigation } \\
\end{array}$} \\
\hline Line \# & Index No. & Risk Area & Description & Relevance & $\begin{array}{l}\text { Qunitessa } \\
\text { FEP } \\
\text { Category }\end{array}$ & $\begin{array}{l}\text { Individual } \\
\text { Comments }\end{array}$ & $\begin{array}{c}\text { IMCCS Project } \\
\text { Specific Information }\end{array}$ & \begin{tabular}{|c|} 
ImCcCS Project \\
Information Gaps \\
or Uncertainties
\end{tabular} & 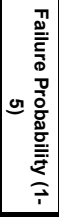 & 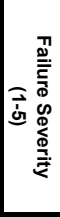 & 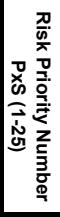 & $\begin{array}{l}\text { Risk Prevention } \\
\text { Steps (Actions } \\
\text { taken to reduce } \\
\text { risk probability) }\end{array}$ & $\begin{array}{l}\text { Risk Mitigation } \\
\text { Steps (Actions taken } \\
\text { to reduce risk } \\
\text { severity) }\end{array}$ \\
\hline 214 & 3.3.07.00. & $\begin{array}{c}\text { Co-migration of } \\
\text { other gases }\end{array}$ & \begin{tabular}{|l|} 
Surface seepages of CO2 may contain \\
significant amounts of other gases due to co- \\
migration, such as hydrogen suluhhide ( (2SS). \\
This is especially the case where the CO2 \\
reservoir is a reducing chemical \\
environment. H2S is derived from the \\
hydration of sulphide minerals (e.g. FeS) or \\
from the chemical reduction of aqueous \\
sulphate species. . H2S is highly toxic and \\
therefore potentially harmful to the \\
biosphere. Even in low concentrations it is \\
deleterious to long-term health \\
(humanlanimal), in addition to being \\
extremely unpleasant.
\end{tabular} & $\begin{array}{l}\text { The co-migration of other gases to the surface } \\
\text { environment may cause areas of leakage to } \\
\text { become uninhabitable - at least temporarily. } \\
\text { The detection of H2S provides a quick (non- } \\
\text { analytical/aesthetic) test for CO2 escape and } \\
\text { thus can be used as a "marker" gas. }\end{array}$ & $\begin{array}{l}\text { Quintessa } \\
\text { original FEP }\end{array}$ & $\begin{array}{l}\text { Potential for } \mathrm{CO} 2 \\
\text { to pick up H2S in } \\
\text { the G-E Arbuckle. }\end{array}$ & & & 3 & 3 & 9 & $\begin{array}{l}\text { Ensure the integrity } \\
\text { of vertical and lateral } \\
\text { seals. }\end{array}$ & \begin{tabular}{|l|} 
Monitor for $\mathrm{H} 2 \mathrm{~S}$ and \\
train operators how to \\
handle $\mathrm{H} 2 \mathrm{~S}$ \\
appropriately.
\end{tabular} \\
\hline 215 & 4.0.00.00. & Geosphere & $\begin{array}{l}\text { This category of FEPs is concerned with the } \\
\text { geology, hydrogeology and geochemistry of } \\
\text { the geosphere. The category covers the } \\
\text { reservoir, overburden and surrounding rock } \\
\text { up to the near-surface which is considered in } \\
\text { a separate FEP category. } \\
\text { Taken together, the FEPs in this category } \\
\text { describe what is known about the natural } \\
\text { system prior to sequestration operations } \\
\text { commencing. The category is divided into } \\
\text { three classes: Geology, Fluids, and } \\
\text { Geochemistry. }\end{array}$ & & $\begin{array}{l}\text { Quintessa } \\
\text { original FEP }\end{array}$ & & & & NA & NA & NA & NA & NA \\
\hline 216 & 4.1.00.00. & Geology & $\begin{array}{l}\text { Geological features of the geosphere, which } \\
\text { comprises of the reservoir, overburden and } \\
\text { surrounding rock prior to injection of } \mathrm{CO} 2 .\end{array}$ & $\begin{array}{l}\text { An understanding of the natural system into } \\
\text { which the carbon dioxide is injected is essential } \\
\text { for the assessment of long-term performance } \\
\text { and safety. }\end{array}$ & $\begin{array}{l}\text { Quintessa } \\
\text { original FEP }\end{array}$ & $\begin{array}{l}\text { Very unlikely to be } \\
\text { an issue. }\end{array}$ & $\begin{array}{l}\text { G-E and T-A have } \\
\text { isolated oil reservoirs } \\
\text { with multiple seals and } \\
\text { sinks above. }\end{array}$ & & 1 & 2 & 2 & $\begin{array}{l}\text { Fully characterize } \\
\text { the EOR and DSA } \\
\text { sites. }\end{array}$ & NA \\
\hline 217 & 4.1.01.00. & $\begin{array}{l}\text { Geographical } \\
\text { location }\end{array}$ & $\begin{array}{l}\text { The geographic location of a } \mathrm{CO} 2 \text { storage } \\
\text { reservoir will lifluence the type of impacts to } \\
\text { consider, e.g. continental or sub-marine, in } \\
\text { the vicinity of a volcano, or tectonic activity, } \\
\text { etc. In addition, proximity to human } \\
\text { populations will increase importance of any } \\
\text { release to the surface. }\end{array}$ & $\begin{array}{l}\text { Proximity to natural hazards will increase their } \\
\text { importance in being considered in the } \\
\text { assessment. Proximity to human populations } \\
\text { place more emphasis on the significance of near- } \\
\text { surface releases. }\end{array}$ & $\begin{array}{l}\text { Quintessa } \\
\text { original FEP }\end{array}$ & $\begin{array}{l}\text { Very unlikely to be } \\
\text { an issue. }\end{array}$ & $\begin{array}{l}\text { G-E has } 216 \\
\text { residences in or near } \\
\text { the project area and T- } \\
\text { A has none. }\end{array}$ & & 1 & 3 & 3 & \begin{tabular}{|l|} 
Avoid siting project \\
near natural hazards \\
and dense \\
population areas.
\end{tabular} & \begin{tabular}{|l|} 
Prepare emergency \\
response plan and \\
educate employees \\
and neighbors on what \\
to do in an \\
emergency.
\end{tabular} \\
\hline 218 & 4.1.01.01. & Onshore reservoir & & $\begin{array}{l}\text { The potential impact on human beings of a } \\
\text { sudden release of CO2 from an onshore } \\
\text { reservoir will be higher than from an onshore } \\
\text { reservoir (Damen 2006) }\end{array}$ & \begin{tabular}{|l} 
Additional \\
[new] FEP
\end{tabular} & \begin{tabular}{|l|} 
Unlikely to be an \\
issue.
\end{tabular} & $\begin{array}{l}\text { G-E and T-A are } \\
\text { located onshore in } \\
\text { sparely populated } \\
\text { areas. }\end{array}$ & & 2 & 3 & 6 & \begin{tabular}{|l|} 
Avoid siting project \\
near dense \\
populations. Ensure \\
the integrity of \\
vertical and lateral \\
seals.
\end{tabular} & \begin{tabular}{|l|} 
Prepare emergency \\
response plan and \\
educate employees \\
and neighbors on what \\
to do in an \\
emergency.
\end{tabular} \\
\hline 219 & 4.1.01.02. & Offshore reservoir & & $\begin{array}{l}\text { The potential impact on human beings of a } \\
\text { sudden release of } \mathrm{CO} 2 \text { from an offshore } \\
\text { reservoir will be lower than from an onshore } \\
\text { reservoir (Damen 2006). However } \mathrm{CO} 2 \text { storage } \\
\text { costs are likely to be higher for offshore } \\
\text { reservoirs. }\end{array}$ & \begin{tabular}{|l} 
Additional \\
[new] FEP
\end{tabular} & NA & NA & & 1 & 2 & 2 & NA & NA \\
\hline 220 & 4.1.02.00. & Natural resources & $\begin{array}{l}\text { Natural resources within the geosphere } \\
\text { including solid mineralogical resources, such } \\
\text { as coal or minerals, fluid and gaseous } \\
\text { resources, such as hydrocarbons EOR and } \\
\text { ECBM) or water, and other resources such } \\
\text { as geothermal or microbial resources. }\end{array}$ & $\begin{array}{l}\begin{array}{l}\text { The presence of natural resources may mean } \\
\text { that future human exploitation of the system } \\
\text { cannot be ignored in assessing long-term } \\
\text { performance since they may increase the } \\
\text { possibility of future human intrusion. }\end{array} \text { Appen } \\
\end{array}$ & $\begin{array}{l}\text { Quintessa } \\
\text { original FEP } \\
\text { dix 6-41 }\end{array}$ & $\begin{array}{l}\text { Very unlikely to be } \\
\text { an issue. }\end{array}$ & $\begin{array}{l}\text { No known mineral } \\
\text { resources other than } \\
\text { oil at sites. }\end{array}$ & & 1 & 2 & 2 & NA & NA \\
\hline
\end{tabular}

Quintessa Original FEP: Taken from Quintessa's on-line CO2 FEP database, which is freely accessible at: http://www.quintessa.org/co2fepdb/ 


\begin{tabular}{|c|c|c|c|c|c|c|c|c|c|c|c|c|c|}
\hline \multicolumn{6}{|c|}{ CO2 Geologic Sequestration Risks for the IMCCS Project } & \multicolumn{3}{|c|}{ Project Specific Information } & \multicolumn{3}{|c|}{ Risk Ranking } & \multicolumn{2}{|c|}{ Prevention and Mitigation } \\
\hline Line \# & Index No. & Risk Area & Description & Relevance & $\begin{array}{l}\text { Qunitessa } \\
\text { FEP } \\
\text { Category }\end{array}$ & $\begin{array}{l}\text { Individual } \\
\text { Comments }\end{array}$ & $\begin{array}{c}\text { IMCCS Project } \\
\text { Specific Information }\end{array}$ & $\mid \begin{array}{c}\text { IMccs Project } \\
\text { Information Gaps } \\
\text { or Uncertainties }\end{array}$ & 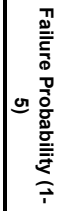 & 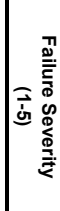 & 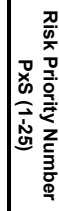 & $\begin{array}{c}\text { Risk Prevention } \\
\text { Steps (Actions } \\
\text { taken to reduce } \\
\text { risk probability) }\end{array}$ & $\begin{array}{l}\text { Risk Mitigation } \\
\text { Steps (Actions taker } \\
\text { to reduce risk } \\
\text { severity) }\end{array}$ \\
\hline 221 & 4.1.02.01. & Mineral resources & & $\begin{array}{l}\text { Owners of mineral rights could claim primacy } \\
\text { over CO2 injection. }\end{array}$ & $\begin{array}{l}\text { Additional } \\
\text { [new] FEP }\end{array}$ & $\begin{array}{l}\begin{array}{l}\text { Very unlikely to be } \\
\text { an issue. }\end{array} \\
\end{array}$ & $\begin{array}{l}\text { No known mineral } \\
\text { resources other than } \\
\text { oil at sites. }\end{array}$ & & 1 & 2 & 2 & NA & NA \\
\hline 222 & 4.1.02.02. & Coal seams & & $\begin{array}{l}\text { Unmineable coal seams could become mineable } \\
\text { with robotic mining systems. }\end{array}$ & \begin{tabular}{|l}
$\begin{array}{c}\text { Additional } \\
\text { [new] FEP }\end{array}$ \\
\end{tabular} & $\begin{array}{l}\text { Very unlikely to be } \\
\text { an issue. }\end{array}$ & $\begin{array}{l}\text { No mineable coal } \\
\text { seams in the area. }\end{array}$ & & 1 & 2 & 2 & NA & NA \\
\hline 223 & 4.1.02.03. & Oil resources & & & \begin{tabular}{|l}
$\begin{array}{l}\text { Additional } \\
\text { [new] FEP }\end{array}$ \\
\end{tabular} & $\begin{array}{l}\text { Unlikely to be an } \\
\text { issue. }\end{array}$ & $\begin{array}{l}\text { G-E and T-A oil } \\
\text { reservoirs are isolated } \\
\text { from other oil } \\
\text { reservoirs in the area. }\end{array}$ & & 2 & 2 & 4 & \begin{tabular}{|l|} 
Obtain leaseholds \\
for the entire \\
isolated reservoir for \\
EOR. Avoid \\
exceeding the spill \\
point
\end{tabular} & $\begin{array}{l}\text { Monitor and model } \\
\text { CO2 plume. Adjust } \\
\text { injection strategy if } \\
\text { necessary. }\end{array}$ \\
\hline 224 & 4.1.02.04. & $\begin{array}{l}\text { Natural gas } \\
\text { resources }\end{array}$ & & & \begin{tabular}{|l} 
Additional \\
[new] FEP
\end{tabular} & $\begin{array}{l}\text { Very unlikely to be } \\
\text { an issue. }\end{array}$ & $\begin{array}{l}\text { Natural gas storage } \\
\text { site located 15 miles } \\
\text { south of G-E }\end{array}$ & & 1 & 2 & 2 & NA & NA \\
\hline 225 & 4.1.02.05. & $\begin{array}{l}\text { Underground } \\
\text { drinking water } \\
\text { sources }\end{array}$ & & & \begin{tabular}{|l}
$\begin{array}{l}\text { Additional } \\
\text { [new] FEP }\end{array}$ \\
\end{tabular} & $\begin{array}{l}\text { Unlikely to be an } \\
\text { issue. }\end{array}$ & \begin{tabular}{|l|} 
There is very little \\
underground drinking \\
water in the $G-E$ and $T$ - \\
A. There are no public \\
or private water wells \\
in the areas.
\end{tabular} & & 2 & 2 & 4 & $\begin{array}{l}\text { Ensure the integrity } \\
\text { of vertical and lateral } \\
\text { seals and wells. }\end{array}$ & $\begin{array}{l}\text { Monitor } \mathrm{CO} 2 \text { content } \\
\text { in ground water } \\
\text { before, during and } \\
\text { after injection. }\end{array}$ \\
\hline 226 & 4.1.02.06. & $\begin{array}{l}\text { Geothermal } \\
\text { resources }\end{array}$ & $\begin{array}{l}\text { Deep aquifers with high porosity suitable for } \\
\text { CO2 storage would also be potentially } \\
\text { suitable for geothermal energy production. } \\
\text { (CO2STORE, page 70) }\end{array}$ & & \begin{tabular}{|l} 
Additional \\
[new] FEP
\end{tabular} & $\begin{array}{l}\text { very unlikely to be } \\
\text { an issue. }\end{array}$ & $\begin{array}{l}\text { There are no } \\
\text { geothermal resources } \\
\text { in the area. }\end{array}$ & & 1 & 2 & 2 & NA & NA \\
\hline 227 & 4.1.02.07. & $\begin{array}{c}\text { Pore space owned } \\
\text { by others }\end{array}$ & & $\begin{array}{l}\text { CO2 from adjacent injection projects could } \\
\text { infringe the project's pore space }\end{array}$ & $\begin{array}{l}\text { Additional } \\
\text { [new] FEP }\end{array}$ & Possible issue. & \begin{tabular}{|l|} 
Kansas does not have \\
any regulations on \\
pore space ownership. \\
Arbuckle has been \\
widely used for \\
disposal by others. \\
EOR sites are \\
isolated.
\end{tabular} & & 3 & 2 & 6 & $\begin{array}{l}\text { Maintain a buffer } \\
\text { around the project } \\
\text { area and CO2 } \\
\text { plume. }\end{array}$ & $\begin{array}{l}\text { Monitor legislation on } \\
\text { pore space ownership }\end{array}$ \\
\hline 228 & 4.1.02.08. & Saline water & 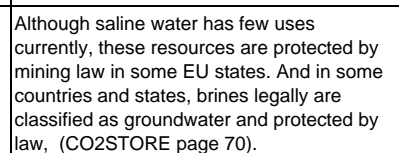 & $\begin{array}{l}\text { Increased demand for water and improvement in } \\
\text { desalination technologies could convert deep } \\
\text { saline aquifers into valuable natural resources } \\
\text { which could lead to restrictions on } \mathrm{CO} 2 \text { injection } \\
\text { into deep saline aquifers in the future. }\end{array}$ & $\begin{array}{l}\text { Additional } \\
\text { [new] FEP }\end{array}$ & $\begin{array}{l}\text { Very unlikely to be } \\
\text { an issue. }\end{array}$ & $\begin{array}{l}\text { Arbuckle is a Class } 1 \\
\text { hazardous waste } \\
\text { reservoir. }\end{array}$ & & 1 & 2 & 2 & NA & NA \\
\hline 229 & 4.1.02.09. & Natural $\mathrm{CO} 2$ & $\begin{array}{l}\text { Depths for known natural major CO2 fields } \\
\text { range from } 200 \mathrm{~m} \text { to 5,000 } \mathrm{m} \text {. (CCP 2009) }\end{array}$ & $\begin{array}{l}\text { Existing natural } \mathrm{CO} 2 \text { within the reservoir may } \\
\text { complicate seismic data and make it difficult to } \\
\text { model and verify } \mathrm{CO} 2 \text { storage. }\end{array}$ & \begin{tabular}{|l} 
Additional \\
[new] FEP
\end{tabular} & $\begin{array}{l}\text { Very unlikely to be } \\
\text { an issue. }\end{array}$ & $\begin{array}{l}\text { No natural } \mathrm{CO} 2 \text { in the } \\
\text { area. }\end{array}$ & & 1 & 2 & 2 & NA & NA \\
\hline 230 & 4.1.03.00. & Reservoir type & $\begin{array}{l}\text { The generic type of reservoir being } \\
\text { considered for storage of CO2. For example: } \\
\text { - oil reservorir (such as the Weyburn project); } \\
\text { - gas reservoir (such as the Coal-Seq } \\
\text { project); } \\
\text { - aquifer (such as at Sleipner); and } \\
\text { - coal beds (such as the Coal-Seq and } \\
\text { RECOPOL projects). }\end{array}$ & $\begin{array}{l}\text { The generic reservoir type will provide a high- } \\
\text { level indication of the geological characteristics of } \\
\text { the storage location. It will also contribute } \\
\text { towards the extent and type of historical } \\
\text { exploitation of any geological resources. }\end{array}$ & $\begin{array}{l}\text { Quintessa } \\
\text { original FEP }\end{array}$ & $\begin{array}{l}\text { Very unlikely to be } \\
\text { an issue. }\end{array}$ & $\begin{array}{l}\text { G-E and T-A are } \\
\text { mature oil fields. }\end{array}$ & & 1 & 2 & 2 & NA & NA \\
\hline 231 & 4.1.03.01. & Oil reservoir (EOR) & & & $\begin{array}{c}\text { Expansion of } \\
\text { Q FEP } \\
\text { dix } 6-42\end{array}$ & Possible issue. & Yes & & 3 & 2 & 6 & $\begin{array}{l}\text { Ensure the integrity } \\
\text { of vertical and lateral } \\
\text { seals and wells. }\end{array}$ & $\begin{array}{l}\text { Monitor and model the } \\
\text { reservoir. If } \\
\text { necessary, extract } \\
\text { CO2 from a leaky } \\
\text { reservoir and inject it } \\
\text { into a sealed reservoir }\end{array}$ \\
\hline
\end{tabular}

Quintessa Original FEP: Taken from Quintessa's on-line CO2 FEP database, which is freely accessible at: http://www.quintessa.org/co2fepdb/ 


\begin{tabular}{|c|c|c|c|c|c|c|c|c|c|c|c|c|c|}
\hline \multicolumn{6}{|c|}{ CO2 Geologic Sequestration Risks for the IMCCS Project } & \multicolumn{3}{|c|}{ Project Specific Information } & \multicolumn{3}{|c|}{ Risk Ranking } & \multicolumn{2}{|c|}{ Prevention and Mitigation } \\
\hline Line \# & 4 Index No. & Risk Area & Description & Relevance & $\begin{array}{l}\text { Qunitessa } \\
\text { FEP } \\
\text { Category }\end{array}$ & $\begin{array}{l}\text { Individual } \\
\text { Comments }\end{array}$ & $\begin{array}{c}\text { IMCCS Project } \\
\text { Specific Information }\end{array}$ & $\begin{array}{c}\text { IMCcs Project } \\
\text { Information Gaps } \\
\text { or Uncertainties }\end{array}$ & 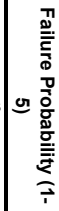 & 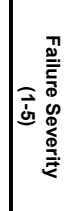 & 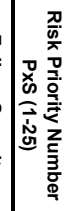 & $\begin{array}{l}\text { Risk Prevention } \\
\text { Steps (Actions } \\
\text { taken to reduce } \\
\text { risk probability) }\end{array}$ & $\begin{array}{l}\text { Risk Mitigation } \\
\text { Steps (Actions taker } \\
\text { to reduce risk } \\
\text { severity) }\end{array}$ \\
\hline 232 & 4.1.03.02. & Gas reservoir & & & \begin{tabular}{|c}
$\begin{array}{c}\text { Expansion of } \\
\text { Q FEP }\end{array}$ \\
\end{tabular} & $\begin{array}{l}\text { Very unlikely to be } \\
\text { an issue. }\end{array}$ & NA & & 1 & 2 & 2 & NA & NA \\
\hline 233 & 4.1.03.03. & Deep saline aquifer & & & $\begin{array}{c}\text { Expansion of } \\
\text { Q FEP }\end{array}$ & fossible issue. & Yes & & 3 & 2 & 6 & $\begin{array}{l}\text { Ensure the integrity } \\
\text { of vertical and lateral } \\
\text { seals. }\end{array}$ & $\begin{array}{l}\text { Monitor and model the } \\
\text { reservoir. If } \\
\text { necessary, extract } \\
\text { CO2 from a leaky } \\
\text { reservoir and inject it } \\
\text { into a sealed reservoi }\end{array}$ \\
\hline 234 & 4.1.03.04. & $\begin{array}{l}\text { Coal seams } \\
\text { (ECBM) }\end{array}$ & & & \begin{tabular}{|c}
$\begin{array}{c}\text { Expansion of } \\
\text { Q FEP }\end{array}$ \\
\end{tabular} & $\begin{array}{l}\text { f Very unlikely to be } \\
\text { an issue. }\end{array}$ & NA & & 1 & 2 & 2 & NA & NA \\
\hline 235 & 4.1.03.05. & Brownfield site & $\begin{array}{l}\text { Brownfield developments, for example in } \\
\text { mature oil and gas fields, will offer the } \\
\text { benefit of beginning with a well-characterized } \\
\text { system and a significant amount of } \\
\text { infrastructure. However, field } \\
\text { redevelopments for CO2 storage will require } \\
\text { a significant amount of work to assess the } \\
\text { integrity and re-usability of existing well, flow } \\
\text { lines and facilities. (CCP 2009) }\end{array}$ & $\begin{array}{l}\text { Development in these fields can expect to } \\
\text { include a significant number of well re- } \\
\text { completions, abandonments and possibly re- } \\
\text { abandonment of old wells, new driling and } \\
\text { upgrades to surface infrastructure. (CCP 2009) }\end{array}$ & \begin{tabular}{|l} 
Additional \\
[new] FEP
\end{tabular} & Possible issue. & $\begin{array}{l}\text { G-E and T-A are } \\
\text { mature oil fields. }\end{array}$ & & 3 & 3 & 9 & $\begin{array}{l}\text { Ensure the integrity } \\
\text { of vertical and lateral } \\
\text { seals and wells. }\end{array}$ & \begin{tabular}{|l} 
Monitor and model the \\
reservoir. If \\
necessary, extract \\
CO2 from a leaky \\
reservoir and inject it \\
into a sealed reservoi
\end{tabular} \\
\hline 236 & 4.1.03.06. & Greenfield site & $\begin{array}{l}\text { Greenfield developments, such as deep } \\
\text { saline aquifers, require significant new } \\
\text { infrastructure and additional initial } \\
\text { characterization work and are associated } \\
\text { with greater uncertainty. A steeper learning } \\
\text { curve is to be expected and modifications to } \\
\text { an initial development plan may occur as } \\
\text { addititonal knowledge is gained during early } \\
\text { development work. (CCP 2009) }\end{array}$ & $\begin{array}{l}\text { More time and money to develop sufficient site } \\
\text { characterization data but less likely to have } \\
\text { leakage through existing wells due to the lack of } \\
\text { existing wells. }\end{array}$ & \begin{tabular}{|l} 
Additional \\
[new] FEP
\end{tabular} & $\begin{array}{l}\text { Very unlikely to be } \\
\text { an issue. }\end{array}$ & NA & & 1 & 3 & 3 & NA & NA \\
\hline 237 & 4.1.04.00. & Reservoir geometry & $\begin{array}{l}\text { Geometry of the CO2 storage reservoir } \\
\text { including the spatial distribution, depth and } \\
\text { the topography of the top. }\end{array}$ & $\begin{array}{l}\text { The geometry of the storage reservoir helps to } \\
\text { determine the capacity of the geosphere. } \\
\text { The geometry of the top is particularly important } \\
\text { because supercritical CO2 is buoyant and will } \\
\text { therefore migrate to the top of a reservoir. Once } \\
\text { at the top of the reservoir, it will migrate } \\
\text { according to the precise topography of the top. } \\
\text { Local "highs" could produce small-scale traps } \\
\text { within the overall aquifer; bigger structures would } \\
\text { produce bigger traps. } \\
\text { Spill points are determined by the lowest point } \\
\text { that can retain the sequestered CO2. }\end{array}$ & $\begin{array}{l}\text { Quintessa } \\
\text { original FEP }\end{array}$ & $\begin{array}{l}\text { Very unlikely to be } \\
\text { an issue. }\end{array}$ & \begin{tabular}{|l} 
G-E is a dome \\
structure. The T-A \\
Bartlesville oil \\
reservoir is an isolated \\
bottle structure. The T- \\
A Arbuckle top is $1 \%$ \\
dipping monocline.
\end{tabular} & & 1 & 3 & 3 & $\begin{array}{l}\text { Avoid exceeding the } \\
\text { spill point in the G-E } \\
\text { dome. Minimize the } \\
\text { amount of } \mathrm{CO} 2 \\
\text { injection into the } \\
\text { Arbuckle at the T-A. }\end{array}$ & $\begin{array}{l}\text { Monitor and model the } \\
\text { reservoir. If } \\
\text { necessary, extract } \\
\text { CO2 from a leaky } \\
\text { reservoir and inject it } \\
\text { into a sealed reservoi }\end{array}$ \\
\hline 238 & 4.1.04.01. & $\begin{array}{l}\text { Insufficient } \\
\text { reservoir depth }\end{array}$ & $\begin{array}{l}\text { It is desirable to store } \mathrm{CO} 2 \text { at depths below } \\
\text { approximately } 800-10000 \mathrm{~m} \text { where } \mathrm{CO} 2 \text { is } \\
\text { compressed to a supercritical (dense) phase. } \\
\text { (CCP 2009) }\end{array}$ & $\begin{array}{l}\text { Insufficient reservoir depth may result in } \\
\text { pressures that are too low for keeping } \mathrm{CO} 2 \text { in a } \\
\text { supercritical state }\end{array}$ & $\begin{array}{l}\text { Additional } \\
\text { [new] FEP } \\
\text { dix 6-43 }\end{array}$ & $\begin{array}{l}\text { Likely to be an } \\
\text { issue. }\end{array}$ & $\begin{array}{l}\text { The T-A has marginal } \\
\text { depth and the CO22 } \\
\text { may transfer from } \\
\text { supercritical to gas } \\
\text { phase after injection. } \\
\text { There is also } \\
\text { insufficient range for } \\
\text { operating pressure } \\
\text { between minimum } \\
\text { miscible pressure and } \\
\text { maximum operating } \\
\text { pressure. }\end{array}$ & & 4 & 4 & 16 & $\begin{array}{l}\text { Increase pressure of } \\
\text { Bartlesville } \\
\text { Sandstone with } \\
\text { water prior to } \\
\text { injecting CO2 to } \\
\text { compensate for } \\
\text { shallow depth. Inject } \\
\text { deep into the } \\
\text { Arbuckle of DSA. }\end{array}$ & $\begin{array}{l}\text { Monitor and model the } \\
\text { reservoir. If } \\
\text { necessary, extract } \\
\text { CO2 from a leaky } \\
\text { reservoir and inject it } \\
\text { into a sealed reservoi }\end{array}$ \\
\hline
\end{tabular}

Quintessa Original FEP: Taken from Quintessa's on-line CO2 FEP database, which is freely accessible at: http://www.quintessa.org/co2fepdb/ 


\begin{tabular}{|c|c|c|c|c|c|c|c|c|c|c|c|c|c|}
\hline \multicolumn{6}{|c|}{ CO2 Geologic Sequestration Risks for the IMCCS Project } & \multicolumn{3}{|c|}{ Project Specific Information } & \multicolumn{3}{|c|}{ Risk Ranking } & \multicolumn{2}{|c|}{ Prevention and Mitigation } \\
\hline Line \# & Index No. & Risk Area & Description & Relevance & $\begin{array}{l}\text { Qunitessa } \\
\text { FEP } \\
\text { Category }\end{array}$ & $\begin{array}{l}\text { Individual } \\
\text { Comments }\end{array}$ & $\begin{array}{c}\text { IMCCS Project } \\
\text { Specific Information }\end{array}$ & $\begin{array}{c}\text { IMccs Project } \\
\text { Information Gaps } \\
\text { or Uncertainties }\end{array}$ & 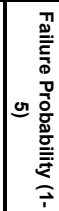 & 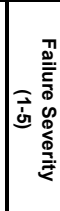 & 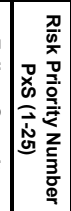 & $\begin{array}{l}\text { Risk Prevention } \\
\text { Steps (Actions } \\
\text { taken to reduce } \\
\text { risk probability) }\end{array}$ & $\begin{array}{l}\text { Risk Mitigation } \\
\text { Steps (Actions taker } \\
\text { to reduce risk } \\
\text { severity) }\end{array}$ \\
\hline 239 & 4.1.04.02. & $\begin{array}{l}\text { Insufficient } \\
\text { hydrostatic } \\
\text { pressure }\end{array}$ & $\begin{array}{l}\text { Pressure too low for keeping } \mathrm{CO} 2 \text { in a } \\
\text { supercritical state. }\end{array}$ & $\begin{array}{l}\text { At low pressure, } \mathrm{CO} 2 \text { could revert back to a gas } \\
\text { state requiring greater pore volume for storage. }\end{array}$ & \begin{tabular}{|l} 
Additional \\
[new] FEP
\end{tabular} & Possible issue. & $\begin{array}{l}\text { The Bartlesville and } \\
\text { Arbuckle formations } \\
\text { are under pressured } \\
\text { and the CO2 may } \\
\text { transfer from } \\
\text { supercritical to gas } \\
\text { phase after injection. }\end{array}$ & & 3 & 3 & 9 & $\begin{array}{l}\text { Increase pressure of } \\
\text { Bartlesville } \\
\text { Sandstone with } \\
\text { water prior to } \\
\text { injecting CO2 to } \\
\text { compensate for } \\
\text { shallow depth. Inject } \\
\text { deep into the } \\
\text { Arbuckle of DSA. }\end{array}$ & $\begin{array}{l}\text { Monitor and model the } \\
\text { reservoir. If } \\
\text { necessary, extract } \\
\text { CO2 from a leaky } \\
\text { reservoir and inject it } \\
\text { into a sealed reservoir }\end{array}$ \\
\hline 240 & 4.1.04.03. & \begin{tabular}{|c|}
$\begin{array}{c}\text { Excessive reservoir } \\
\text { depth }\end{array}$ \\
\end{tabular} & & $\begin{array}{l}\text { Excessive reservoir depth will significantly } \\
\text { increase the cost of } \mathrm{CO} 2 \text { injection }\end{array}$ & \begin{tabular}{|l}
$\begin{array}{c}\text { Additional } \\
\text { [new] FEP }\end{array}$ \\
\end{tabular} & $\begin{array}{l}\begin{array}{l}\text { Very unlikely to be } \\
\text { an issue. }\end{array} \\
\end{array}$ & NA & & 1 & 3 & 3 & NA & NA \\
\hline 241 & 4.1.04.04. & \begin{tabular}{|c|}
$\begin{array}{c}\text { Excessive } \\
\text { hydrostatic } \\
\text { pressure }\end{array}$ \\
\end{tabular} & & Increased cost for $\mathrm{CO} 2$ compression. & \begin{tabular}{|l} 
Additional \\
[new] FEP
\end{tabular} & $\begin{array}{l}\text { Very unlikely to be } \\
\text { an issue. }\end{array}$ & NA & & 1 & 3 & 3 & NA & NA \\
\hline 242 & 4.1.04.05. & $\begin{array}{c}\text { Insufficient } \\
\text { reservoir thickness }\end{array}$ & $\begin{array}{l}\text { Normally, a formation thickness of around } 20 \\
\text { meters would be considered as a minimum } \\
\text { requirement, but this varies with injection } \\
\text { volume requirements. }\end{array}$ & $\begin{array}{l}\text { Insufficient reservoir thickness will result in an } \\
\text { extended CO2 plume and limit the storage } \\
\text { capacity of the reservoir }\end{array}$ & \begin{tabular}{|l} 
Additional \\
[new] FEP
\end{tabular} & $\begin{array}{l}\text { Very unlikely to be } \\
\text { an issue. }\end{array}$ & $\begin{array}{l}\text { Bartlesville is over } 100 \\
\mathrm{ft} \text { thick and Arbuckle is } \\
600 \mathrm{ft} \text { thick, }\end{array}$ & & 1 & 3 & 3 & NA & NA \\
\hline 243 & 4.1.04.06. & $\begin{array}{l}\text { Insufficient } \\
\text { reservoir lateral } \\
\text { continuity (spacial } \\
\text { distribution) }\end{array}$ & & $\begin{array}{l}\text { Insufficient lateral continuity (or spacial } \\
\text { distribution) of a reservoir will limit its } \mathrm{CO} 2 \\
\text { storage capacity }\end{array}$ & \begin{tabular}{|l} 
Additional \\
[new] FEP
\end{tabular} & $\begin{array}{l}\text { Very unlikely to be } \\
\text { an issue. }\end{array}$ & $\begin{array}{l}\text { CO2 storage capacity } \\
\text { for G-E and T-A are } \\
\text { sufficient for the } \\
\text { project needs }\end{array}$ & & 1 & 3 & 3 & $\begin{array}{l}\text { Characterize and } \\
\text { model the reservoirs } \\
\text { and prepare an } \\
\text { injection plan } \\
\text { compatible with } \\
\text { reservoir capacity. }\end{array}$ & NA \\
\hline 244 & 4.1.04.07. & $\begin{array}{l}\text { Dipping top } \\
\text { topography } \\
\text { (monocline) }\end{array}$ & $\begin{array}{l}\text { Reservoirs with dipping top topography } \\
\text { (monocline) are susceptible to buoyancy- } \\
\text { driven up dip CO2 migration. The migration } \\
\text { uud dip may enhance CO2/brine contact and } \\
\text { CO2 dissolution in the brine. }\end{array}$ & $\begin{array}{l}\text { Dipping top topography of the reservoir may } \\
\text { make it difficult to trap buoyant CO2. Injected } \\
\text { CO2 migrates up dip out of closure. }\end{array}$ & \begin{tabular}{|l} 
Additional \\
[new] FEP
\end{tabular} & $\begin{array}{l}\text { Unlikely to be an } \\
\text { issue. }\end{array}$ & $\begin{array}{l}\text { At T-A, the Arbuckle } \\
\text { top dips from East to } \\
\text { West by } 1 \% \text {. This dip } \\
\text { is shallow enough and } \\
\text { the amount of CO2 to } \\
\text { be injected is small } \\
\text { enough to allow the } \\
\text { plume to stabilize in } 60 \\
\text { years (based on } \\
\text { modeling). } \\
\end{array}$ & \begin{tabular}{|l|} 
Need 3-d seismic \\
to identify potential \\
traps in top of \\
Arbuckle at T-A..
\end{tabular} & 2 & 3 & 6 & \begin{tabular}{|l} 
Limit the amount of \\
CO2 injected for \\
DSA at T-A to \\
approximately \\
50,000 tpy over 3 \\
years.
\end{tabular} & $\begin{array}{l}\text { Monitor and model the } \\
\text { reservoir. If } \\
\text { necessary, extract } \\
\text { CO2 from a leaky } \\
\text { reservoir and inject it } \\
\text { into a sealed reservoir }\end{array}$ \\
\hline 245 & 4.1.04.08. & Flat top topography & $\begin{array}{l}\text { The preferred top topography is an anticline } \\
\text { or dome structure to restrict the flow of } \\
\text { injected CO2 on multiple sides. }\end{array}$ & $\begin{array}{l}\text { Flat top topography of the reservoir may make it } \\
\text { difficult to contain the CO2 plume }\end{array}$ & \begin{tabular}{|l} 
Additional \\
[new] FEP
\end{tabular} & $\begin{array}{l}\text { Very unlikely to be } \\
\text { an issue. }\end{array}$ & $\begin{array}{l}\text { At T-A, the top of the } \\
\text { Arbuckle is almost flat } \\
\text { (1\% dip) with no lateral } \\
\text { seals. }\end{array}$ & & 1 & 3 & 3 & \begin{tabular}{|l} 
Limit the amount of \\
CO2 injected for \\
DSA at T-A to \\
approximately \\
50,000 tpy over 3 \\
years.
\end{tabular} & $\begin{array}{l}\text { Monitor and model the } \\
\text { reservoir. If } \\
\text { necessary, extract } \\
\text { CO2 from a leaky } \\
\text { reservoir and inject it } \\
\text { into a sealed reservoir }\end{array}$ \\
\hline 246 & 4.1.04.09. & Shallow spill points & $\begin{array}{l}\text { Spill point is the lowest point that can retain } \\
\text { sequestered } \mathrm{CO} 2\end{array}$ & $\begin{array}{l}\text { Shallow spill point may limit the amount of } \mathrm{CO} 2 \\
\text { that can be locally contained in a reservoir }\end{array}$ & \begin{tabular}{|l} 
Additional \\
[new] FEP
\end{tabular} & $\begin{array}{l}\text { Very unlikely to be } \\
\text { an issue. }\end{array}$ & $\begin{array}{l}\text { The G-E spill points } \\
\text { gives } 100 \mathrm{ft} \text { of working } \\
\text { space in the dome. }\end{array}$ & & 1 & 3 & 3 & $\begin{array}{l}\text { Avoid exceeding the } \\
\text { spill point in the G-E } \\
\text { dome. Switch to } \\
\text { other dome if more } \\
\text { capacity needed. }\end{array}$ & $\begin{array}{l}\text { Monitor and model } \\
\text { CO2 plume. Adjust } \\
\text { injection strategy if } \\
\text { necessary if spill point } \\
\text { is exceeded. }\end{array}$ \\
\hline
\end{tabular}




\begin{tabular}{|c|c|c|c|c|c|c|c|c|c|c|c|c|c|}
\hline \multicolumn{6}{|c|}{ CO2 Geologic Sequestration Risks for the IMCCS Project } & \multicolumn{3}{|c|}{ Project Specific Information } & \multicolumn{3}{|c|}{ Risk Ranking } & \multicolumn{2}{|c|}{ Prevention and Mitigation } \\
\hline Line \# & Index No. & Risk Area & Description & Relevance & $\begin{array}{l}\text { Qunitessa } \\
\text { FEP } \\
\text { Category }\end{array}$ & $\begin{array}{l}\text { Individual } \\
\text { Comments }\end{array}$ & $\begin{array}{c}\text { IMCCS Project } \\
\text { Specific Information }\end{array}$ & $\mid \begin{array}{c}\text { IMccs Project } \\
\text { Information Gaps } \\
\text { or Uncertainties }\end{array}$ & 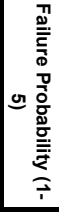 & 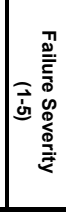 & 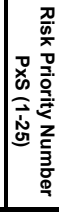 & $\begin{array}{l}\text { Risk Prevention } \\
\text { Steps (Actions } \\
\text { taken to reduce } \\
\text { risk probability) }\end{array}$ & $\begin{array}{l}\text { Risk Mitigation } \\
\text { Steps (Actions taken } \\
\text { to reduce risk } \\
\text { severity) }\end{array}$ \\
\hline 247 & 4.1.04.10. & $\begin{array}{l}\text { Insufficient buffer } \\
\text { zone for CO2 } \\
\text { plume }\end{array}$ & & $\begin{array}{l}\text { Potential for } \mathrm{CO} 2 \text { plume to infringe on third party } \\
\text { pore space. }\end{array}$ & \begin{tabular}{|l} 
Additional \\
[new] FEP
\end{tabular} & $\begin{array}{l}\text { Very unlikely to be } \\
\text { an issue. }\end{array}$ & $\begin{array}{l}\text { G-E and T-A EOR } \\
\text { plumes are contained } \\
\text { vertically and laterally. } \\
\text { G-E and T-A DSA } \\
\text { plumes are not } \\
\text { expected to exceed } \\
\text { the project area. }\end{array}$ & $\begin{array}{l}\text { Need to verify } \\
\text { through modeling }\end{array}$ & 1 & 3 & 3 & $\begin{array}{l}\text { Model CO2 plume } \\
\text { and provide } \\
\text { sufficient buffer zone } \\
\text { around site to } \\
\text { accommodate the } \\
\text { predicted plume } \\
\text { area plus } \\
\text { contingency. Or limit } \\
\text { the amount of CO2 } \\
\text { injection to keep the } \\
\text { plume within the site } \\
\text { boundaries. }\end{array}$ & $\begin{array}{l}\text { e } \\
\text { Monitor and model } \\
\text { CO2 plume. Adjust } \\
\text { injection strategy, or } \\
\text { increase the project } \\
\text { area, if plume is likely } \\
\text { to exceed the project } \\
\text { boundary. }\end{array}$ \\
\hline 248 & 4.1.04.11. & $\begin{array}{l}\text { Insufficient } \\
\text { reservoir CO2 } \\
\text { storage capacity }\end{array}$ & $\begin{array}{l}\text { Reservoir CO2 storage capacity is primarily } \\
\text { determined by pore volume. }\end{array}$ & $\begin{array}{l}\text { Requirement for alternative storage site(s). } \\
\text { Increased storage costs. }\end{array}$ & \begin{tabular}{|l} 
Additional \\
[new] FEP
\end{tabular} & $\begin{array}{l}\text { very unlikely to be } \\
\text { an issue. }\end{array}$ & \begin{tabular}{|l} 
G-E and T-A sites \\
have been modeled \\
and nearby back up \\
reservoirs have been \\
identified.
\end{tabular} & & 1 & 3 & 3 & $\begin{array}{l}\text { Characterize and } \\
\text { model the storage } \\
\text { reservoir prior to } \\
\text { injection. Identify } \\
\text { alternative reservoirs } \\
\text { nearby that could be } \\
\text { used as backup. }\end{array}$ & \begin{tabular}{|l} 
Monitor and model \\
CO2 plume and \\
reservoir pressure. \\
sswitch to backup \\
e \\
reservoir if necessary.
\end{tabular} \\
\hline 249 & 4.1.04.12. & $\begin{array}{c}\text { Lack of lateral } \\
\text { sealing of reservoir }\end{array}$ & \begin{tabular}{|l|} 
Lateral flow barriers can include \\
unconformities or pinch-outs that erode the \\
porous and permeable material and provide \\
direct contact to a low permeability seal, \\
faults and naturally over pressured zones.
\end{tabular} & $\begin{array}{l}\text { Potential for CO2 plume to infringe on third party } \\
\text { pore space or escape. }\end{array}$ & \begin{tabular}{|l} 
Additional \\
[new] FEP
\end{tabular} & Possible issue. & $\begin{array}{l}\text { The G-E and T-A EOR } \\
\text { reservoirs are laterally } \\
\text { sealed. The TTA DSA } \\
\text { is not laterally sealed. }\end{array}$ & $\left|\begin{array}{l}\text { Need 3-d seismic } \\
\text { to identify potential } \\
\text { traps in top of } \\
\text { Arbuckle at T-A.. }\end{array}\right|$ & 3 & 3 & 9 & $\begin{array}{l}\text { Characterize the T-A } \\
\text { DSA to identify traps } \\
\text { on the top of the } \\
\text { Arbuckle. Limit the } \\
\text { amount of CO2 } \\
\text { injected for DSA at T } \\
\text { A to approximately } \\
50,000 \text { tpy over } 3 \\
\text { years. }\end{array}$ & \begin{tabular}{l|l} 
A \\
$s \mid \begin{array}{l}\text { Monitor and model the } \\
\text { reservoir. If } \\
\text { necessary, extract } \\
\text { CO2 from a leaky } \\
\text { reservoir and inject it } \\
\text { into a sealed reservoir. }\end{array}$
\end{tabular} \\
\hline 250 & 4.1.04.13. & \begin{tabular}{|c|} 
Reservoir and \\
caprock structural \\
geology too \\
complex \\
\end{tabular} & $\begin{array}{l}\text { In tectonically complex areas, there are too } \\
\text { many small structures to be identified, } \\
\text { delineated and investigated individually. }\end{array}$ & $\begin{array}{l}\text { Greater difficulty in modeling, monitoring and } \\
\text { controlling } \mathrm{CO} 2 \text { storage. }\end{array}$ & \begin{tabular}{|l} 
Additional \\
[new] FEP
\end{tabular} & $\begin{array}{l}\text { Very unlikely to be } \\
\text { an issue. }\end{array}$ & $\begin{array}{l}\text { The structural geology } \\
\text { at G-E and T-A is not } \\
\text { complex. }\end{array}$ & & 1 & 3 & 3 & NA & NA \\
\hline 251 & 4.1.04.14. & $\begin{array}{c}\text { Reservoir } \\
\text { compartmentalizatio } \\
\mathrm{n}\end{array}$ & $\begin{array}{l}\text { A once continuous reservoir can become } \\
\text { compartmentalized. CO2 migration restricted } \\
\text { to an isolated part of the formation. } \\
\text { Unexpected bottom hole pressure increase. } \\
\text { Pressure transient analysis suggests } \\
\text { hydraulically isolated wells. }\end{array}$ & $\begin{array}{l}\text { Greater difficulty in modeling, monitoring and } \\
\text { controlling } \mathrm{CO} 2 \text { storage. }\end{array}$ & \begin{tabular}{|l} 
Additional \\
[new] FEP
\end{tabular} & $\begin{array}{l}\text { Unlikely to be an } \\
\text { issue. }\end{array}$ & $\begin{array}{l}\text { Variation in bottom } \\
\text { hole pressure suggest } \\
\text { that the Arbuckle is } \\
\text { compartmentalized at } \\
\text { G-E. }\end{array}$ & $\begin{array}{l}\text { Determine if the G- } \\
\text { E and T-A oil } \\
\text { reservoirs are } \\
\text { compartmentalize } \\
\text { d. }\end{array}$ & 2 & 3 & 6 & $\begin{array}{l}\text { Characterize and } \\
\text { model the EOR } \\
\text { reservoir and } \\
\text { provide input into } \\
\text { reservoir } \\
\text { engineering. }\end{array}$ & $\begin{array}{l}\text { Adjust the injection } \\
\text { strategy to take into } \\
\text { account } \\
\text { compartmentalizing if } \\
\text { it exists. }\end{array}$ \\
\hline 252 & 4.1.04.15. & $\begin{array}{c}\text { Reduced pore } \\
\text { volume or } \\
\text { distribution limiting } \\
\text { CO2 injection }\end{array}$ & $\begin{array}{l}\text { Rate of long-term pressure build-up greater } \\
\text { than expected }\end{array}$ & $\begin{array}{l}\text { Increased CO2 injection costs. Need for } \\
\text { additional wells. }\end{array}$ & \begin{tabular}{|l} 
Additional \\
[new] FEP
\end{tabular} & $\begin{array}{l}\text { very unlikely to be } \\
\text { an issue. }\end{array}$ & $\begin{array}{l}\text { Modeling suggests } \\
\text { that salt buildup could } \\
\text { be an issue in the } \\
\text { arbuckle. }\end{array}$ & & 1 & 3 & 3 & $\begin{array}{l}\text { Characterize and } \\
\text { model the EOR and } \\
\text { DSA reservoirs. } \\
\text { Inject fresh water } \\
\text { prior to CO2 } \\
\text { injection to help } \\
\text { avoid salt buildup } \\
\text { due to water } \\
\text { evaporation near the } \\
\text { well. }\end{array}$ & \begin{tabular}{|l} 
Monitor BHP during \\
injection. Adjust \\
injection strategy if \\
pressure begins \\
building up. Determine \\
root cause of pressure \\
build up and take \\
corrective action such \\
as treating for \\
asphaltene or paraffin \\
buildup.
\end{tabular} \\
\hline 253 & 4.1.04.16. & $\begin{array}{l}\text { Lack of stacked } \\
\text { reservoirs }\end{array}$ & $\begin{array}{l}\text { Stacked reservoirs consist of multiple } \\
\text { alternating seals and reservoirs above the } \\
\text { primary reservoir. The additional reservoirs }\end{array}$ & $\begin{array}{l}\text { No fallback position if } \mathrm{CO} 2 \text { escapes from primary } \\
\text { reservoir. }\end{array}$ & \begin{tabular}{|l} 
Additional \\
[new] FEP
\end{tabular} & $\begin{array}{l}\text { Very unlikely to be } \\
\text { an issue. }\end{array}$ & $\begin{array}{l}\text { Multiple stacked sinks } \\
\text { and seals. }\end{array}$ & & 1 & 3 & 3 & NA & NA \\
\hline
\end{tabular}

Quintessa Original FEP: Taken from Quintessa's on-line CO2 FEP database, which is freely accessible at: http://www.quintessa.org/co2fepdb/ 


\begin{tabular}{|c|c|c|c|c|c|c|c|c|c|c|c|c|c|}
\hline \multicolumn{6}{|c|}{ CO2 Geologic Sequestration Risks for the IMCCS Project } & \multicolumn{3}{|c|}{ Project Specific Information } & \multicolumn{3}{|c|}{ Risk Ranking } & \multicolumn{2}{|c|}{ Prevention and Mitigation } \\
\hline Line \# & flndex No. & Risk Area & Description & Relevance & $\begin{array}{l}\text { Qunitessa } \\
\text { FPP } \\
\text { Category }\end{array}$ & $\begin{array}{l}\text { Individual } \\
\text { Comments }\end{array}$ & $\begin{array}{c}\text { IMCCS Project } \\
\text { Specific Information }\end{array}$ & $\begin{array}{c}\text { IMccs Project } \\
\text { Information Gaps } \\
\text { or Uncertainties }\end{array}$ & 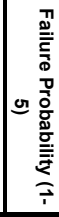 & 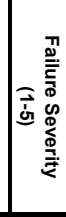 & 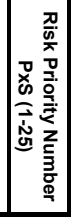 & \begin{tabular}{|c|} 
Risk Prevention \\
Steps (Actions \\
taken to reduce \\
risk probability) \\
\end{tabular} & $\begin{array}{c}\text { Risk Mitigation } \\
\text { Steps (Actions taken } \\
\text { to reduce risk } \\
\text { severity) }\end{array}$ \\
\hline 254 & 4.1.04.17. & $\begin{array}{c}\text { Reservoir } \\
\text { chemically reactive } \\
\text { with } \mathrm{CO} 2\end{array}$ & & $\begin{array}{l}\text { Greater difficulty in modeling, monitoring and } \\
\text { controlling } \mathrm{CO} \text { storage. }\end{array}$ & \begin{tabular}{|l} 
Additional \\
[new] FEP
\end{tabular} & $\begin{array}{l}\text { Unlikely to be an } \\
\text { issue. }\end{array}$ & $\begin{array}{l}\text { Arbuckle dolomite } \\
\text { reactive. Bartlesville } \\
\text { Sandstone not as } \\
\text { reactive. }\end{array}$ & & 2 & 3 & 6 & $\begin{array}{l}\text { Incorporate reservoir } \\
\text { chemical reactions in } \\
\text { modeling and take } \\
\text { into account in } \\
\text { reservoir } \\
\text { engineering. }\end{array}$ & $\begin{array}{l}\text { Monitor and model } \\
\text { reservoir to determine } \\
\text { impact on } \\
\text { performance. }\end{array}$ \\
\hline 255 & 4.1.05.00. & $\begin{array}{l}\text { Reservoir } \\
\text { exploitation }\end{array}$ & $\begin{array}{l}\text { Degree to which geoological resources (such } \\
\text { as oil and gas) have been exploited prior to } \\
\text { the injection of } \mathrm{CO} 2 \text {. }\end{array}$ & 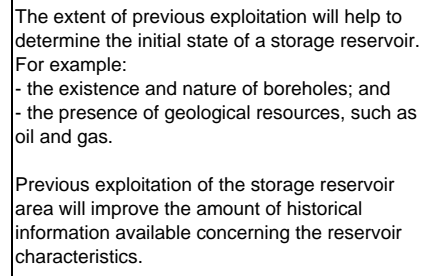 & $\begin{array}{l}\text { Quintessa } \\
\text { original FEP }\end{array}$ & $\begin{array}{l}\text { Very unlikely to be } \\
\text { an issue. }\end{array}$ & $\begin{array}{l}\text { Historical data has } \\
\text { been reviewed for the } \\
\text { G-E and T-A sites. } \\
\text { Residual oil saturation } \\
\text { has been estimated. }\end{array}$ & & 1 & 3 & 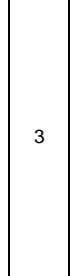 & \begin{tabular}{|l|} 
Thoroughly review \\
and analyze \\
historical production \\
data and incorporate \\
results into site \\
characterization and \\
modeling.
\end{tabular} & \begin{tabular}{|l} 
Thoroughly review and \\
analyze historical \\
production data and \\
incorporate results into \\
site characterization \\
and modeling.
\end{tabular} \\
\hline 256 & 4.1.05.01. & Existing boreholes & & & \begin{tabular}{|l} 
Additional \\
[new] FEP
\end{tabular} & Definite issue. & $\begin{array}{l}\text { T-A has } 370 \text { existing } \\
\text { wells. G-E has } 247 \\
\text { existing wells. }\end{array}$ & & 5 & 4 & 20 & \begin{tabular}{|l|} 
Plug and seal old \\
wells. Increase \\
pressure Bartlesville \\
reservoir with water, \\
check for leaky wells \\
and fix them prior to \\
injecting $\mathrm{CO} 2$.
\end{tabular} & $\begin{array}{l}\text { Monitor old wells and } \\
\text { replug if necessary. }\end{array}$ \\
\hline 257 & 4.1.05.02. & $\begin{array}{l}\text { Oil previously } \\
\text { removed }\end{array}$ & & & \begin{tabular}{|l} 
Additional \\
[new] FEP
\end{tabular} & $\begin{array}{l}\text { Possible impact } \\
\text { on oil recovery }\end{array}$ & $\begin{array}{l}\text { Over } 25 \text { million barrels } \\
\text { of oil removed from G- } \\
\text { E south dome. } 21 \\
\text { million barrels of oil } \\
\text { removed from T-A. }\end{array}$ & & 3 & 3 & 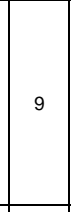 & $\begin{array}{l}\text { Historical oil } \\
\text { production used in } \\
\text { modeling to } \\
\text { determine residual } \\
\text { oil saturation today } \\
\text { and potential EOR } \\
\text { yield with CO2 } \\
\text { injection. } \\
\end{array}$ & $\begin{array}{l}\text { Historical oil } \\
\text { production used in } \\
\text { modeling to determine } \\
\text { residual oil saturation } \\
\text { today and potential } \\
\text { EOR yield with CO2 } \\
\text { injection. }\end{array}$ \\
\hline 258 & 4.1.05.03. & $\begin{array}{l}\text { Gas previously } \\
\text { removed }\end{array}$ & & & \begin{tabular}{|l} 
Additional \\
[new] FEP
\end{tabular} & Not an issue & $\begin{array}{l}\text { T-A initially had } 600 \\
\text { scf/bbl associated gas. } \\
\text { It produces none } \\
\text { today. G-E has no } \\
\text { historical data on gas } \\
\text { production and none is } \\
\text { produced today. }\end{array}$ & & 1 & 2 & 2 & NA & NA \\
\hline 259 & 4.1.05.04. & $\begin{array}{l}\text { Existing mine } \\
\text { workings }\end{array}$ & This would be applicable to ECBM. & & \begin{tabular}{|l}
$\begin{array}{l}\text { Addititional } \\
\text { [new] FEPP }\end{array}$ \\
\end{tabular} & $\begin{array}{l}\text { Very unlikely to be } \\
\text { an issue. }\end{array}$ & None & & 1 & 1 & 1 & NA & NA \\
\hline 260 & 4.1.05.05. & $\begin{array}{l}\text { In-situ coal } \\
\text { gasification }\end{array}$ & This would be applicable to ECBM. & & $\begin{array}{l}\begin{array}{c}\text { Additional } \\
\text { [new] FEP }\end{array} \\
\end{array}$ & $\begin{array}{l}\text { Very unlikely to be } \\
\text { an issue. }\end{array}$ & None & & 1 & 1 & 1 & NA & NA \\
\hline 261 & 4.1.05.06. & Natural gas storage & & & $\begin{array}{l}\begin{array}{l}\text { Additional } \\
\text { [new] FEP }\end{array} \\
\end{array}$ & \begin{tabular}{|l}
$\begin{array}{l}\text { Very unlikely to be } \\
\text { an issue. }\end{array}$ \\
\end{tabular} & $\begin{array}{l}\text { Natural gas storage } \\
\text { site located } 15 \text { miles } \\
\text { south of G-E }\end{array}$ & & 1 & 1 & 1 & NA & NA \\
\hline 262 & 4.1.05.07. & \begin{tabular}{|c|}
$\begin{array}{c}\text { Compressed air } \\
\text { storage }\end{array}$ \\
\end{tabular} & & & \begin{tabular}{|l} 
Additional \\
[new] FEP
\end{tabular} & $\begin{array}{l}\begin{array}{l}\text { Very unlikely to be } \\
\text { an issue. }\end{array} \\
\end{array}$ & None & & 1 & 1 & 1 & NA & NA \\
\hline 263 & 4.1.05.08. & \begin{tabular}{|c|}
$\begin{array}{c}\text { Radioactive waste } \\
\text { disposal }\end{array}$ \\
\end{tabular} & & & \begin{tabular}{|l}
$\begin{array}{l}\text { Additional } \\
\text { [new] FEP }\end{array}$ \\
\end{tabular} & $\begin{array}{l}\text { Very unlikely to be } \\
\text { an issue. }\end{array}$ & None & & 1 & 1 & 1 & NA & NA \\
\hline 264 & 4.1.05.09. & $\begin{array}{l}\text { Ground water } \\
\text { extraction }\end{array}$ & & Ap & $\begin{array}{l}\text { Additional } \\
\text { [new] FEP } \\
\text { dix 6-46 }\end{array}$ & $\begin{array}{l}\text { Unlikely to be an } \\
\text { issue. }\end{array}$ & $\begin{array}{l}\text { No public or private } \\
\text { water wells in the area. } \\
\text { Groundwater not } \\
\text { sufficient for use. } \\
\text { Limited to top } 200 \text { feet } \\
\text { below ground. }\end{array}$ & & 2 & 2 & 4 & NA & NA \\
\hline
\end{tabular}

Quintessa Original FEP: Taken from Quintessa's on-line CO2 FEP database, which is freely accessible at: http://www.quintessa.org/co2fepdb/ 


\begin{tabular}{|c|c|c|c|c|c|c|c|c|c|c|c|c|c|}
\hline \multicolumn{6}{|c|}{ CO2 Geologic Sequestration Risks for the IMCCS Project } & \multicolumn{3}{|c|}{ Project Specific Information } & \multicolumn{3}{|c|}{ Risk Ranking } & \multicolumn{2}{|c|}{ Prevention and Mitigation } \\
\hline Line \# & Index No. & Risk Area & Description & Relevance & $\begin{array}{l}\text { Qunitessa } \\
\text { FEP } \\
\text { Category }\end{array}$ & $\begin{array}{l}\text { Individual } \\
\text { Comments }\end{array}$ & $\begin{array}{c}\text { IMCCS Project } \\
\text { Specific Information }\end{array}$ & $\begin{array}{c}\text { IMCCS Project } \\
\text { Information Gaps } \\
\text { or Uncertainties }\end{array}$ & 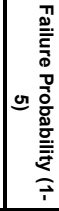 & 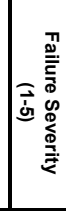 & 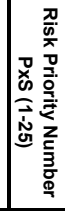 & $\begin{array}{l}\text { Risk Prevention } \\
\text { Steps (Actions } \\
\text { taken to reduce } \\
\text { risk probability) }\end{array}$ & $\begin{array}{l}\text { Risk Mitigation } \\
\text { Steps (Actions taken } \\
\text { to reduce risk } \\
\text { severity) }\end{array}$ \\
\hline 265 & 4.1.06.00. & $\begin{array}{l}\text { Caprock or sealing } \\
\text { formation }\end{array}$ & $\begin{array}{l}\text { The nature of the relatively impermeable } \\
\text { layer of rock overlying the storage reservoir } \\
\text { that forms a barrie to the upward migration } \\
\text { of buoyant fluids, such as sequestered CO2. }\end{array}$ & $\begin{array}{l}\text { The caprock or sealing formation plays a key roll } \\
\text { in preventing the sequestered CO2 from } \\
\text { migrating to the surface environment. }\end{array}$ & $\begin{array}{l}\text { Quintessa } \\
\text { original FEP }\end{array}$ & $\begin{array}{l}\text { Unlikely to be an } \\
\text { issue. }\end{array}$ & $\begin{array}{l}\text { Multiple seals and } \\
\text { sinks above primary } \\
\text { reservoir and caprock. }\end{array}$ & & 2 & 3 & 6 & $\begin{array}{l}\text { Keep injection } \\
\text { pressure below } \\
\text { fracture pressure. }\end{array}$ & $\begin{array}{l}\text { Monitor and model the } \\
\text { reservoir. If } \\
\text { necessary, extract } \\
\text { CO2 from a leaky } \\
\text { reservoir and inject it } \\
\text { into a sealed reservoir. }\end{array}$ \\
\hline 266 & 4.1.06.01. & Caprock geometry & $\begin{array}{l}\text { Geometry of the caprock including the } \\
\text { spatial distribution, depth and the topography } \\
\text { of the bottom. }\end{array}$ & $\begin{array}{l}\text { CO2 migration diverges from expected path. } \\
\text { Significant } \mathrm{CO} \text { volumes migrate off structure. } \\
\text { y } \\
\text { Insufficient capacity for planned injection volume } \\
\text { of } \mathrm{CO} \text {. Unexpected pressure increase during } \\
\text { injection. }\end{array}$ & \begin{tabular}{|l} 
Additional \\
[new] FEP
\end{tabular} & $\begin{array}{l}\text { Unlikely to be an } \\
\text { issue. }\end{array}$ & $\begin{array}{l}\text { The G-E caprock is a } \\
\text { dome structure. The T- } \\
\text { A caprock encloses } \\
\text { the oil reservoir. The T- } \\
\text { A Simpson Shale } \\
\text { caprock is a slightly } \\
\text { dipping monocline } \\
\text { above the Arbuckle. }\end{array}$ & & 2 & 3 & 6 & $\begin{array}{l}\text { Keep injection } \\
\text { pressure below } \\
\text { fracture pressure. }\end{array}$ & $\begin{array}{l}\text { Monitor and model the } \\
\text { caprock and sinks } \\
\text { above it. If necessary, } \\
\text { extract CO2 from a } \\
\text { leaky reservoir and } \\
\text { inject it into a sealed } \\
\text { reservoir. }\end{array}$ \\
\hline 267 & 4.1.06.02. & Caprock thickness & & $\begin{array}{l}\text { Insufficient caprock thickness could lead to } \\
\text { caprock failure and/or release of CO2 from the } \\
\text { reservoir. }\end{array}$ & \begin{tabular}{|l} 
Additional \\
[new] FEP
\end{tabular} & $\begin{array}{l}\text { Unlikely to be an } \\
\text { issue. }\end{array}$ & $\begin{array}{l}\text { Primary caprock } \\
\text { above Arbuckle is the } \\
\text { Simpson shale which } \\
\text { is very thin (11 ft). } \\
\text { However, this is } \\
\text { backed up by the } \\
\text { Kinderhook shale } \\
\text { which is } 72 \text { feet thick. }\end{array}$ & & 2 & 3 & 6 & $\begin{array}{l}\text { Keep injection } \\
\text { pressure below } \\
\text { fracture pressure. }\end{array}$ & $\begin{array}{l}\text { Monitor and model the } \\
\text { caprock and sinks } \\
\text { above it. If necessary, } \\
\text { extract CO2 from a } \\
\text { leaky reservoir and } \\
\text { inject it into a sealed } \\
\text { reservoir. }\end{array}$ \\
\hline 268 & 4.1.06.03. & $\begin{array}{c}\text { Caprock } \\
\text { discontinuous }\end{array}$ & & $\begin{array}{l}\text { CO2 escapes through gap in caprock into higher } \\
\text { formation or aquifer }\end{array}$ & \begin{tabular}{|l} 
Additional \\
[new] FEP
\end{tabular} & $\begin{array}{l}\text { Unlikely to be an } \\
\text { issue. }\end{array}$ & $\begin{array}{l}\text { Caprock in G-E and T- } \\
\text { A appears to be } \\
\text { continuous. }\end{array}$ & $\begin{array}{l}\text { Use } 3 d \text { seismic } \\
\text { survey to verify } \\
\text { that caprock is } \\
\text { continuous. }\end{array}$ & 2 & 3 & 6 & $\begin{array}{l}\text { Input results of } 3 d \\
\text { seismic survey into } \\
\text { site characterization } \\
\text { and models. Avoid } \\
\text { sites where caprock } \\
\text { is discontinuous. }\end{array}$ & $\begin{array}{l}\text { Monitor and model the } \\
\text { caprock and sinks } \\
\text { above it. If necessary, } \\
\text { extract CO2 from a } \\
\text { leaky reservoir and } \\
\text { inject it into a sealed } \\
\text { reservoir. }\end{array}$ \\
\hline 269 & 4.1.06.04. & $\begin{array}{l}\text { Caprock } \\
\text { geochemical } \\
\text { properties }\end{array}$ & $\begin{array}{l}\text { CO2 chemical reaction with caprock can } \\
\text { weaken the physical strength of the caprock. } \\
\text { High permeability zones might exist or be } \\
\text { formed by reaction of CO2 with the caprock, } \\
\text { causing the caprock to dissolve. CO2 can } \\
\text { dehydrate clay shales in the caprock, } \\
\text { thereby increasing its permeability. (Damen } \\
\text { 2006) }\end{array}$ & $\begin{array}{l}\text { Unintended migration of } \mathrm{CO} 2 \text { by chemical } \\
\text { reaction induced breaching of the caprock. }\end{array}$ & \begin{tabular}{|l} 
Additional \\
[new] FEP
\end{tabular} & $\begin{array}{l}\text { Unlikely to be an } \\
\text { issue. }\end{array}$ & $\begin{array}{l}\text { Caprock in G-E and T- } \\
\text { A is a shale backed up } \\
\text { by multiple seals and } \\
\text { sinks above. }\end{array}$ & $\begin{array}{l}\text { Characterize } \\
\text { caprock } \\
\text { mineralogy. }\end{array}$ & 2 & 3 & 6 & $\begin{array}{l}\text { Characterize and } \\
\text { model caprock } \\
\text { mineralogy and } \\
\text { geochemical } \\
\text { properties. }\end{array}$ & $\begin{array}{l}\text { Monitor and model the } \\
\text { caprock and sinks } \\
\text { above it. If necessary, } \\
\text { extract CO2 from a } \\
\text { leaky reservoir and } \\
\text { inject it into a sealed } \\
\text { reservoir. }\end{array}$ \\
\hline 270 & 4.1.06.05. & $\begin{array}{l}\text { Caprock } \\
\text { geomechanical } \\
\text { properties }\end{array}$ & Low fracturing pressure & $\begin{array}{l}\text { Could limit } \mathrm{CO} 2 \text { injection rate. Increased } \mathrm{CO} 2 \\
\text { injection cost. }\end{array}$ & \begin{tabular}{|l} 
Additional \\
[new] FEP
\end{tabular} & $\begin{array}{l}\text { Unlikely to be an } \\
\text { issue. }\end{array}$ & \begin{tabular}{|l|} 
Caprock above T-A \\
Bartlesville Sandstone \\
has withstood \\
pressures up to 1700 \\
psig. G-E reservoir \\
can't be pressurized.
\end{tabular} & $\begin{array}{l}\text { Obtain caprock } \\
\text { geomechanical } \\
\text { properties through } \\
\text { testing of core } \\
\text { samples. }\end{array}$ & 2 & 3 & 6 & $\begin{array}{l}\text { Keep injection } \\
\text { pressure below } \\
\text { fracture pressure. }\end{array}$ & $\begin{array}{l}\text { Monitor and model the } \\
\text { caprock and sinks } \\
\text { above it. If necessary, } \\
\text { extract CO2 from a } \\
\text { leaky reservoir and } \\
\text { inject it into a sealed } \\
\text { reservoir. }\end{array}$ \\
\hline 271 & 4.1.06.06. & $\begin{array}{l}\text { Permeable zones in } \\
\text { caprock }\end{array}$ & $\begin{array}{l}\text { Mudstone caprock permeability is typically } \\
\text { less than } 0.001 \text { milli-darcies (mD). }\end{array}$ & $\begin{array}{l}\text { Permeable zones in the caprock could form } \mathrm{CO} 2 \\
\text { pathways of escape. }\end{array}$ & \begin{tabular}{|l} 
Additional \\
[new] FEP
\end{tabular} & $\begin{array}{l}\text { Unlikely to be an } \\
\text { issue. }\end{array}$ & $\begin{array}{l}\text { Caprock integrity has } \\
\text { been demonstrated at } \\
\text { G-E and T-A through } \\
75 \text { to } 80 \text { years of oil } \\
\text { production. }\end{array}$ & $\begin{array}{l}\text { Characterize } \\
\text { caprock } \\
\text { permeability. }\end{array}$ & 2 & 3 & 6 & $\begin{array}{l}\text { Characterize and } \\
\text { model caprock } \\
\text { permeability. Avoid } \\
\text { sites where caprock } \\
\text { permeability is high. }\end{array}$ & $\begin{array}{l}\text { Monitor and model the } \\
\text { caprock and sinks } \\
\text { above it. If necessary, } \\
\text { extract CO2 from a } \\
\text { leaky reservoir and } \\
\text { inject it into a sealed } \\
\text { reservoir. }\end{array}$ \\
\hline
\end{tabular}

Quintessa Original FEP: Taken from Quintessa's on-line CO2 FEP database, which is freely accessible at: http://www.quintessa.org/co2fepdb/ 


\begin{tabular}{|c|c|c|c|c|c|c|c|c|c|c|c|c|c|}
\hline \multicolumn{6}{|c|}{ CO2 Geologic Sequestration Risks for the IMCCS Project } & \multicolumn{3}{|c|}{ Project Specific Information } & \multicolumn{3}{|c|}{ Risk Ranking } & \multicolumn{2}{|c|}{ Prevention and Mitigation } \\
\hline Line \# & Index No. & Risk Area & Description & Relevance & $\begin{array}{l}\text { Qunitessa } \\
\text { FEP } \\
\text { Category }\end{array}$ & $\begin{array}{l}\text { Individual } \\
\text { Comments }\end{array}$ & $\begin{array}{c}\text { IMccs Project } \\
\text { Specific Information }\end{array}$ & $\mid \begin{array}{c}\text { Imccs Project } \\
\text { Information Gaps } \\
\text { or Uncertainties }\end{array}$ & 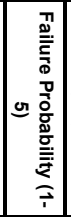 & 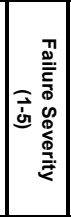 & 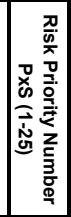 & $\begin{array}{l}\text { Risk Prevention } \\
\text { Steps (Actions } \\
\text { taken to reduce } \\
\text { risk probability) }\end{array}$ & $\begin{array}{l}\text { Risk Mitigation } \\
\text { Steps (Actions taken } \\
\text { to reduce risk } \\
\text { severity) }\end{array}$ \\
\hline 272 & 4.1.06.07. & $\begin{array}{l}\text { Caprock capillary } \\
\text { entry pressure }\end{array}$ & $\begin{array}{l}\text { No rocks have zero porosity, but the sealing } \\
\text { layer provides a seal because the pore } \\
\text { throats are too small to permit CO2 to enter } \\
\text { the water-filled pores. (CCP 2009) }\end{array}$ & $\begin{array}{l}\text { If the } \mathrm{CO} 2 \text { injection pressure exceeds the } \\
\text { capillary pressure of the caprock, } \mathrm{CO} 2 \text { can } \\
\text { penetrate or pass through the caprock }\end{array}$ & \begin{tabular}{|l} 
Additional \\
[new] FEP
\end{tabular} & \begin{tabular}{|l|} 
Unlikely to be an \\
issue.
\end{tabular} & \begin{tabular}{|l|} 
Caprock above T-A \\
Bartlesville Sandstone \\
has withstood \\
pressures up to 1700 \\
psig. G-E reservoir \\
can't be pressurized.
\end{tabular} & $\begin{array}{l}\text { Confirm caprock } \\
\text { capillary pressure }\end{array}$ & 2 & 3 & 6 & $\begin{array}{l}\text { Keep injection } \\
\text { pressure below } \\
\text { caprock capillary } \\
\text { pressure. }\end{array}$ & $\begin{array}{l}\text { Monitor and model the } \\
\text { caprock and sinks } \\
\text { above it. If necessary, } \\
\text { extract CO2 from a } \\
\text { leaky reservoir and } \\
\text { inject it into a sealed } \\
\text { reservoir. }\end{array}$ \\
\hline 273 & 4.1.06.08. & $\begin{array}{l}\text { Caprock fracture } \\
\text { pressure }\end{array}$ & $\begin{array}{l}\text { The critical pressure to avoid exceeding is } \\
\text { the fracture pressure of the confining interval } \\
\text { (caprock) above the reservoir, which is } \\
\text { normally higher than the fracture pressure in } \\
\text { the injection interval. (CCP 2009) }\end{array}$ & $\begin{array}{l}\text { If the } \mathrm{CO} 2 \text { injection pressure exceeds the } \\
\text { fracture pressure of the caprock, the caprock } \\
\text { could fracture and allow CO2 to pass through the } \\
\text { caprock. }\end{array}$ & $\begin{array}{l}\text { Additional } \\
\text { [new] FEP }\end{array}$ & \begin{tabular}{|l|} 
Unlikely to be an \\
issue.
\end{tabular} & \begin{tabular}{|l|} 
Caprock above T-A \\
Bartlesville Sandstone \\
has withstood \\
pressures up to 1700 \\
psig. G-E reservoi \\
can't be pressurized.
\end{tabular} & $\begin{array}{l}\text { Confirm caprock } \\
\text { fracture pressure }\end{array}$ & 2 & 3 & 6 & $\begin{array}{l}\begin{array}{l}\text { Keep injection } \\
\text { pressure below } \\
\text { fracture pressure. }\end{array} \\
\end{array}$ & $\begin{array}{l}\text { Monitor and model the } \\
\text { caprock and sinks } \\
\text { above it. If necessary, } \\
\text { extract CO2 from a } \\
\text { leaky reservoir and } \\
\text { inject it into a sealed } \\
\text { reservoir. }\end{array}$ \\
\hline 274 & 4.1.07.00. & $\begin{array}{l}\text { Additional seals } \\
\text { (Caprock- } \\
\text { secondary) } \\
\text { (a) }\end{array}$ & $\begin{array}{l}\text { This concerns the concept of successive } \\
\text { lithological, hydraulic and/or chemical } \\
\text { barriers acting successively to prevent flluid } \\
\text { escape to surface environments. From a } \\
\text { geological point of view the permeability } \\
\text { barrier is probably the most important, in } \\
\text { comparison with other types of traps. } \\
\text { However, it may be necessary to consider a } \\
\text { sequence of traps in CO2 migration models } \\
\text { in addition to the conventional low } \\
\text { permeability barriers. } \\
\text { For example, within the Weyburn } \\
\text { sequestration project, the primary caprock is } \\
\text { the Watrous formation, however, low } \\
\text { permeability formations at higher } \\
\text { stratigraphical layers provide potential } \\
\text { additional seals, preventing upward } \\
\text { migration of sequestered cO2. }\end{array}$ & & $\begin{array}{c}\text { Quintessa } \\
\text { FEP with } \\
\text { additional text }\end{array}$ & $\begin{array}{l}\text { Very unlikely to be } \\
\text { an issue. }\end{array}$ & $\begin{array}{l}\text { Multiple seals and } \\
\text { sinks above primary } \\
\text { reservoir and caprock. }\end{array}$ & $\begin{array}{l}\text { Characterize } \\
\text { multiple seals and } \\
\text { sinks above } \\
\text { reservoirs. }\end{array}$ & 1 & 4 & 4 & $\begin{array}{l}\text { Characterize and } \\
\text { model multiple seals } \\
\text { and sinks above } \\
\text { reservoir. }\end{array}$ & $\begin{array}{l}\text { Monitor and model the } \\
\text { caprock and sinks } \\
\text { above it. If necessary, } \\
\text { extract CO2 from a } \\
\text { leaky reservoir and } \\
\text { inject it into a sealed } \\
\text { reservoir. }\end{array}$ \\
\hline 275 & 4.1.08.00. & Lithology & $\begin{array}{l}\text { The systematic description of rocks in terms } \\
\text { of their mineral assemblage and texture. } \\
\text { The lithology of the geosphere (including } \\
\text { both the reservoir and the caprock) } \\
\text { determines the reserviri physical and } \\
\text { transport properties (including porosity and } \\
\text { permeability). It concerns the mineralogical } \\
\text { composition, texture (grain size, sorting) and } \\
\text { fabric (sedimentary structures, vertical and } \\
\text { horizontal heterogeneities). Potential } \\
\text { reservoir lithologies include sandstones and } \\
\text { limestones. }\end{array}$ & $\begin{array}{l}\text { The physical and chemical and mineralogical } \\
\text { properties of the reservoir rocks affect: the } \\
\text { capacity to store CO2; fluid flow and CO2 } \\
\text { migration; determine which water-rock reactions } \\
\text { can take place; and influence the rock strength } \\
\text { and elastic properties (such as compressibility, } \\
\text { shear strength, Poisson's ratio etc). }\end{array}$ & $\begin{array}{l}\text { Quintessa } \\
\text { original FEP }\end{array}$ & $\begin{array}{l}\text { Very unlikely to be } \\
\text { an issue. }\end{array}$ & & & 1 & 3 & 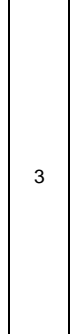 & $\begin{array}{l}\text { Characterize the } \\
\text { reservoir and } \\
\text { incorporate lithology } \\
\text { into the model. Use } \\
\text { results to optimize } \\
\text { reservoir } \\
\text { engineering. }\end{array}$ & $\begin{array}{l}\text { Monitor and model the } \\
\text { reservoir. If } \\
\text { necessary, extract } \\
\text { CO2 from a leaky } \\
\text { reservoir and inject it } \\
\text { into a sealed reservoir. }\end{array}$ \\
\hline 276 & 4.1.08.01. & Reservoir lithology & $\begin{array}{l}\text { Reservoirs are typical composed of porous } \\
\text { limestone, dolomite, sandstone, or in the } \\
\text { case of ECBM, coal. }\end{array}$ & & $\begin{array}{l}\begin{array}{l}\text { Additional } \\
\text { [new] FEP }\end{array} \\
\text { dix 6-48 }\end{array}$ & $\begin{array}{l}\text { Unlikely to be an } \\
\text { issue. }\end{array}$ & $\begin{array}{l}\text { Arbuckle dolomite and } \\
\text { Bartlesville sandstone }\end{array}$ & & 2 & 3 & 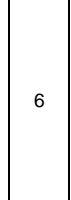 & $\begin{array}{l}\text { Characterize the } \\
\text { reservoir and } \\
\text { incorporate lithology } \\
\text { into the model. Use } \\
\text { results to optimize } \\
\text { reservoir } \\
\text { engineering. }\end{array}$ & $\begin{array}{l}\text { Monitor and model the } \\
\text { reservoiri If } \\
\text { necessary, extract } \\
\text { CO2 from a leaky } \\
\text { reservoir and inject it } \\
\text { into a sealed reservoir. }\end{array}$ \\
\hline
\end{tabular}

Quintessa Original FEP: Taken from Quintessa's on-line CO2 FEP database, which is freely accessible at: http://www.quintessa.org/co2fepdb/ 


\begin{tabular}{|c|c|c|c|c|c|c|c|c|c|c|c|c|c|}
\hline \multicolumn{6}{|c|}{ CO2 Geologic Sequestration Risks for the IMCCS Project } & \multicolumn{3}{|c|}{ Project Specific Information } & \multicolumn{3}{|c|}{ Risk Ranking } & \multicolumn{2}{|c|}{ Prevention and Mitigation } \\
\hline Line \# & Index No. & Risk Area & Description & Relevance & $\begin{array}{l}\text { Qunitessa } \\
\text { FEP } \\
\text { Category }\end{array}$ & $\begin{array}{l}\text { Individual } \\
\text { Comments }\end{array}$ & $\begin{array}{c}\text { IMCCS Project } \\
\text { Specific Information }\end{array}$ & $\begin{array}{c}\text { IMCCS Project } \\
\text { Information Gaps } \\
\text { or Uncertainties }\end{array}$ & 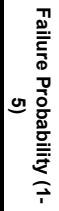 & 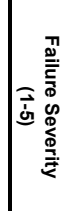 & 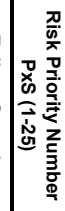 & $\begin{array}{l}\text { Risk Prevention } \\
\text { Steps (Actions } \\
\text { taken to reduce } \\
\text { risk probability) }\end{array}$ & $\begin{array}{l}\text { Risk Mitigation } \\
\text { Steps (Actions taken } \\
\text { to reduce risk } \\
\text { severity) }\end{array}$ \\
\hline 277 & 4.1.08.02. & Caprock lithology & $\begin{array}{l}\text { Caprock or sealing formations are typically } \\
\text { composed of mudstone, claystone, shale, } \\
\text { andor evaporites such as anhydrites and } \\
\text { halites. }\end{array}$ & $\begin{array}{l}\text { Mudstone sequences can vary significantly and } \\
\text { generally require more detailed investigation. } \\
\text { (CCP 2009) }\end{array}$ & \begin{tabular}{|l} 
Additional \\
[new] FEP
\end{tabular} & \begin{tabular}{|l} 
Unlikely to be an \\
issue.
\end{tabular} & $\begin{array}{l}\text { Simpson Shale and } \\
\text { Kinderhook Shale }\end{array}$ & & 2 & 3 & 6 & $\begin{array}{l}\text { Characterize the } \\
\text { caprock and } \\
\text { incorporate lithology } \\
\text { into the model. Use } \\
\text { results to optimize } \\
\text { reservoir } \\
\text { engineering. }\end{array}$ & $\begin{array}{l}\text { Monitor and model the } \\
\text { caprock and sinks } \\
\text { above it. If necessary, } \\
\text { extract CO2 from a } \\
\text { leaky reservoir and } \\
\text { inject it into a sealed } \\
\text { reservoir. }\end{array}$ \\
\hline 278 & 4.1.08.01. & $\begin{array}{l}\text { Lithification / } \\
\text { diagenesis }\end{array}$ & \begin{tabular}{|l|} 
The slow physical, chemical and//or biological \\
processes by which unconsolidated \\
sediments become sedimentary rock. These \\
processes can result in changes to the \\
original mineralogy.
\end{tabular} & $\begin{array}{l}\text { The state of lithification/diagenesis contributes to } \\
\text { determining the physical and chemical } \\
\text { characteristics of sedimentary rock. For example, } \\
\text { porosity usually decreases during diagenesis, } \\
\text { except in rare cases such as dissolution of } \\
\text { minerals and dolomitization. }\end{array}$ & $\begin{array}{l}\text { Quintessa } \\
\text { original FEP }\end{array}$ & $\begin{array}{l}\text { very unlikely to be } \\
\text { an issue. }\end{array}$ & $\begin{array}{l}\text { Reaction time on the } \\
\text { order of thousands of } \\
\text { years. }\end{array}$ & & 1 & 3 & 3 & $\begin{array}{l}\text { Include lithification } \\
\text { reactions in model. }\end{array}$ & $\begin{array}{l}\text { Include lithification } \\
\text { reactions in model. }\end{array}$ \\
\hline 279 & 4.1.08.02. & Pore architecture & $\begin{array}{l}\text { Structure and density of discrete voids within } \\
\text { the rock (pores). }\end{array}$ & $\begin{array}{l}\text { The pore architecture determines the porosity } \\
\text { and permeability of the rock, which are key } \\
\text { features when considering the mobility of fluids } \\
\text { and gases within the rock. }\end{array}$ & \begin{tabular}{|l} 
Quintessa \\
original FEP
\end{tabular} & $\begin{array}{l}\text { Unlikely to be an } \\
\text { issue }\end{array}$ & & $\begin{array}{l}\text { Characterize } \\
\text { reservoir and } \\
\text { caprock pore } \\
\text { architecture }\end{array}$ & 2 & 3 & 6 & $\begin{array}{l}\text { Characterize and } \\
\text { model reservoir } \\
\text { porosity, } \\
\text { permeability and } \\
\text { heterogeneity and } \\
\text { take into account in } \\
\text { optimizing reservoir } \\
\text { engineering. }\end{array}$ & $\begin{array}{l}\text { Monitor and model } \\
\text { CO2 injection } \\
\text { performance. Adjust } \\
\text { injection strategy if } \\
\text { necessary. }\end{array}$ \\
\hline 280 & 4.1.08.02.01 & $\begin{array}{c}\text { Insufficient } \\
\text { reservoir injectivity }\end{array}$ & $\begin{array}{l}\text { Injectivity is impacted by porosity and } \\
\text { permeability. Low injectivity can be partially } \\
\text { compensated for by greater injection } \\
\text { pressure. }\end{array}$ & $\begin{array}{l}\text { Low reservoir injectivity will limit the rate of } \mathrm{CO} 2 \\
\text { injection and require increased bottom hole } \\
\text { pressure. }\end{array}$ & \begin{tabular}{|l}
$\begin{array}{l}\text { Additional } \\
\text { [new] FEP }\end{array}$ \\
\end{tabular} & $\begin{array}{l}\text { Unlikely to be an } \\
\text { issue }\end{array}$ & & $\begin{array}{l}\text { Confirm reservoir } \\
\text { injectivity }\end{array}$ & 2 & 3 & 6 & \begin{tabular}{|l|} 
Characterize and \\
model reservoir \\
porosity, \\
permeability and \\
heterogeneity and \\
take into account in \\
optimizing reservoir \\
engineering.
\end{tabular} & $\begin{array}{l}\text { Monitor and model } \\
\text { CO2 injection } \\
\text { performance. Adjust } \\
\text { injection strategy if } \\
\text { necessary. }\end{array}$ \\
\hline 281 & 4.1.08.02.02 & $\begin{array}{c}\text { Decreasing } \\
\text { reservoir injectivity }\end{array}$ & $\begin{array}{l}\text { Initial injection rate meets expectations but } \\
\text { overall pore space is limited. Gradual } \\
\text { increase in bottom hole pressure. }\end{array}$ & & $\begin{array}{l}\text { Additional } \\
\text { [new] FEP }\end{array}$ & $\begin{array}{l}\text { Unlikely to be an } \\
\text { issue }\end{array}$ & & $\begin{array}{l}\text { Confirm reservoir } \\
\text { injectivity }\end{array}$ & 2 & 3 & 6 & \begin{tabular}{|l|} 
Characterize and \\
model reservoir \\
porosity, \\
permeability and \\
heterogeneity and \\
take into account in \\
optimizing reservoir \\
engineering.
\end{tabular} & $\begin{array}{l}\text { Monitor and model } \\
\text { CO2 injection } \\
\text { performance. Adjust } \\
\text { injection strategy if } \\
\text { necessary. }\end{array}$ \\
\hline 282 & 4.1.08.02.03 & Reservoir porosity & $\begin{array}{l}\text { Porosity values greater than } 10 \% \text { in } \\
\text { carbonate formations or } 15 \% \text { in clastic } \\
\text { formations are generally desirable. (CCP } \\
\text { 2009) }\end{array}$ & $\begin{array}{l}\text { Low porosity makes } \mathrm{CO} 2 \text { injection more difficult } \\
\text { and can limit the rate of injection into a reservoir. }\end{array}$ & \begin{tabular}{|l} 
Additional \\
[new] FEP
\end{tabular} & $\begin{array}{l}\text { Unlikely to be an } \\
\text { issue. }\end{array}$ & \begin{tabular}{|l|} 
Arbuckle porosity \\
ranges from $3-22 \%$ \\
with an average of \\
$11 \%$. Bartlesville \\
porosity ranges from \\
15 to $24 \%$ with an \\
average of $18 \%$.
\end{tabular} & $\begin{array}{l}\text { Confirm reservoir } \\
\text { porosity }\end{array}$ & 2 & 3 & 6 & $\begin{array}{l}\text { Characterize and } \\
\text { model reservoir } \\
\text { porosity and take } \\
\text { into account in } \\
\text { optimizizing reservoir } \\
\text { engineering. }\end{array}$ & $\begin{array}{l}\text { Monitor and model } \\
\text { CO2 injection } \\
\text { performance. Adjust } \\
\text { injection strategy if } \\
\text { necessary. }\end{array}$ \\
\hline
\end{tabular}




\begin{tabular}{|c|c|c|c|c|c|c|c|c|c|c|c|c|c|}
\hline \multicolumn{6}{|c|}{ CO2 Geologic Sequestration Risks for the IMCCS Project } & \multicolumn{3}{|c|}{ Project Specific Information } & \multicolumn{3}{|c|}{ Risk Ranking } & \multicolumn{2}{|c|}{ Prevention and Mitigation } \\
\hline Line \# & Index No. & Risk Area & Description & Relevance & $\begin{array}{l}\text { Qunitessa } \\
\text { FEP } \\
\text { Category }\end{array}$ & $\begin{array}{l}\text { Individual } \\
\text { Comments }\end{array}$ & $\begin{array}{c}\text { IMccS Project } \\
\text { Specific Information }\end{array}$ & $\begin{array}{c}\text { IMccs Project } \\
\text { Information Gaps } \\
\text { or Uncertainties }\end{array}$ & 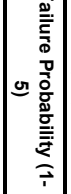 & 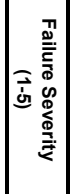 & 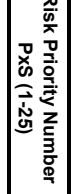 & $\begin{array}{l}\text { Risk Prevention } \\
\text { Steps (Actions } \\
\text { taken to reduce } \\
\text { risk probability) }\end{array}$ & $\begin{array}{c}\text { Risk Mitigation } \\
\text { Steps (Actions taker } \\
\text { to reduce risk } \\
\text { severity) }\end{array}$ \\
\hline 283 & 4.1.08.02.03 & $\begin{array}{l}\text { Reservoir } \\
\text { permeability }\end{array}$ & $\begin{array}{l}\text { Permeability measures the ability of fluids to } \\
\text { flow through a formation. High values } \\
\text { indicate a well-connected pore space while } \\
\text { low values indicate convoluted conduits that } \\
\text { disconnect the pores. Porous rocks have a } \\
\text { wide range in permeability between around } \\
\text { O.1 milli-Darcy (mD) for very tight rocks, to } \\
\text { several darcies for very permeable } \\
\text { formations. (CCP 2009) } \\
\text { In general, the better the porosity, the better } \\
\text { the permeability (and thus injectivity) - } \\
\text { however, large variations in permeability } \\
\text { mean the porosity and permeability } \\
\text { variations need to be mapped in detail (CCP } \\
\text { 2009) } \\
\text { Ideally, CO2 storage requires high } \\
\text { permeability (>100 mD) to ensure near well } \\
\text { bore injectivities for quick access to pore } \\
\text { space. However, this is not always possible } \\
\text { and near wellbore permeabilities may need } \\
\text { to be enhanced by artificially stimulating the } \\
\text { wells to allow for improved injectivity. (CCP } \\
\text { 2009) }\end{array}$ & $\begin{array}{l}\text { Low permeability makes CO2 injection more } \\
\text { difficult and can limit the rate of injection into a } \\
\text { reservoir. } \\
\text { While high permeabilities are generally desirable, } \\
\text { very high permeability pathways or conduits can } \\
\text { enhance CO2 migration along concentrated } \\
\text { pathways reducing the effective storage within } \\
\text { the target formation. (CCP 2009) } \\
\text { In moderate to low permeability, or poorly } \\
\text { connected reservoirs, a higher well density will be } \\
\text { needed to limit pressure evolution and allow for } \\
\text { efficient injection. (CCP 2009) }\end{array}$ & $\begin{array}{l}\text { Additional } \\
\text { [new] FEP }\end{array}$ & $\begin{array}{l}\text { Unlikely to be an } \\
\text { issue. }\end{array}$ & $\begin{array}{l}\text { Arbuckle is known to } \\
\text { be more permeable } \\
\text { horizontally than } \\
\text { verticallly. Permeability } \\
\text { ranges from } 1 \mathrm{mD} \text { to } \\
3000 \mathrm{mD} \text {. Bartlesville } \\
\text { ranges from } 1 \text { to } 200 \\
\mathrm{mD} \text {. With an average } \\
\text { of } 30 \mathrm{mD} \text {. }\end{array}$ & $\begin{array}{l}\text { Confirm reservoir } \\
\text { permeability }\end{array}$ & 2 & 3 & 6 & $\begin{array}{l}\text { Characterize and } \\
\text { model reservoir } \\
\text { permeability and } \\
\text { take into account in } \\
\text { optimizing reservoir } \\
\text { engineering. }\end{array}$ & $\begin{array}{l}\text { Monitor and model } \\
\text { CO2 injection } \\
\text { pressure and } \mathrm{CO} 2 \\
\text { plume. Watch out for } \\
\text { irregularities. Adjust } \\
\text { injection strategy if } \\
\text { necessary. }\end{array}$ \\
\hline 284 & 4.1.09.00. & Unconformities & $\begin{array}{l}\text { Geological surfaces separating older from } \\
\text { younger rocks and representing a gap in the } \\
\text { geologic record. Such a surface might result } \\
\text { from a hiatus in deposition of sediments, } \\
\text { possibly in combination with erosion, or } \\
\text { deformation such as faulting. An angular } \\
\text { unconformity separates younger strata from } \\
\text { eroded, dipping older strata. A disconformity } \\
\text { represents a time of nondeposition, possibly } \\
\text { combined with erosion, and can be difficult to } \\
\text { distinguish within a series of paralllel strata. A } \\
\text { nonconformity separates overlying strata } \\
\text { from eroded, older igneous or metamorphic } \\
\text { rocks. }\end{array}$ & $\begin{array}{l}\text { Unconformities can act both as potential seals or } \\
\text { lateral migration pathways for fluids. For } \\
\text { example, the impermeable barrier resulting from } \\
\text { the widespread development of diagenic } \\
\text { anhydritized carbonate associated with the } \\
\text { unconformity between the Mississippian beds } \\
\text { and overlying Triassic Watrous Formation in the } \\
\text { vicinity of the Weyburn pool. }\end{array}$ & $\begin{array}{l}\text { Quintessa } \\
\text { original FEP }\end{array}$ & $\begin{array}{l}\text { Possible that } \\
\text { some } \\
\text { unconformities } \\
\text { have not been } \\
\text { identified yet. }\end{array}$ & & \begin{tabular}{|l} 
Use $3 \mathrm{~d}$ seismic \\
survey to identify \\
unconformities.
\end{tabular} & 3 & 3 & 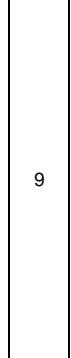 & $\begin{array}{l}\text { Incorporate } 3 d \\
\text { seismic results into } \\
\text { site characterization } \\
\text { and modeling and } \\
\text { take into account in } \\
\text { reservoir } \\
\text { engineering. }\end{array}$ & $\begin{array}{l}\text { Monitor and model } \\
\text { CO2 plume for } \\
\text { irregularities. } \\
\text { Determine root cause. } \\
\text { If necessary, adjust } \\
\text { injection strategy. }\end{array}$ \\
\hline 285 & 4.1.1.10.00. & Heterogeneities & $\begin{array}{l}\text { Heterogeneities are variations in the rock } \\
\text { properties of a geological formation. }\end{array}$ & $\begin{array}{l}\text { Heterogeneities can result in directional } \\
\text { variations in permeability, which affects the } \\
\text { mobility of fluids and gases in the rock. For } \\
\text { example, experience from the Saline Aquifer } \\
\text { CO2 Storage project (SACS) has shown that } \\
\text { both stratitiraphical and structural local } \\
\text { permeability heterogeneities have the potential to } \\
\text { profoundly affect CO2 distribution and migration } \\
\text { (Chadwick et all, 2003). } \\
\text { The image below shows seismic sections through } \\
\text { the SSleipner injection sitit from Zweigel et al. } \\
\text { (2001). The strong amplitudes are taken to be } \\
\text { CO2 accumulations. }\end{array}$ & $\begin{array}{l}\text { Quintessa } \\
\text { original FEP }\end{array}$ & $\begin{array}{l}\text { Likely to be an } \\
\text { issue. }\end{array}$ & $\begin{array}{l}\text { The Arbuckle and } \\
\text { Bartlesville are known } \\
\text { to be heterogeneous. }\end{array}$ & $\begin{array}{l}\text { Characterize } \\
\text { reservoir and } \\
\text { caprock } \\
\text { heterogeneity }\end{array}$ & 4 & 3 & 12 & $\begin{array}{l}\text { Characterize and } \\
\text { model reservoir and } \\
\text { caprock } \\
\text { heterogeneity and } \\
\text { incorporate into } \\
\text { reservoir } \\
\text { engineering. }\end{array}$ & $\begin{array}{l}\text { Monitor and model } \\
\text { CO2 plume for } \\
\text { irregularities. If } \\
\text { necessary, adjust } \\
\text { injection strategy. }\end{array}$ \\
\hline
\end{tabular}

Appendix 6-50

Quintessa Original FEP: Taken from Quintessa's on-line CO2 FEP database, which is freely accessible at: http://www.quintessa.org/co2fepdb/ 


\begin{tabular}{|c|c|c|c|c|c|c|c|c|c|c|c|c|c|}
\hline \multicolumn{6}{|c|}{ CO2 Geologic Sequestration Risks for the IMCCS Project } & \multicolumn{3}{|c|}{ Project Specific Information } & \multicolumn{3}{|c|}{ Risk Ranking } & \multicolumn{2}{|c|}{ Prevention and Mitigation } \\
\hline Line \# & Index No. & Risk Area & Description & Relevance & $\begin{array}{l}\text { Qunitessa } \\
\text { FEP } \\
\text { Category }\end{array}$ & $\begin{array}{l}\text { Individual } \\
\text { Comments }\end{array}$ & $\begin{array}{c}\text { IMCCS Project } \\
\text { Specific Information }\end{array}$ & \begin{tabular}{|c} 
IMccs Project \\
Information Gaps \\
or Uncertainties
\end{tabular} & 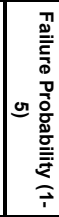 & 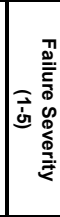 & 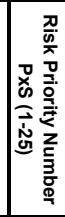 & $\begin{array}{l}\text { Risk Prevention } \\
\text { Steps (Actions } \\
\text { taken to reduce } \\
\text { risk probability) }\end{array}$ & $\begin{array}{l}\text { Risk Mitigation } \\
\text { Steps (Actions taken } \\
\text { to reduce risk } \\
\text { severity) }\end{array}$ \\
\hline 286 & 4.1.1.10.01. & $\begin{array}{c}\text { Reservoir } \\
\text { heterogeneity }\end{array}$ & $\begin{array}{l}\text { CO2 cannot be injected at required rates. } \\
\text { Unexpected bottom hole pressure increase. } \\
\\
\text { Unexpected migration of CO2 plume. } \\
\text { Detection of unexpected plume distribution } \\
\text { possibly related to stratigraphic or } \\
\text { depositional geometry (otherwise structure, } \\
\text { high permeability layers or hydrodynamic } \\
\text { flow). Lower than expected bottom hole } \\
\text { pressure. } \\
\text { Baffles or barriers in reservoir influencing } \\
\text { CO2 migration }\end{array}$ & & \begin{tabular}{|l} 
Additional \\
[new] FEP
\end{tabular} & $\begin{array}{l}\text { Likely to be an } \\
\text { issue. }\end{array}$ & $\begin{array}{l}\text { The Arbuckle and } \\
\text { Bartlesville are known } \\
\text { to be heterogeneous. }\end{array}$ & \begin{tabular}{|l} 
Characterize \\
reservoir \\
heterogeneity
\end{tabular} & 4 & 3 & 12 & $\begin{array}{l}\text { Characterize and } \\
\text { model reservoir } \\
\text { heterogeneity and } \\
\text { incorporate into } \\
\text { reservoir } \\
\text { engineering. }\end{array}$ & $\begin{array}{l}\text { Monitor and model } \\
\text { CO2 plume for } \\
\text { irregularities. If } \\
\text { necessary, adjust } \\
\text { injection strategy. }\end{array}$ \\
\hline 287 & 4.1.1.10.02. & $\begin{array}{l}\text { High permeability } \\
\text { layers in reservoir }\end{array}$ & $\begin{array}{l}\text { CO2 migrates rapidly and preferentially } \\
\text { along a specific stratignaphic horizon } \\
\text { (possibly off structure). Indications of rapid } \\
\text { migration through a restricted stratigraphic } \\
\text { horizon. Lower than expected downhole } \\
\text { pressure and flow rate. }\end{array}$ & & $\begin{array}{l}\text { Additional } \\
\text { [new] FEP }\end{array}$ & Possible issue. & \begin{tabular}{|l|} 
Arbuckle is known to \\
be more permeable \\
horizontally than \\
verticilly. Permeability \\
ranges from $1 \mathrm{mD}$ to \\
$3000 \mathrm{mD}$. Bartlesville \\
ranges from 1 to 200 \\
$\mathrm{mD}$. With an average \\
of $30 \mathrm{mD}$.
\end{tabular} & & 3 & 2 & 6 & \begin{tabular}{|l|} 
Characterize and \\
model reservoir \\
permeability and \\
take into account in \\
optimizing reservoir \\
engineering.
\end{tabular} & $\begin{array}{l}\text { Monitor and model } \\
\text { CO2 injection } \\
\text { pressure and } \mathrm{CO} 2 \\
\text { plume. Watch out for } \\
\text { irregularities. Adjust } \\
\text { injection strategy if } \\
\text { necessary. }\end{array}$ \\
\hline 288 & 4.1.10.03. & $\begin{array}{c}\text { Caprock } \\
\text { heterogeneity }\end{array}$ & & & $\begin{array}{l}\text { Additional } \\
\text { [new] FEP }\end{array}$ & Possible issue. & $\begin{array}{l}\text { Simpson caprock is } \\
\text { known to be } \\
\text { heterogeneous. }\end{array}$ & $\begin{array}{l}\text { Characterize } \\
\text { caprock } \\
\text { heterogeneity }\end{array}$ & 3 & 3 & 9 & $\begin{array}{l}\text { Characterize and } \\
\text { model caprock } \\
\text { heterogeneity and } \\
\text { incorporate into } \\
\text { reservoir } \\
\text { engineering }\end{array}$ & $\begin{array}{l}\text { Monitor sinks above } \\
\text { caprock for CO2 } \\
\text { content. Back off on } \\
\text { injection pressure if } \\
\text { leak is detected. Plug } \\
\text { leak or extract } \mathrm{CO} 2 \\
\text { from leaky reservoir } \\
\text { and inject into sealed } \\
\text { reservoir if necessary. }\end{array}$ \\
\hline 289 & 4.1.10.04. & $\begin{array}{l}\text { Interstitial layers of } \\
\text { shale in reservoir }\end{array}$ & & & \begin{tabular}{|l}
$\begin{array}{c}\text { Additional } \\
\text { [new] FEP }\end{array}$ \\
\end{tabular} & \begin{tabular}{|l} 
Unlikely to be an \\
issue.
\end{tabular} & $\begin{array}{l}\text { Bartlesville is known to } \\
\text { have interstitial layers } \\
\text { of shale }\end{array}$ & $\begin{array}{l}\text { Characterize } \\
\text { reservoir } \\
\text { heterogeneity }\end{array}$ & 2 & 2 & 4 & $\begin{array}{l}\text { Characterize and } \\
\text { model reservoir } \\
\text { heterogeneity and } \\
\text { incorporate into } \\
\text { reservoir } \\
\text { engineering. } \\
\end{array}$ & $\begin{array}{l}\text { Monitor and model } \\
\text { CO2 plume for } \\
\text { irregularities. If } \\
\text { necessary, adjust } \\
\text { injection strategy. }\end{array}$ \\
\hline 290 & 4.1.10.05. & $\begin{array}{l}\text { Heterogeneity of } \\
\text { overlying aquifers }\end{array}$ & $\begin{array}{l}\text { Heterogeneity in aquifers overlying the } \\
\text { reservoir may increase the difficulty of } \\
\text { monitoring them for leaked CO2, which may } \\
\text { increase monitoring costs andlor impair } \\
\text { project image. Heterogeneity could also } \\
\text { increase dispersal or mineral interaction of } \\
\text { CO2 with aquifers, reducing physical } \\
\text { impacts. }\end{array}$ & & \begin{tabular}{|}
$\begin{array}{c}\text { Additional } \\
\text { [new] FEP }\end{array}$ \\
\end{tabular} & $\begin{array}{l}\text { Unlikely to be an } \\
\text { issue. }\end{array}$ & $\begin{array}{l}\text { Groundwater aquifers } \\
\text { above the oil } \\
\text { reservoirs are very } \\
\text { limited at G-E and T-A }\end{array}$ & $\begin{array}{l}\text { Conduct baseline } \\
\text { survey of } \\
\text { groundwater } \\
\text { quality }\end{array}$ & 2 & 2 & 4 & \begin{tabular}{|l|} 
Characterize and \\
model groundwater \\
aquifers above oil \\
reservoirs. Monitor \\
changes in \\
chemistry.
\end{tabular} & $\begin{array}{l}\text { Monitor aquifer } \\
\text { chemistry. Identify any } \\
\text { changes and } \\
\text { determine root cause. }\end{array}$ \\
\hline 291 & 4.1.11.00. & Fractures and faults & $\begin{array}{l}\text { Fractures are cracks or breaks in rock. } \\
\text { Fractures along which displacement has } \\
\text { occurred are called faults. Fractures and } \\
\text { faults can occur over a wide range of scales. }\end{array}$ & $\begin{array}{l}\text { Fractures can enhance conductivity, for example, } \\
\text { by a conductive fracture connecting permeable } \\
\text { regions together. They can also act as seals, by } \\
\text { bringing a relatively permeable region into } \\
\text { contact with low conductivity rock, for example. }\end{array}$ & $\begin{array}{l}\text { Quintessa } \\
\text { original FEP }\end{array}$ & Possible issue. & \begin{tabular}{|l|} 
Fault(s) exist at G-E. \\
Fractures exist in \\
Arbuckle, but Arbuckle \\
can't be over \\
pressured.
\end{tabular} & $\begin{array}{l}\text { Characterize faults } \\
\text { and fractures at } \\
\text { injection sites. }\end{array}$ & 3 & 3 & 9 & \begin{tabular}{|l|} 
Characterize and \\
model fractures and \\
faults at injection \\
sites and incorporate \\
into reservoir \\
engineering.
\end{tabular} & $\begin{array}{l}\text { Monitor and model } \\
\text { pressure and plume } \\
\text { migration in direction } \\
\text { of fault(s). Adjust } \\
\text { injection strategy if } \\
\text { necessary. Monitor } \\
\text { micro-seismicity. }\end{array}$ \\
\hline
\end{tabular}

Appendix 6-51

Quintessa Original FEP: Taken from Quintessa's on-line CO2 FEP database, which is freely accessible at: http://www.quintessa.org/co2fepdb/ 


\begin{tabular}{|c|c|c|c|c|c|c|c|c|c|c|c|c|c|}
\hline \multicolumn{6}{|c|}{ CO2 Geologic Sequestration Risks for the IMCCS Project } & \multicolumn{3}{|c|}{ Project Specific Information } & \multicolumn{3}{|c|}{ Risk Ranking } & \multicolumn{2}{|c|}{ Prevention and Mitigation } \\
\hline Line \# & Index No. & Risk Area & Description & Relevance & $\begin{array}{l}\text { Qunitessa } \\
\text { FEP } \\
\text { Category }\end{array}$ & $\begin{array}{l}\text { Individual } \\
\text { Comments }\end{array}$ & $\begin{array}{c}\text { IMCCS Project } \\
\text { Specific Information }\end{array}$ & $\begin{array}{c}\text { IMCCS Project } \\
\text { Information Gaps } \\
\text { or Uncertainties }\end{array}$ & 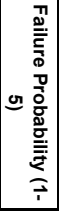 & 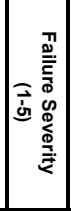 & 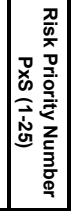 & $\begin{array}{l}\text { Risk Prevention } \\
\text { Steps (Actions } \\
\text { taken to reduce } \\
\text { risk probability) }\end{array}$ & $\begin{array}{c}\text { Risk Mitigation } \\
\text { Steps (Actions taken } \\
\text { to reduce risk } \\
\text { severity) }\end{array}$ \\
\hline 292 & 4.1.11.01. & Fault movement & & $\begin{array}{l}\text { Movement on a fault that transverses a wellbore } \\
\text { could damage or sever casing or tubing. }\end{array}$ & \begin{tabular}{|l} 
Additional \\
[new] FEP
\end{tabular} & $\begin{array}{l}\text { Unlikely to be an } \\
\text { issue }\end{array}$ & $\begin{array}{l}\text { Faults exist at G-E, but } \\
\text { are inactive, down dip, } \\
\text { don't penetrate the } \\
\text { caprock and Arbuckle } \\
\text { can't be over } \\
\text { pressured. }\end{array}$ & $\begin{array}{l}\text { Characterize faults } \\
\text { at injection site }\end{array}$ & 2 & 3 & 6 & $\begin{array}{l}\text { Characterize and } \\
\text { model faults at } \\
\text { injection sites and } \\
\text { incorporate into } \\
\text { reservoir } \\
\text { engineering. }\end{array}$ & $\begin{array}{l}\text { Monitor and model } \\
\text { pressure and plume } \\
\text { migration in direction } \\
\text { of fault(s). Adjust } \\
\text { injection strategy if } \\
\text { necessary. Monitor } \\
\text { micro-seismicity. }\end{array}$ \\
\hline 293 & 4.1.12.00. & $\begin{array}{l}\text { Undetected } \\
\text { features }\end{array}$ & $\begin{array}{l}\text { Natural or man-made features within the } \\
\text { geological environment that may not be } \\
\text { detected during site investigations. } \\
\text { Examples of possible undetected features } \\
\text { are fracturelfault zones, the presence of } \\
\text { brines or old mine workings. Some physical } \\
\text { features of the storage environment may } \\
\text { remain undetected during site surveys and } \\
\text { even during preliminary borenole drilling. } \\
\text { The nature of the geological environment will } \\
\text { indicate the likelihood that certain types of } \\
\text { undetected features may be present and the } \\
\text { site investigation may be able to place } \\
\text { bounds on the maximum size or minimum } \\
\text { proximity to such features. }\end{array}$ & $\begin{array}{l}\text { Undetected features could significantly affect the } \\
\text { performance of a sequestration system. For } \\
\text { example, local permeability heterogeneities with } \\
\text { the potential to profoundly affect the distribution } \\
\text { and migration of CO2 at Sleipner (within the } \\
\text { Saline Aquifer CO2 Storage project, SACS) were } \\
\text { | only discovered after effectively being illuminated } \\
\text { by the sequestered CO2 (Chadwick et al., 2003). }\end{array}$ & $\begin{array}{l}\text { Quintessa } \\
\text { original FEP }\end{array}$ & $\begin{array}{l}\text { Possible that } \\
\text { some features } \\
\text { have been } \\
\text { undetected. }\end{array}$ & & $\begin{array}{l}\text { Use 3d seismic } \\
\text { survey to detect } \\
\text { subsurface } \\
\text { features. }\end{array}$ & 3 & 3 & 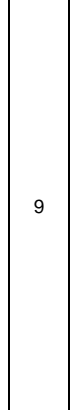 & $\begin{array}{l}\text { Incorporate 3d } \\
\text { seismic results into } \\
\text { site characterization } \\
\text { and modeling and } \\
\text { take into account in } \\
\text { reservoir } \\
\text { engineering. }\end{array}$ & $\begin{array}{l}\text { Monitor and model } \\
\text { CO2 plume for } \\
\text { irregularities. } \\
\text { Determine root cause. } \\
\text { If necessary, adjust } \\
\text { injection strategy. }\end{array}$ \\
\hline 294 & 4.1.12.01. & $\begin{array}{c}\text { Underground } \\
\text { cavities (natural or } \\
\text { manmade) }\end{array}$ & & & \begin{tabular}{|l} 
Additional \\
[new] FEP
\end{tabular} & Possible issue. & $\begin{array}{l}\text { Arbuckle is full of } \\
\text { karsts at G-E. }\end{array}$ & $\begin{array}{l}\text { Characterize the } \\
\text { site for karsts }\end{array}$ & 3 & 3 & 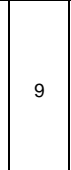 & $\begin{array}{l}\text { Characterize and } \\
\text { model karsts in } \\
\text { reservoir and } \\
\text { incorporate into } \\
\text { reservoir } \\
\text { engineering. }\end{array}$ & $\begin{array}{l}\text { Monitor and model } \\
\text { CO2 plume for } \\
\text { irregularities. } \\
\text { Determine root cause. } \\
\text { If necessary, adjust } \\
\text { injection strategy. }\end{array}$ \\
\hline 295 & 4.1.12.02. & $\begin{array}{l}\text { Existing faults or } \\
\text { fracture zone }\end{array}$ & $\begin{array}{l}\text { The presence of a fault does not imply a } \\
\text { leakage problem. Most rocks are faulted and } \\
\text { fractured in some way over geological time. } \\
\text { The critical question for CO2 storage is } \\
\text { whether there are any faults or fractures that } \\
\text { could provide leakage pathways under } \\
\text { present day geological conditions. In } \\
\text { addition to the basic geometry of connected } \\
\text { rocks and flow paths, this involves the study } \\
\text { of geomechanics, stress fields and fracture } \\
\text { behavior. Simply put many "faults: do not } \\
\text { leak at all and many huge oil and gas fields } \\
\text { that include faults prove the point. (CCP } \\
\text { 2009) }\end{array}$ & $\begin{array}{l}\text { CO2 might leak through open (no-sealing) faults, } \\
\text { which extend into the caprock. } \\
\text { CO2 might leak through natural fractures in the } \\
\text { caprock. }\end{array}$ & $\begin{array}{l}\text { Additional } \\
\text { [new] FEP }\end{array}$ & Possible issue. & $\begin{array}{l}\text { G-E has existing } \\
\text { inactive fault on west } \\
\text { side that doesn't } \\
\text { intersect the primary } \\
\text { caprock. } \\
\text { T-A is } 25 \text { miles away } \\
\text { from the Humboldt } \\
\text { fault zone which is } \\
\text { somewhat active but } \\
\text { down dip from the } \\
\text { injection reservoirs. }\end{array}$ & $\begin{array}{l}\text { Characterize faults } \\
\text { at injection site }\end{array}$ & 3 & 3 & 9 & $\begin{array}{l}\text { Characterize and } \\
\text { model faults at } \\
\text { injection sites and } \\
\text { incorporate into } \\
\text { reservoir } \\
\text { engineering. }\end{array}$ & $\begin{array}{l}\text { Monitor and model } \\
\text { pressure and plume } \\
\text { migration in direction } \\
\text { of fault(s). Adjust } \\
\text { injection strategy if } \\
\text { necessary. Monitor } \\
\text { micro-seismicity. }\end{array}$ \\
\hline 296 & 4.1.12.03. & $\begin{array}{l}\text { Existing boreholes } \\
\text { in the area }\end{array}$ & & & \begin{tabular}{|l} 
Additional \\
[new] FEP
\end{tabular} & $\begin{array}{l}\text { Likely to be an } \\
\text { issue. }\end{array}$ & $\begin{array}{l}\text { T-A: } 370 \text { boreholes } \\
\text { G-E: } 247 \text { boreholes }\end{array}$ & $\begin{array}{l}\text { Complete more } \\
\text { thorough analysis } \\
\text { of existing } \\
\text { boreholes }\end{array}$ & 4 & 3 & 12 & \begin{tabular}{|l|} 
Analyze boreholes. \\
Identify at risk \\
boreholes and plug \\
them prior to CO2 \\
injection.
\end{tabular} & $\begin{array}{l}\text { Monitor boreholes } \\
\text { during CO2 injection } \\
\text { and replug them if } \\
\text { they begin leaking. }\end{array}$ \\
\hline
\end{tabular}




\begin{tabular}{|c|c|c|c|c|c|c|c|c|c|c|c|c|c|}
\hline \multicolumn{6}{|c|}{ CO2 Geologic Sequestration Risks for the IMCCS Project } & \multicolumn{3}{|c|}{ Project Specific Information } & \multicolumn{3}{|c|}{ Risk Ranking } & \multicolumn{2}{|c|}{ Prevention and Mitigation } \\
\hline Line \# & Index No. & Risk Area & Description & Relevance & $\begin{array}{l}\text { Qunitessa } \\
\text { FEP } \\
\text { Category }\end{array}$ & $\begin{array}{l}\text { Individual } \\
\text { Comments }\end{array}$ & $\begin{array}{c}\text { IMCCS Project } \\
\text { Specific Information }\end{array}$ & $\begin{array}{c}\text { IMCCS Project } \\
\text { Information Gaps } \\
\text { or Uncertainties }\end{array}$ & 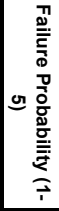 & 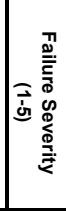 & 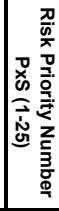 & $\begin{array}{l}\text { Risk Prevention } \\
\text { Steps (Actions } \\
\text { taken to reduce } \\
\text { risk probability) }\end{array}$ & $\begin{array}{l}\text { Risk Mitigation } \\
\text { Steps (Actions taken } \\
\text { to reduce risk } \\
\text { severity) }\end{array}$ \\
\hline 297 & 4.1.12.04. & $\begin{array}{c}\text { Subsurface } \\
\text { infrastructure }\end{array}$ & $\begin{array}{l}\text { Subsurface infrastructure can include steam, } \\
\text { drainage, electrical, natural gas, water, } \\
\text { sewer, and communications lines, and other } \\
\text { features. Such features can enable or } \\
\text { impede geophysical investigations or } \\
\text { complicate the soili-chemical background. } \\
\text { They can also become migration paths for } \\
\text { CO2 that reaches soil levels. }\end{array}$ & & \begin{tabular}{|l} 
Additional \\
[new] FEP
\end{tabular} & $\begin{array}{l}\text { Unlikely to be an } \\
\text { issue. }\end{array}$ & $\begin{array}{l}\text { G-E and T-A are } \\
\text { mature sites and may } \\
\text { have some subsurface } \\
\text { infrastructure in place. }\end{array}$ & $\begin{array}{l}\text { Use one-call } \\
\text { system and } \\
\text { consult with } \\
\text { previous lease } \\
\text { holders about } \\
\text { subsurface } \\
\text { infrastructure. }\end{array}$ & 2 & 2 & 4 & $\begin{array}{l}\text { Use one-call system } \\
\text { before excavating or } \\
\text { drilling. Consult with } \\
\text { previous lease } \\
\text { holders. }\end{array}$ & $r \begin{array}{l}\text { Monitor CO2 content } \\
\text { in soil air and water. } \\
\text { ldentify any } \\
\text { irregularities/ Define } \\
\text { root cause. Remediate } \\
\text { leaks. }\end{array}$ \\
\hline 298 & 4.1.12.05. & Gas chimneys & & & \begin{tabular}{|l} 
Additional \\
[new] FEP
\end{tabular} & $\begin{array}{l}\text { very unlikely to be } \\
\text { an issue. }\end{array}$ & $\begin{array}{l}\text { Mature oil fields. } \\
\text { Caprock has } \\
\text { demonstrated integrity } \\
\text { for } 75-80 \text { years. }\end{array}$ & & 1 & 2 & 2 & $\begin{array}{l}\text { Characterize and } \\
\text { model site and } \\
\text { incorporate into } \\
\text { reservoir } \\
\text { engineering. }\end{array}$ & \begin{tabular}{|l} 
Monitor and model \\
CO2 plume for \\
irregularities. \\
Determine root cause. \\
If necesssary, adjust \\
injection strategy.
\end{tabular} \\
\hline 299 & 4.1.12.06. & $\begin{array}{l}\text { Shallow gas / drift } \\
\text { gas }\end{array}$ & $\begin{array}{l}\text { Shallow gas (above bedrock) can cause } \\
\text { drilling problems and impede monitoring. } \\
\text { cO2 entry into shallow groundwwater could } \\
\text { increase drift-gas exsolution. }\end{array}$ & & \begin{tabular}{|l} 
Additional \\
[new] FEP
\end{tabular} & $\begin{array}{l}\text { very unlikely to be } \\
\text { an issue. }\end{array}$ & $\begin{array}{l}\text { Limited groundwater } \\
\text { resources. Multiple } \\
\text { stacked sinks and } \\
\text { seals. }\end{array}$ & & 1 & 2 & 2 & $\begin{array}{l}\text { Characterize and } \\
\text { model site and } \\
\text { incorporate into } \\
\text { reservoir } \\
\text { engineering. }\end{array}$ & $\begin{array}{l}\text { Monitor CO2 content } \\
\text { on site for } \\
\text { irregularities. } \\
\text { Determine root cause. } \\
\text { Remediate any leaks. }\end{array}$ \\
\hline 300 & 4.1.12.07. & $\begin{array}{l}\text { Clustered small gas } \\
\text { related amplitude } \\
\text { anomalies along } \\
\text { fault planes }\end{array}$ & & & \begin{tabular}{|l} 
Additional \\
[new] FEP
\end{tabular} & $\begin{array}{l}\text { Very unlikely to be } \\
\text { an issue. }\end{array}$ & $\begin{array}{l}\text { G-E has existing } \\
\text { inactive fault on west } \\
\text { side that doesn't } \\
\text { intersect the primary } \\
\text { caprock. } \\
\text { T-A is } 25 \text { miles away } \\
\text { from the Humboldt } \\
\text { fault zone which is } \\
\text { somewhat active but } \\
\text { down dip from the } \\
\text { injection reservoirs. }\end{array}$ & & 1 & 2 & 2 & \begin{tabular}{|l} 
Characterize and \\
model site and \\
incorporate into \\
reservoir \\
engineering.
\end{tabular} & $\begin{array}{l}\text { Monitor and model } \\
\text { pressure and plume } \\
\text { migration in direction } \\
\text { of fault(s). Adjust } \\
\text { injection strategy if } \\
\text { necessary. Monitor } \\
\text { micro-seismicity. }\end{array}$ \\
\hline 301 & 4.1.13.00. & $\begin{array}{l}\text { Vertical geothermal } \\
\text { gradient }\end{array}$ & $\begin{array}{l}\text { Temperature profile in the geosphere prior to } \\
\text { the injection of CO2. } \\
\text { The critical temperature for CO2 is } 31.1 \\
\text { degrees centigrade. The average } \\
\text { geothermal gradient is approximately } 2.4 \\
\text { degrees centigrade per kilometer. If the } \\
\text { surface temperature is } 10 \text { degrees } \\
\text { centigrade, the critical temperature will be } \\
\text { reached at a depth of } 840 \text { meters. However, } \\
\text { a considerable variation in geothermal } \\
\text { gradients and sub-surface temperatures can } \\
\text { be expected at a depth of } 1000 \text { meters. For } \\
\text { example, in Europe temperatures at } 1000 \mathrm{~m} \\
\text { range from } 20 \text { to } 75 \text { degrees centigrade, with } \\
\text { local temperatures of more than } 200 \\
\text { degrees centigrade in volcanic areas. }\end{array}$ & $\begin{array}{l}\text { Relevant to temperature dependent } \\
\text { physical/chemical/biological/hydraulic processes, } \\
\text { such as CO2 phase behavior. }\end{array}$ & $\begin{array}{l}\text { Quintessa } \\
\text { original FEP }\end{array}$ & Not a problem. & $\begin{array}{l}\text { G-E and T-A have } \\
\text { normal vertical } \\
\text { geothermal gradients }\end{array}$ & & 1 & 1 & 1 & NA & NA \\
\hline
\end{tabular}




\begin{tabular}{|c|c|c|c|c|c|c|c|c|c|c|c|c|c|}
\hline \multicolumn{6}{|c|}{ CO2 Geologic Sequestration Risks for the IMCCS Project } & \multicolumn{3}{|c|}{ Project Specific Information } & \multicolumn{3}{|c|}{ Risk Ranking } & \multicolumn{2}{|c|}{ Prevention and Mitigation } \\
\hline Line \# & Index No. & Risk Area & Description & Relevance & $\begin{array}{l}\text { Qunitessa } \\
\text { FEP } \\
\text { Category }\end{array}$ & $\begin{array}{l}\text { Individual } \\
\text { Comments }\end{array}$ & $\begin{array}{c}\text { IMCCS Project } \\
\text { Specific Information }\end{array}$ & $\begin{array}{c}\text { IMCCS Project } \\
\text { Information Gaps } \\
\text { or Uncertainties }\end{array}$ & 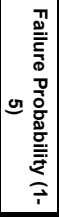 & 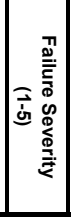 & 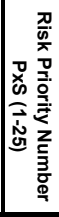 & $\begin{array}{l}\text { Risk Prevention } \\
\text { Steps (Actions } \\
\text { taken to reduce } \\
\text { risk probability) }\end{array}$ & $\begin{array}{c}\text { Risk Mitigation } \\
\text { Steps (Actions taken } \\
\text { to reduce risk } \\
\text { severity) }\end{array}$ \\
\hline 302 & 4.1.14.00. & Formation pressure & $\begin{array}{l}\text { The pressure of fluids within the pores of a } \\
\text { formation, normally hydrostatic pressure, or } \\
\text { the pressure exerted by a column of water } \\
\text { from the formations depth to the sea level } \\
\text { prior to the injection of CO2. } \\
\text { The critical pressure of CO2 is } 7.38 \text { mega- } \\
\text { Pascals. The average underground } \\
\text { hydrostatic pressure increases with depth by } \\
\text { approximately } 10.5 \text { mega-Pascals per } \\
\text { kilimemeter for aquifers that are in open } \\
\text { communication with surface water. Applying } \\
\text { this average gradient, the critical pressure of } \\
\text { cO2 will be reacheded at a depth of around } \\
690 \text { meters. However, aquifers or } \\
\text { hydrocarbon reservoirs (e.g., EOR and } \\
\text { ECBM) that are sealed off from the rest of } \\
\text { the sub-surface may be under- or over } \\
\text { pressured. }\end{array}$ & $\begin{array}{l}\text { Contributes towards determining the mobility of } \\
\text { sequestered CO2. }\end{array}$ & $\begin{array}{l}\text { Quintessa } \\
\text { original FEP }\end{array}$ & Not a problem. & \begin{tabular}{|l|} 
Difficult to increase \\
Arbuckle pressure. \\
Bartlesville pressure \\
needs to be increased \\
$400-500$ psi.
\end{tabular} & & 1 & 4 & 4 & $\begin{array}{l}\text { Characterize and } \\
\text { model formation } \\
\text { pressure and } \\
\text { incoropoate into } \\
\text { reservoir in } \\
\text { engineering. }\end{array}$ & $\begin{array}{l}\text { Monitor and model } \\
\text { formation pressure } \\
\text { and CO2 migration. } \\
\text { Identify any } \\
\text { regularities. Determine } \\
\text { root cause. Adjust } \\
\text { injection strategy if } \\
\text { necessary. }\end{array}$ \\
\hline 303 & 4.1.15.00. & $\begin{array}{l}\text { Stress and } \\
\text { mechanical } \\
\text { properties }\end{array}$ & $\begin{array}{l}\text { The stress condition and mechanical } \\
\text { properties of the geosphere prior to injection } \\
\text { of CO2. }\end{array}$ & $\begin{array}{l}\text { The initial stress state and mechanical properties } \\
\text { are a baseline from which the potential effect of } \\
\text { injecting supercritical CO2 can be assessed. }\end{array}$ & $\begin{array}{l}\text { Quintessa } \\
\text { original FEP }\end{array}$ & Not a problem. & $\begin{array}{l}\text { The Arbuckle can't be } \\
\text { over pressured and } \\
\text { the Bartlesville is } \\
\text { isolated and under } \\
\text { pressured. }\end{array}$ & & 1 & 4 & 4 & $\begin{array}{l}\text { Characterize and } \\
\text { model formation } \\
\text { stress and } \\
\text { mechanical } \\
\text { propenties and } \\
\text { incorporate into } \\
\text { reservoir } \\
\text { engineering. }\end{array}$ & $\begin{array}{l}\text { Monitor and model } \\
\text { formation stress and } \\
\text { CO2 migration. } \\
\text { Identify any } \\
\text { irregularities. } \\
\text { Determine root cause. } \\
\text { Adjust injection } \\
\text { strategy if necessary. }\end{array}$ \\
\hline 304 & 4.1.16.00. & $\begin{array}{l}\text { Petrophysical } \\
\text { properties }\end{array}$ & $\begin{array}{l}\text { Petrophysical properties of the geosphere } \\
\text { prior to the injection of CO2. This includes } \\
\text { features such as permeability, porosity, } \\
\text { residual saturation, capillary pressure and } \\
\text { wettability. }\end{array}$ & $\begin{array}{l}\text { Petrophysical properties influence how injected } \\
\text { CO2 will migrate in the geosphere. For example, } \\
\text { permeability influences the direction and rate of } \\
\text { CO2 movement, and porosity and residual } \\
\text { saturation influence the dimensions of the } \mathrm{CO} 2 \\
\text { plume. }\end{array}$ & $\begin{array}{l}\text { Quintessa } \\
\text { original FEP }\end{array}$ & $\begin{array}{l}\text { Very unlikely to be } \\
\text { an issue. }\end{array}$ & & $\begin{array}{l}\text { Confirm } \\
\text { petrophysical } \\
\text { properties of } \\
\text { Arbucke. } \\
\text { Bartlesville and } \\
\text { Caprock. }\end{array}$ & 1 & 3 & 3 & $\begin{array}{l}\text { Characterize and } \\
\text { model petrophysical } \\
\text { properties stress } \\
\text { and mechanical } \\
\text { properties and } \\
\text { incorporate into } \\
\text { reservoir } \\
\text { engineering. }\end{array}$ & $\begin{array}{l}\text { Monitor and model } \\
\text { injectivity and CO2 } \\
\text { plume migration. } \\
\text { Identify any } \\
\text { irregularities. } \\
\text { Determine root cause. } \\
\text { Adjust injection } \\
\text { strategy if necessary. }\end{array}$ \\
\hline 305 & 4.2.00.00. & Fluids & $\begin{array}{l}\text { Details of fluids in the geosphere, which } \\
\text { comprises of the reservoir, overburden and } \\
\text { surrounding rock prior to the injection of } \\
\text { cO2. Water will generally be present, but } \\
\text { other fluids, particularly hydrocarbons (e.g., } \\
\text { EOR and ECBM), may be important, } \\
\text { dependent on the sequestration concept. }\end{array}$ & $\begin{array}{l}\text { Water and other fluids in the sequestration } \\
\text { system will affect the transport and interactions of } \\
\text { injected carbon dioxide. }\end{array}$ & $\begin{array}{l}\text { Quintessa } \\
\text { original FEP }\end{array}$ & \begin{tabular}{|l|} 
Unlikely to be an \\
issue,
\end{tabular} & $\begin{array}{l}\text { G-E and T-A have } \\
\text { residual oil and brine. }\end{array}$ & $\begin{array}{l}\text { Confirm analysis } \\
\text { of residual oil and } \\
\text { brine at G-E and T- } \\
\text { A. }\end{array}$ & 2 & 3 & 6 & $\begin{array}{l}\text { Characterize and } \\
\text { model oil and brine } \\
\text { analyses and } \\
\text { incorporate into } \\
\text { reservoir } \\
\text { engineering. }\end{array}$ & $\begin{array}{l}\text { Monitor and model } \\
\text { EOR performance. } \\
\text { Identify irregularities. } \\
\text { Determine root cause. } \\
\text { Adjust injection } \\
\text { strategy if necessary. }\end{array}$ \\
\hline 306 & 4.2.01.00. & Fluid properties & $\begin{array}{l}\text { Properties of the geosphere fluids prior to } \\
\text { injection of CO2, including composition and } \\
\text { geochemistry. }\end{array}$ & $\begin{array}{l}\text { The fluid properties and geochemistry of the } \\
\text { geosphere will contribute towards determining } \\
\text { how injected } \mathrm{CO} 2 \text { will behave in the geosphere. }\end{array}$ & $\begin{array}{l}\text { Quintessa } \\
\text { original FEP }\end{array}$ & \begin{tabular}{|l|} 
Unlikely to be an \\
issue,
\end{tabular} & $\begin{array}{l}\text { G-E and T-A have } \\
\text { residual oil and brine. }\end{array}$ & $\begin{array}{l}\text { Confirm properties } \\
\text { of residual oil and } \\
\text { brine at G-E and T- } \\
\text { A. }\end{array}$ & 2 & 2 & 4 & $\begin{array}{l}\text { Characterize and } \\
\text { model oil and brine } \\
\text { properties and } \\
\text { incorporate into } \\
\text { reservoir } \\
\text { engineering. }\end{array}$ & $\begin{array}{l}\text { Monitor and model } \\
\text { EOR performance. } \\
\text { Identify irregularities. } \\
\text { Determine root cause. } \\
\text { Adjust injection } \\
\text { strategy if necessary. }\end{array}$ \\
\hline 307 & 4.2.01.01. & $\begin{array}{l}\text { Fluid chemical } \\
\text { composition }\end{array}$ & & $\begin{array}{l}\text { CO2 causing change in fluid chemical } \\
\text { composition } \\
\end{array}$ & $\begin{array}{l}\text { Additional } \\
\text { [new] FEP } \\
\text { dix 6-54 }\end{array}$ & $\begin{array}{l}\text { Very unlikely to be } \\
\text { an issue. }\end{array}$ & $\begin{array}{l}\text { G-E and T-A have } \\
\text { residual oil and brine. }\end{array}$ & $\begin{array}{l}\text { Confirm analysis } \\
\text { of residual oil and } \\
\text { brine at G-E and T } \\
\text { A. }\end{array}$ & 1 & 2 & 2 & $\begin{array}{l}\text { Characterize and } \\
\text { model oil and brine } \\
\text { analyses and } \\
\text { incorporate into } \\
\text { reservoir } \\
\text { engineering. }\end{array}$ & $\begin{array}{l}\text { Monitor and model } \\
\text { EOR performance. } \\
\text { Identify irregularities. } \\
\text { Determine root cause. } \\
\text { Adjust injection } \\
\text { strategy if necessary. }\end{array}$ \\
\hline
\end{tabular}

Quintessa Original FEP: Taken from Quintessa's on-line CO2 FEP database, which is freely accessible at: http://www.quintessa.org/co2fepdb/ 


\begin{tabular}{|c|c|c|c|c|c|c|c|c|c|c|c|c|c|}
\hline \multicolumn{6}{|c|}{ CO2 Geologic Sequestration Risks for the IMCCS Project } & \multicolumn{3}{|c|}{ Project Specific Information } & \multicolumn{3}{|c|}{ Risk Ranking } & \multicolumn{2}{|c|}{ Prevention and Mitigation } \\
\hline Line \# & Index No. & Risk Area & Description & Relevance & $\begin{array}{l}\text { Qunitessa } \\
\text { FEP } \\
\text { Category }\end{array}$ & $\begin{array}{l}\text { Individual } \\
\text { Comments }\end{array}$ & $\begin{array}{c}\text { IMCCS Project } \\
\text { Specific Information }\end{array}$ & $\begin{array}{c}\text { IMCCS Project } \\
\text { Information Gaps } \\
\text { or Uncertainties }\end{array}$ & 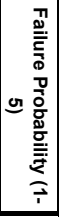 & 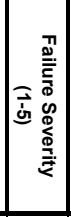 & 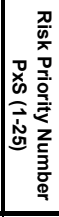 & $\begin{array}{l}\text { Risk Prevention } \\
\text { Steps (Actions } \\
\text { taken to reduce } \\
\text { risk probability) }\end{array}$ & $\begin{array}{l}\text { Risk Mitigation } \\
\text { Steps (Actions taker } \\
\text { to reduce risk } \\
\text { severity) }\end{array}$ \\
\hline 308 & 4.2.01.02. & High salinity fluid & $\begin{array}{l}\text { The high salinity of deep aquifers is, } \\
\text { generally, an indication of very low or } \\
\text { insignificant throughput of meteoric waters. }\end{array}$ & $\begin{array}{l}\text { Very high salinity can lead to deposition of halite } \\
\text { in pore spaces and cause decreased } \\
\text { permeability and injectivity. }\end{array}$ & $\begin{array}{l}\text { Additional } \\
\text { [new] FEP }\end{array}$ & $\begin{array}{l}\text { Very unlikely to be } \\
\text { an issue. }\end{array}$ & $\begin{array}{l}\text { G-E and T-A have } \\
\text { brine. }\end{array}$ & $\begin{array}{l}\text { Confirm analysis } \\
\text { of brine at G-E } \\
\text { and T-A. }\end{array}$ & 1 & 2 & 2 & \begin{tabular}{|l|} 
Characterize and \\
model brine \\
composition and salt \\
deposition and \\
incorporate into \\
reservoir \\
engineering. Inject \\
fresh water into the \\
DSA before injecting \\
CO2 to minimize salt \\
build up due to water \\
evaporation near the \\
injection well.
\end{tabular} & $\begin{array}{l}\text { Monitor and model } \\
\text { injectivity. Identify } \\
\text { irregularities. } \\
\text { Determine root cause. } \\
\text { Adjust injection } \\
\text { strategy if necessary. } \\
\text { stecess. }\end{array}$ \\
\hline 309 & 4.2.02.00. & Hydrogeology & $\begin{array}{l}\text { Natural formation water flow pathways } \\
\text { (directions, velocities) in the geosphere will } \\
\text { be important in determining the long-erm } \\
\text { migration paths for CO2. This depends on } \\
\text { factors including: hydraulic heads, } \\
\text { permeability and porosity distribution, the } \\
\text { existence of fracture networks, connection } \\
\text { between aquifers, position of the recharge } \\
\text { and discharge areas. }\end{array}$ & $\begin{array}{l}\text { This will affect the migration of dissolved } \mathrm{CO} 2 \text { in } \\
\text { the reservoir and the geosphere (direction, } \\
\text { timing), the position of the interface between } \\
\text { supercritical CO2 and aquifer water (inclined } \\
\text { interface). There may also be a possible effect } \\
\text { on overlying aquifers used for drinking water. }\end{array}$ & $\begin{array}{l}\text { Quintessa } \\
\text { original FEP }\end{array}$ & $\begin{array}{l}\text { Very unlikely to be } \\
\text { an issue. }\end{array}$ & $\begin{array}{l}\text { Arbuckle is a large, } \\
\text { very slow moving } \\
\text { DSA. The G-E domes } \\
\text { and T-A Bartlesville } \\
\text { bottles are isolated } \\
\text { somewhat from } \\
\text { hydrogeology of the } \\
\text { Arbuckle. }\end{array}$ & $\begin{array}{l}\text { Characterize the } \\
\text { Arbuckle DSA } \\
\text { local hydrogeology }\end{array}$ & 1 & 3 & 3 & \begin{tabular}{|l|} 
Characterize and \\
model the Arbuckle \\
DSA local \\
hydrogeology and \\
incorporate into the \\
DSA engineering.
\end{tabular} & $\begin{array}{l}\text { Monitor and model } \\
\text { DSA CO2 plume } \\
\text { migration. Identify } \\
\text { irregularities. } \\
\text { Determine root cause. } \\
\text { Adjust injection } \\
\text { strategy if necessary. }\end{array}$ \\
\hline 310 & 4.2.02.01. & $\begin{array}{l}\text { Connection } \\
\text { between deep } \\
\text { saline aquifer and } \\
\text { shallow drinking } \\
\text { water aquifer }\end{array}$ & & & \begin{tabular}{|l} 
Additional \\
[new] FEP
\end{tabular} & $\begin{array}{l}\text { Very unlikely to be } \\
\text { an issue. }\end{array}$ & $\begin{array}{l}\text { The Arbuckle outcrops } \\
\text { and interfaces with } \\
\text { shallow drinking water } \\
\text { about } 200 \text { miles East } \\
\text { of T-A. Modeling } \\
\text { indicates the CO2 } \\
\text { DSA plume will } \\
\text { stabilize about a half } \\
\text { mile from injection. }\end{array}$ & $\begin{array}{l}\text { Characterize the } \\
\text { Arbuckle DSA } \\
\text { regional } \\
\text { hydrogeology }\end{array}$ & 1 & 3 & 3 & \begin{tabular}{|l|} 
Characterize and \\
model the Arbuckle \\
DSA regional \\
hydrogeology and \\
incorporate into the \\
DSA engineering.
\end{tabular} & $\begin{array}{l}\text { Monitor and model } \\
\text { DSA CO2 plume } \\
\text { migration. Identify } \\
\text { irregularities. } \\
\text { Determine root cause. } \\
\text { Adjust injection } \\
\text { strategy if necessary. }\end{array}$ \\
\hline 311 & 4.2.02.02. & $\begin{array}{l}\text { Position of aquifer } \\
\text { recharge and } \\
\text { discharge areas }\end{array}$ & & & \begin{tabular}{|l} 
Additional \\
[new] FEP
\end{tabular} & $\begin{array}{l}\text { Very unlikely to be } \\
\text { an issue. }\end{array}$ & $\begin{array}{l}\text { The Arbuckle outcrops } \\
\text { and interfaces with } \\
\text { shallow drinking water } \\
\text { about } 200 \text { miles East } \\
\text { of T-A. }\end{array}$ & $\begin{array}{l}\text { Characterize the } \\
\text { Arbuckle DSA } \\
\text { regional } \\
\text { hydrogeology }\end{array}$ & 1 & 3 & 3 & \begin{tabular}{|l|} 
Characterize and \\
model the Arbuckle \\
DSA regional \\
hydrogeology and \\
incorporate into the \\
DSA engineering.
\end{tabular} & $\begin{array}{l}\text { Monitor and model } \\
\text { DSA CO2 plume } \\
\text { migration. Identify } \\
\text { irregularities. } \\
\text { Determine root cause. } \\
\text { Adjust injection } \\
\text { strategy if necessary. }\end{array}$ \\
\hline 312 & 4.2.02.03. & $\begin{array}{l}\text { Natural fluid flow } \\
\text { pathways }\end{array}$ & $\begin{array}{l}\text { Direction and velocity of fluid in saline } \\
\text { aquifer }\end{array}$ & & \begin{tabular}{|l} 
Additional \\
[new] FEP
\end{tabular} & $\begin{array}{l}\text { Very unlikely to be } \\
\text { an issue. }\end{array}$ & \begin{tabular}{|l|} 
Arbuckle is a large, \\
very slow moving \\
DSA. The G-E domes \\
and T-A Bartlesville \\
bottles are isolated \\
somewhat from \\
hydrogeology of the \\
Arbuckle.
\end{tabular} & $\begin{array}{l}\text { Characterize the } \\
\text { Arbuckle DSA } \\
\text { local hydrogeology }\end{array}$ & 1 & 3 & 3 & \begin{tabular}{|l|} 
Characterize and \\
model the Arbuckle \\
DSA local \\
hydrogeology and \\
incorporate into the \\
DSA engineering.
\end{tabular} & $\begin{array}{l}\text { Monitor and model } \\
\text { DSA CO2 plume } \\
\text { migration. Identify } \\
\text { irregularities. } \\
\text { Determine root cause. } \\
\text { Adjust injection } \\
\text { strategy if necessary. }\end{array}$ \\
\hline
\end{tabular}




\begin{tabular}{|c|c|c|c|c|c|c|c|c|c|c|c|c|c|}
\hline \multicolumn{6}{|c|}{ CO2 Geologic Sequestration Risks for the IMCCS Project } & \multicolumn{3}{|c|}{ Project Specific Information } & \multicolumn{3}{|c|}{ Risk Ranking } & \multicolumn{2}{|c|}{ Prevention and Mitigation } \\
\hline Line \# & Index No. & Risk Area & Description & Relevance & $\begin{array}{l}\text { Qunitessa } \\
\text { FEP } \\
\text { Category }\end{array}$ & $\begin{array}{l}\text { Individual } \\
\text { Comments }\end{array}$ & $\begin{array}{c}\text { IMCCS Project } \\
\text { Specific Information }\end{array}$ & \begin{tabular}{|c} 
IMccs Project \\
Information Gaps \\
or Uncertainties
\end{tabular} & 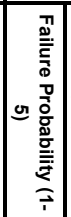 & 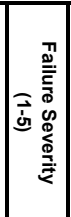 & 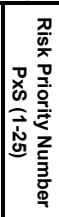 & $\begin{array}{l}\text { Risk Prevention } \\
\text { Steps (Actions } \\
\text { taken to reduce } \\
\text { risk probability) }\end{array}$ & $\begin{array}{l}\text { Risk Mitigation } \\
\text { Steps (Actions taken } \\
\text { to reduce risk } \\
\text { severity) }\end{array}$ \\
\hline 313 & 4.2.03.00. & Hydrocarbons & $\begin{array}{l}\text { The presence and distribution of } \\
\text { hydrocarbons, such as oil and/or gas (e.g., } \\
\text { EOR and ECBM), within the storage system. }\end{array}$ & $\begin{array}{l}\text { Hydrocarbons have potentially important } \\
\text { implications for a storage system, by both } \\
\text { influencing the likelihood of previous geological } \\
\text { exploitation of the area, and by being an } \\
\text { important component of the system with which } \\
\text { sequestered } \mathrm{CO} 2 \text { can interact. }\end{array}$ & $\begin{array}{l}\text { Quintessa } \\
\text { original FEP }\end{array}$ & $\begin{array}{l}\text { Likely to be an } \\
\text { issue. }\end{array}$ & $\begin{array}{l}\text { G-E and T-A contain } \\
\text { residual oil suitable for } \\
\text { EOR. CO2 injected } \\
\text { near the bottom of the } \\
\text { Arbuckle at G-E would } \\
\text { ultimately interface } \\
\text { with oil in the dome. }\end{array}$ & & 4 & 2 & 8 & \begin{tabular}{|l|} 
Characterize and \\
model the G-E DSA \\
and incorporate into \\
the DSA and \\
reservoir \\
engineering.
\end{tabular} & $\begin{array}{l}\text { Monitor and model G- } \\
\text { E DSA CO2 plume } \\
\text { migration. Identify } \\
\text { irregularities. } \\
\text { Determine root cause. } \\
\text { Adjust injection } \\
\text { strategy if necessary. }\end{array}$ \\
\hline 314 & 5.0.00.00. & Boreholes & $\begin{array}{l}\text { This category of FEPs is concerned with the } \\
\text { way that activity by humans alters the natural } \\
\text { system. Both boreholes used in the } \\
\text { sequestration operations and those drilled } \\
\text { for other purposes are relevant to the long- } \\
\text { term performance of the system. The } \\
\text { category is divided into two classes for the } \\
\text { drilling process, and sealing and } \\
\text { abandonment. }\end{array}$ & & $\begin{array}{l}\text { Quintessa } \\
\text { original FEP }\end{array}$ & & $\begin{array}{l}\text { T-A: } 370 \text { old wells } \\
\text { G-E: } 247 \text { old wells }\end{array}$ & & NA & NA & NA & NA & NA \\
\hline 315 & 5.1.00.00. & $\begin{array}{l}\text { Drilling and } \\
\text { completion }\end{array}$ & $\begin{array}{l}\text { FEPs relevant to the operation of boreholes } \\
\text { drilled within the system domain. }\end{array}$ & $\begin{array}{l}\text { Boreholes can potentially provide short circuits } \\
\text { for carbon dioxide transport. }\end{array}$ & $\begin{array}{l}\text { Quintessa } \\
\text { original FEP }\end{array}$ & Possible issue. & $\begin{array}{l}\text { T-A: } 370 \text { old wells } \\
\text { G-E: } 247 \text { old wells }\end{array}$ & $\begin{array}{l}\text { How early wells } \\
\text { were constructed } \\
\text { (primary cement) }\end{array}$ & 3 & 2 & 6 & \begin{tabular}{|l|}
$\begin{array}{l}\text { Examine and } \\
\text { recomplete old wells } \\
\text { as needed }\end{array}$ \\
\end{tabular} & $\begin{array}{l}\text { Monitor for leaks to } \\
\text { stop them early }\end{array}$ \\
\hline 316 & 5.1.01.00. & Formation damage & $\begin{array}{l}\text { Alteration of the far-field or virgin } \\
\text { characteristics of a formation, usually by } \\
\text { exposure to drilling fluids. Fracturing } \\
\text { associated with formation damage can } \\
\text { increase porosity, whereas the water or solid } \\
\text { particles in the drilling fluids, or both, can } \\
\text { decrease the pore volume and effective } \\
\text { permeability of the formation in the near- } \\
\text { welllbore region. } \\
\text { A number of mechanisms can result in a } \\
\text { decrease in porosity, including: } \\
\text { - solid particles from the drilling flluid } \\
\text { physicially plug or bridge across flow paths in } \\
\text { the porous formation; } \\
\text { - when water contacts certain clay minerals } \\
\text { in the formation, the clay typically swells, } \\
\text { increasing in volume and decreasing the } \\
\text { pore volume; and } \\
\text { - chemical reactions between the drilling fluid } \\
\text { and the formation rock and fluids can } \\
\text { precipitate solids or semisolids that plug pore } \\
\text { spaces. }\end{array}$ & $\begin{array}{l}\text { Formation damage has a number of potential } \\
\text { implications for assessing CO2 sequestration: } \\
\text { - it can make information from affected boreholes } \\
\text { non-representative of the true characteristics of } \\
\text { the damaged formations; and } \\
\text { - damaged regions themselves may provide flow } \\
\text { paths for CO2 migration, particularly if damage } \\
\text { results in fracturing. }\end{array}$ & $\begin{array}{l}\text { Quintessa } \\
\text { original FEP }\end{array}$ & \begin{tabular}{|l|} 
These are old \\
fields so it seems \\
likely that there \\
has been some \\
formation \\
alteration. \\
However, that may \\
not necessarily be \\
in the caprock
\end{tabular} & $\begin{array}{l}\text { Early wells in T-A used } \\
\text { explosive fracing. } \\
\text { Later wells used } \\
\text { hydrofracing. }\end{array}$ & $\begin{array}{l}\text { Determine } \\
\text { damage done by } \\
\text { explosive and } \\
\text { hydrofracing. }\end{array}$ & 3 & 3 & 9 & $\begin{array}{l}\text { Run fall off tests and } \\
\text { characterize } \\
\text { responses in } \\
\text { overlying formations. } \\
\text { Replug and seal at } \\
\text { risk wells. Pressurize } \\
\text { reservoir with water } \\
\text { prior to injecting } \\
\text { CO2 to check for } \\
\text { leaks. }\end{array}$ & $\begin{array}{l}\text { Monitor wells for } \mathrm{CO} 2 \\
\text { leakage and replug if } \\
\text { necessary. }\end{array}$ \\
\hline 317 & 5.1.01.01. & $\begin{array}{c}\mathrm{CO} 2 \text { can't be } \\
\text { injected at required } \\
\text { rates due to } \\
\text { formation damage }\end{array}$ & $\begin{array}{l}\text { Unexpected bottom hole pressure increase } \\
\text { and change in formation fluid chemistry. }\end{array}$ & Appe & $\begin{array}{l}\text { Expansion of } \\
\text { Q FEP } \\
\text { dix 6-56 }\end{array}$ & $\begin{array}{l}\text { f Unlikely to be an } \\
\text { issue. }\end{array}$ & & $\begin{array}{l}\text { Determine } \\
\text { damage done by } \\
\text { explosive and } \\
\text { hydrofracing. }\end{array}$ & 2 & 3 & 6 & \begin{tabular}{|l|} 
Careful \\
characterization of \\
injection formations \\
to understand fluid \\
and formation \\
chemistry and CO2- \\
water-rock \\
interactions. Replug \\
and seal at risk \\
wells. Pressurize \\
reservoir with water \\
prior to injecting \\
CO2 to check for \\
leaks.
\end{tabular} & $\begin{array}{l}\text { Monitor wells for } \mathrm{CO} 2 \\
\text { leakage and replug if } \\
\text { necessary. }\end{array}$ \\
\hline
\end{tabular}

Quintessa Original FEP: Taken from Quintessa's on-line CO2 FEP database, which is freely accessible at: http://www.quintessa.org/co2fepdb/ 


\begin{tabular}{|c|c|c|c|c|c|c|c|c|c|c|c|c|c|}
\hline \multicolumn{6}{|c|}{ CO2 Geologic Sequestration Risks for the IMCCS Project } & \multicolumn{3}{|c|}{ Project Specific Information } & \multicolumn{3}{|c|}{ Risk Ranking } & \multicolumn{2}{|c|}{ Prevention and Mitigation } \\
\hline Line \# & Index No. & Risk Area & Description & Relevance & $\begin{array}{l}\text { Qunitessa } \\
\quad \text { FEP } \\
\text { Category }\end{array}$ & $\begin{array}{l}\text { Individual } \\
\text { Comments }\end{array}$ & $\begin{array}{c}\text { IMccs Project } \\
\text { Specific Information }\end{array}$ & $\begin{array}{c}\text { IMCCS Project } \\
\text { Information Gaps } \\
\text { or Uncertainties }\end{array}$ & 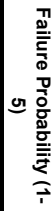 & 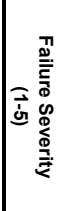 & 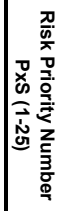 & $\begin{array}{l}\text { Risk Prevention } \\
\text { Steps (Actions } \\
\text { taken to reduce } \\
\text { risk probability) }\end{array}$ & $\begin{array}{l}\text { Risk Mitigation } \\
\text { Steps (Actions taken } \\
\text { to reduce risk } \\
\text { severity) }\end{array}$ \\
\hline 318 & 5.1.01.02. & $\begin{array}{l}\text { Solid particles from } \\
\text { drilling plugging } \\
\text { pore spaces }\end{array}$ & & & $\begin{array}{c}\text { Expansion of } \\
\text { Q FEP }\end{array}$ & $\begin{array}{l}\text { Very unlikely to be } \\
\text { an issue. }\end{array}$ & \begin{tabular}{|l|} 
This is an old field so it \\
seems like if this were \\
going to be a problem \\
that we would know \\
about it prior to the \\
start
\end{tabular} & & 1 & 3 & 3 & NA & NA \\
\hline 319 & 5.1.01.03. & $\begin{array}{l}\text { Water from drilling } \\
\text { causing clay } \\
\text { particles to swell }\end{array}$ & & & $\begin{array}{c}\text { Expansion of } \\
\text { Q FEP }\end{array}$ & $\begin{array}{l}\text { Very unlikely to be } \\
\text { an issue. }\end{array}$ & \begin{tabular}{|l} 
This is an old field so it \\
seems like if this were \\
going to be a problem \\
that we would know \\
about it prior to the \\
start
\end{tabular} & & 1 & 2 & 2 & NA & NA \\
\hline 320 & 5.1.01.04. & $\begin{array}{c}\text { Chemical reaction } \\
\text { between drilling } \\
\text { fluids and formation } \\
\text { flluids precipititating } \\
\text { solids }\end{array}$ & & $\begin{array}{l}\text { Near wellbore injectivity reduction due to } \\
\text { geochemical reactions (CCP 2009) }\end{array}$ & $\begin{array}{c}\text { Expansion of } \\
\text { Q FEP }\end{array}$ & $f \begin{array}{l}\text { Very unlikely to be } \\
\text { an issue. }\end{array}$ & & & 1 & 3 & 3 & $\begin{array}{l}\text { Characterize the } \\
\text { formation fluid and } \\
\text { identify any possible } \\
\text { reactions. Include in } \\
\text { models. }\end{array}$ & \begin{tabular}{|l} 
Monitor CO2 injection \\
pressure. Identify \\
irregularities. \\
Determine root cause. \\
Relocate well if \\
necessary.
\end{tabular} \\
\hline 321 & 5.1.01.05. & $\begin{array}{l}\text { Fracturing near } \\
\text { borehole }\end{array}$ & & & $\begin{array}{c}\text { Expansion of } \\
\text { Q FEP }\end{array}$ & $\begin{array}{l}\text { Unlikely to be an } \\
\text { issue. }\end{array}$ & $\begin{array}{l}\text { Early wells in T-A used } \\
\text { explosive fracing. } \\
\text { Later wells used } \\
\text { hydrofracing. }\end{array}$ & $\begin{array}{l}\text { Determine } \\
\text { damage done by } \\
\text { explosive and } \\
\text { hydrofracing. }\end{array}$ & 2 & 3 & 6 & $\begin{array}{l}\text { Run FMI in new } \\
\text { wells. Do vit or } \\
\text { falloff tests in old } \\
\text { wells to ID problems. } \\
\text { Recomplete wells or } \\
\text { find a work-around } \\
\text { for problem wells }\end{array}$ & $\begin{array}{l}\text { Monitor wells for } \mathrm{CO} 2 \\
\text { leakage and replug if } \\
\text { necessary. }\end{array}$ \\
\hline 322 & 5.1.02.00. & $\begin{array}{l}\text { Well lining and } \\
\text { completion }\end{array}$ & $\begin{array}{l}\text { At the time of driling, boreholes are lined } \\
\text { with a metal casing. Cement is pumped } \\
\text { downhole inside the casing string, and it is } \\
\text { pushed upward under and outside the casing } \\
\text { lower end, between the casing and the rock } \\
\text { wall. In multi-stage cement jobs, cement is } \\
\text { squeezed between the casing and the rock } \\
\text { wall though purpose made perforations. The } \\
\text { cement could be pushed behind casing from } \\
\text { the bottom hole to the surface, or to a } \\
\text { predetermined depth. } \\
\text { Curing of cement is the process of } \\
\text { maintaining the proper temperature and } \\
\text { moisture conditions to promote optimum } \\
\text { cement hydration immediately after } \\
\text { placement. Proper moisture conditions are } \\
\text { critical because water is necessary for the } \\
\text { hydration of cementitious materials. As } \\
\text { cement hydrates, strength increases and } \\
\text { permeability decreases. When hydration } \\
\text { stops, strength gain ceases. Therefore, } \\
\text { proper hydration of the cement is important } \\
\text { in the fabrication of strong, durable concrete. } \\
\text { Alteration of borehole linings will occur with } \\
\text { time, depending on the natural fluid wid } \\
\text { composition of the deep reservoir and the } \\
\text { input of high concentrations of CO2 carrying } \\
\text { natural H2S, which may accelerate } \\
\text { corrosion. }\end{array}$ & $\begin{array}{l}\text { Borehole lining and completion will contribute to } \\
\text { determining the performance of a borehole both } \\
\text { during its operational and post-closure phases. } \\
\text { This is important from the perspective of CO2 } \\
\text { sequestration, since boreholes may provide } \\
\text { preferential short circuits to the surface with } \\
\text { potential release of CO2 and contamination of } \\
\text { upper aquifers. }\end{array}$ & $\begin{array}{l}\text { Quintessa } \\
\text { original FEP }\end{array}$ & $\begin{array}{l}\text { Unlikely to be an } \\
\text { issue. }\end{array}$ & $\begin{array}{l}\text { Early wells may have } \\
\text { no primary cement. } \\
\text { Cement never stops } \\
\text { hydrating }\end{array}$ & & 2 & 4 & 8 & $\begin{array}{l}\text { For new holes use } \\
\text { best available } \\
\text { methods for } \\
\text { completion. Use } \\
\text { best cements and } \\
\text { characterize using } \\
\text { logging tools. For } \\
\text { old wells } \\
\text { characterize and } \\
\text { recomplete if } \\
\text { needed }\end{array}$ & $\begin{array}{l}\text { Monitor wells for } \mathrm{CO} 2 \\
\text { leakage and replug if } \\
\text { necessary. }\end{array}$ \\
\hline
\end{tabular}

Quintessa Original FEP: Taken from Quintessa's on-line CO2 FEP database, which is freely accessible at: http://www.quintessa.org/co2fepdb/ 


\begin{tabular}{|c|c|c|c|c|c|c|c|c|c|c|c|c|c|}
\hline \multicolumn{6}{|c|}{ CO2 Geologic Sequestration Risks for the IMCCS Project } & \multicolumn{3}{|c|}{ Project Specific Information } & \multicolumn{3}{|c|}{ Risk Ranking } & \multicolumn{2}{|c|}{ Prevention and Mitigation } \\
\hline Line \# & Index No. & Risk Area & Description & Relevance & $\begin{array}{l}\text { Qunitessa } \\
\text { FEP } \\
\text { Category }\end{array}$ & $\begin{array}{l}\text { Individual } \\
\text { Comments }\end{array}$ & $\begin{array}{c}\text { IMccs Project } \\
\text { Specific Information }\end{array}$ & \begin{tabular}{|c|} 
IMccs Project \\
Information Gaps \\
or Uncertainties
\end{tabular} & 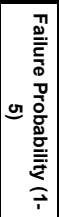 & 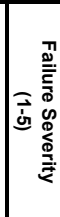 & 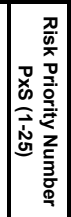 & $\begin{array}{l}\text { Risk Prevention } \\
\text { Steps (Actions } \\
\text { taken to reduce } \\
\text { risk probability) }\end{array}$ & $\begin{array}{l}\text { Risk Mitigation } \\
\text { Steps (Actions taken } \\
\text { to reduce risk } \\
\text { severity) }\end{array}$ \\
\hline 323 & 5.1.03.00. & Workover & $\begin{array}{l}\text { The process of performing major } \\
\text { maintenance or remedial treatments on a } \\
\text { borehole often associated with the re-use of } \\
\text { existing boreholes. Workover techniques } \\
\text { include flushing of the formation and the } \\
\text { removal and replacement of the borehole } \\
\text { lining. } \\
\text { Well control procedures during workovers } \\
\text { must provide for unique phase behavior of } \\
\text { any CO2 being circulated out. (CCP 2009) }\end{array}$ & $\begin{array}{l}\text { Workover will result in modified borehole } \\
\text { properties that may need consideration within an } \\
\text { assessment. }\end{array}$ & \begin{tabular}{c|} 
Quintessa \\
FEP with \\
additional text
\end{tabular} & $\begin{array}{l}\text { Unlikely to be an } \\
\text { issue. }\end{array}$ & & & 2 & 2 & 4 & $\begin{array}{l}\text { Use procedures that } \\
\text { allow for workover } \\
\text { with } \mathrm{CO} 2 \text { in the } \\
\text { formation }\end{array}$ & $\begin{array}{l}\text { Have monitors and } \\
\text { alarms in place and } \\
\text { standard procedures } \\
\text { for dealing with CO2 } \\
\text { leakage on site. }\end{array}$ \\
\hline 324 & 5.1.03.01. & $\begin{array}{c}\text { Improper } \\
\text { modification or re- } \\
\text { use of existing } \\
\text { boreholes }\end{array}$ & & & \begin{tabular}{|l} 
Additional \\
[new] FEP
\end{tabular} & $\begin{array}{l}\text { Unlikely to be an } \\
\text { issue. }\end{array}$ & & & 2 & 2 & 4 & \begin{tabular}{|l|} 
Recomplete using \\
proper cements and \\
materials. \\
Characterize well \\
after recompletion
\end{tabular} & $\begin{array}{l}\text { Monitor wells for } \mathrm{CO} 2 \\
\text { leakage and replug if } \\
\text { necessary. }\end{array}$ \\
\hline 325 & 5.1.04.00. & $\begin{array}{c}\text { Monitoring wells } \\
\text { (Verification wells) }\end{array}$ & 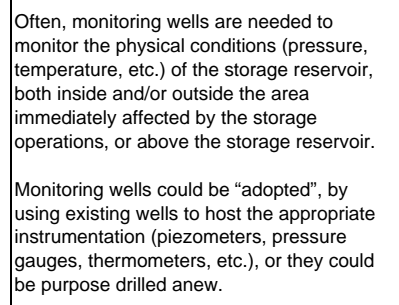 & $\begin{array}{l}\text { Observation or monitoring wells may provide an } \\
\text { accidental leakage route for the stored } \mathrm{CO} 2, \\
\text { particularly wells drilled inside the area of } \\
\text { storage. }\end{array}$ & $\begin{array}{c}\text { Quintessa } \\
\text { FEP with } \\
\text { additional text }\end{array}$ & $\begin{array}{l}\text { Unlikely to be an } \\
\text { issue. }\end{array}$ & $\begin{array}{l}\text { There are } 100 \text { s of old } \\
\text { wells available for } \\
\text { MVA. }\end{array}$ & & 2 & 2 & 4 & $\begin{array}{l}\text { MVA wells need to } \\
\text { be designed to } \\
\text { account for leakage } \\
\text { potential. }\end{array}$ & $\begin{array}{l}\text { Monitor wells for } \mathrm{CO} 2 \\
\text { leakage and replug if } \\
\text { necessary. }\end{array}$ \\
\hline 326 & 5.1.04.01. & $\begin{array}{l}\text { Lack of or } \\
\text { insufficient number } \\
\text { of monitoring wells }\end{array}$ & $\begin{array}{l}\text { Direct monitoring techniques usually require } \\
\text { access from wellbores that penetrate the } \\
\text { containment system into the storage } \\
\text { reservoir (CCP 2009) } \\
\text { Direct measurements can also be obtained } \\
\text { from observation wells at shallower horizons } \\
\text { above the expected seal. Wells of this type } \\
\text { might provide direct and early indication of } \\
\text { unexpected movement. (CCP 2009) }\end{array}$ & & $\begin{array}{l}\text { Additional } \\
\text { [new] FEP }\end{array}$ & \begin{tabular}{|l|} 
Unlikely to be an \\
issue.
\end{tabular} & $\begin{array}{l}\text { There are } 100 \text { s of old } \\
\text { wells available for } \\
\text { MVA. }\end{array}$ & & 2 & 1 & 2 & $\begin{array}{l}\text { Design such that the } \\
\text { project starts with } \\
\text { the right number of } \\
\text { MVA wells. }\end{array}$ & $\begin{array}{l}\text { Add more MVA wells } \\
\text { if needed. }\end{array}$ \\
\hline 327 & 5.1.04.02. & $\begin{array}{c}\text { Too many } \\
\text { monitoring wells }\end{array}$ & $\begin{array}{l}\text { General the concept is to minimize } \\
\text { monitoring wells that penetrate the seal } \\
\text { because they are, by default, potential } \\
\text { leakage pathways. (CCP 2009) }\end{array}$ & & \begin{tabular}{|l} 
Additional \\
[new] FEP
\end{tabular} & $\begin{array}{l}\text { Very unlikely to be } \\
\text { an issue. }\end{array}$ & $\begin{array}{l}\text { There are } 100 \text { s of old } \\
\text { wells available for } \\
\text { MVA. }\end{array}$ & & 1 & 1 & 1 & $\begin{array}{l}\text { Design such that the } \\
\text { project starts with } \\
\text { the right number of } \\
\text { MVA wells }\end{array}$ & NA \\
\hline 328 & 5.1.04.03. & $\begin{array}{l}\text { Improperly located } \\
\text { monitoring wells }\end{array}$ & & & \begin{tabular}{|l} 
Additional \\
[new] FEP
\end{tabular} & \begin{tabular}{|l|} 
Unlikely to be an \\
issue.
\end{tabular} & $\begin{array}{l}\text { There are } 100 \text { s of old } \\
\text { wells available for } \\
\text { MVA. }\end{array}$ & & 2 & 2 & 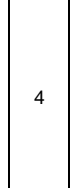 & $\begin{array}{l}\text { Us characterization } \\
\text { and modeling to site } \\
\text { or choose wells such } \\
\text { that they catch the } \\
\text { plume, pressure } \\
\text { increase, or monitor } \\
\text { sensitive areas }\end{array}$ & $\begin{array}{l}\text { Monitor and model } \\
\text { CO2 plume. Modify } \\
\text { MVA well spacing if } \\
\text { necessary. }\end{array}$ \\
\hline
\end{tabular}




\begin{tabular}{|c|c|c|c|c|c|c|c|c|c|c|c|c|c|}
\hline \multicolumn{6}{|c|}{ CO2 Geologic Sequestration Risks for the IMCCS Project } & \multicolumn{3}{|c|}{ Project Specific Information } & \multicolumn{3}{|c|}{ Risk Ranking } & \multicolumn{2}{|c|}{ Prevention and Mitigation } \\
\hline Line \# & Index No. & Risk Area & Description & Relevance & $\begin{array}{l}\text { Qunitessa } \\
\text { FEP } \\
\text { Category }\end{array}$ & $\begin{array}{l}\text { Individual } \\
\text { Comments }\end{array}$ & $\begin{array}{c}\text { IMCCS Project } \\
\text { Specific Information }\end{array}$ & \begin{tabular}{|c|} 
Imccs Project \\
Information Gaps \\
or Uncertainties
\end{tabular} & 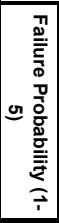 & 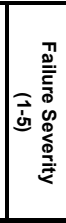 & 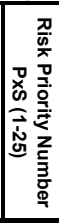 & $\begin{array}{l}\text { Risk Prevention } \\
\text { Steps (Actions } \\
\text { taken to reduce } \\
\text { risk probability) }\end{array}$ & $\begin{array}{l}\text { Risk Mitigation } \\
\text { Steps (Actions taken } \\
\text { to reduce risk } \\
\text { severity) }\end{array}$ \\
\hline 329 & 5.1.05.00. & Well records & 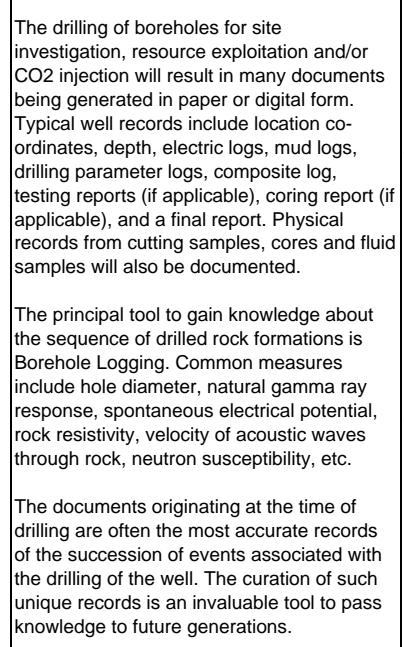 & $\begin{array}{l}\text { Well records provide a key source of baseline } \\
\text { information regarding the sequestration site. } \\
\text { They provide information concerning the nature } \\
\text { of the rocks drilled by the well and their } \\
\text { petrophysical characteristics in terms of sealing } \\
\text { potential and reservoir potential. Additionally, } \\
\text { records from wells drilled over a period of time } \\
\text { can give a picture of how the system is evolving } \\
\text { either naturally, or as a result of the exploitation } \\
\text { of geological resources. This baseline } \\
\text { information is an important input both into the } \\
\text { initial conditions relevant to the system to be } \\
\text { assessed, as well as providing an indication of } \\
\text { the likely importance of other FEPs. }\end{array}$ & $\begin{array}{l}\text { Quintessa } \\
\text { original FEP }\end{array}$ & $\begin{array}{l}\text { Unlikely to be an } \\
\text { issue. }\end{array}$ & $\begin{array}{l}\text { Many of the wells are } \\
\text { too old for the records } \\
\text { to provide the needed } \\
\text { info on the initial } \\
\text { condition and the } \\
\text { condition of concern is } \\
\text { the pre-co2 injection } \\
\text { condition as opposed } \\
\text { to the condition after } \\
\text { construction }\end{array}$ & & 2 & 3 & 6 & $\begin{array}{l}\text { Characterize the } \\
\text { existing wells }\end{array}$ & $\begin{array}{l}\text { Monitor wells for } \mathrm{CO} 2 \\
\text { leakage and replug if } \\
\text { necessary. }\end{array}$ \\
\hline 330 & 5.1.05.01. & $\begin{array}{l}\text { Well records and } \\
\text { data management }\end{array}$ & & $\begin{array}{l}\text { Large amounts of data will be generated by the } \\
\text { project. Data could be poorly communicated } \\
\text { between groups, or be badly managed to the } \\
\text { point that important data is lost, or used } \\
\text { incorrectly. }\end{array}$ & \begin{tabular}{|l} 
Additional \\
[new] FEP
\end{tabular} & $\begin{array}{l}\text { Very unlikely to be } \\
\text { an issue. }\end{array}$ & $\begin{array}{l}\text { Project currently has } \\
\text { secure website for } \\
\text { access to and digital } \\
\text { retention of } \\
\text { documents. }\end{array}$ & & 1 & 1 & 1 & $\begin{array}{l}\text { Centralized data } \\
\text { repository and } \\
\text { planning. Use } \\
\text { secure website. }\end{array}$ & $\begin{array}{l}\text { Keep backup } \\
\text { database. }\end{array}$ \\
\hline 331 & 5.1.05.02. & $\begin{array}{l}\text { Lack of or } \\
\text { incomplete existing } \\
\text { well records }\end{array}$ & & & \begin{tabular}{|l} 
Additional \\
[new] FEP
\end{tabular} & $\begin{array}{l}\text { There are likely to } \\
\text { be undocumented } \\
\text { wells in G-E and T- } \\
\text { A. }\end{array}$ & & & 4 & 3 & 12 & $\begin{array}{l}\text { Characterize the } \\
\text { site. Use magnetic } \\
\text { surveys, old photos } \\
\text { and other } \\
\text { techniques to locate } \\
\text { undocumented } \\
\text { wells. }\end{array}$ & \begin{tabular}{|l|} 
Pressurize reservoir \\
with water prior to \\
CO2 injection to locate \\
unknown leaky wells. \\
Replug leaky wells.
\end{tabular} \\
\hline 332 & 5.2.00.00. & $\begin{array}{c}\text { Borehole seals and } \\
\text { abandonment }\end{array}$ & $\begin{array}{l}\text { FEPs relevant to the closure of boreholes } \\
\text { drilled within the system domain. }\end{array}$ & $\begin{array}{l}\text { The way that boreholes are closed and sealed is } \\
\text { directly relevant to the likelihood that they could } \\
\text { act as short circuits for carbon dioxide transport. }\end{array}$ & $\begin{array}{l}\text { Quintessa } \\
\text { original FEP }\end{array}$ & $\begin{array}{l}\text { Likely to be an } \\
\text { issue. }\end{array}$ & & & 4 & 4 & 16 & \begin{tabular}{|l} 
Characterize \\
abandoned wells. \\
Replug high risk \\
wells
\end{tabular} & $\begin{array}{l}\text { Monitor abandoned } \\
\text { wells. Replug leaky } \\
\text { wells. }\end{array}$ \\
\hline
\end{tabular}

Appendix 6-59

Quintessa Original FEP: Taken from Quintessa's on-line CO2 FEP database, which is freely accessible at: http://www.quintessa.org/co2fepdb/ 


\begin{tabular}{|c|c|c|c|c|c|c|c|c|c|c|c|c|c|}
\hline \multicolumn{6}{|c|}{ CO2 Geologic Sequestration Risks for the IMCCS Project } & \multicolumn{3}{|c|}{ Project Specific Information } & \multicolumn{3}{|c|}{ Risk Ranking } & \multicolumn{2}{|c|}{ Prevention and Mitigation } \\
\hline Line \# & Index No. & Risk Area & Description & Relevance & $\begin{array}{l}\text { Qunitessa } \\
\text { FEP } \\
\text { Category }\end{array}$ & $\begin{array}{l}\text { Individual } \\
\text { Comments }\end{array}$ & $\begin{array}{c}\text { IMCCS Project } \\
\text { Specific Information }\end{array}$ & \begin{tabular}{|c} 
IMccS Project \\
Information Gaps \\
or Uncertainties
\end{tabular} & 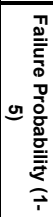 & 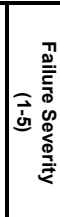 & 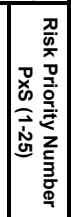 & $\begin{array}{l}\text { Risk Prevention } \\
\text { Steps (Actions } \\
\text { taken to reduce } \\
\text { risk probability) }\end{array}$ & $\begin{array}{l}\text { Risk Mitigation } \\
\text { Steps (Actions taker } \\
\text { to reduce risk } \\
\text { severity) }\end{array}$ \\
\hline 333 & 5.2.01.00. & $\begin{array}{c}\text { Closure and sealing } \\
\text { of boreholes }\end{array}$ & $\begin{array}{l}\text { Features related to the cessation of CO2 } \\
\text { injection operations at a site and the sealing } \\
\text { of injection and monitoring wells. } \\
\text { When a borehole is drilled to the potential } \\
\text { storage reservoir, it creates communication } \\
\text { with possible overlying reservoirs and with } \\
\text { the surface. Cementing and abandonment } \\
\text { procedures are designed to permanently } \\
\text { plug such communication channel. } \\
\text { The cement plugs are commonly located } \\
\text { across potential problem spots, to minimize } \\
\text { leaking risks. Particular artention should be } \\
\text { paid to the quality of the original cement job } \\
\text { behind the casing string. If uncemented } \\
\text { space is detected, known or suspected } \\
\text { behind casing, depending on the lithology } \\
\text { across such interval, it may be important to } \\
\text { squeeeze extra cement tetween the rock face } \\
\text { and the casing to complement the final } \\
\text { abandonment plugs inside the casing. } \\
\text { Individual boreholes may be closed in } \\
\text { sequence, but closure refers to final closure } \\
\text { of the whole system, and may include } \\
\text { removal of surface installations. The } \\
\text { schedule and procedure for sealing and } \\
\text { closure may need to be considered in the } \\
\text { assessment. }\end{array}$ & $\begin{array}{l}\text { The intention of borehole sealing is to prevent } \\
\text { human access to the sequestered CO2 and to } \\
\text { prevent the borehole from providing a migration } \\
\text { pathway for the CO2. Correct cementing and } \\
\text { abandonment operations are essential to achieve } \\
\text { restoration of pristine sealing above the designed } \\
\text { storage reservoir formation. }\end{array}$ & $\begin{array}{l}\text { Quintessa } \\
\text { original FEP }\end{array}$ & Possible issue. & & & 3 & 4 & 12 & \begin{tabular}{|l|} 
Use closure plug \\
materials that are \\
compatible with the \\
CO2 and the \\
expected long-term \\
conditions
\end{tabular} & $\begin{array}{l}\text { Post closure MVA and } \\
\text { remediation. }\end{array}$ \\
\hline 334 & 5.2.02.00. & $\begin{array}{c}\text { Seal failure } \\
\text { (Wellbore failure) }\end{array}$ & $\begin{array}{l}\text { Degradation of borehole linings (metal and } \\
\text { cementt will occur with time, depending on } \\
\text { the natural fluid composition of the deep } \\
\text { reservoir and the input of high } \\
\text { concentrations of C2.2. Any } \mathrm{H} 2 \mathrm{~S} \text { present } \\
\text { may accelerate corrosion of metal linings. } \\
\text { Cement will be antacked by high partial } \\
\text { pressures of } \mathrm{CO} 2 \text { 2. low pH and appreciable } \\
\text { concentrations of sulphate, chloride, and } \\
\text { magnesium ions in the formation fluids. Seal } \\
\text { failure will occur once liners have degraded } \\
\text { and corroded. }\end{array}$ & $\begin{array}{l}\text { Seal failure may provide preferential short circuits } \\
\text { to the surface with potential release of CO2 and } \\
\text { associated contaminants to the surface or near- } \\
\text { surface environment. The failure may provide a } \\
\text { preferential pathway either through the borehole } \\
\text { annulus or around the outside of the casing. }\end{array}$ & \begin{tabular}{|c|} 
Quintessa \\
FEP with \\
additional text
\end{tabular} & Possible issue. & & & 3 & 3 & 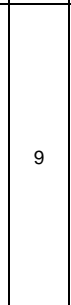 & \begin{tabular}{|l|} 
Recomplete old \\
wells using CO2 \\
resistant materials \\
and use CO2 \\
resistant materials in \\
new construction too
\end{tabular} & $\begin{array}{l}\text { Monitor abandoned } \\
\text { wells. Replug leaky } \\
\text { wells. }\end{array}$ \\
\hline 335 & 5.2.02.01. & $\begin{array}{l}\text { CO2 leakage at } \\
\text { cement-casing } \\
\text { interface }\end{array}$ & $\begin{array}{l}\text { Cement interfaces, not cement matrix are } \\
\text { the most likely path for migration. (CCP } \\
\text { 2009) }\end{array}$ & & \begin{tabular}{|l} 
Additional \\
[new] FEP
\end{tabular} & $\begin{array}{l}\text { Very likely to be } \\
\text { an issue. }\end{array}$ & & & 5 & 3 & 15 & \begin{tabular}{|l} 
Characterize \\
leakage pathways \\
within wells
\end{tabular} & $\begin{array}{l}\text { Monitor abandoned } \\
\text { wells. Replug leaky } \\
\text { wells. }\end{array}$ \\
\hline
\end{tabular}




\begin{tabular}{|c|c|c|c|c|c|c|c|c|c|c|c|c|c|}
\hline \multicolumn{6}{|c|}{ CO2 Geologic Sequestration Risks for the IMCCS Project } & \multicolumn{3}{|c|}{ Project Specific Information } & \multicolumn{3}{|c|}{ Risk Ranking } & \multicolumn{2}{|c|}{ Prevention and Mitigation } \\
\hline Line \# & Index No. & Risk Area & Description & Relevance & $\begin{array}{l}\text { Qunitessa } \\
\text { FEP } \\
\text { Category }\end{array}$ & $\begin{array}{l}\text { Individual } \\
\text { Comments }\end{array}$ & $\begin{array}{c}\text { IMCCS Project } \\
\text { Specific Information }\end{array}$ & \begin{tabular}{|} 
IMCcs Project \\
Information Gaps \\
or Uncertainties
\end{tabular} & 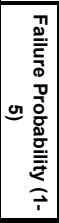 & 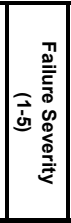 & 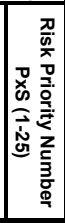 & $\begin{array}{l}\text { Risk Prevention } \\
\text { Steps (Actions } \\
\text { taken to reduce } \\
\text { risk probability) }\end{array}$ & $\begin{array}{l}\text { Risk Mitigation } \\
\text { Steps (Actions taken } \\
\text { to reduce risk } \\
\text { severity) }\end{array}$ \\
\hline 336 & 5.2.02.02. & $\mid$\begin{tabular}{c|c} 
cO2 leakage \\
through the cement \\
matrix
\end{tabular} & 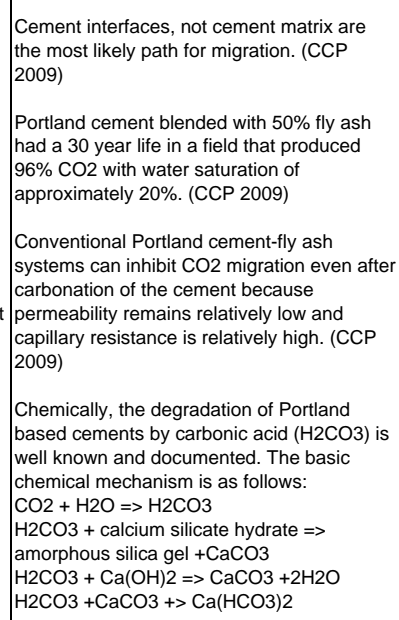 & & \begin{tabular}{|l} 
Additional \\
[new] FEP
\end{tabular} & $\begin{array}{l}\text { Unlikely to be an } \\
\text { issue. }\end{array}$ & & & 2 & 2 & 4 & $\begin{array}{l}\text { Characterize } \\
\text { leakage pathways } \\
\text { within wells }\end{array}$ & $\begin{array}{l}\text { Monitor abandoned } \\
\text { wells. Replug leaky } \\
\text { wells. }\end{array}$ \\
\hline 337 & 5.2.02.03. & $\begin{array}{l}\text { CO2 leakage } \\
\text { through pathways } \\
\text { created by bulk } \\
\text { chemical dissolution } \\
\text { of the cement }\end{array}$ & & $\begin{array}{l}\text { Cement can be attacked by } \mathrm{CO} 2 \text {, low } \mathrm{pH} \text {, and } \\
\text { appreciable concentrations of sulfate, chloride } \\
\text { and magnesium ions in the formation fluids. }\end{array}$ & \begin{tabular}{|l} 
Additional \\
[new] FEP
\end{tabular} & \begin{tabular}{|l|} 
Unlikely to be an \\
issue. The initial \\
pathways would \\
already have to be \\
present to allow \\
for advective \\
transport.
\end{tabular} & & & 2 & 3 & 6 & \begin{tabular}{|l|} 
Characterize (map) \\
the cement in the \\
well to identify \\
potential pathways \\
and remediate them \\
if needed
\end{tabular} & $\begin{array}{l}\text { Monitor wells. Replug } \\
\text { leaky wells. }\end{array}$ \\
\hline 338 & 5.2.02.04. & $\begin{array}{c}\text { CO2 leakage } \\
\text { through fractures in } \\
\text { the cement }\end{array}$ & & & \begin{tabular}{|l} 
Additional \\
[new] FEP
\end{tabular} & Possible issue. & Possible & & 3 & 3 & 9 & \begin{tabular}{|l|} 
Characterize (map) \\
the cement in the \\
well to identify \\
potential pathways \\
and remediate them \\
if needed \\
\end{tabular} & $\begin{array}{l}\text { Monitor wells. Replug } \\
\text { leaky wells. }\end{array}$ \\
\hline 339 & 5.2.02.04. & \begin{tabular}{|c|} 
CO2 leakage \\
through an open \\
annular region due \\
to inadequate \\
cement placement \\
\end{tabular} & $\begin{array}{l}\text { The Basis of Design for new wells should } \\
\text { emphasize barrier performance using } \\
\text { fundamentals of wellbore preparation, mud } \\
\text { removal and cement placement to provide } \\
\text { tight interfaces that inhibit fluid migration. } \\
\text { Material selection of cement and metellurgy } \\
\text { are important, but should be considered } \\
\text { secondary to the process of cement } \\
\text { placement. (CCP 2009) }\end{array}$ & & \begin{tabular}{|} 
Additional \\
[new] FEP
\end{tabular} & Possible issue. & & & 3 & 3 & 9 & \begin{tabular}{|l|} 
Characterize (map) \\
the cement in the \\
well to identify \\
potential pathways \\
and remediate them \\
if needed
\end{tabular} & $\begin{array}{l}\text { Monitor wells. Replug } \\
\text { leaky wells. }\end{array}$ \\
\hline 340 & 5.2.02.05. & $\begin{array}{c}\text { CO2 leakage at the } \\
\text { cement-caprock } \\
\text { interface }\end{array}$ & $\begin{array}{l}\text { The cement interfaces between the } \\
\text { boreholes and the casing through the } \\
\text { caprock are the key to well integrity and seal } \\
\text { integrity. Good isolation requires tight } \\
\text { cement interfaces with the formation and } \\
\text { casing. (CCP 2009) }\end{array}$ & & \begin{tabular}{|l} 
Additional \\
[new] FEP
\end{tabular} & Possible issue. & & & 3 & 3 & 9 & \begin{tabular}{|l|} 
Characterize (map) \\
the cement in the \\
well to identify \\
potential pathways \\
and remediate them \\
if needed
\end{tabular} & $\begin{array}{l}\text { Monitor wells. Replug } \\
\text { leaky wells. }\end{array}$ \\
\hline 341 & 5.2.02.06. & $\begin{array}{l}\text { CO2 leakage } \\
\text { through corroded or } \\
\text { cracked casing }\end{array}$ & & $\begin{array}{l}\text { Metal casing can be attacked by } \mathrm{H} 2 \mathrm{~S} \text { contained } \\
\text { in the } \mathrm{CO} 2 \text {. }\end{array}$ & \begin{tabular}{|l} 
Additional \\
[new] FEP \\
dix 6-61
\end{tabular} & $\begin{array}{l}\text { Very unlikely to be } \\
\text { an issue. }\end{array}$ & & & 1 & 3 & 3 & \begin{tabular}{|l|} 
Characterize the \\
casing using \\
ultrasonic or em \\
tools
\end{tabular} & $\begin{array}{l}\text { Monitor wells. Replug } \\
\text { leaky wells. }\end{array}$ \\
\hline
\end{tabular}

Quintessa Original FEP: Taken from Quintessa's on-line CO2 FEP database, which is freely accessible at: http://www.quintessa.org/co2fepdb/ 


\begin{tabular}{|c|c|c|c|c|c|c|c|c|c|c|c|c|c|}
\hline \multicolumn{6}{|c|}{ CO2 Geologic Sequestration Risks for the IMCCS Project } & \multicolumn{3}{|c|}{ Project Specific Information } & \multicolumn{3}{|c|}{ Risk Ranking } & \multicolumn{2}{|c|}{ Prevention and Mitigation } \\
\hline Line \# & Index No. & Risk Area & Description & Relevance & $\begin{array}{l}\text { Qunitessa } \\
\text { FEP } \\
\text { Category }\end{array}$ & $\begin{array}{l}\text { Individual } \\
\text { Comments }\end{array}$ & $\begin{array}{c}\text { IMCCS Project } \\
\text { Specific Information }\end{array}$ & \begin{tabular}{|c|} 
IMccs Project \\
Information Gaps \\
or Uncertainties
\end{tabular} & 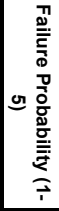 & 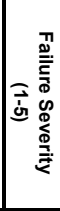 & 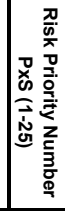 & $\begin{array}{l}\text { Risk Prevention } \\
\text { Steps (Actions } \\
\text { taken to reduce } \\
\text { risk probability) }\end{array}$ & $\begin{array}{l}\text { Risk Mitigation } \\
\text { Steps (Actions taken } \\
\text { to reduce risk } \\
\text { severity) }\end{array}$ \\
\hline 342 & 5.2.02.07. & $\begin{array}{c}\text { CO2 leakage due to } \\
\text { improper hydration } \\
\text { of cement in } \\
\text { borehole linings }\end{array}$ & & & \begin{tabular}{|l} 
Additional \\
[new] FEP
\end{tabular} & $\begin{array}{l}\text { Very unlikely to be } \\
\text { an issue. }\end{array}$ & & & 1 & 3 & 3 & \begin{tabular}{|l} 
Characterize (map) \\
the cement in the \\
well to identify \\
potential pathways \\
and remediate them \\
if needed \\
\end{tabular} & $\begin{array}{l}\text { Monitor wells. Replug } \\
\text { leaky wells. }\end{array}$ \\
\hline 343 & 5.2.03.00. & Blowouts & $\begin{array}{l}\text { Uncontrolled flow from depth leading to gas } \\
\text { and/or fluid erupting from a well or borehole } \\
\text { to either the terrestrial or marine } \\
\text { environments. } \\
\text { Blowout is an ordinary drilling hazard, well } \\
\text { understood and controlled by current } \\
\text { technology. Assuming that ordinary blow-out } \\
\text { risk controls are present, particular risks } \\
\text { might include: (1) A monitoring or verification } \\
\text { well drilled into a porous formation that has } \\
\text { elevated pressure due to CO2, or (2) A } \\
\text { drilled formation with significant unexpected } \\
\text { H2S (MCSG 2009). } \\
\text { The frequency of blowouts from offshore gas } \\
\text { wells has been estimated at } 1 \times 10-4 \text { per well } \\
\text { per year, based on a database of blowouts in } \\
\text { the Gulf Coast of Mexica and the North Sea } \\
\text { between 1980 and 1996 (CMPT 1999). } \\
\text { Other estimates based on both oil and gas } \\
\text { wells give a frequency of } 3 \times 1 \times 0-4 \text { per well per } \\
\text { year (IEA GHG, 2300) (Damen 2006). }\end{array}$ & $\begin{array}{l}\text { A surface or undersea blowout would provide a } \\
\text { rapid pathway for } \mathrm{CO} 2 \text { to reach the surface. }\end{array}$ & $\left|\begin{array}{c}\text { Quintessa } \\
\text { FEP with } \\
\text { additional text }\end{array}\right|$ & $\begin{array}{l}\text { Very unlikely to be } \\
\text { an issue. }\end{array}$ & & & 1 & 4 & 4 & $\begin{array}{l}\text { Design, construct } \\
\text { and operate wells } \\
\text { properly to prevent } \\
\text { blowouts. }\end{array}$ & \begin{tabular}{|l} 
Have standard \\
procedures in place \\
and train operators to \\
deal with blowouts.
\end{tabular} \\
\hline 344 & 5.2.03.01. & Packer failure & \begin{tabular}{|l|} 
In CO2 injectors, the design of the packer \\
assembly should take into consideration the \\
importance of limited or no movement of the \\
packer seal while providing the ability to \\
regularly pull the tubing for inspection. (CCP \\
2009)
\end{tabular} & $\begin{array}{l}\text { Failure of the back-flow preventer or packer may } \\
\text { result in a well blowout (Holloway 1996). A blow } \\
\text { out is an uncontrolled fllow of reservoir fluids } \\
\text { (which can be CO2, but also salt water, oil, gas } \\
\text { or a mixture of these) into the well bore to the } \\
\text { surface. A Apart from the CO2 release, the } \\
\text { potential consequences are casualties among } \\
\text { operators and economic damage caused by } \\
\text { explosion or fire when upcoming hydrocarbons } \\
\text { are iginited or by parts of the well, which can be } \\
\text { launched by the pressure release.(Damen 2006) }\end{array}$ & $\begin{array}{l}\text { Additional } \\
\text { [new] FEP }\end{array}$ & $\begin{array}{l}\text { Unlikely to be an } \\
\text { issue. }\end{array}$ & & & 2 & 2 & 4 & $\begin{array}{l}\text { Design, construct } \\
\text { and operate wells } \\
\text { properly to prevent } \\
\text { blowouts. }\end{array}$ & \begin{tabular}{|l} 
Have standard \\
procedures in place \\
and train operators to \\
deal with blowouts.
\end{tabular} \\
\hline 345 & 5.2.03.02. & $\begin{array}{c}\text { Failure of the } \\
\text { blowout preventer } \\
\text { (BOP) }\end{array}$ & & & \begin{tabular}{|l} 
Additional \\
[new] FEP
\end{tabular} & $\begin{array}{l}\text { Unlikely to be an } \\
\text { issue. }\end{array}$ & & & 2 & 2 & 4 & $\begin{array}{l}\text { Design, construct } \\
\text { and operate wells } \\
\text { properly to prevent } \\
\text { blowouts. }\end{array}$ & \begin{tabular}{|l|} 
Have standard \\
procedures in place \\
and train operators to \\
deal with blowouts.
\end{tabular} \\
\hline 346 & 5.2.03.03. & Well failure & $\begin{array}{l}\text { In the majority of well failures, an amount } \\
\text { equal to the content of the well tubing will be } \\
\text { released. In normal cases, this leak will be } \\
\text { detected by the monitoring system, resulting } \\
\text { in the closure of the back fllow preventer and } \\
\text { the emergency shutdown valve at the well } \\
\text { head (Holloway, 1996) }\end{array}$ & & $\begin{array}{l}\begin{array}{l}\text { Additional } \\
\text { [new] FEP }\end{array} \\
\end{array}$ & $\begin{array}{l}\text { Unlikely to be an } \\
\text { issue. }\end{array}$ & & & 2 & 2 & 4 & $\begin{array}{l}\text { Design, construct } \\
\text { and operate wells } \\
\text { properly to prevent } \\
\text { well failure. }\end{array}$ & $\begin{array}{l}\text { Monitor and shut down } \\
\text { if needed }\end{array}$ \\
\hline
\end{tabular}

Appendix 6-62

Quintessa Original FEP: Taken from Quintessa's on-line CO2 FEP database, which is freely accessible at: http://www.quintessa.org/co2fepdb/ 


\begin{tabular}{|c|c|c|c|c|c|c|c|c|c|c|c|c|c|}
\hline \multicolumn{6}{|c|}{ CO2 Geologic Sequestration Risks for the IMCCS Project } & \multicolumn{3}{|c|}{ Project Specific Information } & \multicolumn{3}{|c|}{ Risk Ranking } & \multicolumn{2}{|c|}{ Prevention and Mitigation } \\
\hline Line \# & Index No. & Risk Area & Description & Relevance & $\begin{array}{l}\text { Qunitessa } \\
\text { FEP } \\
\text { Category }\end{array}$ & $\begin{array}{l}\text { Individual } \\
\text { Comments }\end{array}$ & $\begin{array}{c}\text { IMCCS Project } \\
\text { Specific Information }\end{array}$ & \begin{tabular}{|l} 
IMccS Project \\
Information Gaps \\
or Uncertainties
\end{tabular} & 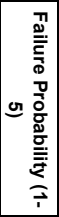 & 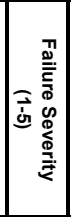 & 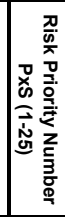 & $\begin{array}{l}\text { Risk Prevention } \\
\text { Steps (Actions } \\
\text { taken to reduce } \\
\text { risk probability) }\end{array}$ & $\begin{array}{l}\text { Risk Mitigation } \\
\text { Steps (Actions taken } \\
\text { to reduce risk } \\
\text { severity) }\end{array}$ \\
\hline 347 & 5.2.03.04. & $\begin{array}{l}\text { Elastomer seal } \\
\text { failure }\end{array}$ & $\begin{array}{l}\text { Since supercritical CO2 is a solvent, many } \\
\text { elastomers, plastics, rubber, or resins } \\
\text { present in a well coudld be subject to } \\
\text { chemical attack or dissolution. When } \\
\text { designing a cO2 injector, material should be } \\
\text { based on performance expectations. } \\
\text { Elastomers, in particular, are a common part } \\
\text { of well hardware used to seal different } \\
\text { components. Elastomers must be made of } \\
\text { material that is chemically compatible or inert } \\
\text { to the injection fluid and must be of sufficient } \\
\text { strength or adequately anchored to } \\
\text { withstand the different pressure and } \\
\text { explosive decompression that might exist } \\
\text { across a seal, Since the physical and } \\
\text { performance characteristics of many } \\
\text { elastomer materials change with pressure } \\
\text { and temperature, the elastomer must be } \\
\text { able to perform reliably across the full range } \\
\text { of differential pressures and temperatures } \\
\text { expected through the design life of the well } \\
\text { at the location of the seal within the well. } \\
\text { (CCP 2009) }\end{array}$ & & \begin{tabular}{|l} 
Additional \\
[new] FEP
\end{tabular} & $\begin{array}{l}\text { Very unlikely to be } \\
\text { an issue. EOR is } \\
\text { common now, we } \\
\text { should be able to } \\
\text { choose proved } \\
\text { materials. }\end{array}$ & & & 1 & 3 & 3 & $\begin{array}{l}\text { Choose proved } \\
\text { materials }\end{array}$ & $\begin{array}{l}\text { Monitor and shut down } \\
\text { if needed }\end{array}$ \\
\hline 348 & 5.2.03.05. & Sand blocking & $\begin{array}{l}\text { Sand blocking is a problem when the } \\
\text { reservoir is unconsolidated and the wellbore } \\
\text { is shut in for maintenance or upsets. (CCP } \\
\text { 2009) }\end{array}$ & & \begin{tabular}{|l} 
Additional \\
[new] FEP
\end{tabular} & $\begin{array}{l}\text { Very unlikely to be } \\
\text { an issue. }\end{array}$ & $\begin{array}{l}\text { The reservoir isn't } \\
\text { unconsolidated. }\end{array}$ & & 1 & 3 & 3 & $\begin{array}{l}\text { Characterize the } \\
\text { formations }\end{array}$ & Monitor \\
\hline 349 & 5.2.03.06. & \begin{tabular}{|c|} 
Dissolution of sand \\
control resins
\end{tabular} & $\begin{array}{l}\text { Sand control may be necessary to maintain } \\
\text { the structure of the reservooir around the } \\
\text { wellbore. Migration of sand and fines into the } \\
\text { near wellbore area may severely restrict } \\
\text { production/injection. }\end{array}$ & & $\begin{array}{l}\text { Additional } \\
\text { [new] FEP }\end{array}$ & $\begin{array}{l}\text { Very unlikely to be } \\
\text { an issue. }\end{array}$ & & & 1 & 3 & 3 & $\begin{array}{l}\text { Choose } \mathrm{CO} 2 \\
\text { compatible resins if } \\
\text { they are needed }\end{array}$ & Monitor \\
\hline 350 & 5.2.03.07. & \begin{tabular}{|c|} 
Dehydration and \\
deposition of gravel \\
pack contents \\
\end{tabular} & $\begin{array}{l}\text { Dehydration and deposition of gravel pack } \\
\text { contents that cannot be displaced or } \\
\text { removed from the well (CCP 2009) }\end{array}$ & & $\begin{array}{l}\text { Additional } \\
\text { [new] FEP }\end{array}$ & $\begin{array}{l}\text { Very unlikely to be } \\
\text { an issue. }\end{array}$ & & & 1 & 2 & 2 & NA & NA \\
\hline 351 & 5.2.03.08. & \begin{tabular}{|c|}
$\begin{array}{c}\text { Fluids left in } \\
\text { wellbore for } \\
\text { extended amounts } \\
\text { of time }\end{array}$ \\
\end{tabular} & \begin{tabular}{|l|} 
Once the well is completed, impairment \\
implications of the fluids or non-fluids left in \\
the wellbore during startup will need to be \\
considered. (CCP 2009)
\end{tabular} & $\begin{array}{l}\text { Flluids left in the wellbore for extended amounts } \\
\text { of time could potentially corrode the tubulars, } \\
\text { drop out precipitants, or cause bacterial growth. } \\
\text { (CCP 2009) }\end{array}$ & \begin{tabular}{|l} 
Additional \\
[new] FEP
\end{tabular} & $\begin{array}{l}\text { Very unlikely to be } \\
\text { an issue. }\end{array}$ & & & 1 & 3 & 3 & Flush well if needed & Monitor \\
\hline 352 & 5.2.03.09. & $\begin{array}{c}\text { Negative impact of } \\
\text { startup fluids on } \\
\text { injectivity }\end{array}$ & $\begin{array}{l}\text { It is important to consider the displacement } \\
\text { of any fluids into the reservoir during start up } \\
\text { and the effect of injectivity resulting from the } \\
\text { introduction of the fluids. (CCP 2009) }\end{array}$ & & \begin{tabular}{|l} 
Additional \\
[new] FEP
\end{tabular} & $\begin{array}{l}\text { Very unlikely to be } \\
\text { an issue. }\end{array}$ & & & 1 & 1 & 1 & $\begin{array}{l}\text { Use compatible } \\
\text { fluids }\end{array}$ & Monitor \\
\hline
\end{tabular}




\begin{tabular}{|c|c|c|c|c|c|c|c|c|c|c|c|c|c|}
\hline \multicolumn{6}{|c|}{ CO2 Geologic Sequestration Risks for the IMCCS Project } & \multicolumn{3}{|c|}{ Project Specific Information } & \multicolumn{3}{|c|}{ Risk Ranking } & \multicolumn{2}{|c|}{ Prevention and Mitigation } \\
\hline Line \# & Index No. & Risk Area & Description & Relevance & $\begin{array}{l}\text { Qunitessa } \\
\text { FEP } \\
\text { Category }\end{array}$ & $\begin{array}{l}\text { Individual } \\
\text { Comments }\end{array}$ & $\begin{array}{c}\text { IMccs Project } \\
\text { Specific Information }\end{array}$ & $\begin{array}{c}\text { IMCCS Project } \\
\text { Information Gaps } \\
\text { or Uncertainties }\end{array}$ & 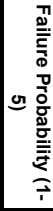 & 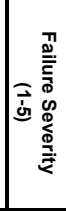 & 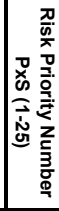 & $\begin{array}{l}\text { Risk Prevention } \\
\text { Steps (Actions } \\
\text { taken to reduce } \\
\text { risk probability) }\end{array}$ & $\begin{array}{l}\text { Risk Mitigation } \\
\text { Steps (Actions taken } \\
\text { to reduce risk } \\
\text { severity) }\end{array}$ \\
\hline 353 & 5.2.03.10. & Hydrate formation & $\begin{array}{l}\text { The prevention of hydrate formation in the } \\
\text { well during startup will need to be } \\
\text { considered. It is ilikely that methanol spacers } \\
\text { will need to be used. (CCP 2009) } \\
\text { Hydrate potentially could form in the well } \\
\text { when starting back up after a shut down. } \\
\text { During the process of shutting down, } \\
\text { measures should be taken to mitingate the } \\
\text { formation of hydrates when starting back up. } \\
\text { Often a methanol "cap" is pumped in the top } \\
\text { of the tubulars. (CCP 2009) } \\
\text { As a consequence of well control using a } \\
\text { brine or similar fluid, there can be intermixing } \\
\text { of the CO2 and the well control fluid that } \\
\text { could result in hydrate formation or hydrate } \\
\text { blocks, Using hydrate inhibited fluids or } \\
\text { having operational practices that minimize } \\
\text { the amount of CO2 inflow during workovers } \\
\text { should be considered. (CCP 2009) }\end{array}$ & & \begin{tabular}{|l} 
Additional \\
[new] FEP
\end{tabular} & $\begin{array}{l}\text { Very unlikely to be } \\
\text { an issue. }\end{array}$ & & & 1 & 1 & 1 & $\begin{array}{l}\text { Identify possible fluid } \\
\text { interactions and plan } \\
\text { for them }\end{array}$ & Monitor \\
\hline 354 & 5.2.03.11. & $\begin{array}{l}\text { Lack of sufficient } \\
\text { startup pressure }\end{array}$ & $\begin{array}{l}\text { Facilities sometimes do not have sufficient } \\
\text { pressures to re-start injection. In these } \\
\text { cases, injection tubing should be loaded with } \\
\text { sufficient fluids to allow for a re-start. (CCP } \\
\text { 2009) }\end{array}$ & & \begin{tabular}{|l} 
Additional \\
[new] FEP
\end{tabular} & $\begin{array}{l}\text { Very unlikely to be } \\
\text { an issue. }\end{array}$ & & & 1 & 1 & 1 & \begin{tabular}{|l|} 
Design compression \\
or pumps sufficient \\
to overcome \\
restarting the \\
injection
\end{tabular} & Monitor \\
\hline 355 & 5.2.03.12. & $\begin{array}{l}\text { Stimulation or } \\
\text { hydraulic fracturing } \\
\text { compromising the } \\
\text { reservoir seal }\end{array}$ & $\begin{array}{l}\text { Fracturing may occur in some of the different } \\
\text { stimulation treatments sused to increase } \\
\text { injectivity around the wellbore. The fractures } \\
\text { should not compromise the reservoir seal. } \\
\text { (CCP 2009) }\end{array}$ & $\begin{array}{l}\text { Unintended migration of } \mathrm{CO} 2 \text { through stress- } \\
\text { induced fractures or faults. }\end{array}$ & \begin{tabular}{|l} 
Additional \\
[new] FEP
\end{tabular} & $\begin{array}{l}\text { Very unlikely to be } \\
\text { an issue. }\end{array}$ & & $\begin{array}{l}\text { Do we plan to } \\
\text { frac? }\end{array}$ & 1 & 4 & 4 & $\begin{array}{l}\text { Do not frac above } \\
\text { the confining unit's } \\
\text { frac pressure }\end{array}$ & Monitor \\
\hline 356 & 5.2.03.13. & $\begin{array}{l}\text { Stimulation fluids } \\
\text { incompatibility }\end{array}$ & $\begin{array}{l}\text { Stimulation fluids should be carefully } \\
\text { selected in terms of compatibility with the } \\
\text { well materials, workover materials and } \\
\text { reservoir. (CCP 2009) }\end{array}$ & & \begin{tabular}{|l} 
Additional \\
[new] FEP
\end{tabular} & $\begin{array}{l}\text { Very unlikely to be } \\
\text { an issue. }\end{array}$ & & & 1 & 1 & 1 & $\begin{array}{l}\text { Identify possible fluid } \\
\text { interactions and plan } \\
\text { for them }\end{array}$ & Monitor \\
\hline 357 & 5.2.03.14. & $\begin{array}{l}\text { Lack of well } \\
\text { monitoring }\end{array}$ & $\begin{array}{l}\text { Well monitoring for CO2 storage seeks } \\
\text { confident validation that: } \\
\text { - Cement integrity and bond is maintained } \\
\text { - Pressure isolation barriers are maintained } \\
\text { and functioning } \\
\text { - Corrosion is being controlled } \\
\text { - The CO2 injection profile is being } \\
\text { maintained } \\
\text { - Barriers after plug and abandonment } \\
\text { provide confidence. (CCP 2009) }\end{array}$ & & \begin{tabular}{|l} 
Additional \\
[new] FEP
\end{tabular} & $\begin{array}{l}\text { Unlikely to be an } \\
\text { issue. UlC has } \\
\text { min requirements } \\
\text { for injection well } \\
\text { monitoring. }\end{array}$ & & & 2 & 4 & 8 & $\begin{array}{l}\text { Monitor wells above } \\
\text { the UIC min } \\
\text { requirements. Also } \\
\text { monitor projection } \\
\text { wells }\end{array}$ & $\begin{array}{l}\text { Monitor wells. Replug } \\
\text { leaky wells. }\end{array}$ \\
\hline 358 & 5.2.03.15. & $\begin{array}{l}\text { Inadequate } \\
\text { abandonment } \\
\text { procedures }\end{array}$ & $\begin{array}{l}\text { A typical well abandonment may include the } \\
\text { following: } \\
\text { - Remove tubing and packer } \\
\text { - Permanently seal the formation with a fluid } \\
\text { that reduces permeability } \\
\text { - Place plugs of cement or other materials } \\
\text { for isolation } \\
\text { - Test the plugs } \\
\text { - Place a cap on the casing at the surface } \\
\text { - Backilil with soil and accurately record well } \\
\text { location. (CCP 2009) }\end{array}$ & & \begin{tabular}{|l} 
Additional \\
[new] FEP
\end{tabular} & $\begin{array}{l}\text { Unlikely to be an } \\
\text { issue. }\end{array}$ & & & 2 & 2 & 4 & $\begin{array}{l}\text { Design plugging } \\
\text { plan to account for } \\
\text { post injection } \\
\text { conditions }\end{array}$ & Monitor \\
\hline
\end{tabular}

Quintessa Original FEP: Taken from Quintessa's on-line CO2 FEP database, which is freely accessible at: http://www.quintessa.org/co2fepdb/ 


\begin{tabular}{|c|c|c|c|c|c|c|c|c|c|c|c|c|c|}
\hline \multicolumn{6}{|c|}{ CO2 Geologic Sequestration Risks for the IMCCS Project } & \multicolumn{3}{|c|}{ Project Specific Information } & \multicolumn{3}{|c|}{ Risk Ranking } & \multicolumn{2}{|c|}{ Prevention and Mitigation } \\
\hline Line \# & Index No. & Risk Area & Description & Relevance & $\begin{array}{l}\text { Qunitessa } \\
\text { FEP } \\
\text { Category }\end{array}$ & $\begin{array}{l}\text { Individual } \\
\text { Comments }\end{array}$ & $\begin{array}{c}\text { IMCCS Project } \\
\text { Specific Information }\end{array}$ & $\begin{array}{c}\text { IMCCS Project } \\
\text { Information Gaps } \\
\text { or Uncertainties }\end{array}$ & 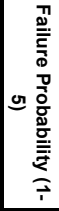 & 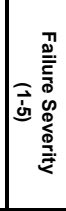 & 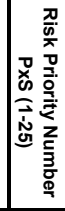 & $\begin{array}{l}\text { Risk Prevention } \\
\text { Steps (Actions } \\
\text { taken to reduce } \\
\text { risk probability) }\end{array}$ & $\begin{array}{c}\text { Risk Mitigation } \\
\text { Steps (Actions taken } \\
\text { to reduce risk } \\
\text { severity) }\end{array}$ \\
\hline 359 & 5.2.03.16. & $\begin{array}{c}\text { Submersible pump } \\
\text { failure in production } \\
\text { well }\end{array}$ & $\begin{array}{l}\text { While normally very reliable, the submersible } \\
\text { pump in an EOR or ECBM production well } \\
\text { can fail. }\end{array}$ & & \begin{tabular}{|l} 
Additional \\
[new] FEP
\end{tabular} & $\begin{array}{l}\text { Possible issue. } \\
\text { Mechanical stuff } \\
\text { fails }\end{array}$ & & & 3 & 2 & 6 & $\begin{array}{l}\text { Design, construct } \\
\text { and operate, and } \\
\text { maintain wells } \\
\text { properly. }\end{array}$ & $\begin{array}{l}\text { Have a plan or extra } \\
\text { parts to replace or } \\
\text { repair pumps }\end{array}$ \\
\hline 360 & 5.2.04.00. & $\begin{array}{l}\text { Orphan wells } \\
\text { (Old wells) }\end{array}$ & $\begin{array}{l}\text { CO2 storage projects may be part of an } \\
\text { Enhanced Oil Recovery (EOR) project or } \\
\text { stand-alone deep saline aquifer projects. } \\
\text { Either way, it is likely that the target } \\
\text { geological structure has been the object of } \\
\text { past exploration efforts, possibly involving } \\
\text { drilling wells. } \\
\text { The existence of old wells could be obvious } \\
\text { if the wells are still active, but could be } \\
\text { overlooked if the old (orphan) wells have } \\
\text { been long cemented and abandoned. } \\
\text { Technical details of such abandoned vintage } \\
\text { wells may in fact not be readily available, or } \\
\text { altogether lost. In such a case, the old } \\
\text { cementing (sealing) job could be } \\
\text { substandard. }\end{array}$ & $\begin{array}{l}\text { Old substandard plugged well could provide a } \\
\text { potential CO2 leakage route to the surface or to } \\
\text { possible reservoirs above the designed CO2 } \\
\text { storage reservoir. } \\
\text { There is little chance of detecting a substandard } \\
\text { well abandonment before the beginning of CO2 } \\
\text { iniection to the designed reservoir, particularly if } \\
\text { the existence of an old well has been overlooked. } \\
\text { If old abandoned wells are known in the area of } \\
\text { the CO2 injection operations, the risk is } \\
\text { minimized by carefully check any potential cO2 } \\
\text { leak to the surface at the old well head location. } \\
\text { If old wells are unknown and not suspected, it is } \\
\text { good practice to run a baseline soil gas survey (if } \\
\text { applicable) and successive soil gas surveys at } \\
\text { intervals after the beginning of CO2 injection. }\end{array}$ & 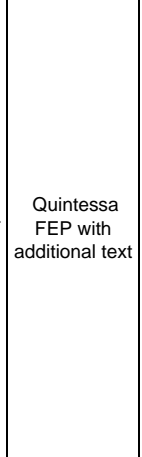 & Very likely issue. & $\begin{array}{l}\text { There are 100s of old } \\
\text { plugged wells }\end{array}$ & & 5 & 3 & 15 & \begin{tabular}{|l|} 
Identify old wells \\
using records, \\
surveys, and photos. \\
Characterize \\
overlying formations \\
and the surface for \\
CO2 and brine \\
composition/concent \\
rations. Replug wells \\
at risk. Pressurize \\
reservoir with water \\
and check for leaks.
\end{tabular} & $\begin{array}{l}\text { Monitor wells. Replug } \\
\text { leaky wells. } \\
\end{array}$ \\
\hline 361 & 5.2.04.01. & $\begin{array}{l}\text { Open borehole } \\
\text { collapse }\end{array}$ & $\begin{array}{l}\text { Some coal bed methane operations used } \\
\text { open completion wells ( no casing). It is } \\
\text { possible to stabilize a hole without casing } \\
\text { with gravel packing or sorted liners }\end{array}$ & $\begin{array}{l}\text { Open completion wells are more likely to leak } \\
\text { than other wells and subject to collapsing. }\end{array}$ & \begin{tabular}{|l} 
Additional \\
[new] FEP
\end{tabular} & $\begin{array}{l}\text { Unlikely to be an } \\
\text { issue. }\end{array}$ & & $\begin{array}{l}\text { Do we have open } \\
\text { borehole } \\
\text { completions at G- } \\
\text { E or T-A? }\end{array}$ & 2 & 3 & 6 & $\begin{array}{l}\text { Try to avoid site } \\
\text { with these types of } \\
\text { completions }\end{array}$ & $\begin{array}{l}\text { Monitor wells. Replug } \\
\text { leaky wells. }\end{array}$ \\
\hline 362 & 5.2.04.02. & \begin{tabular}{|c|}
$\begin{array}{c}\text { Failure to properly } \\
\text { plug, seal, close old } \\
\text { wells }\end{array}$ \\
\end{tabular} & & $\begin{array}{l}\text { CO2 escapes via poorly plugged old abandoned } \\
\text { well }\end{array}$ & \begin{tabular}{|l} 
Additional \\
[new] FEP
\end{tabular} & $\begin{array}{l}\text { Likely to be an } \\
\text { issue. }\end{array}$ & & & 4 & 3 & 12 & $\begin{array}{l}\text { Replug the riskiest } \\
\text { wells }\end{array}$ & $\begin{array}{l}\text { Monitor wells. Replug } \\
\text { leaky wells. }\end{array}$ \\
\hline 363 & 5.2.04.03. & $\begin{array}{c}\text { CO2 injection } \\
\text { impact on old wells }\end{array}$ & Major operational issue (CCP 2009) & & \begin{tabular}{|l} 
Additional \\
[new] FEP
\end{tabular} & Possible issue & & & 3 & 3 & 9 & $\begin{array}{l}\text { Characterize all } \\
\text { existing wells }\end{array}$ & $\begin{array}{l}\begin{array}{l}\text { Monitor the wells and } \\
\text { area for signs of } \\
\text { change or leakage }\end{array} \\
\end{array}$ \\
\hline 364 & 5.2.04.04. & $\begin{array}{c}\mathrm{CO} 2 \text { migrates to } \\
\text { overlying formations } \\
\text { due to old well } \\
\text { failure }\end{array}$ & Indication of $\mathrm{CO} 2$ in shallower stratigraphy & & \begin{tabular}{|l} 
Additional \\
[new] FEP
\end{tabular} & $\begin{array}{l}\text { Likely to be an } \\
\text { issue. }\end{array}$ & & & 4 & 3 & 12 & \begin{tabular}{|l|} 
Characterize \\
abandoned and old \\
wells and replug or \\
recomplete as \\
needed
\end{tabular} & \begin{tabular}{|l|} 
Monitor potential \\
zones where fluids \\
may enter from the \\
injection zone through \\
old wells
\end{tabular} \\
\hline 365 & 5.2.04.05. & $\begin{array}{l}\text { CO2 leakage at } \\
\text { surface due to old } \\
\text { well failure }\end{array}$ & Elevated CO2 present in vicinity of well(s) & & \begin{tabular}{|l} 
Additional \\
[new] FEP
\end{tabular} & $\begin{array}{l}\text { Unlikely to be an } \\
\text { issue. }\end{array}$ & & & 2 & 3 & 6 & \begin{tabular}{|l|} 
Characterize \\
abandoned and old \\
wells and replug or \\
recomplete as \\
needed \\
\end{tabular} & Surface monitoring \\
\hline 366 & 5.2.04.06. & $\begin{array}{l}\text { Leakage of } \\
\text { displaced formation } \\
\text { fluid in shallower } \\
\text { stratigraphy due to } \\
\text { old well failure }\end{array}$ & & & \begin{tabular}{|l} 
Additional \\
[new] FEP
\end{tabular} & $\begin{array}{l}\text { Likely to be an } \\
\text { issue. }\end{array}$ & & & 4 & 3 & 12 & \begin{tabular}{|l|} 
Characterize \\
abandoned and old \\
wells and replug or \\
recomplete as \\
needed
\end{tabular} & $\begin{array}{l}\text { Monitor potential } \\
\text { zones where fluids } \\
\text { may enter from the } \\
\text { injection zone through } \\
\text { old wells }\end{array}$ \\
\hline
\end{tabular}




\begin{tabular}{|c|c|c|c|c|c|c|c|c|c|c|c|c|c|}
\hline \multicolumn{6}{|c|}{ CO2 Geologic Sequestration Risks for the IMCCS Project } & \multicolumn{3}{|c|}{ Project Specific Information } & \multicolumn{3}{|c|}{ Risk Ranking } & \multicolumn{2}{|c|}{ Prevention and Mitigation } \\
\hline Line \# & Index No. & Risk Area & Description & Relevance & $\begin{array}{l}\text { Qunitessa } \\
\text { FEP } \\
\text { Category }\end{array}$ & $\begin{array}{l}\text { Individual } \\
\text { Comments }\end{array}$ & $\begin{array}{c}\text { IMCCS Project } \\
\text { Specific Information }\end{array}$ & \begin{tabular}{|c|} 
IMccs Project \\
Information Gaps \\
or Uncertainties
\end{tabular} & 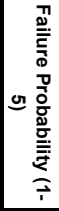 & 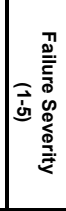 & 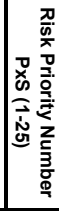 & $\begin{array}{l}\text { Risk Prevention } \\
\text { Steps (Actions } \\
\text { taken to reduce } \\
\text { risk probability) }\end{array}$ & $\begin{array}{l}\text { Risk Mitigation } \\
\text { Steps (Actions taken } \\
\text { to reduce risk } \\
\text { severity) }\end{array}$ \\
\hline 367 & 5.2.04.07. & $\begin{array}{l}\text { Improper re- } \\
\text { completion of old } \\
\text { wells }\end{array}$ & $\begin{array}{l}\text { EOR operations often re-complete old wells. } \\
\text { Proper re-completion includes: } \\
\text { Examining cement bond logs to evaluate } \\
\text { bonding between the casing and adjoining } \\
\text { formation. Use of squeeze cement if } \\
\text { insulficient or inadequate bonding was } \\
\text { detected. } \\
\text { Wellbore drilling of plugged and abandoned } \\
\text { wells to bottom of target formation. } \\
\text { Run a casing mechanical integrity test. If } \\
\text { pressure fall off was observed, the leaking } \\
\text { section of casing should be identified and } \\
\text { resealed by squeeze cementing or, in } \\
\text { extreme cases, install a liner over the leaking } \\
\text { section. }\end{array}$ & & \begin{tabular}{|l} 
Additional \\
[new] FEP
\end{tabular} & $\begin{array}{l}\text { Unlikely to be an } \\
\text { issue. We should } \\
\text { be able to log and } \\
\text { see how the } \\
\text { recompletion goes } \\
\text { to get an idea of } \\
\text { the quality of the } \\
\text { job. It will need to } \\
\text { be more than a } \\
\text { CBL or temp log }\end{array}$ & & & 2 & 2 & 4 & $\begin{array}{l}\text { Log to see how the } \\
\text { cement looks behind } \\
\text { the casing before } \\
\text { and after } \\
\text { recompletion jobs }\end{array}$ & $\begin{array}{l}\text { Monitor wells. Replug } \\
\text { leaky wells. }\end{array}$ \\
\hline 368 & 5.2.05.00. & $\begin{array}{l}\text { Soil creep around } \\
\text { boreholes }\end{array}$ & $\begin{array}{l}\text { The slow downward gravitational movement } \\
\text { of soil around boreholes. }\end{array}$ & $\begin{array}{l}\text { This process results in changing properties of the } \\
\text { soil around borehole casings after abandonment. } \\
\text { It may either increase or decrease the degree of } \\
\text { sealing and therefore the potential for the region } \\
\text { immediately around the borehole to act as a } \\
\text { migration pathway for } \mathrm{CO} 2 \text { and/or associated } \\
\text { contaminants. }\end{array}$ & $\begin{array}{l}\text { Quintessa } \\
\text { original FEP }\end{array}$ & \begin{tabular}{|l|} 
Unlikely to be an \\
issue.
\end{tabular} & $\begin{array}{l}\text { There are lots of old } \\
\text { wells we should be } \\
\text { able to see if this has } \\
\text { happened and then } \\
\text { know if it will be a risk } \\
\text { in the future }\end{array}$ & & 2 & 4 & 8 & $\begin{array}{l}\text { Examine existing } \\
\text { abandoned wells to } \\
\text { get an idea of the } \\
\text { problem. If there are } \\
\text { wells with this } \\
\text { problem. Identify } \\
\text { what was the } \\
\text { difference between } \\
\text { them and the wells } \\
\text { without the problem } \\
\text { and use the } \\
\text { successful } \\
\text { techniques on newly } \\
\text { abandoned wells }\end{array}$ & $\begin{array}{l}\text { Monitor for this } \\
\text { problem. }\end{array}$ \\
\hline 369 & 6.0 .00 .00 & $\begin{array}{l}\text { Near-Surface } \\
\text { Environment }\end{array}$ & $\begin{array}{l}\text { This category of FEPs is concerned with } \\
\text { factors that can be important if sequestered } \\
\text { carbon dioxide returns to the accessible } \\
\text { environment. The environment could be } \\
\text { terrestrial or marine, and human behavior in } \\
\text { that environment needs to be described. The } \\
\text { category is divided into three classes: } \\
\text { Terrestrial Environment; Marine } \\
\text { Environment; and Human Behavior. }\end{array}$ & & $\begin{array}{l}\text { Quintessa } \\
\text { original FEP }\end{array}$ & & & & NA & NA & NA & NA & NA \\
\hline 370 & 6.1.00.00. & $\begin{array}{l}\text { Terrestrial } \\
\text { environment }\end{array}$ & $\begin{array}{l}\text { This class of FEPs is concerned with factors } \\
\text { that can be important if sequestered carbon } \\
\text { dioxide returns to the accessible terrestrial } \\
\text { environment. }\end{array}$ & $\begin{array}{l}\text { The near-surface environment is where most } \\
\text { potential impacts would be incurred. The FEPs in } \\
\text { this class are relevant if that environment is } \\
\text { terrestrial. }\end{array}$ & $\begin{array}{l}\text { Quintessa } \\
\text { original FEP }\end{array}$ & $\begin{array}{l}\text { very unlikely to be } \\
\text { an issue. }\end{array}$ & & & 1 & 1 & 1 & $\begin{array}{l}\text { Take terrestrial } \\
\text { environment into } \\
\text { account in } \\
\text { evaluating site } \\
\text { selection. }\end{array}$ & NA \\
\hline 371 & 6.1.01.00. & $\begin{array}{l}\text { Topography and } \\
\text { morphology }\end{array}$ & $\begin{array}{l}\text { Features related to the relief and shape of } \\
\text { the surface environment and its evolution. }\end{array}$ & $\begin{array}{l}\text { This FEP refers to local land form and land form } \\
\text { changes with implications for the surface } \\
\text { environment, e.g. plains, hills, valleys, and } \\
\text { effects of river and glacial erosion thereon. In the } \\
\text { long term, such changes may occur as a } \\
\text { response to other geological changes. }\end{array}$ & $\begin{array}{l}\text { Quintessa } \\
\text { original FEP }\end{array}$ & $\begin{array}{l}\text { very unlikely to be } \\
\text { an issue. }\end{array}$ & $\begin{array}{l}\text { The sites are relatively } \\
\text { flat. }\end{array}$ & & 1 & 3 & 3 & $\begin{array}{l}\text { Characterize } \\
\text { injection site for low } \\
\text { surface areas. }\end{array}$ & $\begin{array}{l}\text { Monitor low areas for } \\
\text { CO2 accumulation. } \\
\text { Install alarm systems. } \\
\text { Train operators and } \\
\text { educate residents } \\
\text { what to do if a CO2 } \\
\text { leak occurs. }\end{array}$ \\
\hline
\end{tabular}

Appendix 6-66

Quintessa Original FEP: Taken from Quintessa's on-line CO2 FEP database, which is freely accessible at: http://www.quintessa.org/co2fepdb/ 


\begin{tabular}{|c|c|c|c|c|c|c|c|c|c|c|c|c|c|}
\hline \multicolumn{6}{|c|}{ CO2 Geologic Sequestration Risks for the IMCCS Project } & \multicolumn{3}{|c|}{ Project Specific Information } & \multicolumn{3}{|c|}{ Risk Ranking } & \multicolumn{2}{|c|}{ Prevention and Mitigation } \\
\hline Line \# & Index No. & Risk Area & Description & Relevance & $\begin{array}{l}\text { Qunitessa } \\
\text { FEP } \\
\text { Category }\end{array}$ & $\begin{array}{l}\text { Individual } \\
\text { Comments }\end{array}$ & $\begin{array}{c}\text { IMCCS Project } \\
\text { Specific Information }\end{array}$ & $\mid \begin{array}{c}\text { Imccs Project } \\
\text { Information Gaps } \\
\text { or Uncertainties }\end{array}$ & 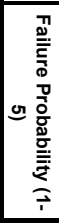 & 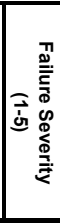 & 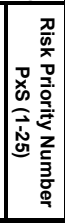 & $\begin{array}{l}\text { Risk Prevention } \\
\text { Steps (Actions } \\
\text { taken to reduce } \\
\text { risk probability) }\end{array}$ & $\begin{array}{l}\text { Risk Mitigation } \\
\text { Steps (Actions taken } \\
\text { to reduce risk } \\
\text { severity) }\end{array}$ \\
\hline 372 & 6.1.01.01. & Low surface areas & valleys & $\begin{array}{l}\text { Leaked } \mathrm{CO} 2 \text { can accumulate in low surface } \\
\text { areas. }\end{array}$ & \begin{tabular}{|l} 
Additional \\
[new] FEP
\end{tabular} & $\begin{array}{l}\text { Very unlikely to be } \\
\text { an issue. }\end{array}$ & None in area & & 1 & 3 & 3 & \begin{tabular}{|l|} 
Characterize \\
injection site for low \\
surface areas.
\end{tabular} & $\begin{array}{l}\text { Monitor low areas for } \\
\text { CO2 accumulation. } \\
\text { Install alarm systems. } \\
\text { Train operators and } \\
\text { educate residents } \\
\text { what to do if a CO2 } \\
\text { leak occurs. }\end{array}$ \\
\hline 373 & 6.1.01.02. & Rugged terrain & & $\begin{array}{l}\text { Rugged terrain may make it difficult to access the } \\
\text { site, difficult to lay pipeline and difficult to monitor } \\
\text { or conduct seismic studies }\end{array}$ & \begin{tabular}{|c} 
Additional \\
[new] FEP
\end{tabular} & $\begin{array}{l}\text { Very unlikely to be } \\
\text { an issue. }\end{array}$ & None in area & & 1 & 3 & 3 & $\begin{array}{l}\text { Avoid areas of } \\
\text { rugged terrain in site } \\
\text { selection. }\end{array}$ & $\begin{array}{l}\text { Monitor low areas for } \\
\text { CO2 accumulation. } \\
\text { Install alarm systems. } \\
\text { Train operators and } \\
\text { educate residents } \\
\text { what to do id a CO2 } \\
\text { leak occurs. }\end{array}$ \\
\hline 374 & 6.1.01.03. & Confined spaces & Caves or canyons & & \begin{tabular}{|l} 
Additional \\
[new] FEP
\end{tabular} & $\begin{array}{l}\text { Very unlikely to be } \\
\text { an issue. }\end{array}$ & None in area & & 1 & 3 & 3 & \begin{tabular}{|l} 
Characterize \\
injection site for \\
confined spaces
\end{tabular} & $\begin{array}{l}\text { Monitor confined } \\
\text { spaces for CO2 } \\
\text { accumulation . Install } \\
\text { alarm systems. Train } \\
\text { operators and educate } \\
\text { residents what to do if } \\
\text { a CO2 leak occurs. }\end{array}$ \\
\hline 375 & 6.1 .02 .00 & $\begin{array}{c}\text { Soils and sediments } \\
\text { impact on project }\end{array}$ & $\begin{array}{l}\text { Features related to the characteristics of the } \\
\text { soils and sediments and their evolution. } \\
\text { Different soil and sediment types, e.g. } \\
\text { characterized by mineralogy, particle-size } \\
\text { distribution and organic content, will have } \\
\text { different properties with respect to } \\
\text { erosion/deposition, sorption etc. }\end{array}$ & $\begin{array}{l}\text { Soil and sediment characteristics will influence } \\
\text { the type of vegetation and land use. They will } \\
\text { also determine relevant processes to consider } \\
\text { should CO2 and/or associated contaminants } \\
\text { migrate to the terrestrial surface environment. }\end{array}$ & $\begin{array}{l}\text { Quintessa } \\
\text { original FEP }\end{array}$ & $\begin{array}{l}\text { Very unlikely to be } \\
\text { an issue. }\end{array}$ & & & 1 & 1 & 1 & $\begin{array}{l}\text { Characterize soil } \\
\text { and sediments. }\end{array}$ & $\begin{array}{l}\text { Monitor soils for } \mathrm{CO} 2 \\
\text { and H2S. Identify any } \\
\text { irregularities. } \\
\text { Determine root cause. } \\
\text { Locate and plug leaks. }\end{array}$ \\
\hline 376 & 6.1 .03 .00 & $\begin{array}{l}\text { Erosion and } \\
\text { deposition }\end{array}$ & $\begin{array}{l}\text { FEPs related to all the erosional and } \\
\text { depositional processes that operate in the } \\
\text { surface environment, and their evolution with } \\
\text { time. Relevant processes may include fluvial } \\
\text { and glacial erosion and deposition, } \\
\text { denudation, aeolian erosion and deposition. } \\
\text { These processes will be controlled by factors } \\
\text { such as the climate, vegetation, topography } \\
\text { and geomorphology. }\end{array}$ & $\begin{array}{l}\text { Erosional and depositional processes will } \\
\text { influence the way in which the surface } \\
\text { environment has evolved and will evolve over the } \\
\text { time-scale of interest. }\end{array}$ & \begin{tabular}{|l} 
Quintessa \\
original FEP
\end{tabular} & $\begin{array}{l}\text { Very unlikely to be } \\
\text { an issue. }\end{array}$ & $\begin{array}{l}\text { Site areas are } \\
\text { relatively flat. About } \\
2.1 \% \text { of the CVR-T-A } \\
\text { pipeline has steep } \\
\text { slopes. About } 60 \% \text { of } \\
\text { the pipeline ROW is } \\
\text { considered highly } \\
\text { erodible by wind or } \\
\text { water. }\end{array}$ & & 1 & 1 & 1 & \begin{tabular}{|l|} 
Avoid steep slopes \\
$>18 \%$ in pipeline \\
ROW and site \\
selection if possible. \\
Provide erosion \\
control on slopes.
\end{tabular} & $\begin{array}{l}\text { Regularly inspect } \\
\text { steep slopes cuts and } \\
\text { gullies for erosion and } \\
\text { deposition. Provide } \\
\text { erosion control on } \\
\text { slopes. }\end{array}$ \\
\hline
\end{tabular}




\begin{tabular}{|c|c|c|c|c|c|c|c|c|c|c|c|c|c|}
\hline \multicolumn{6}{|c|}{ CO2 Geologic Sequestration Risks for the IMCCS Project } & \multicolumn{3}{|c|}{ Project Specific Information } & \multicolumn{3}{|c|}{ Risk Ranking } & \multicolumn{2}{|c|}{ Prevention and Mitigation } \\
\hline Line \# & Index No. & Risk Area & Description & Relevance & $\begin{array}{l}\text { Qunitessa } \\
\text { FEP } \\
\text { Category }\end{array}$ & $\begin{array}{l}\text { Individual } \\
\text { Comments }\end{array}$ & $\begin{array}{c}\text { IMCCS Project } \\
\text { Specific Information }\end{array}$ & \begin{tabular}{|c} 
IMccs Project \\
Information Gaps \\
or Uncertainties
\end{tabular} & 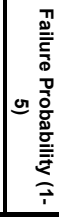 & 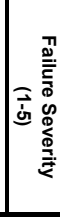 & 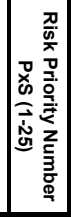 & $\begin{array}{l}\text { Risk Prevention } \\
\text { Steps (Actions } \\
\text { taken to reduce } \\
\text { risk probability) }\end{array}$ & $\begin{array}{c}\text { Risk Mitigation } \\
\text { Steps (Actions taken } \\
\text { to reduce risk } \\
\text { severity) }\end{array}$ \\
\hline 377 & 6.1.04.00. & Atmosphere and & 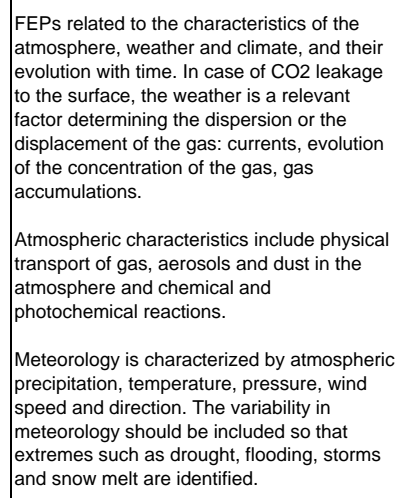 & $\begin{array}{l}\text { This information will determine the behavior of } \\
\text { CO2 should it reach the atmosphere and is } \\
\text { therefore an important factor when considering } \\
\text { exposure of the local population and of the local } \\
\text { environment. } \\
\text { Meteorological characteristics also influence the } \\
\text { near-surface hydrological regime with its } \\
\text { subsequent consequences for } \mathrm{CO} 2 \text { migration. }\end{array}$ & \begin{tabular}{|l} 
Quintessa \\
original FEP
\end{tabular} & $\begin{array}{l}\text { Very unlikely to be } \\
\text { an issue. }\end{array}$ & $\begin{array}{l}\text { The site areas usually } \\
\text { have moderate winds } \\
\text { which would help with } \\
\text { cO2 dispersion. The } \\
\text { annual average wind } \\
\text { speed in Kansas is } \\
12.1 \text { miles per hour. }\end{array}$ & & 1 & 1 & 1 & $\begin{array}{l}\text { Monitor atmospheric } \\
\text { CO2 on site. Stop } \\
\text { and fix leaks. }\end{array}$ & $\begin{array}{l}\text { Monitor atmospheric } \\
\text { CO2 on site. Train } \\
\text { operators and educate } \\
\text { residents what to do if } \\
\text { a cO2 leak occurs. }\end{array}$ \\
\hline 378 & 6.1.05.00. & $\begin{array}{c}\text { Hydrological regime } \\
\text { and water balance }\end{array}$ & $\begin{array}{l}\text { Processes related to near-surface hydrology } \\
\text { at a catchment scale and also soil water } \\
\text { balance, and their evolution with time. } \\
\text { The hydrological regime is a description of } \\
\text { the movement of water through the surface } \\
\text { and near-surface environment. It includes } \\
\text { the movement of materials associated with } \\
\text { the water such as gas or particulates and } \\
\text { extremes such as drought, flooding, storms } \\
\text { and snow melt. }\end{array}$ & $\begin{array}{l}\text { The hydrological regime and water balance will } \\
\text { influence the way in which } \mathrm{CO} 2 \text { migrates should } \\
\text { it reach the near-surface environment. }\end{array}$ & $\begin{array}{l}\text { Quintessa } \\
\text { original FEP }\end{array}$ & $\begin{array}{l}\text { Very unlikely to be } \\
\text { an issue. }\end{array}$ & $\begin{array}{l}\text { The site areas have } \\
\text { limited groundwater. } \\
\text { There are no public or } \\
\text { private water wells. }\end{array}$ & $\begin{array}{l}\begin{array}{l}\text { Conduct baseline } \\
\text { survey of } \\
\text { groundwater } \\
\text { quality }\end{array} \\
\end{array}$ & 1 & 2 & 2 & $\begin{array}{l}\text { Characterize the } \\
\text { local hydrological } \\
\text { regime and } \\
\text { incorporate results } \\
\text { into models. }\end{array}$ & \begin{tabular}{|l} 
Monitor near surface \\
aquifers for increases \\
in $\mathrm{CO} 2$ or salinity. \\
Determine root cause \\
for any increase. Use \\
tracers if necessary.
\end{tabular} \\
\hline 379 & 6.1.05.01. & $\begin{array}{c}\text { CO2 and } \\
\text { associated } \\
\text { contaminants } \\
\text { leakage affecting } \\
\text { hydrological regime } \\
\text { and water balance }\end{array}$ & & & \begin{tabular}{|l} 
Additional \\
[new] FEP
\end{tabular} & $\begin{array}{l}\text { Very unlikely to be } \\
\text { an issue. }\end{array}$ & \begin{tabular}{|l|} 
The sites have \\
multiple stacked seals \\
and sinks separating \\
the injection \\
formations from fresh \\
water aquifer \\
formations. \\
\end{tabular} & $\begin{array}{l}\begin{array}{l}\text { Conduct baseline } \\
\text { survey of } \\
\text { groundwater } \\
\text { quality }\end{array} \\
\end{array}$ & 1 & 3 & 3 & $\begin{array}{l}\text { Select sites with } \\
\text { multiple stacked } \\
\text { seals and sinks. } \\
\text { Ensure integrity of } \\
\text { seals. }\end{array}$ & \begin{tabular}{|l} 
Monitor near surface \\
aquifers for increases \\
in CO2 or salinity. \\
Determine root cause \\
for any increase. Use \\
tracers if necessary.
\end{tabular} \\
\hline 380 & 6.1.05.02. & $\begin{array}{c}\text { Displaced saline } \\
\text { fluids affecting the } \\
\text { hydrological regime } \\
\text { and water balance }\end{array}$ & & & \begin{tabular}{|} 
Additional \\
[new] FEP
\end{tabular} & $\begin{array}{l}\text { very unlikely to be } \\
\text { an issue. }\end{array}$ & \begin{tabular}{|l} 
Available data \\
indicates the saline \\
aquifers and fresh \\
water aquifers are not \\
connected locally.
\end{tabular} & $\begin{array}{l}\begin{array}{l}\text { Conduct baseline } \\
\text { survey of } \\
\text { groundwater } \\
\text { quality }\end{array} \\
\end{array}$ & 1 & 3 & 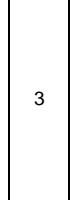 & $\begin{array}{l}\text { Characterize the } \\
\text { saline aquifer. } \\
\text { Confirm that there } \\
\text { are no local open } \\
\text { connections } \\
\text { between fresh and } \\
\text { saline water } \\
\text { aquifers. }\end{array}$ & \begin{tabular}{|l} 
Monitor near surface \\
aquifers for increases \\
in $\mathrm{CO} 2$ or salinity. \\
Determine root cause \\
for any increase. Use \\
tracers if necessary.
\end{tabular} \\
\hline
\end{tabular}




\begin{tabular}{|c|c|c|c|c|c|c|c|c|c|c|c|c|c|}
\hline \multicolumn{6}{|c|}{ CO2 Geologic Sequestration Risks for the IMCCS Project } & \multicolumn{3}{|c|}{ Project Specific Information } & \multicolumn{3}{|c|}{ Risk Ranking } & \multicolumn{2}{|c|}{ Prevention and Mitigation } \\
\hline Line \# & Index No. & Risk Area & Description & Relevance & $\begin{array}{l}\text { Qunitessa } \\
\text { FEP } \\
\text { Category }\end{array}$ & $\begin{array}{l}\text { Individual } \\
\text { Comments }\end{array}$ & $\begin{array}{c}\text { IMCCS Project } \\
\text { Specific Information }\end{array}$ & $\begin{array}{c}\text { IMCCS Project } \\
\text { Information Gaps } \\
\text { or Uncertainties }\end{array}$ & 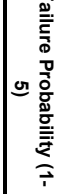 & 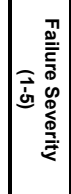 & 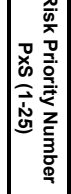 & $\begin{array}{l}\text { Risk Prevention } \\
\text { Steps (Actions } \\
\text { taken to reduce } \\
\text { risk probability) }\end{array}$ & $\begin{array}{l}\text { Risk Mitigation } \\
\text { Steps (Actions taker } \\
\text { to reduce risk } \\
\text { severity) }\end{array}$ \\
\hline 381 & 6.1.05.03. & $\begin{array}{l}\text { Groundwater } \\
\text { withdrawal causing } \\
\text { change in } \mathrm{CO} 2 \text { or } \\
\text { brine migration }\end{array}$ & & & \begin{tabular}{|} 
Additional \\
[new] FEP
\end{tabular} & $\begin{array}{l}\text { very unlikely to be } \\
\text { an issue. }\end{array}$ & $\begin{array}{l}\text { There are no public or } \\
\text { private water wells at } \\
\text { the sites. }\end{array}$ & \begin{tabular}{|l|} 
Characterize \\
groundwater levels
\end{tabular} & 1 & 3 & 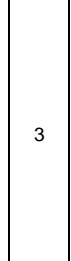 & $\begin{array}{l}\text { Characterize the } \\
\text { saline aquifer. } \\
\text { Confirm that there } \\
\text { are no local open } \\
\text { connections } \\
\text { between fresh and } \\
\text { saline water } \\
\text { aquifers. Incorporate } \\
\text { information in } \\
\text { models. }\end{array}$ & $\begin{array}{l}\text { Monitor near surface } \\
\text { aquifers for increases } \\
\text { in CO2 or salinity. } \\
\text { Determine root cause } \\
\text { for any increase. Use } \\
\text { tracers if necessary. }\end{array}$ \\
\hline 382 & 6.1 .06 .00 & $\begin{array}{l}\text { Near-surface } \\
\text { aquifers and } \\
\text { surface water } \\
\text { bodies }\end{array}$ & $\begin{array}{l}\text { Features related to the characteristics of } \\
\text { aquifers and water-bearing features and } \\
\text { their evolution. }\end{array}$ & $\begin{array}{l}\text { Shallow Aquifers } \\
\text { Aquifers may yield significant amounts of water } \\
\text { to wells or surface springs and may thus be a } \\
\text { fliw path for CO2 to the surface environment. } \\
\text { The presence of aquifers and other water- } \\
\text { bearing features will be determined by the } \\
\text { geoological, hydrological and climatic factors. } \\
\text { Shallow aquifers will be able to dissolve CO2, } \\
\text { reducing further upward migration. The amount } \\
\text { of CO2 that can dissolve will depend on factors } \\
\text { such as the location of the water table, the } \\
\text { chemical composition of pore waters, CO2 flux } \\
\text { rates, and hydrogeology. } \\
\text { Surface Water Bodies } \\
\text { Streams, rivers and lakes often act as } \\
\text { boundaries of hydrogeological systems. They } \\
\text { may represent a significant source of dilution for } \\
\text { cO2 and contaminants entering these systems, } \\
\text { or act as reservoirs. In hot dry environments, } \\
\text { where evaporation dominates, concentration or } \\
\text { essolutiton of gas is possible. Water with } \\
\text { dissolved CO2 is denser than pure water, which } \\
\text { can result in stratification and the potential for } \\
\text { limnic eruption. }\end{array}$ & $\begin{array}{l}\text { Quintessa } \\
\text { original FEP }\end{array}$ & $\begin{array}{l}\text { Very unlikely to be } \\
\text { an issue. }\end{array}$ & $\begin{array}{l}\text { The site areas have } \\
\text { limited groundwater. } \\
\text { There are no public or } \\
\text { private water wells. } \\
\text { Surface water is } \\
\text { limited to some small } \\
\text { ponds. }\end{array}$ & $\begin{array}{l}\text { Conduct baseline } \\
\text { survey of } \\
\text { groundwater and } \\
\text { surface water } \\
\text { quality }\end{array}$ & 1 & 2 & 2 & $\begin{array}{l}\text { Characterize } \\
\text { groundwater } \\
\text { aquifers and surface } \\
\text { water bodies near } \\
\text { the sites. }\end{array}$ & $\begin{array}{l}\text { Monitor near surface } \\
\text { aquifers and surface } \\
\text { water bodies for } \\
\text { increases in } \mathrm{CO} \text { or } \\
\text { salinity. Determine } \\
\text { root cause for any } \\
\text { increase. Use tracers } \\
\text { if necessary. }\end{array}$ \\
\hline 383 & 6.1.07.00. & $\begin{array}{c}\begin{array}{c}\text { Terrestrial flora and } \\
\text { fauna }\end{array} \\
\end{array}$ & $\begin{array}{l}\text { Features and processes related to the } \\
\text { characteristics of terrestrial and freshwater } \\
\text { flora and fauna, and their evolution. Includes } \\
\text { plants, animals, fungi, algae and microbes. } \\
\text { Plants usually have a higher resistance } \\
\text { against CO2 than mammals, but persistent } \\
\text { leaks could suppress respiration in the root } \\
\text { zone. Tree kills associated with soil gas } \\
\text { concentrations in the range of 20-30\% have } \\
\text { been observed at Mammoth Mountain, } \\
\text { California, where volcanic outgassing of CO2 } \\
\text { (0.13-0.44 Mttyr) has been occuring since } \\
\text { at least } 1990 \text {. The leakage rate (flux) varies } \\
\text { between } 25 \text { and } 7000 \mathrm{~g} \text { CO2/day/m2. } \\
\text { (Damen 2006). }\end{array}$ & $\begin{array}{l}\text { Flora and fauna may be affected by } \\
\text { concentrations of } \mathrm{CO} \text { in the near-surface } \\
\text { environment and may be indicators of } \mathrm{CO} 2 \\
\text { leakage. } \\
\\
\end{array}$ & $\begin{array}{l}\text { Quintessa } \\
\text { original FEP }\end{array}$ & $\begin{array}{l}\text { very unlikely to be } \\
\text { an issue. }\end{array}$ & $\begin{array}{l}\text { The sites are primarily } \\
\text { grass lands with very } \\
\text { little flora or fauna. }\end{array}$ & & 1 & 1 & 1 & $\begin{array}{l}\text { Characterize the } \\
\text { flora and fauna on } \\
\text { sites. }\end{array}$ & $\begin{array}{l}\text { Monitor flora and } \\
\text { fauna for unexplained } \\
\text { dead zones. } \\
\text { Determine root cause } \\
\text { Check CO2 content in } \\
\text { the area. Locate and } \\
\text { plug leaks if any. }\end{array}$ \\
\hline
\end{tabular}

Appendix 6-69

Quintessa Original FEP: Taken from Quintessa's on-line CO2 FEP database, which is freely accessible at: http://www.quintessa.org/co2fepdb/ 


\begin{tabular}{|c|c|c|c|c|c|c|c|c|c|c|c|c|c|}
\hline \multicolumn{6}{|c|}{ CO2 Geologic Sequestration Risks for the IMCCS Project } & \multicolumn{3}{|c|}{ Project Specific Information } & \multicolumn{3}{|c|}{ Risk Ranking } & \multicolumn{2}{|c|}{ Prevention and Mitigation } \\
\hline Line \# & Index No. & Risk Area & Description & Relevance & $\begin{array}{l}\text { Qunitessa } \\
\quad \text { FEP } \\
\text { Category }\end{array}$ & $\begin{array}{l}\text { Individual } \\
\text { Comments }\end{array}$ & $\begin{array}{c}\text { IMCCS Project } \\
\text { Specific Information }\end{array}$ & $\begin{array}{c}\text { IMCCS Project } \\
\text { Information Gaps } \\
\text { or Uncertainties }\end{array}$ & 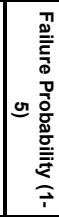 & 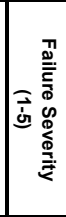 & 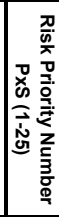 & $\begin{array}{l}\text { Risk Prevention } \\
\text { Steps (Actions } \\
\text { taken to reduce } \\
\text { risk probability) }\end{array}$ & $\begin{array}{l}\text { Risk Mitigation } \\
\text { Steps (Actions taken } \\
\text { to reduce risk } \\
\text { severity) }\end{array}$ \\
\hline 384 & 6.1 .08 .00 . & $\begin{array}{c}\text { Terrestrial } \\
\text { ecological systems }\end{array}$ & 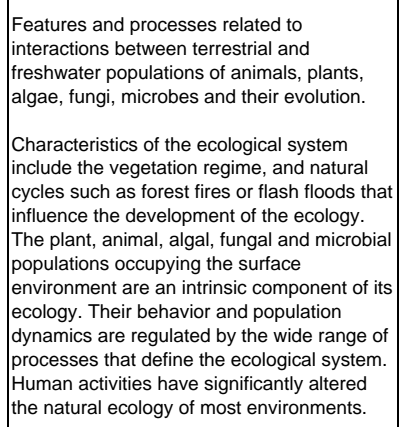 & $\begin{array}{l}\text { The ecology of the terrestrial near-surface } \\
\text { environment determines the types of organisms } \\
\text { present and their inter-dependencies. These can } \\
\text { influence the types of impact of interest and can } \\
\text { provide a mechanism for monitoring CO2 } \\
\text { leakage. }\end{array}$ & $\begin{array}{l}\text { Quintessa } \\
\text { original FEP }\end{array}$ & $\begin{array}{l}\text { Very unlikely to be } \\
\text { an issue. }\end{array}$ & $\begin{array}{l}\text { The sites are primarily } \\
\text { grass lands with very } \\
\text { little flora or fauna. }\end{array}$ & & 1 & 1 & 1 & $\begin{array}{l}\text { Characterize the } \\
\text { ecological systems } \\
\text { on the sites. }\end{array}$ & $\begin{array}{l}\text { Monitor flora and } \\
\text { fauna for unexplained } \\
\text { dead zones. } \\
\text { Determine root cause. } \\
\text { Check CO2 content in } \\
\text { the area. Locate and } \\
\text { plug leaks if any. }\end{array}$ \\
\hline 385 & 6.2.00.00. & Marine environment & $\begin{array}{l}\text { This class of FEPs is concerned with factors } \\
\text { that can be important if sequestered carbon } \\
\text { dioxide returns to the accessible marine } \\
\text { environment. }\end{array}$ & $\begin{array}{l}\text { The near-surface environment is where most } \\
\text { potential impacts would be incurred. The FEPs in } \\
\text { this class are relevant if that environment is } \\
\text { marine. }\end{array}$ & \begin{tabular}{|l} 
Quintessa \\
original FEP
\end{tabular} & $\begin{array}{l}\text { very unlikely to be } \\
\text { an issue. }\end{array}$ & $\begin{array}{l}\text { Not a marine } \\
\text { environment. }\end{array}$ & & 1 & 1 & 1 & NA & NA \\
\hline 386 & 6.2.01.00. & Coastal features & $\begin{array}{l}\text { Features and processes related to the } \\
\text { characteristics of coasts and the near shore, } \\
\text { and their evolution. Coastal features include } \\
\text { headlands, bays, beaches, spits, cliffs and } \\
\text { estuaries. }\end{array}$ & $\begin{array}{l}\text { The processes operating on these features, e.g. } \\
\text { active erosion, deposition, long shore transport, } \\
\text { may affect mechanisms for the migration of } \mathrm{CO} 2 \text {, } \\
\text { and associated contaminants, entering the } \\
\text { surface environment. }\end{array}$ & $\begin{array}{l}\text { Quintessa } \\
\text { original FEP }\end{array}$ & $\begin{array}{l}\text { very unlikely to be } \\
\text { an issue. }\end{array}$ & $\begin{array}{l}\text { Not a marine } \\
\text { environment. }\end{array}$ & & 1 & 1 & 1 & NA & NA \\
\hline 387 & 6.2.02.00. & $\begin{array}{c}\text { Local } \\
\text { oceanography }\end{array}$ & \begin{tabular}{|l|} 
Features and processes related to the \\
characteristics of seas and oceans and their \\
evolution. This includes the topography and \\
morphology of the seabed; thermal \\
stratification and salinity gradients; and \\
marine currents.
\end{tabular} & $\begin{array}{l}\text { The local oceanographic features and processes } \\
\text { determine the potential for dilution or } \\
\text { accumulation of CO2, or associated } \\
\text { contaminants in the marine environment. }\end{array}$ & $\begin{array}{l}\text { Quintessa } \\
\text { original FEP }\end{array}$ & $\begin{array}{l}\text { very unlikely to be } \\
\text { an issue. }\end{array}$ & $\begin{array}{l}\text { Not a marine } \\
\text { environment. }\end{array}$ & & 1 & 1 & 1 & NA & NA \\
\hline 388 & 6.2.03.00. & Marine sediments & $\begin{array}{l}\text { Features and processes associated with } \\
\text { sediments in the marine environment. This } \\
\text { includes both the physical and chemical } \\
\text { characteristics of the sediments, along with } \\
\text { sedimentation and resuspension processes. }\end{array}$ & $\begin{array}{l}\text { Marine bed sediment characteristics will influence } \\
\text { the ecology of the marine environment. They will } \\
\text { also determine relevant processes to consider } \\
\text { should } \mathrm{CO} 2 \text { and/or associated contaminants } \\
\text { migrate to the marine environment. }\end{array}$ & $\begin{array}{l}\text { Quintessa } \\
\text { original FEP }\end{array}$ & $\begin{array}{l}\text { very unlikely to be } \\
\text { an issue. }\end{array}$ & $\begin{array}{l}\text { Not a marine } \\
\text { environment. }\end{array}$ & & 1 & 1 & 1 & NA & NA \\
\hline 389 & 6.2.04.00. & $\begin{array}{c}\text { Marine flora and } \\
\text { fauna }\end{array}$ & \begin{tabular}{|l|}
$\begin{array}{l}\text { Features and processes related to the } \\
\text { characteristics of marine flora and fauna, } \\
\text { and their evolution. Includes plants, animals, } \\
\text { fungi, algae and microbes. }\end{array}$ \\
\end{tabular} & $\begin{array}{l}\text { Flora and fauna may be affected by } \\
\text { concentrations of } \mathrm{CO} 2 \text { in the marine environment } \\
\text { and may be indicators of } \mathrm{CO} 2 \text { leakage. }\end{array}$ & $\begin{array}{l}\text { Quintessa } \\
\text { original FEP }\end{array}$ & $\begin{array}{l}\text { very unlikely to be } \\
\text { an issue. }\end{array}$ & $\begin{array}{l}\text { Not a marine } \\
\text { environment. }\end{array}$ & & 1 & 1 & 1 & NA & NA \\
\hline 390 & 6.2 .05 .00 & $\begin{array}{l}\text { Marine ecological } \\
\text { systems }\end{array}$ & $\begin{array}{l}\text { Features and processes related to } \\
\text { interactions between populations of algae, } \\
\text { animals, microbes and their evolution. } \\
\text { Characteristics of the ecological system. The } \\
\text { algal, animal and microbial populations } \\
\text { occuuping the marine environment are an } \\
\text { intrinsic component of its ecology. Their } \\
\text { behavior and population dynamics are } \\
\text { regulated by the wide range of processes } \\
\text { that define the ecological system. }\end{array}$ & $\begin{array}{l}\text { The ecology of the marine environment } \\
\text { determines the types of organisms present and } \\
\text { their inter-dependencies. These can influence the } \\
\text { types of impact of interest and can provide a } \\
\text { mechanism for monitoring CO2 leakage. }\end{array}$ & $\begin{array}{l}\text { Quintessa } \\
\text { original FEP }\end{array}$ & $\begin{array}{l}\text { very unlikely to be } \\
\text { an issue. }\end{array}$ & $\begin{array}{l}\text { Not a marine } \\
\text { environment. }\end{array}$ & & 1 & 1 & 1 & NA & NA \\
\hline
\end{tabular}

Appendix 6-70

Quintessa Original FEP: Taken from Quintessa's on-line CO2 FEP database, which is freely accessible at: http://www.quintessa.org/co2fepdb/ 


\begin{tabular}{|c|c|c|c|c|c|c|c|c|c|c|c|c|c|}
\hline \multicolumn{6}{|c|}{ CO2 Geologic Sequestration Risks for the IMCCS Project } & \multicolumn{3}{|c|}{ Project Specific Information } & \multicolumn{3}{|c|}{ Risk Ranking } & \multicolumn{2}{|c|}{ Prevention and Mitigation } \\
\hline Line \# & Index No. & Risk Area & Description & Relevance & $\begin{array}{l}\text { Qunitessa } \\
\text { FEP } \\
\text { Category }\end{array}$ & $\begin{array}{l}\text { Individual } \\
\text { Comments }\end{array}$ & $\begin{array}{c}\text { IMCcS Project } \\
\text { Specific Information }\end{array}$ & $\begin{array}{c}\text { IMccs Project } \\
\text { Information Gaps } \\
\text { or Uncertainties }\end{array}$ & 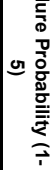 & 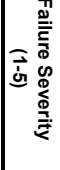 & 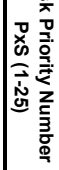 & $\begin{array}{l}\text { Risk Prevention } \\
\text { Steps (Actions } \\
\text { taken to reduce } \\
\text { risk probability) }\end{array}$ & \begin{tabular}{|c|} 
Risk Mitigation \\
Steps (Actions taken \\
to reduce risk \\
severity)
\end{tabular} \\
\hline 391 & 6.3.00.00. & Human behavior & $\begin{array}{l}\text { Details of the human behavior in the near- } \\
\text { surface environment where impacts may be } \\
\text { incurred. }\end{array}$ & $\begin{array}{l}\text { Human behavior will affect the nature and } \\
\text { magnitude of potential impacts to human beings. }\end{array}$ & $\begin{array}{l}\text { Quintessa } \\
\text { original FEP }\end{array}$ & $\begin{array}{l}\text { Very unlikely to be } \\
\text { an issue. }\end{array}$ & $\begin{array}{l}\text { Population is very } \\
\text { sparse at sites. } \\
\text { T-A: no residences } \\
\text { G-E: } 216 \text { residences }\end{array}$ & & 1 & 1 & 1 & \begin{tabular}{|l|} 
Avoid densely \\
populated areas. \\
Train operators and \\
educate residents \\
what to do in case of \\
a CO2 leak.
\end{tabular} & \begin{tabular}{|l} 
Maintain an \\
emergency response \\
plan. Train operators \\
and educate residents \\
what to do in case of a \\
CO2 leak.
\end{tabular} \\
\hline 392 & 6.3.01.00. & $\begin{array}{c}\text { Human } \\
\text { characteristics }\end{array}$ & $\begin{array}{l}\text { Features and processes related to } \\
\text { characteristics, e.g. physiology, metabolism, } \\
\text { of individual humans. This includes } \\
\text { considerations of variability, in individual } \\
\text { humans, of physiology and metabolism due } \\
\text { to age and other variations. } \\
\text { Physiology refers to body and organ form } \\
\text { and function. Metabolism refers to the } \\
\text { chemical and biochemical reactions which } \\
\text { occur within an organism, or part of an } \\
\text { organism, in connection with the production } \\
\text { and use of energy. } \\
\text { Children and infants, although similar to } \\
\text { adults, often have characteristic differences, } \\
\text { e.g. metabolism and respiratory rates, which } \\
\text { may lead to different characteristics of } \\
\text { exposure to cO2 or contaminants. }\end{array}$ & $\begin{array}{l}\text { Human physiology and metabolism determine the } \\
\text { affect of exposure to CO2 and associated } \\
\text { contaminants. }\end{array}$ & $\begin{array}{l}\text { Quintessa } \\
\text { original FEP }\end{array}$ & $\begin{array}{l}\text { Very unlikely to be } \\
\text { an issue. }\end{array}$ & $\begin{array}{l}\text { There are no sensitive } \\
\text { receptor areas } \\
\text { (schools, hospitals, } \\
\text { care centers, prisons, } \\
\text { churches) near the } \\
\text { sites }\end{array}$ & & 1 & 1 & 1 & $\begin{array}{l}\text { Avoid densely } \\
\text { populated areas or } \\
\text { sensitive receptor } \\
\text { areas in site } \\
\text { selection. }\end{array}$ & \begin{tabular}{|l|} 
Maintain an \\
emergency response \\
plan. Train operators \\
and educate residents \\
what to do in case of a \\
CO2 leak.
\end{tabular} \\
\hline 393 & 6.3.02.00. & $\begin{array}{l}\text { Diet and food } \\
\text { processing }\end{array}$ & $\begin{array}{l}\text { Features related to intake of food and water } \\
\text { by individual humans and the compositions } \\
\text { and origin of intake. This includes } \\
\text { considerations of how diets, of individual } \\
\text { humans, may vary with age and other } \\
\text { variations (ingestion of soil by infants, for } \\
\text { example). } \\
\text { This FEP also includes processes related to } \\
\text { the treatment of foodstuffs and water } \\
\text { between origin and consumption. For } \\
\text { example, once a crop is harvested it may be } \\
\text { subject to a variety of storage, processing } \\
\text { and preparational activities prior to human or } \\
\text { livestock consumption. Water sources may } \\
\text { be treated prior to human or livestock } \\
\text { consumption, e.g. chemical treatment and/or } \\
\text { filtration. }\end{array}$ & \begin{tabular}{|l|} 
The human diet provides a potentially important \\
exposure pathway to contaminants released into \\
the food chain as a result of the $\mathrm{CO} 2$ \\
sequestration system. \\
Food preparation processes may change the \\
distribution and content of CO2 and/or \\
associated contaminants in the product.
\end{tabular} & $\begin{array}{l}\text { Quintessa } \\
\text { original FEP }\end{array}$ & $\begin{array}{l}\text { Very unlikely to be } \\
\text { an issue. }\end{array}$ & $\begin{array}{l}\text { The sites are primary } \\
\text { grass lands and } \\
\text { possibly some wheat } \\
\text { farming. }\end{array}$ & & 1 & 1 & 1 & $\begin{array}{l}\text { Characterize and } \\
\text { soils, water and } \\
\text { crops in the site } \\
\text { areas. Conduct } \\
\text { baseline survey for } \\
\text { potential } \\
\text { contaminants. }\end{array}$ & $\begin{array}{l}\text { Monitor soils and } \\
\text { water for } \\
\text { contaminants. }\end{array}$ \\
\hline
\end{tabular}




\begin{tabular}{|c|c|c|c|c|c|c|c|c|c|c|c|c|c|}
\hline \multicolumn{6}{|c|}{ CO2 Geologic Sequestration Risks for the IMCCS Project } & \multicolumn{3}{|c|}{ Project Specific Information } & \multicolumn{3}{|c|}{ Risk Ranking } & \multicolumn{2}{|c|}{ Prevention and Mitigation } \\
\hline Line \# & Index No. & Risk Area & Description & Relevance & $\begin{array}{l}\text { Qunitessa } \\
\text { FEP } \\
\text { Category }\end{array}$ & $\begin{array}{l}\text { Individual } \\
\text { Comments }\end{array}$ & $\begin{array}{c}\text { IMCCS Project } \\
\text { Specific Information }\end{array}$ & \begin{tabular}{|c|} 
IMccs Project \\
Information Gaps \\
or Uncertainties
\end{tabular} & 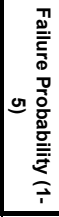 & 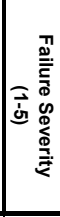 & 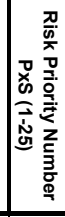 & $\begin{array}{l}\text { Risk Prevention } \\
\text { Steps (Actions } \\
\text { taken to reduce } \\
\text { risk probability) }\end{array}$ & $\begin{array}{c}\text { Risk Mitigation } \\
\text { Steps (Actions taken } \\
\text { to reduce risk } \\
\text { severity) }\end{array}$ \\
\hline 394 & 6.3.03.00. & Lifestyles & $\begin{array}{l}\text { Features related to non-diet related behavior } \\
\text { of individual humans, including time spent in } \\
\text { various environments, pursuit of activities } \\
\text { and uses of materials. This includes } \\
\text { consideration of variability of the habits of } \\
\text { individuals due to age and other factors. } \\
\text { The human habits refer to the time spent in } \\
\text { different environments in pursuit of different } \\
\text { activities and other uses of materials. The } \\
\text { diet and habits will be influenced by } \\
\text { agricultural practices and human factors } \\
\text { such as culture, religion, economics and } \\
\text { technology. }\end{array}$ & $\begin{array}{l}\text { Human habits will determine the exposure } \\
\text { pathways of interest in an assessment. Smoking, } \\
\text { plowing, fishing, and swimming are examples of } \\
\text { behavior that might give rise to particular modes } \\
\text { of exposure to CO2 and/or contaminants } \\
\text { mobilized as a result of the CO2 sequestration } \\
\text { system. }\end{array}$ & \begin{tabular}{|l} 
Quintessa \\
original FEP
\end{tabular} & $\begin{array}{l}\text { Very unlikely to be } \\
\text { an issue. }\end{array}$ & $\begin{array}{l}\text { Population is very } \\
\text { sparse at sites. } \\
\text { T-A: } 0 \text { ro residences } \\
\text { G-E: } 216 \text { residences }\end{array}$ & & 1 & 1 & 1 & $\begin{array}{l}\text { Avoid densely } \\
\text { populated areas or } \\
\text { sensitive receptor } \\
\text { areas in site } \\
\text { selection. }\end{array}$ & \begin{tabular}{|l} 
Maintain an \\
emergency response \\
plan. Train operators \\
and educate residents \\
what to do in case of a \\
CO2 leak.
\end{tabular} \\
\hline 395 & 6.3.04.00. & Land and water use & \begin{tabular}{|l|} 
FEPs related to land and water use by \\
humans in the near-surface environment and \\
the resulting implications for Co2 leakage \\
and contaminant transport and exposure \\
pathways. This includes consideration of: \\
-the use of natural or semi-natural tracts of \\
land and water such as forest, brush, rivers, \\
lakes and the sea; \\
-rural and agricultural land and water use \\
(including freshwater and marine fisheries); \\
- ruban and industrial land and water use \\
related to developments, including transport, \\
and their effects on hydrology; and \\
- leisure and other uses of environment. \\
\end{tabular} & $\begin{array}{l}\text { These FEPs can influence the potential transport } \\
\text { and exposure pathways for CO2 and its } \\
\text { associated contaminants as well as the potential } \\
\text { evolution of the system during the timescales of } \\
\text { interest. Particular considerations are relevant for } \\
\text { each type of land use addressed, for example: } \\
\text { - special foodstuffs and resources may be } \\
\text { gathered from natural land and water which may } \\
\text { lead to significant modes of exposure to CO2 or } \\
\text { contaminants; } \\
\text { - an important set of processes are those related } \\
\text { to agricultural practices, their effects on land } \\
\text { form, hydrology and natural ecology, and also } \\
\text { their impact in determining contaminant uptake } \\
\text { through food chains and other exposure paths; } \\
\text { - human populations are concentrated in urban } \\
\text { areas in modern societies. Significant areas of } \\
\text { land may be devoted to industrial activities. } \\
\text { Water resources may be diverted over } \\
\text { considerable distances to serve urban and/or } \\
\text { industrial requirements; } \\
\text { - significant areas of land, water, and coastal } \\
\text { areas may be devoted to leisure activities. e.g. } \\
\text { water bodies for recreational uses, } \\
\text { mountains willderness areas for hiking and } \\
\text { camping activities. }\end{array}$ & $\begin{array}{l}\text { Quintessa } \\
\text { original FEP }\end{array}$ & $\begin{array}{l}\text { Very unlikely to be } \\
\text { an issue. }\end{array}$ & $\begin{array}{l}\text { The sites are sparsely- } \\
\text { populated, mostly } \\
\text { grassland, mature oil } \\
\text { fields. There have } \\
\text { been no conflicts of } \\
\text { land and water use } \\
\text { over the past } 75 \text { to } 80 \\
\text { years. }\end{array}$ & & 1 & 1 & 1 & $\begin{array}{l}\text { Avoid densely } \\
\text { populated areas or } \\
\text { sensitive receptor } \\
\text { areas in site } \\
\text { selection. }\end{array}$ & \begin{tabular}{|l} 
Maintain an \\
emergency response \\
plan. Train operators \\
and educate residents \\
what to do in case of a \\
CO2 leak.
\end{tabular} \\
\hline 396 & 6.3.05.00. & $\begin{array}{c}\text { Community } \\
\text { characteristics }\end{array}$ & $\begin{array}{l}\text { Features related to characteristics, behavior } \\
\text { and lifestyle of groups of humans that might } \\
\text { be considered as target groups in an } \\
\text { assessment. } \\
\text { Relevant characteristics might be the size of } \\
\text { a group and degree of self-sufficiency in } \\
\text { food stuffs/diet. Associated with this is a } \\
\text { consideration of the amount of resources } \\
\text { required to meet the needs of the } \\
\text { community. }\end{array}$ & $\begin{array}{l}\text { This FEP involves a consideration of aggregated } \\
\text { human behavior in order to consider their } \\
\text { dependency on and interactions with their } \\
\text { environment. It therefore provides input to a } \\
\text { consideration of potential human interference } \\
\text { with the CO2 storage system as well as input to } \\
\text { considering potential exposure pathways. }\end{array}$ & \begin{tabular}{|l} 
Quintessa \\
original FEP
\end{tabular} & $\begin{array}{l}\text { Very unlikely to be } \\
\text { an issue. }\end{array}$ & $\begin{array}{l}\text { The sites are several } \\
\text { miles away from any } \\
\text { communities. }\end{array}$ & & 1 & 1 & 1 & $\begin{array}{l}\text { Avoid densely } \\
\text { populated areas or } \\
\text { sensitive receptor } \\
\text { areas in site } \\
\text { selection. }\end{array}$ & \begin{tabular}{|l|} 
Maintain an \\
emergency response \\
plan. Train operators \\
and educate residents \\
what to do in case of a \\
CO2 leak.
\end{tabular} \\
\hline
\end{tabular}

Appendix 6-72

Quintessa Original FEP: Taken from Quintessa's on-line CO2 FEP database, which is freely accessible at: http://www.quintessa.org/co2fepdb/ 


\begin{tabular}{|c|c|c|c|c|c|c|c|c|c|c|c|c|c|}
\hline \multicolumn{6}{|c|}{ CO2 Geologic Sequestration Risks for the IMCCS Project } & \multicolumn{3}{|c|}{ Project Specific Information } & \multicolumn{3}{|c|}{ Risk Ranking } & \multicolumn{2}{|c|}{ Prevention and Mitigation } \\
\hline Line \# & Index No. & Risk Area & Description & Relevance & $\begin{array}{l}\text { Qunitessa } \\
\text { FEP } \\
\text { Category }\end{array}$ & $\begin{array}{l}\text { Individual } \\
\text { Comments }\end{array}$ & $\begin{array}{c}\text { IMCCS Project } \\
\text { Specific Information }\end{array}$ & $\begin{array}{c}\text { IMCCS Project } \\
\text { Information Gaps } \\
\text { or Uncertainties }\end{array}$ & 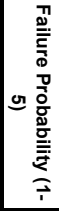 & 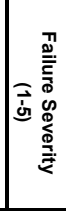 & 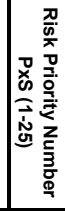 & $\begin{array}{l}\text { Risk Prevention } \\
\text { Steps (Actions } \\
\text { taken to reduce } \\
\text { risk probability) }\end{array}$ & $\begin{array}{l}\text { Risk Mitigation } \\
\text { Steps (Actions taken } \\
\text { to reduce risk } \\
\text { severity) }\end{array}$ \\
\hline 397 & 6.3.06.00. & Buildings & $\begin{array}{l}\text { Features related to houses, or other } \\
\text { structures or shelters, in which humans } \\
\text { spend time. }\end{array}$ & $\begin{array}{l}\text { The structure or materials used in building } \\
\text { construction be significant factors for determining } \\
\text { potential exposure pathways to } \mathrm{CO} 2 \text { or } \\
\text { contaminants. For example, given that } \mathrm{CO} 2 \text { is } \\
\text { denser than air, it may accumulate in the } \\
\text { basements/cellars of dwellings. }\end{array}$ & $\begin{array}{l}\text { Quintessa } \\
\text { original FEP }\end{array}$ & $\begin{array}{l}\text { Very unlikely to be } \\
\text { an issue. }\end{array}$ & $\begin{array}{l}\text { Buildings near the } \\
\text { sites tend to be mostly } \\
\text { houses, work sheds or } \\
\text { barns. }\end{array}$ & $\begin{array}{l}\text { Survey the type of } \\
\text { buildings on site. } \\
\text { Check for } \\
\text { basements. }\end{array}$ & 1 & 1 & 1 & \begin{tabular}{|l} 
Avoid densely \\
populated areas or \\
sensitive receptor \\
areas in site \\
selection. \\
Characterize the \\
buildings on site. \\
Check for \\
basements. Install \\
monitors in \\
basements.
\end{tabular} & $\begin{array}{l}\text { Maintain an } \\
\text { emergency response } \\
\text { plan. Train operators } \\
\text { and educate residents } \\
\text { what to do in case of a } \\
\text { CO2 leak. }\end{array}$ \\
\hline 398 & 7.0.00.00. & Impacts & $\begin{array}{l}\text { This category of FEPS is concerned with any } \\
\text { endpoint that could be of interest in an } \\
\text { assessment of performance and safety. The } \\
\text { classes of impact considered are: Impacts to } \\
\text { Humans; Impacts to Flora and Fauna; and } \\
\text { Impacts to the Physical Environment. Note } \\
\text { that: } \\
\text { - financial impacts are assumed to be } \\
\text { implicitly considered within each of the } \\
\text { impact FEPs; and } \\
\text { - unless stated, the FEPs refer to both CO2 } \\
\text { and mobilized contaminants (minerals, heavy } \\
\text { metals, hydrocarbons (e.g., EOR and } \\
\text { ECBM), gases). }\end{array}$ & & $\begin{array}{l}\text { Quintessa } \\
\text { original FEP }\end{array}$ & & & & NA & NA & NA & NA & NA \\
\hline 399 & 7.1.00.00. & $\begin{array}{c}\text { System } \\
\text { performance }\end{array}$ & $\begin{array}{l}\text { Performance of the sequestration system } \\
\text { from the perspective of its success at } \\
\text { preventing sequestered CO2 from reaching } \\
\text { the atmosphere. }\end{array}$ & $\begin{array}{l}\text { The fate of sequestered } \mathrm{CO} 2 \text { is a fundamental } \\
\text { endpoint for an assessment. }\end{array}$ & $\begin{array}{l}\text { Quintessa } \\
\text { original FEP }\end{array}$ & $\begin{array}{l}\text { Very unlikely to be } \\
\text { an issue. }\end{array}$ & $\begin{array}{l}\text { Sites are mature oil } \\
\text { fields that have } \\
\text { demonstrated seal } \\
\text { integrity and have } \\
\text { multiple stacked seals } \\
\text { and sinks. }\end{array}$ & $\begin{array}{l}\text { Need improved } \\
\text { methods of } \\
\text { verifying and } \\
\text { accounting for } \\
\text { cO2 stored. }\end{array}$ & 1 & 3 & 3 & $\begin{array}{l}\text { Characterize and } \\
\text { model injection sites } \\
\text { and optimize } \\
\text { reservoir } \\
\text { engineering to } \\
\text { ensure long-term } \\
\text { CO2 storage. }\end{array}$ & $\begin{array}{l}\text { Monitor site } \\
\text { performance and } \\
\text { document CO2 } \\
\text { storage. }\end{array}$ \\
\hline 400 & 7.1.01.00. & $\begin{array}{l}\text { Loss of } \\
\text { containment }\end{array}$ & $\begin{array}{l}\text { Loss of sequestered CO2 from the intended } \\
\text { storage reservoir. Loss includes both } \\
\text { consideration of loss to other parts of the } \\
\text { geosphere and to the near-surface and } \\
\text { surface environments, such as loss to } \\
\text { marine water and surface water bodies, } \\
\text { where CO2 may result in stratificication or } \\
\text { pooling. }\end{array}$ & $\begin{array}{l}\text { Loss of containment may be an endpoint of } \\
\text { interest to the assessment. For example, the } \\
\text { assessment context may dictate that near- } \\
\text { surface or surface processes are outside the } \\
\text { scope of the assessment. }\end{array}$ & $\begin{array}{l}\text { Quintessa } \\
\text { original FEP }\end{array}$ & \begin{tabular}{|l|} 
Unlikely to be an \\
issue.
\end{tabular} & $\begin{array}{l}\text { Sites are mature oil } \\
\text { fields that have } \\
\text { demonstrated seal } \\
\text { integrity and have } \\
\text { multiple stacked seals } \\
\text { and sinks. }\end{array}$ & & 2 & 4 & 8 & \begin{tabular}{|l|} 
Characterize and \\
model injection sites \\
and optimize \\
reservoir \\
engineering to \\
ensure long-term \\
CO2 storage. Keep \\
reservoir pressure \\
below the fracture \\
pressure. \\
\end{tabular} & $\begin{array}{l}\text { Monitor and model } \\
\text { CO2 plume migration. } \\
\text { Identify and plug } \\
\text { leaks. }\end{array}$ \\
\hline 401 & 7.2.00.00. & $\begin{array}{l}\text { Impacts on the } \\
\text { physical } \\
\text { environment }\end{array}$ & $\begin{array}{l}\text { FEPs relevant to adverse impacts on the } \\
\text { physical environment. Note that these may } \\
\text { be endpoints of interest in themselves, but } \\
\text { may also cause other impacts of interest. }\end{array}$ & $\begin{array}{l}\text { Adverse impacts on the environment can be } \\
\text { postulated as a result of sequestration } \\
\text { operations, even if there are no associated } \\
\text { impacts to humans or on flora and fauna. }\end{array}$ & $\begin{array}{l}\text { Quintessa } \\
\text { original FEP }\end{array}$ & $\begin{array}{l}\text { very unlikely to be } \\
\text { an issue. }\end{array}$ & \begin{tabular}{|l} 
Sites are mature oil \\
fields that have \\
demonstrated seal \\
integrity and have \\
multiple stacked seals \\
and sinks.
\end{tabular} & & 1 & 3 & 3 & $\begin{array}{l}\text { Select sites with } \\
\text { multiple stacked } \\
\text { seals and sinks. } \\
\text { Plug old wells. Avoid } \\
\text { over pressuring the } \\
\text { reservoir. }\end{array}$ & $\begin{array}{l}\text { Monitor and model } \\
\text { CO2 plume migration. } \\
\text { Identify and plug } \\
\text { leaks. }\end{array}$ \\
\hline
\end{tabular}




\begin{tabular}{|c|c|c|c|c|c|c|c|c|c|c|c|c|c|}
\hline \multicolumn{6}{|c|}{ CO2 Geologic Sequestration Risks for the IMCCS Project } & \multicolumn{3}{|c|}{ Project Specific Information } & \multicolumn{3}{|c|}{ Risk Ranking } & \multicolumn{2}{|c|}{ Prevention and Mitigation } \\
\hline Line \# & Index No. & Risk Area & Description & Relevance & $\begin{array}{l}\text { Qunitessa } \\
\text { FEP } \\
\text { Category }\end{array}$ & $\begin{array}{l}\text { Individual } \\
\text { Comments }\end{array}$ & $\begin{array}{c}\text { IMccs Project } \\
\text { Specific Information }\end{array}$ & $\begin{array}{c}\text { IMCCS Project } \\
\text { Information Gaps } \\
\text { or Uncertainties }\end{array}$ & 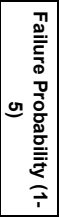 & 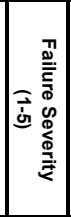 & 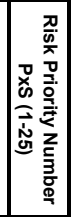 & $\begin{array}{l}\text { Risk Prevention } \\
\text { Steps (Actions } \\
\text { taken to reduce } \\
\text { risk probability) }\end{array}$ & $\begin{array}{l}\text { Risk Mitigation } \\
\text { Steps (Actions taker } \\
\text { to reduce risk } \\
\text { severity) }\end{array}$ \\
\hline 402 & 7.2.01.00. & $\begin{array}{l}\text { Contamination of } \\
\text { groundwater }\end{array}$ & $\begin{array}{l}\text { The existence of water aquifers may be } \\
\text { important if they are subject to CO2-induced } \\
\text { chemical changes or CO2-induced saline } \\
\text { intrusion. The migration of CO2 into an } \\
\text { aquifer will result in the acidification of the } \\
\text { water. Depending on the mineralogical } \\
\text { composition of the aquifer and the chemical } \\
\text { composition of the water, chemical reactions } \\
\text { may occur which release heavy metals from } \\
\text { the solid phase. The mechanisms which may } \\
\text { cause this release include dissolution of } \\
\text { metal oxides or oxyhydroxides, the } \\
\text { reaction/diagenesis of clay minerals, and the } \\
\text { desorption of metals that are adsorbed on } \\
\text { clay surfaces or organic complexes. }\end{array}$ & $\begin{array}{l}\text { Contamination of groundwater resources may } \\
\text { result in impacts on flora, fauna and//or humans if } \\
\text { the water is abstracted or flows to the surface } \\
\text { environment. These potential impacts are } \\
\text { considered in the subsequent FEP classes, } \\
\text { however, contamination of groundwater may be } \\
\text { an endpoint of interest in itself. } \\
\text { Foundations of buildings could be damaged by } \\
\text { seepage of groundwater containing CO2 in } \\
\text { shallow unconsolidated sediments and soils. This } \\
\text { could be a problems if CO2 were to be stored } \\
\text { (and leak) underneath, for example, historical city } \\
\text { centers, other heritage objects, or archeological } \\
\text { sites (CO2STORE) }\end{array}$ & \begin{tabular}{|c|} 
\\
Quintessa \\
FEP with \\
additional text \\
\end{tabular} & $\begin{array}{l}\text { Very unlikely to be } \\
\text { an issue. }\end{array}$ & \begin{tabular}{|l|} 
Sites are mature oil \\
fields that have \\
demonstrated seal \\
integrity and have \\
multiple stacked seals \\
and sinks separating \\
them from \\
groundwater.
\end{tabular} & $\begin{array}{l}\begin{array}{l}\text { Conduct baseline } \\
\text { survey of } \\
\text { groundwater. }\end{array} \\
\end{array}$ & 1 & 3 & 3 & \begin{tabular}{|l|} 
Select sites with \\
multiple stacked \\
seals and sinks. \\
Plug old wells. Avoid \\
over pressuring the \\
reservoir.
\end{tabular} & $\begin{array}{l}\text { Monitor and model } \\
\text { CO2 plume migration } \\
\text { and groundwater } \\
\text { quality. Identify and } \\
\text { plug leaks. }\end{array}$ \\
\hline 403 & 7.2.01.01. & $\begin{array}{l}\text { Contamination of } \\
\text { underground } \\
\text { drinking water } \\
\text { sources }\end{array}$ & $\begin{array}{l}\text { Fresh, potable, groundwater, located in the } \\
100-200 \mathrm{~m} \text { of the subsurface, could be } \\
\text { contaminated by leakage of CO2. Even } \\
\text { small CO2 leaks may possibly cause } \\
\text { significant deterioration in the quality of } \\
\text { potable groundwater. }\end{array}$ & $\begin{array}{l}\text { An increase in } \mathrm{CO} 2 \text { concentration might cause a } \\
\text { decrease in } \mathrm{pH} \text { to a level of } 4-5 \text {, which might } \\
\text { cause calcium dissolution, increase in the } \\
\text { hardness of water and alteration of minerals from } \\
\text { minerals from rocks and soils that could release } \\
\text { elements such as heavy metals into the water } \\
\text { supply. }\end{array}$ & $\begin{array}{l}\text { Additional } \\
\text { [new] FEP }\end{array}$ & $\begin{array}{l}\text { Very unlikely to be } \\
\text { an issue. }\end{array}$ & $\begin{array}{l}\text { There are no public or } \\
\text { private water wells at } \\
\text { the sites. }\end{array}$ & $\begin{array}{l}\text { Conduct baseline } \\
\text { survey of } \\
\text { groundwater. }\end{array}$ & 1 & 3 & 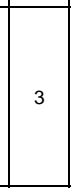 & $\begin{array}{l}\text { Select sites with } \\
\text { multiple stacked } \\
\text { seals and sinks. } \\
\text { Plug old wells. Avoid } \\
\text { over pressuring the } \\
\text { reservoir. }\end{array}$ & $\begin{array}{l}\text { Monitor and model } \\
\text { CO2 plume migration } \\
\text { and groundwater } \\
\text { quality. Identify and } \\
\text { plug leaks. }\end{array}$ \\
\hline 404 & 7.2.01.02. & $\begin{array}{l}\text { Contamination of } \\
\text { surface waters }\end{array}$ & $\begin{array}{l}\text { Surface water could be contaminated by } \\
\text { CO2 leakage, which could affect aquatic } \\
\text { ecosystems by decreasing pH, especially in } \\
\text { stagnant or stratified waters (Damen 2006) }\end{array}$ & & $\begin{array}{l}\text { Additional } \\
\text { [new] FEP }\end{array}$ & $\begin{array}{l}\text { Very unlikely to be } \\
\text { an issue. }\end{array}$ & $\begin{array}{l}\text { There are only a few } \\
\text { small ponds at or near } \\
\text { the sites. }\end{array}$ & $\begin{array}{l}\text { Conduct baseline } \\
\text { survey of surface } \\
\text { water. }\end{array}$ & 1 & 3 & 3 & $\begin{array}{l}\text { Characterize surface } \\
\text { water and } \\
\text { groundwater aquifer. } \\
\text { Monitor third-party } \\
\text { activity in the area. }\end{array}$ & $\begin{array}{l}\text { Monitor and model } \\
\text { CO2 plume migration } \\
\text { and surface water } \\
\text { quality. Identify and } \\
\text { plug leaks. }\end{array}$ \\
\hline 405 & 7.2.01.03. & $\begin{array}{l}\text { Contamination of } \\
\text { groundwater by } \\
\text { displaced brine }\end{array}$ & $\begin{array}{l}\text { The injection of } \mathrm{CO} 2 \text { in aquifers might cause } \\
\text { displacement of saline groundwater (brine). }\end{array}$ & \begin{tabular}{|l} 
Displaced brine may cause undesirable effects \\
such as a rise of the water table (which could \\
have negative impact on land quality and use) \\
and an increase in salinity of sweet water \\
reservoirs used for drinking water extraction and \\
irrigation (Damen 2006)
\end{tabular} & \begin{tabular}{|l} 
Additional \\
[new] FEP
\end{tabular} & $\begin{array}{l}\text { Very unlikely to be } \\
\text { an issue. }\end{array}$ & \begin{tabular}{|l|} 
Available data \\
indicates the saline \\
aquifers and fresh \\
water aquifers are not \\
connected locally.
\end{tabular} & $\begin{array}{l}\text { Conduct baseline } \\
\text { survey of } \\
\text { groundwater. }\end{array}$ & 1 & 3 & 3 & $\begin{array}{l}\text { Characterize saline } \\
\text { aquifer for contact } \\
\text { with groundwater. }\end{array}$ & $\begin{array}{l}\text { Monitor and model } \\
\text { groundwater salinity. } \\
\text { Identify and plug } \\
\text { leaks. }\end{array}$ \\
\hline 406 & 7.2.02.00. & $\begin{array}{l}\text { Impacts on soils } \\
\text { and sediments }\end{array}$ & 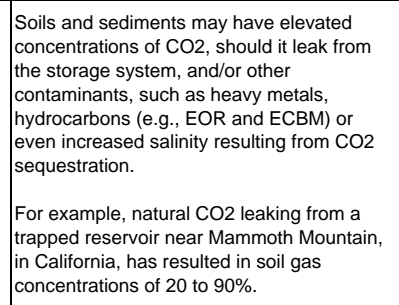 & $\begin{array}{l}\text { Increased } \mathrm{CO} 2 \text { concentrations and/or } \\
\text { contamination of soils and sediments with } \\
\text { associated substances may be sufficient to } \\
\text { modify the ecology and/or use of the impacted } \\
\text { area by humans. }\end{array}$ & $\begin{array}{l}\text { Quintessa } \\
\text { original FEP }\end{array}$ & $\begin{array}{l}\text { Very unlikely to be } \\
\text { an issue. }\end{array}$ & \begin{tabular}{|l|} 
Sites are mature oil \\
fields that have \\
demonstrated seal \\
integrity and have \\
multiple stacked seals \\
and sinks.
\end{tabular} & $\begin{array}{l}\text { Conduct baseline } \\
\text { survey of soil. }\end{array}$ & 1 & 1 & 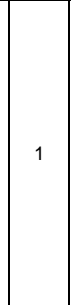 & \begin{tabular}{|l|} 
Characterize soil. \\
Select sites with \\
multiple stacked \\
seals and sinks. \\
Plug old wells. Avoid \\
over pressuring the \\
reservoir.
\end{tabular} & $\begin{array}{l}\text { Monitor and model } \\
\text { CO2 plume migration } \\
\text { and soil CO2 content. } \\
\text { ldentify and plug } \\
\text { leaks. }\end{array}$ \\
\hline 407 & 7.2.02.01. & $\begin{array}{c}\text { Contamination of } \\
\text { soil }\end{array}$ & & & \begin{tabular}{|} 
Additional \\
[new] FEP
\end{tabular} & $\begin{array}{l}\text { Very unlikely to be } \\
\text { an issue. }\end{array}$ & $\begin{array}{l}\text { Sites are mature oil } \\
\text { fields that have } \\
\text { demonstrated seal } \\
\text { integrity and have } \\
\text { multiple stacked seals } \\
\text { and sinks. }\end{array}$ & & 1 & 2 & 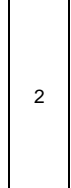 & \begin{tabular}{|l|} 
Characterize soil. \\
Select sites with \\
multiple stacked \\
seals and sinks. \\
Plug old wells. Avoid \\
over pressuring the \\
reservoir.
\end{tabular} & $\begin{array}{l}\text { Monitor and model } \\
\text { CO2 plume migration } \\
\text { and soil CO2 content. } \\
\text { ldentify and plug } \\
\text { leaks. }\end{array}$ \\
\hline
\end{tabular}

Appendix 6-74

Quintessa Original FEP: Taken from Quintessa's on-line CO2 FEP database, which is freely accessible at: http://www.quintessa.org/co2fepdb/ 


\begin{tabular}{|c|c|c|c|c|c|c|c|c|c|c|c|c|c|}
\hline \multicolumn{6}{|c|}{ CO2 Geologic Sequestration Risks for the IMCCS Project } & \multicolumn{3}{|c|}{ Project Specific Information } & \multicolumn{3}{|c|}{ Risk Ranking } & \multicolumn{2}{|c|}{ Prevention and Mitigation } \\
\hline Line \# & Index No. & Risk Area & Description & Relevance & $\begin{array}{c}\text { Qunitessa } \\
\text { FEP } \\
\text { Category }\end{array}$ & $\begin{array}{l}\text { Individual } \\
\text { Comments }\end{array}$ & $\begin{array}{c}\text { IMCcS Project } \\
\text { Specific Information }\end{array}$ & $\begin{array}{c}\text { IMCCS Project } \\
\text { Information Gaps } \\
\text { or Uncertainties }\end{array}$ & 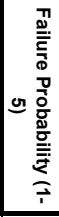 & 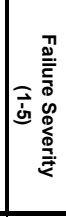 & 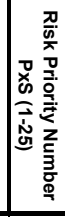 & $\begin{array}{l}\text { Risk Prevention } \\
\text { Steps (Actions } \\
\text { taken to reducee } \\
\text { risk probability) }\end{array}$ & $\begin{array}{c}\text { Risk Mitigation } \\
\text { Steps (Actions taken } \\
\text { to reduce risk } \\
\text { severity) }\end{array}$ \\
\hline 408 & 7.2.03.00. & $\begin{array}{l}\text { Release to the } \\
\text { atmosphere }\end{array}$ & $\begin{array}{l}\text { Release of } \mathrm{CO} 2 \text { to the atmosphere from the } \\
\text { storage system or other contaminants, such } \\
\text { as radon or methane, mobilized as a result } \\
\text { of the sequestration. }\end{array}$ & $\begin{array}{l}\text { Release of sequestered } \mathrm{CO} 2 \text { or mobilized } \\
\text { methane to the atmosphere will reduce the } \\
\text { effectiveness of the storage system at preventing } \\
\text { greenhouse gases from being emitted to the } \\
\text { atmosphere. } \\
\text { Atmospheric contamination could also lead to } \\
\text { health impacts on humans and wildlife. } \\
\text { Rapid release likely to effectively disperse the } \\
\text { CO2 higher in the atmosphere. } \\
\text { Moderate release likely to concentrated CO2 } \\
\text { near the ground, representing the highest risk. } \\
\text { Slow release likely to disperse } \mathrm{CO} 2 \text { in the soil } \\
\text { and atmosphere. }\end{array}$ & \begin{tabular}{|c|} 
\\
Quintessa \\
FEP with \\
additional text \\
\end{tabular} & $\begin{array}{l}\text { Unlikely to be an } \\
\text { issue. }\end{array}$ & \begin{tabular}{|l|} 
Sites are mature oil \\
fields that have \\
demonstrated seal \\
integrity and have \\
multiple stacked seals \\
and sinss. Sites are \\
relatively flat and \\
exposed to wind to \\
help disperse any CO2 \\
leaks.
\end{tabular} & $\begin{array}{l}\text { Conduct baseline } \\
\text { survey of } \\
\text { atmospheric } \mathrm{CO} 2 \\
\text { at the sites, }\end{array}$ & 2 & 4 & 8 & $\begin{array}{l}\text { Characterize the } \\
\text { site. Select sites with } \\
\text { multiple stacked } \\
\text { seals and sinks. } \\
\text { Plug old wells. Avoid } \\
\text { over pressuring the } \\
\text { reservoir. }\end{array}$ & $\begin{array}{l}\text { Monitor atmospheric } \\
\text { CO2 at the sites. } \\
\text { Identify any } \\
\text { irregularities in CO2 } \\
\text { content. Determine } \\
\text { root cause. Model } \\
\text { CO2 dispersion in air. } \\
\text { Locate and plug any } \\
\text { leaks. Train operators } \\
\text { and educate residents } \\
\text { on what to do if a CO2 } \\
\text { leak occurs. }\end{array}$ \\
\hline 409 & 7.2.04.00. & $\begin{array}{c}\text { Impacts on } \\
\text { exploitation of } \\
\text { natural resources }\end{array}$ & \begin{tabular}{|l} 
The impact of CO2 sequestration on the \\
exploitation of natural resources such as oil \\
and gas. \\
Enhanced oil recovery (EOR) and enhanced \\
coal bed methane (ECBM) recovery projects \\
involving the injection of CO2 are based on \\
improved recovery of oil and methane \\
respectively resulting from CO22 \\
sequestration. However, CO2 sequestration \\
may result in the contamination of geological \\
resources (such as hydrocarbons and \\
minerals) or inhibit their recovery or future \\
exploitation. \\
Note that the potential impact on \\
groundwater resources is considered in \\
Impacts on groundwater.
\end{tabular} & $\begin{array}{l}\text { Impacts on the exploitation of natural resources } \\
\text { can be positive (such EOR and ECBM) and/or } \\
\text { negative (such as inhibited recovery). These may } \\
\text { result in other (for example, financial) impacts, or } \\
\text { may be endpoints of interest in themselves. }\end{array}$ & $\begin{array}{l}\text { Quintessa } \\
\text { original FEP }\end{array}$ & $\begin{array}{l}\text { Very unlikely to be } \\
\text { an issue. }\end{array}$ & $\begin{array}{l}\text { No known mineral } \\
\text { resources other than } \\
\text { oil at sites. }\end{array}$ & & 1 & 2 & 2 & NA & NA \\
\hline 410 & 7.2.04.01. & $\begin{array}{l}\text { Contamination of } \\
\text { mineral resources }\end{array}$ & & & \begin{tabular}{|l} 
Additional \\
[new] FEP
\end{tabular} & \begin{tabular}{|l|} 
Very unlikely to be \\
an issue.
\end{tabular} & $\begin{array}{l}\text { No known mineral } \\
\text { resources other than } \\
\text { oil at sites. }\end{array}$ & & 1 & 2 & 2 & NA & NA \\
\hline 411 & 7.2.04.02. & $\begin{array}{c}\text { Contamination of } \\
\text { mineable coal } \\
\text { seams }\end{array}$ & & & \begin{tabular}{|l} 
Additional \\
[new] FEP
\end{tabular} & $\begin{array}{l}\text { Very unlikely to be } \\
\text { an issue. }\end{array}$ & $\begin{array}{l}\text { e } \begin{array}{l}\text { No mineable coal } \\
\text { seams in the area }\end{array} \\
\end{array}$ & & 1 & 2 & 2 & NA & NA \\
\hline 412 & 7.2.04.03. & $\begin{array}{c}\text { Contamination of oil } \\
\text { resources }\end{array}$ & & & \begin{tabular}{|l} 
Additional \\
[new] FEP
\end{tabular} & \begin{tabular}{|l|} 
Unlikely to be an \\
issue.
\end{tabular} & $\begin{array}{l}\text { G-E and T-A oil } \\
\text { reservoirs are isolated } \\
\text { from other oil } \\
\text { reservoirs in the area. }\end{array}$ & & 2 & 2 & 4 & \begin{tabular}{|l} 
Obtain leaseholds \\
for the entire \\
isolated reservoir for \\
EOR. Avoid \\
exceeding the spill \\
point
\end{tabular} & $\begin{array}{l}\text { Monitor and model } \\
\mathrm{CO} 2 \text { plume. Adjust } \\
\text { injection strategy if } \\
\text { necessary. }\end{array}$ \\
\hline 413 & 7.2.04.04. & $\begin{array}{l}\text { Contamination of } \\
\text { natural gas } \\
\text { resources }\end{array}$ & & & \begin{tabular}{|l}
$\begin{array}{l}\text { Additional } \\
\text { [new] FEP }\end{array}$ \\
E
\end{tabular} & $\begin{array}{l}\text { Very unlikely to be } \\
\text { an issue. }\end{array}$ & $\begin{array}{l}\text { There is very little } \\
\text { underground drinking } \\
\text { water in the G-E and T } \\
\text { A. There are no public } \\
\text { or private water wells } \\
\text { in the areas. }\end{array}$ & & 1 & 2 & 2 & NA & NA \\
\hline 414 & 7.2.04.05. & $\begin{array}{l}\text { Contamination of } \\
\text { geothermal } \\
\text { resources }\end{array}$ & & & \begin{tabular}{|l} 
Additional \\
[new] FEP
\end{tabular} & $\begin{array}{l}\text { Very unlikely to be } \\
\text { an issue. }\end{array}$ & \begin{tabular}{|l} 
e lhere are no \\
geothermal resources \\
in the area.
\end{tabular} & & 1 & 2 & 2 & $\begin{array}{l}\text { Maintain a buffer } \\
\text { around the project } \\
\text { area and CO2 } \\
\text { plume. }\end{array}$ & $\begin{array}{l}\text { Monitor legislation on } \\
\text { pore space ownership. }\end{array}$ \\
\hline
\end{tabular}

Quintessa Original FEP: Taken from Quintessa's on-line CO2 FEP database, which is freely accessible at: http://www.quintessa.org/co2fepdb/ 


\begin{tabular}{|c|c|c|c|c|c|c|c|c|c|c|c|c|c|}
\hline \multicolumn{6}{|c|}{ CO2 Geologic Sequestration Risks for the IMCCS Project } & \multicolumn{3}{|c|}{ Project Specific Information } & \multicolumn{3}{|c|}{ Risk Ranking } & \multicolumn{2}{|c|}{ Prevention and Mitigation } \\
\hline Line \# & Index No. & Risk Area & Description & Relevance & $\begin{array}{l}\text { Qunitessa } \\
\text { FEP } \\
\text { Category }\end{array}$ & $\begin{array}{l}\text { Individual } \\
\text { Comments }\end{array}$ & $\begin{array}{c}\text { IMCCS Project } \\
\text { Specific Information }\end{array}$ & $\begin{array}{c}\text { IMccs Project } \\
\text { Information Gaps } \\
\text { or Uncertainties }\end{array}$ & 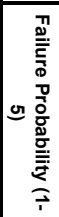 & 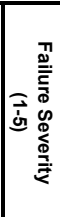 & 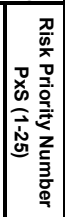 & $\begin{array}{l}\text { Risk Prevention } \\
\text { Steps (Actions } \\
\text { taken to reduce } \\
\text { risk probability) }\end{array}$ & $\begin{array}{l}\text { Risk Mitigation } \\
\text { Steps (Actions taken } \\
\text { to reduce risk } \\
\text { severity) }\end{array}$ \\
\hline 415 & 7.2.04.06. & $\begin{array}{c}\text { Contamination of } \\
\text { pore space owned } \\
\text { by others }\end{array}$ & & $\begin{array}{l}\text { CO2 could migrate into pore space owned by } \\
\text { others resulting in trespassing. }\end{array}$ & \begin{tabular}{|l} 
Additional \\
[new] FEP
\end{tabular} & Possible issue. & \begin{tabular}{|l|} 
Kansas does not have \\
any regulations on \\
pore space ownership. \\
Arbuckle has been \\
widely used for \\
disposal by others. \\
EOR sites are \\
isolated. \\
\end{tabular} & & 3 & 2 & 6 & $\begin{array}{l}\text { Maintain a buffer } \\
\text { around the project } \\
\text { area and CO2 } \\
\text { plume. }\end{array}$ & $\begin{array}{l}\text { Monitor legislation on } \\
\text { pore space ownership }\end{array}$ \\
\hline 416 & 7.2.05.00. & $\begin{array}{l}\text { Modified hydrology } \\
\text { and hydrogeology }\end{array}$ & $\begin{array}{l}\text { The injection of CO2 may result in } \\
\text { modifications to both the deep hydrogeology } \\
\text { and near-surface hydrology. }\end{array}$ & $\begin{array}{l}\text { Changes in the deep hydrogeology or near- } \\
\text { surface hydrology may affect aquifer abstraction } \\
\text { or even surface hydrology for groundwater driven } \\
\text { features. These impacts may be either positive or } \\
\text { negative. }\end{array}$ & $\begin{array}{l}\text { Quintessa } \\
\text { original FEP }\end{array}$ & $\begin{array}{l}\text { Unlikely for CO2 } \\
\text { injection at these } \\
\text { sites to modify } \\
\text { both deep and } \\
\text { near-surface } \\
\text { hydrology except } \\
\text { through leaks in } \\
\text { old boreholes. }\end{array}$ & $\begin{array}{l}\text { Near-surfaced and } \\
\text { deep aquifers } \\
\text { separated by multiple } \\
\text { stacked seals and } \\
\text { sinks. }\end{array}$ & & 2 & 2 & 4 & $\begin{array}{l}\text { Characterized and } \\
\text { model stratigraphy } \\
\text { and hydrology of } \\
\text { sites. Plug old } \\
\text { boreholes. }\end{array}$ & $\begin{array}{l}\text { Monitor and model } \\
\text { Co2 migration and } \\
\text { near-surface water } \\
\text { chemistry. Identify } \\
\text { irregularities. } \\
\text { Determine root cause. } \\
\text { Locate and plug leaks. } \\
\text { Extract CO2 from } \\
\text { leaky sinks and } \\
\text { reinject into sealed } \\
\text { sinks of necessary. }\end{array}$ \\
\hline 417 & 7.2.06.00. & $\begin{array}{l}\text { Modified } \\
\text { geochemistry }\end{array}$ & $\begin{array}{l}\text { The injection of } \mathrm{CO} 2 \text { will modify the } \\
\text { geochemistryy of the sequestration system. } \\
\text { This may be confined to the immediate } \\
\text { vicinity of the storage location, or, through } \\
\text { leakage from the reservoir, may affect other } \\
\text { locations. }\end{array}$ & $\begin{array}{l}\text { The extent of geochemical modifications may be } \\
\text { an endpoint of interest, due to resulting changes } \\
\text { to geological processes. For example, the } \\
\text { acidification of the geochemical regime may } \\
\text { cause minerals to be dissolved, with potential } \\
\text { implications for the porosity and stability of the } \\
\text { geological formations. }\end{array}$ & $\begin{array}{l}\text { Quintessa } \\
\text { original FEP }\end{array}$ & $\begin{array}{l}\text { Unlikely to be an } \\
\text { issue. }\end{array}$ & $\begin{array}{l}\text { CO2 may react with } \\
\text { Arbuckle dolomite. }\end{array}$ & & 2 & 2 & 4 & $\begin{array}{l}\text { Characterize and } \\
\text { model the an } \\
\text { geochemistry of } \\
\text { sites. }\end{array}$ & \begin{tabular}{|l} 
Monitor and model \\
CO2 migration and \\
near-surface water \\
chemistry. Identify \\
irregularities. \\
Determine root cause. \\
Locate and plug leaks. \\
Extract CO2 from \\
leaky sinks and \\
reinject into sealed \\
sinks of necessary.
\end{tabular} \\
\hline 418 & 7.2.07.00. & Modified seismicity & $\begin{array}{l}\text { Injection of supercritical } \mathrm{CO} 2 \text { into a } \\
\text { geological formation may induce seismic } \\
\text { events and processes. }\end{array}$ & \begin{tabular}{|l|} 
Induced seismicity may be an endpoint of interest \\
in itself, or it can result in other impacts, such as \\
physical disruption of the surface environment.
\end{tabular} & $\begin{array}{l}\text { Quintessa } \\
\text { original FEP }\end{array}$ & $\begin{array}{l}\text { Unlikely to be an } \\
\text { issue. }\end{array}$ & $\begin{array}{l}\text { T-A Bartlesville } \\
\text { Sandstone has } \\
\text { demonstrated } \\
\text { operation at } 1700 \text { psig } \\
\text { with water flooding. } \\
\text { The CO2 EOR will } \\
\text { operate below what. } \\
\text { The G-E can't be } \\
\text { pressurized. Volume } \\
\text { increase from CO2 } \\
\text { injection will be } \\
\text { compensated for by } \\
\text { water/oil production in } \\
\text { EOR. }\end{array}$ & & 2 & 3 & 6 & \begin{tabular}{|l|} 
\\
Operate below $80 \%$ \\
of fracture pressure. \\
Volume increase \\
from CO2 injection \\
will be compensated \\
for by water/oil \\
production in EOR.
\end{tabular} & $\begin{array}{l}\text { Operate below } 80 \% \text { of } \\
\text { fracture pressure. } \\
\text { Monitor injection } \\
\text { pressure, tiltmeter and } \\
\text { micro-seismicity. } \\
\text { Volume increase from } \\
\text { CO2 injection will be } \\
\text { compensated for by } \\
\text { waterloil production in } \\
\text { EOR. }\end{array}$ \\
\hline
\end{tabular}

Appendix 6-76

Quintessa Original FEP: Taken from Quintessa's on-line CO2 FEP database, which is freely accessible at: http://www.quintessa.org/co2fepdb/ 


\begin{tabular}{|c|c|c|c|c|c|c|c|c|c|c|c|c|c|}
\hline \multicolumn{6}{|c|}{ CO2 Geologic Sequestration Risks for the IMCCS Project } & \multicolumn{3}{|c|}{ Project Specific Information } & \multicolumn{3}{|c|}{ Risk Ranking } & \multicolumn{2}{|c|}{ Prevention and Mitigation } \\
\hline Line \# & Index No. & Risk Area & Description & Relevance & $\begin{array}{l}\text { Qunitessa } \\
\text { FEP } \\
\text { Category }\end{array}$ & $\begin{array}{l}\text { Individual } \\
\text { Comments }\end{array}$ & $\begin{array}{c}\text { IMCCS Project } \\
\text { Specific Information }\end{array}$ & $\begin{array}{c}\text { IMccs Project } \\
\text { Information Gaps } \\
\text { or Uncertainties }\end{array}$ & 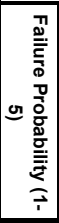 & 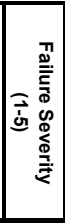 & 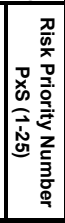 & $\begin{array}{l}\text { Risk Prevention } \\
\text { Steps (Actions } \\
\text { taken to reduce } \\
\text { risk probability) }\end{array}$ & $\begin{array}{l}\text { Risk Mitigation } \\
\text { Steps (Actions taker } \\
\text { to reduce risk } \\
\text { severity) }\end{array}$ \\
\hline 419 & 7.2.08.00. & $\begin{array}{l}\text { Modified surface } \\
\text { topography }\end{array}$ & $\begin{array}{l}\text { The gradual or sudden sinking (subsidence) } \\
\text { or elevation (uplift) of the topography of the } \\
\text { terrestrial surface or marine sea-bed. }\end{array}$ & $\begin{array}{l}\text { Deformation of the terrestrial surface or sea-bed } \\
\text { may be an endpoint of interest in itself, or may } \\
\text { result in other impacts, such as damage to } \\
\text { property. }\end{array}$ & $\begin{array}{l}\text { Quintessa } \\
\text { original FEP }\end{array}$ & \begin{tabular}{|l|} 
Unlikely to be an \\
issue.
\end{tabular} & \begin{tabular}{|l|} 
T-A Bartlesville \\
Sandstone has \\
demonstrated \\
operation at 1700 psig \\
with water flooding. \\
The CO2 EOR will \\
operate below that. \\
The G-E can't be \\
pressurized. Volume \\
increase from CO2 \\
injection will be \\
compensated for by \\
waterloil production in \\
EOR.
\end{tabular} & & 2 & 3 & 6 & $\begin{array}{l}\text { Characterize seals } \\
\text { and sinks and model } \\
\text { CO2 injection. }\end{array}$ & $\begin{array}{l}\text { Monitor surface } \\
\text { change with tiltmeters } \\
\text { Compare with model. } \\
\text { Identify any } \\
\text { irregularities and take } \\
\text { corrective action if } \\
\text { necessary. }\end{array}$ \\
\hline 420 & 7.2.08.01. & Sinkhole formation & $\begin{array}{l}\text { Addition of } \mathrm{CO} 2 \text { in a limestone or carbonate- } \\
\text { rich aquifer could result in dissolution of the } \\
\text { rock matrix and the enlargement of voids. If } \\
\text { this process takes place at relatively shallow } \\
\text { depth collapse may result in subsidence at } \\
\text { the surface and sinkhole formation. } \\
\text { For example, CO2 leakage around a } \\
\text { borehole drilled to extract natural } \mathrm{CO} 2 \text { from } \\
\text { a reservoir in Florina, Greece, resulted in } \\
\text { subsidence around the borehole that filled up } \\
\text { with water. }\end{array}$ & $\begin{array}{l}\text { Large scale collapse structures may cause } \\
\text { significant change to surface topography and } \\
\text { possible CO2 migration paths. Sinkholes can } \\
\text { provide locatitons where leaking CO2 can } \\
\text { accumulate. }\end{array}$ & \begin{tabular}{|l} 
Quintessa \\
original FEP
\end{tabular} & $\begin{array}{l}\text { Unlikely to be an } \\
\text { issue due to the } \\
\text { limited amount of } \\
\text { CO2 injected at } \\
\text { the sites and } \\
\text { depth of injection }\end{array}$ & $\begin{array}{l}\text { CO2 may react with } \\
\text { Arbuckle dolomite. } \\
\text { The injection depth in } \\
\text { the Arbuckle is } 2900 \text { to } \\
3800 \mathrm{ft} .\end{array}$ & & 2 & 3 & 6 & $\begin{array}{l}\text { Characterize seals } \\
\text { and sinks and model } \\
\text { CO2 injection in } \\
\text { Arbuckle. } \\
\end{array}$ & $\begin{array}{l}\text { Monitor surface } \\
\text { change with tiltmeters } \\
\text { Monitor subsurface } \\
\text { change with } 3 \mathrm{~d} \\
\text { seismic and/or VSP. } \\
\text { Compare with model. } \\
\text { Identify any } \\
\text { irregularities and take } \\
\text { corrective action if } \\
\text { necessary. }\end{array}$ \\
\hline 421 & 7.3.00.00. & $\begin{array}{l}\text { Impacts on flora } \\
\text { and fauna }\end{array}$ & FEPs relevant to impacts on flora and fauna. & $\begin{array}{l}\text { Impacts on flora and fauna can be postulated as } \\
\text { a result of sequestration operations, even if there } \\
\text { are no associated impacts to humans. }\end{array}$ & $\begin{array}{l}\text { Quintessa } \\
\text { original FEP }\end{array}$ & \begin{tabular}{|l} 
Very unlikely to be \\
an issue.
\end{tabular} & $\begin{array}{l}\text { The sites are primarily } \\
\text { grass lands with very } \\
\text { little flora or fauna. }\end{array}$ & & 1 & 1 & 1 & $\begin{array}{l}\text { Characterize the } \\
\text { flora and fauna on } \\
\text { sites. }\end{array}$ & $\begin{array}{l}\text { Monitor flora and } \\
\text { fauna for unexplained } \\
\text { dead zones. } \\
\text { Determine root cause } \\
\text { Check CO2 content in } \\
\text { the area. Locate and } \\
\text { plug leaks if any. }\end{array}$ \\
\hline
\end{tabular}




\begin{tabular}{|c|c|c|c|c|c|c|c|c|c|c|c|c|c|}
\hline \multicolumn{6}{|c|}{ CO2 Geologic Sequestration Risks for the IMCCS Project } & \multicolumn{3}{|c|}{ Project Specific Information } & \multicolumn{3}{|c|}{ Risk Ranking } & \multicolumn{2}{|c|}{ Prevention and Mitigation } \\
\hline Line \# & Index No. & Risk Area & Description & Relevance & $\begin{array}{l}\text { Qunitessa } \\
\text { FEP } \\
\text { Category }\end{array}$ & $\begin{array}{l}\text { Individual } \\
\text { Comments }\end{array}$ & $\begin{array}{c}\text { IMccs Project } \\
\text { Specific Information }\end{array}$ & \begin{tabular}{|c} 
IMCCS Project \\
Information Gaps \\
or Uncertainties
\end{tabular} & 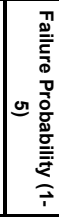 & 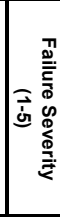 & 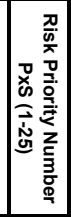 & $\begin{array}{l}\text { Risk Prevention } \\
\text { Steps (Actions } \\
\text { taken to reduce } \\
\text { risk probability) }\end{array}$ & $\begin{array}{c}\text { Risk Mitigation } \\
\text { Steps (Actions taker } \\
\text { to reduce risk } \\
\text { severity) }\end{array}$ \\
\hline 422 & 7.3.01.00. & Asphyxiation effects & \begin{tabular}{|l} 
Asphyxiation effects of CO2 on terrestrial \\
and aquatic fauna. \\
Oxygen is an essential requirement for \\
respiration in animals and is therefore \\
needed to sustain life. High concentrations \\
of CO2 in air or water will lead to suffocation \\
of terrestrial and aquatic animalas due to a \\
lack of oxygen reaching the blood stream. \\
If meteorological conditions do not disperse \\
CO2 released to the atmosphere, it can \\
gather close to the surface and remain in \\
depressions, such as natural hollows. This \\
property allows CO2 to reach high \\
soncentrations if released in sufficient \\
quantities under particular atmospheric \\
conditions. \\
$\begin{array}{l}\text { The } 1986 \text { Lake Nyos disaster in Cameroon } \\
\text { provides a graphic example of the potential } \\
\text { effects of high atmospheric concentrations of } \\
\text { cO2. A large limnic eruption resulted in the } \\
\text { death of wildlife and approximately } 1800 \\
\text { people in the surrounding area and up to } 27 \\
\text { km away. } \\
\text { In a similar way to gaseous co2 being } \\
\text { denser than air, water containing high } \\
\text { concentrations of dissolved CO2 is denser } \\
\text { than pure water, a factor that contributes to } \\
\text { the limnic eruption phenomenon observed at }\end{array}$ \\
\end{tabular} & \begin{tabular}{|l} 
\\
Levels of CO2 from a sequestration project \\
sufficient to cause asphyxiation of fauna would \\
be an endpoint of concern in assessing the \\
geological sequestration of CO2.
\end{tabular} & \begin{tabular}{|l} 
Quintessa \\
original FEP
\end{tabular} & $\begin{array}{l}\text { Very unlikely to be } \\
\text { an issue. }\end{array}$ & $\begin{array}{l}\text { Population is very } \\
\text { sparse at sites. } \\
\text { T-A: no residences } \\
\text { G-E: } 216 \text { residences }\end{array}$ & & 1 & 5 & 5 & \begin{tabular}{|l} 
Avoid densely \\
populated areas. \\
Train operators and \\
educate residents \\
what to do in case of \\
a CO2 leak.
\end{tabular} & $\begin{array}{l}\text { Maintain an } \\
\text { emergency response } \\
\text { plan. Train operators } \\
\text { and educate residents } \\
\text { what to do in case of a } \\
\text { CO2 leak. }\end{array}$ \\
\hline 423 & 7.3.02.00. & 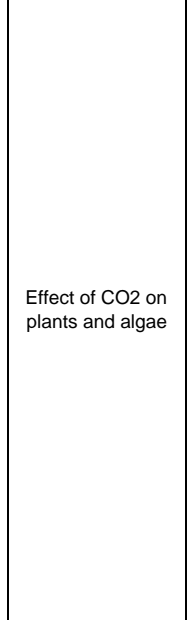 & 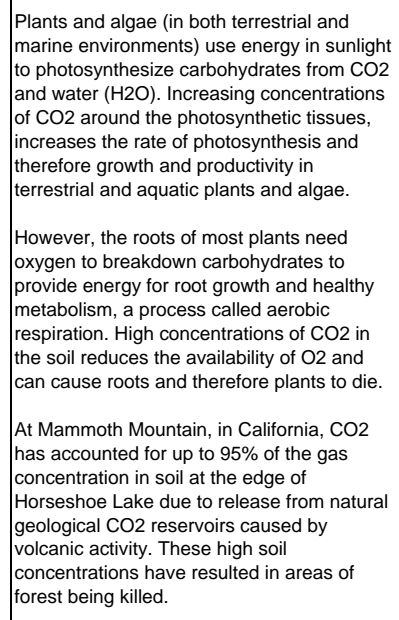 & $\begin{array}{l}\text { Concentrations of } \mathrm{CO} 2 \text { in the soil, atmosphere } \\
\text { and/or water sufficient to impact on the growth of } \\
\text { plants and algae would be an endpoint of interest } \\
\text { in assessing the geological sequestration of } \\
\text { CO2. }\end{array}$ & $\begin{array}{c}\text { Quintessa } \\
\text { original FEP }\end{array}$ & $\begin{array}{l}\text { Very unlikely to be } \\
\text { an issue. }\end{array}$ & $\begin{array}{l}\text { The sites are primarily } \\
\text { grass lands with very } \\
\text { little plants and algae. }\end{array}$ & & 1 & 1 & 1 & $\begin{array}{l}\text { Characterize the } \\
\text { plants and algae on } \\
\text { sites. }\end{array}$ & $\begin{array}{l}\text { Monitor plants and } \\
\text { algae for unexplained } \\
\text { dead zones. } \\
\text { Determine root cause } \\
\text { Check CO2 content in } \\
\text { the area. Locate and } \\
\text { plug leaks if any. }\end{array}$ \\
\hline
\end{tabular}

Appendix 6-78

Quintessa Original FEP: Taken from Quintessa's on-line CO2 FEP database, which is freely accessible at: http://www.quintessa.org/co2fepdb/ 


\begin{tabular}{|c|c|c|c|c|c|c|c|c|c|c|c|c|c|}
\hline \multicolumn{6}{|c|}{ CO2 Geologic Sequestration Risks for the IMCCS Project } & \multicolumn{3}{|c|}{ Project Specific Information } & \multicolumn{3}{|c|}{ Risk Ranking } & \multicolumn{2}{|c|}{ Prevention and Mitigation } \\
\hline Line \# & Index No. & Risk Area & Description & Relevance & $\begin{array}{c}\text { Qunitessa } \\
\text { FEP } \\
\text { Category }\end{array}$ & $\begin{array}{l}\text { Individual } \\
\text { Comments }\end{array}$ & $\begin{array}{c}\text { IMCCS Project } \\
\text { Specific Information }\end{array}$ & $\begin{array}{c}\text { IMCCS Project } \\
\text { Information Gaps } \\
\text { or Uncertainties }\end{array}$ & 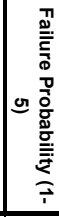 & 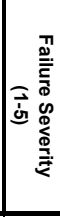 & 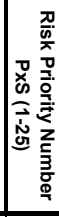 & $\begin{array}{l}\text { Risk Prevention } \\
\text { Steps (Actions } \\
\text { taken to reduce } \\
\text { risk probability) }\end{array}$ & \begin{tabular}{|c} 
Risk Mitigation \\
Steps (Actions taken \\
to reduce risk \\
severity)
\end{tabular} \\
\hline 424 & 7.3.03.00. & $\begin{array}{l}\text { Ecotoxicology of } \\
\text { contaminants }\end{array}$ & $\begin{array}{l}\text { Contaminants other than } \mathrm{CO} 2 \text { may be } \\
\text { introduced to the biosphere as a result of } \\
\text { geological CO2 sequestration due to: } \\
\text {-impurities associated with the sequestration } \\
\text { fluid, such as hydrogen sulphide (H2S), } \\
\text { methane }(\mathrm{CH} 4) \text {, nitrogen oxides (NOx) and } \\
\text { mercaptans; } \\
\text { - the mobilization of substances in the } \\
\text { geological environment due to the } \\
\text { sequestration of CO2, such as hydrocarbons } \\
\text { (e.g., EOR and ECBM), brine, CH4 and } \\
\text { heavy metals. } \\
\text { These substances may have a toxic effect } \\
\text { on organisms in the biosphere, including } \\
\text { plants, animals, algae and fungi. }\end{array}$ & $\begin{array}{l}\text { The potential for contaminants associated with } \\
\text { and/or mobilized by CO2 sequestration to have a } \\
\text { toxic effect on organisms should they migrate to } \\
\text { the biosphere will be of interest in an assessment } \\
\text { of the geological sequestration of } \mathrm{CO} 2 \text {. }\end{array}$ & $\begin{array}{l}\text { Quintessa } \\
\text { original FEP }\end{array}$ & Possible issue. & $\begin{array}{l}\text { H2S has been } \\
\text { reported in the } \\
\text { Arbuckle. }\end{array}$ & $\begin{array}{l}\text { Characterize the } \\
\text { sites for } \\
\text { contaminants. }\end{array}$ & 3 & 3 & 9 & $\begin{array}{l}\text { Characterize and } \\
\text { monitor the sites for } \\
\text { contaminants }\end{array}$ & $\begin{array}{l}\text { Monitor and model the } \\
\text { sites for contaminants. } \\
\text { Maintain a risk } \\
\text { management plan. } \\
\text { Train operators how to } \\
\text { deal with } \\
\text { contaminants. }\end{array}$ \\
\hline 425 & 7.3.03.01. & Methane leakage & $\begin{array}{l}\text { CO2 injection might cause methane (CH4) } \\
\text { present in the reservoir to migrate out of the } \\
\text { reservoir to other formations and possibly } \\
\text { into the atmosphere. (Damen 2006) }\end{array}$ & $\begin{array}{l}\text { Methane leakage may affect shallow water } \\
\text { quality and pose a lethal threat when } \\
\text { accumulating in confined spaces such as } \\
\text { bosements/cellars. The global warming potential } \\
\text { of methane is circa } 23 \text { times that of CO2 (Damen } \\
\text { 2006) }\end{array}$ & $\begin{array}{l}\text { Additional } \\
\text { [new] FEP }\end{array}$ & $\begin{array}{l}\text { Very unlikely to be } \\
\text { an issue. }\end{array}$ & $\begin{array}{l}\text { Production records } \\
\text { indicate an absence of } \\
\text { methane at the sites. }\end{array}$ & & 1 & 3 & 3 & $\begin{array}{l}\text { Characterize the } \\
\text { sites for methane. }\end{array}$ & $\begin{array}{l}\text { Monitor for methane. } \\
\text { Train operators how to } \\
\text { deal with methane } \\
\text { leaks. }\end{array}$ \\
\hline 426 & 7.3.04.00. & Ecological effects & $\begin{array}{l}\text { Geological sequestration of CO2 may have } \\
\text { an inpact on the biosphere at a community, } \\
\text { population and//or ecological level, with } \\
\text { subsequent implications for biodiversity. The } \\
\text { potential impact of releases of CO2 and } \\
\text { associated or mobilized contaminants into } \\
\text { the biosphere may dissupt biological } \\
\text { interactions sufficiently to modify the } \\
\text { terrestrial or marine ecosystems affected. } \\
\text { For example, the sudden release of natural } \\
\text { CO2 due to the limnic eruption at Lake Nyos, } \\
\text { Cameroon, resulted in the sudden death of } \\
\text { wildlife, but was unlikely to affect the ecology } \\
\text { in the longer term. However, the continued } \\
\text { gradual release of natural CO2 into soil near } \\
\text { Mammoth Mountain, California, has been } \\
\text { sufficient to kill trees and damage the local } \\
\text { ecosystem since } 1996 \text { until the present day. }\end{array}$ & $\begin{array}{l}\text { The degree of potential ecological disruption } \\
\text { resulting from geological } \mathrm{CO} \text { sequestration may } \\
\text { be an endpoint of interest, especially if the } \\
\text { ecosystem affected is considered valuable and/or } \\
\text { sensitive to perturbations. }\end{array}$ & $\begin{array}{l}\text { Quintessa } \\
\text { original FEP }\end{array}$ & $\begin{array}{l}\text { Very unlikely to be } \\
\text { an issue. }\end{array}$ & $\begin{array}{l}\text { Sites are sparsely } \\
\text { populated grasslands }\end{array}$ & & 1 & 1 & 1 & $\begin{array}{l}\text { Characterize site } \\
\text { ecology. }\end{array}$ & $\begin{array}{l}\text { Monitor and model } \\
\text { CO2 migration and } \\
\text { near-surface water } \\
\text { chemistry. Identify } \\
\text { irregularities. } \\
\text { Determine root cause. } \\
\text { Locate and plug leaks. } \\
\text { Extract CO2 from } \\
\text { leaky sinks and } \\
\text { reinject into sealed } \\
\text { sinks of necessary. }\end{array}$ \\
\hline 427 & 7.3.05.00. & $\begin{array}{l}\text { Modification of } \\
\text { microbiological } \\
\text { systems }\end{array}$ & $\begin{array}{l}\text { Microbes will be present in the geosphere as } \\
\text { well as in the terrestrial and/or marine } \\
\text { environments above the CO2 storage } \\
\text { reservoir. CO2 sequestration may disrupt } \\
\text { microbial aerobic respiration but may } \\
\text { enhance anaerobic respiration, with } \\
\text { subsequent implications for the processes in } \\
\text { which the microbes are involved. } \\
\text { Microbes play an important roll in all } \\
\text { terrestrial and marine ecosystems, including } \\
\text { those associated with extreme } \\
\text { environments, such as deep sea } \\
\text { hydrothermal vents. }\end{array}$ & $\begin{array}{l}\text { The potential impact of CO2 sequestration on } \\
\text { aerobic and anaerobic microbial respiration in the } \\
\text { geosphere, terrestrial and marine biosphere may } \\
\text { be an endpoint of interest. }\end{array}$ & $\begin{array}{l}\text { Quintessa } \\
\text { original FEP }\end{array}$ & $\begin{array}{l}\text { very unlikely to be } \\
\text { an issue. }\end{array}$ & & $\begin{array}{l}\text { Identify any } \\
\text { significant } \\
\text { subsurface } \\
\text { microbial cultures } \\
\text { at the injection } \\
\text { sites. }\end{array}$ & 1 & 1 & 1 & $\begin{array}{l}\text { Monitor for microbial } \\
\text { activity if injection } \\
\text { pressures increase } \\
\text { unexpectedly. Avoid } \\
\text { O2 content in the } \\
\text { CO2 stream. }\end{array}$ & $\begin{array}{l}\text { Use chemical } \\
\text { treatment if necessary } \\
\text { to control microbial } \\
\text { growth. }\end{array}$ \\
\hline
\end{tabular}

Quintessa Original FEP: Taken from Quintessa's on-line CO2 FEP database, which is freely accessible at: http://www.quintessa.org/co2fepdb/ 


\begin{tabular}{|c|c|c|c|c|c|c|c|c|c|c|c|c|c|}
\hline \multicolumn{6}{|c|}{ CO2 Geologic Sequestration Risks for the IMCCS Project } & \multicolumn{3}{|c|}{ Project Specific Information } & \multicolumn{3}{|c|}{ Risk Ranking } & \multicolumn{2}{|c|}{ Prevention and Mitigation } \\
\hline Line \# & Index No. & Risk Area & Description & Relevance & $\begin{array}{l}\text { Qunitessa } \\
\text { FPP } \\
\text { Category }\end{array}$ & $\begin{array}{l}\text { Individual } \\
\text { Comments }\end{array}$ & $\begin{array}{c}\text { IMCCS Project } \\
\text { Specific Information }\end{array}$ & \begin{tabular}{|c|} 
IMccs Project \\
Information Gaps \\
or Uncertainties
\end{tabular} & 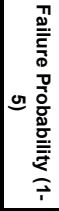 & 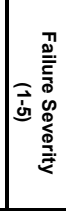 & 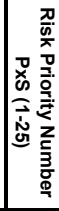 & $\begin{array}{l}\text { Risk Prevention } \\
\text { Steps (Actions } \\
\text { taken to reduce } \\
\text { risk probability) }\end{array}$ & $\begin{array}{l}\text { Risk Mitigation } \\
\text { Steps (Actions taken } \\
\text { to reduce risk } \\
\text { severity) }\end{array}$ \\
\hline 428 & 7.4.00.00. & Impacts on humans & FEPs relevant to adverse impacts on people. & $\begin{array}{l}\text { A range of possible impacts to human beings can } \\
\text { be postulated as a result of sequestration } \\
\text { operations. }\end{array}$ & $\begin{array}{l}\text { Quintessa } \\
\text { original FEP }\end{array}$ & $\begin{array}{l}\text { Very unlikely to be } \\
\text { an issue. }\end{array}$ & $\begin{array}{l}\text { Population is very } \\
\text { sparse at sites. } \\
\text { T-A: no residences } \\
\text { G-E: } 216 \text { residences }\end{array}$ & & 1 & 4 & 4 & \begin{tabular}{|l|} 
Avoid densely \\
populated areas. \\
Train operators and \\
educate residents \\
what to do in case of \\
a CO2 leak.
\end{tabular} & $\begin{array}{l}\text { Maintain an } \\
\text { emergency response } \\
\text { plan. Train operators } \\
\text { and educate residents } \\
\text { what to do in case of a } \\
\text { CO2 leak. }\end{array}$ \\
\hline 429 & 7.4.01.00. & $\begin{array}{l}\text { Health effects of } \\
\mathrm{CO} 2\end{array}$ & 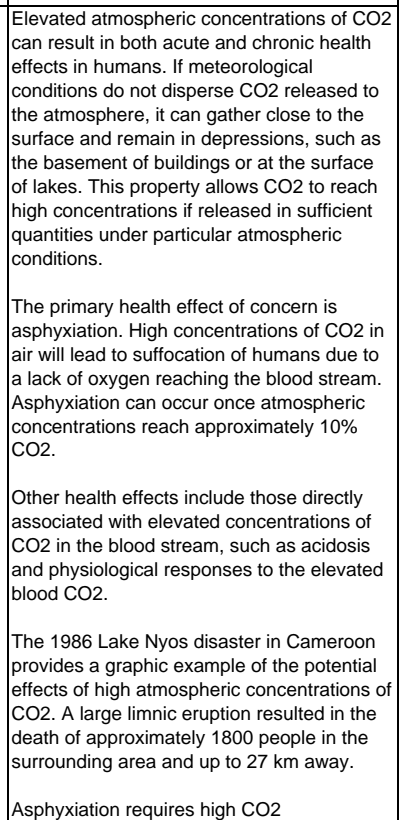 & $\begin{array}{l}\text { The potential for CO2 to be released to the } \\
\text { atmosphere in sufficient quantities to cause } \\
\text { health effects in humans sill be an endpoint of } \\
\text { interest in assessing the geological sequestration } \\
\text { of CO2. }\end{array}$ & $\begin{array}{c}\text { Quintessa } \\
\text { FEP with } \\
\text { additional text }\end{array}$ & $\begin{array}{l}\text { Very unlikely to be } \\
\text { an issue. }\end{array}$ & $\begin{array}{l}\text { Population is very } \\
\text { sparse at sites. } \\
\text { T-A: no residences } \\
\text { G-E: } 216 \text { residences }\end{array}$ & & 1 & 4 & 4 & \begin{tabular}{|l|} 
Avoid densely \\
populated areas. \\
Train operators and \\
educate residents \\
what to do in case of \\
a CO2 leak.
\end{tabular} & $\begin{array}{l}\text { Maintain an } \\
\text { emergency response } \\
\text { plan. Train operators } \\
\text { and educate residents } \\
\text { what to do in case of a } \\
\text { CO2 leak. }\end{array}$ \\
\hline
\end{tabular}




\begin{tabular}{|c|c|c|c|c|c|c|c|c|c|c|c|c|c|}
\hline \multicolumn{6}{|c|}{ CO2 Geologic Sequestration Risks for the IMCCS Project } & \multicolumn{3}{|c|}{ Project Specific Information } & \multicolumn{3}{|c|}{ Risk Ranking } & \multicolumn{2}{|c|}{ Prevention and Mitigation } \\
\hline Line \# & Index No. & Risk Area & Description & Relevance & $\begin{array}{c}\text { Qunitessa } \\
\text { FEP } \\
\text { Category }\end{array}$ & $\begin{array}{l}\text { Individual } \\
\text { Comments }\end{array}$ & $\begin{array}{c}\text { IMccs Project } \\
\text { Specific Information }\end{array}$ & $\begin{array}{c}\text { IMCCS Project } \\
\text { Information Gaps } \\
\text { or Uncertainties }\end{array}$ & 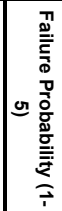 & 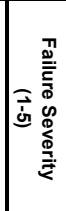 & 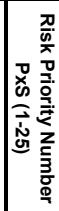 & $\begin{array}{l}\text { Risk Prevention } \\
\text { Steps (Actions } \\
\text { taken to reduce } \\
\text { risk probability) }\end{array}$ & $\begin{array}{c}\text { Risk Mitigation } \\
\text { Steps (Actions taken } \\
\text { to reduce risk } \\
\text { severity) }\end{array}$ \\
\hline 430 & 7.4.01.01. & Elevated $\mathrm{CO}_{2}$ in air & 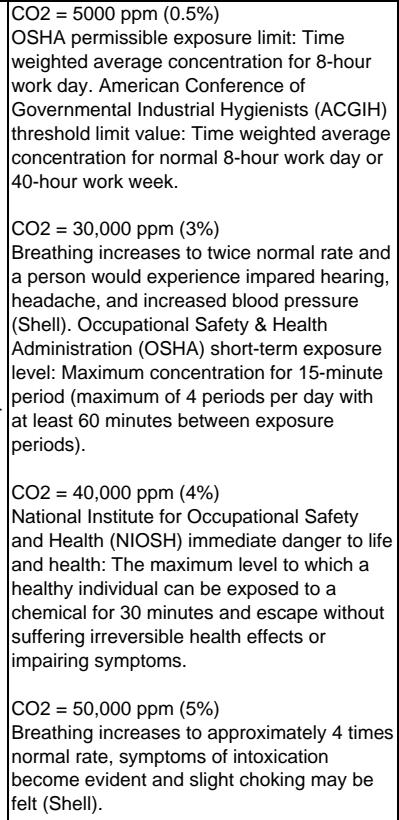 & & \begin{tabular}{|l}
$\begin{array}{l}\text { Additional } \\
\text { [new] FEP }\end{array}$
\end{tabular} & $\begin{array}{l}\text { very unlikely to be } \\
\text { an issue. }\end{array}$ & & $\begin{array}{l}\text { Baseline survey of } \\
\text { atmospheric CO2 } \\
\text { at the sites. }\end{array}$ & 1 & 4 & 4 & $\begin{array}{l}\text { Monitor } \mathrm{CO} 2 \text { content } \\
\text { in air. Model } \mathrm{CO} 2 \\
\text { dispersion. Train } \\
\text { operators and } \\
\text { educate residents } \\
\text { what to do if a } \mathrm{CO} 2 \\
\text { leak occurs. }\end{array}$ & $\begin{array}{l}\text { Monitor } \mathrm{CO} 2 \text { content } \\
\text { in air. Model CO22 } \\
\text { dispersion. Train } \\
\text { operators and educate } \\
\text { residents what to do if } \\
\text { a CO2 leak occurs. }\end{array}$ \\
\hline
\end{tabular}




\begin{tabular}{|c|c|c|c|c|c|c|c|c|c|c|c|c|c|}
\hline \multicolumn{6}{|c|}{ CO2 Geologic Sequestration Risks for the IMCCS Project } & \multicolumn{3}{|c|}{ Project Specific Information } & \multicolumn{3}{|c|}{ Risk Ranking } & \multicolumn{2}{|c|}{ Prevention and Mitigation } \\
\hline Line \# & Index No. & Risk Area & Description & Relevance & $\begin{array}{l}\text { Qunitessa } \\
\text { FEP } \\
\text { Category }\end{array}$ & $\begin{array}{l}\text { Individual } \\
\text { Comments }\end{array}$ & $\begin{array}{c}\text { IMCCS Project } \\
\text { Specific Information }\end{array}$ & \begin{tabular}{|c|} 
IMCcS Project \\
Information Gaps \\
or Uncertainties
\end{tabular} & 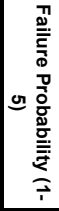 & 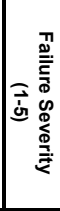 & 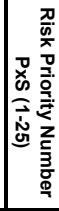 & $\begin{array}{l}\text { Risk Prevention } \\
\text { Steps (Actions } \\
\text { taken to reduce } \\
\text { risk probability) }\end{array}$ & $\begin{array}{l}\text { Risk Mitigation } \\
\text { Steps (Actions taken } \\
\text { to reduce risk } \\
\text { severity) }\end{array}$ \\
\hline 431 & 7.4.02.00. & $\begin{array}{c}\text { Toxicity of } \\
\text { contaminants }\end{array}$ & 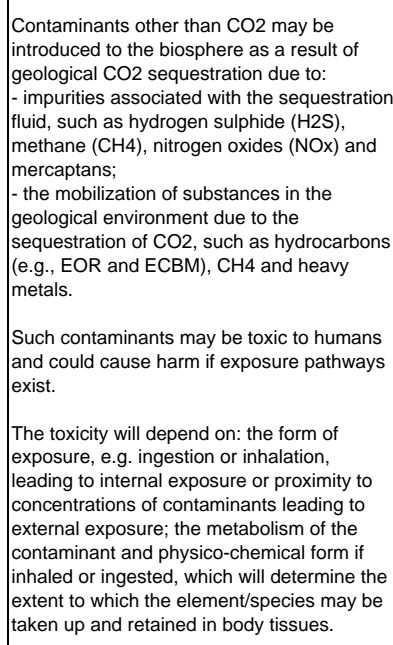 & $\begin{array}{l}\text { The potential for contaminants associated with } \\
\text { an/or mobilized by CO2 sequestration to cause } \\
\text { harm to humans is an endpoint of interest when } \\
\text { assessing the geological sequestration of CO2. }\end{array}$ & $\begin{array}{l}\text { Quintessa } \\
\text { original FEP }\end{array}$ & Possible issue. & $\begin{array}{l}\text { H2S has been } \\
\text { reported in the } \\
\text { Arbuckle. }\end{array}$ & $\begin{array}{l}\text { Characterize the } \\
\text { sites for } \\
\text { contaminants. }\end{array}$ & 3 & 3 & 9 & $\begin{array}{l}\text { Characterize and } \\
\text { monitor the sites for } \\
\text { contaminants }\end{array}$ & $\begin{array}{l}\text { Monitor and model the } \\
\text { sites for contaminants. } \\
\text { Maintain a risk } \\
\text { management plan. } \\
\text { Train operators how to } \\
\text { deal with } \\
\text { contaminants. }\end{array}$ \\
\hline 432 & 7.4.03.00. & $\begin{array}{c}\text { Impacts from } \\
\text { physical disruption }\end{array}$ & $\begin{array}{l}\text { Impacts on humans due to physical } \\
\text { disruption of the environment caused by } \\
\text { geological CO2 sequestration. For example, } \\
\text { damage to buildings due to induced } \\
\text { seismicity, damage to farmland due to } \\
\text { subsidence or uplift. }\end{array}$ & $\begin{array}{l}\text { Physical disruption of the environment caused by } \\
\text { CO2 sequestration may have a detrimental } \\
\text { impact on humans. }\end{array}$ & $\begin{array}{l}\text { Quintessa } \\
\text { original FEP }\end{array}$ & $\begin{array}{l}\text { very unlikely to be } \\
\text { an issue. }\end{array}$ & $\begin{array}{l}\text { Population is very } \\
\text { sparse at sites. } \\
\text { T-A: no residences } \\
\text { G-E: } 216 \text { residences }\end{array}$ & & 1 & 3 & 3 & \begin{tabular}{|l} 
Avoid densely \\
populated areas. \\
Train operators and \\
educate residents \\
what to do in case of \\
a cO2 leak.
\end{tabular} & $\begin{array}{l}\text { Maintain an } \\
\text { emergency response } \\
\text { plan. Train operators } \\
\text { and educate residents } \\
\text { what to do in case of a } \\
\text { CO2 leak. }\end{array}$ \\
\hline 433 & 7.4.04.00. & $\begin{array}{l}\text { Impacts from } \\
\text { ecological } \\
\text { modification }\end{array}$ & $\begin{array}{l}\text { Impacts on humans due to ecological } \\
\text { modification. These may be negative (for } \\
\text { example, reduced timber yields due to } \\
\text { damage caused to trees by CO2 in the soil) } \\
\text { or positive (for example, increased crop } \\
\text { yields due to higher atmospheric CO2). }\end{array}$ & $\begin{array}{l}\text { Ecological modification caused by } \mathrm{CO} 2 \\
\text { sequestration may have a positive or negative } \\
\text { impact on humans. }\end{array}$ & $\begin{array}{l}\text { Quintessa } \\
\text { original FEP }\end{array}$ & $\begin{array}{l}\text { very unlikely to be } \\
\text { an issue. }\end{array}$ & $\begin{array}{l}\text { Population is very } \\
\text { sparse at sites. } \\
\text { T-A: no residences } \\
\text { G-E: } 216 \text { residences }\end{array}$ & & 1 & 3 & 3 & $\begin{array}{l}\text { Avoid densely } \\
\text { populated areas. } \\
\text { Train operators and } \\
\text { educate residents } \\
\text { what to do in case of } \\
\text { a CO2 leak. }\end{array}$ & $\begin{array}{l}\text { Maintain an } \\
\text { emergency response } \\
\text { plan. Train operators } \\
\text { and educate residents } \\
\text { what to do in case of a } \\
\text { CO2 leak. }\end{array}$ \\
\hline
\end{tabular}




\section{Appendix 6-B}

Surface and Programmatic Risks for the IMCCS Project 


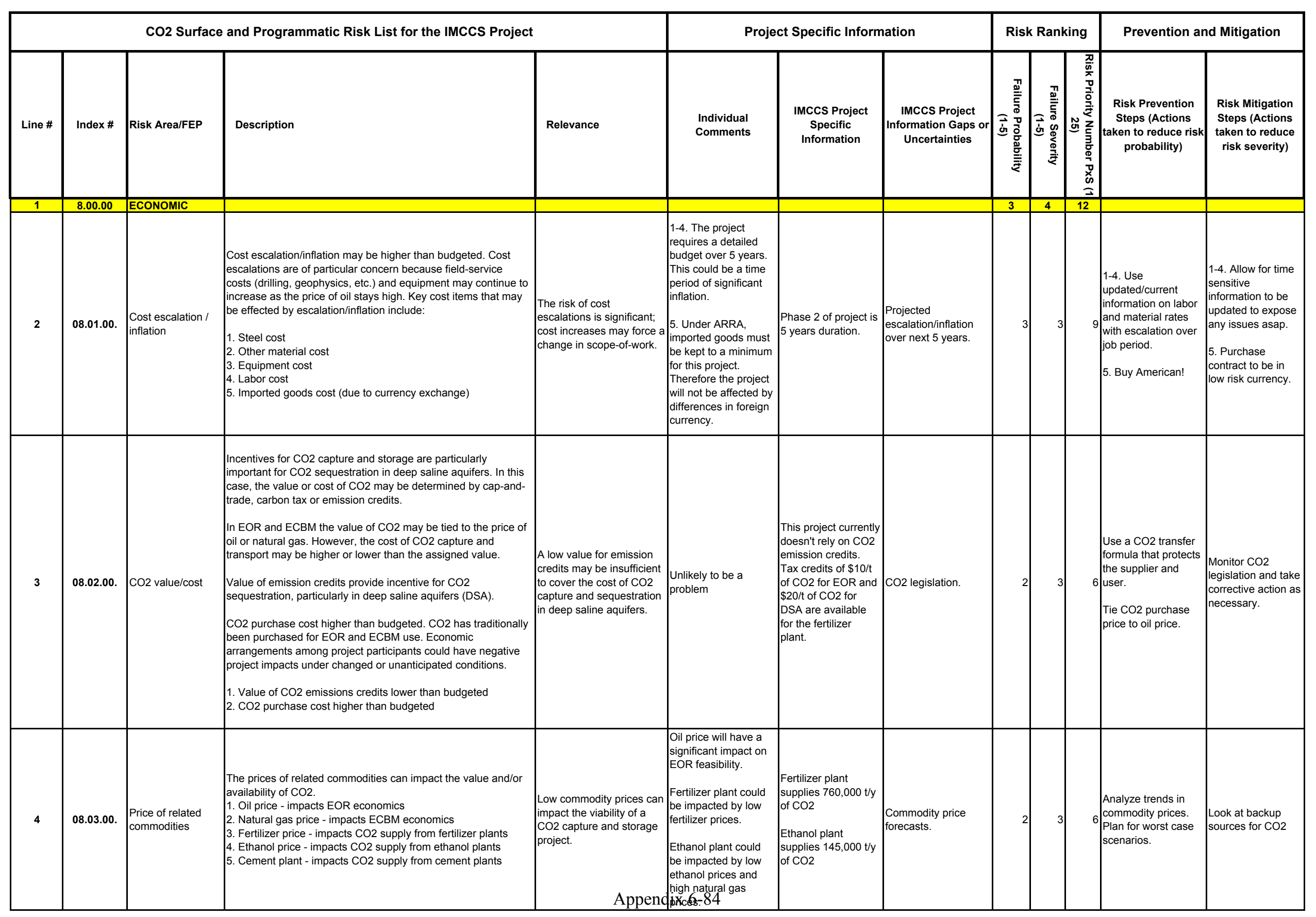




\begin{tabular}{|c|c|c|c|c|c|c|c|c|c|c|c|c|}
\hline \multicolumn{5}{|c|}{ CO2 Surface and Programmatic Risk List for the IMCCS Project } & \multicolumn{3}{|c|}{ Project Specific Information } & \multicolumn{3}{|c|}{ Risk Ranking } & \multicolumn{2}{|c|}{ Prevention and Mitigation } \\
\hline Line \# & Index \# & Risk Area/FEP & Description & Relevance & $\begin{array}{l}\text { Individual } \\
\text { Comments }\end{array}$ & $\begin{array}{l}\text { IMCCS Project } \\
\text { Specific } \\
\text { Information }\end{array}$ & $\begin{array}{c}\text { IMCCS Project } \\
\text { Information Gaps or } \\
\text { Uncertainties }\end{array}$ & 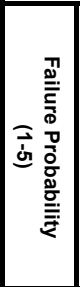 & 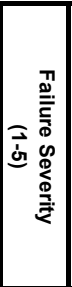 & 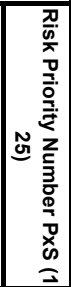 & \begin{tabular}{|c|} 
\\
Risk Prevention \\
Steps (Actions \\
taken to reduce risk \\
probability) \\
\end{tabular} & $\begin{array}{c}\text { Risk Mitigation } \\
\text { Steps (Actions } \\
\text { taken to reduce } \\
\text { risk severity) }\end{array}$ \\
\hline 5 & 08.04.00. & \begin{tabular}{|l|} 
Project \\
development costs
\end{tabular} & $\begin{array}{l}\text { Project development costs that could be higher than expected } \\
\text { or budgeted include: } \\
\text { 1. Surface land and/or pore space access costs -purchase or } \\
\text { lease } \\
\text { 2. Water rights costs } \\
\text { 3. Mineral rights costs - needed for EOR or ECBM } \\
\text { 4. Pipeline right-of-way (ROW) costs } \\
\text { 5. Site characterization costs } \\
\text { 6. Permitting costs } \\
\text { 7. Technology licensing costs } \\
\text { 8. Engineering, procurement and construction (EPC) costs } \\
\text { 9. Insurance costs } \\
\text { 10. Project financing costs } \\
\text { 11. Legal costs }\end{array}$ & $\begin{array}{l}\text { High project development } \\
\text { costs can make the project } \\
\text { economically infeasible. } \\
\text { Project may be halted if } \\
\text { some of the necessary } \\
\text { requirements are } \\
\text { unobtainable. }\end{array}$ & $\begin{array}{l}\text { 1-8. Unlikely to be a } \\
\text { problem. } \\
\text { 9. Insurance and } \\
\text { project financing costs } \\
\text { likely to be high. }\end{array}$ & $\begin{array}{l}\text { IMCCS uses existing } \\
\text { pipeline corridors. } \\
\text { EOR does not } \\
\text { normally involve } \\
\text { pore space issues. }\end{array}$ & $\begin{array}{l}\text { Insurance availability } \\
\text { and costs. }\end{array}$ & 3 & 2 & & 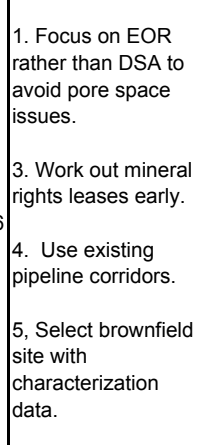 & $\begin{array}{l}\text { 1. Have back ups } \\
\text { for site selection, } \\
\text { 4. Have backup for } \\
\text { pipeline right of } \\
\text { way. } \\
\text { 6. Use public } \\
\text { outreach effectively } \\
\text { to keep permitting } \\
\text { costs down. } \\
\text { 9. Self insure. } \\
\text { 10. Get equity } \\
\text { financing. }\end{array}$ \\
\hline 6 & 08.05 .00 . & $\begin{array}{l}\text { Project capital } \\
\text { costs }\end{array}$ & $\begin{array}{l}\text { Project capital costs that could be higher than budgeted include: } \\
\text { 1. CO2 capture system } \\
\text { 2. CO2 dehydration } \\
\text { 3. CO2 compression } \\
\text { 4. CO2 pipeline } \\
\text { 5. Well head system } \\
\text { 6. CO2 recycle system - for EOR } \\
\text { 7. Oil tankage - for EOR } \\
\text { 8. Natural gas processing system - for ECBM } \\
\text { 9. Water tankage - for EOR or ECBM } \\
\text { 10. Water treatment system - for EOR or ECBM } \\
\text { 11. New well drilling and completion } \\
\text { 12. Old well remediation/replugging } \\
\text { 13. Old well workover } \\
\text { 14. Site preparation } \\
\text { 15. Access roads } \\
\text { 16. Power supply system } \\
\text { 17. Water supply system } \\
\text { 18. Communications system } \\
\text { 19. Monitoring system costs } \\
\text { 20. Accidental loss }\end{array}$ & \begin{tabular}{|l|} 
High project capital costs \\
can make the project \\
economically infeasible. \\
Accidental loss can result \\
in Business Interruption / \\
Advanced Loss of Profit \\
type exposure, or even \\
result in the project \\
becoming uneconomic to \\
continue. \\
CO2 capture and CO2 \\
compression tend to be \\
big ticket items and long \\
lead time.
\end{tabular} & $\begin{array}{l}\text { Unlikely to be a } \\
\text { problem }\end{array}$ & $\begin{array}{l}\text { CO2 capture existing } \\
\text { at Coffeyville and } \\
\text { Kansas Ethanol. }\end{array}$ & $\begin{array}{l}\text { Need final site } \\
\text { selection and hard } \\
\text { quotes on major } \\
\text { items }\end{array}$ & 2 & 3 & & $\begin{array}{l}\text { Obtain hard quotes } \\
\text { from manufacturers } \\
\text { with time sensitive } \\
\text { escalation and time } \\
\text { period of validity } \\
\text { defined. } \\
\text { Use conservative } \\
\text { estimates and } \\
\text { escalations. } \\
\text { Use experienced } \\
\text { contractors. }\end{array}$ & \begin{tabular}{|l} 
Track actual vs. \\
budgeted \\
expenses. \\
Prioritize expenses \\
and cut low priority \\
costs. \\
Renegotiate scope \\
of work. \\
Obtain additional \\
equity funding.
\end{tabular} \\
\hline
\end{tabular}




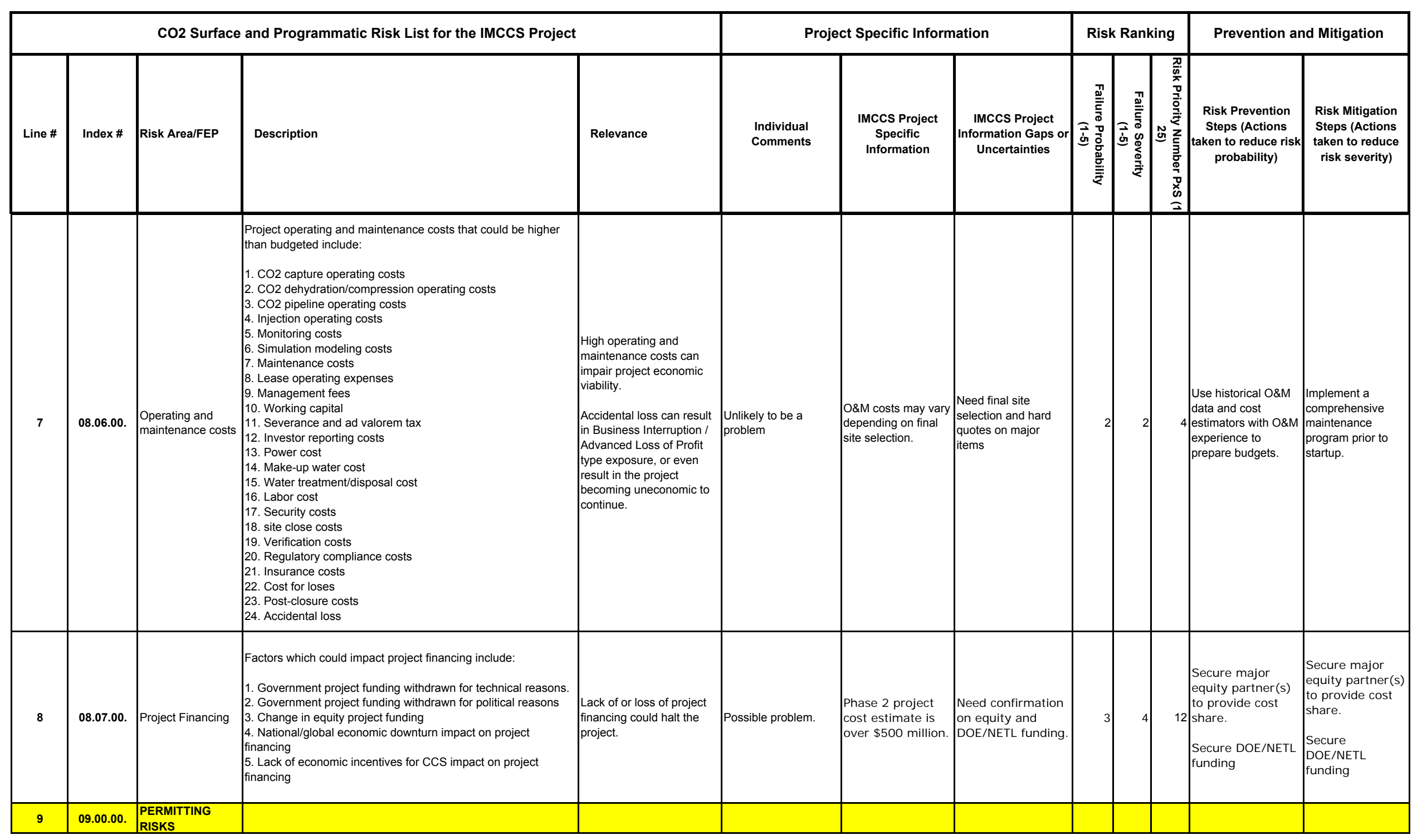




\begin{tabular}{|c|c|c|c|c|c|c|c|c|c|c|c|c|}
\hline \multicolumn{5}{|c|}{ CO2 Surface and Programmatic Risk List for the IMCCS Project } & \multicolumn{3}{|c|}{ Project Specific Information } & \multicolumn{3}{|c|}{ Risk Ranking } & \multicolumn{2}{|c|}{ Prevention and Mitigation } \\
\hline Line \# & Index \# & Risk Area/FEP & Description & Relevance & $\begin{array}{l}\text { Individual } \\
\text { Comments }\end{array}$ & $\begin{array}{l}\text { IMCCS Project } \\
\text { Specific } \\
\text { Information }\end{array}$ & $\begin{array}{c}\text { IMCCS Project } \\
\text { Information Gaps or } \\
\text { Uncertainties }\end{array}$ & 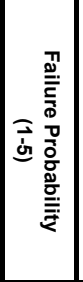 & 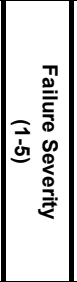 & 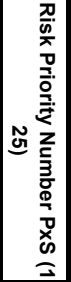 & \begin{tabular}{|c} 
\\
Risk Prevention \\
Steps (Actions \\
taken to reduce risk \\
probability) \\
\end{tabular} & $\begin{array}{c}\text { Risk Mitigation } \\
\text { Steps (Actions } \\
\text { taken to reduce } \\
\text { risk severity) }\end{array}$ \\
\hline 10 & 09.01.00. & Permit compliance & $\begin{array}{l}\text { Permitting and NEPA compliance are lengthy processes, and } \\
\text { are subject to even more delays because of uncertainty } \\
\text { associated with permitting sequestration (a relatively new issue } \\
\text { for regulatory agencies). The procedures for permit compliance } \\
\text { could cause delays. Potential permits required for a CCS project } \\
\text { include: } \\
\text { 1. National Environmental Policy Act (NEPA) } \\
\text { - Environmental Assessment (EA) } \\
\text { - Environmental Impact Statement (EIS) } \\
\text { 2. Underground Injection Control (UIC) permit } \\
\text { 3. CO2 storage permit } \\
\text { 4. Drilling permit } \\
\text { 5. Water discharge/disposal permit } \\
\text { 6. Crossing permits for wetlands, federal land, tribal land, } \\
\text { railroads, highways, roads } \\
\text { 7. Construction general permit } \\
\text { 8. Storm water discharge permit } \\
\text { 9. Air quality construction permit } \\
\text { 10. Seismic permit } \\
\text { 11. Storage tank permit }\end{array}$ & $\begin{array}{l}\text { Lack of permit could halt } \\
\text { or restrict construction or } \\
\text { operation; permit delay } \\
\text { could have other impacts } \\
\text { including increased costs. }\end{array}$ & $\begin{array}{l}\text { Unlikely to be a } \\
\text { problem }\end{array}$ & $\begin{array}{l}\text { Using existing } \\
\text { injection sites and } \\
\text { pipeline corridors. }\end{array}$ & $\begin{array}{l}\text { Need to make final } \\
\text { site and pipeline } \\
\text { ROW selections. }\end{array}$ & 2 & 3 & & $\begin{array}{l}\text { Use experienced } \\
\text { permitting manager / } \\
\text { consultant. }\end{array}$ & $\begin{array}{l}\text { Use experienced } \\
\text { permitting manager } \\
\text { / consultant }\end{array}$ \\
\hline 11 & 09.02.00. & $\begin{array}{l}\text { Public outreach } \\
\text { and education }\end{array}$ & $\begin{array}{l}\text { Public acceptance support and trust is critical to obtaining } \\
\text { environmental permits. Public outreach and education can be } \\
\text { more difficult than expected. } \\
\text { 1. Lack of public acceptance that CO2 emissions contribute to } \\
\text { global warming } \\
\text { 2. Lack of public acceptance that global warming is an eminent } \\
\text { danger to society } \\
\text { 3. Lack of public that carbon capture and storage (CCS) is safe } \\
\text { 4. Poor public perception of CCS projects } \\
\text { 5. Local community actions and reactions } \\
\text { 6. Special interest groups or non-governmental organizations } \\
\text { actions and reactions } \\
\text { 7. Lack of political support for the project }\end{array}$ & $\begin{array}{l}\text { Failure to get public } \\
\text { acceptance for a project } \\
\text { can lead to significant } \\
\text { delays in, and costs for, } \\
\text { permitting } \\
\text { An unexpected situation } \\
\text { arises that is not } \\
\text { technically impacting but } \\
\text { the appearance of } \\
\text { unpreparedness spurs } \\
\text { public concern. }\end{array}$ & $\begin{array}{l}\text { Unlikely to be a } \\
\text { problem }\end{array}$ & $\begin{array}{l}\text { Local public have } \\
\text { long history of good } \\
\text { working relationship } \\
\text { with oil companies. }\end{array}$ & $\begin{array}{l}\text { Need to make final } \\
\text { site and pipeline } \\
\text { ROW selections. }\end{array}$ & 2 & 4 & & $\begin{array}{l}\text { Comprehensive } \\
\text { public outreach } \\
\text { program based on } \\
\text { DOE best practices } \\
\text { manual. }\end{array}$ & $\begin{array}{l}\text { Comprehensive } \\
\text { public outreach } \\
\text { program based on } \\
\text { DOE best practices } \\
\text { manual. }\end{array}$ \\
\hline
\end{tabular}




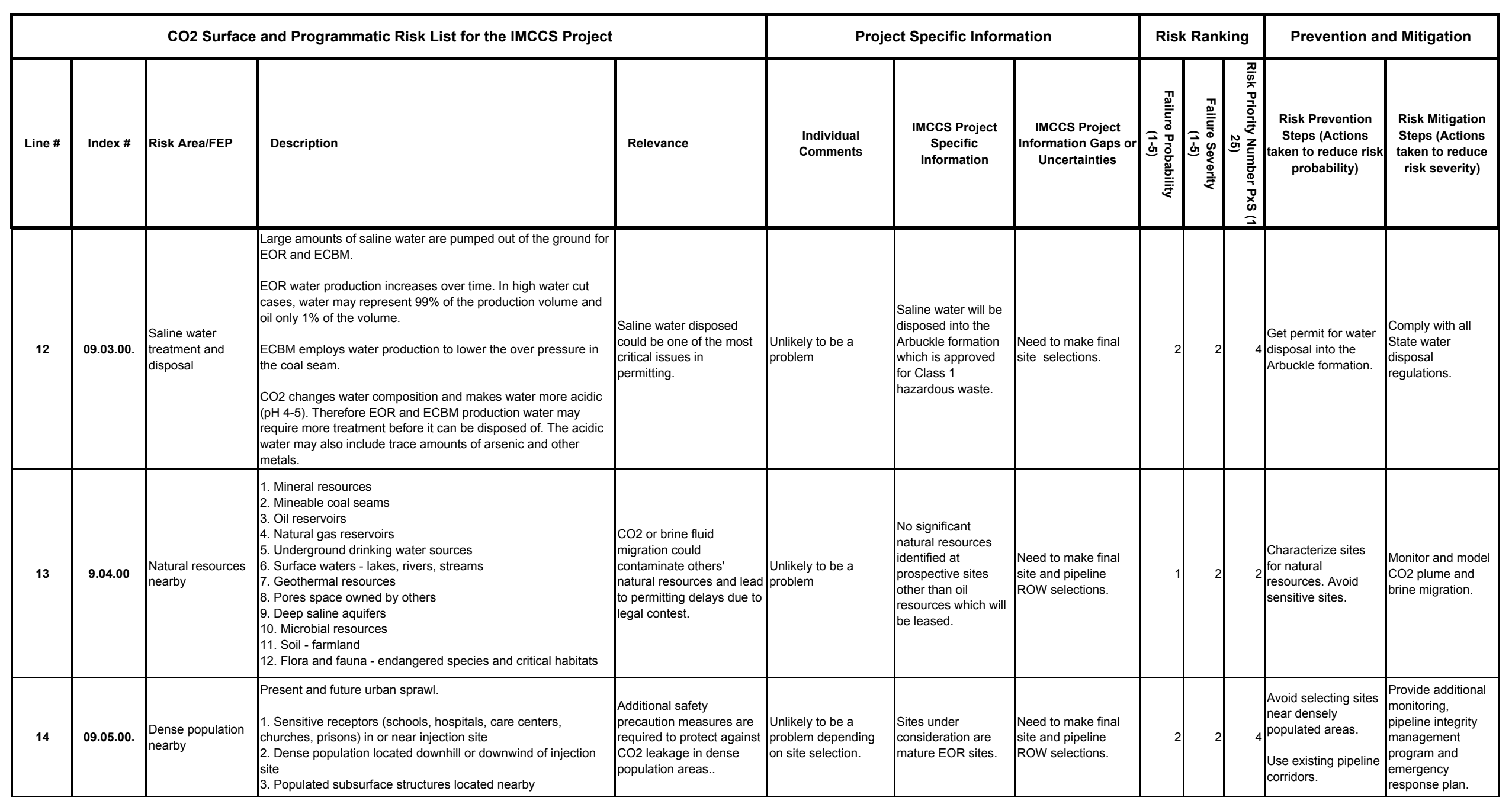




\begin{tabular}{|c|c|c|c|c|c|c|c|c|c|c|c|c|}
\hline \multicolumn{5}{|c|}{ CO2 Surface and Programmatic Risk List for the IMCCS Project } & \multicolumn{3}{|c|}{ Project Specific Information } & \multicolumn{3}{|c|}{ Risk Ranking } & \multicolumn{2}{|c|}{ Prevention and Mitigation } \\
\hline Line \# & Index \# & Risk Area/FEP & Description & Relevance & $\begin{array}{l}\text { Individual } \\
\text { Comments }\end{array}$ & $\begin{array}{l}\text { IMCCS Project } \\
\text { Specific } \\
\text { Information }\end{array}$ & $\begin{array}{c}\text { IMCCS Project } \\
\text { Information Gaps or } \\
\text { Uncertainties }\end{array}$ & 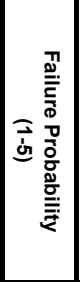 & 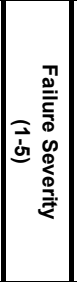 & 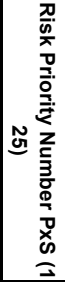 & \begin{tabular}{|c|} 
Risk Prevention \\
Steps (Actions \\
taken to reduce risk \\
probability)
\end{tabular} & $\begin{array}{c}\text { Risk Mitigation } \\
\text { Steps (Actions } \\
\text { taken to reduce } \\
\text { risk severity) }\end{array}$ \\
\hline 15 & 09.06 .00 . & $\begin{array}{l}\text { Conflicts with use } \\
\text { of surface }\end{array}$ & $\begin{array}{l}\text { Conflicts with use of the surface may include } \\
\text { 1. Agriculture } \\
\text { 2. Fishing } \\
\text { 3. National parks/monuments } \\
\text { 4. Wetlands } \\
\text { 5. Timberland } \\
\text { 6. Recreational areas } \\
\text { 7. Military areas } \\
\text { 8. Heavy industry sites } \\
\text { 9. Urban areas } \\
\text { 10. Archeological sites } \\
\text { 11. Tribal sacred ground } \\
\text { 12. Endangered species critical habitats } \\
\text { 13. Bird sanctuaries } \\
\text { 14. Historical sites } \\
\text { 15. Groundwater protection zones. } \\
\text { 17. Change in land use (zoning change) }\end{array}$ & \begin{tabular}{|l|} 
Some land uses may \\
impact site selection and \\
permitting. Others may \\
require additional \\
monitoring and modeling \\
to provide added \\
protection from CO2 \\
leakage. \\
Nearby heavy industry can \\
interfere with seismic \\
readings. \\
Land use changes could \\
restrict access to and use \\
of land for CO2 \\
sequestration
\end{tabular} & $\begin{array}{l}\text { Unlikely to be a } \\
\text { problem }\end{array}$ & $\begin{array}{l}\text { Existing injection } \\
\text { sites and pipeline } \\
\text { corridors. } \\
\text { No activity except } \\
\text { farming, ranching } \\
\text { and oil production at } \\
\text { injection site areas. }\end{array}$ & $\begin{array}{l}\text { Need to make final } \\
\text { site and pipeline } \\
\text { ROW selections. }\end{array}$ & 2 & 2 & & \begin{tabular}{|l} 
Use of existing \\
injection sites and \\
pipeline corridors. \\
\\
Avoid sensitive \\
areas or habitats for \\
endangered or \\
protected species. \\
Characterize sites \\
for potential surface \\
land use.
\end{tabular} & $\begin{array}{l}\text { Design around } \\
\text { sensitive areas. } \\
\text { Monitor CO2 plume } \\
\text { and brine } \\
\text { migration. }\end{array}$ \\
\hline 16 & 09.07.00. & $\begin{array}{l}\text { Conflicts with use } \\
\text { of subsurface }\end{array}$ & $\begin{array}{l}\text { Conflicts with use of the subsurface may include: } \\
\text { 1. Natural gas storage } \\
\text { 2. Compressed air storage } \\
\text { 3. Geothermal plants } \\
\text { 4. Radioactive waste disposal } \\
\text { 5. Petroleum production } \\
\text { 6. Coal mining } \\
\text { 7 Health spas }\end{array}$ & $\begin{array}{l}\text { Could impact site } \\
\text { selection and permitting. }\end{array}$ & $\begin{array}{l}\text { Unlikely to be a } \\
\text { problem. }\end{array}$ & $\begin{array}{l}\text { No activity except } \\
\text { farming, ranching } \\
\text { and oil production at } \\
\text { injection site areas. }\end{array}$ & $\begin{array}{l}\text { Need to make final } \\
\text { site and pipeline } \\
\text { ROW selections. }\end{array}$ & 1 & 2 & & $2 \mid \begin{array}{l}\text { Use of existing } \\
\text { injection sites and } \\
\text { pipeline corridors. } \\
\text { Avoid sites with } \\
\text { conflicting } \\
\text { subsurface use. } \\
\text { Characterize sites } \\
\text { for potential } \\
\text { subsurface. }\end{array}$ & $\begin{array}{l}\text { Design around } \\
\text { conflicting areas. } \\
\text { Monitor CO2 plume } \\
\text { and brine } \\
\text { migration. }\end{array}$ \\
\hline 17 & 09.08.00. & $\begin{array}{l}\text { Permit denied or } \\
\text { modified by } \\
\text { government } \\
\text { agency }\end{array}$ & $\begin{array}{l}\text { A permit may be modified by government agency to require } \\
\text { increase data access and approval by NGOs and/or public } \\
\text { 1. Permit denied because the project is considered high risk to } \\
\text { public } \\
\text { 2. Permit denied because there is uncertainty over the safety of } \\
\text { the project } \\
\text { 3. Permit revoked due to owner failing to comply with } \\
\text { regulations (action or inaction) } \\
\text { 4. Permit delayed due to owner action or inaction }\end{array}$ & $\begin{array}{l}\text { Causes delays leading to } \\
\text { price escalation. Could } \\
\text { halt the project. }\end{array}$ & $\begin{array}{l}\text { Unlikely to be a } \\
\text { problem. }\end{array}$ & $\begin{array}{l}\text { Using existing } \\
\text { injection sites and } \\
\text { pipeline corridors. }\end{array}$ & $\begin{array}{l}\text { Need to make final } \\
\text { site and pipeline } \\
\text { ROW selections. }\end{array}$ & 2 & 2 & & $\begin{array}{l}\text { Use experienced } \\
\text { permitting manager } / \\
\text { consultant. }\end{array}$ & $\begin{array}{l}\text { Use experienced } \\
\text { permitting manager } \\
\text { / consultant. }\end{array}$ \\
\hline
\end{tabular}




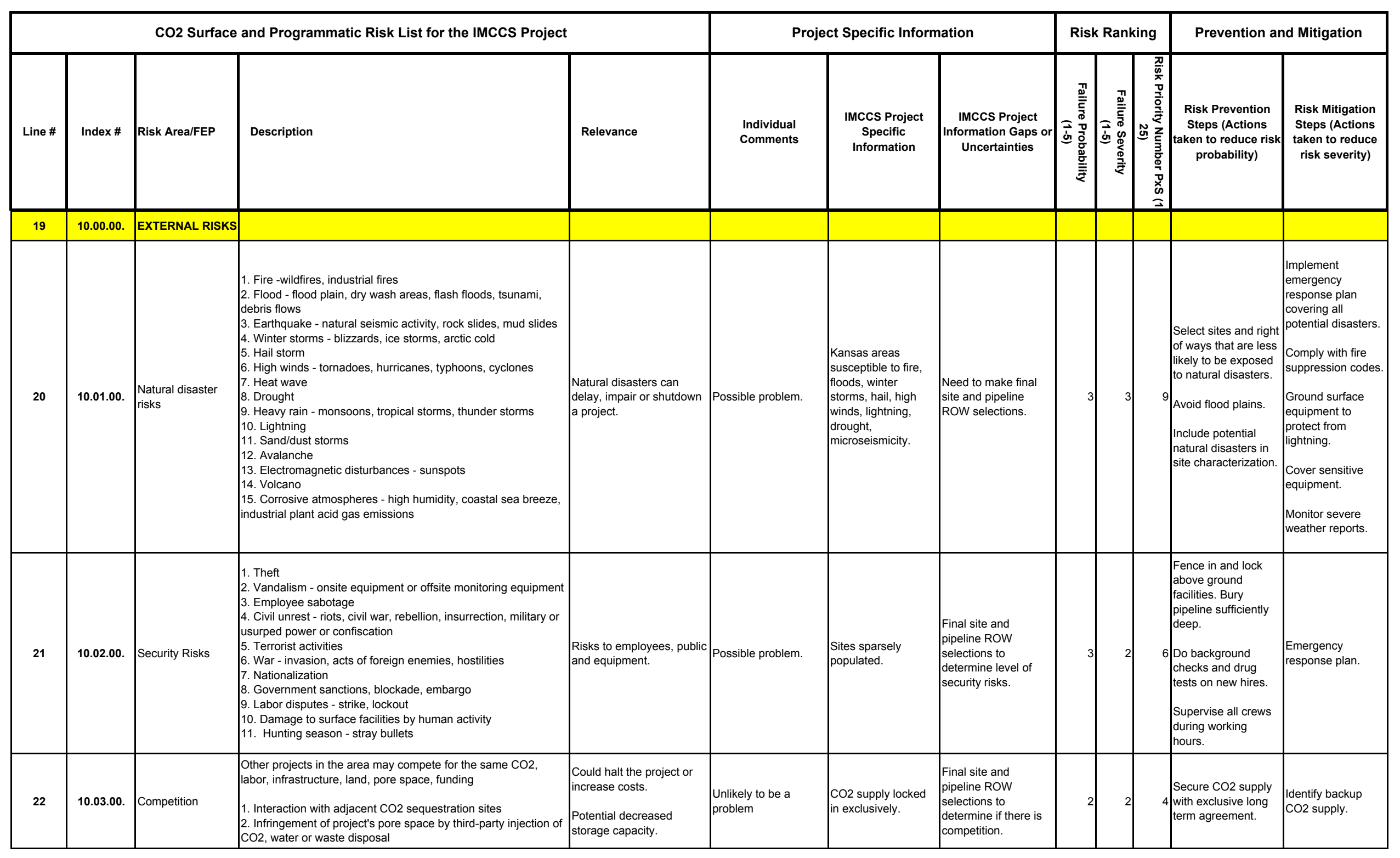




\begin{tabular}{|c|c|c|c|c|c|c|c|c|c|c|c|c|}
\hline \multicolumn{5}{|c|}{ CO2 Surface and Programmatic Risk List for the IMCCS Project } & \multicolumn{3}{|c|}{ Project Specific Information } & \multicolumn{3}{|c|}{ Risk Ranking } & \multicolumn{2}{|c|}{ Prevention and Mitigation } \\
\hline Line \# & Index \# & Risk Area/FEP & Description & Relevance & $\begin{array}{l}\text { Individual } \\
\text { Comments }\end{array}$ & $\begin{array}{l}\text { IMCCS Project } \\
\text { Specific } \\
\text { Information }\end{array}$ & $\begin{array}{c}\text { Imccs Project } \\
\text { Information Gaps or } \\
\text { Uncertainties }\end{array}$ & 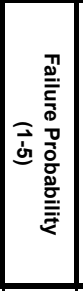 & 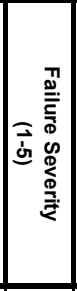 & 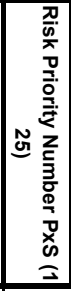 & \begin{tabular}{|c|} 
\\
Risk Prevention \\
Steps (Actions \\
taken to reduce risk \\
probability) \\
\\
\end{tabular} & $\begin{array}{c}\text { Risk Mitigation } \\
\text { Steps (Actions } \\
\text { taken to reduce } \\
\text { risk severity) }\end{array}$ \\
\hline 23 & 10.04.00. & CO2 supply & $\begin{array}{l}\text { Changes in the operation of the CO2 source plant may impact } \\
\text { CO2 properties and/or flow rate. } \\
\text { Unanticipated change in demand for injected CO2 (flow rate, } \\
\text { pressure, water content, etc.) due to either uncontrollable } \\
\text { physical changes or operating decisions, will affect operations } \\
\text { of the CO2 source facility and potentially impose stresses upon } \\
\text { surface and down hole equipment and borehole. Changes may } \\
\text { be gradual or sudden. Also includes changes arising from } \\
\text { characterization data, e.g., limits placed by reservoir on } \\
\text { injectivity, capacity, etc. } \\
\text { CO2 sources and sinks need to coordinate supply and demand } \\
\text { and scheduled outages to avoid constraint startup/shutdown of } \\
\text { compression facilities and maintain consistent pipeline } \\
\text { pressure. This is normally done through a nomination process } \\
\text { at least one week in advance. } \\
\text { Operators of CO2 storage projects may incorporate excess } \\
\text { injection capacity (i.e. spare wells) to permit continued injection } \\
\text { during planned or unplanned well downtime. (CCP 2009) } \\
\text { 1. CO2 outside of design specification - flow rate, composition, } \\
\text { pressure, temperature } \\
\text { 2. Change in CO2 supply conditions } \\
\text { 3. Change in CO2 demand conditions } \\
\text { 4. CO2 supply interruptions due to source plant outage/failure } \\
\text { 5. CO2 supply interruptions due to CO2 capture outage/failure } \\
\text { 6. CO2 supply interruptions due to compressor outage/failure } \\
\text { 7. CO2 supply interruptions due to pipeline outage } \\
\text { 8. Disparity in timing of supply/demand for CO2 } \\
\text { 9. CO2 interruption due to accident at the } \mathrm{CO} 2 \text { supplier }\end{array}$ & \begin{tabular}{|l|} 
Interruption of CO2 supply \\
could result in a Business \\
Interruption / Advanced \\
Loss of profit type \\
exposure, or even result in \\
the project becoming \\
uneconomic to continue. \\
Lack of adequate CO2 \\
supply could halt or limit \\
injection. Intermittent \\
injection schedule could \\
increase stress on surface \\
and down hole mechanical \\
elements, could affect \\
EOR/ECBM sweep \\
efficiency, and could \\
increase concentrations of \\
various contaminants in \\
the injected gas. \\
The timing of CO2 \\
availability may not match \\
up with the time when \\
CO2 is needed for EOR or \\
ECBM.
\end{tabular} & \begin{tabular}{|l|} 
Unlikely to be a \\
problem with \\
Coffeyville CO2 \\
supply. Possible \\
problem with Kansas \\
Ethanol CO2 supply.
\end{tabular} & $\begin{array}{l}\text { Kansas Ethanol has } \\
\text { not demonstrated } \\
\text { that it can maintain a } \\
\text { consistent CO2 } \\
\text { quality within spec. }\end{array}$ & $\begin{array}{l}\text { Need to confirm the } \\
\text { composition and } \\
\text { consistency of } \\
\text { Kansas Ethanol CO2 } \\
\text { supply. }\end{array}$ & 3 & 3 & & \begin{tabular}{|l|} 
\\
Define $\mathrm{CO} 2$ \\
specification. \\
Require historical \\
data or performance \\
test and quality \\
guarantee from CO2 \\
suppliers. \\
Implement a \\
nomination \\
procedure for \\
balancing CO2 \\
supply and demand.
\end{tabular} & $\begin{array}{l}\text { Monitor } \mathrm{CO} 2 \\
\text { quality. } \\
\text { Require } \mathrm{CO} 2 \\
\text { supplier to vent off } \\
\text { spec } \mathrm{CO} 2 \text {. }\end{array}$ \\
\hline 24 & 10.05.00. & Water supply & $\begin{array}{l}\text { 1. Water supply design specifications } \\
\text { - Flow rates } \\
\text { - Composition } \\
\text { - Pressure } \\
\text { - Temperature } \\
\text { 2. Water supply interruptions }\end{array}$ & $\begin{array}{l}\text { Could impact water and } \\
\text { gas (WAG) flooding }\end{array}$ & Possible problem. & $\begin{array}{l}\text { Water supplied from } \\
\text { Arbuckle may } \\
\text { contain } \mathrm{H} 2 \mathrm{~S} \text {. }\end{array}$ & $\begin{array}{l}\text { Need to confirm water } \\
\text { quality. }\end{array}$ & 3 & 2 & & $\begin{array}{l}\text { Take water supply } \\
\text { volume and quality } \\
\text { into account in } \\
\text { system design. } \\
\text { Consider redundant } \\
\text { pumps and water } \\
\text { storage tanks. }\end{array}$ & \begin{tabular}{|l} 
Monitor for leaks in \\
water piping. \\
\\
Add pumps, \\
filtration or water \\
treatment to \\
resolve water \\
volume or quality \\
issues. \\
Treat water for \\
corrosion, scale \\
and/or microbial \\
control.
\end{tabular} \\
\hline 25 & 10.06.00. & Power supply & $\begin{array}{l}\text { 1. Power surges } \\
\text { 2. Power brown outs } \\
\text { 3. Power interruptions (black outs) }\end{array}$ & \begin{tabular}{|l|}
$\begin{array}{l}\text { Could shut operations } \\
\text { down. } \\
\text { Append }\end{array}$ \\
\end{tabular} & $\begin{array}{l}\text { Possible problem. } \\
\text { ix 6-91 }\end{array}$ & $\begin{array}{l}\text { Power supply lines } \\
\text { in or near injection } \\
\text { sites. }\end{array}$ & \begin{tabular}{|l} 
Total kva \\
needed/available. \\
Reliability of grid in \\
area.
\end{tabular} & 3 & 2 & & $6 \begin{array}{l}\text { Install } \\
\text { generator/battery } \\
\text { backup system if } \\
\text { necessary. }\end{array}$ & \begin{tabular}{|l} 
Install surge \\
protection if it is an \\
issue.
\end{tabular} \\
\hline
\end{tabular}




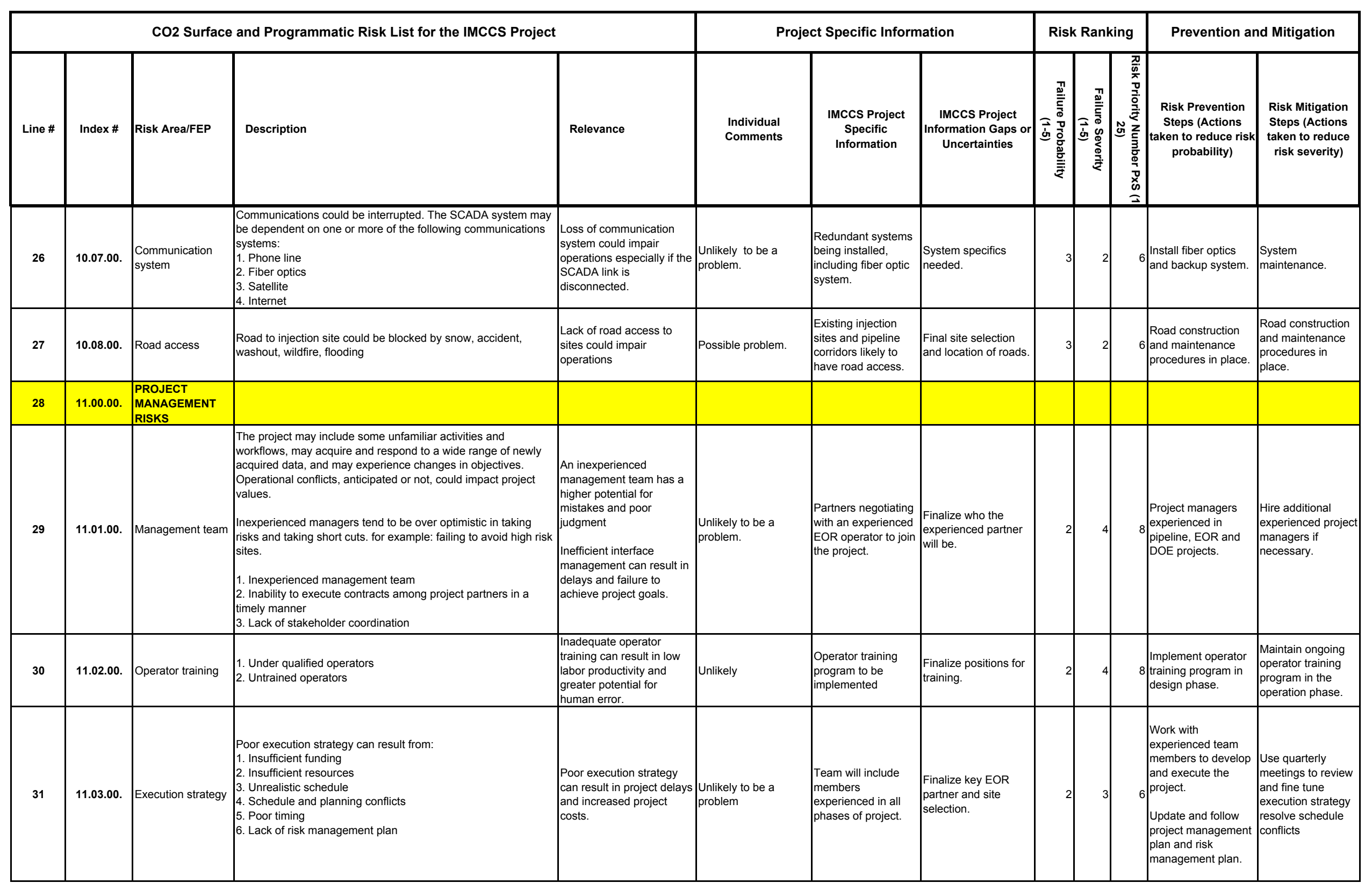




\begin{tabular}{|c|c|c|c|c|c|c|c|c|c|c|c|c|}
\hline \multicolumn{5}{|c|}{ CO2 Surface and Programmatic Risk List for the IMCCS Project } & \multicolumn{3}{|c|}{ Project Specific Information } & \multicolumn{3}{|c|}{ Risk Ranking } & \multicolumn{2}{|c|}{ Prevention and Mitigation } \\
\hline Line \# & Index \# & Risk Area/FEP & Description & Relevance & $\begin{array}{l}\text { Individual } \\
\text { Comments }\end{array}$ & $\begin{array}{l}\text { IMCCS Project } \\
\text { Specific } \\
\text { Information }\end{array}$ & $\begin{array}{c}\text { Imccs Project } \\
\text { Information Gaps or } \\
\text { Uncertainties }\end{array}$ & 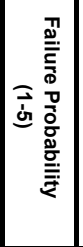 & 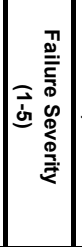 & 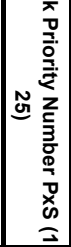 & $\begin{array}{c}\text { Risk Prevention } \\
\text { Steps (Actions } \\
\text { taken to reduce risk } \\
\text { probability) }\end{array}$ & $\begin{array}{l}\text { Risk Mitigation } \\
\text { Steps (Actions } \\
\text { taken to reduce } \\
\text { risk severity) }\end{array}$ \\
\hline 32 & 11.04.00. & Record keeping & $\begin{array}{l}\text { Large amounts of data will be generated by the project. Data } \\
\text { could be poorly communicated between groups, or be badly } \\
\text { managed to the point that important data is lost, or used } \\
\text { incorrectly. } \\
\text { 1. Poor data management } \\
\text { 2. Loss of archives/records } \\
\text { 3. Unable to accurately verify the amount of } \mathrm{CO} 2 \text { retained in } \\
\text { storage }\end{array}$ & $\begin{array}{l}\text { Insufficient record keeping } \\
\text { could lead to } \\
\text { noncompliance with } \\
\text { regulations and failure to } \\
\text { achieve project goals. }\end{array}$ & $\begin{array}{l}\text { Unlikely to be a } \\
\text { problem. }\end{array}$ & $\begin{array}{l}\text { Data management } \\
\text { for the project } \\
\text { coordinated by } \\
\text { PNNL. }\end{array}$ & $\begin{array}{l}\text { Scope of data and } \\
\text { system to bed. }\end{array}$ & 2 & 3 & & $\begin{array}{l}\text { Set up electronic } \\
\text { data management } \\
\text { system with off-site } \\
\text { backups. } \\
\text { Standardize data } \\
\text { formats. }\end{array}$ & $\begin{array}{l}\text { Maintain data } \\
\text { management } \\
\text { system and } \\
\text { standardized } \\
\text { formats. }\end{array}$ \\
\hline 33 & 11.05.00. & Multi-party project & $\begin{array}{l}\text { CCS projects may involve multiple participants for } \mathrm{CO} 2 \text { supply, } \\
\text { CO2 transportation, EPC (engineering, procurement and } \\
\text { construction), CO2 storage, computer simulation, MVA } \\
\text { (monitoring, verification and accounting), carbon trading. and } \\
\text { risk management. There are challenges and risks in } \\
\text { coordinating the responsibilities and liabilities among multiple } \\
\text { organizations involved in a project. }\end{array}$ & \begin{tabular}{|l|} 
Lack of communication, \\
coordination and \\
cooperation among project \\
participants can lead to \\
project delays and failure \\
to achieve project \\
objectives.
\end{tabular} & $\begin{array}{l}\text { Unlikely to be a } \\
\text { problem. }\end{array}$ & $\begin{array}{l}\text { Project involves } \\
\text { multiple parties. } \\
\text { Successful system } \\
\text { set up in Phase I to } \\
\text { coordinate work. }\end{array}$ & $\begin{array}{l}\text { Finalize parties that } \\
\text { will be involved in } \\
\text { Phase } 2 \text {. }\end{array}$ & 2 & 3 & & $\begin{array}{l}\text { Maintain weekly } \\
\text { secure website, } \\
\text { weekly conference } \\
\text { calls, cross- } \\
\text { functional working } \\
\text { groups and } \\
\text { management team. }\end{array}$ & $\begin{array}{l}\text { Maintain weekly } \\
\text { secure website, } \\
\text { weekly conference } \\
\text { calls, cross- } \\
\text { functional working } \\
\text { groups and } \\
\text { management team. }\end{array}$ \\
\hline 34 & 12.00 .00 . & $\begin{array}{l}\text { ENGINEERING } \\
\text { RISKS } \\
\end{array}$ & & & & & & & & & & \\
\hline 35 & 12.01.00. & Technical design & $\begin{array}{l}\text { Technical design errors can be cause by: } \\
\text { 1. Insufficient data } \\
\text { 2. Lack of data - typical of greenfield sites } \\
\text { 3. Inaccurate data } \\
\text { 4. Misinterpretation of data } \\
\text { 5. Use of wrong standards - unit conversion } \\
\text { 6. Specification errors } \\
\text { 7. Undefined specifications } \\
\text { 8. Ignoring data } \\
\text { 9. Calculation and modeling errors } \\
\text { 10. Failure to design for full range of operating conditions and } \\
\text { climate conditions. } \\
\text { 11. Failure to design for high operating availability } \\
\text { 12. Failure to design for failsafe protection for compression, } \\
\text { pipeline, injection well control systems to ensure no unintended } \\
\text { release of CO2 }\end{array}$ & $\begin{array}{l}\text { Technical design errors } \\
\text { can lead to poor } \\
\text { performance or failure of } \\
\text { equipment/systems and } \\
\text { possible CO2 release. }\end{array}$ & Possible problem. & \begin{tabular}{|l|} 
Sites may have large \\
number of existing \\
wellbores that may \\
have insufficient \\
records.
\end{tabular} & $\begin{array}{l}\text { Accuracy and } \\
\text { completeness of } \\
\text { subsurface and } \\
\text { wellbore data. }\end{array}$ & 3 & 3 & & $\begin{array}{l}\text { Conduct periodic } \\
\text { design reviews with } \\
\text { cross-functional } \\
\text { team of experts. }\end{array}$ & $\begin{array}{l}\text { Conduct periodic } \\
\text { design reviews with } \\
\text { cross-functional } \\
\text { team of experts. }\end{array}$ \\
\hline 36 & 12.02 .00 . & $\begin{array}{l}\text { Modeling and } \\
\text { simulation }\end{array}$ & $\begin{array}{l}\text { Use of multiple static and dynamic models that are populated } \\
\text { and run by different people using different assumptions and } \\
\text { methods can result in errors. }\end{array}$ & \begin{tabular}{|l|} 
Modeling and simulation \\
errors can result in \\
uncertainties, interpretive \\
disagreements and poor \\
operational choices.
\end{tabular} & Possible problem. & $\begin{array}{l}\text { Using Eclipse as } \\
\text { basic simulation } \\
\text { model }\end{array}$ & $\begin{array}{l}\begin{array}{l}\text { Accuracy and } \\
\text { completeness of } \\
\text { subsurface and } \\
\text { wellbore data. }\end{array} \\
\text { Accuracy of model(s). }\end{array}$ & 3 & 3 & & $\begin{array}{l}\text { Standardize on } \\
\text { model(s) to be used. } \\
\text { Review of simulation } \\
\text { model results for } \\
\text { accuracy and } \\
\text { completeness by } \\
\text { cross-functional } \\
\text { team of experts. }\end{array}$ & $\begin{array}{l}\text { Periodic review of } \\
\text { simulation model } \\
\text { results. }\end{array}$ \\
\hline
\end{tabular}

Appendix 6-93 


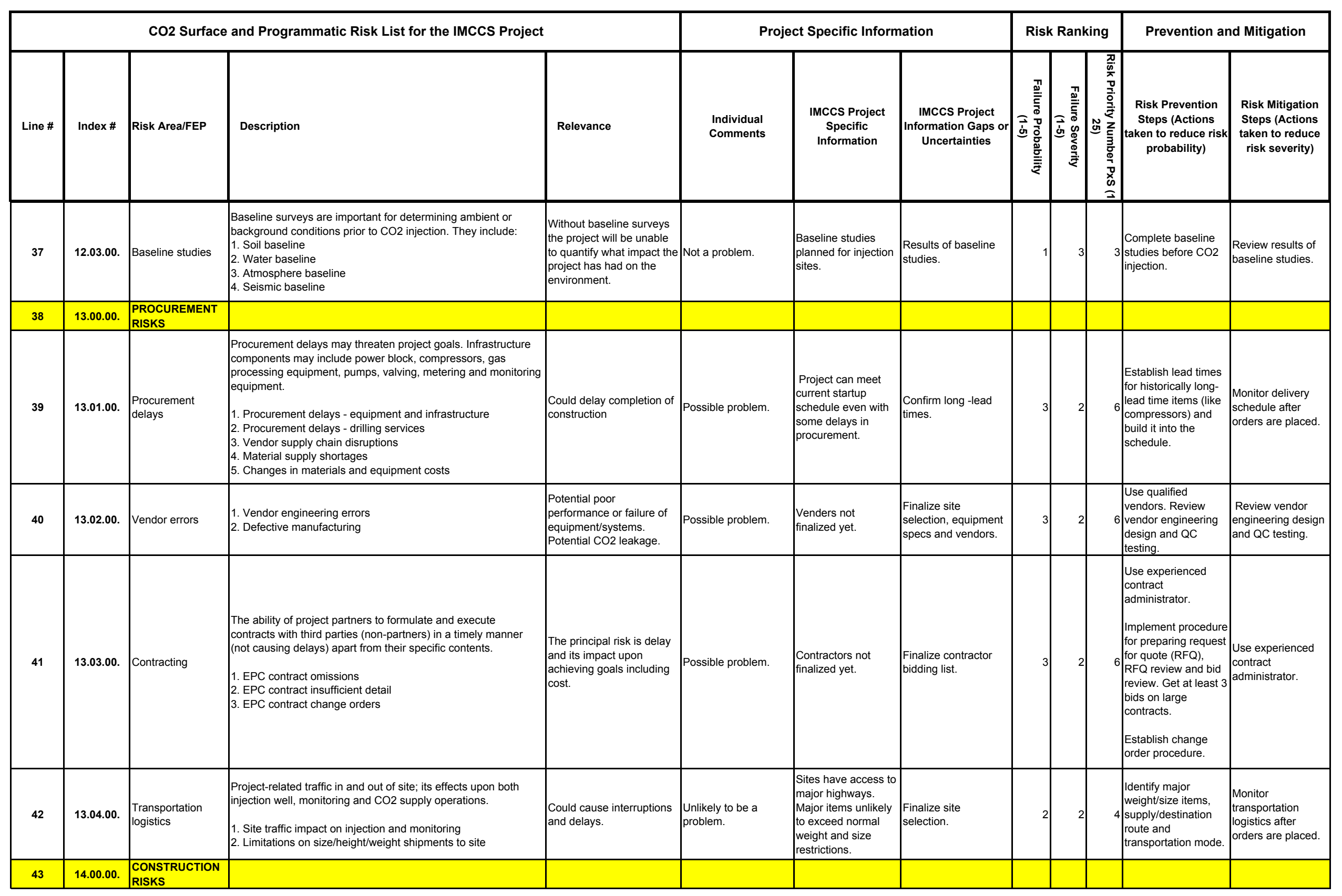

Appendix 6-94 


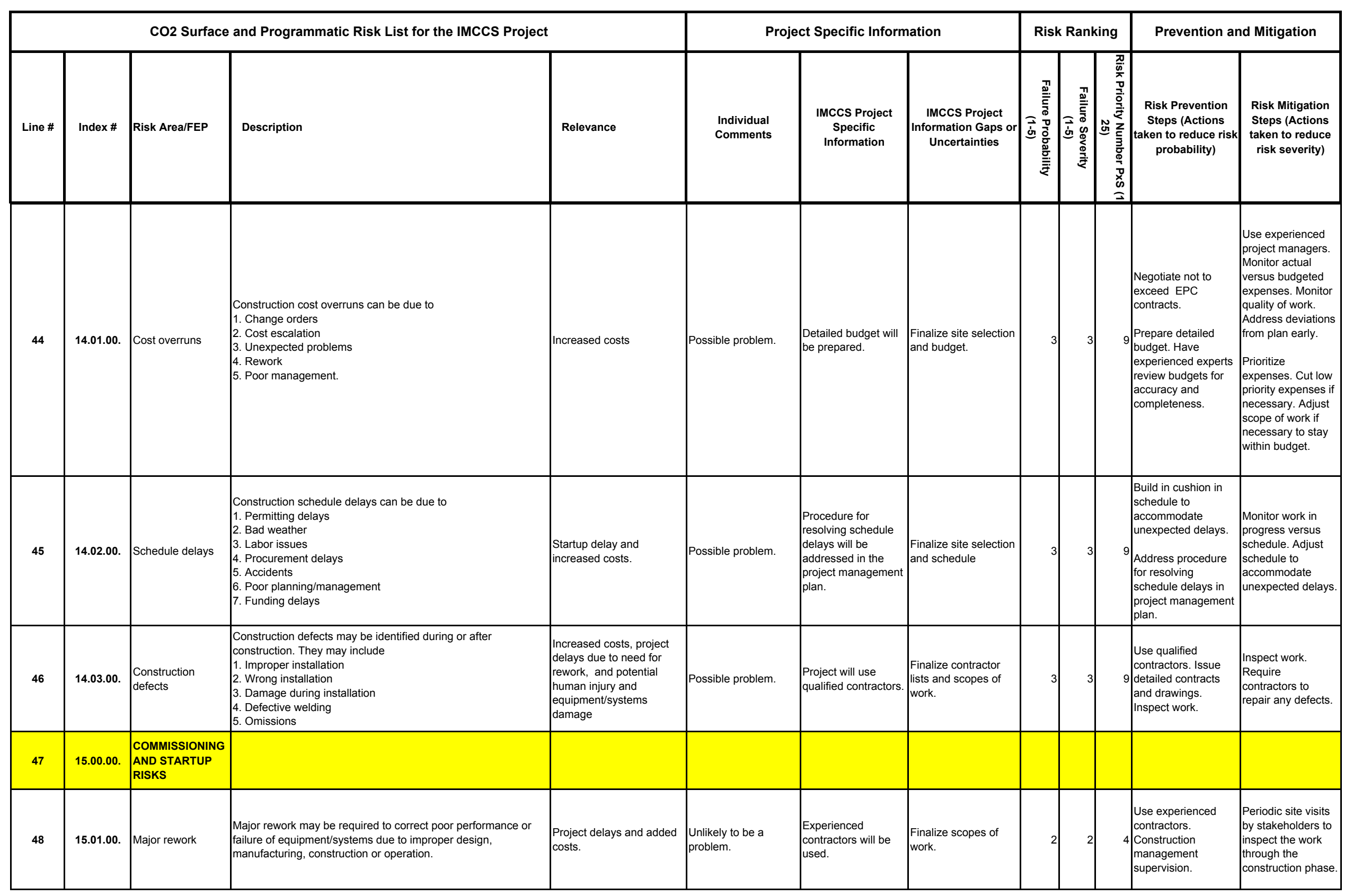

Appendix 6-95 


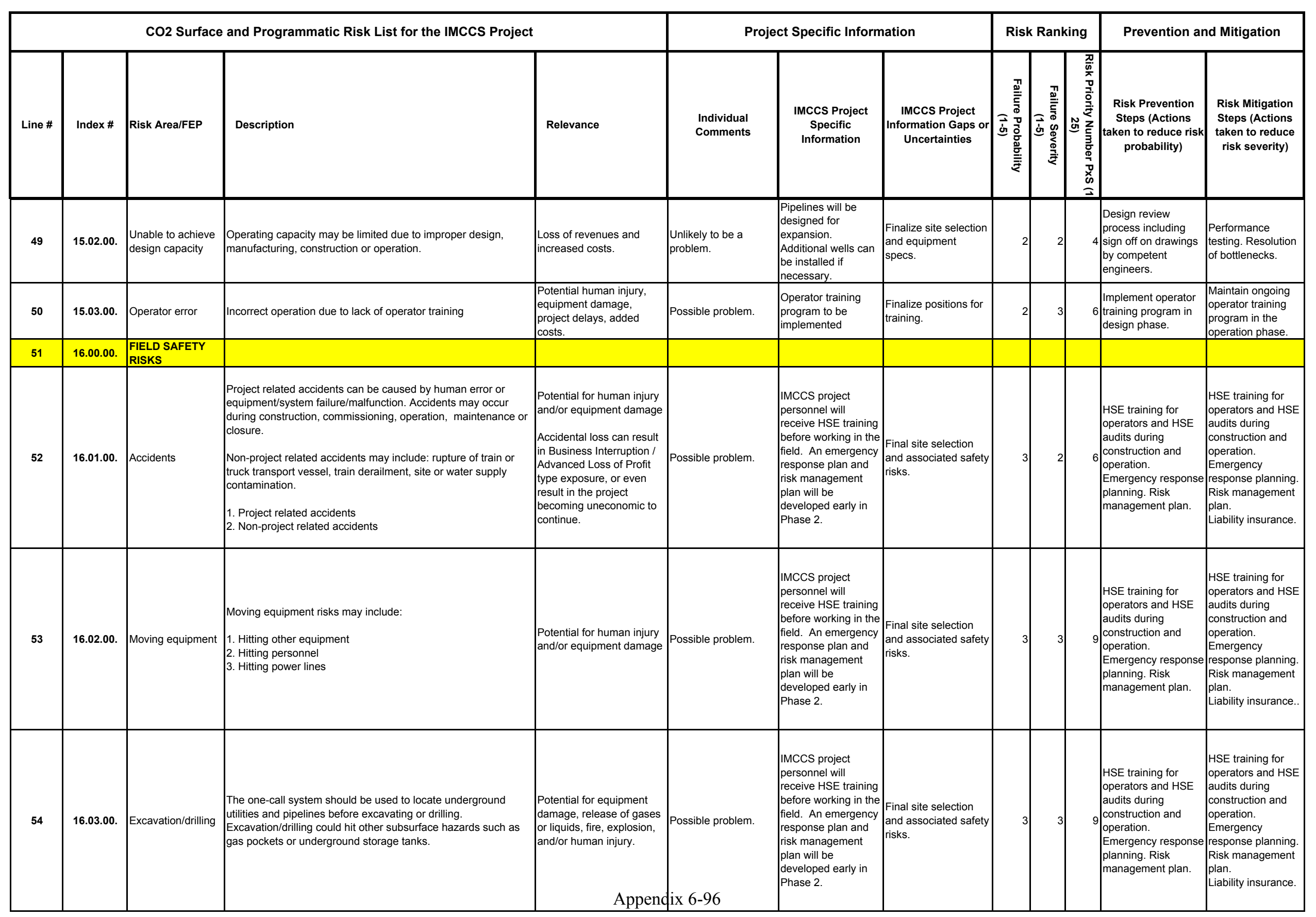




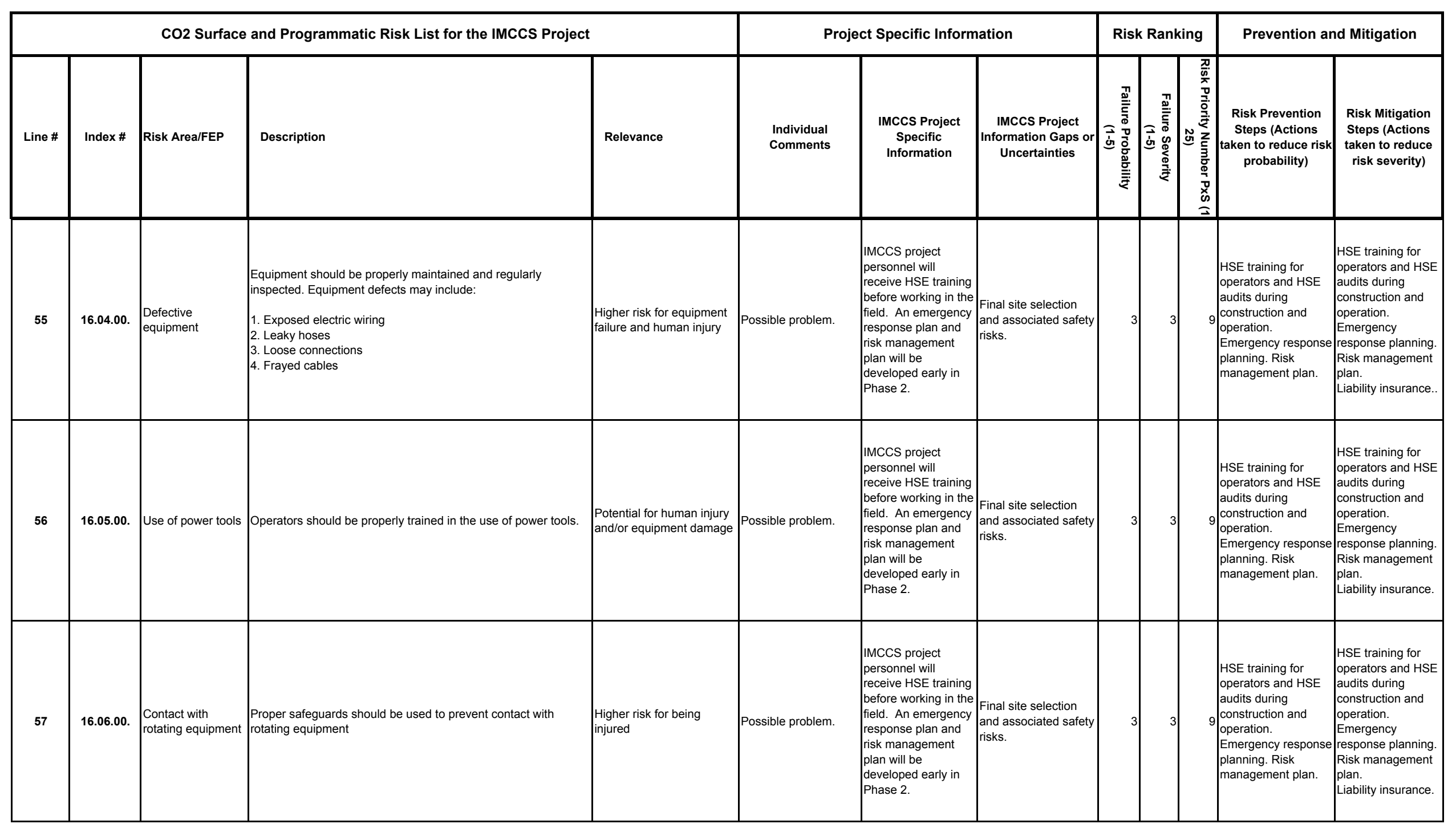




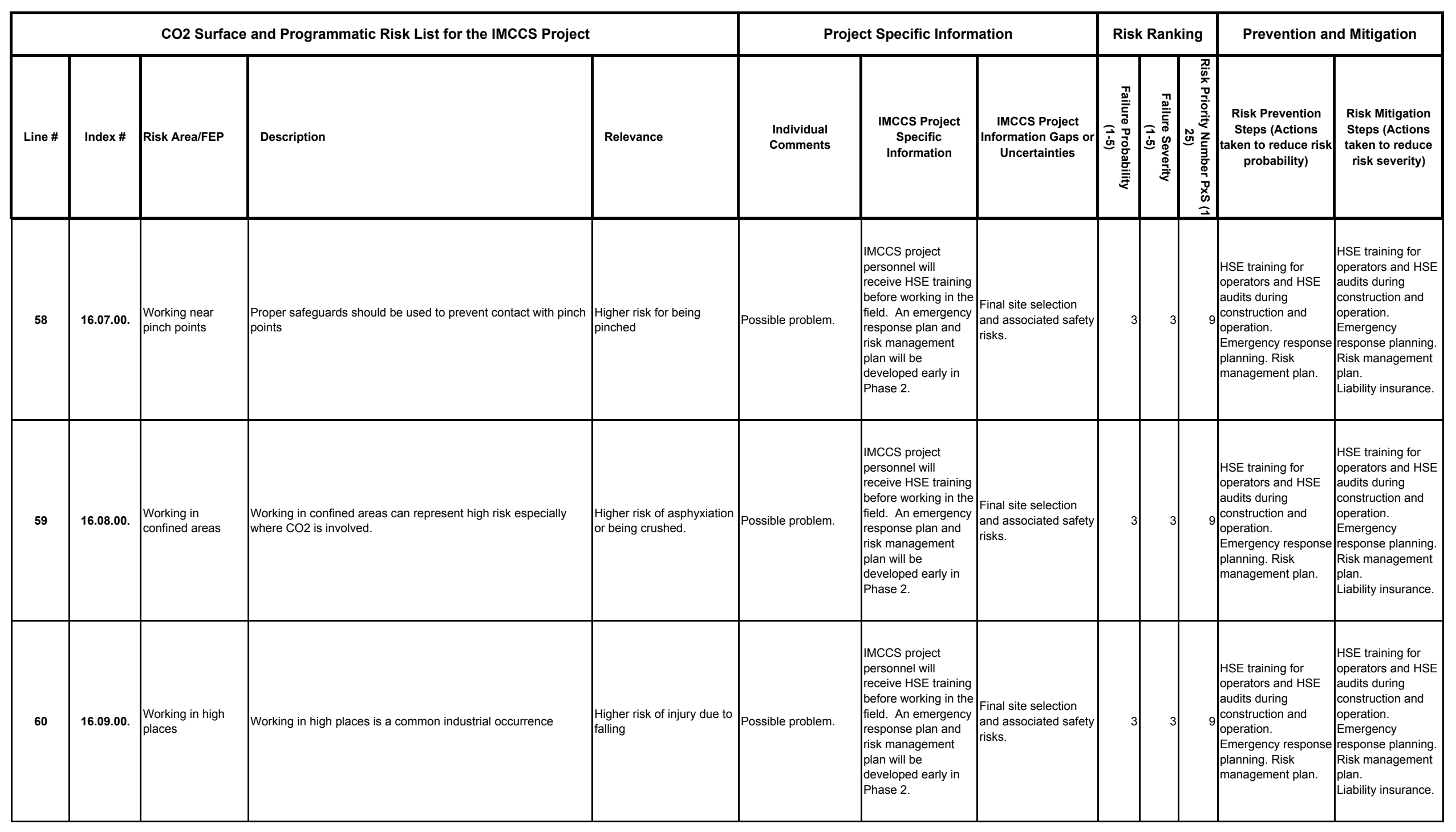




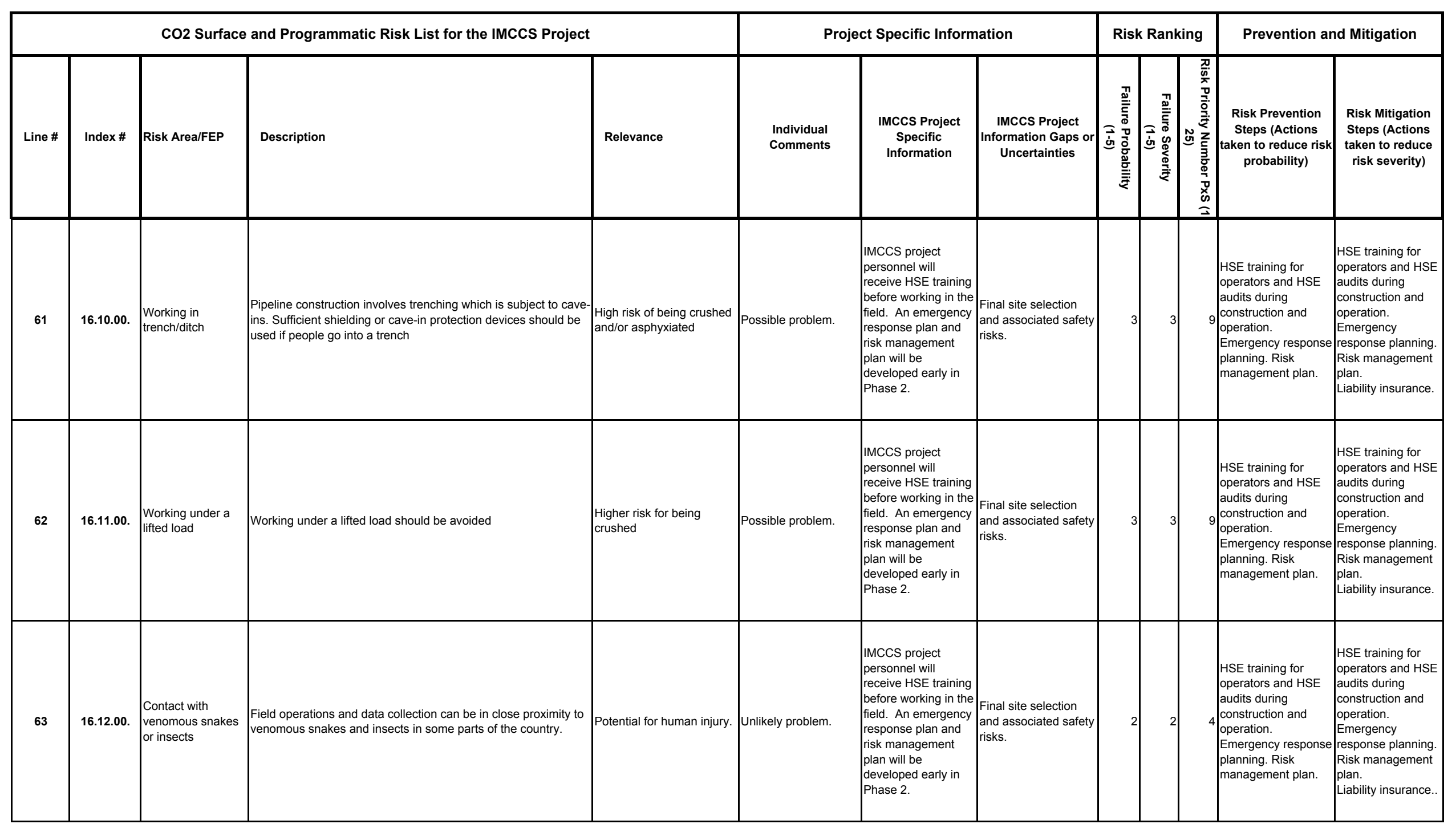




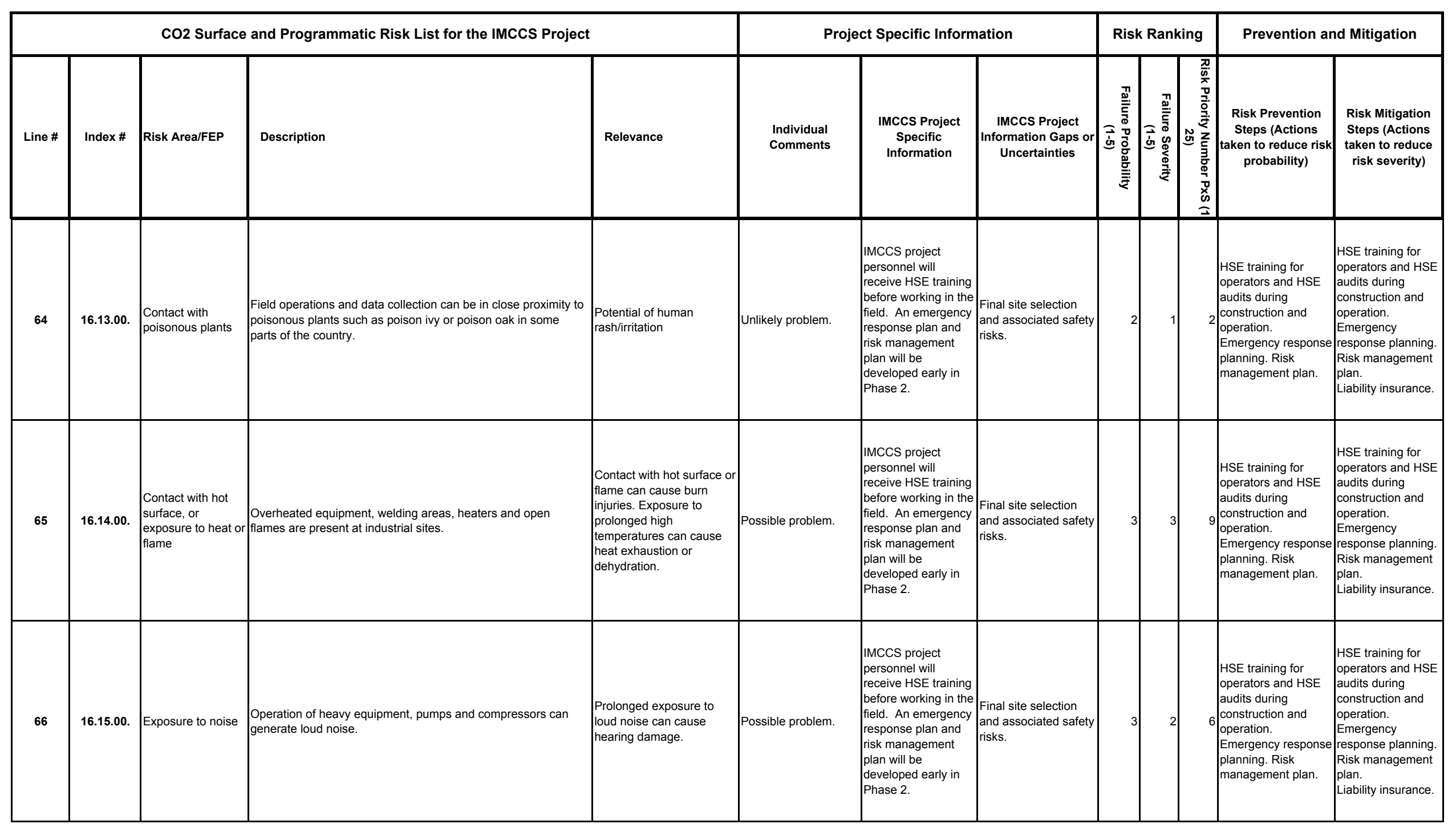




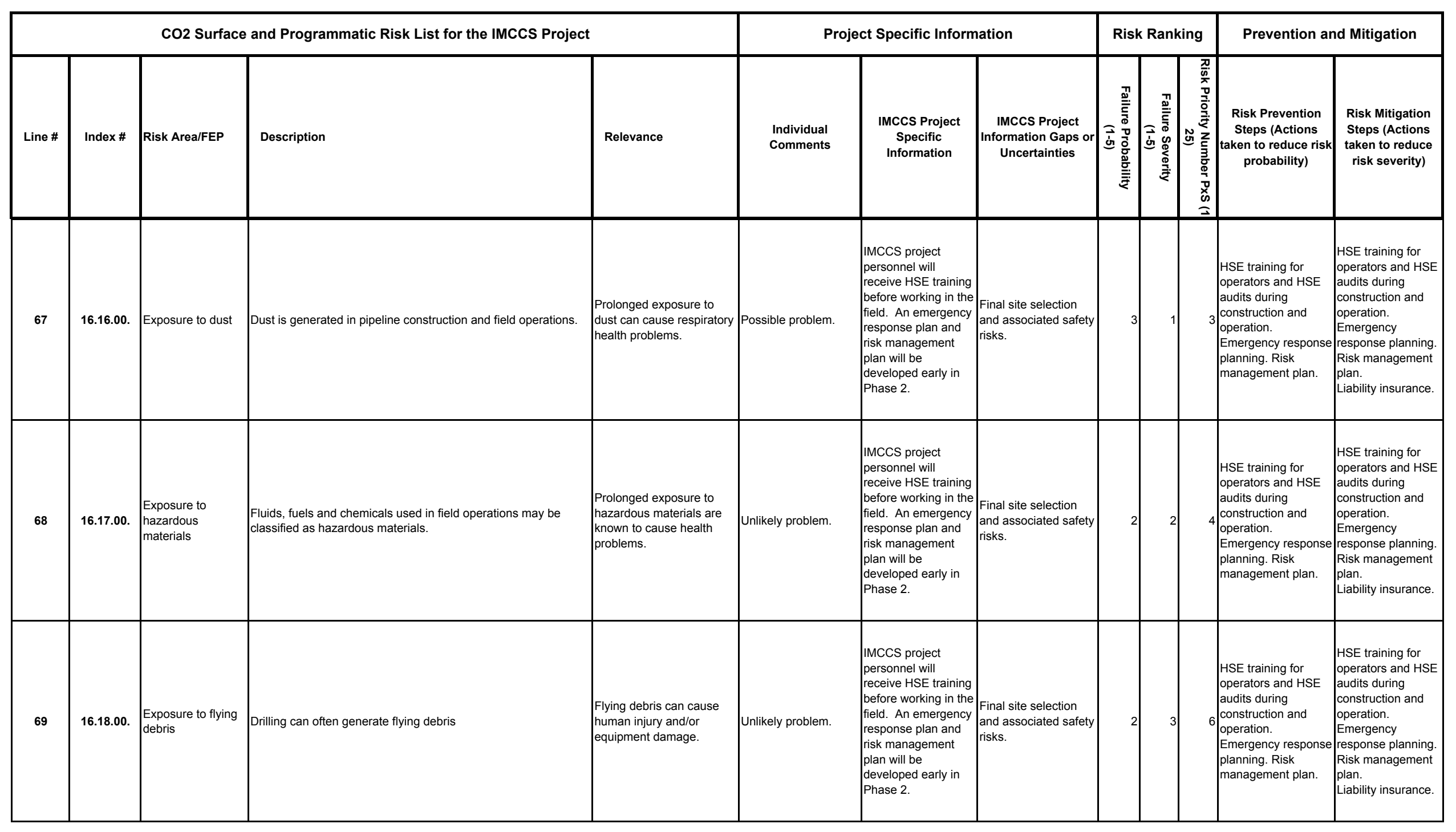




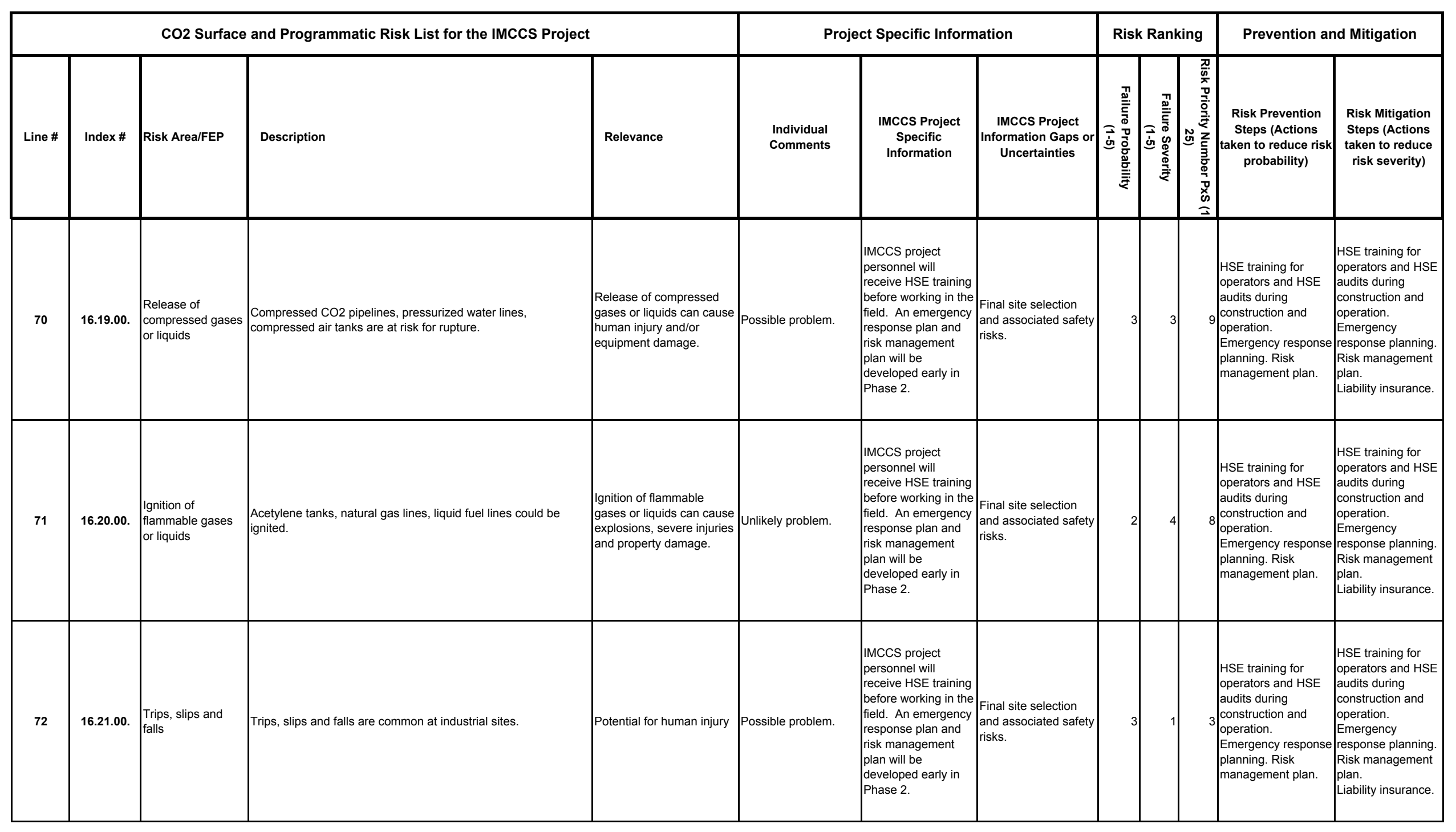




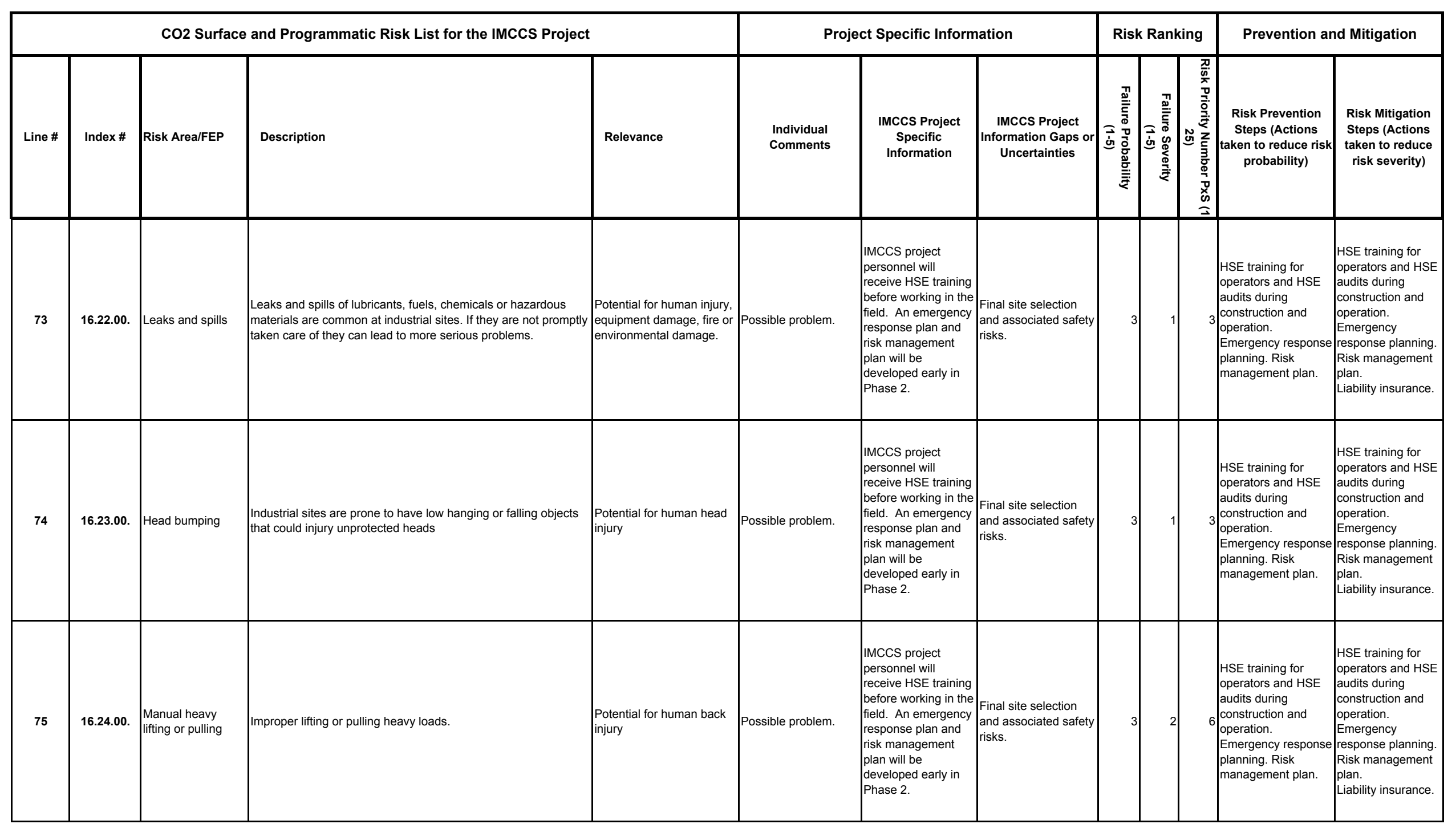




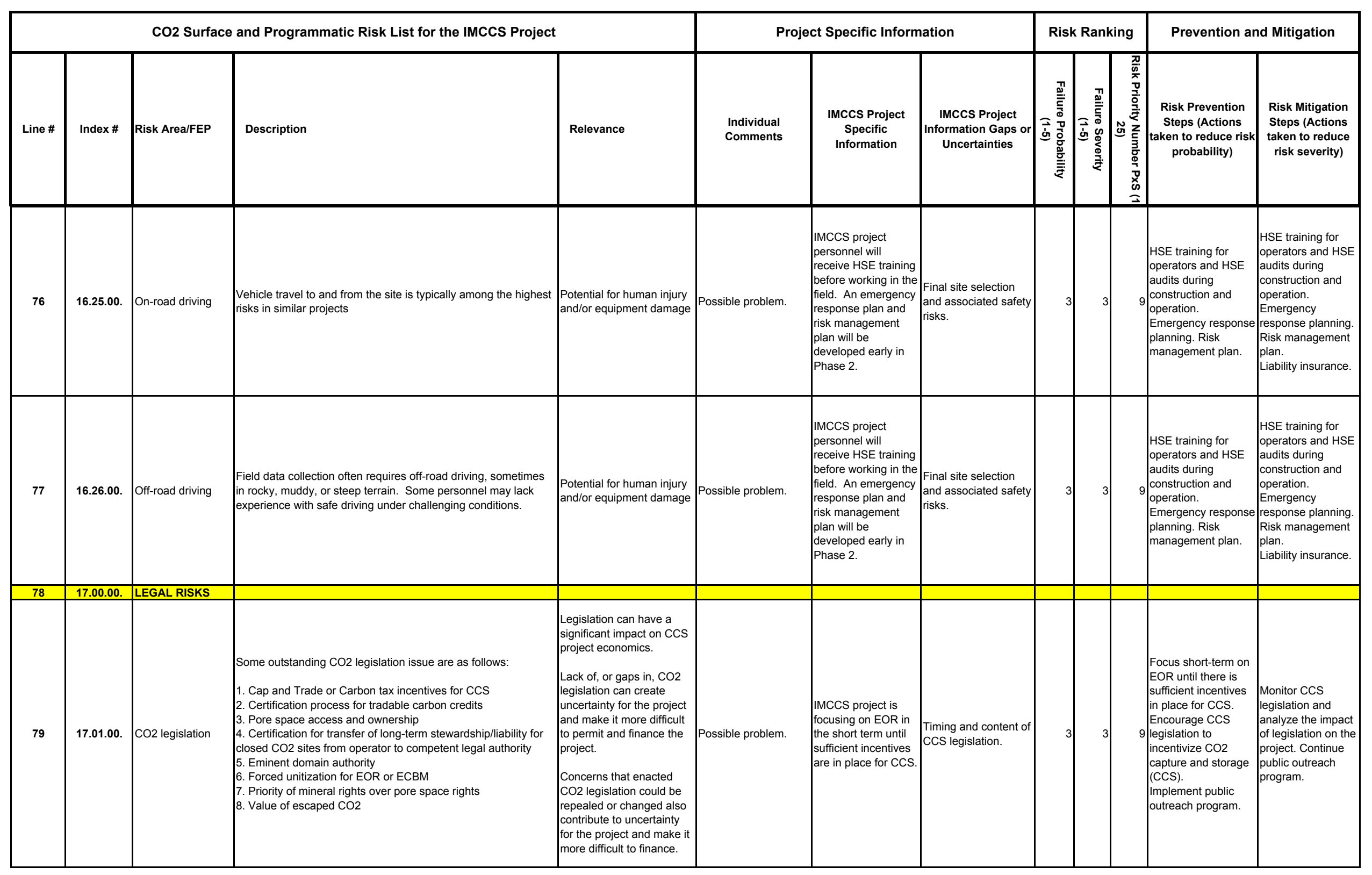




\begin{tabular}{|c|c|c|c|c|c|c|c|c|c|c|c|c|}
\hline \multicolumn{5}{|c|}{ CO2 Surface and Programmatic Risk List for the IMCCS Project } & \multicolumn{3}{|c|}{ Project Specific Information } & \multicolumn{3}{|c|}{ Risk Ranking } & \multicolumn{2}{|c|}{ Prevention and Mitigation } \\
\hline Line \# & Index \# & Risk Area/FEP & Description & Relevance & $\begin{array}{l}\text { Individual } \\
\text { Comments }\end{array}$ & $\begin{array}{l}\text { IMCCS Project } \\
\text { Specific } \\
\text { Information }\end{array}$ & $\begin{array}{c}\text { IMCCS Project } \\
\text { Information Gaps or } \\
\text { Uncertainties }\end{array}$ & 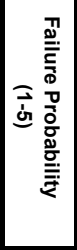 & 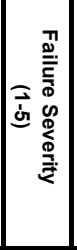 & 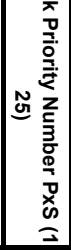 & $\begin{array}{c}\text { Risk Prevention } \\
\text { Steps (Actions } \\
\text { taken to reduce risk } \\
\text { probability) }\end{array}$ & $\begin{array}{c}\text { Risk Mitigation } \\
\text { Steps (Actions } \\
\text { taken to reduce } \\
\text { risk severity) }\end{array}$ \\
\hline 80 & 17.02.00. & $\mathrm{CO} 2$ regulations & $\begin{array}{l}\text { Some outstanding } \mathrm{CO} 2 \text { regulation issue are as follows: } \\
\text { 1. CO2 storage permitting and compliance requirements } \\
\text { 2. Permitting and compliance for Class VI wells } \\
\text { 3. Permitting and compliance for hybrid Class II and VI wells } \\
\text { (wells used for both EOR and DSA) } \\
\text { 4. Post-injection site care (monitoring) period - EPA proposing } \\
50 \text { years with some flexibility } \\
\text { 5. Safety guidelines - DOE best practices guidelines } \\
\text { 6. Monitoring protocols - DOE guidelines } \\
\text { 7. Verification and accounting procedures } \\
\text { 8. Classification of CO2 as a pollutant rather than a commodity } \\
\text { 9. CO2 emission controls and reporting }\end{array}$ & \begin{tabular}{|l|} 
Regulations can have a \\
significant impact on CCS \\
project economics. \\
Lack of, or gaps in, CO2 \\
regulations can create \\
uncertainty for the project \\
and make it more difficult \\
to permit and finance the \\
project. \\
Classification of $\mathrm{CO} 2$ as a \\
pollutant rather than a \\
commodity could impact \\
EOR/ECBM operations.
\end{tabular} & Possible problem. & $\begin{array}{l}\text { IMCCS project is } \\
\text { focusing on EOR in } \\
\text { the short term } \\
\text { because } \\
\text { current/proposed } \\
\text { regulations would } \\
\text { make DSA } \\
\text { sequestration } \\
\text { uneconomic. }\end{array}$ & $\begin{array}{l}\text { Timing and content of } \\
\text { CCS regulations. }\end{array}$ & 3 & 3 & & \begin{tabular}{|l} 
Focus short-term on \\
EOR until \\
regulations for CCS \\
are finalized. \\
Implement public \\
outreach program.
\end{tabular} & $\begin{array}{l}\text { Comply with } \\
\text { regulations as they } \\
\text { are issued. }\end{array}$ \\
\hline 81 & 17.03.00. & CO2 liabilities & $\begin{array}{l}\text { Responsibility for the injected CO2 and any associated liability, } \\
\text { during and after active project phase, is currently an unresolved } \\
\text { legal issue. Project participants could reduce their involvement } \\
\text { if this issue remains unresolved, or is resolved in a manner that } \\
\text { unacceptably increases their exposure. } \\
\text { 1. CO2 ownership and custody } \\
\text { 2. Tort-injury to a third party (person or property) } \\
\text { 3. Property-rights dispute } \\
\text { 4. Trespass - contamination of third-party natural resources } \\
\text { 5. Trespass - infringement on third-party pore space } \\
\text { 6. Breach of duty - leakage sufficient to undermine the value of } \\
\text { carbon credits } \\
\text { 7. Frivolous lawsuits private or organizational based legal } \\
\text { challenges } \\
\text { 8. Surface ownership and associated liability } \\
\text { 9. Assigning liability responsibility in a multi-party project }\end{array}$ & $\begin{array}{l}\text { Liability for potential } \\
\text { damages associated with } \\
\text { sequestration or } \\
\text { operational aspects could } \\
\text { preclude the project from } \\
\text { moving forward. } \\
\\
\text { Property-right disputes } \\
\text { over surface rights, } \\
\text { mineral rights or pore } \\
\text { space could halt or restrict } \\
\text { construction, CO2 } \\
\text { injection or monitoring } \\
\text { operations for CCS } \\
\text { projects. }\end{array}$ & Possible problem. & $\begin{array}{l}\text { IMCCS project is } \\
\text { focusing on EOR in } \\
\text { the short term. This } \\
\text { is likely to have } \\
\text { fewer liability issues } \\
\text { than CCS. }\end{array}$ & $\begin{array}{l}\text { Availability and cost } \\
\text { of insurance to cover } \\
\text { liabilities. }\end{array}$ & 3 & 2 & & $\begin{array}{l}\text { Obtain liability } \\
\text { insurance. }\end{array}$ & $\begin{array}{l}\text { Obtain liability } \\
\text { insurance. }\end{array}$ \\
\hline 82 & 17.03 .01 & \begin{tabular}{|l} 
Lack of available \\
insurance
\end{tabular} & $\begin{array}{l}\text { There are many types of insurance coverage. Some of those } \\
\text { that pertain to CCS include: } \\
\text { 1. physical damage } \\
\text { 2. machinery breakdown } \\
\text { 3. business interruption (advanced loss of profit) } \\
\text { 4. environmental, and } \\
\text { 5. third-party liability. }\end{array}$ & \begin{tabular}{l|} 
Insurance coverage may \\
not be available for CCS \\
projects until there is a \\
sufficient track record of \\
perforce (or failure) to \\
determine the probability \\
of failure occurring.
\end{tabular} & 6-105 & $\begin{array}{l}\text { Marsh has been } \\
\text { assigned to obtain } \\
\text { insurance for the } \\
\text { IMCCS project. }\end{array}$ & $\begin{array}{l}\text { Availability and cost } \\
\text { of insurance. }\end{array}$ & 4 & 3 & 12 & $\begin{array}{l}\text { Self insure. } \\
\text { Work with a } \\
\text { competent insurance } \\
\text { broker to prepare } \\
\text { Estimated Maximum } \\
\text { Loss Analyses and } \\
\text { underwriting reports } \\
\text { for the project and } \\
\text { source insurance } \\
\text { coverage }\end{array}$ & $\begin{array}{l}\text { Self insure. } \\
\text { Work with a } \\
\text { competent } \\
\text { insurance broker to } \\
\text { prepare Estimated } \\
\text { Maximum Loss } \\
\text { Analyses and } \\
\text { underwriting } \\
\text { reports for the } \\
\text { project and source } \\
\text { insurance } \\
\text { coverage }\end{array}$ \\
\hline
\end{tabular}




\begin{tabular}{|c|c|c|c|c|c|c|c|c|c|c|c|c|}
\hline \multicolumn{5}{|c|}{ CO2 Surface and Programmatic Risk List for the IMCCS Project } & \multicolumn{3}{|c|}{ Project Specific Information } & \multicolumn{3}{|c|}{ Risk Ranking } & \multicolumn{2}{|c|}{ Prevention and Mitigation } \\
\hline Line \# & Index \# & Risk Area/FEP & Description & Relevance & $\begin{array}{l}\text { Individual } \\
\text { Comments }\end{array}$ & $\begin{array}{l}\text { IMCCS Project } \\
\text { Specific } \\
\text { Information }\end{array}$ & $\begin{array}{c}\text { IMCCS Project } \\
\text { Information Gaps or } \\
\text { Uncertainties }\end{array}$ & 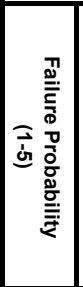 & 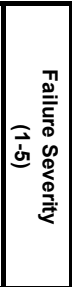 & 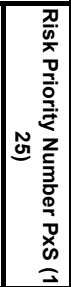 & \begin{tabular}{|c|} 
\\
Risk Prevention \\
Steps (Actions \\
taken to reduce risk \\
probability) \\
\end{tabular} & $\begin{array}{c}\text { Risk Mitigation } \\
\text { Steps (Actions } \\
\text { taken to reduce } \\
\text { risk severity) }\end{array}$ \\
\hline 83 & 17.03.02 & $\begin{array}{l}\text { Transfer of long- } \\
\text { term } \\
\text { liability/stewardshi } \\
p\end{array}$ & $\begin{array}{l}\text { Public companies cannot take on long-term liability for } 50 \text { years } \\
\text { or more. There is no guarantee companies will stay in business } \\
\text { that long. Therefore it is up to a government entity to take on } \\
\text { responsibility. The federal government would be preferred } \\
\text { because it would level the playing field among states and } \\
\text { spread the risks. A sinking fund could be used to cover the } \\
\text { costs of such a program. }\end{array}$ & $\begin{array}{l}\text { Companies are unlikely to } \\
\text { invest in deep saline } \\
\text { aquifer (DSA) } \\
\text { sequestration projects } \\
\text { without some assurance } \\
\text { that the long-term liability } \\
\text { is transferable or } \\
\text { manageable. }\end{array}$ & $\begin{array}{l}\text { Unlikely to be a } \\
\text { problem with EOR but } \\
\text { definitely a problem } \\
\text { with DSA. }\end{array}$ & $\begin{array}{l}\text { The IMCCS project } \\
\text { has focused on EOR } \\
\text { rather than DSA in } \\
\text { part because of the } \\
\text { additional liabilities } \\
\text { associated with } \\
\text { DSA. }\end{array}$ & $\begin{array}{l}\text { Legislation covering } \\
\text { long-term liability of } \\
\text { CO2 sequestration. }\end{array}$ & 4 & 3 & 12 & $\begin{array}{l}\text { Encourage the } \\
\text { federal government } \\
\text { to establish a sinking } \\
\text { fund for CCS and } \\
\text { pass legislation to } \\
\text { allow transfer of long- } \\
\text { term liability }\end{array}$ & $\begin{array}{l}\text { Monitor } \mathrm{CO} 2 \\
\text { legislation and take } \\
\text { corrective action as } \\
\text { necessary. }\end{array}$ \\
\hline 84 & 18.00.00. & \begin{tabular}{|l|} 
CO2 CAPTURE \\
RISKS
\end{tabular} & & & & & & & & & & \\
\hline 85 & 18.01.00. & $\begin{array}{l}\mathrm{CO} 2 \text { capture } \\
\text { system } \\
\text { performance }\end{array}$ & $\begin{array}{l}\text { Performance risks for } \mathrm{CO} 2 \text { capture systems could include: } \\
\text { 1. Production below design capacity } \\
\text { 2. Unable to meet product specification } \\
\text { 3. Low } \mathrm{CO} 2 \text { recovery } \\
\text { 4. Low thermal efficiency - greater heat losses than expected, } \\
\text { low heat recovery } \\
\text { 5. Excess solvent or sorbent consumption } \\
\text { 6. Excess power consumption } \\
\text { 7. Excess steam consumption } \\
\text { 8. Excess cooling water circulation required } \\
\text { 9. Excess maintenance } \\
\text { 10. Low process availability } \\
\text { 11. Low mechanical availability }\end{array}$ & $\begin{array}{l}\text { Poor performance of the } \\
\text { CO2 capture system can } \\
\text { result in higher operating } \\
\text { and maintenance costs, } \\
\text { interruption of } \mathrm{CO} 2 \\
\text { supply, and/or off spec } \\
\text { CO2. }\end{array}$ & \begin{tabular}{|l} 
Likely problem at \\
Kansas Ethanol \\
meeting CO2 \\
specification due to \\
batch operation \\
resulting in \\
inconsistent $\mathrm{CO} 2$ \\
quality.
\end{tabular} & \begin{tabular}{|l|} 
CO2 capture \\
existing at \\
Coffeyville \\
Resources and \\
Kansas Ethanol. C
\end{tabular} & $\begin{array}{l}\text { CO2 quality and } \\
\text { consistency at } \\
\text { Kansas Ethanol. }\end{array}$ & 4 & 3 & 12 & $\begin{array}{l}\text { Require performance } \\
\text { data from Kansas } \\
\text { Ethanol to prove } \\
\text { they can consistently } \\
\text { meet } \mathrm{CO} 2 \text { spec. } \\
\text { Require } \mathrm{CO} 2 \text { quality } \\
\text { guarantee from } \\
\text { Kansas thanol and } \\
\text { Coffeyville } \\
\text { Resources. }\end{array}$ & $\begin{array}{l}\text { Adjust Kansas } \\
\text { Ethanol system } \\
\text { design to } \\
\text { consistently meet } \\
\text { CO2 specification. }\end{array}$ \\
\hline 86 & 18.02.00. & $\begin{array}{l}\text { CO2 capture } \\
\text { system design }\end{array}$ & $\begin{array}{l}\text { Design deficiencies for } \mathrm{CO} 2 \text { capture systems could include: } \\
\text { 1. Scale-up errors } \\
\text { 2. Equipment undersized/oversized for proper residence time } \\
\text { 3. Equipment undersized/oversized for proper surface area } \\
\text { 4. Excess velocities } \\
\text { 5. Inadequate expansion joints } \\
\text { 6. System bottlenecks } \\
\text { 7. Inadequate instrumentation } \\
\text { 8. Inadequate process controls and alarms } \\
\text { 9. Inadequate computer simulation models } \\
\text { 10. Wrong sorption model for the contacting devise } \\
\text { 11. Insufficient winterization } \\
\text { 12. Wrong materials of construction } \\
\text { 13. Lack of emergency flare/vent } \\
\text { 14. Lack of surge capacity } \\
\text { 15. Lack of redundancy -backup systems }\end{array}$ & $\begin{array}{l}\text { Design deficiencies can } \\
\text { result in poor } \\
\text { performance, higher } \\
\text { operating and } \\
\text { maintenance costs, } \\
\text { interruption of } \mathrm{CO} 2 \\
\text { supply, and/or off-spec } \\
\text { CO2.. }\end{array}$ & Not a problem. & $\begin{array}{l}\text { CO2 capture } \\
\text { existing at } \\
\text { Coffeyville } \\
\text { Resources and } \\
\text { Kansas Ethanol. } \\
\text { No new CO2 } \\
\text { capture unit in } \\
\text { IMCCS project. }\end{array}$ & $\begin{array}{l}\text { CO2 quality and } \\
\text { consistency at } \\
\text { Kansas Ethanol. }\end{array}$ & 1 & 3 & & $\begin{array}{l}\text { Source } \mathrm{CO} 2 \text { from } \\
\text { existing capture } \\
\text { facilities with } \\
\text { proven reliability } \\
\text { and consistent } \\
\text { product quality. . }\end{array}$ & $\begin{array}{l}\text { Identify backup } \\
\text { sources of CO2 } \\
\text { supply. }\end{array}$ \\
\hline
\end{tabular}




\begin{tabular}{|c|c|c|c|c|c|c|c|c|c|c|c|c|}
\hline \multicolumn{5}{|c|}{ CO2 Surface and Programmatic Risk List for the IMCCS Project } & \multicolumn{3}{|c|}{ Project Specific Information } & \multicolumn{3}{|c|}{ Risk Ranking } & \multicolumn{2}{|c|}{ Prevention and Mitigation } \\
\hline Line \# & Index \# & Risk Area/FEP & Description & Relevance & $\begin{array}{l}\text { Individual } \\
\text { Comments }\end{array}$ & $\begin{array}{l}\text { IMCCS Project } \\
\text { Specific } \\
\text { Information }\end{array}$ & $\begin{array}{c}\text { IMCCS Project } \\
\text { Information Gaps or } \\
\text { Uncertainties }\end{array}$ & 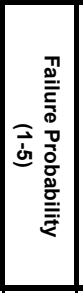 & 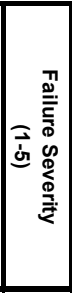 & 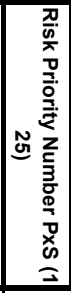 & \begin{tabular}{|c|} 
Risk Prevention \\
Steps (Actions \\
taken to reduce risk \\
probability) \\
\end{tabular} & $\begin{array}{c}\text { Risk Mitigation } \\
\text { Steps (Actions } \\
\text { taken to reduce } \\
\text { risk severity) }\end{array}$ \\
\hline 87 & 18.03.00. & $\begin{array}{l}\text { CO2 capture } \\
\text { system economies- } \\
\text { of-scale }\end{array}$ & $\begin{array}{l}\text { The limits on scale up of the } \mathrm{CO} 2 \text { capture system could include: } \\
\text { 1. Equipment size limits - manufacturing, transport, or structural } \\
\text { load limits } \\
\text { 2. Heat transfer limits } \\
\text { 3. Mass transfer limits } \\
\text { 4. Diffusion limits } \\
\text { 5. Surface area limits } \\
\text { 6. Reaction kinetics limits }\end{array}$ & $\begin{array}{l}\text { Limits in scale up of the } \\
\text { CO2 capture system can } \\
\text { lead to higher capital cost } \\
\text { and higher operating } \\
\text { costs. }\end{array}$ & Not a problem. & $\begin{array}{l}\text { CO2 capture } \\
\text { existing at } \\
\text { Coffeyville } \\
\text { Resources and } \\
\text { Kansas Ethanol. } \\
\text { No new } \mathrm{CO} 2 \\
\text { capture unit in } \\
\text { I MCCS project. }\end{array}$ & $\begin{array}{l}\text { Type of } \mathrm{CO} 2 \\
\text { capture unit to be } \\
\text { used if source } \\
\text { other than Kansas } \\
\text { Ethanol or } \\
\text { Coffeyville } \\
\text { Resources. }\end{array}$ & 1 & 3 & & $\begin{array}{l}\text { Source CO2 from } \\
\text { existing capture } \\
\text { facilities with } \\
\text { proven reliability } \\
\text { and consistent } \\
\text { product quality. . }\end{array}$ & $\begin{array}{l}\text { Identify backup } \\
\text { sources of CO2 } \\
\text { supply. }\end{array}$ \\
\hline 88 & 18.04.00. & $\begin{array}{l}\text { CO2 capture } \\
\text { system operations }\end{array}$ & $\begin{array}{l}\text { System operating risks for } \mathrm{CO} 2 \text { capture systems could include: } \\
\text { 1. Non-equilibrium or non-steady-state conditions } \\
\text { 2. Exothermic reactions overheating the process } \\
\text { 3. Endothermic reactions overcooling the process } \\
\text { 4. Pressure/stress buildup } \\
\text { 5. Non-uniform mass distribution/dispersion/mixing - dead } \\
\text { zones, stratification } \\
\text { 6. Non-uniform temperature distribution - hot/cold spots, } \\
\text { stratification } \\
\text { 7. Mass and energy imbalance } \\
\text { 8. System imbalance } \\
\text { 9. Pressure or temperature cycling } \\
\text { 10. System upset - unexpected high flow rate/temperature, } \\
\text { carryover of upstream contaminants } \\
\text { 11. Off-spec or inconsistent feed and/or product } \\
\text { 12. Abrasion/erosion } \\
\text { 13. Corrosion } \\
\text { 14. Fouling } \\
\text { 15. Contactor plugging } \\
\text { 16. CO2 escape/leakage to the atmosphere } \\
\text { 17. Scale build up causing heat exchanger failure } \\
\text { 18. Air leakage - nitrogen dilution } \\
\text { 19. Equipment failure due to defects, plugging, wear } \\
\text { 20. Control system failure } \\
\text { 21. Material/weld failure - leaks } \\
\text { 22. Operator error }\end{array}$ & $\begin{array}{l}\text { Operation and } \\
\text { maintenance problems } \\
\text { can result in higher } \\
\text { operating and } \\
\text { maintenance costs, } \mathrm{CO} 2 \\
\text { supply interruptions and } \\
\text { off-spec } \mathrm{CO} 2 \text {. }\end{array}$ & $\begin{array}{l}\text { Unlikely to be a } \\
\text { problem. }\end{array}$ & $\begin{array}{l}\text { CO2 capture } \\
\text { existing at } \\
\text { Coffeyville } \\
\text { Resources and } \\
\text { Kansas Ethanol. } \\
\text { Consistently high } \\
\text { plant availability } \\
\text { demonstrated. }\end{array}$ & $\begin{array}{l}\text { Actual } \\
\text { performance data } \\
\text { from Kansas } \\
\text { Ethanol and } \\
\text { Coffeyville } \\
\text { Resources. }\end{array}$ & 2 & 3 & & $\begin{array}{l}\text { Comprehensive } \\
\text { maintenance } \\
\text { program. } \\
\text { Maximize time at } \\
\text { steady-state } \\
\text { operation. }\end{array}$ & $\begin{array}{l}\text { Comprehensive } \\
\text { maintenance } \\
\text { program. } \\
\text { Maximize time } \\
\text { at steady-state } \\
\text { operation. }\end{array}$ \\
\hline
\end{tabular}




\begin{tabular}{|c|c|c|c|c|c|c|c|c|c|c|c|c|}
\hline \multicolumn{5}{|c|}{ CO2 Surface and Programmatic Risk List for the IMCCS Project } & \multicolumn{3}{|c|}{ Project Specific Information } & \multicolumn{3}{|c|}{ Risk Ranking } & \multicolumn{2}{|c|}{ Prevention and Mitigation } \\
\hline Line \# & Index \# & Risk Area/FEP & Description & Relevance & $\begin{array}{l}\text { Individual } \\
\text { Comments }\end{array}$ & $\begin{array}{l}\text { IMCCS Project } \\
\text { Specific } \\
\text { Information }\end{array}$ & $\begin{array}{c}\text { Imccs Project } \\
\text { Information Gaps or } \\
\text { Uncertainties }\end{array}$ & 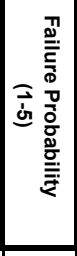 & 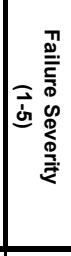 & 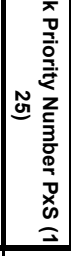 & $\begin{array}{c}\text { Risk Prevention } \\
\text { Steps (Actions } \\
\text { taken to reduce risk } \\
\text { probability) }\end{array}$ & $\begin{array}{c}\text { Risk Mitigation } \\
\text { Steps (Actions } \\
\text { taken to reduce } \\
\text { risk severity) }\end{array}$ \\
\hline 89 & 18.05.00. & $\begin{array}{l}\text { CO2 capture } \\
\text { solvent or sorbent }\end{array}$ & $\begin{array}{l}\text { Solvent or sorbent risks for } \mathrm{CO} 2 \text { capture could include: } \\
\text { 1. Off-spec or inconsistent solvent or sorbent } \\
\text { 2. Unexpected contamination (SOx, NOx, Cl, } \mathrm{H} 2 \mathrm{O} \text {, } \\
\text { hydrocarbons, trace metals, chemical slip, particulate matter) } \\
\text { 3. Gradual buildup of contaminants in circulating loads } \\
\text { 4. Foaming } \\
\text { 5. Chemical reactions with contaminants - precipitation of solids } \\
\text { 6. Excess viscosities } \\
\text { 7. Chemical degradation of solvent or sorbent } \\
\text { 8. Thermal degradation of solvent or sorbent } \\
\text { 10. Aging (deactivation) of solvent or sorbent } \\
\text { 11. Hazardous material handling }\end{array}$ & $\begin{array}{l} \\
\text { Off spec or degraded } \\
\text { solvent or sorbent can } \\
\text { result in poor } \mathrm{CO} 2 \\
\text { capture, higher operating } \\
\text { costs, CO2 supply } \\
\text { interruptions, and off-spec } \\
\text { CO2. }\end{array}$ & $\begin{array}{l}\text { Unlikely to be a } \\
\text { problem. }\end{array}$ & $\begin{array}{l}\text { CO2 capture } \\
\text { solvents and } \\
\text { sorbents not used } \\
\text { at Kansas } \\
\text { Ethanol. }\end{array}$ & $\begin{array}{l}\text { Performance of } \\
\text { Selexol solvent at } \\
\text { Coffeyville } \\
\text { Resources. }\end{array}$ & 2 & 3 & & \begin{tabular}{|l} 
Monitor solvent \\
performance. \\
Avoid conditions \\
that would result \\
in solvent foaming \\
or degradation.
\end{tabular} & $\begin{array}{l}\text { Monitor solvent } \\
\text { performance. } \\
\text { Avoid conditions } \\
\text { that would result } \\
\text { in solvent } \\
\text { foaming or } \\
\text { degradation. }\end{array}$ \\
\hline 90 & 19.00.00. & $\begin{array}{l}\text { DEHYDRATION } \\
\text { RISKS }\end{array}$ & & & & & & & & & & \\
\hline 91 & 19.01.00. & $\begin{array}{l}\mathrm{CO} 2 \text { dehydration } \\
\text { system } \\
\text { performance }\end{array}$ & $\begin{array}{l}\text { Performance risks for } \mathrm{CO} 2 \text { dehydration systems could include: } \\
\text { 1. Production below design capacity } \\
\text { 2. Unable to meet product specification } \\
\text { 3. Excess glycol consumption } \\
\text { 4. Carryover of glycol into downstream systems } \\
\text { 5. Excess utility consumption } \\
\text { 6. Excess maintenance } \\
\text { 7. Low plant process and/or mechanical availability }\end{array}$ & $\begin{array}{l}\text { Poor performance of the } \\
\text { CO2 dehydration system } \\
\text { can result in higher } \\
\text { operating and } \\
\text { maintenance costs, } \\
\text { interruption of } \mathrm{CO} 2 \\
\text { supply, off spec } \mathrm{CO} 2 \text {, and } \\
\text { corrosion of downstream } \\
\text { systems. }\end{array}$ & $\begin{array}{l}\text { Dehydration units are } \\
\text { normally fairly reliable } \\
\text { as long as they are } \\
\text { maintained, and avoid } \\
\text { upset conditions } \\
\text { and/or contamination. } \\
\text { Performance } \\
\text { problems are most } \\
\text { likely occur in the } \\
\text { Kansas Ethanol } \\
\text { dehydration unit } \\
\text { because of } \\
\text { inconsistent feed gas } \\
\text { composition and flow } \\
\text { rate. }\end{array}$ & $\begin{array}{l}\text { Dehydration units } \\
\text { will be installed at } \\
\text { Coffeyville } \\
\text { Resources and } \\
\text { Kansas Ethanol. }\end{array}$ & $\begin{array}{l}\text { Performance } \\
\text { data/experience } \\
\text { for the specific } \\
\text { dehydration units. } \\
\text { Performance data } \\
\text { for Kansas Ethanol } \\
\text { flow rate and gas } \\
\text { composition over a } \\
\text { batch cycle. }\end{array}$ & 3 & 3 & & $\begin{array}{l}\text { Implement a } \\
\text { preventative } \\
\text { maintenance } \\
\text { program. Try to } \\
\text { maximize steady- } \\
\text { state operation. } \\
\text { Avoid upsets and } \\
\text { contamination. }\end{array}$ & $\begin{array}{l}\text { Resolve } \\
\text { maintenance, } \\
\text { system upset } \\
\text { and } \\
\text { contamination } \\
\text { problems } \\
\text { quickly. }\end{array}$ \\
\hline
\end{tabular}




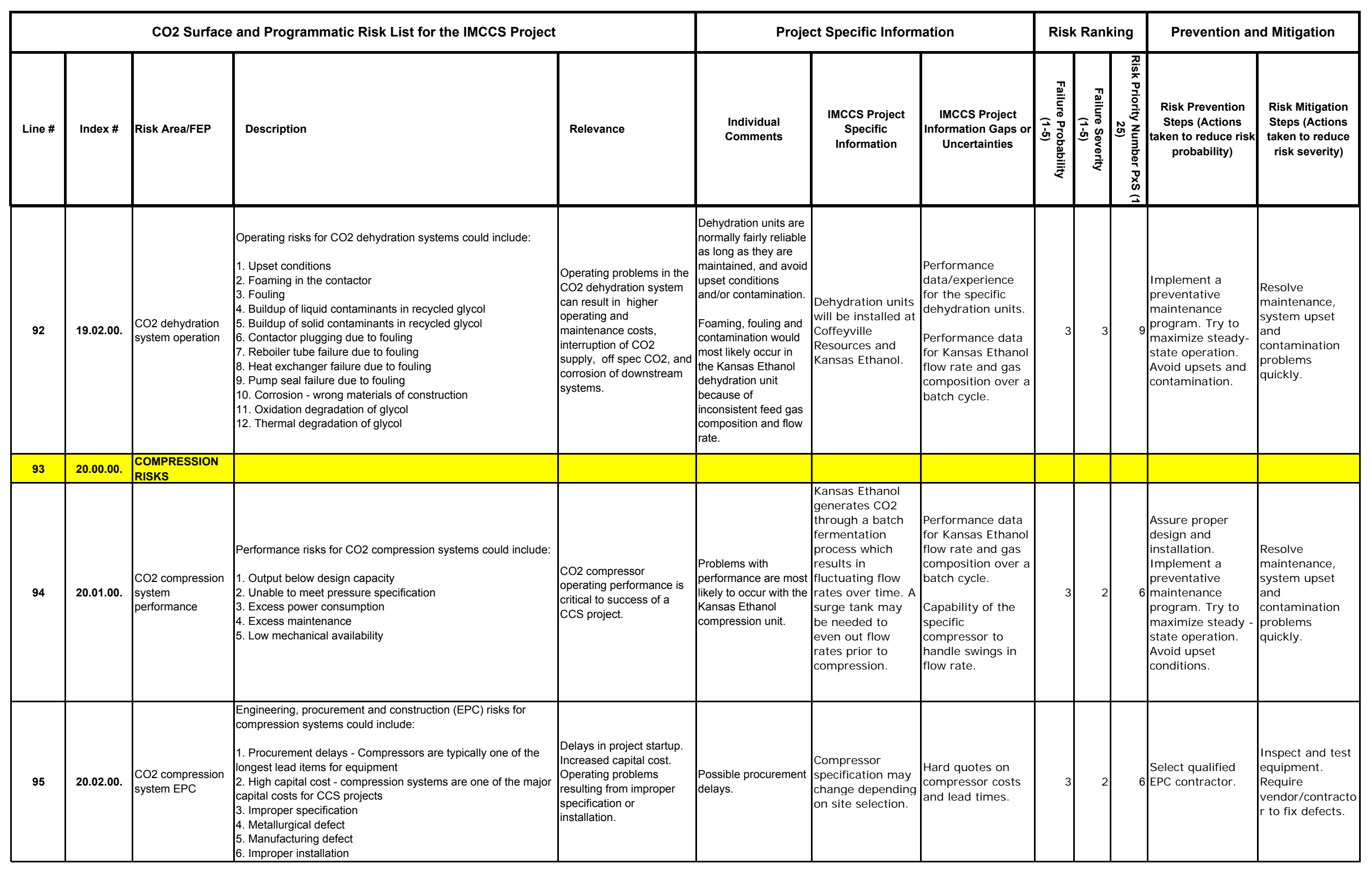




\begin{tabular}{|c|c|c|c|c|c|c|c|c|c|c|c|c|}
\hline \multicolumn{5}{|c|}{ CO2 Surface and Programmatic Risk List for the IMCCS Project } & \multicolumn{3}{|c|}{ Project Specific Information } & \multicolumn{3}{|c|}{ Risk Ranking } & \multicolumn{2}{|c|}{ Prevention and Mitigation } \\
\hline Line \# & Index \# & Risk Area/FEP & Description & Relevance & $\begin{array}{l}\text { Individual } \\
\text { Comments }\end{array}$ & $\begin{array}{l}\text { IMCCS Project } \\
\text { Specific } \\
\text { Information }\end{array}$ & $\begin{array}{c}\text { IMCCS Project } \\
\text { Information Gaps or } \\
\text { Uncertainties }\end{array}$ & 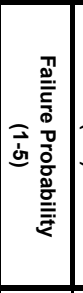 & 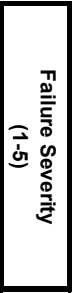 & 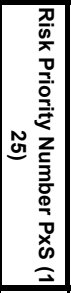 & $\begin{array}{c}\text { Risk Prevention } \\
\text { Steps (Actions } \\
\text { taken to reduce risk } \\
\text { probability) } \\
\end{array}$ & $\begin{array}{c}\text { Risk Mitigation } \\
\text { Steps (Actions } \\
\text { taken to reduce } \\
\text { risk severity) }\end{array}$ \\
\hline 96 & 20.03.00. & Compressor type & $\begin{array}{l}\text { 1. Reciprocating compressors - lower capital, higher } \\
\text { maintenance, may require spare capacity } \\
\text { 2. Centrifugal compressors - higher capital, lower maintenance } \\
\text { 3. Screw compressors (dry type) }\end{array}$ & $\begin{array}{l}\text { Type of compressors } \\
\text { selected can impact } \\
\text { capital costs, operating } \\
\text { costs and operating } \\
\text { availability. }\end{array}$ & $\begin{array}{l}\text { Unlikely to be a } \\
\text { problem }\end{array}$ & \begin{tabular}{|l|} 
Kansas Ethanol \\
will use \\
reciprocating \\
compressors. \\
Coffeyville \\
Resources will use \\
centrifugal \\
compressors/pum \\
ps.
\end{tabular} & $\begin{array}{l}\text { Performance } \\
\text { data/experience } \\
\text { for the specific } \\
\text { compressor units. }\end{array}$ & 2 & 2 & & $\begin{array}{l}\text { Select qualified } \\
\text { engineering } \\
\text { company and } \\
\text { vendors. } \\
\text { Proper selection of } \\
\text { the compressor } \\
\text { type for the } \\
\text { specific } \\
\text { application. } \\
\end{array}$ & \begin{tabular}{|l} 
\\
Proper \\
installation, \\
operation and \\
maintenance. \\
\end{tabular} \\
\hline 97 & 20.04.00. & $\begin{array}{l}\text { Compression } \\
\text { system operation }\end{array}$ & $\begin{array}{l}\text { Operating risks for CO2 compression systems: } \\
\text { 1. Improper operation } \\
\text { - Intermittent operation of the compressor } \\
\text { - Operating above/below recommended limits } \\
\text { - Upset conditions } \\
\text { - Operating compressor with control valve closed } \\
\text { - Fouling by dust or liquid droplets } \\
\text { - Plugging relief valves during depressurization } \\
\text { - Corrosion - due to water in CO2 stream } \\
\text { 2. Improper maintenance } \\
\text { - Vibration } \\
\text { - Noise } \\
\text { - Overheating } \\
\text { - Leakage } \\
\text { 3. Wear and failure } \\
\text { - Rod drop due to ring wear on recip. comp. } \\
\text { - Rod run out or rod deflection on recip. comp. } \\
\text { - Valve failure on recip. comp. } \\
\text { - Bearing wear/failure } \\
\text { - Tip wear on cent. comp. } \\
\text { - Impeller blade failure on cent. comp. } \\
\text { - Shaft failure } \\
\text { - Compressor catastrophic failure }\end{array}$ & $\begin{array}{l}\text { Downtime, loss of } \\
\text { revenue, increased } \\
\text { maintenance costs. }\end{array}$ & $\begin{array}{l}\text { Unlikely to be a } \\
\text { problem. }\end{array}$ & \begin{tabular}{|l|} 
The $\mathrm{CO} 2$ \\
compression units \\
will operate for a \\
three year period \\
during the \\
project.
\end{tabular} & $\begin{array}{l}\text { Performance } \\
\text { data/experience } \\
\text { for the specific } \\
\text { compressor units. }\end{array}$ & 2 & 2 & & $\begin{array}{l}\text { Assure proper } \\
\text { design and } \\
\text { installation. } \\
\text { Implement a } \\
\text { preventative } \\
\text { maintenance } \\
\text { program. Try to } \\
\text { maximize steady - } \\
\text { state operation. } \\
\text { Avoid upset } \\
\text { conditions. }\end{array}$ & $\begin{array}{l} \\
\text { Resolve } \\
\text { maintenance, } \\
\text { system upset } \\
\text { and } \\
\text { contamination } \\
\text { problems } \\
\text { quickly. }\end{array}$ \\
\hline 98 & 21.00 .00 . & \begin{tabular}{|l} 
PIPELINE RISKS \\
\end{tabular} & & & & & & & & & & \\
\hline 99 & 21.01.00. & \begin{tabular}{|l|}
$\begin{array}{l}\text { Pipeline routing } \\
\text { risks }\end{array}$ \\
\end{tabular} & & & & & & & & & & \\
\hline 100 & 21.01.01. & \begin{tabular}{|l} 
New versus \\
existing right-of- \\
way (ROW)
\end{tabular} & $\begin{array}{l}\text { ROW issues include: } \\
\text { 1. Single or multiple pipeline rights } \\
\text { 2. Width of ROW } \\
\text { 3. Rights for above ground facilities } \\
\text { 4. Access to site for repair/modification and inspections } \\
\text { 5. Payment for original and continued use of ROW } \\
\text { 6. Damage awards for the property owner } \\
\text { 7. Requirement for pipeline removal upon abandonment of the } \\
\text { pipeline. } \\
\text { 8. Eminent domain - used as a last resort to gain access to } \\
\text { ROW }\end{array}$ & $\begin{array}{l}\text { Developing a new ROW is } \\
\text { significantly more riskier } \\
\text { than using an existing } \\
\text { utility ROW. }\end{array}$ & $\begin{array}{l}\text { Unlikely to be a } \\
\text { problem. }\end{array}$ & $\begin{array}{l}\text { Pipelines will use } \\
\text { existing pipeline } \\
\text { corridors. }\end{array}$ & $\begin{array}{l}\text { Final site and } \\
\text { pipeline ROW } \\
\text { selections. }\end{array}$ & 2 & 3 & & $\begin{array}{l}\text { Maximize use of } \\
\text { existing pipeline } \\
\text { corridors in laying } \\
\text { out pipeline ROW. }\end{array}$ & $\begin{array}{l}\text { Design around } \\
\text { problem areas. }\end{array}$ \\
\hline
\end{tabular}




\begin{tabular}{|c|c|c|c|c|c|c|c|c|c|c|c|c|}
\hline \multicolumn{5}{|c|}{ CO2 Surface and Programmatic Risk List for the IMCCS Project } & \multicolumn{3}{|c|}{ Project Specific Information } & \multicolumn{3}{|c|}{ Risk Ranking } & \multicolumn{2}{|c|}{ Prevention and Mitigation } \\
\hline Line \# & Index \# & Risk Area/FEP & Description & Relevance & $\begin{array}{l}\text { Individual } \\
\text { Comments }\end{array}$ & $\begin{array}{l}\text { IMCCS Project } \\
\text { Specific } \\
\text { Information }\end{array}$ & $\begin{array}{c}\text { IMCCS Project } \\
\text { Information Gaps or } \\
\text { Uncertainties }\end{array}$ & 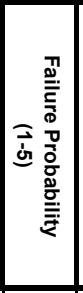 & 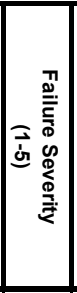 & 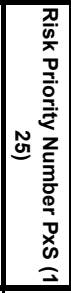 & \begin{tabular}{|c|} 
\\
Risk Prevention \\
Steps (Actions \\
taken to reduce risk \\
probability) \\
\end{tabular} & $\begin{array}{c}\text { Risk Mitigation } \\
\text { Steps (Actions } \\
\text { taken to reduce } \\
\text { risk severity) }\end{array}$ \\
\hline 101 & 21.01.02. & Climate conditions & $\begin{array}{l}\text { Weather conditions can impact pipeline surface facilities } \\
\text { 1. Severe high or low temperatures } \\
\text { 2. Significant winds (tornadoes) } \\
\text { 3. Lightning - common cause of pipeline damage } \\
\text { 4. Heavy rain fall - flooding } \\
\text { 5. Severe winter storms }\end{array}$ & $\begin{array}{l}\text { Delays in construction and } \\
\text { damage to surface } \\
\text { facilities. }\end{array}$ & $\begin{array}{l}\text { Possible problem with } \\
\text { tornadoes, heavy } \\
\text { rain, lightning, severe } \\
\text { winter storms. }\end{array}$ & $\begin{array}{l}\text { Pipelines will be } \\
\text { buried under } \\
\text { ground. Surface } \\
\text { areas may be } \\
\text { exposed to } \\
\text { climate } \\
\text { conditions. }\end{array}$ & $\begin{array}{l}\text { Final site and } \\
\text { pipeline ROW } \\
\text { selections. }\end{array}$ & 3 & 2 & & $\begin{array}{l}\text { Design pipeline } \\
\text { surface facilities } \\
\text { for full range of } \\
\text { climate } \\
\text { conditions. }\end{array}$ & $\begin{array}{l}\text { Monitor for } \\
\text { severe weather } \\
\text { reports. }\end{array}$ \\
\hline 102 & 21.01.03. & $\begin{array}{l}\text { Soil and terrain } \\
\text { conditions }\end{array}$ & $\begin{array}{l}\text { 1. Thin soil - insufficient to bury pipeline to depth } \\
\text { 2. Corrosive soil - high moisture, high electrical conductivity, } \\
\text { high acidity, and high dissolved salts } \\
\text { 3. Rocky soil - special care needed in backfilling to protect } \\
\text { pipeline } \\
\text { 4. Unstable land } \\
\text { - subsidence } \\
\text { - uplift } \\
\text { - landslides } \\
\text { - earthquake area } \\
\text { - active fault zone } \\
\text { - high erosion areas } \\
\text { - flood plains, dry wash } \\
\text { - permafrost } \\
\text { - frost heaves } \\
\text { - high water table (marshes, swamps, peat bogs) } \\
\text { - moving sand dunes } \\
\text { - underground mine/coal mine areas } \\
\text { - steep slopes >18\% (landslides or erosion) } \\
\text { 5. Rugged terrain/topography - mountains, hills, canyons, } \\
\text { gorges } \\
\text { 6. Significant elevation increase or variation over length of } \\
\text { pipeline } \\
\text { 7. Low lying areas } \\
\text { 8. Exposed granite bedrock }\end{array}$ & $\begin{array}{l}\text { 1. Need to add soil to } \\
\text { achieve } 1.2-1.8 \mathrm{~m} \text { (4-6ft) } \\
\text { burial depth } \\
\text { 2. Accelerated external } \\
\text { corrosion } \\
\text { 3. Need fine backfill to } \\
\text { protect pipeline } \\
\text { 4. Can lead to unintended } \\
\text { movement or abnormal } \\
\text { loading of a pipeline } \\
\text { resulting in mechanical } \\
\text { damage, leakage or } \\
\text { rupture. } \\
\text { 5. Significantly higher } \\
\text { installation cost } \\
6 \text { 6. Increased compression } \\
\text { or pumping costs due to } \\
\text { higher pressure drop } \\
\text { across pipeline } \\
\text { 7. Potential for leaked } \\
\text { CO2 to accumulate in low } \\
\text { lying areas if there is } \\
\text { insufficient escape } \\
\text { velocity or wind to } \\
\text { disperse the leaked CO2 } \\
\text { to the atmosphere. } \\
\text { 8. Very high costs for } \\
\text { blasting a pipeline trench }\end{array}$ & $\begin{array}{l}\text { Possible problems } \\
\text { with erosion and } \\
\text { flooding. }\end{array}$ & $\begin{array}{l}\text { Pipelines will be } \\
\text { buried under } \\
\text { ground. }\end{array}$ & $\begin{array}{l}\text { Final site and } \\
\text { pipeline ROW } \\
\text { selections. }\end{array}$ & 3 & 2 & & $\begin{array}{l}\text { Avoid steep } \\
\text { slopes, rugged } \\
\text { terrain, flood } \\
\text { plains, low-lying } \\
\text { areas, rocky } \\
\text { areas, unstable } \\
\text { land. }\end{array}$ & $\begin{array}{l}\text { Bring in fine } \\
\text { Backfill for } \\
\text { pipeline in rocky } \\
\text { areas. Regularly } \\
\text { inspect and } \\
\text { repair unstable } \\
\text { areas. }\end{array}$ \\
\hline
\end{tabular}




\begin{tabular}{|c|c|c|c|c|c|c|c|c|c|c|c|c|}
\hline \multicolumn{5}{|c|}{ CO2 Surface and Programmatic Risk List for the IMCCS Project } & \multicolumn{3}{|c|}{ Project Specific Information } & \multicolumn{3}{|c|}{ Risk Ranking } & \multicolumn{2}{|c|}{ Prevention and Mitigation } \\
\hline Line \# & Index \# & Risk Area/FEP & Description & Relevance & $\begin{array}{l}\text { Individual } \\
\text { Comments }\end{array}$ & $\begin{array}{l}\text { IMCCS Project } \\
\text { Specific } \\
\text { Information }\end{array}$ & $\begin{array}{c}\text { IMCCS Project } \\
\text { Information Gaps or } \\
\text { Uncertainties }\end{array}$ & 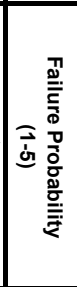 & 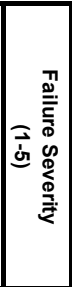 & 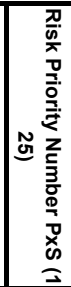 & \begin{tabular}{|c|} 
\\
Risk Prevention \\
Steps (Actions \\
taken to reduce risk \\
probability) \\
\end{tabular} & \begin{tabular}{|c} 
Risk Mitigation \\
Steps (Actions \\
taken to reduce \\
risk severity)
\end{tabular} \\
\hline 103 & 21.01.04. & Populated areas & $\begin{array}{l}\text { A high population area means an urbanized area, as defined by } \\
\text { the Census Bureau, that contains } 50,000 \text { or more people and } \\
\text { has a population density of at least } 1000 \text { people per square } \\
\text { mile. This is designated a high consequence area. (49 CFR } \\
\text { Part } 195.450 \text { ) Other populated areas are also designated as } \\
\text { high consequence areas. Non rural areas categorized as high } \\
\text { risk. Rural areas categorized as low risk. (49 CFR Part } 195 \\
\text { Appendix B) } \\
\text { Pipeline right-of-way must be selected to avoid, as far as } \\
\text { practicable, areas containing private dwellings, industrial } \\
\text { buildings, and places of public assembly. No pipeline may be } \\
\text { located within } 15 \mathrm{~m} \text { ( } 50 \text { feet) of any private dwelling, or any } \\
\text { industrial building or place of public assembly in which persons } \\
\text { work, congregate or assemble, unless it is provided with at least } \\
0.3 \mathrm{~m}(12 \text { inches) of cover in addition to that prescribed in } \\
\text { Section } 195.238 \text { (49 CFR Part } 195.210 \text { ). } \\
\text { cO2-CRC recommends a } 30 \mathrm{~m} \text { (100 ft) wide easement } \\
\text { restricting access to the buried pipeline, a distance of } 100 \mathrm{~m} \\
\text { (330 ft) minimum distance from residential buildings and a } 1,000 \\
\mathrm{~m} \text { (3,300 ft) consultation zone on either side of the pipeline for } \\
\text { emergency notification. } \\
\text { 1. High population density nearby } \\
\text { 2. Sensitive receptors (schools, hospitals, nursing homes, } \\
\text { prisons) nearby } \\
\text { 3. Business/industry/mining nearby } \\
\text { 4. Residences nearby }\end{array}$ & \begin{tabular}{|l} 
The greater the number of \\
people, the greater the \\
risk of exposure to CO2.
\end{tabular} & $\begin{array}{l}\text { Unlikely to be a } \\
\text { problem. }\end{array}$ & $\begin{array}{l}\text { Pipelines will use } \\
\text { existing pipeline } \\
\text { corridors. }\end{array}$ & $\begin{array}{l}\text { Final site and } \\
\text { pipeline ROW } \\
\text { selections. }\end{array}$ & 2 & 2 & & $\begin{array}{l}\text { Avoid dense } \\
\text { population areas } \\
\text { for pipeline } \\
\text { routing. }\end{array}$ & $\begin{array}{l} \\
\text { Design around } \\
\text { densely } \\
\text { populated areas. } \\
\text { Implement a } \\
\text { pipeline integrity } \\
\text { management } \\
\text { program in high } \\
\text { consequence } \\
\text { areas. Follow } 49 \\
\text { CFR Part } 195 \\
\text { regulations. }\end{array}$ \\
\hline
\end{tabular}




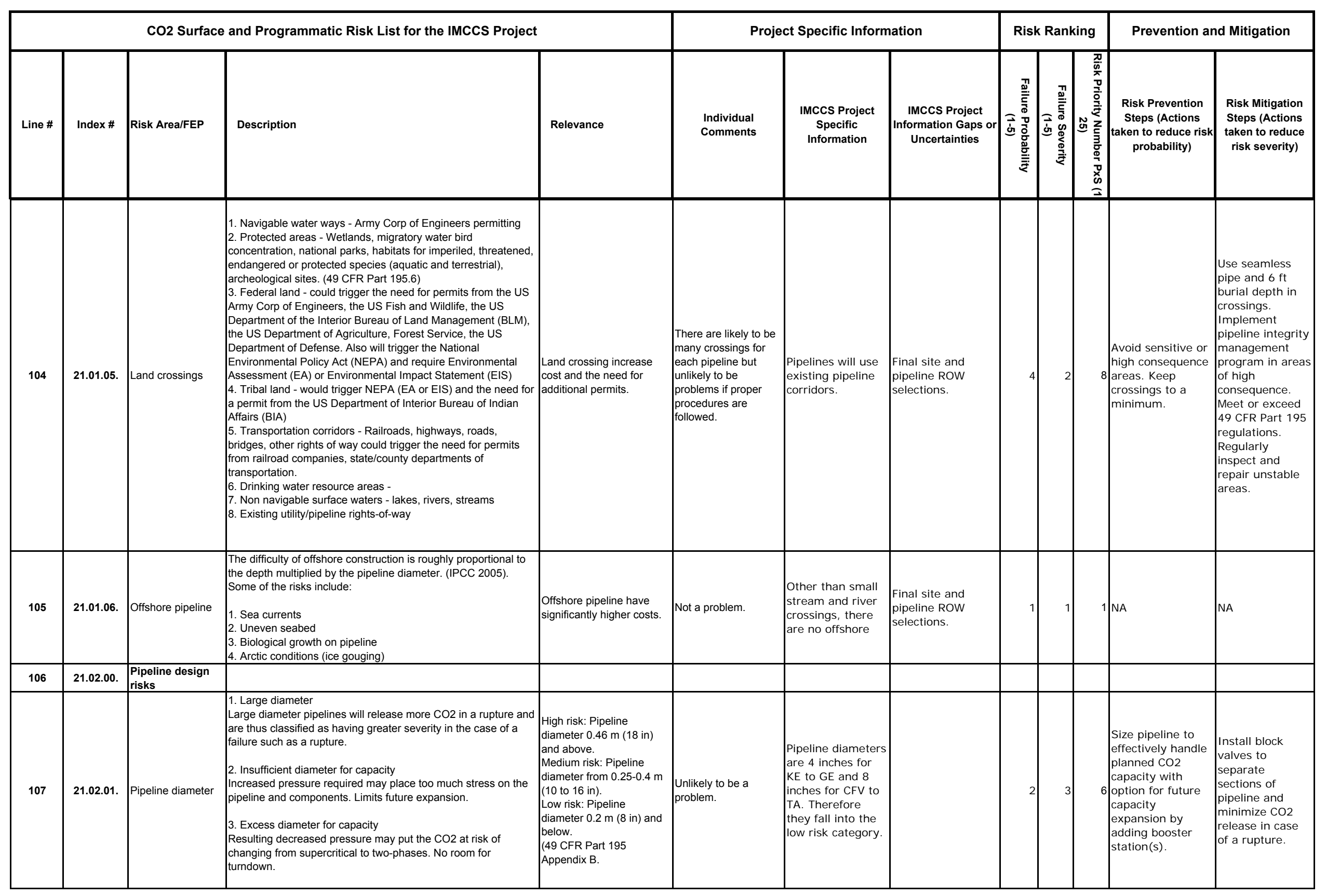

Appendix 6-113 


\begin{tabular}{|c|c|c|c|c|c|c|c|c|c|c|c|c|}
\hline \multicolumn{5}{|c|}{ CO2 Surface and Programmatic Risk List for the IMCCS Project } & \multicolumn{3}{|c|}{ Project Specific Information } & \multicolumn{3}{|c|}{ Risk Ranking } & \multicolumn{2}{|c|}{ Prevention and Mitigation } \\
\hline Line \# & Index \# & Risk Area/FEP & Description & Relevance & $\begin{array}{l}\text { Individual } \\
\text { Comments }\end{array}$ & $\begin{array}{l}\text { IMCCS Project } \\
\text { Specific } \\
\text { Information }\end{array}$ & $\begin{array}{c}\text { IMccs Project } \\
\text { Information Gaps or } \\
\text { Uncertainties }\end{array}$ & 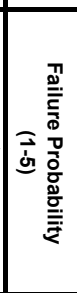 & 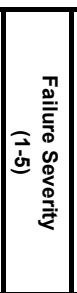 & 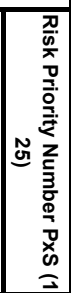 & \begin{tabular}{|c|} 
\\
Risk Prevention \\
Steps (Actions \\
taken to reduce risk \\
probability) \\
\end{tabular} & $\begin{array}{l}\text { Risk Mitigation } \\
\text { Steps (Actions } \\
\text { taken to reduce } \\
\text { risk severity) }\end{array}$ \\
\hline 108 & 21.02.02. & Pipeline length & The longer the pipeline, the greater the risks. & $\begin{array}{l}\text { Long pipeline more } \\
\text { expensive, more potential } \\
\text { for failure. }\end{array}$ & $\begin{array}{l}\text { Very unlikely to be a } \\
\text { problem. }\end{array}$ & $\begin{array}{l}\text { Depending on site } \\
\text { selection, the } \\
\text { pipeline lengths } \\
\text { will range from } 14 \\
\text { miles to } 120 \\
\text { miles. }\end{array}$ & $\begin{array}{l}\text { Final site and } \\
\text { pipeline ROW } \\
\text { selections to } \\
\text { determine pipeline } \\
\text { length. }\end{array}$ & 1 & 2 & & $\begin{array}{l}\text { Keep pipeline } \\
\text { length to a } \\
\text { minimum without } \\
\text { causing right of } \\
\text { way issues. }\end{array}$ & \begin{tabular}{|l} 
Install block \\
valves to \\
separate \\
sections of \\
pipeline and \\
minimize $\mathrm{CO} 2$ \\
release in case \\
of a rupture.
\end{tabular} \\
\hline 109 & 21.02.03. & $\begin{array}{l}\text { Pipeline failure } \\
\text { history (for existing } \\
\text { pipeline) }\end{array}$ & $\begin{array}{l}\text { Pipeline failure history for time-dependent defects can indicate } \\
\text { probability of future failures. }\end{array}$ & $\begin{array}{l}\text { High risk: }>3 \text { leaks in last } \\
10 \text { years. } \\
\text { Low risk: } \leq 3 \text { leaks in last } \\
10 \text { years. } \\
\text { (49 CFR Part } 195 \\
\text { Appendix B) }\end{array}$ & Not a problem. & $\begin{array}{l}\text { Project will use } \\
\text { new pipelines. }\end{array}$ & NA & 1 & 1 & & NA & or a rupture. \\
\hline 110 & 21.02.04. & \begin{tabular}{|l} 
Pipeline age(for \\
existing pipeline)
\end{tabular} & $\begin{array}{l}\text { Safety risk increases with the age of the pipeline depending on } \\
\text { the pipeline's coating and corrosion condition, and steel quality, } \\
\text { toughness, welding. }\end{array}$ & $\begin{array}{l}\text { High risk: }>25 \text { years old } \\
\text { Low risk: }<25 \text { years old } \\
\text { (49 CFR Part } 195 \\
\text { Appendix C) }\end{array}$ & Not a problem. & $\begin{array}{l}\text { Project will use } \\
\text { new pipelines. }\end{array}$ & NA & 1 & 1 & & NA & NA \\
\hline 111 & 21.02.05. & Pipeline pressure & $\begin{array}{l}\text { All pipeline components must be designed and tested for at } \\
\text { least } 125 \% \text { of maximum operating pressure (MOP). If, within a } \\
\text { pipeline system, two or more components are to be connected } \\
\text { at a place where one will operate at a higher pressure than } \\
\text { another, the system must be designed so that any component } \\
\text { operating at the lower pressure will not be overstressed. (49 } \\
\text { CFR Part 195.104) } \\
\text { Pipelines should be designed with sufficient pressure to } \\
\text { maintain CO2 as a supercritical fluid. } \\
\text { 1. Operating pipeline in excess of maximum operating pressure } \\
\text { (MOP). } \\
\text { 2. Operating pipeline below the CO2 supercritical pressure } \\
\text { (CSP). } \\
\text { 3. Insufficient working range between MOP and CSP. }\end{array}$ & $\begin{array}{l}\text { Components operating at } \\
\text { excessive operating } \\
\text { pressure will be } \\
\text { overstressed and subject } \\
\text { to failure. } \\
\text { Operating the pipeline at } \\
\text { or below the supercritical } \\
\text { pressure of CO2 can lead } \\
\text { to CO2 phase change in } \\
\text { the pipeline. If the } \\
\text { supercritical CO2 drops } \\
\text { back into the liquid-vapor, } \\
\text { two-phase region (which } \\
\text { occurs below } 6.9 \mathrm{MPa} \\
\text { (1000 psig) at ambient } \\
\text { temperature), there would } \\
\text { be freeze-up issues and a } \\
\text { much higher pressure } \\
\text { drop in the pipeline. }\end{array}$ & $\begin{array}{l}\text { Very unlikely to be a } \\
\text { problem. }\end{array}$ & $\begin{array}{l}\text { Pipelines will } \\
\text { operate at less } \\
\text { than } 80 \% \text { of } \\
\text { design pressure. }\end{array}$ & $\begin{array}{l}\text { Final site and } \\
\text { pipeline ROW } \\
\text { selections to } \\
\text { determine pipeline } \\
\text { operating } \\
\text { pressure. }\end{array}$ & 1 & 4 & & $\begin{array}{l}\text { Operate pipeline } \\
\text { at less than } 80 \% \\
\text { of design } \\
\text { pressure. }\end{array}$ & $\begin{array}{l}\text { Operate pipeline } \\
\text { at less than } 80 \% \\
\text { of design } \\
\text { pressure. }\end{array}$ \\
\hline
\end{tabular}




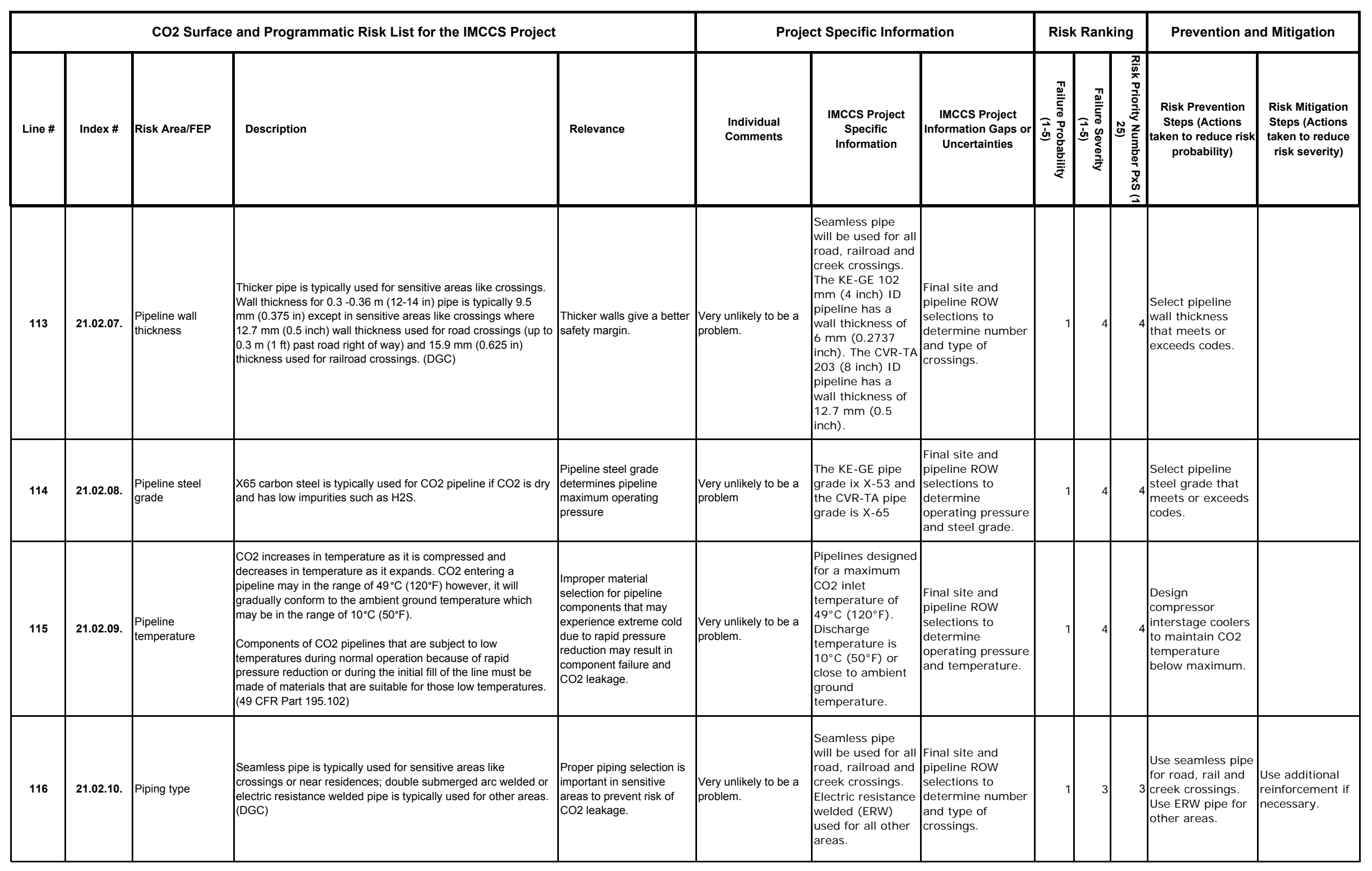




\begin{tabular}{|c|c|c|c|c|c|c|c|c|c|c|c|c|}
\hline \multicolumn{5}{|c|}{ CO2 Surface and Programmatic Risk List for the IMCCS Project } & \multicolumn{3}{|c|}{ Project Specific Information } & \multicolumn{3}{|c|}{ Risk Ranking } & \multicolumn{2}{|c|}{ Prevention and Mitigation } \\
\hline Line \# & Index \# & Risk Area/FEP & Description & Relevance & $\begin{array}{l}\text { Individual } \\
\text { Comments }\end{array}$ & $\begin{array}{l}\text { IMCCS Project } \\
\text { Specific } \\
\text { Information }\end{array}$ & $\begin{array}{c}\text { Imccs Project } \\
\text { Information Gaps or } \\
\text { Uncertainties }\end{array}$ & 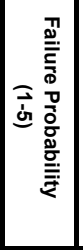 & 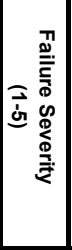 & 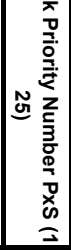 & $\begin{array}{c}\text { Risk Prevention } \\
\text { Steps (Actions } \\
\text { taken to reduce risk } \\
\text { probability) } \\
\end{array}$ & $\begin{array}{c}\text { Risk Mitigation } \\
\text { Steps (Actions } \\
\text { taken to reduce } \\
\text { risk severity) }\end{array}$ \\
\hline 117 & 21.02.11. & Pipeline coating & $\begin{array}{l}\mathrm{CO} 2 \text { pipelines are typically coated with fusion bonded epoxy to } \\
\text { prevent corrosion. In addition piping used at bored crossings is } \\
\text { overcoated with an abrasion resistant coating to prevent } \\
\text { damage to the epoxy coating during installation. (DGC) } \\
\text { 1. External coating } \\
\text { 2. Internal coating }\end{array}$ & $\begin{array}{l}\text { Damage to pipeline } \\
\text { coating during installation } \\
\text { or due to third-party } \\
\text { excavation can result in } \\
\text { external corrosion. }\end{array}$ & $\begin{array}{l}\text { Unlikely to be a } \\
\text { problem. }\end{array}$ & $\begin{array}{l}\text { The pipelines will } \\
\text { be externally } \\
\text { coated with 14-16 } \\
\text { mil fusion bond } \\
\text { epoxy. }\end{array}$ & $\begin{array}{l}\text { Final site and } \\
\text { pipeline ROW } \\
\text { selections to } \\
\text { determine } \\
\text { corrosiveness of } \\
\text { the soil. }\end{array}$ & 2 & 4 & & $\begin{array}{l}\text { Coat pipelines } \\
\text { with fusion bond } \\
\text { epoxy. }\end{array}$ & $\begin{array}{l}\text { Avoid damaging } \\
\text { coating during } \\
\text { transport or } \\
\text { installation. }\end{array}$ \\
\hline 118 & 21.02.12. & $\begin{array}{l}\text { Pipeline cathodic } \\
\text { protection }\end{array}$ & $\begin{array}{l}\text { Cathodic protection on } \mathrm{CO} 2 \text { pipelines is maintained by rectifiers } \\
\text { located at main-line valve stations every } 32 \mathrm{~km} \text { ( } 20 \text { miles) or } \\
\text { less along the pipeline. Cathodic protection is measured in } \\
\text { voltage at test posts located at } 1.6 \mathrm{~km}(1 \mathrm{mi}) \text { intervals over the } \\
\text { length of the pipeline. The rectifier output is adjusted to } \\
\text { maintain voltage levels between } 0.85 \text { and } 1.4 \text { volts at each test } \\
\text { station. (DGC) }\end{array}$ & $\begin{array}{l}\text { Insufficient or lack of } \\
\text { cathodic protection could } \\
\text { lead to external corrosion } \\
\text { and CO2 leakage. }\end{array}$ & $\begin{array}{l}\text { Unlikely to be a } \\
\text { problem. }\end{array}$ & $\begin{array}{l}\text { The pipelines will } \\
\text { be equipped with } \\
\text { cathodic } \\
\text { protection. }\end{array}$ & $\begin{array}{l}\text { Final site and } \\
\text { pipeline ROW } \\
\text { selections to } \\
\text { determine } \\
\text { corrosiveness of } \\
\text { the soil. }\end{array}$ & 2 & 3 & & \begin{tabular}{|l|} 
\\
Install cathodic \\
protection and \\
voltage test posts \\
at every mile \\
along pipelines.
\end{tabular} & $\begin{array}{l}\text { Monitor cathodic } \\
\text { protection } \\
\text { voltage over the } \\
\text { length of the } \\
\text { pipeline and } \\
\text { adjust rectifier } \\
\text { output to } \\
\text { maintain } \\
\text { appropriate } \\
\text { voltage level. }\end{array}$ \\
\hline 119 & 21.02.13. & $\begin{array}{l}\text { Pipeline booster } \\
\text { stations or } \\
\text { pumping stations }\end{array}$ & $\begin{array}{l}\text { Booster or pumping stations are typically needed every } 80-320 \\
\mathrm{~km} \text { (50 to } 200 \text { mi) depending on end-use pressure (EERC). } \\
\text { Adequate ventilation must be provided in pumping station } \\
\text { buildings to prevent the accumulation of } \mathrm{CO} 2 \text { gas, Warning } \\
\text { devices must be installed to warn of the presence of } \mathrm{CO} 2 \text { gas in } \\
\text { the pumping building. Safety devices to prevent over pressuring } \\
\text { of primary and auxiliary pumping equipment and a device for } \\
\text { emergency shutdown of each pumping station should be } \\
\text { included. If power is necessary to actuate the safety devices, an } \\
\text { auxiliary power supply should be included. (49 CFR Part } \\
195.262 \text { ) } \\
\text { Take into account noise levels. }\end{array}$ & $\begin{array}{l}\text { Insufficient booster or } \\
\text { pumping stations could } \\
\text { lead to low pressure at the } \\
\text { end of the pipeline. }\end{array}$ & $\begin{array}{l}\text { Very unlikely to be a } \\
\text { problem. }\end{array}$ & $\begin{array}{l}\text { Booster stations } \\
\text { not needed at } \\
\text { current capacity. } \\
\text { Space reserved } \\
\text { for booster } \\
\text { stations if it is } \\
\text { desired to } \\
\text { increase pipeline } \\
\text { capacity. }\end{array}$ & $\begin{array}{l}\text { Final site and } \\
\text { pipeline ROW } \\
\text { selections to } \\
\text { determine length } \\
\text { of pipeline and } \\
\text { number of booster } \\
\text { stations needed } \\
\text { now and in the } \\
\text { future. }\end{array}$ & 1 & 3 & & \begin{tabular}{|l|} 
Size pipeline to \\
effectively handle \\
planned $\mathrm{CO} 2$ \\
capacity with \\
option for future \\
capacity \\
expansion by \\
adding booster \\
station(s).
\end{tabular} & $\begin{array}{l}\text { Leave space for } \\
\text { booster stations }\end{array}$ \\
\hline 120 & 21.02.14. & $\begin{array}{l}\text { Pipeline future } \\
\text { expansion }\end{array}$ & $\begin{array}{l}\text { If there is potential for future expansion, it is practical to install } \\
\text { taps for future branches, leave room for booster stations and } \\
\text { design the pipeline to allow for expansion at higher pressure } \\
\text { without having to replace piping and components. } \\
\text { Pipeline diameter and pressure should take into account } \\
\text { potential for future expansion through addition of booster } \\
\text { stations and increased operating pressure. }\end{array}$ & $\begin{array}{l}\text { Lack of reserved locations } \\
\text { for booster stations, } \\
\text { insufficient pipeline } \\
\text { diameter, and excess } \\
\text { operating pressure may } \\
\text { make future expansion of } \\
\text { pipeline capacity more } \\
\text { difficult and more } \\
\text { expensive. }\end{array}$ & $\begin{array}{l}\text { Unlikely to be a } \\
\text { problem. }\end{array}$ & $\begin{array}{l}\text { Pipelines will be } \\
\text { designed to } \\
\text { accommodate } \\
\text { future expansion } \\
\text { with the addition } \\
\text { of a booster } \\
\text { station. }\end{array}$ & $\begin{array}{l}\text { Final site and } \\
\text { pipeline ROW } \\
\text { selections to } \\
\text { determine length } \\
\text { of pipeline and } \\
\text { number of booster } \\
\text { stations needed in } \\
\text { the future. Also } \\
\text { determine likely } \\
\text { capacity expansion } \\
\text { in the future. }\end{array}$ & 2 & 3 & & \begin{tabular}{|l|} 
Size pipeline to \\
effectively handle \\
planned CO2 \\
capacity with \\
option for future \\
capacity \\
expansion by \\
adding booster \\
station(s).
\end{tabular} & $\begin{array}{l}\text { Leave space for } \\
\text { booster stations }\end{array}$ \\
\hline
\end{tabular}




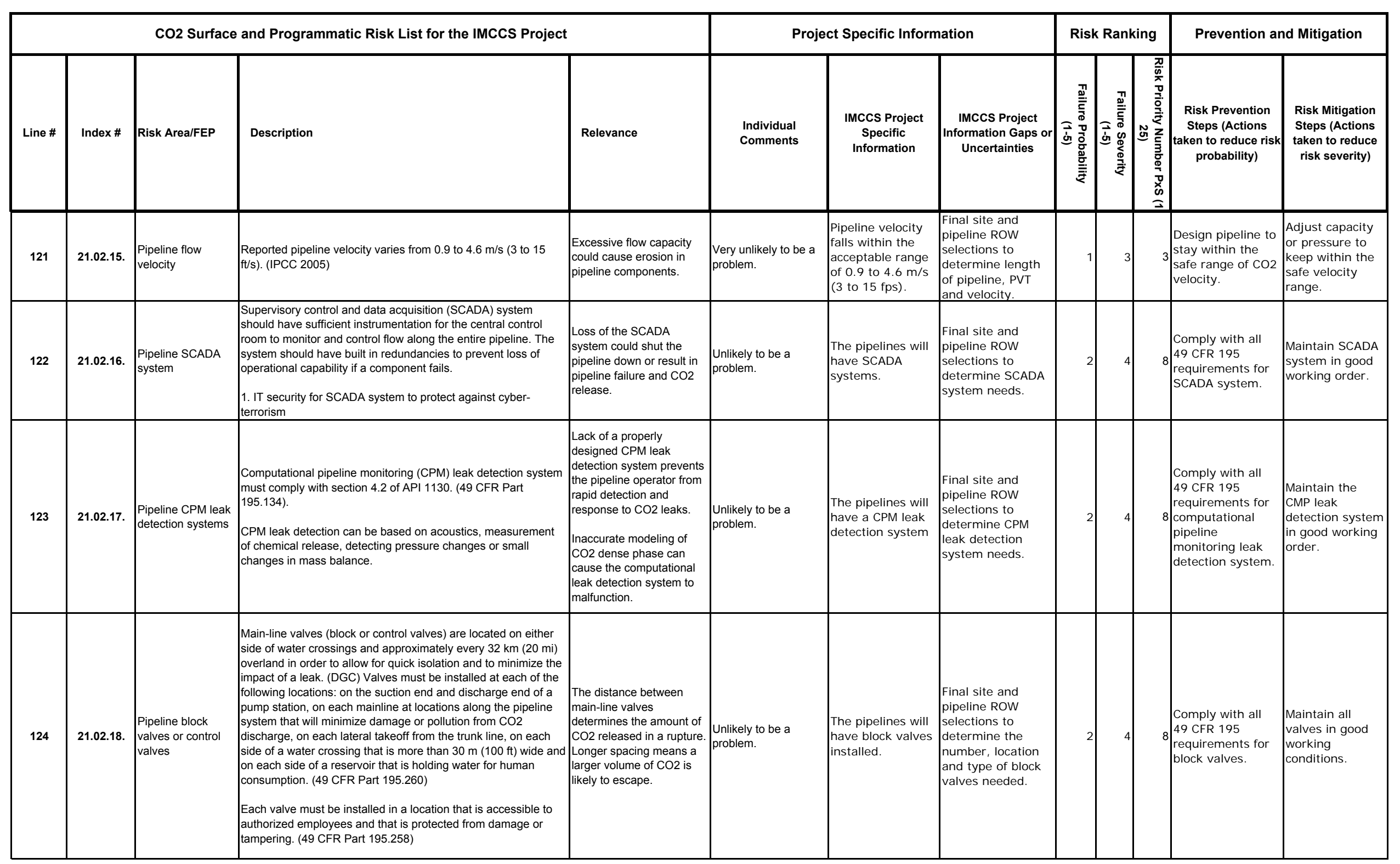




\begin{tabular}{|c|c|c|c|c|c|c|c|c|c|c|c|c|}
\hline \multicolumn{5}{|c|}{ CO2 Surface and Programmatic Risk List for the IMCCS Project } & \multicolumn{3}{|c|}{ Project Specific Information } & \multicolumn{3}{|c|}{ Risk Ranking } & \multicolumn{2}{|c|}{ Prevention and Mitigation } \\
\hline Line \# & Index \# & Risk Area/FEP & Description & Relevance & $\begin{array}{l}\text { Individual } \\
\text { Comments }\end{array}$ & $\begin{array}{l}\text { IMCCS Project } \\
\text { Specific } \\
\text { Information }\end{array}$ & $\begin{array}{c}\text { IMCcS Project } \\
\text { Information Gaps or } \\
\text { Uncertainties }\end{array}$ & 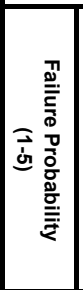 & 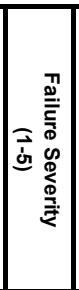 & 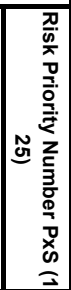 & \begin{tabular}{|c|} 
\\
Risk Prevention \\
Steps (Actions \\
taken to reduce risk \\
probability) \\
\end{tabular} & $\begin{array}{l}\text { Risk Mitigation } \\
\text { Steps (Actions } \\
\text { taken to reduce } \\
\text { risk severity) }\end{array}$ \\
\hline 125 & 21.02.19. & $\begin{array}{l}\text { Pipeline internal } \\
\text { inspection devices }\end{array}$ & $\begin{array}{l}\text { Pipelines must be designed and constructed to accommodate } \\
\text { the passage of instrumented internal inspection devices (i.e. } \\
\text { smart pig). } 49 \text { CFR Part 195.120) No operator may use a } \\
\text { launcher or receiver that is not equipped with a relief device } \\
\text { capable safely relieving pressure in the barrel before insertion } \\
\text { or removal of scrapers or spheres. (49 CFR Part 195.426) }\end{array}$ & $\begin{array}{l}\text { Internal inspection devices } \\
\text { are important tools for } \\
\text { detecting corrosion or } \\
\text { mechanical damage in } \\
\text { pipelines before they fail. }\end{array}$ & $\begin{array}{l}\text { Unlikely to be a } \\
\text { problem. }\end{array}$ & $\begin{array}{l}\text { The pipelines will } \\
\text { be designed to } \\
\text { use internal } \\
\text { inspection devices } \\
\text { (smart pigs) }\end{array}$ & $\begin{array}{l}\text { Final site and } \\
\text { pipeline ROW } \\
\text { selections to } \\
\text { determine the } \\
\text { specifications for } \\
\text { internal inspection } \\
\text { devices. }\end{array}$ & 2 & 3 & & $\begin{array}{l}\text { Comply with all } \\
49 \text { CFR } 195 \\
\text { requirements for } \\
\text { internal inspection } \\
\text { devices. }\end{array}$ & $\begin{array}{l}\text { Maintain internal } \\
\text { inspection } \\
\text { devices and } \\
\text { systems in good } \\
\text { working order. }\end{array}$ \\
\hline 126 & 21.02.20. & Pipeline seals & $\begin{array}{l}\text { Teflon or nylon have been used for seals to prevent swelling. } \\
\text { (API 2007). }\end{array}$ & $\begin{array}{l}\text { Improper sealing materials } \\
\text { may react with } \mathrm{CO} 2 \text { and } \\
\text { cause } \mathrm{CO} 2 \text { leakage }\end{array}$ & $\begin{array}{l}\text { Unlikely to be a } \\
\text { problem. }\end{array}$ & $\begin{array}{l}\text { The pipelines will } \\
\text { be designed with } \\
\text { proper seals for } \\
\text { handling } \mathrm{CO} 2 \text {. }\end{array}$ & $\begin{array}{l}\text { Final site and } \\
\text { pipeline ROW } \\
\text { selections to } \\
\text { determine } \\
\text { number, location } \\
\text { and type of seals. }\end{array}$ & 2 & 2 & & $\begin{array}{l}\text { Select seal } \\
\text { materials that } \\
\text { have been } \\
\text { successfully } \\
\text { tested for use } \\
\text { with CO2. }\end{array}$ & $\begin{array}{l}\text { Maintain seals in } \\
\text { good working } \\
\text { order. Monitor } \\
\text { for leaks. }\end{array}$ \\
\hline 127 & 21.02.21. & \begin{tabular}{|l} 
Pipeline \\
winterization
\end{tabular} & $\begin{array}{l}\text { Winterization (protection from severe cold/ice) may be needed } \\
\text { for above ground facilities in cold climates. }\end{array}$ & \begin{tabular}{|l|} 
Lack of winterization can \\
cause $\mathrm{CO} 2$ pipeline \\
instrumentation lines and \\
valves to freeze up in \\
severe cold/icy weather.
\end{tabular} & $\begin{array}{l}\text { Unlikely to be a } \\
\text { problem. }\end{array}$ & $\begin{array}{l}\text { Surface facilities } \\
\text { will be designed } \\
\text { appropriately for } \\
\text { Kansas winter } \\
\text { climate. }\end{array}$ & $\begin{array}{l}\text { Final site and } \\
\text { pipeline ROW } \\
\text { selections to } \\
\text { determine } \\
\text { number, location } \\
\text { and type of } \\
\text { surface facilities. }\end{array}$ & 2 & 2 & & $\begin{array}{l}\text { Provide sufficient } \\
\text { shelter/insulation } \\
\text { for sensitive } \\
\text { surface facilities. }\end{array}$ & $\begin{array}{l}\text { Monitor severe } \\
\text { weather } \\
\text { conditions. Train } \\
\text { operators how to } \\
\text { maintain } \\
\text { operation during } \\
\text { severe winter } \\
\text { weather. }\end{array}$ \\
\hline 128 & 21.02.22. & $\begin{array}{l}\text { Pipeline burial } \\
\text { depth }\end{array}$ & 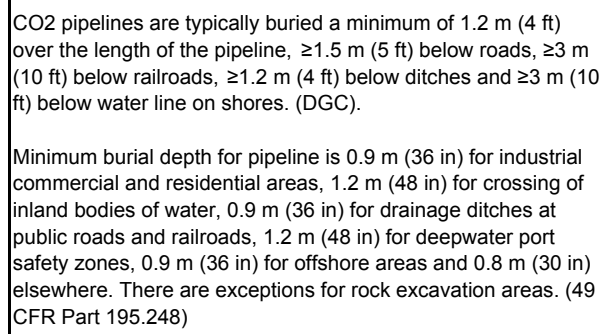 & \begin{tabular}{|l|} 
Insufficient burial depth \\
makes pipeline more \\
susceptible to excavation \\
damage, sabotage, \\
climate damage etc.
\end{tabular} & $\begin{array}{l}\text { Very unlikely to be a } \\
\text { problem. }\end{array}$ & $\begin{array}{l}\text { Pipelines will be } \\
\text { buried deeper } \\
\text { than required by } \\
49 \text { CFR } 195 .\end{array}$ & \begin{tabular}{|l|} 
Final site and \\
pipeline ROW \\
selections to \\
determine number \\
of crossings and \\
pipeline burial \\
depth.
\end{tabular} & 1 & 3 & & $\begin{array}{l}\text { Bury pipelines to } \\
\text { meet or exceed } \\
\text { compliance with } \\
49 \text { CFR } 195 .\end{array}$ & $\begin{array}{l}\text { Regularly } \\
\text { inspect and } \\
\text { maintain burial } \\
\text { depth of } \\
\text { pipeline. }\end{array}$ \\
\hline
\end{tabular}




\begin{tabular}{|c|c|c|c|c|c|c|c|c|c|c|c|c|}
\hline \multicolumn{5}{|c|}{ CO2 Surface and Programmatic Risk List for the IMCCS Project } & \multicolumn{3}{|c|}{ Project Specific Information } & \multicolumn{3}{|c|}{ Risk Ranking } & \multicolumn{2}{|c|}{ Prevention and Mitigation } \\
\hline Line \# & Index \# & Risk Area/FEP & Description & Relevance & $\begin{array}{l}\text { Individual } \\
\text { Comments }\end{array}$ & $\begin{array}{l}\text { IMCCS Project } \\
\text { Specific } \\
\text { Information }\end{array}$ & $\begin{array}{c}\text { IMccs Project } \\
\text { Information Gaps or } \\
\text { Uncertainties }\end{array}$ & 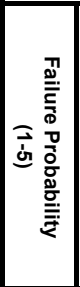 & 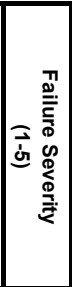 & 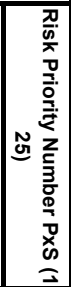 & $\begin{array}{c}\text { Risk Prevention } \\
\text { Steps (Actions } \\
\text { taken to reduce risk } \\
\text { probability) }\end{array}$ & $\begin{array}{c}\text { Risk Mitigation } \\
\text { Steps (Actions } \\
\text { taken to reduce } \\
\text { risk severity) }\end{array}$ \\
\hline 130 & 21.03 .00 . & $\begin{array}{l}\text { Pipeline material } \\
\text { defects }\end{array}$ & $\begin{array}{l}\text { During the manufacturing of steel, impurities can sometimes } \\
\text { remain in the molten steel. These impurities can cause an } \\
\text { incomplete bonding of the material in the steel plate or solid } \\
\text { round billet used to produce pipe and other pipeline } \\
\text { components. reduce the wall thickness of the pipe or pipeline } \\
\text { component, and, if large enough, can reduce the pressure- } \\
\text { carrying capacity of the pipe or component. } \\
\text { Some pipeline material defects include: } \\
\text { 1. Propagating cracks - very rapid propagating cracks can occur } \\
\text { that "unzip" the pipeline along its length. } \\
\text { 2. Laminations and inclusions - caused by oxides or impurities } \\
\text { trapped in the steel } \\
\text { 3. Blisters and scabs - raised spots on steel surface caused by } \\
\text { expansion of trapped gases within the steel } \\
\text { 4. Hard spots - created by localized cooling of the steel plate } \\
\text { (ERW pipe) during rolling } \\
\text { 5. Indentations - formed by the expanders or mandrels used to } \\
\text { make seamless pipe } \\
\text { 6. Transit fatigue - cracks formed when pipes are repeated } \\
\text { flexed during transportation and handling } \\
\text { 7. Cyclic fatigue - cracks caused by stress from repeated } \\
\text { fluctuating operating pressure within the pipe } \\
\text { 8. Elastomer and polymer - failure due to reaction with cO2 } \\
\end{array}$ & \begin{tabular}{|l|} 
1. Propagating cracks can \\
lead to pipeline rupture. \\
2. A lamination or \\
inclusion can eventually \\
lead to failure if they \\
eventually grow to the \\
inner or outer wall of the \\
pipe or pipeline \\
component through \\
pressure cycles. \\
3. Blisters and scabs \\
reduce the wall thickness \\
of the pipe and, if large \\
enough, can reduce the \\
pressure-carrying capacity \\
of the pipe or component. \\
4. Cracking can occur at \\
hard spots that eventually \\
grows in size over time. \\
5. Stress risers can occur \\
at indentations if they are \\
too deep, eventually \\
leading to pipe failure. \\
6. Transit fatigue cracks \\
are typically discovered \\
during the hydrostatic \\
pressure testing however, \\
some can remain and \\
grow during pipeline \\
pressure cycles until a \\
failure occurs. \\
7. Can lead to cO2 \\
lo
\end{tabular} & \begin{tabular}{|l} 
\\
Unlikely to be a \\
problem.
\end{tabular} & \begin{tabular}{|l} 
Pipelines will be \\
inspected and tested \\
before burial. \\
Crack arrestors will \\
be installed to \\
minimize \\
propagating cracks.
\end{tabular} & $\begin{array}{l}\text { Qualifications and } \\
\text { QC programs of pipe } \\
\text { manufacturer }\end{array}$ & 2 & 4 & & $\begin{array}{l}\text { Selection of a } \\
\text { competent pipe } \\
\text { manufacturer. } \\
\text { Inspection and } \\
\text { testing of } \\
\text { pipelines before } \\
\text { burial. } \\
\text { Proper design, } \\
\text { manufacturing, } \\
\text { installation and } \\
\text { maintenance of } \\
\text { the pipelines. }\end{array}$ & $\begin{array}{l}\text { Use of crack } \\
\text { arrestors to } \\
\text { mitigate } \\
\text { propagating } \\
\text { cracks. }\end{array}$ \\
\hline
\end{tabular}




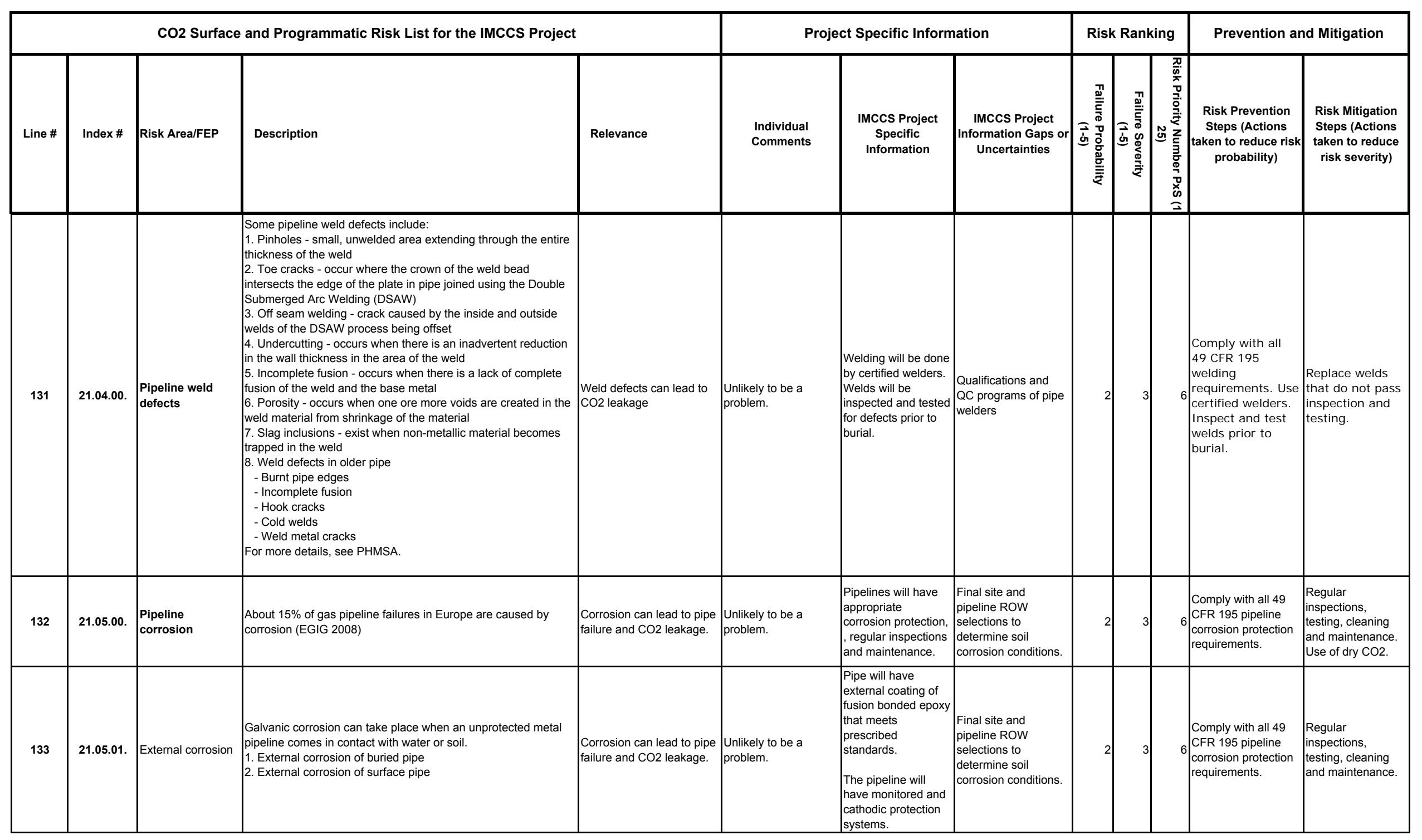




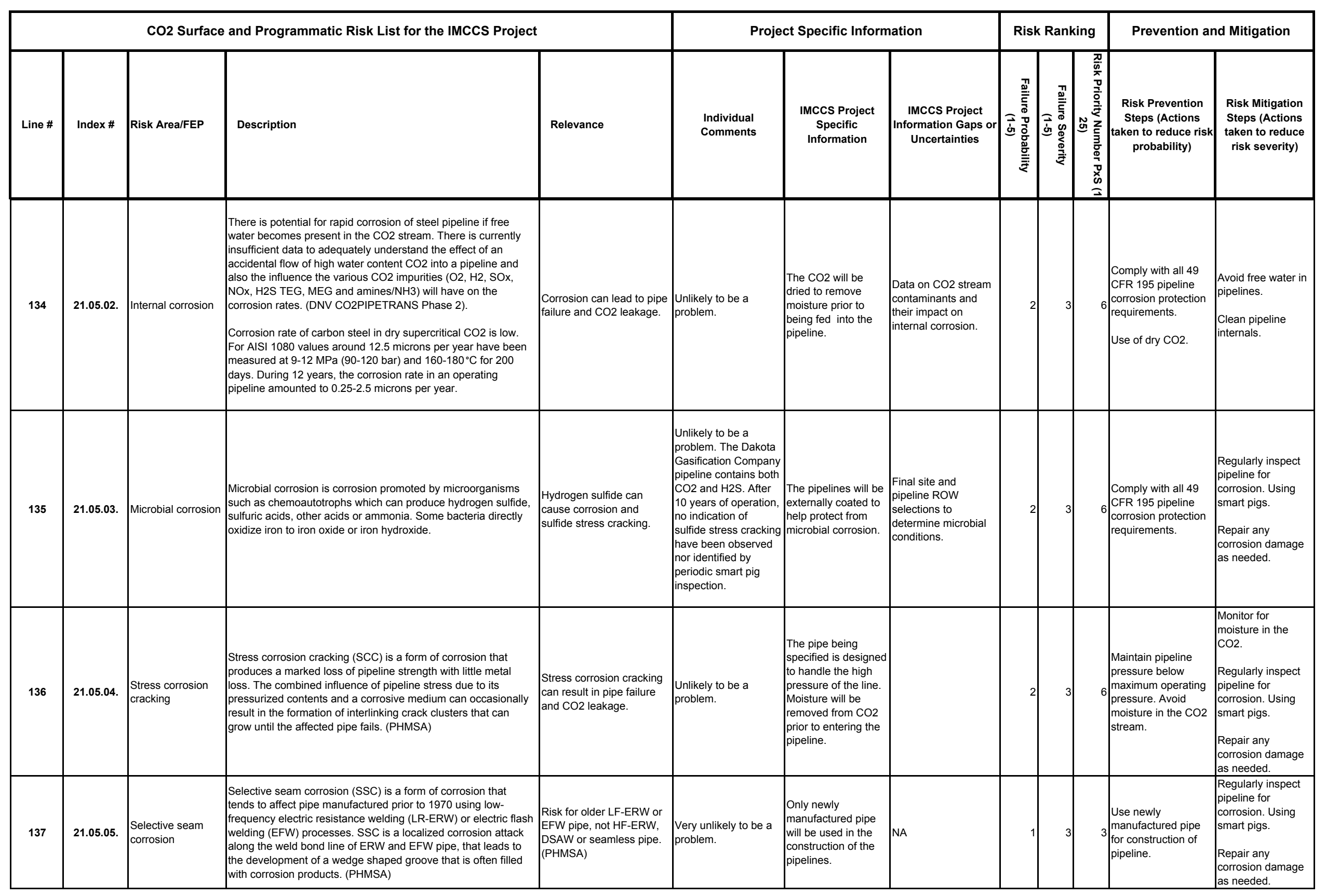

Appendix 6-121 


\begin{tabular}{|c|c|c|c|c|c|c|c|c|c|c|c|c|}
\hline \multicolumn{5}{|c|}{ CO2 Surface and Programmatic Risk List for the IMCCS Project } & \multicolumn{3}{|c|}{ Project Specific Information } & \multicolumn{3}{|c|}{ Risk Ranking } & \multicolumn{2}{|c|}{ Prevention and Mitigation } \\
\hline Line \# & Index \# & Risk Area/FEP & Description & Relevance & $\begin{array}{l}\text { Individual } \\
\text { Comments }\end{array}$ & $\begin{array}{l}\text { IMCCS Project } \\
\text { Specific } \\
\text { Information }\end{array}$ & $\begin{array}{c}\text { IMccs Project } \\
\text { Information Gaps or } \\
\text { Uncertainties }\end{array}$ & 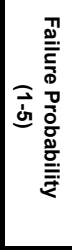 & 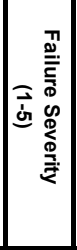 & 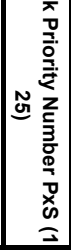 & $\begin{array}{c}\text { Risk Prevention } \\
\text { Steps (Actions } \\
\text { taken to reduce risk } \\
\text { probability) }\end{array}$ & $\begin{array}{l}\text { Risk Mitigation } \\
\text { Steps (Actions } \\
\text { taken to reduce } \\
\text { risk severity) }\end{array}$ \\
\hline 138 & 21.06.00. & $\begin{array}{l}\text { Pipeline } \\
\text { equipment failure }\end{array}$ & $\begin{array}{l}\text { Equipment failures involve pumps, compressors, valves, } \\
\text { meters, tanks, control/relief equipment and other components } \\
\text { and devices on pipeline systems. (PHMSA). Can include broken } \\
\text { couplings, stripped threads. }\end{array}$ & $\begin{array}{l}\text { Equipment is often located } \\
\text { on company property that } \\
\text { is not accessible to the } \\
\text { public. Equipment failure } \\
\text { usually results in a CO2 } \\
\text { release that is contained } \\
\text { on public property, } \\
\text { typically not resulting in } \\
\text { injury to the general } \\
\text { public. (PHMSA) }\end{array}$ & $\begin{array}{l}\text { Unlikely to be a } \\
\text { problem. }\end{array}$ & $\begin{array}{l}\text { Equipment will be } \\
\text { properly operated } \\
\text { and maintained. }\end{array}$ & \begin{tabular}{l|} 
Final site and \\
pipeline ROW \\
selection to \\
determine the amount \\
and type and size of \\
equipment needed.
\end{tabular} & 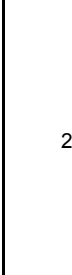 & 3 & & \begin{tabular}{|l|} 
Proper operation and \\
regular preventative \\
maintenance \\
program in place.
\end{tabular} & $\begin{array}{l}\text { Monitor for } \\
\text { equipment } \\
\text { vibration or } \\
\text { performance } \\
\text { changes. } \\
\text { Determine root } \\
\text { cause and repair }\end{array}$ \\
\hline 139 & 21.07.00. & $\begin{array}{l}\text { Pipeline } \\
\text { mechanical } \\
\text { damage }\end{array}$ & $\begin{array}{l}\text { Mechanical damage consists of dents, gouges, cracks, } \\
\text { punctures, stress risers or ruptures. }\end{array}$ & \begin{tabular}{|l|} 
Mechanical damage of a \\
pipeline can lead to \\
immediate or \\
eventual/accelerated $\mathrm{CO} 2$ \\
leakage.
\end{tabular} & & & & & & & & \\
\hline 140 & 21.07.01. & $\begin{array}{l}\text { Excavation } \\
\text { damage }\end{array}$ & $\begin{array}{l}\text { About } 50 \% \text { of pipeline failures in Europe and } 33 \% \text { in the US are } \\
\text { caused by excavation damage. Excavation damage can include } \\
\text { damage to the external coating of the pipe, or dents, scrapes, } \\
\text { cuts, or punctures directly into the pipeline itself. The damage } \\
\text { can be caused by any type of excavation, including digging, } \\
\text { grading, trenching and boring, road and highway maintenance, } \\
\text { general construction and farming activities. It normally occurs } \\
\text { when excavators fail to call their local one-call system to mark } \\
\text { where underground facilities are located prior to excavating. } \\
\text { (PHMSA) }\end{array}$ & $\begin{array}{l}\text { Excavation can lead to } \\
\text { pipeline damage and } \mathrm{CO} 2 \\
\text { leakage. }\end{array}$ & Possible problem. & $\begin{array}{l}\text { Pipeline ROW will } \\
\text { be properly marked } \\
\text { and regularly } \\
\text { inspected by air and } \\
\text { ground. Regular } \\
\text { internal inspection } \\
\text { with smart pigs. One } \\
\text { call system will be } \\
\text { employed to protect } \\
\text { against third-party } \\
\text { excavation damage. }\end{array}$ & $\begin{array}{l}\text { Final site and } \\
\text { pipeline ROW } \\
\text { selection to } \\
\text { determine specific } \\
\text { steps to be taken to } \\
\text { protect against } \\
\text { excavation damage. }\end{array}$ & 3 & 3 & & \begin{tabular}{|l|} 
Comply with all \\
49CFR 195 \\
excavation safety \\
requirements \\
including deep burial \\
of pipeline, proper \\
marking of ROW, \\
regular ROW \\
inspections, \\
supervision of third- \\
party excavation and \\
one call system.
\end{tabular} & \begin{tabular}{|l|} 
Trained emergency \\
response team to \\
rapidly address \\
excavation \\
damage. \\
Educate local \\
residents how to \\
identify and report \\
leaks or damage
\end{tabular} \\
\hline 141 & 21.07.02. & $\begin{array}{l}\text { Natural force } \\
\text { damage }\end{array}$ & $\begin{array}{l}\text { Natural force damage includes damage from landslide, flood, } \\
\text { heavy rains, riverbed scouring and washouts, dike breaks, } \\
\text { subsidence, earthquakes, high winds, tornadoes, hurricanes, } \\
\text { lightning, frost heaves, and frozen instrumentation lines. } \\
\text { (PHMSA) }\end{array}$ & $\begin{array}{l}\text { Can lead to unintended } \\
\text { movement or abnormal } \\
\text { loading of a pipeline } \\
\text { resulting in mechanical } \\
\text { damage, leakage or } \\
\text { rupture. }\end{array}$ & Possible problem. & \begin{tabular}{|l|} 
Pipeline ROW will \\
be regularly \\
inspected by air \\
and ground. \\
Regular internal \\
inspection with \\
smart pigs.
\end{tabular} & $\begin{array}{l}\text { Final site and } \\
\text { pipeline ROW } \\
\text { selection to } \\
\text { determine likely } \\
\text { scenarios for } \\
\text { natural force } \\
\text { damage. }\end{array}$ & 3 & 3 & & $\begin{array}{l}\text { Comply with all } \\
\text { 49CFR } 195 \text { ROW } \\
\text { inspection } \\
\text { requirements. }\end{array}$ & $\begin{array}{l}\text { Maintain ROW to } \\
\text { make it visually } \\
\text { accessible from the } \\
\text { air and physically } \\
\text { accessible on the } \\
\text { ground. Repair any } \\
\text { eroded or damaged } \\
\text { areas. Educate } \\
\text { local residents how } \\
\text { to identify and } \\
\text { report leaks or } \\
\text { damage. }\end{array}$ \\
\hline
\end{tabular}




\begin{tabular}{|c|c|c|c|c|c|c|c|c|c|c|c|c|}
\hline \multicolumn{5}{|c|}{ CO2 Surface and Programmatic Risk List for the IMCCS Project } & \multicolumn{3}{|c|}{ Project Specific Information } & \multicolumn{3}{|c|}{ Risk Ranking } & \multicolumn{2}{|c|}{ Prevention and Mitigation } \\
\hline Line \# & Index \# & Risk Area/FEP & Description & Relevance & $\begin{array}{l}\text { Individual } \\
\text { Comments }\end{array}$ & $\begin{array}{l}\text { IMCCS Project } \\
\text { Specific } \\
\text { Information }\end{array}$ & $\begin{array}{c}\text { IMCCS Project } \\
\text { Information Gaps or } \\
\text { Uncertainties }\end{array}$ & 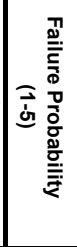 & 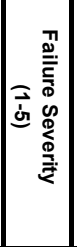 & 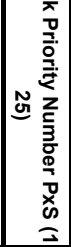 & $\begin{array}{c}\text { Risk Prevention } \\
\text { Steps (Actions } \\
\text { taken to reduce risk } \\
\text { probability) }\end{array}$ & $\begin{array}{l}\text { Risk Mitigation } \\
\text { Steps (Actions } \\
\text { taken to reduce } \\
\text { risk severity) }\end{array}$ \\
\hline 142 & 21.07.03. & \begin{tabular}{|l|} 
Other outside force \\
damage
\end{tabular} & $\begin{array}{l}\text { Other outside force damage excludes excavation but include } \\
\text { such things as vehicle accident (hitting above ground valve or } \\
\text { booster station), electric arcing from nearby powerlines, } \\
\text { vandalism, sabotage, terrorist attack, theft, fires from other } \\
\text { businesses or industries, etc. (PHMSA) } \\
\begin{array}{l}\text { Most susceptible to this particular type of damage are above } \\
\text { ground pipeline facilities which are in close proximity to } \\
\text { highways or large population and industrial centers. }\end{array}\end{array}$ & $\begin{array}{l}\text { Mechanical damage of a } \\
\text { pipeline can lead to } \\
\text { immediate or } \\
\text { eventual/accelerated CO2 } \\
\text { leakage. }\end{array}$ & Possible problem. & $\begin{array}{l}\text { Surface facilities } \\
\text { will be fenced in } \\
\text { and secured to } \\
\text { prevent public } \\
\text { access. }\end{array}$ & \begin{tabular}{|l|} 
Final site and \\
pipeline ROW \\
selection to \\
determine specific \\
security and safety \\
needs.
\end{tabular} & 3 & 3 & & $\mid \begin{array}{l}\text { Comply with } 49 \text { CFR } \\
195 \text { security } \\
\text { requirements. Fence } \\
\text { in and secure } \\
\text { surface facilities. } \\
\text { Direct traffic patterns } \\
\text { and speeds to } \\
\text { prevent accidents. }\end{array}$ & $\begin{array}{l}\text { Monitor site } \\
\text { activity. Train } \\
\text { operators to handle } \\
\text { security issues and } \\
\text { emergencies. }\end{array}$ \\
\hline 143 & 21.07.04. & $\begin{array}{l}\text { Mechanical } \\
\text { damage requiring } \\
\text { immediate repair }\end{array}$ & $\begin{array}{l}\text { Metal loss greater than } 80 \% \text { of nominal wall thickness. } \\
\text { Dent located on the pipeline (above } 4 \text { and } 8 \text { o'clock positions) } \\
\text { that has any indication of metal loss, cracking or a stress riser. } \\
\text { Dent located on the pipeline (above } 4 \text { and } 8 \text { o'clock positions) } \\
\text { with a depth greater than } 6 \% \text { of the nominal pipe diameter. } \\
\text { (49 CFR Part 195.452) }\end{array}$ & $\begin{array}{l}\text { Mechanical damage can } \\
\text { require immediate repair } \\
\text { to prevent CO2 leakage. }\end{array}$ & Possible problem. & \begin{tabular}{|l|} 
The pipelines will \\
be internally \\
inspected with \\
smart pigs in \\
compliance with \\
49 CFR 195. Any \\
mechanical \\
damage detected \\
will be repaired.
\end{tabular} & $\begin{array}{l}\text { Final site and } \\
\text { pipeline ROW } \\
\text { selection }\end{array}$ & 3 & 3 & & \begin{tabular}{|l|} 
Comply with 49 CFR \\
195 repair of \\
mechanical damage \\
requirements.
\end{tabular} & $\begin{array}{l}\text { Train employees to } \\
\text { repair mechanical } \\
\text { damage in a timely } \\
\text { basis. }\end{array}$ \\
\hline 144 & 21.07.05. & \begin{tabular}{|l|} 
Mechanical \\
damage requiring \\
evaluation and \\
remediation within \\
60 days of \\
discovery
\end{tabular} & $\begin{array}{l}\text { Dent on the bottom of the pipeline that has any indication of } \\
\text { metal loss, cracking or a stress riser. } \\
\text { Dent located on the pipeline (above } 4 \text { and } 8 \text { o'clock positions) } \\
\text { with a depth between } 3 \% \text { and } 6 \% \text { of the nominal pipe diameter. } \\
\text { (49 CFR Part } 195.452 \text { ) }\end{array}$ & $\begin{array}{l}\text { Mechanical damage can } \\
\text { require timely evaluation } \\
\text { and remediation to } \\
\text { prevent CO2 leakage. }\end{array}$ & Possible problem. & \begin{tabular}{|l|} 
The pipelines will \\
be internally \\
inspected with \\
smart pigs in \\
compliance with \\
49 CFR 195. Any \\
mechanical \\
damage detected \\
will be repaired.
\end{tabular} & $\begin{array}{l}\text { Final site and } \\
\text { pipeline ROW } \\
\text { selection }\end{array}$ & 3 & 2 & & \begin{tabular}{|l|} 
Comply with 49 CFR \\
195 repair of \\
mechanical damage \\
requirements.
\end{tabular} & $\begin{array}{l}\text { Train employees to } \\
\text { repair mechanical } \\
\text { damage in a timely } \\
\text { basis. }\end{array}$ \\
\hline 145 & 21.08.00. & \begin{tabular}{|l|}
$\begin{array}{l}\text { Pipeline } \\
\text { procurement } \\
\text { risks }\end{array}$ \\
\end{tabular} & & & & & & & & 0 & & \\
\hline 146 & 21.08.01. & $\begin{array}{l}\text { Used pipe or old } \\
\text { pipe }\end{array}$ & $\begin{array}{l}\text { Used pipe must comply with the same quality requirements as } \\
\text { new pipe. Used pipe must not have any mechanical damage } \\
\text { (buckles, cracks, gouges, dents) or corroded areas that } \\
\text { threaten the integrity of the pipe. (49 CFR Part 195.114). }\end{array}$ & $\begin{array}{l}\text { Use of defective used pipe } \\
\text { could result in pipe failure } \\
\text { and CO2 leakage. }\end{array}$ & Not a problem. & $\begin{array}{l}\text { New pipe will be } \\
\text { used in } \\
\text { construction of } \\
\text { the pipelines. }\end{array}$ & NA & 1 & 3 & & 3 Use new pipe. & $\begin{array}{l}\text { Inspect and test all } \\
\text { used pipe prior to } \\
\text { its use. }\end{array}$ \\
\hline 147 & 21.08.02. & Pipeline valves & $\begin{array}{l}\text { Each valve must be of sound engineering design, compatible } \\
\text { with pipe and fittings, successfully hydrostatically tested, clearly } \\
\text { marked for open and closed positions (except check valves), } \\
\text { properly marked (nameplate) and properly sized. (49 CFR Part } \\
\text { 195.116) }\end{array}$ & \begin{tabular}{|l|} 
Defective or off-spec \\
valves could result in \\
valve failure and $\mathrm{CO} 2$ \\
leakage. \\
Wrong sized valves could \\
lead to additional pressure \\
stress or failure.
\end{tabular} & $\begin{array}{l}\text { Unlikely to be a } \\
\text { problem }\end{array}$ & $\begin{array}{l}\text { All valves will be } \\
\text { new build and will } \\
\text { meet the } \\
\text { appropriate } \\
\text { specifications for } \\
\text { the service for } \\
\text { which they are } \\
\text { being installed. }\end{array}$ & $\begin{array}{l}\text { Final site and } \\
\text { pipeline ROW to } \\
\text { determine the } \\
\text { number, location, } \\
\text { type and size of } \\
\text { valves. }\end{array}$ & 2 & 3 & & $\begin{array}{l}\text { Comply with } 45 \text { CFR } \\
195 \text { valve } \\
\text { requirements. Select } \\
\text { competent valve } \\
\text { manufacturers. } \\
\text { Select the proper } \\
\text { type and size of } \\
\text { valve. }\end{array}$ & $\begin{array}{l}\text { Inspect and test all } \\
\text { valves prior to } \\
\text { being used. } \\
\text { Properly install, } \\
\text { operate and } \\
\text { maintain valves. }\end{array}$ \\
\hline
\end{tabular}




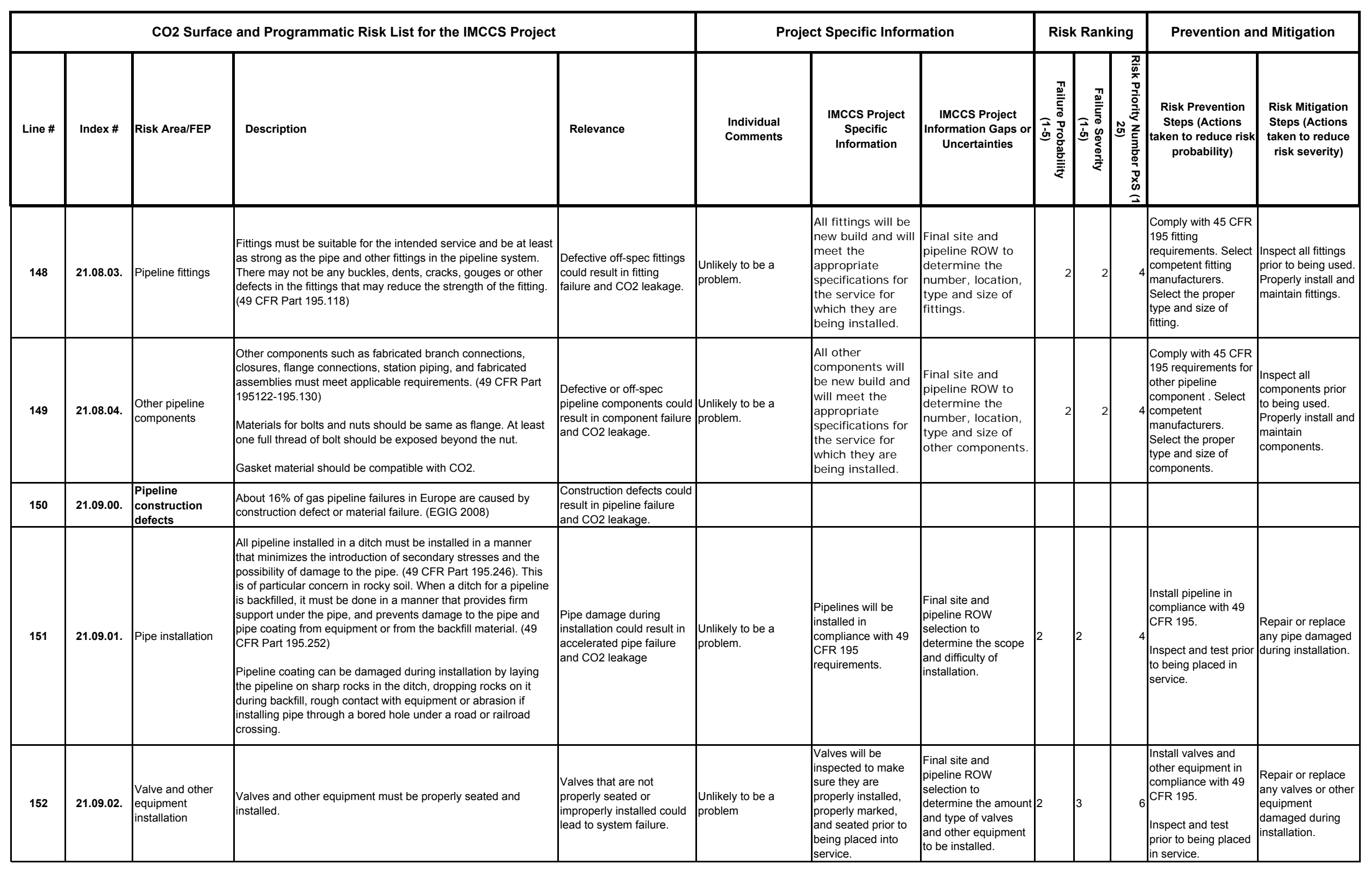




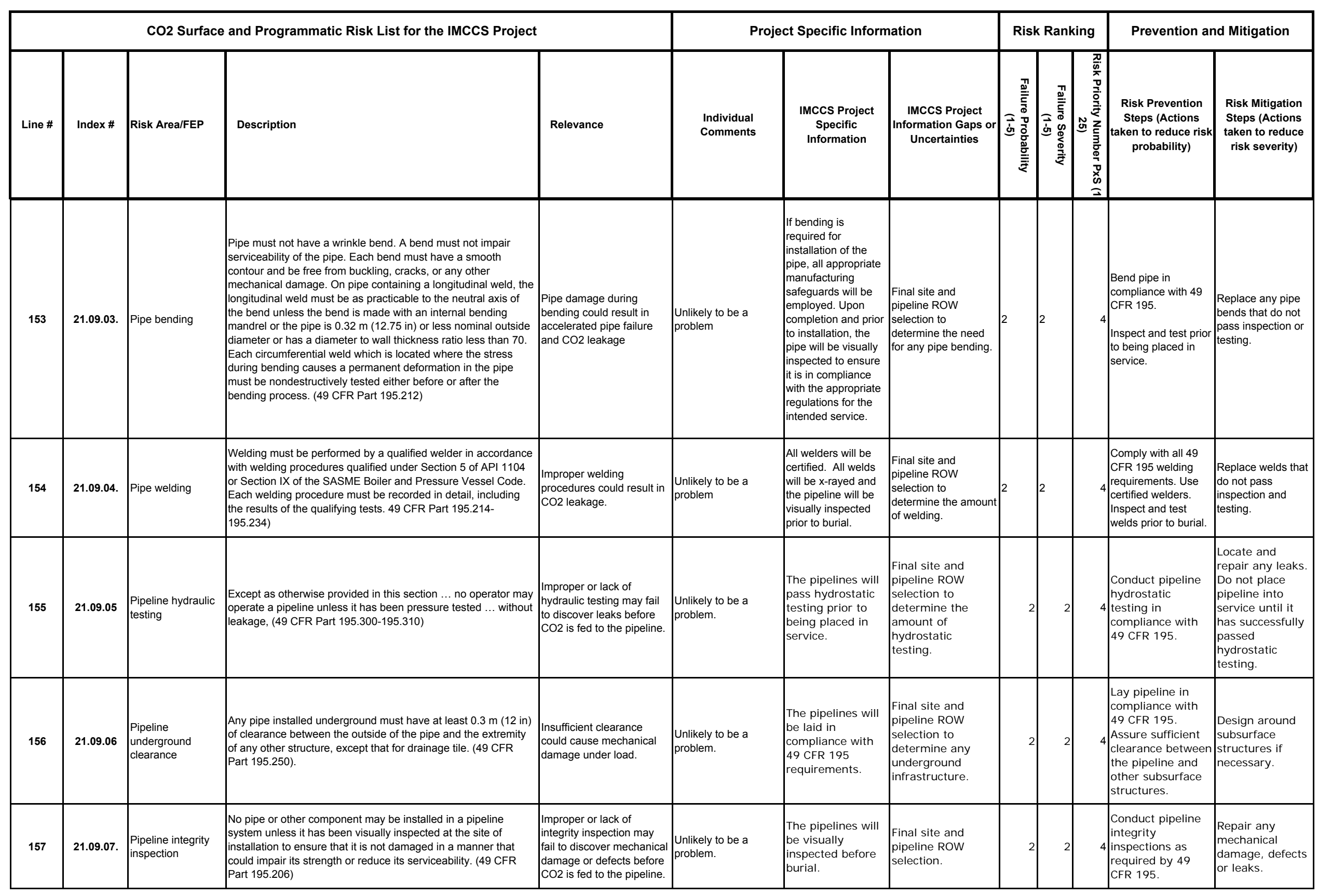

Appendix 6-125 


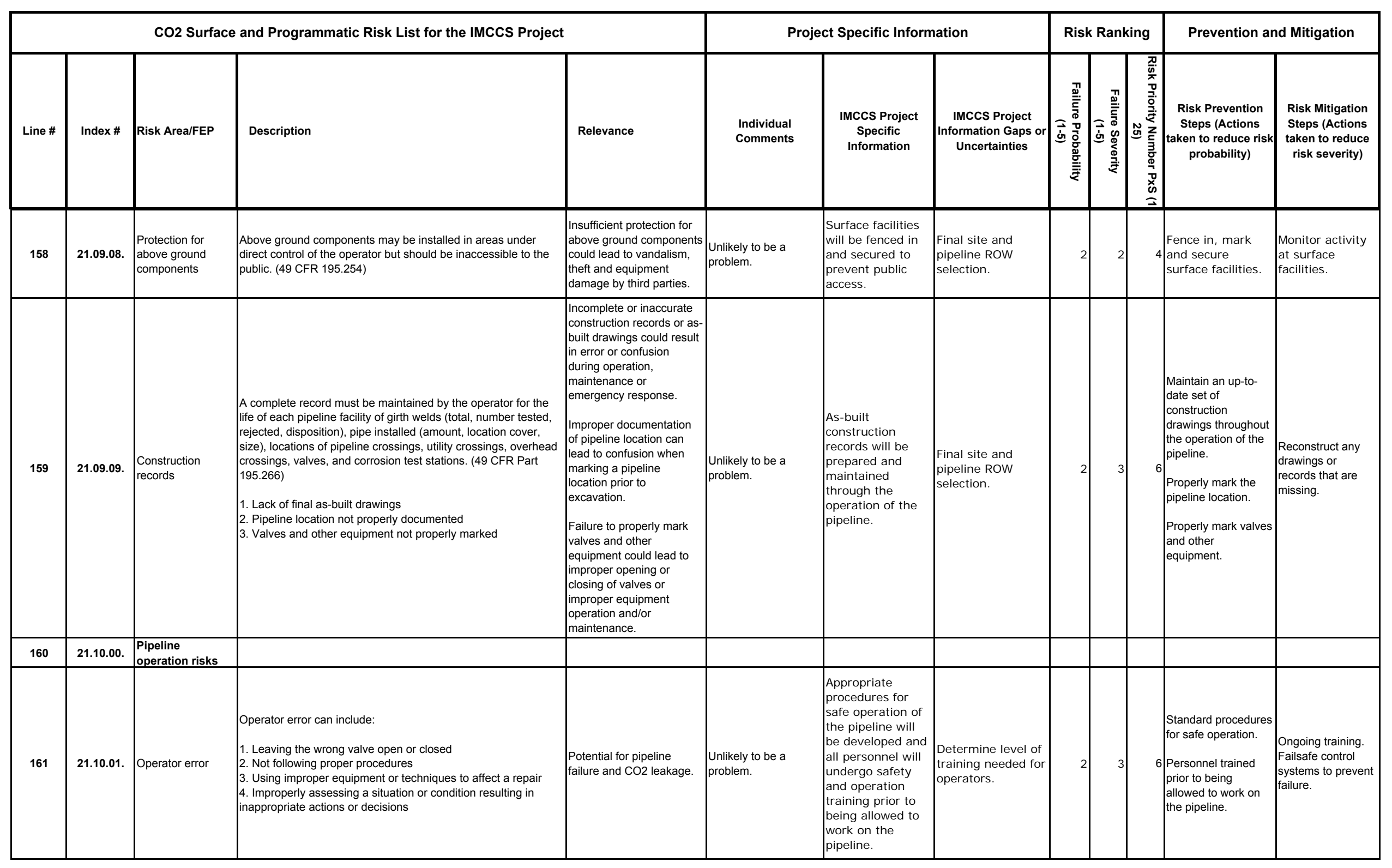




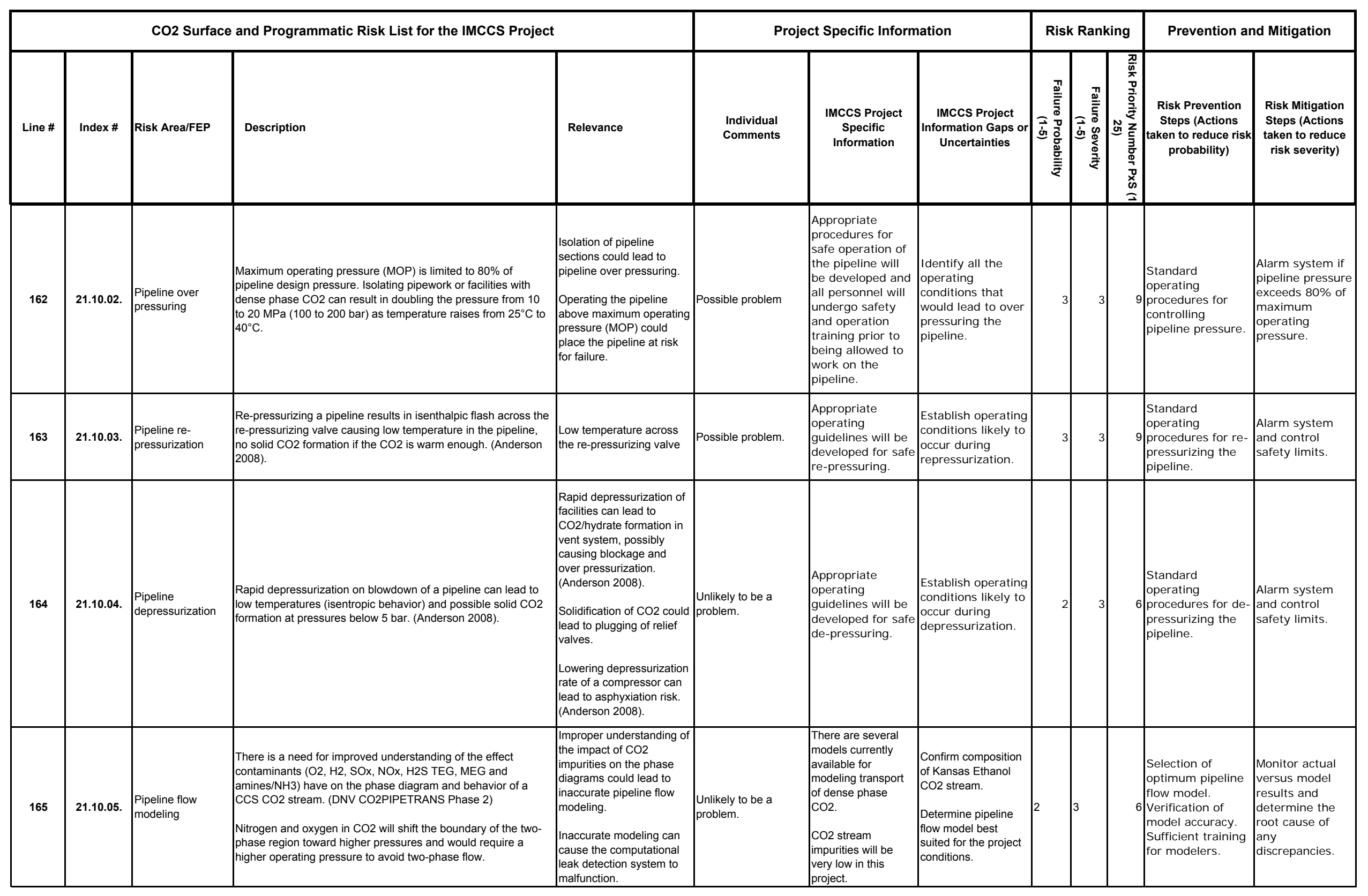




\begin{tabular}{|c|c|c|c|c|c|c|c|c|c|c|c|c|}
\hline \multicolumn{5}{|c|}{ CO2 Surface and Programmatic Risk List for the IMCCS Project } & \multicolumn{3}{|c|}{ Project Specific Information } & \multicolumn{3}{|c|}{ Risk Ranking } & \multicolumn{2}{|c|}{ Prevention and Mitigation } \\
\hline Line \# & Index \# & Risk Area/FEP & Description & Relevance & $\begin{array}{l}\text { Individual } \\
\text { Comments }\end{array}$ & $\begin{array}{l}\text { IMCCS Project } \\
\text { Specific } \\
\text { Information }\end{array}$ & $\begin{array}{c}\text { IMccs Project } \\
\text { Information Gaps or } \\
\text { Uncertainties }\end{array}$ & 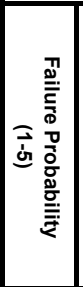 & 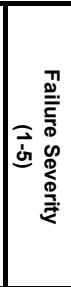 & 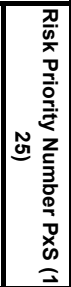 & \begin{tabular}{|c|} 
\\
Risk Prevention \\
Steps (Actions \\
taken to reduce risk \\
probability) \\
\end{tabular} & $\begin{array}{c}\text { Risk Mitigation } \\
\text { Steps (Actions } \\
\text { taken to reduce } \\
\text { risk severity) }\end{array}$ \\
\hline 166 & 21.10.06. & \begin{tabular}{|l|} 
Boiling liquid \\
expanding vapor \\
explosion (BLEVE)
\end{tabular} & $\begin{array}{l}\text { Boiling liquid expanding vapor explosion (BLEVE) is a type of } \\
\text { explosion that can occur when a vessel or pipeline containing a } \\
\text { pressurized liquid is ruptured. Such explosions can be } \\
\text { extremely hazardous. } \\
\text { A BLEVE results from the rupture of a vessel containing a liquid } \\
\text { substantially above its atmospheric boiling point. The substance } \\
\text { is stored partly in liquid form, with a gaseous vapor above the } \\
\text { liquid filling the remainder of the container. } \\
\text { If the vessel is ruptured - for example, due to corrosion, or } \\
\text { failure under pressure - the vapor portion may rapidly leak, } \\
\text { lowering the pressure inside the container. This sudden drop in } \\
\text { pressure inside the container causes violent boiling of the } \\
\text { liquid, which rapidly liberates large amounts of vapor. The } \\
\text { pressure of this vapor can be extremely high, causing a } \\
\text { significant wave of overpressure (an explosion) which may } \\
\text { completely destroy the storage vessel and project fragments } \\
\text { over the surrounding area. } \\
\text { (Wikipedia) }\end{array}$ & $\begin{array}{l}\text { Supercritical } \mathrm{CO} 2 \text { can } \\
\text { have significant density } \\
\text { variations with changes in } \\
\text { pressure and temperature. } \\
\text { If a pipeline ruptures, this } \\
\text { could lead to a boiling } \\
\text { liquid expanding vapor } \\
\text { explosion (Anderson } \\
\text { 2008). }\end{array}$ & $\begin{array}{l}\text { Unlikely to be a } \\
\text { problem }\end{array}$ & $\begin{array}{l}\text { The pipeline will be } \\
\text { designed and } \\
\text { operated to prevent } \\
\text { two-phase flow from } \\
\text { occurring. The } \\
\text { SCADA system and } \\
\text { main-line control } \\
\text { valves will allow } \\
\text { sections of the } \\
\text { pipeline to be shut in } \\
\text { to maintain line } \\
\text { pressure should a } \\
\text { section experience a } \\
\text { leak and } \\
\text { depressurization. }\end{array}$ & \begin{tabular}{|l|} 
\\
Actual cases of \\
BLEVE occurring with \\
CO2.
\end{tabular} & 2 & 4 & & $\begin{array}{l}\text { Standard } \\
\text { procedures for } \\
\text { safe operation and } \\
\text { maintenance of } \\
\text { pipeline. }\end{array}$ & 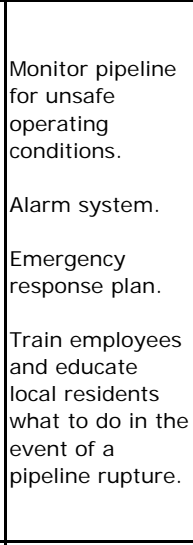 \\
\hline 167 & 21.10.07. & $\begin{array}{l}\text { Pipeline scheduled } \\
\text { maintenance }\end{array}$ & $\begin{array}{l}\text { Typical scheduled maintenance jobs and frequency: Aerial } \\
\text { patrols } 26 \text { times per year. Population density survey every other } \\
\text { year. ROW inspection } 26 \text { times per year. Emergency systems } \\
\text { tested annually. Rectifier maintenance completed } 6 \text { times per } \\
\text { year. Cathodic protection survey annually, Internal inspection of } \\
\text { pipeline using an electronic tool, every } 5 \text { years or more } \\
\text { frequently if necessary. Overpressure safety devices checked } \\
\text { annually. Public awareness and damage prevention program } \\
\text { reviewed annually. (DGC). Inspect each mainline valve twice a } \\
\text { year } \\
\text { 1. Pipeline cleaning }\end{array}$ & $\begin{array}{l}\text { Failure to properly inspect } \\
\text { and maintain the pipeline } \\
\text { could lead to pipeline } \\
\text { failure and CO2 leakage. }\end{array}$ & $\begin{array}{l}\text { Unlikely to be a } \\
\text { problem }\end{array}$ & $\begin{array}{l}\text { Operation and } \\
\text { maintenance of } \\
\text { the pipelines will } \\
\text { follow } 49 \text { CFR } 195 \\
\text { safety } \\
\text { requirements. } \\
\text { Frequency of } \\
\text { inspection will be } \\
\text { monitored and } \\
\text { increased should } \\
\text { an issue arise } \\
\text { that requires } \\
\text { more attention. }\end{array}$ & $\begin{array}{l}\text { Pipeline scheduled } \\
\text { maintenance plan }\end{array}$ & 2 & 3 & & $\begin{array}{l}\text { Comply with } 49 \\
\text { CFR } 195 \text { pipeline } \\
\text { scheduled } \\
\text { maintenance } \\
\text { requirements. }\end{array}$ & $\begin{array}{l}\text { Review status } \\
\text { and results of } \\
\text { pipeline } \\
\text { scheduled } \\
\text { maintenance } \\
\text { annually. }\end{array}$ \\
\hline
\end{tabular}




\begin{tabular}{|c|c|c|c|c|c|c|c|c|c|c|c|c|}
\hline \multicolumn{5}{|c|}{ CO2 Surface and Programmatic Risk List for the IMCCS Project } & \multicolumn{3}{|c|}{ Project Specific Information } & \multicolumn{3}{|c|}{ Risk Ranking } & \multicolumn{2}{|c|}{ Prevention and Mitigation } \\
\hline Line \# & Index \# & Risk Area/FEP & Description & Relevance & $\begin{array}{l}\text { Individual } \\
\text { Comments }\end{array}$ & $\begin{array}{l}\text { IMCCS Project } \\
\text { Specific } \\
\text { Information }\end{array}$ & $\begin{array}{c}\text { IMCCS Project } \\
\text { Information Gaps or } \\
\text { Uncertainties }\end{array}$ & 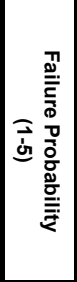 & 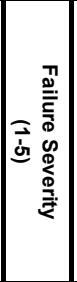 & 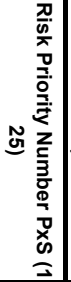 & $\begin{array}{c}\text { Risk Prevention } \\
\text { Steps (Actions } \\
\text { taken to reduce risk } \\
\text { probability) }\end{array}$ & $\begin{array}{c}\text { Risk Mitigation } \\
\text { Steps (Actions } \\
\text { taken to reduce } \\
\text { risk severity) }\end{array}$ \\
\hline 168 & 21.10.08. & \begin{tabular}{|l} 
Pipeline \\
malfunctions
\end{tabular} & $\begin{array}{l}\text { Some pipeline malfunctions could include: } \\
\text { 1. Equipment malfunction or failure } \\
\text { 2. Unintended valve closure or shutdown } \\
\text { 3. Loss of communication (SCADA system) } \\
\text { 4. Power outage } \\
\text { 5. Pig stuck in pipeline causing a shutdown }\end{array}$ & $\begin{array}{l}\text { Pipeline malfunctions } \\
\text { could lead to unintended } \\
\text { shutdown or CO2 leakage. }\end{array}$ & Possible problem. & \begin{tabular}{|l|} 
Appropriate \\
procedures and \\
systems for \\
handling pipeline \\
malfunctions will \\
be developed.
\end{tabular} & $\begin{array}{l}\text { Comprehensive list } \\
\text { of potential project } \\
\text { specific pipeline } \\
\text { malfunctions. }\end{array}$ & 3 & 3 & & $\begin{array}{l}\text { Alarm system for } \\
\text { equipment/valve } \\
\text { malfunction or } \\
\text { failure. } \\
\text { Backup } \\
\text { communication } \\
\text { system for } \\
\text { SCADA. } \\
\text { Backup power } \\
\text { generator or } \\
\text { batteries. } \\
\text { Standard } \\
\text { operating } \\
\text { procedures for } \\
\text { inline inspection } \\
\text { system (pig } \\
\text { system) }\end{array}$ & $\begin{array}{l}\text { Train personnel } \\
\text { to properly } \\
\text { respond to } \\
\text { pipeline } \\
\text { malfunctions on } \\
\text { a timely basis. }\end{array}$ \\
\hline 169 & 21.10.09. & \begin{tabular}{|l} 
Pipeline \\
leak/rupture
\end{tabular} & $\begin{array}{l}\text { Pipeline leaks/ruptures can include: } \\
\text { 1. Pinhole leak - small leak (visible due to dry ice forming on the } \\
\text { surface) } \\
\text { 2. Pipeline puncture small diameter leak } \\
\text { 3. Pipeline puncture large diameter leak } \\
\text { 4. Pipeline rupture - a circumferential or longitudinal } \\
\text { propagation fracture }\end{array}$ & $\begin{array}{l}\text { CO2 leakage. Low } \\
\text { severity for pinhole leak. } \\
\text { Moderate severity for } \\
\text { pipeline puncture. High } \\
\text { severity for pipeline } \\
\text { rupture. }\end{array}$ & Possible problem. & \begin{tabular}{|l} 
CPM leak \\
detection system \\
will be used to \\
locate leaks, \\
Crack arrestors \\
will be installed to \\
minimize \\
propagating \\
cracks. \\
Block valves will \\
be installed to \\
minimize the \\
volume of CO2 \\
release in a \\
puncture or \\
rupture.
\end{tabular} & $\begin{array}{l}\text { Finalize site and } \\
\text { pipeline Row } \\
\text { selections to } \\
\text { determine } \\
\text { potential impact } \\
\text { of CO2 } \\
\text { leaks/ruptures } \\
\text { along the pipeline } \\
\text { ROW. }\end{array}$ & 3 & 4 & 12 & $\begin{array}{l}\text { Standard } \\
\text { procedures for safe } \\
\text { operation and } \\
\text { maintenance of } \\
\text { pipeline. }\end{array}$ & $\begin{array}{l}\text { CPM leak detection } \\
\text { system. } \\
\text { Crack arrestors to } \\
\text { minimize } \\
\text { propagating } \\
\text { cracks. } \\
\text { Block valves to } \\
\text { section off the } \\
\text { pipeline in case of } \\
\text { a rupture. } \\
\text { Personnel training } \\
\text { and local resident } \\
\text { education on how } \\
\text { to identify and } \\
\text { respond to a } \\
\text { pipeline } \\
\text { leak/rupture. } \\
\text { Emergency } \\
\text { response plan. }\end{array}$ \\
\hline
\end{tabular}




\begin{tabular}{|c|c|c|c|c|c|c|c|c|c|c|c|c|}
\hline \multicolumn{5}{|c|}{ CO2 Surface and Programmatic Risk List for the IMCCS Project } & \multicolumn{3}{|c|}{ Project Specific Information } & \multicolumn{3}{|c|}{ Risk Ranking } & \multicolumn{2}{|c|}{ Prevention and Mitigation } \\
\hline Line \# & Index \# & Risk Area/FEP & Description & Relevance & $\begin{array}{l}\text { Individual } \\
\text { Comments }\end{array}$ & $\begin{array}{l}\text { IMCCS Project } \\
\text { Specific } \\
\text { Information }\end{array}$ & $\begin{array}{c}\text { IMccs Project } \\
\text { Information Gaps or } \\
\text { Uncertainties }\end{array}$ & 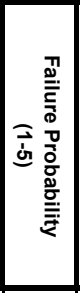 & 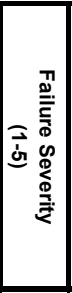 & 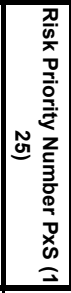 & \begin{tabular}{|c|} 
\\
Risk Prevention \\
Steps (Actions \\
taken to reduce risk \\
probability) \\
\\
\end{tabular} & $\begin{array}{c}\text { Risk Mitigation } \\
\text { Steps (Actions } \\
\text { taken to reduce } \\
\text { risk severity) }\end{array}$ \\
\hline 170 & 21.10.10. & $\begin{array}{l}\text { Pipeline safety } \\
\text { measures }\end{array}$ & $\begin{array}{l}\text { Pipeline safety measures can include: } \\
\text { 1. Emergency response plan } \\
\text { 2. Reverse } 911 \text { call system - emergency alert } \\
\text { 3. One-call system - prior to drilling or excavating } \\
\text { 4. Supervision of excavation near pipelines } \\
\text { 5. Regular inspection and maintenance of pipeline and ROW } \\
\text { 6. CO2 monitors and alarms at booster stations } \\
\text { 7. Oxygen packs at booster stations } \\
\text { 8. Fire fighting equipment at booster stations } \\
\text { 9. Public emergency response plan } \\
\text { 10. Fencing and barricades to protect above ground facilities } \\
\text { 11. Markers for ROW, valves and equipment }\end{array}$ & $\begin{array}{l}\text { Lack of pipeline safety } \\
\text { measures could lead to } \\
\text { human injury and/or } \\
\text { pipeline damage. }\end{array}$ & $\begin{array}{l}\text { Possible problem if } \\
\text { safety measures are } \\
\text { not implemented. }\end{array}$ & \begin{tabular}{|l|} 
The project will \\
employ all of the \\
safety measures \\
required by 49 \\
CFR 195.
\end{tabular} & $\begin{array}{l}\text { Determine } \\
\text { appropriate safety } \\
\text { measures for the } \\
\text { project. }\end{array}$ & 3 & 3 & & $\begin{array}{l}\text { Comply with all } \\
\text { safety measures } \\
\text { required by } 49 \\
\text { CFR } 195 .\end{array}$ & $\begin{array}{l}\text { Review safety } \\
\text { measures } \\
\text { regularly to } \\
\text { ensure they are } \\
\text { operational. } \\
\text { Make } \\
\text { adjustments if } \\
\text { necessary to } \\
\text { ensure safety. }\end{array}$ \\
\hline 171 & 22.00 .00 . & \begin{tabular}{|l|} 
ON-SITE \\
FACILITIES \\
RISKS \\
\end{tabular} & & & & & & & & & & \\
\hline 172 & 22.01.00. & \begin{tabular}{|l|} 
On-site facilities for \\
DSA
\end{tabular} & $\begin{array}{l}\text { On-site facilities for deep saline aquifer (DSA) CO2 injection } \\
\text { can include: } \\
\text { 1. Injection } \mathrm{CO} 2 \text { distribution system trunk and laterals } \\
\text { 2. Power supply } \\
\text { 3. Injection and monitoring wells }\end{array}$ & $\begin{array}{l}\text { Potential problems could } \\
\text { include, blowout, } \\
\text { equipment failure. }\end{array}$ & $\begin{array}{l}\text { Unlikely to be a } \\
\text { problem. }\end{array}$ & $\begin{array}{l}\text { DSA is currently } \\
\text { not planned in } \\
\text { Phase } 2 \text { of the } \\
\text { project, unless } \\
\text { legislation } \\
\text { provides sufficient } \\
\text { economic } \\
\text { justification. }\end{array}$ & $\begin{array}{l}\text { Climate change } \\
\text { legislation timing } \\
\text { and content. }\end{array}$ & 2 & 3 & & $\begin{array}{l}\text { Experienced/train } \\
\text { ed operators and } \\
\text { managers. } \\
\text { Proper } \\
\text { specification, } \\
\text { engineering, } \\
\text { manufacturing } \\
\text { and installation of } \\
\text { equipment and } \\
\text { other } \\
\text { components. } \\
\text { Appropriate } \\
\text { procedures for } \\
\text { safe operation and } \\
\text { maintenance of on } \\
\text { site facilities. } \\
\text { Compliance with } \\
\text { Kansas } \\
\text { Corporation } \\
\text { Commission rules } \\
\text { and regulations } \\
\text { for CO2 storage } \\
\text { facilities. }\end{array}$ & \begin{tabular}{|l} 
Risk \\
management \\
plan in place.
\end{tabular} \\
\hline
\end{tabular}




\begin{tabular}{|c|c|c|c|c|c|c|c|c|c|c|c|c|}
\hline \multicolumn{5}{|c|}{ CO2 Surface and Programmatic Risk List for the IMCCS Project } & \multicolumn{3}{|c|}{ Project Specific Information } & \multicolumn{3}{|c|}{ Risk Ranking } & \multicolumn{2}{|c|}{ Prevention and Mitigation } \\
\hline Line \# & Index \# & Risk Area/FEP & Description & Relevance & $\begin{array}{l}\text { Individual } \\
\text { Comments }\end{array}$ & $\begin{array}{l}\text { IMCCS Project } \\
\text { Specific } \\
\text { Information }\end{array}$ & $\begin{array}{c}\text { IMccs Project } \\
\text { Information Gaps or } \\
\text { Uncertainties }\end{array}$ & 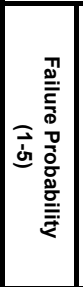 & 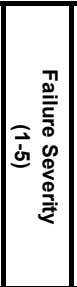 & 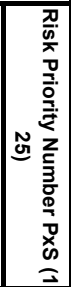 & \begin{tabular}{|c|} 
Risk Prevention \\
Steps (Actions \\
taken to reduce risk \\
probability)
\end{tabular} & $\begin{array}{c}\text { Risk Mitigation } \\
\text { Steps (Actions } \\
\text { taken to reduce } \\
\text { risk severity) }\end{array}$ \\
\hline 173 & 22.02.00. & $\begin{array}{l}\text { On-site facilities for } \\
\text { EOR }\end{array}$ & $\begin{array}{l}\text { On-site facilities for } \mathrm{CO} 2 \text { enhanced oil recovery (EOR) can } \\
\text { include: } \\
\text { 1. Recycle } \mathrm{CO} 2 \text { compression system and building } \\
\text { 2. Injection } \mathrm{CO} 2 \text { distribution system trunk and laterals } \\
\text { 3. Production gathering system } \\
\text { 4. Oil, water and slop storage tanks } \\
\text { 5. CO2 dehydration system } \\
\text { 6. CO2 gas scrubber/knockout drum } \\
\text { 7. Flare system } \\
\text { 8. Circulation and transfer pumps } \\
\text { 9. Instrument air system } \\
\text { 10. Control room, motor control center and building } \\
\text { 11. Power supply transformers, UPS, PLCs, cables } \\
\text { 12. Injection, production, disposal and monitoring wells } \\
\text { 13. Water treatment/disposal facilities }\end{array}$ & $\begin{array}{l}\text { Potential problems could } \\
\text { include blowout, oil } \\
\text { leaks/spills } \\
\text { ignition/explosion, } \\
\text { equipment failure, water } \\
\text { quality, water disposal }\end{array}$ & $\begin{array}{l}\text { Possible problem of } \\
\text { equipment failure. }\end{array}$ & $\begin{array}{l}\text { EOR operations } \\
\text { will be managed } \\
\text { by a company } \\
\text { with significant } \\
\text { EOR experience. }\end{array}$ & $\begin{array}{l}\text { Finalize site } \\
\text { selection to } \\
\text { determine the on- } \\
\text { site facilities } \\
\text { required. }\end{array}$ & 3 & 3 & & $\begin{array}{l}\text { Experienced/train } \\
\text { ed operators and } \\
\text { managers. } \\
\text { Proper } \\
\text { specification, } \\
\text { engineering, } \\
\text { manufacturing } \\
\text { and installation of } \\
\text { equipment and } \\
\text { other } \\
\text { components. } \\
\text { Appropriate } \\
\text { procedures for } \\
\text { safe operation and } \\
\text { maintenance of on } \\
\text { site facilities. } \\
\text { Compliance with } \\
\text { Kansas } \\
\text { Corporation } \\
\text { Commission rules } \\
\text { and regulations } \\
\text { for EOR } \\
\text { operations. }\end{array}$ & $\begin{array}{l}\text { Risk } \\
\text { management } \\
\text { plan in place. } \\
\text { Monitor for CO2, } \\
\text { oil or water } \\
\text { leaks. }\end{array}$ \\
\hline 174 & 22.03.00. & $\begin{array}{l}\text { On-site facilities for } \\
\text { ECBM }\end{array}$ & $\begin{array}{l}\text { On-site facilities for } \mathrm{CO} 2 \text { enhanced coal bed methane (ECBM) } \\
\text { can include: } \\
\text { 1. Recycle } \mathrm{CO} 2 \text { compression system and building } \\
\text { 2. Injection } \mathrm{CO} 2 \text { distribution system trunk and laterals } \\
\text { 3. Production gathering system } \\
\text { 4. Water storage tanks } \\
\text { 5. CO2 dehydration system } \\
\text { 6. CO2 capture system - removal of } \mathrm{CO} 2 \text { from nat. gas } \\
\text { 7. Flare system } \\
\text { 8. Circulation and transfer pumps } \\
\text { 9. Instrument air system } \\
\text { 10. Control room, motor control center and building } \\
\text { 11. Power supply transformers, UPS, PLCs, cables } \\
\text { 12. Injection, production, disposal and monitoring wells } \\
\text { 13. Water treatment/disposal facilities }\end{array}$ & $\begin{array}{l}\text { Potential problems could } \\
\text { include blowout, methane } \\
\text { leaks ignition/explosion, } \\
\text { equipment failure, water } \\
\text { disposal. }\end{array}$ & NA & $\begin{array}{l}\text { No ECBM is } \\
\text { planned at this } \\
\text { stage of the } \\
\text { project. However } \\
\text { there is } \\
\text { significant } \\
\text { opportunities for } \\
\text { ECBM in } \\
\text { Southeastern } \\
\text { Kansas.. }\end{array}$ & NA & 1 & 1 & & NA & NA \\
\hline
\end{tabular}




\begin{tabular}{|c|c|c|c|c|c|c|c|c|c|c|c|c|}
\hline \multicolumn{5}{|c|}{ CO2 Surface and Programmatic Risk List for the IMCCS Project } & \multicolumn{3}{|c|}{ Project Specific Information } & \multicolumn{3}{|c|}{ Risk Ranking } & \multicolumn{2}{|c|}{ Prevention and Mitigation } \\
\hline Line \# & Index \# & Risk Area/FEP & Description & Relevance & $\begin{array}{l}\text { Individual } \\
\text { Comments }\end{array}$ & $\begin{array}{l}\text { IMCCS Project } \\
\text { Specific } \\
\text { Information }\end{array}$ & $\begin{array}{c}\text { IMccs Project } \\
\text { Information Gaps or } \\
\text { Uncertainties }\end{array}$ & 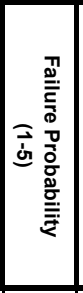 & 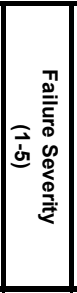 & 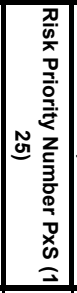 & \begin{tabular}{|c|} 
Risk Prevention \\
Steps (Actions \\
taken to reduce risk \\
probability) \\
\end{tabular} & $\begin{array}{c}\text { Risk Mitigation } \\
\text { Steps (Actions } \\
\text { taken to reduce } \\
\text { risk severity) }\end{array}$ \\
\hline 175 & 22.04.00. & $\begin{array}{l}\text { Injection well } \\
\text { components }\end{array}$ & $\begin{array}{l}\text { CO2 injection well components generally include: } \\
\text { 1. Wellhead and tree } \\
\text { 2. Tubing and casing } \\
\text { 3. Safety valve } \\
\text { 4. Packer } \\
\text { 5. Packer fluid } \\
\text { 6. Elastomers } \\
\text { 7. Sand control - for unconsolidated reservoirs }\end{array}$ & $\begin{array}{l}\text { Component failure could } \\
\text { result in } \mathrm{CO} 2 \text { leakage. }\end{array}$ & Possible problem. & $\begin{array}{l}\text { Injection } \\
\text { components will } \\
\text { be properly } \\
\text { designed to } \\
\text { handle CO2 } \\
\text { and/or water } \\
\text { injection. }\end{array}$ & $\begin{array}{l}\text { Finalize site } \\
\text { selection to } \\
\text { determine CO2 } \\
\text { injection well } \\
\text { components } \\
\text { needed. }\end{array}$ & 3 & 2 & & 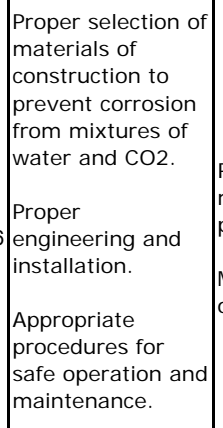 & $\begin{array}{l}\text { Risk } \\
\text { management } \\
\text { plan in place. } \\
\text { Monitor for co2 } \\
\text { or water leaks. }\end{array}$ \\
\hline 176 & 22.05.00. & $\begin{array}{l}\text { Injection well } \\
\text { materials of } \\
\text { construction }\end{array}$ & $\begin{array}{l}\text { DSA CO2 injection well components are typically carbon steel. } \\
\text { Typical materials of construction for EOR CO2 injection wells } \\
\text { include: } \\
\text { - Upstream metering \& piping runs: } 316 \text { SS, Fiberglass } \\
\text { - Christmas tree (trim): } 316 \text { SS, Nickel, Monel } \\
\text { - Valve packing and seals: Teflon, Nylon } \\
\text { - Wellhead (trim): } 316 \text { SS, Nickel, Monel } \\
\text { - Tubing hanger: } 316 \text { SS, Incoloy } \\
\text { - Tubing: fiberglass lined carbon steel, internally plastic coated } \\
\text { carbon steel, corrosion resistant alloys } \\
\text { - Tubing joint seals: Seal ring (fiberglass lined), coated threads } \\
\text { and collars (internally plastic coated) } \\
\text { - On/off tool, profile nipple: Nickel plated wetted parts, } 316 \text { SS } \\
\text { - Packers: Internally coated hardened rubber of } 80-90 \\
\text { durometer strength (Buna--N), Nickel plated wetted parts } \\
\text {-Cements and cement additives: API cements and/or acid } \\
\text { resistant specialty cements and additives } \\
\text { - Production liner 316 SS, Incoloy } \\
\text { - Casing: carbon steel J-55 and K-55 grades; corrosion resistant } \\
\text { alloy used in intervals where potential potable water aquifers } \\
\text { exist or where H2S is present (API } 2007 \text { ) } \\
\text { Elastomers - Teflon or nylon have been used to prevent } \\
\text { swelling }\end{array}$ & $\begin{array}{l}\text { Corrosion can occur when } \\
\text { tubulars are exposed to } \\
\text { wet CO2. } \\
\text { Sufficient quantities of } \\
\text { H2S in CO2 can cause } \\
\text { corrosion or sulfide stress } \\
\text { cracking. (CCP 2009) } \\
\text { The reservoir fluid affects } \\
\text { corrosivity near the } \\
\text { wellbore and compaction } \\
\text { resistance where } \\
\text { formation dissolution has } \\
\text { occurred. In significant } \\
\text { dissolution cases, the well } \\
\text { tubulars must be designed } \\
\text { to resist column buckling } \\
\text { in the injection interval. } \\
\text { (CCP 2009) } \\
\text { CO2 phase behavior can } \\
\text { impact velocity. High } \\
\text { velocity of injection can } \\
\text { cause erosion to materials } \\
\text { exposed to the CO2 } \\
\text { stream (CCP 2009) }\end{array}$ & \begin{tabular}{|l} 
Unlikely to be a \\
problem.
\end{tabular} & $\begin{array}{l}\text { Water from the } \\
\text { Arbuckle may } \\
\text { contain } \mathrm{H} 2 \mathrm{~S} \text { and } \\
\text { be highly } \\
\text { corrosive. } \\
\text { Materials of } \\
\text { construction will } \\
\text { be selected for } \\
\text { injection wells } \\
\text { that are resistant } \\
\text { to corrosion. }\end{array}$ & $\begin{array}{l}\text { Finalize site } \\
\text { selection. } \\
\text { Confirm H2S } \\
\text { content and } \\
\text { corrosiveness of } \\
\text { Arbuckle water. } \\
\\
\text { Determine the } \\
\text { likelihood of scale } \\
\text { build up in the } \\
\text { injection well } \\
\text { when brine is } \\
\text { injected. }\end{array}$ & 4 & 3 & 12 & $\begin{array}{l}\text { Determine the } \\
\text { characteristics of } \\
\text { brine to be } \\
\text { handled in the } \\
\text { injection wells. } \\
\text { Select materials } \\
\text { that will resist } \\
\text { corrosion, and/or } \\
\text { scale build up. }\end{array}$ & $\begin{array}{l}\text { Monitor } \\
\text { corrosion and } \\
\text { scale buildup in } \\
\text { injection wells } \\
\text { and take } \\
\text { necessary } \\
\text { corrective action } \\
\text { such as pre- } \\
\text { treating the } \\
\text { injected water. }\end{array}$ \\
\hline
\end{tabular}




\begin{tabular}{|c|c|c|c|c|c|c|c|c|c|c|c|c|}
\hline \multicolumn{5}{|c|}{ CO2 Surface and Programmatic Risk List for the IMCCS Project } & \multicolumn{3}{|c|}{ Project Specific Information } & \multicolumn{3}{|c|}{ Risk Ranking } & \multicolumn{2}{|c|}{ Prevention and Mitigation } \\
\hline Line \# & Index \# & Risk Area/FEP & Description & Relevance & $\begin{array}{l}\text { Individual } \\
\text { Comments }\end{array}$ & $\begin{array}{l}\text { IMCCS Project } \\
\text { Specific } \\
\text { Information }\end{array}$ & $\begin{array}{c}\text { IMccs Project } \\
\text { Information Gaps or } \\
\text { Uncertainties }\end{array}$ & 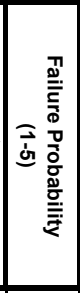 & 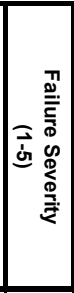 & 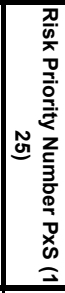 & \begin{tabular}{|c|} 
Risk Prevention \\
Steps (Actions \\
taken to reduce risk \\
probability)
\end{tabular} & $\begin{array}{c}\text { Risk Mitigation } \\
\text { Steps (Actions } \\
\text { taken to reduce } \\
\text { risk severity) }\end{array}$ \\
\hline 177 & 22.05.01. & Elastomer seals & $\begin{array}{l}\text { Since supercritical CO2 is a solvent, many elastomers, plastics, } \\
\text { rubber, or resins present in a well could be subject to chemical } \\
\text { attack or dissolution. When designing a CO2 injector, material } \\
\text { should be based on performance expectations. } \\
\text { Elastomers, in particular, are a common part of well hardware } \\
\text { used to seal different components. Elastomers must be made of } \\
\text { material that is chemically compatible or inert to the injection } \\
\text { fluid and must be of sufficient strength or adequately anchored } \\
\text { to withstand the different pressure and explosive } \\
\text { decompression that might exist across a seal, Since the } \\
\text { physical and performance characteristics of many elastomer } \\
\text { materials change with pressure and temperature, the elastomer } \\
\text { must be able to perform reliably across the full range of } \\
\text { differential pressures and temperatures expected through the } \\
\text { design life of the well at the location of the seal within the well. } \\
\text { (CCP 2009) } \\
\text { Teflon or nylon have been used for seals to prevent swelling. } \\
\text { (API 2007). }\end{array}$ & $\begin{array}{l}\text { Elastomer seal failure can } \\
\text { result in CO2 leakage. }\end{array}$ & $\begin{array}{l}\text { Unlikely to be a } \\
\text { problem. }\end{array}$ & $\begin{array}{l}\text { Elastomers will be } \\
\text { selected based on } \\
\text { successful } \\
\text { performance with } \\
\text { CO2. }\end{array}$ & \begin{tabular}{|l|} 
Get performance \\
data for \\
elastomers used in \\
other CO2 EOR \\
projects.
\end{tabular} & 2 & 2 & & $\begin{array}{l}\text { Select elastomers } \\
\text { that have a } \\
\text { successful track } \\
\text { record in handling } \\
\text { CO2. }\end{array}$ & $\begin{array}{l} \\
\text { Replace } \\
\text { elastomer seals } \\
\text { that fail. } \\
\text { Determine root } \\
\text { cause. Monitor } \\
\text { development of } \\
\text { improved } \\
\text { elastomers. }\end{array}$ \\
\hline 178 & 22.06.00. & $\begin{array}{l}\text { Injection well } \\
\text { safety measures }\end{array}$ & $\begin{array}{l}\text { Safety measures for injection wells include: } \\
\text { 1. Casing corrosion protection } \\
\text { - Impressed and passive currents } \\
\text { - Oxygen, biocide corrosion inhibiting chemicals } \\
\text { 2. Gentle handling to prevent damage to tubing coatings } \\
\text { 3. Casing leak detection testing } \\
\text { 4. Fencing, monitoring and atmospheric dispersion monitoring } \\
\text { if near populated areas } \\
\text { 5. Automatic shutdown controls for unsafe conditions }\end{array}$ & $\begin{array}{l}\text { Lack of safety precautions } \\
\text { can lead to greater risk of } \\
\text { CO2 leakage }\end{array}$ & Unlikely to be a pr & \begin{tabular}{|l|} 
The project will \\
comply with \\
Kansas \\
Corporation \\
Commission rules \\
and regulations \\
covering safety \\
measures for \\
injection wells.
\end{tabular} & $\begin{array}{l}\text { Final site selection } \\
\text { to determine what } \\
\text { well safety } \\
\text { measures will } \\
\text { actually be } \\
\text { required. }\end{array}$ & 2 & 4 & & $\begin{array}{l}\text { Comply with } \\
\text { Kansas Corporate } \\
\text { Commission rules } \\
\text { and regulations } \\
\text { covering safety } \\
\text { measures for } \\
\text { injection wells. }\end{array}$ & $\begin{array}{l}\text { Annual review of } \\
\text { safety measures, } \\
\text { rules and } \\
\text { regulations to } \\
\text { confirm the } \\
\text { project is in } \\
\text { compliance. }\end{array}$ \\
\hline 179 & 22.07.00. & $\begin{array}{l}\text { Production well } \\
\text { submersible pump }\end{array}$ & $\begin{array}{l}\text { While normally very reliable, the submersible pump in an EOR } \\
\text { or ECBM production well can fail. }\end{array}$ & $\begin{array}{l}\text { Failure of the submersible } \\
\text { pump can result in } \\
\text { operating delays and } \\
\text { maintenance costs. }\end{array}$ & Possible problem. & \begin{tabular}{|l|} 
Production well \\
submersible pump \\
will have Teflon \\
coating to \\
minimize \\
asphaltene/paraffi \\
n deposition. \\
\end{tabular} & \begin{tabular}{|l} 
Final site selection \\
to determine \\
characteristics of \\
brine and oil.
\end{tabular} & 3 & 2 & & \begin{tabular}{|l} 
Proper selection, \\
installation, \\
operation and \\
maintenance of \\
submersible \\
pump.
\end{tabular} & \begin{tabular}{|l} 
Monitor \\
submersible \\
pump for \\
corrosion, \\
hydrocarbon \\
deposition or \\
scale buildup. \\
\end{tabular} \\
\hline
\end{tabular}




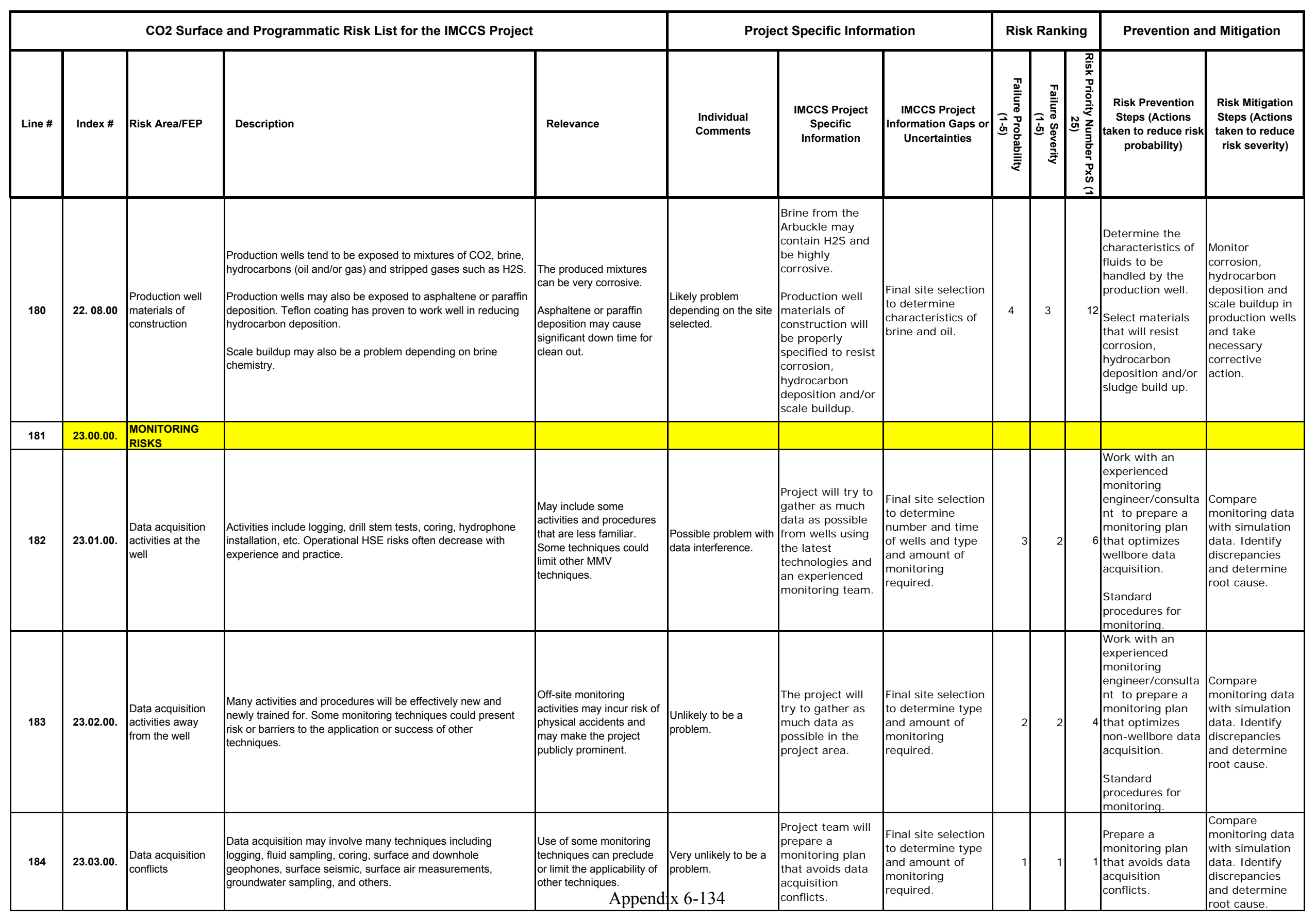




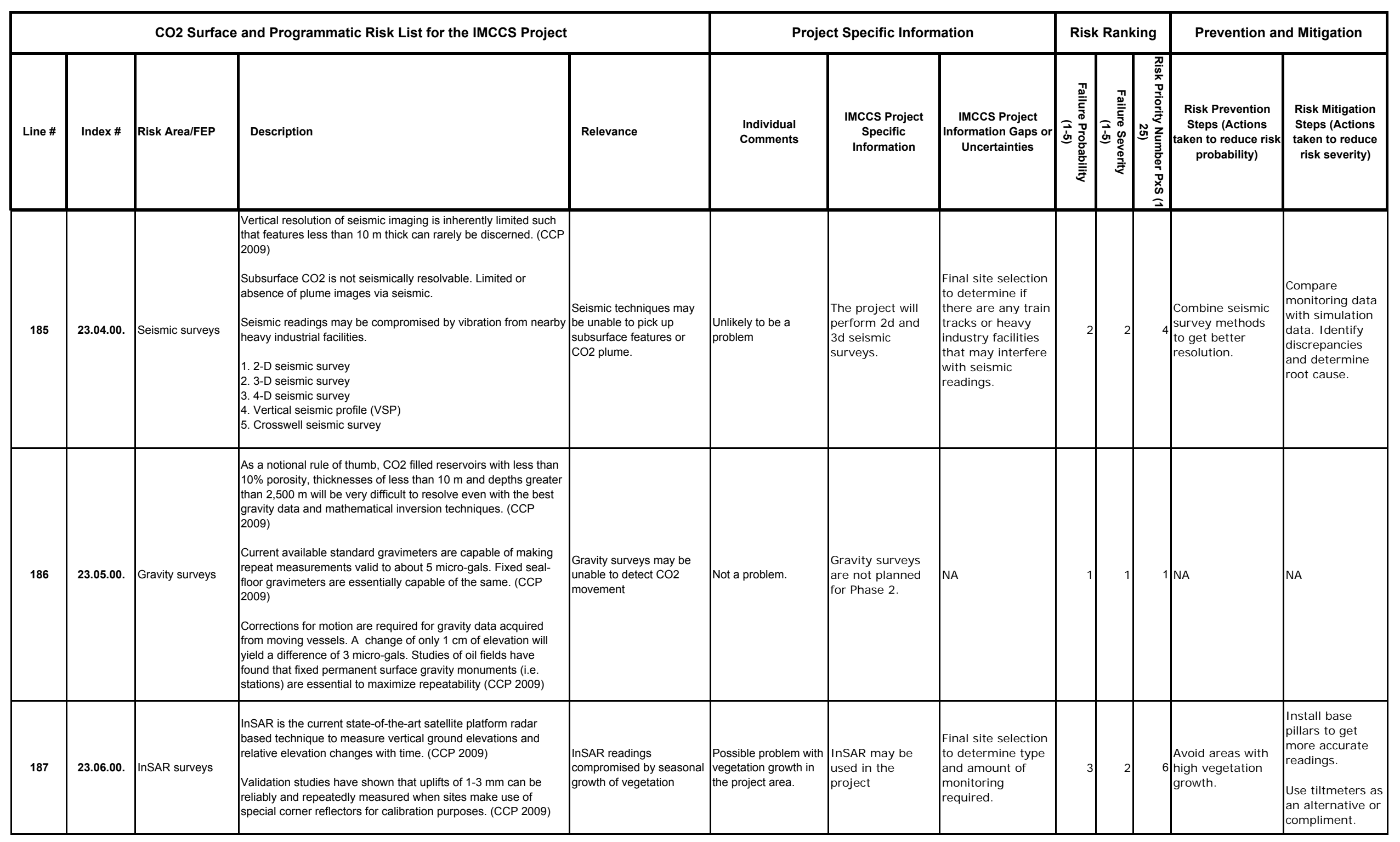




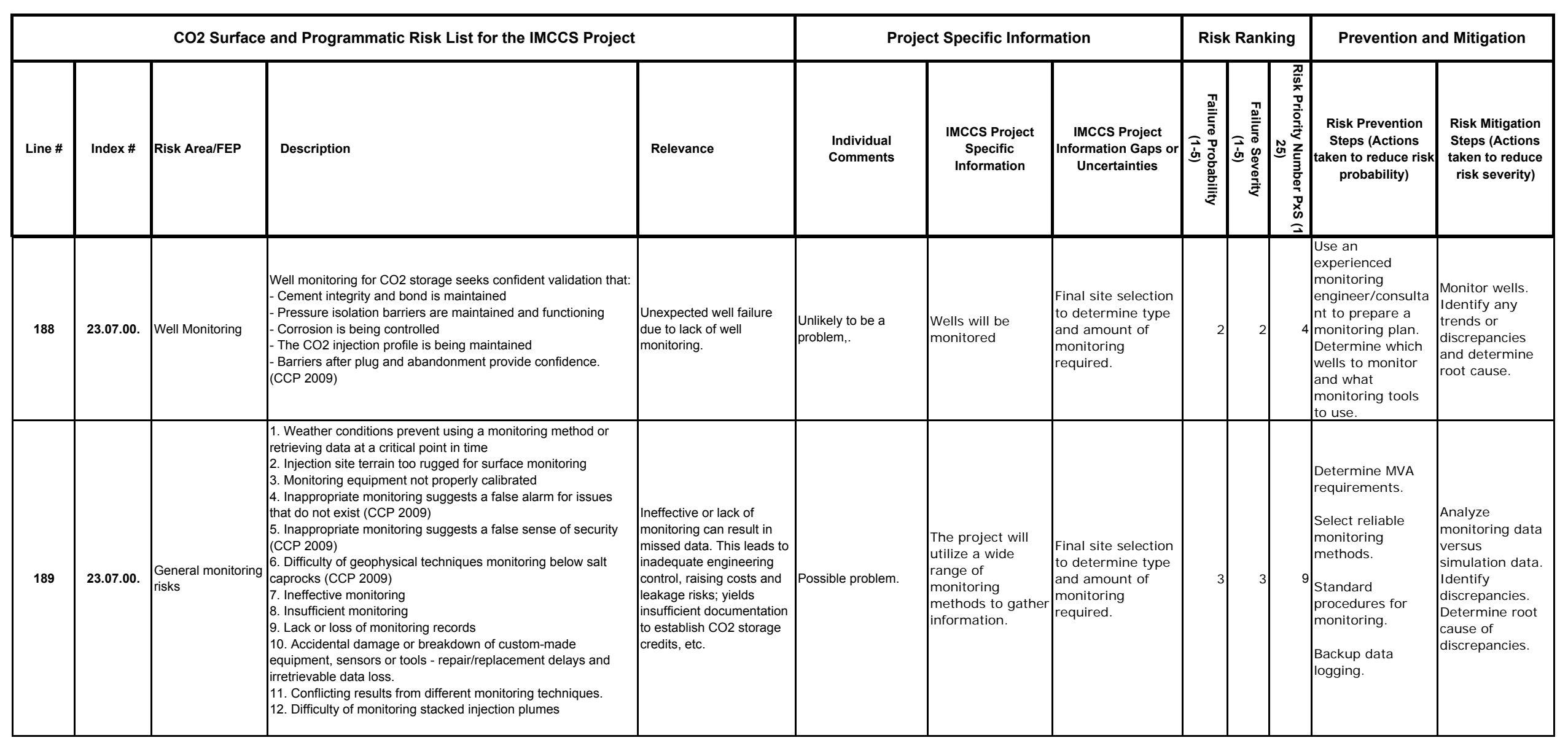




\section{Appendix 6-C}

\section{Wellbore Integrity Risk Assessment}




\section{Wellbore Integrity Risk Assessment}

A wellbore integrity risk assessment was performed for the Thrall-Aagard (TA) field by Dr. Andrew Duguid of Schlumberger Carbon Services. The assessment was reviewed by the risk assessment working group and revised based on the group's comments. The assessment strategy was to use

$$
\begin{aligned}
\text { Risk }= & \text { Probability of occurrence } \times \text { Severity of the impact [Equation 1] } \\
& \text { Risk }=\text { Risk Factor } \times \text { Severity of the impact [Equation 2] }
\end{aligned}
$$

For the TA site the population of wells was completed between 1922 and 1991 with most in the 1920 s and 1950s and most wells were plugged in the 1960s. As shown in Figure 1, there are around 457 abandoned and active wells in the study area with 7 producing wells. Within these wells 13 wells had noted casing issues and 19 wells had noted plug issues

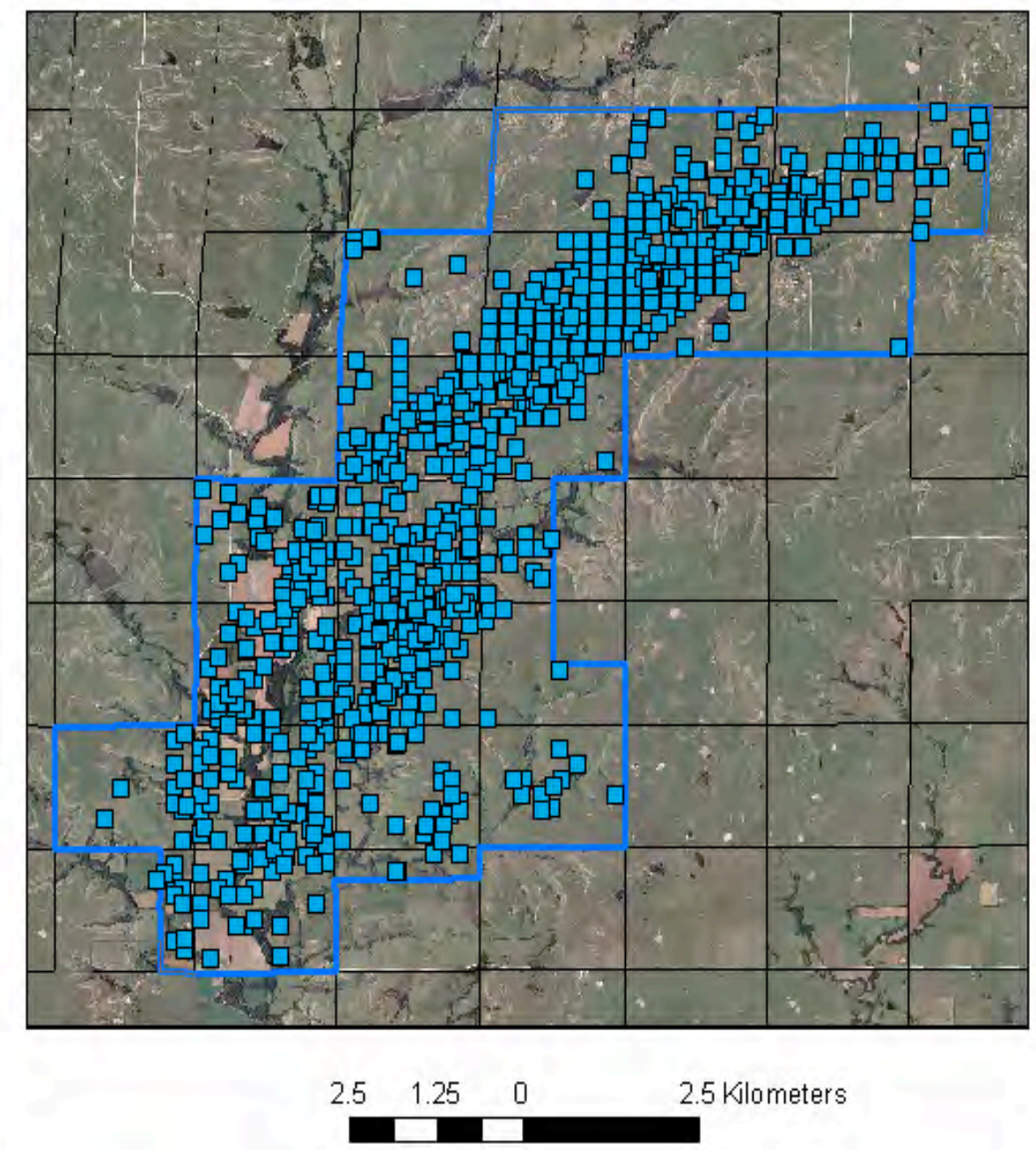

Figure 1: Map of Thrall-Aagard field showing the location of existing wells. 
Well records were gathered by Dr. Martin Dubois of CAPCO2 from Kansas Geological Survey and private sources. Well completion and well plugging reports were incomplete or missing and the reports were not standard over time or between operators.

STATI STAE OP KANSAS
STORUTHON COSOOSSION

Form CP.4
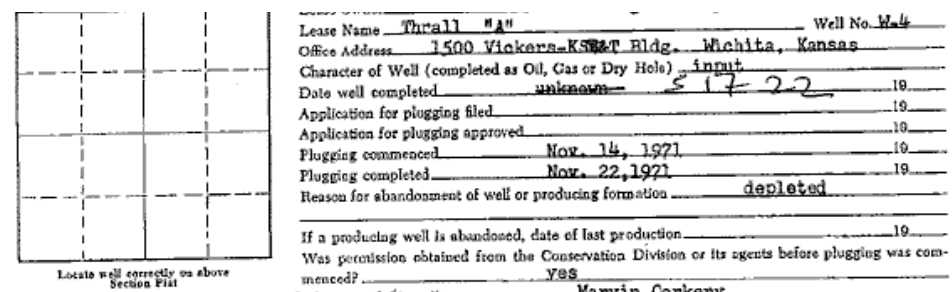

If a produclag well is abandoned, tate of last production _

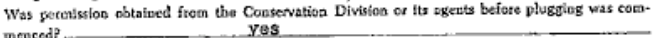

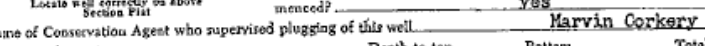

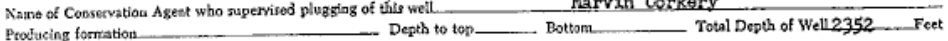
Sbow depth und thickness of all water, oil and gas fornations.

\begin{tabular}{|c|c|c|c|c|c|c|}
\hline FRERATIOE & EonteAt & FROM & to & 5128 & tat in & Fususo aur \\
\hline$\pi$ & & & & St: & & $1900 \mathrm{ft}$. \\
\hline- & State 9 & & & & & \\
\hline & & & & $7^{11}$ & & $75 \% \mathrm{ft}$. \\
\hline 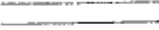 & & 50 & & & & \\
\hline & $\mathrm{CO}_{N} \mathrm{SER}_{\mathrm{F}}$ & 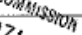 & & & & \\
\hline & 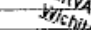 & 71 & & & & \\
\hline
\end{tabular}

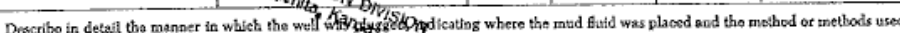

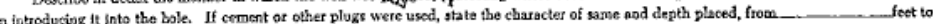

In introducing it into the bole. If cement

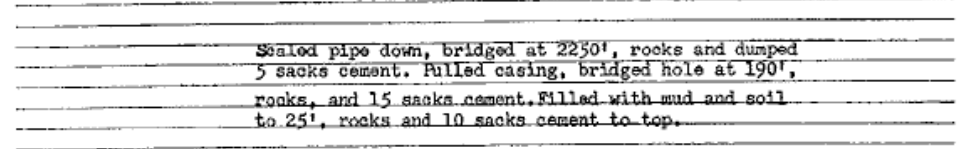

Figure 2: Example of a typical well plugging report

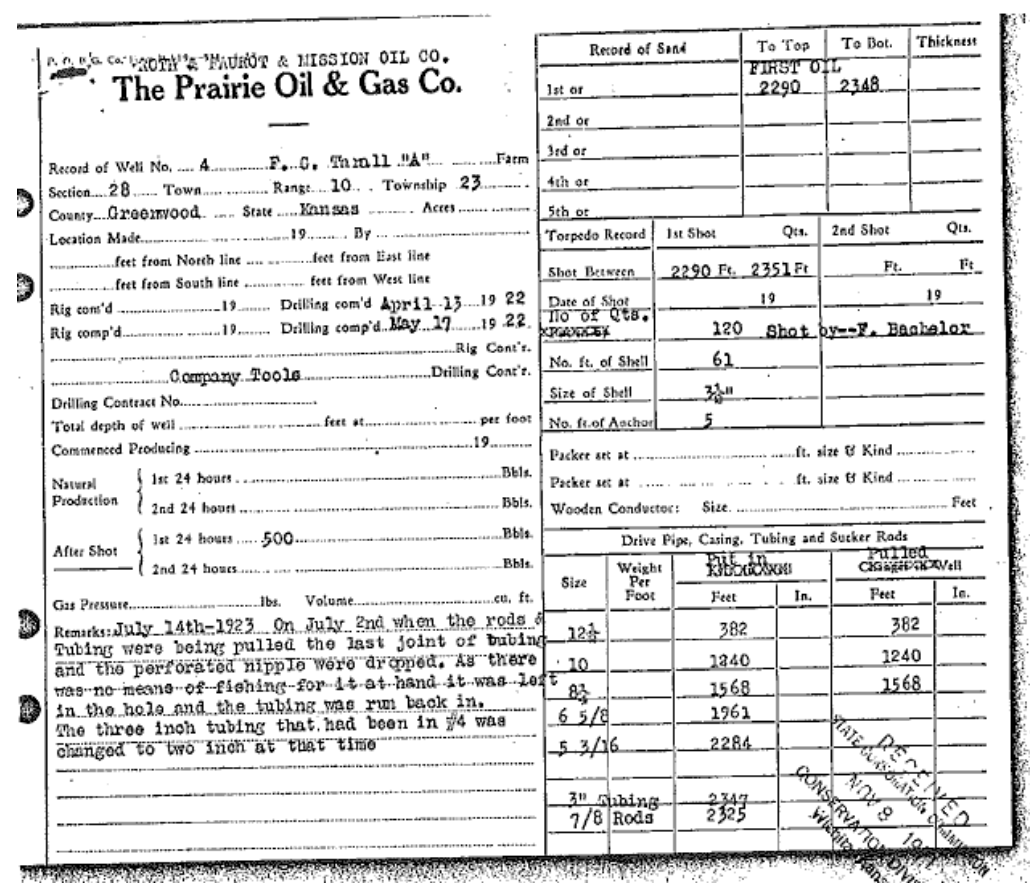

Figure 3: Example of a typical well completion report. 
The overall well risk factor was the sum of individual risk factors. The individual risk factors were each ranked between 0 and 5 . The factors used were:

- Completion date: 1920s, 1930s, 1940s, 1950s, 1960s, 1970s, 1980s, 1990s, 2000s

not found, plug issue

- Bottom plug depth: Above $200 \mathrm{ft}$, between 200 and $1800 \mathrm{ft}$, below $1800 \mathrm{ft}$

- Total plugged length: Less that $50 \mathrm{ft}$, between 50 and $100 \mathrm{ft}$, between 100 and $1000 \mathrm{ft}$, and greater than $1000 \mathrm{ft}$

- Percent plugged: Less than $5 \%$, between 5 and $15 \%$, between 15 and $50 \%$, greater that $50 \%$

- Section: Section 29, section 32, other sections

- Previous casing issue: Previous issue, No reported casing issue

- Well type: Dry, EOR, gas, injection, oil, other, unknown

- Well operator: Sinclair, Cities, others

By selecting a risk factor as a proxy for probability the risk calculation still looks very much like that which uses Equation 1 where the aim is to reduce the risk to the lowest practicable level. For this project the severity of the impact was considered the same for all of the wells, although the actual level was not estimated.

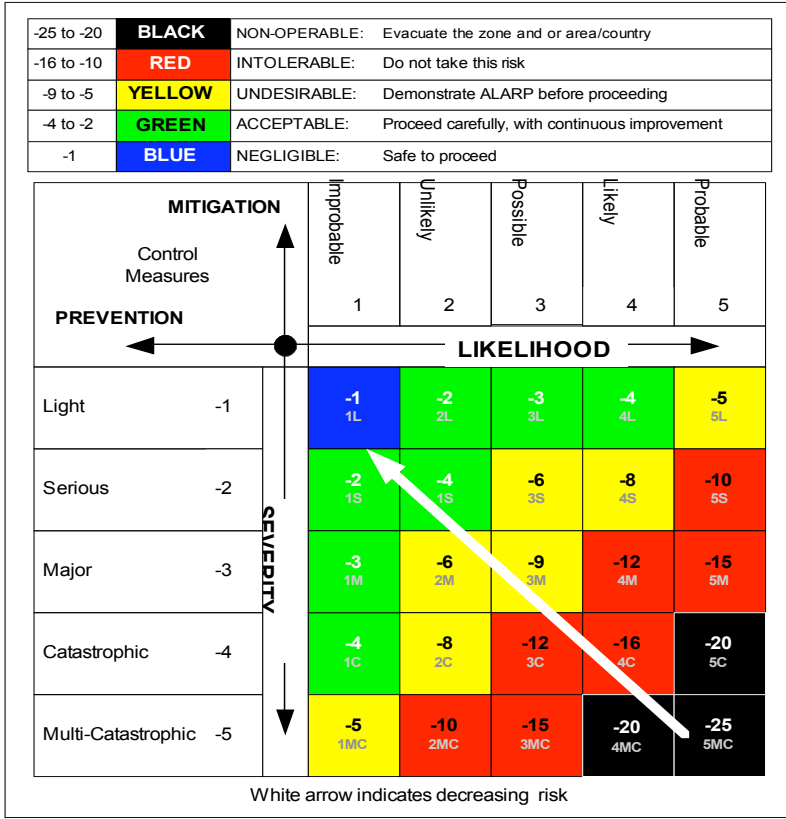

Figure 4: Risk matrix showing the possible combinations of severity and likelihood (probability of occurrence) 
In order to calculate data such as hole diameter, location of remaining casing, plug diameter, and plug length, a series of assumptions were made. The assumptions included:

- All strings of casing in the wells originate at the surface (Figure 3 ). In the few instances where hanging casing was noted in the records, it was taken into account.

- In wells plugged post-1950 that were constructed prior to 1950, casing sizes were assumed to be the early (pre-1950) designations and weights for estimation of casing weight and hole size. For example, in a plugging report where 5.5-inch casing was removed during the plugging operation, it was actually $53 / 16$ " casing that was installed.

- Cement volume was calculated assuming $1.05 \mathrm{ft}^{3}$ of cement paste per sack of cement.

- Plug length was estimated by dividing the estimated plug-cement volume by the calculated/estimated plug-cross-sectional area (based on estimated or actual hole diameters).

- Casing was always cut from the top of the string.
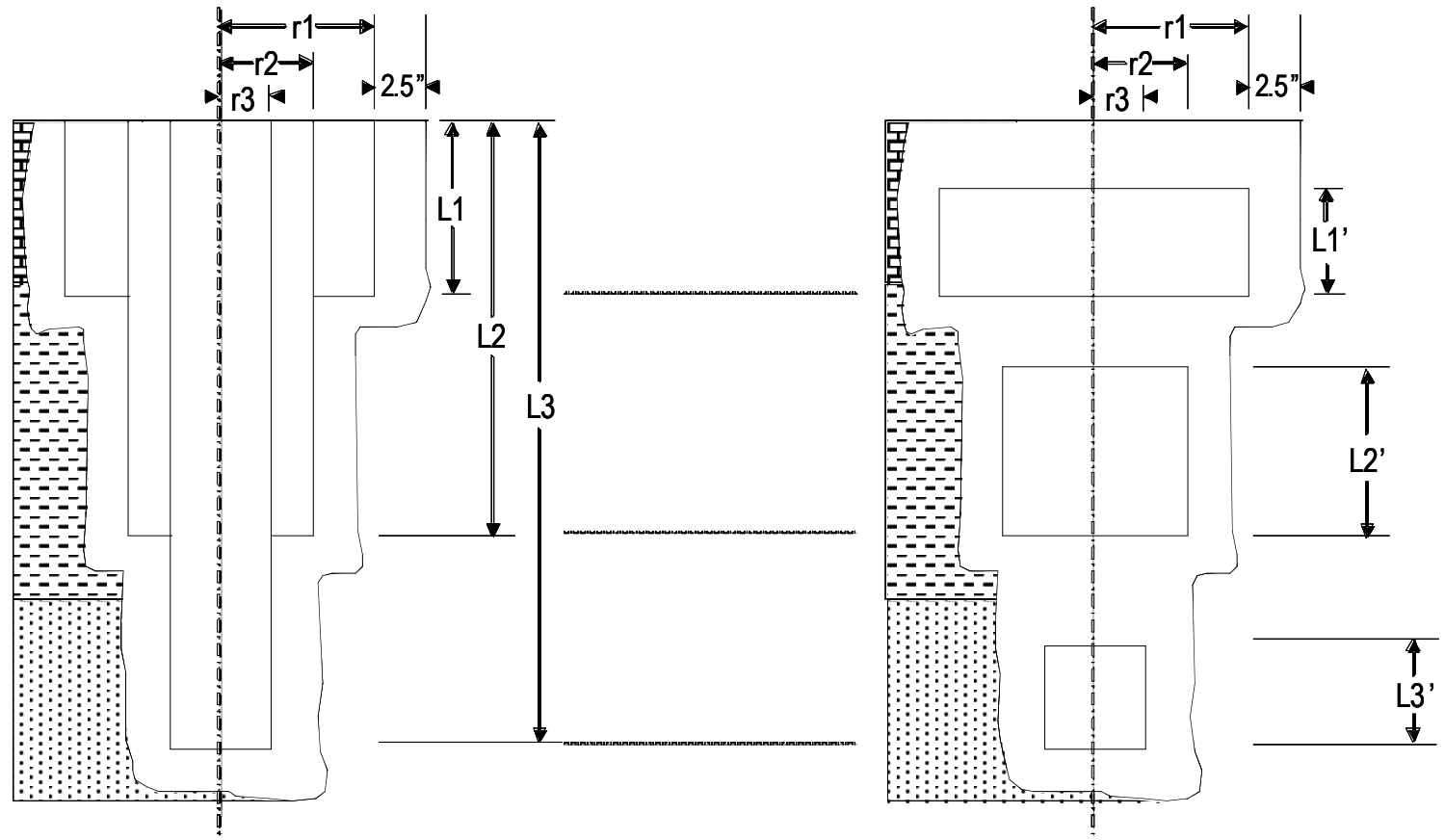

Figure 5: Assumed well construction with all casings originating at the top at the time of construction (left) and after partial casing removal (right) 
Figure 6 shows the well risk factor based on well age.
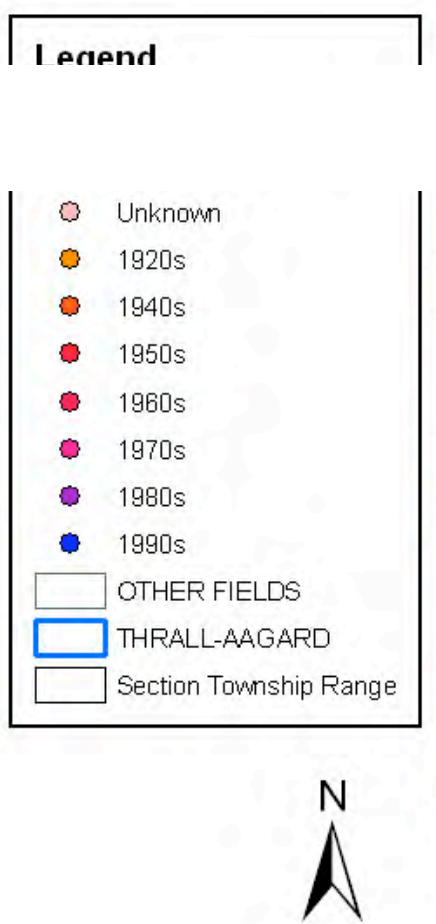
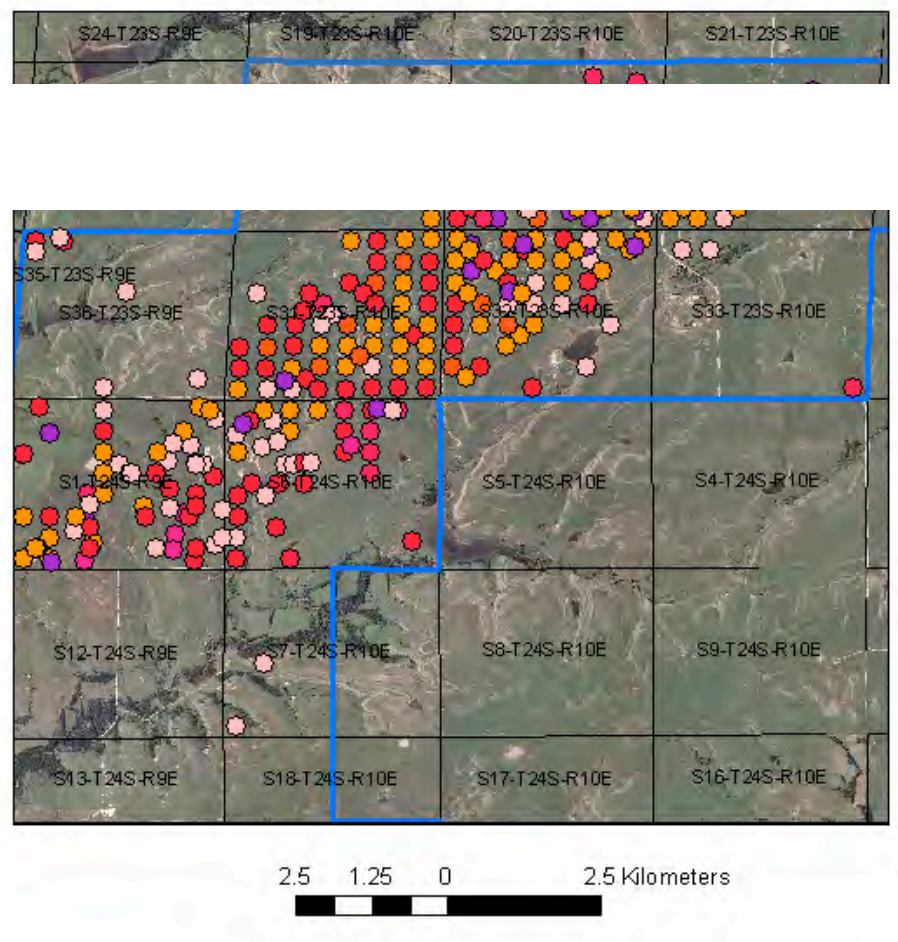

Figure 6: Wells plotted in the Thrall-Aagard field indicating age risk factor

Figure 7 shows well risk factor based on well plug category.

\begin{tabular}{|c|c|}
\hline \multicolumn{2}{|c|}{ Legend } \\
\hline \multicolumn{2}{|c|}{ Wells by } \\
\hline \multicolumn{2}{|c|}{ Plug Category } \\
\hline 붑 & Plugged \\
\hline 0 & No Casing Information \\
\hline 0 & Inactive Well \\
\hline 0 & No Plugging Information \\
\hline 0 & Not Plugged \\
\hline - & Plug Issue \\
\hline 둔 & Producing \\
\hline$\varphi$ & Well Not Found \\
\hline & OTHER FIELDS \\
\hline & THRALL-AAGARD \\
\hline & Section Township Range \\
\hline
\end{tabular}

$N$
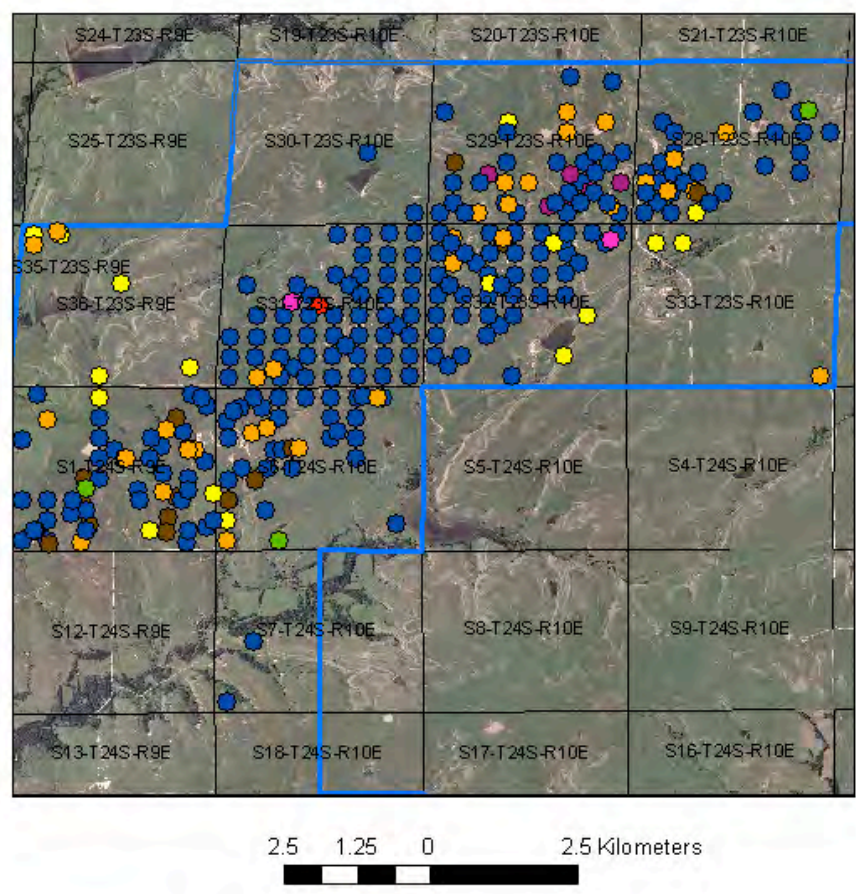

Figure 7: Wells plotted in the Thrall-Aagard field indicating plug category risk factor 
The individual risk factors were summed to calculate an overall risk factor for each well. The overall risk factors for the wells are shown mapped in Figure 8 and the associated statistics are provided in Table 1
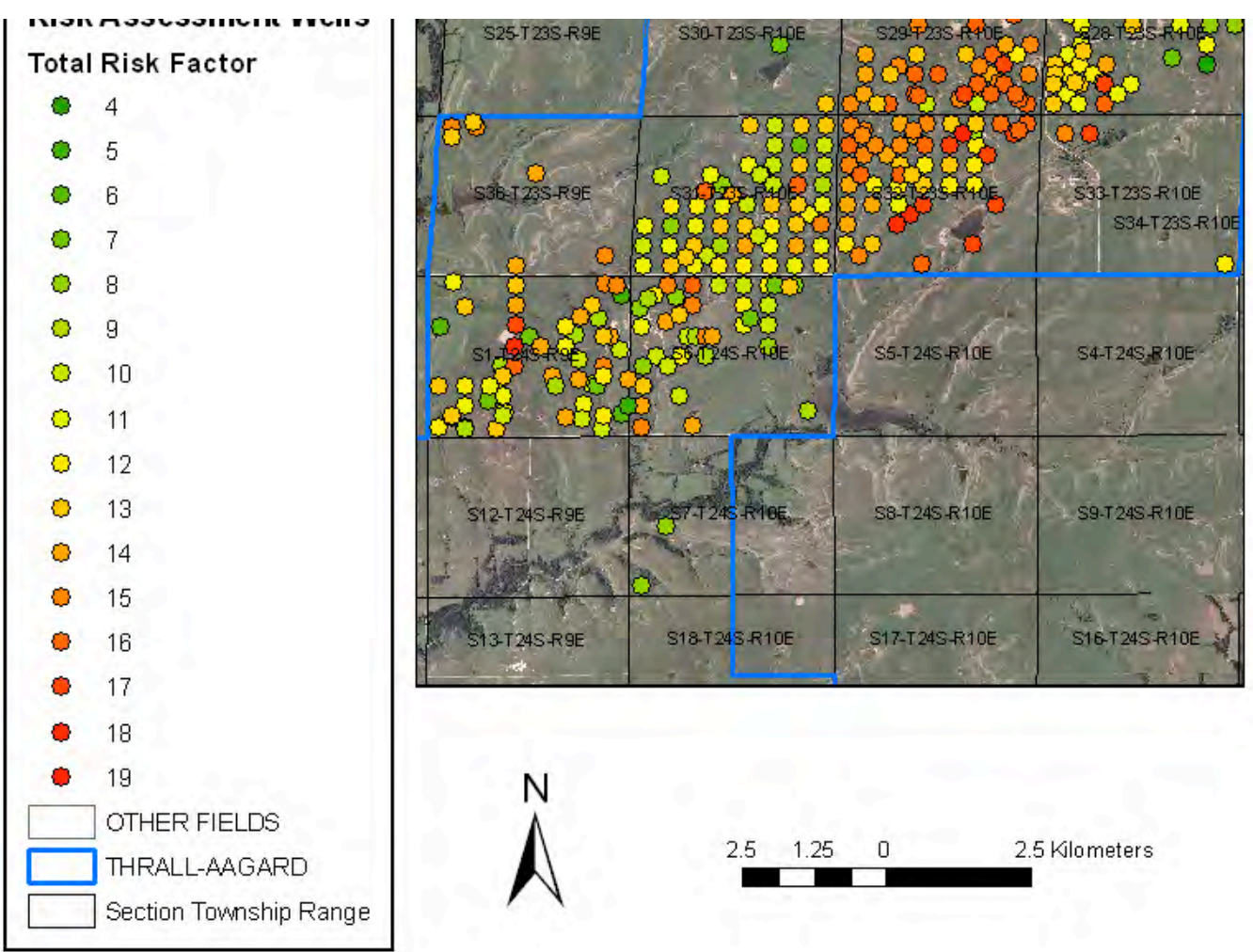

Figure 8: Wells plotted in the Thrall-Aagard Field showing the total risk factor for each well.

Table 1: Total risk factor statistics for wells in the Thrall-Aagard field

\begin{tabular}{|l|r|}
\hline \multicolumn{2}{|c|}{ Total Risk Factor Statistics } \\
\hline Mean & 12.74 \\
\hline Standard Error & 0.12 \\
\hline Median & 13 \\
\hline Mode & 13 \\
\hline Standard Deviation & 2.65 \\
\hline Sample Variance & 7.00 \\
\hline
\end{tabular}


It was found that the distribution of the risk factors was normally distributed (Figures 9 and 10)
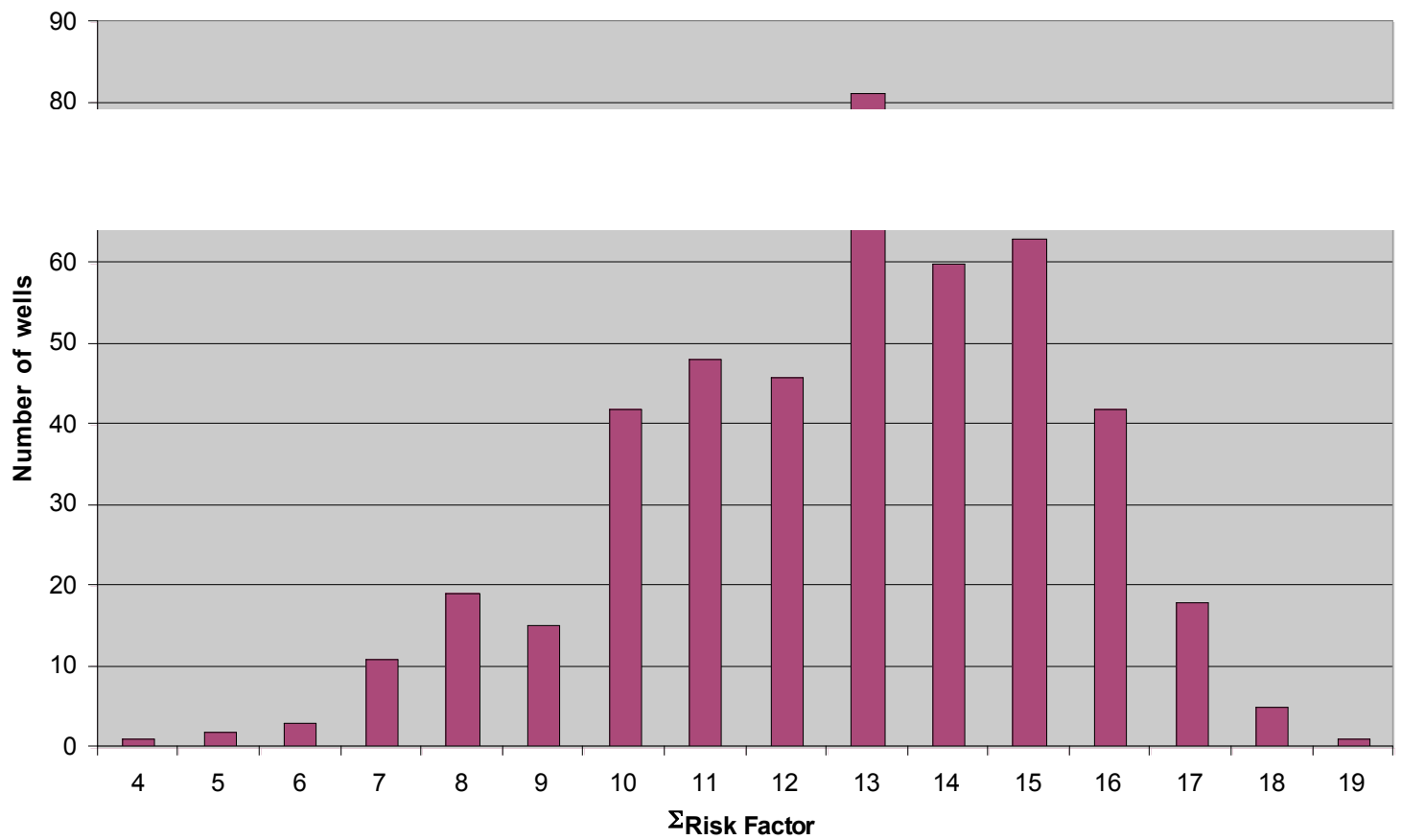

Figure 9: Histogram of the total risk factor data for the TA wells

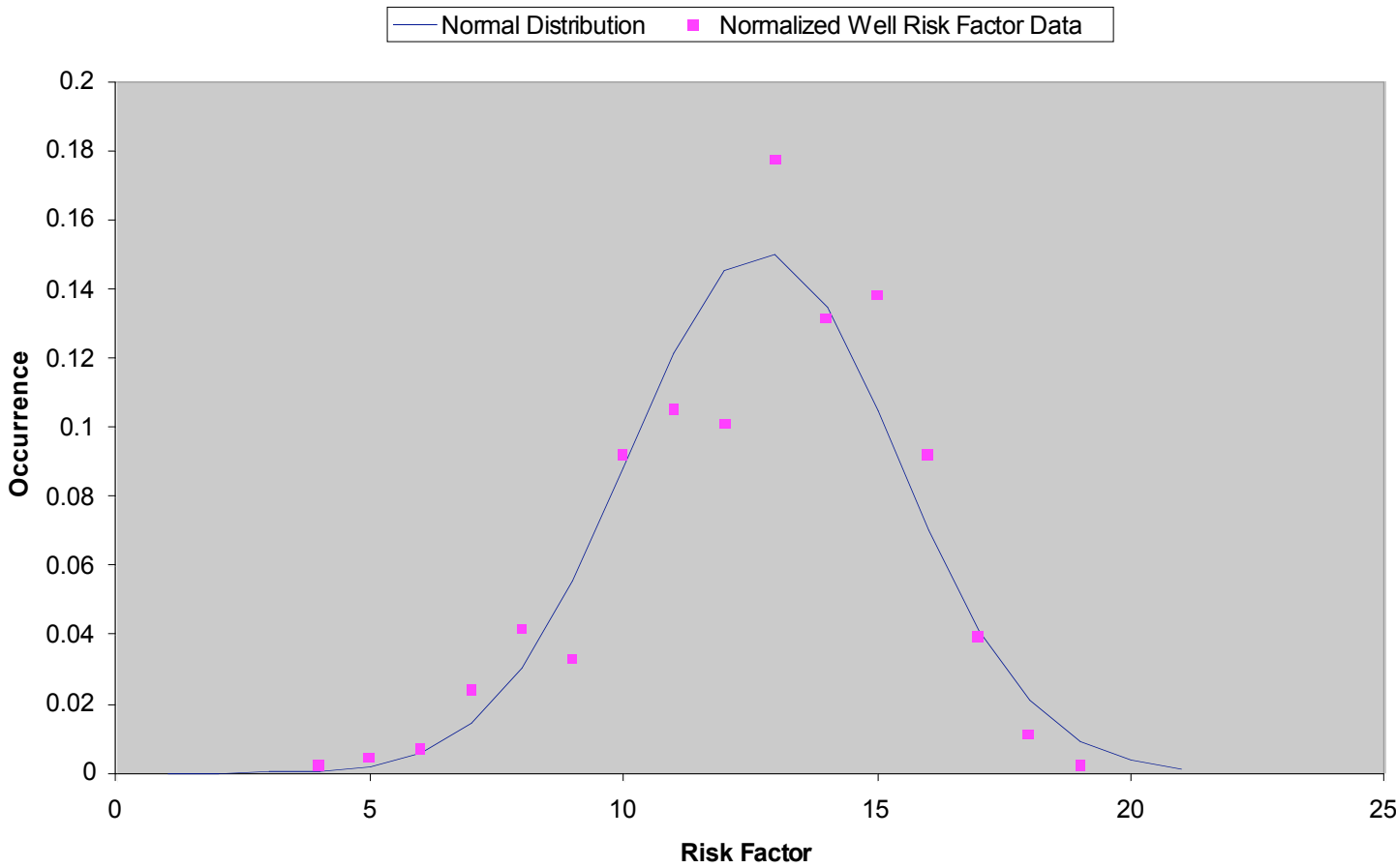

Figure 10: Normalized TA wells risk factor data plotted with a normal distribution using the TA well risk factor statistics. 
If we assume the severity of impact is equal for all wells, then the risk of leakage is directly proportional to the total risk factor as shown in Figure 11. Expert based scaling will be needed.
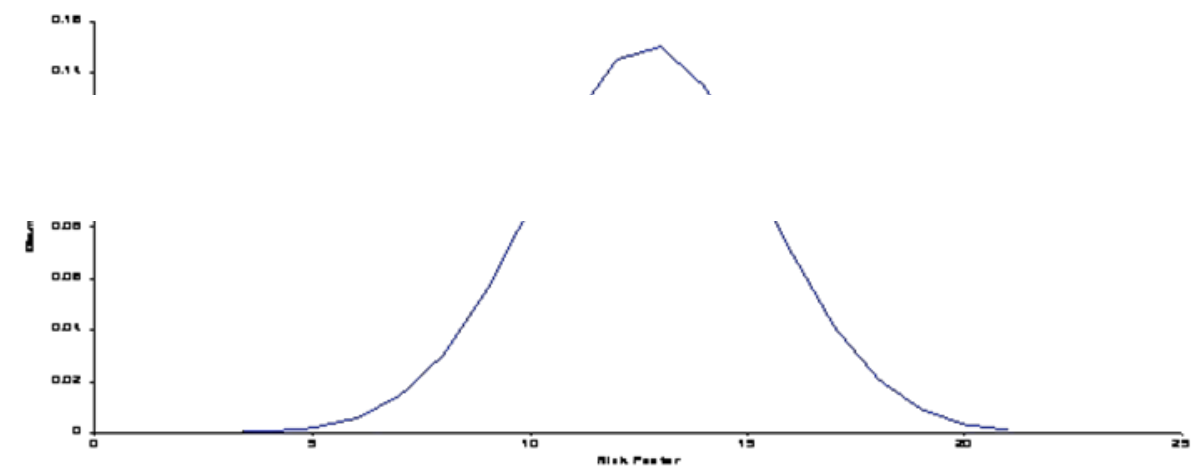

\section{\begin{tabular}{l|l|l|l|l} 
Very Unlikely & Unlikely & Possible & Likely & Very Likely
\end{tabular}}

Figure 11: Scaling the risk factor density function.

The field development plan calls for recompleting some abandoned wells and monitoring others.

Expert opinion sets the average at the boundary between possible and likely. For example, we may choose to replug wells with a risk factor over 13 (270 wells) and monitor wells with a risk factor over 11 (94 wells) as shown in Figure 12.

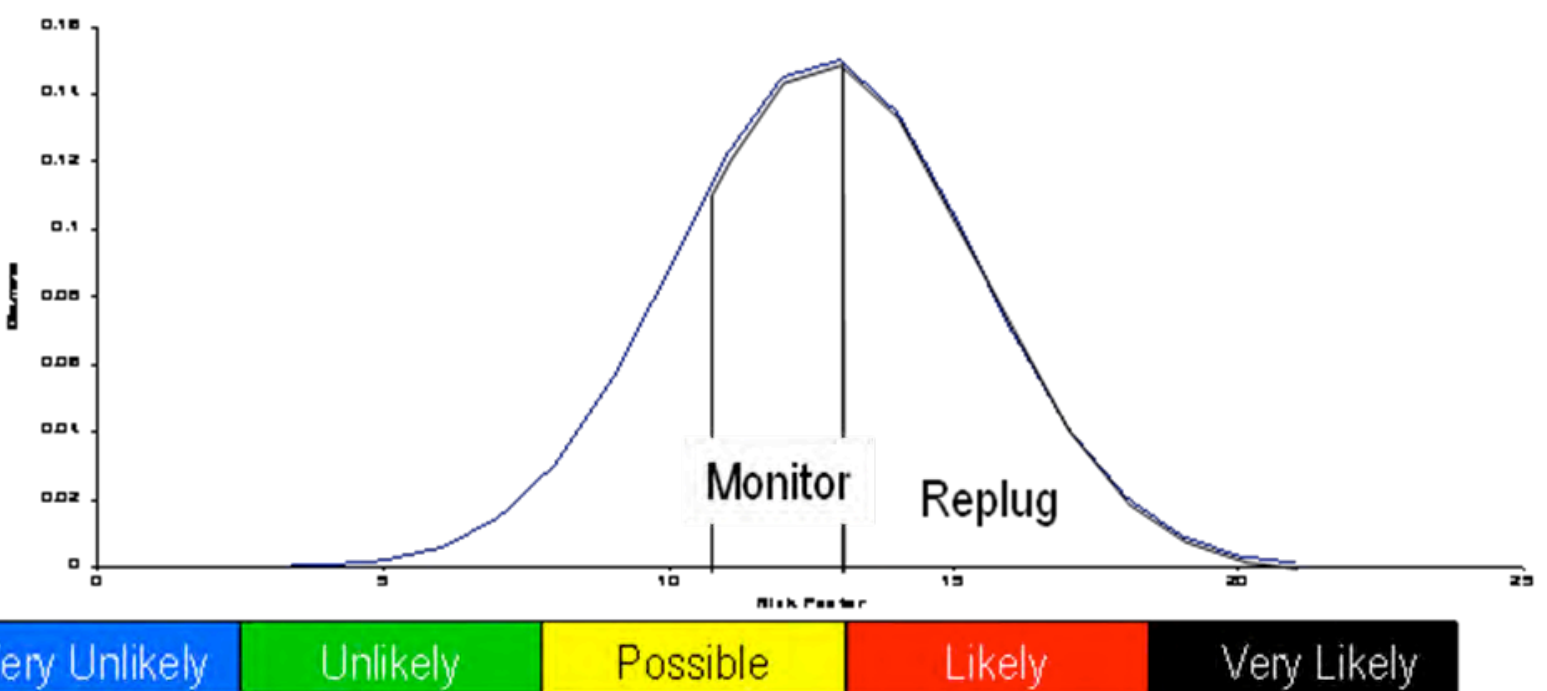

Figure 12: Example of cut-off points for replugging and monitoring based on expert opinion. 